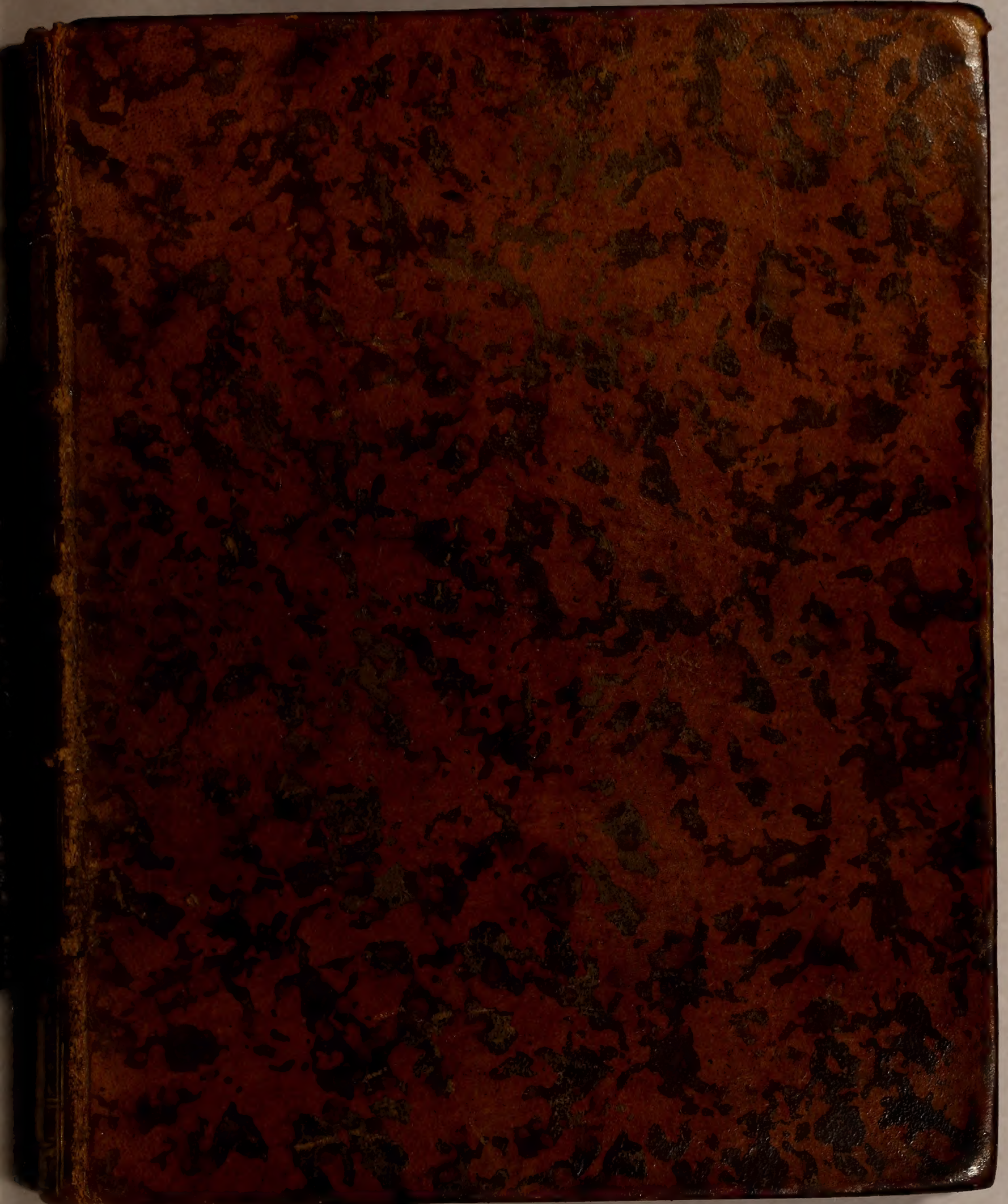




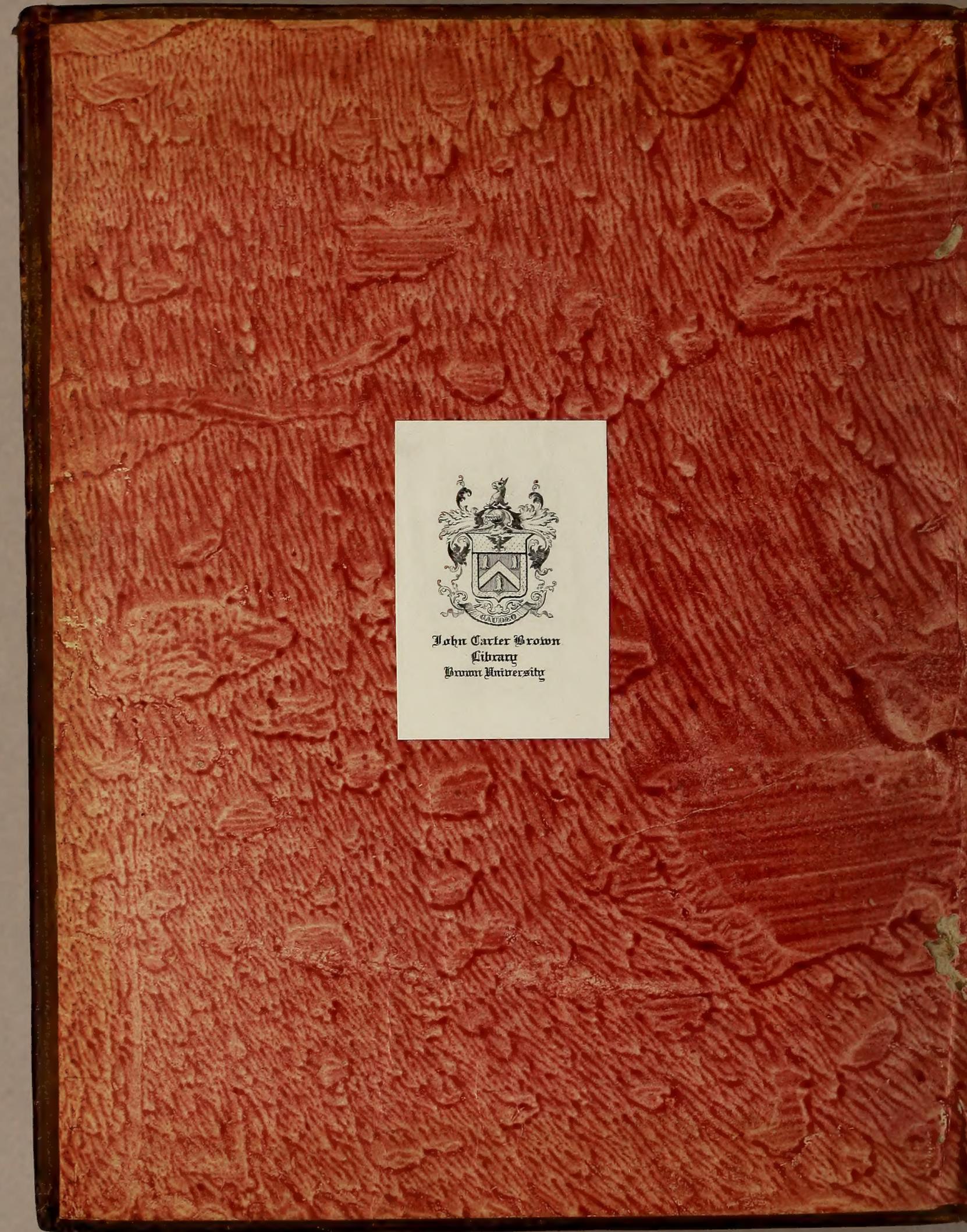




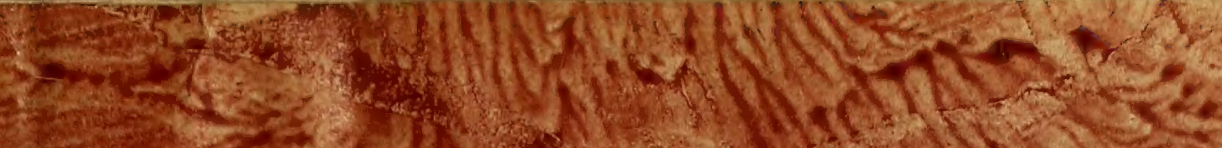

tets Nes? $4+28$ $1+$

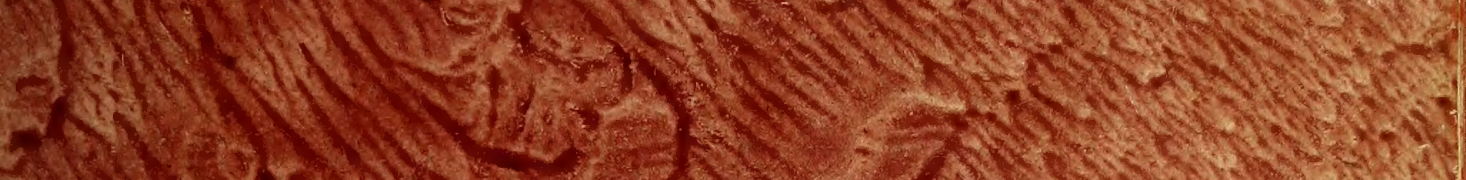

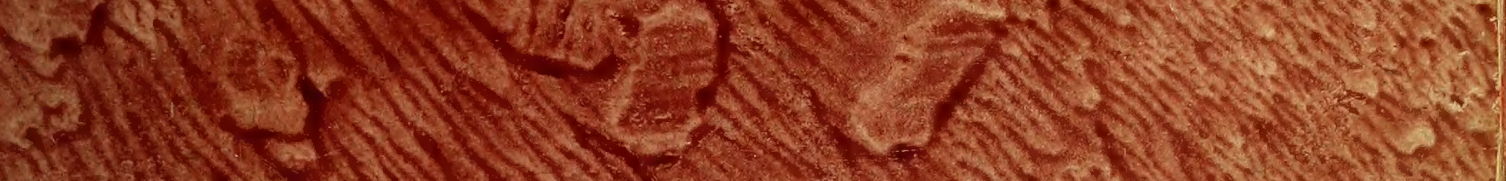
thin

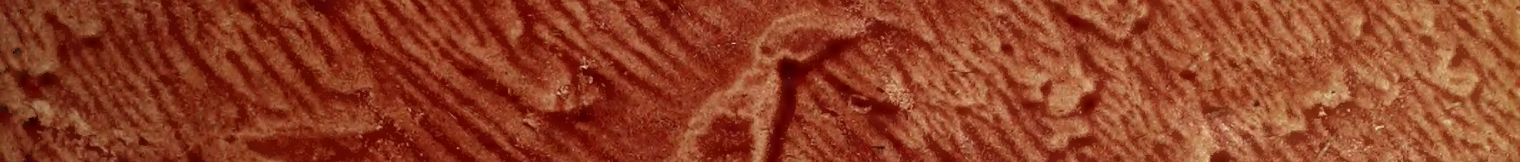

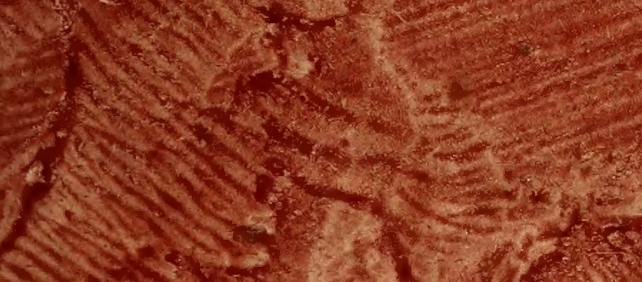
Luint

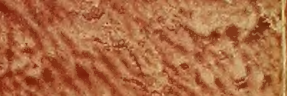

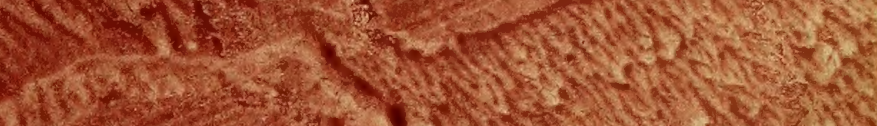

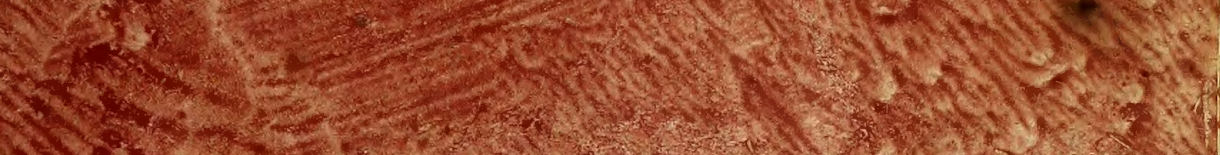

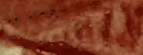
a

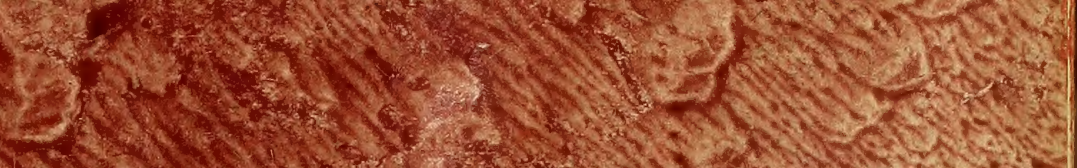
A. 


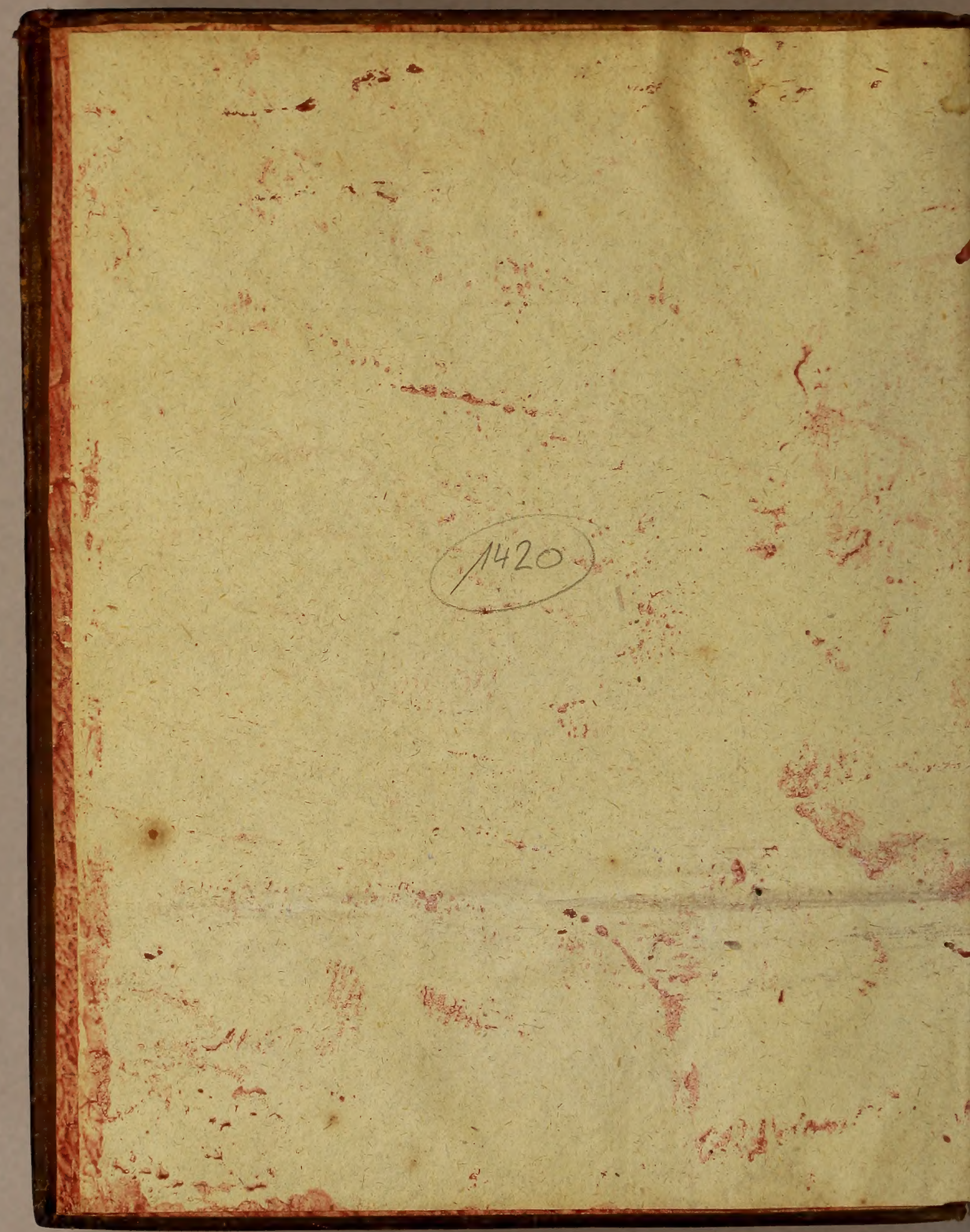


Him geol $\pi+$ a

$$
\begin{aligned}
& 500- \\
& \text { rexxy } \\
& 61626 \\
& 6
\end{aligned}
$$




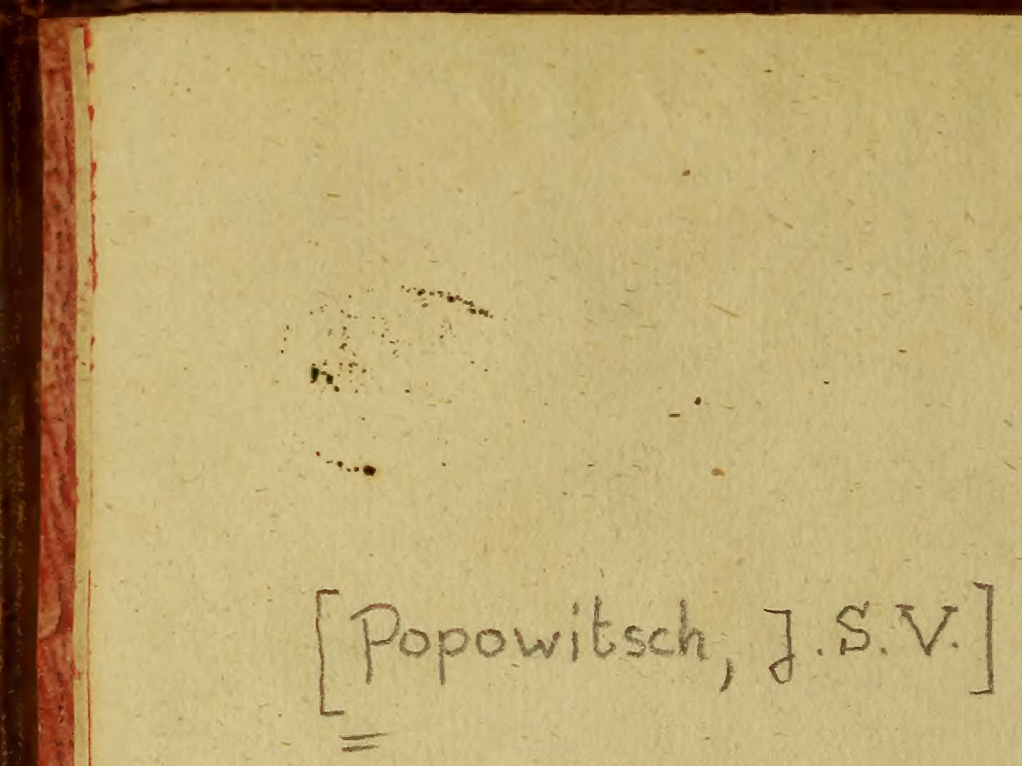




\section{Siterfud)ungen}

vom
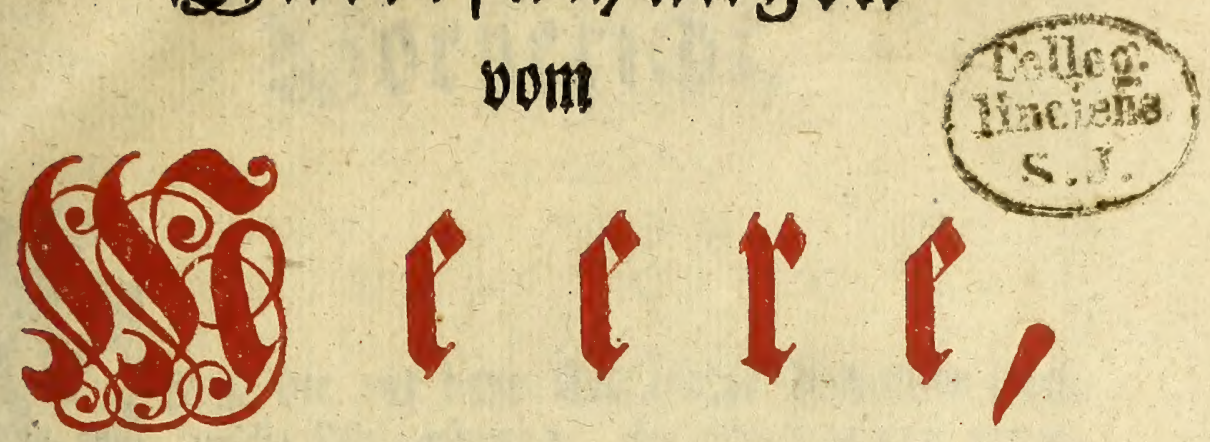

Die auf Seranlafiung einer Sădyrift, DE

COLVMNIS HERCVLIS, weldie ber hodberuibumte Proferfor int Siltorf,

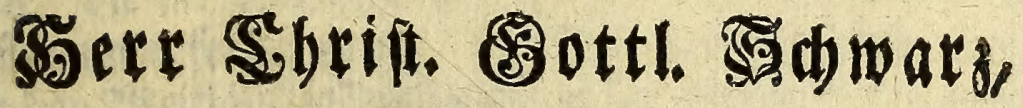
berausgegrbeth, nebft andern su Derfelber geborigen

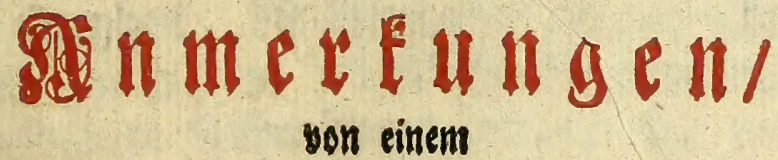

Riebiaber Ser Staturtebte uns Der Fbillologie, borgetragett werdett.

Stantfurt uno Seipsig 1750 


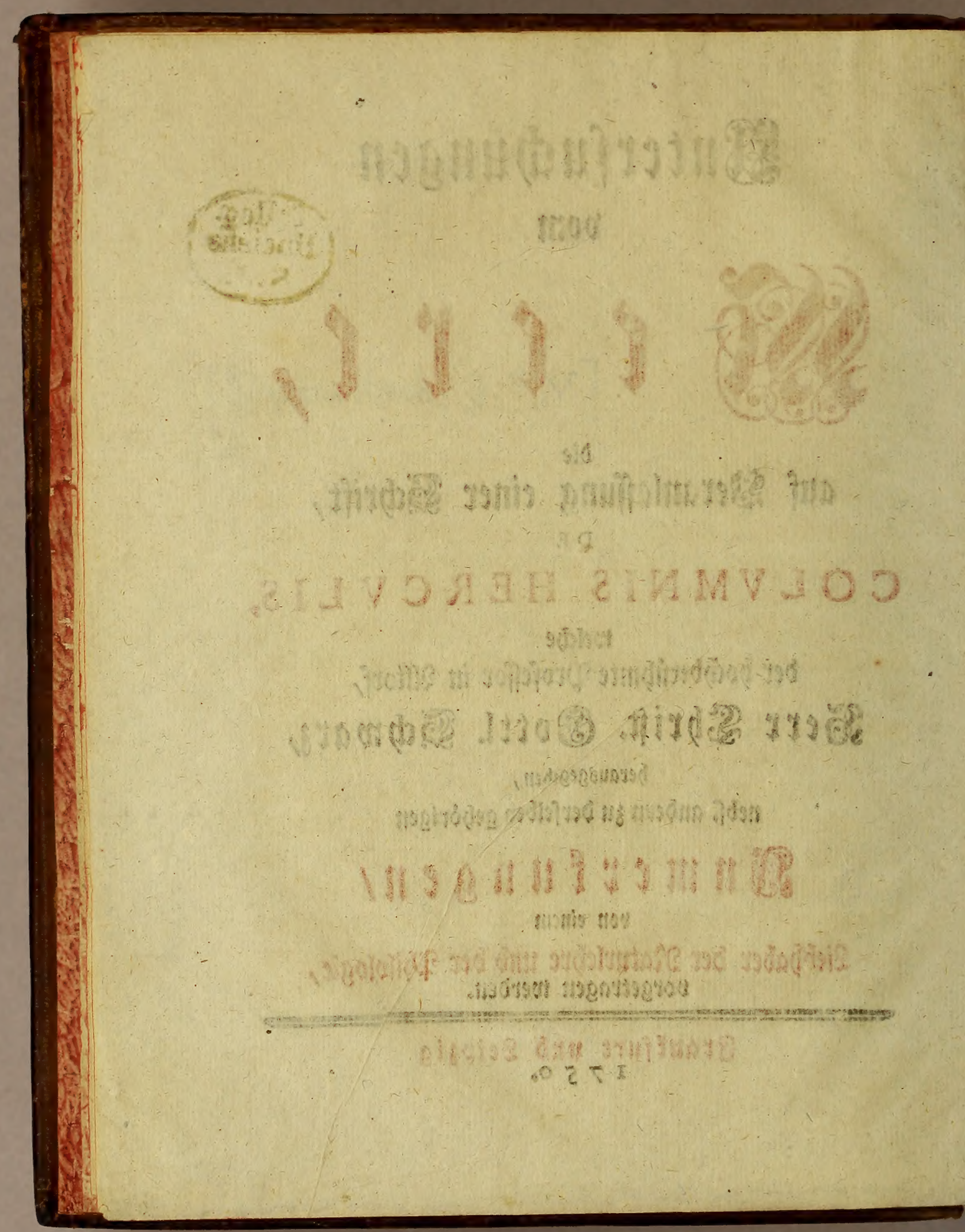




\section{Sorberiat.}

s ift sie auf bem sitelblatte benannte late: nifble 2Ibbanblung, de coLVMNIS HERcVLIs, ben bergangenten Sommer, auf 34 Suartieiten, 3u IIltorf gebructet, utto

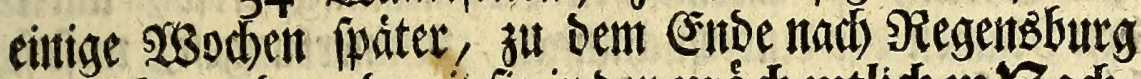
gejthift morben, Dantit fie in bent wódbentliden had) ridten von gelebrten Saden, verfitnoiget werbe.

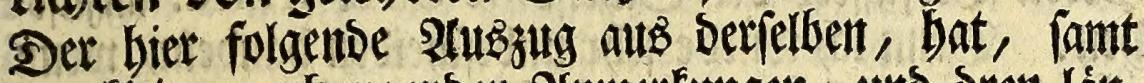
ben fleinett antyangenben Simmerfungen, unto brey laits gern, bie int Ynbange ftelen, unt Das Ende bes Tht guftmonats fertig gelegett. SY3eil berfelbe aber, theils.

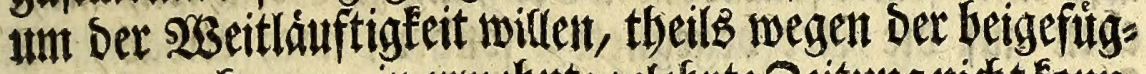
tent P(nnterfungen, int erwebnte gelebrte Beitung nidht fonn te fingliti eingetragen merben, io babe iii), llad erlangter gróferer frenbeit, Die Inmerfungen bermebret, utts biejenigen, bie zu bem VI Irbjontitte gemiomet waken, in eine befonbere S(bbanblung betwantolt, weldbe bier inter Dem Titel Des II Theiles exfocinet. 2Bon Diefem netten Suffaze nolite id borgebahten Sutbeguif bes las

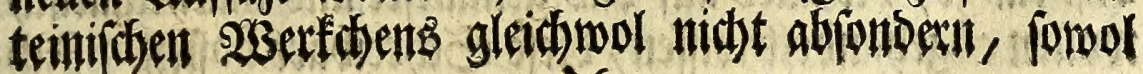

$$
x_{2}
$$

นIII 


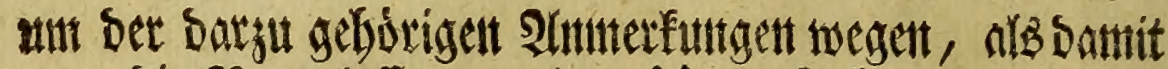
malt bie Szeranlafinting meiner. Unterfitbungen vont

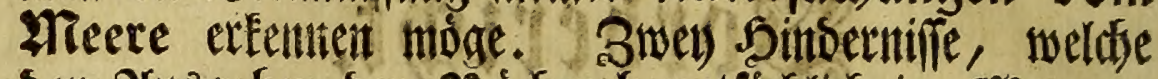

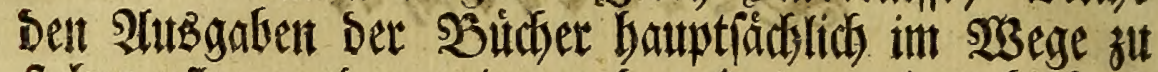

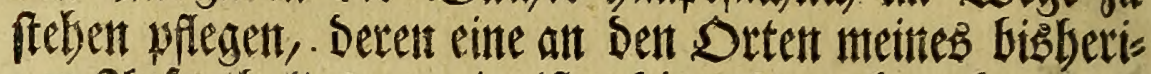
geri Prufenthaltes gentein ift, bie andere aber éven bats

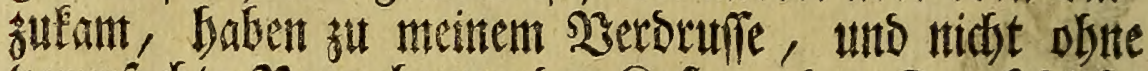

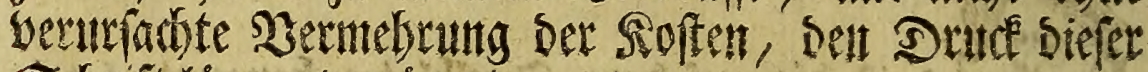
Sthrift lainget vergigett.

$23 a B$ ftt Den 230 atten Der Siecenfion, obet stt eitti

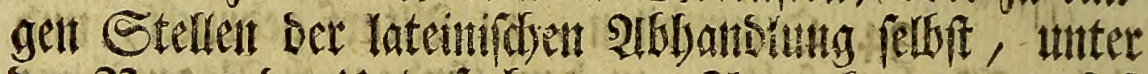

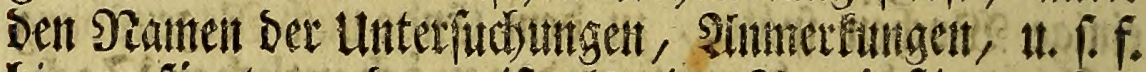
bintugefinget worben, ift als eine SHergonftigung Des

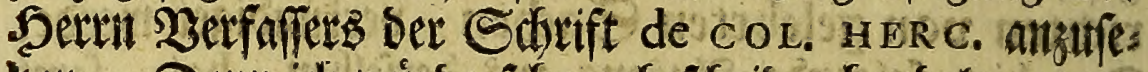

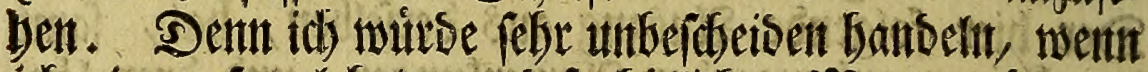

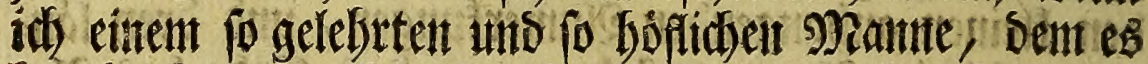

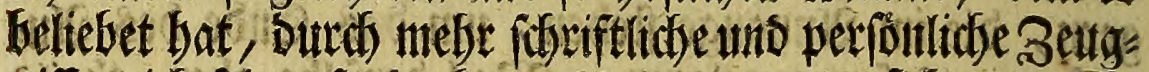

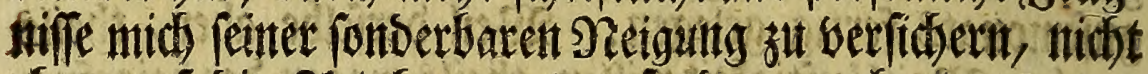
eben auf bie ant begegutete, fortbont nod etwas, es fer) autch mut bas gyeringfe, bortibinte, fo bemferben eite

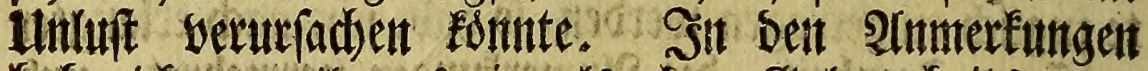
babe iff subeilen (nientals obne (belegenbeit) bont Dent Sauptboutrage mitis) etwas entfernet, unt ben $\Omega_{e}$

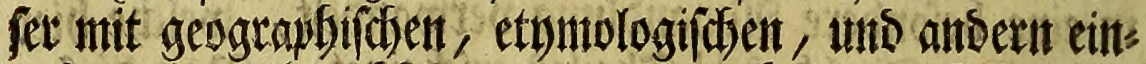

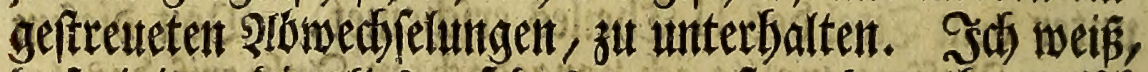
bás elinige, Die alles auf das gentautefte unto matbematioú woffen absebandelt wiffen, Diefe Stherbart bafent. gob babe 


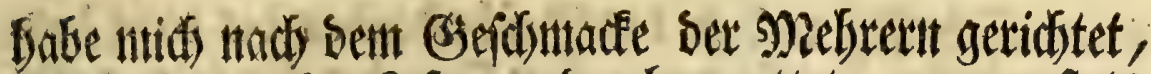
weldefe fagen, ber Rejer werbe abgemtattet, wemt er fiets

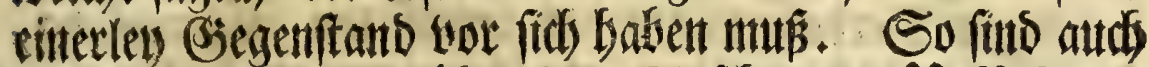

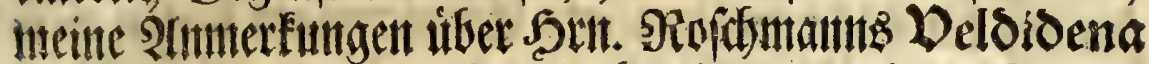

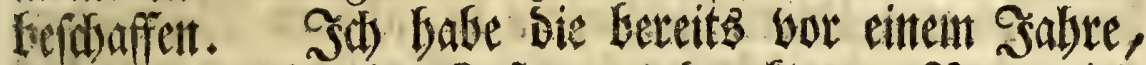

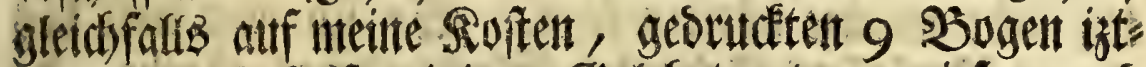

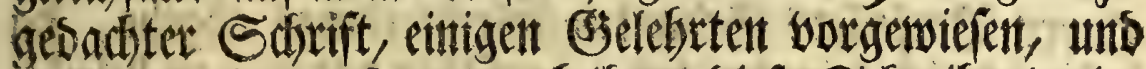

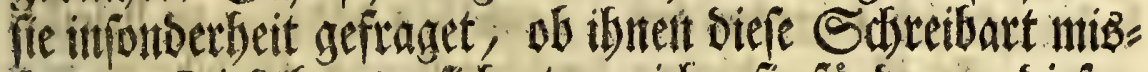

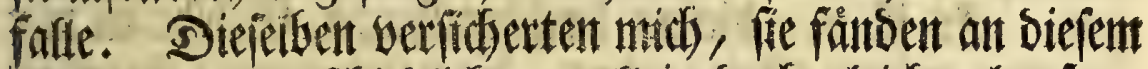

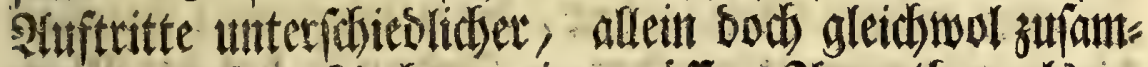
inctbangenber Sachen, einte grofiere 2inmuth, als alt

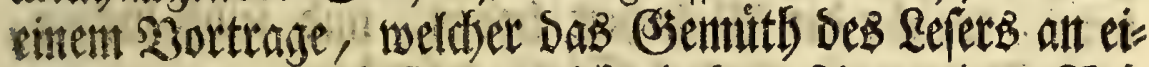

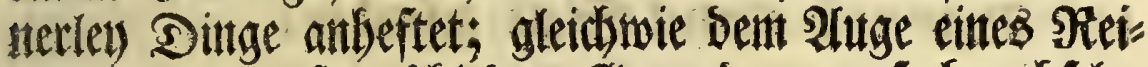

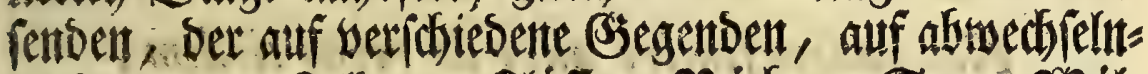

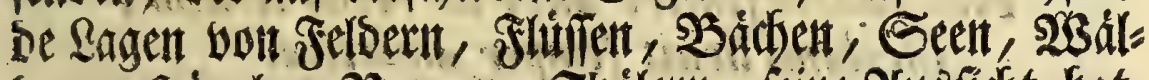

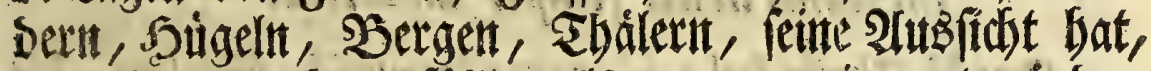

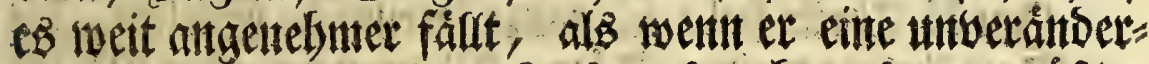

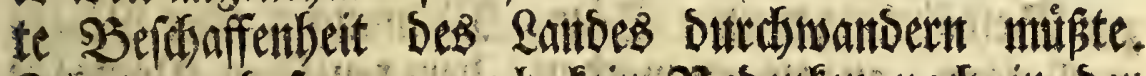

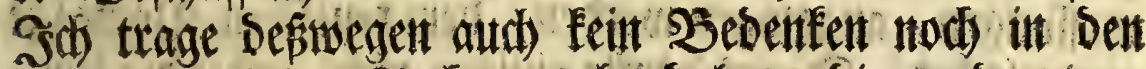

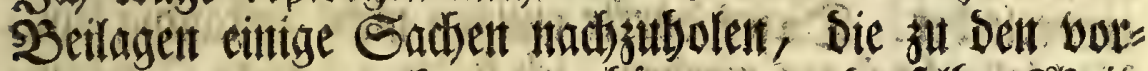

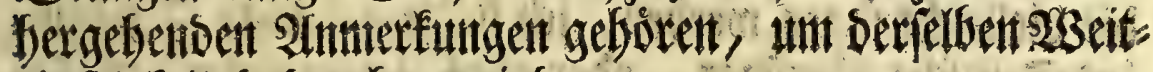
läuftigfeit badurds zu mintoern.

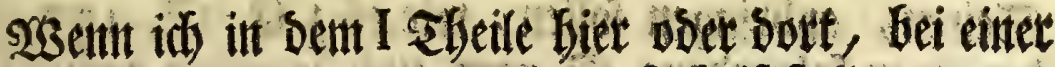

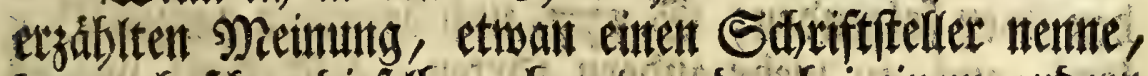
Der attof f(foun biejerbe gebeget, ober bei cintent anberit

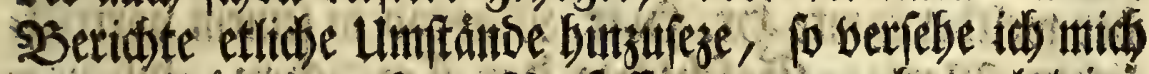

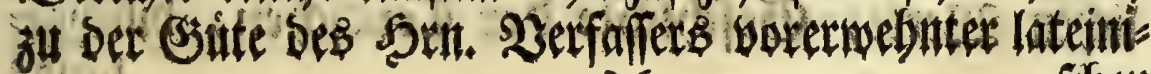
$x_{3}$

估en 


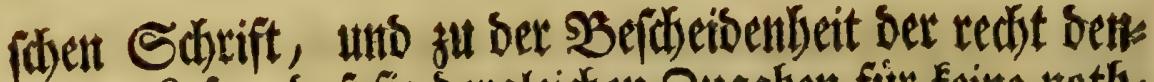

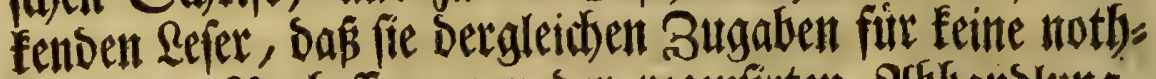

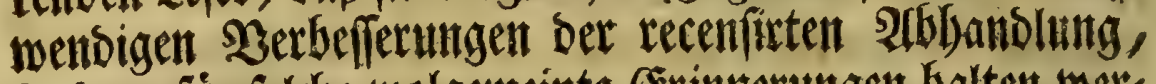
fonbern fiur foldbe nolgemeinte Erintrerungen balten wers

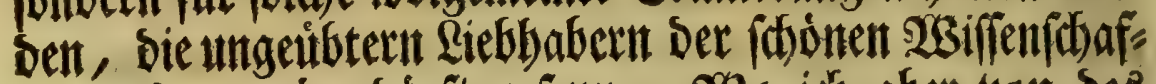

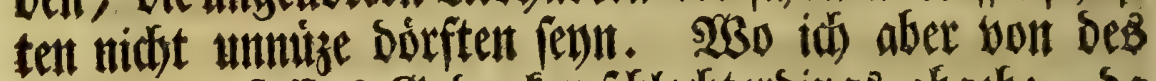

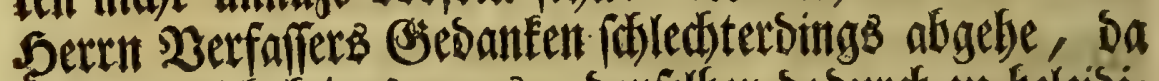

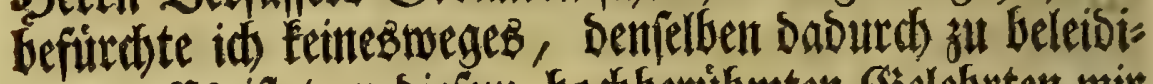

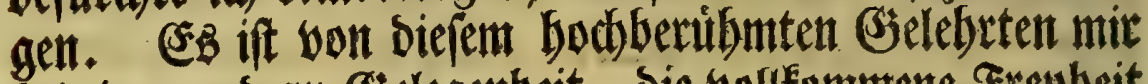

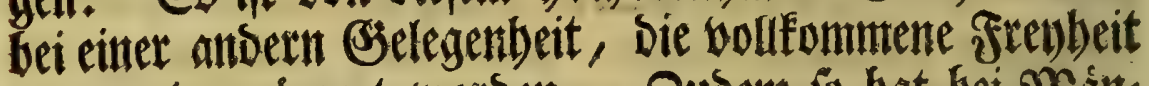
bierłu eingeråuntet worben. Zubem ố bat bei sRailt

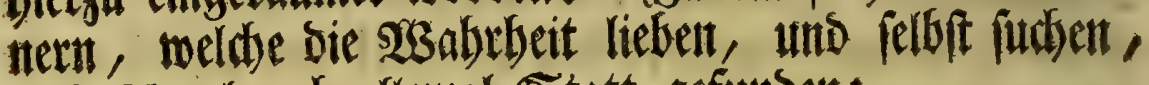
biefe Regel nod) allemtal Statt gefunben:

Non eadem fentire alios de rebus iisdem, Incolumi licuit femper amicitia.

Sint II Treile babe ing gantse latentitifhe Stetlen, bie

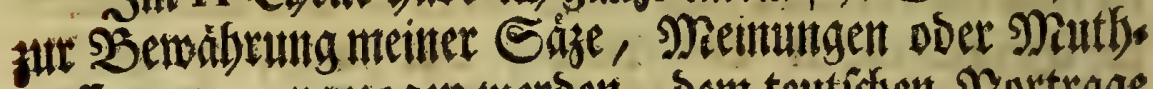

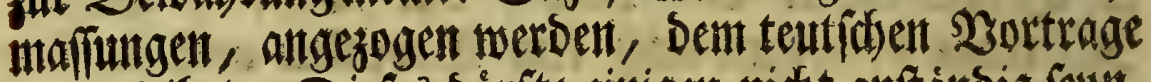

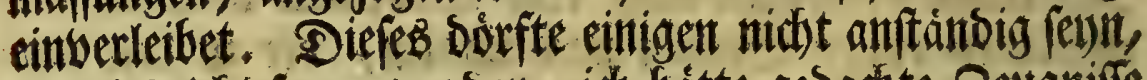
bie viefleidet fagen werben, id battte gebadite Seugniffe

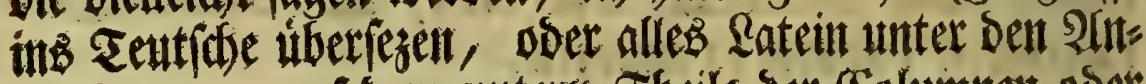
merfungen, auf Dem unterfi Theile Der Columnen ober Eeiten, anbringent foften, wie bent jwey folgenden; S. 177 , und berfélbent ganzent 2 bi: lage, auth an mebr anbern sorten, gef́belsen; wie es

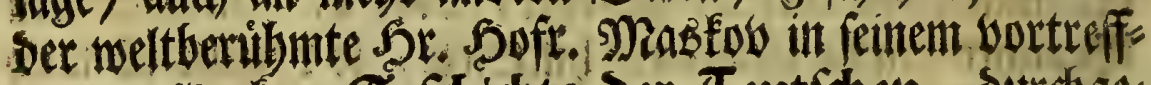

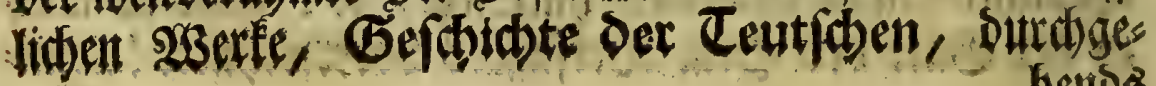
Itotit? 


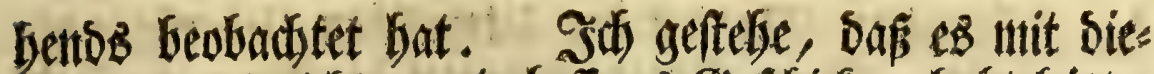

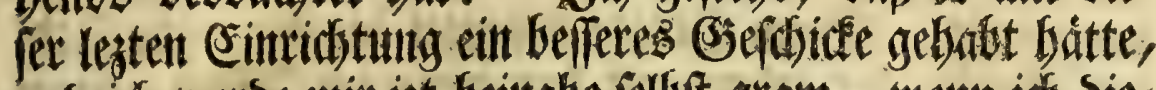

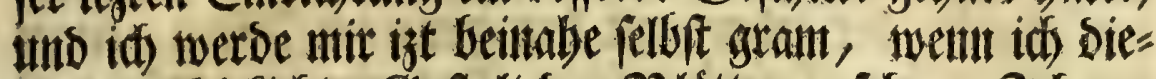

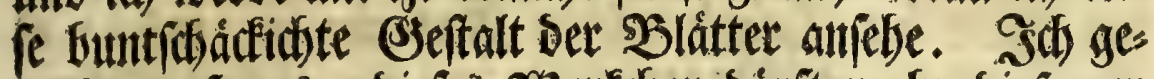

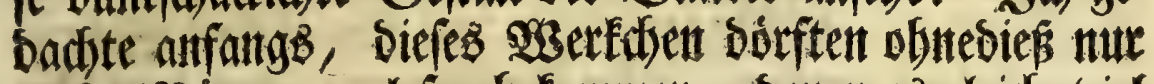
folde Meanturer fu lefen befonmen, betten es gleid' viel

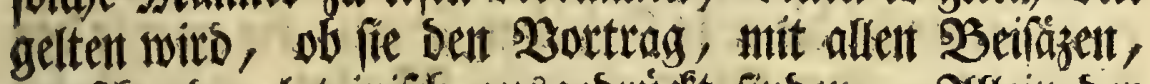

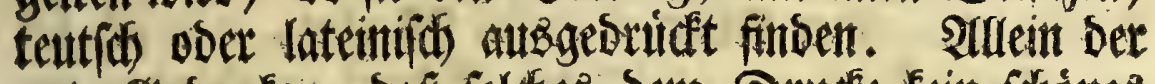

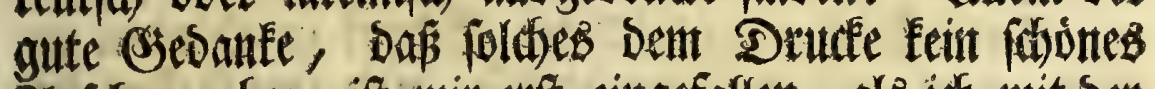

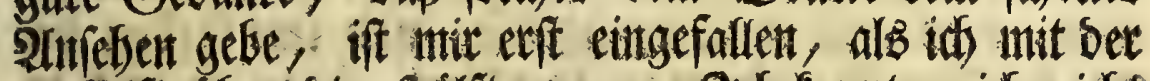

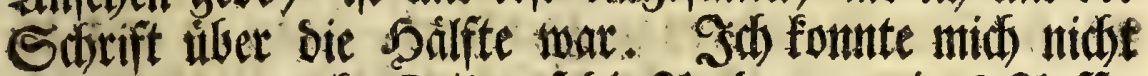

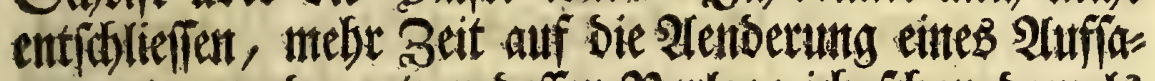

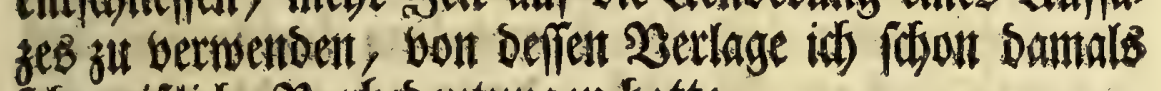
fefyr misklidse 23orbedeutunget batte.

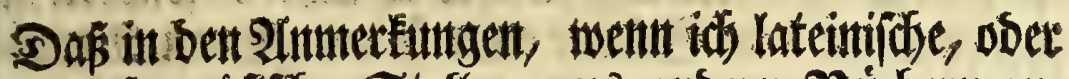
zumeilent franzónifobe Stellen, aus anbern Bitidern ante

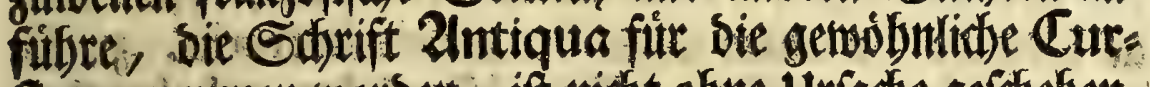

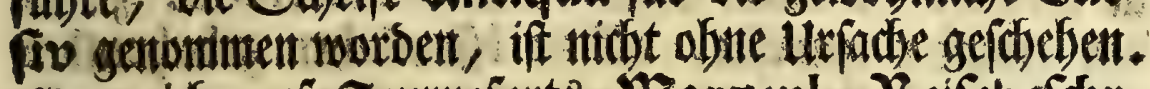

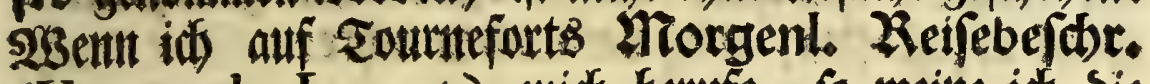
(Voyage du Levant) mids) beruffe, (o meinte if Die

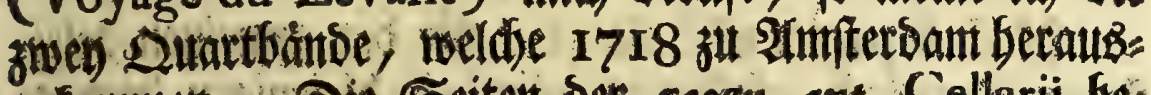
getommett. Die Seiteit ber geogr. ant. Cellarii bes

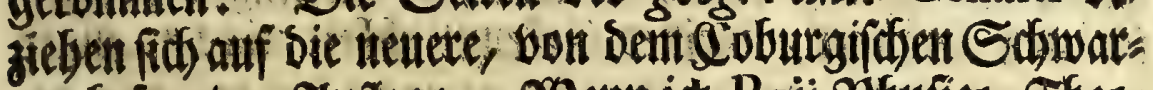

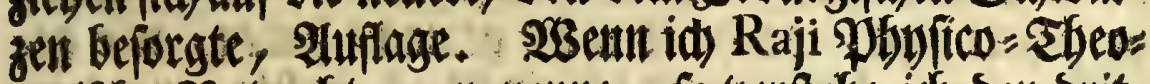
logindse Betraditungen neture, fo gerftehe id Den brit:

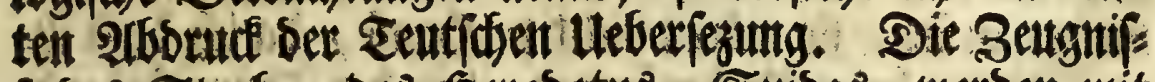

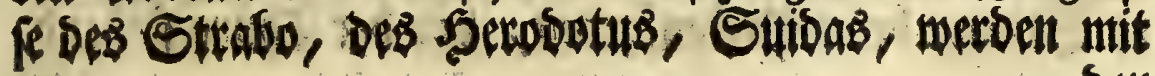




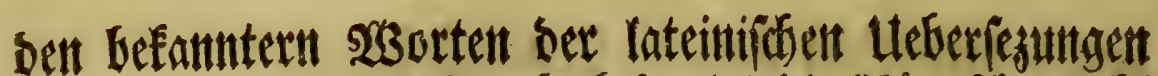
vorgeleget. Beim Strabo beseutet sie SRómiche Babs

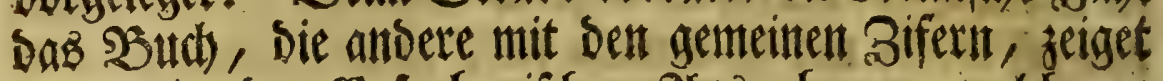

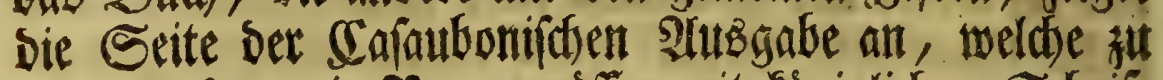

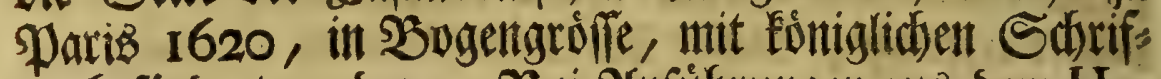
tent befórsert morben.

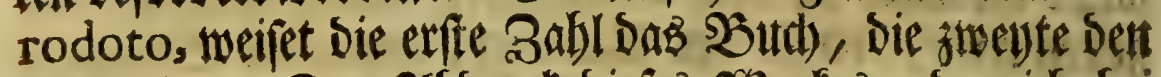

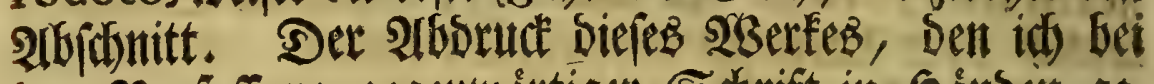

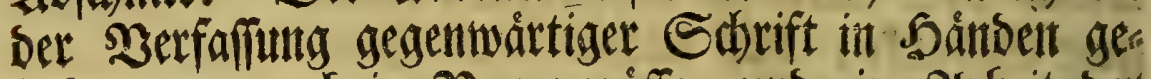
babt, twat auth int Bogengroffe, und eine Prbeit bee

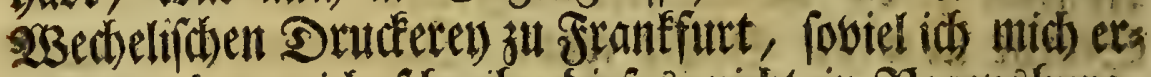

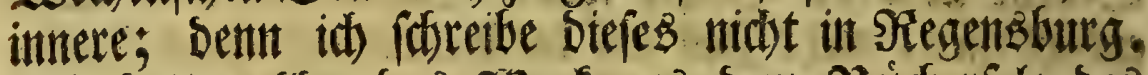

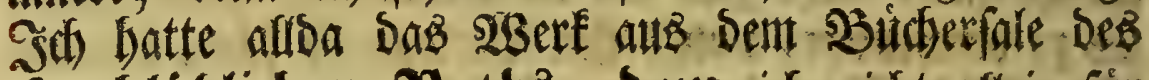

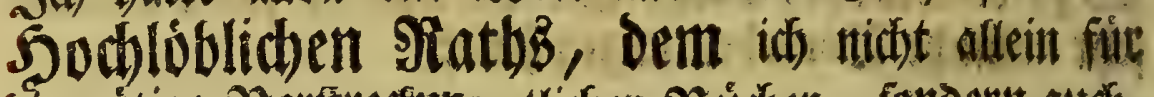

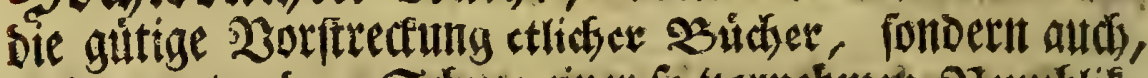
Dá̧ mir iber zwew) Jabre, als einem Mitburger, obne cintige $\mathfrak{A l f g a b e}$, in eiment ungeft'serten otio literario, $3 \mathfrak{l} \mathfrak{l}=$

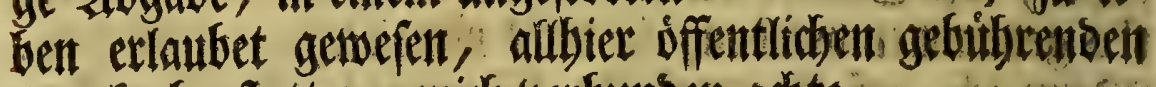
Danf a abjuttatten, mich verbumben adjte.

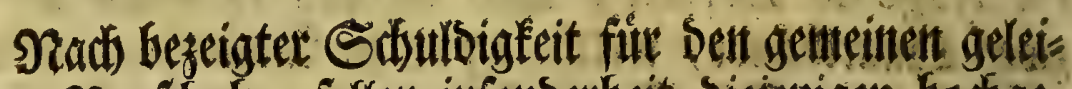

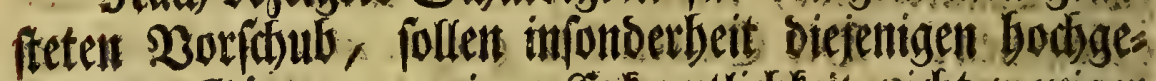

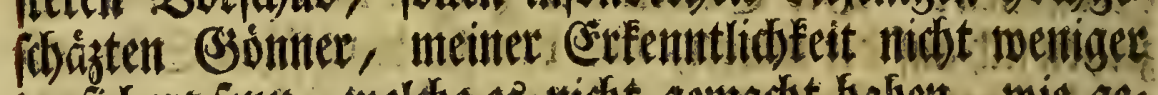

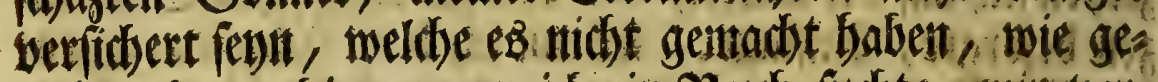
wiffe anbere, bie, meent id sin Buth futhte, mir ber

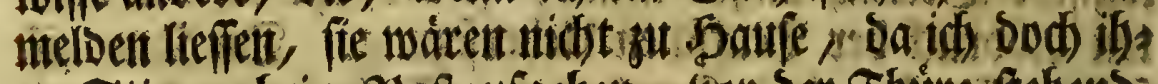

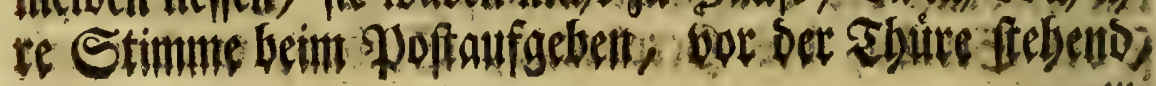




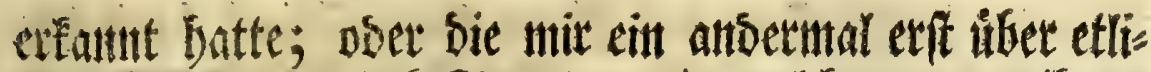
we Tage citte 3eit befitintuttelt, int weldfer, bor ibnent

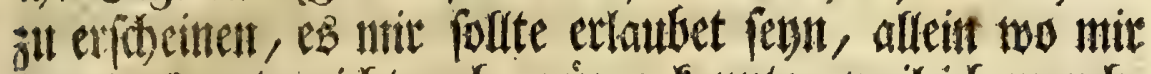

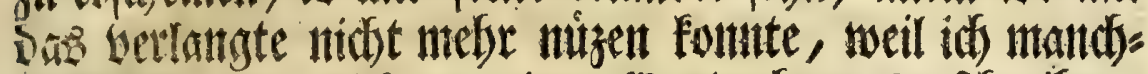

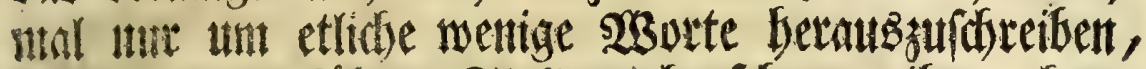

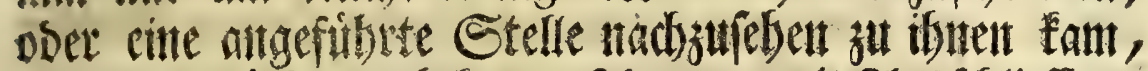

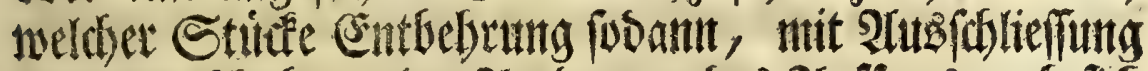

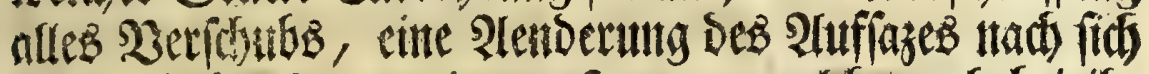

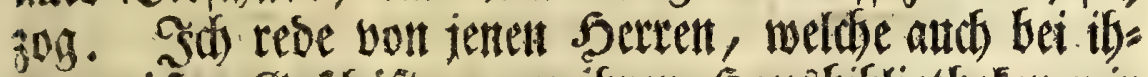

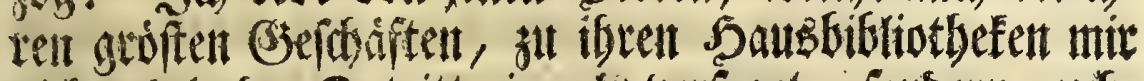
nihat allein Den Suttritt nientals ber jaget, fonbert auto, weilit fie antoersmoljin gertfett morben, ober went fie

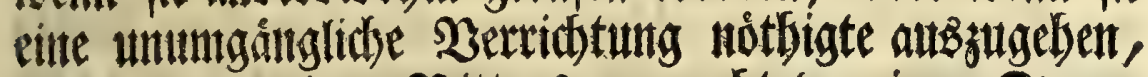

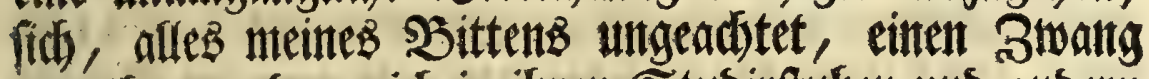
antgetfan, ober mids in ibrent Stubirftutbent utto antoern Gemádern, bei ibren Sthriften unt Softbarfeiten, gans alleine gelaffert, afs weent id iffer sint ober berféts

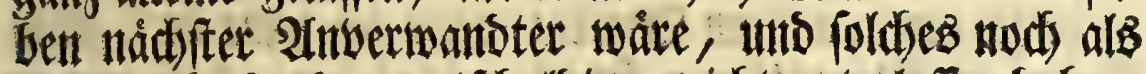

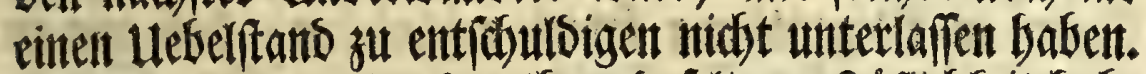

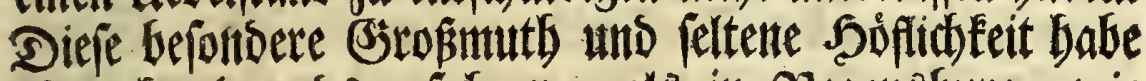

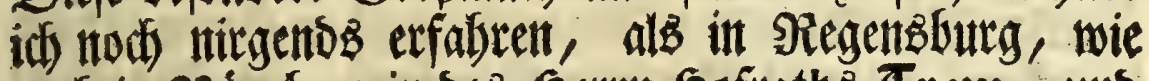

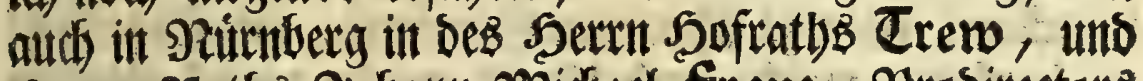

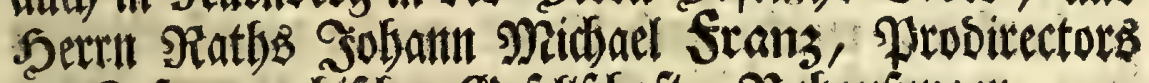

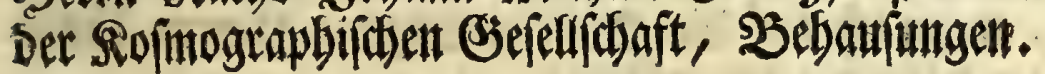

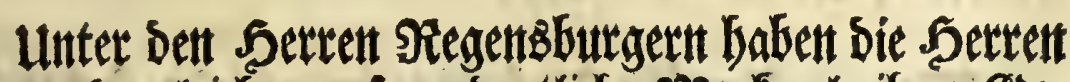

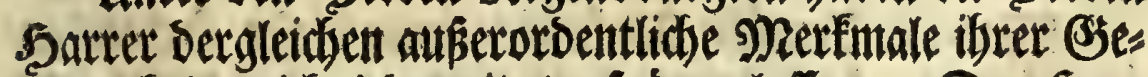
topgenbeit mid jederzeit verfpurtent laffer. Der Sere

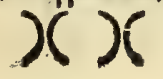

Settat 


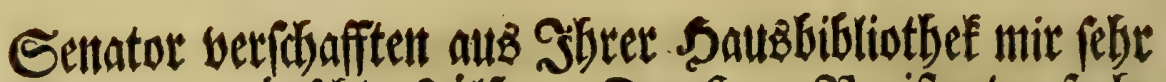
oft eine errwitur(t)te Suilfe. Der Serr PRegiftrator fitt)=

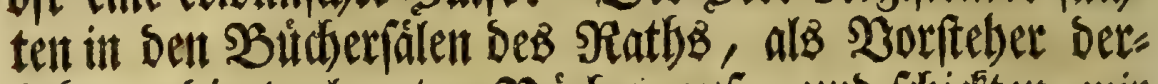

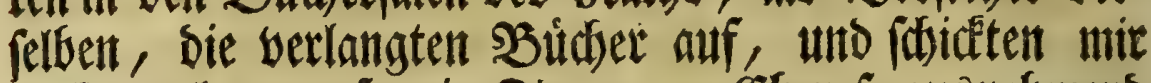

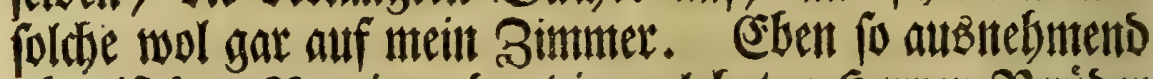

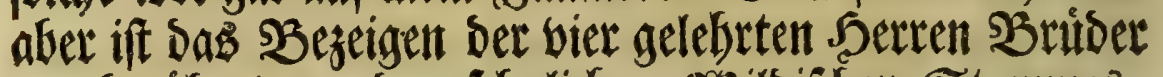

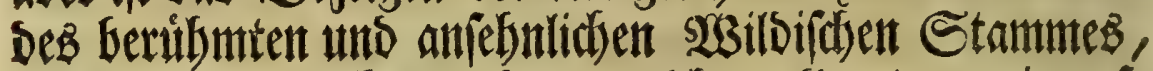

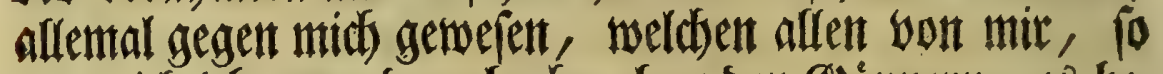

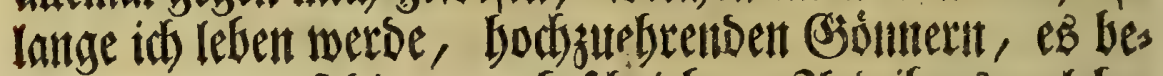

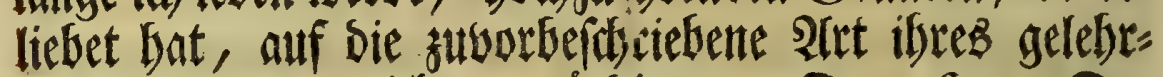

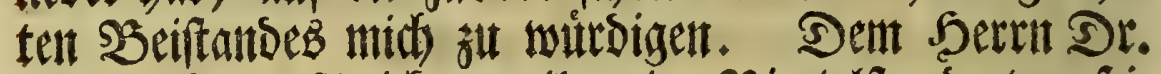

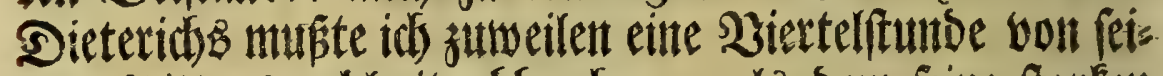

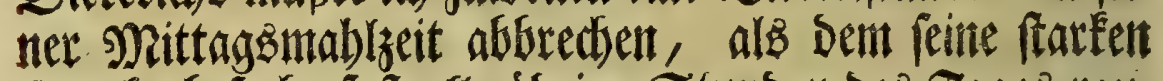
Seranfenbejithe faft afle uibrige Stunbent des Tagez rauts bert. (5a baben aber autch sie Serreen Patres ber Sd)ott=

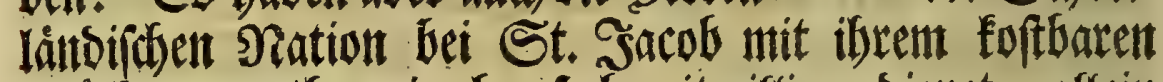

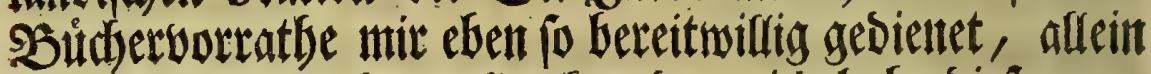

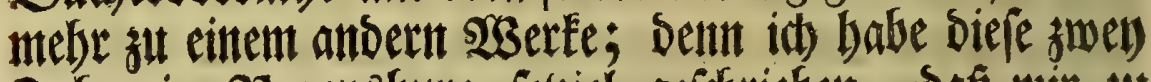

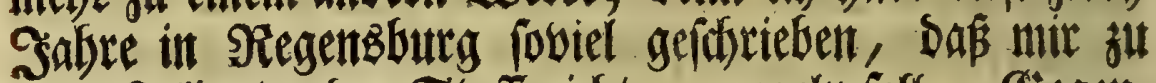
zwen Sollianten Der Stoff nidht ermantgelln foff. Bjegent=

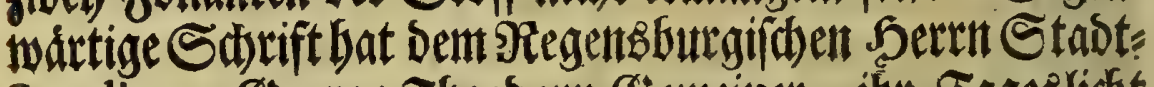

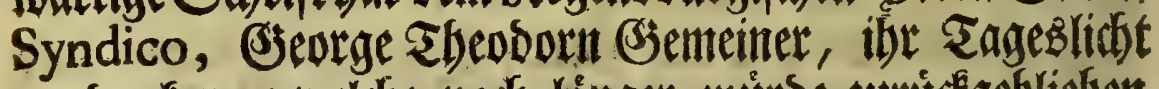

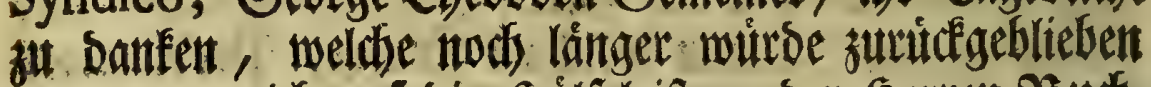

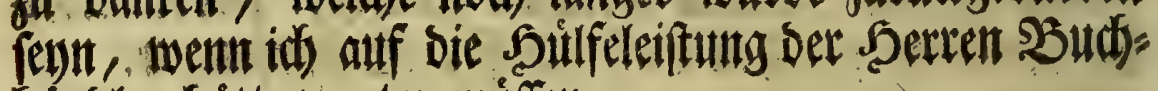
bannoler båtte warten mứffen.

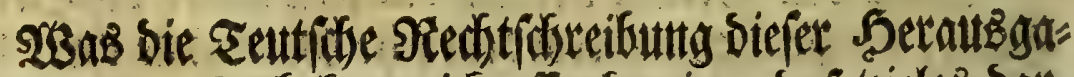

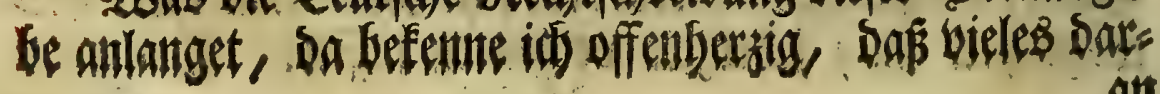




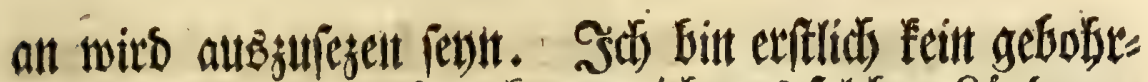

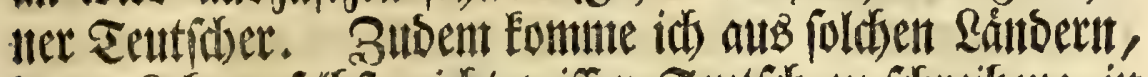

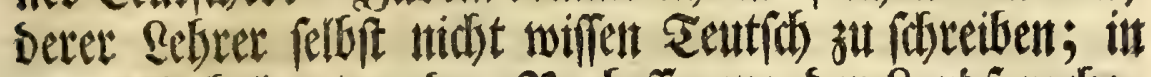

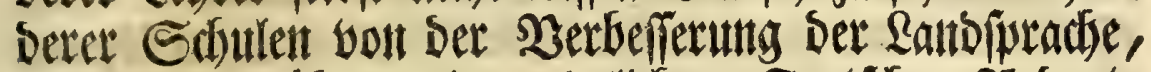

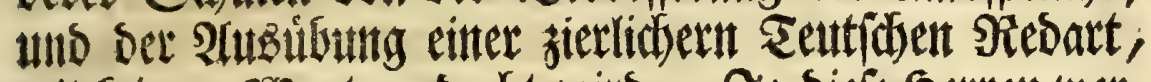

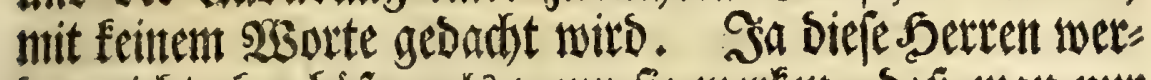

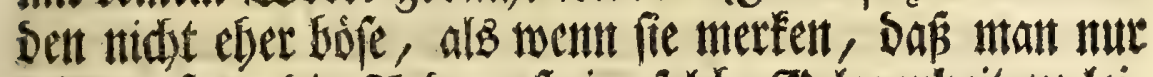

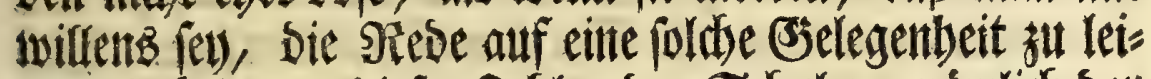

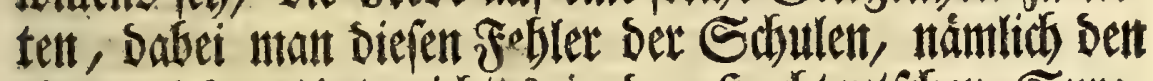

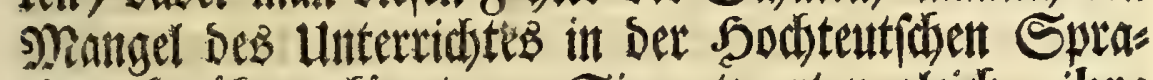
die, berifhen fointe. Sie antwortent gleid, ibre P lidst ware, Sie lateinif be Spradbe zu lebren. Wer nidt Teut Th verftunde, oer foll fid von ets nem Teut Die Sdfranfent eitter 20 orrebe geftattent nire nidst, Sutrd

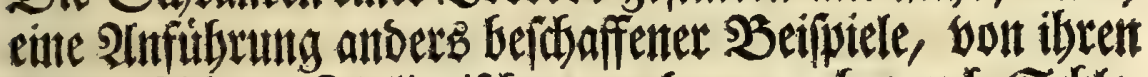

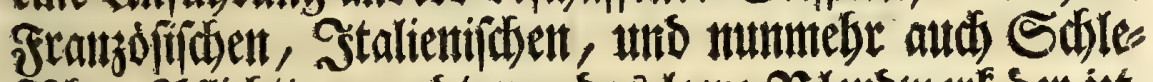

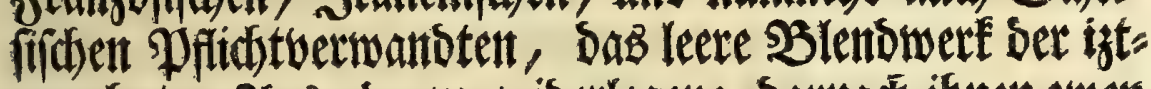

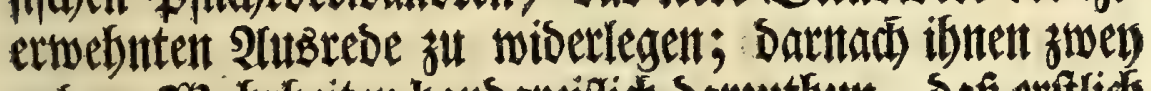

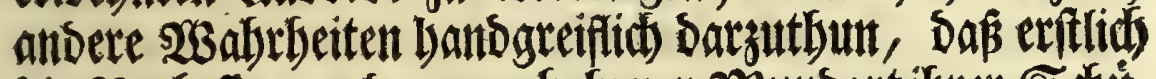

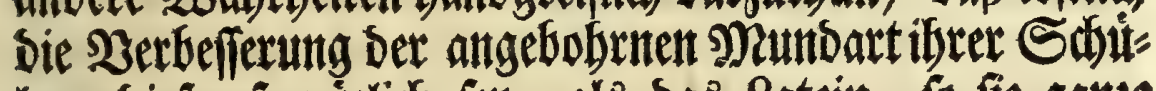

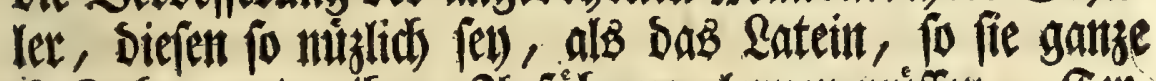

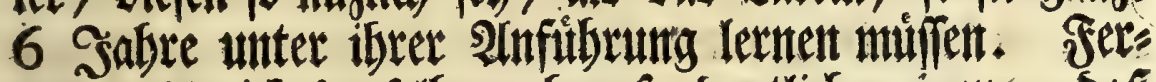

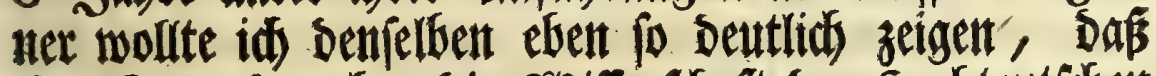

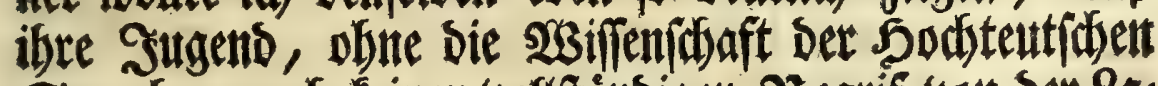

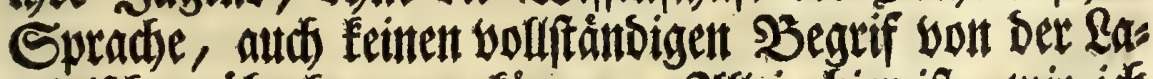

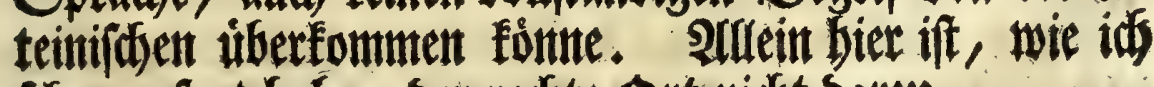
fafon gefagt babe, Det redfete ort nidft Datju.

$$
x^{2} x^{2}
$$




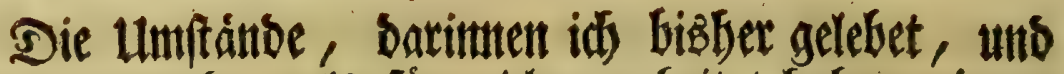
fúr anbere mebre, als fiute mich gearbeitet babe, goimtes

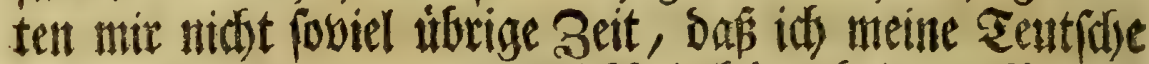

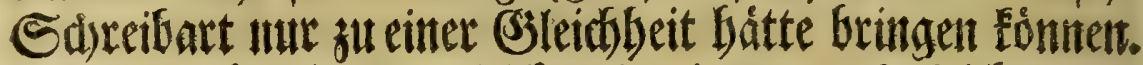

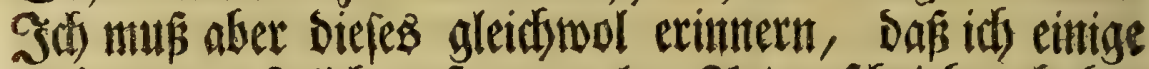

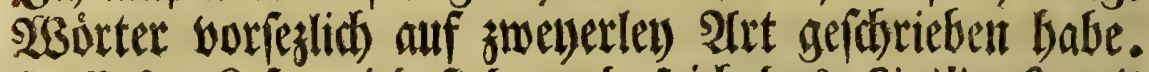

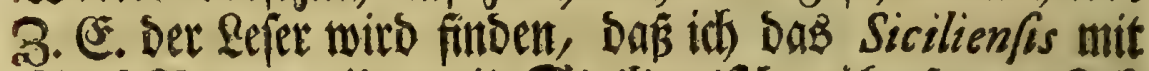

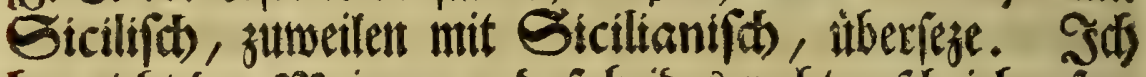

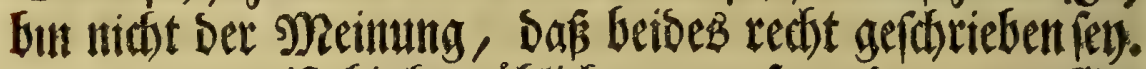
Das zweente ift bisher itblicher gewejen, Der gute G3es

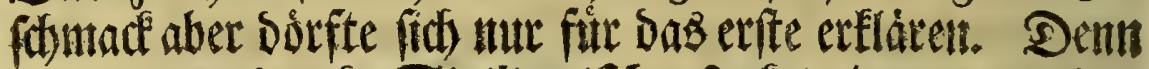

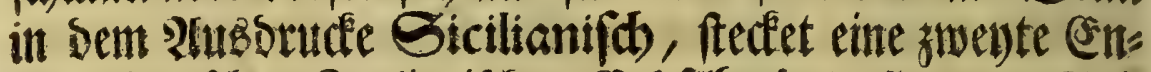

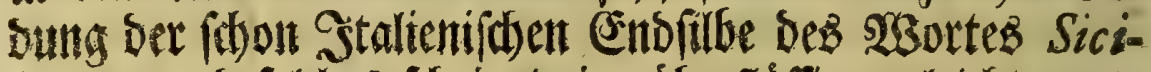

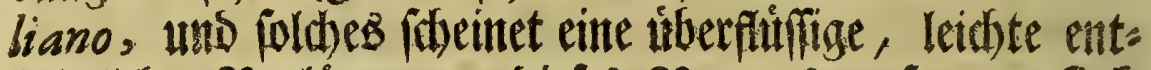

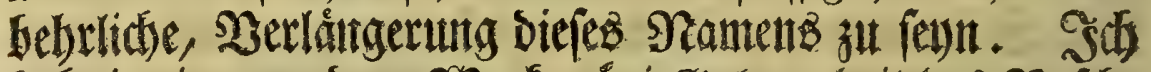

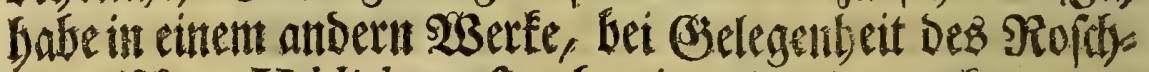

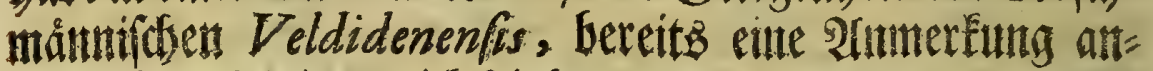

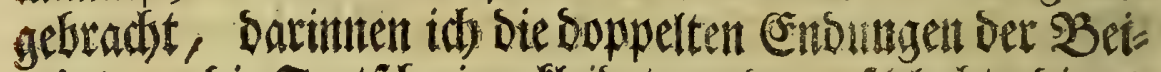

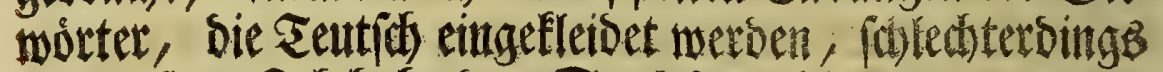

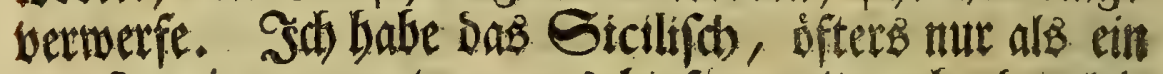

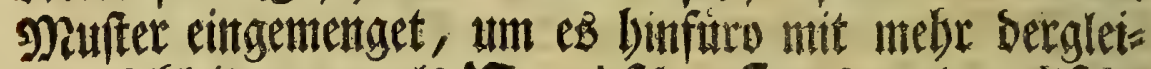

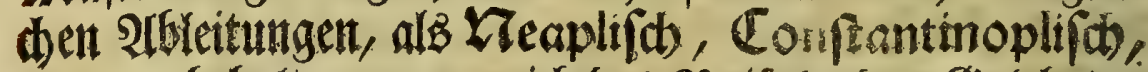

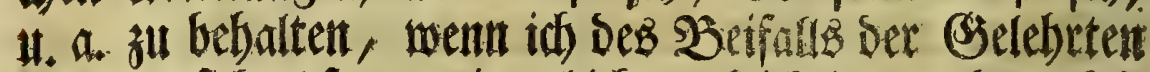

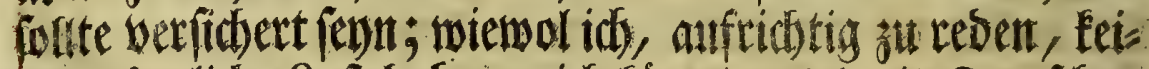
ine ponberlidse Quit babe, mich fing tig viel mit Tettritent

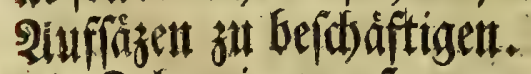

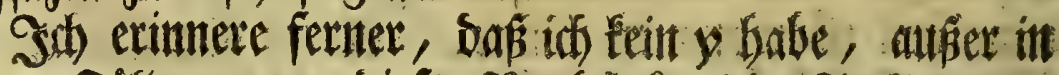

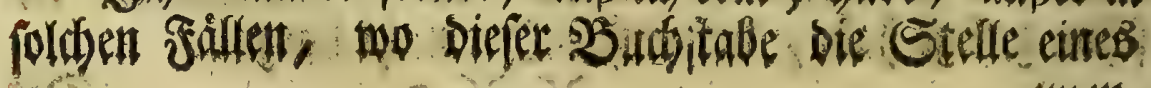




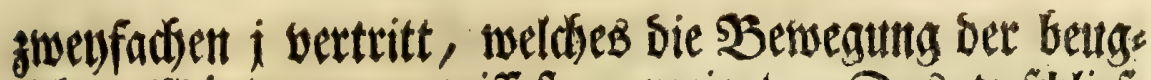

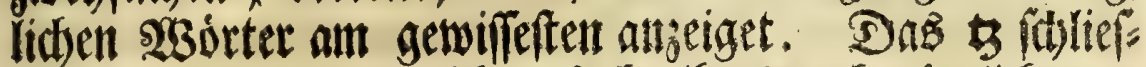

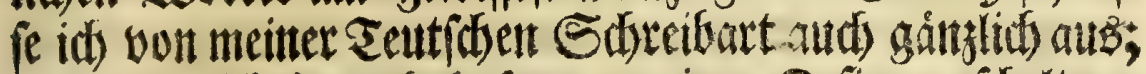

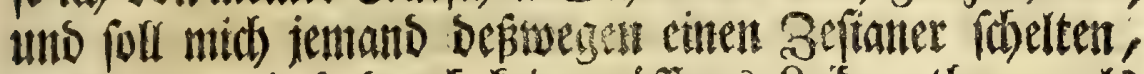

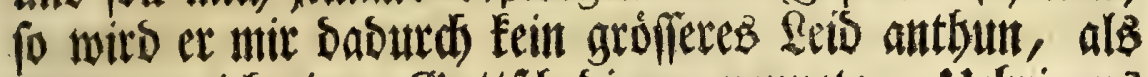
wernt er mid) einen Gonttid esianer nentnete. Ulebrigents

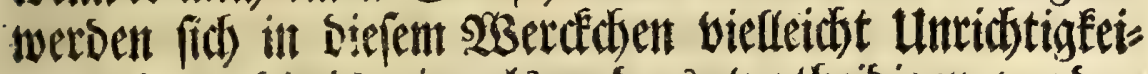
ten finden, bie ich nientals anders vertheibigen werbe,

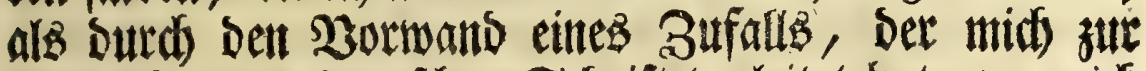

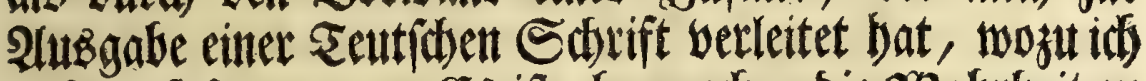
nidft gefajt war. (Es ift aber auth), bie $23 a b r b e i t ~ z u$ gefteben, eben iat bas SRidten, bas Tenbern, bas

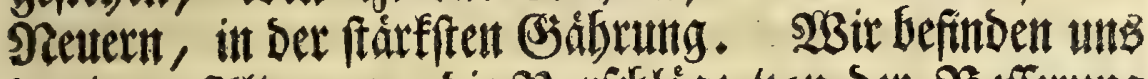

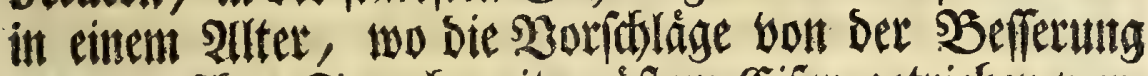
ber Tentefien Spracte nit groftem Eifer getriebent wer: ben, und borfte folglich eloent iat am wentigften eine Firt

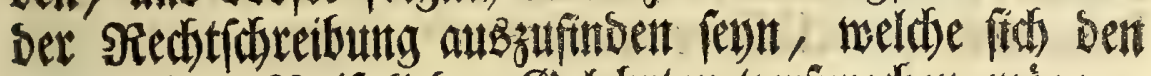
allgemeinen 2 eifall Der Gelebrtent berpurethen móge.

Dent id benfe mol nidt, wie ber Str. Berfaflet

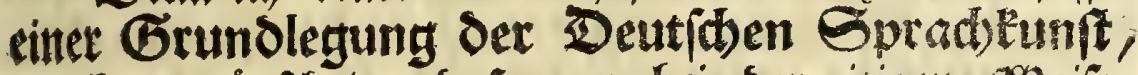

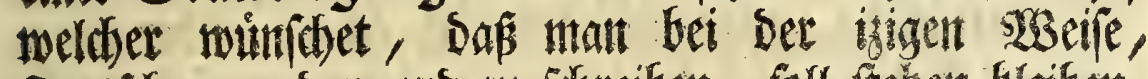

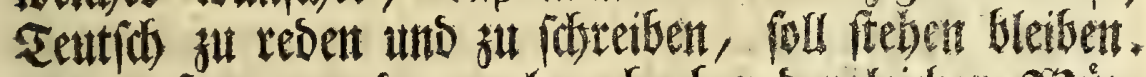
Die Befianter werdent wol auth eben bergleicten 23 itt

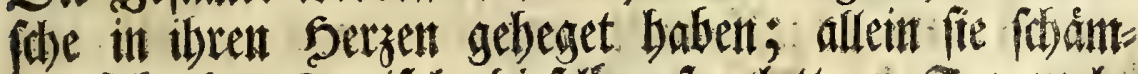

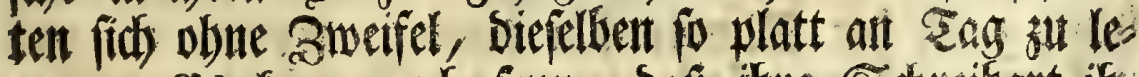

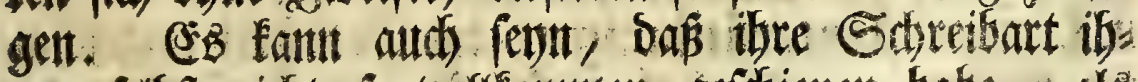

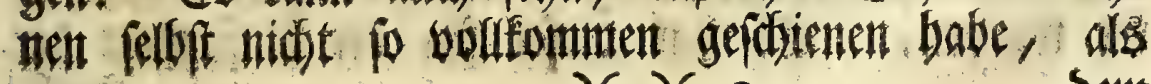
$x x_{3}$ 
Dent Grumbleger biejer Surad)funtit bie Seinige. Dent

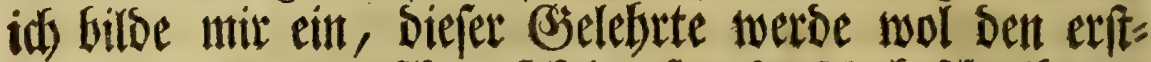

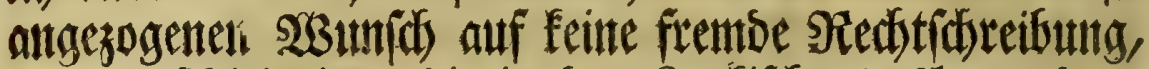

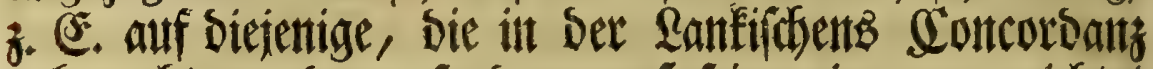
gebrautfit morsen, fondern autf feime eigene, getidstet

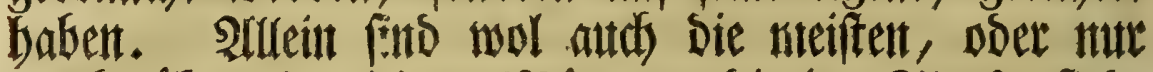

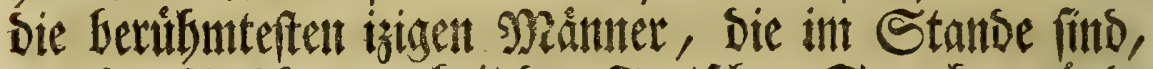
vout Der 20 offonmmentbeit Der Tentifitent Spradbe grimb:

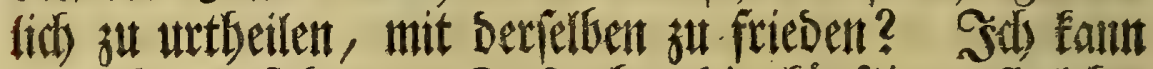

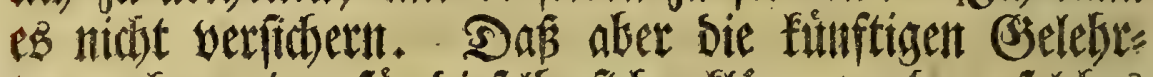

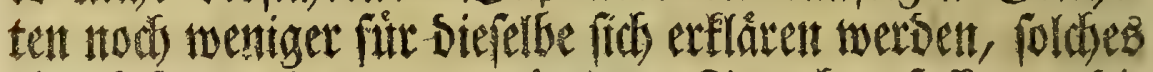

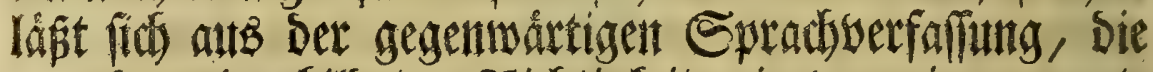

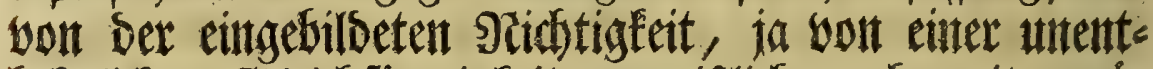

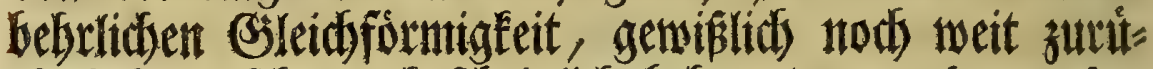

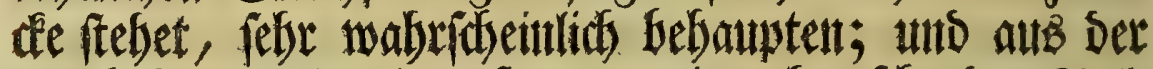

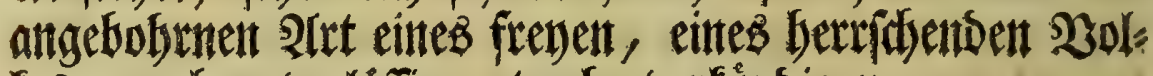

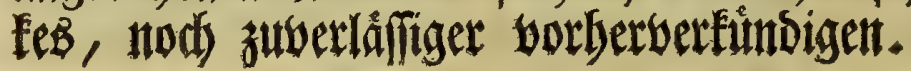

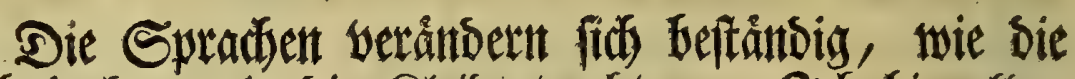

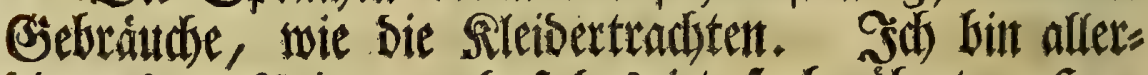

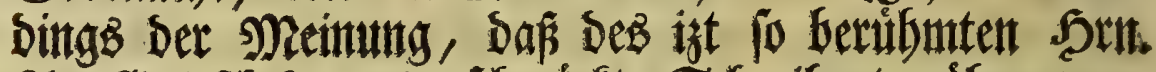

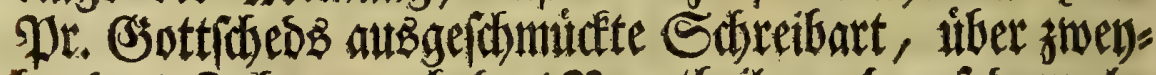

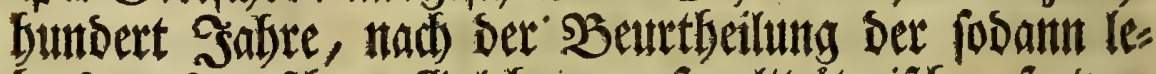

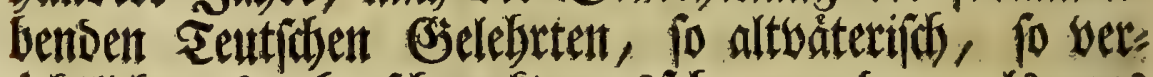

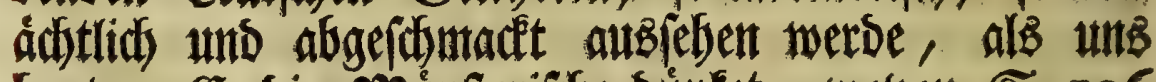
bente 3. E. Die Minnferifose suinfet, trobont S. 196

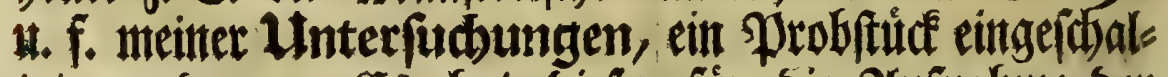

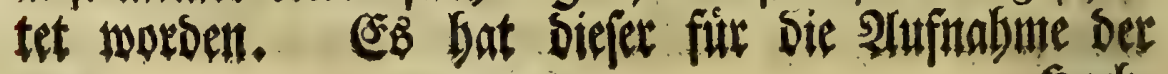
Sold) 


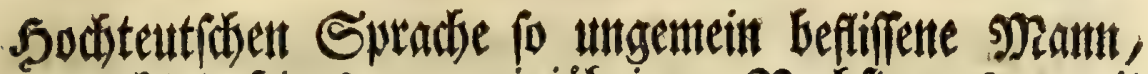

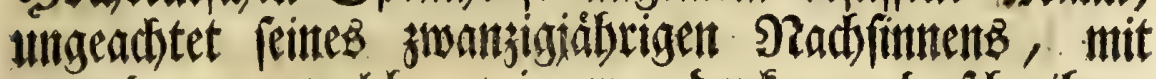
alleen Denten, weldse; wie er, benfen tnto iftreiben,

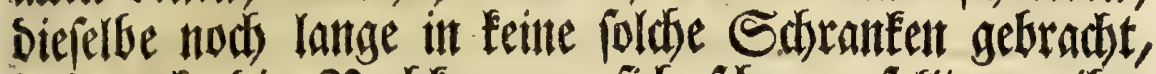

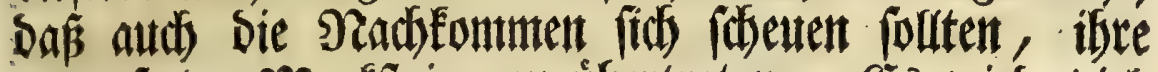

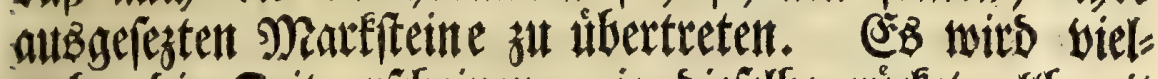

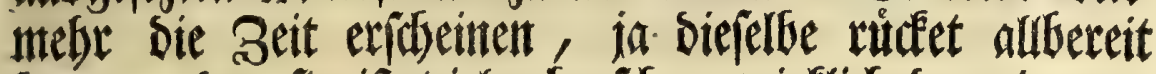

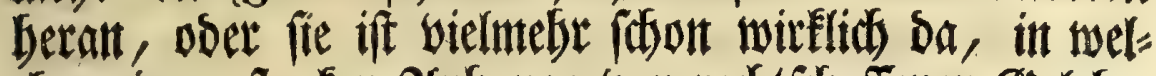

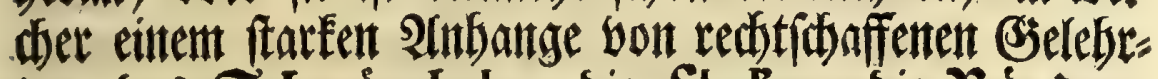
tetr, Das Sdimáutbeln, bie flecter, bie Rámber, ento weis nidft miebiel anbere Dergleidsen $\mathfrak{Y} 3$ sirter, fo bejontoer yorkonment Dorften, all Den 2 Bertheibigern

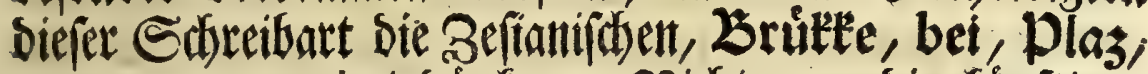
puzen, uttgereimt buintent. Saidst nutr bie funftigent

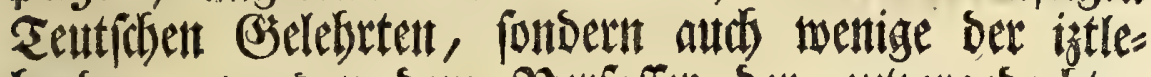
benbert, werbent Dem $\mathfrak{B e r f a f f e r}$ Der ztuorgebadtent Sorunblegung, das banketiren, bankerutiren, calciniren, cambiren, canoniren, canonifiten, capelliren, capiteln, cafitiren, caviten, citiren, collationiren, communicien, componiren, cons

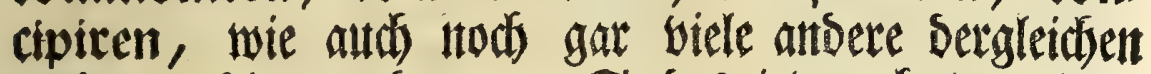

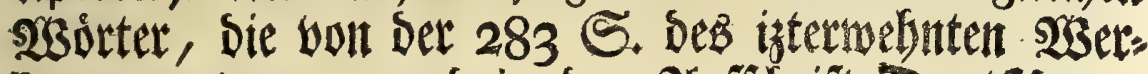

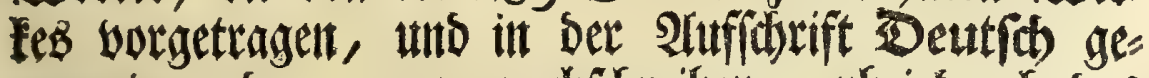

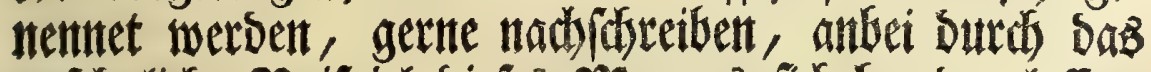

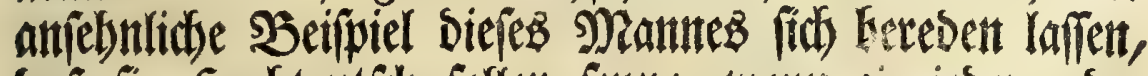

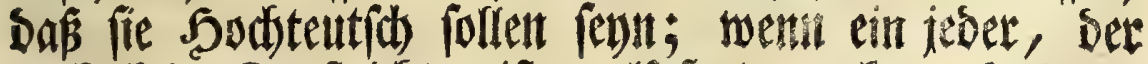

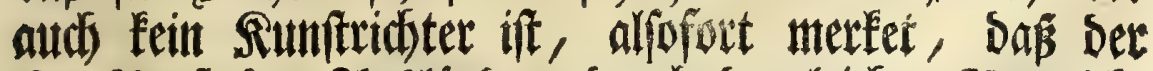

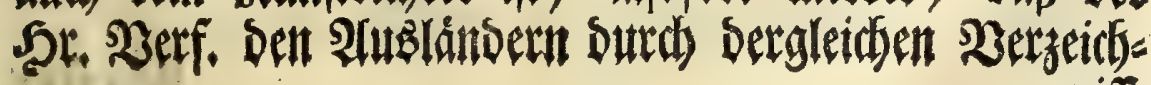
nifie 


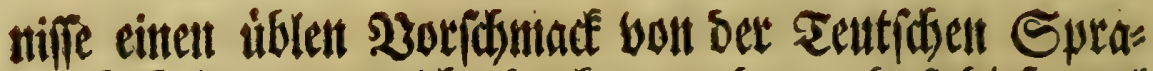

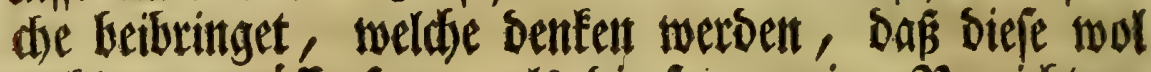

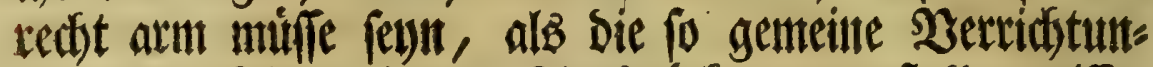
gen, mit feinen eigenent 2It Die Sdutlo liegt nidgt ant ber Spradse, fonbert ant

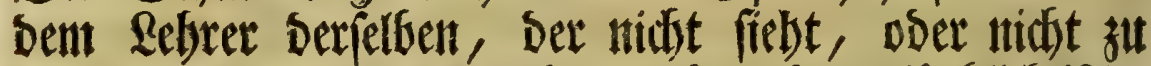

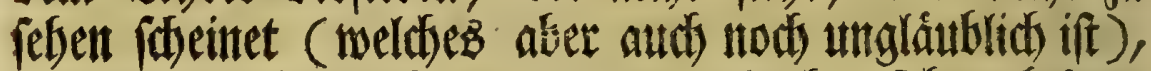

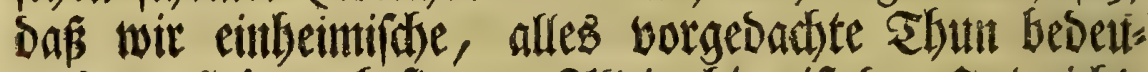

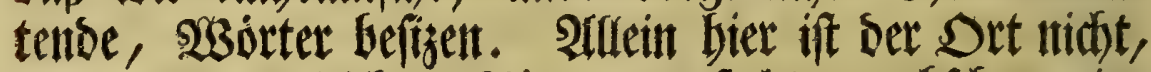

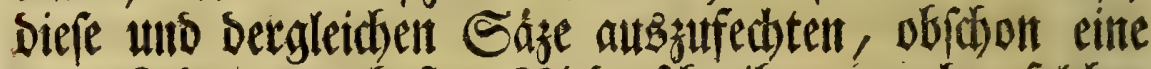

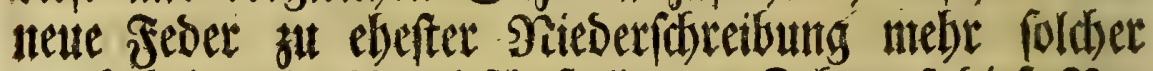

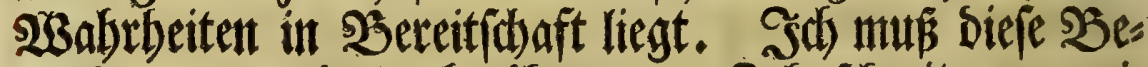

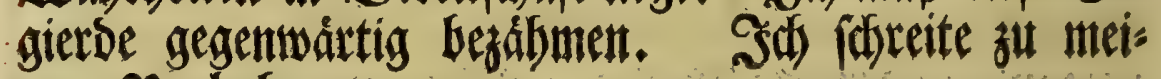
nem Sorbaben. 


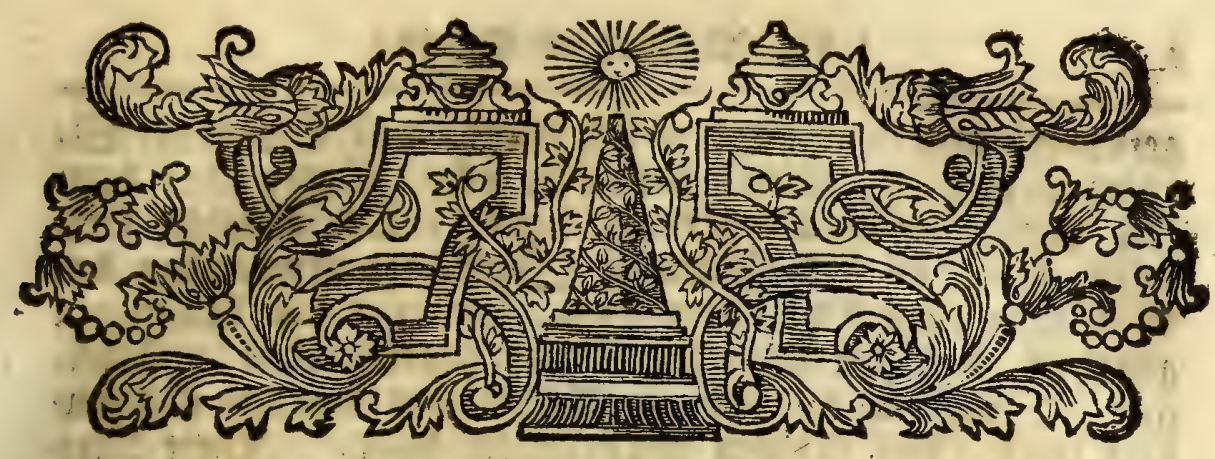

\section{Geriter Silfeil.}

Recenfid bet Sifurift

DE

\section{COLVMNIS HERCVLIS,}

\section{mit furfen 2utmerkungen.}

920 m I $26 / 4$ it te beridtet Der Serr 3 erfaffer, Daß́B Dic Columnæ Herculis von den meiften Sdbrift: fellern an der Gaditanifasen Meetenge gefiudt werden; allein barimnen fímen fie nidto úberein, ob eв ronfirfafte Sáulen, Statuen, Sf hirme, gewefen: doer ob man zwed Zorgebirge dadurd veritefen foll.

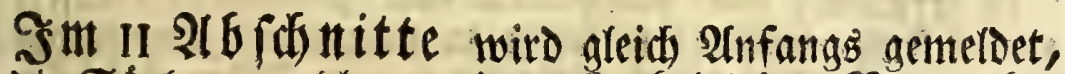
das die Sáulen, welde von dem bertuleg den Namen ba: ben, zuneilen folechtwea und ofne Beinamen, Columne,

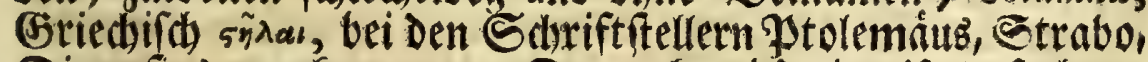
Dionyfius, vorénmen. Darnadh wird eine linterfudsung

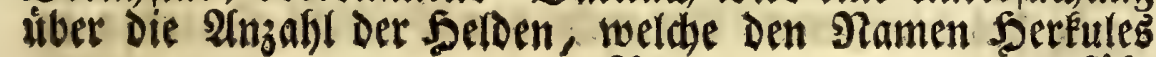
wathl? gefiut): 


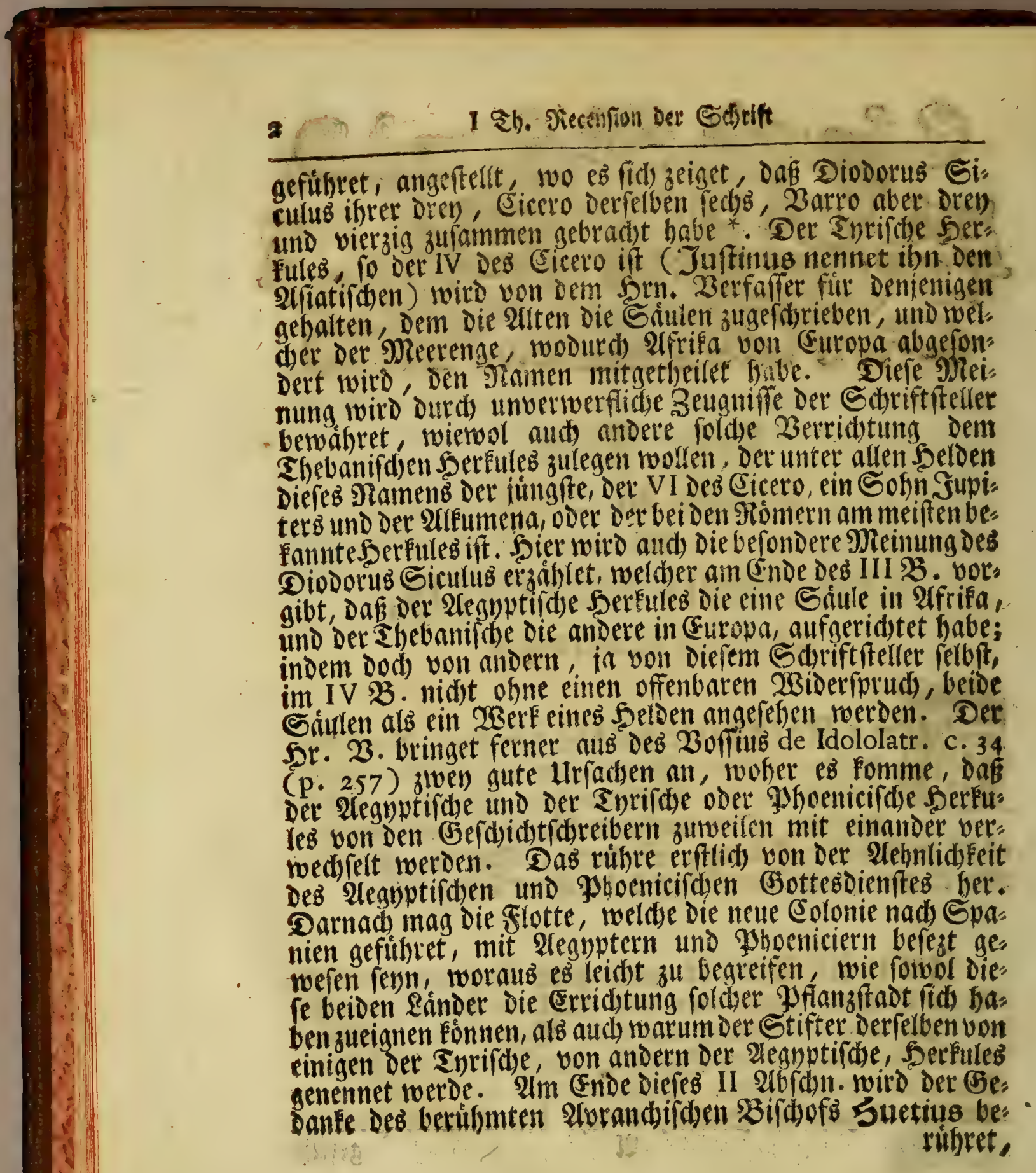


rifbret, welder im Bude Demonftratio Evangelica prop. IV, zu erweifen fid bemuhet, Das Die (S)efdidhte Dez Sofua und Eamfons unter Den Namen Der Serfulifden Shaten toiren vorgeftellet worden. Soldeb will der $\mathfrak{5 r}$. 3 erf. midst unterfuden; fernet audiefes midbt, ob die zwey Siulen des Gebiudes zu Saja zur (5rdid)tung der (3a:

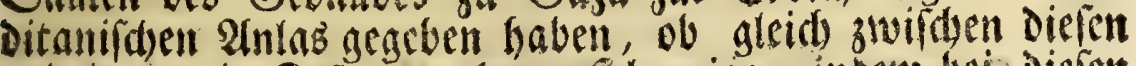
und ienen ein Burammenbang fid zeige, inbem bei biefen Serkules feine Steife, wie bei jenen Samion (I ) fein Ee $^{2}$ bes, geenoiget hat.

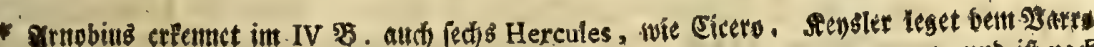

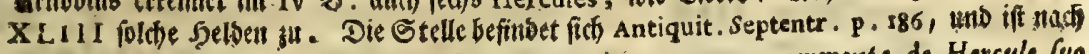
vem billigen Gubalte io nbgefaffet: Qui aguo animo vetersn commenta de Hercule fuo penficaveris, facile doprebendet, Romanos et Grecos, quiliquid unquam infigne ac mogrificum bellice virtutis proditum fwit, ad Herculem fwum retultfie, ac pere non tams unicum beroen, fed omnes fere robore ac egregtis jacinoribss inclytos hos indigitaffe cognomine. Inde profelte eft. qued Varro quadraginta tres Hercules nominat. Fio:

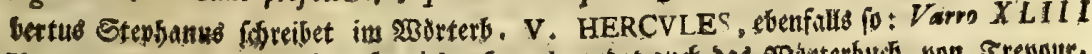

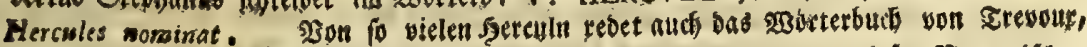

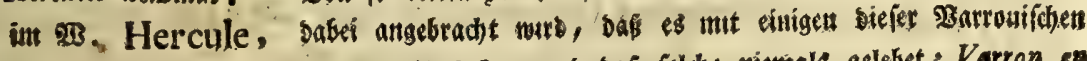
Sgelden eine figurlidje Bewanonif babe, unb tap foldhe niemals gelebet: Varron en compte jusqu' à 43; mais parmi lofguels il y en avoit plufeurs allégoriques et fymbolio

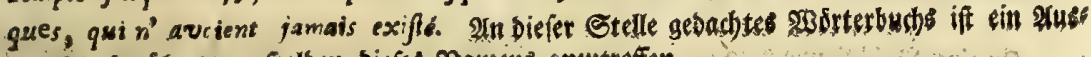

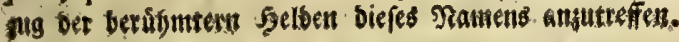

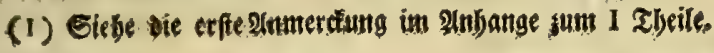

Fm III 2(bfit). nimmt Der. St. 23. Den Saz an; weldten Cellarius Geogr, ant. 1I, 93I, alta alten Edbrift,

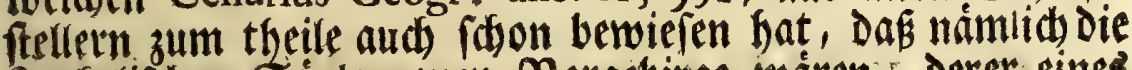

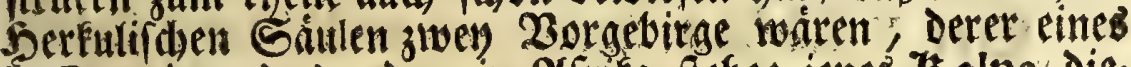

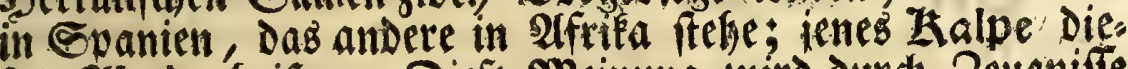
fez 2lbyla feife. Diefe Meinung wiro Durd) Beugniffe

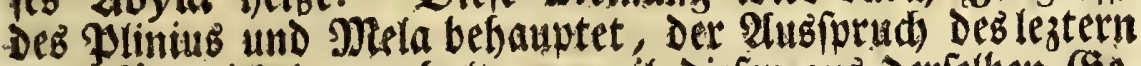
aud für widstiger gebalten, weil Diefer aus Derfelben bes gend Des alten Spaniens burtia geweien, folglid sine wabe: if 2 baftere 
Gaftere Rad)ridt Davon baben und geben Fonnte; weldses aud erftgemeldter Sellarius Geogr.ant.I. 7 I, n. 32, bei ei: nem anjern (Evmeife, als eine Siegel beobadset hat. Sm VIII Ábrd. Wetden aus mebr andern Sdbrifteflern fernere Beftátigungen diefez Sazeb nadigebolet.

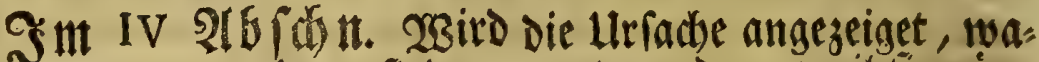
rum diefe SEerge Schulen find genanut worden; weil fie thim:

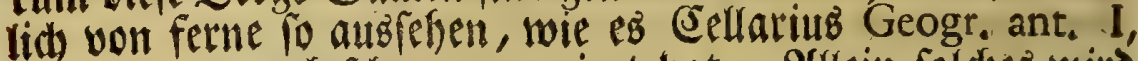

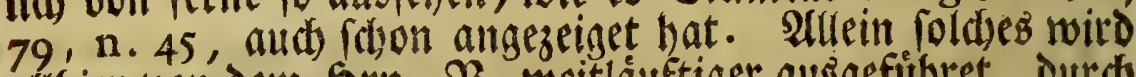

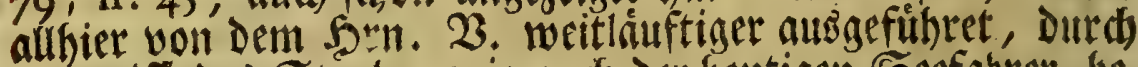
Beugniffe Dez Etratvo, wie aud) Der heutigen Seefahree, be:

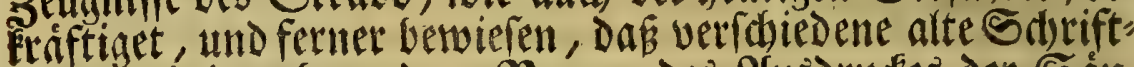

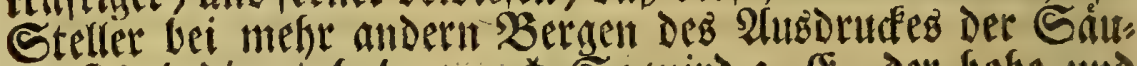
len fid bedienet haben. * Eo wird 3. E. Der hohe und

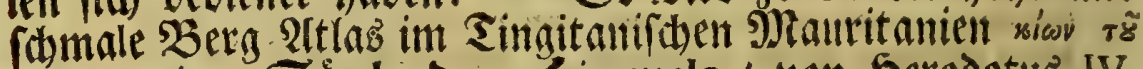

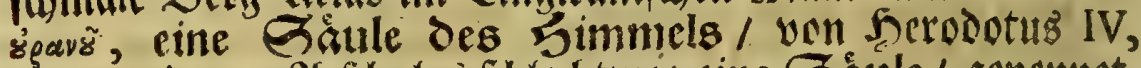

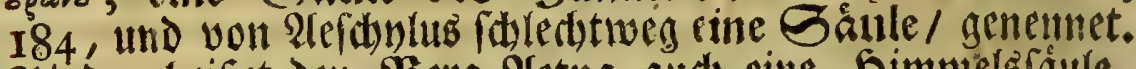

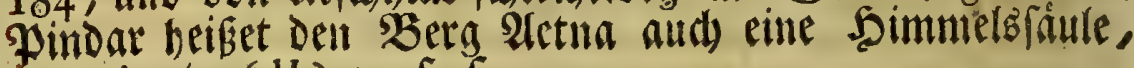

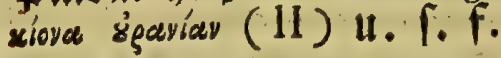

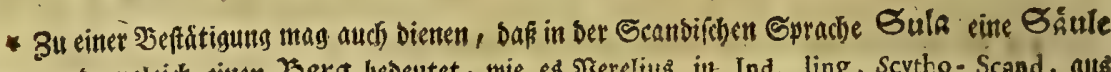

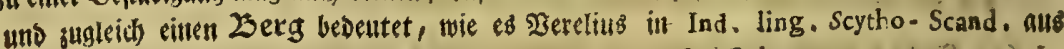
bem 29 Sauptit. Det êtutrefs Gaga beweifet: SVLA, Columna, mons.

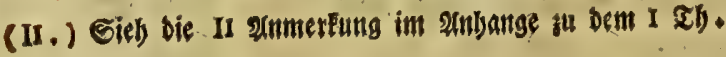

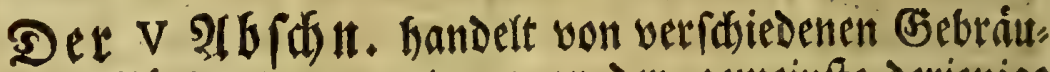
den Der Sialen, worunter zwar Der gemeinfte Derienige ift, Das fie bei šebriuden zur. Bierde, oder zur Nothdurft

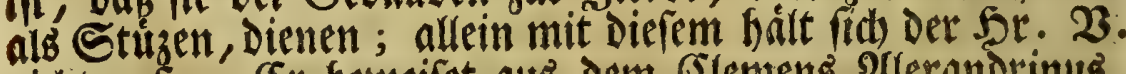
nidit auf. Er beweifet aus Dem Elemens Qllerandrinus,

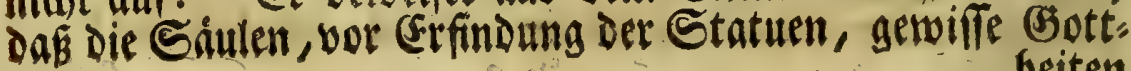
beiten 


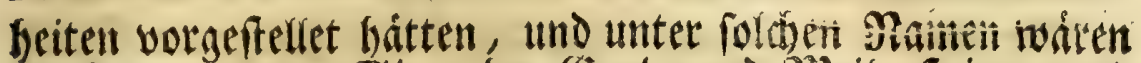
berehret worden. Sie gaben Grab" und gjeilenfteine, aud Eforen = und Denfinale ab, Darauf man rubmlidbe Shaten Det Selden, groffet Serten, und anderer um das gemeine

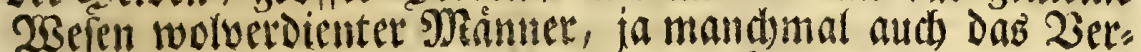
bredien derienigen, aufäzcidunen gewohnt war, die man mit ciner offentliden $\mathfrak{B}$ efdinufung ftrafen wollte. Snlonbers beit aber pflag man getroffene Siundniffe auf Saulen einzu:

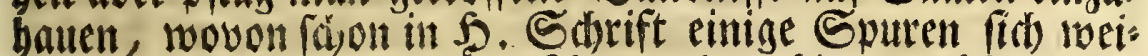
fell. 2Aefdines und Demoftfenes thun biervon iftere Er" wehnung, und \&ivius fithret im 33 Sauptît. Des $2 \mathfrak{B}$. ein Dergleideen mertwurdiges Scipiel an (III). (Endidb babe man die Seaulen aud) alz Drarefteine gebraudt. Der St. 23. beweifet foldsez aus Dem Pollux und Strabo. Altz die Pelopontefier und Soner der Brinizen halber einen Streit

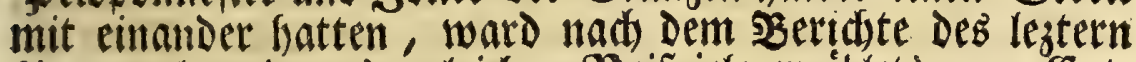
(Der nod) andere Dergleiden Beipiele ergáblet), zur (Ent: fheidung ifrer Gebiete, auf Der (Erdenge eine Saule aufges

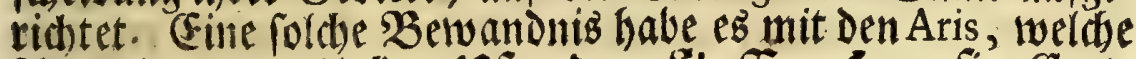
Alexander (am linten ufer des Jlufes 5ypafis Eurt. IX, 3, I 9; qliu. VI, I7, Sard. 2 I), fum angedentern, wie weit er mit feinem feld juge in Sftindien gereidet, nads dem (stempel Des Bachus hat fezen laffen. Sm vorigen 2 b. fduntte erimnerte Der $\mathfrak{S t}$. $\mathfrak{Z}$. Dás aud vou Den Siumern Bacbi are am $\Re$ hein waren aufgefubret worben, wovon nod) Der Name 2 ad)arad) als eine Spur anjuréten fey.

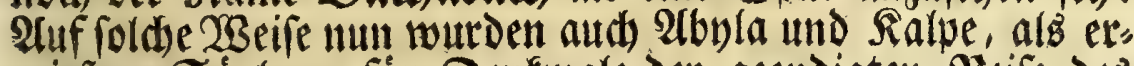
wiefene Saullen, fiur Denfmale der geendigten \$ieife des Sertuleš. gefalten.

(1II) Sieb) Die III Ifrmertung in 2tnbange zum I xb.

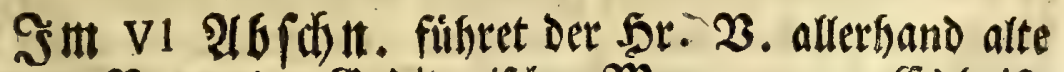

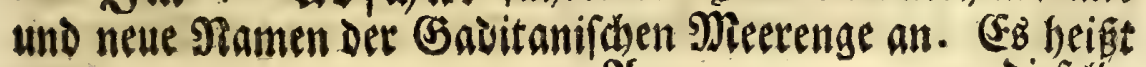
$\mathfrak{A} 3$ Diefelbe 
Diepieibe Fretam Gaditanum, von Der Dabei gelegenen Stadt

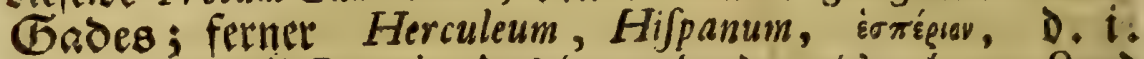
occiduum, weil Spanien Daz lezte abendwerto gelegene Rand von (5uropa ift. Sicero beift Diefe Meerenge pro 1. Manil. 12, die Mundung oes groffen Weltmeeres / Oceani

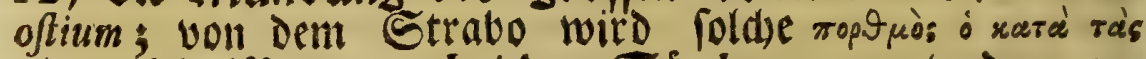

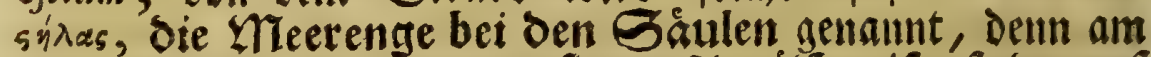
offliden ende derfelben, wo fie am fidmalfen ift, fteben auf

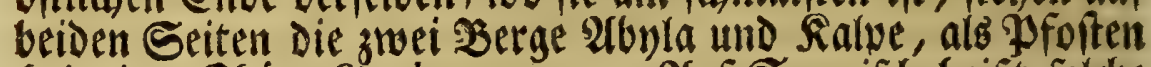
bei einer Sfitre Sirab. $p, 172$. Auf Spanifd beist foldue Geutiges Sagez Eftrecbo de Gibraltar, franz. Detroit de Gibraltar, (Jtal. Stretto di Gibraltar) Seutifis die Strafle, Daber man Diejenigen, fo aus Der Atlantifden See nad Dem

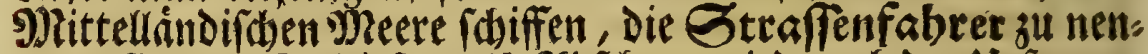

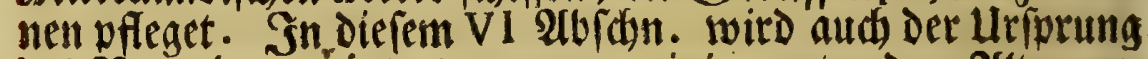
DeB 3 orgebens erortert, warum einige unter den alten ge: glaubet, das afrifa, vor Den Beiten Des Serfules, mit

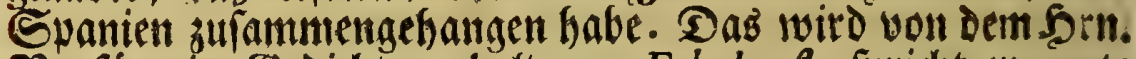
2. fúr ein Sedidste gebalten. Fabula eft, fpridbt er, ante Herculem Hifpaniam \&s Africam iftbmo cobefiffe. (Er be: mibet fid, mit Des 2 offuts 2 borten, die Suelle diefes 2Bafns aufzudecfen, und fagt, man werde Snfangs von diefer Meerenge nidbts gewuit haben. Sndem aber der Sy. rifde Serfules auf Der Spanifden Seite cine Snifl bevol: fert, und Darauf Die Stadt Babes / Die izt Cadit heifit (IV), erbautet, to waite erft gedadbte Meerenge befannt worben, und fódann Die Meinung aufnefommen, Serkules habe Die Erodenge Durdbeftoden und Dem átlantifden Meer Den Eingang in Das Mittellándifbe erofnet. Sier trẹgt Der 5 r. 3 . Die feltfame Meinung Des Diodorus Sis culus vor, welder im IIII $\mathfrak{B}$. a. D. $158 \mathrm{G}$. fdureibet, er wolle den Grund ober Ungrund Derienigen Erzaiflung, wo

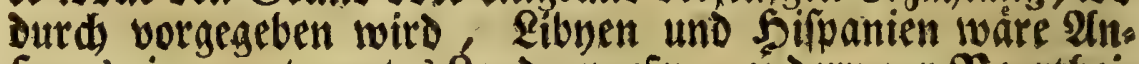
fangs ein ungetrenntes $\mathfrak{E}$ and gewelen, andern zur $\mathfrak{B}$ curtbei. 
Iung überlaffen. $233 a b$ inn betreffe, hielte er vielmete da,

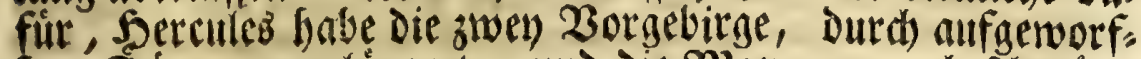
fene Dónume, verlängert, und Die Mietrenge nod fđumáler gemadt, um den $23 a$ alfirctien Dadurd) Den (Eingang auz Der groffen See in Daß̉ Mittellindifdye Meer zll verwebren. Sei Diefer Selegentheit wird von bem Strn. 23. eine 2\{n:

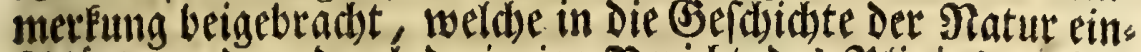

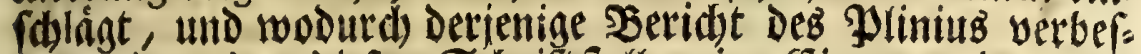
fert wird, Den Diefer Sdyrifteftller im Eingange Dez Drit:

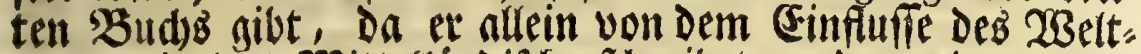

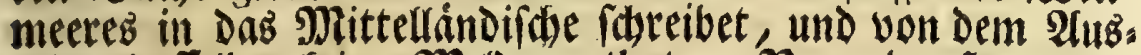
tritte deffelben feine Meldung thut. Nun aber $\mathfrak{C E n}^{\mathrm{ez}}$ ges

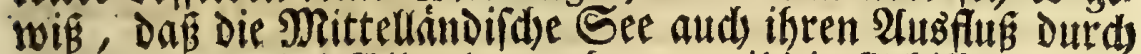
Die Meerenge bei Sibraltar nehme, weil die Sdjiffe auf Der:

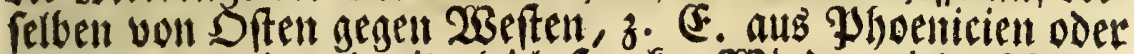

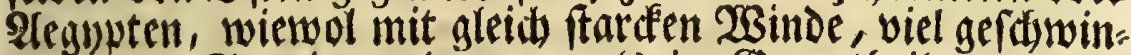
Der naw Spanien gelangen, als im Eegentheile von Den

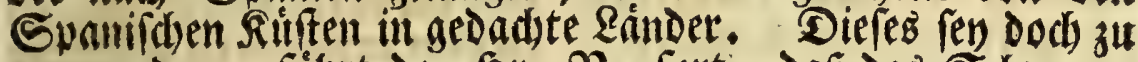

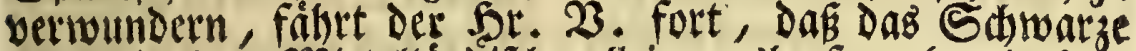

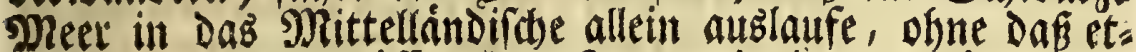
was von dem Gewéffer diefes \&eztern in jenes zurúté gefe;

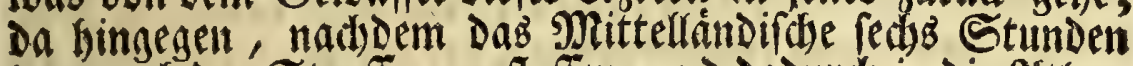

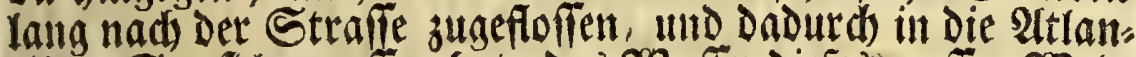

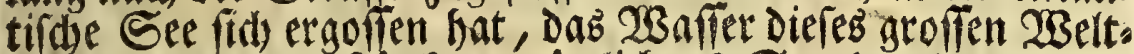

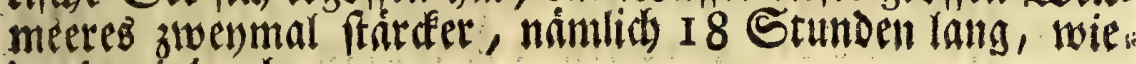
Der bereintredbe.

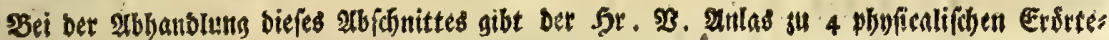

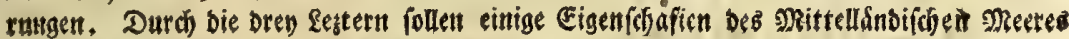

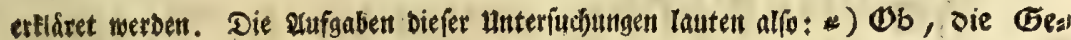
fhichte, ooer oie fabeln oes bettules beifit gefert, es alleroings für ein

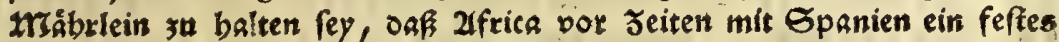
Lano geweén. 6) Dokum ein Schiff mit gleid farfem Doinoe, bon

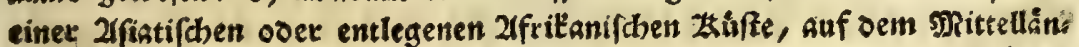
sifhen treere, boch eber nad Spanien fomme, als pon oort zuxúdte: 


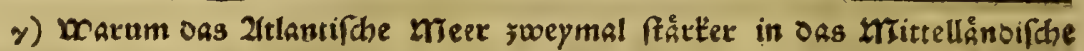

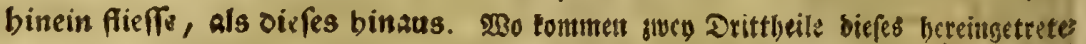

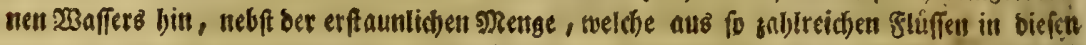
grofen bejalter von allen Geiten rimet? 8) Datum oas Schwarze Mieex nut einen 2usfuß in oas Mittellánoifare, obne einigen boleoerfuß̉, babe; D. i. mober es fonme, Daf in ben guen geerengen, beren cine bei Eonftantisopel, bie andere zmiffeell Den Darbantllen fich befindet, feine Slutl) uno Ebbe gefpuret twerbe, gleidj:

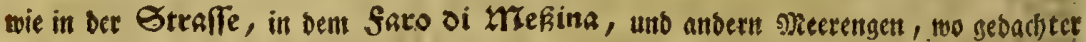

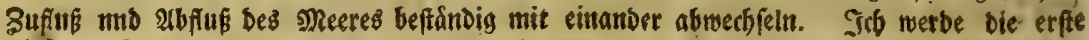
biejer $\mathfrak{2}$ ufgaben mit Nein benntworten, bie lejte nach meiner menigen Einficft unterits:

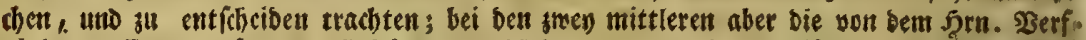

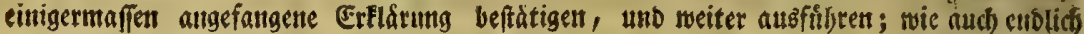

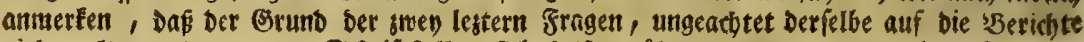
vieler alten uno netern Sdfrifffeller fich fieifet, fiberbaupt zu reben, nid)t fonme alt

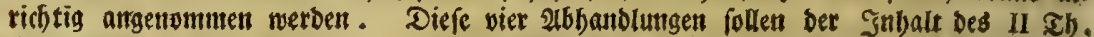

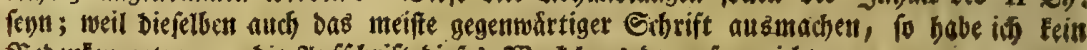

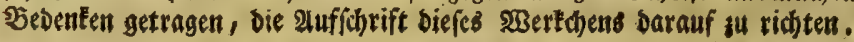

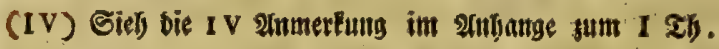

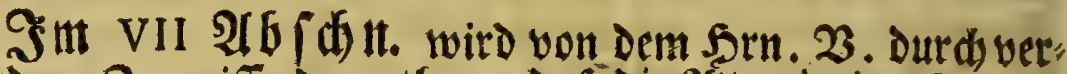
idjiedene Beugniffe Dargethan, dấ Die Vliten in Der (Segend Der berkullifthen Säulen, D. i. an dem vermeinten Ende der

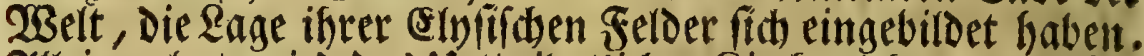

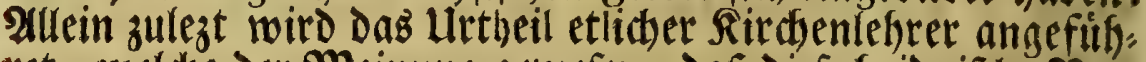

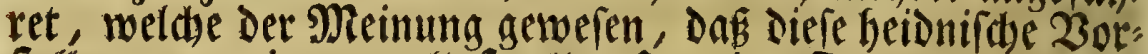
ffellung von einem wolluftuollen Sote der Frommen, aus̉ der $\mathfrak{B}$ erdareibung Des Yaradiefes entlefynet fen, indem die alten Griedifden Sabriftiteller Die Gerddidbte von dem glidefeli: gen aufenthalte der zueb erfiten Menfichen geleien, diefelbe aber nadugebendo mit fabelfaften 3uffázen ganj verféfget und verftellet bátten.

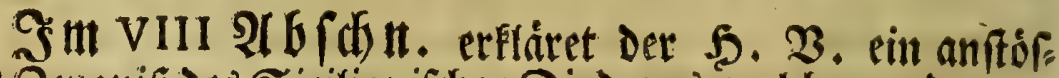
figez Beugnis des Sicilianirden D iodorus, weld er a. D. 157

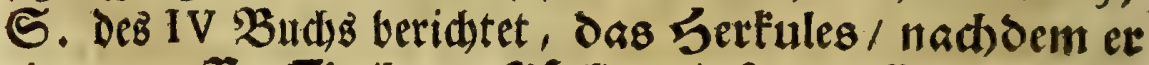
einen grofien Cbeil von 21 frita mit feinem Kriegsbeere ourd)geftrid)en / enolid bei Gades an die See gelan: 
get fey. Dort babe er 3 u beiden Geiten bes feffer Landes Sakulen aufgeftellet / und fooann nach Jbes

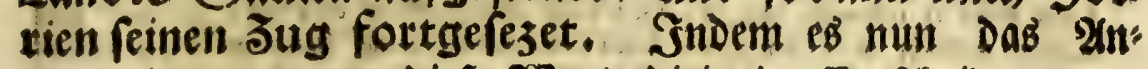
rehen hat, als werm Diefe 2Borte Diejenige Entfheidung vers nidsteten, weldse die Serfulifwen Ssiulen auf Die Berge $\mathcal{A}_{3}$

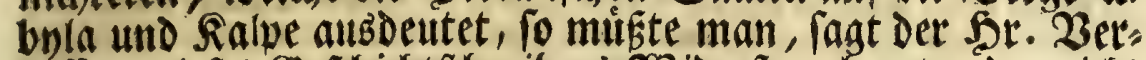

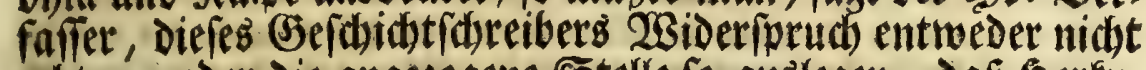
adbten, oder die angezogene Stelle fo auglegen, Daß berfü

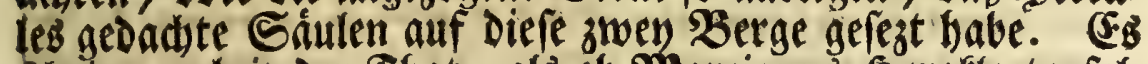
ideine aud in Der Shat, als ob Mrarcianus Serafleota for, dez bekráftigen wollte, indem er bei Errwelinung Dez̉ Ralpe, Die abgefonderten Namen eines̉ Bergez und einer Sónule bei

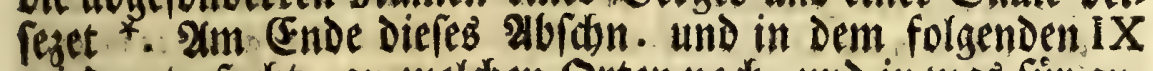
wirb unterfudet, an welden Srten nod, und in wab fü an: Dern Eandern mehr, andere Sdyriftifeller wollen Serkulifitse Eniten aefunden baben; Ferner, wie foldse befidaffen ges ivefert. Suf Der erften angedeuteten Stelle, D. i. beim

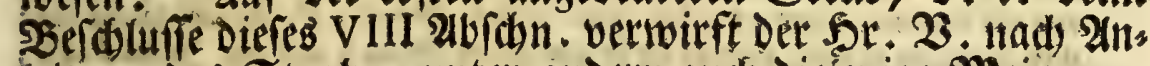
leitung Deb̄ Strabo, unter andern audi dieienige Mieimung, weldte igt gedaditer Sdiriftiteller III, 170 , vortrígt, Da Durd fidon vorlängit wollte befauptet werden, Das die ftrei. tigen Saulen, diejenigen metallenen Sáulen wären, die in

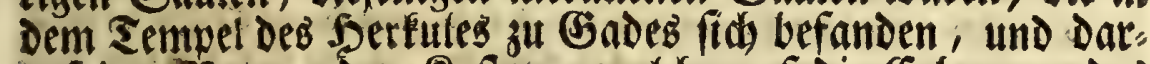
auf Der Betrag Der Roften, weldhe auf Die Grbaunng Des Sempels verweendet worden, aufgeseidunet ftund. Ere jagt,

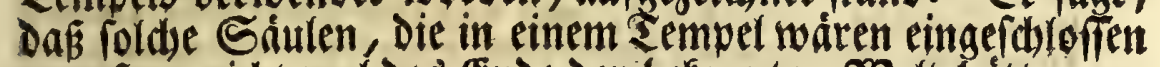

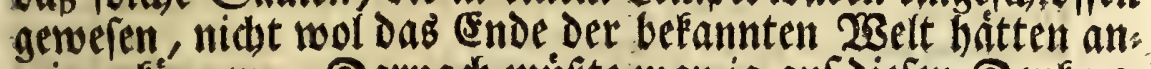
zeigen fónnen. Darnad múste man ja auf Diefen Denfmas

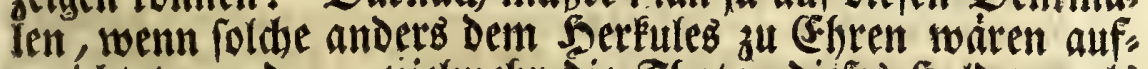
geridutet worden, vielmefhe bie Shaten Diefes Shelden, als ein Zerzeidunis Der $\mathfrak{A}$ uzgaben, welde Die Yhoenicier zut 2luffúfrung erwebntes esebáudes ju beftreiten gefabt, ein: gebauen le én ** 


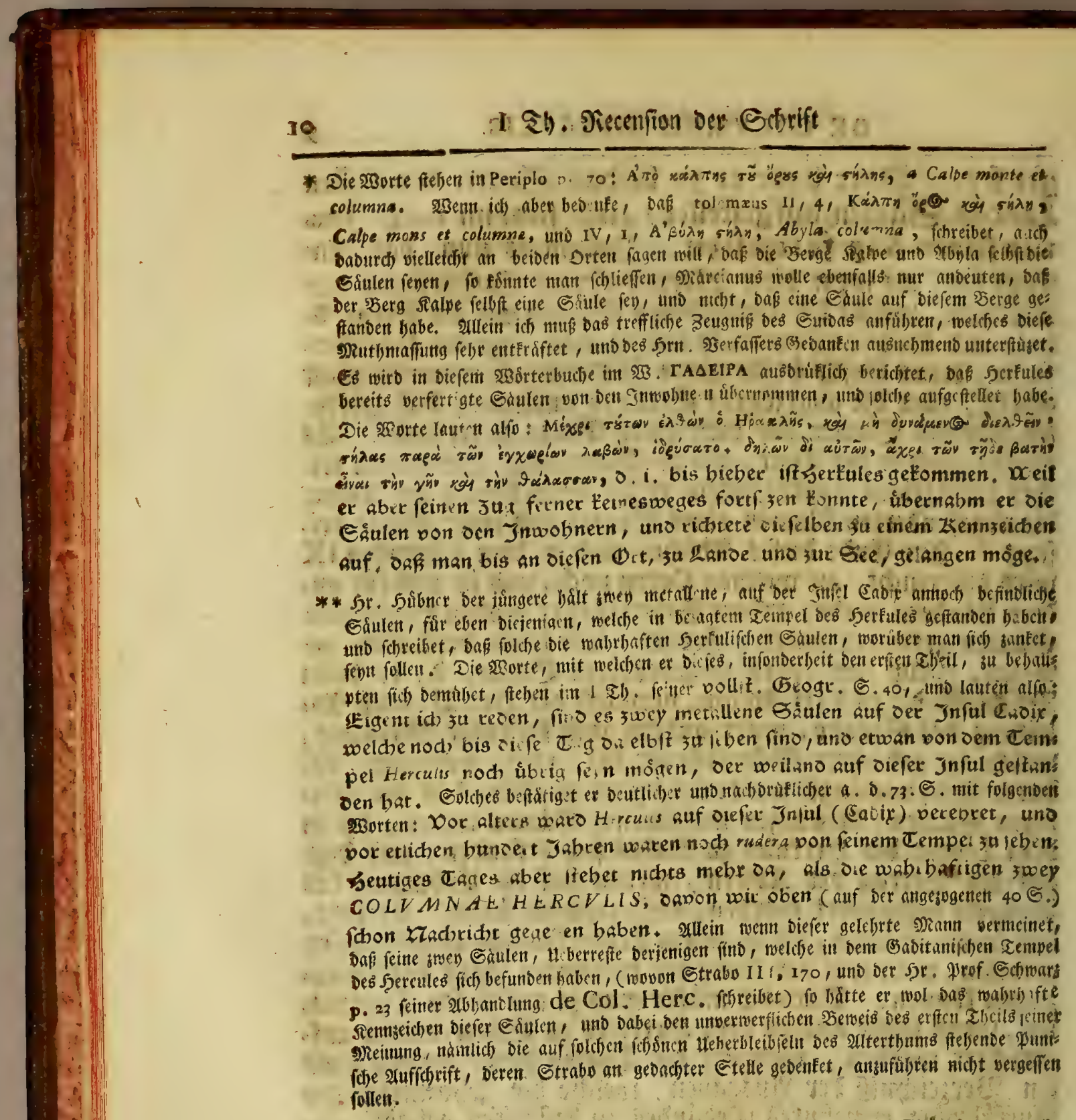


Den mitternidtigen 2 olfern abgefprodsen, wenn gleid $T$ a: citus, Da ex von den Frtefen handelt, Das Gegentheil ver: fitibert: Et fupereffe adhuc Herculis columnas fama vulgavit, Germ. 34,3. (E. ftimmet Der Sar. 23. Sengletn bierinnen bei, weldher Dasjenige, waš fdon Sacitus von dem (Serúdbte eines nordifhen Sertulez gemuthmaffet, in groffere Berwis. beit fezet, ong nermlid Die stomet, was fie von den einbeimi fhen 5eldender Seutiden rifimen geforet, wegen 2 ebnlid feit Der shaten, auf ifren Serrules ausgeleget batten. Denn Sacitus zocifelt relbit, ob der Serfules jentals in die mitter: nadtigen Rander gefommen fen, weil er an erftgedadter Stelle lo fortfáfer: Sive adiit Hercules, Jeu quidquid ubique magnificun eft, in claritatem ejus referre confuevimus. Die in Sorden an mebr Drten befindlidben Denemale von uberaus aroffen jufammengetragenen Steinen, hitten Den Fomern 2lnlas gegeben, foldbe fü Saulen des Sertules zu balten.

Sit X Rffott. wird die Frage aufgerworfen uno beantwortet, ob in Spanien annod einige Spuren bon den

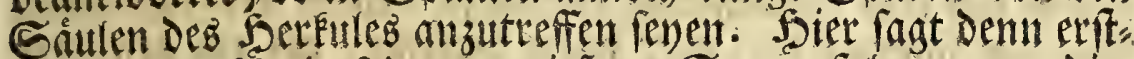
lid Der $\mathfrak{S r}$. 3 . Daf dem erwiefenen Saze zufolge, wenn die:

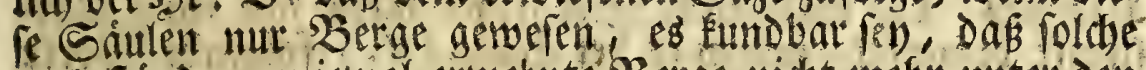
nod fintiden, wiewol erwehnte Berge nidt megr unter Den Ramen 2lbyla und Zalpe, fondern unter andern neuern be: fannt waren. Der erfte beift in Spanifber Gpradbe Sierra Ximiera, oder Sierra de las Monas, Der Zlfenberg. (Se witd aud won Det nafe gelegenen Stadt, oer Serg von Ceuta, beigenannt. Der Berg Ralpe, welder am (snde von Evanien nad) Qfrifa zu, und Dem Śbyla gegenuber ftebet, hat von Der theilb Darauf gebauten, theils Dabei liegenden weltbefanten Feftung und Stadt Bibraltar feime neuere Benennung úberemmen ${ }^{*}$. Sier wiro eine ungegrübete SB 2 und 
und ungereimte Meinung Der peutigen Epanier miderleget, welde zwey bei Sadix befinditue, ungefábr is Sobub bobe, und im Durd)fonitte 12 oder I 5 Gdub breite Sfurme, Des

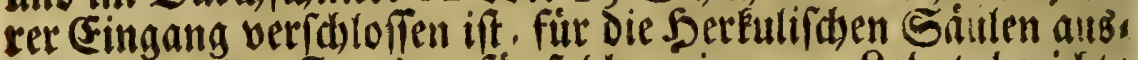
geben, und den fremben fir folde zeigen. Rabat berifite in feinem Voyage d'Efpagne, er babe Dieje sluteme mit feis nen Keifegefíbrten beobadbtet, fie batten aber foldse einbel. lig fut zwen betlaffene 2 Bindmublen gebalten, die in foatern Beiten alloa waren erbauet worden. Diefe Rabatifibe Sr: seblung Gat Alvarez de Colmenar in feinen A inal. Hifp. \& Lufit. wiederfolet nito beftritiget. Ferner befennet Der Sr. 23. Daf́ er in Dem geograpbifduen 23 orterbude bon Mart: niere niduts angetro fen babe, auber was er bereits gejamm:

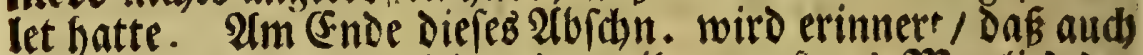
Der berúbmte 2 Bagenteil, ein weil. gewefenes Matalied der boben Sdule zu sutorf, auf feiner redbólábrigen Reife, die ef mit Fero. Srnft Srafen von Sraun und abetsbera Durd ganz Suropa gethan , mit Dem er Spanien, und von Danmen aud Das nidit gelegene afrifa, befud)t bat, feine lleberrefte von den Gaulen des Serfules mit Te entoedet haben, fonft wurbe fid) eine (Stwebnung Davon in feinem geograpbifden Subzuge finden; tool aber bárte derferbe, als ein gelebrter

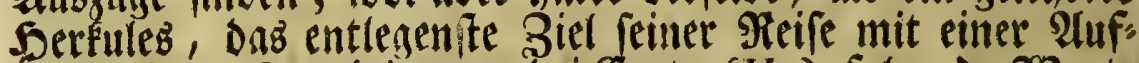
furift bemerfet, indem er bei Seuta (V.) folgende 2Borte in einen Gtein eingebauen binterlaffen:

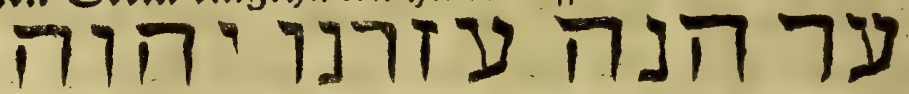

bif bieber bat uns oer SKer gebolfen/ wie er es felbit im swenten Fadue feiner Pera Juvenilis, und gnar im XXXVIII Sauptif. feiner Synopf. geogr. beridtet.

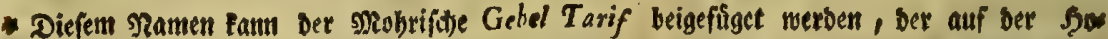

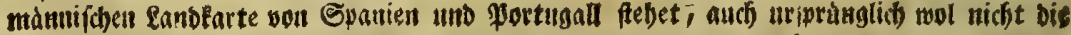
Gtabt Sibraitar, fondern Den शjerg, baran lie gebauet ift, mofite angezeiget baben. Gebel Tarif beift io viel, als oex Zarg oes Earifs, oer Carifoberg, meldben 


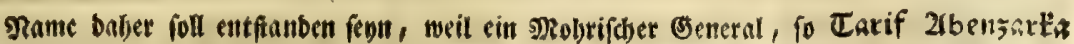

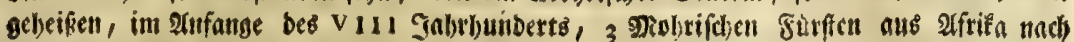

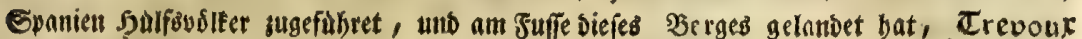
Im $203 . G I B R A L T A K$ aus bes Neuville hif. de Portug. T. I, p. 17. Don cket

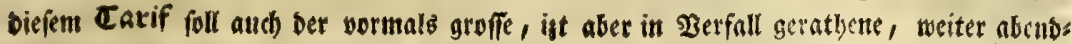
werts an Der Straffe gelegene Drt Carifia ben Ramen uberfonmen baben. Ciebe bie

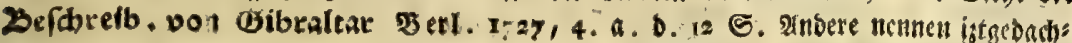

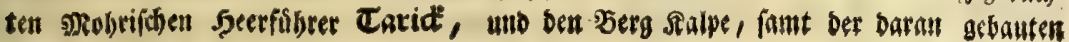
Etadt, Gibel, Catict.

(V.) Cieb vie V anmertung in anbange jun I 2 h.

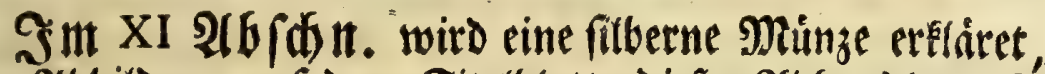
Deren Qlblildung auf Dem Sitelblatte Diefer 2 bbandiung de COL. HERC. fid) befindet. (Fiz fellet diefelbe auf der baupt:

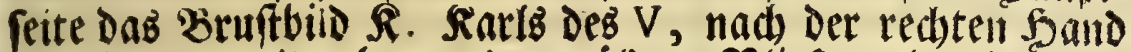

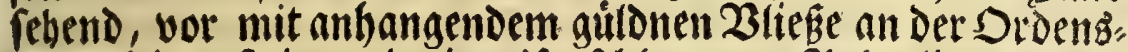
fette, die auf einem breiten Ulmíthlage von Pelze liegt. Das Saupt deş Saifers ift mit einem Barete bedect. Die Llm. fdrift lautet 10: CAR. V. ROM. IMP. AVG. HISP. REX.

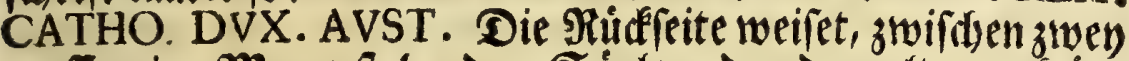
aroffen im Meere ftehenden Skifen, Den Dopuelten gefron.

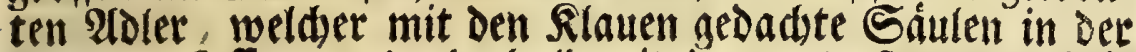
Mitte anfaffet, und oberhalb mit Den ausegeipannten $\mathfrak{s}$ :

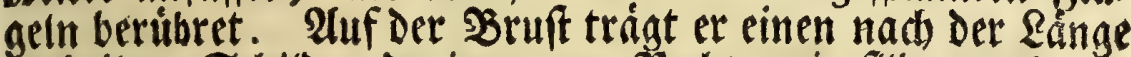

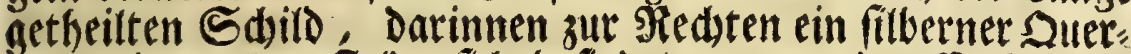
balfen im rotben Felde fid befindet, wegen Des serzherzog, thumz Sefterteid). Bur Sinten follen, wegen Des Serzog,

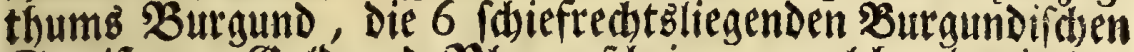
Streife bon Gold und Blau erfacinen, welde aber in ber figur unredst mit Silber und Roth voraeftellet werden.

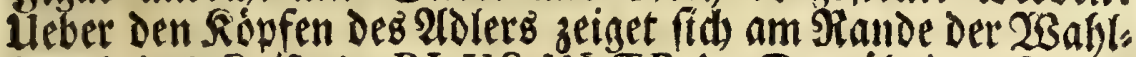

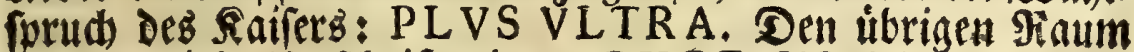
nimmt diffe LImfdrift ein: QVOD IN CELIS SOL HOC IN TRA C ESAR EST. A . 1548. 2(uF Dem redten Arme Des Saifers find Diefe Bwen mit einem Meif $\mathfrak{B} 3$ 
fel gefdnittene Budbraben H. B. zu fefen, wobei Det 5. 23. anifefet, ob rolde den Befizer diefes SEeldefuctes, oder den Minger andeuten rollen. Quf einem andern Stu" dfe, von eben Diefem (jeprige, Gat er Diefe Budbitaben nidts beobatbtet. Sndem um Diérelbe Beit Sans Ziener von Reifnig geburtig, am Sidy)fiben Sofe als Mimzer fith auf: gefolten, to mutimafiet der $\mathfrak{S t}$. 2 . Dab derfelbe auf 2 er: anlaffung Sauriti, Shurfurfens in Sadjen, Der 2 . I 548

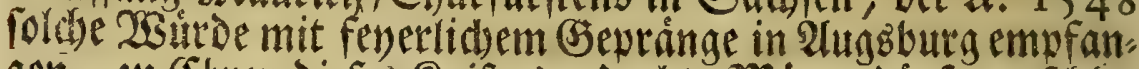

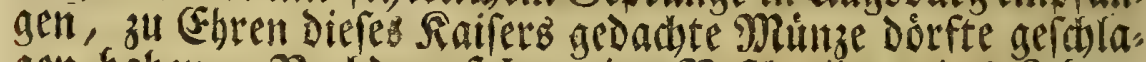
gen baben. Radidem folget eine Beftreibung des Qebens und der Shaten $\Omega$ Rarls des V, wo Der 5 r. 2 . eine 3 erglei:

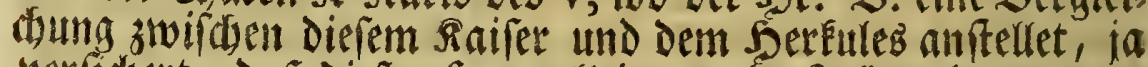
verfitbert, dás diefer Serr alfeine mefr Seldenthaten aus? gevibet, als man Den XXXXIII Serkuln angedidtet bat. Buleat werden die 2 Borte einer Robrede, welde Shuanus auf Diefen Raifer verfertiget, wie auth Die Qubdilderung lei:

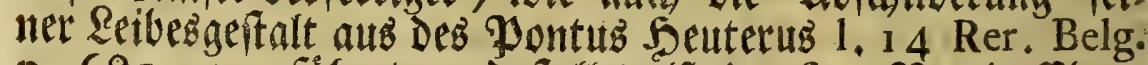

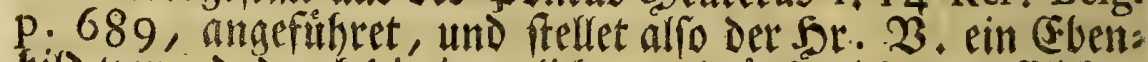
bild vor, Dadurd die innerlicben und siusertidsen trefflidsen Baben Dieles groffen Rairers, auf eine gefdidete art ents worfen werden.

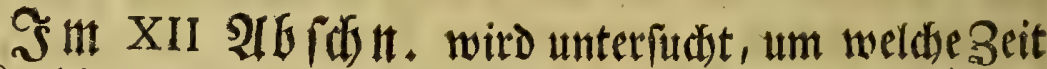
R. Rarl Der V Den $23 a b l$ prud PLVS VLTRA zu fubren angefangen babe. Der $\mathfrak{S} \mathfrak{k}$. $\mathfrak{3}$, folleffet wider Jac. von mellen/ Daf folotes nidit Der im $\$$. I 535 bewerfferligten Eimnabme von Sunis und Der Feftung Soletta in Africa, zu: jufdreiben fer), (wiewol erwefnter (Selebrter fid) auf Das 3eugnis (5nmanuels shefaurus beruffe) indem Reonb. 2Bits lib. Sofmann im Zlten uns t7euen Munz" Sdhluffel/: auf Der VIII Platte zut 288 S. ein guildenes Munzftud $R$ : Sarlz vorfelle, nuf Deften Tưfeite die Jabrzabl MDXXX gwifaen zwey Gáulen ju feben fey. Sa Der bodberubmte Str. $\mathfrak{k}$. 


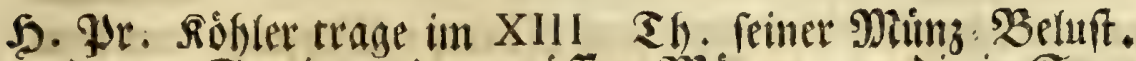
a. D. I2 I S. eine andere groffere Mininge vor, die in Spa: nien efher gepriget worden, als Garl Der V zur Rairertiden 2Buirde gelanget len, auf Deren redber Eeite Die Mamen Des Róniges umd der Rónigin von Epanien und Ssndien, CAROLVS ET IHOANA, zu lefen find; auf der andern Seite aber ffefen zwen Saiulen, mit dem PL VS inder Mit: te. Die $380 r t e$, mit weld)en der Sr. 3 . Die (srorterung

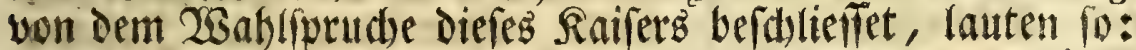
Ea certe fuit tanti C AES AR IS magnitudo animi, ut iredam, eum boc jymbolo (PL VS VLTRA) non tantum progrefjum Hifpanorum in India occidentali refpexiffe; fed etiam figniffiare unluiffe, fe, quae celfifimarum maximarumque mentium indoles eft, nunquam quiefcere in uirtutisftudio, fed, rebus maxim's maximaque gloria dignis, feliciter tam bello, quam pace, g.ftis, Jemper progredi uelle ulterius, ut in dies fe ipfo euaderet melior, ac fe ipfusm tandem boc pado uince et; quae omnium vidariarum eft pulcherrima atque gloriofiffima.

Der Xl1I uns lezte P(bifititt enthált einen Buras.

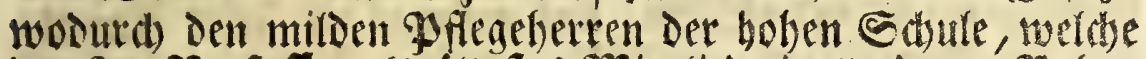

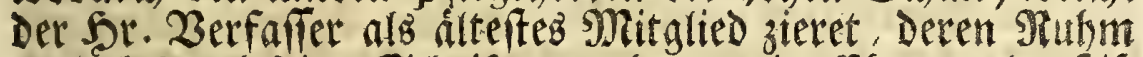

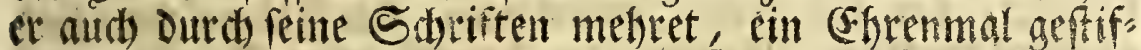
tet twird. (Er behauptet durd eine finnreiche 2 erbindung, Daś auth die Serren Nirnberger an diefem 23 ahlfprudge PLVS VLTRA eincu 2ntheil haben, indem ein Eerhero voriger Beiten, fo alı Der Stadt Nirnberg buirtig geweren, Dả effedeffent vermeinte, und Durd die Serculifden Sinten bejeidunete (Ende Der $23 e l t$, surd feine Edsiffiaheten fo weit

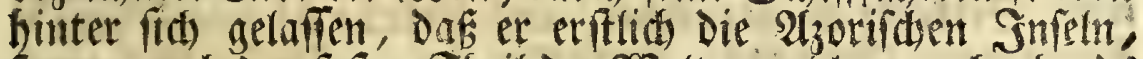
ferner aud den feften Sheil der 23 elt, we lder nadgehenos Qmerifa if genannt worden, fa auth die Mieerenge, welche

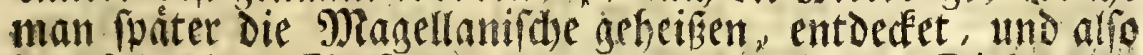
Den folgenden Seefabrern vorgelendetet hat. Diefer eole uno 
I Sb. Fitcenfion bet Edift-

und berufbmte Mitnberger war Martin 25 ebaim, aus dem adelidben, alten, in Nurnberg antod, blíbenden, und um Diefe Siepublik beftens verdienten (Sefdsledte Der Serren

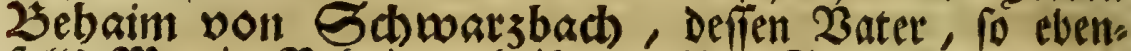
frlls Martiin Bebaim geheisen, allda Senator, uno die

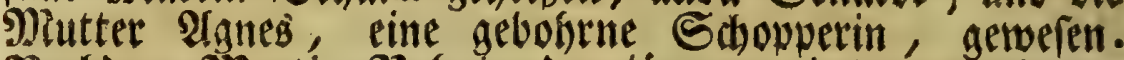
Tadbem Martin Bebaim Der jüngere, in Den matbema tifden $\mathfrak{B}$ iffenfdaften, infonderfeit in Der Sternfebfunf und Erobefdreibung, unter Anweifung deb Sobann Regiomontaluts, eiiten guten Grund geleget, Fam et nods in feiner Sugend in die Siederlande, welde Damals von Der weil. Durdalaudt. Sfabella, Sohannis I Roniges von Pot" tugalf Prinzefin Sodbter, uno bernad Philippi III Serzo" gen bon Burgund, mit Dem Beinamen des frommen, (semablin, nad) ifres Serren Sode beherrfdet murden. SBei diefem Sofe erwarb fid erwehnter Sehaim, fowol Dutes

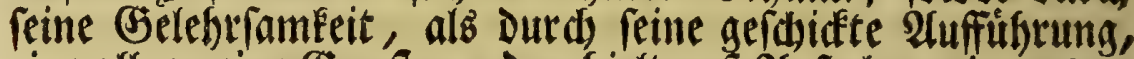
eine allgemeine Gumit, uno erbielt auf $\mathfrak{A}$ nutben ein ausge:

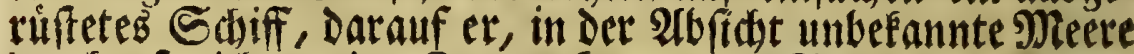
Durchulltreidien, im S. I 460 unter Segel gieng, feine Ieife gegen 2 abend ridbtete, und anfango die Sinfel Jayal,

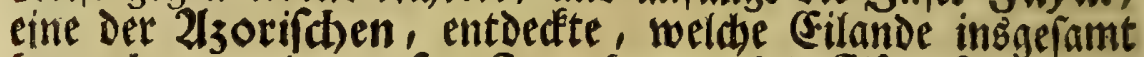
bernad), von den erften Snwohnern, die flamifeben fino genannt worden. Gr úberkam Darauf zwen Gibife, mit Denen er einige Jabre auf Der groffen $\mathfrak{B}$ eftree berum fégelte, bis er endlid aud Den vierten 23 elttheil ausgefund rbaftet, ja fo gat, wie gemeldet worden / bis an die fo genannte Ma: geflanifde Meerenge gefommen ift, wie er foldes alles, be: vor nod, Magellan an die 2 Beftindifbe Meife gedadt, auf ciner Seefarte aufgejeidonet, und derelbe Alphonfo Dem V Sonige von Portugall, úbergeben hat. Dieen Bebaimis foben Entwurf befam fodann Ehriftophorus Solumbus, ein gebolrner Senuefer, an Dem Yoortugiefirdon Sofe zu rében, und Dadurd Die Ruft nad) folden Rendern felbit eine Peife boti 
vorzulebren. Bon Diefer Bebaimifaen Entbedung zenget eine Erofugel, welche diefer gefthictite Mann mit Der Feber feloft geseichnet, uno mit Farben bemablet bat; bie neblt ans Dern fhonen Denfmalen, wie aud Deftatigungen eift vor= getragener Ergäblung, Das vornebme (Befchlecht Der Jerren

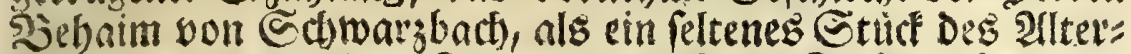
tbumb, nod lyentiges Sages aufweifet. Diefes befroftiget furner, auf eitte tnoerwerfliche 2rrt, Sartmann Edhedel, Der um diefelbe Seit geforieben, in feinem grofien Seitbucte (au

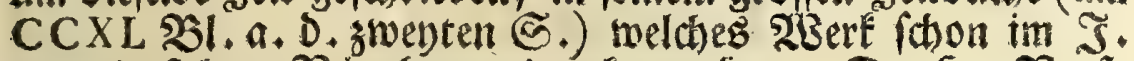

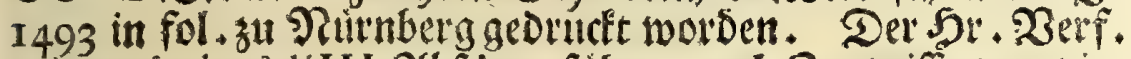

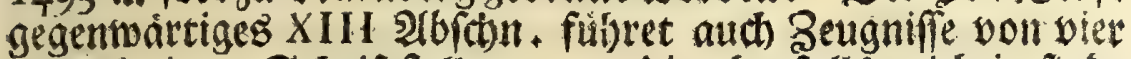
auswartigen Schriftellern an, Die ebenfalls midtig firo, weil Diefen Nannern nidbt zuzumutben, Dấ Diefelben aus

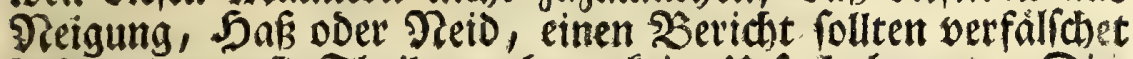
baben, Daran fie Sbeil zu nebmen feine Itrache batten. Die: Re find Sieronymus $\mathbf{3 e n} 50$, ein Maylảnder; Joh. 2 apt. Ricciolus, Der bertibmte Sternfeber, ein Ferrarefer; Job. Tatclius Metellus, ein $\mathfrak{B}$ urgunder; Peter Matthă, ein Jranzofif(her Rechtsgelehrter, aus Oberburguno burtig, De= rer Der erfte in hiftoria navigationis in Brafiliam, Der gwente in Geogr. reformata, Der Dritte in Speculo orbis terra, Der

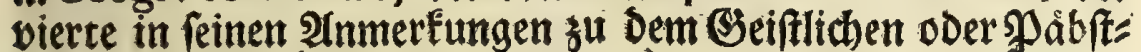
lichen Redte (Frandf́. 1590, 8.) einer byorographifchen Sarte erwebnen, Die von Martin 3 ebaimen fey verfertiget. tworden, und gefteben, Dafi er Dadurch andern Seefabrern, Dem Çbriftophorus Columbus, 2(merifus $\mathfrak{B}$ efputius und

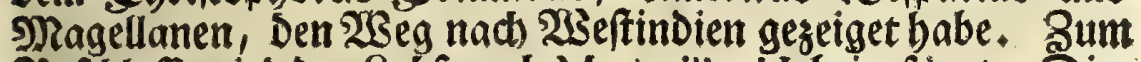
Sefallufe wirb Der $\mathfrak{L}$ b f pruch Maximilianil beigefuget. Dies fer Serr fagte, oaf Fein Ceutfher ourd Reifen in oie ents. legenften Theile ber Delt, es Martin $2 \mathrm{eb}$ aimen juvorgethan babe. (VI,)

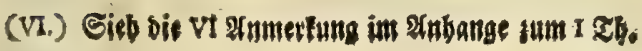




\section{$\mathfrak{A}$ nbang \\ bou eittigen Innerfuthent

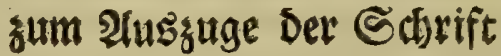 \\ DE \\ C O L V M I S HER C V LIS.}

\section{Inmerfung,}

Sun II 20fdin. S.3.

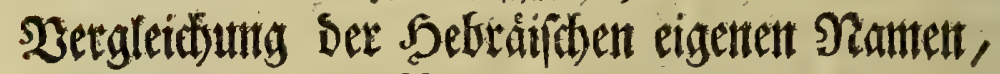
wie fie in Der $\mathfrak{B u l g a t a}$ ftefen, mit Der

Sdreibart bes Girunbtertes.

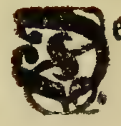

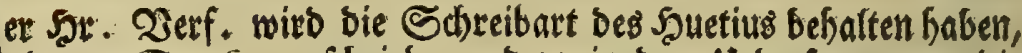
Da et Gamfon gefhrieben; Denn in Den lleberfesungen, Die

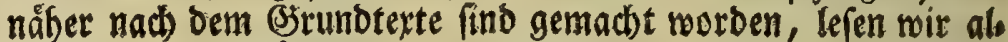

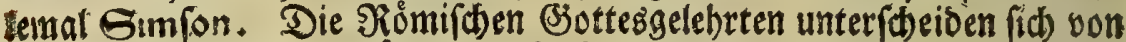
allen Sdriftftellern Der übrigen Efriftliden (Semeinden, bei foldben 21 b: banblungen, daraus man ifre Retigion fonft nicht erfennen fann, buris

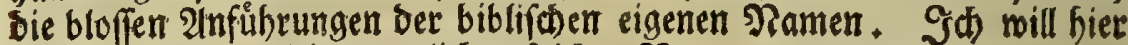
eine Eurge $\mathfrak{Z}$ ergleidjung etlid)er fold)er Namen bortragen, to biejeni: gen, bie an ber erften Stelle fich befinden, andeuten follen, wie fie yon Den Fatholifen nach Der 23 ulgata geidrieben werben. Die Namen ber

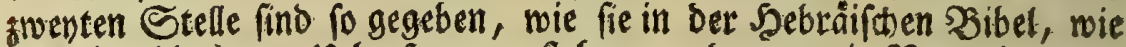
aus) in obbeiagten Heberiesungen ftehen; uns menn ein Name orenmal

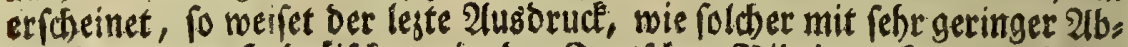

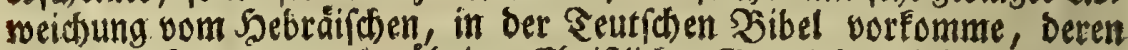
Die Wroteftanten, und úbrige (Ehrifliche (Bemeinden fich bebienen. Aran, Jaran. Jaalaam, Bileam. Dalila, Detila. Esechias,

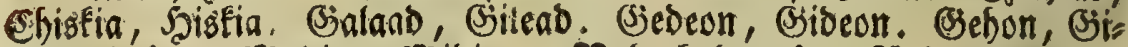
thon, (Sibon. Madian, MRisian. Nabucbobonofor, Mebudtadnezar, Rebufaonejar Whacee, Pefach, Pefab). Tloboam, Rechabeam, SRebabeam. Samion, Schimichon, Simion. Sion, Bion. Sheglathofalafar, Siglathpilefer 26 . 
Orenn id biefe Entfermung ber gemeinen lateinifhen lleberfesung vont bem Srund texte betradte, fo buntet mich, eines aus beiben muffe wafye

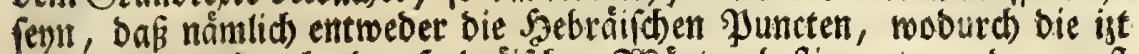

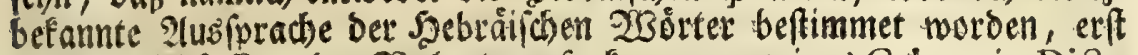
nach bet dibfafung bet Dutgata aufgetommen, wie es Calmet im Dict. Bibl. im 23. Maffore $p .640$, ermeifet; ober bafman bei biefer latei. nifben Heberfejung mebr auf Die Griechifhen Exemplare, als auf ben.

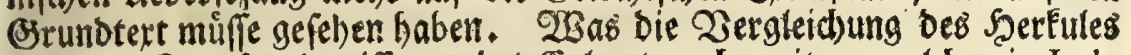
nit bem Samion betriff, geher Ealmet nach weiter, welcher in Jud. c. I6 anmerfet, bas bem 5ertules unb Eamion bie Erlegung eines gowen zugerthrieben wetbe, Daf bes Serfules Dmphale mit Samfons S)alita eine qubntiofeit babe $u, f+f_{a}$

\section{II : Inmetertuts,}

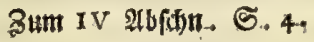

Die bont ber frerne fith Darftellende Geftalt Des Berges 2etna wird beratrieben, und Dadurch Pindars Bengniß ertflaret, weldber Denfelber eine Sånle genennet hat.

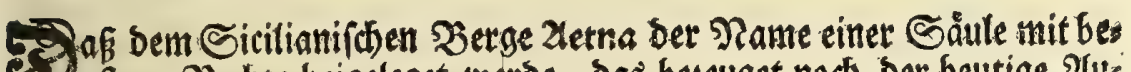
38. fiem Sied)te beigeleget werbe, bas bejeuget nod ber heutige 2 (u: genichein. Denn biejenigen, weld)e auf biefe snjel zufabren, fehen bon weiten, mitten im sneere, etwas aufgethürmtes, als einen ungeheuren Saudbfang, ober eine úberaus groffe bolperidte Săule, bebor fie nod einigen andern $\mathfrak{B e r g}$, ober bas mindefte von biefer Srnfel entbec'en mó. gen, ungeadtet forche, auf allen Seiten boll anfehnlicber Sberge ftecfet. Das begegnete aud mir, als id) vor einigen Jahren von Malta nad Ferranova in Sicilien fhiffete, welde Stabtauf ber mittågigen Seite biefer Sarel gelegen ift. Das Sdiff, barauf ids midh befand, war noch Faum 2 23äl(f)e sheilen bon Malta entfernt, fo erbliçte id) gegen Mits ternacht eine groffe Såule, bie aus dem meere felbft fich ju etheben focien. Um biefelbe berum fah ich nichts, als bie platte Sberfládse bes Meeres. 2Als id bie Schiffleute fragte, was biejes fur ein shurm soåre, ber bort im Neere flübe; ob es eine fo geftaltete 230 lde fen?

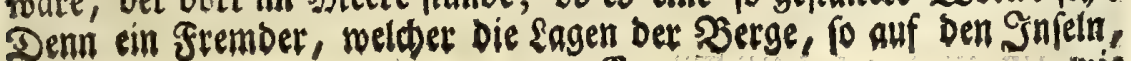


toie aud auf bem feften sanbe hin unb wieber ftehen, und von weiten ges

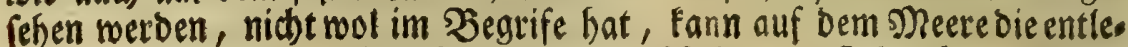

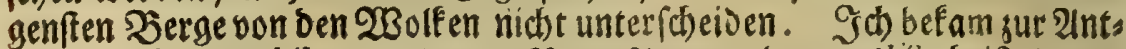
wort, è il Mongibélo, es fey oer Serg Zetria ; benn Gibélo beist Aetna in ber Sicilianer sanofprad), und das Stalieniche monte, Berg, lafs fen fie bei ber Bufammenfezung, wie die Franzofen ifre mont, lauten.

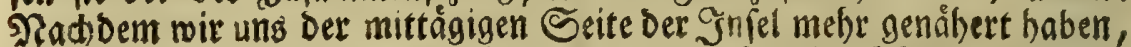
Da fiengen erft bie oberften Spigen anderer, auf biefem Sheile von Sicis lien befinolic)er, Berge an, aus bem speere empor zu fommen. Denn ungeadtet diefelben alle oor bem Iletna fteben, uno von uns um viele Seutfose Meilen weniger entfernt waren, als biefer, fo fab id bod ans fangs Den letna allein; Die übrigen, wiewol náberen SBerge, weil fie aber niebriger fino, fteciten alle noch hinter ber erhabenen Rrummung, weld) Das Meerwaffer rit dem Erofreife gemein hat. Nach einer zus rudfgelegten Gtrecte von einigen झneilen, erfachen enolich bie fleinern Soben, die nicht weit vom fublichen Neerftrande liegen; und das flacte

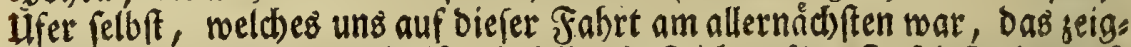
te fich am allerlezten. Es ift mit leio, das ich auf ber Jniel malta nad Det Segend von Sicilien ntwt fleiffiger mich umgejehen, uno 2(d)t ges geben babe, ob aus Der neuen Şauptitabt uno Feftung Waletta, ober yon Der alten Sauptftadt (Die $\mathfrak{2}$ rab. Médina, Stal. Città Veccbiabeif́t,

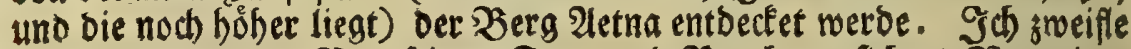
gar nicht Daran. Don feinem Feuer uno Rauche verfichert Jareniuz, Dak beibeg to gar aus bem Seehafen, beffen sage viel niebriger ift, su beobacten fey. Atna mons Sicilia, (prid)t er Geogr. gener. c. 10, prop. $3, \mathrm{n} 4$, ex cujus vertice ejaculati ignes confpiciuntur in ipfa infula Melite, unde integri milliaris altitudinem babere putatur ad minimum. Prop. $[$, n. I, foreibet er fo: Celeberrimus ef Etna, Sicilie mons, bodie Gibel, e cujus vertice eject a flamme E fumi, longifima diftantia in mari mediterraneo cernuntur, nempe in ipso Melite infule portu, qui tamen 40 milliaribus Germanicis a littore Sicilie abeft. 2(llein, ob ber s) ?eerbafen von

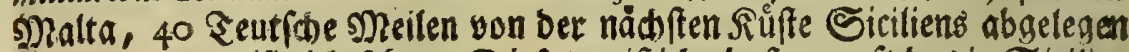
fev, baran sweifle id) fefr. Diefes weifich, bas gar oft bas in Sicilien cingefdiffte Brob, fo bald es vom Bactofen fommet, beigutem 2 Bin: be nod warm nad) Malta uberbradt werbe. 2llein fold is erweifet nid)t:. Die Sanofarten treffen eś, meines (Erachtenz, am beften, welçe

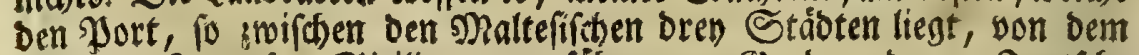

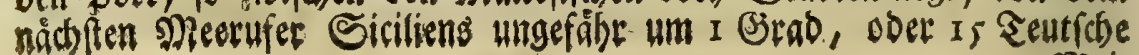
Nei: 
Meilen, und yom Berge (etna faft nod) einmal fo weit entfernen. Dies fes fommet mit bem Berid)te bes glinius siemlid) úberein, weldher III, 8, 5̧ard. 14, Den 2lbftand ber Gnjel trietice von Camerina (Dab war

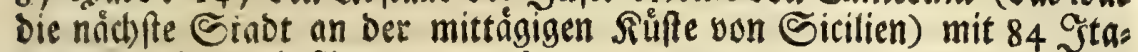
lienifonen Meilenbeftinmet: Infula funt in Africam verfe: Gaulos, Melita a Camerina $L X X X I V . M$. paffuum. Soldes beftátiget aud Mar:

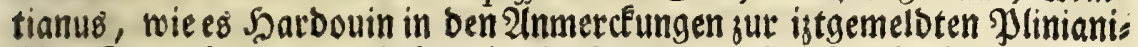
fhen Stelle bezeuget. Es hat aber biefes alles mit ben $\mathfrak{B}$ eobadtungen ber beutigen Franjofen gleidjfalls guten 3ufammentang; Denn im 280 orterb. bon Srevour ftehet, bás bie Snfel Dialtn (ich) verftebe ihre mitternädtige Súfte) von dem nádbften Siciliamifben Gjeftabe 25 Jrans. Meilen abges

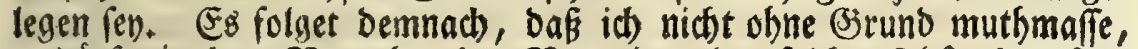
es borfte in bem Jorgeben des Darenius, ber folchen 21bfant auf 40

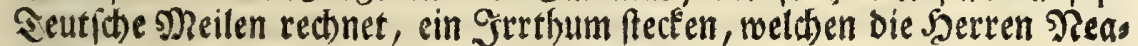
politaner, oa fie bem Sierge 2letna nåher wohnen, bei ibrer 2luflage Diefer Seograpbie, wol bătten verbeffern ober anzeigen follen.

\section{Beitring \\ Su Diefer 2rnmerfung. \\ Tautologie Deż Sicilianif̧ten Namenz \\ Mongibélo.}

(Fe) $s$ if gleid vorfer gemelbet worben, Daf ber $\mathfrak{B}$ erg Aetna in Sici: 20 lianifher Spradte Mongibélo beífe. Monte gibélo, im muna be des gemeinen Mannes Mongibélo, ift eine tautologirase Soenennung,

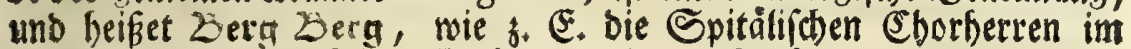
Sante ob ber Ens, fid Collegiatæ Ecclefix ad pedem montis Pyri Cano-nicos fhreiben. Py: ober Dy: $n$ ift, meines Erachtens, aud fein eiges ner, fondern ein gemeiner Prame, bet fo biel bedeutet als collis, mons, mie es bie vielen Şingel uno Berge, to Pyen beífen, ja Das S3ebirge

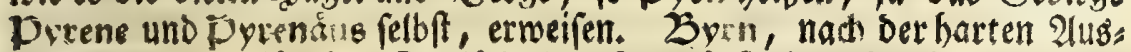
fpradie pyon, ift ofne Zweifel eine Metathefis des Cambriften ober Geltifhen Zrynn, collis, fo in నjortborns Lex. Ant. Brit. Ptehet.

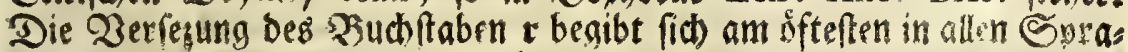

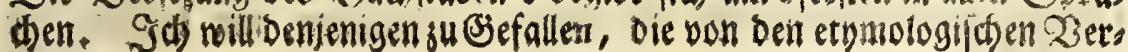
$\mathfrak{E}_{3}$

roando 
mandlungen feinen Degrif haben, eine furge 2lusidweifung vornefmen,

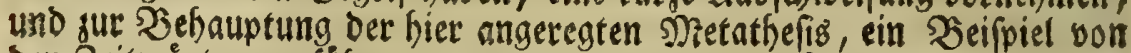
ben Seitwơrtern anfúfren, weldbe in vielen Europaíchen Sprachenardere und cremare bedeuten. Die alten Nundarten baben ben Selbfts lauter yor bem $r$, die neuern und heutigen nad) bem $r$. $23 a$ ist bren. nen beist, ons muffen bie Alten bernen gefagt haben, weil Zeinftein, fuccinum, fo viel als ber 2 tennftein if. Die 2(ngelíachfen forachen in ber That bárnan für cremare, unb byenan fur ardere, bie Siried)en

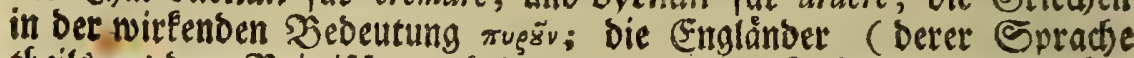
theils aus Dem Brittif fennbare Ueberrefte ber ålteften norbichen Sebart aufweifet) fagen in beiberley Werftande to burn. In bem 2lemannif́nen, mie noch in ben beutigen, Stenermårfíd)en, Sefterreidiid)en, Banerifchen, Dialeften, beift ardere prinnen; urere prennen, fo nur eine Metathefis bes 2In.

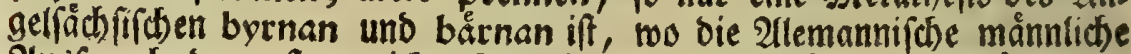

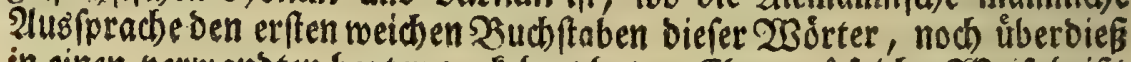
in einen verwanden harten verfehret hat. Eben auf folde 2 seife heift in ber beutigen Seutíten Sprache fons, ein 3runn, weldes 230 re

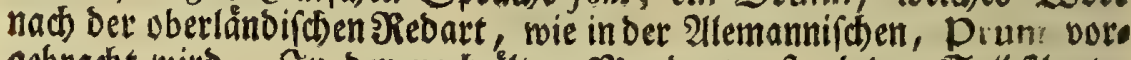
gebradt wirb. Sn ben nod âltern Dunbarten fund ber Selbftlauter abermal bor bem $x$, wie es aus ber Englif́chen zu erfehen ift, in wels Wer burn rivum, und an einigen Srten, bei bem gemeinen Manne, auch fontem bebeutet. Sin Der SBergfdbottif(hen Sprad)e, die ein wabres und åd)tes Heberbleiblel ber (Eettifhen ift, beift puin fidedetweg to af rer und aud ein rinnenoes tleines Woffer.

Das SBeifpiel bes tautologifoten 2 lusbructs mons Pyrus, hat mid

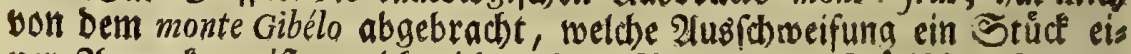

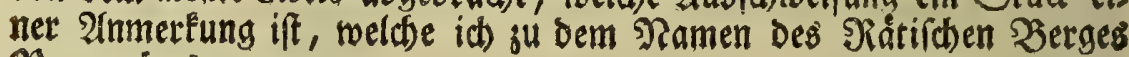
Pyrenåus (Rofchm, veLDID, p. 103. fequ, ) verfaft habe. Tă

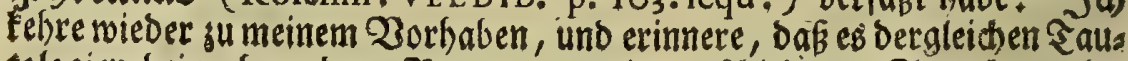

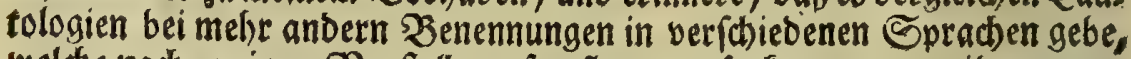

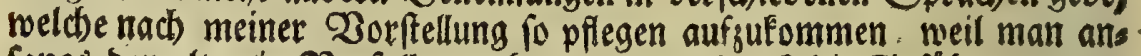
fangs Den alten in 2 erfall gerathenen, ober burd) Die Einfühtung neuer Sprachen unvernehmlich geworbenen 280 ortern, neuere befannte uns eben Dns bebeutende zur Erflårung beifüget, wo es aber zum oftern fich)

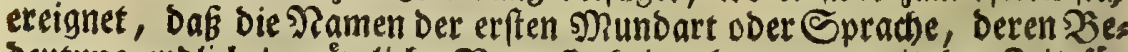
Deutung endlich in gånglidbe Wergeffenbeit getommen, mit oer Zeit fúc 
eigene Tamen gebaiten merben. (Ein foldes Deifpiel ift aud, wenn mir fagen die Etsot meoina. Denn Medina beift in Irabifber Sprache ebenfalla eine Gradt. Gibel ift aud ein Irabift)er Name. Denn bie Sicilianifd) beutige Mundart weifet Spuren von ben Swra:

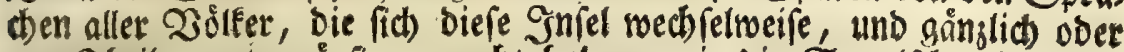
zum Sheile, unterwurfig gemadt haben, wie die Spanifhe Eprad)e

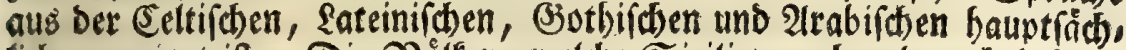
fid) gemenget ift. Die Dodfer, welde Sicilien nad) und nach behert: fart haben, und von beter Sprad)e in ber Sictianifonen mebrete ober wenigere Leberrefte zu finden find, waren, Die allererften Jnwohner zu ges fofweigen, bie alten, und (nach langem 3wifhenraume) Die fpatern (Strieben, bie Siarthaginenfer, Fơmet, Saracenen, Sormąnet, Franofen, Spanier, unb endich die Seutfden. Allein von ber Spras de Der lestern wollte biefes innen nidt beftens geneigte Dolf, wenigin bie Seinige übernetmen, tool aber múffen bie Sicrlianer wegelt Erlernung eí: niger zut Saushaltung bienlicher, vorfin bajalbft umbefannter Wortheis 1e, ifnen verbunben fern. Die Pamen ber Derter unb Berge fins in Sicilien, wie in Spanien, grofientbeits nod Saracenifo. 2lus biefer Bahl ift nun aud gibel, ein Zera, woburd bie Barbarn ben Berg Zetna verfunben, welden fie jwab bad (gebel alnar) ben Bery

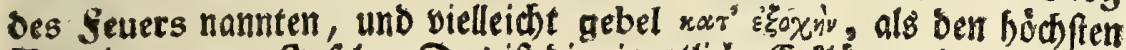
Rerg Der gaitzen Sniel. Das ift bie eigentliche Ertlärung Des Sirilias nifden Monte Gibélo, weld)en Namen aud Die Franjofen bebalten,

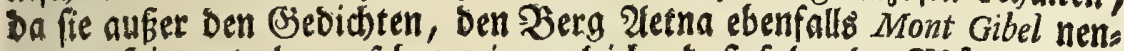
nen. Sieraus aber erfehen wit fugleid), Daß folgende 230 orter, Das

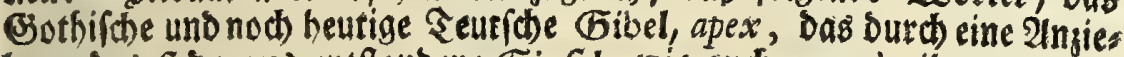

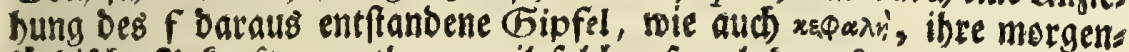
Iånoifthe Anfunft nerrathen weil fold)e, fomol bem saute als ber

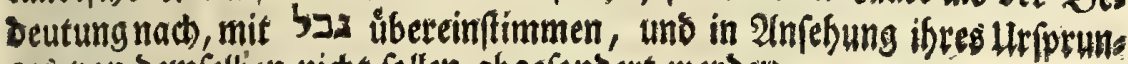
ges bon bemlelben nidst follen abgefondert werbert. 


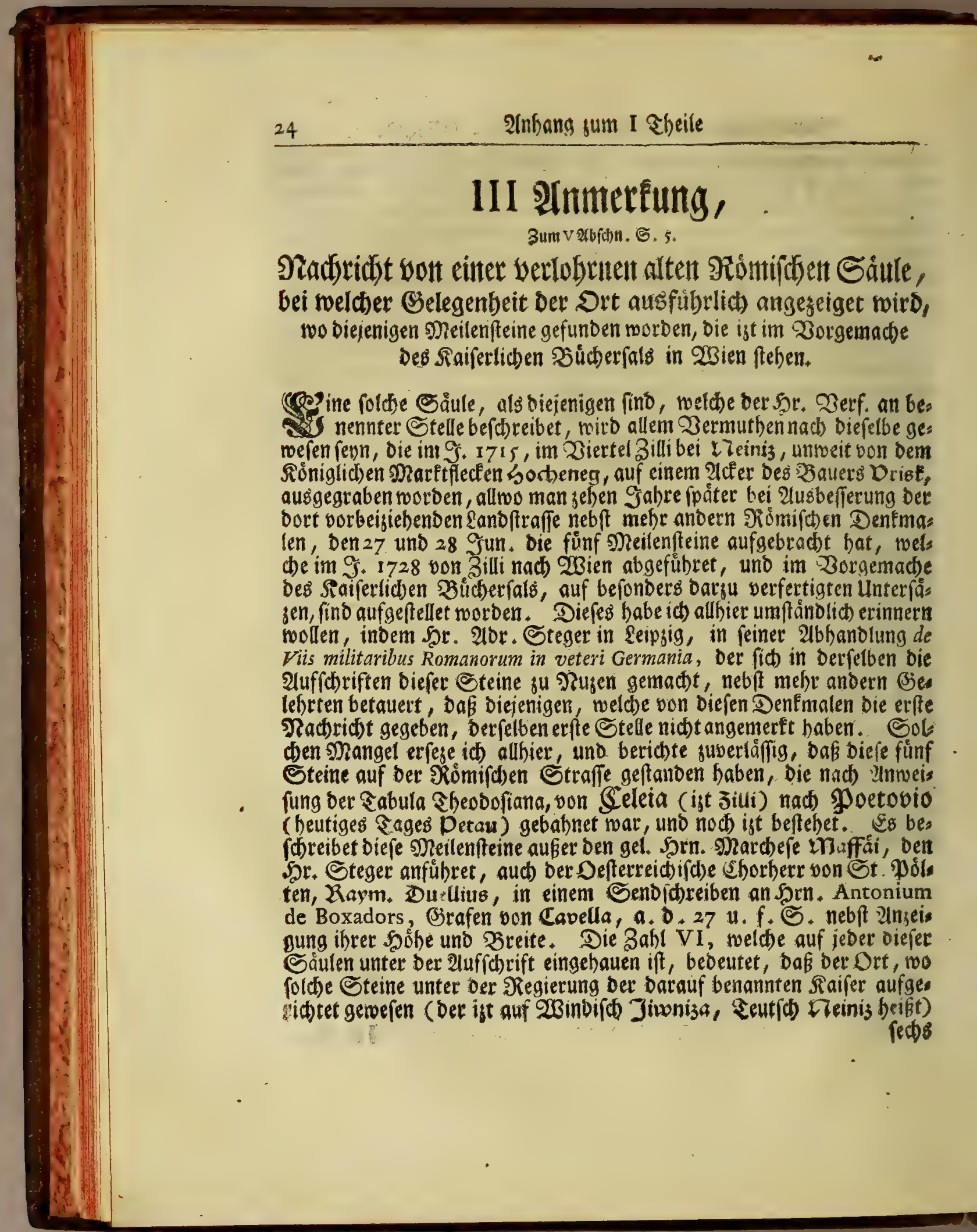


fects gtalienifibe meilen, D. i. VI. m. p. fechs taufeno geometrifche

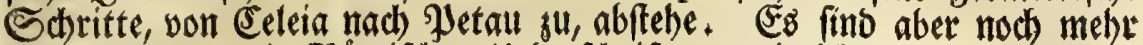
anbere Stcine mit Kơmifden Uleberfd)riften, wie idh allbereit erinnert habe, an eben biefer Stelle bajumal aufgebracht worben, bie nach 2 Bien

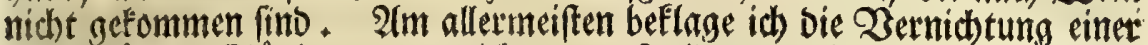
weit groffern Säule, bon ber ich zuvor Melbung gethan babe, bie zehen Sabre vorber, aus eben biefem Ader beroorgegraben worben, und eine

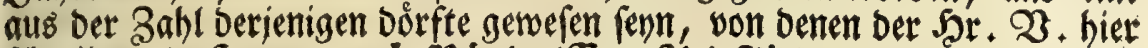

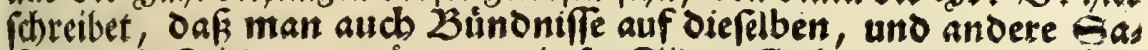
dben (alв Friedensovertråge, nambafte Siege, Eroberungen Der Stạote uno ganjer \{ánber) welche Thaten oet Rachwelt follten verkindi: tet werben, oetzeichnet babe. Denn es funo ein ganjer Berid)t auf biefem Steine. Sr wat won allen Seiten überfobrieben, uno lag eine ges raume Beit mitten im Dorfd)en an Der Straffe. Sie Sieiftlichen bet

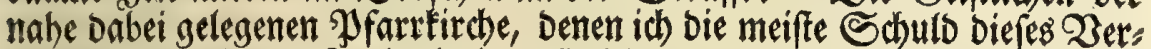
fuftes zulege, inbem fie die einjigen Selebrten Derfelben Siegeno fino, gien: gen ofters alloa borbei. Sie wurben von ben Sauern erfucht, baf fie

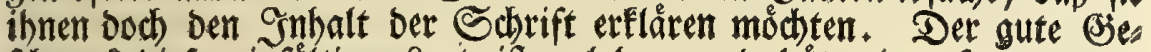
fantace biefer sinfáltigen \&eute if ju loben, uno båtte jene herren fum wenigften vermógen follen, bie Sdbrift abjufbreiben, fo gut fie fonnten, nadboen biefelben mit ber 2 luslegung nidht fortfamen. Denn bie bei Auf:

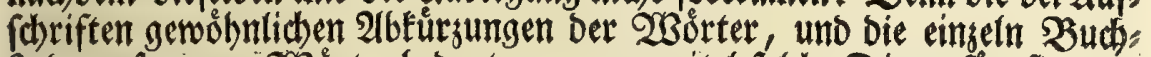
ftaben, fo gante 2 Borter bebeuten, waren eitel foldhe Dinge fü fie, Da bei fie feiten singang ober Aubgang fanden. Ser erwad) fene Sobn bes Bauers folug Der (Semeinde vor, diefelbe foll biefen bertlichen Stein mitten im Dorfe an Der Straffe, allwo cin frener ઝlas, wie ein Marft, fich befindet, aufrichten, uno ein Sreus Darauf ftellen lafen, mithin biefes

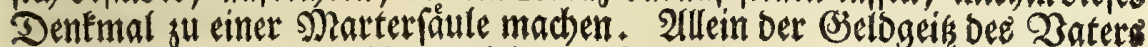
bat Diefen guten Rath bintertrieben. Denn als nach einigen Monaten

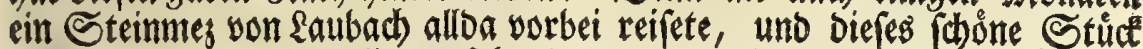
weifen Marmels Dort liegen fab, bot er Dem Slten 3 Gsulden Dafur an. Er befam biefes bertlide Dentmal, wo id meines Srtes nur fur Dagies nige, was die (Seiftidien zu thun unterlaffen baben, nåmlich fur bie Ret: tung Der 2fuffchrift, gerne fo viel ausgelegt båtte, was ber ben ganzen Stein befommen bat. . Sllein ich erfubr folches erft nach 20 Sabien. Das war zu fpát, und mein Tachfragen alsbenn vet: geblich. Ein anderer \farrer eben biefes Drtes bat eimige Sabre Darauf, Den Sieblabern Der alterthumer einen andern berben Stob ver fest, Da et 
etlide Srómifhe 2lufforiften, bie zu S. Margarethen gefimben worben, nicht anderş alb einer Der wildoeften Barbarn, vernichtet hat. Es: fethet biefe Rircte auf ber alten Semifthen (uno nod) beutigen) Randfrafe, Die yon Celeia nach Poetovio gehet, uno ift von ber erftern Stadt, poviel

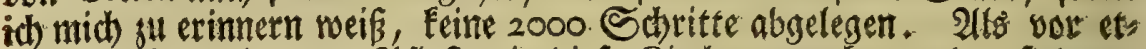

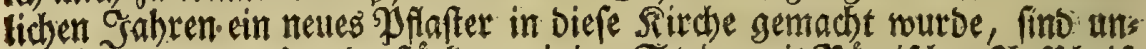

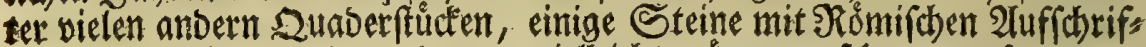
ten auggegraben woroen, daraus vielleid) wäke zu erfehen gewefen, was. bie in Celeia roohnenten stómer allba gehabt baben; benn es geigen fich: Hebertefte von einem gróffern Bzebáude, weld)e theils bei ber Sirche lies gen, theils bei einer unweit bavon befind lidhen Mruble eingemautert fino.

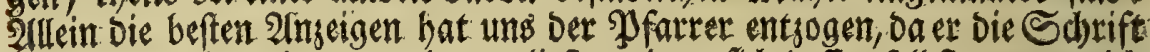
von Den Steinen berunter bauen lię, wie er fid Deflen félbf: gegen mids: geribmet bat. Einen Sheil Der vermufteten Stúcte vertuande er zue Erbouung einter neuert fteinernen Samsel. Die Siebbaber Der Seltenbeis ten, to über Zilli nach Statien reifen, follen fich bie Berweilung von eis nigen Mimuten nicht reuen laffen, fondern bei biefer firdbe abfeigen,

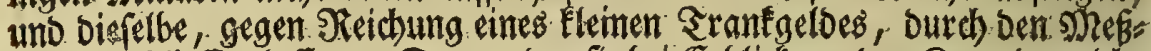
ner auffitliefien laffer. Dr. Derden fie bei Erblickung ber samsel, welde

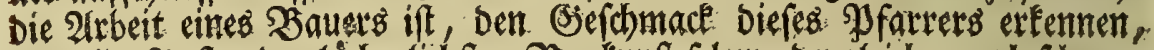

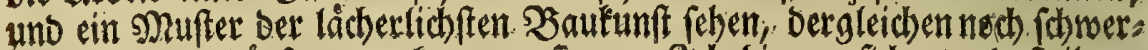

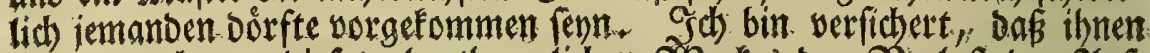

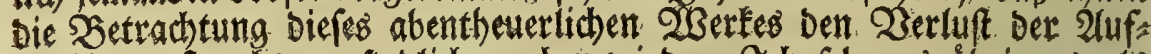

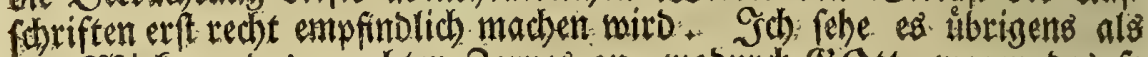
eine 2Birfung Des gered)ten Bornes an, woburd (SSOtt, wegen Des fo mannigfaltigen verubten (Greuels Der Sheiden, ibr Andenfen eber will aus: gerottet, als bervorgejudst und Der Padbrelt verfunbiget haben: reil

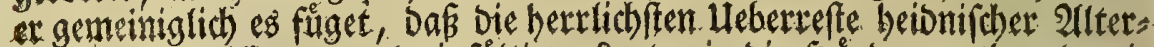
thumer, unwoiffenden uno cinfáltigen \&euten in bie Sånbe gerathen, Damit

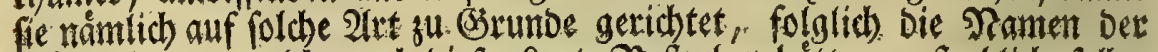

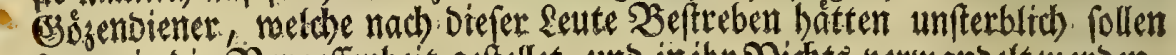
fenn, in bie Sergeffenbeit geftellet, und in ihr Nidjts vermandelt neetben. So făllt auf diefe Bottlofen die billige Wieberbergeltung beffen, was fie:

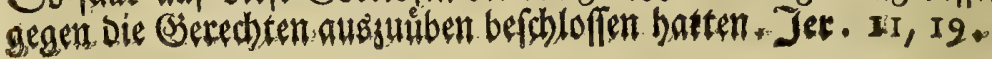

IV 21: 


\section{IV 'Ninmertung/}

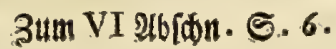

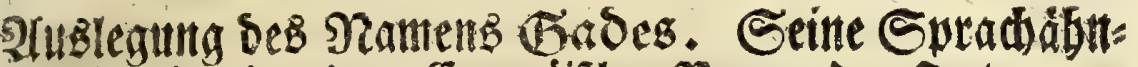

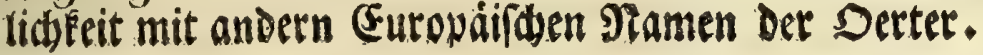

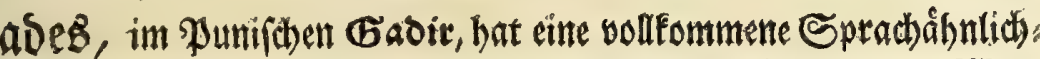

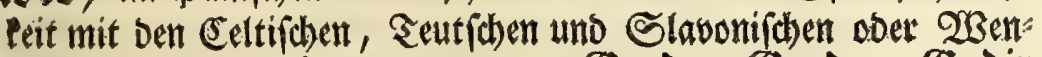
sifhen Ramen ber Stáde, DVNVM, Gard, Grad. Gadir beoeutete in Der Wunichen Spradbe einen 3aun, und einen eingezàun.

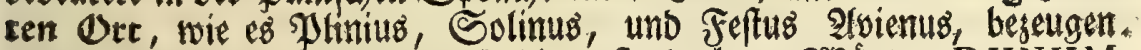

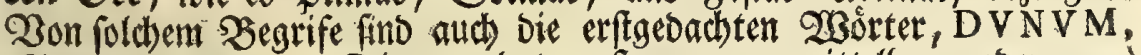
Garo uno Grao. Die zaver lestern ftammen unmittelbar, doer watà

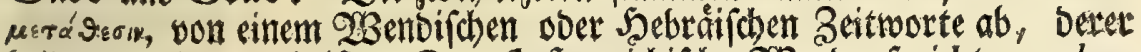

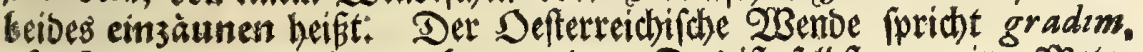
ich jăane ein, gradi, er 3 ăunet ein. Das ift felbft nut cine Metas

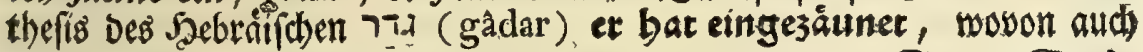
bas Sunifhe Gadir feine abtunft hat. Die ramen, Sun, Gard,

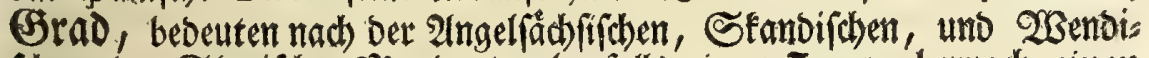

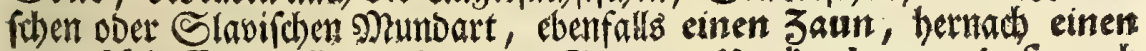
eingefdblofenen Ort, ats einen Garten, Park, baus, sof, aud

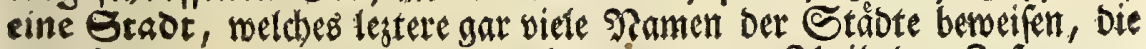
nus dunum, garo uno grad, als Dem swenten Sbeile ber Bufammen fejung, beftehen; wie s. E. 2luguftodunum, eine Grabroes Zugu; fus, હarrodunum, \&ugounum u. . f. So auch Stutgard im $2 \mathfrak{B}$ urtembergifthen, $\mathfrak{B}$ elgard und Etargard, Yommerifiter Stäbte Namen, wovon ber lezte nad) 2 Bendifder 2 tublegung oie alce

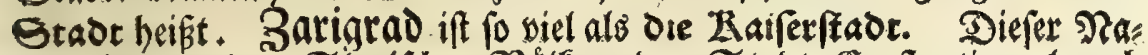
me wirb uon den Silavifaben 3 ólfern der Stad Comfantinopel nod

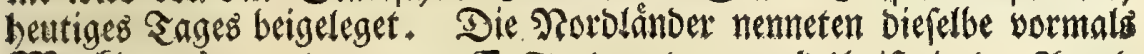
Madélegard, D. i. Die groffe Staor, denn muel heist in ber Angels

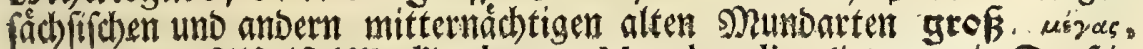

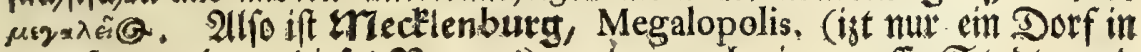
Dem Sertogthume diefes :2amens) worbem auct) sine groffe Stadt, uno D 2 als 
als ein norbifches Conftantinopel gewejen. Novigrad, D, i. Teus fabloE, ober Feultaor, Neapolis, ein Name etficher Sdblóffer uno Ståbte in Sånoern, two Slawonifd gefprod)en roiro, in Dalmatien, Rrabaten und ungern. Belgrad, bie ehemals weltberuihme Feftung

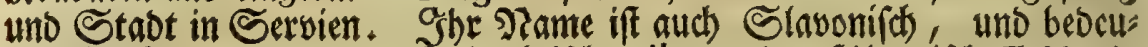

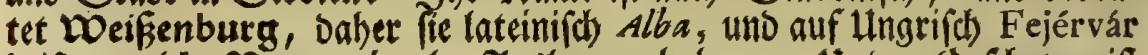
beißst, welde Namen einerlen Aluslegung baben. Utnter Srfithona ift ein Feld auf Dem linfen Ufer Der Donau, wo fich Uteberrefte von einem verlaffenen Bjebåube zeigen. Unweit Davon ftehen an beiben Seiten Des

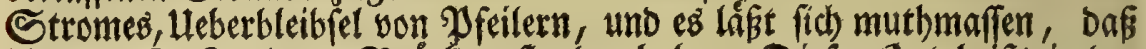
bier DeẼ $\mathfrak{K}$. Irajamus Bruede geftanden habe. Diefer Drt beift in Der

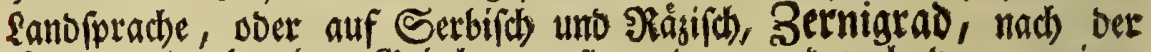
Sundart ber beutigen (Briecben maṽpov ráspov, uno nact) ber gemeinen

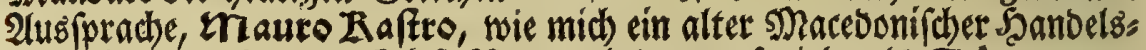
mann beridhtet bat. Diefe গamen bebeuten foviel, als Scbwarzena burg, oder Das fabwarze Scblof, als wollte man Daburch Den Biegen: fás yon $\mathfrak{B}$ elgrad ober Deifenburg andeuten; Daher aud won bem erftgedachten Srte, sielleid) Der etwas abjeits gelegenen Stadt C fobers

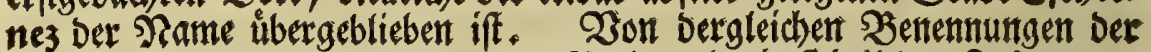
Serter, bei Denen Das Grao ooer Gard, alse ein Theil Der Bufammens

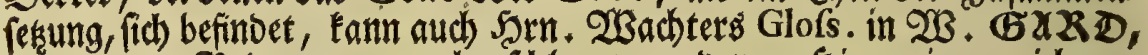
ber zwenten 2 ebeutung, nat)ge(t)lagen werben. Shier erimere id nur

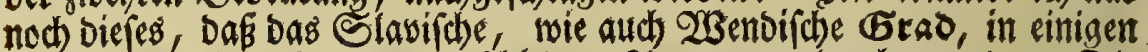
Dialeften noch auf andere verichiebene 2arten vorgebracht werde. Die Doblen (pred)en Groo, Die Yuffen mit einer Epenthefis Goroo, Die

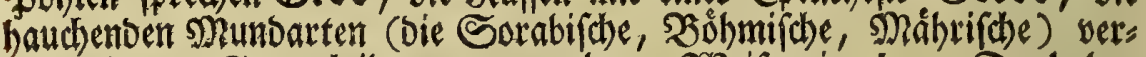
wandein $D a s \bar{G}$, nadb itrer unangenebmen 2 seife, in $\delta$. Da baben nun bie in ber \&aufis wohnenden ङorben, aus bem Yolinifden Groo, z:00 gemacht. Die Sogkmen und Mábret bringen Das redbte Slavi:

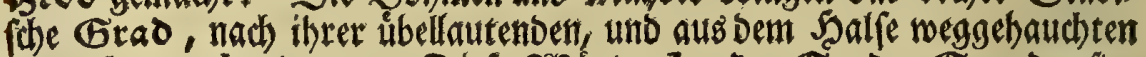
Spred)art, Srao vor. Diefe Ysouter zrao, Groo, Gorod, fint Det man mieber in ben eigenten gufammengefestent গamen ber Ståbte uno

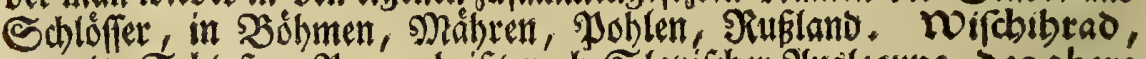

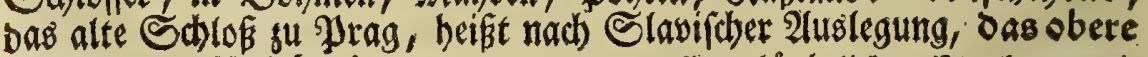
Bcblof. Weelebrad, die weilano groffe, fooniglidbe Marfomanni

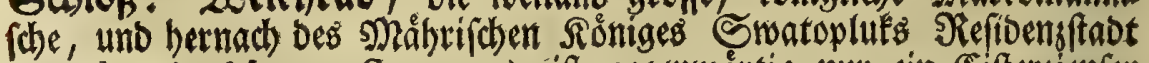
(Stredowsky Morav, S.p. 17) ift gegenwårtig nur cin Cifterzienfer. silofter 
Slofter in Nåbren. Der Name bebeutet eine groffe Stabt.

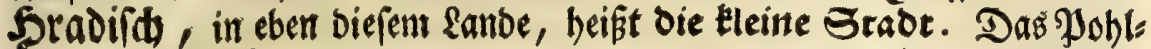

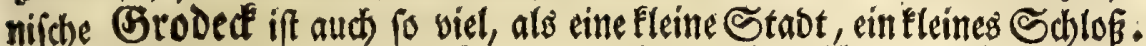

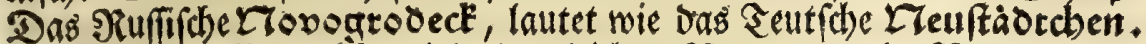
In Mogfau gibt es iehr viele bergleiden $\mathfrak{N a n t e n}$, als Zielogorob, Dontagoros, Michailogoros, mirogorod, Kovogoros, wab filogoros $u_{\text {. a. }} \mathrm{m}$. Derer Auslegungen in Srenzels Origg. Sorab. Eol. 381 und 382 ftehen. Bielogoroo ift fo viel als Zelgrao ber Sla:

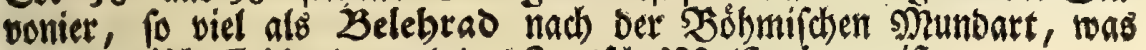
Das Ungrifhe Fejérvar, und Das ?eutfhe Do eificnburg ift.

\title{
V İnmetkung/
}

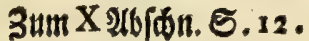

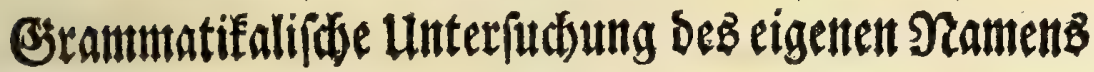

\author{
S E P T A.
}

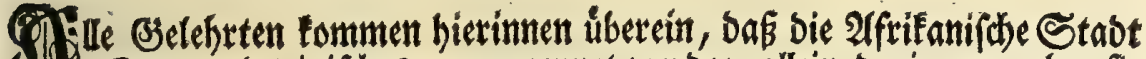
Sey Ceura, lateinifh septa genennet werbe; allein barinnen gehen fie

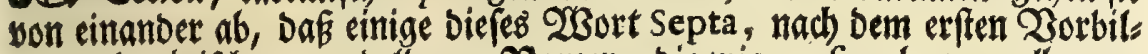
be Der lateinifhen wanbelbaren slamen, bie wie mufa gehen, wollen ges bogen baben, andere faredben Septa, orum. Die meiften erwäblen ei.

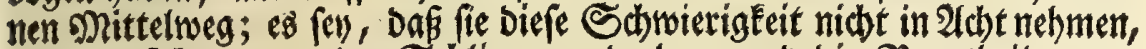
ober um fid) nur aus ber Shlinge zu breben, uno bie Beurtheilung gu vermeiden. Diefe lafen bie $\mathfrak{A n z e i g e ~ D e r ~ z w e n t e n ~ E n d u n g ~ g a r ~ w e g , ~ m i t s ~}$ hin wei man nicht, ob fie fúr Septa, $x$, ober für Septa, orum, fid) ers

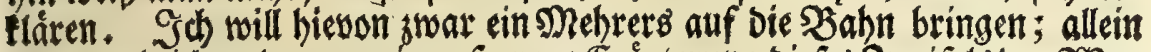

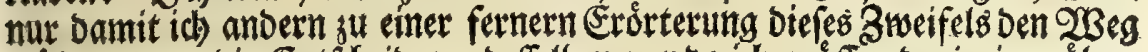

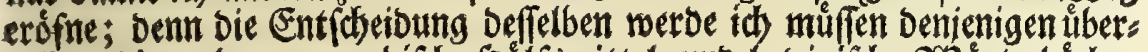

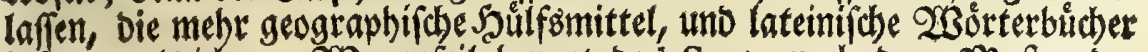
befuen, alo id. Cragenfeil beuget das Septa nad Dem Mufter der

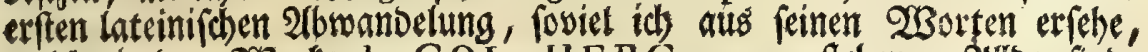
welde in bem 2 Berte de COL. HE RC. p. 27 ftehen. Allloa finde id): CEVTA latine Septa appellatur; eft enim urbs fita in uno colliwm, qui septem bic numerantur, of Fratres vocart folent, a $\int_{i-}$ 
mili altirudine. Berna(): SEPTAE vicinus eft Abyla mons or.

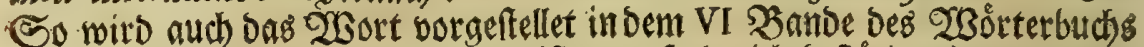
won Srebour, im lateinifichen Segiffer. Sheberich beftátiget in Promtua-

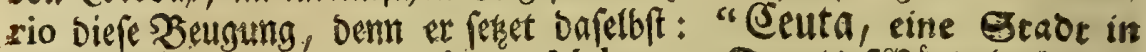

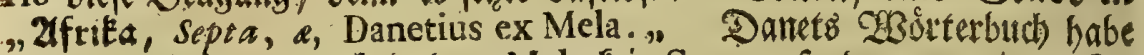
id nidht; id finbe outh in bent Mela Feit Septa, fonoern nur im i $\mathfrak{B}$. V Sauptit. Den 3 erg Septem fratres, Defen aud) Sllinius V, I, unter

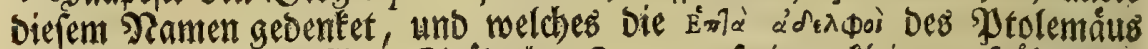
fivio, Dakei Das befeftigte Stábechen Septa auf einer Fleinern Scỏbe lag. Das allgemeine \&exicon gibt biefe Erffărung bei Ceuta: "Die Xómet , nannten fie (erwelynte Stavt) Civitas, uno Pomponius Mela

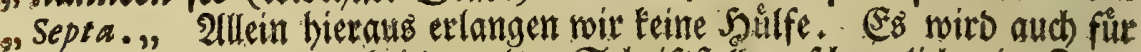
ben Namen Septa, a, bei Den alten Sdriftefellern fonwerlich ein Zeugs

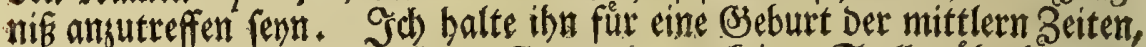
Daher berfelbe auds in cellarii Geogr. ant. Feine Stalle ubertommen formte. Sch bente wol, bie åltefte $\mathfrak{B}$ enennung biefes Sortes borfte $A d$ Septem fratres Anton. Fent, weld)es aber fowol, als folgendes, ob

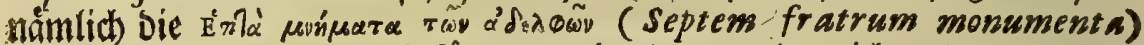
Strab. XVI1, 827, Damit fonnen verbunoen werben, id andern nactsus foridhen ubergebe. \&åfit fich aber bie gwente Enoung, Septa, or um, yiels

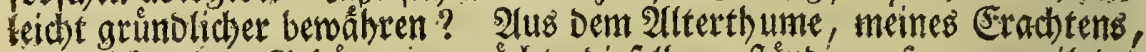

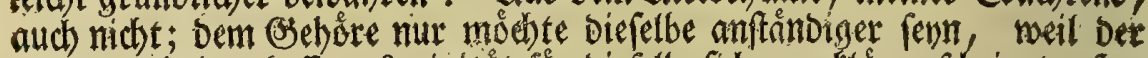

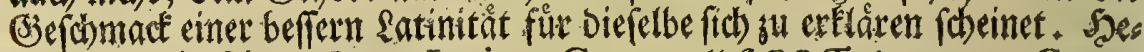
Derid hat in feinem Lex. Latino Germ. "SEPT $A$, orum, Ceuta, eine Sraor in Zfrita, an Dem Freto Herculeo; "allein obne babei

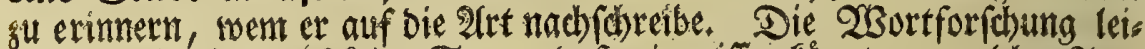

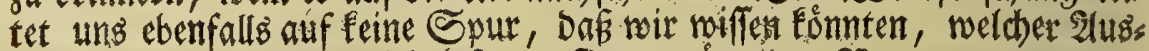
gang bem andern borstutelen fey. Denn wáre Der siame von lepare,

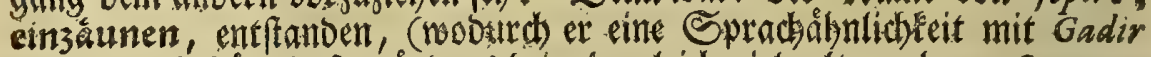

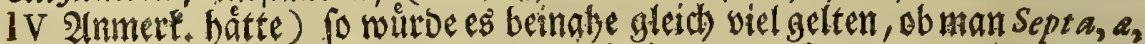
ooer Septa, orum, fpreche, aufer bap die swente Enoung, wie gefigt, vor ber anbert den 2 Bolklang einigermafen zum 2 oraus hat, uno àlter

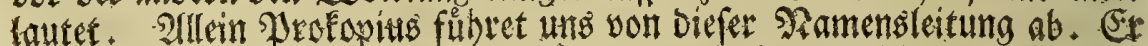

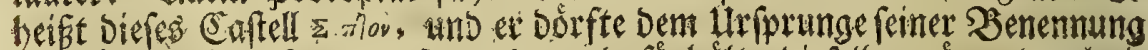

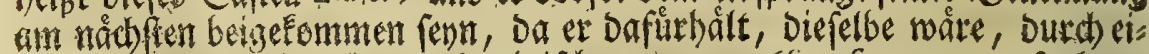
ne vertehrte 2 (us fprad)e Des lateiniforen Septem (fc. fratres) aufgefont men. Slefe Stelle Deg \$rofoping bat Soh. Jo. Sofmann bereits gefes ben, 
Gen, weil er in feinem Eexico univerfali alfo foreibet: SEP TA, gracis Septon, urbs parva Mauritanie TEngitane. - in colleSEPTEM FRATREs: dicto, Plin. Mel. Septenfem arcem babet boc loco. Procopius, ad alteram Herculis columnam; eamque fic vocatam adidit, ob VII montes ibi apparentes. Er berufet fich am Enbe auf bes sinarmotius 1. 4 , c. s r, auf des Sirammáus 1. I 8, c. 7, und Mirai Geogr. Ecclef. Die 2 sorte bes Jrofopius, auf bie er fict anfangs beziebet, lauten fo:

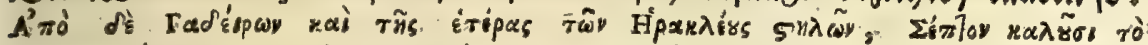

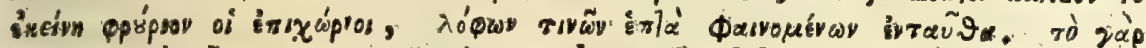

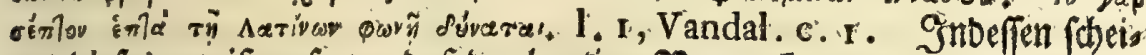

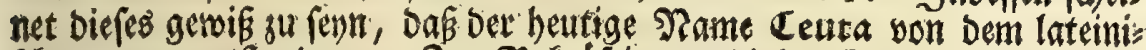

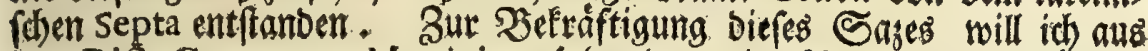
bem Dict. Geogr. von Martiniere folgenbe attige $\mathfrak{A}$ mmerfung beifugen.

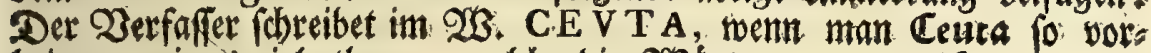
bringe, wie viele thun, weldbe die 2 sorter, eucbariftia, autor, evchariftia, avtot, fúr ewobariftia, awotor, ausiprechen; fo wáre Der \&aut bes beutigen গamens Ceuta, bon bem áltern Bepta nidit viel unterfdieben. Die Franjofen werben biefen (Sebanten ohne Rrweifel nod, mehr nath ibrem sefdmade finoen, weil bei ibnen aud bas Ce, alo se lautet.

\section{Sinmertutg/}

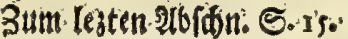

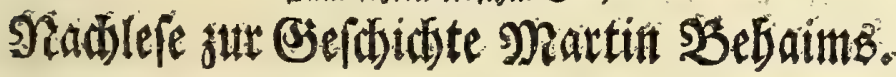

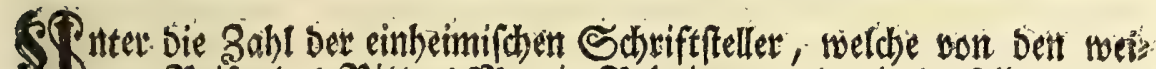

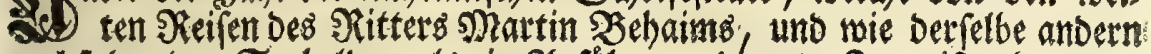
nach folgenben Seehelben, als ein. Infubrer gebienet, Beugnis geben, ges boret mit allem Sechte Der berubmte Polnhifor 2 Bagenfeil, welcher aus.

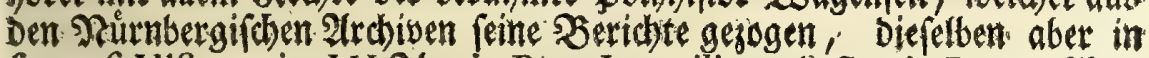
fynopf. Hift. univ. I II Th) . in Pera Juvenili, uno Sacris Parentalibus

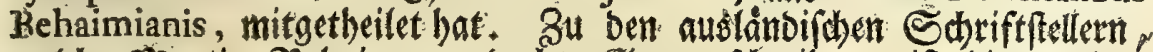

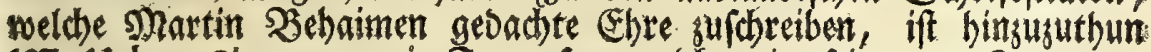
17. Urban Chaveton, ein Franjofe, weldher in feinem Difcours /ur Benzo, im $\mathrm{I}_{4}$ Şaupt t, beridhtet, oafs ber Portugiefe Hagellan eine Alectkarte pon Martin de Bobeme. wis man 34 feiner Jeir lagte, 
bei fich gefúbrer, die ex bei dem Könige von portugall gefeben, in weldber alles verseidbnet woat, uno welche berfelbe febr ges heim verwabret babe. Diefe 2 inseige ftehet in Levini Hulfii $\mathfrak{Z}_{e}$, fbreibung oer Scbifffaber Sers. Magellans, welde bie erfte Der vieren ift, Die anfangs um Den gansen Erofreiz fino verridbtet worben, bie aud istgemeloter Sdriftfeller, im VI Sh). Der Sammlung von fol, dhen Abbandlungen, an Der erften Stelle vortrågt. Diefes Stúce if

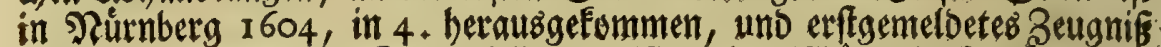
befindet fid auf Der 2 S. Deffelben. $23 a s$ im 230 orterbuche bon stes

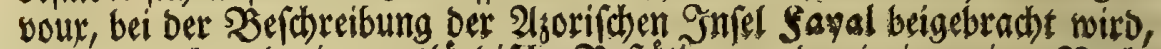

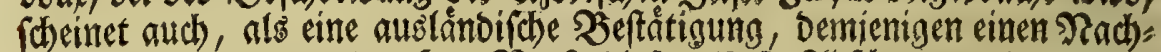

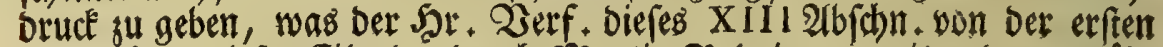
EntbecFung Diejes Eilandes Durch) Martin Behaimen, mit andern erzåh: let hat. Die Erfindung Diefer Snfel roiro Den Flandren zugeidsteben: Elle fut d'abord decouverte of habitée par des Flamans, of il y en

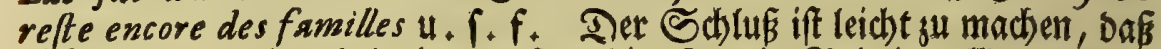

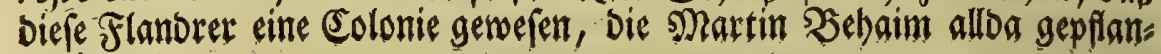
jet bat.

(Es wiro nicht unbienlich fenn, wenn wir aud einige Derfehen anseigen, Die fich in bie Gefhichte biefes Seehetben, ober ber Damit ver:

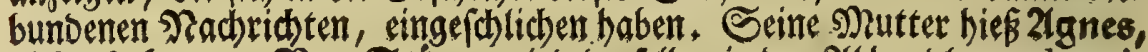
nid)t Zelena. Zon Stuben wirb Derfelben in der 2lbbandlung, de pri. mo novi orbis Inventore, Der 30 ornatne 2 gnes beigeleget. Soh. W3ults

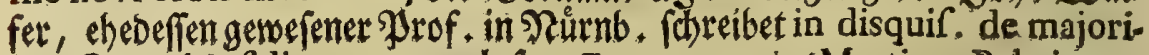
bus Oceani Infulis, p.99, aud 10: Erat autem is (Martinus Behaimus) patria Norimbergenfis, genitus Martino Bebaimo, magnifico quors. dam Reip. noftra Señatore, qui 1474 diem furm obierat; natus matre Agnefia Schopperia, ut e MS. generof quondam Viri Conradi Halleri codice, qui arario noftro publico facer eft, didici, cum nuper ejus in/piciendi pro bumanitate fua copinm mibi fecifjent, quorum

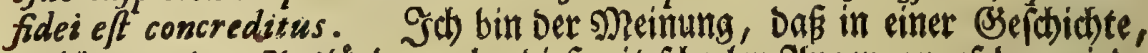

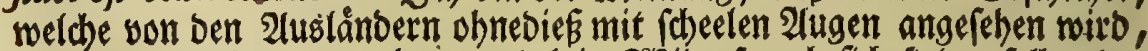
alles wol aufeimander gehen, uno kein $23 i b e r(p r u c h$ fich finden foll, $D a=$ mit bie Mnisgunft bieraus feine 2inlas nelymen Eonne, Diefelbe su beftreis ten. Weniger hat auf fich jene lunricbtigfeit, wenn in Dem Sciftorifchen gemeinen, wie aud) in bem groffen allgemeinen Lexico, Job. Mrietellus, Deffen wir in Der Recenfion S. 17 gedact)t habea, mit bem swenten 2 or:

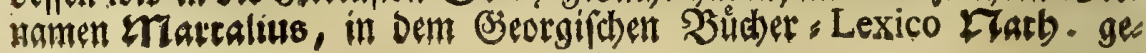


nennet mirb. Der Shr. Detf. Der 21bhanol. de COL. HER C.

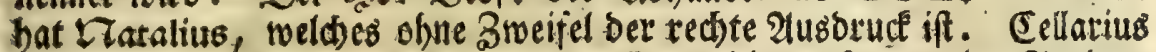

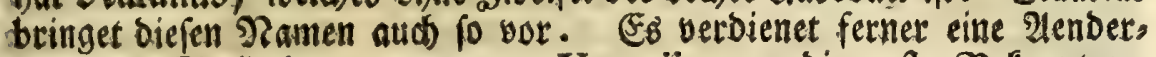
ung jene Stelle ber Geogr. gen. Varenii, wo bie erfte Betanntmas d)ung ber Magellanifकen meerenge, erft auf bas 9.1513 geferet, uno folde Erfinoung einem Dafeus Runaius de Valboa fugerignet wits. Denn c. I4, prop. 7 (bet Reapolit. 2ufl. p. Irg) (d)rei-

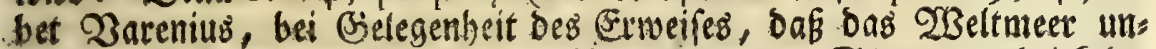

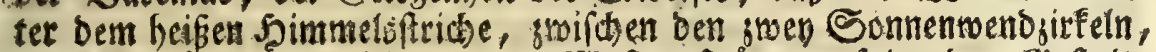
obne Aufboren bon Dfen gegen $2 B e f t e n$ frome, folgender Beftalt: Deprebenditur is motus maris manifefte navigantibus ab India ad Madagafcar et Africam Gc. Sic per fretum Magellanis fertur mare ab Oriente in Occidentem motu incitatifimo, ut inde Magellanes (vel qui ante Magellanem id detexit, ut volunt) conjecerit effe fretum, per quad ex Atlantico in Pacificum Oceanum perveniatur. Saf aber 23 axenius mit oiefen QBorten, vel qui ante Magellanem id detexit, nicht auf Martin Bebai. men siele, bas etbellet aus c. 12, prop. 7. Da er von Der Magellas nifden Meerenge diefer Serior gibt: Magellanes primus invenit, et navigavit anno 1520: etfi Vafcus Nunius de Valboa prius, nempe anno Is 13, illud animadvertije dicitur, cum ad Auftralem regionem luftrandam

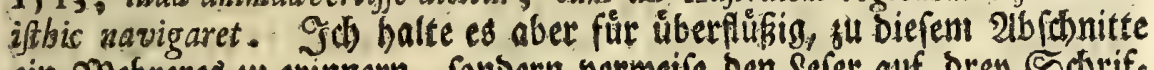
cin Mehrares zu erinnern, ponbern bermerfe ben \&efer auf bren Edrif.

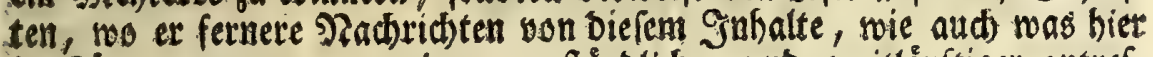

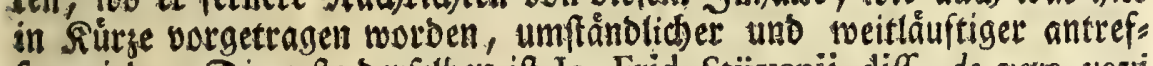
fen mito. Die erfte berfelben ift. Jo. Frid. Stuivenii diff. de vero novi orbis Inventore, Frf ad Mcnum I7 I4 8. weldser abbanolung aluf: fortift auf Martin $\mathfrak{B}$ efaimen gerichet ift, Den ber Betfaffer berfelben a. $0.38 \mathrm{~S}$. divinum beroëm nennet. Das V 5auptit. Diefes 2uffases berfpridt in bet Anjeige bes Snbaltes , folgenbe 2lufgabe aus: gufubren : Martinus Bobemus feu Bebaimus verus America inventor.

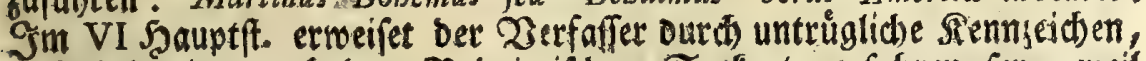
Daf Columbus naw Der Delyaimifosen Seefarte gefahren fet, toeil er gerabe uad ben Imerifanifion Infeln feimen ?auf gerid)tet, ferner eben bie Straffe gebalten babe, welde bie Spanier nod) beutiges ges nefmen, uno in eben fo furser Beit Dahin getanget fen, bie man nod igt biergu bebarf. Das beftátiget er úberbies auf eine fehr waft:

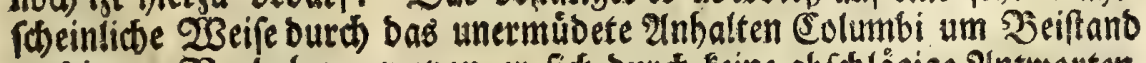
zu feinem Dorbaben, wovon ex fid Durd feine abjeligige Antworten, weber: 


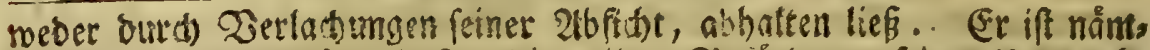

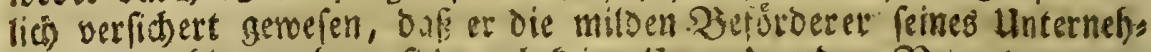

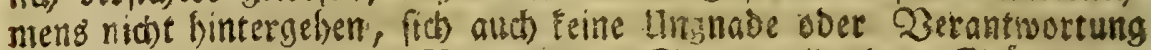

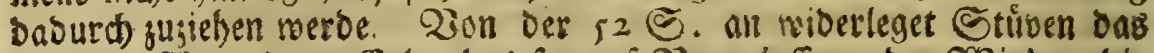
betannte Ziorgeben, Eolumbus fen auf jeranlafiung ber $23 i n t e, ~ b i e$ er von $23 e f t e n$ veripuret babe, auf bie suthmaffung verfallen, fie wes beten von einem feften sente. Er bencifet, Das biefes nus ein SBlenos. werf gewefen, moourd) fich Esolumbus ben samen eines Erfinders vers

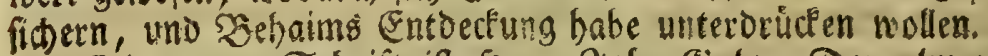

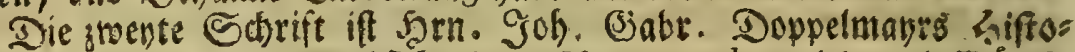

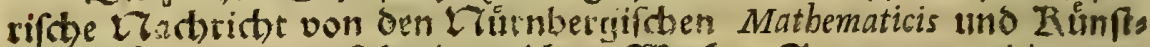

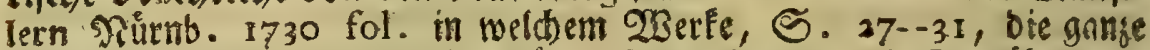

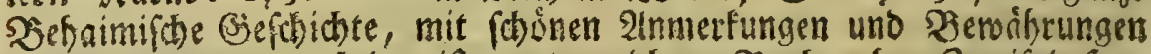

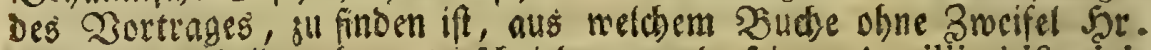
p. Deftng beibeg herallgefdrieben, und feinen Auxiliis hiftoricis einuetleibet hat. Die oritte Schrift ift ein Aluffas bes Scrn. Wrof. Sd) warsen, Zerfaffers bes 2Berfichens de COL. HER C. Der bes reits bor 9 Gabren, an Petri und Pauli ₹age, als an bcm getwohntis

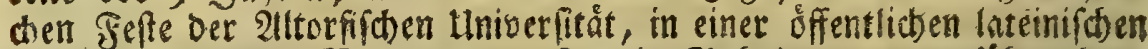
Sebe, eben biefen Jortrag von Mattin $\mathfrak{B e h a i m e n , ~ a u s g e f u h t e r ~ b a t , ~}$ Regensb. wöd)entl. Lache. von gel. Saduen 1740, S. 212, Art. 2ultorff. Zur $\mathfrak{B e f r a ̊ f t i g u n g ~ b e r ~ i n ~ b i e f e m ~ l e s t e n ~} 16$ fobn. ents hattenen Erzåhiung, mus id) ood) smey Steflen aus zwey neuern 23 er. fen, uno bie erfte ziwar aus Stúnens obbefagter albhanblung, von bem

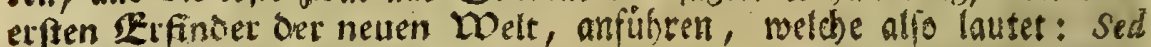
quid multa? Martino Bobemo fuo jure meritoque prime detectionis America gloria debetur. Ex boc fonte fua baufit Columbus, et viam in novum orbem melius aperuit. Sit fua laus Bobemo, fit fua laus Columbo. Ambo magni fuerunt navarcbi, egregiis animi dotibus inuniti, et quod ille feliciter incepit, bic adbuc felicius ad finem perduxit. Nunquam de fua in Americam expeditione cogitaffet Columbus, nifi Bobemum babuiffet predecefJoreme et bodegum, pag. 6.1, Das andere einftimmende Bengnis, melders allfier eine Stelle veroienet, fino die Crotte Des groffen Runftridters Chriftoph. Cellarii, Der in Hift. univerf. (Der Rhsgabe von $1741,12$. S. 202 u.f.) alfo (d)reibet: Felicior Ferdinandus erat et Ifabella, quorum fumtu et aufpiciis Cbrifítophorus Columbus, Genuenfis civis, ultra Atlanticum mare infulas Hifpaniolnm, Cubam, et proximas, iteratis curribus detexit, quod alios, prafertim Vefpucium simericum, infit- 
gavit, ut ulteriora frutarentur, et vaftiffimum illum orbem Americanum invenirent, quamquam non tam ingenium fuum Columbus, aut belicen et cynofuram coli fecutus videatur, quam Martini Bebaimi antiquiorem precurjionem. Is enim ab rfabella, Joannis I Lufitania regis filia, que poft norten mariti (Pbilippus III Burgundus erat) Belgicis provinciis imperitabat, navem impetravit, qua, ducem genium fuum fecutus, ignota maria et intentata vada fcrutaretur. Nec modo Fagalem infulam, quam primus invenit, aut alias circumjetas, quas Ajores, ab accipitruna multitudine $L u$ fitani, nojtri Flandricas a Bebaimi comitibus nominant, perluftrandas fibi cenfuit, verun etiam in aufram magis et magis progreffus usque ad ultimum fretum, quod Ferdinandus Magellanus, bujus ductum fecutus, pertranjit, et de fuo id nomine adpellavit. SIC MAIORA ALIA, ALIA CLARIORA SUNT (Plin. epift. III, 16, I), nec Martini bujus nomen taitopese celebratur, quanto Columbi, Americi, aut Magellani, quamvis merito fuo bis tribus fit praferendum. G() übergebe andere Beugo siffe ber (Jelefrten, weide in Diefem Sabrbunbert gejdrieben baben, und bie nidt nur bie enfte Entbectung Des viexten $\mathcal{T B}$ elttbeiles burds

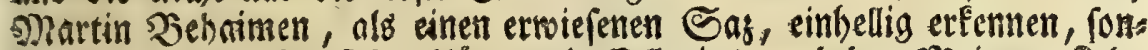

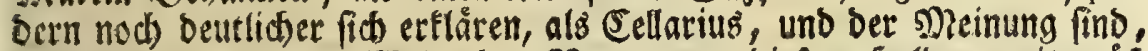

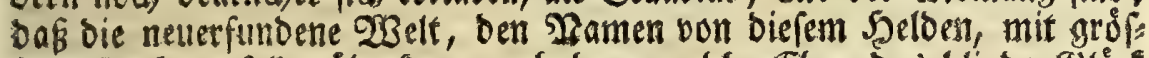
ferm Sechte, folte ubertommen baben, welde (5)re das blinbe (S)luce

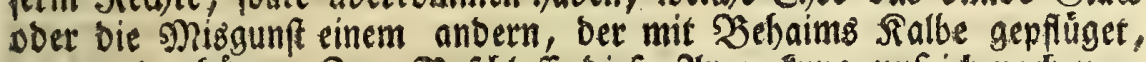

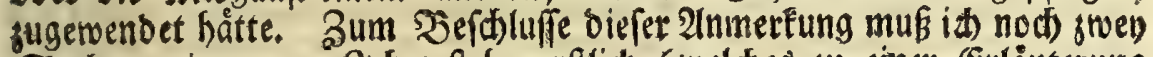

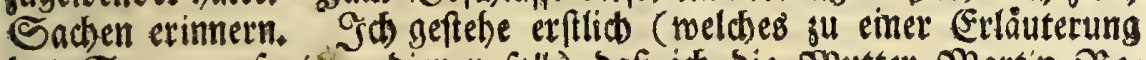

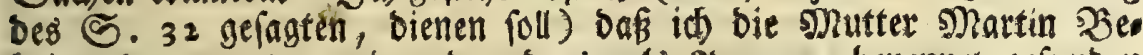
baims bes zwenten, nirgeno anbers, als 2tgnes, benennet sefunben babr. 2Beil ith aber nicht alle Siucher uno Sibriften nadichlas gen fonnte, fo wurbe id unweife banbeln, wenn id) befjaupten wolls te, baf Selena nirgent angetroffen rerbe. Diejes fann id bod fut getwif ausfagen, Daß bie mefrere Zaht det fowol georucten, als

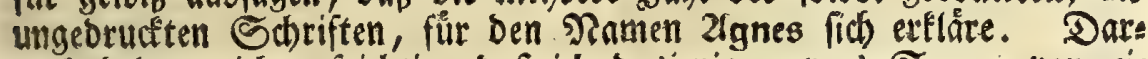

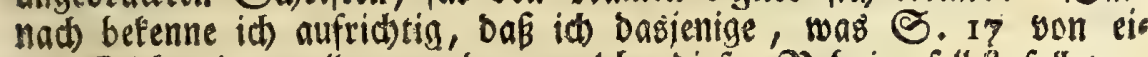

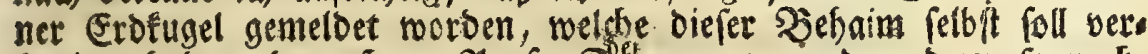
fertiget baben, Dem Strn. Prof. Cebwargen, uno anbern fo nach: gerdrieben babe. Selbft babe io erwebntes Wetk nicht gereben.

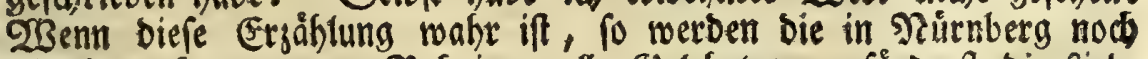
lebenden Serren von Sebaim, alle Belebrten, fuforderft die sieb. baber ber 23 eltbefdreibung, fid befonders verbindid madien, 
wenn Diefelben fich entfhlieffen fornnen, biefen Şebaimifthen Ent, sourf gróffer abjeichnen uno flecben su lafien, alo es in Sarn. Boppels

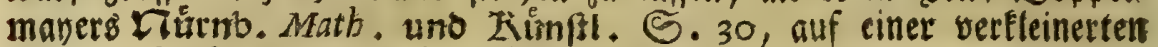
platten Erbfugel, gefohehen ift, wie aud Die 21borucle bavon meh: rern mittbeilen wollen, roelde Irbeit bie Rofinograpfifiche (jefells foraft sang gerne auf fic nefmen miro.

\section{Swey andere abgenothigte Erinnerungen.}

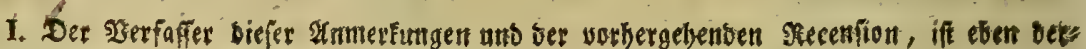

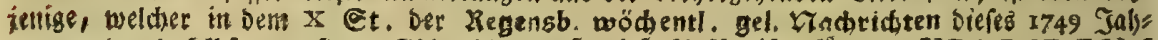

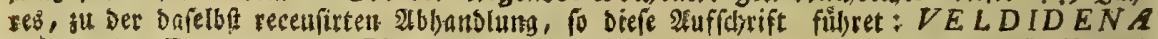

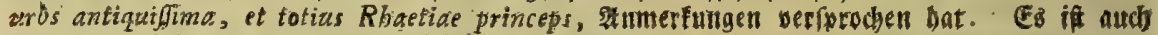

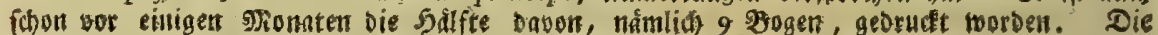

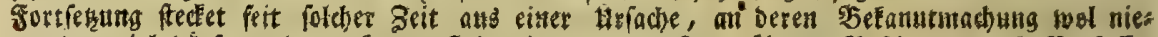

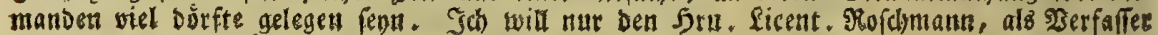

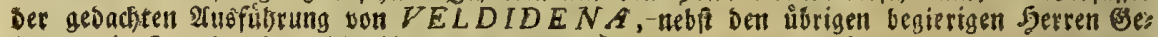

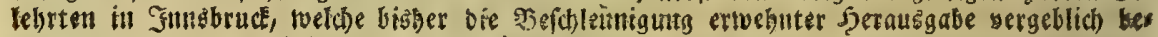

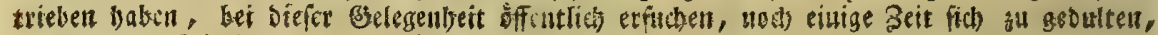

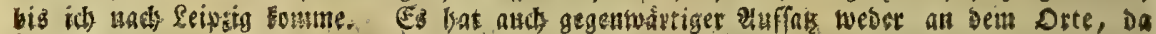

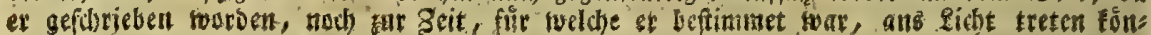

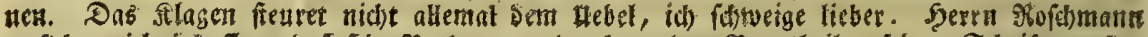

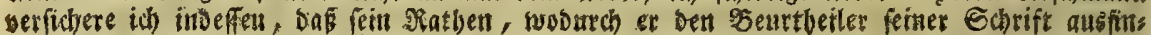

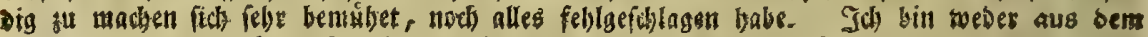

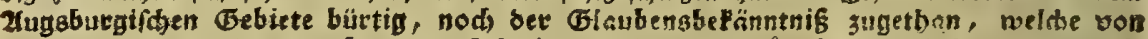

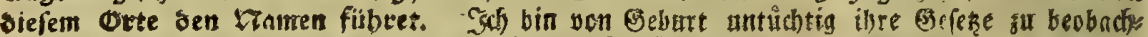

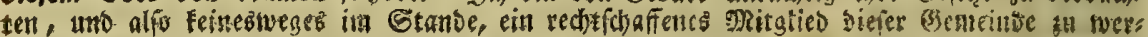

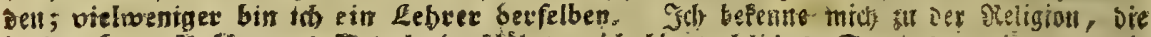

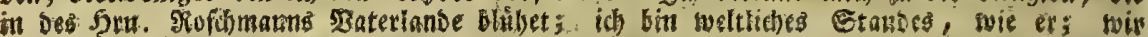

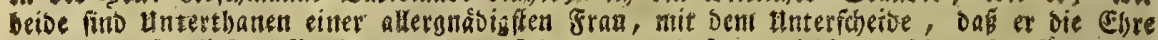

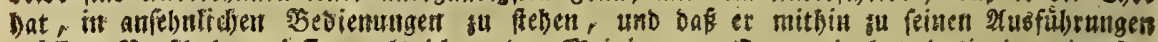

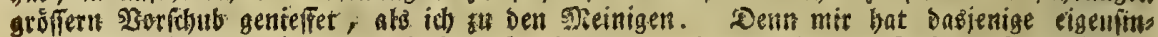

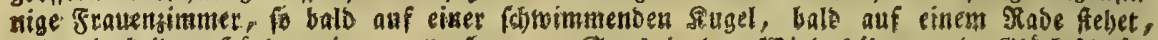

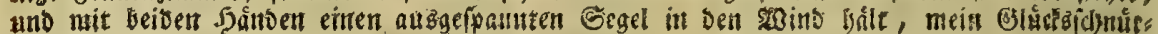

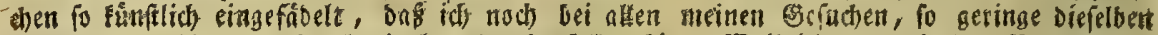

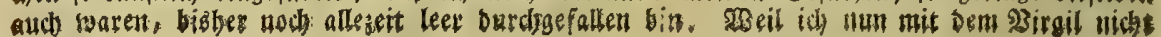
fagen foul:

\section{O Meliboe, deusetrobis bac otia fecit,}

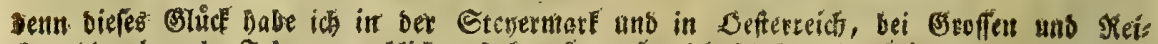

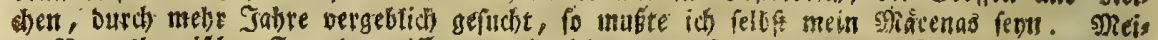

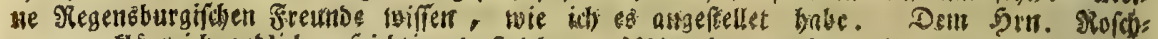

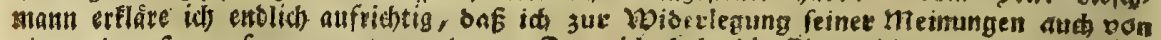

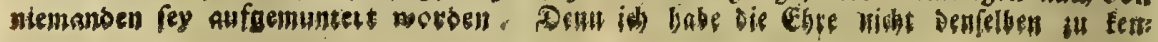




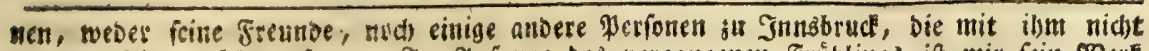

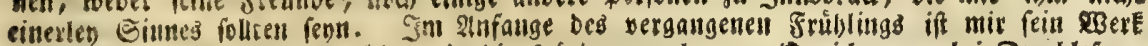

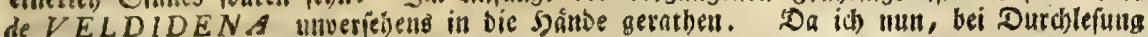

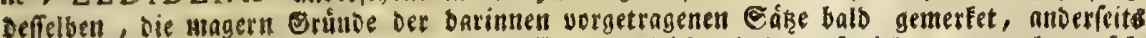

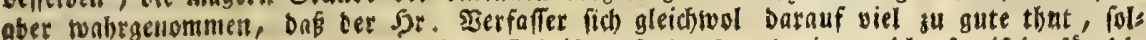

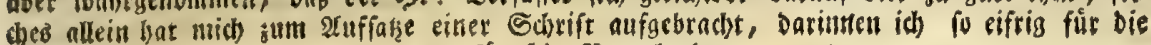

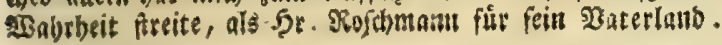

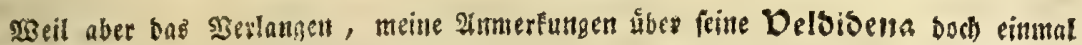

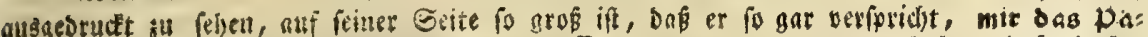

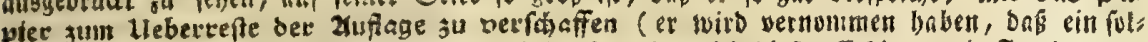

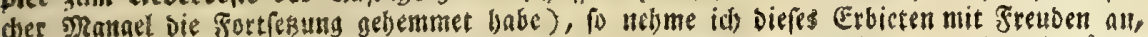

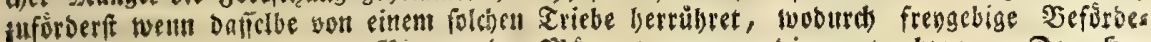

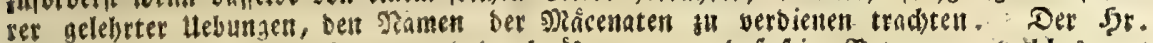

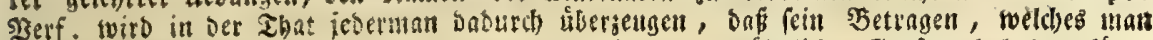

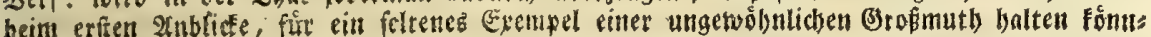
te, in fid) nur eine folge Der Sid)ergeit fen. Denn man wird leidst Den Edhlus baraus

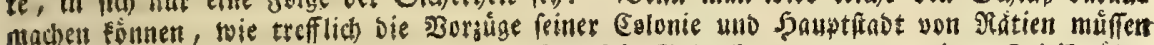
verwabret fenn, wenn man felsen foll, Daỉ er fein Bebenfen trage, za einer Sritif über

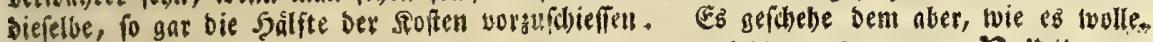
Es bringe meine geringe Feurtbeilsng Des vermeinten Ratifiden Souptortes Deloroena,

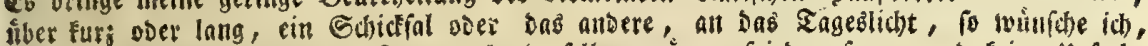

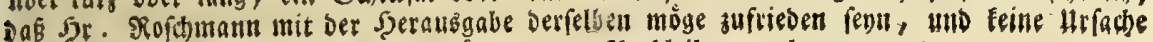
babe, feine gat zh beftige Hngebult uber oeren 2ubbleiben su bereuen.

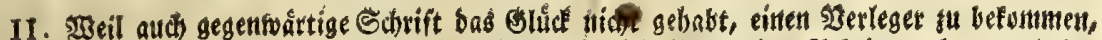

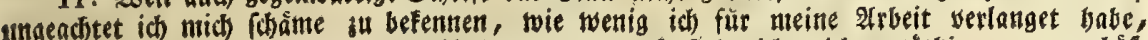
folglich felbft muste die foften ber 2Auflage traget! fo finbe id) mich geriotliget, gegen bofe

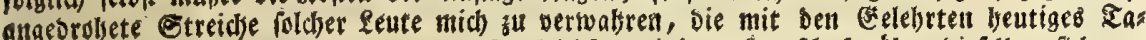

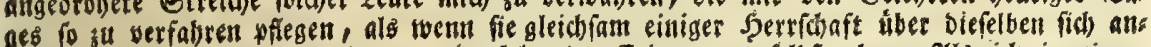
maffen wolten. Diefe oringen mir folgende Erinnerung felbft $a b$. All ib in einentin Subblaben vorfellte, id wate gestoungen, felbf meine Edbrift su verlegen, warb nein

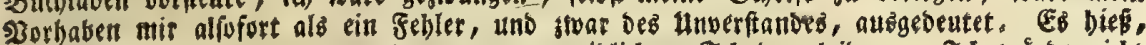
id tourbe bei meiner Internebmung unvermeiolid)en Sdhaben leiven. Ith wutbe nidst

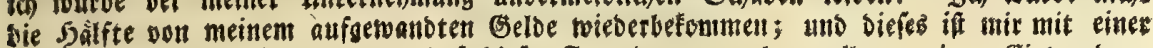
colden suberficht gefagt worben, baf biefer freund, ungeadhet aller meitier cintwendun

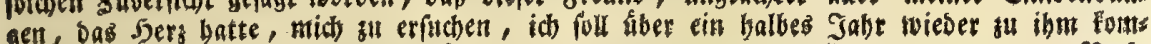

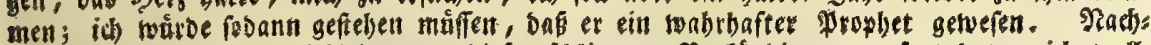

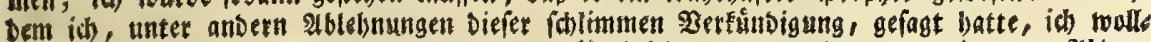

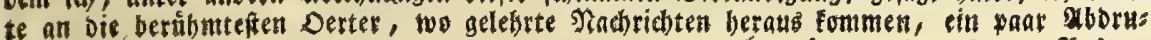

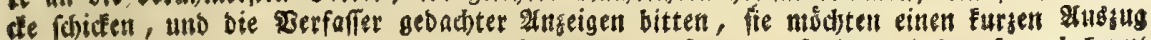
son Dem Tnhalte meiner abbandang, wie aud ben Sot, wo foldhe gu basan fen, befannt

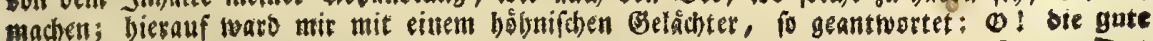
3eit if nummebro vorbeil in welder bie Kecenfonen etwas gegolsen baben. Das

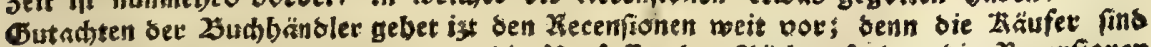

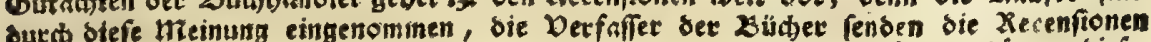

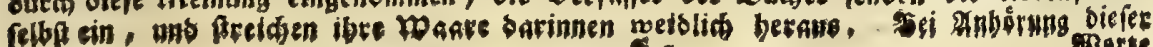
( 3

Parte 


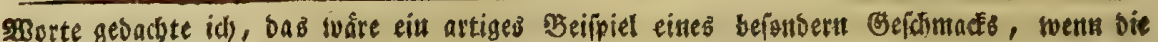

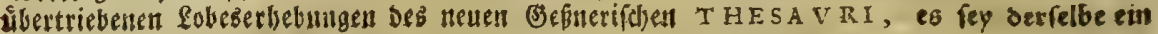

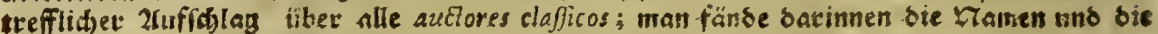
Defdreibungen vol sllem bem, wovon bie Rönter su reben gerouft bätten; es fey ein fold unvergleid)lides Wetr, bem sie Dölfet von Europa mit cuggefonnnten armen

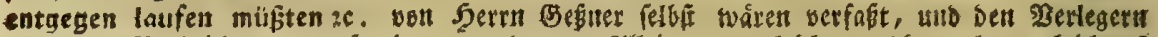
gelebrter Tadridsten sugeferciget worben. 2allein aus gleibent Thone bat glcidbrol

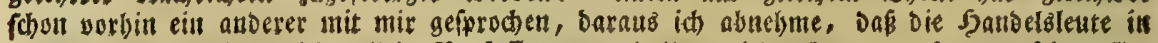

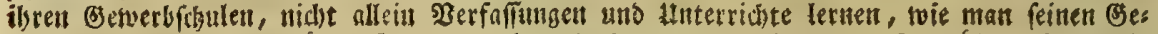
tvinn reblid) erlangen ntoge, fonbern audh collegia pivata uno privatifima úber bie funfts

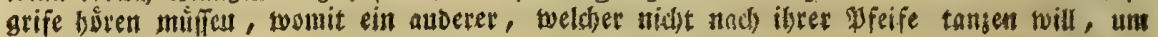
Das Ecinige su bringen fey. Das ift aber noth gut, Das eben sieienigend bie ibr Eigent

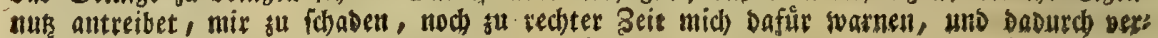
anlaffen, mich gegen folden Eintrag atf bie Jout ju fez̧en.

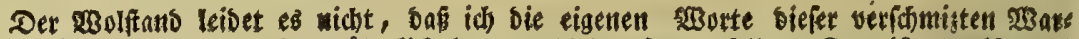
ner, sie fúr biefelben gar nicht rúbmlich lauten, bieker fezen foll. Dab if getwib, baf

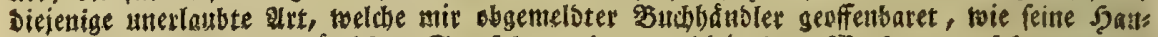
belggenoffen nad) alfer moglidben Sorgfalt tradteten, biejenigen goerfe ju verfolgen unb su

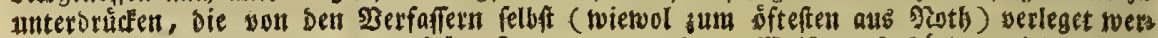
ben, Eeine Sache fen, weldbe biefen Eeuten ungerechtes 2 Beife aufgeburdet wiro. Die

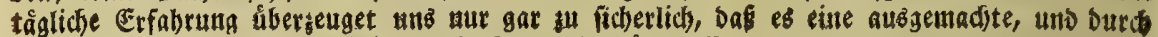
butpert Exempel beftatigte 20 abrbeit fen. Jd) ùberlaffe aber gans gerne anbern bell Eis

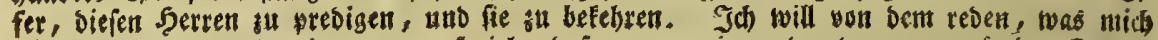
náber angebet, uno eriunere nur foviel, Daś, vent jemano, oer gegentuartige Sdhrift fid fulegen wollte, boren foll, biefelbs fen eill Shmatterwert, ober foidje ware an bet Orten nicht su baben, wo fie in ben iffentlidjen Deridbtent angefagt twiro; biefer fieblisas ber lvird exiudb, wegen bes erffern fich lieber nadb Belegenbeit bei einem Belebrten su er:

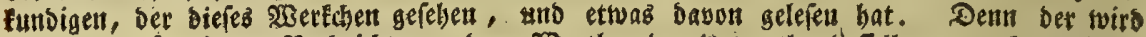

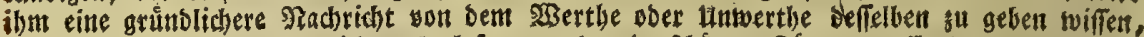

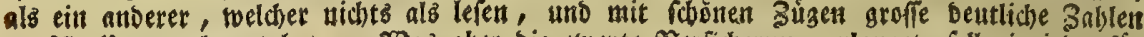
su idjeiben, gelernet bat. Wab aber bie swente serfichertug anlanget, fotl ein ieber füs

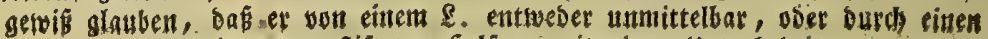
sritten angeftifteten Selfer, mit einer Huwabrbeit feg berichtet worden. 


\section{wevter}

\section{gefondere Mubandlung \\ vom}
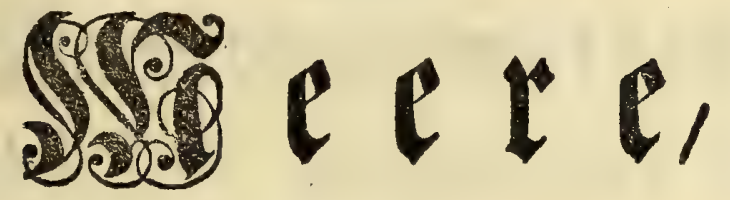

baburdis

reinige in Der Sarift de COLVMNIS HERCVLIS,

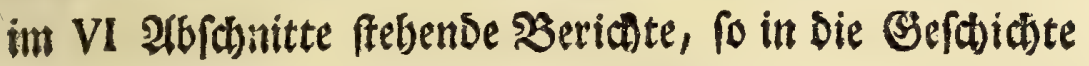

bes sneeres cinfinlagen,

\section{in vier $\mathfrak{A}$ brágen}

unterfuct,

swie atd

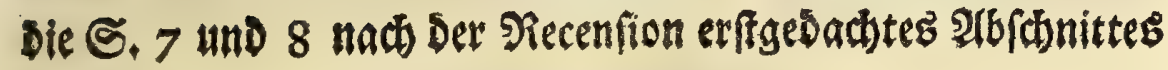
vorgetragene

\section{dufgaben}

ด 45

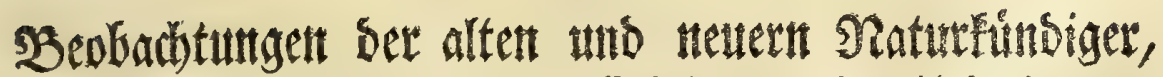
zum Igeile aud Durch eigene Enfabrung Doer Lteberleguns von bea Derfaffer vorfergehender Itamerfungen aufgetofiet wertern. 


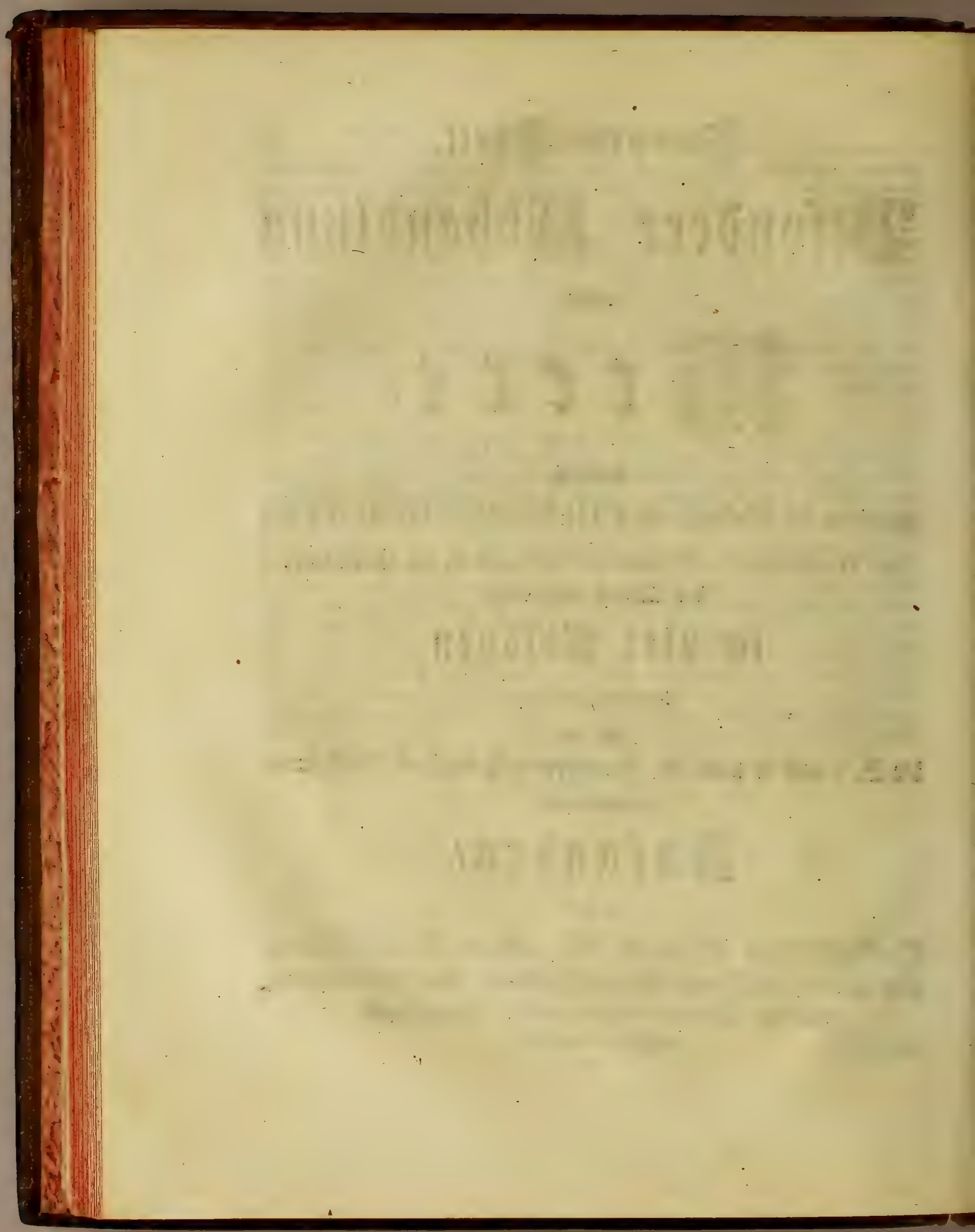


Dettent

\section{Shodedélgebofunetit}

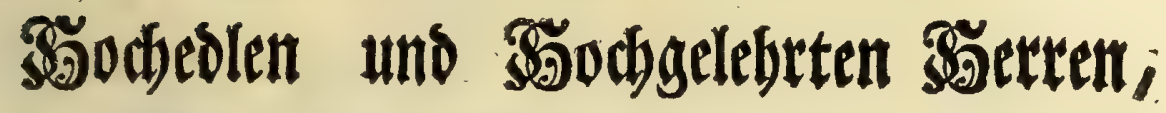

Sernoditector，

und

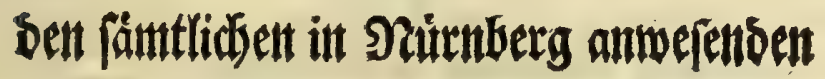

ssitgliedern

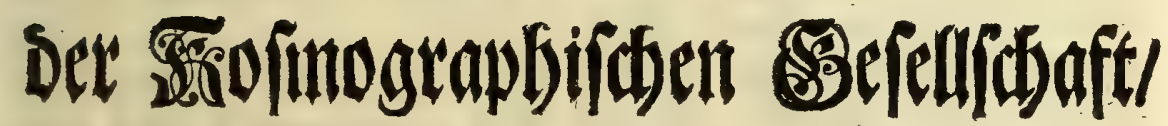

meinent wertbeftent

(o)onnern und areunden. 


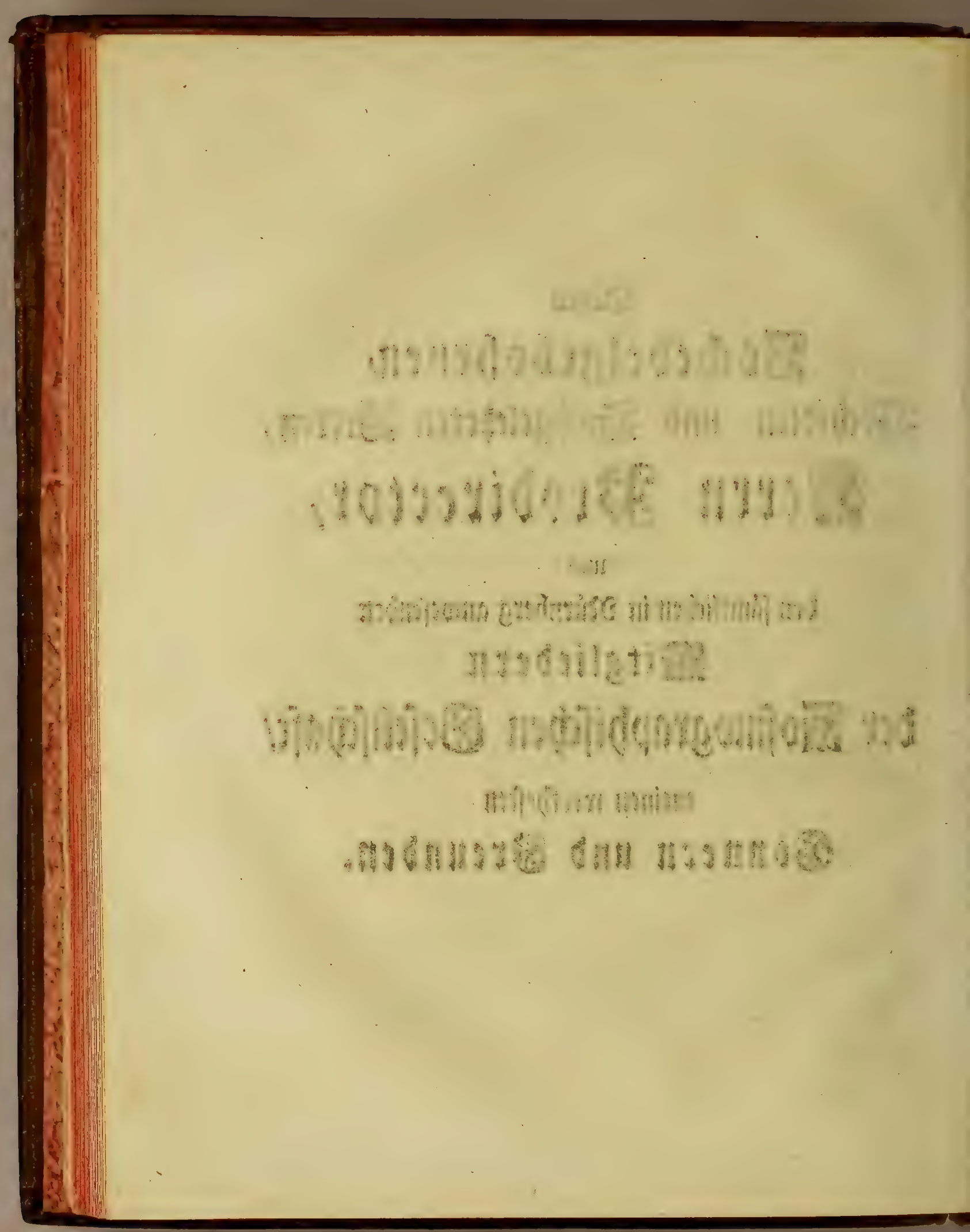




\section{siscine setren,}

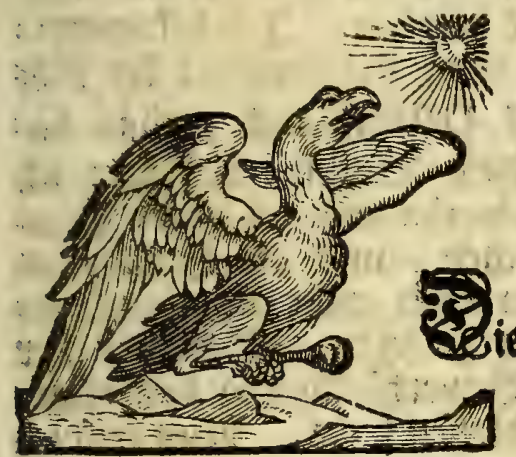

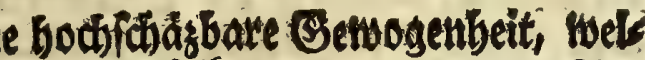
de Diefelfen mir bei meiner Ins kunft alfogleidt) sugefaget, sold be Sie mich nod) inmerfort genieffen laffen, forbert von mir alle erfinnlide (Erfenmtlidteit. Jid murbe audi) unredst bane

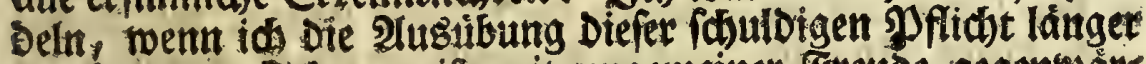

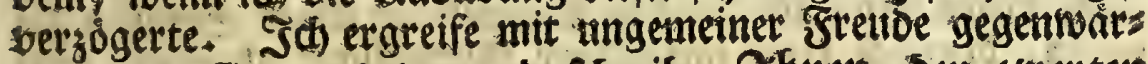
trige erfte Selegenbeit, und phreibe Shinent Dent swenten

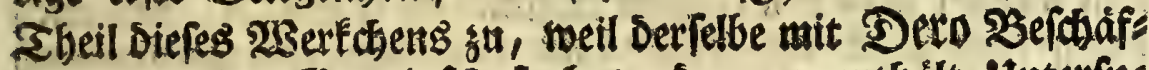
tigungen eime Bemeinifiaft bat; Denn er entballt $\mathfrak{u n t e r f u s}$ chungen vom Meere, welchez ein nefentlicher Eegenffand

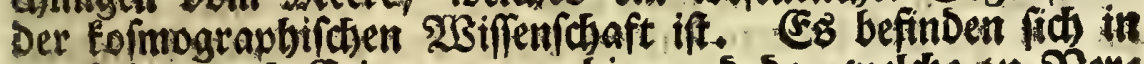
Demielben and (Erinnerungen bier und Da, meld)e zu Bets befferungen 2Iniấ geben fonnen, Deren die Befobreibungen berichiedener feften IGheile Des Erofreifes nod benoibiget

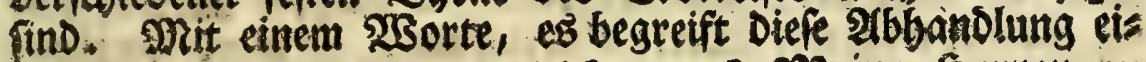

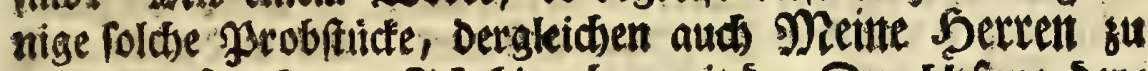
liefern verfpredsen. Id) bin eben mit ber Durchlefung bers jenigen Bonf́blôge fertig worden, welde Diefelben, um A 2 Das 
Das Sunthmen Det izterwebntert eden und mislichen fhaft zu befórbern, aufgefezt, uno bor Dren Sabren berausges gehen; von Denen Sie mir aud neulich ein abgeoructes Stidf zu verebren die Stute gebabt . Diefe Schrift vergmigs te mich ungemein, weil iç auz Derfelben erfab, Dafs id nach Den Darinnen aufgeftellten $\mathfrak{B}$ orriffen gearbeitet, uno bereits bor vielen Jabren an Die 2lusfubrung einiger Sadjen ges Dacht babe, als menn Shle Berfaffungen mir fichon längft

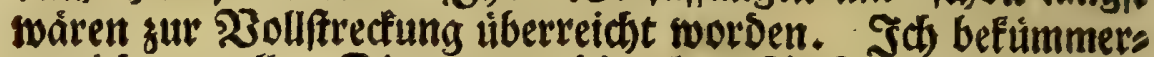
te mid vor allen Dingen um Die alten $\Re$ eiferegifter Der $\Re$ Rs mer, wie ich febe; Daß̧ es Meinte Serren aud getban bas ben, und noch thun. Durd Diefe Seibulfe beftebte ich mid, Die sweifelbaften Derter Des Norici uno Des obern \$Pan noniens auszufpuren, su unterfuchen, uno Die Etellungen Derjenigen, wortiber bie Selebrten nod nidjt ubereingefoms ment fins, in móglidsfte Sewisheit zu fezen. Das war Der ciffe Srunofas, Dem ich bei Der $\mathfrak{B}$ enertifelligung Des iztges meloeten 2(nfoblages zu folgen beichlofen babe. Tun will ich auch Den ztoenten erófnen.

Jch fab bald ein, Daßs die 2ngeigen Dex Meilen, welcte in Den binterlaffenen Werfen Der Piomer fteben, wie fleisig auch Diefes $\mathfrak{B}$ olf úbrigen: in 2 tusmeffung feinet Straffen ges wefen, Dennow feine unfeblbare Fichtichnur abyeben, mits telft weldser man Den rediten 2lbftand ibrer Stäbte, wie auch Der groffen झoft und Saftbaufer (mutationum, manfionum) finden uns feftregenfónnte. Die bandgreiflichen XSiberfpruche biefer. Schriften, nelche man hier und Da beobadjtet, erweifen jur Enitge, Daf befagte Zablen, Durd Das vielfältige $2(b$ foreis ben unerfahrner Seute, Derer man fich oor Der Erfindung Der Sudboruderfunft bedienen mufite, gar oft fafándid find vers pechfelt, oder berfálfchet worben. Wenn ich merfte, Daß bie Bablen mebrerer গ̧Serfe tibereinfamen, fo ward id jiems lichermaffen vor Dem Jirthume gefichert. 2rllein Da ith aud Diefe Berseidniffe, in Prnfebung Der angegebenen Meilen, feinesmeges einftimmig fand, fo sog io dod Diefen Pugen (1) Dars 


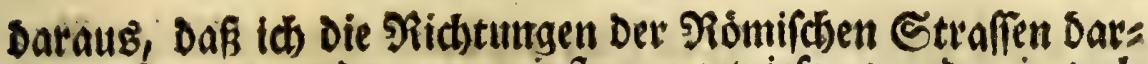
aแz erfannte, und zum wenigften angewiefen wurbe, in mels dien Etrichen von Sändern ich ungefabr eines uno bas andes re aufzufuchen bătte. Hum nun audb Die eigentlichen $\mathfrak{E} a g e n$ Der Derter ausfindig zu machen, nabm id meine sweyte

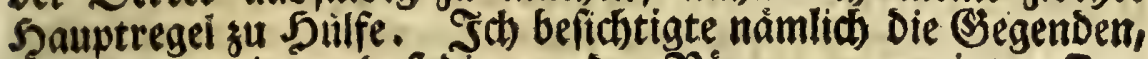
wo id) vermeinte, Unß Die von Den Fiómern angegeigten Det: ter mochten geftanden baben. Denn ich babe auf meiner Feife, welche ich Durch gans Stalien gethan, Die mich uber

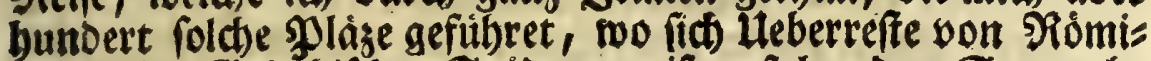
ichen ober Eriechifhen Etộten meifen, folgenden Eas wabe

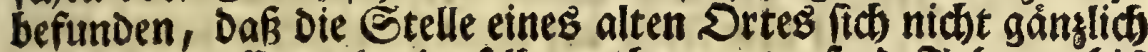
Derbergen laffe, ware Derfelbe auch vor taufeno Jabren biz auf Den Srund gefdhleifet worden. Die Stridte Del zerbrod)es nen Biegel, Die Scherben Der Samifchen Elefohirre, Derer feinfe bioletichnarze oder bellirothe Lafur (wenn fie gleid mebr hundert Jable in Der ErDe gelegen baben, oder Durch Den 2(derbau Dfterg fino auggegraben, Dem Piegen und Der Eonme ausgefest, wie aud mieder verfcharret wors Den ) fo lebhaft in Die 2lugen pielet, als wenn fie erfit geftern Diefe Schminfe vom Iopfer uberfommen bátten; ferner gers

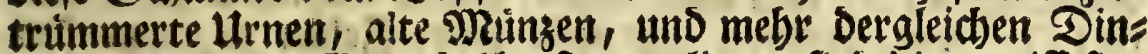
ge, womit eine Segend tiberitreuet liegt, find Die gewiffeften Tennzeichen eines bon Den \$ómern ober Griechen ehemals bewobnten, feitbem aber eingegangenen Drtes. 22m Deuts lichiften zeigen fich biefe Spuren auf Den Baufeldern, meil Derfelben Soden Durch Die Adterlente febr oft umgenuiblet, uno Daburch immer etwas neues zum 20ricteine gebract) swird. Man fiebt auch), Daß Folde falpetridhte Státten, wes gen Der ungemeinen Srudhtbarfeit, gemeiniglich) zu 2tectern erfiefet merben. Saaben Die Befizer Dergleichen Drte, aus unverftande oder aus NotbDurft, zu sisiefen liegen laffen, fo verrathen gleidswol Die an Den Rainen befindlichen Saus fen von Steinen und zerbrochenen Biegeln, (weld)e bie \&ands leute bon foldhen Grinden binaugichaffen müffen, weil fie Die Eenfen Der Mäber ftumpf madien) Daß vorbem \$obnun=
A 3
gen 
gett alloa gewelett. Nun babe iđ Durch die vielfältige श̧es tradtung alter in Italien noch ftebender Bjebảube, mie atud ofters auf Dem Sande bin und wieder angetroffener Fuinen, ferner biefe Senntnifí erlanget, Dafs id Die Státten neuerer gerfitorter Derter von Den alten zu erfennen, ja ein Stude eis Hes $\mathfrak{R o m i r a t e n ~ B i e g e l s ~ b o n ~ e i n e m ~ b e u t i g e n ~ z u ~ u n t e r i d i e i d e n ~}$ weifs, und, twenn nut bret ober bier Quaderfeine nod) libers cinanber fich befinben, zuberlaffig anfagen twill, ob es ein Ueberbleibfel eines Romifhen Semáuers fer. So hat mid Der bloffe 2̂ugenfhein tiberfibret, Daß Das meftliche, Doer Das naw Stalien gefebrte Stud Der beutigen Billerifonen Stabtmauer, auf Dem Fuffe ber alten romischen ftebe, wo: burd uns bie Dritte Seite, uno folgliob beinabe die gange. vorige Sróffe diefer PRomif́chen municipii, weld)ez CELELA gebeisen, befannt wiro; indem ber Fluß sóding Die oftlidue Seite, Die San aber Die fitolidbe beftimmet. Durd) foldse Mittel nun Eónnen niobt allein Die Sagen Det alten Etảdte am fidserften ausgeforforet, fonbern aud Die irrigen $3 a b l e n$ Der Meilen in Den Momischen Meiferegiftern verbeffert werbent.

ख̉sen ein Selebrter Durch feine Llebungen in Der alten (Steographie, th will nidht fagen, etwas mislidbes su Stans be su bringen, fondern nur viele grobe. Febler su bermeident gedentet, fo mus er infonderbeit oon bet tabelbaften 2irt

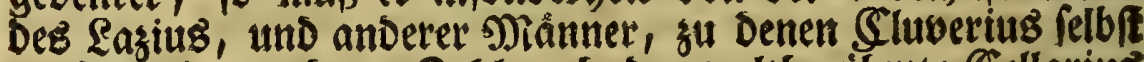
geboret, ja von Derer 3 ald aud Der weltberibmte Sellarius

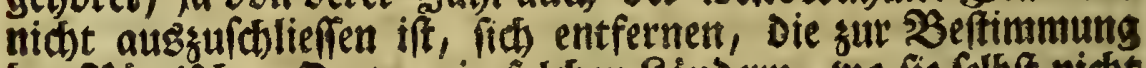
Der Pomischen Derter, in polden Lanbern, wo fie felbit nicht gewefen, ober meldse oiefielben nidt gebuhreno Durdhgefucht,

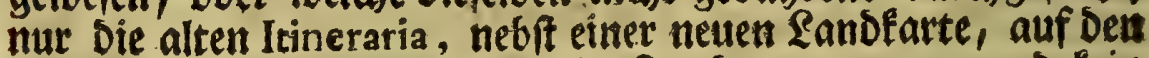
Fiid) geleger, Den Birfel in Die 5and genommen, uno fein Bebenten getragen baben, Die Sagen Der alten Derter foldjen Segenten zusufdreiben, Dabin Diefelben Das Maấ Der Pid:

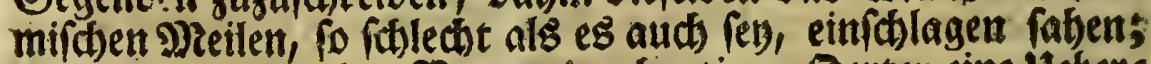
zumal ment fie in Den Famen Der beutigen Derter eine Ueber cinfunft mit ben lateinifón beobaditetet. So ftellet $\%$. Sluberius Das SANTICVM Anton. nad Saned, fo ein Śblö́ 
Schloß in bem beutigen $\Re$ Biertel Billi ift, DaB STIRIATE Tab. in Den Gtoder, to ein Ibal in Dem Defterreichifden Sande

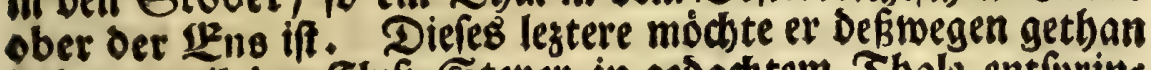
baben, weil Der Sluk Stener in gedact)tem Ibale entiprins

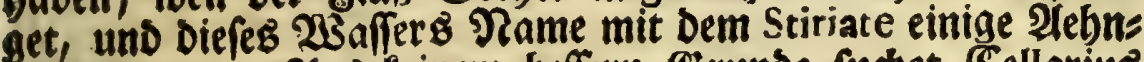

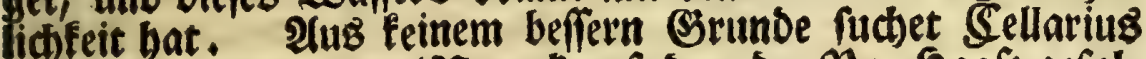
MVROELAM Ptol. zu MTuredt auf, Dem Der Spr, Jjaafe gefols get ift. Das find aber gewirfe geographifose Jrthumer. Die angegebene Stelle Des Santici bat weder Die oben erwebnten

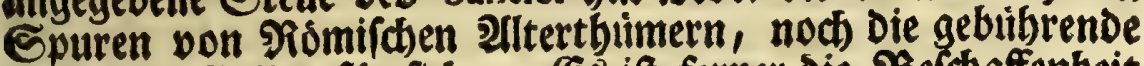
Sabl Der Meilen für fid). (Es ift ferner Die SBeidaffenbeit bes beutigen DrteB, zu einem Sebáube, fo auf Der \$ỏmis fchen Strafie foll geftanben baben, gans untübtig. Roch cin Jauptfebler ftecetet endlic) Darinnen, Daß Cluberius Das Ganticum an Den 2 Beg fezet, welcher fid) von Celeia nacis

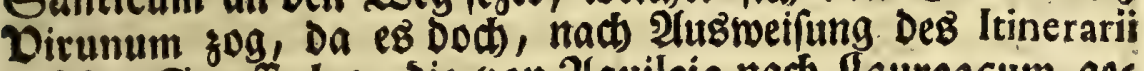
auf Der Straféte lag, Die von 2quileia nad Laureacum ges richtet war, bie Celeiam nicht beruibrte, fondern weiter auf Der linten Seite oben meglief. $\mathfrak{B}$ mús alfo Das Santicum Ant. in Dem Striche vom beutigen Sårnten, und nicht in Der Graffidaft 3illi aufgefuctit merden. Der bloffe Gleichlaut ber Samen, santicum und Ganed, bat Den Sluverius auf Diefen falróen $23 a b n$ gebrad)t. (Ex batte aber auth, bei

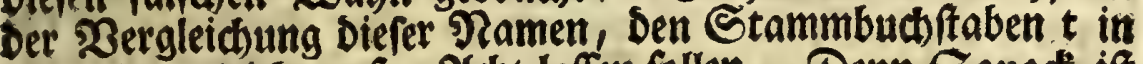
Ganticum nid)t auker 2 dat lafen follen. Denn Ganed if

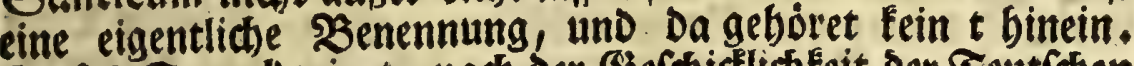

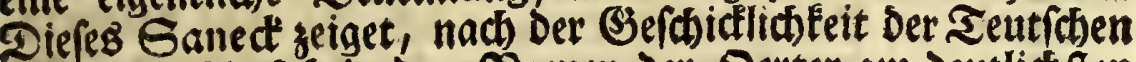
Eorache, Die fid in Den Pamen Der Derter am Deutlichifen berbortbut, Durch zwey Sillben vieles an, námlich) Diefes (şes báube (Re) arx impofisca promontorio, grod in Sanam amnems ex-

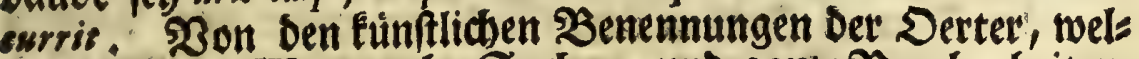
we Durd) ein 250 rt mebr Sachen, und ganze Begebenbeiten, gu erfennen geben; ferner, wie biefe Namen immer flirzet ano figurlicher merben, bátte id ein MRebreres su erinnen, wenn mir Der Siaum Darsu nidit mangelte. 
Ebent fo merelich ift Der Jrrthum, weldien Cluberius it Der Etellung Des Etiriate begangen bat. Dem Die :Bef thafs fenbeit Des Stoders befannt if, Der muß susleich einfeben, Dấ Die Rơmer, mit ber Anlegung einer Straffe Dura) biefes. Ibal, fid lácherlid) aemadit batten. Das Etiriate feget Die Sbeobofifdie Sanofarte auf bie Straffe, sold aus Dam. Striche Des beutigen Defterreidif(t)en Dambes ober oer. IIns, in Das nacbbero fo genannte Etevermärfifaje Sebiete. gieng. EB bat aber ber Stober, Durd fteile 26 bange eines for officten SEteingebirges, nur einen, uno swar fo fomalen

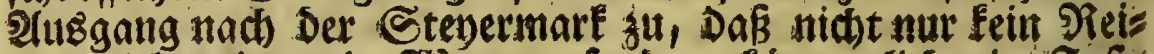
ter, vielmeniger sin $\mathfrak{X}^{3}$ agen, fondern fummerlich ein Sufs ganger binduir fommen fann. Sollte eirre 2ingabl Sußsools tez fid genotbiget reben, Diefen $23 e g$ su nebmen, fo ift eit einziger Sierl im Stande, wenn er genug geladenes Sewebr bat, einen Mann nad) Dem andern toot su fotiefien, und als fo allein Den $\mathfrak{P a \beta}$ z Diefes eine Derientgen Sergengen, Die $\pi v i \lambda$ genennet perben. Die Fomiftie Jabrtftraffe zog fid, wie now Die beutige, lins Eer 5 and oor befagtem Thale vorbei, uno gieng tiber Dent Syrn, welcher 3 erg Die vorerivebnte Dberofterreidifobe (Bes geno von Der Stevermark foheibet. Jstgedadte Sichtung Der Straffe beftátiget einigormaffen Das am Juffe Des Pytm: liegende Stift Epitäl, fo meilano gu einer Serberge fur Die nach Jerufalem ziebenden 23 alfabrter aufgerichtet worben, Soldes Deutet Der Rame felbft an. Es wird Diefer Berg nod beutiges Tages mit Laftwagen uns Suticten befabren. Durc Das 2 Bort Pyen veritunden Die Celten einen 2 ers insgemein, wie id im 21nbange sum 1 Sh. S. 21, unterfucht uno geurtbeilet babe. Derjenige Serg in Srain, Der auf Det Straffe nach Stalien liegt; und nunmebr Den Tamen Sirnbaumerwals fubret, bat aud vorseiten mu Pyri, $D . i$ fiflectitweg Zerg, gebeiren, wie foldes auB Dem Itin. Hier of. zu erfeben, it weldem Reiferegifter Die Benennung, AD PIRVM vortommet, uno auf eben diefe Begend eintrifft. Racboem Das alte Ppen unpernebmlic geworden, to eite 
unbermeiblicfe Folge ber Berånberungen if, betten alle Spracten unterliegen, baben (mie ich vermutbe) Die $\mathfrak{T a} d$ b= Enmmen geglaubet, pyrn bebeute allbier pirum arborem. Durch Diefen Unweritand pheinet Dei fallche Name Sirns

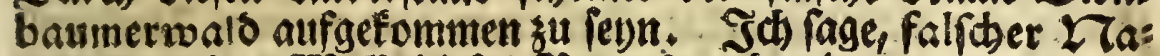

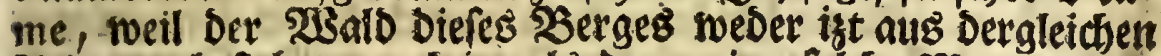
Banumen beftefet, noch jemals Derer eine folche Menge noiro

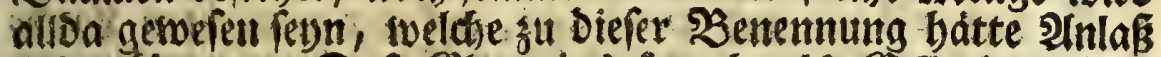
geben tonneti. Dafs SThering fowol, als Cellarius, bem alten nturoela eine failste Lage angemieren baben, if bereits

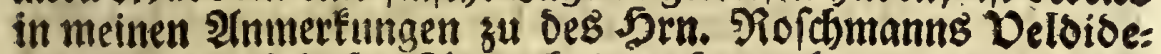

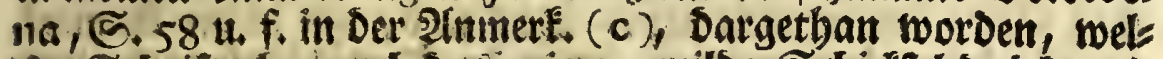
the Echrift aber noch Dasienige unmilbe Schidffal bructet und belet, To mir Die Seratsgabe Der gegentwartigen auch fibon fater mactis.

2rle Diefe, und nocb viele andere unriditigfeiten entoes ctet nun Die unentbebrliche 2 efichtigung Der Derter. NSeil man aber ein fo gewiffes, und zur \$erbefferung Der Bseogras

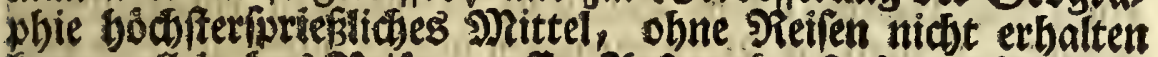
fann, allein bas Peifen grofien 2lufwand erforbert, fo baben Meinte Serren volffommen recht, Daßs Sie febriftlich und

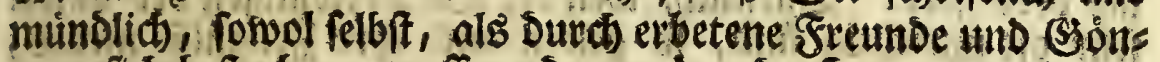
ner, fich beftreben, groffe und sermogende serren zur unters

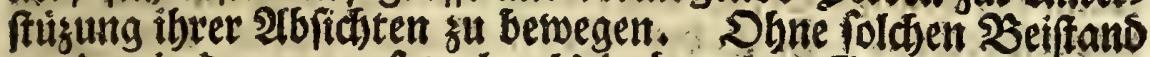
werDen in Der neten fowol, als in Der alten Seograpbie, un=

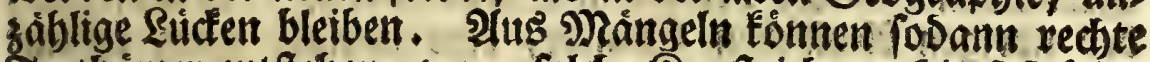

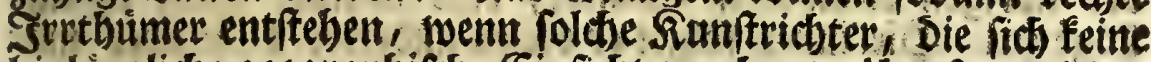
binlingliche geograpbif(che (Finficht sugeleget, uber Dergleidsent Ctellen geratben, und in Der Mieinung Die Ranbearten vou Invollfommenbeiten fu fäubern, offenbare J゙ebler bineinseid): nen. Id bin ein Jeind Derienigen vorgegebenen geographis

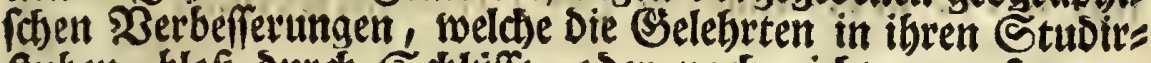
fuben, bloß Durd Sdjluffe, oder nach nidjt genugfam gé

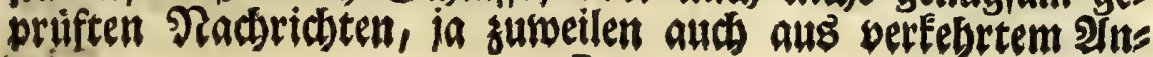


triebe einer redit abgottifeten (Ebrerbietung gegen Die alten

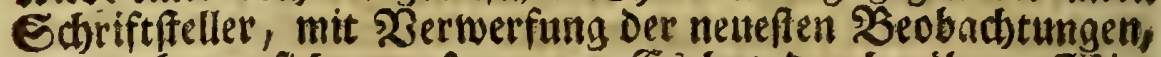
vorgunebmen fid unterfangen. (58 bat Der berwhmte शisits tenbergifabe Profefior Mathef. Joh. Mattb. Saafe, in श्th febung Der Sormographie, fich einen ungemeinen erworben. 2lllein id Fann Dod erftlich Diefes feinesweges billigen, Dafier mandbmal die Pamen gewiffer Derter, roie 3. E. Das Tábtali und Demírkapi, auf gut gemacten Sanos tarten weggeftrichen, unb auf jeiner $\mathfrak{B}$ orftellung bon Ungern auggelaffen, weil er etwan in Den gemeinen Sitbern Eeine Erwebnung Diefer Namen; oder feine Befchreibung Der Sas chen felbfi, angetroffen bat. Das fino, wie in ber 21nmerf. (ffff, Dargethan worben, zroed in Jeutidland noch siems lich unbefannte, allein in ungern, Servien, und andern mits tágigen Elavíften (Segenden, bertibmte Drte, uns zwed Der mertivirbigenen, Die auf Dem untern Fheile ber Donatt fit) befinden, weldbe Daber viel eber, als Nova, Talia, Sip. severin, U. D. g. auf Der Eand larte eine Etelle berbienet bats ten, went vielleidit jemano ourdh eine vorgetwande erspas rung Des Faums, Das 5aafifhe Berfabren entichuloigen wollte. Durd Die $\mathfrak{B}$ ernichtungen foldher widjtigen und nuts lichen 2 ingeigen, werben die Land Earten mehr verichlimmert, als verbeffert. Darnach, weil bie Sefdreibungen Der 2lten febr oft unridhtig fins, fo gelten and ibre Beugniffe nichtb, wenn bie beutige Erfabrung, und Der Pugenfobein Denfelben miderfpreaten. 3. E. Der Sprof. Saafe eignet Der tynfel Gtromboll (welde Der Alten Gtrongyle ift) in Infebung Det tibrigen Pedifhen cilande, eine beinabe gans oftiche Rage zu. Sierinnen folget er vielen andern; diefe aber mos gen Dem Plînio nadjgegangen fenn, Der III, 9x Saro, 14 ,

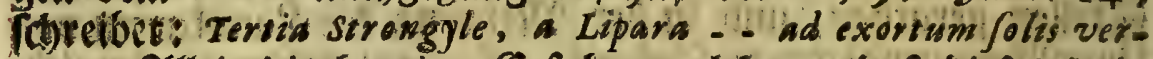
gens, 2fllein Die Gentige Erfabrung legret, Daß Diefs irris red, wie es in ber Inmerf, (oo) erwiefen worden. 
25seil Meite Serten inbrinfiglich multriten, Durch

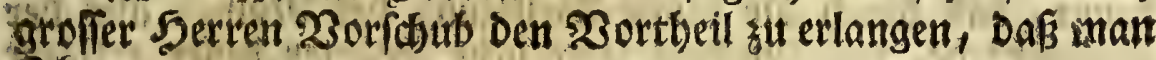

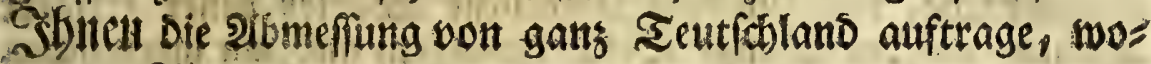

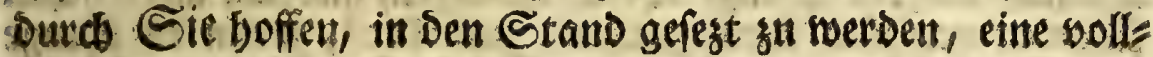
ftanbige Tatur = unt Gtantsgeographie ausarbeiten fut Tönnen, fo gefâfle mir unter Den Borfdriften, welche Die: fefteit fiat ferbit vorgeleget baben, unto weldse Sie, bet bet

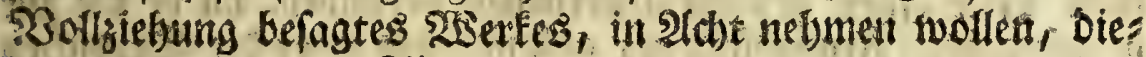
Serige fegre gut, Da Sie werfpredien, bei Betretung aller Ses genden eines jeden Lanbes, audj bie Befchid)te Der $\mathfrak{N a s}$

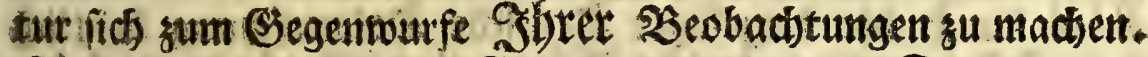

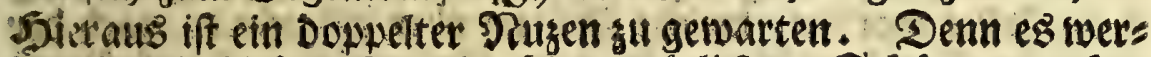
Det burds Diefes Mittel, bie naturlliden Sdáge mandier Ranbictaft, ben snwohnern aufgedect, und Derfelben Ees beruct ifnen gegetget werben, Die fie bišber, aus tabelhafter Sorglofigfeit, ibren eigenen Shitern nachsufphiren, stwar wol befeffen, allein za nuzen nidht getwust baben. Darnach Fann

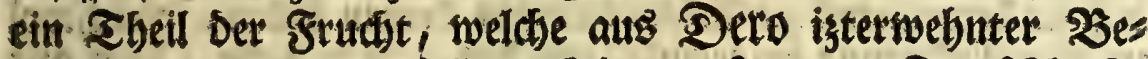
f(chaftigung entfteben forl, auch Dem gefammten ₹eutichlande zuffatten fommen, wenn Meine Setren, Die Feuticten Ramen aller Dinge, weldse Das breyfache Pieid) Der Ratur ausmadjen, wie Sie Diế Ramen von Den Berglenten, Bautrn, Jägern, Silten, vernebmen werben, gu fammlen,

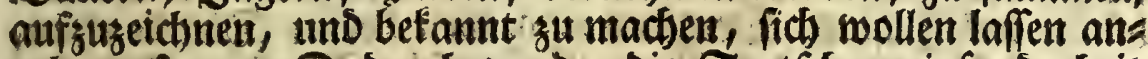
gelegen fenn. Daburch werben bie Ieutfichen, infonberbeit Die Serren Gotticheder, Die unertráglidhen Epótter Dee

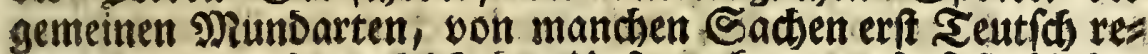

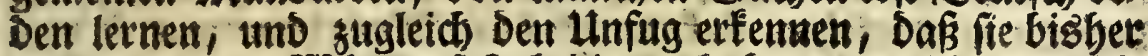

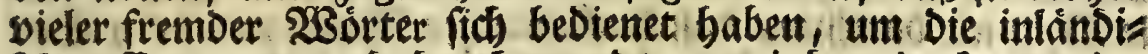
fehen (Erzengungen Daburch) anzudeuten, indem Dod gemeine

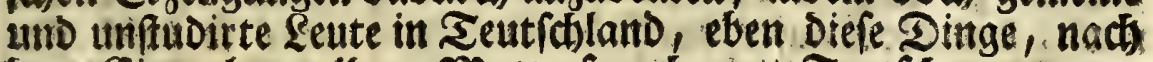
Dem (Eigentbume ibver Mutter(nrache gut Ieutich) zu nennen B 2 . wiffen t133014 
miffet. Es if mit aus langwieriger eigener Srfabrung bes fannt, Das Durch Die bloffe Seifezung Der Namen aus DeE Lanbiprache, viele hundert Inteinifabe 3 órter beffer erflliret werDen, als Durch) lange 23efforeibungen, und mit lateinif ben SBorten verfaiste Aublegungen; zuforderft, went es Dinge

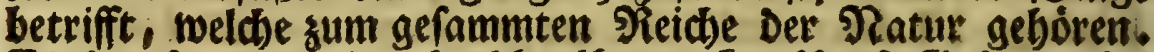
Sz bat Demnad Der bochbertibmte Shr. Şrof. Sefner, bei Der neueften Serauggabe Des Stephanifhen THESAVRI, reine $\mathcal{L e f e r}$ eines groffen $\mathfrak{B}$ ortbeiles beraubet, Da or die gut angebrachten Stangofifchen, abronderlich aber bie Ieutichen Namen, aus Dem Sabrif Febeutung vieler hundert 230 rter if in Dem Thefaure Erwdit. Schol. Durch Die beigefigte ₹eutide Dolmetifiung Deutlid

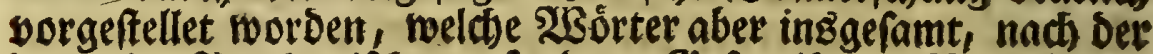
igt nicht Stephanifonen, fondern Befnerifchen Berfafung, in ibre tieffe. Dunfelbeit surtictewandern miffen, Da ibnen nur einige magere Stellen, auš einem auctore claffico obes Deret mebrern, Darinnen ber bloffe ?ame ftebet, uno weld)e

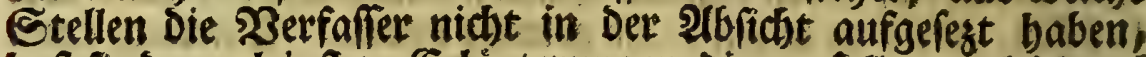
Dafi fie Dermaleinit zu Erláuterungen dienen follen, gleid wol zu aller Erflairung beigeructet worden. Thb babe (Dem gus ten (Seftimade fen Dant!) auf meinen Sieifen er it swey) (Se: lebrten angetroffen, Die fid biefen neueften sefnerifonen Thefaurum sugeleget babent: allein betbe bebauerten ibr berwors fenes (S) ter qu erfabren, die nicht jedermann befannt fino, Die Dctabs

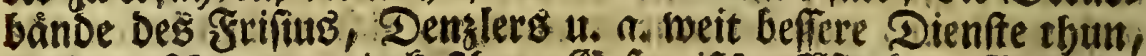

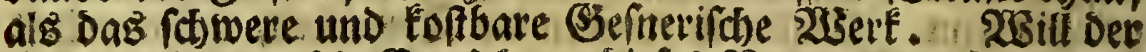
5r. sprof, etwa Die Sntziebung Diefes Pluzenz nicht einfeben; fonbern flaget: bieIme $\bar{k}$, Dafs ihm Durch meine 2 Seurtheilung inrecht wiederfabre, fo fann ich diefe 2 abrbeit surch fo vies

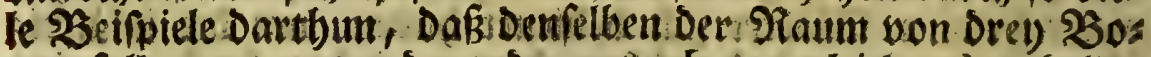
gen foll zat enge worden; Daraus aber sugleith I) ethellen

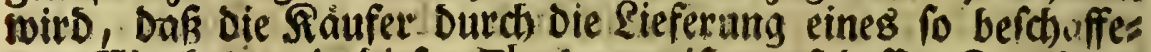
nen 2 Serfeg, wie Diefer Thef urus if, auf Deffen Sitelblat:

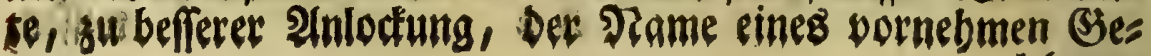
lebrten 
lebrten fohimmert, in ber That mely beruift uno gepfliteft, als rechtichaffen bebienet werden; 2) Daßs. STr. Gefner wol Daran fey, Daß̧ er mit Der Jerausgabe Der Raturgefchichte Dez glimius, Die obne Sweifel, nad feiner Einbildung, befs Per ausfallen foll, als bie Sarbuinische, fo lange zaubert; ia er wirs am beften tham, toen er Damit gar zurtidfebleibet;

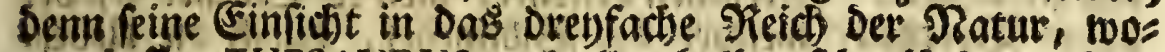
pon Deffen THESAVRVS unz allentbalben febr ubel geratbene sorobfticte aufmeifet, ermedtet in ung ein billiges פMistraus en, Daß wir beforgen, Der Sor. Srof. Dérfte etliche bunbert gylinifhe Stellen, die einer Sulfe benothiget find, viel eber nod) nebr nerberben, alo berbeffern.

Sch bin ber Meinung, Das in gegentwărtigem Jabrbuns

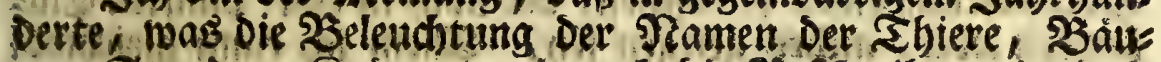
me stauden, Sidauter, wie auch Die SEeforeibung Derieni=

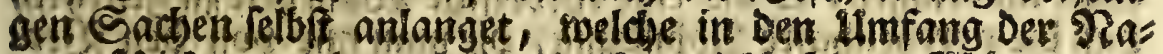

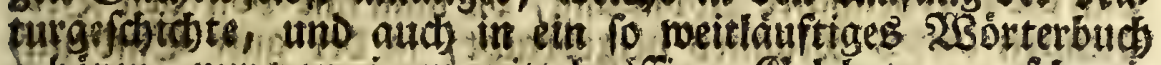
geboren, nur bon einem mittelmáfitgen Selebrten, gejab weet ge bon einem Manme, Der in fo groffen siubme lebet, als 5 r.

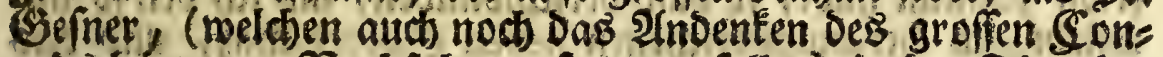
rabs batte zur शadjfolge anfoomen follen) in ber Shat feis ne 2ribeit fonne ans Sidjt geffellet twerben, Die eber eine $\mathfrak{B}$ er adtung ober sin Mitleiden, als Die nieDerträchtig jobmeichels baften Sobfpriche verdiene, welche in einigen gelebrten Beis

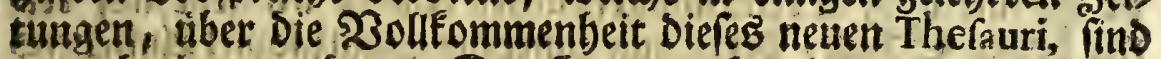
ausgebreitet morben. Der Seraugigeber iztgebachtes 230 of

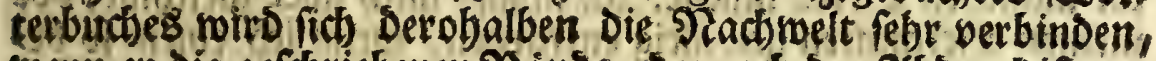
wenn er bie gefchriebenen 2 ände, Darmach Der 2iboruct if ges mactit worben, Dem 2Bucherfale Der boben Echule einverleiben läśt, von weldhem $20 r b a b e n$ die óffentlichen 2 lätter eins nal Erwefnung getban baben, Dem die funftigen Seleby

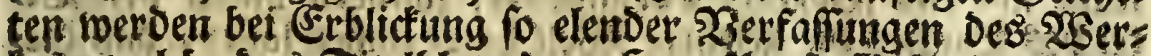

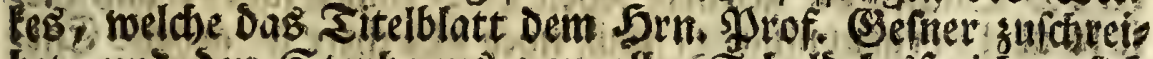
bet, uno Den Stephanus von aller Schuld losipridst, fich

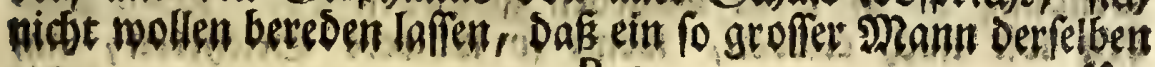
9.6 
Utheber gewerent. Eie werben benten, es reb ein stunftgtif

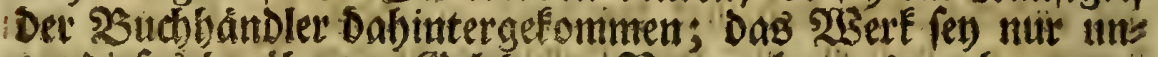
ter Diefes berubmten Selebrten' Tamen berausgegeben wor: Den, Damit es beffern 2 lGgang finde. Diefes Befonente wirb nun Derienigen, ofe fo urtheilen Dorften, bartnåcfigen Unglat: ben zerfteuten. Sierinnen beftebet, meines Erachtens, Det. ganze Sortbeil, welcher Der Sibliotbef, Durch Die Hebers nabme diefer Derebrung, fumadhen foll, bis etroa Das Mas nufcript 1000 Jabre in Derfelben liege, und Die foiten Sadse

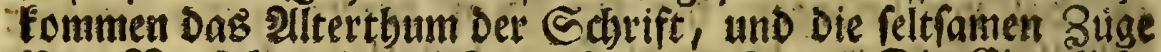
ifrer 2 orfabren Daren Getwunbern werben. Die Eigenliebe muite mid febr blenben, menn id diefes nidit etmabe, bafs Dem weitgenriefenen Serausgeber Diefes. Thefauri, an Der Sochadtung eines Menfoten, Det noth in einer buntlen Cins famfeit leber, nid)ts gelegen fey. 2lllein id fann gleidbrool

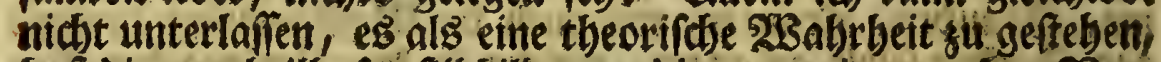

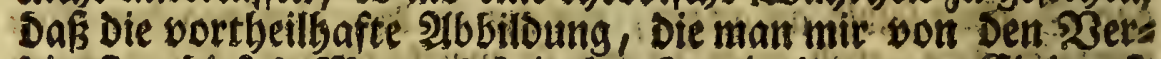
Dienften Diefes Manne's beigebrad)t, ja Dex gute Cimbruct, Den ich mir burch Die Sefung anberer feiner भiusfertigungen felbit gemadte babe, ro balo verfetwinden, als idb Den fo une murbiglid berausgeftridenen neuen Eprad)foras, uno Das auf fein Ônathen, unter Dem Pamen feines Sebulfen, soie auch mit einer beränberteh Pufidbrift, ans Richt geftelite Rirfoifde :Sorterbud, zu feben betommen babe. Jab ftes be gegenwaitig in feinem offentlidien 2umte; idis lebe auf teis net boben Schule, Deren zunebmender S̈lang foviel 2uffebens an mandien Srten madit: ich metiste midy aber gleidsivel bot meinen Sefannten gemaltig entfäben, menn ich einem fo bes phaffenten Suche, wie eg ein gelehrter Siegensturgifoter Sans Dibat, in Dem Şorberidte zut netreften adtern uno verbef ferten 2luflage Deg Jirfotiftien Cornucopia, befdietbet, nicht nue eine Borrede vorangefegt, fondern Durd Den Siv

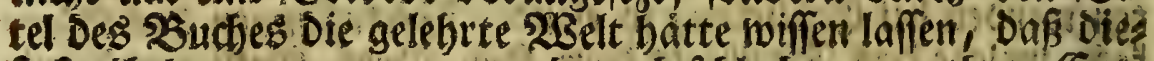
re fo ubel oorgenommene, und nod rahledter geratbere ent

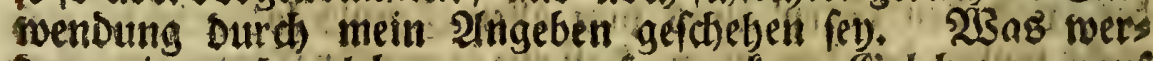
Den wir noch erlebed, wenn fo madere Selebrten, aut $\therefore$ 
Die ein groffer Ibeil won Europa fiebt, fein $2 B$ edentert tragen, nidst alleim, fics felbif, Conbern noct andere mit, eimer allge

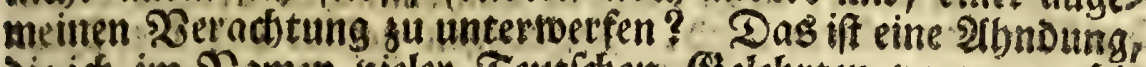
Die ids im Samen vieler. Teutifhen Gelebrten vortrage, Die teine morofuli find, fondern welche gelernt baben, wie man

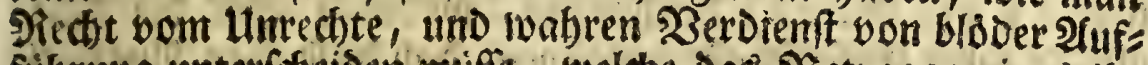
fiibrumg unterfiffeiden miphe, welche das setrngen cines ibs ree Mitgliedor, fo wiele ifg nodb Davon foredben gebort babe, einbellig verabidsenen, uno allen Intbeil Der Echande von fich wollen abgelebnet wiffen. Shegen biefen Mrann srbiete id mich, obne gefthethene 2fufbegung, oder stertuartende Seloh:

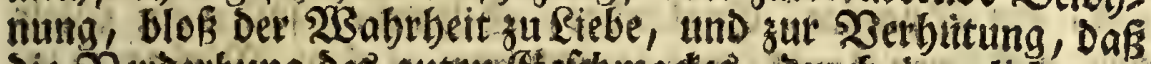

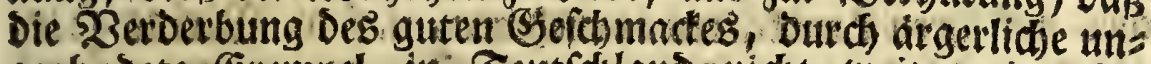
geabnoete (Erempel, in Seut (d)land nicht weiter einreife, Das bier tirşlich angezeigte weitláuftiger auszufúbren. Ders ienige, Den biefe Slage angebet, mus fich auch allein, uns mit erlaubten $2 S$ affer, D. 1. mit feiner Seder, und mit Sirne Den, nidit Durch Edjmábsoute, berfechten, went er Eann; oder es leiden, wenn er bes tunfuges wird aberwiefen fern.

Dridf yon Dem Tusen Der Eandpradben gut reben an= gefangen babe, weldben biefe zur Er flartung vieler lateinifchen

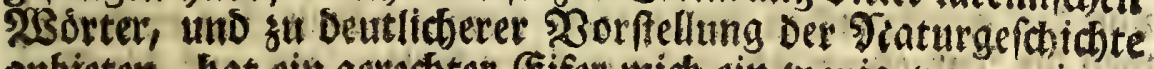
anbieten, bat ein getedter (Eifer mich ein wentg von meinem

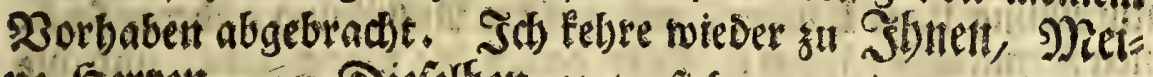
ne Serten, um Diefelben guverfictern, wie eb mich bes fonders vergnuige, Daß́ auch Sie gleiches Sinnes mit mie find; weil Diefelben ebenfalls bie gemeinen Epracten, als

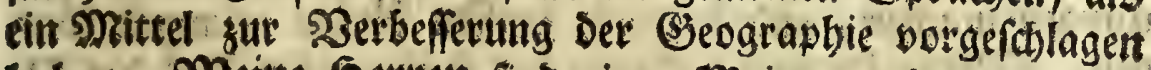
Gaben. Meitte Serten find einer Deinung, Der id) volls fommen beipflidte, Daf námlid die Mamen Der Derter, welche auf Den Landfarten fteben, groffentbeils irrig gefobris ben, und mandimal auf eine unerturiglicte sert muifen bers ftümmelt erícheinen, moferne fie nidst bie Snmobner eined jes: 
Den Landes pelbft auffegen, ober wenn Die eigentlicje 2fuspuras de Diefer Namen, nidt won Den einbeimifhen Eeuten Durd

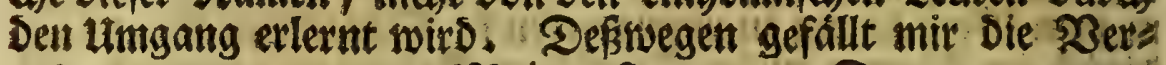

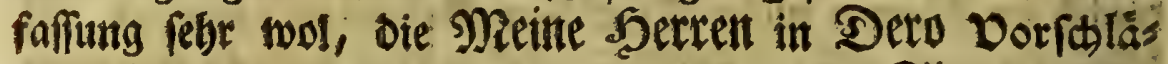
gen (\$ 43, S. 48 ) befthreiben, modur(t) Sie die Mits glieder ibrer Sefellíchaft ermabnen, Daß̧ Diefe ibre 2lusfertis gungen nach Den Sprachen eintbeilen módten. Ein Italies ner foll Inmertungen von Jtalien, unt infonderbeit bon feis ner Landid)aft, eimfenden, wie auch bie Namen auf Der Eandetarte feines $\mathfrak{B a t e r l a n b e g s ~ i n g ~ F e i n e ~ b r i n g e n ; ~ e i n ~ J r a n s ~}$ zofe, ein Spanier, Engländer, Śdwede, follen ein B̈leie des auf ibren Ranofarten vornebmen, u. f, w. Meine Jer

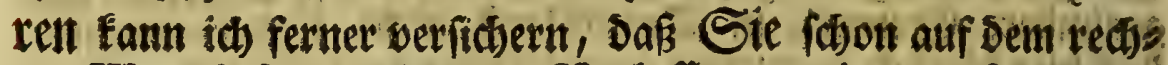
ten Sthites Der Seograpbie fubret, foferne Diefelfent fortfab:

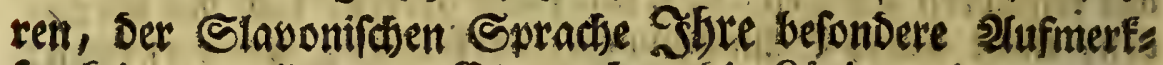
ramkeit sa midmen. Es maḑen Die Ränder, in welden

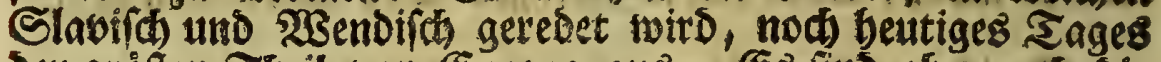
Den groften Theil von Europa atr. Es fino aber aud Die Landfarten Des meiften Fbeils Diefer weitläuftigen Strecte, von ber gebuibrenden Pidthtigfeit noch am weiteften entfernt; weil bie snmobner fich mekt auf Den Sirieg, als auf bie se:

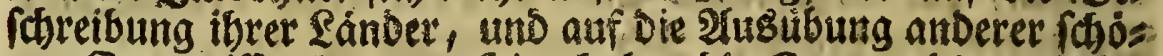
nen Senntniffe, legen. Ster baben Die Geographi, uno bie. Berfaffer Der Jlaturgefdichte, nod) gleidfam eine neue

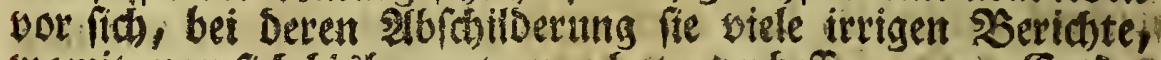
womit man fich bisher setragen bat, oerbefern, netre Entoen cfungen mactien, und baomeds grofien siubm etlangen tons nen. Meine Sertent betlagen Den frubseitigen IoD Des Do

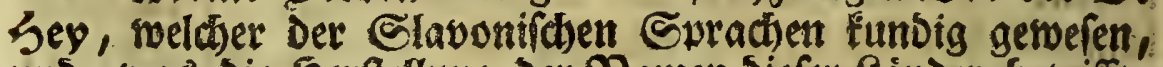
und, was Die Jerftellung Der Nainen Diefer fänder betrifft, allbereit einige goroben vou feiner (Gefchicllichteit an Jag ges

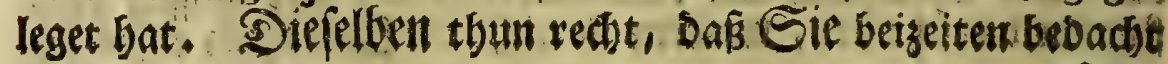


Find, Duth 2tusforftung und Ifnnebmung anderet Mitglies Der, Diefen Berluft zu erfezen. Derofetben Erbieten, Da Sie

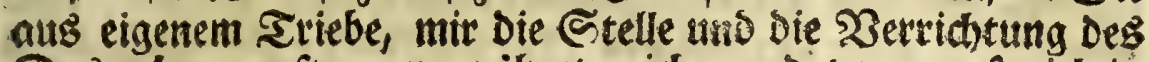
Dro. Seg auftragen, ribret mich, und vermag fostel in meinem Semuthe, Dafs id ein 2lme nicht ausifblagen fann, fo su meiner (E) ruf mids in einen foldien Stano fege, soo ich Diefes $\mathfrak{B}$ ertata gen zu erfüllen, Die Gelegenbeit uno Beit io gut baben mó ge, als igt Den Millen.

Ja) babe eg pifterg zu meinen freunden geliggt, uno swies

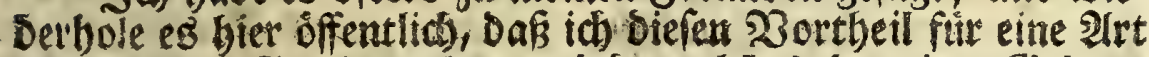

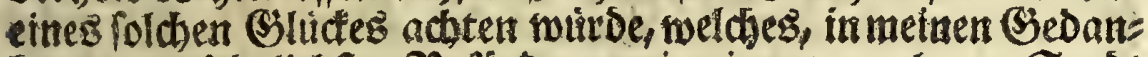
fen, Der anfehnlidyften 2 efórberung in einer vornebmen Stabt

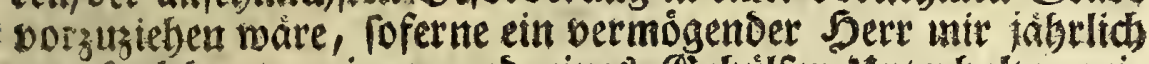
nur foviel, zu meinem und eines Seftulfen Unterbalte, rei= den!liefs. Dafs ich mit Diefem ouf einige Jabre, in Demienigen Crricte von Europa, Der von Defterreio' aus auf Der einen

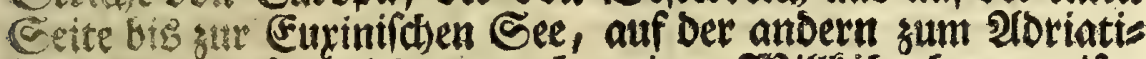

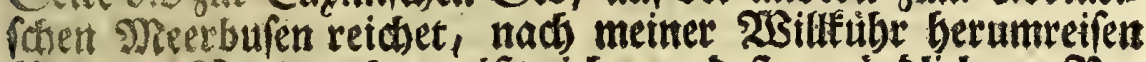

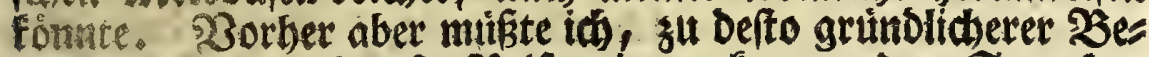
urtheilung Der auf Diefer Pieife mir vorfommenden Spradjen und Dinnarten, Das 2trabifche lernen, Deffen Unfundigfeit, für meiue etymologifasen ?achforfdungen, bisher ein bes

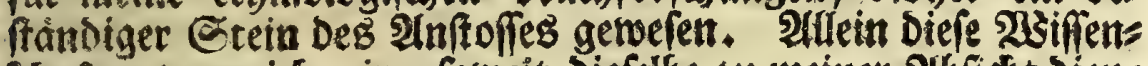

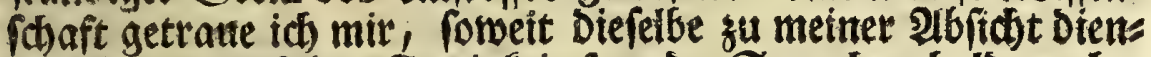
lid ift, mittelf Der Sertigfeit frembe Spradien bald zu bes

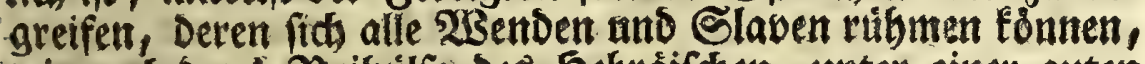

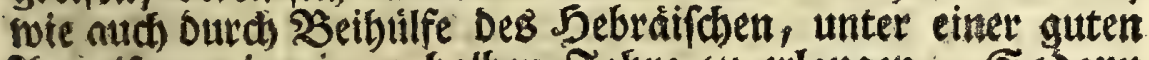
शinneifung, in einem balben Jabre qu erlangen. Sobann wollte id sedactete Segenden Durchftreichen, und vornebinlich Die Unterfuchung Der Slavif(c)en Munbarten, weld)e auf Dies rer Etrecte Der Lảnder geredet werben, sum Jauptziele mei= ner Reife madien, obne iedoch Die Radhforichung Der Rojmis

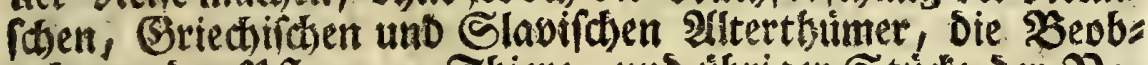

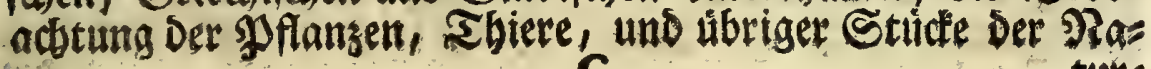
$C^{-1}$ turs 


\section{XVII}

\section{as ) o. (sen}

turgefachicte, git bernacbläfigen. In 2(nfebung Der Clas vonifden Eprache, wurbe id langer in 20 finien mich aufs balten, welefes Landeg ReDart, nach Dem urtbeile aller Slavifhen und 2 Bendifden Sprachfenner, wie aud) nads meiner eigenen Shrúfung, Die reinfte, Die artigfte und Die giers lichfe, unter allen fowol Slavirdien als 2 Bendifcien Dialeften; gleichtie die Sulgarifđe Dagegen Die grobfte, iff. Die feime und liebliche श्थusprache Der $\mathfrak{S o f n i e r ~ u n d ~ D e r ~ S e r b e n , ~ l a w s ~}$ tet, in Bergleichung mit Der båuerifoben Der Sulgarer, wie

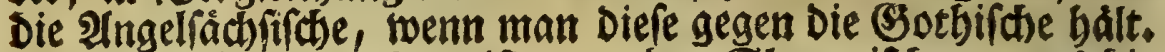
Die $\mathfrak{B}$ ofnifhe Mundart ift unter Den Slavonificen, toas Die Ittifite unter Den Srriectifden war. Mein Qlufentbalt in Sofnien wurbe Den Eiebbabern Der Serwäche, Die aufet Seutid)land erseuget werden, eine gans neue Floram Moefiacam liefern, Darinnen fich Die Namen vieler $\mathfrak{Y}$ flangen befinden follen, Die in beifen Säbern wachfen, als in Stalien, mit Deffen unterm Sbeile $\mathfrak{B}$ ofnien einerley Torberbreite hat.

ఇach $\mathfrak{B o l l b r i n g u n g ~ D e s j e n i g e n , ~ w a s ~ i c h ~ v o n ~ D e n ~ S l a s ~}$ vonifoten Munbarten zu fammlen begebre, whirbe id mis aud einen milben 2 efortberer tounfhen, Der su einigen neuen Suchftaben Die Stămpel foneiben lieffe, woDurch Das lateis nifche श्Alphabet mus vermebret werDen, Das zur Sdjreibung Der Europairchen annoch blitbenden Spracben gan untaug: lich if. Jat babe (S. 268 u. f. in Der Znmert.) ein sprobftict Don swenen Diefer unentbebrlichen SSuchftaben eingefobaltet; allein Die find nod nicht gut auggefallen. $\mathbb{E}$ mus ber eine weder über Die Beile bimaufragen, nod) berunterbangen; es miffen aud Die Bacten bes andern nidht peiter auseinanbet fteben, als beim m; beibe follen Der ubrigen Şrift ábnlis cher gemadit werden. Das find nur Solsfinitte. In Sols je läst fid) nicht allez vorftellen, was man will; auf gegoffes nen Regeln foll alles beffer angubringen, wie auch gerchictlis cher Damit absubructen rent. Das Teutidje 2ilpbabet ift eis

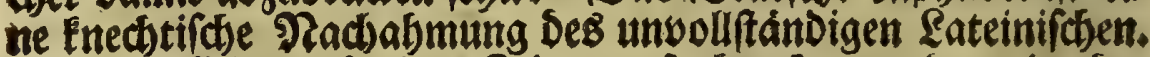
Fo ift Daffelbe in foldbet aeitent aufgebradit worben, Da Det

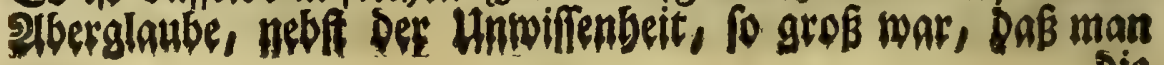


Sie Einf(haltung eines ganz neuten Buchffaben, für eine Sùn

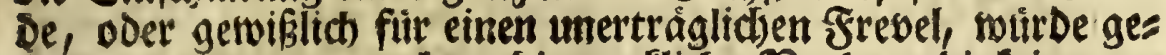
balten baben, ungead)tet Die merfliche Nothmenbigfeit vors handen war. Die Salbgelebrten Derfelben Beit Elagten aber Die Paubigfeit Der Seutichen Sprache, und betbeuerten, Daß fienicht fönne redit gefकhrieben werben. Ja mit lateinifhen

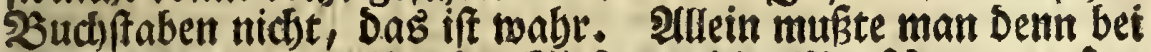
oiefer Sflaverey bleiben? Sind es nicht Menfthen gewefen,

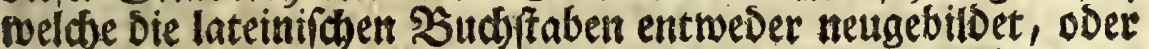
von andern Bölfern úbernommen baben? Sollet nidjt ans Dere Menichen sum wenigften Die '3abl Derfelben, Durch einen Diefer zwen 23 ege, zu vergrofiern im Stande fenn? Ia) meis nes Drtes balte benienigen fitr Den tummften Mann, Der bes Gaupten woute, aller Menfchentwis wáre Durd Die Siomer bereits erfchôfet worden. (Ermeifet nid)t eime groffe Menge mizlither, fohoner und finnetcher Errfinoungen, Die feit Dem sum 2 orfecteine gefommen, Die auch genwistich Die lesten nidb)

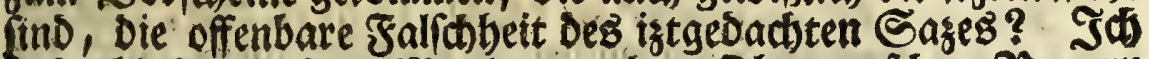
babe bisher in Den Mundarten Der Dbertentichen 2 Bauern

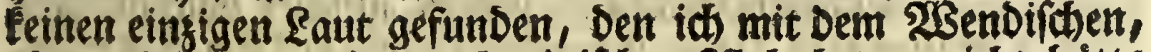
ober mit Dem ergångten lateinifhen Ilpbabete, nicht hâtte

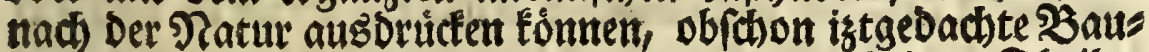
orn, nebft vielen alten 23 órtern, bie in Den tubrigen Iheilen

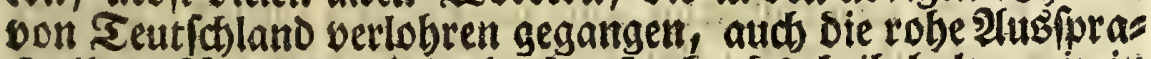
che ibrer 3 orältern beinabe Durchgebends beibebalten, ja itt einigen Studen, weldhes leidst su betweifen ift, nod bers folimmert baben. WBeil man fidt aber einmal in ben Ropf gefest, von Der Bahl Der lateinifhen 2 Huthitaben nicht absus toeiden, 10 bat Diefer lächerliche Swang, mit ber Notbourft, Die neue 23 und faben erforberte, Die faubern Mnisgeburten,

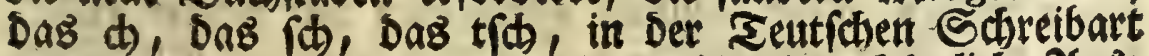
ausgebectt; ferner bas c, nach Dem Die eigenthümlid)e 2 (uss furache Diefes Sudhffaben vermift worden, wie zu einem

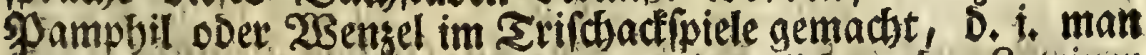
bat Diefem Zeidfen, weld)es Das eigentlidbe $\mathrm{k}$ Der Lateiner Dorftellen, unb Diefen Dienft in Eefellfhaft aller Buchftabent $\mathrm{C}_{2}$

vers 
vertreten follte, bei nabe in einer jeben neuern (Empodifonen Sprad)e, Daß Bermógen einen anoern Laut auszubrüten, uns bor ober nachgemiffen andern 3 uchffaben, aud befagte Setwalt von neuem zu verándern, eingeraumet. Bu Diefer Stumpes rey haben zwar fhon bie Tiomer 2nlap, gegeben, Da fie felbft,

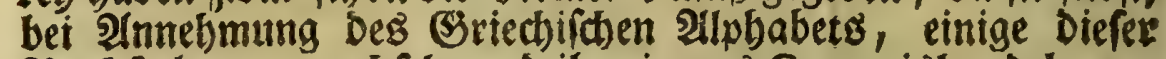
2udhftaben verwedhrelt, uno ibre eigenes $C$ zu misbandeln ans gefangen, weilfie Dur屯 Die ungereimte 2 eigefellung Deg $\mathrm{H}$, Das Sriedirthe X Damit vorgebildet. Durch Den Misbrauch Des C, welder nachgebenos obne siel uno Maas fid) ausges breitet bat, iftein weit grofferer unterfobeid in Die Sdreib: art Der Euradien eingefibtet norDen, als Den man in Ders

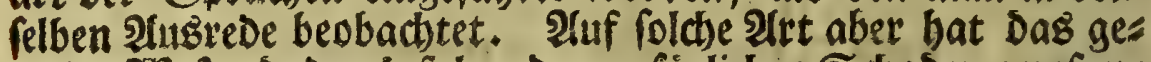

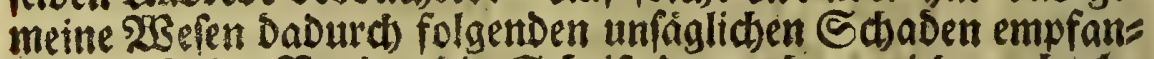
gen, Daf eitre Nation Die Schrift Der andern nidht recht les fen fann, weldes Die Erlernung Der Grrahen allen Jrems. Den umfouft beforoerlid macht

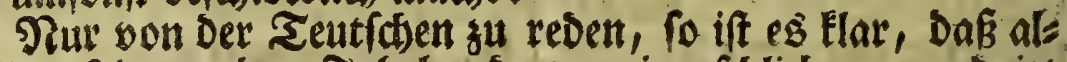
lein Der feit wenigen Sabrbunderten eingefoblidhene, und ist Durchgangig befätigte (Sebrauch Des 5 , weldes balo gehoret

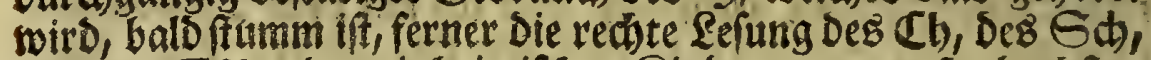

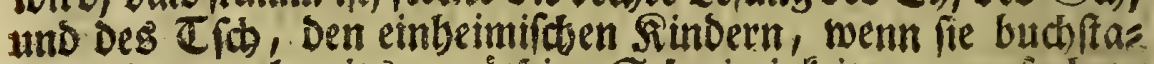
biren lernen, bereits unnotbige Gobierigfetten berurjadjet, Durd welde unvernuinftige Sufammenfesung swever, orever, ja vier unterchiedener, und zur 2 orftellung Der vorbabendent

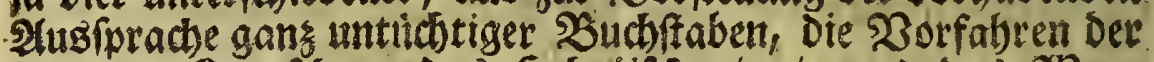
beutigen Seutiosen, Das Sebraifobe 'o ind Das : 1 Ben

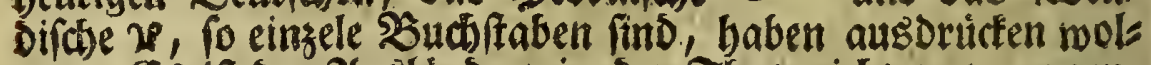
len. ES ift Den 2usldndern in Der shat nicht su berargen, menn fie Diefe: Saufung Der Sudffaben, Die nur einen vers treten miffen, alber nennen; allein man hat nieber rect, wenn man Dem 2lublånder, o. Ee einem Italiener fein feltia

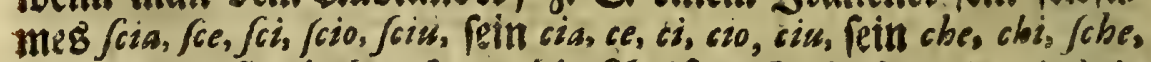
fchi, vormirft, Dadurch er Die श्रugfarad)e Des w iv

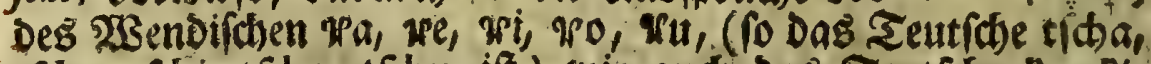

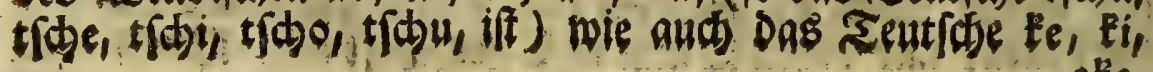


EFe, sfi, Durch unleiblichen Misbrauth Der lateinifden Buchiftaben, vorfellet; is man verlactet Denfelben nictst obne

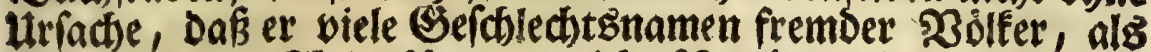

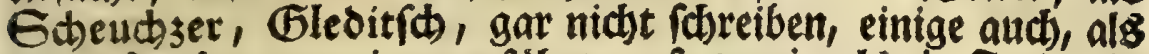
Den erften Der zmen iztangefíbrten, fo wenig als ein Sramzofe, ausfprechen fann. Es wird ibm fohon viele Mlibe forten,

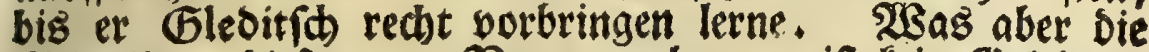
Sd)reibung Diefer zmey Ramen anlanget, ift fein Belehrtes in gang Stalien im Stande Diefelben mit reinen lateinifchen

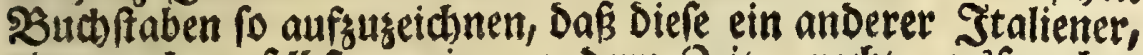
Doer aud) er felbft zu einer andern seit, recht ausforecten

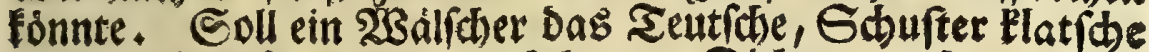
nidbt, lefen, fo mird er nach langem Didsten, und nach felts fament Eseberden Dez Esefichtes, Die alz Rennzeichen feiner

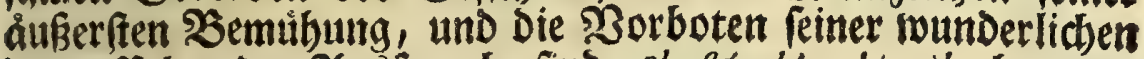
Darauffolgenden 2 usfiprache find, skufter klatské zikt beraugs gaxen. Ja mus nid)t foton im Ieutichen Das d) (zu einer vollfommenen Heberseugung, Das aus Der Finfchräntung Der bis ist lublich gewefenen Sdrreibart, Der Lunrichtigfeiten noch fein (Ende za getwarten iff ) balb Die Etelle Deg $\pi$ erfezen, bals als ein P (k) vorgebracht werden? In Redt, Todter, ruchlos, wird es gebaudt; in Drectsler. Ods, Suds, als ein $k$ ausgefwrochen. In Rect vertritt Das c Die Etel' le eines b, Denn Das 23 ort lautet, als wenn Das b gedops pelt ftumbe. In Drectbler vermaltet $\mathfrak{e g}$, wie id gefagt bas be, Die Stelle eines $\mathfrak{L}^{2}$, Denn ber Lefer mußs Deetslet fores chen. Eben Diefen Dienft berricteter es vor Den barten $20=$ calen und Den Mitlautern. 23 enn Daffelbe zu einem 1 gefest mird, fo mus ez auch nocb Den Laut Dez 1 verboppeln. Denn in wadeer, ftreden, fliden, troden, 3uder, beforbert es

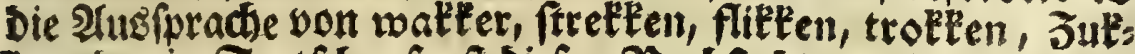
Eer; Da ein Ieuticher fonft Diefem 2uchifaben nod eln Drittes

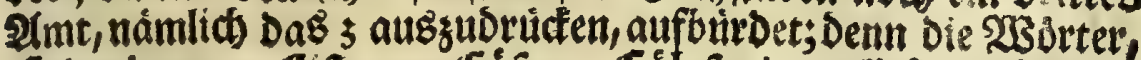
Cederbaum, Ciftern, Cáfar, Cólefyrien, lieft er Jeder: baum, Jiftern, Jâfar, Jólefyrien; woruber ein Staliener C.3 
toll wird, went ex Seutio lefen lernet. 2(llein biefer sets fäbrt felbit mit Dem c nidit beffer. $\mathcal{B}$ or Dem a, o, u, und Dent Mitlautern, iff es fein getoofbnlides k. 23or Dem h muf es ibm aud nod Das $\mathrm{k}$ vorbilden, wie in che, chi, weldjes Der Ŝáliche ke, ki, vorbringet. Sor Dem e und i erfeget er Das

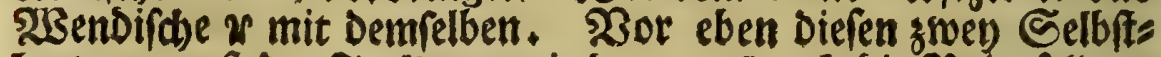
Iautern mus Der Stalienter mit Dem c, Durch Die Seigefellung Des $f$, ein $v$ sufammenfliden, wie id S. XX bereits erwies ren babe. Der Jranzofe braudset diefen 2 undiftaben aud nod theils su Den erzáblten, theils zu andern Dienften. Bot

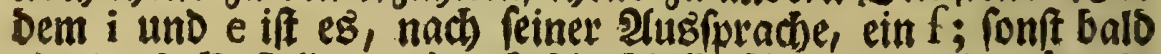
ein $k$, balb ftellet er, Durch Die bloffe 2 seifitgung Des $h$, ein * Damit oor. Die ubrigen Europátichen Bolfer, melde

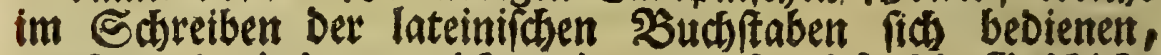
machen eB mit Dem c nidjt anders; und murde Die (Sefdich)

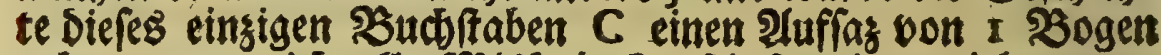
geben, wenn io alle Misbráuche, Die Damit getrieben mers ben, anfübren wollte; mebr andere Dergleichen ungereimte Folgen zu gefdyeigen, weld)e Die 2(nnabme Des lateinifhen श्lphabets, infonderbeit aber Die abgefemmacte Gurcht, Dafs

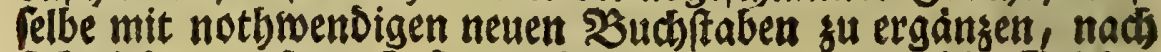
fich siebet, und nod) ferner båufen wird, wern bie selebrs ten Dem Ulebel nidht fteuren. Sisill man eine Sprache fo fobreis ben, Daf fie ein jeder obne Mntube lefen fónne, fo muifen Die

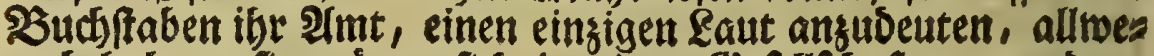
ge bebalten, fie mogen fid in einer (Sefellifiaft von anbern Suchitaben befinden, weld)e es auch fet. So if Die erfte Pus? fpradje Der Lateiner befibaffen geweren. Racjoem man fids aber son Derfelben binmegbegeben, und Das c vor Den Selbit lautern " $e$, i und $y$, anders vorsubringen angefangen, als in Den ubrigen Jállen; nachbem man Dem $t$ bor Dem i, bei ges niffen Figungen, aud bie Eigenfebaft eines 3 angedichtet, to bat diefe Frenteit weiter eingeriffen, und etlidbe SBuch faben, infonderbeit Das $g, h, x, z$, nebft Dem $c$, su willfubrlicben Senngeiden gemacht, als tònte man biefelben liberallhit brauchen, Daraus Denn unumgrnglich Die Hnordnung entifes

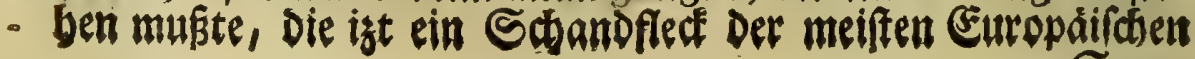


Epradjet, uns infonberbeit ibrer Sdreibarten, ift. Mit meinem verbefferten lateinifosen . 2riphabete fónnen nicht nur alle Slavifchen und 2 Sendifcten Munbarten, fondern alle noc beftebenden Sprachen von Europa bergeffalt gef́chrieben

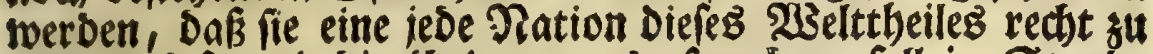
lefen, uno fo, wie bie tibrigen, augzufprecthen, foll im Stande

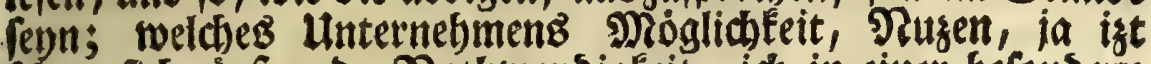
faton fich ausernde Potbmendigfeit, id in eimer befondern 9ibhandlung su errweifen mich) erbiete, fobald ich, Durch Den Borídub eines Qiebbabers, etlide Suchftaben erbalte, Des rer Stámpel, nach meiner Beidjnung, neu gefḑnitten, und zn Der curfiven Mittel oder Certia muiffen geridjtet merben; Denn idi will lateinifo fobreiben, auf Daß Mebrere mich ver: fteben.

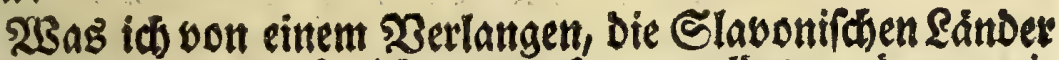
mittagmerts Durchşuftreidien, vorber gemelbet, wäre vor et nigen Jabren beinabe zue Erfülung gedieben, als id nach Conftantinopel batte fommen follen, um allba, zum Dienfe

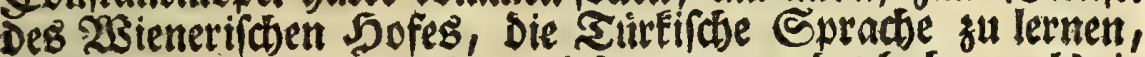
weld)e Snabe idh nuslider wurbe angemendet baben, als eis nige, Die mebr zu ibrer (Semäcblichteit, und um bes Sitels willen, als um ibre Sdjulbigfeit in 2(d)t su nebmen, DeE Tammer su einer wol entbebrlichen Laft, viele Jabie Da fisen.

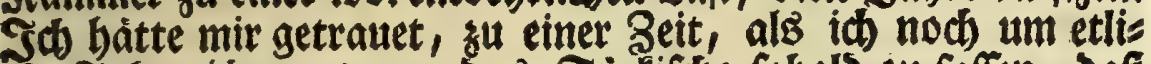
d)e Jabre junger war, bas Juntifiche fobalo zu faffen, $\mathrm{Das}$ id innerbalb stwen Jabren, mundliche und foriftliche Dient fte in Diefer Sprache zu Jeiften, im Stande gewefen wäre.

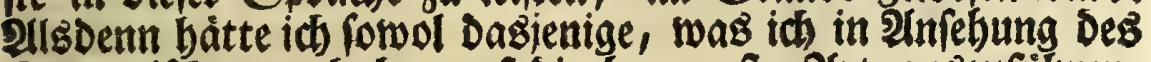
Slavonifosen vorbabe, auf Die bequemfte 2int auşzufubren,

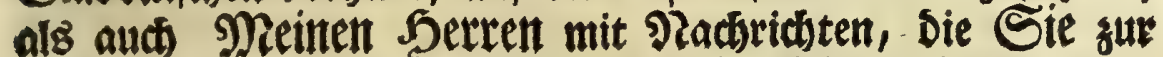
Berbefferung Der Landfarten vom Jürtifhen Peiche ver: langen, an Die Shand zu geben, Die beffe Belegenheit gebabt. 2illein mein Schicfial bat Diefen 21njhlag berfebret. Die Neigung eines Defterreidiroben Sabaliers, eines Der bers

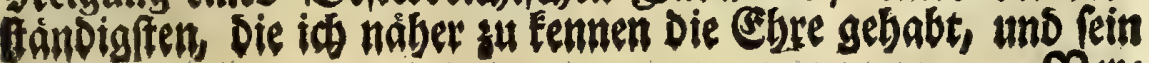
RPes 
Berlangett, mid) als 50 fmeifter bei einem itntgen 5 errt zu re: ben, Deffen $\mathfrak{B}$ ormunb er twar, bintertrieb Die $\mathfrak{B}$ ollsiebung Der Conftantinoplifonen PReife; uno foldes geifjab Dergeftalt, Dafs bieienigen, weldbe fich meiner su Dem Ende angenomnten, uno Die Sacte beinabe bis su meiner Ibreife bereits gebradt bat: ten, Feinen Utmoillen Daruber fasten, Denn fie waren dieles $\mathbb{C}$ as valierg Jreunde. Iक nabm fein Erbieten an, tweil es mit ber 21usfibrung eines aubern mir anftờnoigen 2 Berfes berbunden var. Diefe Sedienung bátte, naর̆ Dem $\mathfrak{B}$ erlaufe einiget Sabre, wenn Der Savalier ware grof worden, eine botanis foje Seffireibung Des von Clufio fo oft geribmten Gchees berges in Unterofferreid, und die Serausgabe eines Bers geidhniffes ber (Sewaid) fe nach fid gesogen, welde in Det Prein, auf Dem Gemeringe, $\mathfrak{D}$ faffen, $\mathfrak{W}$ ed fel, uno attoeru

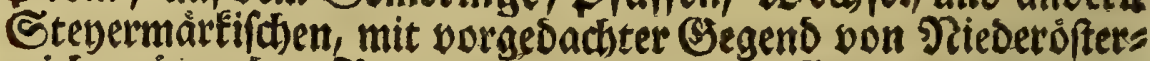
reich grånzenden, 3ergen bervorfommen. BHleichtwie aber Das

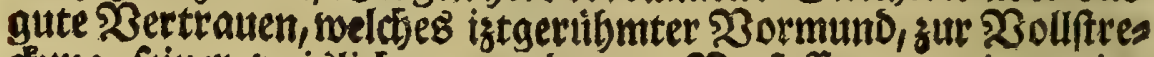

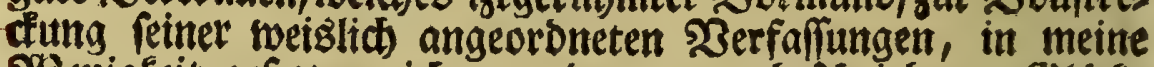
Fisenigfeit gefegt, mid von Dem zuvorbefdriebenen (Ssluicte abgefuthret, fo bat Deffelben nad) swey Jabren erfolgter Joo fall, mir und Den Riebbabern Der Defterteichif ben (sewäctse, aud Den andern $\mathfrak{B}$ ortbeil entriffen, mid) itber Diefes zu Dem (Entfd)luffe gebrad)t, ein $2(m t$, Deffen id bereits vor Derfelben lesten 3 sedtenung fatt wat, auf lebenblang niebersulegen, tweil $\mathfrak{B E}$ mir viele faure, meiftentbeils vergebliche 2 (rbeit, Daourd aber (d)lechte Bufriebenbeit verforift bat, und foldhes baupts fáblich Darum, weil inmer Dergleiden Perfonen, fum groften und augenfdeinliden $\mathfrak{B}$ erberban Des Staats, Das Meifte

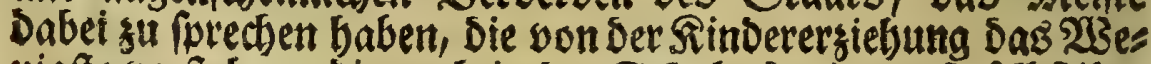
nigite verfteben, bie aud in Der Sdjule, Darimen fie felbft ibre : S(t) verlies Diefe Sebensart endich aud Deswegen, weil fie mir einen guten Sheil ber edlen Beit wegnahm, Die id mit

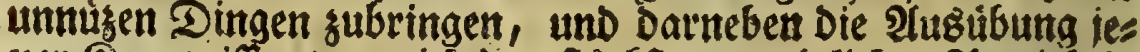
ner Senntniffe, wozu ich Dett ftärfften natirlidsen Antrieb it mit verfpurte, vernabláfítgen muste. J屯 reife feit Der Seit 
beftärtbig, utto fuche Mácenaten. In Diefent Suffande ift

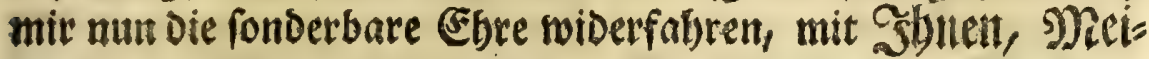
ne Sertelt betant zu werden. Ith febe wol, Daf wir eine gemeine Sadie miteinander baben; utto Daß Sie gegentwars

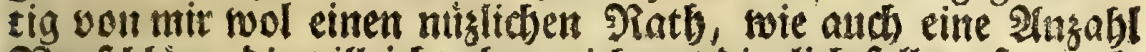

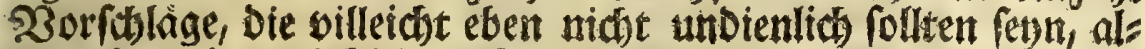

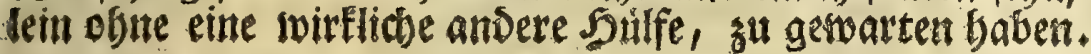

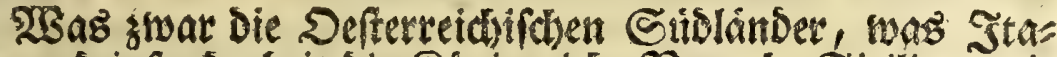
lien, und infonderbeit Die Aonigreiche Meapel, Sicilien, wie autc) Die Jniel Malta, anlanget, fönnen Meitte Sctren,

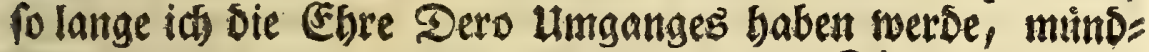
fid) von mir einige Sachen erfabren, Die Sie bielleidst in Butchern nicht antreffen swerben. So babe id vor einigen

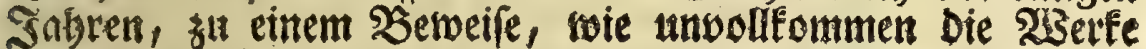
bon Martiniere, Mhoreri, und andere Diefer 2 (nt , find, Dem

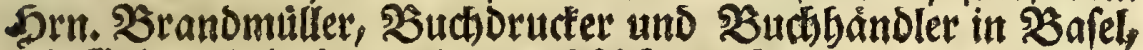
bei Gelegenbeit Des mir zugefdictent Moreri, Den 2rrtidel Recce sugefertiget, Den ich theils aus Der nod frifhern Ers innerung, theils aus meinem fursen Reifeberseichniffe aufges fest, Darinnen fowol Die Irthtumer als Die itnoolleommens beiten Der Beftbreibung, weld)e Maty, Martiniere und M) revi Dartiber verfaßst baben, verbeffert und erganget worden. Secce (letfde) ift ein Drt, Dem man in Der Sabl Der fojon $=$ fen uno urådutigften Stäbte von Stalien, eine Der erfen Etels len einráumen muß ; allein man weî́ anderwerts von Dernfels ben nidit biel, meil er in einer foldsen sage fich befindet, $D a=$ hin Die Sremben wenig reifen. SOon Den Defterreichifthen

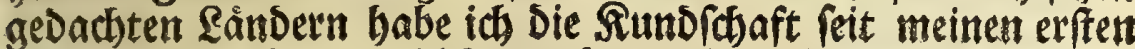
Jabren ermorben, weil id aus Derer einem butrtig bitt, Die tib= rigen aber entweder Durchgewandert, oder Durch bie siele (S)es meinf(h)aft, weldye ich mit Den andermerts lebenden Inmobs= nern gepflogen, nå̉ber aus̉gefor(c)et, einige aud) Durd låns gern 2Uufenthalt felbif fennen gelernt habe. Stalien iff mir Durch eine beftandige Sieffe von 3 Jabren siemlich befannt 
morden. But Malta bin id einige 3eit fteben geblieben. Die öftliden, fitolichen und weftliden Strände von Sicilien, roie audh alle Lanofdaften Des Sionigreides Jieapel, babe id freugneife Durchgeftrichen, und farn Jłnent von Diefen stwey anfehnlichen Stitcen Staliens, bon Der Bewandtnis ibres SoDens, morinnen bie Sauptguter Der itgedaditen \&ands fhaften befteben, oon Der Rabrung, von Den Reigungen, Sitten und (Serwobnbeiten Der Jnwobner, beinabe eine fo eis gentliđ)e Ractricht geben, als wenn ioh ein gebohrner Sicis

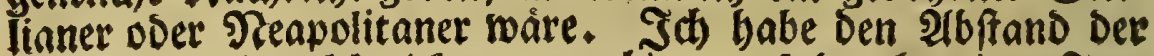

- Derter, Durd welche ih gezogen bin, nach Den beutigen Jtas

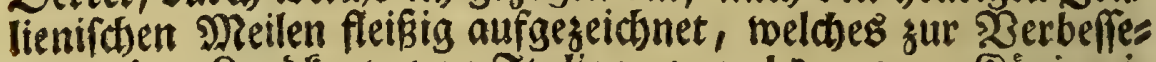
rung einer Lanbfarte von Italien, fumal Der vom Sonigreis ()e Deapel, bieles beitragen fann. Shier mus id auch Dies

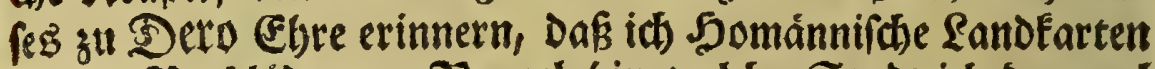
in Den Suthlaben zul Treapel (in welche Stabt id) Drebmal gefommen bin), angetroffen, und Die von biefem Sonigreide allo fitr 24 Sreuget gefauft babe, weld ich), bei meiner er: ften Abreife nad Den verfaitebenen Sheilen Diefes fónen Ses bietes, in fleine Ettiffe serfohnitten, um folche in meiner Sobreibetafd)e bequemlich mit berumgutragen. $\mathfrak{X}^{3}$ as an Dem

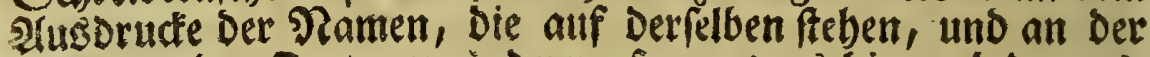
Stellung Der Derter zu ăndern, ferner toas bier und Da aus: gelaffenes nod) einzuverleiben fer), Eann Sbnen zu einer ans Dern Beit aus meiner Reifebefdreibung angedeutet werden. Bur Berbefferung Der Landfarten, welche Den alten Suftand bon Italien, wie aud Derienigen, welthe Das Proricum und Oberpannonien vorftellen, als Diefe Segenden unter Der Serrs f(t)aft Der alten soomer geftanden Gaben, Eann ich ebenfalls mit einigen nutgichen Inmertungen Dienen, weil id auth ben Plltertbumern erwebnter Eoinder nadgefptiret babe. Indeffen nebme ids Die Frenbeit, Meine Serren zu erfuchen, Das Sie sum biften Der liebbaber, welche Die alten von Shnen beraus: gegebenen Landfarten brauthen werben, einen Bortbeil an bringen modten, Der von feiner geringen Setractung ift. 


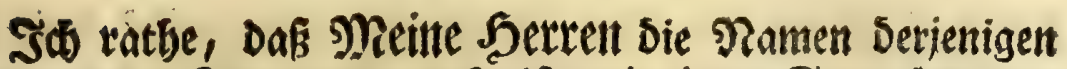
Derter, Deter Lage ausgemadit ift, mit eimem Sternchen von

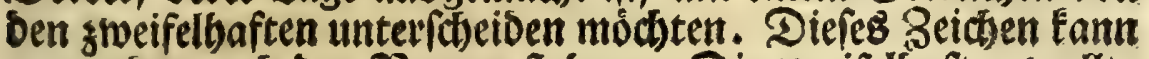
yor, ober nach Den Pramen fteben. Die grveifelbaften wolle (id) unmafigeblid mit einem Rreuze bemerken, uno Die unge" wiffen, Derer Sabl auf mancten Landfarten Die groffe ift, obne Beichen laffen. 3. E. folgende Derter in Norico und Pannonia fuper. fónnten fo vorgeffeflet werden: Boiodurum * Ovilia Tab. * viefleid)t Ovilaba [orum] Antonini, Lentia* Laureacum* Solva* Aemona * Nauportum* Celeia * Poetovio * Muroëla s Sabaria $_{*}$ Carnuntum* Vindobona $*$ und noch andere, Denn

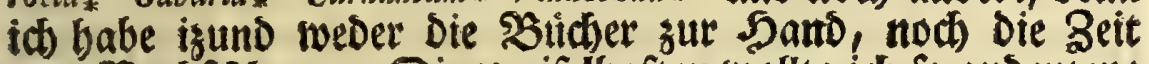
zum Rachichlagen. Die sweifelbaften wollte ich fo andeuten:

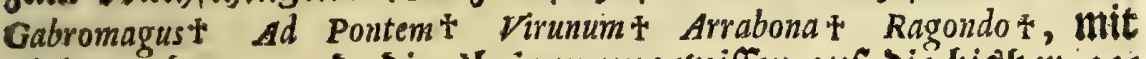
vielen andern, und Die ubrigen ungewiffen auf Die bisber ges bräucblidbe 2Irt fo fteben laffen, Ernolatia, Tutatio, Elegium, No-

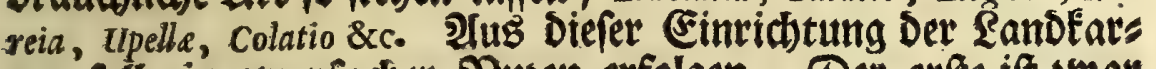
ten foll ein zweyfadier Natusen erfolgen. Der erfte ift stwar nur eine $\mathfrak{B}^{3}$ erhutung Dez Schadens, weld es aber gleichmol auch fann ein Rusen beifen. Denn Durch fo Derfaßste Land: farten wird erfflid niemand verfitbret werden, Da ponft ein

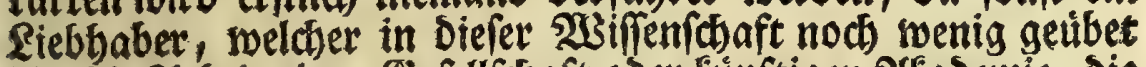

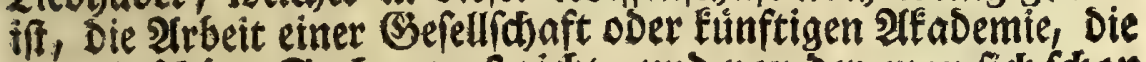

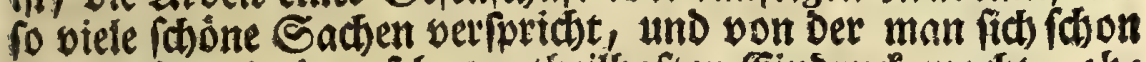
Durd)gebends einen fehr vortheilhaften (Eindruct madit, obs

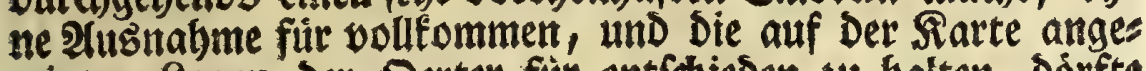
zeigten Eagen Der Derter fur entfhieden zu balten, Dórfte Werleitet werDen. Der andere $\mathfrak{B}$ ortheil iff, Daß bie Eelebrs ten Derienigen SSegenden, in weldje Die alten piomifchen Ders ter, Durch 2Inzeige Der Landiarte, fu fehen fommen, Durd Das beigefugte Sreus werden aufgemuntert werben, genaue: nad) zuforf(t)en, Die angeDeuteten Lagen zu betreten, und nad): zufehen, ob feine MertEmale Rómifcher Gsebáube tibrig feryen, weld)e 2(rt Der Unterfuctung, meines (Eractens, eine Dee widbtigften und fidberften ift. Meine Setren follen finder D 2 Dá 
Daß Diefe Sreuge Der alten Seographie ein groffes Ridht an sunden, und Shlten mandje gute Rachrichten liefern wets Den, Die Sie auser Dem nitht úberfommen bätten. Dent Durch Die EntDecfungen Der (S)elebrten, welche Der SEegent Den fundig fino, und die ungerne feben serben, Daf man of fentlid) besenge, Der alte Burtand ibres Baterlandes fey nod wenig betannt, Dorfte bier und Dort Das Sirew in ein Citern chen verwandelt werDen; bei andern Dertern aber follen Durds etwehnte fleisige, bieburch beranlafite, Pachforfhung viele mertlithe Srrtbimer an Sag su bringen fenn, und Die red)tent Sagen fiti grimblicher befrimmen laffen. Tach biefer (Fin ridjtutg werben endlich gelebrte, uno befagter fandfriche funbige Nanner, auch viele gànglich ungewiffe, uno obne Beis den angebradte Stellungen Der Derter, in eine zuverlafinge (S) ewisheit zu fegen angemabnet werden.

TुBarum iđ auf Der Ranofarte von Roricum und Dbers pannonien, zu Dem Ramen Gabromagus Ant. und Tab. wie auch su Dem Ragosndo Ant. ( fo Das Ragando Tab. und Ragindo It. Hieror. iff) ein Sireus binftellen laffe, beneget mid Die nod) Eeinesweges, auf eine verficherte शrrt, ausgefundente Eage diefer Derter. Denn Das Kagonoo fezen einige nacis Seis, welcbes Rlofter in einem Shale Des zu Ende laufenden Cetii liegt, und die erife Siartbaufe in Seutfoland iff, ande: re (wie Edsonleben) rtiden mit Demfelben um etliche Etuns Den weiter oftwerts nack Fobitfd. Cellarius meinet, es babe fith gar alle Spux von Diefer Tlomifenen Einfehr (manfio) berlobren, weil er in Der श्Abbandlung von Der Pannonia

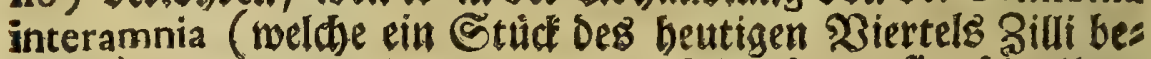
greift) Geogr. ant. I, 444 , n. Is, folgendermaffen fohreibet: Inter Poetovionem et Celeiam medius. Iocus Ragondo in Tabula et Itinerariis, qui periit. Meine Serten fonnen gegentwårtig Diefen Ort, Dem angegebenen Mraaffe Der Stalienifchen alten Dieilen sus folge, auf Der Landerste wol to ftellen, Daf er mitten stwis foren Seleia uno soetopio feinen Stand erbalte; allein wie 
Der eigentlicje slaz beutiges Iages beike, werben Sie, olne (S) efabr eineg Jrrtbumes, nicht beftimmen fỏnuten, Da

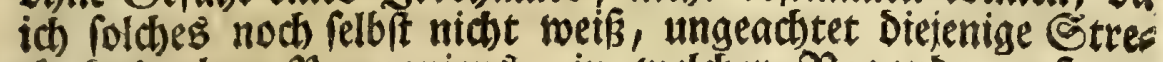
de Des alten Samnoniens, in welcher Ragondo muß ges ftanden baben, won meinem 'seburt Diefe (S)erwisbeit folt aber Durds eine vorfesliche, und auf Die

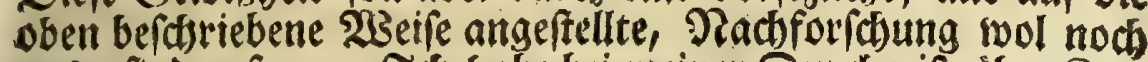
auszuffinden fenn. Ith babe bei meiner Durchreife tiber Rers (pach), Da id) von Etudenis fam, in isterwebnter Rirche, und

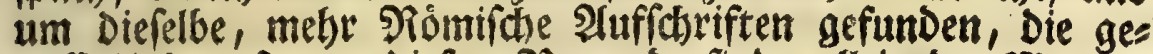
miffe Heberrefte von Diefem Siagondo fino, allein Der Mangel Der Qeit lies es nicbt zu, Dấ ich Durdi Die anfangs bef(driebe: ne Şeficjtigung Des $30 D e n s$, und 2(uffuctung Der Renuzei=

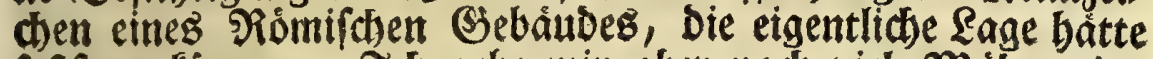
feffesen fónnen. Jah gebe mir aber nod viele Maibe, eine genauere Sund phaft ichriftlich einzuholen, und laffe mict nicht

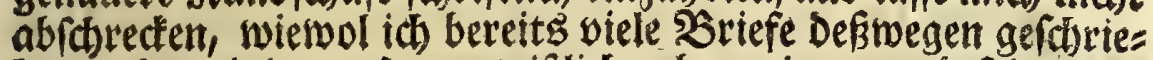
ben, obne einige, oder gewislich obne eine vernumftige und mir Dienliche, 2Antwort su tiberfommen.

2Inlangend Des Gabromagus, welden sort ith unter Den zmeifellhaften an Der erften Stelle nenne, meinet Slus berius, Das Derfelbe in Dem Sremsthale, und smar an Dem Drte geftanden babe, Der ist 5. Zleus beist. Joh laffe aber nicbt obne Srund auch Diefem Ramen ein Nrent beifezen, weil

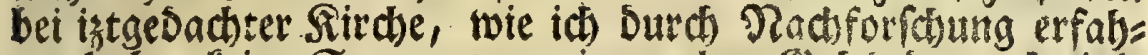
ren babe, feine Spuren von einem alten (Beteantbe, noch eimis

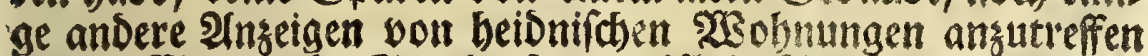
find. Eine balbe Stunde Davon iffein Berg, Der Thurns bomberg genannt, auf weldhem fith etliche Ueberbleibfel von altem Semåuer zeigen follen, Dabin auch einige Der unliegen Den abergläubifhen Intoobner, um Scháse aušzugraben, fiđ verfugen. Da ́a man vielmebr muthmafien fonnte, an Diefem Drte babe Der 2्llten Gabromagus geftumben, Dunfet mich Der शRame felbft eine 2 (nnleitung zu geben, welcher, nach meinem Sinne, eine Seftung bei einem 23 udwalde, Doen 
XXX

as ) $\circ$ ( 50

Die auf eintr bergleiden Reute ( Rode) erbaut gewefen, ans zubeuten fot)einet. Denn in Dem 20 Sorte magus febe id Feis nen $\mathfrak{s e g r i f}$ bon einem Jluffe, Den Sluberius, meines $233 i f$

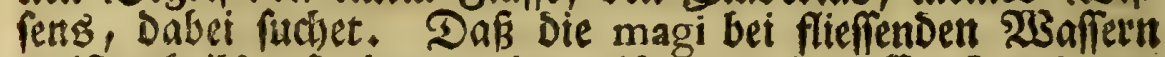
meiftentbeils gefunden werden, ift es meines Eradtens nut ein Beichen, Dof Die alten, infonberbeit Die Seutfon, germe

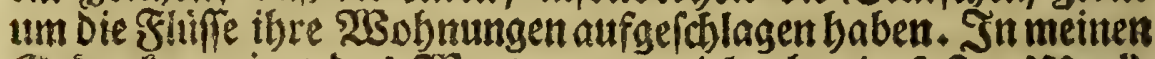
Sedanten zeiget Das sibort magus vielmebr ein feftes Dert, cine Seftung an, weil bas alte itaga, valere, posentem effe, bedeutete. Daf́ Diefes feit erdiditetes Stammmort fey, ers

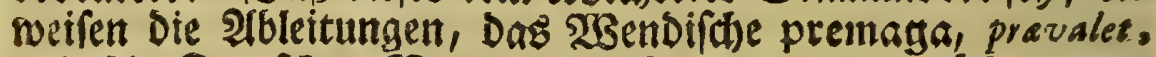
und Die Seutichen গamen Madbt, potentia, mádtig, potens, vaidus; weldes maga erfflich in mogen (wovon bas beutige Seutide modte, vermobt, liturig if ) uno endich in bas izt gebräudidide mégen, verwandelt soordent.

Indem id eben einem Stammworte qu magus nachitits ne, fitbret mid Der offenbare Zufammenhang Der Spradjen nod) weiter. Jd) febe, Das aus mogen, Durd eine Sufams

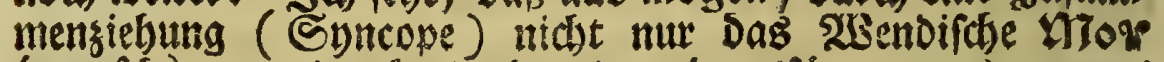
(motfof) potentia, fortitudo, vis, rohur, (fír mogon) moxni fortis, fondern aud) Das ETofd, vir, fonne gefommen feyt,

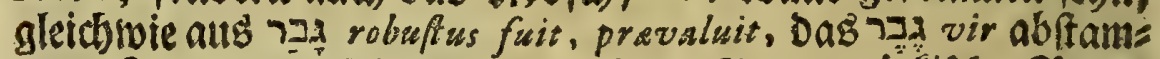
met. Ja, wenn id betradte, Dafs Der Gtenermártif the Sauer

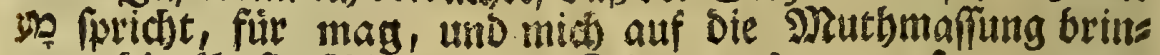
get, bie áltefte 2 illoung Des Beittwortes maga, fey maa ges weren, mit elnem rhinefmo, fo folget, Daf fowol Das Dunfle lat. mas (befeben Sie Jeberiobs Lex. lat.) als Das Ieutfics thann, nod citter volicomenen Sprachábnliobfeit mit Dem

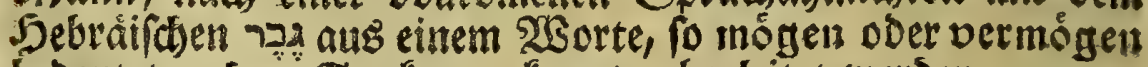
bebeutet, obne Sonfope, fonnte abgeleitet werDen.

Gaber, fo Der erfte Sheil won Gabromagus su fent

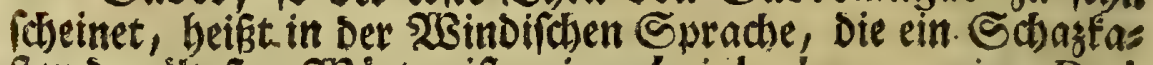
ften Der alteften 2 Sorter ift, eine Sainbude, carpinus Dod. In Den túbrigen EnDungen fálit Das e von Gaber (weld)es obnes 


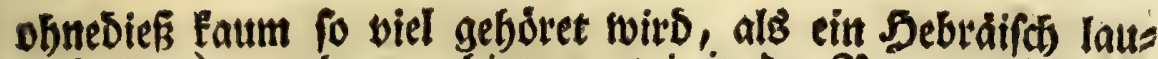

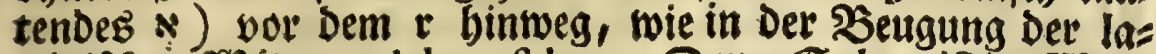
teinischen woorter, glaber, faber. Denn Gabra if im $23 e n=$ Dirchen Die zwente Endung Der einzeln Sabl, carpini, wie qucí) Die erffe uno vierte im Dwali, duo carpini, duos carpinos; Gabru, carpino, Gabri, bie $\mathfrak{S a i n b u c t ) e n , ~ m e h r e r e ~ f o l s ~}$

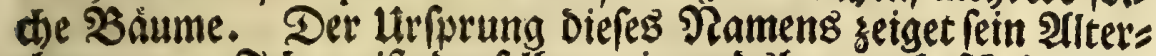
thum an. Ith weis Denfelben nirgendsber wabrfcheinlicher

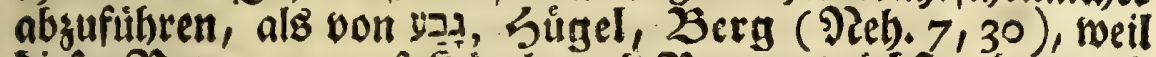
Diefer Baum nur auf Stugelin und $\mathfrak{b e r g e n ~ w a ̈ h i f , ~ o d e r ~ n o c h ~}$ bon רבּ und Feeftigfeit DeB 5 olzes, weldhe Diefem 3 aume eigenthum lich) ift. Nun befindet jia auf Dem vorangeregten Iburnbams berge noch bentiges כinges ein Sainbuchentwalo, moourch sum menigifen fobiel Dargethan wird, Daß̧, in 2Iniebung Des Srunbes, auch ebedeffen einer allo a fóme gewefen feyn. Das nabe miitseloorf, welcher Fame cill grofles Dorf bedeutet,

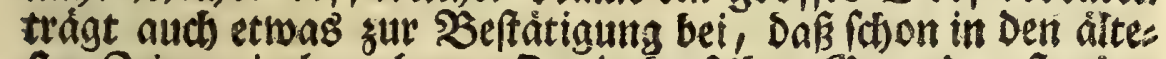
ften aeiten ein bemohnter Drt in berfelben Segend geftanden babe. Wielleid)t waren es einige Derjentgen Echmisden, De: ren Fetuers Dvibius Met. 14, 712, Der Ecthwerter aber, bie

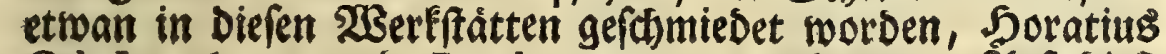
Od. I, 16, 9, und Epod. 17, 71, erwebnert. 2luf Dieje Mhutbmaffung bringen mich Die gablereichen, noch igt berufbmten Sc)mieden biefez Ihales, Deren 2rbeit, inronderbeit Die Senfen, Durch ganz Europa, und vielleidis noch in andere

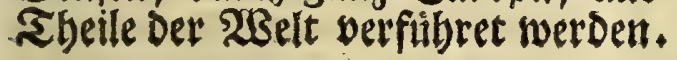

Das find aber nur erff flübtige 2rnzeigen, weldie bie Borfteber und Sebrer Der Aremsmumfterifthen neuen 2ffade= mie grundlicher auszufubren Die Shite baben merden, Denn

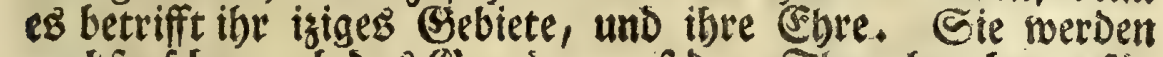
nachforíchen, ob Das Ssemáuer auf bem Iburnbamberge für Siomifot lonne gebalten werben; oder ob man vielmeth auf Dem St. Jörgenberge, auf Der rechten Seite Der Rrems, Das. Gabromagus auffuden muife; Denn id bin an Eemen biefer 
swey Drte gefonment. Saben istgedacte Ferge eine foldse Lage, Dâs unten eine Strafie fonnte borbeizieben, und rollen (iid) vielleid)t Sputen bon Tiomiroben Sebăuben in Der Nies Dere finden, fo fónnte allo a Der Yiomer Manfio ober Mutatio

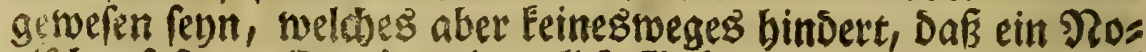
rifher fefterer Dit, Der eigentlich Babromagus gebeisen, auf einem befagter S3:rge geftanden habe; wie nod beutiges Iages bei vielen Bergfeftungen untenber andere Derter lies gen, Die mit ienen eimerles Damen fubren. Die vorges ribmten Jerren werden ung ferner belebren, ob ibr Sis Das TVTATIO Ant. oder Das. Tutaftio Tab. geweren, waldes Jes Derich in Lex. lat. meinet, allein Zetulius ( Sigm. von \$irs fen) auf feiner Sarte Des Donaultromes ausonuditich fezet. (Eben Diefe Mănner merden endlich fich bemuiben, Die Rage vou ERNOLATIA Tab. ausfindig zu macien. TSollen fie ibs rer Gemàdichteit pflegen, uno lieber auf einter gebrochenent Sabn einbergeben, als liber holperidjte Derter fich erfit eine bereiten, fo famm ich ihnen sielleicht mit Diefer Erimnerumg Dies

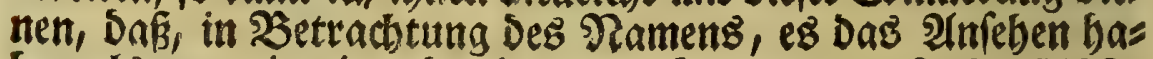
be, als went in einer ber bettigen 5od laiten, Das ERNO.

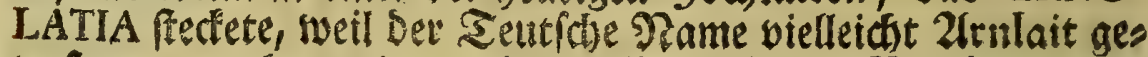
we Fen, arn aber und ern, in Der Cprade Der Porifer, Dasies nige Dorffte bedentet baben, was beutiges Sages erbaben beist. Zu Diefer Mutbmofiung leitet mid Das (Sriechifde aipesy, furfum tollere, weldieg felbft von Dem Seltifchen AR, fuper (Boxh, $L E X, A N T$, BRIT.) absultammen fiteinet. Sie wollen fies mun ferter Darum befimmern, wem ibnen meine Borbereitung gefált, molche Saiten ibrer $\Re a c b$ barfhaft, Des ren $e s$ alld a fo viele gibt, fiut tiobtig fonme gebalten werben, Daf man Das Enolatia Dabinftelle. Es gibt noch andere wichtige Stweifel tiber Die Siomifonen 2lterthumer, welche im

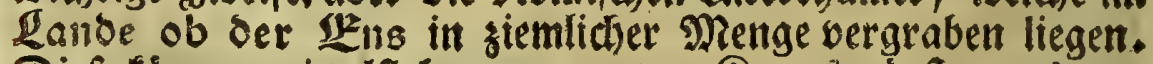
Diefe fonnen mittelf bequemer, bon Aremsmtiniter aus ans geffellter, Spazierfabrten, tnterfucht uns leidit entidifedent

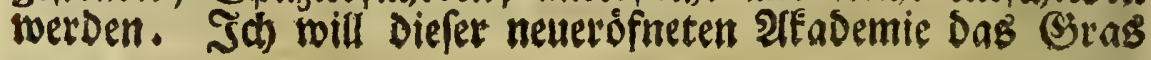


felbe verftummet wol auds, wenn er Deret einige borbringen foll. So lieft die Englänoifonen, nie Diefelben nad) Der beus tigen Rebart eigentlid) lauten follen, nut ein (Englänoer,

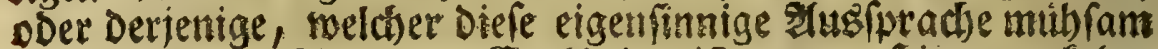

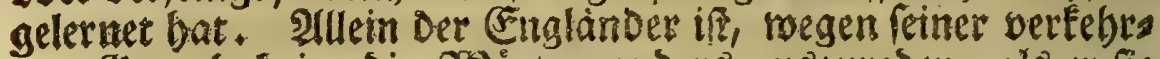
ten (S) fdretbet, nodj biel ungefdicter, menn et Die DRamen anderet :oblfer nachipredien foll. Er fann fich aud Durch fein Latein nidht erflären, Denn Die Jremben berfteben baffelbe beinabe eben fo wentg, als feine Matterfuractse. Fin Sentfoter want

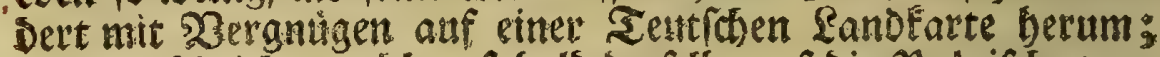

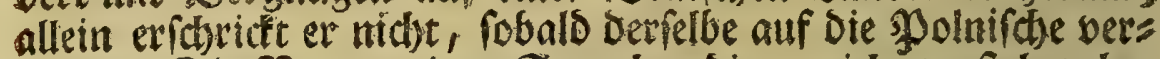
fallt? Die Ramen ener Eprache, Die er nicht berftebet, bes fremben ibn foton. Sgseil aber Diefelben tiber Diefes Durch eine befondere Schreibat, namlich Durch eine ungeroobnliche Zufommenfesung mebr lateinifober Mnitlauter, einige aut Duta gewiffe bei Den Suchftaben angebrachte Beidjen, sut Derer SBedeutung er feine Einleitung bat, noch mebr beeftels let werden, fo verlieret er allen Mruth; berfelbe bemubet fids gat nicht Diefe siamen augzuforechen, weil er billig beforget, antggelactit za werben, wenn er diefelben in einer (Sefellidhaft befer berid)teter Leate ungereimt berfagen foll; eben fo von mebrern andern Rand arten su reden.

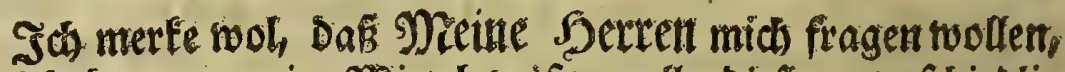

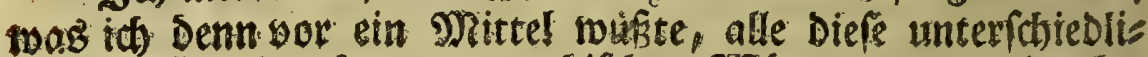

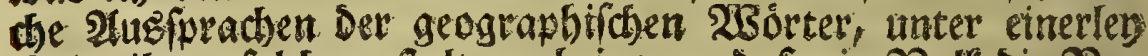

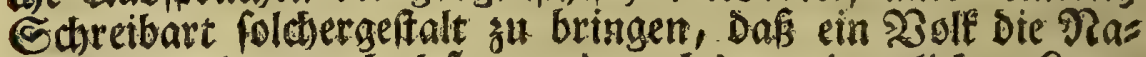
men Des andern recht lefen, uno nach Dem eigenticher Saute mit Dem Munde ausoricten Hỏne. Sierauf biene ich, Dafs in Der Beit, in welder Meine Serken Die erwefnten geos guaphiften Namen, zu einer Grunolegung Des oben befinvie beren Auffhlagbudies, aus Den Zanofarten uns Suchern, famniten werben, thi hoffe einen oermogenten Mácenaten su exbalten, ber fich entfichlieffen wiro, gut Bethanntmachung.

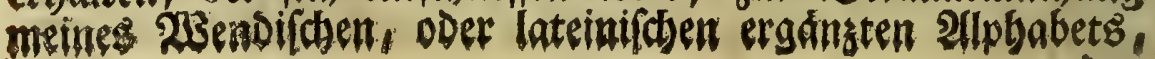
Den 
Sett bentothigten 2rufwand su beforgen. Diefes gilphabet miro Der Merfur repn, Der ung alle 2lusfpracten bolmetichen, uno

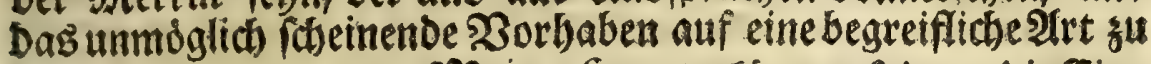
Stanbe bringen foll. Meine Serten fonsen fodann Die ein

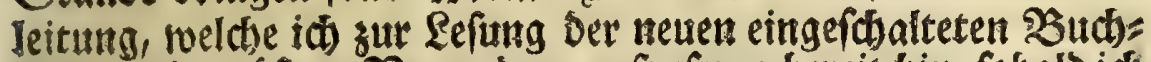
faben mit gróftem $\mathfrak{B}$ ergntigen aufsufezen bereit bin, robald ich

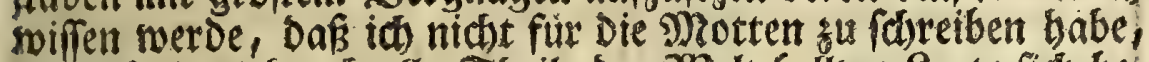

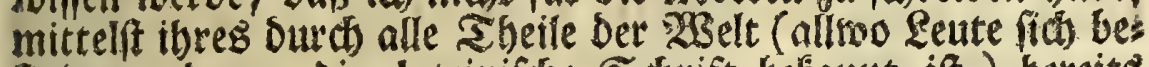
finden, benen Die lateiniche Schrift befannt ift ) bereits babeuben ober noct) funftig zuerrichtenden şriefmedfels,

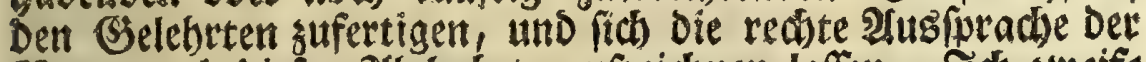

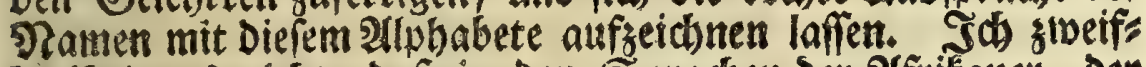
le tibrigens nifft, Dâs in Den Sprachen Der 2ffrifaner, Der 2imeritaner, wie autch in Denea, weldhe von Den $\mathfrak{B o ̈ l f e r n}$ bes

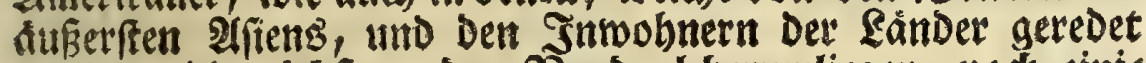
werben, Die nádbit um Den Pioropol berumliegen, noch einis ge Eaute (fich mogen finden, Die id nid)e gebort habe, und folglich auf Derfelben fabriftliche $\mathfrak{B o r f t e l l u n g}$ nicht fonnte bes Dacht feyn. Allein aud Diefe werben Durd bas allgemeine son mit vorgef hlagene 2llphabet eber, als Durch ein andes res, weldies es aud) fey, entweder nur mit $\mathfrak{B}$ eibullfe einiger Suncten, Die ith Den bereits vorbandenen, und Der 2 hus: furache gedachter Eaute nabe fommenden $\mathfrak{B u c j i f t a b e n}$ beifes gen werbe, oder Durch gans neue, und in Der Einleitung sus ertlárende Beichen, fich andeuten laffen.

Die vierte Berbefferung, bie id zu Dem bisher abgefdils

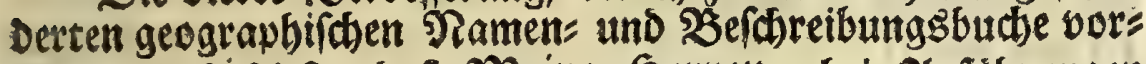
faslage, ift Diefe, Das Meente Serren, bei 2unfübrungen Der fateinifden Namen, Die Edhriftifeller mit anzieben mòds= ten, weldhe jeden Derfeleen zuerfi gebraudst baben, wie man bei Den lateinifhen ober (Sried if then gemeinen 2 Sortern, bie

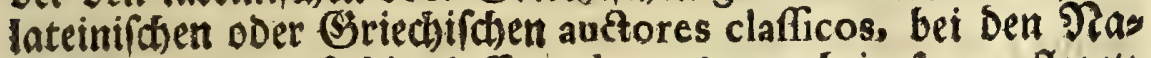
men Der Ssenwad)fe Die clafficos botanicos, beizufezen pfleget; uno foldhes Definegen, Damit man aud bei $\mathfrak{B}$ erfafiungen geograpbifder Edyiften Die guten lateinifden eigenen Na: E 2 men 
men wiffe vor Den fallecttern su wäblen. EB gehơren Dlefe श्Sorter ebenfalls in Den Umfang ber gefamten Eprache. Da fie mun von einigen Serausgebern Der $2 B$ enterbuther ungereds ter $\mathfrak{2}$ Beife verfolget, und aus Den lateinifoben Regiftern bers ausgeworfen werden (io haben ifnen Facciolatus und $\mathbf{5 r}$. Matth. (Sefner mitgefabren), fo ift ez billig, Dafi man diefels

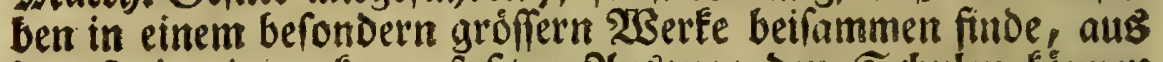
Dem fie in einem furgefaßsten 2lusguge Den Edulen fónen

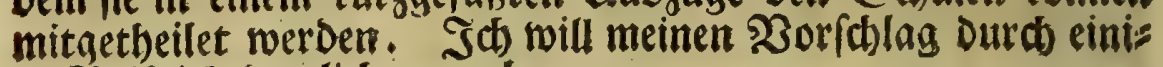
ge 2Seifpiele Deutlicher machen.

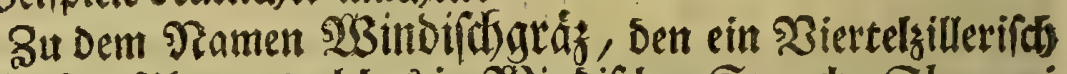
Gtàbtchen fitbret, welches in Sisindifder Eprache Sloweni Grade3, D. i. ber Glavonier Gtádthen beifst, wollte ich bie lateinifa)en fynonyma fo fezen: VINVNDRIA Lazio, Meriano: VINVDRIA Betulio in Tabula Danubiana, vulgo VENDOGRAECIVM, VINDOGRAECIVM, SLAVOGRAECIVM. EB minfen aber Die Etellen Der angefubrten Sitcher mit angeseiget werben, melches ich allhier bei Den शRamet

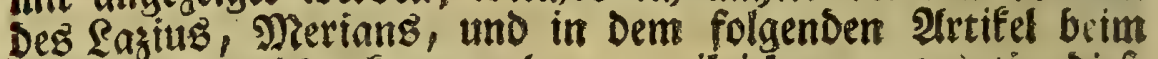
Cluberius, nicht fonnte thun, weil id gegenwartig Diefe

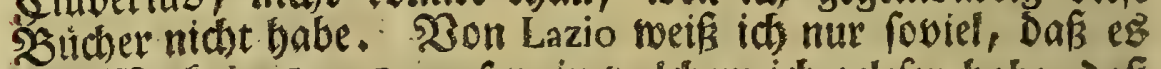

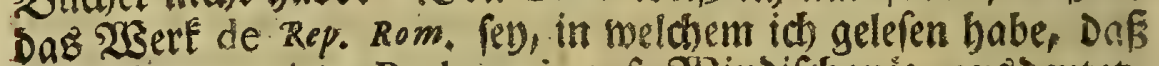
et Das Vinundris Ptolemæi auf 2 sinoifchgră ausDeutet. Sielleicht fommet eine Seit, in Der man, Durd Seibilfe Det Interfudiungen, Das COLATIO Tab. wird allen igtangefibe ten lateinifhen Ramen vorfegen fonner. Der Shaum geftats tet mir nicht, Dafi idf Die Hrfachen meiner Mrutbmaffungen bier anbringe. Aflle lateinifche, uno aus andern Eurachen genommene fynonyma, wie biel Vinundria, Vendograciom. Vindngræcium, Slavogræcium, Grabes ( Cloneni), muif fen an ihret Etelle, bie innen bie alphabetiche Dronung an: weifet, in Diefem 2 betfe beionders wieder eingetragen wer: Den. Das Vinundria berdienet fut fich eine eiaene Erflás rung. Set Den úbrigen foll rut Diefer seridht feben: Gieb ssintoifdogtát. 


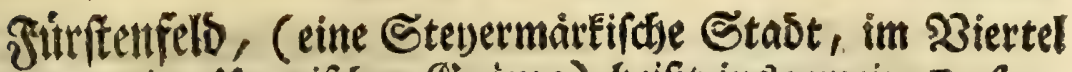
Borau, an Der Ungrifchen Srànze) beifst inggemein Furften. felda; allein man fónnte binzufuigen, SALLA istonini Cluverio, AUVAE perperam Lazio. Denn es muifen auch die falfchen Namen nicht weggelafien werden, indem diefelbent

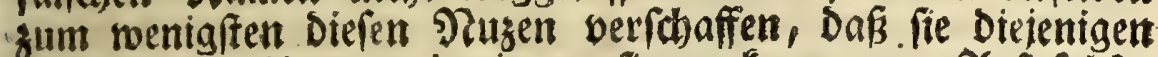
Edriften erläutern, Darinnen fie vortommen. IIuf folche

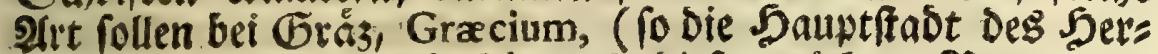
sogthums Stepermarf ift auth Diefe unaichten Benennun gen, SABARIA Lazii, MVROELA Ptol. Cluverio, nicht weg:

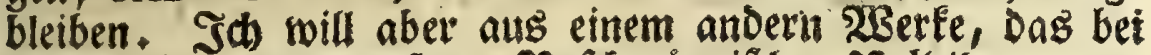
Selegenheit Des recenfirten Rofchmåmmifchen Veloidens ver:

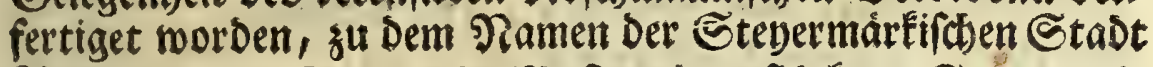
Detau an Der Drau, ein Mufter einer ftarfern Evnonymie auf folgende $\Re$ Seife sorlegen:

POETOVIO, onis, lap. Rem. item Antomini Cellario.

POETAVIO, onis, Antonini Launoio Diff. de Viczorino, Opp.

p. 640. Etbici Simlero, p. m. 116; Launoio p.640; Tasiti et Marcellini Lazio in R. R.

PETAVIO, onis, Tabule; Taciti et Ethici Launoio 1.1. Anto. mini Cellario; Antonini, Marcellini, Ambrofii, Aventino l. 2 Ann. j. 192 edit, Ingolftad. \&c.

PETABIO, onis, Marcellini Launoin Opp. p. 640 fequ, Hiero. mymi, sophronii, et in membranis Javav. Aventino, apud Launoium 1.1. HIERONYMI in Script. Eccl. Opp. edit, Parif. 1706 fol. Tom. IV, parte 2, col. 120, it. col. 141. Vid. comment. Martianæi a hh. ll. IETABION, wVos, Græcorum Launoio p. 64I. nITABION, wVos, Sophromii eidem p. 637.

PITABIO, onis, Bibl. miax. vett. Patrum Lugd, 1677.

Patavio, onis, s. Ambrofii Opp. edit. Parif, 1690 fol. Tom. II, col. 809 .

E 3 IA- 
XXXVIII

$05) \circ\left(560^{\circ}\right.$

natarion Prol. II. I5, Bertio. Das ift eitte Berwechfolung mit Dem Ramen Patavium, weldien zwey andere Stabte gefitbret haben, eine Italienifde (Dag beutige Pasua), und eitte andere in 53 itbynien. (EB muß allo das Dannos nifie Iaráviov Prol. weder mit erftgedactem Ramen, nod) mit Dem neuert Patavia, Palfou, nod aud mit Dem vico Patavicenfium in Dacia (1. I, $\$$, ff. de cenfibus), wo: bon in Dem bier nachgefegten sitel Petovium ein Mebrers nachsureben ift, oon neuem verwectifelt werden.

PETOVIO, onis, Taciti bift. III, I, Berneggero, Cellario, et Itin. Hiero/, primæ edit.

PETOBIO, onis, Marcellini XIV, 37, Cellario.

VETOVIO, quorundam Lazio R. R. p. 985.

POETOVIVM, ii, et frequentius POETOVIA, $\boldsymbol{x}$, Lazio in

R. R. paffim.

PETOVIVM, ii, nunc vulgo; aliquando etiam Lazio.

E\& muß aber Das PETOVIVM Dacia, (melches Der yors borbergemeldete Vicus Patavicenfum ift, und auf Riomifden Steinen aud eine Stadt genennet wird) mit Diefem fpátern Ramen Det ehemals Sberpannonifden Stadt petau nicht vermenget weroen. Die Erwebnung Des Dacifonen Petovii fommet in Zamofii Analectis Dac. in sweven Plufidififen bor. IX. Settent Sefeben auch Cellarii Geogr. ant. I, 48, n. 95 . Die erife Ilufichrift lautet Po: D. M. P. AELIO, T. F. QVAEST. R, AVRI. LVSTRALIS, COACTORI, AC. CIVITATVM. VOLMERII. ET. PETOVII. CVRATORI. Q. LAELIVS. AESOPIVS. B. M. M. P. Die andere fo: D. M. M. AVREL. CRESCENTI. AVG, LIB. VIX. AN. LXI. ET. AVRELIAE, FLORAE. FILIAE, EIVS. DEFVN. CTAE. PETOVII. VIX. A. XXIII. M. XI. DIEB. XX, AEL. IVLIANVS. SOCERO. ET, CONIVGI. PIENTISSI. B, M. P. Anal, DAC, pi $3^{2}$. 
Der Sberpannoniche Drt Poetovio an Der Drau, miro beutiges 3 ages von Den Seutichen, twie auch von Den Seutfi redenden SBinden und Slaven, petau oder pettau genannt. Der $\mathfrak{W}$ indifdie Rame ift Cuy, welcher angugeigen rdseinet, Dafs biefe Stabt von einem fremben 30 le erbauet worben, Denn tuy und ptup beifit auf SBendife fremb, peregrinus.

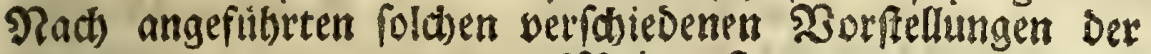
Ramen Der Derter werden Meilte Serten erfuctit, aud) ein Urtheil su fällen, weldsen Derfelbet Cie für Den äbten oder beffern balten, wie id) allbier verfictere, Daf Die Ramen Vetovio, Patavio, Patavium (IIoráviov), Pitabio, Die unrich)= tigften find. Der erfte hingegen POETOVIO, onis, if unter allen Der áltefte und Der befte. Sine Romifche Pruffchift, De: ren 2 uchitaben von Denienigen nidht viel abgeben, Die toir auf

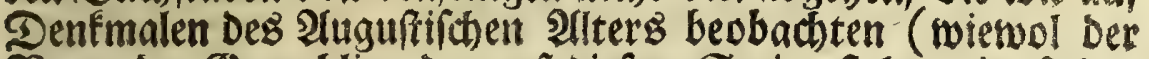
Эame Der (Semablin, Der auf Diefem Steine ftebet, eine fucite: re Seit su verrathen focheinet) if zu Netau noch vorbanden, und zeiget uns Die rechte Benenuung Deg Drtes alt. SXjenn man aus Det Dedjantey Eommet, und tiber etlidje Stuffen in Den Sirchbof fteiget, wirb Diefe Sd)rift linfer 5 and auf einer Slatte weifien Marmels gefeben, Deren Inbalt iff: C. CAE. SIVS. C, F. PAPIRIA. INGENVVS. POETOVIONE, V. F. SIBI, ET, VLPIAE. ADIVTAE. CONIVGI. ET. CAESIAE cet. Diefes Dentmal babe ich zu setau felbft abgefchrieben. 2(llein eb findet fich Deffen 2uffochrift bereits in Lazii R. R. p. 987; (Sruters Samnlung wird Diefelbe obne aneifel aud enthal ten. SWeil id) aber Das bisher entworfene geographifóse श्रerE nicht ein bloffes Namenbud), fondern aud sugleid ein Befchreibungsbuch nenne, fo mus bei jebem Pamen aud) eis ne Deutliche und furze Befhreibung angebradt werben, mo: Durch Der Lefer von Der Sefhaffenbeit Des benennten eine Rachridterbalte. Da id num Den Irtictel von Sotau zu cinem sprobfticte, wie Die ubrigen Diefes 2luffolagbuches un gefäbr ausfeben fónnten, errwáblet babe, fo follte ich aud et:

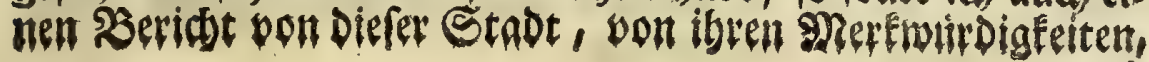

und 
und einen furgen 2 (usging ibrer (Befdichte, mit anfigen. श्llein ich will ben Faum zu nothwendigern Sachen fparen. Diefes alles finden SMeint Sertent in Lazii Rep. Rom. in (P. Pufch) Chronol. Sacra styr, an mebr Stellen, weldie Das शies giffer angeiget; in (P. Granelli) Germ. Auftr. P. 45, in Topogr. Duc. Styr. p. 6o, u. a. Sotriften. Den Sauptnamen fins aud Die Davon nógeleiteten Beimorter, als Potovionenfis \&c. beigufigen, welches iob gu thun vergeffen babe.

Den PRzen einer fold)en geograpbifchen शrbeit werden sneinte Serrent felbft einfeben. Fibenn Die Frangofen ein fo befobaffenes Tamenbuch gebabt bàtten, fo wurben fie gewifs (ich) in Den 2 Serten Der alten Rirchenlebrer, uno in Den Rirs dientgefobiditen, Dag Petabionenfis und Pitabionenfis, (wel d)e Seimorter bei Erwebmungen von Dem 5 . VICTORINO angebracht werber) nicht fut Pidtavionenfis und Pictavienfis, gelefen, ausgeleget, gutgebeifen und felbft gefdrieben babent. EB folite aud nid)t fo weit gefommen retn, als es wirtlich gefcheben, ba fie zu 2̂nfange Des vergangenen Jabrbunderts, Den armen Setauern an Der Drau, ibren Landsmann uno $\mathfrak{B i}$ fot) of, erwebnten 5. VICTORINVM, weggenommen, zu ei:

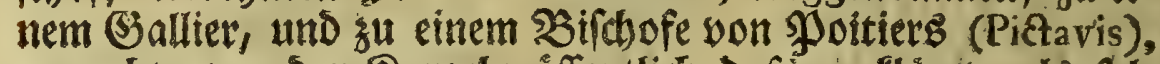
gemadt, won Den Rangeln offentlich Dafur ertäret, als fols d)en in ifre Sitaned und ins Szrevier gefegt, aud feinen (Ses burtstag als ein Doppelfeft zu febern veroronet baben. Das Durch wurben fie Dem Eporte entgangen febn, Da fie ist Dies fen groben Irrthum in allen ibren Sdriften geftehen, wibers

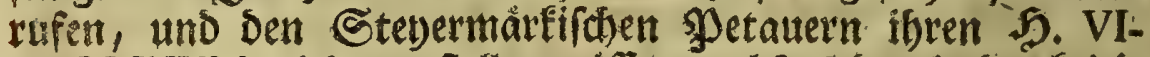
CTORINVM wieber zuftellen muffen, weldhes Der in Der fritis foten Sirchengefohich te vortlefflich bewanderte Frangofe Law. noi, in ciner befondern 2 Ibbanolung, de Viatorino Epifc. et Mart. Opp. Tom. II, part. I, yon Der 634 S. an, erwiefert; und ich in einem 2 (n) Srn. Rofd)manns Deloidenc gemacht worben, mit nod mebrern Beugniffen beleget babe. 


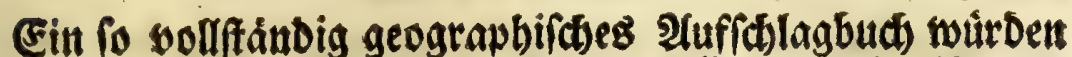
auth unlingit bie \&elebrten einer groffen und bertibmten Etabt in Zeutraland febr wol gentizet baben, Dabin vor 3 235odhen aus Stalien, won einem groffen Manne, Den gams Europa, um feiner $\mathfrak{s}$ surde und Gelebrfamfeit willen, großs= ad)tet, ein \$äcthen angetanget ift, um ferner an Jrn. Corm. Val. $V$... ck befórbert zu werden. Der Mann, welcher Das ctet, unter andern $\mathfrak{B}$ eifalliffen, empfangen bat, wuste nidit, wobin et es fenden follte. Er fragte Die Bjelebrten Des Dra tez. Diefe rietben wol, allein zuwerlaffig fonnten fie nicht ragen, weldse beutige Stabt Das NEOMAGVS VLTONVM

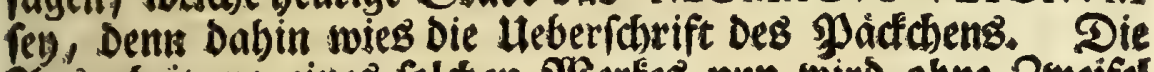

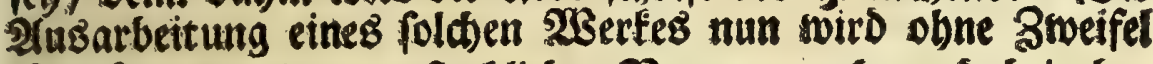
M. Serren einen unferblichen Ramen maden, Dabei aber

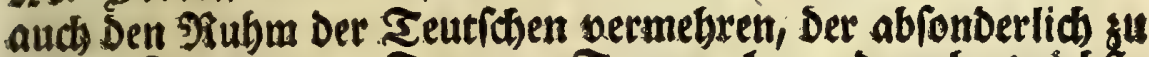

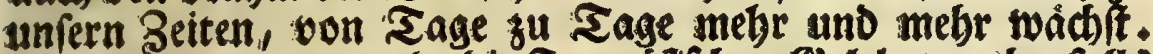
Eg geftehen es nunmebr Die Fransoifichen (Bejebrten ebenfalls (d)on, wie bart ibnera auch diefes Befenntmi bon ber Geber

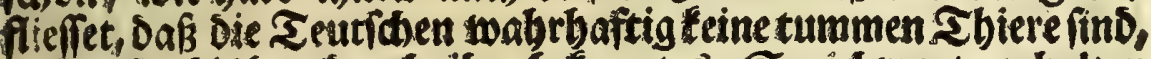
bafir fie bisher Durch ibe befanntes Spridhmort gebalten murder. Sie bedauren bei Selegenfeit bier und Da in offents

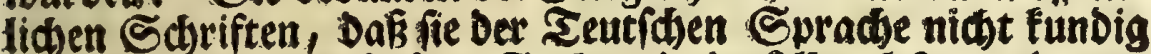
find, weil fie viele fajone Sadten in derfetben lefen und vers feben móditen, Die fie in ibren und andern 2 lichern nicht fins

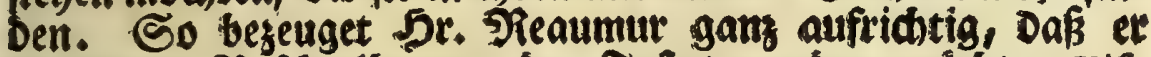
Frifchens Befhreibungen ber Infecten nuizen móthe, Hift. des Inf. Tom. IV, Der Parif. श्रuBgabe S. 116. MMit einem 23orte Die Heberseugung von Der Gelebrfamfeit Der beutigen

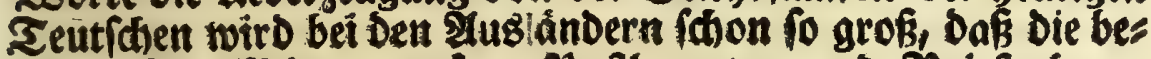
ruhmeften Mainner unfern Yoftbeamten und Briefträgern eine ftárfere geographif the (Einficht zumuthen, als biejenige war, Die Sellarius und Martiniere befeffen baben; Denn Dies fe tousten nidit, twas Neomagus Vltonum fey. $233 i$ múffen uns Demnad) bemulben eine Meinung gu unter ftigen, weldje Det Ration einen fo ausnebmenden $\mathcal{B}$ orgug und S 


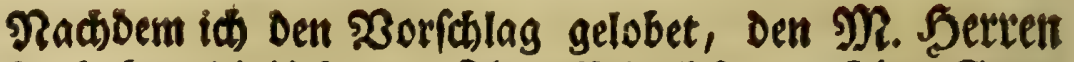
ergrifen baben, Die Hebungen Jbrer Mitglieder nach Den Spras wen einzutbeilen, fo erinnere id nur nod) biefez, daßs es febr bienlid) werde feyn, wenn Sie aud tracten, in Shrer Bes Pellfhafft ober finftigen \&fabemie, Leute su baben, welche bie etymologif be 23 iffenf(haft wol innebaben. Denn, weil Dero Abreben ift, etwas vollftåndiges von Der Seographie zu liefern, fo Dinfet mich, ein Copographifdes Glofiarium, ober eine in alphabetif́cer Dronung abgefafite Finleitung

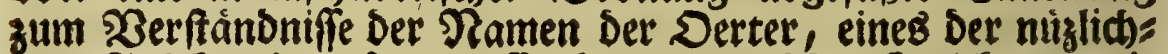
ften Stticfe mit zu feon. Es fommen auf Den Sandfarten eis nerley Namen ifters oor. Der Lefer mutbmaffet nicht ob: ne Şruno, Daf $\mathfrak{e B}$ gemeine Renntoórter (nomina appellativa) miffen feyn, zu Derer nåberer Seftimmung, Damit fie nảms lid einen gewiffen Drt bedeuten, nod ein anber 250 ort zum unterfheibe vorangefezet wird. 3. E. auf Der Landfarte von Safweben befinden fid in Dem Sheile Der Ditee, Der Upland und Esdermanland anfpulet, überaus viele Rlippen, oder felfichte Infeln, weldje Glearen beisen, und die von ben

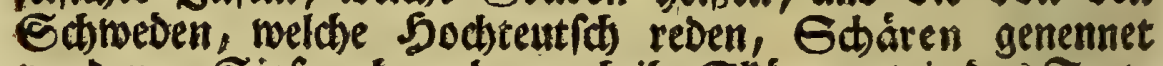
merden. Eiefprechen aber auch ibr Głár nur twie das Ieut: fhe fobar aus, zu einem Beweife, Daß Die beutigen Jnwob-

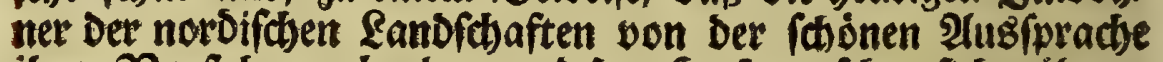
ibrer 2 orfabren abgeben, und Der Sochteutichen fich nåbern.

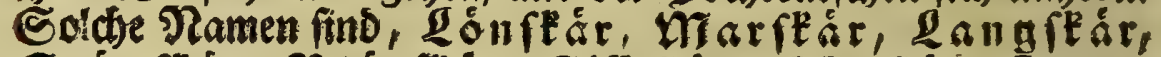

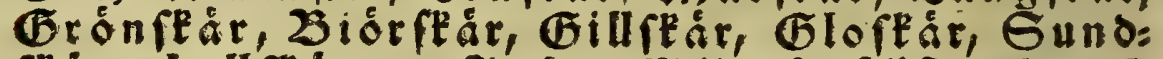

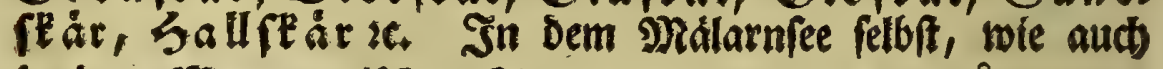
in Dem Meere grwichen Finnlano uno Der Sinfel gilano, ia

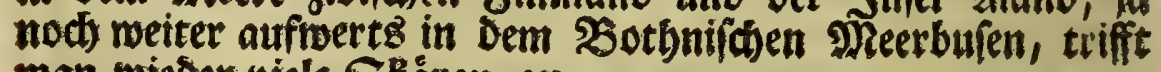
man wieber viele Stáren an.

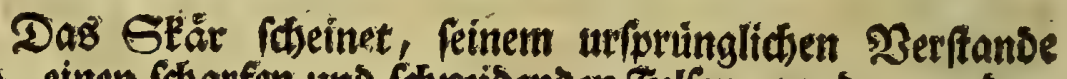
nach, einen for arfen und fonteidenden Jelfen anzubeuten, Ders gleichen mebrere in befagen SEgenden aus Dem 23 affer bers

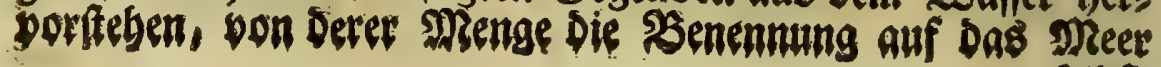


Pelbft, ferner auf Die nảd)ften Sưften, bei welchen Diefe flippichs ten "Eilande fid befinden, und auf Die Jnwobner gefallen,

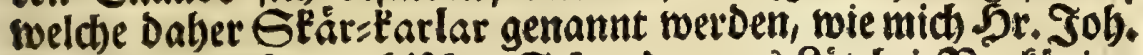

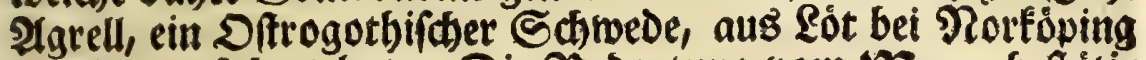
burtig, verfichert hat. Die Bedeutung vom meere beftátis gen biefe Senennungen, Die ich) im 23 örterbucte finde: rk ars gædda, ber ̧́ebt (eit Meerwolf), fkærgard, mit einem

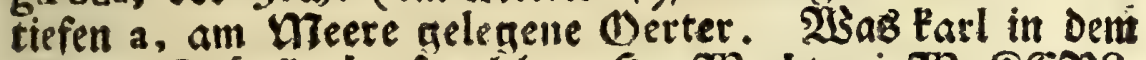

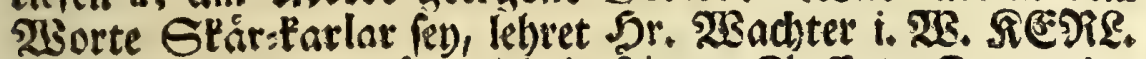
Das istgedadite $\mathcal{S F}^{2} a r$ mird in feinem Gloffario Germanico

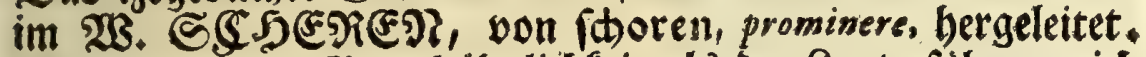

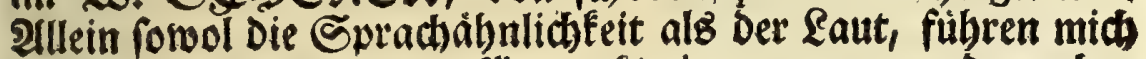

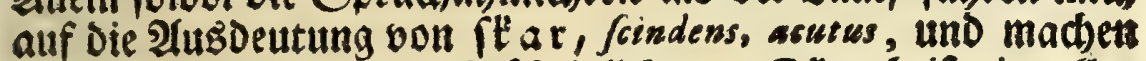
mir biefen uriprung wabricheinlicher. Gtar beist in allen nordiften Mundarten etwas ítmeibendes, und injonderbeit Das PAdermerkzeug, welches lateinifh vomer genennet wirb.

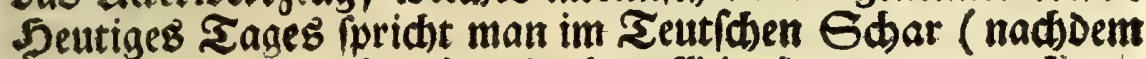
Die liebliche alte 2(usfurache Des ft in Den unangenefimen Bifchlaut $\Psi$ verwandelt worden) und gemeiniglich mit einem

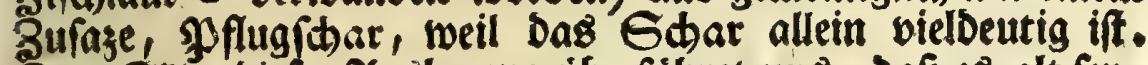
Das Etar biefer 2luslegung liberfitbret uns, Daß̧ eE alt fey, Durd feine Hebereinfunft mit $y$ ? P er bat ent3wey geriflen,

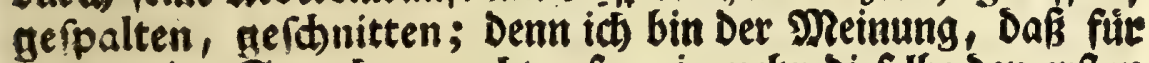

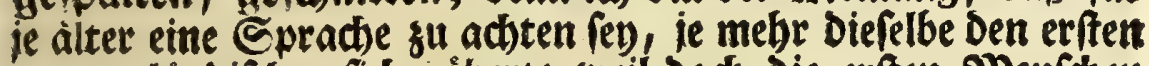
morgenlänbifchen fíd nábert; weil Dod Die erften Menfchen

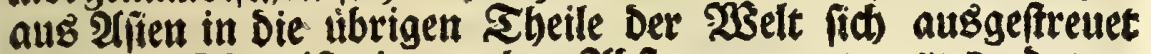
baben. Gkar if eine wabre 2fbftammung von ע

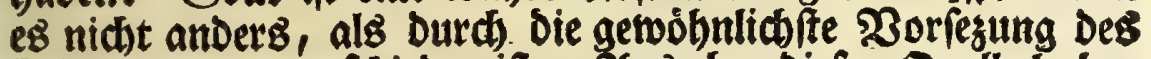
Bifdlautes, unteríchieden iff. 2Tus eben biefer Duelle baben

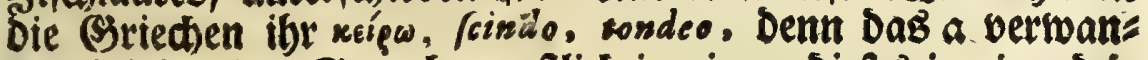
Delt fid in allen Sprachen erftlid in ein e, Diefes in ei und $i$. Soldhes bezenget Die Mantoart Der Rurnberger, welche Daz, geb fragen, ob er ein Gelo fuch, fo vorbringen: qei fregm,

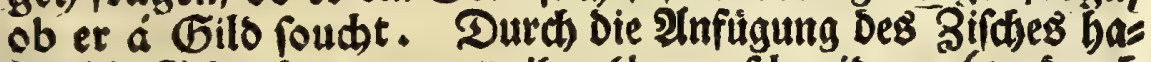

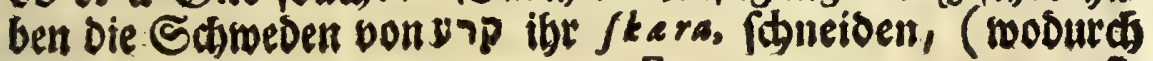


fie auch eine Cidbel verfteben) und /kar, forfex, in Dem $\mathfrak{Z}$.

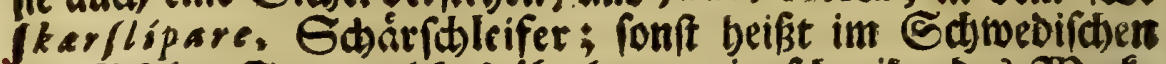

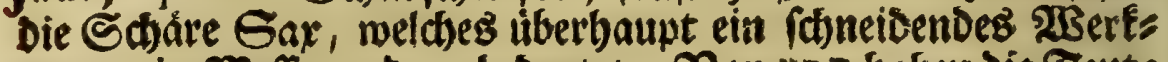
geug, ein MReffer u. D. g. bebeutet. Bon y p baben Die Seuts

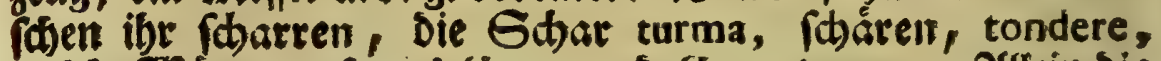
welde 53 orter anfángs / $k$ a r a und $/ k$ a r a waren. Illein bie Bendifde Sprache fann weniger verfiellte 2 bleitungent von yาp aufweifen. a) Kart beift in Derrelbett talpa, ein ntouls

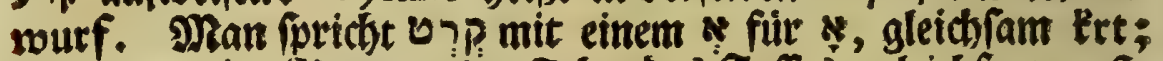
wie part, ein Singer, eine Zehe bez Suffez, gleidhfam prft, oon 0 רפ

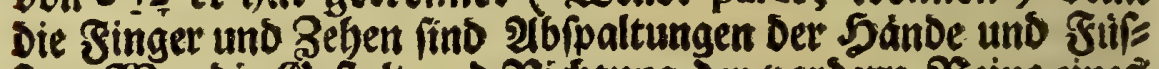

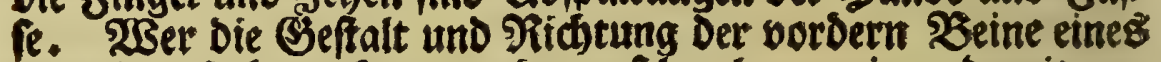
Maul(wurfi betradtet, und zugefeben bat, wie ex bamit ar: beitet, wit' geftehen, Das kart, ein voneinander reiffendes

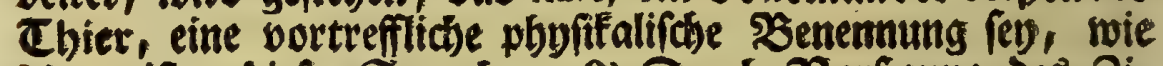

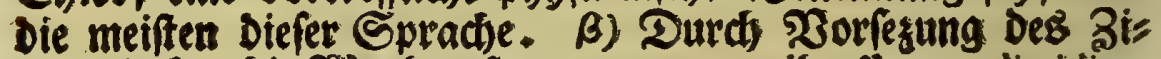

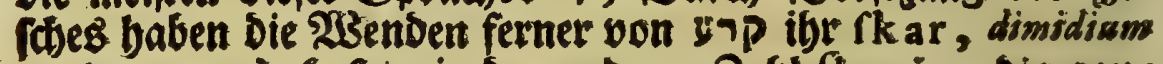
(culter unus) forficis, in Dex mebrem Babl fkarje, ote gans ;e Gdáce, forfex; $\gamma$ ) rkarne, er Eneipet $a b$, wieder mit

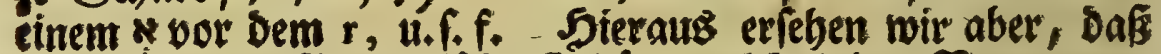

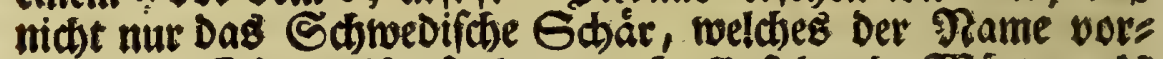

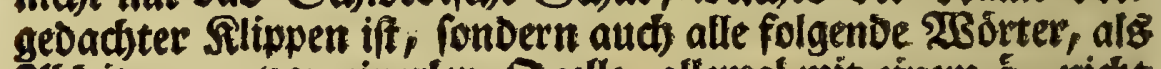
2(bleitungen bon einerlen Surlle, allemal mit einem $\sigma_{\text {, nicht }}$ mit e ober ee, muffen geforieben werben: a) Der Dborteus

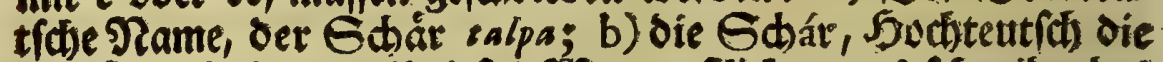

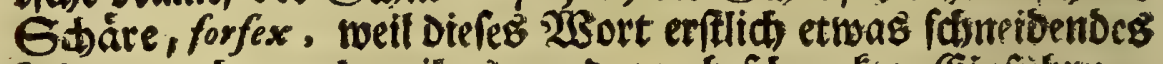
bedeutet; Darnach weil es vor Der unbefdranften Einfithrung

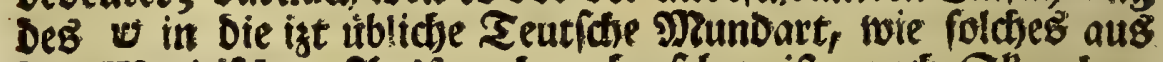

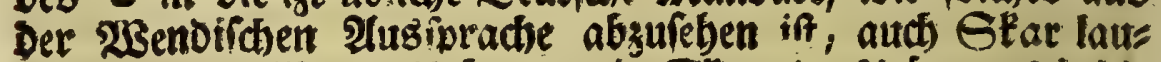
tete; c) Die Irebsicháren uno EForpionfcháren (chele),

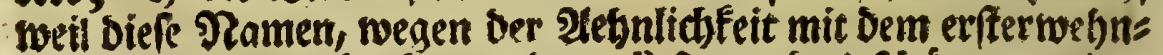

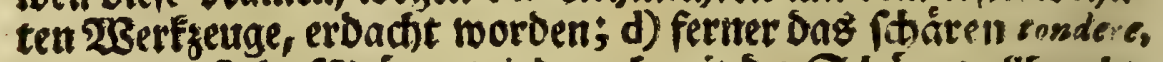
Denn Das $\sigma \pitchfork a f i \hbar$ áren twiro nod mit Der $\sigma$ táre vollbracht; alfo aud e) Das Gdármeffer, novaculo, wei der erfte Sheil 


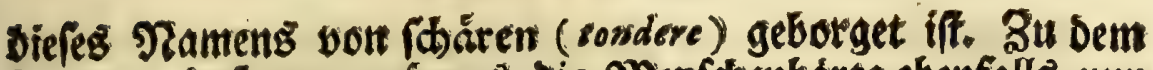
fommet, Daf man anfangỏ Die Menfchenbárte ebenfalls nue mit Der Gd)are abgef(hnitten, wie in einer Gef(d)ichte von

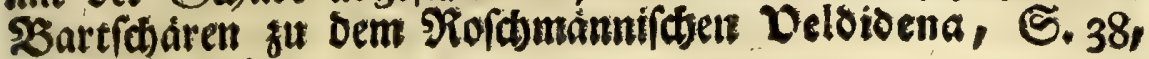
erimert roorden.

Diefe Sdreibart will id fernet beffräftigen, Durch eine Bernichtung DeE Jaautgrundes, Darauf diejenigen fich begies ben, welche Die isterwebnten 2 siorter auf eine Dreyfache ât

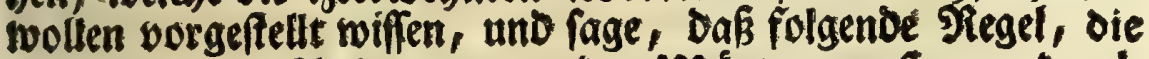

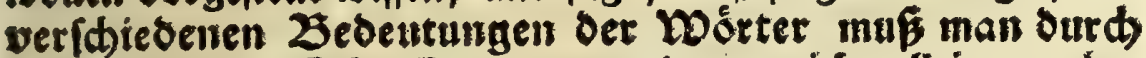
unterfbiedene Sdareibarten anseigen, nidbt allein unntize, Condern unvernưnftig, uno Der ₹eutichen Eprad)e bóchits

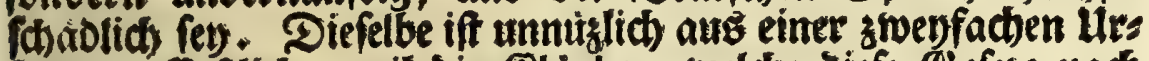
fache. Erftlids, weil bie Slutgler, weld)e Diefe ESefeze nach

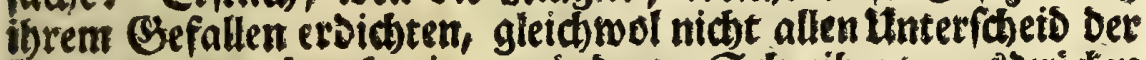
Bebeutungen burch eine geánderte Sdireibart auborticten fönen. Denn wie wollen fie * E. Den Sart eines Menf(t)en,

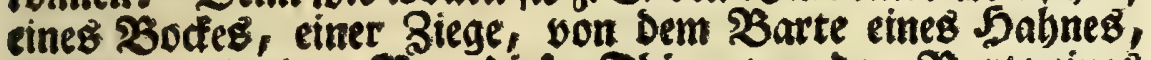
Sirches, uno einen $\mathfrak{S a r t}$ Diefer Ibiere yon Dem $\mathfrak{3 a r t e}$ eines

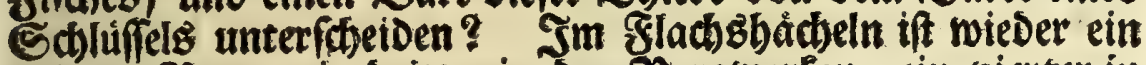
anderes Sart, ein Dritter in Den SBergwerten, ein vierter in

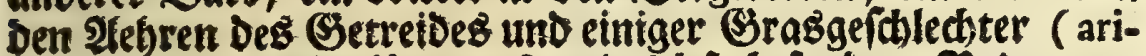

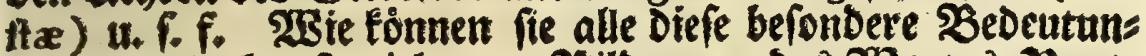

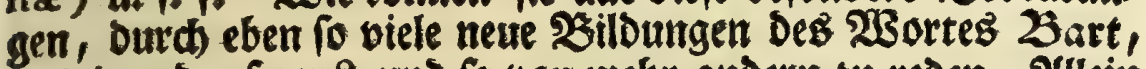
anseinander fesen? und fo von mebr andern fu reden. Allein es iff einesttbeils noch gut, Das Diefe Serren vielleicht von Eeinen anberm 3 árten Sundictaft baben, alg von Denen, Die fie bei Den Menfaten, Söcfen uno Biegen feben. Denn wás

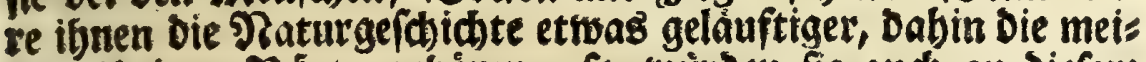
fen ubrigen 2 árte geboren, fo muirben fie auch an Diefem 2 Earte ibre Episfinoigfeit geubet, uno Demfelben obne Sweis fel mandierlen Eeeftalten angefunftelt haben. Sie hätten die Barte fison längft in Slaffen eingetheilet, uno eine Derfitben mit $\mathbf{2}$ art, elne andere mit $\mathbf{S a r t b}$, eine britte mit $\mathbf{S a a r t}$ ans gedeutet, Darnad wären nod bie 2 Berwandelungen Des 23 
in $D$, und Des $t$ in $b$, als fernere bequeme Mittel neuer Bet: Eappungen, librig gewefen, woourch fie Das 'TSort 2 art

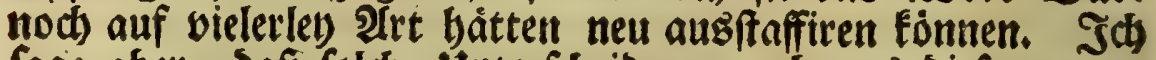
fage aber, Daş folche unterficheidung audi aus Diefer swet)= ten Urfacbe zu nichts diene, weil in bundert 2 seifpielen, wo Diefe Elugbenfenden Spradifinfter eine arwendeutigfeit fus chen uno vermeiben wollen, feine su beforgen if. W3es gen eines Salles oder stwener, Die man erfinmen Eónnte, mils fen uidht நauptregeln umgeftoffen, Die Sprachen verworren uno berfchlimmert werben. Zubem ift bie Teutiche gefdicft,

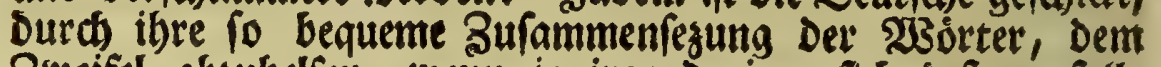
Sweifel abzubelfen, wenn ia irgend einer fich ausern foll.

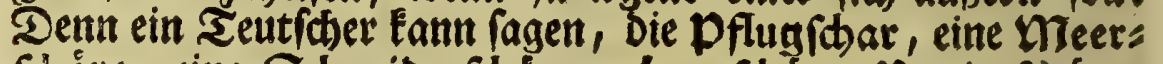

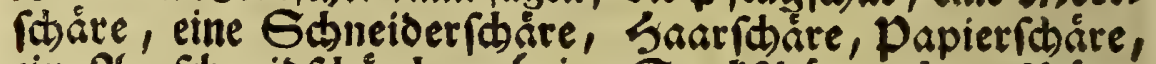

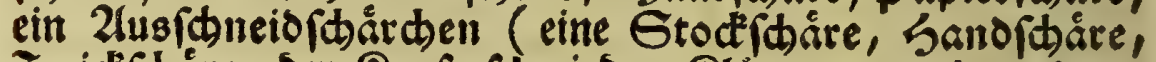
Jwoideftáre, Der Supferfomiede, Slämperer und anderes

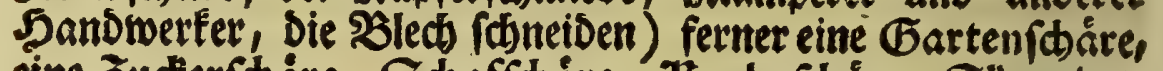
eine Judterfháre, Gdafidáre, Krebsfháre, Glorpion: fd) áre u.f.f. EB ift aber auch Diefes nicht allemal vonnotbent. Die 4 mftånde ber $\Re$ Rede felbff heben gemeiniglich Die Sweys: Deutigfeit auf. Denn wenn ich fage, Daß̧ ein Sabrseug bei einer Suáre vor Gtodtholm Ģ̉iffbruch gelitten bat, wer wird wol biedurd auf eine swerbeutige श्aslegung vers leitet (werben, und fid) ettoa vorbilben, Das Schif mutfe an ciner Arebs: ober Sonneiberfhåre geftranbet ober gefdheitert

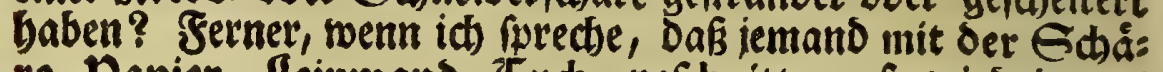
re, Papier, Deinwant, Cub, geftuitten, fo wird ia wol

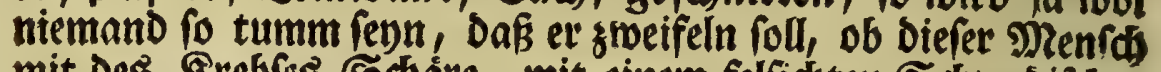

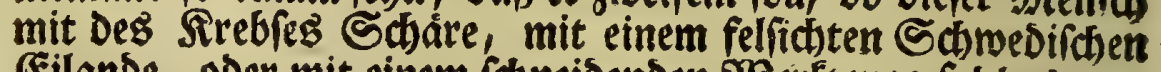

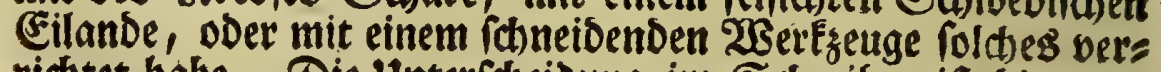
rid)tet babe. Die Unteridheidung im Sarreiben if hier uns nize. ABenn Demnađ Die Seutithen Eprachlebrer fich lieber befummern wollten, Die eigentlicben 2 bleitungen Der $\mathfrak{B}$ Borter ausjuforfichen, und die Edreibart nach Diefer Pidctichnur bes

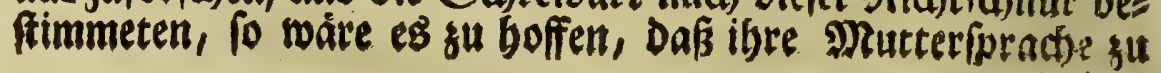


einer bleibenden (Sleidjförmigfeit Konnte gebractit merden; und Das ware eine red)te Befferung fu nennen. Denn an fols

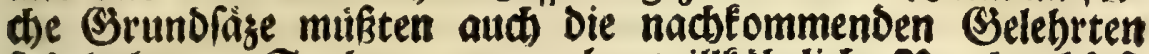
fich balten. So lange man aber willfibrliche piegeln abfaf́ ren wiro, wie ez bisher geftheben, und wie ez Der Sr. (Sottíthed nod) macht, Der S. 106 feiner Grumolegung vow fabeibet: Gdbeere, forceps; die Gdáren vor Gtodtholm, gewviffe Llippen in oer Gee; fheren, tondere, fo wirb ein anderer fommen, und fagen: Id) babe fo gut Das Recht, mei= ne (Srillen zu Marfte zu bringen, als Du; it) will Gdeers meffer und Shneideridere fhreiben; ein Dritter wirb Diefes mieder berfebren, DDer ez noch anders machen; allein auf fold)e 2Art mird Des 2Tenderns und Des bermeinten Befferns fein Ende feyn, fo lange Die ₹entichen ₹eutíh reden werden. Stiemit babe iđ meines Eractens Dargetban, Daß bie vor: gemeldete Bemuibung, Die veríchiebenen Bebeutungen Der

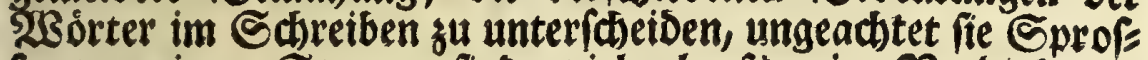
fen von einem Stamme find, vielmebr für eine $\mathfrak{B}$ erberbung,

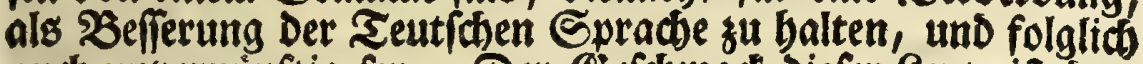
auch unverninftig fey. Der Sefhmad Diefer Leute if Dem Meinigen fhnur/fracks entgegen gefest. Sie Denfen nach,

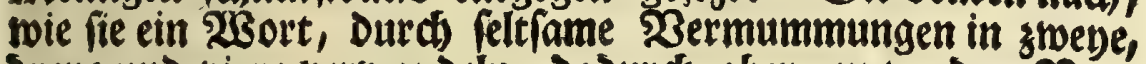
Dreve und viere vertwandeln, Daburch aber, unter Dem $\mathfrak{B}$ ors mande, Die Deutlichteit ơ befốrDern, Die Errlernung und rchriftliche 2abfafiung Der Spracthen, mógen recht mitbram uno bef(d)werlich machen. Idh Dagegen beftrebe mich Diefes alles zu erleidtern, und die Spraden, nach meiner wenigen (Einfid)t, zu ibrer erften (Einigkeit binanzurtiden. Jd erinnere

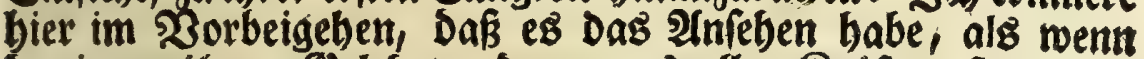
Der istgeribmte Selebrte, Da er aus allen Rráften fich bears

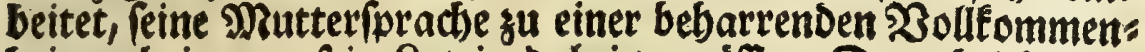
heit zu bringen, fein \&atein Dabei vergáffe. Denn bei folchen Erflârungen, wie biejenige ift, Die ich suvor aus feiner (Grunt:

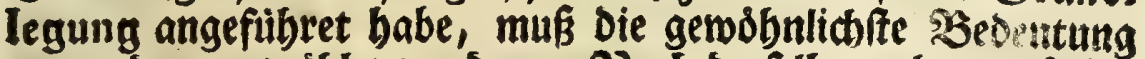
bor anbern gewáblet werben. Tlach Derfelben abe: verftefet man Durw forceps eine Gdmiedezange; .. verfanigue temaci, 
maci forcipe ferrum Virg Die Wortforfatung Iefret, off Dies fes die erite und eigentliche 2Ablegung von torceps fey, Denu Der Rame fommet won ferrum und capio, wie auceps, ein

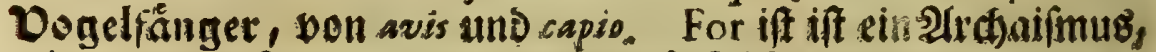
wie vertic anftat vertit, wovon biefe -2Abftammungen, vorsex, divortium, nod) librig fino; wie fort anftatt fer, wowon for: suna. Fine Sdeere (i由) bilbe mir ein, $5 \mathrm{r}$. Srottid)e wirb eine Gdneiorribeere, ober Dergleidjen Schneidezeng, meis nen) beift nad Dem üblid)fen (5ebraud forfex.

Bum Beftallufe Diefer Interfuchung muß id nod) meldent

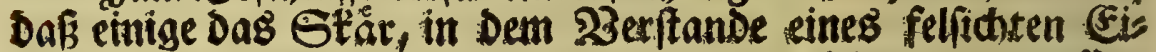
landes, bom abtremien, abreifjen, wollen fo genannt wiffens weil biefe Silippen eritich oon Dem feften Ranoe, uno foDan felbit von einander, waren abgefondent toorden. Das if ein gemeiner urfprung vieler Jnfeln, id geftebe ez. Diefe $216=$

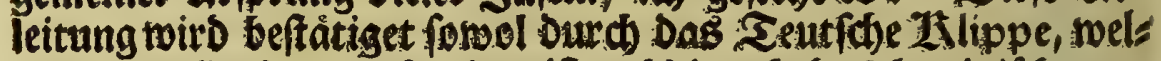

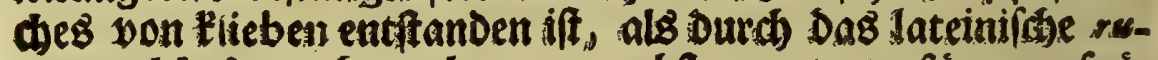
pes, weldhes son Dem alten rapo abftammet, foofir man fpas ter, mit $\mathfrak{B}$ eibehaltung Des alten prateriti uno fupini, rumpo su forechen angefangen. Ifllein Diefe BSortforftiung entfers net fid) von Dex Meinigen nidit; fa eine fernere Setrad)tung Derfelben, mus einem jeten Den offenbaren Zufamment)ang Det

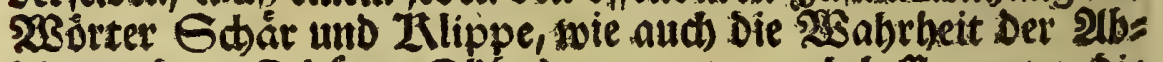

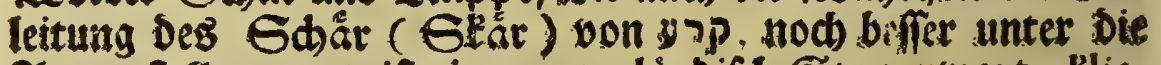
2ugen ftetien. $->p$ if ein morgenlåndif( Stammwort, Plie: ben ein Furopdirabez; beibe baben eine bollfándige Sprachs dhntichfeit mit einander. Denn dere, Das tlieben bat eben Diefe given Sedentungen. Die erfe if in Dberteutf(a)land befannt, Die sweyte toerbe ich aus ber Sdwoobif)en Munbart erweifen. FSsenn id aber Das Zlieben ein Stammwort nente, fo oreftebe id fein eigentis: d)eE; Denn Daffelbe grundet fid ferner in Dem Seltifden kla

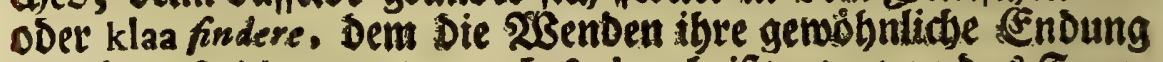
angefest, bei benen klat auch fredere beifi, wooon bas Srans goifiche éclat, ein Span, eclater fpalten, Durd die \$orfes sung 
fung eines e euphonici, gefommen. D $x 8$ x xaw Der Brite d)en ift von ber erifen Sedeutung etrons abgewichen; allein ihr $x \lambda$ a'dos ein 2lit, erhält nod) Den worigen $\mathfrak{B}$ egrif; Denn die 2lefte find 3eripaltene Cheile Der Bäume, wie Die Finge:

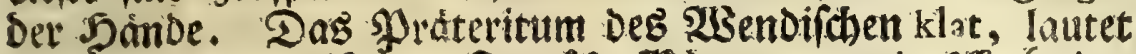
ťlau. Daraus ift Das Seutiche Irlaue, ungula fifsa (oder

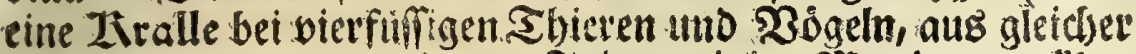
Unfache) ersenget worden. Jindem etnige Mlundarten Plou (wrechen, erfiebt man, twie Das Seutiche Indefinitum getloben, ferner der Lloben, baculus aucupazorius fifus oder bipatens, a.

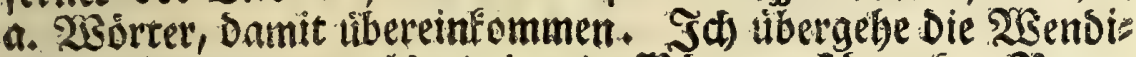
ihen 2 bleitungen, als klada, ein INloz, auf Dem Der $\mathfrak{B a t u e t}$ Die Scheiter fpaltet; kol, ein gefpaltener Jaumpfabl, Dena Die erfte sperion Pras. Indic. oon klat, if kolem. Eine ges

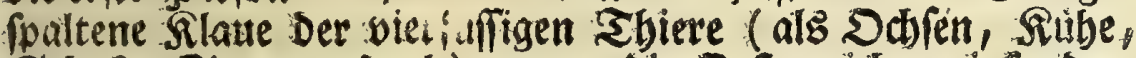
echafe, Biegen u. D. gl. ) nennen die Defterreicher, infonders

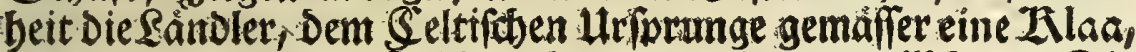
unb in ber mebrern abl and unveräneert die ZNlac. Die

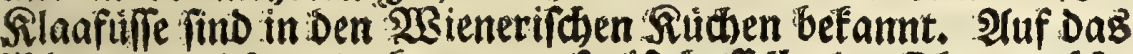
KNlieben mieder zu fonmen, to if Daffelbe in Dberteut/ct) land tiblitier als palten, und in meinen "Sébanten, feiner 2(bfunft naథ, mit Dem Schwedifhen kLIPPA, Diefez aber mit

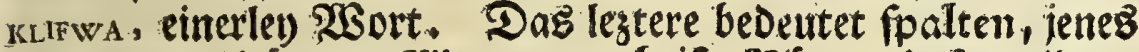

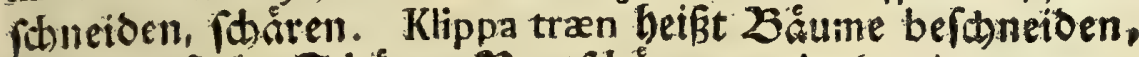
klippare iffein St)irer, Barticharer ; und fropalum nennen

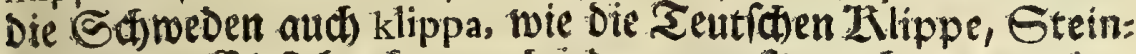
klippe. Es ftehet Demnach federman frey, ob er unter Den 'isortern Gabarten, Lilippen, einen Begrif pon abtrennen, fpalten, ober ben von faneidan, fich vorifellen will; Die Etammmorter bleiben. Die Meinumg Derienigen, weldhe, bie Gdbiren, fcopulos, auf etivas fineibenoes, ausbens

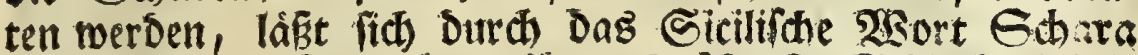
befraftigen. Dem jene tiberaus foharfe Echlactenfeine,

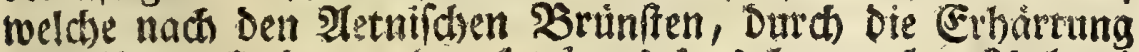

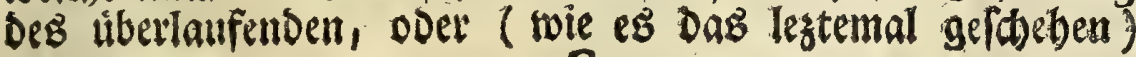
$\mathbf{G}$

uns 
unten ausbrectenden feurigen Fluffes ber gefamolgenen 5ar ze uno Erge, entfieben, werden in Der Sanofpradje Gdas: re genennet, uno wegen Det befondern Edărfe in gans Eicilien zu Múblfteinen gebraudist. Die bisher angeftell

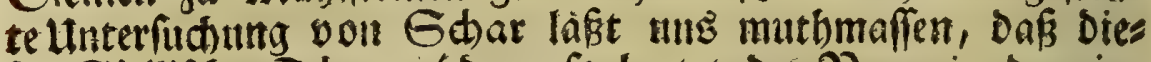

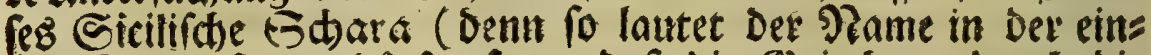
zeln Zabl) fo alt Dörte fenn, Daß Die (Sriechen, Durch Die

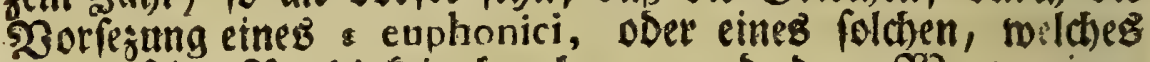
Dem veine Raubtgfeit benehmen, uno bem NBorte einen

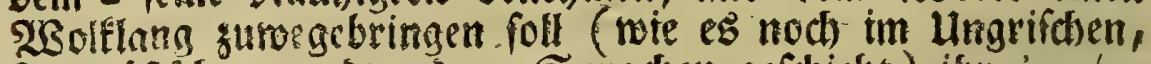

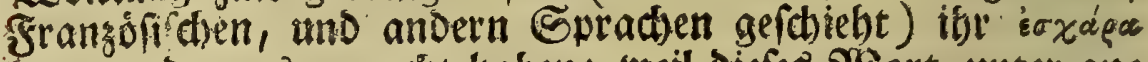
fonnten Daraus gemari)t baben; weil biefes $\mathfrak{A}$ Sort, unter ans Dirn 2 Eedutungen, auth foldyen rauben und foneidenden Aurnumf angeiget. Dafis bie Gdare foneiden, fann ein jes Der fellef erfabren, inelcher von Der Etadt Reapel, um ben Befusiften (Ed)ho gu beobadten, zu biefem 2 serge fid)

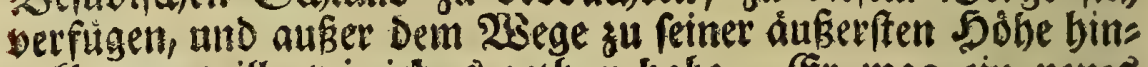
anflettern will, wie iob es getban babe, er mag ein neuez Paar Sdube anbaben, fo notro er Diefelben flein serfónitter zurtictebringen, wemn or aus Unmiffenbeit oder Unachtfamfeit, Biefe Felfen im (Seben ofter mit Den Seiten Des Dberleders bertibret.

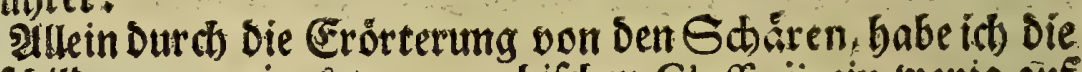
Ibfohiloerun! meines topographifchen Glo far ii ein wenig auff Die Seite gefegt. Joh febre vieder Dabin, und erimnere, Daf biefes einem Qtebhaber Der (Steographie Die Refung Del mands: mal febr frembe flingenden Senennungen Der Derter, unges mein erleict)tern foll, wern er Die Grflárung Des gemeinern, meiftentheils zmenten İbeiles derfelben (wie bei

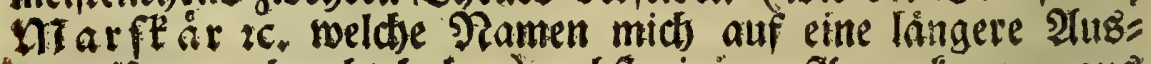
(ch)weifung gebrach baben) mebft einigen Inmerfingen aus

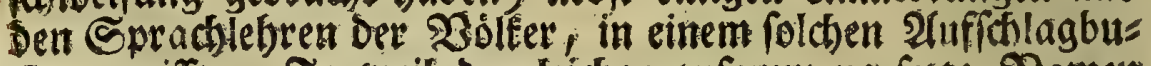
d)e antrifft. Ta weil Dergleichen zafammengefeste Rament Der Derter, die mit Dem einen Theile einander gleidhfeben, auf allen Landfarten, tho in Sändern bon verfdiedenen. Sptadsen, in grofler Menge oorfommen, folglich Der Refer, 


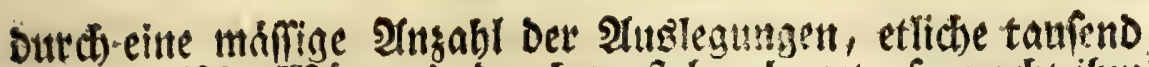
geographifche sasorter Dadurd verfteben lernet, fo madt ihm

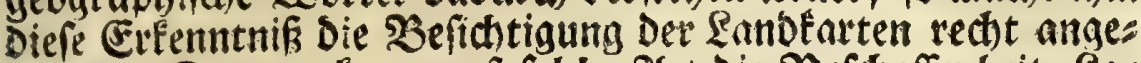
stebm. Denn er Eann auf foldie ant Die Befdaffenthest, $\mathfrak{E a}=$ ge, Den urforung, oder andere Umftánbe vieler Derter, als

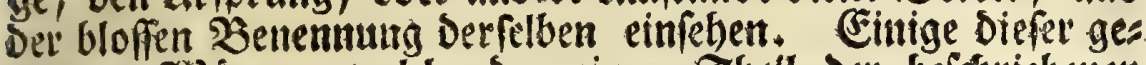

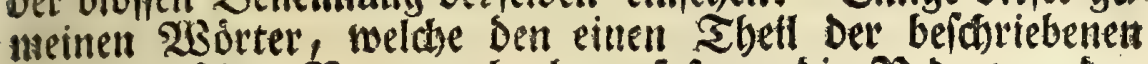
geograpbifchen samen abgeben, foferne bie Rede yon ben

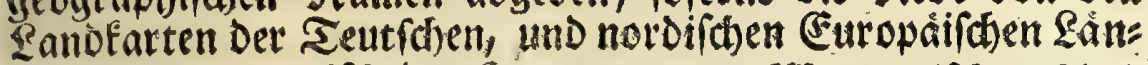
Der iff, werden. Meilte Serrell in Dem 23 adterifthen Gloffario Germanico, uns in Frifchens Seutichem 2 soorterbuche, crlfiutert finden, fir Die tibrigen aber fidh aus andern Sprachs butche"n behelfen miffen. 3. E. in Den शamen Der Sd) wedi= fd)en Eanbearten feben auf eben Die Ârt, wie ez Die $\mathfrak{B}$ eifpies

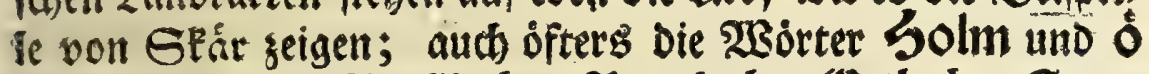
bintenan; wie in Sorkbolm, Bornbolm, 坚tholm, Gaag: bolm, Etodrbolm, und vielen andern. Nur su und nád) unm Stodholm gibt $e z$ ichon viele Solmen, als Riodares bolmell, Ritterinfel; Gkeppsbolmen, eine Edbiffinfel. Man furicht f́céppsholmen, mit einem f́barfen e, wie bie Iern berger an Der Ens Das Gd)eff, navis, vorbringen. Ferner

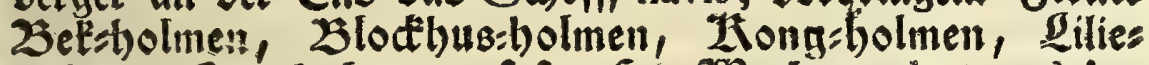

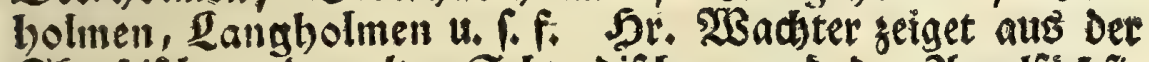

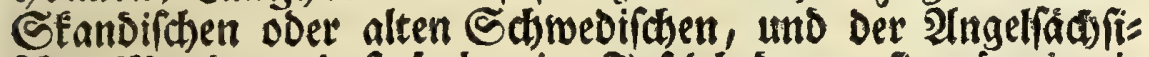
fiten Mundart, Dafi bolm eine Infel bedeute, fie moge in ei= nem Sluffe, in einem See, oder im Mreere liegen. Der erfte Theil nut Der aus Solm gufummengefesten Ranten weifet Den Unterfacid. 3. E. Sangbolmen bedeutet eine lange Infel, wodurd) auf ithe (3)eftalt, Die fie wirflid) bat, gegielet wird. Gtodtholm (Die Sauptftadt in Echweden) beist vielleidst po wegen Der $\mathfrak{P}$ fáble, Darauf Die im $2 B$ affer treberdoen Bebáube fiiti gegrindet worben, wie sit $\mathfrak{B e n e b i g . ~ M a n ~ t r i g t ~ f i c h ~}$ swar aud) mit einer andern Namensleitung won einem Sto: dfe, welcher mit Selde angefiullt getwefen, Die aber etwas po: belbaft lautet. 
Die Tament weld)e in o ausigeben, find auf betr Sdjwes: Dirchen Landearten febrzablecid), wie Gando, Kindo, Gom:

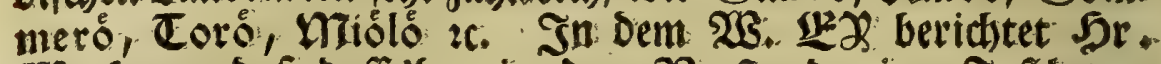
X3achter, Dafs Daffelbe, in Dem Berftande einer Infel, von Den Eatweden und Dånen ós volgebracht werde. Illein Dr. Wachter, Der fo vortrefflichen Whilologifden Borwath, bei Der Plusarbeitung feines: Glnffarii qu Dienfte gehabt, folls te auch Den Unterfiche zmifiten Solm und so angemert bos ben, um ung zu vetfichern, of ez sutreffe, Dẩ Solm eine Heine Infel (en liten: Werterb fo 1738 zu Storth. in Dctavgroffe berausgegeben worden, und in ber bfter: alloort geducten Janua linguarum, vorgegeben wiro.

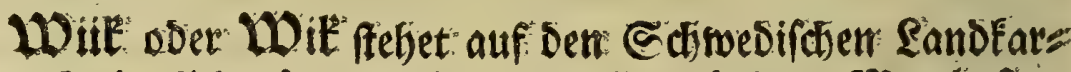
tent audi) fiemlid) oft, und bedeutet einem fleinen MReerbufen, oDer Die Srimmung, Die ein See ein Flufi, ins Eand macht;

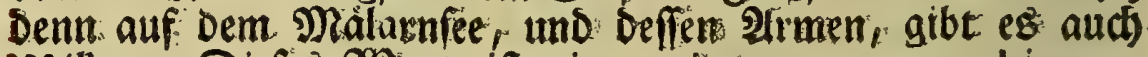

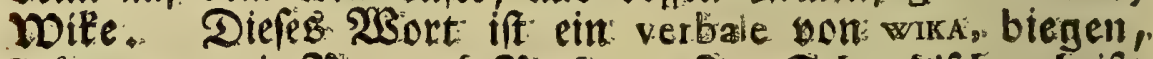

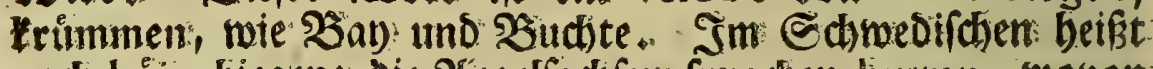

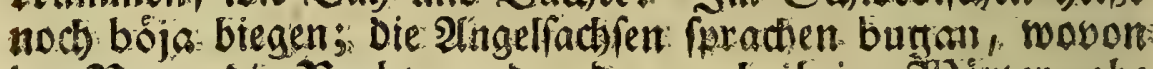

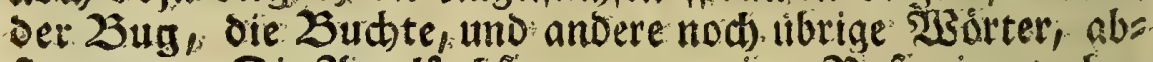

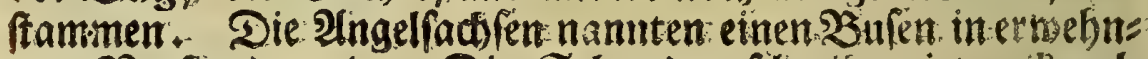

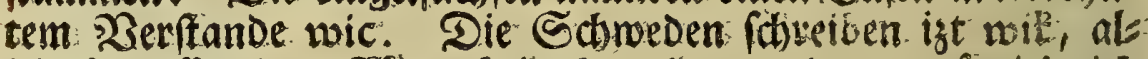

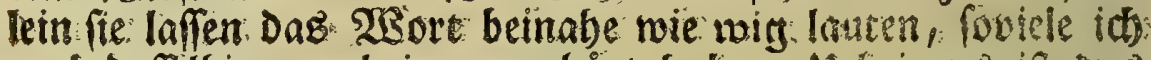
noch Daffelbige vorbringen gehort babe. Llorigens if Das.

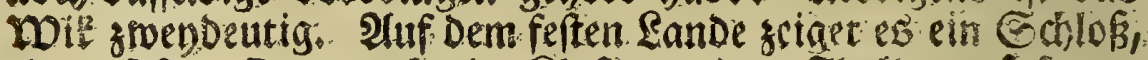

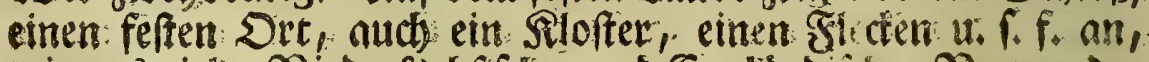

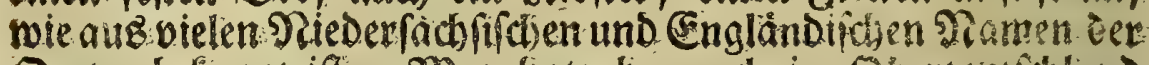

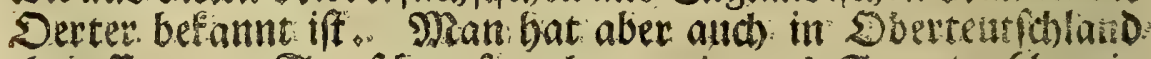

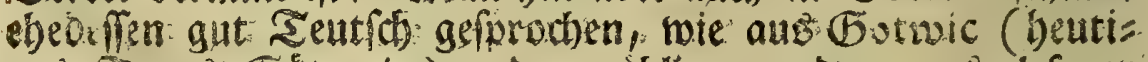

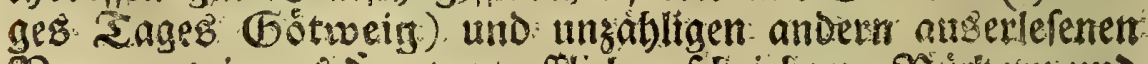

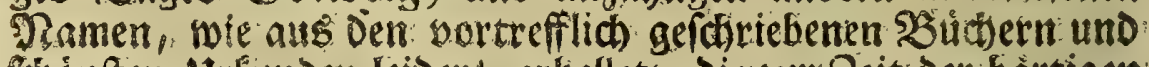

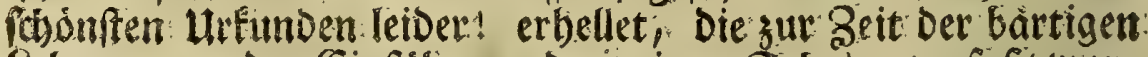

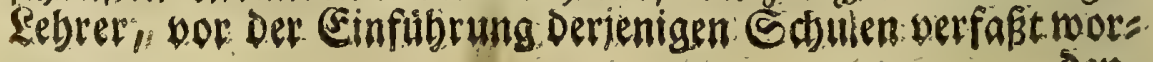


Den, Deren 2 Ggott Der berDammte Serkfomannus, uno Die

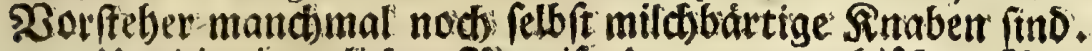

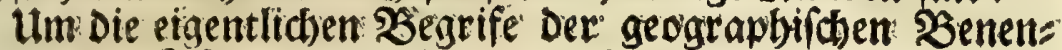
nungen Den Sefern beizubringen, und bie rect)te 2lusfpracthe Derfelbert zut Iebren, werben Meine Serten aud sumsilen

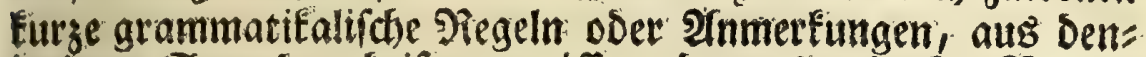
jerigen (Spracten beifesen milfer, Daraus gebachte Namen

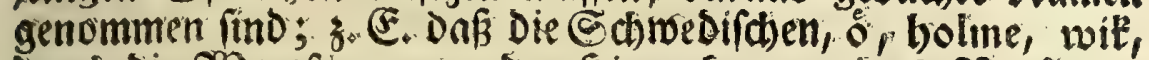

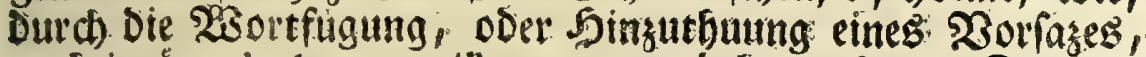
auch in on, bolmen, witen, verwandelt werden. Denn es

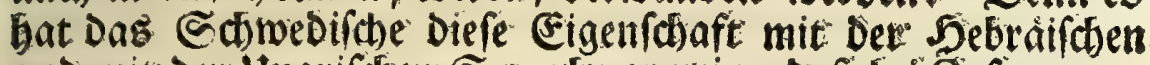

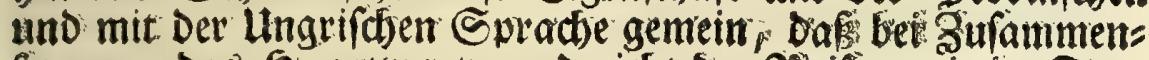
fezungen Das Sauptwort, und nicht Der Seifar, noie im Sew

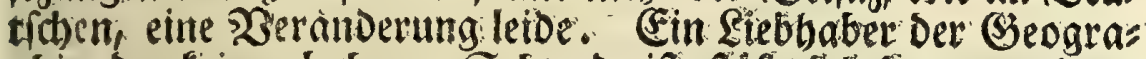
whie, Der fein gebohrner Schwede iff, ftoffief fich fertrer an bem,

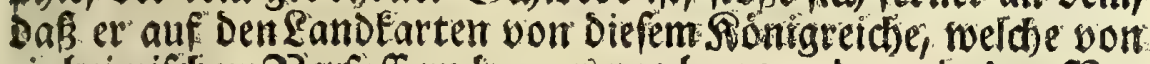

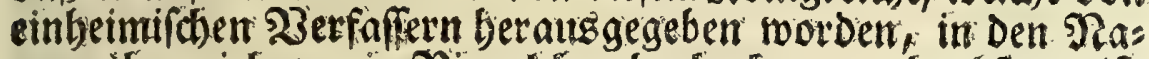

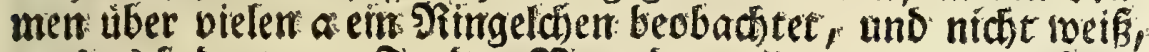

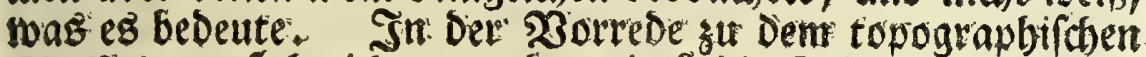
Gloffario muß berichtet nerben, Dak Die Escjweden, wie Die Inngern, zweverley a baben; Denin bie Pfusfipracte Des Dritten

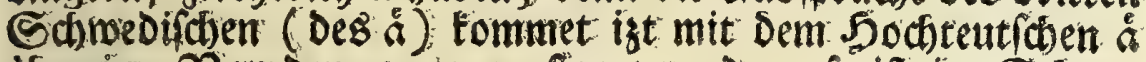

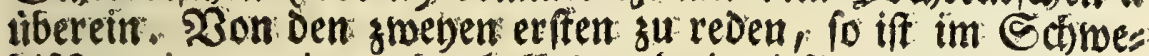
Difhen ein gemeines oder belfes, und ein tieflautendes a, wels c)es leztere Dem o fich nábert, und zwar noch mebr, als Das. gemeine bunffe a Der Baatern, und Defferterdter. Diefes a nun bezeichnen Die Echimeden mit einem Piingeldben, oder las

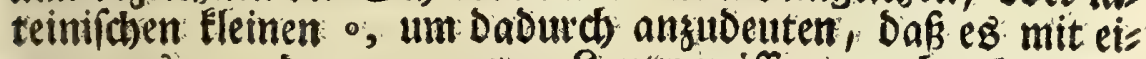
nem aus a und o gemengten $\mathfrak{E a u t e}$ múfe vorgebracht toers

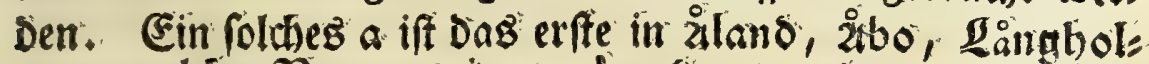

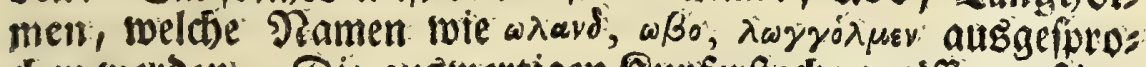
chen werden. Die auswertigen Iupferfted)er muffen auf Den

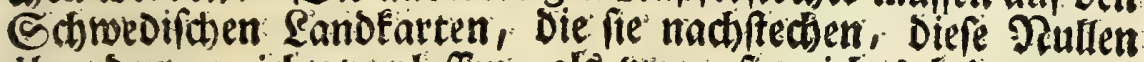
tiber ben a nicht weglaffen, als wenn fie nidt ts bebeuteten.

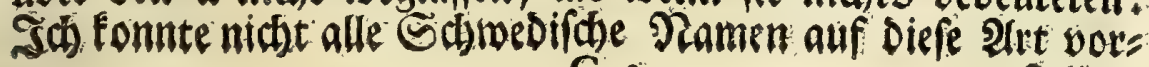
G 3

fiellen, 
ftellen, weil bie Seutfitsen Drutferenen feine fo gegoffenen: has ben. Sei einigen ift nux su einem Mufter ein - angeftuntelt worden. Die ungern, in Derer Gpradse diefes a fich ebenfalls b.findet, baben die Schreibart verfebret. Sie bemerken ibe belles a mit einem ritarfen Prcente. Jhe tieflautendes, und mit Dem o verwanotes a, ift Dagienige, fo in ibren Sdrifs ten ohne Merf́tgeidien ftebet. Dergleidien Erinnerungen mur: fen, zur Erráuterung Der geographifchen Namen, aus allen antern Eprachen, wo gleide '3 meifel entiteben moditen, ges bolet, und in Dem Borberichte zu Dem topograpbificen Glof. fario, ober zu Dem oben entworfenen geographifhen Damens. bucke, vorgetragen werden.

2uf Den Sopograpbien von Edyeden, oder auf foldhen RanbEarten, Die fleinere Strecfen weitläuftig vorftellen, Ders gleiden die by brographif(je und zugleid) doorograpbifiche vom Málarnee ift, werben tiberaus viele Godn, $\mathbf{2} y$, Corp, mit einem andern vorgefesten $\mathfrak{B}_{\text {B }}$ orte, angetroffen. Dab Sod)n fprechen bie Edweden fokn aus, uno fdreiben

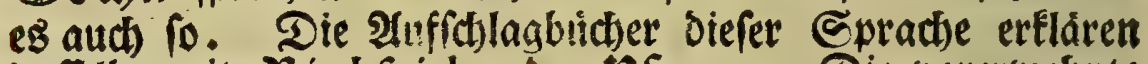
Daffelbe mit Rirchipicl, stne Pfarre. Die vorerwebnte Schmedifde JANVA LINGVARVM Comenii bat Gochn parecia. Verelii index: Gokn, diffrictus Ecclefarficus, parochia.

By beifst ist ein Slecten. Dergleichen Namen find,

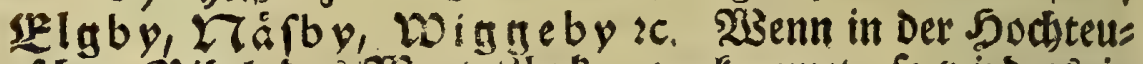
tichen $\mathfrak{B}$ ibel Das 23 ort Sleden vorfommet, fo wirb $\mathrm{eB}$ in Der Edwebifden gemeiglid mit by überiezt. Sbedeffen wat Die 2 edeutung Diefes Celtifhen Tamens von grofferm 1 m: fange; Denn 3 erelius gibt Das by mit predium, pagus, civicas.

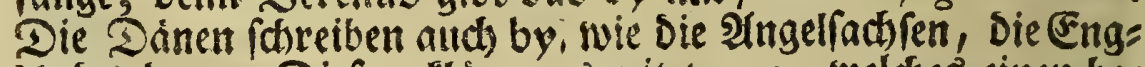
lánber bye. Diefe erflâren es mit town, welches einen bes wohnten Dit uiberhaupt bedeutet. In Den sufammengefesten Pamen fdreiben fie aud nur by, nis 2 arnby, Mtellenby, Goutberby แ. f. . 


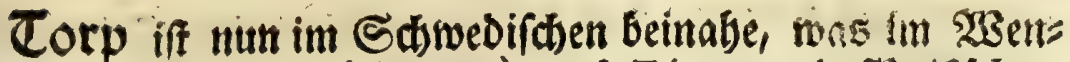

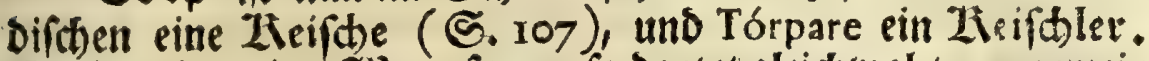
Etehet ein ander asort forne, to Deutet gleichiwol torp gemeis niglic) eimen Drt vou inebr Sצobnungen an, Dabei alth manct)mal eine Rirche fich befindet. 2Allein $25 y$ ift allezeit grófer. DaE Jorp Diefer leztern (Erflärung näbert fith) melor Dem Begrife vom Seutiden Dorf, und Der alten Edwedi= fiten $\mathfrak{B}$ ebeutung von $\mathbb{C}$ borp, wriches $\mathfrak{B}$ erelius nid)t nur mit predium, fondern aud mit caftellum und pagus thberfeget. EES geben auch viele Engländifche Namen Der Derter in thorp aus, wie Seltborp, Meneythorp, Denstborp, Miltborp.

Zlóping wirb mit Dem $\mathfrak{3 o r f a z e}$ eines andern 230 ottes, infonderbeit in Demienigen Stuiffe Der Schmedirchen Eandét: te, weldse Den Strich won $23 e$ figotbland um Die Seen $2 B e n=$ ner uno 2 setter voritellet, ofters angetroffen. Derter ebedeffen Jandelsyläze, oder nur Marftflecten, was

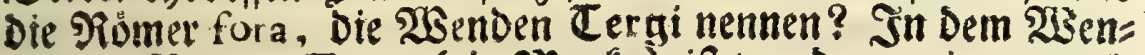
Difcten Ramen Terg, (ein Marfet) if vor Dem r ein w, wel= des alle Eelbftlauter vertritt. Die SDolen und andere Sla: ben baben ein s Davor, Die Sabtweden ein o, Denn Torg

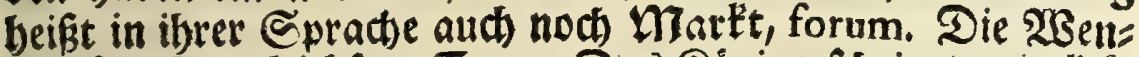
Den prectien gleidffam $\mathrm{Crg}$. Das Roping fobeinet von tió: $\mathfrak{p a}$, emere, berzufommen, Deffen alte Edreibart kopa iff, wie auz Dem Solländirchen Foopen abzufehen. Die 23 enden fureden kupi cr Erouft, kup ber Zlouf. Soldhe Edhedifde Ramen find: Rort'sping, welcher lautet, wie forum feptentrionale; Goocrt'sping, forum auftrale; $\mathbb{K}^{2} \mathfrak{H}^{2}$ ping, Lins

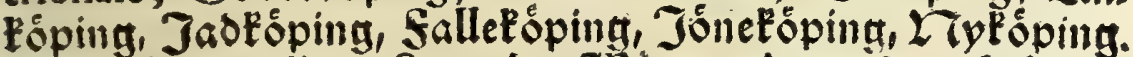

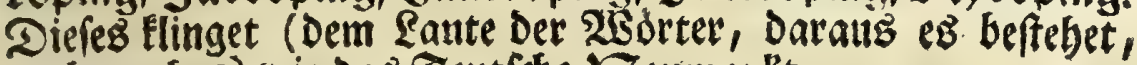
nactsugeben) wie Das Teutiche Reumartt.

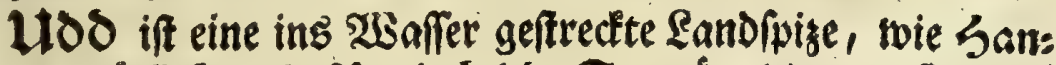

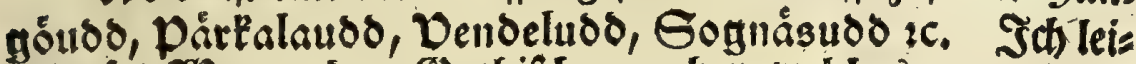

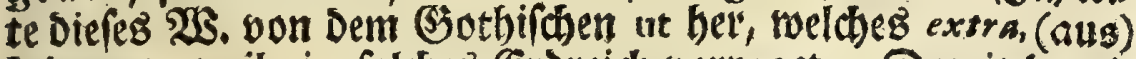
bedeutet, weil cin foldes Erdreid wotraget, Damit bateis 


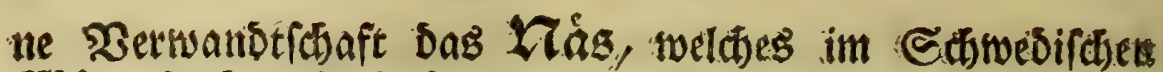

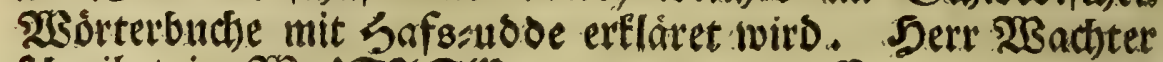

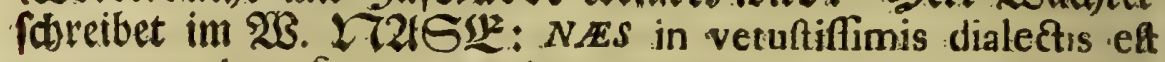
promontorium feu peninfula, fimilitudine a nafo manifefto defumpta. Nieine Sertent mollen von gelebrten Sdywe Den, oder Der Geegegenden erfabrnen Mámnern, fich Den Ins

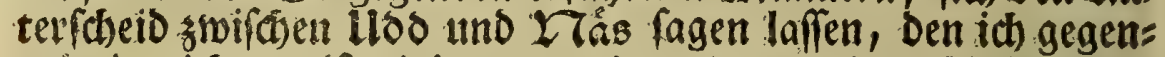
wartig nicht weif, indem es miv an Den nothwendigften $23 t=$ doen gebricht, Die zu folden Unterfuthungen geboren. Die

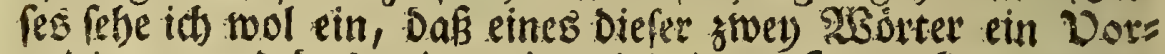
tsebirge, und Dab andere eine nieorigere Dandede, was Die Srangofen nach Den Lateinern ane langue de terre nennen, be:

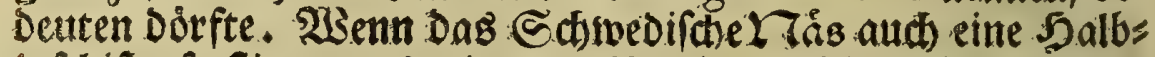
infel if, fo ftimmet es mit vños tiberein, welches nicht allema

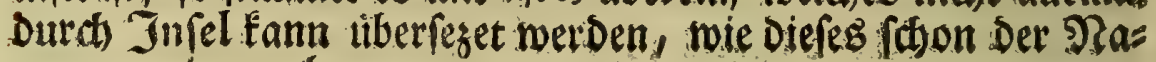

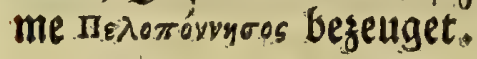

Die Ewrodirchen Eunó find Meerengen, als ma: lefund, Zlalefund, Rano fund, und siele andere. Verel. in indice: Sund, fretum. 51 . 2Suffon bătte alfo (Hin. Nat. L. 400, uno anderwerts) befer gefdrieben dans le Sund, als dars le détroit du sund, Denn Diefes lautet: in ber Hieerenge

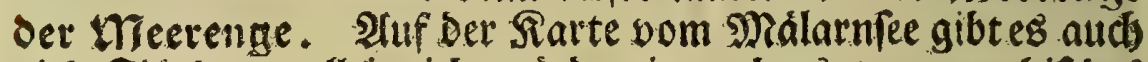
wiele Fiåroen; allein id mit:be ein rechtes topographifches oder geographiftes (sloffarim, anfatt eines Mhufters, an Sag bringen, wenn tió bei Den Randéarten aller $\mathfrak{B}$ olfer mich folange aufbalten roolte, als bei ber Echmedifonen. Das herbe Indenten Der Beit, in weldier Die 2 orfalsren metner Sandegleute, Der Defferteichifhen 2 Binden, eines ist-(Durd)

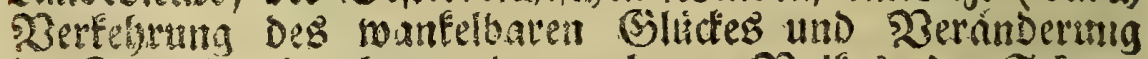

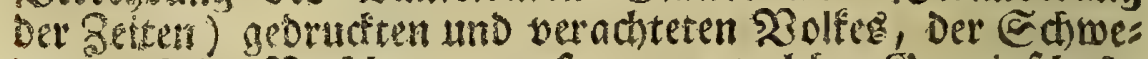
Den macherge Dradbarn gewefen, won weldier Semeinidhaft,

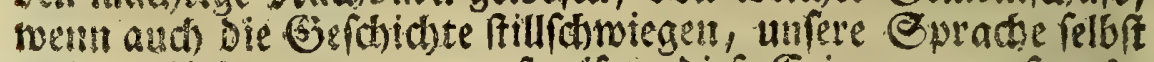
mebrete 1leberzeugungen aufwetfet, diefe Erinmerung, forethe

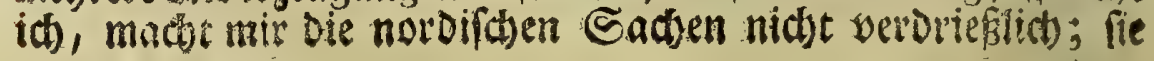




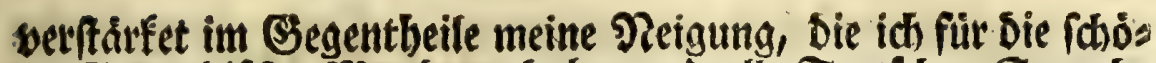
ne Schnediche Dumbart babe, und alle Seutichen Spract): fenter baben follten. DaDurd ift meinte Erflarung einiger Daraus gebolter Namen, foferne fie in Das topographíctse (Sloffarium geboren, etwas weitláuftiger geworben. Die Schwedifben (selebrten wollen gegenwartiges geringe ftud, sum ?uzen Der Şeographie, beffern und vermebren. Ja) babe Daffelbe obne vieles Rachfinnen fo niedergefchrieben.

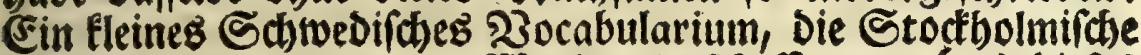

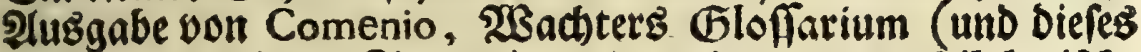
micht auf meinem Bimmer), war meine gange pbilologiface

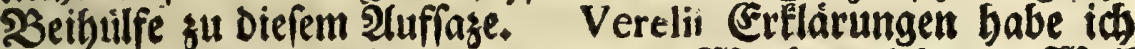

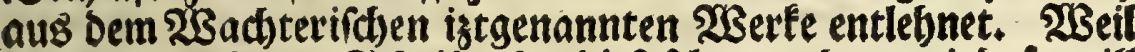
nun gegentwartige Schrift obnebies fajon zu lang wirb, fo wilf ich in (Eile nur noch etliche Der fo bef(h)affenen fremben ?amen erlautern, uno fooann aud oon Den Seutiकen einen fursen Birfuch beirticten.

Mar3a ober Mrarja ift ein शrabifh פSort, und bebelt tet einen Eeebafen. श्llein ich babe igt auch folche SButher ni(i) beibanden, Daraus id nur foviel anzeigen fonnte, was

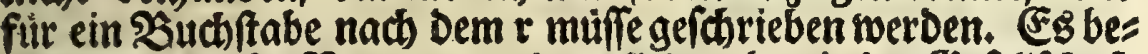
findet fich Diefer Rame entweder allein, obef in Der (Sefellifhaft

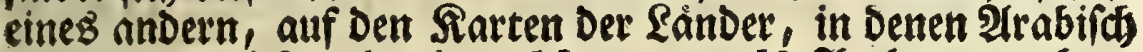
gefurodien wirb, ober in welchen bormals Traber gewohnet baben. Pach Sicilien baben ez Die Saracenten gebracht. Aluf Der Infel Malta, allwo Das 2rabifwe noch igt die Sand: pradie ift, boret man diefen Pamen offers. So beifterfts lich Der Sauptport, Der auf Der mittágigen Seite Der Saupts faot liegt. Diefe nennet man Daletta; nid)t Btalta, wie in Dem Zeitungs = Lexico (im 2(uffalage MTalta), nebft vies len anbern Unridtigfeiten, gelebret wirb. Im Den nordichen Fus Der felfichten Sobbe, welche Die isige Sauptfabt eins nimmt, Erimmet fid ein anderer 2 rrm Des Meeres ins Land binein, in tweld)em eine Jnfel liegt, Darauf Der Sirosmeifter

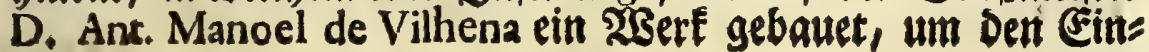


LVIII ....

lauf feindlicher Schiffe zu verbindern. Diefer fleine Bufen

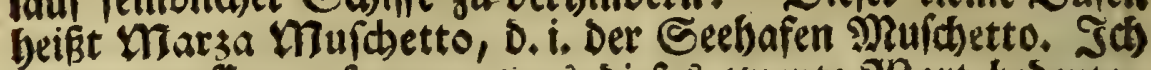
babe vergefien zu fragen, was Diefes zmente 23ort bedeute.

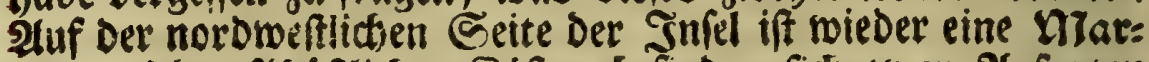

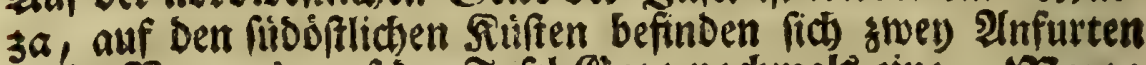

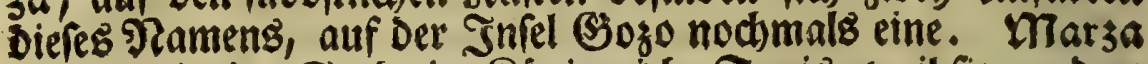
heift aud) eine StaDt im Rónigreiche Suniz, tweil fie an Dem Drte gebautet ift, wo Der Seebafen yon Rartbago war. In Sicilien nennet man fo eine ist verlaffene Sdhifflande, melẩe am mittágigen Strande Der J゙nfel gelegen iff, uns unter Der Botmáfigheit Des Finften von Epaccaforno ftebet, Deren Esegeno, wie mebr andere biefes fidblichen Striches, mit eis nem niebern, faum elleniangen Palmengefthlectite (Chamarepes Plin. XIII, 4, Hard. 9) ganz sidtete bemadfen ift, aus defo Pen $\mathfrak{B l a d t t e r n ~ m a n ~ a n ~ e r w e h n t e n ~ D r t e n ~ n i c h t ~ n u r ~ B e f e m e n ~}$ bindet, rondern noch, wie eg Sylinius berictetet, Siórbe und Seile flio'st, weldese id bei Diejer Marza juerft gefében babe. MTarfala ift Der Saracentrate Name Dez alten Nilybáum in Sicilien, und bedeutet einen 5afen Gottes. So nannten Die \$arbarn Diefen Drt, um feines vortrefflichen Seehafens willem, Deffen Eingang aber von $\mathfrak{M}$. Marl V, Durch Serfens fung groffer Duaderfeine, weldse man bei hellem 2 saffer fiebt, verleget worden. Dabur(h) ift Diefe Stadt in groffen $\mathfrak{B}$ erfall geratben, und tróftet fich nur nodi mit Dem bergebli: wen Sprudse, Der zugleid ibre (Eiferfuct)t uber Das 2ufneb: men Der benachbarten Stadt Irapani zu erfennen gibt:

Se Marfala aveffe un porto,

Trapani farebbe un orto,

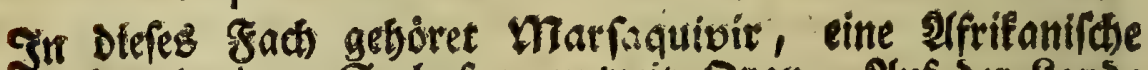
Etabt mit einem Eeehafen, unmeit Dran. 2(uf Der Land:

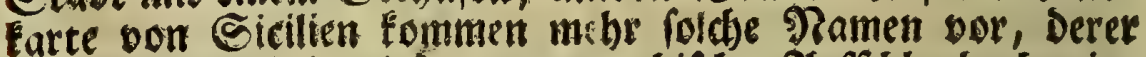

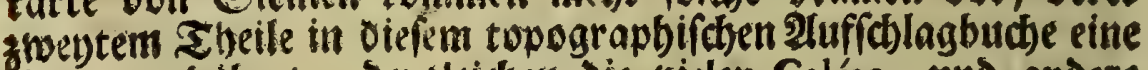
Stelle gebubret, Dergleichen die vielen Caláte, und andere find.

FYRTH 
FYRTH (weld)es 230 orteg 2 (usfpract)e fo wenig, als bas

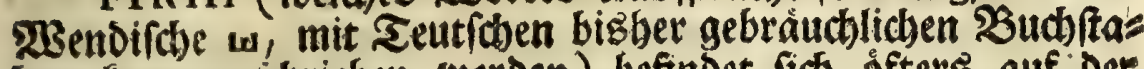
ben Eaun geichrieben werben) befindet fich offters auf Der Shottlandifden Rarte, und bedeutet einen 2tustritt beg

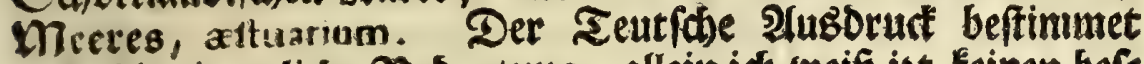

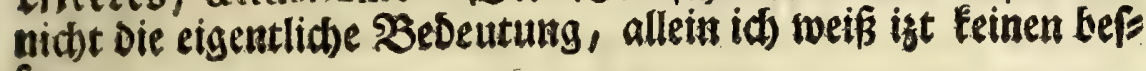
Pern.

HEAD, weldies auf eben biefer Sandtarte aud mebts malen vorfonmet, if bingegen eine tiefer ins Meer geftrectite Ecte doer Evize Des feften Eandeg, und rollten eigentlich nue bie wabren 30 orgebirge to beisen, wie ith in Dem am Ende beigefügten Edtreiben (Signot. a 4 ) angemertt babe.

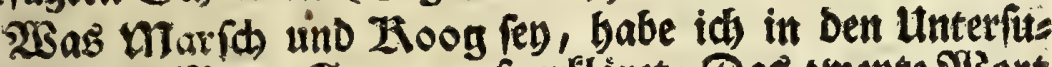
d)ungen vom Neere E. 105 u. f. enfläret. Das zweyte W3ort fitehet in tiberaus bielen marichländif́chen zufammengefesten Diamen am Ende, als in Grafentoog, 2u guftentoog, Fried= ríbstoog, Eroothufentoog, Srejentoog, gundertoog,

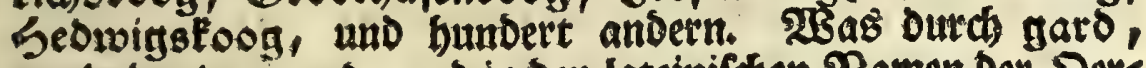
grab, bras, gorod, und in Den lateimiften Namen Der Ders

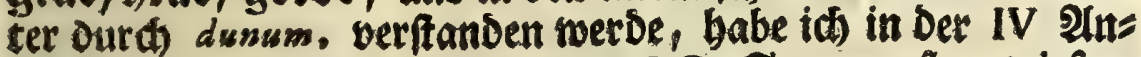
merf. zu Der Gatrift de COL. HERC. S. 27 u. f. getwiefer.

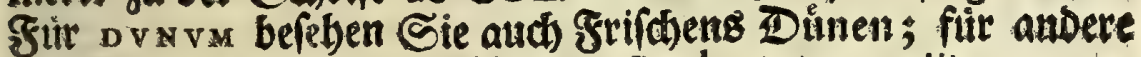
Gallif(be and Brittifche Namen, Boxh, Origg. Gallicas.

Subel bebeutet einen bügel, collem; und twirb unredit 2idtel ober Pidil gefdhrieben (ungeachtet bie Stevermarfer, welche Das ü von Dem i in ber 2lusirede nidt unterídsiden,

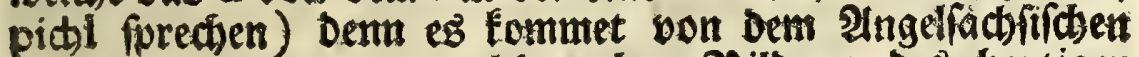
bugan, curvare, von welcher alten $B$ illoung Deß beutigen Beitwortes biegen, Diefe heberrefte, Der 23 ug curvatura,

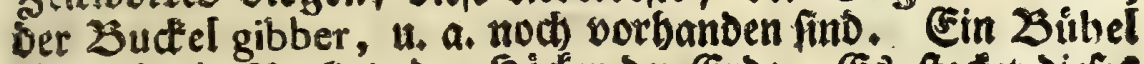

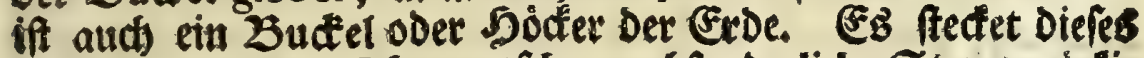
23 intel in vielen Dberteut/chen, abfonderlict) Stevermarftis fchen, Ramen Der Derter, als in Gdónbibel, Lufśbibel, Grinmbúbel, Gteinbúbel tc.

$\mathrm{H}_{2}$ 
ball ift gemeiniglich bie 2 nzeige eines an Dem fogenann ten Drte befindicden Salzbrunmens, oder mebrerer Derfelben; ez ifteine Salzfiederey (ein Salswerf, eine Salzfote) now Da, Doer ebedeffen eine Da getwefen. Ez ftehet aber Der Name bald forne, wie in 5allftatt; bald binten, wie in Reidbentall; ifters befindet fiat) Das Jaall gans allein. Ein Sall ift in bem Defterreidifthen Lande ob der $\mathfrak{E}_{118}$, und bat Den Namen yon einem babei (unten im Ihale) befindlichen Salłbrumnen; ein anders ift in Sirol am Snn, ein Drittes in Edwaben,

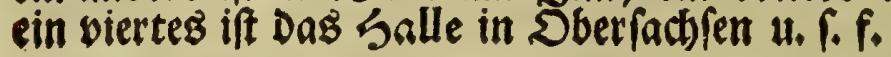

$\mathbf{K}^{\mathbf{E} g}$, egg ober ed bedeutet in Denienigen Namen Des Derter, melche nach Der Eigenf(t)aft Der Teutichen Eprache find erfonten worden, promontorium. Gauret, niured",

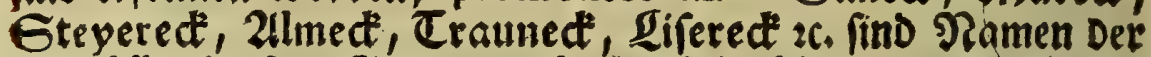
Schloffer in Der Steyermarf, in Dberófterreich, Siärnten, weldhe an Ecten ftehen, Die gegen bie Stluffe, Gan, Mur, Gteyer, 2llm, Eraun, Sifer, berborlaufen.

Rait, Riet, Ried, find Namen, Die ebemals getwif ren Strecten von Bergen, doer auch nur mittelmáffig erbas benen \&ändern, welche fich in Die \&änge binzieben, beigeleget worben. Die lesten zmen 2lusorticfe find vieldeutig, infons Derbeit Das Ries; weil Diefes im Esegentbeile (unter nocb andern Bebeutungen) offters ein niebriges, måfferictteg ober moofictes $\mathfrak{L a n d}_{\text {anzeiget, }}$ Dergleiden Das ulmerried, ift, und

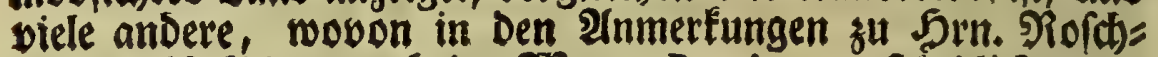
manns Deloiderra, beim $230 r t e$ Raetia, umftinnolicher ge: bandelt mird. Indeffen fónnen Gie Das GLOSSARIYM GERM. im $\mathfrak{X}$. R J I

Reut weldhes man, vielleidt) auš unniffenbeit ber Bes Deutung, manchmal auch reit fohreibet, gibt zu berfteben, Daßs Der Drt an ber Stelle eimes ausgereuteten 23 albes erbauet sorben, Defgleidsen aud Rode. Soldse Ramen find, Kedartoreut, Sriebridareut, Ringeloreut. Die Roben seben 
geben Durch Fhüringen, Seffen, bis ins Lüneburgifhe, uno erbalten Das 2(ndenten Des ausgebauenen ungebeuren S. Sers cuniŕchen 2 SaldeE; Dergleichen, 5ermenrobe, 7 Teffelrode, Walerode, und uberaus viele andere, find.

औTund, múno, múnde, múnden, mono, monde, (Denn fo manigfaltiglich (precten verfatiebene Mundarten) if ein Pame, weldher entweder allein, oder in Der Bufammenfes zung fich) befindet, und foldte Derter anzeiget, Die bei Den Mrundungen Der rinnenden $\mathfrak{1}$ affer angeleget worden, allwo námlid) ein Sluß in einen gróffern Strom, in einen See, oder aus Demfelben gebet; ia auch, wo ein 2̧Saffer unmittelbar in

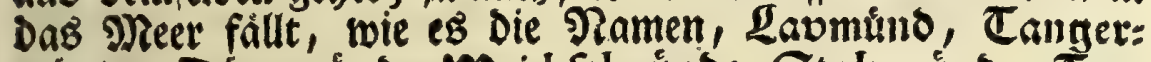

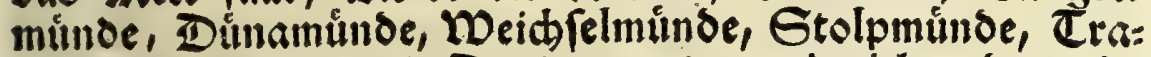
veminde, Zuremond, Dendermonde, und siele andere, fo: wol zufammengeferte, als allein ftebende Miunden, Muinden uno Gemúnden, begengen. Sablagen Sie in Dem GLOSS.

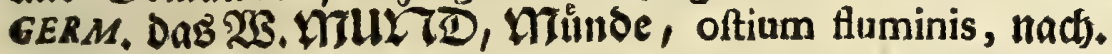

2(us weil, weiler, ober wil, willer, welche 3 soivs

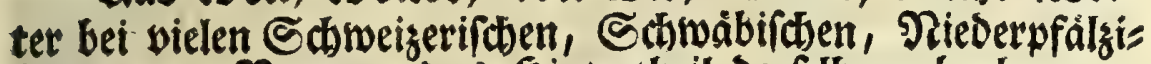
fchen, $\mathfrak{u}$. a. Tamen, Das Shintertbeil Derfelben abgeben, el:

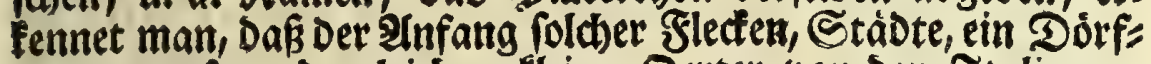
c)en gewefen, Dergleichen fleine Derter bon Den Jtalienern cafali, und von Den Jranzofen hameaux, genennet werden. Diefes ift eine ßerfleinerung aus $5 a m$, welches in Der Fngs lándirónen Eprache noch beftebet. So lauten Die Namen Dietweil, Seimsweil, Seringsweiler, Ealmonsweiler, Ottweiler zc. Soll aber ein einziges șebáude alro beisen, fo fommet Der Fame unmittelbar bon woilen D. I. Wobnen, fich ingent aufbalten, morari, degere, weldhes bie Jrang $0=$ Pen mit fejourner, Die Italiener mit foggionaye, augdricten. Mit Den Ramen Diefer Bebeutung hat Zarlsrub eine volls

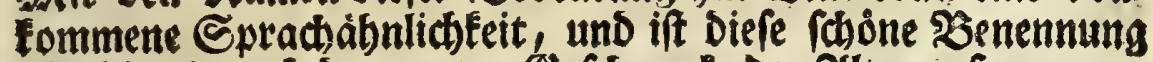
allerdings nac Dem guten Sefकmade Der 2ilten erfonnen. 
Werd if in Dberteut(c)land eine Infel ober 5albinfel, bie ein Sluşwaffer umrinnet, oder weldhe ein Seetwaffer um: gibt, wie Der obere und Der untere Werd, wie autd Der 23 rwoerwerd, Der ftrittige WDerd, zu Regensburg. So beif Fen alle Jnfeln, Die uiber und unter Diefer Stadt in Der Dos nau liegen; fo aut Donauwert, Kaiferswert zc. WDers ift Die eigentliche Echreibart, und fo muß audh Das 2 Sort ausgefprochen werden, nicht wert, woert ober wórth, Denn es fommet von werben, D. i. entfteben, allwvione nafic wie Sduttt von sulfibitten.

Die Sd) intt if aud) infula fuvialis; Daber lautet ber 2usbruct, die Infil Ëbuttt (in Ungern) tautologich, als twenn man fagte die Infel Infel, wie idj ein Gleides von Den Benennungen, monte Gibélo, mons Pyrus, die Etadt Médina, in ber II 2(nmerk. sur @arifit de COL. HERC. S. 2 I u. f. ermiefen babe. Die Rürnberger, melche eine fllußs= infel auch eine Echüt nennen, beftátigen nebft andern $2(n=$

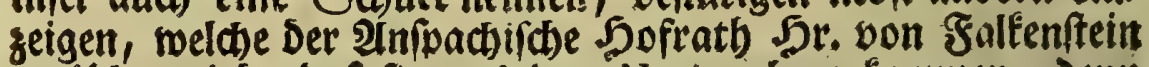
erzáblen wird, Dak fie aus Dem Norico bergefommen, Denn Diefes groffe Land reichte, bevor Die SRömer Davon Jerren ges worben, bis an Die Donau, weil Carnumtum bon Livio nod) eime Rorifhe Etadt genennet mird.

Zell Deutet in Den शamen Der Derter an, Daß Derfels ben Urforung ein Slofter, oder eine Rapelle (fleine Rirche) geween. unún fer if eine Berftummelung von monalterium, ein KAlofter, eine Stiftstirdec, als Riremsminfter, ein Mofter an Der Rrems; Rotenmunfter, Maabmúnfter.

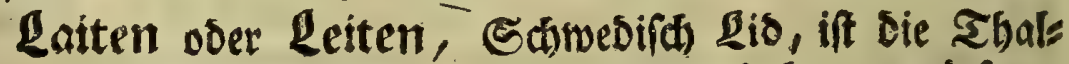
bange eines Bergez, Shugels, ober einer erbabenen und forts laufenden Etrecfe vom Eande, latus declive montis vel collis. Bine winterleiten, declivitas feptentrionalis; eine Gommerleiten, declivitas aprica, auftralis; eime Soljsleiten, declivitas filvofa, u.f.f. Mman boret Den Pamen Seit (Dies 


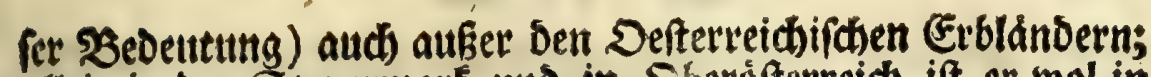
allein in Der Etevermart und in Sberófterreid) iff er wol in

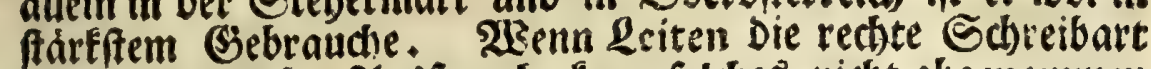
ift, Denn aus ber 2 (us for adje fann foldhes uicht atgenommen werben, (weil in Dberteutrithland das ei nidht, wie in Ries

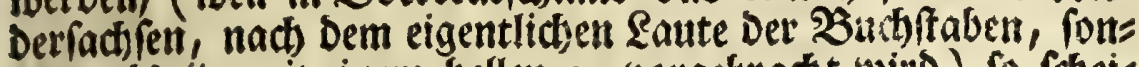
Dern als át, mit einem bellen $a$, vorgebracts wirb) fo fcheis net Das w3ort von liegen bersutommen, weil man ebedeffen leit fur liegt gefagt bat, wie noch einige Mumbarten fprectien.

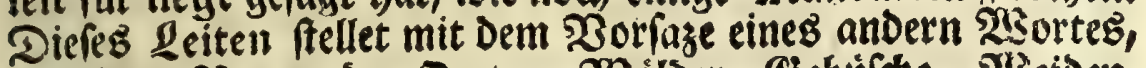

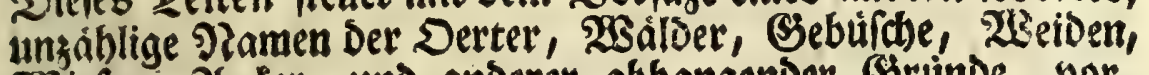
2siefen, 2tecter, und anderer abbangender Srinde, yor, guforderft im Sonde ober Der 促ns. Nur um Rremgmun: fiter, und in Der Rađbarf(j)aft Diefes Srtes, find folgende Eeiten, Deren id mich erimnere, 2(bleiten, fóbrále ten, Ceufelsleiten, 5obleiten, (eine if bel Der Yapiermithle) Edăfersleiten, Gomleiten; allein eg merden nod) mehr als hundert andere feyn, welche Der Rremgminiferifche Schreis berichwarm an Den Singern wird bersáblen fönnen. Gonn= leitent ift foviel, als aprica declivitas, und babe id eime auf

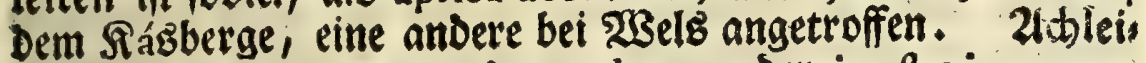
ten beist declivitas aquae impendens, ober in fluvirm vergens, und burd eine Metonymie ein Sebåube, Das auf fol dem Srunde ftebet. Die Sơbráleiten, pinetum declive, bat

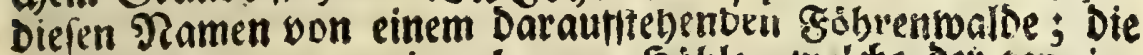
Ceufelsleiten, von einer langen Sobble, wdldbe bet gemeine Mann furr ein Teufelsloch Gält. MRan Dodrfte wol auch sur Beit Des Jeidenthumes Dabei oder in Derfelben mand abers glaubirch Beug verubet baben.

Bei Den Senennungen Der Derter, weldise in is und itfits

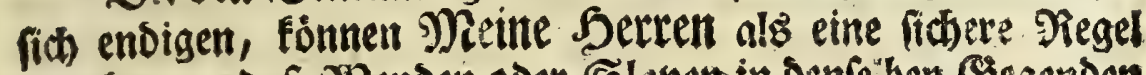
annehmen, Dẩ Wsenden oder Slaven in Danfe ben Segenden getwefen find, oder nodh allda wobnen; Denn das fino eigens thumlide șendifhe ober Slavifate Endungen, Die waiter

nichto 


\section{LXiv}

nichts bedeuten. Das is ift aus Dem meiblittien Slabonifoten

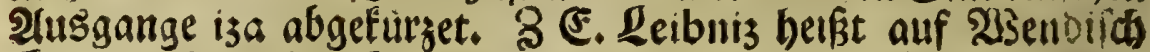
Eipniza, D. i. eine Rindenftaot, oon Lipa, eine Linoe. 2Sat ebemals eine gute Steverifbe Feftung. Sgt ift es nur ein Marftflecten an Der Gulm, bevor fich) Diếer Sluß mit Der Mur vermifát)et, nảctif Der Státte Des alten Mturocla. Dee

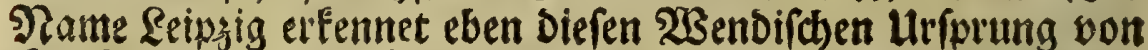
Sipa. 23 ift ro beist feidte. Zíftriza ift noch in Der Mund= art Der spatauerifichen Slaven, zum wenigften an Der Sgefse

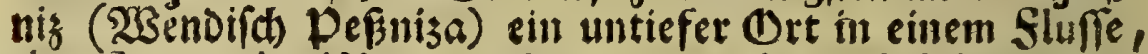
eine Surt, eine $\mathfrak{W}$ at, vadum fluvii; bernad) bedeutet ber Rame Zífrisa einen Eleinen Flup felbft, weldjer fich Durd)=

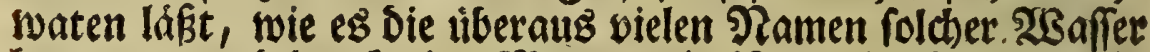

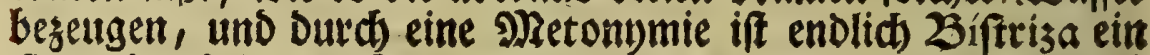
Sit, Der bei einer Surt, ober an einem fold)en fleinern Slufs

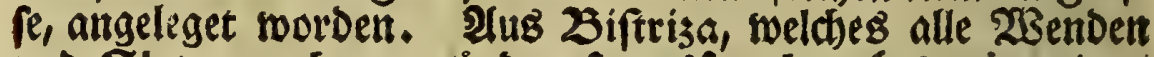
und Slaven noc) unverånbert fo auşprechen (es móge einett Eleinen Slluŝ, oder einen Dabei erbauten Drt bebeuten) has ben die Feutfasen 2 iftris, uno in etlid)en Esegenden erftlid Wiftris, nach ver neuern, nod) fettern uns mebr Debnenden Tlusfprache aber Deiftris, Deiftris, Seiftris, gemacht. Meine Serrelt fonnen auf Den Sandfarten bon Defterreict, Stevermark, Rairnten, Srain, Sirobater, Bobhmen, uns gern, Siebsnburgen, Det Mulbau, mit einem $230 r t e$, wo Slaven oder : Benden find, cDer ebebeffen gewohnet baben, Hber hundert Derter zufammentáblen, Die auf Seution $23 i$ : ftris, Deiftris oder Seiftris beisen; Die Slaven aber und die

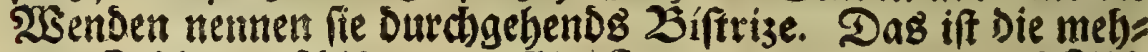
rere Babl von Zifrtisa. Ein Seifris liegt im Wiertel Billi,

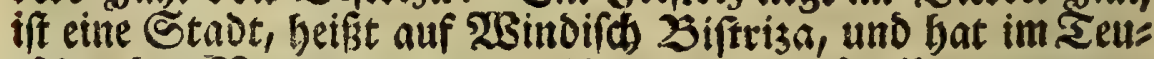

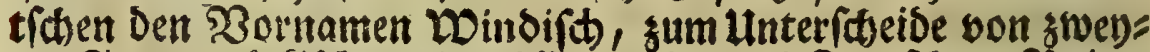

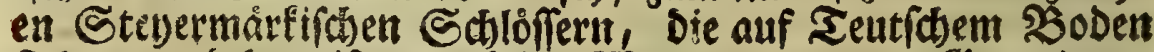

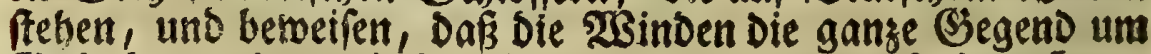
(3) berum innegebabt, bevor fie ber anwadfenden Jerrs fthaft Det 23atern झlas su geben, uno uber Die Drau fich zu 
gieben, find genothiget worden. Hebrigens weis id suvers liffig, Daf nur in Der Stevernarét und in Jirain, nod bis

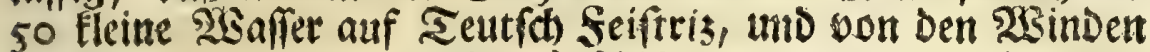
(menn noch einige Da woblten) 23 iftrise genennet werden, bie auf Den Randfarten nicht freben. Solches babe id) aus befons Deun Berzeidniffen eifehen, Die aufgefest werden, wenn Brund: obrigfeiten, etwan um Streitbåndel ju entfedbeiden, ober ans Derer Urfachen balber, gewiffe Drte Dutch abgeordnete 2än= ner genauer betreten und befchreiben lafen.

VA'R bebentet in Der Utnarifesen Spracte, was gras im Clavonifchen, und gard im Seutíchen beif́t, námlich ein

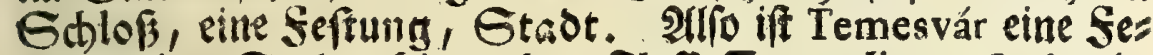
ftunn oder Gtrot, Die an Dem Sluffe Temes liegt; Serinvár,

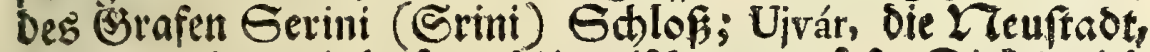
Neapolis, Denn új beift auf ungrif() neu u. f. f. Diefes mirb su einem Mufter genug fern, wodurd id nur seigen mill, wie bas topograpbicthe Siloffarium ungefábr ausfeben fónnte, wel ches die Erfenntnis vieler taufend $\mathfrak{N a m e n}$ Der Derter erleich = tern roll. Jah befitwte nidst, Eie merben fagen, Daß id Die Zabl su milde angebe, Da ich von taurenden fpreche, Denn

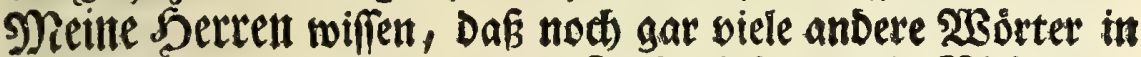
allerley Epractien, bevoraus Soch = Dber = und Nieberteus tiche, vorbanden find, welche Den swevten Ibeil Der bisher befthriebenen $\mathfrak{R a m e n}$ Der Derter ausmachen. ISseil aber bie meiften, zum wenigften bie Seutfecten, fo Deutlich find, Daß fie Eeiner 2 luslegung besurfen, und, wenn etlidhe Derfelben ja

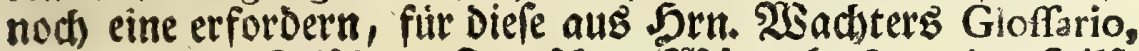

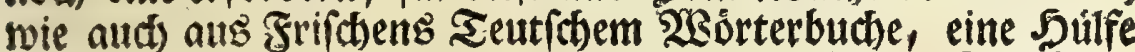
zll erlangen iff, ro will ith fair biefesmal Die ubrigen Sentithen nur it alphabetifether Dronung herfezen, foviel mir Derfelben einfallen werden, uno Das fino folgende: $2 u^{u}, b a b, b a d$, berg, beuen (Engländirs bury) brum und nad) Der âls tern Mundart born, barg ober borg, buí, buttel in Ries Derfactsen, tron, oing; Sorf, nach Der ältern Mundart borp I ober 
oder torp; fels oder feloer, fels, hag oder bager, bain oder hayn, baus und baufen, wie aut bus und bufen, beim, Engli bam, bof oder boferr, bols und Nieber. bolt, but,

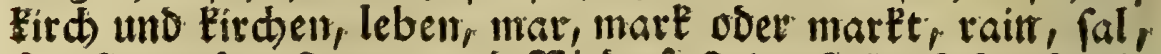
fee, ftatt oder fettem, uno Riederf ftede, freig, ftift, frraf, thal, thutis, wald, want oder wanger. Diefes. Tegifter werder Sie leicte bermebren, wie aud allen 2frtifeln bie ges bơrige Erlåuterung mit Den Exempeln, beifežen Eónten. Denn eE miffen allen Diefen Tamen, auth Denienigen, Die ein Seu= tictev of ne 2inmeifung verftebet, Den 2lusländern zu Riebe, Die. Erfflartmgen beigefüget werben. Sollen Mentte Serrent bet einigent Diefer gemeinen geographifhen Rsovter, ober bet: andern, Die Sie finden, einen 2rmfand haben, Der fict aus: Benamten Sitchern nicht beben lieffe, uno Daber vielleicht in

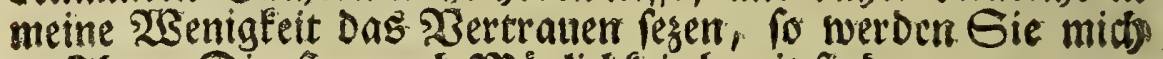
a Ju Shen Dienfer nad Doglidbeit bereit finden .

Etlictbe iztergåblter Tamen baben mit gewiffen lateinifher

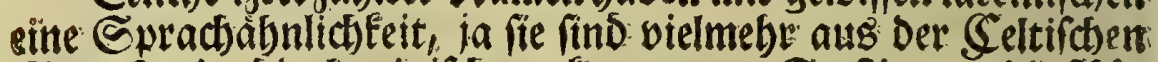
Sprache in Die lateinifhe gefommen . So ftimmet die $\Re_{0}=$ mifd)e Enoung DVRVM, in Pfifebung Der SEedeutung, mit Der Seutichen furt tiberein; ja die erfte iff felbit mur Das C Cel=

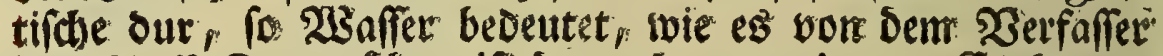
Dez Gloff Germ. fhon ift Dargethan worden. EB batter.

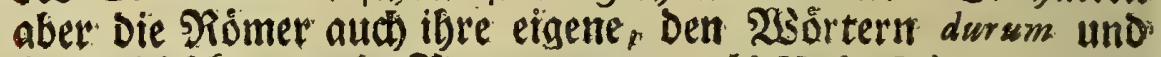
furt gleidh fommende $\mathfrak{B e n e n m u n g e n , ~ a l s ~ V ~ a d a ~ S a b a t i a , ~ V a d a ~}$ Volaterrana: Die neuern lateinifben Sobrifteteller baben Die

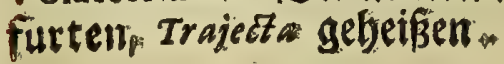

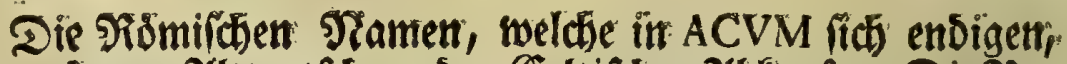

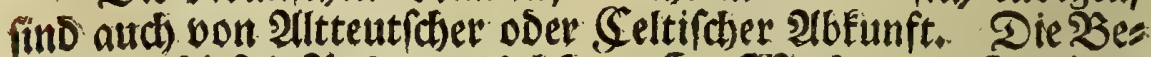

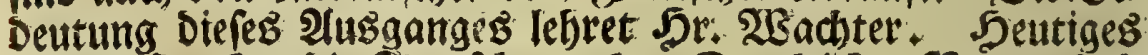
Fage Zaureacum, Tolpiacum, Stanacum ober Stenacum, welche laus ten, wie Saurad, Colpad) oder Eolbad, Etanad), (Etains 


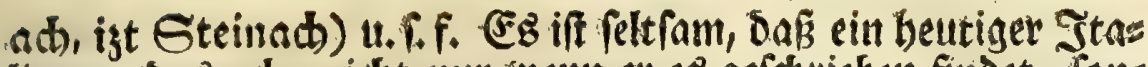
liener, Das a

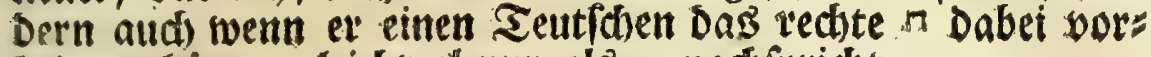
bringen boret, gleidswol nur als ac nadj) furicht.

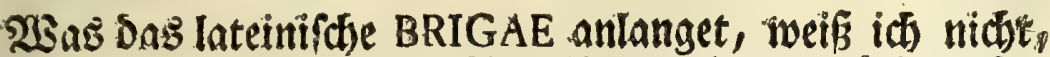

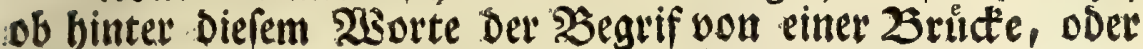
bon einer $\sigma_{t a b t}$, zu futchen Fey. Bereliug bat in Indice: byr, civitas. Dag gibt Durd eine Metathefí bry. Dag $\mathbf{g}$ hat foonnen Daranfommen, wie in Z3ringe. So nannten

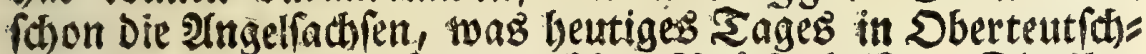

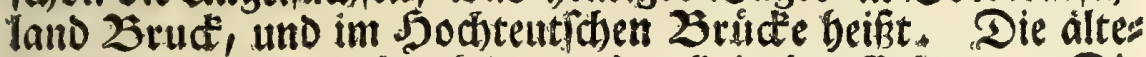
ften Mlumbarten baben feint $g$ oder $\mathbf{t}$ in Der Endung. Die Edsweden forechen nidst nur mit Den 2Ingelfachien brygga,

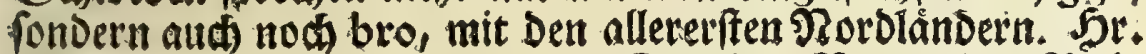
2Sachter fiveifelt, ob brove Der Dänirche Pame einer $\mathfrak{B r t i}$

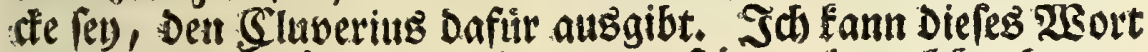

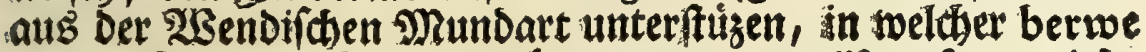
in Der Zabl Der Zweybeit (in numero Duali) gefagt wirD; bon berw (brw) pons, wovon berwi Der Pluralis ift. $2 B$ eil vor Dem $r$ ein N" febet, sweldhes num bie Stefle anderer Selbfts lauter vertritt; Die aber bei Dem $\mathfrak{r}$ Eeine bleibende Státte bas ben, fondern bald vor, bald nact demfelben fteben, fo erfiebt man bieraus, Daßs Das brive Der 2llten, weenn man pontes

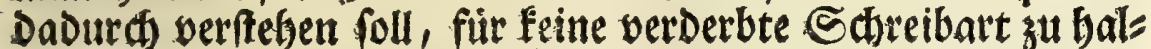
ten fey. 2(us bem Misendifiten berw pons, zeige ich in Den

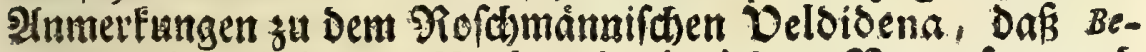
vaserfes Plin. (III, 19, Hard. 23) ein ádbter. Name (et), und Daß aus diefer sylimifaen Stelle viel eber PONS Druf, als VELDIDENA, fónne erzroungen werden.

Das TAN in Den Ramen Britannia, Aquitania, Lufitania, Mauritania, und Das ftan in Den Ramen Der Perfiffeten Eanditbaften, Churdiftan, Chufiftan, 2(rfiftan, Cabriftan

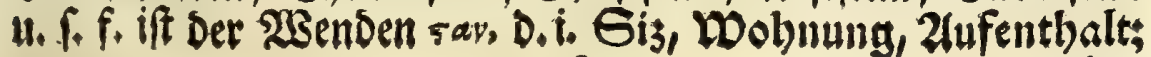


Der vorigen Seutfden, uno nod Der Stevermárêt ftán, ftain, Das Sod)teutho beutige ftein. Britannia if alfo ein Gis Ser 2Britten, Lufitania, Mauritania, Der Bufier, Der nTauren ober Mzoren 2lufenthalt, Rand; Aquitania eine wafferreiche

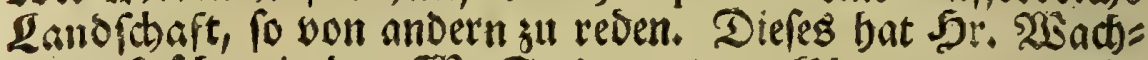
ter aud fajon in bem $\mathfrak{Z}_{3}$. Stein, regio, erilaret, wo el mebr Dergleichen ?amen anfübret, und zeiget, Dafi fian und ften

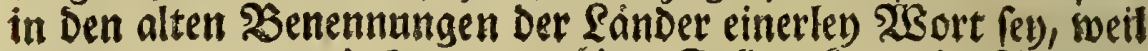
man Sacaftana und Sacaftena (Der Gaten Land in Arrmenis en) gefdrieben finde. Es (prectien aber noch beutiges $\mathfrak{S} a=$ ges einige Seutfhe salundarten Das neuere ftein wie ften ดแยื.

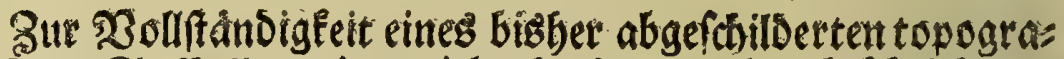
phifden Gloffarii, oder vielmeby Des worber befdriebenen

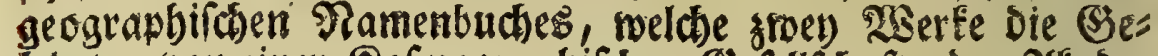
lebrten von einer Rofmographifchen J3efellichaft ober श्ffade: mie billig ertwarten, geboret meines (Erahtens aud eine Er: flărung gewiffer frembe lautender Benennungen Der Sänder,

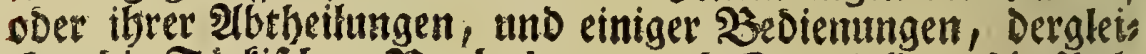

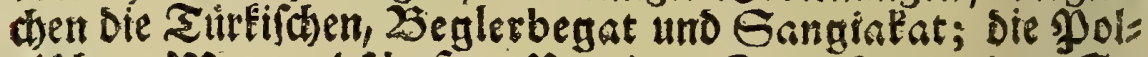
nifben, Woymodfdaft, Powiat, Etaroftey; cine Ge: (pannfchaft in Ungern; Gbire, Sunores, in England, uno noth mebr andere find. Denn es fảllt tool nicht einem jeden gleich bei, Dafis. fpam comes, Dab Shire erfláren die Englänoer felbit mit County, (wodurd) fie eine Srafichaft berifeben) ober. mit provincia, Landofdaft. Befeben Sie aud) Srn. WBachters

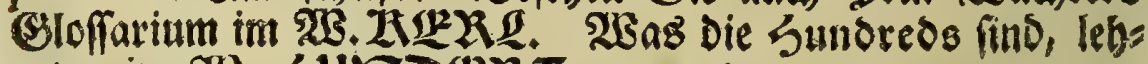

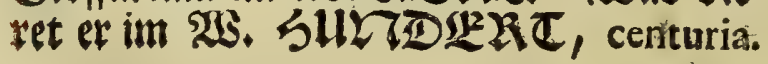

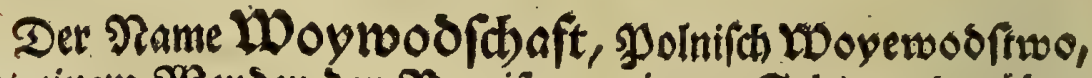
gibt eittem $\mathfrak{W e n d e n ~ D e n ~}$ Begrif von einem Gebiete, Darúber ein Selobert gefezet ift, wenn es gleidh ist eine andere \$゚es wande 
LSF

$\infty 9)$ or sto

3ิon Dem vorelwebnten Stammworte is fommet bet Rame Hodína. vialis ammis. So beist, nad) einer nod) ift

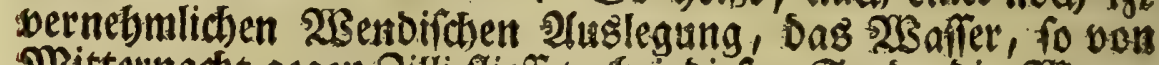

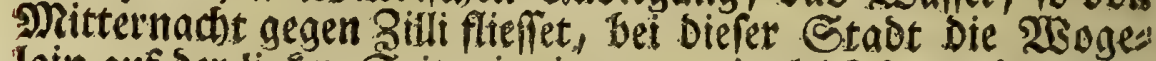
Iain auf Der linten Seite eiminmt, uto gleid) Darauf mit Det

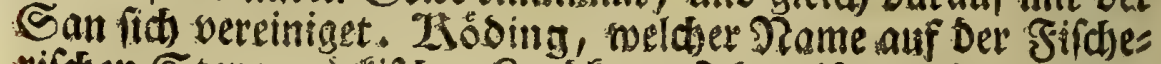

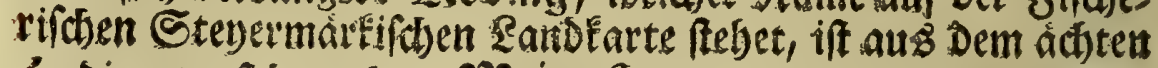
Soding verftimmelt. Meinte Setrent wollen bei ibren tunfs tigen 2uggaben por Ranbfarten, Darauf Dierer Strid) Des alten Norici fallt, (Der ist unter Dem feltfamen 2 lusbutie eines fitmften Biertels zu Stegermate gebolet, worbin aber bie bes rubmte (Srafichaft Bifli vorgeftellet bat) iztgedachtem Fluffe

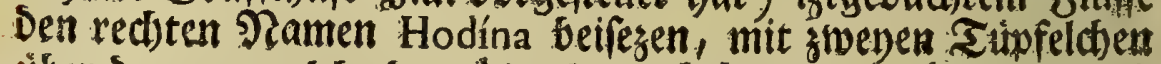
tiber Dem $n$, weldbe Den thinefmum bebeuten. Rhinefmus ift eine Durd Die Rafe getriebene febr alte Puspradte, weldie

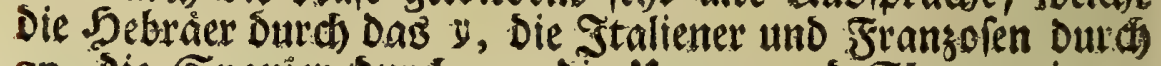
gn, Die Spanier Durd nn, Die ungern und Slaben mit ny, angeigen. SYSarum Diefes 23 affer Hodína genennet werde, wie Diefex Mame mit Dem Heptaporo Des fleinern Mfieng, weldsen Fluß Somerus nennet, uno Etrabo befareibet, libers eintomme, sie folche Betrad)tung su wabrfocinliden M? maffungen bon Dem Urfprunge Der Etabt Celeia, und was

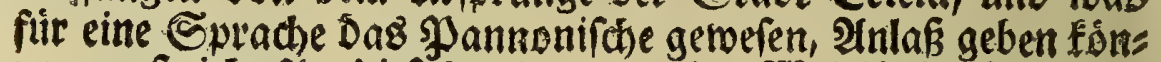

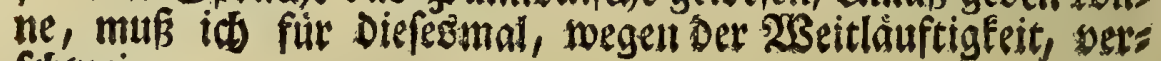
fotweigen.

Powiat, welotes die Solen mit diftrikus erlataren, if Der S?ame einer fleinern Eintbeilung, ein Stinf einer গ3joynodfchaft Denn Das Sioniareid Polen wird in 36 SBoywodfhaften (Palatinatus), Diefe ferner in powiate, ges tbeilet. Staroftey lautet, als wenn iemand fagen wolls te, cine Landvogtey ober Lanoshauptmanmfisaft, oie von einem 2leltermanne verwaltet wird. Bei Der erften Berfaffung mag es nun mol biefe 23erdaffenbeis Damit gebabt baben. 


\section{IXXII}

\section{$05) \circ(56$}

eine Gpur Der vorigen herrfobaftlicben 2 Zerfafunt beibebal

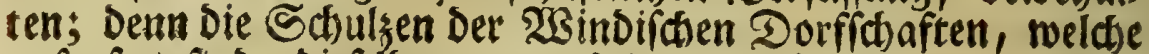
aufgefest find, biefelben zu vorfallenden Rothourften nufzus bieten, ibnen die Befeble Der bóbern Dbrigfeit 3 binterbrin= gen, die geringern $5 a b^{2}$ el eigenmåchtig beizulegen, werden im Biertel Billi wupponi genennet, welche Demnad, fo nunc parva lacet componere magnis, mit Den $\mathfrak{P}$ olnifdent Gtaroften einigermaffen verwandt find. T्ञf Dorfridter and Guppan; in Der mebrern Babl aber fdrei ben die $\mathfrak{B}$ indifden $\mathfrak{B}$ erwalter Gupleute, als wenn $\mathfrak{e g}^{\mathrm{B}}$ it Der einzeln Gup= Mzann getoefen ware, Daburd) unfere erif vorgetragene 2)

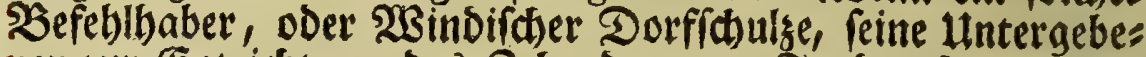
nen zur (Entriditung Deg Debenden, zur Jago, ober anbern Frondienften zufammenberufen foll, fo begibt er fid) auf eine

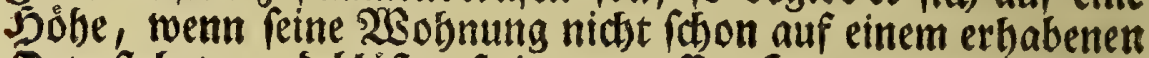
Drte ftebet, und bläft auf einem groffen Sorne gewiffe Shone

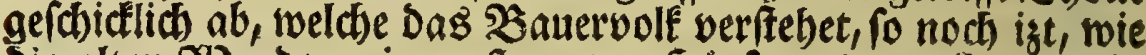

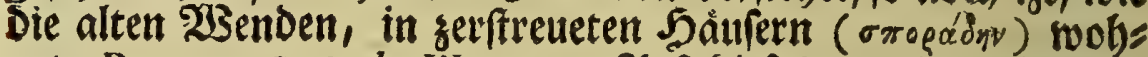
net, Procop. B. Goth. III, 14. 2(uf Diefer gegebene Seichen verfammlet fich Die Siemeinde, oder Dasienige wiro voliftrectet, was Der Guppan Durch fein Blafen angedeutet bat. Jch bin Der fichern Meinung, Daß̧ Die :Benden, als fie noch relbit Serren tiber viele Sänder gewefen, auf Diefe 2irt ibre Manns fijaft zu AriegsDienfen werben aufgeboten baben. Diefes Sornblafen Dinfet mich ein-Heberreft aus Den Sitertbus mern Det mittlern, ja nod) ailterer, Beiten zu feyn.

Da nun alle unpartbebifhen Richter in Sachen, sie भisiffenít)aften betreffen, obne Sweifel erfennen werben, Daf̈ Die meiften bisher vorgetragenen Berichte, Erfiläungen, und

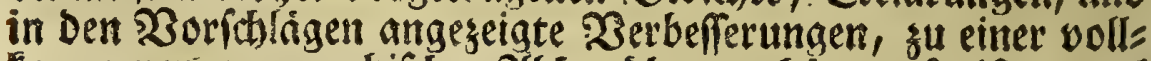

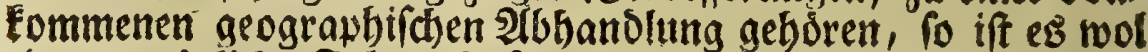
eine untrtigliche Folge, Daf die bochtrabende 2fuffatrift einer: Dollftándigen Geographie febr vermeffen fey, wulche $5 \mathrm{r}$. 
5r. Stibner Der Singere feinen Drey Detaviảnden gu geben fic) unterfanden bat. 23ie viele Dinge fuchet Der \&efer nicht vergeblich in Diefer $\mathcal{D}$ ollitänoigen Geogtaphie! 25ollte fich) Der 5 r. Berfafier etwa mit Den engen Shrans

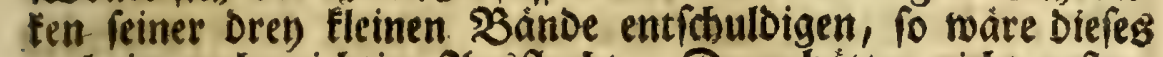
nol eine recht nichtige 2 (usflucht. Denn batten nicht anf(tatt Der oftern, und gemeiniglich mider alles Sefthidfe, aug einent abgefchmacten Eifer, eingeorungenen Sticheleyen mider Die

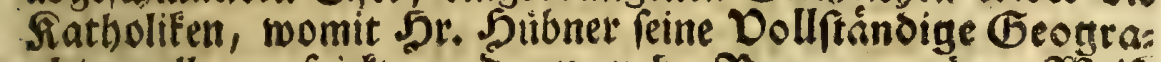
phie boll angefpidt, und um mebr $\mathfrak{B}$ ogen unmizer 2 Seife bermebret bat, viele gute Sachen, ia wefentliche geograpbi= fobe Etude, Slaz finden Eơnnen? Ich Denfe ja, und folches

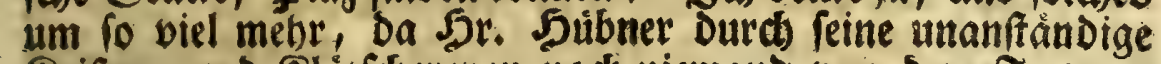
Reiferey) und Rlátícherenen noch niemand von Dem Irnwege nird abgefibret baben.

\section{Sod berthefte Serren,}

\section{Meine Ģơnner unb Freunte!}

23seil id eberi auf bie Stibnerifhe Schreibart verfalle, fo nebme id Die Sreybeit, Sie zu verfichern, Das Diefelben ein billiges $\mathcal{S} 0 b$ von allen wactern Männern zu erwarten baben, menn Gie bei Jhren fünftigen geographifchen 2lusfertigungen, bie RReligions fachen unpartevich erzäblen ober ertláren, uno bon einem to póbelbaften 3 eifpiele, to weit es móglich iff, fid) entfernen werben. Soldhe Sdbriften verdienen eine alts gemeine 2fhnoung, weil fie Dem gefammten Shriftentbume

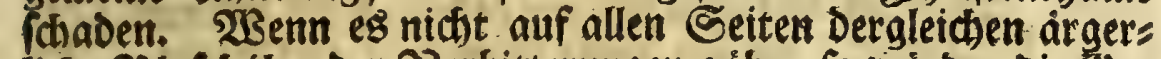

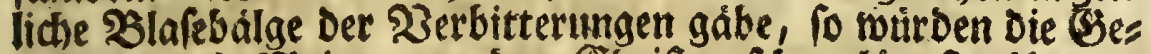

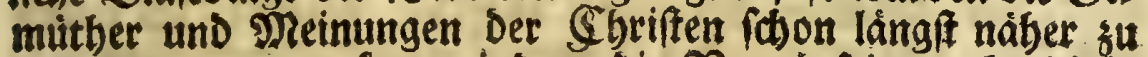
einander getreten feyn, indem Die $\mathfrak{B}$ ernunftigen obnediés, bielleidit mur ein einziges Strict ausgenommen, mebr Durch ein duserlithes Seprảnge, und geniffe von Der Jugend auf eine sefogene $\mathfrak{X}$ orurtbeile (Daruber fie fich aber berioten laffen),

$$
5 \text { als }
$$


LXXIV

$-13) 0(56$

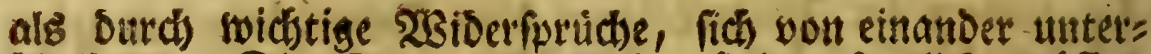
ficheiben. Die Jerren (Seiftichen finden freylich groffere Sdmierigfeiten, uno bemithen fid Diefelben noch grefsidjer vorzuftellen; allein vielleid)t nur folche, Denen Die 5erde (foci)

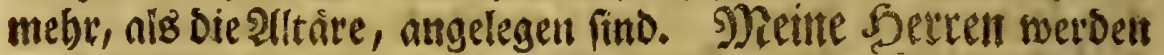

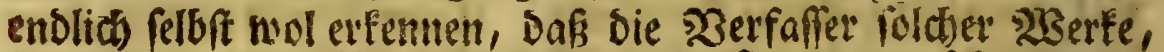
Die bon einem Neumeifretifden (Seifte gar zu febr belebet find, Dem $\mathfrak{B}$ ertaufe und Der 2 fusbreitung Derfelben felbft bin Derlich find; weil to befchaffene Edhriften an Denienigen Dr= ten, wo man nicht fo Denfet, wenn auch feine andere ltrfas che vorbanden ware, nut weil fie Den Befdumad Der Sugeno verberben, eine Interdructung gu befabren baben. Das if

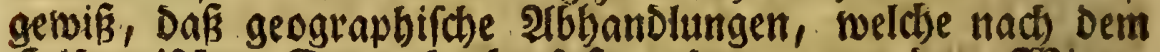
Stibnerifoten Exempel abgefaft maren, von bem sisienes rifhen Jofe nidit fónnten gleid)gulltig angefeben werder, bei Dem aber eine Sofmographifdse (Sefelichaft, Die felbit nidjt allein ben allerbodiften Saiferlid)en Sdus, fondern auds eis nen milden Borfdub fudjt und boffet, fich in Bnaben gu erbalten befreben wiro. Subem fommet endid audi noch Diefer Intrieb, Dấs eben Diefer allerbod fife 5 of aus Denients gen Ländern, Derer geographif he शrbriffe noch febr muift hers feben, uno ber groften wie aud ebeften Sullfe bebirftig fino,

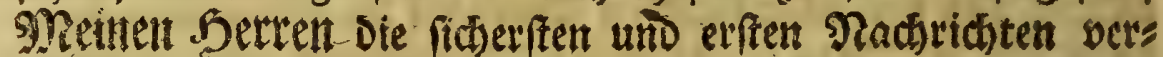
fobaffen Fann. Sie Eennen ubrigeng mein (semutb, uno fes ben gar rool ein, Daßs id aus feiner sparteblidfeit fúr meine Religion, wie Str. Stibner fir Die Ecinige, fondern nut Det Silligkeit gu Riebe, wie aud zu Dero Nugen, lede uns ratbe. NGas iff an einem Manne tabele, wird niemano, Det weiglich urtbeilet, auf Die gange (Semeinbe ausbeutert. Jas mifit: Det gefunben Bernunft abgefagt haben; ich wurbe

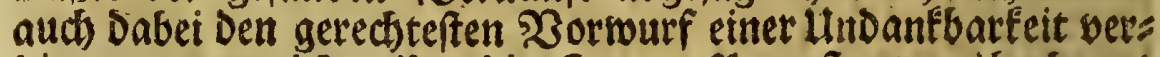
Dienen, wenn ith wiber Die Serren spoteffanten tiberbaupt flagen wollte: Die mir groffere Ebren erweifen als bieienigen, unter Denen id bisber gelebet babz; bie mir in Der Proth mit Tiatbihlógen, mit Sthdern, mit Geide, ausbelfen; nitht als 


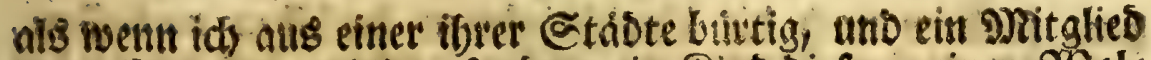
ibrer Sirchengemeinde, fondern ein Sitnd Diefer meinet 's ol tháter wire. Ich finbe unter innen eben fo redliche Saerzen uns wabre frembe, als unter meinen Feligionsverwandem, allein ungleid) weit mebrere uno grêfiete Siebjaber, wie auth

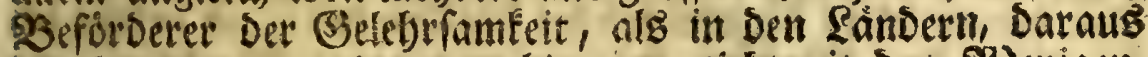
ich eben Darum ausegesogen bin, um nidbt mit Detn 23 enigen, waE ic) Durd viele Jabre, gróftentbeils obne frembe Inteis tung, Durd) eigene Sermibung, erlernet babe, obne andern zu bienen, (weil niemano verlatigte es wieber von mir jul lernen)

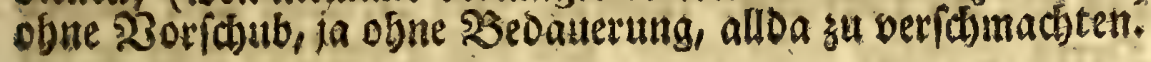

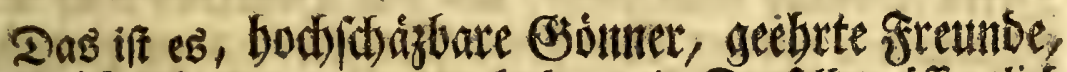
wobon id) mir vorgenommen babe, mit Denfelben offentlid zu pred)en. Die Intede ift etwas länger ausgefallen, id geftehe er felbft. Den fảreffen Sumadjs baben bie êftern 23 ortforfhungen beiget'agen, Die mir, wo nur eine Belegen beit vorbanden iff, auch miber meinen 28 iallen, yon Der Jeber

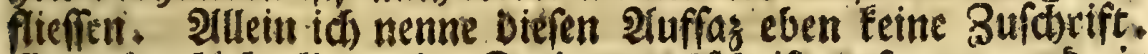
Ez nàre lächerlich, eime aueignungs fobrift auf neun uno eis nen balben Bogen zu berfertigen. Meinte Serren peben, Dafi 28 jugleid) eine 2rbbandlung (ev. Dafur merben aut bie rectot Denfenden Sefer gegenwointigen Bortrag erfennen. Dies fes mus Der iseitladiftigket zur Entichuldigung vienen.

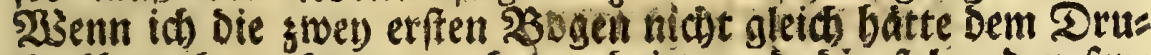
de übergeben, bevor nodi ber Dritte und die folgenden fers tig waren; Denn Die Fortfesung seigte mir erf, twas fir eine weit ausfebende 2irbeit id vorgenommen babe: fo surbe ith Diefe Schrift, als ein beronder 'rberf(t)en, unter folgendem Eitel, meinen unterfudungen vom Meere angebainget $\mathfrak{b a}=$ ben: Vorfhligge an die Klofmographifhe Gefellipaft in L Tirnberg von Derbeflerungen ber alten uno ber neuen Geographie.

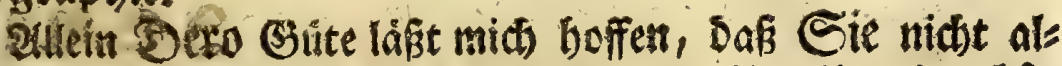
lein biefe aud fo befwaffene Schrift obne Hnwillen Durdhes K 2

ben 
ben, fondern noch Die Unrichtiafeiten Derfelben berbeffern, und mit Diefem $\mathfrak{B}$ orwande Deden werben, Daß ich in Der

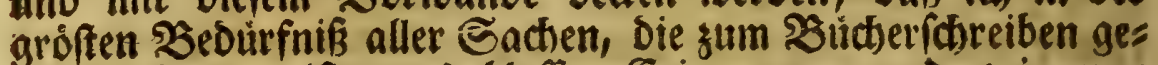
hóren, Das meifte aus bloffer Erinnerung, und, wie man fagt, aus Dem Stegreife, gefhrieben babe. Ja meil mun Die Seit berantudet, Die uns wieder foteiben wird, fo nebme id

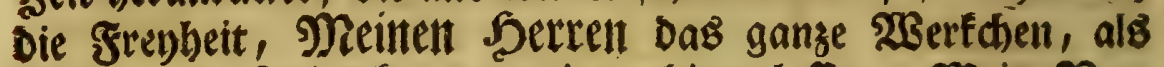
ein geringes ग्andenten bon mir zu hinterlaffen. Mein Bers mogen ift in (Segentwart nod fo Elein, Dak Sie igt nid)t: befé fers von mir empfangen fönnen. ICh serlange aber meines Drtez ebenfalls nicht mebr, als Dấ Diejelben mich in Des

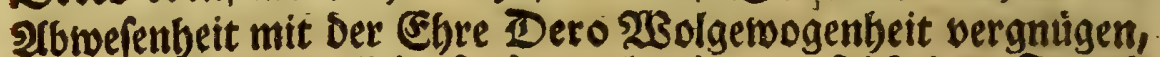
niđt als ein Mitglieb, fondern al: einen aufrid)tigen freund unt Diener, bis wir reben, tas Jhre und meine Eachen fur

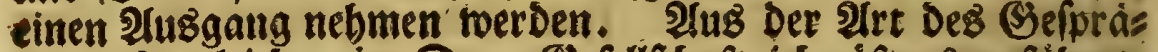
(4) und vielleid)t eben DaDurd) Jbre Reigung getwonnen babe; erfennen Diefelben fabon, wer id bin. Ja werde auds nods funftig nid)t aufboren su feyn.

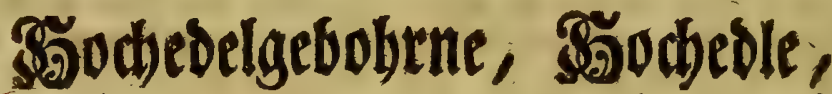 sodigelégrte Satren,}

Dero

Ergebenfer Dientes.

\. S.P. P.

Dat 2tbbande 
ften feften sanbe getrennet, wie aud die swen Snfeln Sor und Syle von" cinanber geriffen: wie es unten, im zwenten श̧ad)trage fur I I Unterfu=

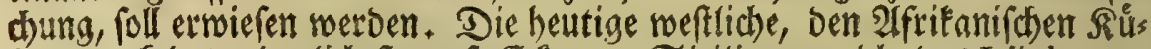
ften zugefebrte, fiemlich fumpfe (Ecte von Sicilien, weld)e das Lilybæum promontorium ber âtten ift, Eann wol niemano, mit ß3eftande Det 2Babrbeit, ein 2010 ebirge nennen. (5s ift biejelbe einflackes, niebriges, in 2 ectern beftehenbes \&ano, nut etlid)e wenige (Sh)ub hober als bas - Sneer, fo Daran ftógt, von bem fold)es auch beftånoig mebr negfpúlet, unt nirb es Der beutigen Stadt tharjala, die ein lleberieft des alten Lilybáum ift, felbft balo zufpred)en, wenn biefelbe feine $23 e b r e n$ fhlas gen, ober Dámme bavor bauen lást. Es mus demnad) einer aus folgens ben bren Gäzen, meiner geringen Dorfellung nach, wabr fent, baf námlich entweder bie snifden Marfala und Srapani, mebr aber im Ant gefitite Der lestern Stad, gegen Ibeno liegenbe Snfeln, etroan anfangs Das britte und weitliche Oorgebirge von Sicilien geweren, weldyes aber von bem Ineere, ober Durch Frobeben, abgeriffen, uno nod ferner in ges Dachte Filande gertbeilet worben. So fdreibet Strabo von folgenden Snieln: Prochyta, Pitbecufe, Caprea, Leucolia, Sirenu/a ón Oenotrides, partes funt continentis avulfa. VI, 258. Allein toas gleich Darauf Eommet, Das befråftiget nod beffer meine, Mutbmaffung: Quse autem (infulæ) ante promontoria fite, aut freto a costinente dividuntur, maxime rationi confentaneum eft, ab ea e/fe abruptas. WBenn abet

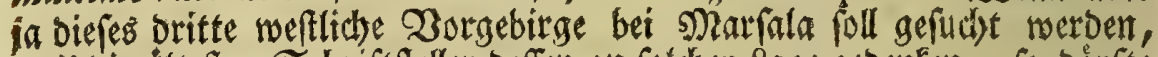
weil die álteften Sduriftfeller Deffen an fold bas wabre und eigentlidbe alte Dorgebirge Durd ein Erobeben fenn ber: fentet worden, aljo bafi nur ber হame úbergeblieben, und man oie zabls reiche bor bem gegenwartigen \&andende ftectende Slippen, Davon Virgil. Aen. 3, 707, etrobnet,

\section{Et vada dura lego, Jaxis Lilybeia cecis.}

für bie tleberbleibjel Seffetber balten Fonnte. Don Derfinfung nidyt al lein ganter Stabte, conoern audi Berge, finden wir mebr Seipiele in

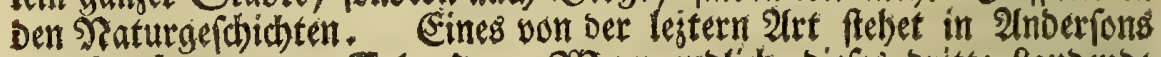
racbrick wn von Joland. Wenn enolich biefes oritte Eantonde bon alters ber inmer ein flaches (sroreidh gewefen ift, fo erweifet foldhes

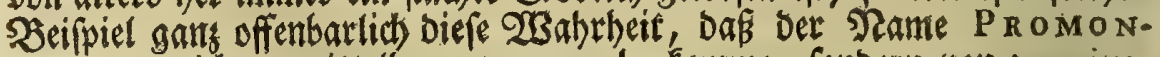
TORIVM nidst unmittelbat bon mons berfonme, fonbern on promine- 


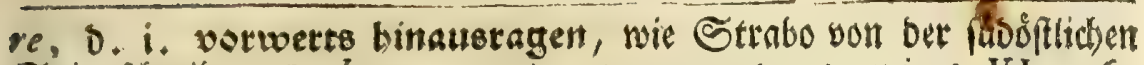
Spige foutcibet: Pachynus, guicontra orientem prominet, VI, 265

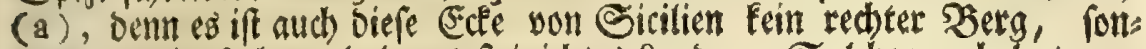
bern nur ein fachte erbabenes fteinid)tes sand. Soldhemnach bat man Sas 2 Gort promontorium im Seutjoen, uberbaupt ju reoen, untecht mit Dorgebirge ausgeoructet, uno wåre es beffer gewefen, wenn man fold es mit Lanoenoe, ober cinem andern tudctigern 2 Borte, uberfest bítte, sum wenigftet foferne es auch Das silnbáifde promontorium. uno andere feintes gleidben, mit begreifen foll.

allein auf bie Stennung Spaniens bon Africa wieberzufommen, fo gibt es nicht allin unter Den satten, fonbern aud su unfern seiten, ba

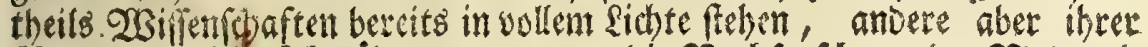

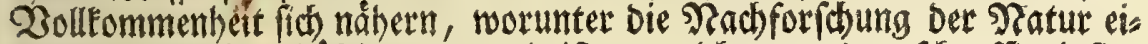
ne Derienigen SBefbaftigungen mit ift, welche von Den fobarfintrigften Seiftern mit groftem Eifer getrieben werben, eš gibt bennod), fpred)e id, auch in biefem alter, gelebrte, uno in Den Senntuifen oon leztgemeloter

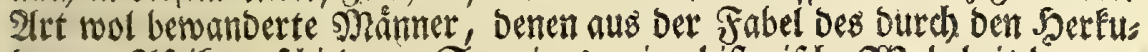
les von Ifrifa gefdiebenen Spaniens, eine biftorifde 2 (ab)rbeit berbor: zuleuchten fokimet. Die Beugniffe will idh barnad anfubren, oorber

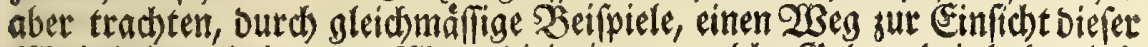

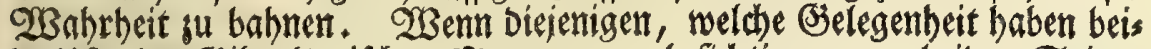
De Ulfer Der (sibraltarifosen sneerenge :H befidhtigen, an beiben Seiten einerley $\mathfrak{B e f}$ affenbeit Der (Erbe, einerley 2 rt Der Steine, uno gleidh be: fiellte \&agen antreffen, fo fómnen fie burch ein folches Beugnifi, zut $\mathfrak{Z} e=$

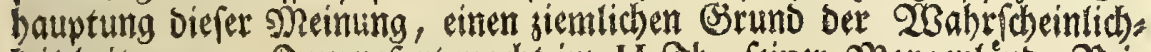
reit beitragen. Sournefort mad)t im II Sh, (einer Notgenláno. Reis rebefur. S. 64, eine Daber einfhlagende Ibbildung, wie burds Das ange: láfene 2 Baffer bes fobroarten Meeres, Der Befpborus Tbracius ent: ftanden, uno durch Denfelben Furopa von afien abgeriffen moroen. Zu (elbiger aeit ift vermuthlich, fpricht er, Die groffe Heberfdowemmung vor fid) gegangen, roovon Dioborus Siculus im V SHud) Der Sciftor. Siblioth. erwebnet, woourd) ein Sheil der afiatifd)en Stäbte verfenfet worben. Sie Fluth reichte, nach bem Beugniffe Diefes alten (Sishidhtforeibers, über Die ऊipfel Der Gamothracifden Serge, wie es bie Jntwobner biefer

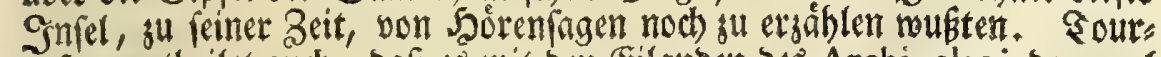
nefort urtbeilet aud), Daf es mit Den Eilanden Des Archipelagi Dajumal (3) 2 eine

(a) So fifreibet alth Pliniws, III, \&, Hard. 14: "Promontorium Pelorus voea" tur, adverfus Scyllam vergens in Italiam; Pachynum in Græciam, 


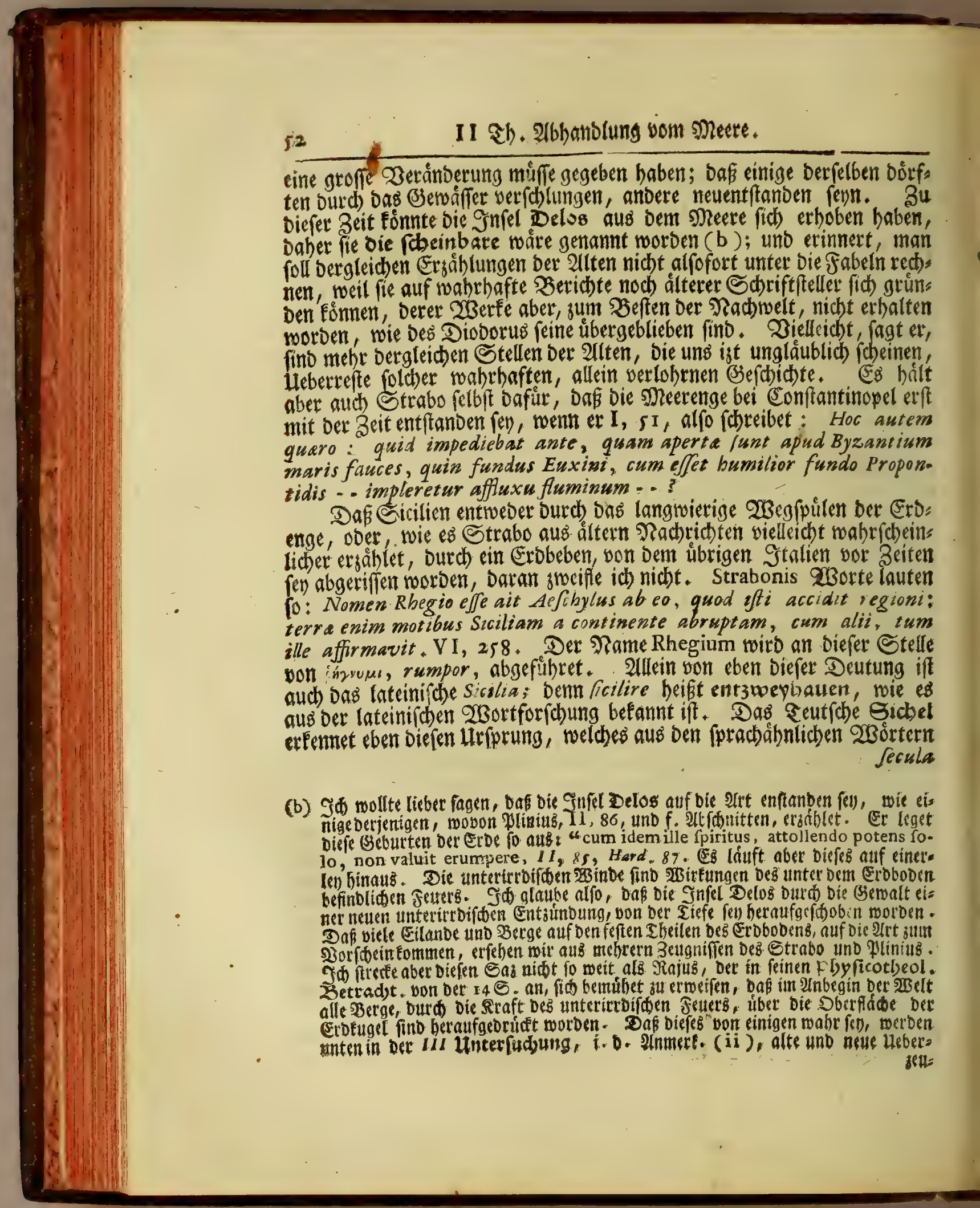




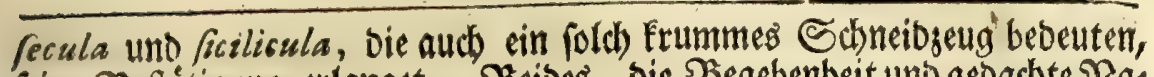

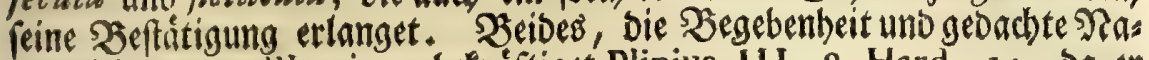
mengleitung von Rhegium, befrǻftiget Plinius, 11 I, 8, Hard, 14, Da er alfo fdrecibet: Verum ante omres (infulas) claritate Sicilia, Sicania Thucydidi dicta, Trinacria pluribus, aut Triguetra, a triangula Bpecie: circuitu patens, ut auctor eft Agrippa, Dcxvi11. M. pafl. quondam Brutio agro cobarens, mox interfuso mari avulsa, Xv. M. in longitudinem freto, in laticudinem astem $\mathrm{M}$. D. paff: (c) juxta columnam Rhegiam. Ab hoc dehifcendi argumento, Rhegium Graci

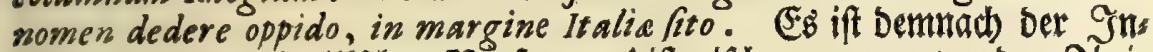
balt folgenoer Birgilifthen Jerfe gang biftorifh, wenn er von bem Sheiz le Siciliens, weldber bem heutigen Ealabrien am nád) fen liegt, Aen , 3 , 414 feqs. alfo (d)reibet:

\section{Hac loca vi quondam, Ev vafta convulfa ruina, (Tantum evi longinqua valet mutare vetuftas) Diffiluiffe ferunt; cum protinus utraque tellus Una foret, venit medio vi pontus, $\mathscr{E}$ undis Hesperium Siculo latus abfcidit, arvaque \& urbes Littore diductas angufto interluit aftu.}

Ebet fo Ovidius, Met. 5, 290:

- Zancle (Meffana) quoque juncta fuifse

Dicitur Italie: donec confinia pontus Abftulit, \&5 media tellurem reppulit unda.

(3) 3

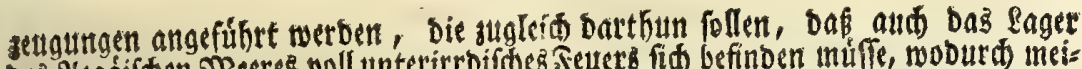

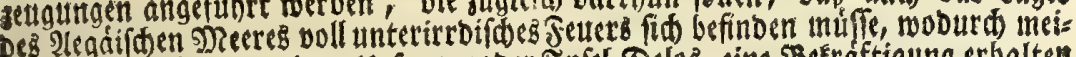

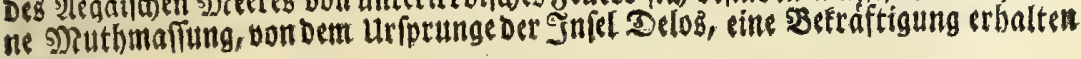
wird.

(c) EE follte viefleib)t beisen, in Tatitudinem autem M M. D. paft. Denn Itthan. Sirber bat Den fleinften 26 fetano Siciliens bon bem hettigen Enlabrien,

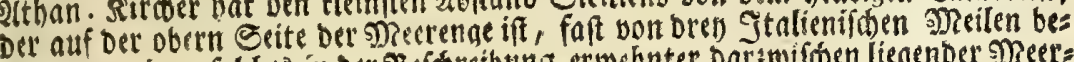

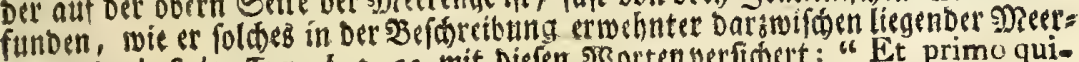
enge, Mund. Subt. Tom. 1, p.99, mit Diefen 20 orten verfíbert: "Et primu qui"dem freti, ubi anguftifimum elt, inter Pelori ripam ad Pharum \& Cala. "briæ promontorium, quod Scyllæum dicitur, latitudinem geometrica diy) menfione reperi 2783 paffuum geometricorum, y 


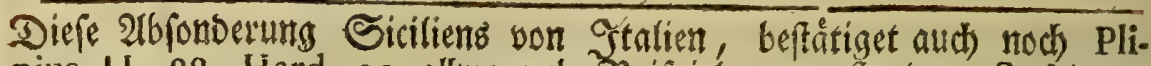
nius, 1I, 88, Hard. 90, allwo mehr 3 bi ipiele neuent tandener Snfelnans gefühtet werben (d), gleidbwie er im 2infange bes barauf folgenoen Jauptf. bingegen ein Jerzeichnis von anbern Eilanoen beibringet, wels de mit bem feften Eroreich fino vereinbaret worben. ETela befraftiget

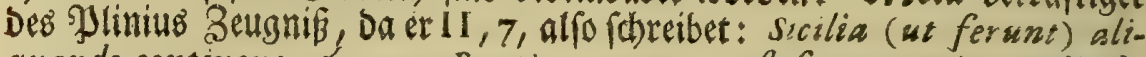
quando continens, o agro Brutio annexa: poft freto maris stculi ab. jciffa eft. Der Sefuit âthan. Sird)er, weldher bie verfdiebenten Siefen ber Sicilifthen Ineerenge mit Dem Sentblen abgemeffen, wie aud

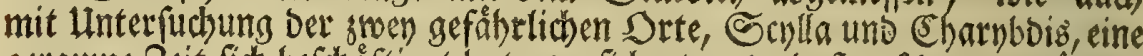

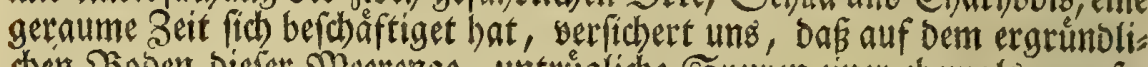
den Boben biejer Meerenge, untrügliche Spuren einer ehemals gemejes

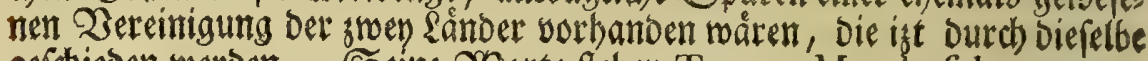
gefthieben werben. Seime 2 Borte ftehen Tom. I Mund. fubt. P.99, in Amfange DeB I 6 Sgauptit. und lauten fo: Conduct is peritis nature loci nautis, fretum ingreffus fum magno florum glomere in bolidis ufum inft ructus. . boc peracto, recto tramite cymiba in transverfum actus a Pharo continuo usque ad dictum promontorium (Scyllæum), continua bolidis projectione maris profunditatem exploravi, in aliis jam 30 , modo 50, 60, nunc 100, subinde 200 pedum fundum reperi; in nonnullis veluti fcopulos quosdam praruptos, inter catera vero, mirum dictu, totum bujus latitudinis fundum fopulorumque tramitem quendam veluti pontem e Calabria in Siciliam, utrimgue fundo in abyfum rubfidente, comperi, gui siciliam olim Calabrix boc faxofo tractu junct am fuiffe, non inobfcura prabebat indicia; ab immemoram bili vero tempore, five terra motu, five Tyribeni maris violentia, bunc difruptum Ifthmus, in fretum degeneraffe, adeoque Trinacrism peninfulam in infulam convertife.

Seneca ift Der Meinung, Daß̧ zur Beit Der groffen lleberfotwemmung, won weldher bie \$oeten fo vieles gefdrieben bátten, Sicilien von Jtalien fen abgeriffen worben: Sic hac inundatione, fpricht er Nat. qu. 6, 29, guam piëtarum maximi celebrant, ab Italia sicilia refect a eft. श्ad bem er, folches zu erweifen, in eben biefem Scauptft. fid Der oben anges

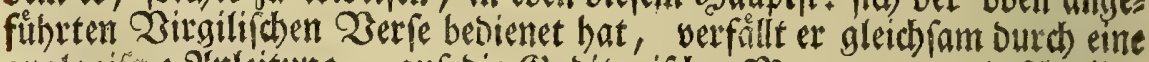

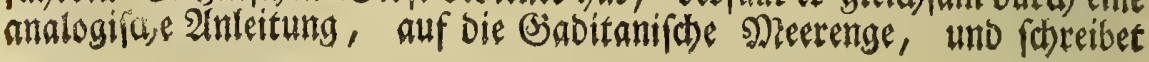

bont

(d) "Namque \& hocmodo infulas rerum natura fecit. Avellit Siciliam Ttaliæ, " Cyprum Syriæ, Lubœam Bœotiæ, Eubœæ Atalantem \& Macrin, Besbycum "Bithyniæ, Leucofiam Sirenum promontorio." 
bon berfelben getabe fo: Sic o Hipanias a contextu Africe mare eripuit. Qaletius Flaccus erwehnet aud ber (Sabitanifhen Meerenge mit Der Sirilifben, und leitet Derfelben Urfprung oon einerlen Urfacbe ber, Da et foreibet:

\section{- neque enim tunc Aeolus illis}

Rector erat, Libya cum rumperet advena Calpen

Oceanus, cum flens Siculos Oenotria fines

Perderet, EO mediis intrarent montibus unde. I, 587.

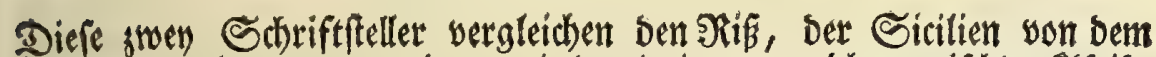
übrigen Stalien getrentet hat, mit bemienigen, weldher zwichen Ifrifa und Spanten erfolget ift. Strato beoienet fich bes Beifpieles ber wei. land entfandenen 2 gantinifhen Meerenge, um Die Baditanifhe aug gleicher Lrfache zu folgern. Stratonis Meinung erzántet Strabo, I, 49, mit folgenden 200 rten: Strato autem ad caufa explicationem magis accedens, exiftimare fe ait, Euxinum mare caruiffe aliquando exitu, qui eft ad Bysantiom: fed fumina. qua in id effunduntur, vi eum aperuiffe, itaque aquam in Propontidew o Hellepontum erupife. Idem noftro quoque mari accid! fe: nam in eo quoque apud columnas fretum perrupiffe, mari a flumintbus repleto: eague effufione aqua detecta effe

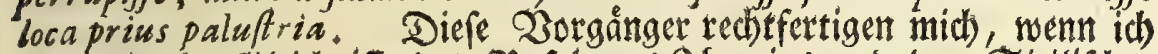
ebenfalls die (Steid)niffe Des Bofphorus Shracius und ber Sicilichen Seerenge vorber beigebradht habe, um Die Trennung Spaniens von

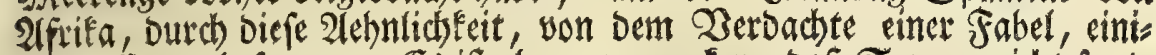
germaffen zu befrenen. Fs ift aber ansumerken, Daß Seneca nidht fagt,

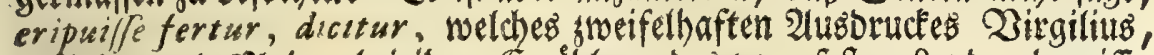
Dovidus und Mela, bei iheer Ergaiblung des vom feften \&ande abgeriffes

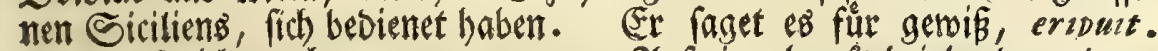
Flaccus fpridht audh, cum remperet. - 2 uf eime eben fo bejabende unto zus verlaffige Art, fuibret Strabo bie abpaltung Spaniens von 2 frifa an, Da er an eiter andern Stelle, nânlidi 1, 58 , alpo fidreibet: Nibil igutur mirabile, fi aliquando ift thess, qui mare Esgyptium a rubro diftinguit, ruptus aut fubfidens, fretum efficiet facietque ut externum mare cum interno confluat, ficut ad fretums apud Herculis columnas evenit. Er faget aud nicht, evenifje fertwr. Dâj aber diefe Ento

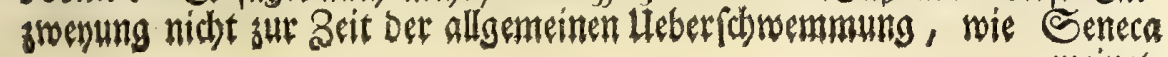
meinet, 


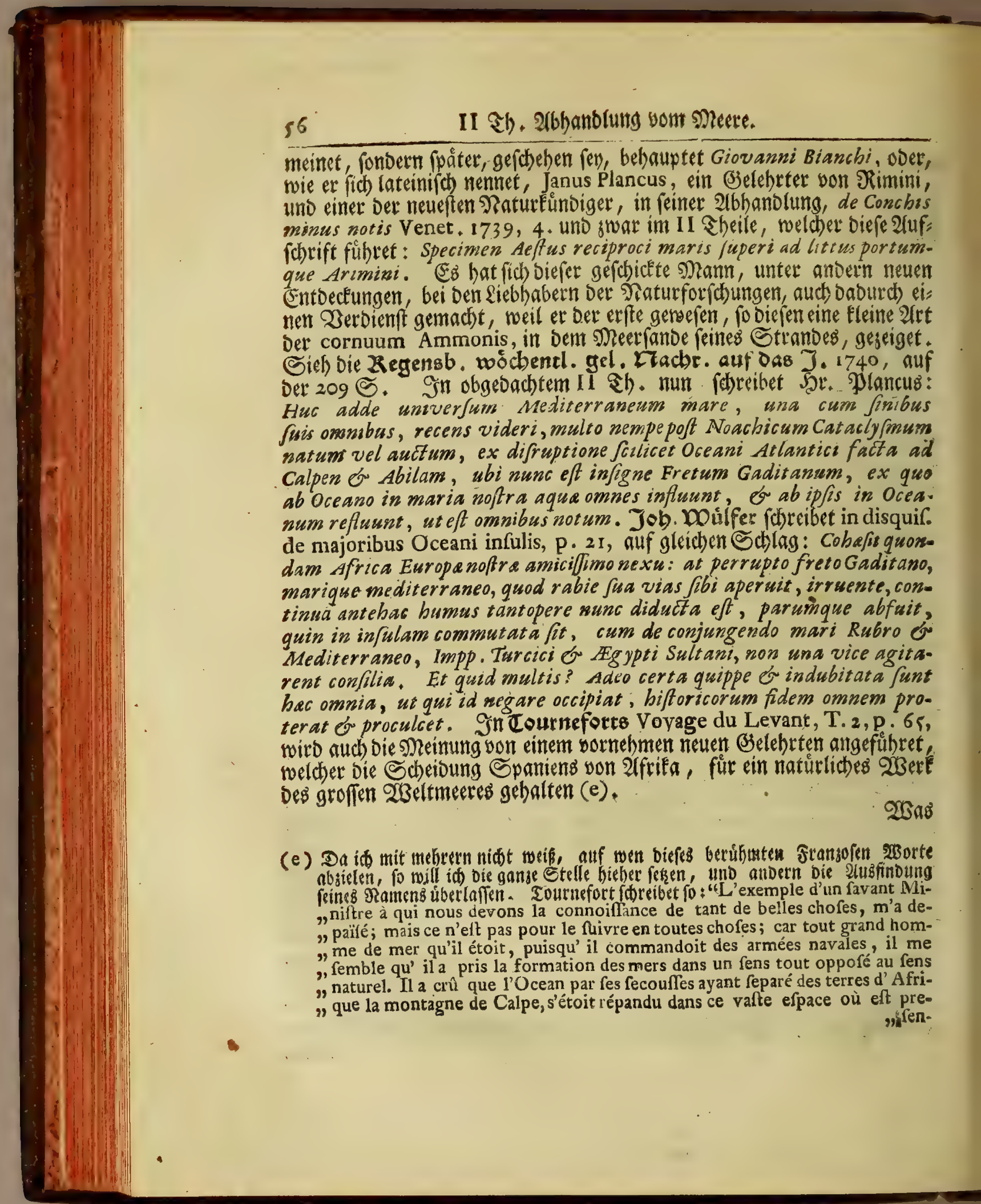


Erfte Unterfuctung.

57

Was die 2inmerfung Deg Doffius anlanget, welde ber $\mathfrak{H} r$. Jerf. bet Sdurift de COL. HERC. in Dem V I 2 bichn. S. I7, anfübret, Da muß idh betennen, oapentroeber id) Derfelben eigentlid)en Sinn nicht faffe, oder ez odrfte biefer (Selehrte eime theologifche Betrachtung unrecht

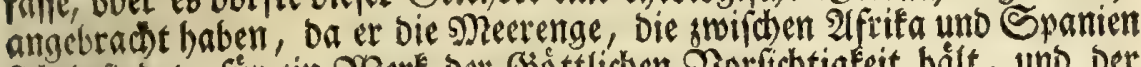
fich befinoet, fur ein 2 Berk ber (Góttlidben Jorfidbtigteit bált, uno Der

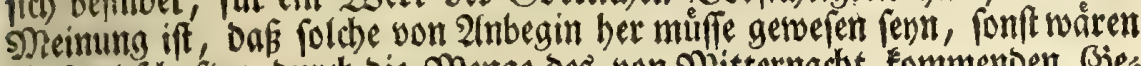

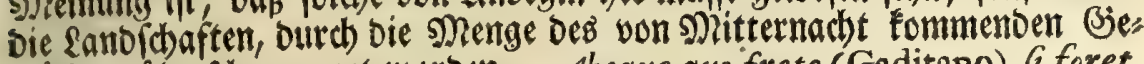
máffers, úberfd) wemmet worben. Absque quo freto (Gaditano) fi foret, (pridht et de idololar. II, 69, p. 669, periculum efjet, ne terra copia aquarum ex feptentrione affluentium, obruerentur. Sch verftebe bie:

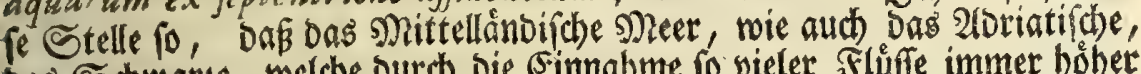

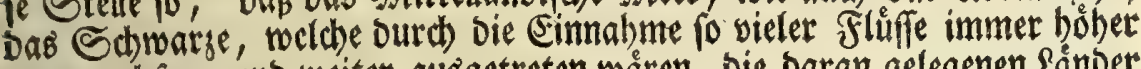
angervachjen, uno weiter aurgetreten wåren, bie baran gelegenen \&ánber fdon lángft würoen unter 2 Baffer gefest baben, woferne Den legtgenann= ten Meeren in bas erfte, uno Diefem burd) bie Meerenge zroifd)en Afrifa uno Spanien, fein 2 (usflus in bie Atlantirche See von bem Schopfer

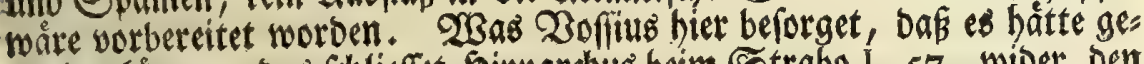
fdeben fonnen, Das fd)lieffet Shippardhus beim Strabo I, 57 , wiber Den Eratofthenes, daj es wirflid) muffe gefdueben fenu. Seine 2 Borte ber: Dienen bier angejogen gu werDen: Dicit deinde, fi mare ante, quamfre. turs ad columnasperrumperet, intumuit guantum Eratofthenes ait, ne. ceffario of totam Africam. Of multas Europe Ajague partes fuifje prius inurdatas: hisque addit, Pontum quoque cum Adria debuiffe quibusdam locis confluere \&c. 2Ullein wenn idh Des Noffius Neinung, uno reine angebracte Sd)wierigfeit, red)t eingereben babe, fo frage id auf gleidse 23 eife, warum uberfdowemmet in einer Beit oon mebr taujento

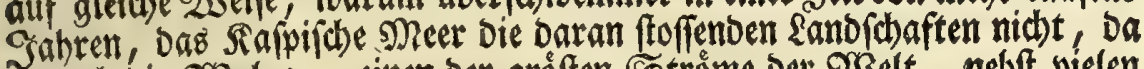
es Dodh Die Y คุ

andern

"fentement 1a Mediterranće: que cette mer avoit enfuite percé les terres ,vers le Nord \& produit la Propontide ou mer de Marmara, la mer Noire. ", et les Palus Meotides u. . F. „, Sournefort hátte anseigen Eonnen, baß Pliniuß

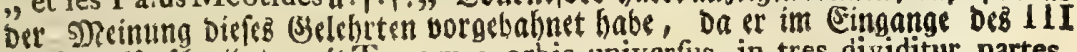

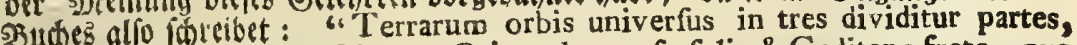
"Europam, Afiam, Africam. Origo ab occafu folis \& Gaditano freto, qua "irrumpens Oceanus Atlanticus in maria interiora diflunditur. " $\mathfrak{B o r}$ Dem $\mathfrak{P l i}=$ IIius hat Strabo eben bicfes, unb nod) Deutlider, gelchret. Eeine 2 orte find fo ab. gefapt: "Quartum 、 $c_{0}$. finwm), qui magnitudine dictos multum fuperat, internum \& noftrum, ut nominant, mare efficit, incipiens ab occafu, \& freto, "quod 


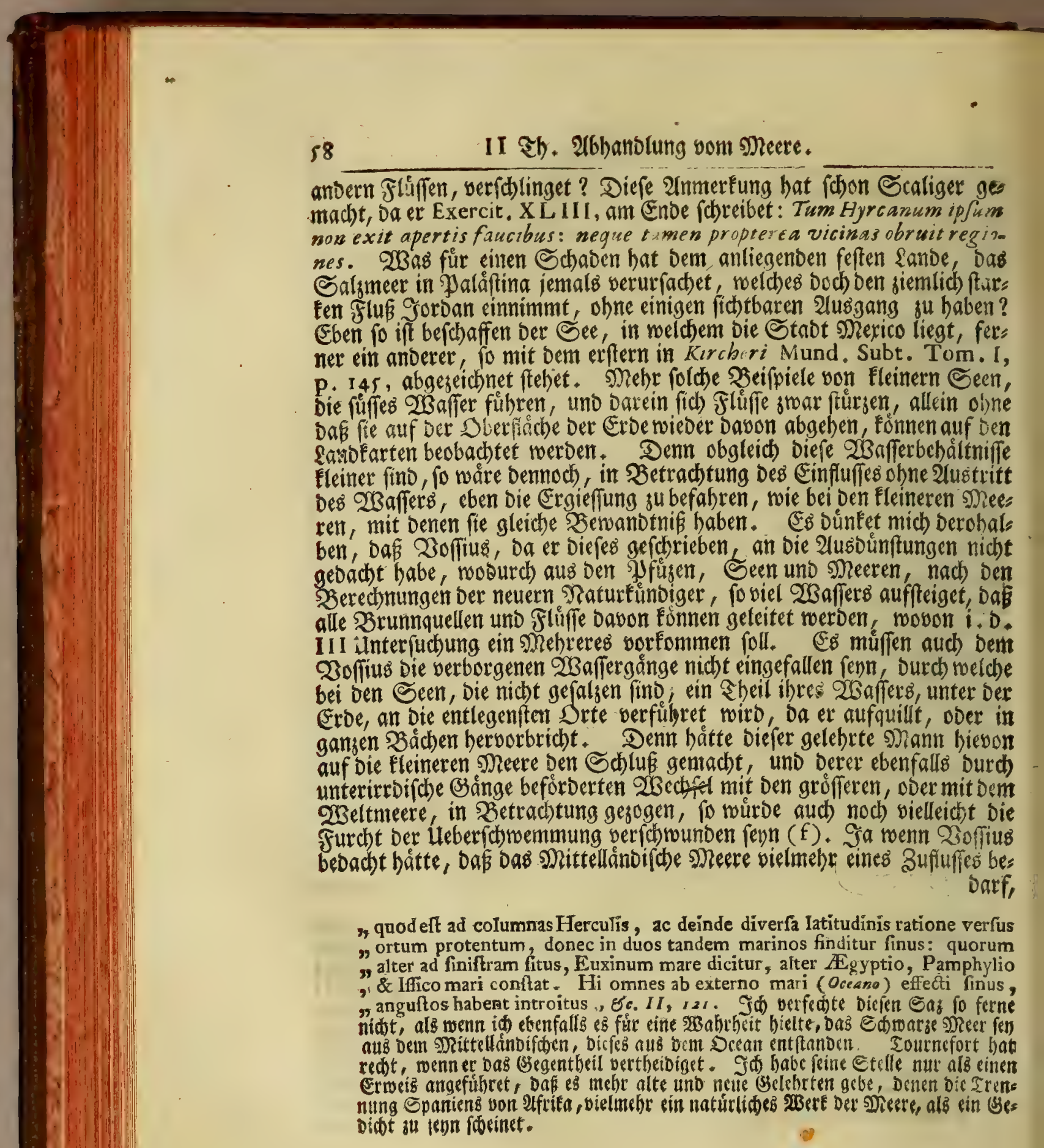




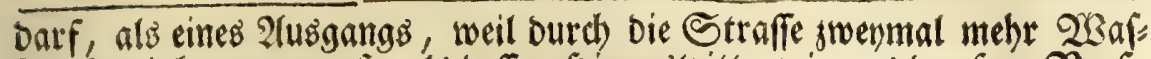

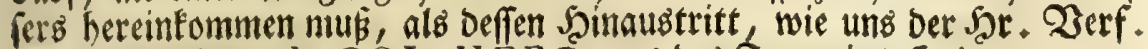

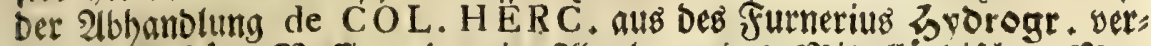
fichert; fo biette 20 offius eher ein 2tbnehmen Des Nittellandichen Nees res beforgen Eơnen. Diefer (Einivurf låpt fich auch folgendermafien, uno ztwar firtser, abfertigen. Man fann Darauf beharren, daß Das Mittel: lândifche Meer anfangs mit feiner Sefnung, fwifthen ben Bergen 2(bnla unt Salpe, veriehen, fondern auf allen Seiten mit sånoern umgeben ge:

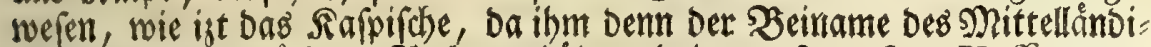
(d)en mit nod) grófferm Siechte gebihbret babe. Man fann Voffio zuges ftethen, Das Daffelte in Der Shat weiter nügebreitet gewefen, und vielleidt

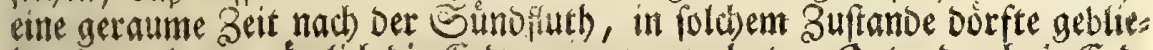
ben jenn, bevor námlich Die Eroenge, an erwehntem Orte, Duras ein Eros beben entywer geborften, ober auf eine anbere Wieife Durchgebrochen worden. Fllein was fann er ungereimtes bieraus folgern? Scátte biefes

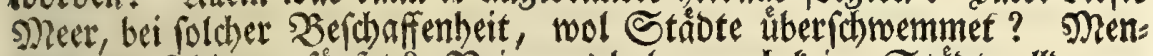

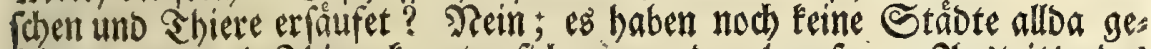

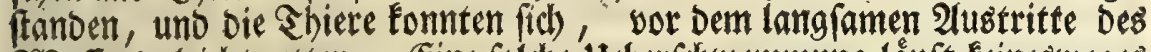
$23 n$ fiers, (eid)t retten. Eine fold)e Heberfitwemmung lăuft feinesweges

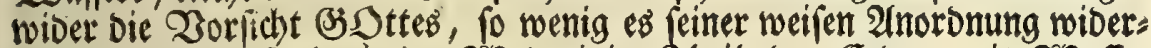

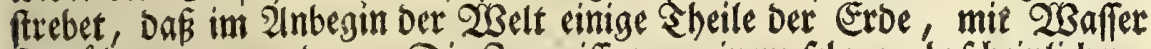
fino überzogen worben. Die Zetugniffe von einem fehr wahricheinlichen,

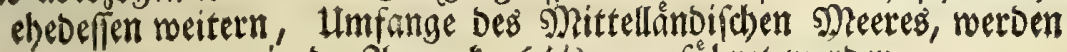
unten i. D. 2Ammerk. (il) angeführet weroen.

\section{ฟุ 2

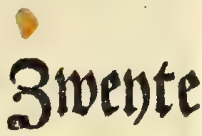

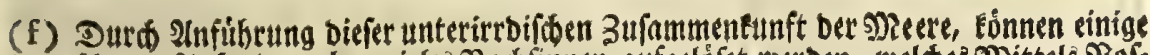

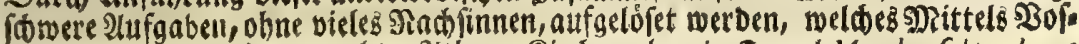
fus an biefer Stelle gar nibt, Fitban. Sirber abet in Tom. I Mund. fubt. $l_{0} 3$

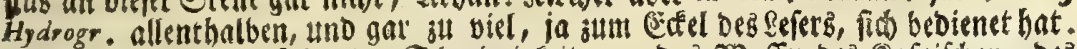

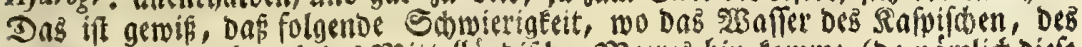

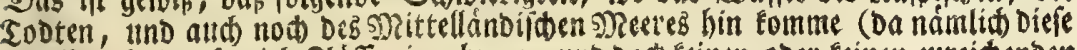

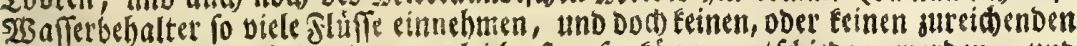
2(usflus, su haben fobeinen), an leidteften fo fonne entidbeben -werden, uno Dá́ man am éfeften Davon fomme, wenn man antroortet, wie Rirober, biefe 9)eere haben einen verborgenen 2Utugang in ben Dcean. Fillein úberkommet Der

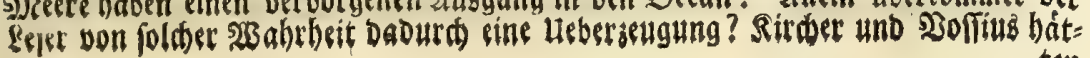

ten 


\title{
(1wente \\ sinterfuttumg.
}

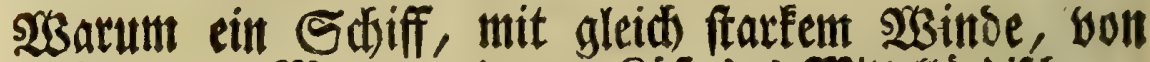
einer gegen Morgen gelegenen Rǘte Des Mittellándif́chen

Meeres, f. $\mathcal{F}$. aus ’aláftina, eher nach Spanien gelange, als von bort wieberfebre.

\begin{abstract}
SE,
ás es in ber Shat fo zugehe, beseuget es det Sht. Werf. Der Sdrift de

COL. HER C. (ohne 3neifel nod) aus Volfii 1. 2 de Idol. c.69, p. 669) mit folgenden 230 orten : Videtur autem non tam Oceanus Atlanticus, grod Plinius, prooemio lib. III ait, per boc fretum (G2ditanum) in maria interiora ordinarie irrumpere, quam mare mediterraneum hac uis in Oceanum diffundi; propterea quod in mediterraneo mari motus ab ortu ad occafum obferuatur, $\sigma$, pari li. cet uesso, multo celerius ex Aegypto, aut Pboenicia, nauigari in Hißaniam, guam rediri, fertur. Sect. VI, P.18. Diefe Nachrid)t beftarefet Die SEedbad)tungen, welde Marfilius und Mlancus vom Meere

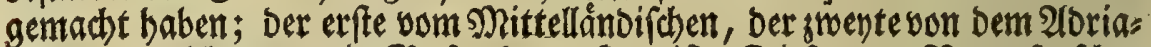
tifchen, weldes nur ein Bufen bes erftern ift. Diefé swen Paturforidher

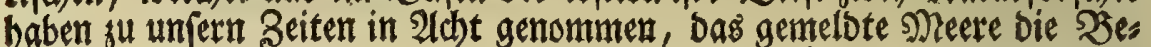
fitaffenteit eines Fluffes baben, inbem fie unaufhoirtich nach ber einen Seite itrer groffen Eager bin, nad) ber andern aber zurudéf fleffen. Sa Marfitius merfet nach vielen anbern, nod) eine befonbere 2 int Der sleers frome an, fraft berer bas obere Bsewånfer auf bie eine Seite, allein Das untere, eben biefer Strecte bes Meeres, nad) einer andern Seite laufe. 1um foldbes zu verfteben ift vorber zu merten, daṕ bei allen Neeren, wels de mit Dem Scean einen frenen 28 sechfel pflegen, eine Drenfade Szenes gung fich finde.
\end{abstract}

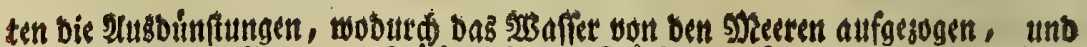

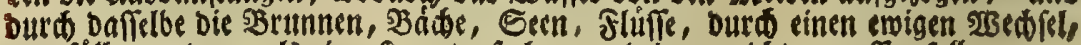

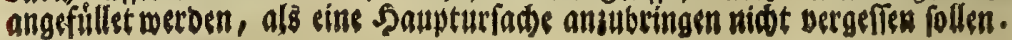




\section{S. I.}

\section{Drevetlen Bemeattuget Des Meeres, Wellen, Stro: me, Sluth und \&2bbe; wo aud von Den Gpringftuthen gehanoelt wirb.}

Eל ie erfte Retwegung Des Meetes beift bie Rrdufetung ober bas 2 Bels ber Dberthiche Der See, welche meiftentheilż von Den 2 Binden berrübret. Die 23 inde aber, fie mógen nod) fo heftig fern, fo tơnten fie ben arieb Der smentent SBewegung nicht ganslich bemmen, wiewol fie mebs

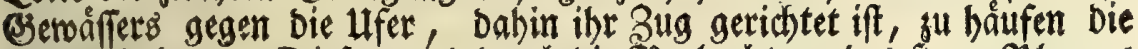

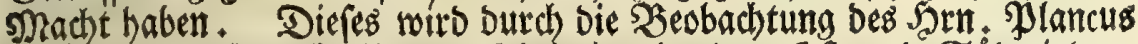

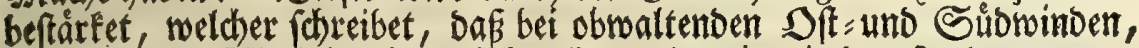
bas झ)eer bei SRimini mehr auffichnelle, und weiter in Das \&and austrete,

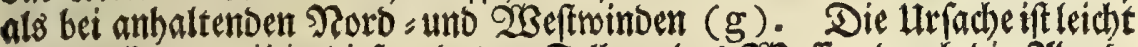

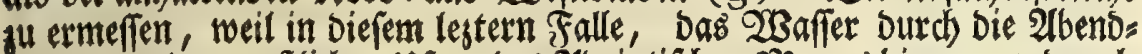

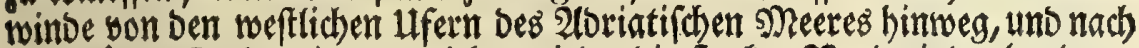

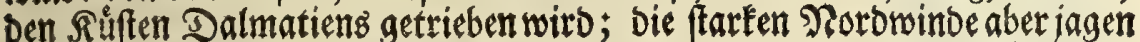
einen groffern Theil beffelben, aus Dem ganzen $\mathfrak{B u}$ fen, in Das Sonifde

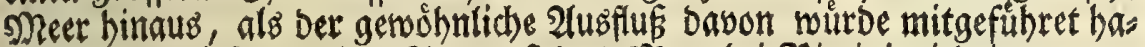

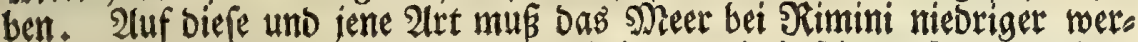
Den. Sin bem erftert Falle hingegen, bringen bie beftigen Mittagswinde mehr 20 affers in ben ganjen seerbujen binein, uno máchtige Morgen:

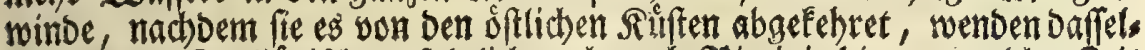

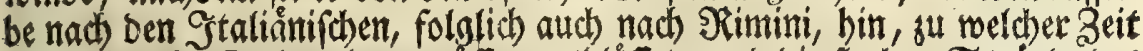
Denn die Ufer Dalmatienb múffen entblóflet, und die hachen Stránve bes

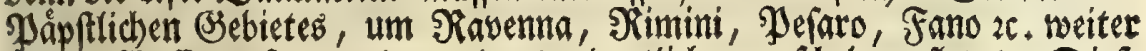

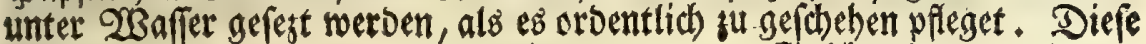

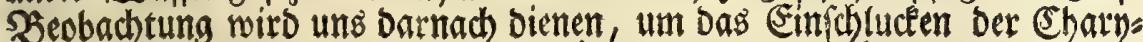
bois, bei herrichenden gewaltigen Subminden, zu erkláren, und Dadurch S马 3

Den

(g) "Aufter, Vulturnus \& fubrolanus (Ariminenfe) mare aliquantulum inflant, ") ut magis tumeat \& afcendat. Aquilo contra \& Circius, fi violenti fint ac ") diuturni, id deprimunt, \& fyrtes breviaque majora ibidem producunt, 


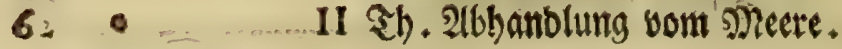

ben $\mathfrak{B}$ eridht ber $\mathfrak{A}$ (lten won biefem 2 Birbel gu befr ftigen; wie id benm

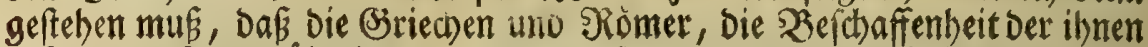
befannten seere, uberbaupt zu reden, fo gut entworfen baben, dafi die neuern szaturf́ndiger, mebr bie Beforeibungen Derfelben nur zu beftóti: gen fabeinen, als neue (Entbectungen zu mad)en, wovon bie qliten nichts follen getouft baben. Man lefe nur, was Şr. Ylancus oon ber Fluth uno (Ebbe Des 2loriatifchen Meeres beridtet, fo wiro man foft argrootnen, er babe nur Dasierige berausgejhrieben, was plintus von biefer (Figenfdaft

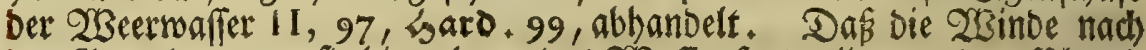
ben Begenden, wo fie binwehen, das 2 Baffer forttreiben, und auffatwel:

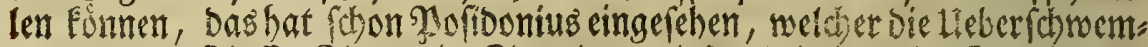
mungen Des fluftes Sberus in Spanien, diefer Urfache, beint Srrabo I I 175, suldreibet. Sie Stelle lautet fo: Novum autem \& peculiare quippiam ille de Ibero fluwio refert, eum aliquando exundare, nullis imbribus aut nivibus caufam prabentibus, eum borea frequentes flant: in caufa effe paludem, per quarn fluit: nam a ventis aquam paluftrem una extorgueri. Safj Diefe fobone (Erflårung, auch nach Den

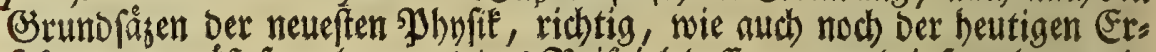
fârung gemáf fen, bezeuget Das Beifpiel Deffen, was bei Samburg, ja an allen von ber Torojee angefpulten niebrigen (segenden, ofters vorges bet, weldhe mandomal groffe lleberficwemmungen ertragen miffen. Dies fe aber entfteben an Den Drten, die s. (E. um die (Elbe liegen (zu Sams

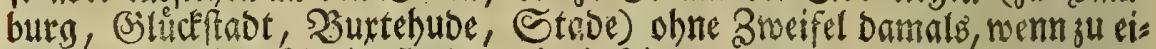
ner ofoentlicken Springfluth, ein beftiger uno anbaltender Noroweft ober 2 beftnoroweft, fid gejellet, welde 2 Binde nod) mebr 2 Baffers bon Der offenen See in Die Snunbung Der Elbe bineintreiben, norauf Derfels ben cigenes 2 Baffer, nad) einer siemliden Strecke aufwerts, nothmenoig

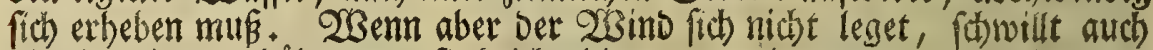
die See immer bober an, fie bricht bier und da in das sano berein, die Jluffe vereinigen fich mit biefem einfallenden 2 Baffer, unb wito enolich aus Dem platten feften \&ande ein sreet (h). Don biefen gewaltigen

sills

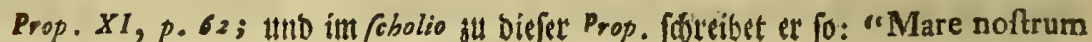
"flantibus ventis orientalibus \& meridionalibus magis tumet, quam fian"tibus occidentalibus \& aquilonaribus."

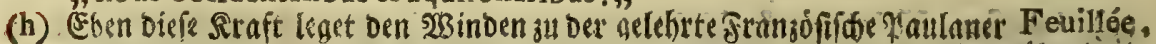

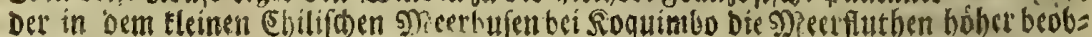

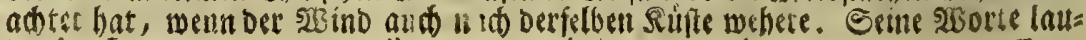
ten 10: Les vents, comme j'as remurqué ailleurs, détournent cette preffion, 


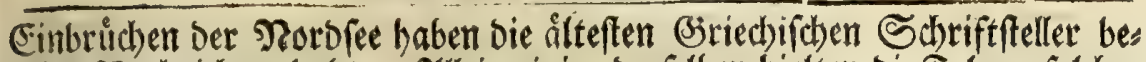

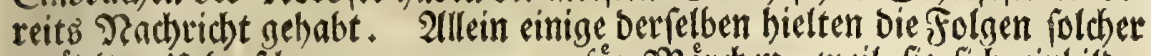

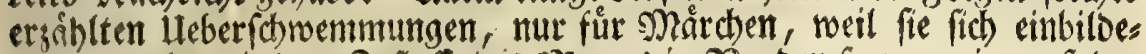

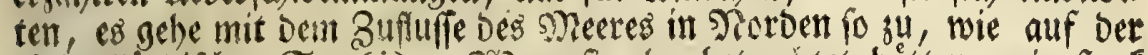

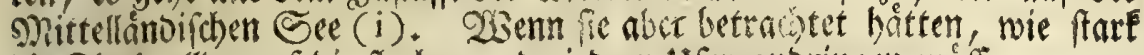
Die Fluth allba auf bie flachen und niedern ufer andringen múfie, wenn

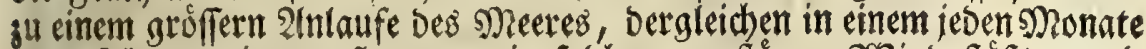

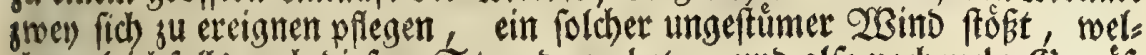

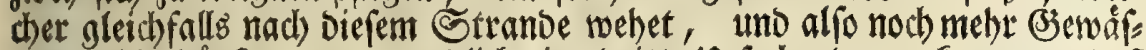

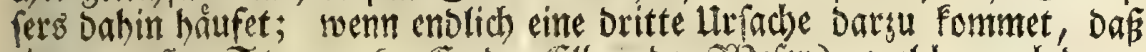

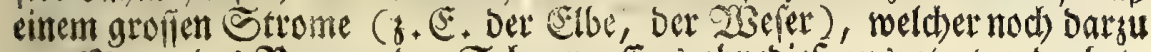

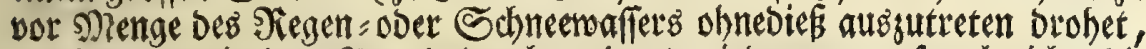

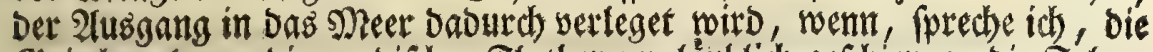

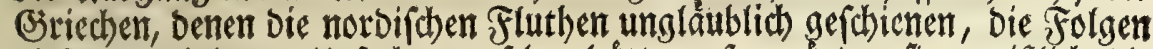

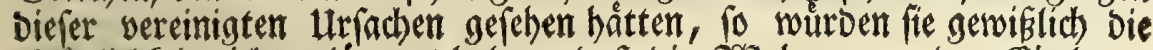

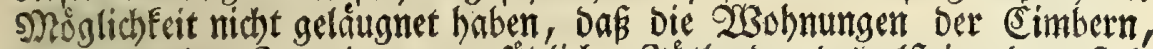

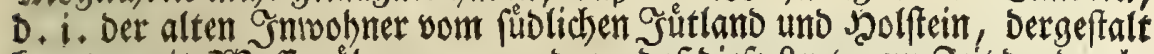

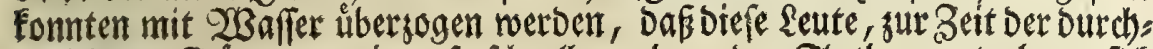

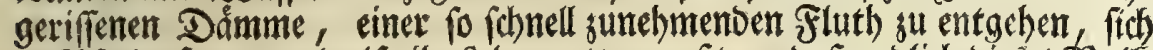

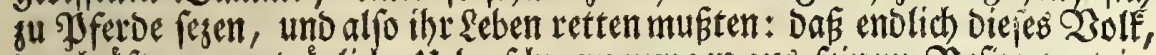

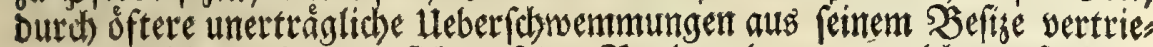

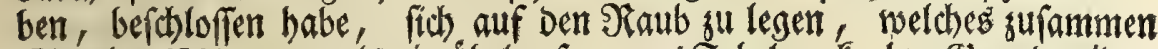

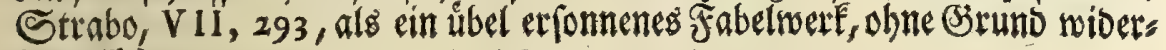
leget $(\mathrm{k})$.

Die swente Betwegung Des Mheeres ift ber Strom, Frang. le coscrast, Ital. il corrente. Warenius beift biefe Bewegung Der groffen See, c. 14, prop. 7, motum Oceani continusm, Scrbinius diff. de Cataract. 1. 2, c. 2 , prop. 3, \$ 1, motum aternum univerfalis Ocea. ni, uno $\$ 2$ auch torrentem Oceani. 21than. Sitcher nennet in Mund. fubt. Die झeerftrome gum offteften fdeled)tweg, currentes maris. Der

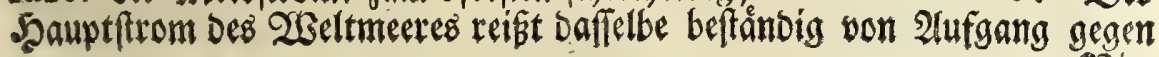

fi leur direction eft entierement oppofée à celle du mouvement des eaux, auquel cas ils retarđent les marées, \& empếchent même qu' elles ne monter. aufi haut qu' elles feroient dans le calme; mais fi les vents concourent avec les eaux, en les poufant, ils les font monter beaucoup plus haut qu' elles ne feroient, fi elles ne fuivoient que la feule preftion de la Lune. Fokrmal des $0 b / e r v \cdot p \cdot 578$.

(i) "Quin \& figmentum videtur, eluviem aliquando immodicam accidifle: cum 


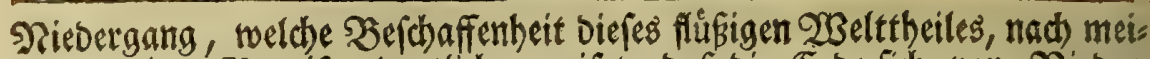
nem wenigen $\mathfrak{B}$ egrife, Deutlid) erweifet, Daf bie Eroe fich von Niebers gang gegen 2lufgang, um ihre 21 dje herumwente, uno fehe ich gar nicht

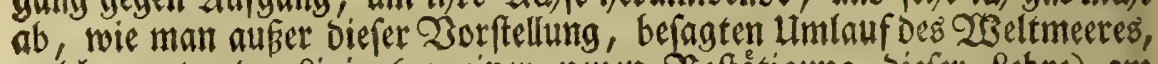
welcher unter Der sinie (3u einer neuen SBeftátigung biefer Sebre) am fádeften ift, invem Dic Erdfugel alloa Den groften limfang bat, uno folgs lich Deren sbeile am gefthminoeften fich alldort umoreben muifen, waht:

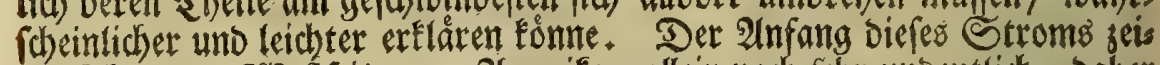

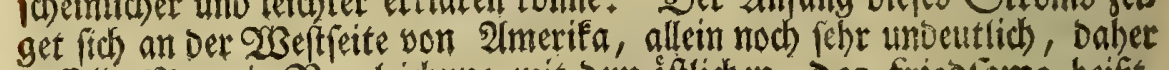

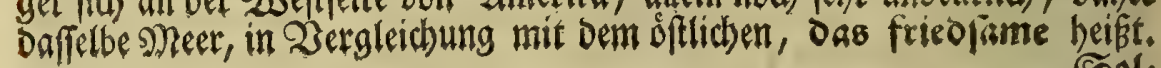
Sol.

" id genus Oceani accidentia intendantur quidem \& remittantur, fed ordine "tamen fuo atque modo Strabo Vit, 293 .

(k) "Non recte etiam is, qui arma adverfus exundationem cepifle Cimbros ait: "neque id, quod Celtæ ad vacuitatem metus fefe adfuefacientes, patiantur ", domos fuas aquis obrui, rurfumque ædificent, pluresque eorum aquis quam ", bello pereant, quod Ephorus tradidit. Nam hæc abfurda non admittit cum "ordo æftuum, tnm notitia regionis illuviem paffa: cum enim bis quotidie " aftus accideret, qui credibile fit, tandem nunquam eos fenfiffe naturalem "effe hanc maris reciprocationem \& innoxiam, nec non fibi cum omnibus " ad Oceanum accolentibus communem? Male etiam Clitarchus, equites ", narrans accurfum maris fpectantes, citatis equis refugifte, \& pene fuilfe a " fuxu obrutos: neque enim tanta celeritate accedere mare deprehendimus, "fed fenfim \& latenter: neque id, quod fieret quotidie, \& omnium fpecta" turorum aures ante, quam accederent, perfonarent, tantum potuit objicere " his terrorem, ut quafi de improvifo oblata re fugam facerent. " Illein bifs

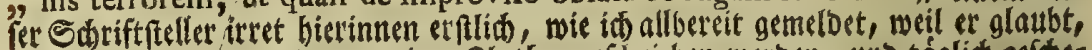

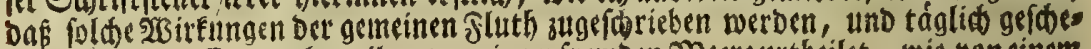
ben musten. Darnad weil er von einem fremoen scere trtheilet, wie voneinem

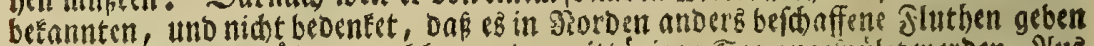

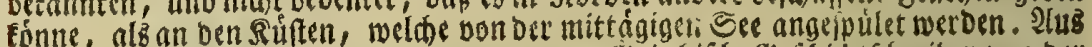

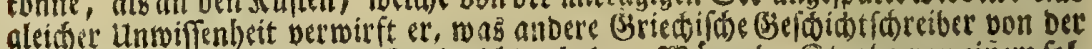

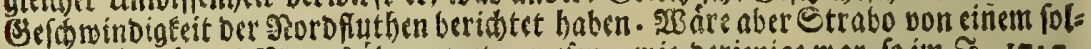

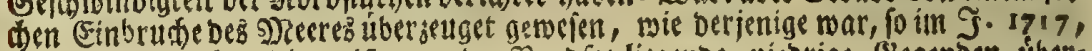
in Dee Ehriftnadt, Die meiffen an Der Sordore liegende niebrige Begenden uber:

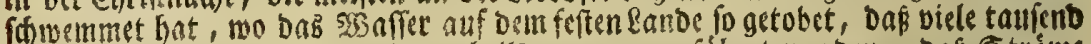
Scufer babur theilg verberbet, theils gents weggefuhret woroen, Dap etreme

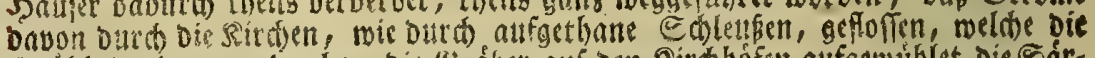

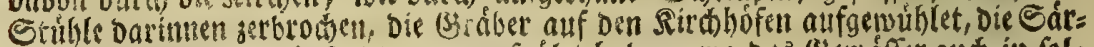

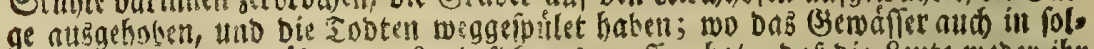

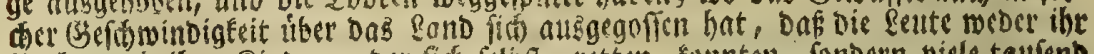

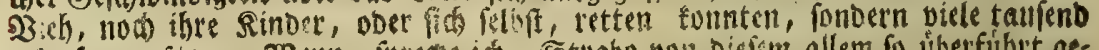

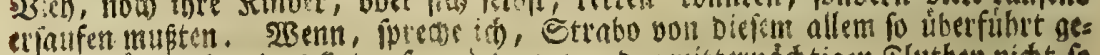

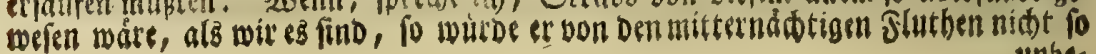
unbes 


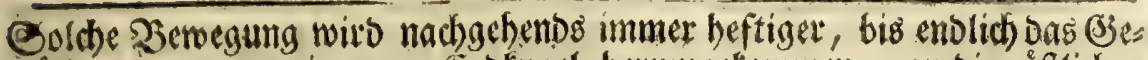
miffer, Dre cs un bie gange Erofugel berumgetommen, an bie offtichen ánber von America mit aller Gerwalt anftútmet, two es benn bie Erbenge,

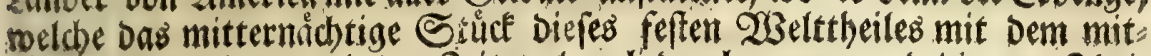

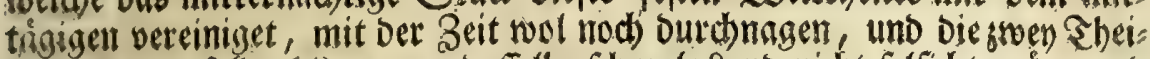

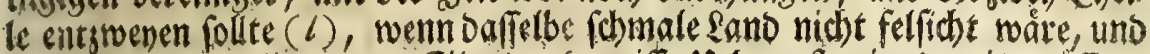
bie vielen Davor liegenton Eilande (gewiffe lleb refefte eines neit groffern

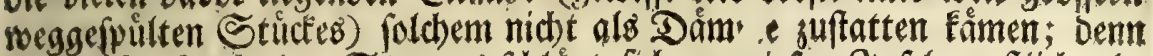

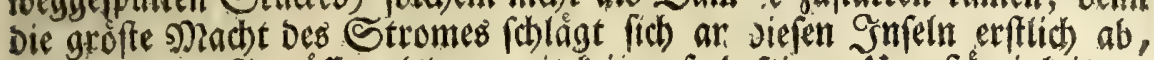

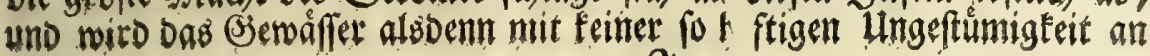
点

unbejomten geurtheilet, unb in ben Sag binein ge/drieben haben. Bie in Sams

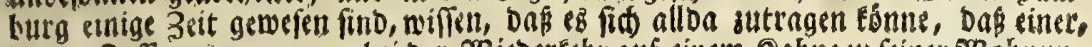

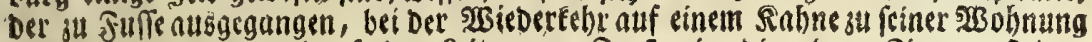
fabten, over aud wol auf einer \&eiter zum Senter in Die obern Zimmer Reigen

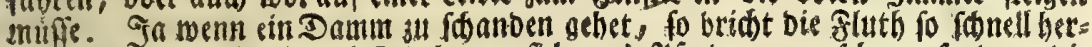
cill, baf man nibt sinmal Zeit bat, fid nad Pferden umatreben, fandern Die

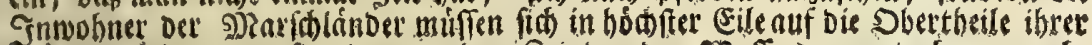

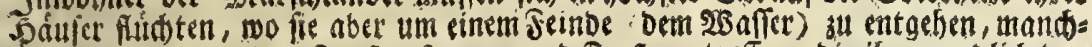
mal Drev andere, Den Surf, Sunger und Finf, antreffen, Die thenen end lid Den Bataus maden. WBas ben Durft anlanget, io ut su wiffen, Dapide Serter, fo náber ain MRere gelegen fino, mit gefalsenem untrintbaren $w_{\text {affer }}$ uberzogen

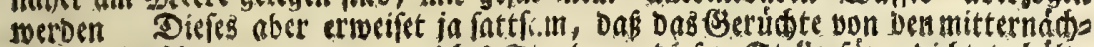

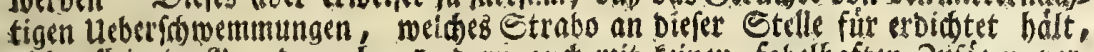

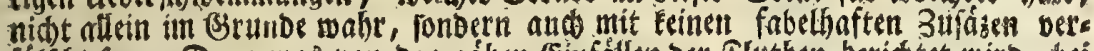

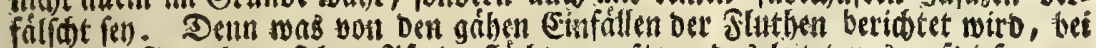

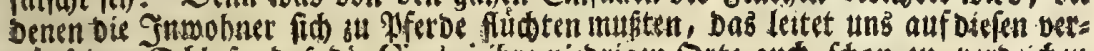

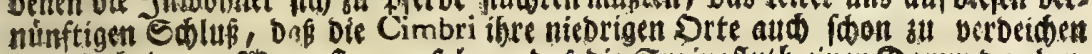

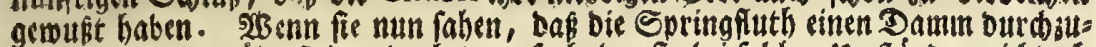
beeden, ober zu iberfteigen brobete. fo baben fie bei folden umftanden nicht at=

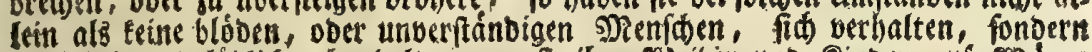

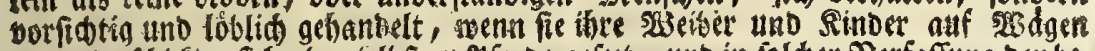

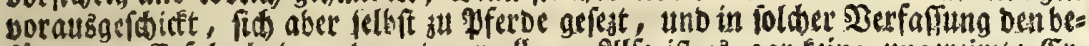

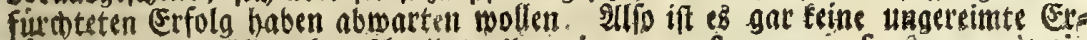

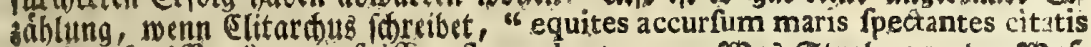

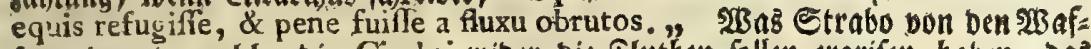
fen erintert, welde bie Cimbri wiber oie Slutben follen ergrifen haben, Das

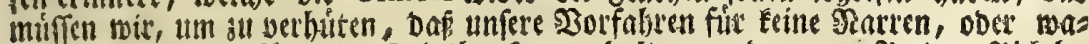
dere Strriftellet fur Eeine fabelhanfen, gehalken werben, oon 2leten, Piteln, Rérten, Salten, Epaten oder Edaufeln, u.D.g. Berdthe berfeben, Damit

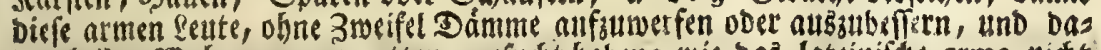

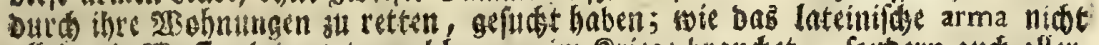

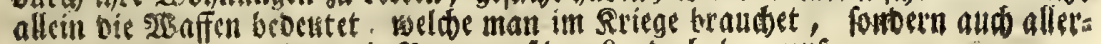

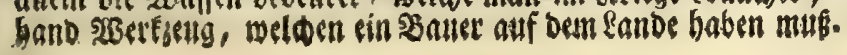




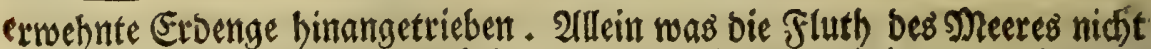
ausrichtet, Das̉ Fann ein Frobeben bermaleinft gumegebringen; wie man

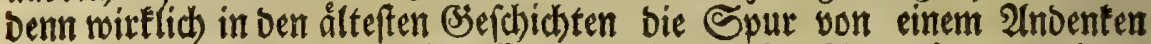
finbet, tootaus einige mutbmafen, dab bie erften Aegyptier von einem vierten Sheile ber 2 Belt Eonnen gewugt baben, allein bavon nur fo viel fagen fonnten, Daf er Durd ein Erobeben, uno barauf erfolgte Heber: fdroemmung Des sneeres, fey verbeeret uno veridhlungen worben. So baben Die Alegyptifden \$riefter Den Athenienfifden 2 Beltweifen Solon beridbtet, wie aus Dem (Sefpråche beim Slato, Das Timaus beift, ju

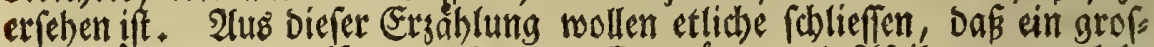
fes Stud yon Imerifa, weld)eb Den Europaern uno Iffifanern zugefehs ret wat, viele Şabrbunderte sor Der sebseit Deb Solon, dorfte cingegan: gen fern, weldbes etwa die alten, wegen einer gar gu weiten Entfernung Des lleberreftes, auf einen gânjlichen Derluft ausgebeutet baben, Varen. Geogr. c. 18, prop. 17. Es ift biefes feine ungereimte Neinung; ja

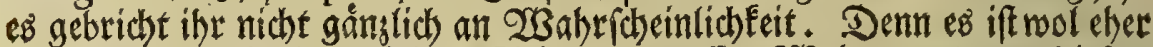
zu glauben, daps die weftliche Seite Des groffen 2 Beltmeeres bon biefem anjebnlichen 2 Belttbeile, weld ber burds baffelbe ebemals angerpulet wors Den, Den Samen Der Xtlantifben See befommen babe, als von einem Serge, Der auf Dem feften sande ftebet. Sndefien urtheilet Cellarius, Geogr. ant. 1, 40, mit mebr andern, Daṕ die aclantis des łlato füt fein wirkliches, fondern fur ein erfonnenes, sand zu balten fer. Das ift

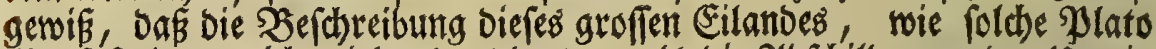
abgefajt bat, nicht viel anbers laute, als bie alb/ditberung ber litopia Des Morus. Sallein fino nicht surd gar zu groffen 2bftano ber Beiten, meht wahthafte (Sefdid)te Des grauen alterthumes in Fabeln serwandelt noroen?

Doffus fdreibęt, de Idolol. II, 69, p. 668, auch bon einem Gros

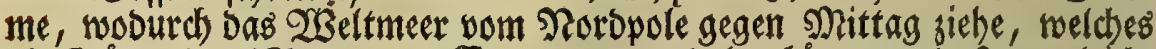
Die Dånen Das L Toroenwaffer nenteten; Daber fáme es, Dás man leith: ter von Mitternad)t gegen Die fübwerts gelegent sånder fohiffen fonnte, als aufioerts; ja nach bem Noropole su, fpureten bie Seefabrer, auds bei gutem Winde, einen 2 Siberfano. Sie llrfache diefer Sefarfen: beit wiro Der bòbern sage Des Meerbodens zugefdrieben. Man beobach: te aber alloa, fbreibet Doffus, auch einen Siegenftrom, ber nach Nite

(2) In ber I Interfubitng if a. D. ss S. eine Stefle aus bem Strabo angefúbret worben, allwo berfelbe auf gleiden Sdlag melbet, es bórfte atth bie Erbenge,

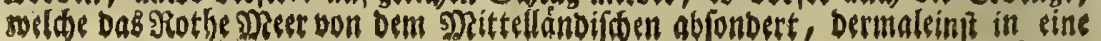


ternacht geridhtet fen, unb von ben Dånen Das Súbenwaffer genenneE werbe, weld

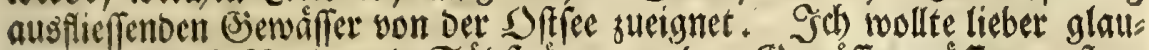

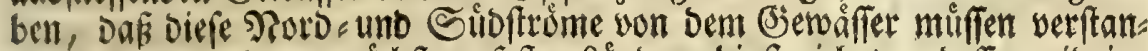
Den werben, bas sunåd)ft an feften \&anoern binftreidset, Deflen wiorige

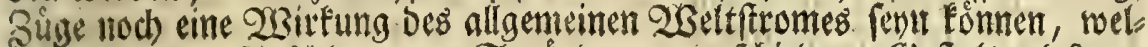
cher burd Das 2Infidagen an Strande von verichiebener Seftalt unt \&age, auf verjobiebene art gebrodsen, uno langs benjelben binjufleffen genothi: get wirb. Aluf Der frenen mittenachtigen See dorfte man Dergleidben Strome wol fowerlich antreffen. Got storfle berowegen auch, ob auf

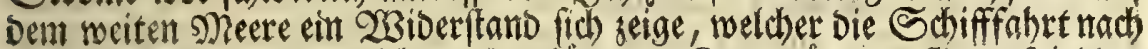

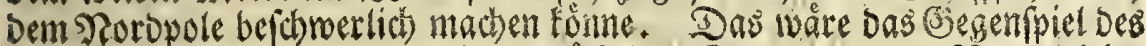
Sorgebens Derienigen, Die einen mådtigen 3ug gegen Den Troropol be: baupten, und baburd ermeifen wollen, baf es in bet auferften norbli:

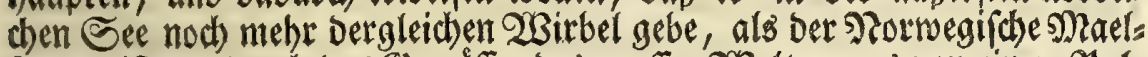
ftoom ift, woourd) Dab Senonffer DeB groffen 2 Beltmeeres von einem Jole zum andert wed) feln, wie audh Die Fluth und Ebbe in Dem Scen, und anbern bawon abbangenden sneeren, verurfachen foll, weld hes sebrgebát:

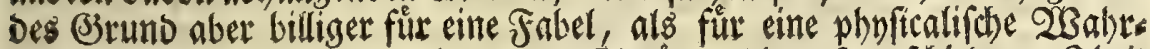
beit, su balten ift. פlebr befonbere Strome, die auf berfobiebenen Theis len Der groffen See beobad)tet werben, erzåblet Darenius Geogr. c. I4, prop. 23 feqq. Allein Derienige Flus Des Sceants, weldher von Not: gen gegen abeno obne Unterlas fortftecictet, ift ohne Broeifel fur ben

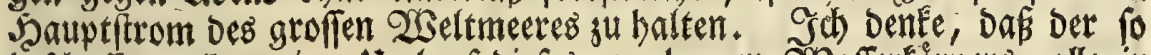

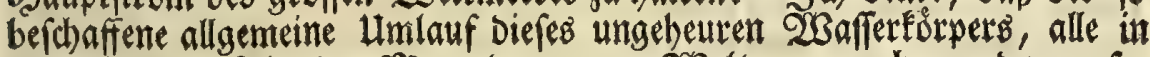
(Semeinjhaft ftehenden Meere der ganjen 2 Selt rege mache, und verurfa be, Daf fie gleid) falls fromen, wiewol nicht alle von (lufgang nach beat Shiebergange; fie fromen aud nicht eines wie Das anoere, fonoern auf

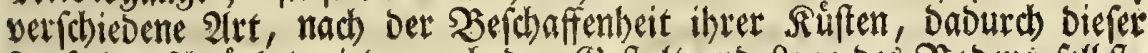
sauf eingefdránfet wirb, nadh Der Seftalt uno \&age Des Booens felbft, Daruber fie wegftreiden, uno nach andern, theils betannten, theils noch feimestweger binlánglich erforfd ten umftånoent.

Das Mittellándifd) Meer fromet auf Det linten Seite, ober nach Statien bin, won Abeno gegen Aufgang. Bei Sicilien (paltet fich Das

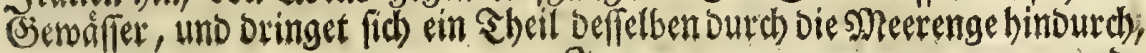

$$
\text { S } 2 \text { a }
$$

Mecrenge vermanbelt merben. 2(flein bort wáre biefer Erfolg mebr zu benun

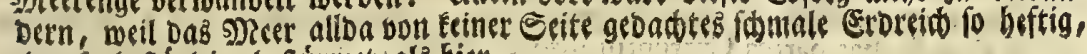
DDet fo beftándig, beftúrmet als Gier. 


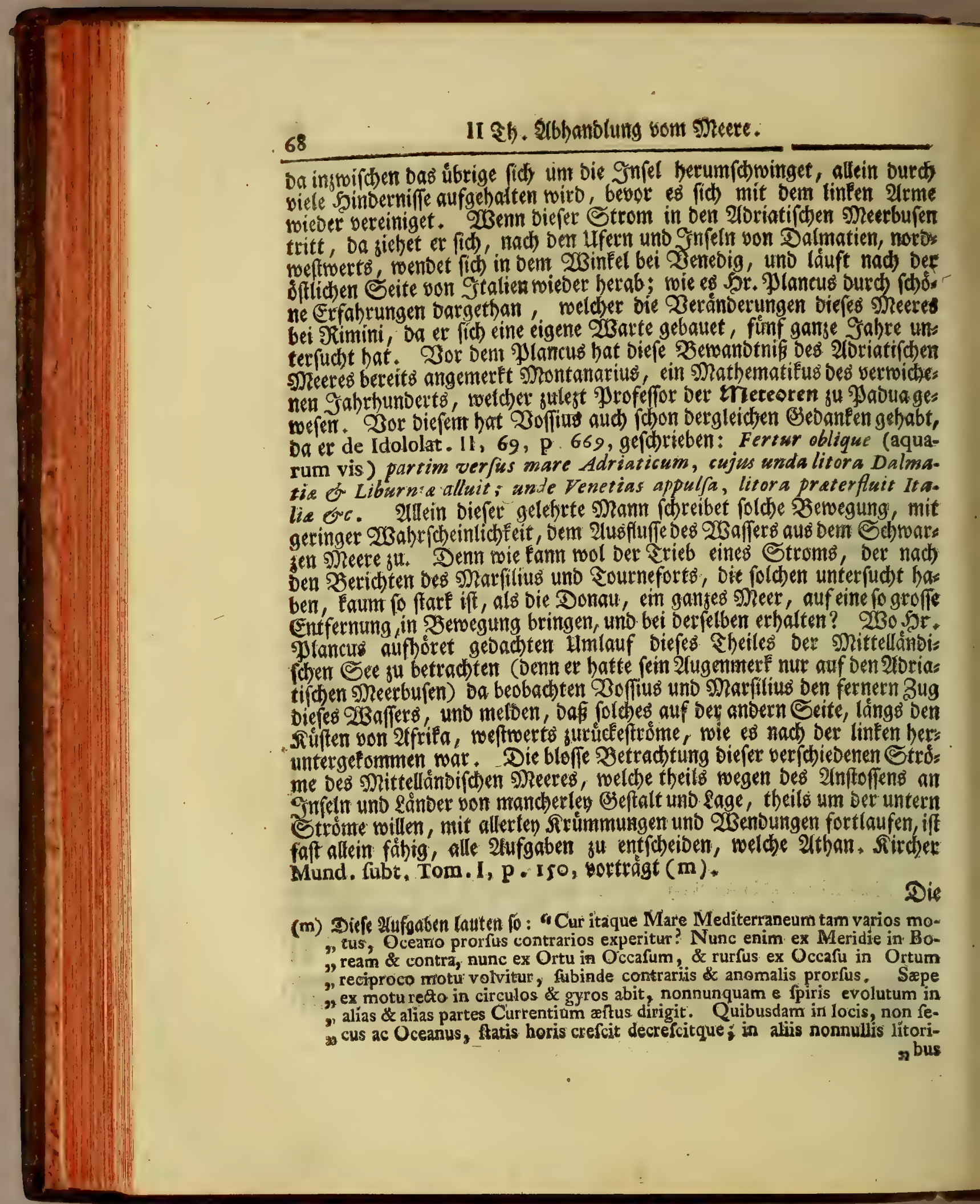




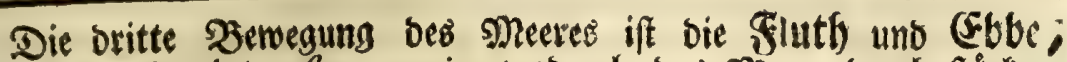
frans. la marée, lat. aft us maris, wodurd) Dab Meer, Durch ftártern

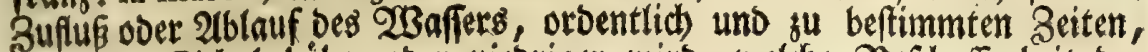

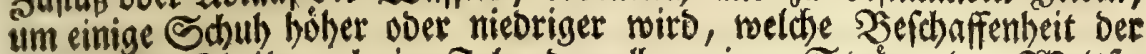
Neere fum Sheile nod) cint Folge Der allgemeinen Strome Der 2 Beltfes ift weil biefes groffe Serwáffer burch fein mannigfaltiges Anprellen an bie feften Sheile Der \&änoer uno Snfeln, auf Die Seiten getrieben wiro, uno fobann in ben Eleineren Meeren fidd) nod ferner verfoblàgt $(n)$. Daber in gewiffen Eeegegenden, Darimen viele Eilande fid befinden, wie in bem Archipelago, juforoerft in berer Meerengen, $\mathfrak{e g}^{8}$ auch óftere, uno jus weilen ungleid)e, 2lbwedhfelungen Der Fluth unt Ebbe gibt. Shingegen

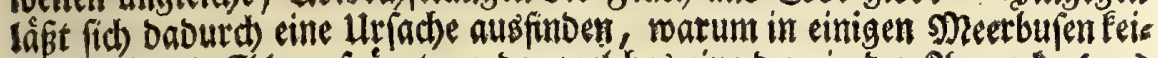
ne Fluth und Ebbe gefpuret werbe, noeldhes eine ber, in Der 2(nmert. (m)

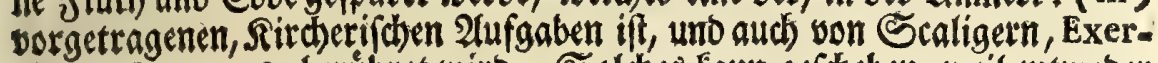
cit. LII, p. 198, beribret wiro. Soldhes fanm gejobehen, weil entweder bei tief attogejdhweiften 11 fern Der Shauptfrom vorbei jiehet, oDer weil ei: nige vor ben ふüften liegende Snfeln, Den 2 nfall beffelben bavon abbalten, wie Denn aud Rirder Mund. fubt. Tom. I, P. is B, uno Sherbinius de Cataract.1.2, c.4, prop. I, $\S 3$, biefe Frage faft auf gleides $\mathfrak{A}$ it auf lófen. Darnach weil die Erbe imnerbalb 24 Stunden eine ganje Jerum: toâlyung um ithe 2ldhe vollbringet, uno allemal über 6 Stumber ein

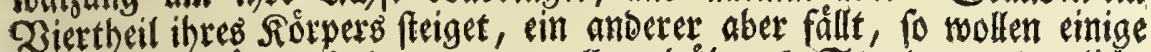
Daher Die Erftárung bolen, warum allemal itber 6 Stutben oroentlibe

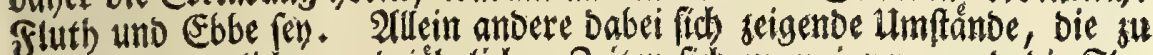

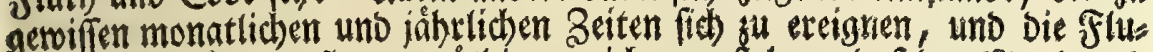
then zu vergroffern pflegen, nothigen mids ju gefteben, Dás ber sono uno bie Sonne (Planc. P. 54 fequ.) infonberbeit aber ber Mond, wie es

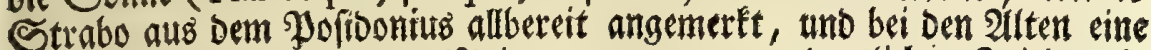
Durchgehenos angenommene skeinung war, fum orbertlichen Triebtoerfe

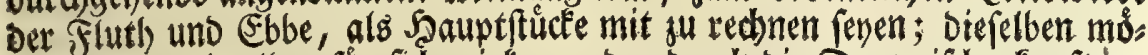
gen nun unmittelbar fïr fich wirken, ober Durds Die Darswifhenfunft an. Derer Dinge, welde von biefen swey geoffen Shimmeloférpern abbangen. $\$ 3$

Dafe

, bus ne veftigium quidem æftus reperias. Qui e Sicilia Arehipelagun pe") tunt, æftu quodam occulto abrepti verfus Adriaticum finum violenter de" torquentur. Contra qui Drepano folventes verfus promontorium vulgo $n$ Bon Andrea fub rhombo Euronotio, quem Scirocco vulgo vocant, navigant, $\rightarrow$ contrario $x$ ftu abrepti, verfus Tripulim Bifertinam ad latus fe derivare fen, tiunt. Qui e Cypro Alexandriam petunt, etfi lineam rhombi directricem 9) omni fudio tenere conentur, æflus tamen vi abrepti Damiatarm $L X$ leu$n^{\mathrm{cis}}$ 
Das ber Mrono etwas babei zu thun babe, foldbes bewábret auf eine un:

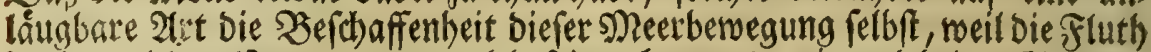
in einem jeben Nonate sweymal heftiger lommet; einmal beim Eintritte Des neuen sichtes, uno Das anberemal weit merÉlicher, wenn Dolmono ift; Daber Fann nicht nur Die Beit Der gewóhnlichen tåglidben, fonbern aud ber groften monatlidben Flutber, in Den Salendern Der Samburger, uno

" cis infra Alexandriam deferuntur; ex Alexandria contra verfus Cyprum abì", turi, aftu detorti in Pamphiliz litora adiguntur. Qui per Archipelagum "Conftantinopolim petunt, fentiunt manifeftam \& fenfibilem maris refiften"tiam: contra Conftantinopoli in Archipelagum folventes, veluti fecundo " vento femper deferuntur, fine ulla mais repugnantia, nifi quam contrarii "venti conciliant,

(n) So uttheilet aut sibbaldus Scot. Tlluftrat. T. $T$, part., , p. 77 , mit folgenben Sorten: "Exiltimandum autem eft, AEftum hunc reciprocum, feu Fluxum " \& Refluxum maris, quo mare duodecim fere homarurn fpatio ad eadem lit" tora fluit \& refluit, ex priore Motu ab Oriente in Occidentem fic pendere, , ut nihil fit nifi ejus affectio aut modus. "D Daß lâf(

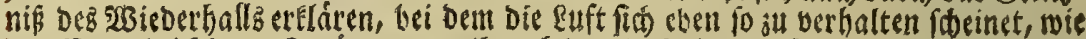
Das פeer beifeinem Strómen, weil aut Da Die Stimmen fo oft wirberbolet wer=

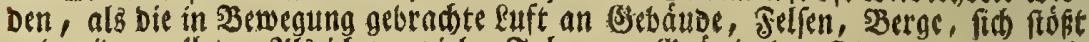
uno wiberpreilet. 2IB id vor vielen Sahren bu (Šrás in Der Stewermatk, an eis

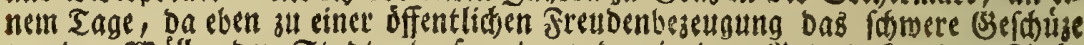

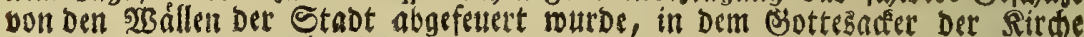

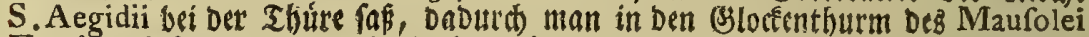
Ferdinandæi fommet, oa beobadtete i Der Sefuitenpafter), und auf Der Raze (ober auf Dem Eavalier) gefdah, in Den

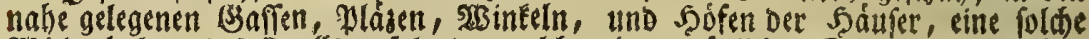
25ieberbolung Des Sinalls erfolgete, welite ein naturlites Donnern vorftellte:

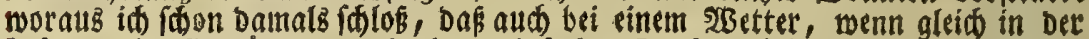

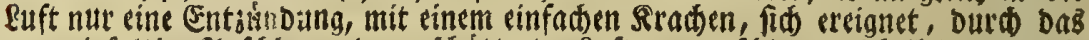

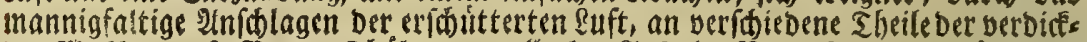

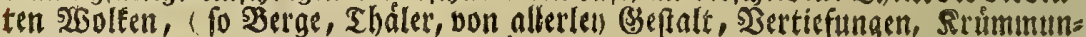

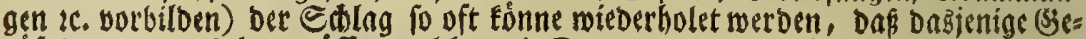

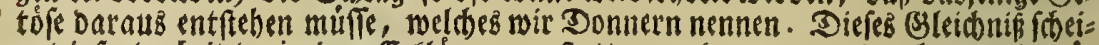
net infondertheit Derjenigen (Erklárung zu ftatten zu fommen, moburd man bemú bet ift, Die urfacbe Der fo oft abmed)islnden Sluth und Ebbe Dez Euripus anzuseis

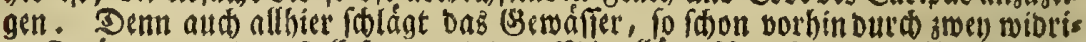

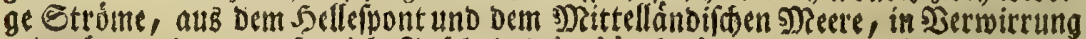
gebrad)t worben, an fo viele Snfeln Dez Archipelagi an, Daß verfótiebene Theile Deffelben, zut verifoiedenen zeiten, unb oft aufeinander, bald auf bicfe, bald auf jene Seite juridefgetrieben wetben, folglid autb ju veríticoenen 3eiten, und in

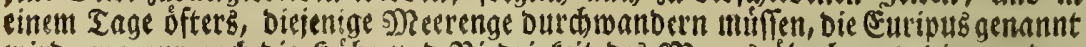

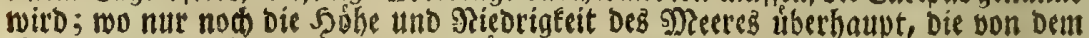

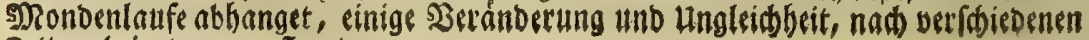
sciten, beijutragen pheget. 
antorer an ber Norbfee gelegenen Dertet, to gewif angejeiget wetben, alb bie Etellungen bes Geftirnes $(0)$.

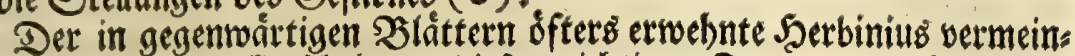
te mit cinigen, bie Entfheibung Diefer wichtigen Ftage am beften geges ben s haben, ba cr 1.2, c. 3, nadh einem auf die pericyclofin Oceani (Kirch. Mund. fubt. I, P. Is 8 ) gegrumbeten Entwutfe, lebrete, Die Fluth

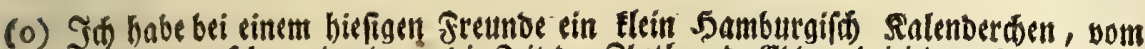
Э. 174I, gereben, Darinnen die 3eit Der Jluth und Ebbe, bei jedem Sage Durd

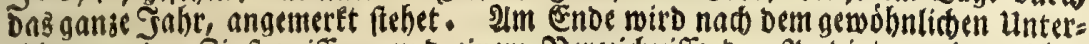

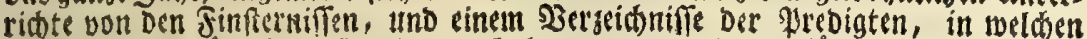

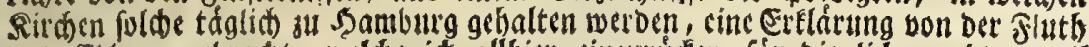

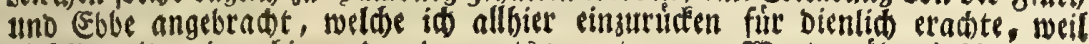
Diefelbe mit meinen bier und anderwerts borgetragenen 20 orten úbereinftimmet.

\section{"Beridt von Der Fluth und Ebbe auf Der Elbe.}

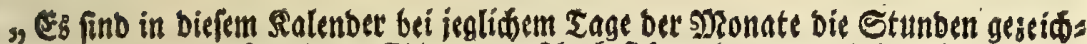
2, net, wenn a Samburg Esbe und Jituth fit ereignen; Dabei bicfez zu mers "Een, bas folde Bejeiten fid alfo verhalten, wemn ftill sosetter ift. Im Jall

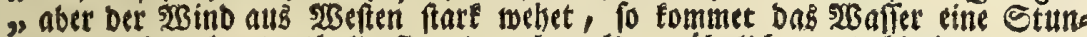
"De, alld wol anderthalb Stunde, eher als gewóbnlits, und bierinnen anges ", seiget wird; mit Dftenwind fo viel fpáter. Weftrind befoleuniget bie

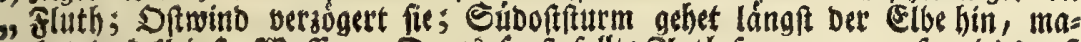

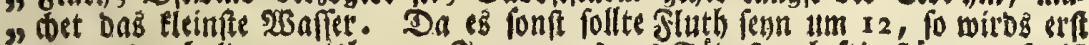
"1me 1 ober balb swey uhren. Sa wenn es aub Suboften heftig fturinet, fo if

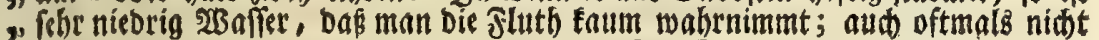
" na屯 Yltona Fommen tann, wegen Der entoeften Sanblerge in ber Elbe. NorD.

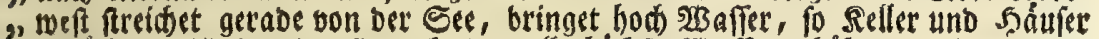

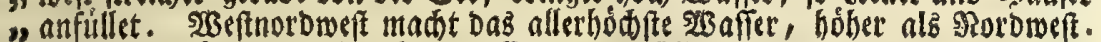
", Felangeno ferner Die fluth und Ebbe Der Elbe, ift zu wiffen, Daß an Der

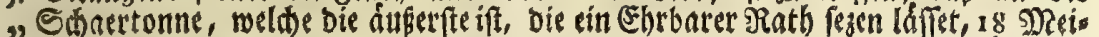
"Ien von Samburg, swifhen Seiliglano und ber Elbe, auf Der Sthaerhórne, im

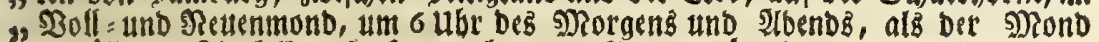

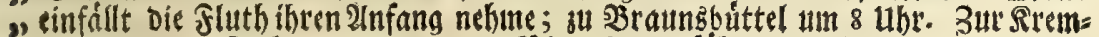

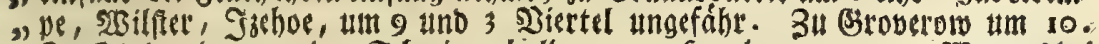

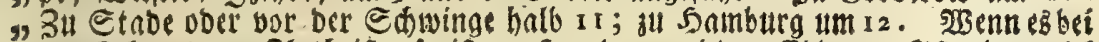
"Der Ebaertonne Jluth ift, fo ift sll Samburg wieber Ebbe. Sift aber viel "Sbenwafler, wie 1624 , wellbes von Den bohen Randen herunter tommet, fo "hált es um Şamburg teine gewifie 3eit." Sieh atth) Happel. Relat. curiof.

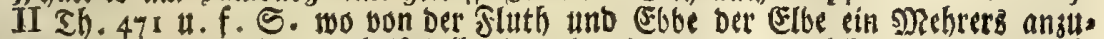

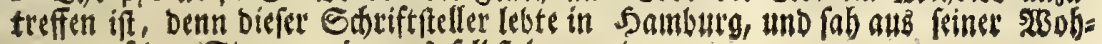
nung auf ben Strom, wie er es felbof bereuget. 


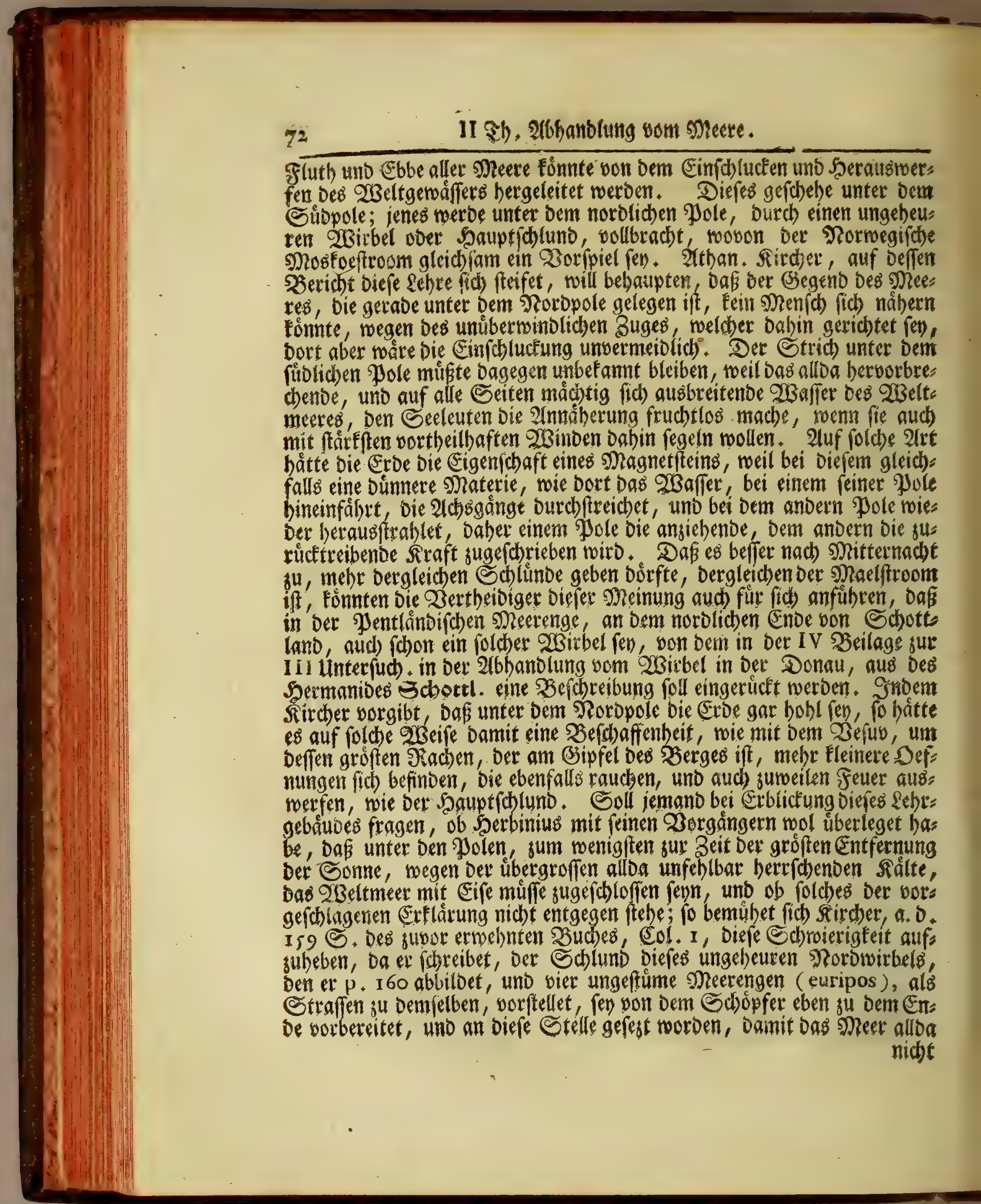


Swente Unterfickung.

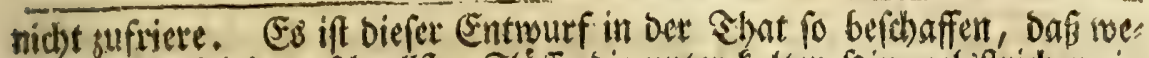

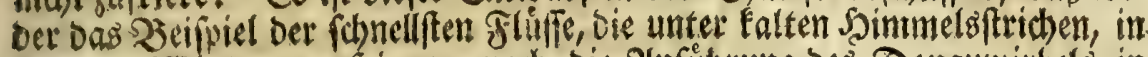

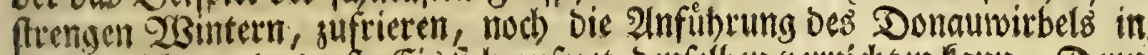

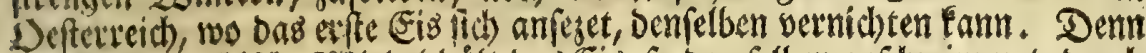

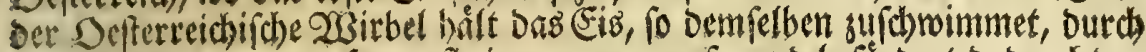

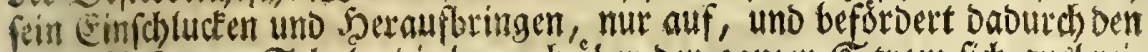

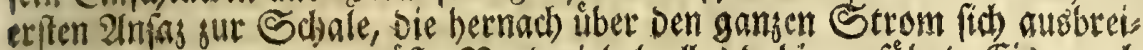

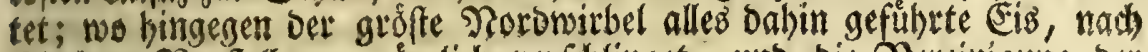

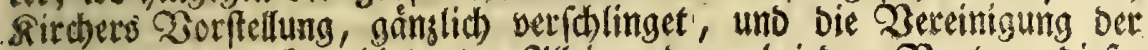
Eirfchollen oadurds verhinoert. Allein andere, bei bem Dortage diefer

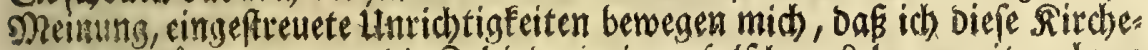

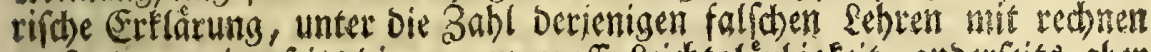
mus, Darzu einerfeitr Die gar zu groffe \&eichtglåubigkeit, anderfeits aber

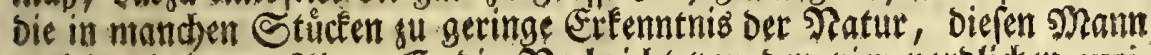

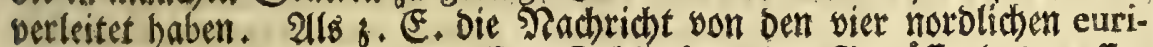

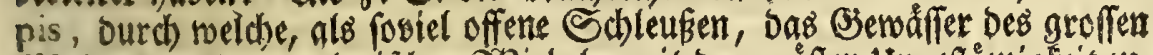
Weltmeeres Dem polarifhen 2 Birbel, mit Der gróften Ungeftumigfeit sus eile, grimbet er auf bie 2 dusfage eines Srforbif hen Mondhen, welder burd Die Zauberfunft unter Den Novopol fen gebrad)t worden, allwo er vier (E) lanoe nit geoachten vier beftig ftrómenten seerengen, und einen Mags

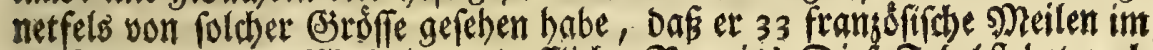

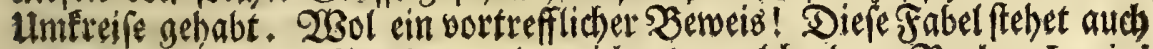
auf ber allgemeinen sambfarte abgegeidmet, weldhe bem Sudbe, Levini Hulfii Sdifffabet in oas Ortentalifbe Inden, $(1606,4$.) forme angefinget ift.

Sn Der $\mathfrak{A} b$ fhilberung biefer feiner Peticyclofis, meloet Rircher fers ner, p. I 59 A, Daß in Dem Meerwaffer, bei feiner unterirebifhen $\mathfrak{W}_{\text {ans }}$ Derung von Den ?orbpole zu Dem füblichen, die Samen Der Metalle und Der Yflanzen, Durch Das Feuer Der (ExDe, ausgefod)t und zubercitet wet

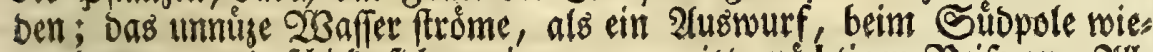

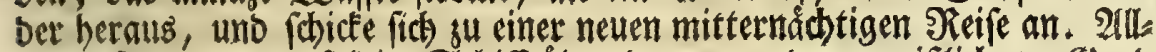

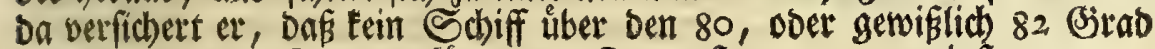
ber Prorobreite, fommen fonnte. Das erftere, funt wentigften was er von ber Ilusarbeitung ber Samen ber (Bjemáchje erinnert, wirb wol allen

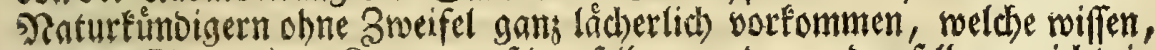
Sá̧ Der Same eines Sitauts auf Demfelteen, uno von Demfelben, nicht in Den Abgrunden Des Meeres, erzeuget, ernêbret, reif uno vollfommen ges madt werbe. $23 a s$ er an bejagter Stelle von Der unmỏglichen Nábes ruttg gegen Den Rordpol, wegen Der gewaltigen Dahin ziehenden Stróme,

$$
\Omega \text { oor }
$$


II Ib. 2lbbanblung yom meere.

vorgibt, Das wiberlegen bie Zeugniffe Der norbifthen Seefahrer, weldhe

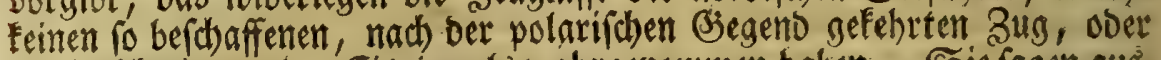

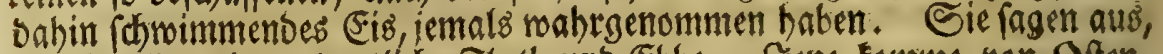
es gebe alloa eine orbentliche Fluth und Ebbe. Tene Fonme von Often, bieje von 2 Beften her, und poldten Bug balte gleichfalls das Eib, weldhes auch nod) Die Serumbrehung Der Erotugel von Niebergang gegen 2lufs gang, und bie Begentwart Des won Morgen gegen 2lbeno geridteten Sauptfromes beftatiget. Sie geftehen, Das goeer fey funádyft unter bem soropole in ber shat nicht gugefroren, allein unt feines Schlunders nillen, fondern weil Eein Eanb alloa fen. Das Eis fese fict nur um bie

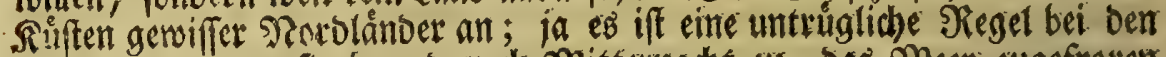

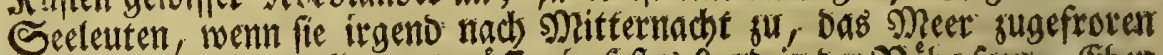
finden, dás fite urtheilen, es múffe ein feftes \&anto in ber Nábe fern. Eben

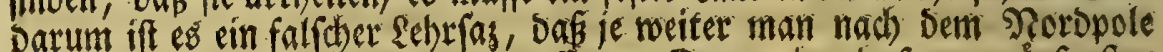
jiebet, ie groffere Rálte man antreffe. Denn eine in frenem åuferfen

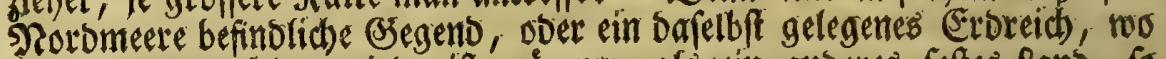
fein Eis angetrieben wiro, ift wärmet, afs ein moeres feftes ano, fo um mehr Srabe fublicher ift, allein bahin bas Eis feinen sug bat, und

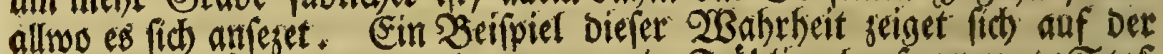

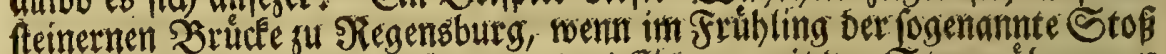
auf Der Donau gebet, D. i. wenn bas Eis, womit Der Strom übersogen

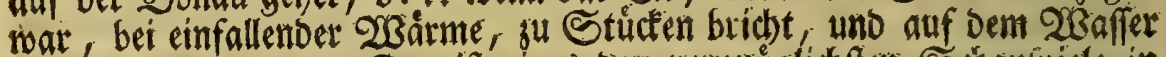

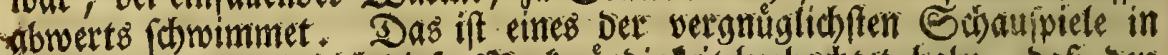

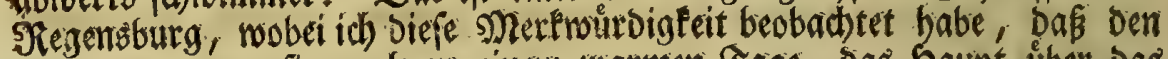
Zurehern, wenn fie auds an einern warmen Tage, Das baupt über bas

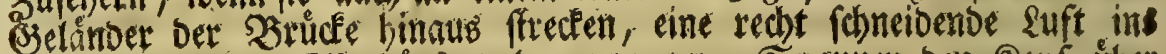
Ssefidste fahre. Sie borfen aber nur um 3 Spannen Den Ropf úber Das Belánder bereintiehen, fo büntet es biefelben, als wenn fie in eine ges histe Stube Eamen. Eben dieje norbifhan Seefabrer wioerlegen Das

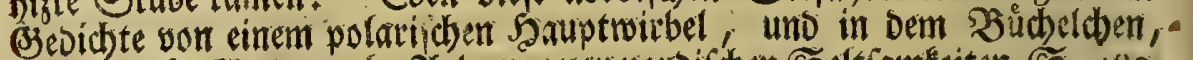

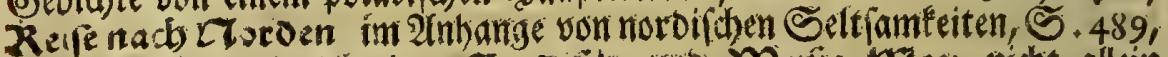

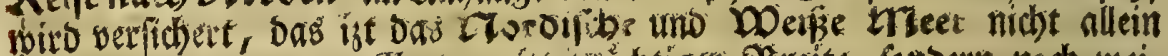

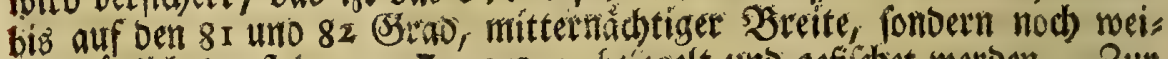

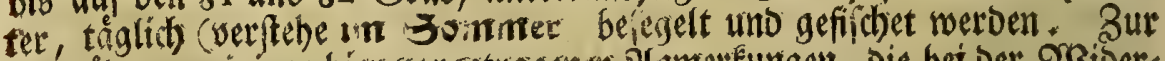

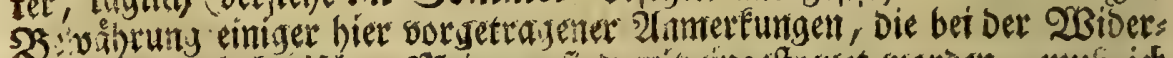

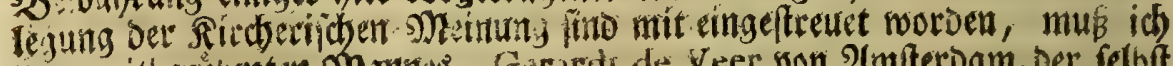

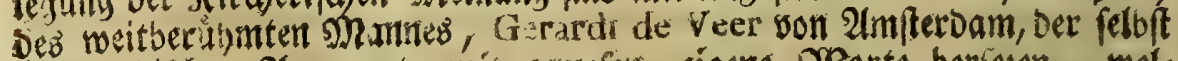

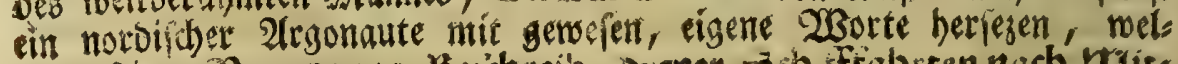

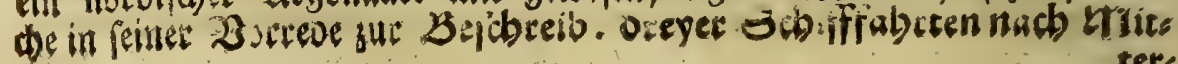
tet: 
cernacbe (námlid von 1594, 1595, 1596) fid befinben, von bicfet Stelle aber obne Sweifel in bas reuentoecte Forden (S. 219) ge:

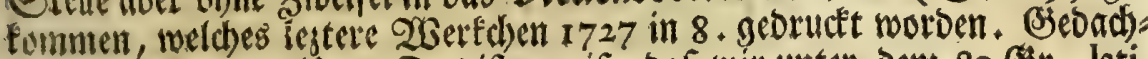
te 2lorte lauten alfo: "Das ift gemís, Das wir unter Dent 80 (3) r. lati"tudinis nicht fo grofie నålte, als unter Dem 76 bei Rova Semla au= "getroffen; wir habell aud unter bem 80 (Sir. im Junio grüne Båunte

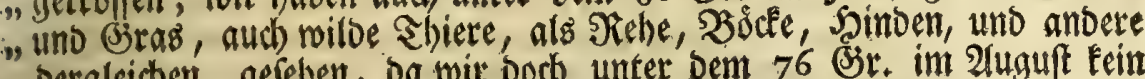

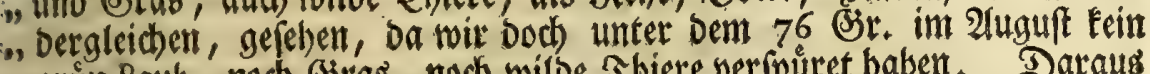
"grum \&aub, nod (Stab", nod wilbe Sbiere serfpuret haben. Daraus

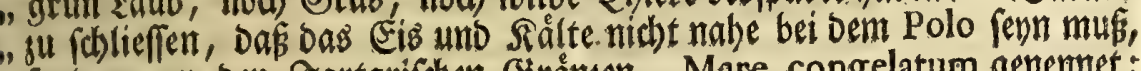
" fonbern an Den Tartarifthen Grånzen, Mare congelatum genennet; Denn Dar Eis allenthalben neben Dem Sande gefunden, uno bafelbift von

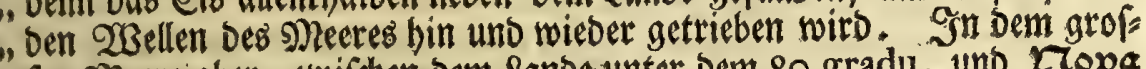
" Fen Meere aber, zwifetben Dem \&ande unter Dem 80 gradu, und Kooa

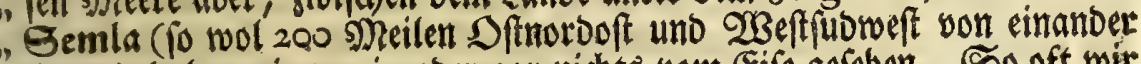
"liegen) baben wir wenig ober gar nichts yom Eife gefeben. So oft wit

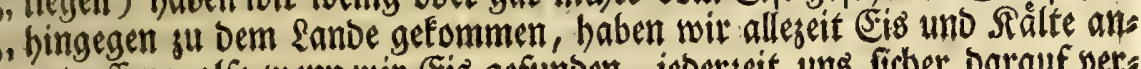
"getroffen; alfo wenn wir Eis gefunben, jeberzeit uns ficher Darauf bers

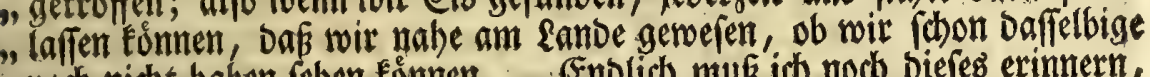

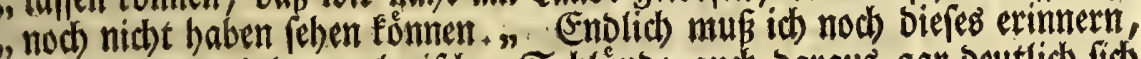

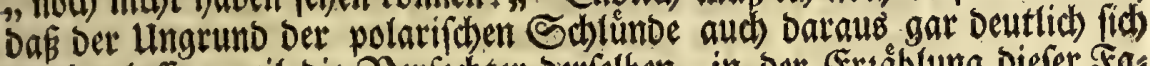
merfen laffe, weil bie Derfechter Derfelben, in Der Erjáblung biefer Fas bel, felbft nicht eins fint, fondern auf eine ládberlidbe 2art einanber wiber:

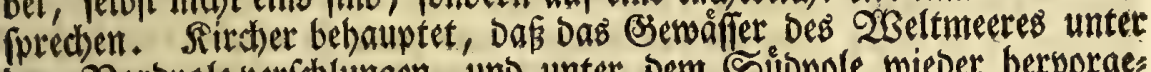
Dem Norbpole verichlumgen, uno unter. Dem Subpole wieber hervorge:

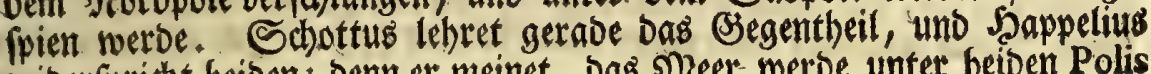
widerfpridt)t beiden; Denn er meinet, Dab \$leer werbe unter beiden Polis

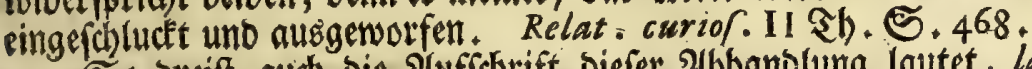

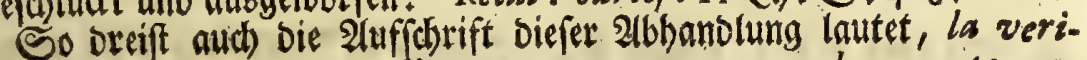
table caufe DU FLUX ET REFLUX DE LA MER decouverte par GASPAR BINNINGER, à Halle I749, 8. fo febt Der $\mathfrak{H} \mathfrak{x}$. Werfaffer aud) feine, in biefer Sd)rift porgetrngene, Erflárung ber Fluth uno Ebbe felbit herausifteid)et, fo gefállt mir Dod) fein Geoante am allerwenigften.

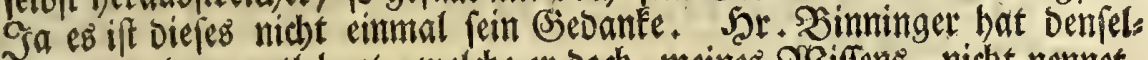
ben von andern entlebnet, weldhe er Dodh, meines 2 Siffens, nicht nennet.

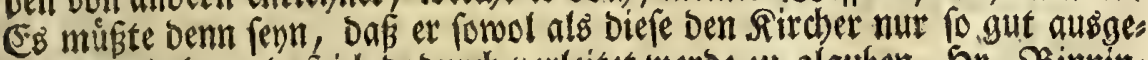

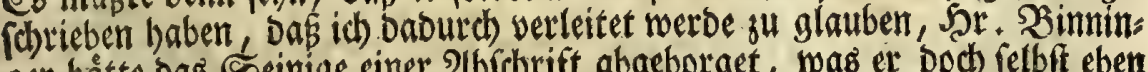

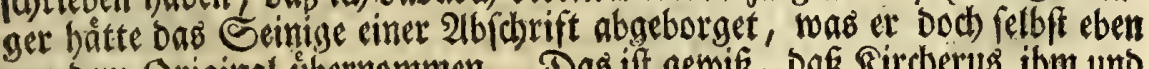

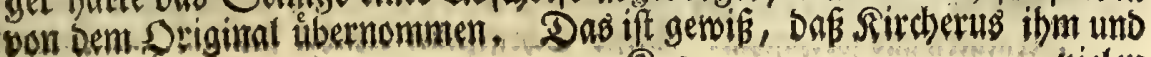
${ }_{2}$. Dielen 
bielen anbern, zu einer feltfamen und fehr umwahridbeinlid)en seeinung yorgebahnet babe. Serbinitus ertlaret bie Fluth uno Ebbe haupt fáthlid burd Die Rircherifbe pericyclolin Oceani, aber Durdh bas Einfdhtucest uno Spenen ber polarifoct Fanutfaltinde. Sat. Simninger behauptet aud eine pericyclofin, allein um foldse qu erweifen, beoienet er fich mehs

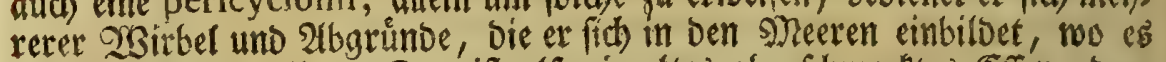

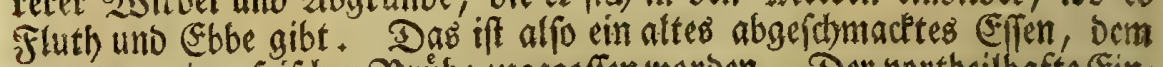
etwas von einet frif

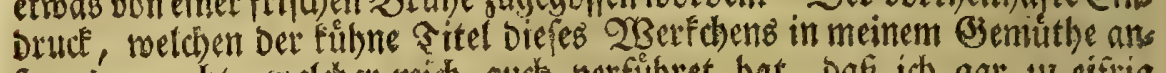
fangss gemadt, welcher mich aud verfithret bat, bas idh gar ju eifrig Darnad frebte, wato gar balb vernichtet, ats ich Dureb bas crfte 2uffchlas

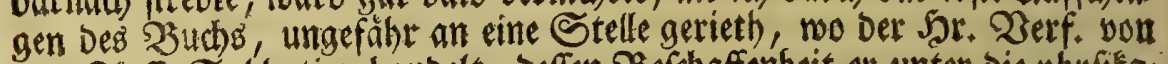
Dem Fluffe Sabbation handelt, Deffen $\mathfrak{B} e$ chaffenbeit er unter bie phufifa

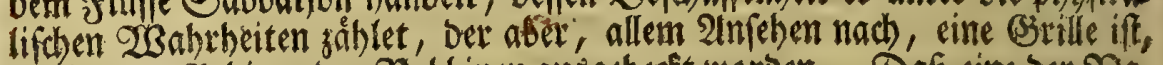
Die in bem (Sethirne Der Siabbinen aubgehect worden. Saf eime ber PRas tur gemáfie Erflárung, bei einem io bejdaffenen $23 a$ affer, fity anbringen laffe, Das will id fo weenig beftreiten, als id weip, Daf man vielen andera

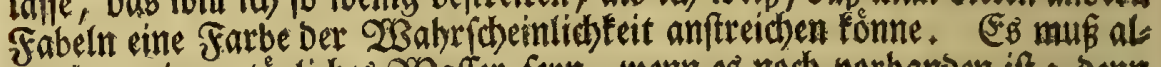
levoings ein naturliches $23_{a}$ afer fenn, wenn es nod vorbanden if: Denu warum follte 3 S tt fur ein abgethane Befes annoch YSumber nirfen?

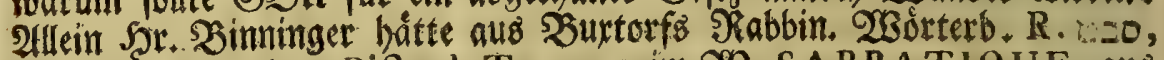
col. 1417, aus Dem Dict. de Trevoux, im 28 . S A B B A T IQUE, aus

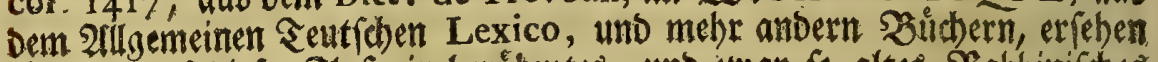

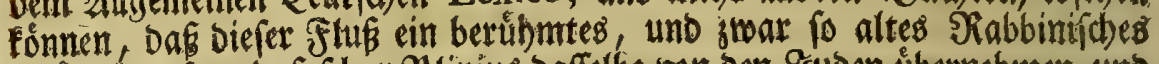

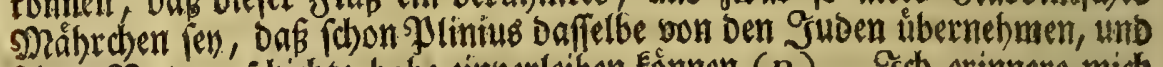

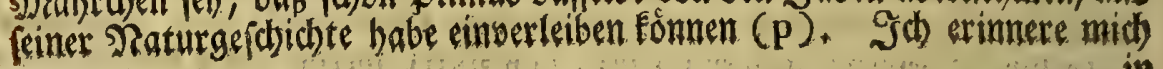

(p) Der gallse Crmets, worauf St. Sinninget, bei Innehmung Diefer vermeinten

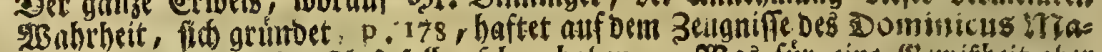

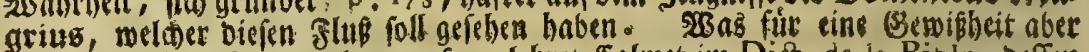
altz. Diefem Beriote ar erlangen fen, Lebret Calmet im Dict, de la Bible, Deffen

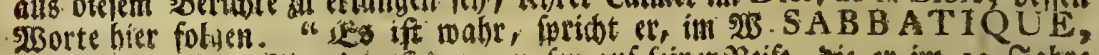

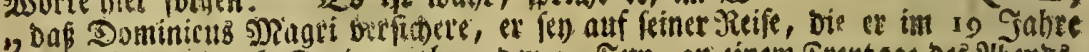
"feines 2lters Durch Snrien gethan, Den 21 Stm, an einem Srentage bes 2benos,

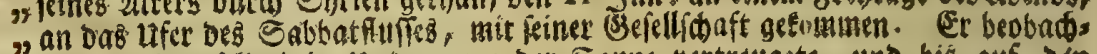
") tete, Dấ Derielbe beim antergange Der Eonne vertreugete, uno bis auf oen

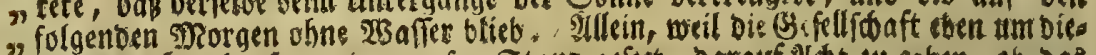

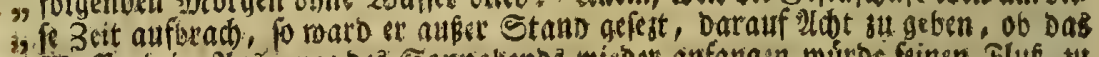

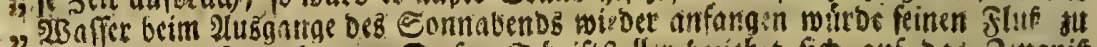

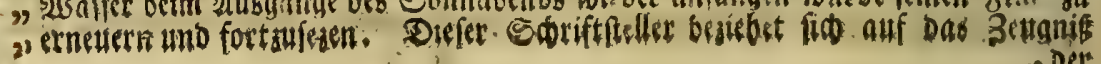




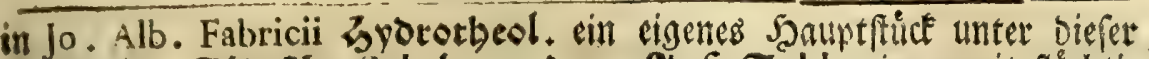
2(uffdrift, Júdifche Jabel von bem Sluf Sabbation, mit flúctit: ges 2lugen gefelyen fu haben; id nabm mir aber bie beit nicht babei fethen

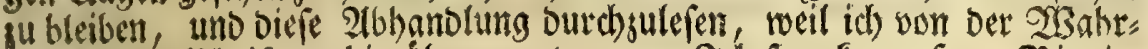

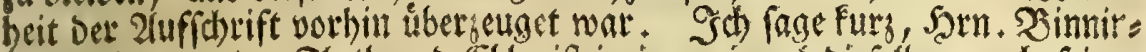
gers sebre von Der Fluth und (Ebbe ift irrig, mierwol biefelbe, nach feiner

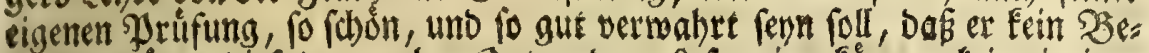

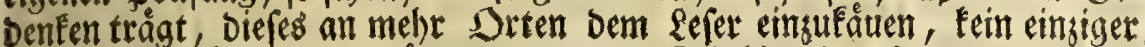
reiner Sige ésnne ifbu geläugnet rerben. Sch bin aber ciner gantarbern Meinung. Sein Sauptgruno, Die WBirflicheeir Der Schlunde in Dert greeren, wo er foldhe angibt, iff feine Dargethane 2 Bahtheit. Die Riv:

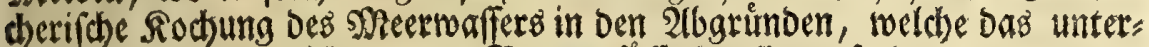
irroifae Feuer verridben, Den Sergen fuffe Quellen zufenden, uno andere. গ⿻? ift Sdywierigfeiten unterworfen, Die er nidht auflofet; fie ift mit folchen limfánben begleitet, welde Diefe 2tuslegung noch Darzu lád)erlich madent.

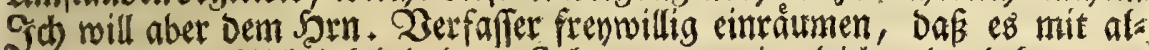

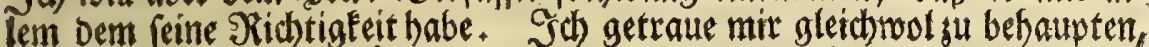
Das feime Sdblunbe untudbtig fenen, ote Befthaffenbeit ber Fluth und Ebbe u erflaren. Denn ez gibt 1.) Eeine Jlutb und sebbe in Mreeren,

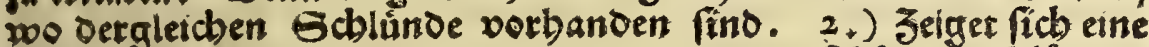

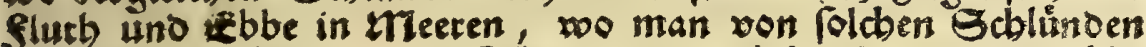
leine Spuren finoet. 3.) If eine ordentlidbe Jlutb und sebbe in andern meeren, um oergleicben Bcblúnde, 3 u foldben Zeiren $3 u$ reben, oa bieje fidb ganz rubig balten, $0 . i$. wenn otefelben tein Doffer mertich bineinfoblingen oder von fich foffen. Den I 3 erften

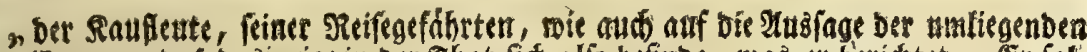
"s Sautern, Dap Dasjentige in Der That fid aljo befinde, was er beridtet. El fol:

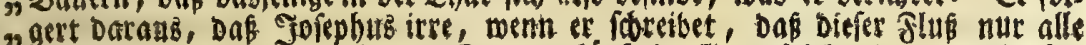
"Sonmabenbe su rimnen pflege. Denn er láft im Begenfpiele die ganze 200 be,

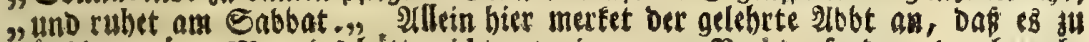

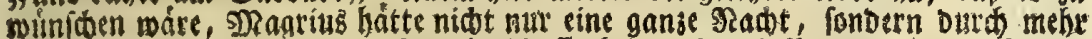

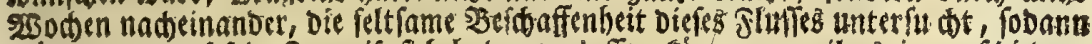

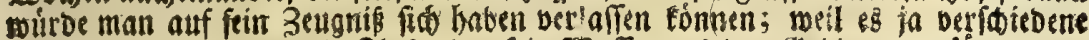

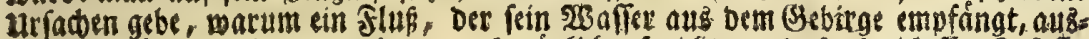
trodnen tonne. Es ift aut gar mol móglí, fprifft et, tap ein blofer 3ufall, eben benfelben Frentag abends, bie oben erwehnte $2 B$ irsung nad fich ge zogen habe.

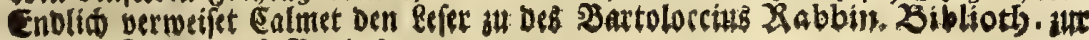

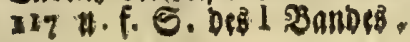


11 3h. 2tbbandlung vom meere.

erften bier vorgetragenen Sas erweipet bas Beifpiel Der Dftee mit itsen Meerburen, Darinnen Serbinius, wie auch Deffen, unt Shtm. Bimningers

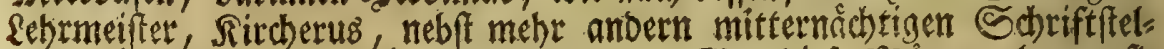

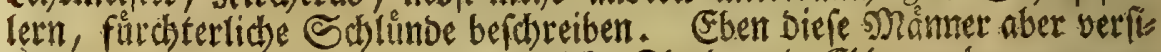

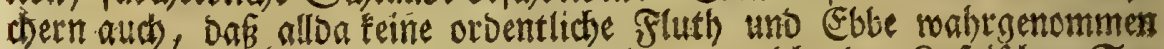
werbe. Sr. Binninger glaubet Denienigen, rolde ber Rafpirchen See

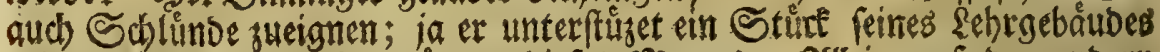

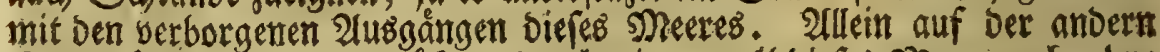

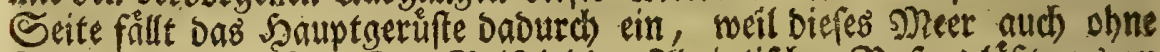

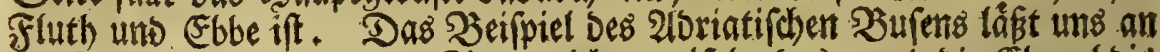

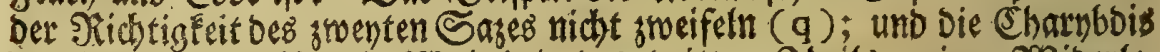

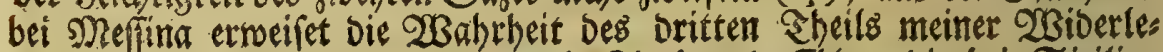
gung. Sar. Simninger foreibet sis Fluth und Ebbe, Die bei Sicilien gefpiret wiro, Dem Sd)luden thino Spenender Scnlla uno Eharnbois zu.

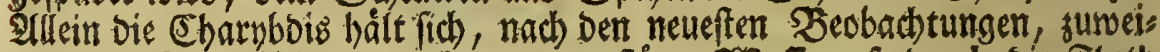

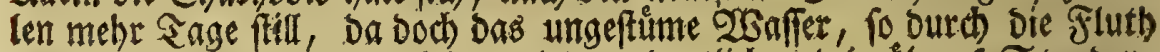
unt Etbbe bin= und hergetrieben wiro, oroentlid uno je uber 6 Stunden, stwiften Ralabrien-und Sicitien bimourd, uno bei biefem 2 Birbel vor:

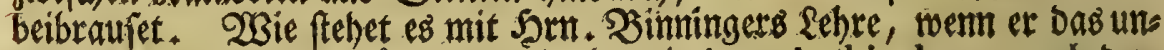
gleidbe Sins uno Serftromen Des Euripus in Dem Archipelago, nach Ders felben erfláren foll? Ereftlich haben wir von ber Begentoart unergrumblis

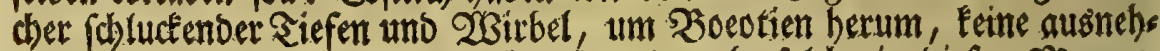
menoe llebersetrgung. Darnadh gefest, es gebe folde in biefer meerges gend, weldhes id) Eeinesweges befteiten will; Denn bas \&ager biefes Miees res ift voll unterirroif́ches Feuers : allein twarum follen fie nicht alle auf einmal Das Seetwaffer hineinziehen, uno wieber von fich geben, baburd aber eine regelmáffige Sluth und Esbbe, nad̆ feinen Srunofäzen, verurfas d)en? YSarum ánbert biefes $23 a f f e r$ mandintal in swen Stunden nur ein: mal feinen \&auf, ein andermal aber in eimer Stunde bisfiebenmal? $28 \mathrm{em}$ Sor. Binninger Diefe Lnridjtigkeit auf Dab ungleich brennende unterirrbis

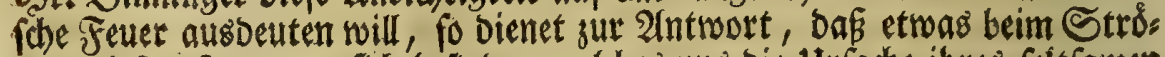
men biefer Meerenge fich befinde, welches uns bie Hrfache ibres feltfamen

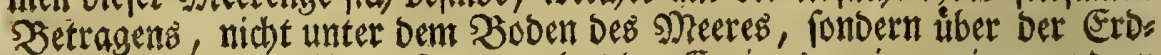
fugel, auffudben beif́t. Denn es̉ bat Der Euripǘ, wie an einem andern Orte foll gefagt werden, im vollen und neuen sonden, feinen orbentlis

(q) Es wirb swar unten in ber Inmert. (yy) yon einem Solunbe Ermelinung get han werden, ben luean in ber B̈egeno von Jllurien befareibet. Slllein, wenn aud

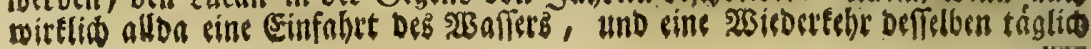




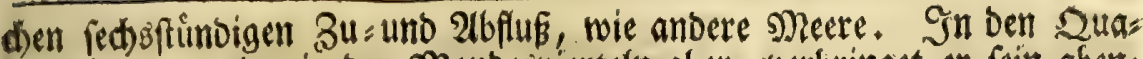
bratafpecten, ober in ben monbesvierteln aber, berbringet er fein abert=

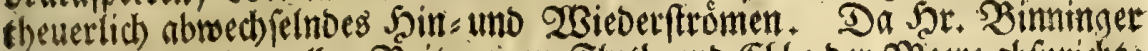
nut Dem Monden allen $\mathfrak{B}$ eitrag fur Fluth uno Ebbe Der Meere abipricht:

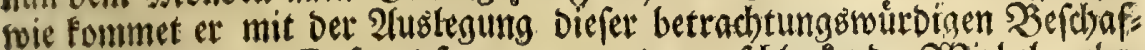
fentheit suredte? Er faget ferner, too eg nur (d)luctende Wirbel gebe, Da finbe fid) feine Flutb und Ebbe ein, wie unter Dem Polo Arctico, Das buntet mich eill neuer Srrtbum zu fenn. Shítte ber 5 r. Derfafter, anftatt

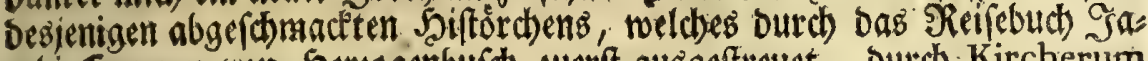
cobi Cnoven von Serzogenburd zuerft aus̉geftecuet, Dutd) Kircherum aber bon neuem aufgewármet worben, die wabrbaften Berichte ber mit: rernád)tigen Seefabrer gelefen, fo wurbe er gefumben haben, daj aud alloa cine regetmáfige frluth uno sobe vor fith gebe. Sar. Binninger entblobet fich nicht an gar vielen Stellen, reine \&ebre mit ungetwohnlidien

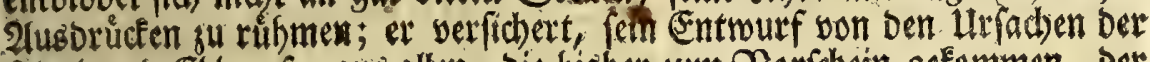
Fluth uno Ebbe, fen aus allen, Die bisher fum Dorfdein gefommen, ber

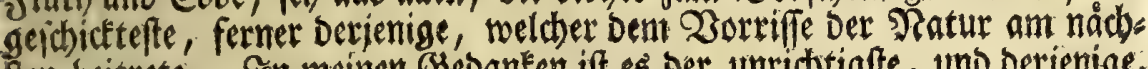
fen beitrete. Sn meinen Sebanten ift ber unridytigfte, uno berjenige;

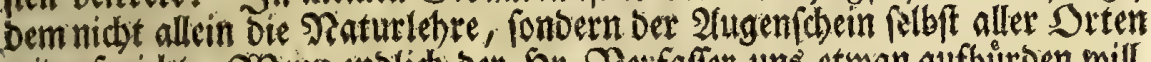
wiberfpridt. Wenn enolid' Der Şr. Zetfafer uns etwan aufburben will, es zu glauben, Dap feine Tublegung Der Fluth unb Ebbe eine neue Erfin oung fen (Demn fo rocit ich oiefe Schrtft in Erle Durd)geblattert habe, fhet net er eine folde Spradse zu fubren, Das ein unbebutfamer \&efer benfel ben fur Den Urbeber diefer (Grelarung balten fonnte) fo fuge id Der 2 Babs

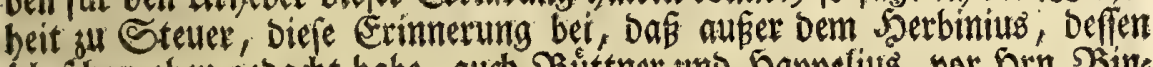

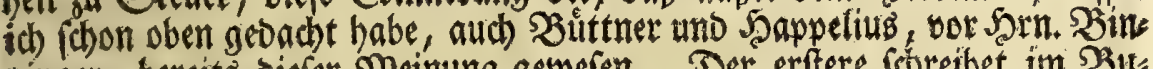
ninger, bereits diefer Meimung getwefen. Ser erfere fer retbet in 3 us: d)e, Rudera Dilnvii teftes, Reips. I710, 4. S. 82: Soll ich meine hleinung etofnen, fo fareibe id ore sebbe uno flutb vielmebr oen Dicbeln' $3 u$, und gratulice mir, oaf Z $\mathbf{r}$. Sappelius parte II Relat. curiof. oiefen Geoanten mit mit gemein bat, uno vielleidet andere mebr. Daber th oie oafelbit befinolidbe Sigut bier babe nadofechen lafen. Darauf fubret er feinen Betweis yon ben Wirbetn, infonderbeit bon Den mitternád)tigen, an. Sie Sappelifhe Ibband fung,

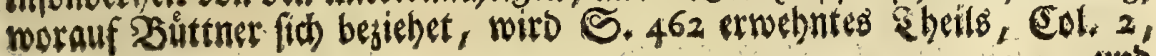
unto

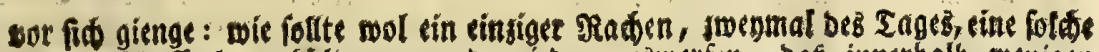

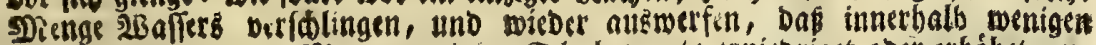

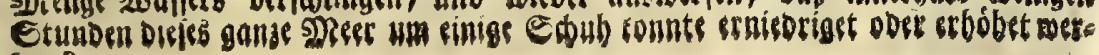
Den? 
und folg. S. ferner 468 u. f. S. vorgetragen. Şr. Binninger båtte aud nur, mie গ̇uttner, bie zut erften angeseigten Stetle beigefüste Sappetie

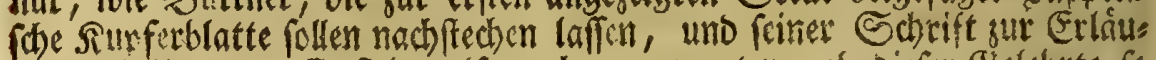
terumg beilegen. E's fehet alfo aud) su gewarten, ob Diefer (S) lehrte fo

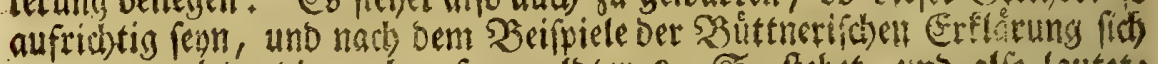
bequemen wiro, bie nod) auf gemeloter $82 \mathrm{~S}$. ftethet, uno allo lautet:

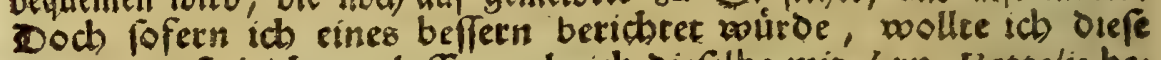
treinung fo leidhe verlaffen, als icb oiefelbe mit satn. Happelio bes lieber babe.

Etmag neuer if ber Bebante eimes gtalieners, Leonardi Pappini

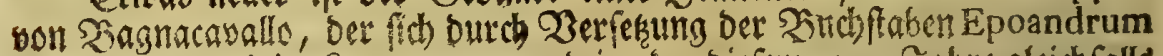
Napilum Betacirienfem nennet, uno in eben biefem 749 Sabre gleichfolls eine Schrift won ber Fluth und Ébbe in Faenga herausgegeten. E⿺ bat

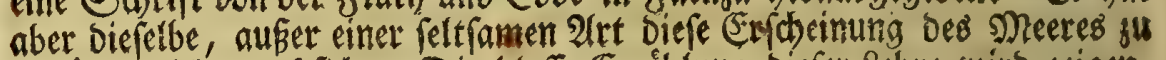
etflaren, nichtş auf fich. Die bloffe Erzáhlung biefer \&elbre wiro jeigen,

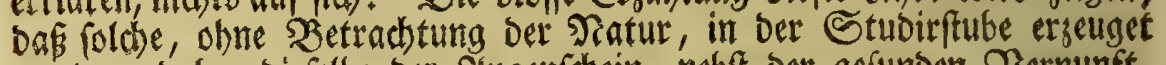
worben, Daber biefelbe der 2usenjthein, nebft Der gefunden Oernunft,

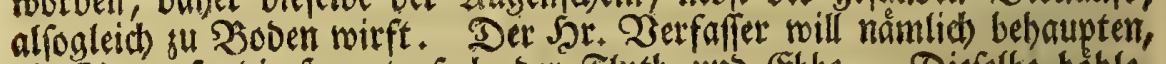
bie Sonne ren Die Saaupturfadhe der Fluth uno Ebbe. Diefelbe hohle, um die 28 elteugel auf ber groflen See, einen Braber aus, weldhen auss

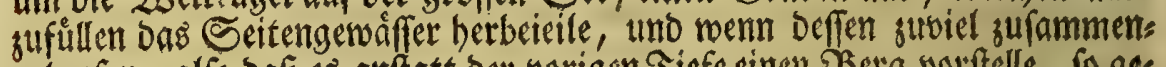

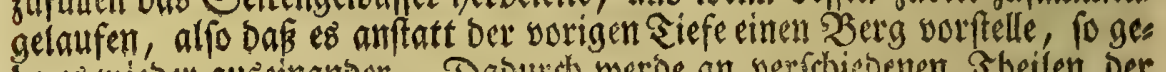

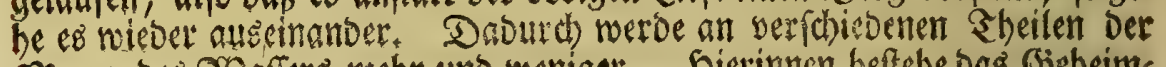
Meere, Des 23 affers mehr uno neniget. Shierimen beftehe das Geheims nis ber Fluth uno Ebbe. QIllein ein Sornben, Deffen 2lusfillung foviel

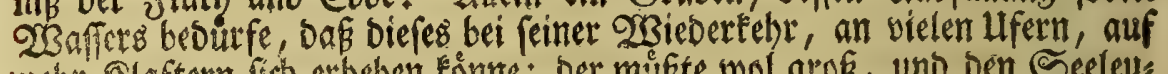

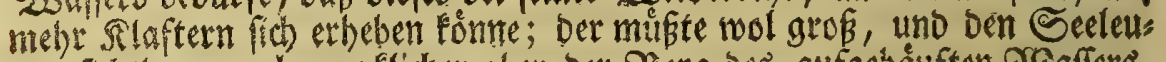

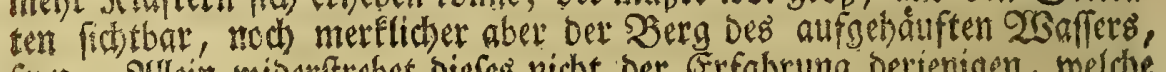
fenn. 2allein roioerftebet biefes nicht ber Erfahrung Derienigen, roeldye

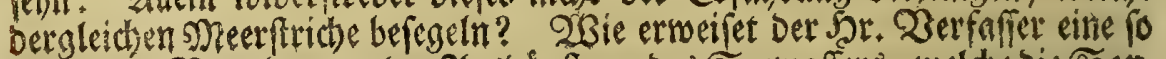

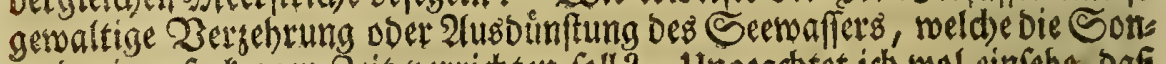

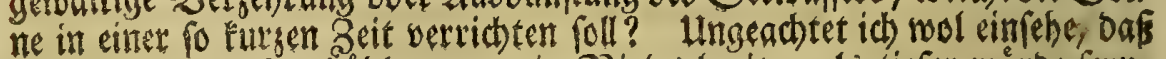
Die borgegetente 2lubhohlung um ein 3 ieles breiter ald tiefer nüroe fenn, fo miste sicfelte gleichwol, in 2infehung ber unbeid)reiblid)en menge bes

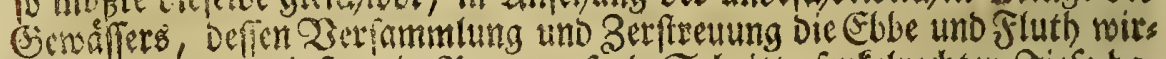
fern foll, sum wenigften ein Jaat taufeno Sdyritte fenfeltechter siefe bas

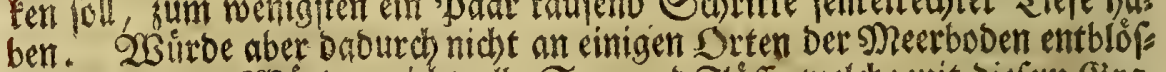

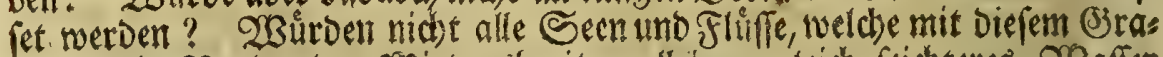

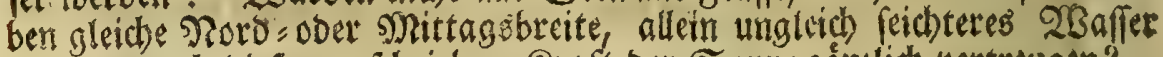
baben, Durd) Diefe sugejdriebene Sraft Der Sonne gánglich vertreugen? 


\section{$\$ 2$.}

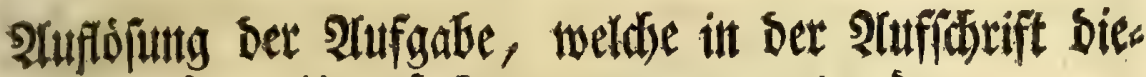 fer II Unterfucjung vorgetragen tworben.}

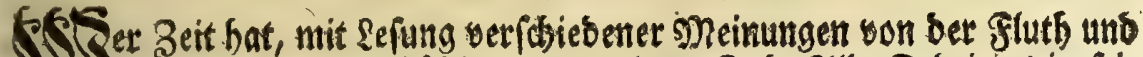
20. (Ebbe fid) zu bef hâftigen, bem leget Joh. Alb. Fabricius in reis

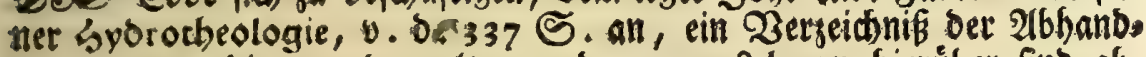
lungen vor, bie von ben alten und neuern sebreen fieruber find $a b$ s

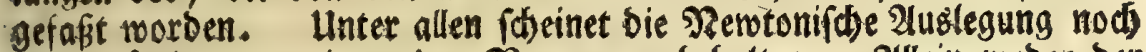
gegenmårtig vor anbern ben 20 orł zu behalten. Allein weber bee Faum Diefer Blätter, noch mein Yorbaben, etlauben mir, baf id) lánger mich) aufhalten foll, um fernere mutbmafiungen ju erjåhlen, twekthe von verfohiedenen $\Re$ aturfinbigern über eine Sache find aufges

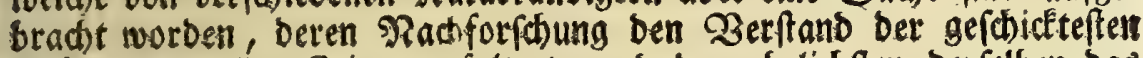
5ianner zu allen Zeiten gefoltert, und ben efrlid)fen berílben bas

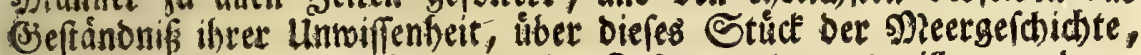
absenothiget hat. Es if nur um bes 3ufammenbanges millen von breys erlen Bewegungen bes Neeres Erwehnung gethan worben. Mein 21bjeben wat auf bie zrente. D.i. auf Das Stromen, geridtet, woyon id) hoffe, eirten fo jureichenden $\mathfrak{B}$ eridbt ertheilet su baben, baf nun bie 2lufgabe biefer unterfuc)ung feht leidts foll aufuloben rent. (EB

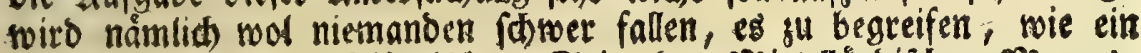

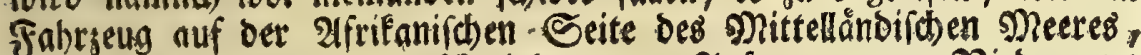

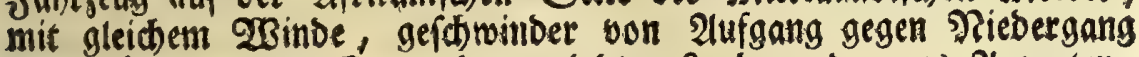
fegeln fónne, und 8 . E. aus bem gelobten fanbe, oder aus Alegupten, eher nad) Spanien fomme, als von borther twiederleftre, meil baffelbe Dahin mit bem natúrlichen Buge bes Meeres gleidjfam fortf(t)mimmet, beruber aber bem Strome entgegen fabten mus. Daburd werben abermal einige Sircherifthe, in Der 2 nnmerE. (m) erwefnte Fragen bee antwortet. Shr. Plancus und Mrontanarius beftátigen biefe $23 a h r s$

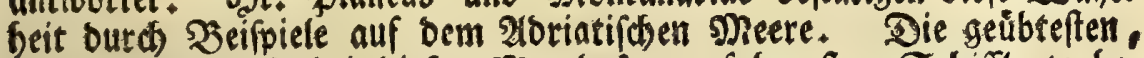

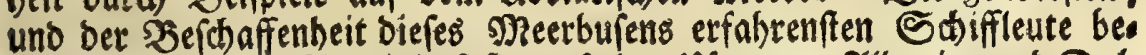
obacten folgende SRegel, Das fie nach ben Ufern bon Hitbanien und Dals matien aufwerts fegeln, wenn fie f. E. von Sorfu nad Zeneoig foms $\&$

men 
men wollen. Die Sdbiffe hingegen, bie bon Denedig nad) Sorfu ges

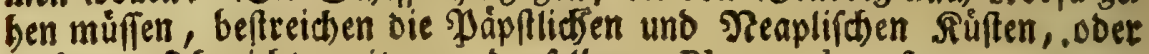

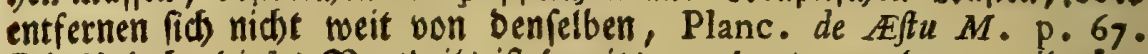
Die Uriache biefes Zortheils ift bereits angebeutet worben, meil nảms

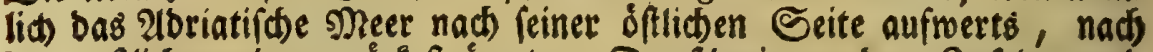
Der weftliđen aber zurúcfeftrómet. Die ṕtwimmenden Snfeln, wels de auf bem obern Theile bes 2roriatifwen meeres, von abgeriffenen

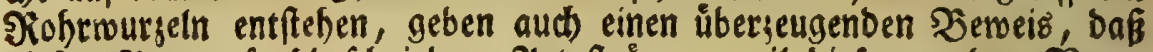

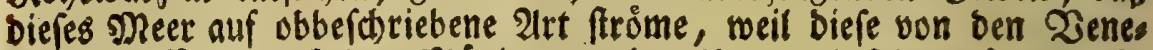

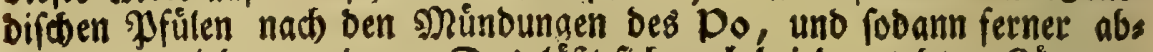
werts, getrieben werben. Das lápt fich aud bei ben tobten Sơrperis, welde auf biefem sneere fotwimmen, in 2tht nefimen. Denn weldbe grenfeben beim 2lusfluffe Des Do erfäufen, bie werben bei Ravenna an bas \&anb aus̉geworfen. Die oberbalb Simini umfommen, bie trågt ber Strom bei SRimini vorbei, und treibet fit unterhalb biejer Stabt

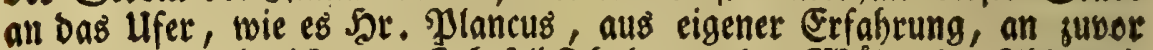

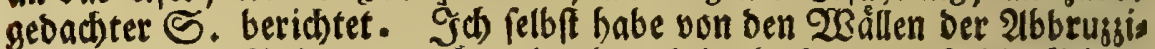
iden Feftung \$eicara, mehr als einmal beobadtet, Dás bie fleinen 2Sogen, wenn bas sReerwaffer burd gelinde 20 inde nur ein wenig gefrăufelt warb, allemal nad) Srtona zuftofien. 2Bietwol id ba ges ftehen mús, bás biefe abmerts gefehrte 23 enoung bes 2loriatifonen

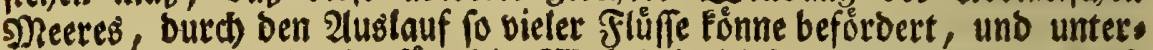

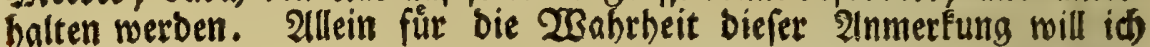
nidft gutperecten. Denn polche ift nichtig, wenn basienine in ber Shat fid) to befindet, was $\mathfrak{5} \mathfrak{r}$. Plancus $S_{\text {. }} 68$, wiber ben (3) befauptet, id aber auf meiner Stalieniften Reife zu unterfud)en bers

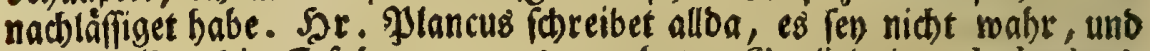
ftreite wiber bie Erfahrung, was ermehnter Biuglielminus $l$. de Fluminum Nat . c. 8, Coroll. 7 , wider bie Zerficherung feines Sehrmeifterg, Des Montanarius, vorgibt, bie Stalienifoben Fluffe ergôffen fid abs

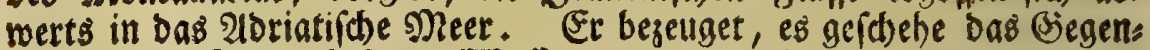

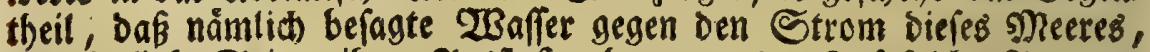
auf bie linfe Seite, ibren 2usflus nejmen ( $r)$. 2uf foldbe 2irt nun wáren

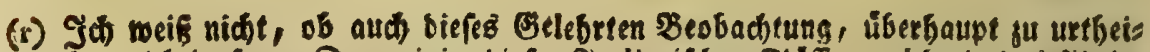

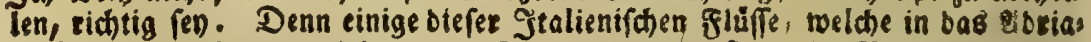
tifche Meer austreten, fieben norboftwerts, anbere offwerts. Bon ben exfern, berer Sauf, unb ouch now gegen Den Ilusflub ifre Settung, etwas nach) Nits

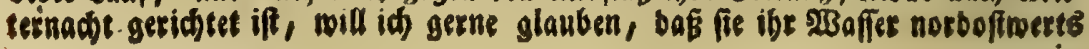




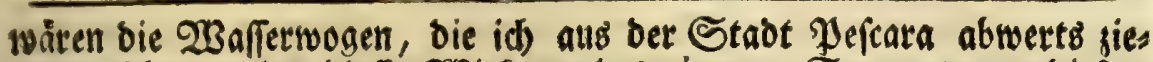
hen gejehen, eine bloffe Wrirfung bes eigenen Stromes von biefem Deere, uno vidit jum Sheile aud eine Folge ber 2 betoegung gewejen,

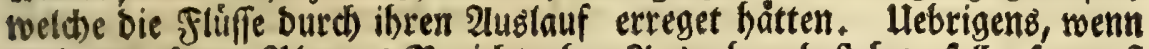
auch Des San. Wlancus ßBeridst ofne 2usinabme beftefen foll, fo muf

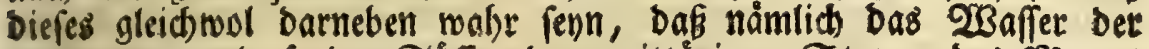
norbwerts nuslaufenden Flüffe, bem mittågigen Strome bes Meeres nicht lange wiberftehen tonne, fonbern balo suruat getrieben, und mit bem meerwaffer fübwerts gelenfet werbe. Denn ich babe bei ben Fluffe Đefiara (Der Alten Aterno), wenn er befonders trüb war, alles

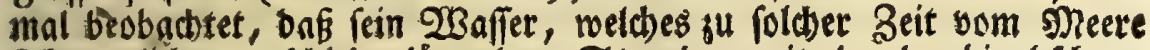

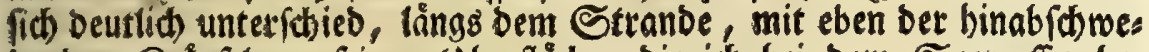
benden Rrăufelung feiner Uberflåche, die iđ bei bem Seenaffer bes merkte, gegen s? itt ag nad) Drtona zuftof.

Scaliger ber áltere ifl fo aufridtig, baß er geftefet, went es ja

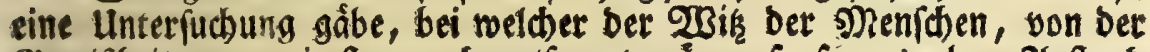
Biemifbeit am weiteften nod entfernet wăke, fo fen es obne 2inftand biejenige, welde von ber Sewegung bes sReeres bandelt. Fortafje magis conducebat ad opinionem bone exiftimationis filentium, quam audacia. Nam quod ubique clamare foleo, nos nibil fcire: maxime convenit buic dis-

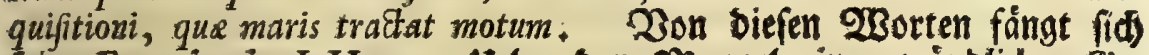
reine Exercitatio LII an. Heber ben Mangel einer grüblidben (jes (d)idte bes Neeres Hlaget aud) Rob. Moravius (Murray), tweiland

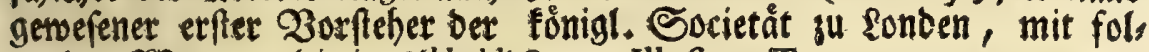
genoen 2 sorten, oie in Sibbaldi Scot. Illuftr. T. I, part. I, P. 18, wie audh in Kirch. Mund. fubt. Tom. I, p. 143, ftehen: Rei nautice perutile effet, hifforiam juftam Maris, Aftus et motus omnes, tam regulares quam anomalos, ubivis occurrentes, fufe explicantem condere. Quicquid bucusque de bac re videre contigit, mancum puto Éc. Shierauf

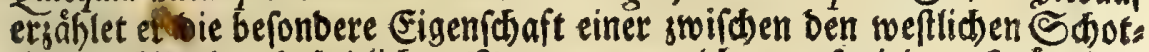
tif́ten Eilanden befindliden sineerenge, welde um foviel mertwurbiget

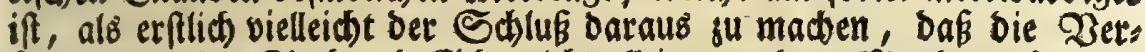
ánberungen bet fluth und (Ebbe nid)t allein von bem פonden, fonbern $\& 2$ aud

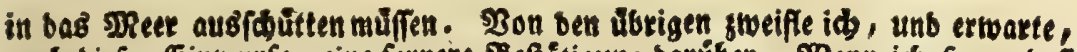

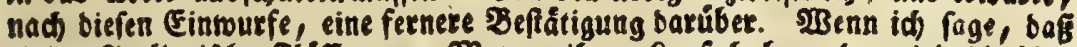

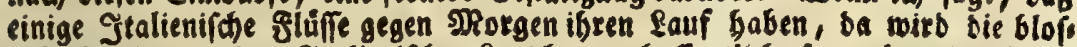

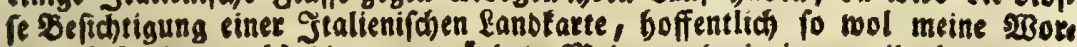
te redtfertigen, alo bie ungegrunbete Reitung berienigen miberlegen, bie 
aud tum Theile bon ber Sonne abbangent. Darnach weil uns bie Radbforidung Diejer Seltenbeit ber Ratur auf eine Spur teiten fann, wie su einer beffern Erflárung biefer Art Der Meerbenegung zu gelans gen fey, weml fold)e Er(d)einung nid)t etroa nur eine 23 irfung ber wi. brigen $23 i n b e$ ift, ba in gerwiffen Segenden zu einer Jahrsizeit biefe, zu einer anbern andere gu berrîtben plegen, wie an einigen Srten in 2ffrifa

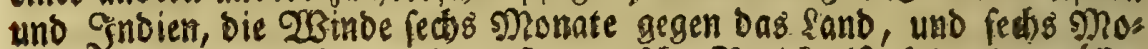

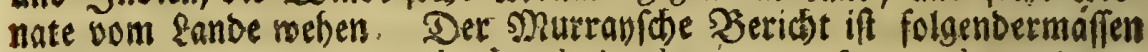
aufgefestst: Mire funt in quibusdam locis Fluxus et Refluxus alternationes. Ego bic narrabo, quod in infulis Hebridibus (Hebudibus) partim propriis oculis obfervavi, partim ab incolis fide dignis didici. Eft locus in freto infulis minufculis, rupibus et fyrtibus frequentibus confperfo, inter majores vulgo Euft et Herres infulas fito. Aftus maximi, i.e. tempore conjunEtionis folis et lune, quo plemmyra fit bofa fexta, ordinate procedunt. Fluxus ab orienate in occidentem, fex borarum fpatio, ficut et refluxus ab occidente is orientem perficitur. Hos duobus diebus ante plenilunium ejusque oppofitum, ac totidem poftea, femper fic fe babet. Tertio autem die et deinceps longe aliter: toto enim tempore diurno, five fluat, five refluat curfus aque. Semsper occidentem verfus dirigitur; nocte vero in orientem vergit. Has egaipfe deprehendi. Sed ferunt infuper indigene, aliud ad. buc magis mirum bic accidere: toto fcilicet die, dum fol figna borealia perluftrat, curfus aque diftos is occidentem tendere: tota autem byeme in contrarium; Darfilius, Der uีber bas Strơmen uno noch einige andere Eigen:

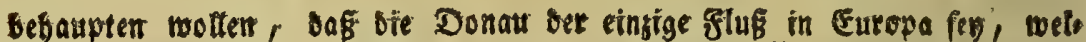

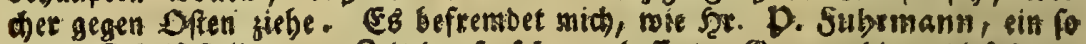

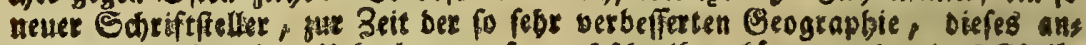

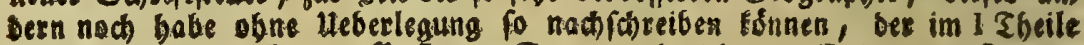
feines ult uns Fieuen Öefter. S. 404 , berid)tet: Eein (Des Donaus frombi Lauff gebet von abens gegen nitorgen, weldjer fouft von fets nem Sluf befbiebet. men verftanben baben, fo mocrleget folden 28 abn nod) ter Po, Dee ges wigtio ben grofien gituffer von Europa verbsinet betgejåblet zu nerben, als melcher um ben porto bel Rago ofcuro, to man über benjelben făbrt,

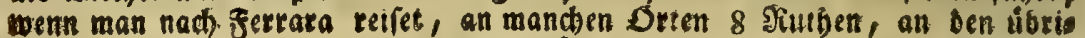

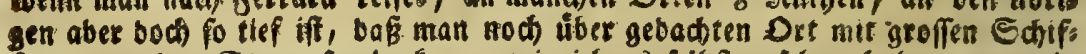
fen gegen den Strom fesela Eann, wie id es felbft gefeben babe, ungendy, tet fein 2 baffer alto nich mege gan beifammen if. Silleis flieffet biejer fo anfefonlidie Strom nidt aud bon 2lbeno gegen SPorgen, wie Die Donau?

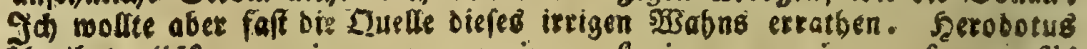

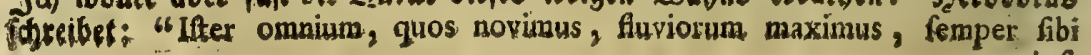
ip is 
Eigenrdbaften bes meeres nud feine guverláfige Erflárung gu geben

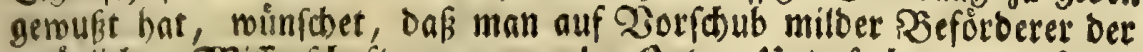
naturlia):n Wifienj(b)aften, an mebr Srten Linterfuchungen anftellen modte. Seine Worte berbienen ebenfalls bier beigerúct zu wer: Den. Solde befinden fic) a. 0.47 S. feiner Hift. de la Mer, unb lauten ungefábr fo: "Go follieffe aus allen biefen betfoiebenen

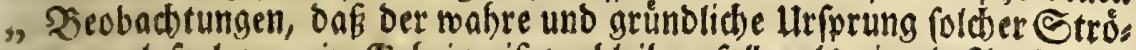
" ne not fo lange cin Seheimnís verbleiben foll, als eingele Woerfonen, \% und nur auf einem Drte, wie id es bei (Saffis gemad)t babe, mít

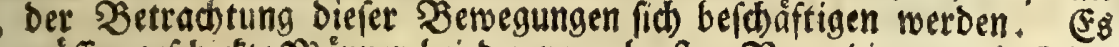
múffen gefdicte Månner bei ben vornebmften Dorgebirgen und Ectent ,

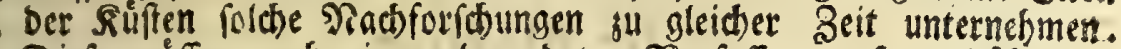
Diefe múffen nad ciner abgeredeten Distraffung, fo wol úber bie "Gefaminoigteit gebacter Etrome, als úber bie Segenden, bahin "Diefelben ziehen, ibre tåglichen Derseidniffe baiten, ofne vie untern "Strome, weld) einen bem obern (Seroáfier wibrigen Rauf nebmen, "auf Die Seite su resen, ohne aud) bie SEeobadtung oer 2 Binse zu

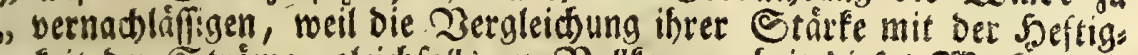
feit ber Stróme, gleichfalls jur $\mathcal{B}$ ollfommenteit diefes 2 Berfes mit erforbert wirb. 2ullein ba eine fold)e, in fid nükstide Unternefmung, " eimen 2ufwano bagebret, fo fann biefelbe aud nur burd Sailfelei. , fung eines groffen Sherrn, ber ein siebbaber uno $\mathfrak{Z}$ efórberer fol

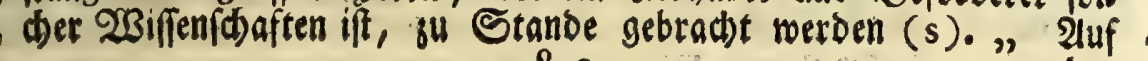

$$
\{3 \text {, Det }
$$

„, ipfi par, tam xeftate quam hyeme; fluit ab occafu primus omnium, qui funt ", in Scythia., IV, 48. Diefe unreche ausgelegte Etelle wito obne Zneis fel jur gebadten faliden Neinung Inlas gegeben baben.

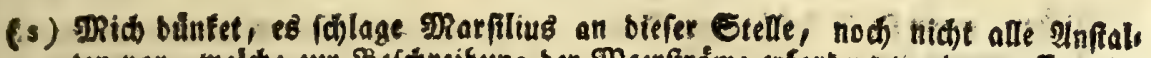
ten vor, weldhe gur Befáreibung ber SDeerfiróme erforbert werben. Et exin nert gang mol, Daß man auf bie untern Etróme gleich fald 210 t geben foll; weil bie şerogung ber obern burch bie untern, auf bie eine ober andere Seite ges

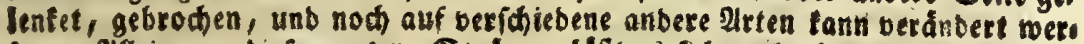
ben. 2ikein von biefen untern Strómen läpit 18 fid nod eber fagen, bas bets felben volfánbige Ettánntnif́ fo lange sin Eebeimnis bleiben nirb; bis mir eis

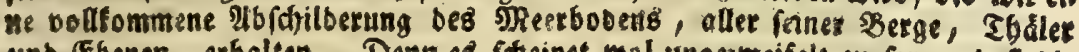
unb Ebenen, erbalten. Denn es fotheinet mol ungezmeifelt fu regn, oaj bie untern Strome, wie bie obern, fids theiler, wenn fis an eine Ede ber untu:

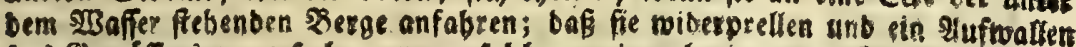
bez Getwaffers. berurfacten, wenn foldse an einen breiten, bor fid befi blishen,

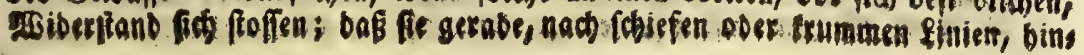
aikbets, 
Der 49 S. erinnert Marfilius, Dap gleide Sdmierigfeit bei ber Un: terfuchung ber 2 Binoe vorfomme, und aud nur auf gebadte $23 e i f e s u$ - beben rey. Was biefer gelebrte Braf bei Eaffis auf Dem stittellänois

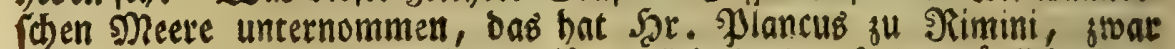

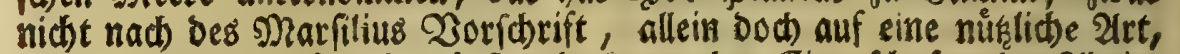

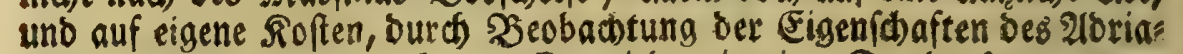
tifhen Meeres, vollbradht. E\& miro mir eine Freube feun, wenn

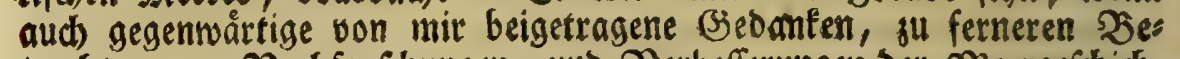

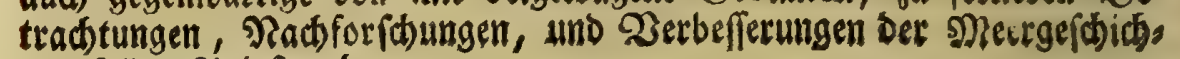
te, follen $\mathfrak{A}$ inlä geben.

\section{Errfter Naditrag \\ su biefer II Unterfud)ung.

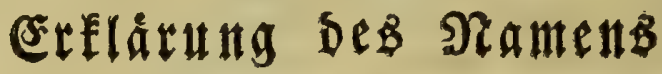

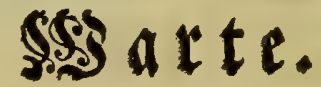

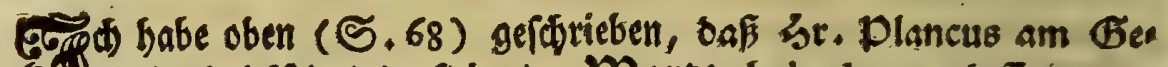
(d)) fabe bei Rimint, fid eine $\mathfrak{W}$ arte babe bauen Iaffen, um - Oaraus bie Bef(haffenbeit Des 20riatifden Meetes unterfuden 34 Cónnen. Diejer $\mathfrak{P a m e}$ Warte mơdte Don einigen angefodten wers ben, bie fich vielleidst einbilden, daf berfelbe nur eimen Shurm bebeu=

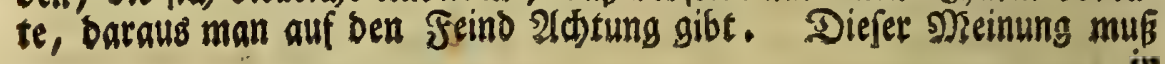

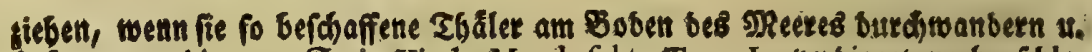
1. f. wopon bie 139 S. in Kirch. Mund. flibt. Tom. I, verbienet nach gefdla:

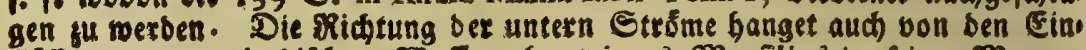

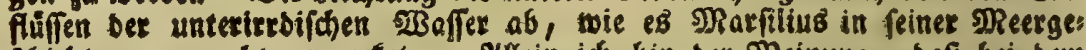

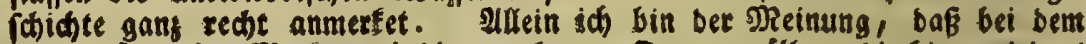

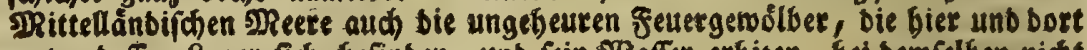
unter beffen lager fich befinben, unb fein $\mathscr{W}_{3}$ affer erbigen, bet bemfelben nidht minbere, gang befonbere, \$eroggungen berutfachen múfen. Da nun ber Ses genftanb biefer unterjudungen, mit ben barzu gebo̊rigen s)Ritteln, unz nidht gênglid betannt ift, to barf fich sol niemand vermunbern, warum aud unfer

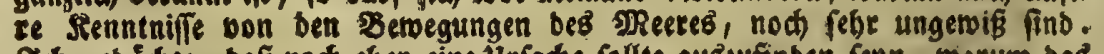

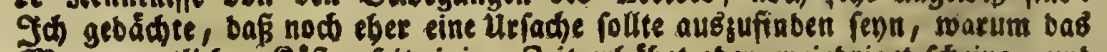

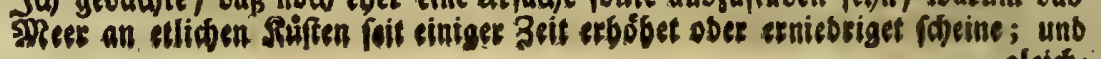
aleíti: 
in ber Fhat bet Merfaffer Derienigen Teutichen lleberfeksung gewefen renn, bie 1740 in bas XXXIII St. Der kiegensb. wóthenti. nel. Liacte eingerúcft worben, indem berfetbe, bei Erdäblung eben biefer (Befdichte, Das lateinifhe obfervatorium befalten. Srine 2 Borte

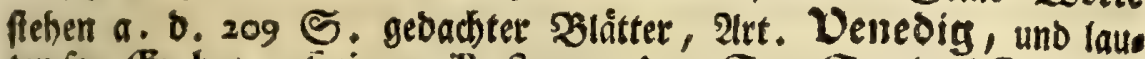
ten 10: Er bat auf eigene Roften an dem Gee = Gtande ( Strande) ein Obfervatorium bauen laffen, und in ber Gtabt Rimini einen 20 os ranifd)en (Earten, nebfe piner Eleinen Specula ober Obfervatorio, anges leqer. Es múffen aber auch bie Zerfaffer ber Woorterbúder, bab

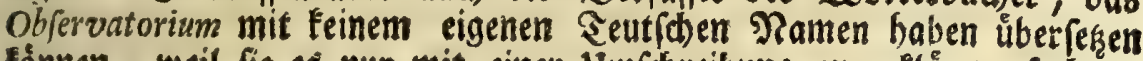

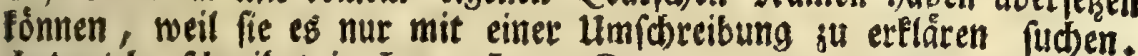
beberid foreibet in Lex. Lat. Germ. OBSERVATORIVM, Gebánde, voorauf man oen Gtern=lauff, und andere Simmels: Zegebenbeiten wohbrnimmt. Das ift aber eine unnothige lange 2uso legung, ba ein einsiges 230 ort eben biefes, uno beffer ausgebrúck hătte.

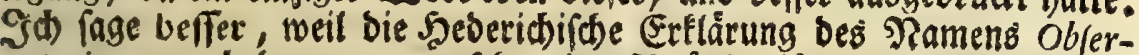
vatorium, nod barzu gat zu fehr eingejhrånfet if. Denn wolte ein Snabe, ober ein Slubthănoer, fo Seutít) lernt, ein bergleichen Obfervatorium, als bas Ylantif́che ift, bataus man bas Meer beobadtet,

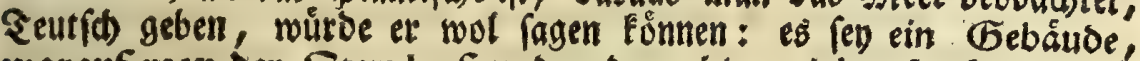
worauf man ben Grernlauf und andere simmelsbegebenbeiten auf bem Meere wabrnimmts Sm Dict. du Voyageur wirb bas Franjos fifde Obfervatoire fo erfläret : ein Ort, oie Gternen 3 u betradbren. Sm Diet. des Paffagers fo: ein Ort, wo man oen Lauff der Ges

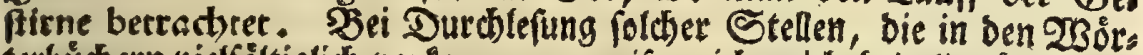

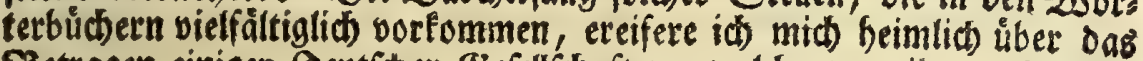

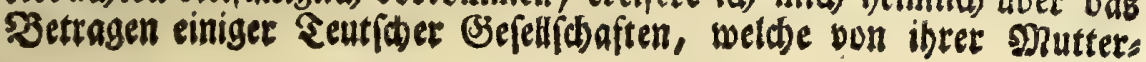
(pract)e

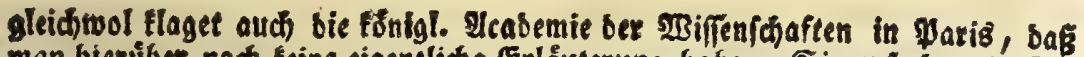
man biectiber nod teine eigentliche Erläuterung babe. Sie exfuchat bie Bies

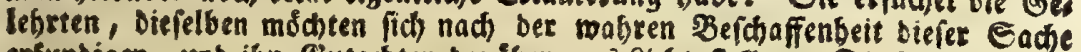
effundigen, unb ibe Butacten barúber ans licht fiellen. Die Worte fteben Mem. de PAcad. 1743, Der soll. भuff. p. 55, unb lauten 69 : "On ne "peut nier cependant que le niveau de la mer n'ait changé à l'égard de " certaines côtes, ou, ce qui $n^{2}$ eft ni moins intéreflant ni moins vraifembla", ble, que les côtes n'ayent baiffé ou hauffé, \& l'Hiftoire nous fournit la g, deffus des temoignages qui ne permettent pas $\mathrm{d}^{2}$ en douter. Mais ces te"moignages, où Pon $n^{\prime} 2$ guère eu en vue d' inftruire les Phyficiens, ne les 3) inftruifent guère en effet, par le defaut de mille circonftances dont il fe"roit à fouhaiter qu' on ent accompagné les faits. Dire au public que nous " manquons d'obfervations fur ce fujet, c'eft inviter les favans à en faire, 
I1. \$f. 26banblung som meet:

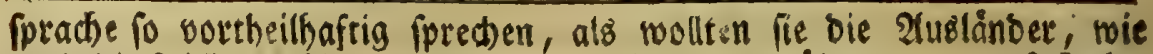

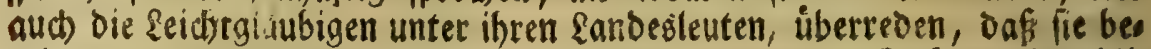
reits in unverbefferliden Stand fen gefert worben. Es fann aber bils lig als ein unseitiges Brobithun angefehen merben, roenn riefe Snerren nur von Dem 3ierliden, von Dem Erbabenen, uno anbern boben Eigens fhaften Diefer sprache fo viel 28 efenz mad)en, aud faft nur bei bet Yoeteren fich aufhalten, als wenn bas librige fition alles in Fiditigfeit

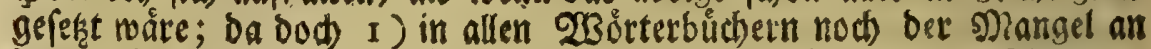
ben nothmendigften 2lusorúcken fid seiget, wel(t) fie aus ben Sberteut: Then Dinleften berfolen, unb ber Sodbteut fiden Eprache einverleiben

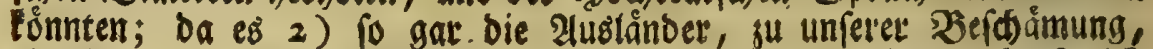

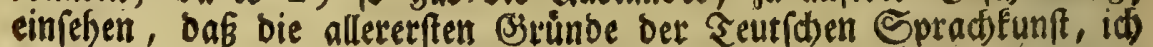
will fagen bie fefre von ben 2 dbrondlungen ber s?ennmoitter, weber su

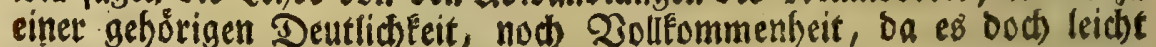
geid)ehen tónnte, gebradt) worben. Den allerneueften Beweib von Diefer bittern 2 Babrheit gibt oie Corunolegung tinet Teuthon Epractunft an bie Sand, welde Edrift, unter ben 3 úchern vou Diefer 2 trt, bie befte regn foll, weldie aber getwiflid) bie Epradse, ober

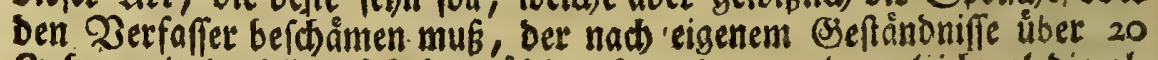
Sabre mit berfelben fich befóaftiget hat, bavon aber gleidjwol bie alo lererfte 2bbanblung, Daran bie Fremben fich gleid) anfangs zu ftoffen, unb bie Suft zu Erlernung biejer Epradje fu vertieren pifegen, fo uns volfommen getiefert. Sollen biefe (jielehrten nidt)t lieber burch allges

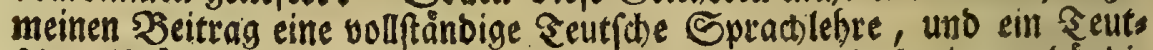

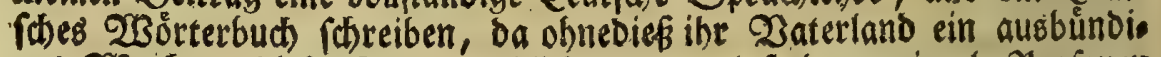

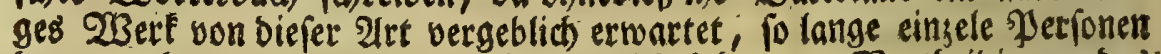

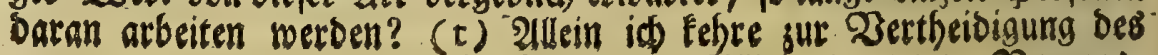
शamens,

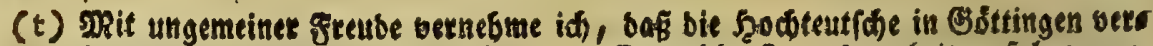
fammlete Befeof

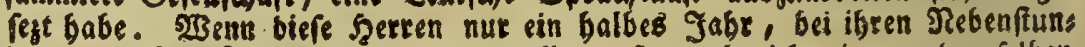
ben, ibre semúbungen vereinigen mollen, fo made id) mit won becofelbett

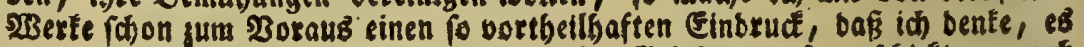

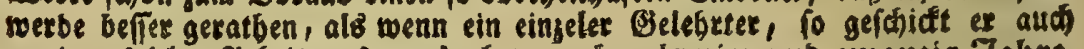
fu einer folden 2rbeit fu fegn glaubet, mehr als vier uns jwanjig Jabre,

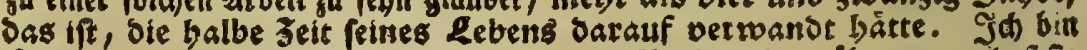

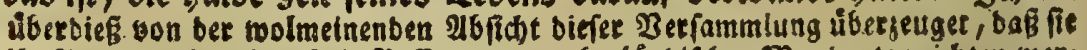

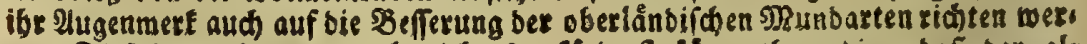

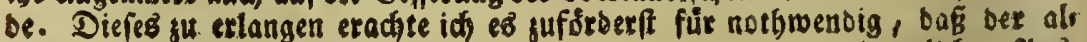

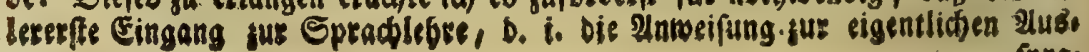
ipras 
श्ameng, womit ich bas lafeinifde Obfervatorium überfest habe.

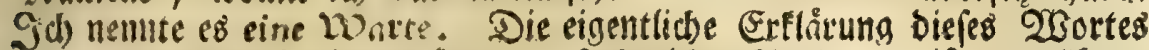

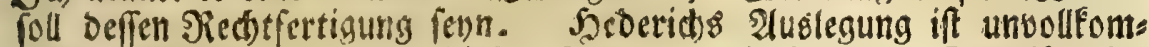

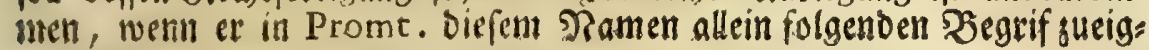
net: Warte, morauf min fich nad, oen Seinoen umfiebet. Denn

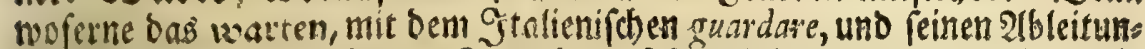
gen (barunter Dag befannte Guardiano fith befinbet), einerlen O2Ort ift, imo unter andern 5 beteutungen ally iberbaupt obfervare, nath etwas

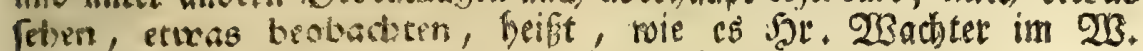

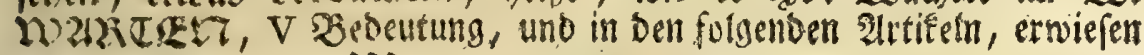
hat fo iff aud eine Woarte, ein foldber $\mathcal{O}_{\mathrm{t}}$, aus oem man fids nact allsin umfeben Eimn. Einen Sfurm, Daraus jemano ben Eauf ber Eterne bedbathet, heife ith eine Eternmatte. Dasienige am llfer bei SRimini aufgeführte Giebáube, baraus 5 t. Wlancus bie Fluth uno (Ebbe, wie auth andere Bufálle bes miegted, beobachtet bat, roollte if eine sleewwatte genennet haben; uno wenn ja biefes ben eigentlid,en S(usbruce nod nidht hintånglid) beftimimete, fondern zwey: beutig toäre, uno audb Speculam maritimam, eine $\mathfrak{W}$ arte, bie nur am trieere gelegen fey, bescutete, fo gedádte iah, baßs ein gants neuts,

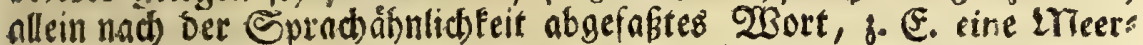

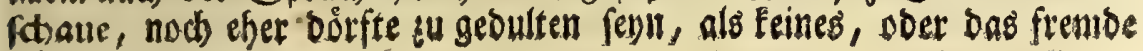
obfervatorium.

\section{MI}

3wely=

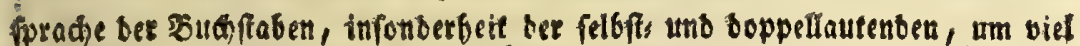

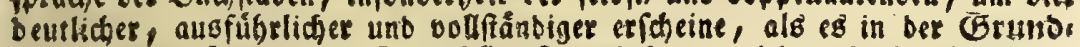
legung einer Deutiden Sprady Hunft geffeben, weldhes gleidiwol bas bes

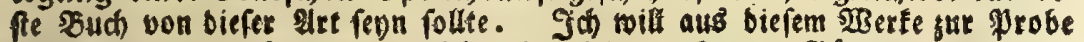
einige Stellen berbringen, welche bie gelebrten Ferren Giơtinger zu bezbefs

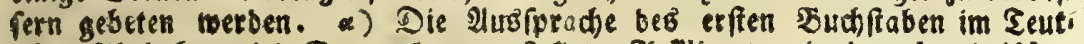
fichen sllphabet wirb $e .21$ fo vorgeffellet: 2 flingt wie bas lateinifoe, italicniphe uns franjofifdoe a. Das ift fon cine pnteutliche lefre. Denn bie granjofen baben zwenerlen a, berer unterfidseio nidit an bem lans gen ober furgen Tbonmaffe bafiet, fonbeen eine anbere Defnung beB sisun: be8 sum Erunde bat. In francbement \&. E. Tautet 68 bunfel ober tief; in

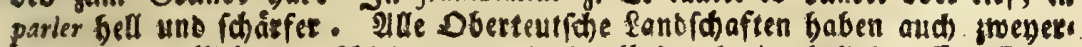
ley rebe merflid) unterfatiebene $a$; ein Dunfles unb ein befles. Ein Eyen! pel bes erfern ift in Dater, mad)el!, unb allen einfeimifden 20 ơrtern, mo eb einen 52 ittellaut zwifden a unb o bat. Man pfieget biefen \&aut burd

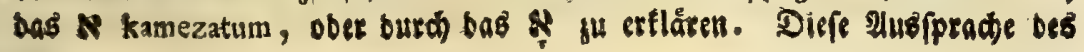




\section{3wenter Sadutrag \\ 3u biefer II Interfudung.}

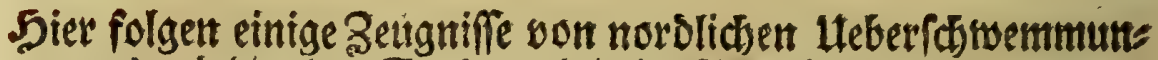

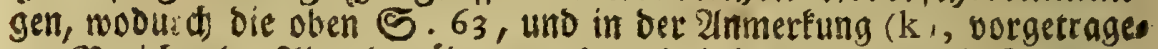

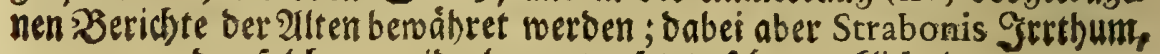
bet foldee su wiberlegen tradtet, fehr merflid in bie 2lugen fällt.

C.

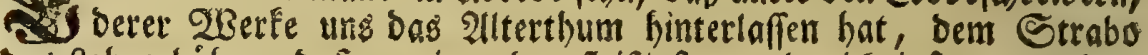

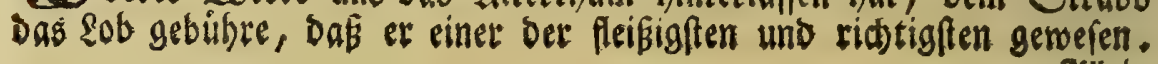
2llkin

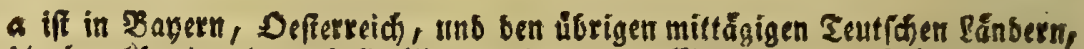

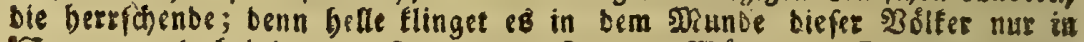

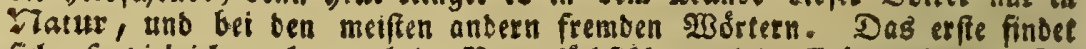

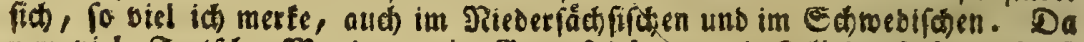

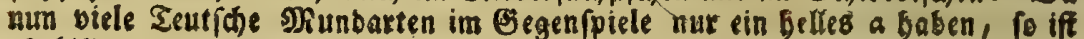

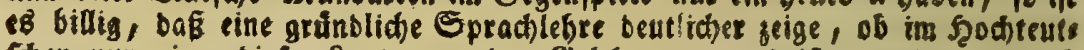
fhen nur eines biefer Raute von bers Gelegrten gutgegei Bent merbe, Doer ob beide ftatt baben, in welderm leztern Ealfe ifnen ibre Eabranfen follten bes

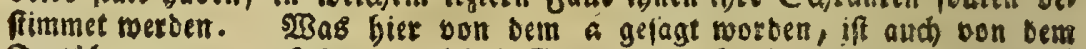

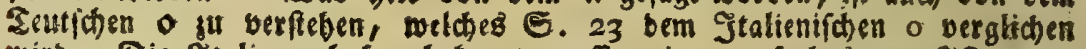

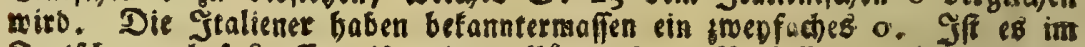

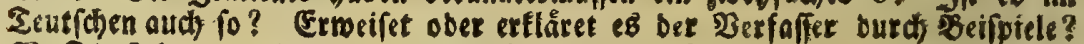
B) Die Regre von bem vermeinten Doppeffaute ó flinget feltfam. Es beisit E. 32: "De, als bớren, Rơnig, nicht wote bấren, Seánig, audy nidte

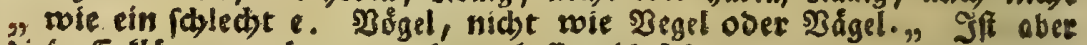
Diefe Ertlårung mol um ein Şaar befier ale folgende, MATERIA PRIMA

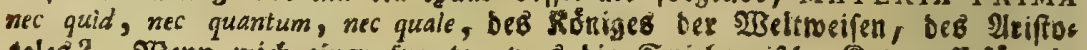
teles? WWenn mich einer fragte, was bie Epigbergifte Sintgegeff für ein

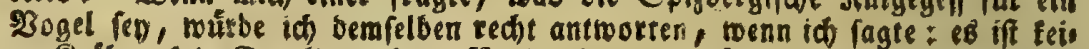

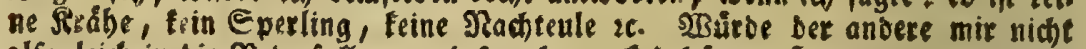

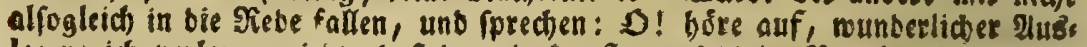

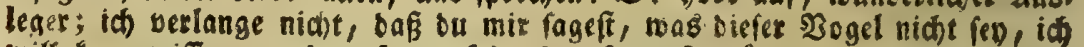

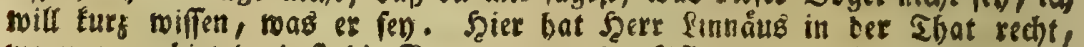

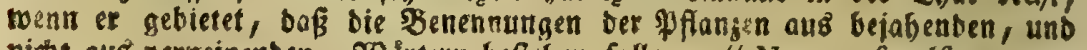

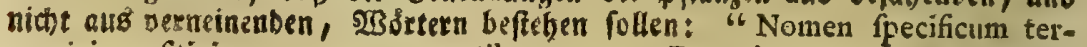
" minis pofitivis, non vero negantibus utatur. Fund. bot. 298. MRsines Ees ad)tens 


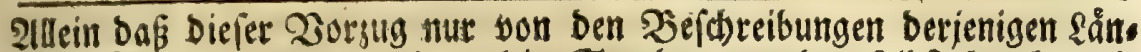
Der múffe verftanden werben, bie Strabo entweber felfoft burchgereis

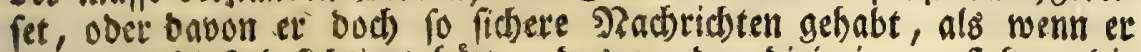
bie Srte felbft befichtiget bàtte, bas werben biejenigen geftehen, bie wiffen, wie verworten ober irrig mandimal feine $\mathfrak{2}$ eridbte lauten, wenn

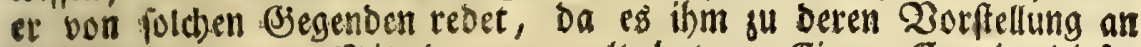
jorgebachten fwen Nitteln gemangelt bat. Einen Erweis biefer 2Gahrheit gibt 3. (E. Die Strabonithe Stelle, VII, 314, von ben

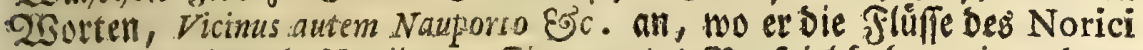
und pannoniens befareibet. Ein gwentes $\mathfrak{B}$ enfpiel haben wir an bems

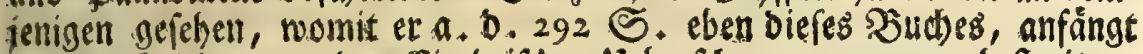

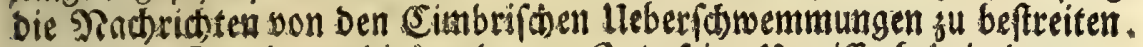
zsie fefre Strabo an biefent leftretn. Orte feine Untwiffenteit in ben norn bifden Sachen blos gegeben babe, wiro aus folgenden Beugniffen ers Bellen, Die Jebren, Dak bie Inwobner Det niedrigen, an Der ?ordfee III 2

geles

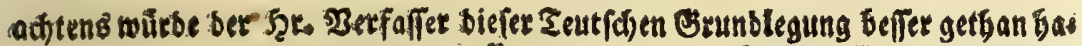
ben, wenn ex gefdrieben båtte: De foll nady ber ådten Ceutjoen Zuss pprade lauten, wie Jas franjofifide eu. Bum menigften bie fereren शies

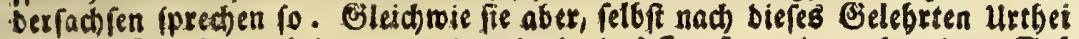

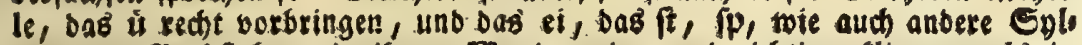
ben unb Suchfaben, in igrem SRunbe reiner und richtiger flingen, als in

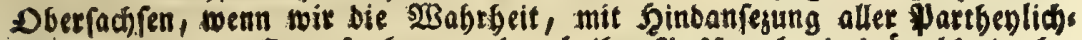
feit, extennen wollen: fo fann wol aud ihre 2luşpradje ses $\delta$ als ein bel

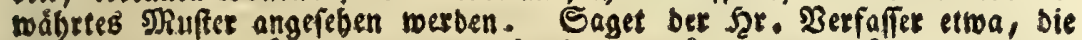

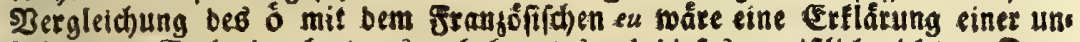
betannten Eache ourch etwas unbefannte8: 0 ! biefes gerwiflich nicht. Denn wo ift wol ift ein Dre in ₹eutichland, wo man nicht einen Franjofen antef,

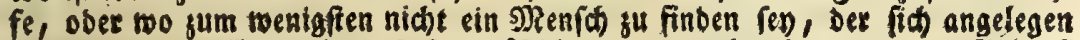
regn laffe gu wiffen, soie bas grangoffiche eu borgebracht metbe. 2ulfo ift

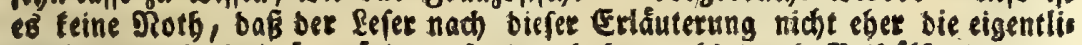

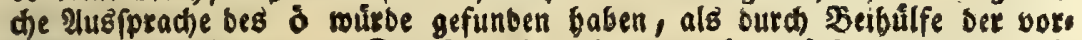

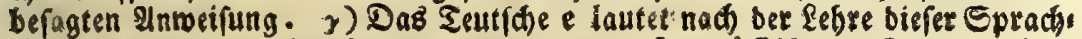

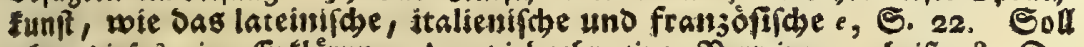
aber Diefes eine Erflarung ober vielmegr eine Serwirtung beifien? Dex

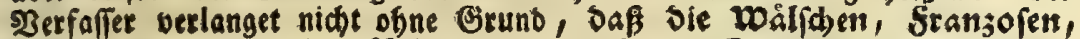
Englander, ibm Die Ueberfejungen feiner Gpradblebre sinfenben modten, Samit er febe, ob alles Sem wabren Ginne gemåf getrofs fen roorben. Er mus felbft gezmeifelt baben, ob bie diublănber fetnen uns

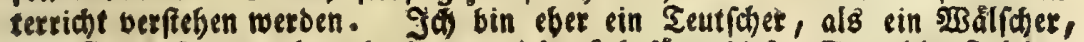
ober grangofe, uno fann bod aue vielen \&ebrfázen biefer Epradjtunft fainen mabren. Sinn beraubbringen. So gebet as mir and bier. Die Jitaliener baben 


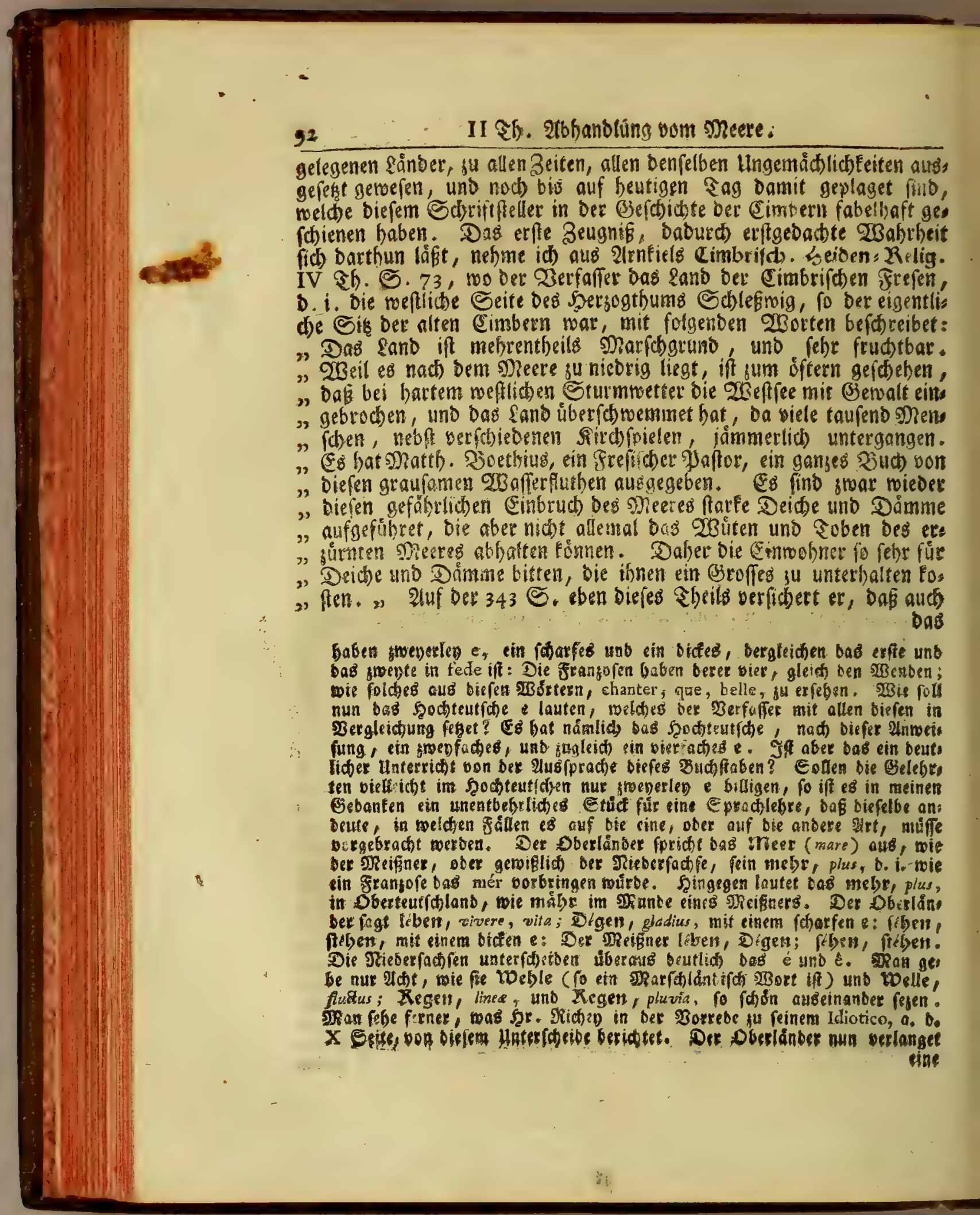




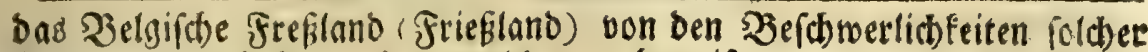
Flutben nidit befrevet fen, welches fu berweifen er aus Langii monachi chron. Citizenfi, ad a. 1220, p. 899, berichtet, Daf in ist erwebntem Sabre eine groffe Sluth Dafelbft entftanden, Darinnen über bunberf taufeno ghenichen umgefommen. Sm III Sh. fúbret er, bei Bjeles

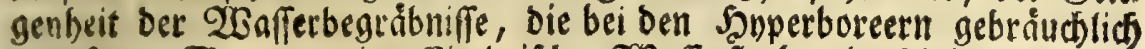
gewejen, $\mathbf{S} .55$, eine cimbrifhe $23 a$ ferfluth mit biefen 230 orten

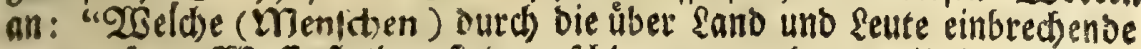
"graufame grafferflutben fino verfoblungen worben, will ich nur ber

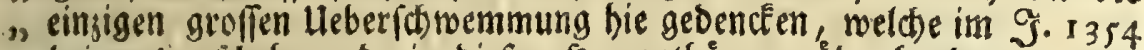
"bei unz gejobefen, Da in biefen Serjogtfumern uber Gunbert taureno " Menichen, fame brensig Firchipielen, untergangen, oa bas Sorb, "frand vom feften Eande ab: und bie beiben Infeln Sylt und Gor von: " einander geriffen worden., Heinr. VValter 1.3. Chron. Fref. fept. c. 13: D. Danckvv. part. 2 Chorograph. Schlesw. et Holfat. c. 5, p. 93. Die allererft erwehnte Infel, bas Foroftrano ges nannt, ift 1634 , vermitteift eines frarken 2 Bimbes, von ber See gans unter $23 a f f e r$ gefest worben, fo bas bei 1300 Şåufer, 6000 ssen: fhen, und s0000 Stůce Dief zu Srunbe gegangen. Da es nun sut Deit ber alten Cimbret in biefen (siegenden vermutblich nidbt anders II 3 niro

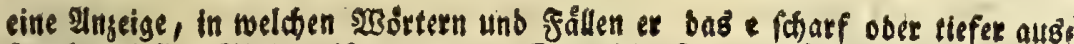
fprechen foll. 2allein trift er in ber Epradtunft rine b̧ulfe an? Er ift ber. laffen. Er trad)tet fich aus Der llebung Grundfáge ju madien. SBenn ex ei

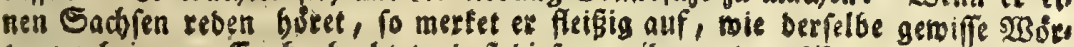

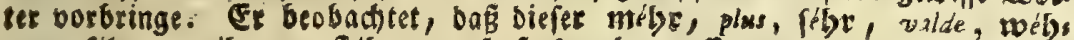
ren, flgen, gethen, fteben u. fo f. fpreche. Ee verfaffet fich folgenbe Regel: Das Ceutfose vor Sem b flinget fäarf. Diefe Rebre wá re beutlich. 2athein ift fie and richtig uns allgemein? Dergleichen Frơrtes zungen unb Enticheioungen nun fuchet ein Desteuticher, bor affen ambern

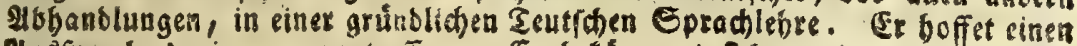

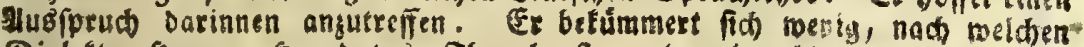

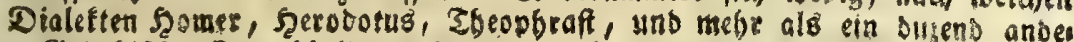

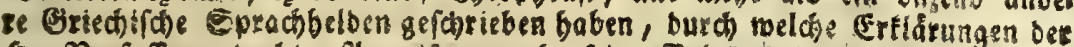

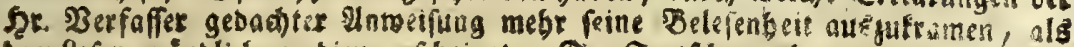

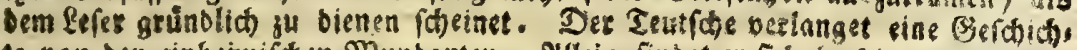

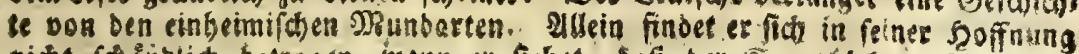

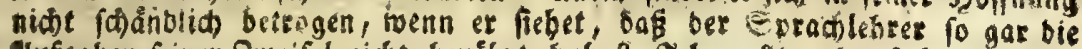

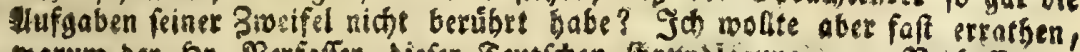

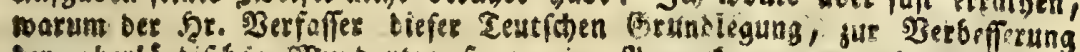

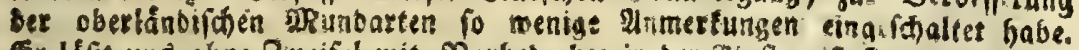

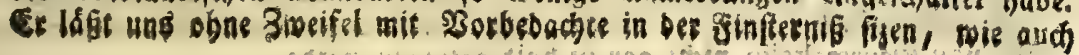


wird ausgefehen baben, was findert uns Dem (Fphorus beisupflicter,

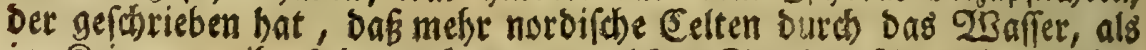
im Rriege, um ifr feben gefommen, toeldes Sttabo (2inmere. k) ofne allen gültigen Bruno für ungläublit bailt .

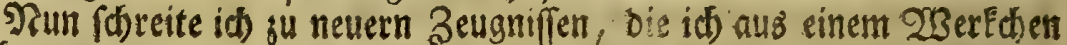
entlefnen werbe, fo 1718 tu Samburg in 8 . unter Diefer Fufforift Geraus gefommen: Umftandlide biftorifd) 2 tad)ridt von oer grof: fen Wafferflutb, welde in Der Cbrifnadbe des I7 17 Jabies, die Serzogrbumer bolftein, Sd)iefwig, Diemen; intleitben Delmets borff, Dloenburg, Jever, Zniepbaufen, Offriefland, Grónin gen, Srieftand, bolland and die übrigen vereinigten Provinzen, bes

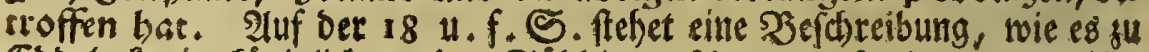
Eobelace, im Eonigliden ober Swboitmarfden, nach ciner toeggeriffes nen groffen Soleuse, auggefefen babe. Diefer Sericht lautet in bet Sbat 10, bafein Silo, baburd man bie allgemeine Sindflutb borjus ftellen pfleget, fu ciner Ertlårung Darju fơnte gefef̧t werben. Dem

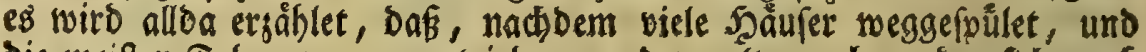
Die meiften Fabrjeuge weggetrieben rorben, "mancher, ber fich now "fümmettid etwan auf bem Dadje, ober auf einem SBaume gebals "ten, bennodh nad) ettidien Sagen, vegen Mangel Effens uno Srin: "Eens, uno wegen Sålte, feinen (Sieift elenbiglid aufgeben múffen. "Denn weil bie fturmenden 2 Binde bis in Den Sennet anbielten, fo 2 war das ganje'sand nidjt anders als eine offenbace See anjureben; " uno narb von bet benadjoarten (Seeft, injonderbeit aus Suberbaftebe "gefabrieben, daf man bes Dadots eil ungemeines Sammergef(bren " in Der uberfotwemmten Marfd von ben Seuten böre, welche nod "auf ben Säbern fáflen, ober aud) die Siopfe aub felbigen berauss " fecten, und erbármlid um Şulfe uno Settung ruffeten, bie ifnen

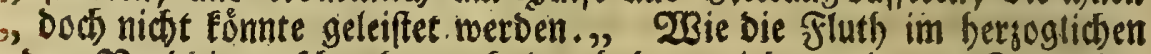

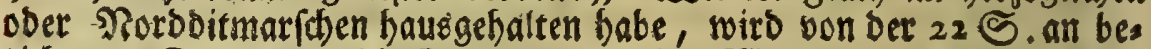
tictet. Dort follen bie S3randungen ober 2 bellen ber See, wol 20

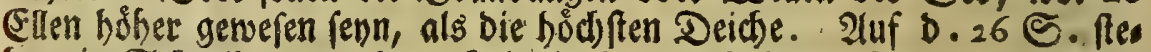
bet ein Schreiben aus bem Sebroigbtooge, d.d. 20 San. 1718 ; fol gendes Snbalts: "Das groffe unglude ber boben fluth bat uns fo bart $n$ betroffen, Dap wir fámtlic faft um unfer (Sut, ja theils gar ums "Blut,

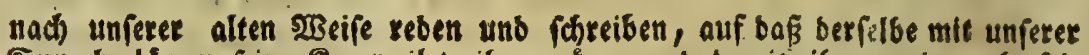
Sprache långet feine Rurzmeil treiben mơge, unb bamit ifm, mie auch fei

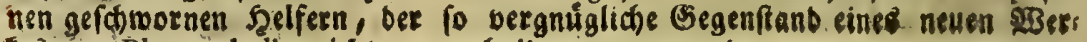
feb von Blaurceckelio niфt gat ju balb entzogen werbe. 
Silut, bieburd gefonmen find. Wrir batten einen ungemein fobonen Deich vor uns, befsgleichen in gams Ditmarfenen nidht war; vermus theten uns berowegen, bei einem fo (h)led)ten $2 B$ inde, Eeines Unbeits und Durdbrudes. 2(llein am 25 Decemb. Des פMorgens um 4

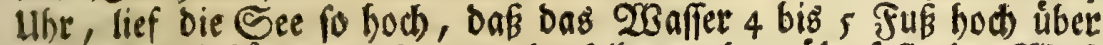
unfern Deich pử sete. Da nun berfelbe von bem úberfallenben 23 afs fer inwendig abgejpulet uno bưner warb, auds bie serwalt bes von aufien fommenoen enoficas ben groffeften Sheil bavon wegnabm, fo

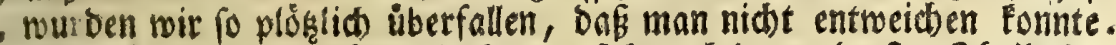
Sinug batte man zu thun, Das man fich nach Dem oberften Sheile bes Saufes, um bas seben bavon su bringen, in bơdjfer (Eile fludstete. Das ungsfunte $23 a f f e r$ füllete mit úberaus boch gehenden 230 ellen , unfern ganzen Soog as. Da faf man, wie burd beffen Macht bie Shaufer jerfed)eitere wurben; und wie bas eine halb, bas andere gam, bie und ba bintrieb (u). Die Mnenfonen, fo fid barinnen befans , ben, fudten auf alle $23 e g e$ iffe seben fu retten, und trieb ber cine , hie auf etroas Stroh, ber andere auf einem Stucfe Scols, ber britte bort auf einem Sfreile oom Scaufe bafin. Die renigfen aber bas von famen gu Sanbe, fonoern musten jåmmerlich ibren Eseift im 20 afa , Rer aufgeben.,

Saieraug erfiebet Der Sefer abermal, wie Strabo unredt hatte,

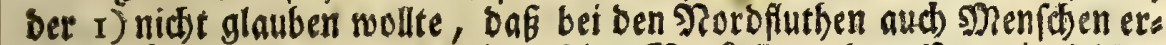
faufen Eonnten. 2) Das biber feine Dorftellung bas Dieer in jolder Giefthwindigfeit einbrecten fonne, bas bie Snnobner ber nabe geleges nen flad)en fånber genug zu thun baben, wie fie ibr feben, mit Dets laffung ibres Butõ, in Sidjerbeit feten mógen. S. 34 roiro bes ridtet, Dás in bem Eiberftábtifonen, im Girafentooge, Der Eigener. fummerlia mit berm 2 agen entfommen. Sieburds mird abermal

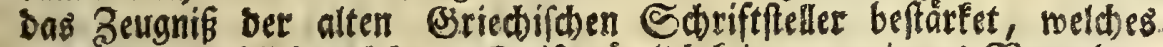
Strabo vergeblid anficht. E\& if nåmlich fein ungereimteg Zuorgeben, wenn (Elitardbus meloet, Daßs aud bie Cimbri fich genothiget faben, ber Sluth zu গferde zu entweichen. Erbärmlich war bie Pad;richt,

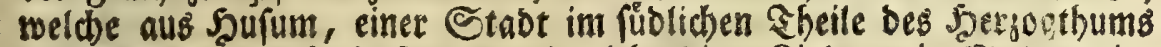

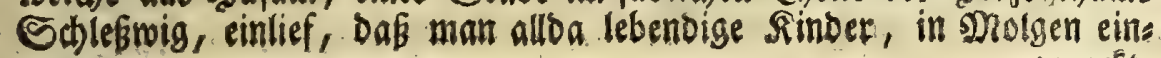
sepact,

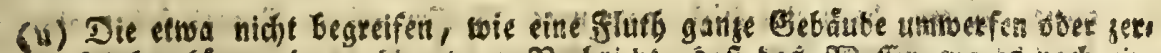

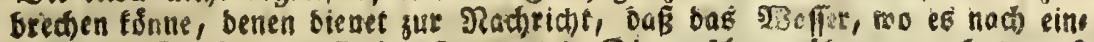
geriffenen Deichen ein flaches Land, wie Ditmarfaren, 16irgogen hat, auf bemielben eben fo fúrme, uno beinabe fo bobe 2 seflen treibe, als auf bem 


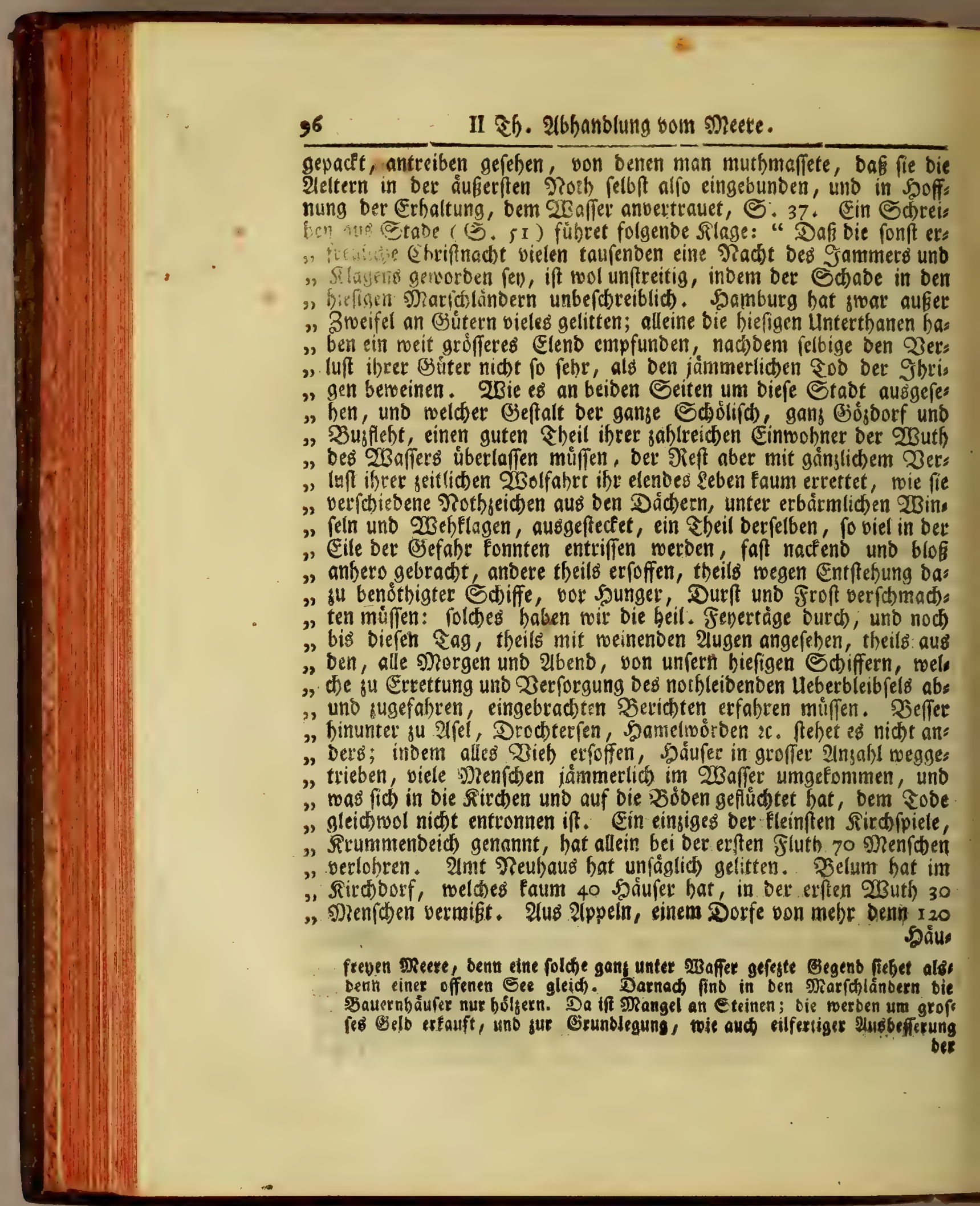


Shåuern, iff, bem bisherigen Werichte nad), auber bem Priefter, " feine lebenoige Seele davon getommen, und von Sháufern fino nut "8 feefien geblieben. Das sano ftefet allenthalben noch voll T3affer,

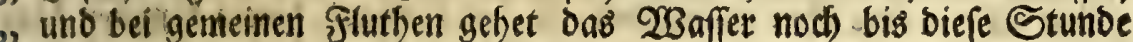
"Dahinein; reldhes, weil $\mathfrak{e B}^{\mathfrak{B}}$ mehrentheils falsig ift, bie 23 interfaat " im Brrunbe verberbet; wie Denn biefem llebel um fo reniger absuhel "fen ift, als bie meiften Sdbleuren weggegangen, bie Deiche allents

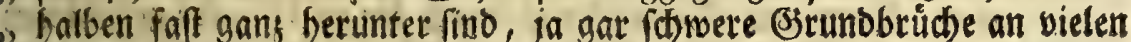
3) Drten fich finden, Die menfichen aber theils auf bie (Bjeeft fich bege: " ben muiffen, um nicbt bei jeber Fluth einer neuen (jefabr ausgefest

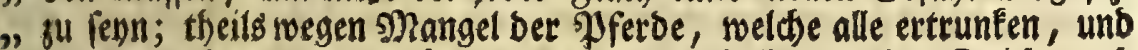
", wegen unbequemer Sahrgseit, Die 2lusbefferung Der Deide uno ") Sd)lenfen, weldbe wenigftens 2 bis 3 शhillionen Eoften Dớrten, bis

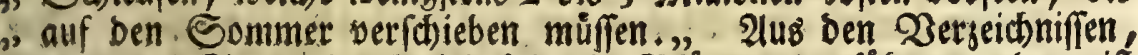
bie 0. 0. 56 S. an, Durd viele folgende 3 lätter, angefúfret werben, ift ber Berluft an Menfchen und Wieh, als fen, Sd)weinen, welden verídiebene anbere Giegenden erlitten, aus: fübrlid) befabrieten.

2sie pehlerhaft biefe 2 nnmerfung bes Strabo (S. 64) wiber Clitarchi $\mathcal{E}_{\mathrm{r} j}$ ahlung (er), neque enim tanta celeritate accedere mare deprebendimus, fed fenfim et latenter, if aus Den bisher angefubrten zeugs niffen ficson gu erfehen geweren. Soldbes aber mirb burch nachgefezten, von 28 remen, aus Dem fanbe 23 urften; Den 27 Decemb. eingefand.

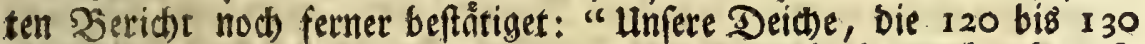
"Fußs unten 2nlage gebabt, und 24 bis 25 Fuß bod, aud) oben fo

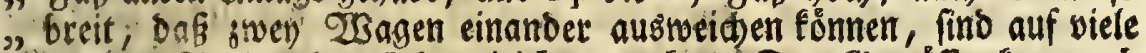
"hundert Siuthen ber Eroe gleid gemadt: Das Bewáffer fam aud " To fotnell, baj fich bie wenigften \&eute anders mohin, als auf ibre ") Seubdoen baben flídten fonnen: bas ủbrige, was fie unten im J̧aus "S Fe, an fahrender Şabe, (Bieråthe und Dieh, gehabt, muste ben sieer. "wellen úberlaffen werben: (Es war erbàrmlid) anzufeben, wie bet

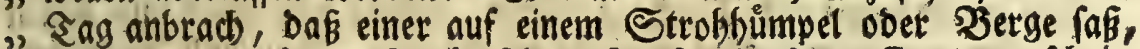
"ein anderer auf Dem Dad)e reines Saaufes, und un Errettung forie.

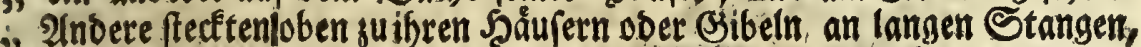
"Bettlacten unb ₹údber aus, uno gaben alfo ibre श्रloth zu etfennen, " Bettlacten unb Tidet alle

ber befdăbigten Dosmme verwenbet. Dergleiden bslleene Bebåube nuth werben burch bas bobe eingefallene 23 affer balb aufgeboben, unb ganf obet

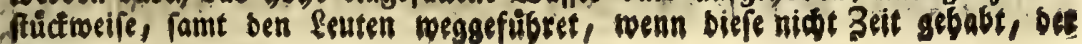
Sefabe fu entwifhen. 


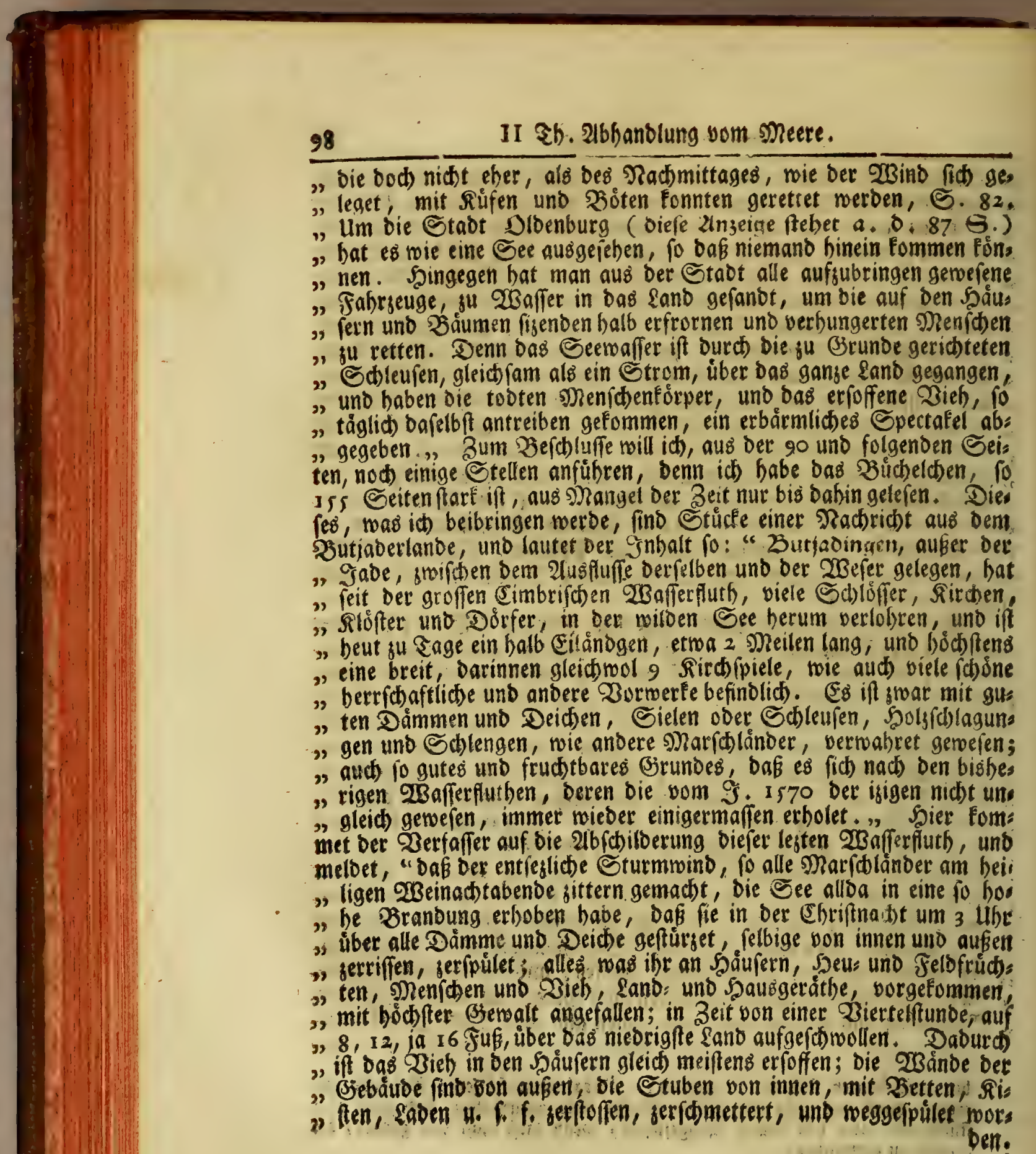




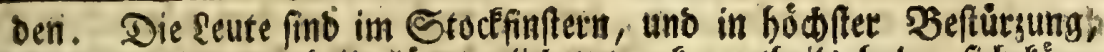

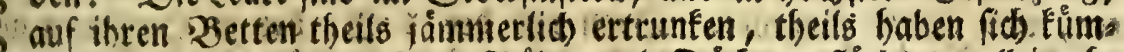
5. metlich in bie Shibe auf bie SBoben uno Dáder gefluchtet, allein oh. " ne bafelbft eine SRettung zu finben. Denn gar viele Şăufer fino but Das hehe $28 a f j e r$ gans weggerifien worben, und haben, wie bie Edhifsfloten, uhne Segel uno Jiuder, wo fie bie milbe See binge: trieben, fortgefchwommen. Daber biefe elenden Nenfonen ba und. oort vieber von benfelben herunter gefturget, berer einige im $23 a$ af fer iffen Beift alfgegeben, andere (Die fids noch mit einem Stude

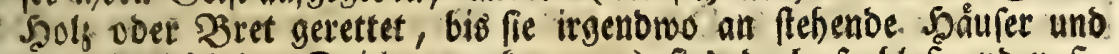

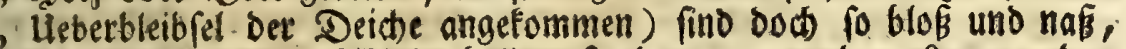
, fa vom Frofte uno 23 inde balb exforben, von andern feuten, ben: anbern und oriften Eag, erthalten worben. - - Biele (báufer, oie bó ber gelenen batten) weil fie won ben Sturmwinben vollenbs gets. 3. fobliftelt worben, find babin gefallen, uno weggefdrwemmet worben.

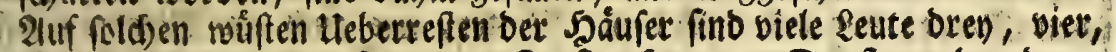
fuinf Tage lang, nactet, von froft, Scunger, Durft, unb andernt (Elenb, halb tobt, etlidse aud) in Silumpen wirflich tobt bei einans ber gefunben worben. Qielen finb bie BStieber iånmerlich erfroren, ods ibnen bas fleich wegfaulet, uno fie faum zu beilen finb $\mathfrak{E}_{0}$ iff

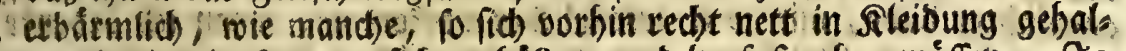
"ten, iso in alte \&umpen fíd verhüllen, uno barfuß gefien múffen. Sa " wie mand)e Sinobetterin, oa fie faum entbunben, mit Dem Sinbe, " und allem im Saure, bor bem hereinbredsenden 23 affer verfoblungen "worben. WBie viele Eheleute, 2leltern unb Finder, und andere.

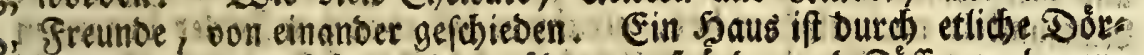
"fer bremiente gefabren, barnuf brey an 5 hânben unb Fúffen verbranns "te Menfchen, um Rettung vergeblich (b)rien: - - - Die Aeltern ") Gaben fich all ben $\mathfrak{B a l f e n}$ mit einer Saano hangenb gehalten, mit ber

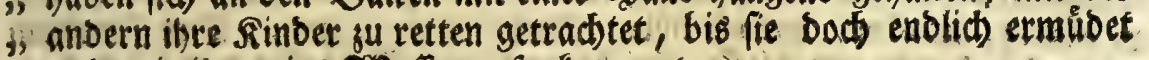

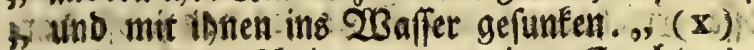

Scieraus erid)einet num meines Erad)tens fur sinuge, oaß Stroi, bo übel baran gewefen, wenn et etwas roibertegen, und als ein unges reimtes Sabelwerf hat ausgeben wollen, weldhes bod vor ifsa, und vers muthlids aud su feinet sebjeit, in ber That fid fo sugetragen; wels

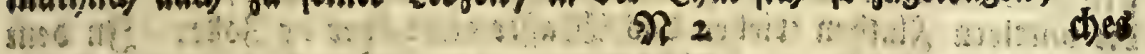

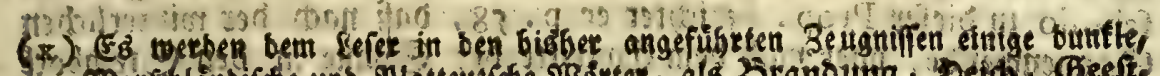

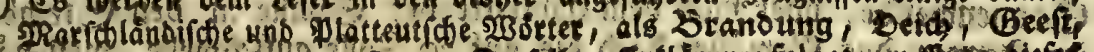

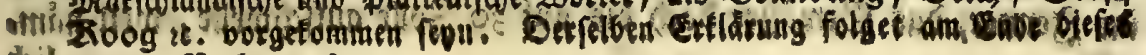
doil zopepten शachtrages. 
Wes reitbem nid)t aufaeforet, fonbern now) ist an ben nåmlichen Drs ten, und ofters vorgehet. Denn aus ber $6 \mathbb{S}$. ber in Samburg ges bruckten शadbridts, woraus id bie borfergehenden Beugniffe gesogen babe, ift zu erfehen, baßs aufer ben greyen barinnen beidbriebenen lles berfatwemmungen Der srorofee, nur gegen Das Ende bes abgewidbenen, und im 2Anfange bes ift laufenden Sahrhunberts, folglich in bem 2llter eines Men(d)en, nod) eilf andere, wo nidbt fo graufame, bennod) jefre bohe, fluthen fith begeben haben. Die Zeiten berfelben feben fo ver: zeichnet: Den s San. 1661. Den 20 Uctob. 1663. Den 25 Nos vemb. 1685. Den 8 Det 1688 . Den 31 Decemb. 1693. Den 22 Sept. 1697, Den 10 Novemb. 1699. Den 17 Det. 1701. Den 28 Febr. 1702. Den 8 Decemb. 1703. Den 4 Shart. 1715. Sooann bie in ber Ehriftmadt 1717. Im folgenden Sabre wutete ei: ne ben 25 unb 26 Febr. eine andere ben 16 Mart. 2lus biefem 2 ers zeidgniffe erfiehet man úberbieß̧, baß bie hơd)ften Fluthen auf bem ₹eut:

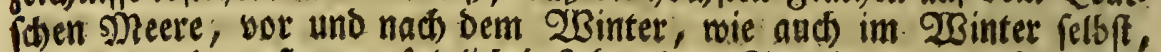
(iic) zu begeben pflegen; folglich beftehet bas Spridbort Der Scamburs gèr, bei benen es beifit, es gefriete nidt, bis bas Waffer die Keller. ausgefpilec babe. 2llein id muß aud geftehen, Daß Das Derrehen Des Strabo, welches dem \&efer Darguthun, id) Diefe vielen Zeugniffe angefúbret babe, mir weit ertriglider vorfomme, wenn ids bebenfe,

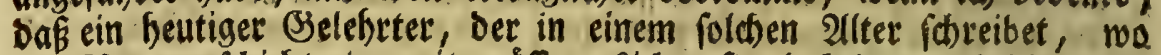
Die Raturge(d)ichte in weit grofferm fid)te fich befindet, uno bie nords liden Saden befannter fino, ber felbft ein fleisiger Naturforideer ift, uno Den (Eigenfabaften bes Meeres feit vielen Jabren mit ungemeiner 2(d)tfameeit nach gefpuret bat, gleidmol faft eben ben Fehler begangen, ben wir an bem Strabo getabelt baben, robalb er fíd unterftanden; fein urtheil auf unerfannte शneere hinauszuftrecten. Das ift ber in biefen

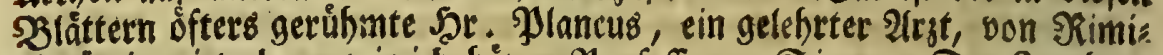
ni burtig, igt aber, mie id höre, Jrofeffor ju Eiena. Der Srethum

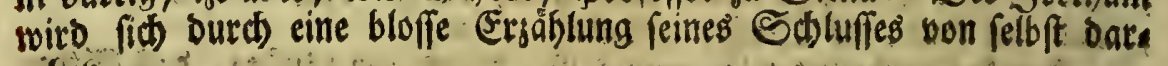
gében.

gin feitrer abhanolung de Aeftu maris fuperi fobreibet ex Prop: VII,

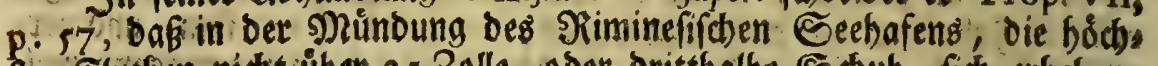
tien Flutfen niđbt úber 25 Bolle, ober britthalbe Ed)ub, fich erbeben; bie mittlern Flluthen trieben bas $20 a f f e r$ nid)t ủber is 3olle. In bem fcholio \{u biefer Prop. berid)tet er P. 58, Dak nach Der winterliden

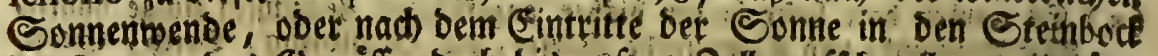

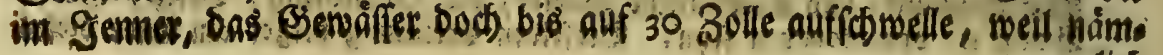


Swente Unterfudsung.

ror

lid) zu biefer aeit (wie in ber III Unterfuch). foll gefagt merben) bie 2loriatifhe Ece überhaupt beinahe um einen Schuh bơber ift. Dee: ftárffe Sinlauf biefes \$ieeres werde zu Zenebig wabrgenommen, wo

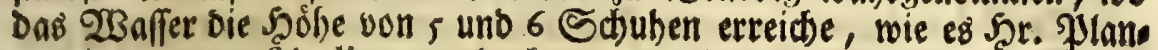
cus, im gwenten fcholio zu gebadtem VII Gase, aus bes Falilaus 4. Eefpr. Syftem. cofm. bezeuget. So hod werbe aud bas 23 affer, zur

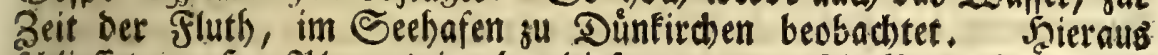

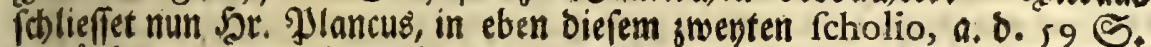
es borfte entweder Banertius bas Steigen beo Seewafiers in bem Dum:

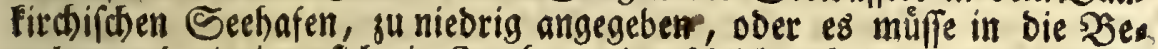
rechnung berienigen fid) ein Jrrthum eingeichlichen baben, weldje (d)rei:

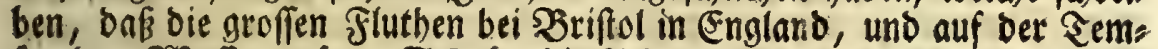
fe, bab 2 affer auf 45 Sकuh, bie fleinern aber ood) auf 25 Schub, binauf brád)ten, weil erwefnte zwey Srte von Düntirdben nidst gar weit abgelegen wåren. Das ift abet eime beinabe fo irrige Beurtheis lung, als bes Strabo feine gewefen. Das Steigen bes $23 a f f e r s$ an ben

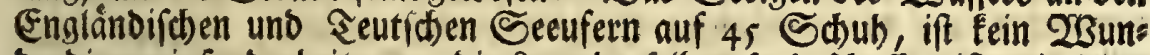
berding, infonberbeit wenn bie \&age berfelben to befchaffen ift, wie bein 2lusfluffe ber Saverne in bem Sanale von Sriftol. Denn Diefer erftes.

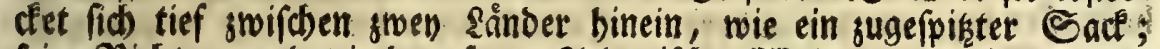

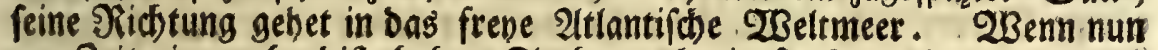
jur Zeit einer ofnedis boben ffluth, noch ein farter und anbaltender Abenowinb, bas Bjetwåffer yon ber offenen See gegen Morgen treibet,

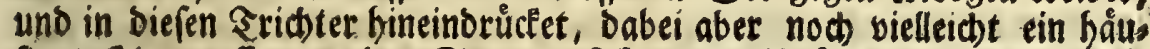
figes Sbenwaffer aus ber Saverne fich barzu fdlägt, fo muß eine fole

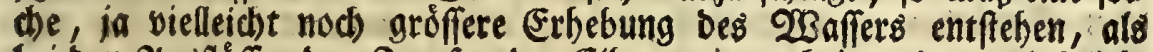
bei ben 2 usfluffen ber ₹emie, ber $\mathcal{E} l b e$, wie aud in anbern winfelicbs:

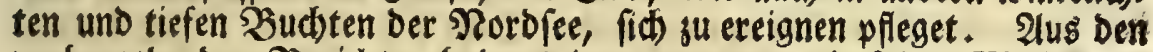

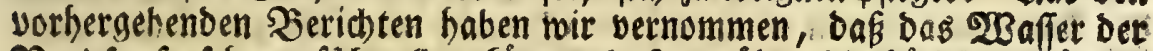

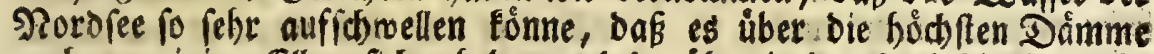
noch um einige (Ellen fich erhebe, unb baruber in bas sand bincin laufe,

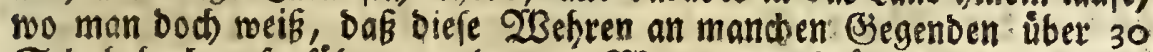
Sd)uh hod) aufgefuhbret werben. 2 Barum ju Dünfird)en bie fluth nicht to bod werben fơnne, Das läßst fid aus bem erften 2inblide einet Eanbfarte ziemlich mol begreifen. (Eg if I) fein Meerbufen allba, bet mie ein tiefer Sadf geftaltet wäre. (Es liegt 2 ) Der Dor nicht 10, baß

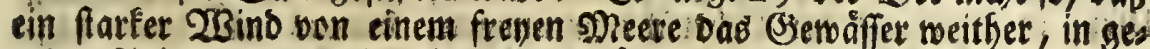

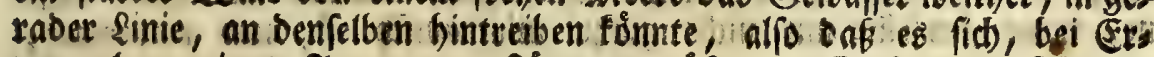

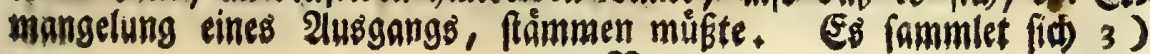
श्र 3 and 
auch Fein gewaltiges Sbenwaffer babin, weides im Stanbe wäre bie Sluth zu bergroffiern.

Es ift berofalken, meines Eractens, eine vergeblid)e $\$$ Bitte, wenn Shr. Wlancus bie Framofen uno Engländer erfucter, fie follen ihre SBeobadbtungen von neuem anfellen, uno barauf $21 \mathrm{~d}$ t haben, ob in ber

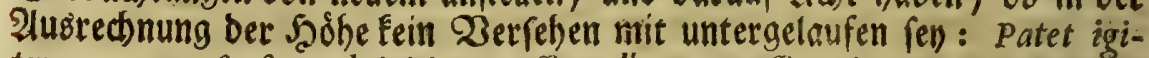
tur, me non fruftra ab initio rogaffe.Gallos, rogafje Britannos, rogafje ceteros, ut iterum fuas obfervationes inftituerent, quemadmodum et modo ro. - gamus Ec. Diefem Erfucben will ich ein anbers entgeger reken. Sh) erfúbne mich, im Namen ber bier angerufenen Naturforf (d)er, ben Wrn. Wlancus zu bitten, Dak er erftlid oon einem eingefhlofienen

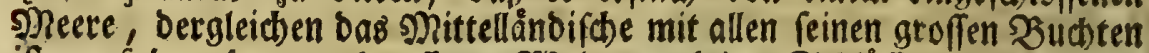
ift, auf bas freve und offene $2 B$ eltmeer Eeine Sdhiffe madie, mie Strabo. Darmads netme id bie Frenbeit biefen Bielefrten zu nas: nen, baḱ berfelbe, wenn er bie ffluthen gwever Segenden mit einanber

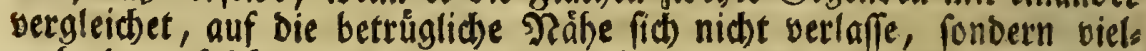

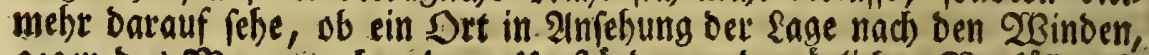

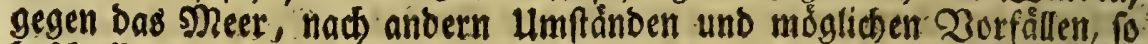
befhaffen fer, wie ber anbere. Endlid wirb biefer fonft fleifige uns.

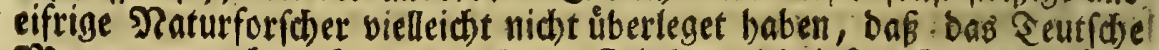
Sleet an manden Srten, aud fur Zeit ber nieorigften Fluthen, hóber: fey, als bie innerbalb ber Dåmme tiegenden \&ånber. Es wäre bemfel: ben bemnad) unmásgeblich anzurathen, baj er bon ber Eigenfataft ber:

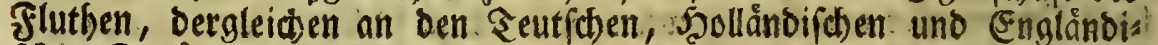
ihen Stránoen, zu erícheinen pflegen, etwas melorers nadbulefen die Mrube fich geben molle, fo dơrfte dab (jeheimnis aufgelofer werhen, und: Dab yermeinte Zerfehen nur auf feiner Seite fich finden. İh befen: ne, baß vieles bievon in ?eutf(her Sprache abgefaft ren, beren bers

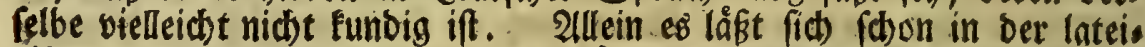
nifhen Serausgabe Der erften Englänoiften Transactionen, uno ans Dern in Der Jiomer Sprache verfertigten phufiealifthen Schriften,

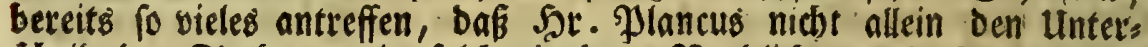

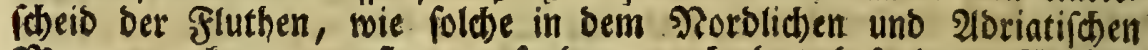
meere zu fommen pfegen, fondern. aud bas befondere Derbals: ten eines an Dem erftern gelegenen Ortes, gegen Die Stalienifchen

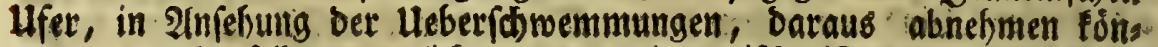
ne, menn Derfelbe nue nicbe gargu mistrauif ift, unb vermeinet, 
bie Belebrten retben eines für bas andere fo bingerdstieben has ben. Go bitte er 3. E. in ben Act. philofoph. Angl. von 16 ग्रovemb. 1668, n. 4I (ber Seips. lat. 2lugigabe 1675, 4. p. 680), aus ben Bes - bad)tungen Samuelö Sturmy, eriehen fơmen, dapj bei śong-road,

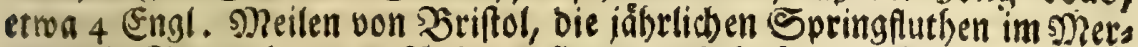
fen uno September zu erfheinen pflegen, uno dás Das TBaffer bei ben. felben auf $7 \frac{1}{2}$ Silafter oder 45 Fuß fteige, bei ber niebrigften Ebbe aber es nod), 3ur erftangeregten Beit; 25 Fuß neue fluth anfommet, bevor bas (jemåffer ber vorigen gánj̧lid) abgelaus fen iff. S. 682 gebactser lateinifichen 2 tuagabe, ftehet folgender $\mathfrak{Z} e s$ ridbt beg zubor geribmten Sturmy: Daßs in Dem fluffe Gaverne, 20

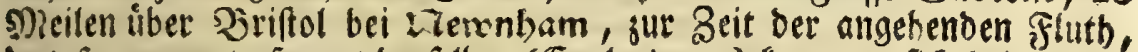
Das fo genainte Shaupt berfelben (Engl. boar) Fomme, fith bei 9 SuB,, wie eine 23 and, erbebe, und in foldter Shibe siele meilen fortlaufe. 28 enn aber Diefer Fluthfopf vorbei ift, fo lågen alle Fluthen wieber tros den, wie vorhin. Die Urfacte biefes fo mereflicten aluflaufes wirb von Dem 2ierfaffer biefes 2 erid)tes, ber Enge ber $\mathfrak{B e t t u n g}$ sugerofrieben; melches nol um foviel eher ju glauben; als foton in ber Elbe, bie viel breiter ift, sur Zeit der fommenden F'luth, Daş aufwerts gegen ben Strom in merflichen Sollen wallende $W_{3}$ nffer, fann beobadtet werben, ob es gleid nidt in Der (Seftalt eines bewegliden Dammes fortlauft, fondern wellens weife unterbroden wirb. In vorgebachtem Fluffe Saverne fiuthet Das Waffer nur zwen Stunden, und fatwillt bis I 8 Fuß hod auf, oa es bin. gegen nur 10 Stunden ebbet. Wer nun diefe unb dergleiden 3 erwand: niffe bes Meeres, welde an ben mitternåd)tigen Strånben gemein find,

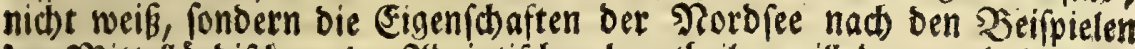

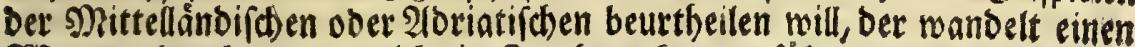
$23 \mathrm{eg}$, woburd er gar teidt in Srrtbum fann gefübret werben.

\section{Ertflärung}

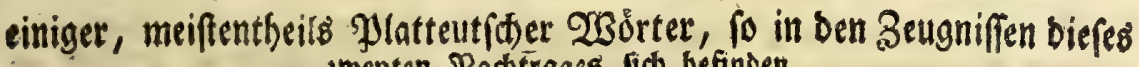
zmepten Nachtrages fich befinden.

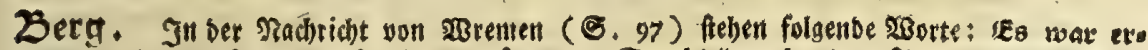

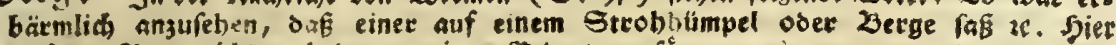
muf dab zeig nidht nad) der gemeinen twirbe erfilid in Diefem Surammenbange, nach foldber Audilegung, fein rechter Serftano

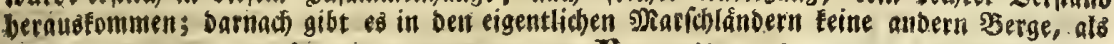

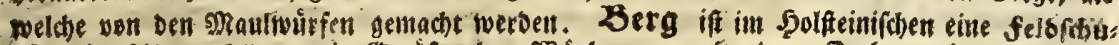

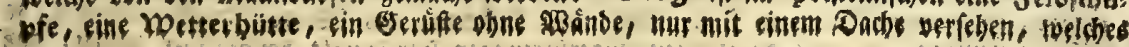


man beben unb fenfen fann, woru ter bas aeidnittene Getreide gebradt twird. Xुon Den Sieberfachen wirb es auf lateinifh gant recht mit torreum perfatile úberfegt. Daz Jetg

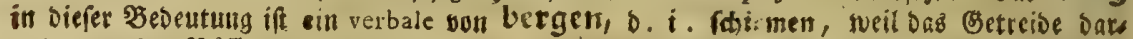

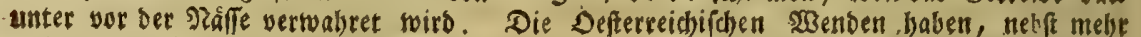
andern ङebrâuden, Diefe Erfinoung von ben norolichen Begenben nach Eiben mitgebracht.

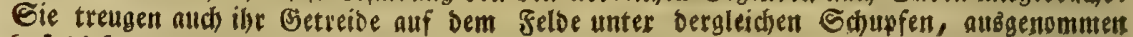

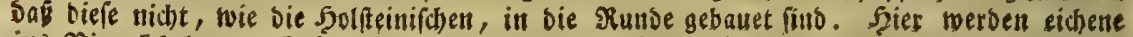

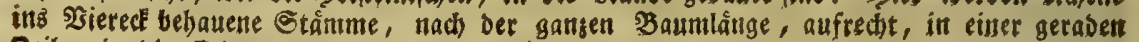

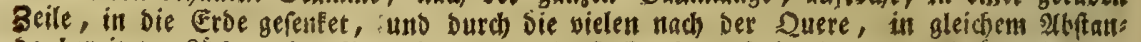

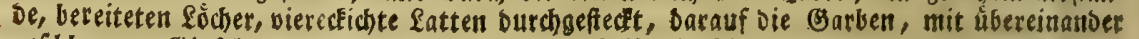

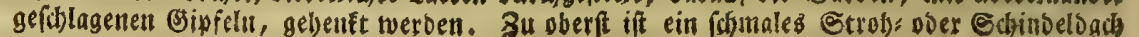

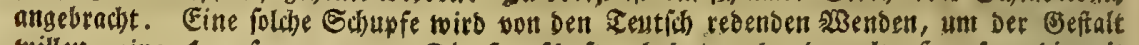
willen, eime 5arpfe genannt. Die Sjerrfd)aften baben auch gevoppelte Sarpfen, Die mit swey von cinanber abftebenden Reifen Basume, mit Durdhesogenen fatten, in Der Beffalt eines parallelogrammi, aufgefúbret, unt beibe Bestuffe unter ein semeine Dnds gefest

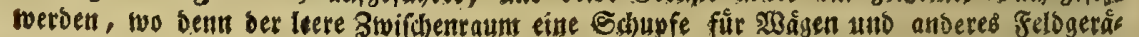

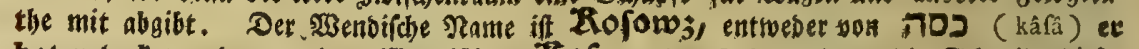

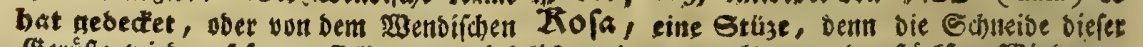

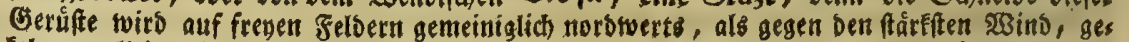

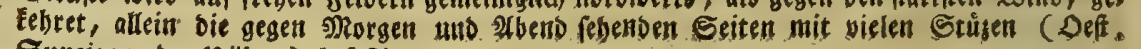
Spreizen ober pölsen) befeftiget.

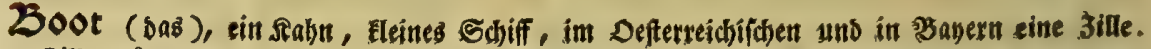

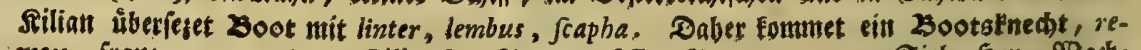

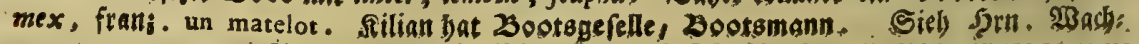
terb Glor. im 23. Z Zot, cymba.

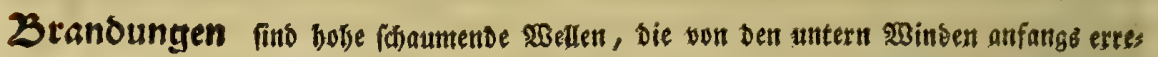
get, und yon ben obern fortgetrieben merben, auch vor ber fluth filh seigen. (Einige wols

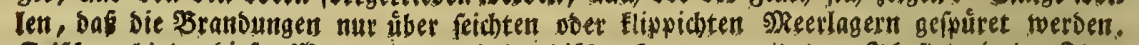

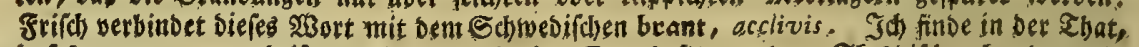

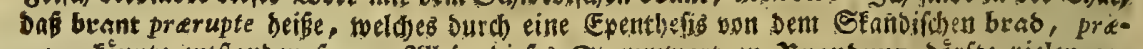

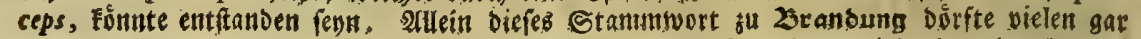

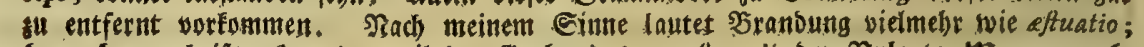

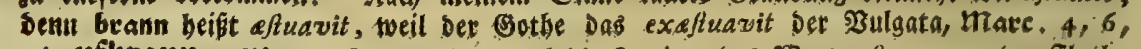

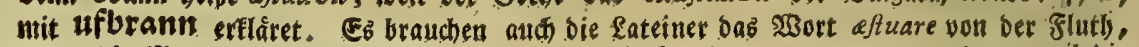
baber bie meerengen auf gleidie 2 eife freta, gleichlam ferveta, gencunet werben, weil bie Stutben batinnen ant ungeftumften su faufen unb zu toben pflegen.

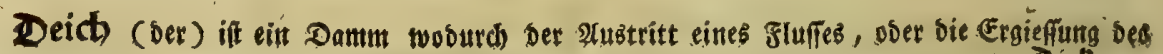

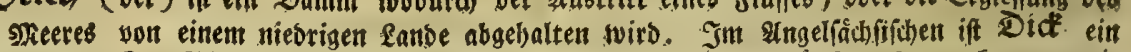

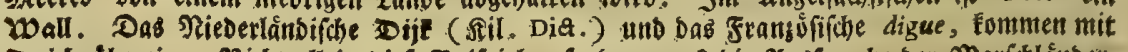

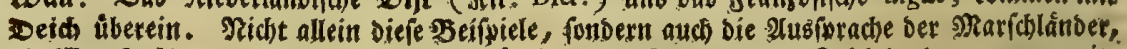

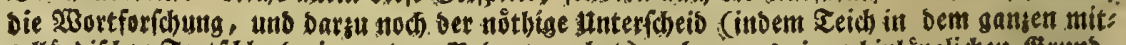

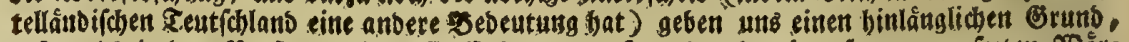

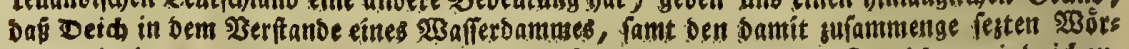
terw mit einemt so su fabreiben. Mlip betiden, abbeiden, ausbeiden, bebeiden, einbeiden,

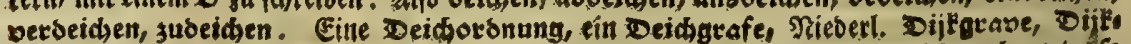

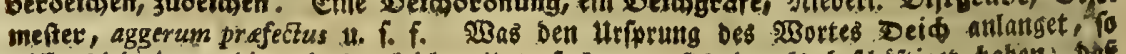
mifen bieienigen, bie mit bergieiden Hnteriudunsen fich iemals befdóftiget baben; buF 


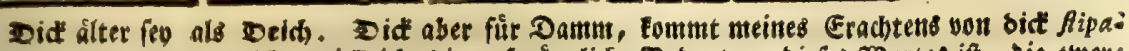

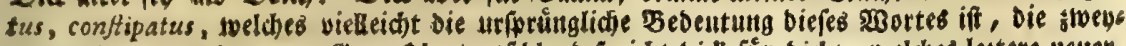

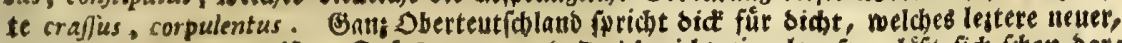

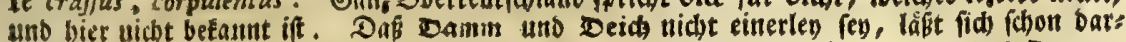
aus abnel)mell, weil su Syanburg eiu Fbor bas Deidtbov' uns ein anberes das Damm: tboe beift. Diefe stwey gzanen werben nach metnem Begrife fo nutetfchieden, baf Deid cill 38 all fen, Der twider Dns 29 affer aufgetworfen wirs. Die Bebentung von Damm if weitlouftiger. Cin Damm fann aud auf bent feften unt trodenen Sanoe fich befinden, als bei einer Straffe, am eis felo, um einen Barten u. f. f.

Rigener if poiel als Der Eigenberr, Der Eigentlummebert.

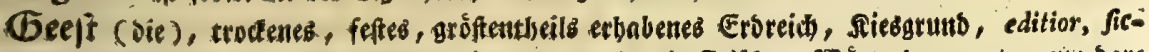

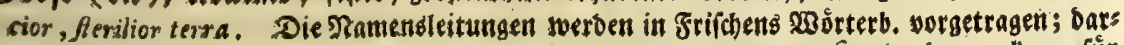

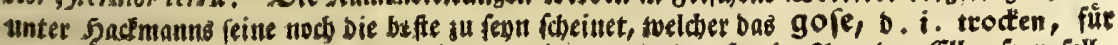

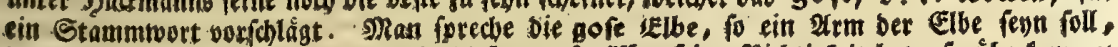

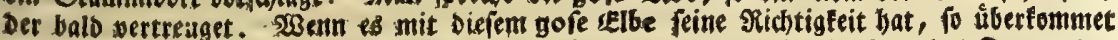

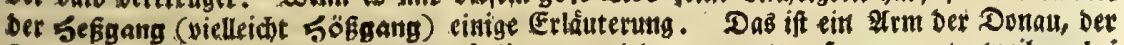
fich um Den Defterreictioiden Strubel fiblinget, und ben man etwa fo genennet, weil er bei

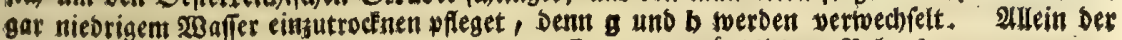

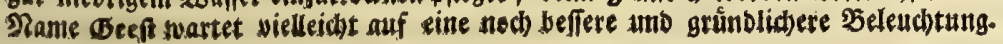

Geseit (oab) fwirb in ben mitterntichtigen Seegegenden für fluth unb ebbe genommen.

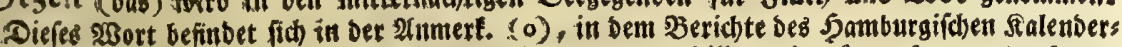
dens. Im Nieberteutfden fagt man Getyoe, weldbes §ilian mit eftus, fluxus et refluxus

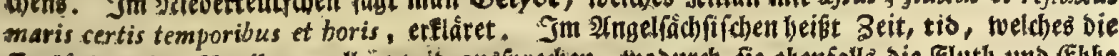

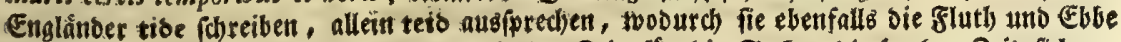

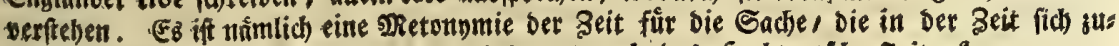

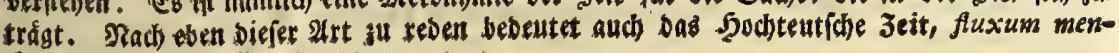
Aruum muliebrem.

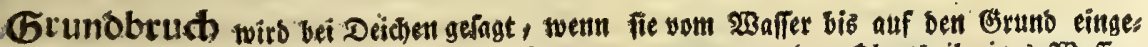
siffen werben; Dagegen beift cine Zammpüryung, wenn nur ber Dbertbeil eines 23 affer:

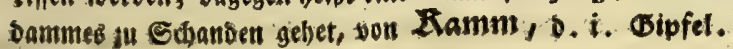

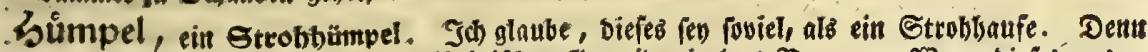

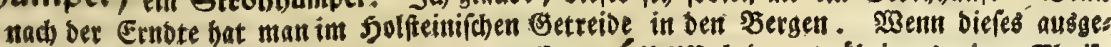
srofhen ift, wiro bas Strob Datein gefdaffit. Sump bebeutet ubrigens einen Cbeil.

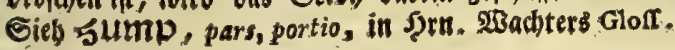

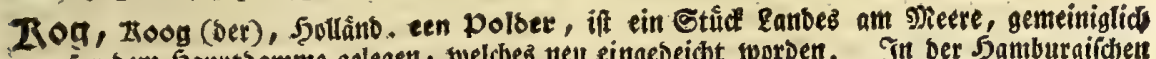

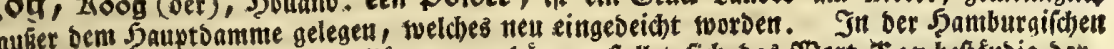

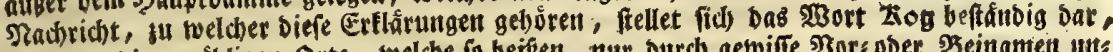
too Denn bie unzábligen Orte, welche fo beifen, nur Durd gewiffe \$ors pber Đeinamen uns

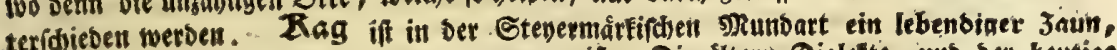
weides vielleicht aus Gebag zufammen gefogen if́. Die áltern Dialefte, unto ber beutige

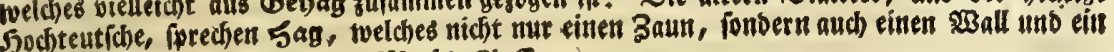
eingef(i)lofenes land bebeutet. Wacht. Glor.

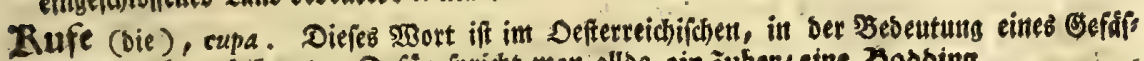
fes, nunmegr unbelannt. Dafúr fpridgt man allor ein כuber/ eine Dobsing. 


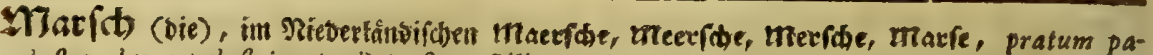
lufire, locus paluftris et alizinofus, Rilian Die. allwo aurd maer : afd mit palus gegeben wiro. Rad sem eigentliben Begrife Def zujanangefenten Roirter beift 17 isers afd

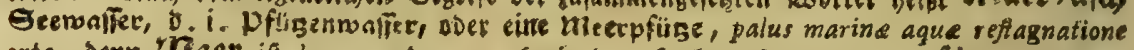

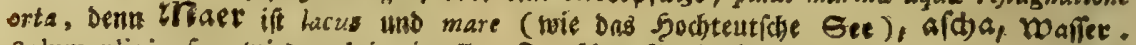

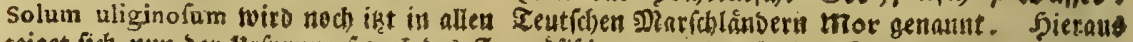

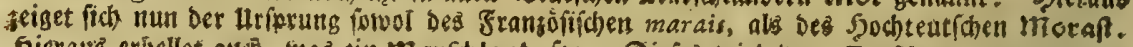

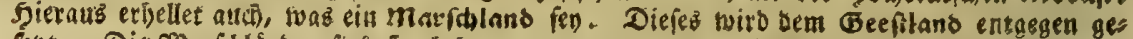

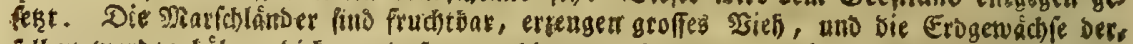

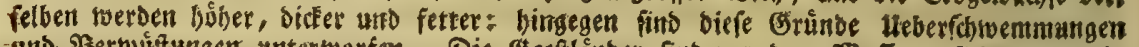

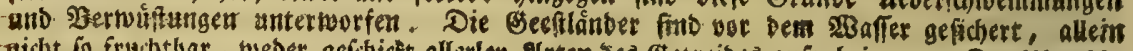

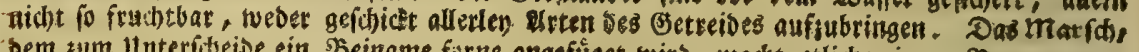

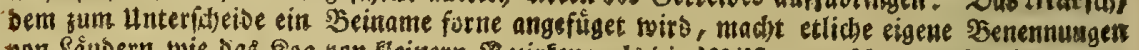

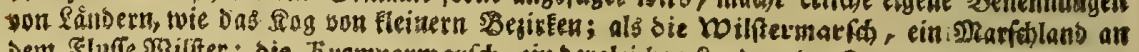

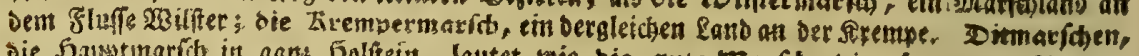

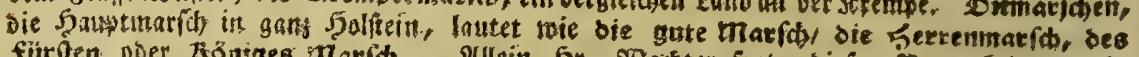

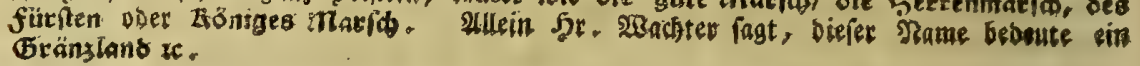

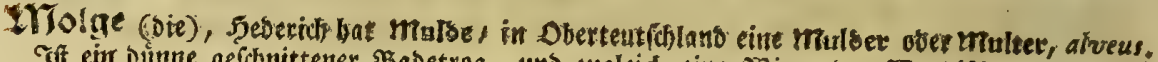

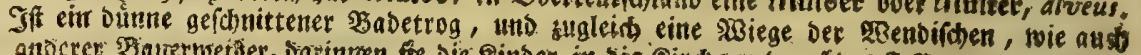

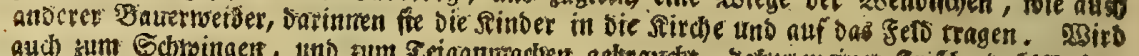

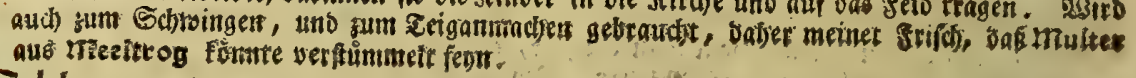

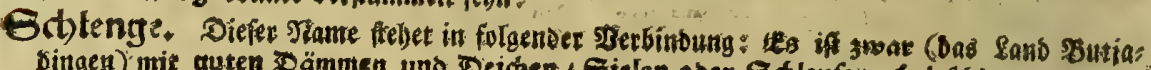
bingen)'mit guten Dämmen und Deichen / Sielen obee Gdlenfen, 5olgfdlagungen uns Shlengen, wote anbere Macfóländer, veknabrt gewefen, 8.98 . Durd Das 20 bort

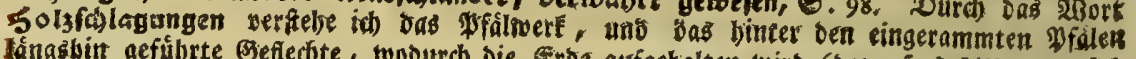

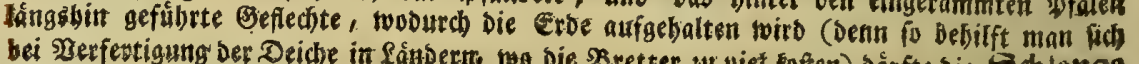

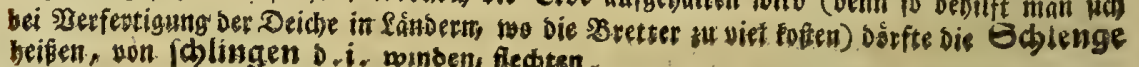
beifen, won folingen 0 .i. winben, flecten.

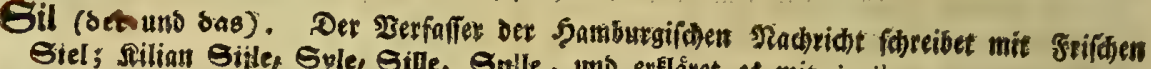
Siel , Silian Sijle, Syle, Sille, Sulle, uns erflàt es mit incile, aquagium, aquch

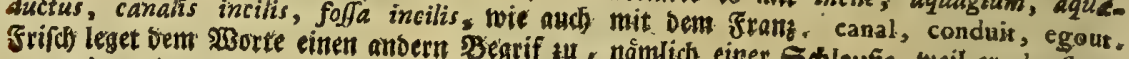
ggerale, uno emiffarium, beifeset. Bif bieten namich einer S\$leuse, weil er claufrum

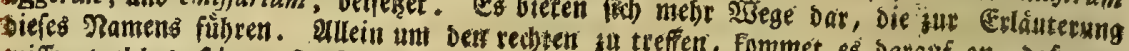

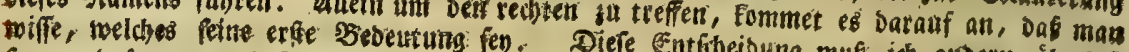

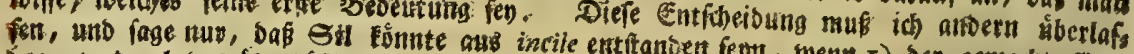
bon, woourd bas thenfúfige 20 affer son einem.

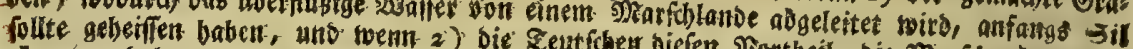

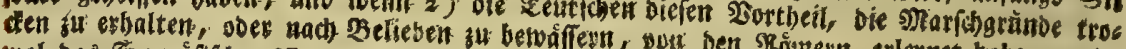

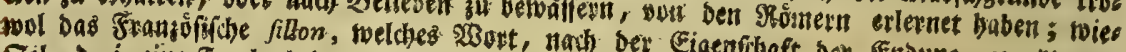

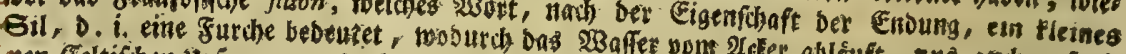
nen eeltichen uriprung Ju lenfer folduet.

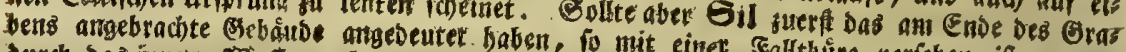

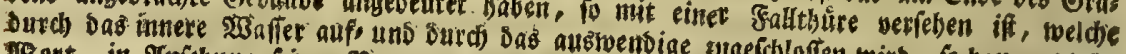

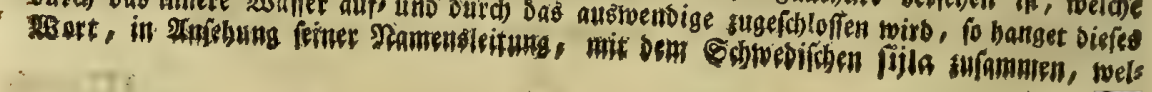


des colare uno percolare beift. Eijhl if colum, ein Geibeforb, ein Dutdihlag.

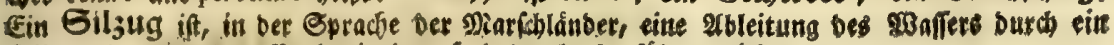
Sil, uno das GilwalTer Dasienige, fo Daburdh abgefúbret mirb.

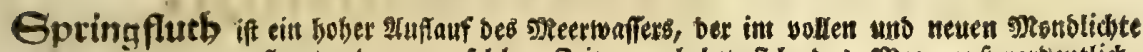
fid su ereignen pfleget; bem su foldben Beiten erbebet fich Das Meer aukerorbentlid.

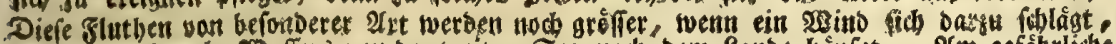

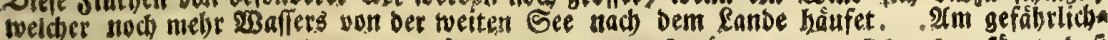

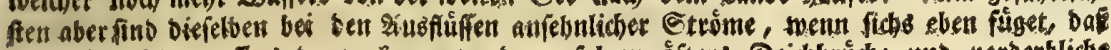
nod viel Dbentwaffers barju Esmmet: Da esfolgen oftens Deidbbriche uno verberbliche

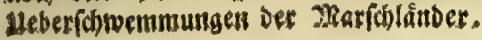

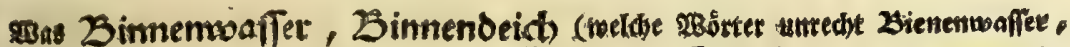

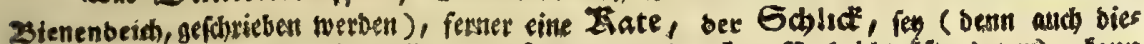

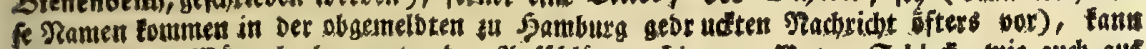

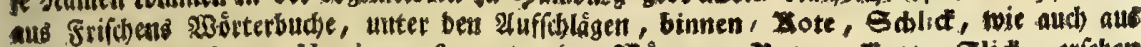

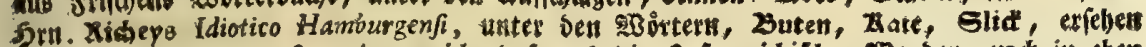

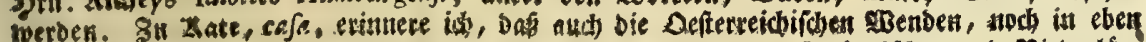

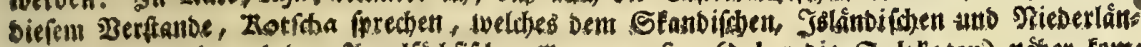

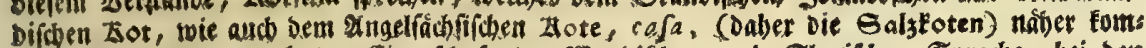

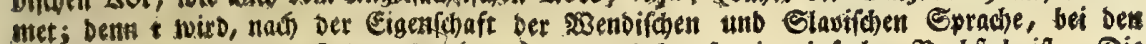

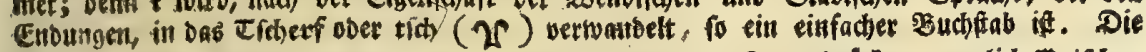

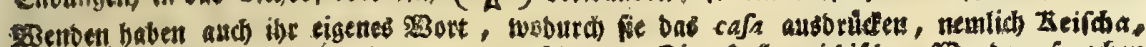

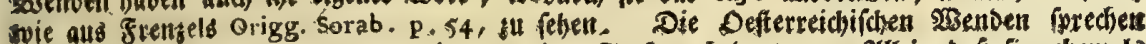

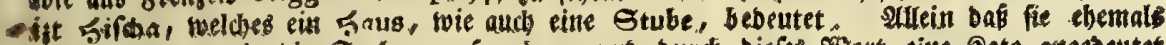

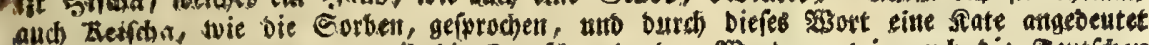

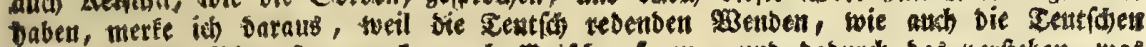

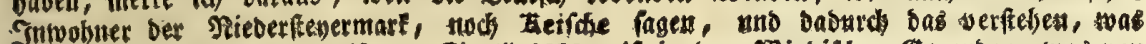

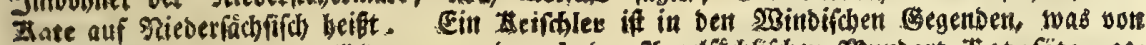

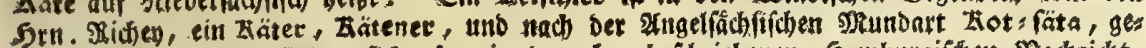

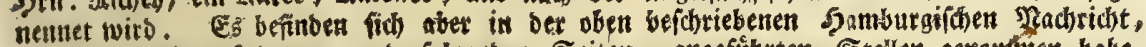
barnuts ids bie auf ber 94 und folgenten Eeitat, angefúbrten Stelden getsontiten babe,

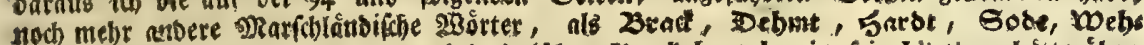

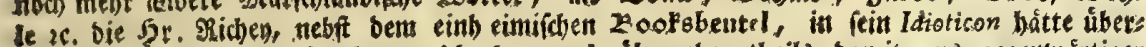

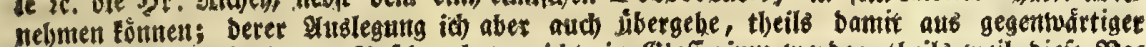

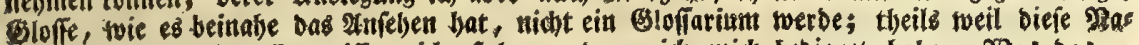

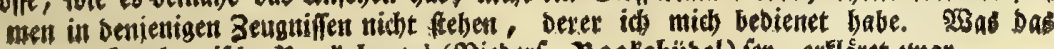

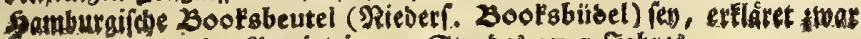
ser Matriot in 79 St. Deb 2725 Sabreb. 


\section{gevistte interiutumg.}

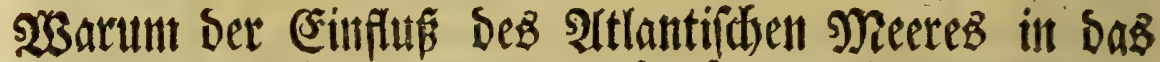

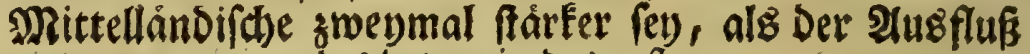 \\ Deś lestern in das erfte.}

(2) Sheinet, ber 5r. Werf. ber Sdrift de COL. HERC. eigs=

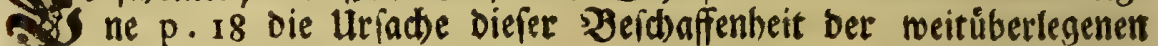

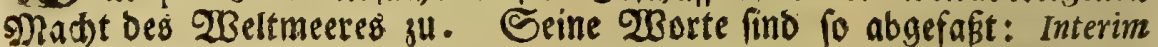
tamen obferuauit Furnerius libr. VIIII hydrogr. cap. 6 , illud effe maximae admirabilitatis, Ponti aquas et Aegaei maris in mediterraneum mare labi; nibil uicifim ex eo in Pontum reffuere; ita, ut nibilo minus, cum mediterraneum mare fex boris in Oceanum effuat. Oceanus ipfe, per Gaditanum fretum, QVASI VICTOR, in mediterraneum pelagus ingrediatur. per boras duodeuiginti. 2fuf folche 21tt wåre Der Eintritt bee 23 elts

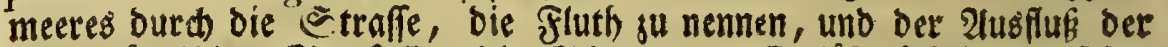

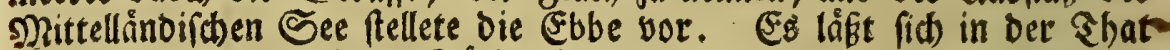
ein Sileides aud bei ben Flúfifen beobahten, bie in gemiffer 23 infeln Der Lffer, melche tiefer in bås \&and fich erffrecten, infonberheit zur zeit,

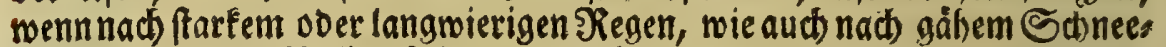

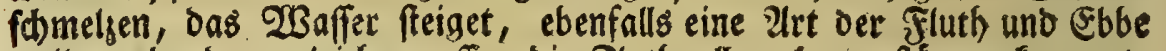
treiben, oa benn gleichermaffen bie Fluth allemal ungeftumer fommet,

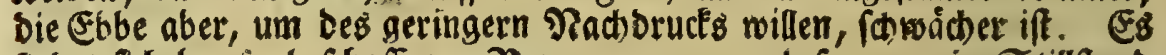

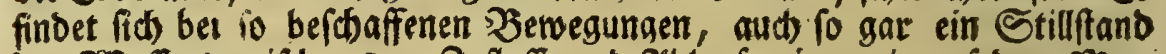

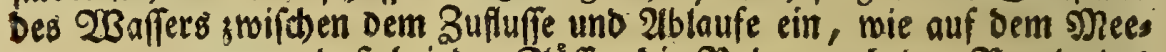

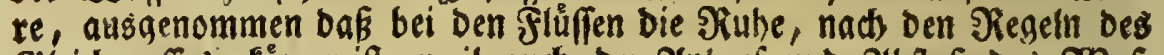

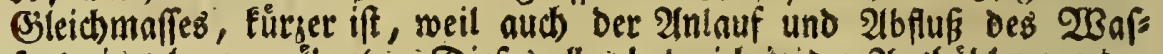

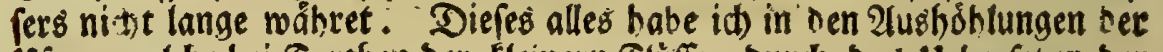

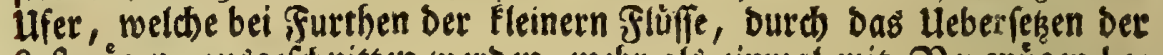
Eafrwo̊gen, ausgefítnitten werden, mehr als einmal mit Wergnugen bes tradtet. Soldes Eann aud jedermann, wenn bie Donau anjchmels

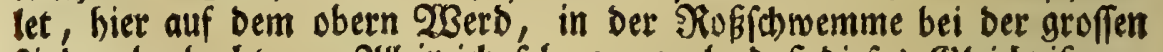
ginbe, beobadten. 2(llein it) Fehe gar wol, nas diefes Bsteidnís uns

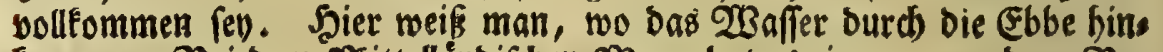

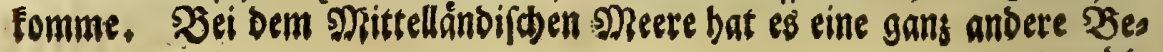
wandes 


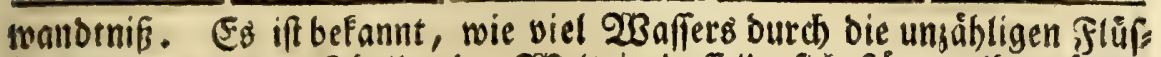
fe, weld)e aus oren Sheilen ber $W_{\text {selt }}$ in Daffelbe fich) fturgen, itsm tringlis zugefubbret werbe. Wenn man nun sugleid) ermáget, daß nod) ein måchtiger $\mathfrak{B}$ eitrag, inmerthalb 24 Stunben, aus bem 2 seltmeere bems. felben gugewandt wiro, to entitehet von relbif bie Frage, no Denn bie

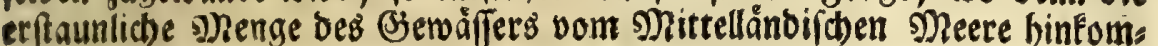
me, weil in einem bưrgerlicben Tage, fo wenig bavon in bie 2ltlanti. the See abgefúbret wiro (y). Sndem num ber Sar. Zerfaffer bie

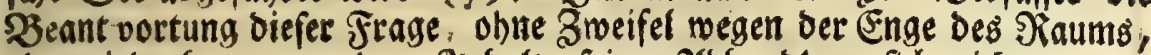

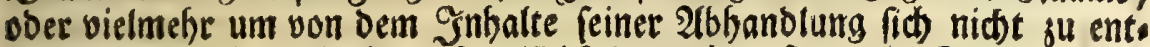
fernen, borbeigelaffen hat, fo will id ber mir geftatteten Frenbeit mid bebienen, und diefelbe nach meiner geringen (Einfid)t aussuführen mich bemuihert. Die Alufiojung biefer 2lufgabe ift mit berienigen 2 (bfand: lung verbunbert, welche den Hriprung ber fúffen $2 S_{\text {affer }}$ unterfuchet.

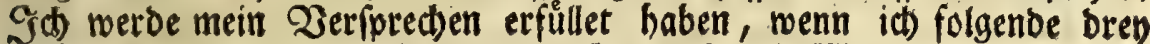

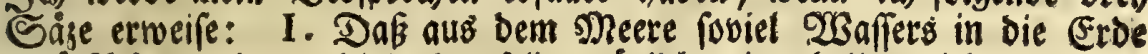

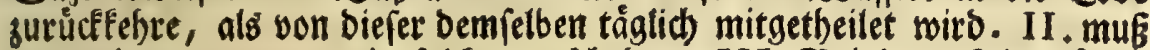
Dargethan werden, wie foldhes geidhebe. III. Bei bem Mittellånois

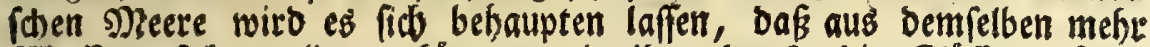
23 affers fich vertieren fơnne, als ithm burdb bie Flúffe zuläuft. भiad)bem id diejeb rerbe gezeiget haben, foll bie Deantwortung ber Frage, weiche ber (segenftand gegentwärtiget unterfuchung ift, von pelbft fich ergeben, b. i. es wirs leidst abjufefien renn, warum fúr bie Nittellănbifá See eitte Berftárfung bes 23 affers aus bet 2itlantifchen erforbert werbe.

$$
\text { \&. I. }
$$

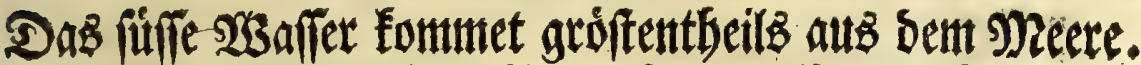
Die $\mathfrak{B e r w a n b e l u n g ~ D e s ~ g e f a l s e n e n ~ D i e r w a f f e r s ~}$ in 1 üffes, wirb erflåret.

Fie erfe ber gleid) vorher angebracten brey Ilufgaben bebarf Eeiner

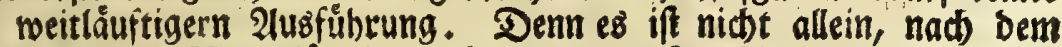

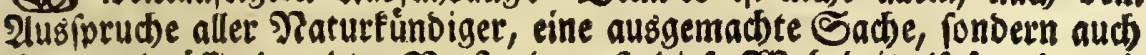
ein mittelmáfig begabter $\mathfrak{W e r f t a n o}$ mußs biefe $\mathfrak{W}_{\text {abrbeit alfofort begreis }}$ D 3

(y) Diefe 2lufgabe wirb auch in Kirch. Mund. fubt. Tom. I, 1. 3 . p. 150, vort

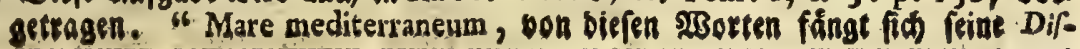




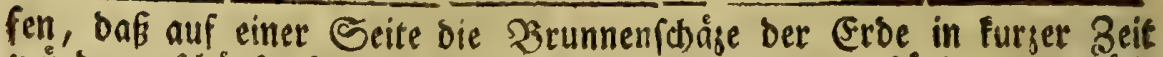

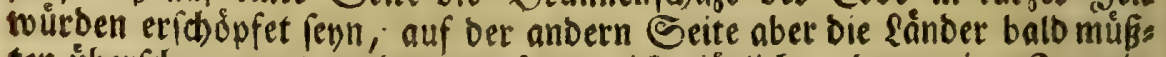
ten úber(d)wemmet werben, noferne nidbt tåglid), ober ennige Sage in bie andern getednnet, aus oen Meeren úberhaupt feviel 23 affers ber Erbe mieder jufame, als fie biefen jugefendet bat. Alfo fabreite id gleid) gur 2luflófung ber gwenten 2ufgabe, b. i. zur Unterfucbung, wie fold)es zugehe,

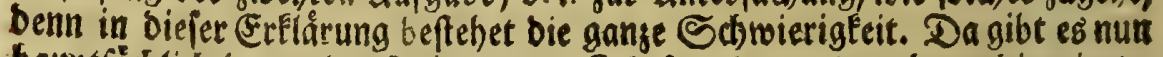
hauptfäb)lich oreverley mieinungen. St lage oreyecley: benn bie vierte,

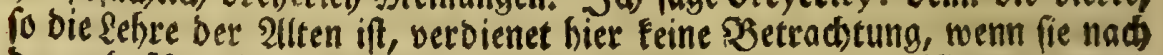

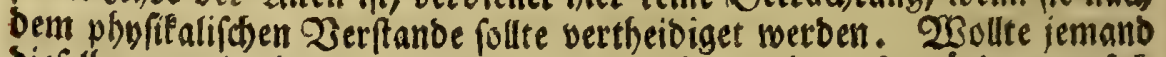
biefelbe nut als einen allegoríchen Entwurf ausgeben, to twurbe man fidi) bamit gerne befdeiben lafien. Die alten 2 Beltweifen nun bractsen vor, bie Erbe fey ein Shier, unb bas $\mathfrak{W B}_{\text {Bfer }}$ gleidjiam ihe Slut; bie Fluth und Ebbe ber Neere werbe burd das 2lthembolen biefes groffen Shies res erreget $(z)$. Sajus fagt a.b. I64 S. Der pbyr. Tbeol. Setr. biefe sebret hätten aud nod Das unterirrbifwe Feuer bergeffen, wo:

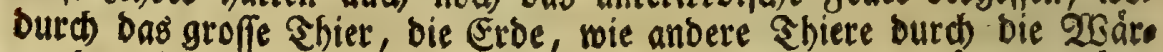

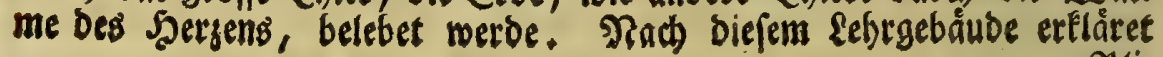

भilio

" quifitio $X$ an, inter Europæ, Africx, Afixque littora, veluti in Portu qqu-

i) dam conclufum, multa habet naturæ miracula, uti-hucusque incognita, ita

" confideratione digniffima. Mirum non Ariftoteli duntaxat, fed et aliis Na-

"turalis Philofophiæ rimatoribus, vifum fuit; quomodo videlicet Mare undi-

" que et undique conclufum, et non nifi per ftrißiffimum Gaditani diftri-

" atus Fretum Oceano pervium, poftquam ingentibus fluviis Bæat, Rhodano,

9) Varo, Tiberi, Pado, Nilo, in id fe fe exonerantibus, ut innumeros alios

" minores fileam, id nen exundet? Accedit hifce perpetuus et conftans Ma-

") ris Euxini, per' Propontidem in Archipelagum, et hinc in Mare Mediter-

" raneum, influxus : cum omnium experientia conftet, dikum mare poten-

" tiffimis et celeberrimis totius Europæ amnibus, Danubio, Borifthene, Ta-

" nai, follicitatum impulfumque, per angiportus Byzantinos perpetuo et

" fine ulla reditus fpe devolvi. 'Paradoxum ergo videri poffet, mare mari

", au\&um, fine exoneratione apparente tanti aquarum oneris incapax,

", nullibi tamen in littoribus exuberare; accedente prafertim Oceani At-

" lantici intumefcentis tempore, quo et illud magno aquarum aucu ditat,

" dum fummo in id fe impetu exonerat; hoc enimvero eft, quod nemo c3-

" pere potuit. Videmus enim fluvios aut paludes, tum nivibus liquefaltis,

". tum aquis pluvialibus auctas, ftatim ob nimiam incrementum, inundationes,

" magno agrorum detrimento, caufare. Quomodo ergo mare maribus inte-

" gris, una cum vaftifimis fuminibus, intra finum fuum exceptis, non exun-

" det, difcutiendum eft; latet enim procul dubio occultum quid, et fcrutinio

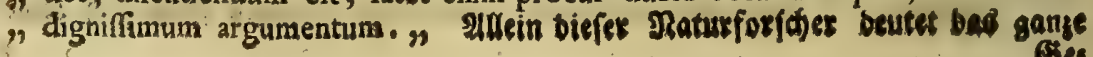




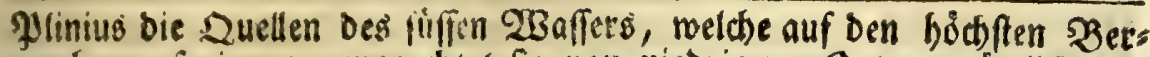
gin bervoripringen, ungeadtet fie oon niebrigern Drten, nämlic aus ocm snere, ifren Zuflus baben, und foeinet es, er wolle gleiøfam bebaupten, Daf ihr Servorbreden auf Den Gipfeln Der Berge, fo menig zu betwunbern fen, als wenn einem Shenfiden aus ber Stir. ne bas ३3lut fleffe, wenn man ifm allba eine 2ber erofnete. Quod ita formalfe, fino feine $230 r t e, 11,65$, baro. 66, artifex Natura credi debet, ut cum terra arida et ficca conftare per fe ac fine bumore non polfet; nec rurfus ftare aqua, nifi fuftinente terra; mutuo implexu jungerentur: bac finus pandente: illa vero permeante totam, intra, extra, fupra, venis, ut vinculis, difcurrentibus: atque etiam in fummis jugis erumpente: quo piritu acta, et terre pondere expreffa, fipbonum modo emicat.

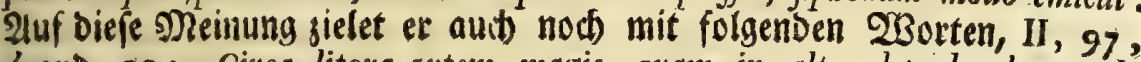
baro. 99: Circa litora autem magis, quam in alto, deprebenduntur hi (maris) motus: quoniam et in corpore extrema pulfum venarum, id eft, Spiritus magis fentiunt. 2luf fold)e Irt baben bie 2 (tten, wie ich bereits gefagt, aud bie Fluth uno Ebbe Des Meeres ju ertlaren gefuch) (aa).

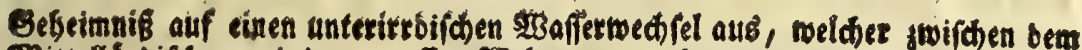

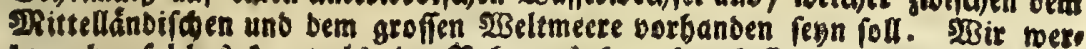
ben aber foldes faum als eine Nebenurfache gelten laffen, unb oiefe 2lufgas be auf eine mabrideinlichere Mrt, an bie Rircher nid)t gebacht bat, auffus Iffen trachten.

(2) Setbinius trăgt Diff. de Catarat, p. 98 biefe Rebte alío vor: "Aliqui ve"terum Mundo animam attribuentes, animatim effe putabant. Sed puta") bant. Democritus et Leucippus philofophi Pythagorici olim ita docebant, 39 Mundum ingens effe Aximal, extra quod effe Vaporem, fpiritum feu Aërem 9 infinite extenfum, quem VACVVM feu INANE MVNDI, vocabant: CH7) jus Vacui aërem Mundo per infpirationem ingeri, e contrario autem per n. refpirationem magni iftius Animalis iterum difpelli. Quam fententiam ho" dienum Democritici feu Vacuifte noftri ftrente propugnant. Sed VACVVM "Iftud fatun fane eft, cujus refutationem Ath. Kircherus et Schottus fris " locis intituerunt. De Animali attem facile inter nos conveniret, fi id de \% Mundo metaphorice, per fimilitudinem quandam, diceretur, fFerner: 1) Stoici de Eftu maris refluo ita pronunciabant: Mundum effe animal, ex cu4\% jus Narium refpiratione, ad inftar balzenæ aquas furfum ejeetantis, tantus marium zeftus fiat. Abfurdum guidem hoc in tanta fapientix luce apud n) philofophos Chrítianos eft. Nefcio tamen, an idem ex recentioribus nong, nulli ftatuentes cum ingenio ludant, an vero ferio et ex animo abfona hae " tradant \& ce. .

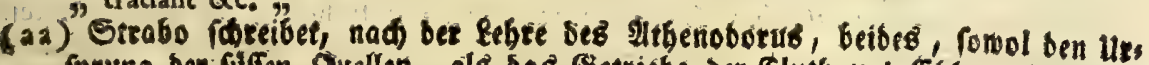

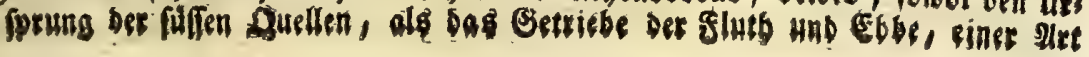


Mela ferget biefe 2luslegung unter ben fretenden Neinungen an bie els fte Stelle, beffen 2 Borte verbienen bier angefúbert zu werben, indem

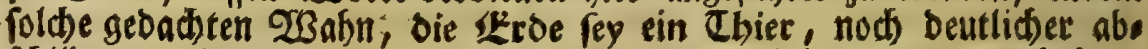
fatilbern, als biejenigen, bie wir aus bem Plinius angesogen baben.

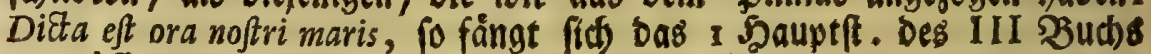
an, dicte infule, quas amplectitur. Reftat ille circuitus, quem (ut initio diximus) cingit Oceanus, ingens et infinitum pelagus, et magnis aftibus concitum, ita enim motus ejus appellant. Modo inundat campos, modo late nudat ac refugit, nunc alios aliosque in vicem, neque alternis acceffibus, nunc in bos, nunc in illos impetu verfum: Sed ubi in omnia littora, quamvis diverfa, terrarum infularumque ex medio pariter effufum eft, rus: fus ab illis colligitur in medium, et in femetipfum redit, tanta vi femper immifjum, ut vajta etiam flumina retroagat, et aut terreftria deprebendat animalia, aut marina deftituat. Neque adbuc fatis cognitum eft, anbelitúne fuo id mundus efficiat, retractamque cum fpiritu regerat undam undique, $f i$ (ut doctioribus placet) unum animal eft : an fint depreffi aliqui specus, quo reciproca maria refidant $\Xi^{2} c$. 2lllein ungeadtet einige ber beus

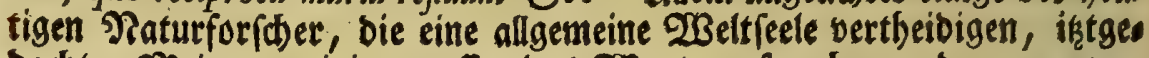
Dadter Meinung einigermafien Das 2 ort ă fprechen, ober gum wes nigften bas eádberlidse berfelben ju minbern f́deinen; fo toollen wir bod) weber burds eine fernere (Erorterung, vielweniger burch eine 2Biberles gung berfelben uns långer babei aufhalten. Es ift genug, Dak man

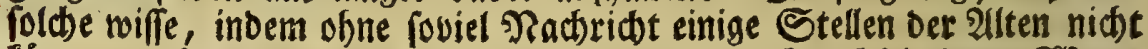

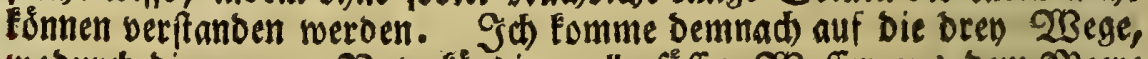

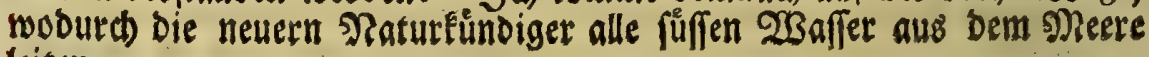
leiten.

Einige haben fich eingebilbet, bab sneerwaffer trete in bie Erbe, und twerbe in ben Shoblen ber Berge burd) Das unterirrdifde Feuer in Dúnfle aufgetófet. Diefe follen fich auf ben oberften Bewoólbern er: wefnter Şoblen, wie bie Sälte in einem Şelme, ober an ber innern Decfe eines DiftillirEolbens, anlegen, Durd) Derer Şerabtreufen fobann Die

bex Itherwbolung fu: "Quod fi, ut Athenodoro videtur, (iprid)t et, III, "173) infpirationis et expirationis fimile quippiam habent naris affluxus et "refluxus, fortaffis quxdam aquarum fluentium funt, quæ per alios meatus ". naturam fecutx effluxus in fuperficiem effundunt (quorum ora fontes et "fcaturigines vocamus) aliis autem meatibus una trahuntur ad profunditatem ". maris : exque aqux mare ita attollunt, ut exundet, quando fit expiratio, " ac tum fuum relinquunt proprium meatum: in quem redeunt, mari deflu"ente. 


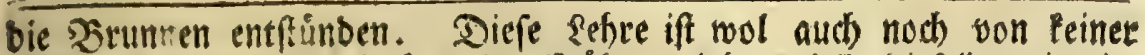

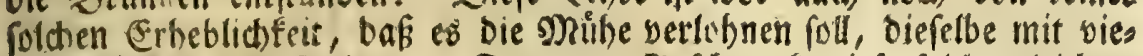
len Girunden ju beftreiten. Der gute Befamace wirft foldbe gleid su 2joben. Es ift oiefelbe eime Erfinoung bes Carteftus, - melde bie Sies fehaffenheit ber übrigen Saze Diefes Eefreers hat, woburd er in ber

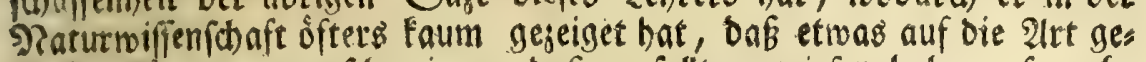
(d)eben fonnte, zu gefdoweigen, bas er follte erroiefen baben, fo geffe es ju. (bb). 2̧iber biefe 2luślegung nur in ₹ürge etwas zu melben,

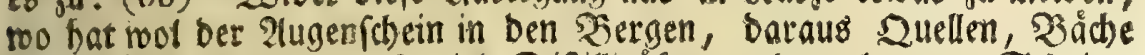
und Jiluffe entipringen, fo biele Diffillitofen, uno mol 1000 Sdritte

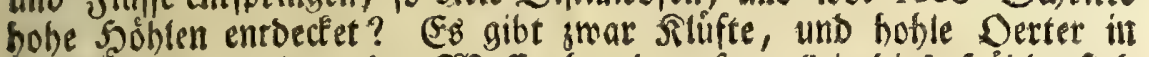

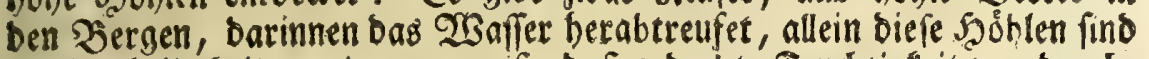

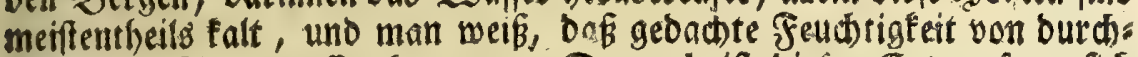
finfenbem Jiegenwaffer fomme. Darnoth ift biefer Entwurf an fich

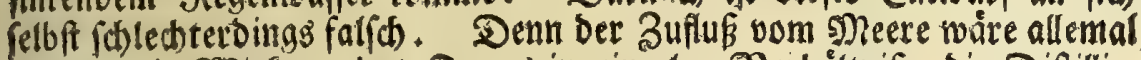

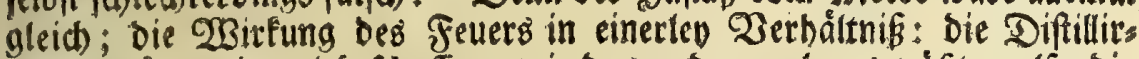
fluben wáren einmal befhaffen, wie bas anderemat: es musten alfo bie Quellen in einem Sabre flieffen, wie in bem anbern, unb bie glúfe als lemal gleid viel 23 affers führen, weldhes Dod' wiber bie Erfahtung ift; sweil in troctnen Sommern viele Quellen ausbleiben, uno andere wenis ger 23 affers bervorbringen, woburd Die Flüfe aud um viel fleiner werben; mehr bergleiden ungereimte Folgen, ober mit diefer abge:

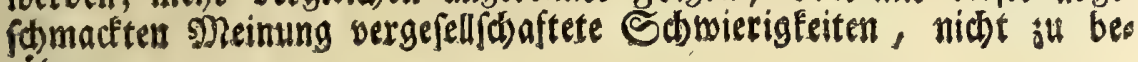
tubren.

2nbere lehren, Das Meerwaffer begebe fich in bie Frose, unb lege

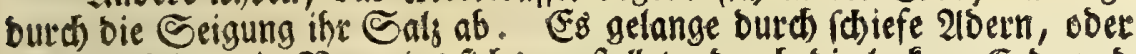
(d) (eiche fid), wie Darenius fid)s vorftellet, Durds bie focfere Eroe uns ben Eano, bis zu ben Bergen; es fteige aud Durch biefes "smittel auf biefelben binauf, uno nad) Dem es von feiner faljichten Eigenfahaft, auf

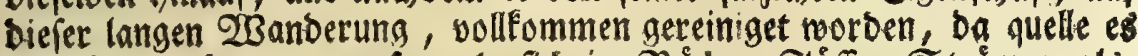

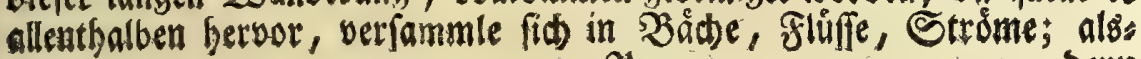
)

benn

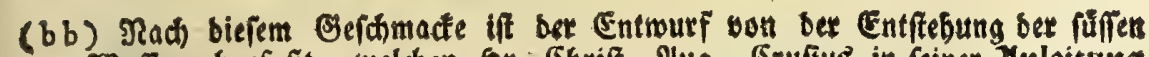
soffer abgefapit, welden f̧r. Ebrift. Alug. Eruffus in feiner Anleitung

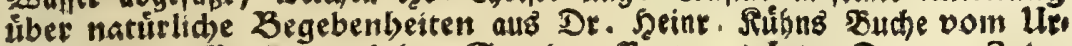
fprunge ber Ouellen uno ses Brunowaffers vortrågt. Der neue Zulas, relcher eine Berbefferung bes Eartefifichen Bebanfens feon foll, bat nicht viel auf fid). Der ḩauptrnangel biefes Regrgebåubes, ber einem achrlamen

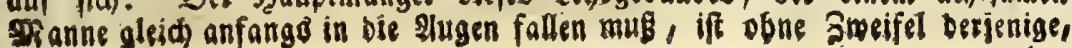




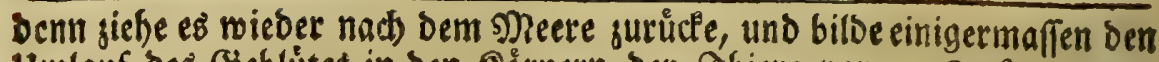
Imlauf Deb Geblutes in ben Siorpern ber Shiere bor. Conftat, Oceanum (ipridt JO. DE MEY Phyfiol. Sacr. p. 25) idem fere effe terreno corpori, quod bepar eft bumano. Quemadmodum enim jecur in corpore animalis fons eft fanguinis, cunctis membris, per corpus undique difperfis venis, fanguinem difpenfans, atque boc minifterio vitam animalis confervans: fic etiam mare, aquarum omnium origo et receptaculum, univerfam terram per occultas venas irrigans vegetat, et in multos redundat fontes ac flumina. Wie es aber bon fatten gefe, dá bas unterirroirde 2Baffer auf bie bód)fen Berge fomme, bas erflaren nicht alle auf eis nerley ant. Etlic)e baben gefagt, foldes fteige Dabin Durd bie Druces Eraft des sneeres, Denn Diefes fen bober als bie Derge, welches aber Oarenius Geogr.c. I6, prop.5, als einen grrthum miberleget. 2its bere meinen, ein belonberer srieb des sneeres bringe das 2Baffer auf

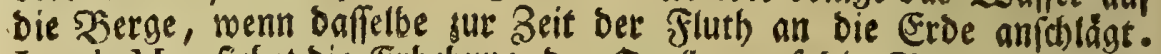
Jo. de Mey fiefet Die Erbebung Der Quellen auf bie Barge, als eine WBirfung Der 2 Binde an, rold)e unter bem 2 Saffer und ber Eroe fid auffalten, Pbyfiol.s.p. 5o. Rircher fareiber biefes Auffeigen ber (J)es walt Det 2 Binde, Dem Drúcfen Der \&uft und bes झneeres zu, Mund.

jubt.

ben Scr. Plúfh Spet. de la Nat: Tom. III, p. 108; anmertet, Daß ęి năm

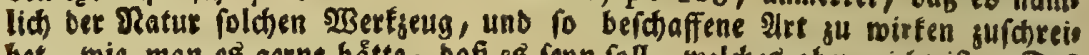
bet, wie man es̉ gerne båtte, baß́ es fegn foll, weldes aber nid)t ift. Des

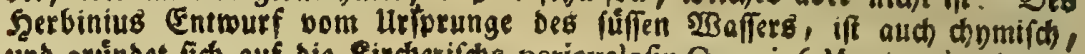
unt grúnbet fich) auf bie Rircherifabe pericyclofin Oceani (Mund. Jubs. Tom. $1,1.3$, feat $3, c_{.}$) von oer in voriger unterfud)ung beteits (Ermegnung

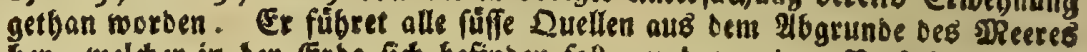
ber, melcher in ber Erbe fid befinden fod, unb ron bem Berfaffer hydrophylacinm fubterraneum genennet wirb. Ee meinet, baßs Das 20 affer in bies

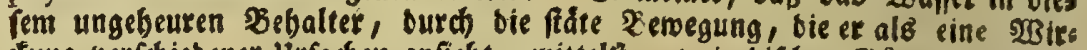
ctung verfhiebener urfachen anfiebt, mittelft unterirrbifher Bange in bie ers babenen Theile der Erbe gebraht, unterwegcz aber burds bas feuer ber uns

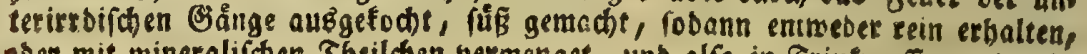
boes mit mineralifinen Tbeilden vermenget, und alfo in Srinfwaffer, ober in in ariberes, jur Befundbeit ber Dienfiden unb ber Sbieze bienliches, vers manbelt werde. "Caufa fontium inftrumentalis, fhreibet et $D i f \int$ DE CA" TARACT. P. 69, eft barathrum fubterraneum (alias hydrophylacium, ma"trix Abyffus, vel mare latens in terræ cavernis) quod aquas illas furfum motu agit continuo." Eieb auth Herbinii $X$ Sgauptft. welches fid $p .52$ ans

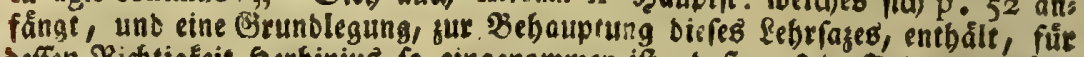

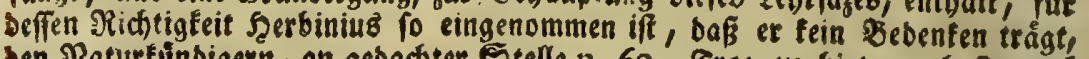

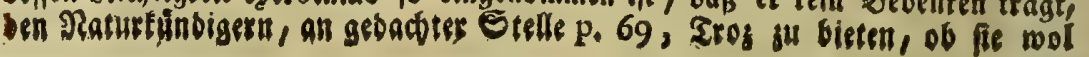
eine 
fubt. Tom. I, p. 230 feqq. Einige lebren mit Varenio, bas 2Baffer gerathe auf fo anfebnlicbe Jobsen ourd) eine Anjiebung, wie in einet \$heefdale, barem man einen 23 rodén bes gencinen Buders, ober ein fdwammichtes Stud Somolle ( 3 robfrume) roirft, oer Saft übet

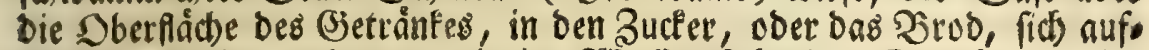
werts ausbreiter; ober mie ein im 2 Baffer ftebender Sanobaufe, bis auf eine ziemliche Şơhe naßs wirb, gemiglid) weit uber ben Strich, to Daв 2Baffer binreidbet. SEefieb Des Warenius geogr. in vorge: nteldet propolit. Detbams Pbyfico: Cbeol. 2 J. 5 Sauptft. 6 Int merf. und Pluche Spect. III, I18. Diefe febre ift, überbaupt bavon zu urtheilen, von grofferer 2 Babrfoneinlidbeit, als bie vorbergebende. Diefelbe vertbeidiget Darenius an fuvor erwefnter Stelle. Diefelbe

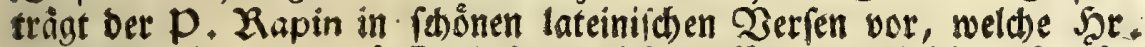
Pluche a. o. 105 U. f. S. befagtes \$h. anfübret; uno id muf geftes Sen, baf biefelbe einen groffen शradbrud erlange, wenn wir betract): ten, baß̧ unter ben nabe am skeere entjpringenben Quellen mebrete ges

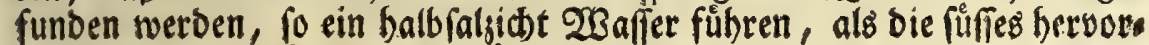
bringen; weil namlich (fo fonnen bie Dertbeioiger biefer \$neinung (c)lieffen) Das Neerwaffer auf einem fo furzen Durdjuge feine vollftån. bige Seinigung nitht erbalten bat . Defwegen leibet Drinoift (Brun-

शु 2 dufium)

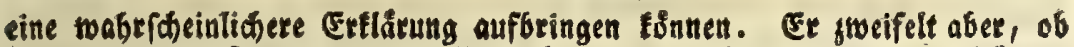
jemanb bamit auftreten roetbe. "Quod qui negat, alium terninum, cui fontes ", et fcaturigines fuam debeant originem, producat neceffum eft. Sed vereor,

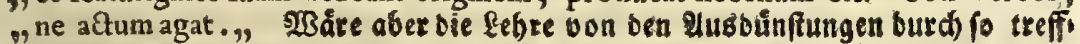

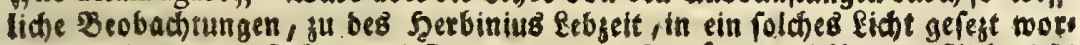
ben, barinnen wir fie beutiges Sages (क)auen, fo wuirbe berfelbe genoïlid nidit so laut getufen baben, uno mit feiner gubfforberung mol zurúdgeblieben fegn. Es fann fưtwabr úber viele Ilufgaben bir Raturlegre niemanb gat gu bebuts

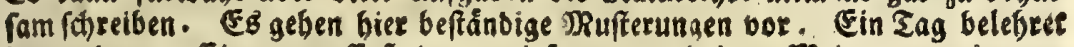
ben anbern. Eime neue Erfinoung wirft soeg und breg Meimungen, ja gans

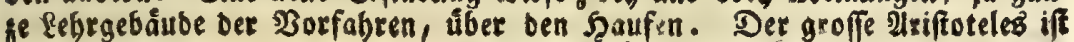
fhon gang flein gemorben. Ein fo ung ftumes Getofe als aud nie neuen SReinungen bes Descarteg, bor nidht gor vielen Jabren nod in bet 23 elf gemactst, fo wenig fraget man ift nad) benfelben. Die Sielebrten folgenbet

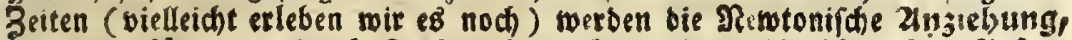

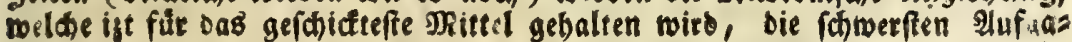
ben in ber Raturlebre aufzuldfen, fu ben Qualitatibus occultis in ein gach les

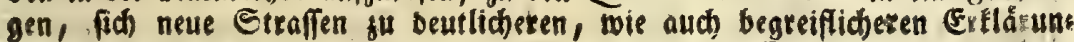
gen, babnen, uns fo mirb man eह immerfort biz jum Enbe ber 230 at treiben,

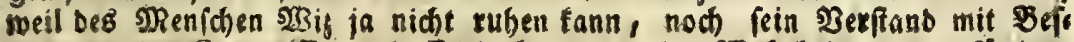

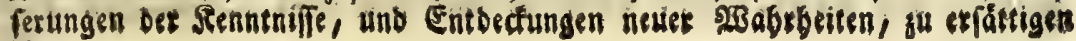
ift. 
dufium) Mangel an fúffem 2 Saffer, ungead ter eg 2 runnen in Hebes: fluffe bat. 2lugufta, Lerranova, und ned andere Sicilifabe Ctåd: te, muffen ibr fuffes, anberwerts bergebradbtes, 2 Baffer faufen, wie

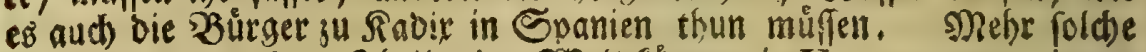
Beippiele von andern Sbeilen ber $2 B e l t$ fonnen in Varen. Geogr. in ges

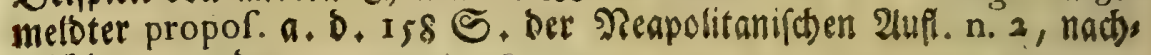
gefdingen werden.

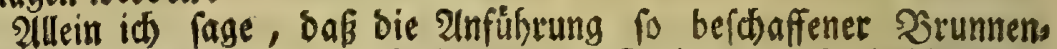

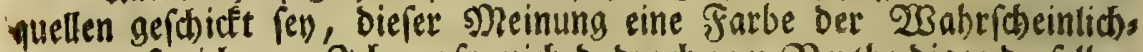
feit anjufteidben. Jot werfe mid) Daburd jum Vertheidiger Derfelben nid)t auf. (Fo ift biefes aud) eine im (Srumbe falidbe Sebre. Denn I) fann bas Deerwaffer burch bie Seigung rol bom Salte befrenet wer: Den, allein bie beiwohnenbe Bitterteit leget eg auf biefe Art nicht gángs

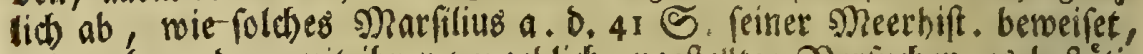
und mehr anoere mit ibren vergeblidh angeftellten Derjuchen es befáti: gen. Nun will it) aber gugeben, Daf oie Natur etwas gumegebringen moge, was ifr bie Runft nidf nadimacten fonn. Senn jene weis burch einen galt; furgen und folecten 2 Beg oer Solveibefunft Die fúfen Dünfte, mit Şinterlaffung Des Salges und ber Bitterfeit, gefchicflics aus Dem शreere zu beben, auch folde in ein trintbares Regennaffer zu serwandeln, welden Zortbeil ibr bod bie snenfosen, mit allem ihren

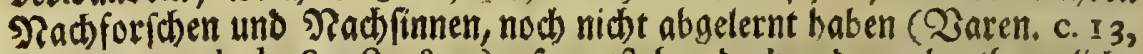
prop. 1 I, plucbe Spect. \&c.): (o entfeben Dod) andere abentheuerlidbe Folgen aus biefer sehre. Denn, wenn bas gefaljene gneerwaffer im. mer auf einer Seite in bie Erbe bineinoringen, uno auf andern 2 Begen in bas sneer zuruce nanbern foll, fo blieb alles Sals in ber Eroe. Da wăre nun erftich, i屯 will nur fagen feit ber Sunbfiuth ber, ber ganze Dorrath bom Salje längf aus bem Meere gefdafft worben. Dars nad), wenn foviel Salies in Der (Erbe blieb, fo murbe fich Das Ders fuffen Des $23 a f f e r s$ von felbft aufbeben. Denn ids ftelle ben Fall, bafs Das nachommende Meernaffer foon bier und oa einen sheil bon feis nem Salte abgefert batte, fo würbe eв Dod) bei feinem Durdjuge Durch fold)e Defnungen und 3 ånge, Darimnen (d)on altes, von andern seitungen zuructgelaffenes, Sals liegt, baffelbe vielmebr aufiojen, und (ic) bantit von neuem fátrigen, anftatt von bem gebabten fich gånjlich zu befreyen. Sinige nelymen biefe Alusflucht, uno fagen, Das Meer: twaffer füle die 2Bege, ba es einmal fich Durchaeleiget hat, mit Salie Dergeftalt an, bafi fein neues 2 affer bort mebr burchoringen moge; conoern oas nacjolgende muffe fooann fid neus Defnungen babnen. 
Dritte Unterfucung.

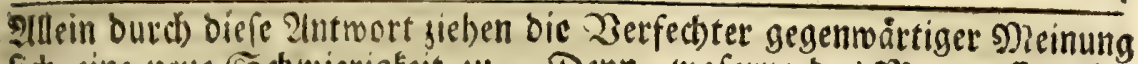
fid) cine neue Schnierigfeit zu. Denn, woferne bas Meerwoffer, bei fenem Eintritte in bie Erbe, immer burd) neue Straffen wanderte, fo mairell innerhalb mehrer taujent Sabre, als biefes Durdseigen Dauret, nicht allsin alle Defnungen Der Eroe mit Ealge Dermaffen zugeftopfét

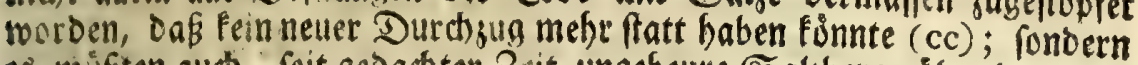
es múfiten auch, feit gedadter Zeit, ungeheure Salgberge úber ber Eró fich aufgethúrmet baben, weil ausgerechnet worben, Daf allein bas

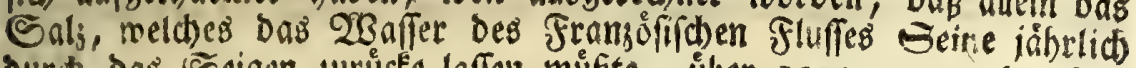
burd Das Eeigen zurucfe laffen múfte, úber roo0000000 (taufend Millionen) Zentmer betragen wirbe, wie in Pluche spect. S. II4 u. F.

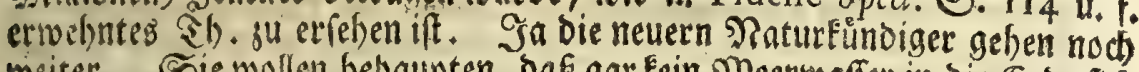
weiter. Sie wollen behaupten, Daf gar fein Neerwaffer in bie (erbe fió) einoringen fionne. Denn oer פneerboben fey mit einer Flebridten Saut úbergogen, weldes ber Blenwurf feigte, weldhes man aud burd Der. fentung eines Steins, ber an eine Sothnur gebunben fen, erfahren Fơnte. Delln, wenn man benfelben ǔber einige syionate wiéber berauf jichet, fo fieht er auf gebad)te 2lrt gans úberfisleimt aus. Diefe

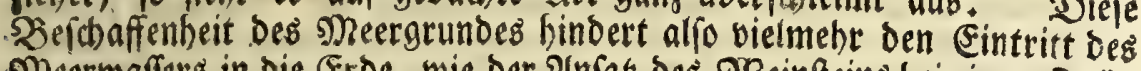
Meerwaffers in bie Erbe, wie ber 2 infá bes 2 Beinfeins bei einem Saffe,

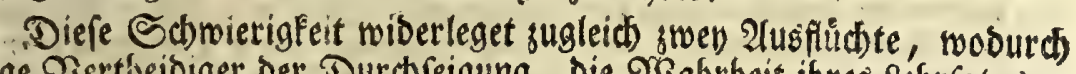

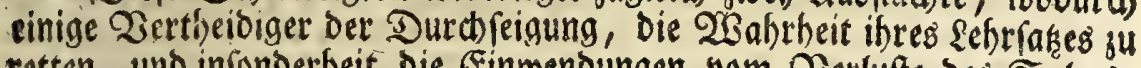

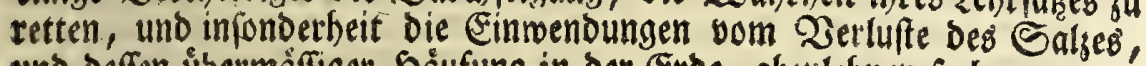
und beffen ủhermáffiger Şåufung in ber Erbe, abjulebnen fudben, wenn fie vorgeben, bie albfonberung bes Salzes vom Meerwaffer, gebe an Booen bes sneeres felbit vor fid, mithin werbe alles Sal; alloort ges laffen. Diejenigen, welde behaupten, bie Seigung werbe in ber Erbe vollbradit, fagen, Das bas berlohrne Sals bem Meere burd) bie in Dempelben befindlicken Salsberge und Saljlagen erfeget werbe. Ders gleiden \&agen feven aud in ber Erbe. Die wiederfehrenden fiffen (fo wol obern als unterirtbifG)en) 2 affer (p pulen biefelben $a b$, uno wenben

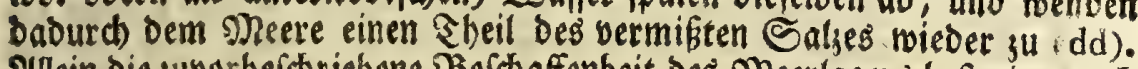

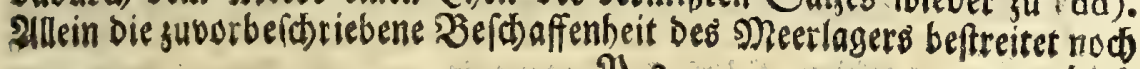
I 3 bieje

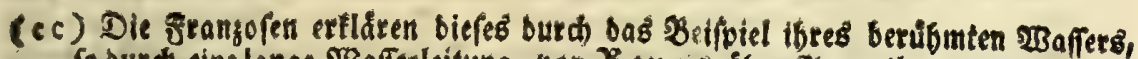

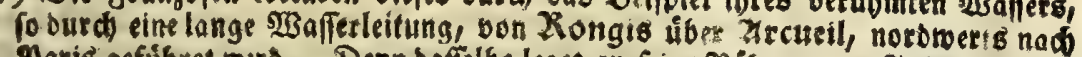

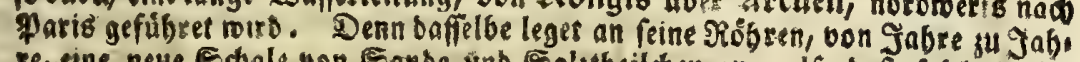
re, eine neue Edals ven Eande und Ealgtbeilden an, alio bas foldes, ins

ner, 
biefe erfte Beantwortung, und Den exften Sheil ber swenten. Denn

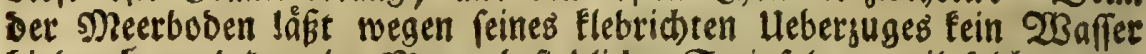
binourd, und bas im Meere befindliche Steinfals, weil folders ver. muthlith auch mit einer bergleiden Saut umgeben ift, fann burd) Das Meerwaffer nict) angegrifen uno aufgelofet werben. $23 a s$ bas Steins

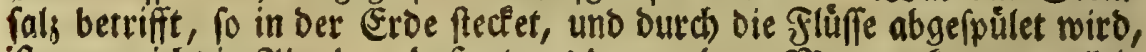
ift man nidt in 2abrebe, Daḱ etwab Davon bem meere zufomme, allein folctes betrágt lange nicbt foviel, als nol zur 2lbftattung Des geborgten erfot:

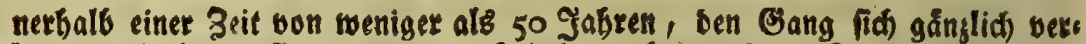

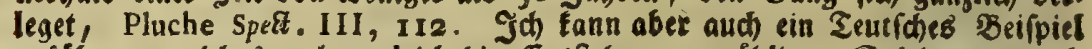
anfúthen, welchę nod) zugleich bie Entitebung unjåbliger Saljberge in alo

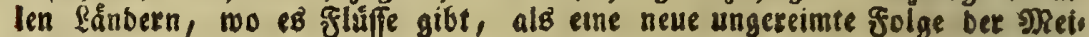
nung ber filttranten, ertocifen foll. 2 on foldter Alrt, mie bas 23 affer von Rongis, fino bie meiften Quelten um Sremsmúnfter. DaB ift sine reiche 26:

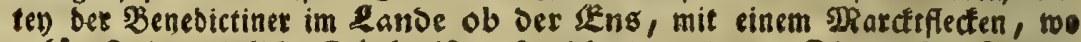

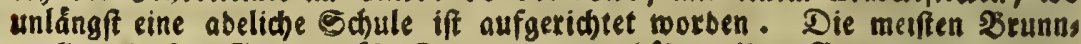
quellen biefer Gegens ubberfeinern uno erbóben ibre Settungen, barin

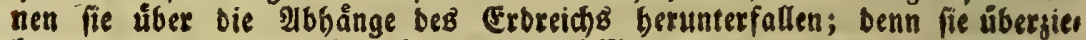
Gen mit einem topbifchen Infake bas MRoos, fo barinnen wáchiet, ies bod fo, Dof eg anfangs noch bie Beffalt einer Pflange begalte. Darnad)

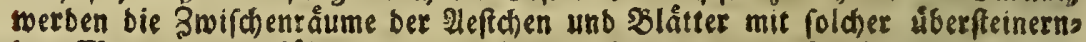
ben Naterie auggefúllet, unb entia) erfcheinen gante Zophfteine, an Des

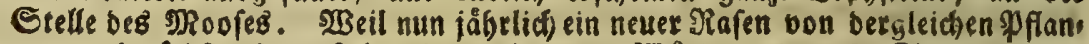

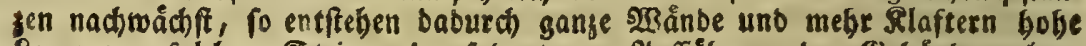

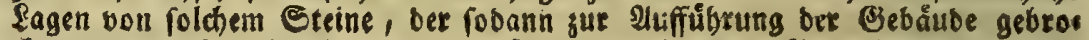

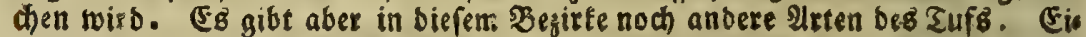

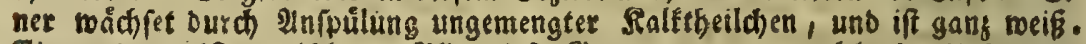

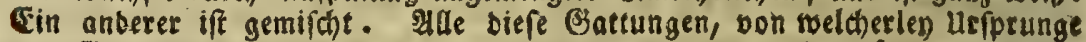

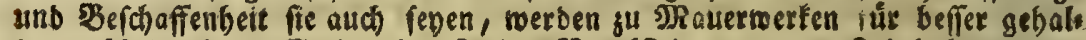
ten, als bet barte Stein, ben fie ben Fagelftein nennen. Ith babe von bet exften Irt, fúr meine Raturalienfammlung, allerlen Stúcte mitgenommen, Das

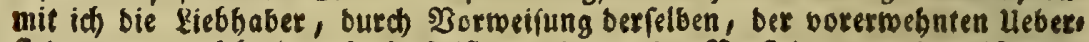
fteinerung, welche intophatio beifit, unb von ber ßerfeinerung (petrificatio)

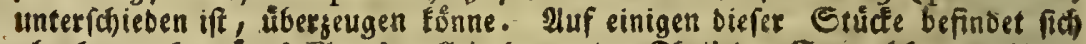
- benber nod) grúnes \$roos, allein ber untere Theil ber Stengelden, mit ben

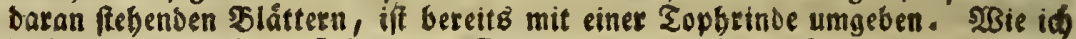
biefes zuerfit gefeben, fiel mir bie Daphne ein, meil ber Entwurf ihrex $\mathfrak{B e r s}$ wandlung auds nod) eine menf(hliche Bieftalt, allein bier und ba f(t)on bere vorbrechenbes forbeetlaub sugleidh meifet. SBti antern Stúcfen zeiget fidh

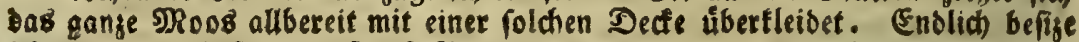
id auch wabrbafter, auf biefe Mrt ergeugten Zophfteill, ber oben annow Epu ren bon úbergogenem SRoofe darftellet, unten aber ein ganger Stein iff, Diefe 
erforbert wútbe, wenn ia bie Serfiffung bes gneerwafferz auf befagte 2urt gejdeben foll. Pod eine Sd) wierigfeit wiber biefe Meinung if folgende, Dab Die Eebrer Derfelben nicht bartbun fonnen, wie bas s)eers raffer, wenn bemjelben aucb die Einfabrt in Die Erbe geftattet werbe, big auf eine Şobe bon 1000 Suritten, auf bie Şerge binauffeigen moge. Das Beifpiel oom Sucter, von ber SBrobfrume, uno von ben

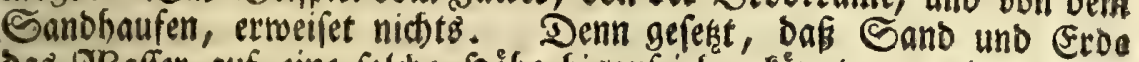
Das 2Baffer auf cine folde şơbe binaufieben fơnnten, (mienol aud

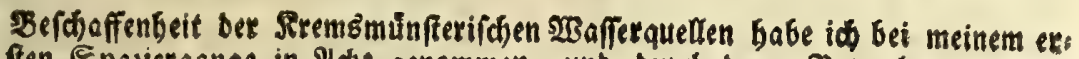
ften Epajiergange in $2 d) t$ genommen, unb burd beren \$ुetradbtung einge: feben, mie innerbalb einigen Taufend Jabren gange faugel baburch erwach fen

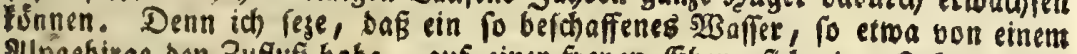
Mlpgebirge ben 3ufluE babe, auf einer freden (Ebene fich eine Defnung mas d)e, uno alloort bersorquelfe. Durd) feine tophifden Inrfpulungen nirb es balb cinen boben Rand um reine গIxüung aufwerfen, biefen eber von Zeit 3ur 3 it erbeben, bis innerbalb megr taufend Jabre eine mertliche \$esfe baraus werbe. Ee ift bie Gegeno vom fanbe ob Der Ens vofl niebriger Sư gel, bie von cinem boben Berge, bergleiden es nach ber Etenermat viele bat, wie ein 2 Reer bolles $23 e$ llen anjufeben fino. Id) getietb fiton auf ben

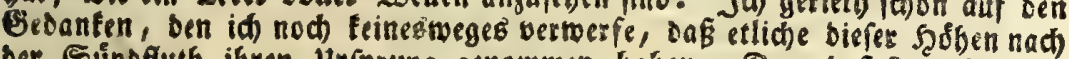
ber Eunoflutb ifren uriprung genommen baben. Denn baß̧ fie nidet gans feinicht, fonoern mit Erbe ưberbecfet finb, bas vernichtet biefe sieinung

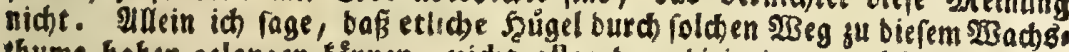
tbume baben gelangen fonnen, nid)t alle; bens diejenigen, weldhe gange Las gen von Ries und Sachfteinen in fid foffen, baben fo wenig auf gebachte Irt entfeben tonnet, als diejenigen, in benen lleberrefte ber Eưnofuth fich fin

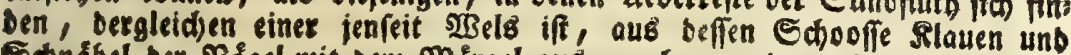

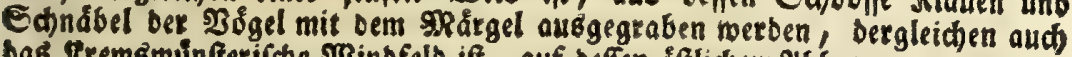
bas Jtremsimunfterifhe 2 Binbfelo ift, auf oeffen sfftidjem 2bbange man vor eis nigen Sabren, beim Steinbrechen, ziemlich tief im Erunbe, mitten in Sans De, Şăbne und aidpfe von unbefannten Sbieren gefunben bat, bie nan fúr Dras chenfopfe aubgibt; weldie ith aber lieber fur uleberefte won Meerfifthen bals ten will. Die ifige Berfaflung Des Drtez, welche meder gelefrte Reute fies ben, now bon andern Begenden babin getatkene erbolten tann, binderte

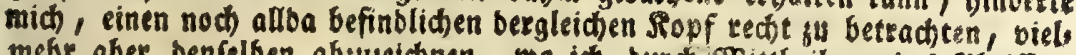

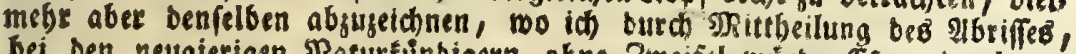
bei ben neugierigen Raturfünbigern ofne 3meifel würbe Ëgre eingeleget, bet गbten aber feinen Eajaben jugefúget baben.

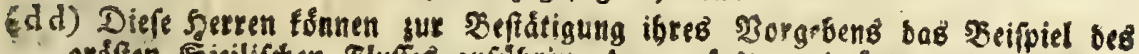
grdfen Eicilif́ch fiuffer anfübren, ber auf ser mittăgigen Eeite biefer grnfel, bei ber Etabt alicata, fid in bas speet fiurget, unb sof gefaljene

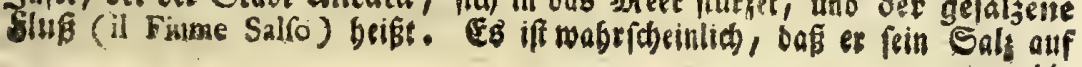
bic. 
Diefes nidft eigentlid) geredet ift): fo wurbe es bod fo menig oabon weglaufen, als baffelbe uon einem getrånften Edwamme flieffet, Den man nidbt oruclet. Sarnach Eann bon biefen (3leidniffen auf eire fo anfebnlid)e Şofbe gar nicht gefd)loffen werben. Denn, wenn man mit Sande ober mit Erbe gefülte Sobren in ein 2 saffer ftectet, wirb fols

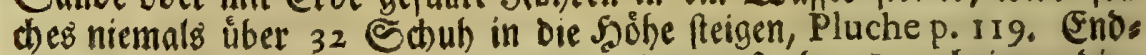
atich gibt es Steinberge, bei benen weoct ausenber, nod inmenbig, Cant ober (Erbe angetroffen wito, die aber bod) an Sirunnquellen reid) fino. QBie haben biefe Berge bas 2 Baffer auf bie obbeftriebene 2rt bon unten binaufaugen fonnen? 2illein nod meht andere (Erfabrungen wiberfesen fioh biefer 20 orfellung vom Urfprunge ber fuffen $2 B a f f e r$. Denn man bat bei io vielen, und an veríbiedenen Drten vorgenommes nen Durthgrabungen ber Erbe, niemals gefunden, Daß das $23 a f f e r$

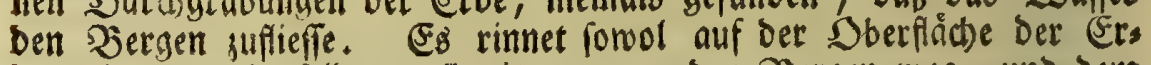
be, als unter berfelben, allezeit nur von Den Bergen weg, uno dem Meere su. Diejenigen, weldbe nidbt lagen wollen, oas ourdgefeigte Dreet:

bie Pet getwinne, wie bie unterirtsifhen glüfe, auf melde bie giltranten fich berufen. Den fiebhabern ber alten Ëeograpbie roill id bier eine Inmertung

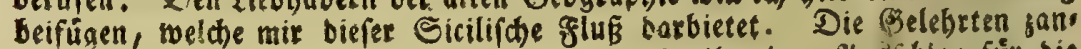

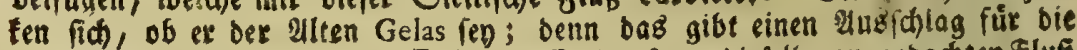

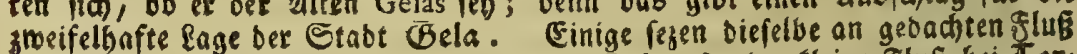
bei Ullicata; andere bebaupten, Der 2 Iten (Belas fen ber fleine Flü bei eer: ranova. Dhe Erunde find beiberfeits fo wichtig, Daß man groen vortreffli,

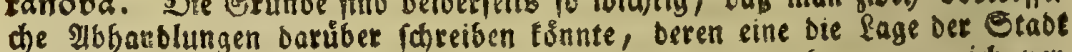
Gela Den Mlicalefern, bie anbere ben Tertanovejern, fueztenne, wo id ber, fidere, bas viele Belehrten beinabe borten unichlief:g bleiben, für melchen Ausfprud fie fid extláren follen; wie benn biefe (Exorterung eine bet fobon ften ift, welcte in ber alten Beograptie fid finden. Die Befdreibungen Des alten Siciliens, unb bie SanbEarten, welche die Derter biefer Injel nach bem Zuftande voriger Zeiten vorftellen, erweifen Durd ifre 23 ideriprúd) jue Ennige, baf bie eine und bie anbere biefer sweb Meinungell bon einet gleid

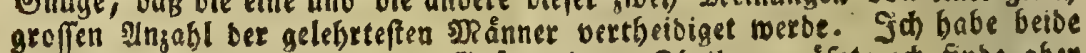
Gegenden beobachtet, unb bie Grúnbe beiber Tbeile geprúfet; ich finbe aber

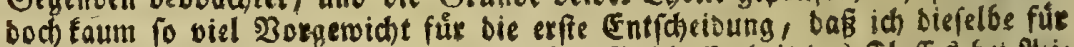

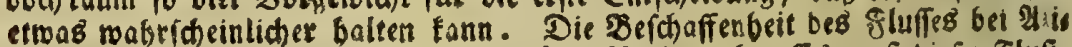

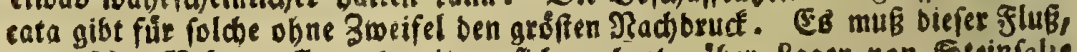
ober feine Nebenquellen, bamit et fich mebret, Liber Ragen von Escinfalje

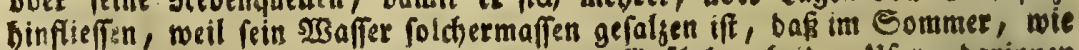
it) reiteft gefegen babe, alle furchen unb (Stübaten beider ufer, barinnen baffelbe firen bleibet unb verfieget, mis Salyfwollen beleget find, mie man in

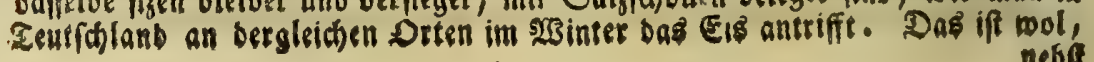




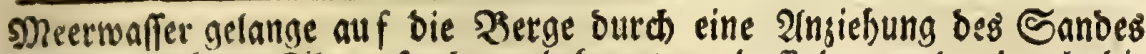
und ber loctern (sibe, fonbern befaupten, baffeibe torbe burch die Schmere bes groffen 2 Baffertérpers, der 2 Beltjee, von ben 2 Binben, . boni feuer, Dura) unterirroifbe (siange auf bie WBeife binaufgetries ben, wie es zum Ibeile Kircber, Mund. Jubt. Tom.I, von Der 230 S. an, befareibet, und burch Figuren entwirft; Die betrachten nicht, Das

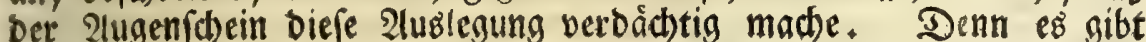

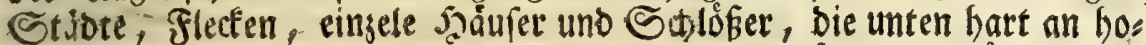
ben Biergen tiegen, uno Brunnen haben. (Es wáre nicht mơglich, baf man Durd) Das (Straben fo vielet Brtunnen, an folden Drten, niemals eine Dergleiden aber treffen und erơfnen foll, weld)e von bem Schópfer wăs re bereitet worben, oas 2 affer auf einen foldben 2 erg, und ztor auf eine Sobse von taujeno Sthriten, qu erbeben. 2Burbe nicht Das $2 B a f$ fer aus einer foldben (Strube, wie bei einem Springbrunnen, genaltig berauffahren, uno biefe 2 Safferfunft beftåndig treiben? 2lllein wo be:

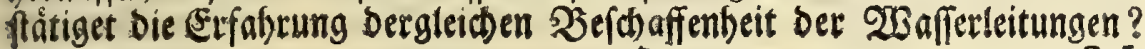

$$
2 \text { Jळ }
$$

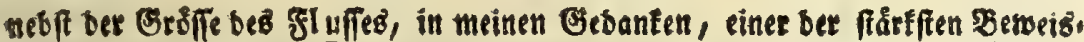
grumbe, Das er bet Belas fen, wenn Gela in bat Dpifer unb Eifuler

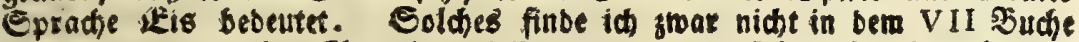
bes fercobotub, babin (Eluberiub, Sicil. ant. p. 104, fich gu betufen idbeinet,

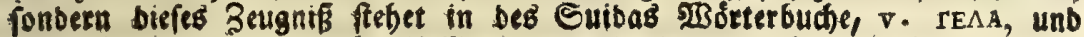
lautet fo: "GELA, urbs Sicilize. Vocatur autem a fluvio Gela, ad quem a, hec urbs eft fita. Hic vero fluvius ita vocatur, quod multam glaciem gi" gnat. Hanc enim Opicorum et Siculorum lingua gelan vocari tradunt."

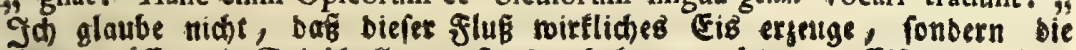

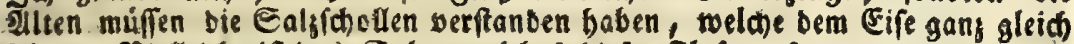

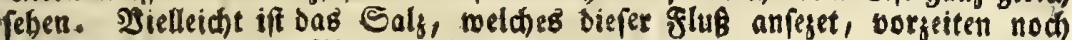

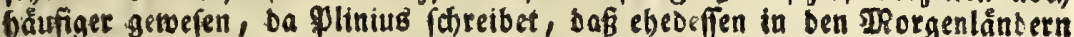
einige gltúffe mit Saljfhalen ganz úbergogen ftunben, twie bie unfrigen im S2Binter mit cife. "Sed et fumma fuminum denfantur in falem. amne reliquo "veluti fub gelu fluente, ut apud Cafpias portas, qux falis-flumina appellan. "tur. Item circa Mardos et Armenios "XXXI, 7, Hard. 39. llebrigens exfeben wir aus ber Etefle bes Euibas jugleic) (meld) legenbeit zu erinnern unterlaffen milf) bie lebereinfunft ber Rebart ber åltes

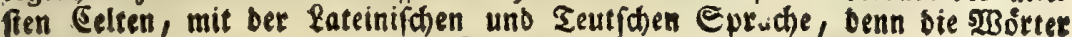
gela, gelu, gelo, (as ), glacies, Glas, fonnen in Infétung ibres Utefprungeb̈,

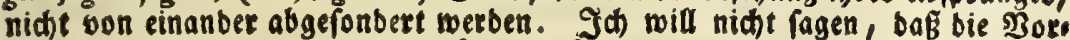
fabren ber Seutfohen in ben natuirliden Dingen fo unerfabeen getwefen, baf

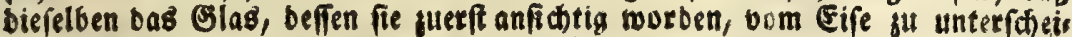
ben nicht follen geworit baben, wie tie Sifuler, welche bie um ben flü lies

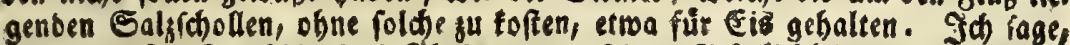

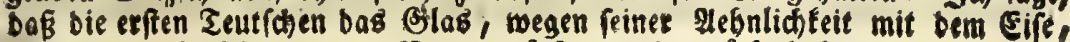

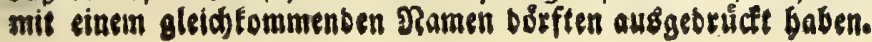




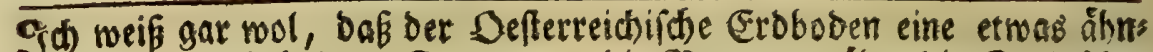

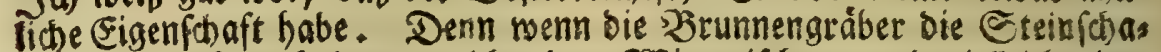

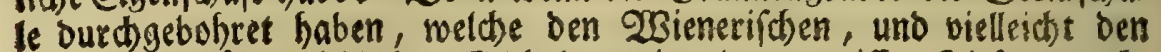
ganten unterofferreidifaten Eroboben, in eimer genviffen siefe, ourch:

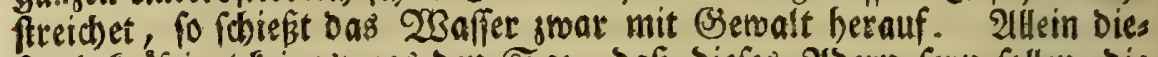

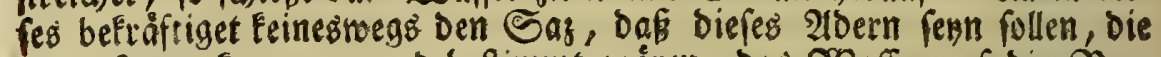

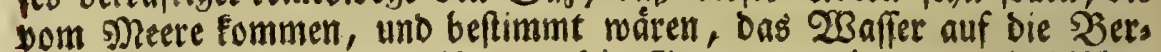
ge su führen. Daś erweifet nur bie Ejegenmart eines unterirroifichen Sees, weld)et Durd) ben Bufluf bes Regen= Schneer und Jiebelwafs fers, aus bem Stevermårfíd

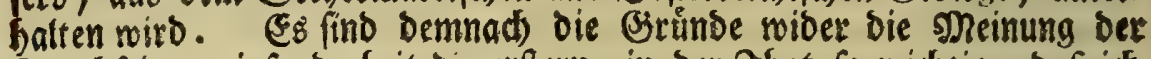
Durdfeiger, infonberbeit bie erftern, in ber shat fo widtig, bas id

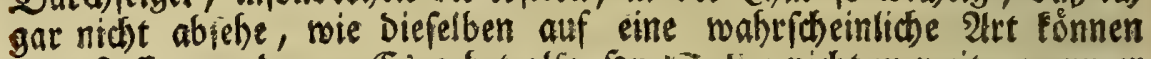

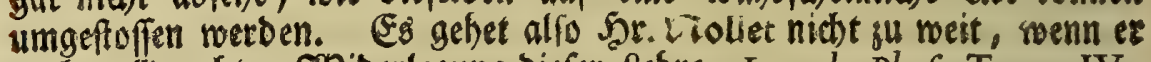
nad) vollbeadter 23 iderlegung biefer Sefre, Lec. de Phys. Tom. IV,

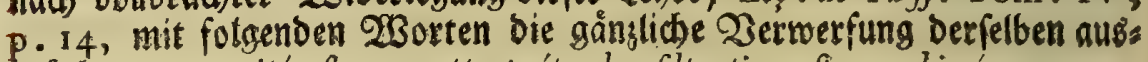
bruciet: $L$ o verité eft que cette prétendue filtration eft une cbimére.

Die oritte, uns meines (Eradtens zu der Zeit wahrideinlidffe,

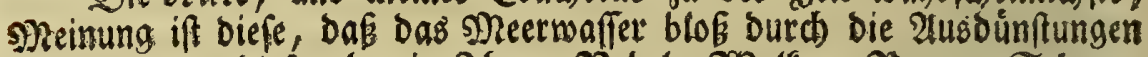
fich minbere, biefe aber in Shau, Mebel, 230 olfen, Siegen, Sdbnee, berwandelt werben. Der Segen făllt auf bie feften sheile bes Erobos

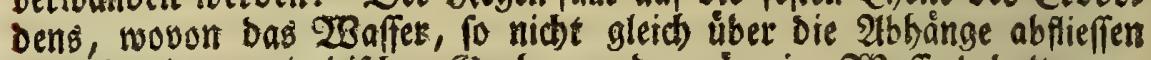

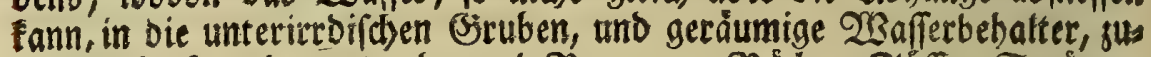

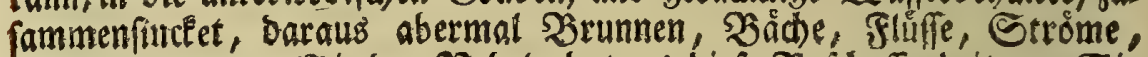
Seen, werden. Mit ben Netetn bat es biefe Bejhaffenbeit. Sié finb nid)ts als Berfammlungen von 2 Bafferbunften, die wit Wolten nennen, wenn fie bod in ber \&uft fhrweben, Febel aber, wenn lie in ber Niebere berumfreiden, denn fie werden yon ben 2 sinben imme: fortgetrieben, fo lange biefe mehen, bis fie auf ihrem 3 ug? an כerge anfabren, und nicht weiter fortrúcten mógen.- Der Nebel vers minbert fid beftánbig. Denn wo er einen Eegenftand antrifft, $D . i$. an bartere Rorper ftóbt, oaran bleiben unzäblige 23 affertheilesen beljan. gen, welches nir bei ben शebeln ber Falten 23 intermonate fehen, oas

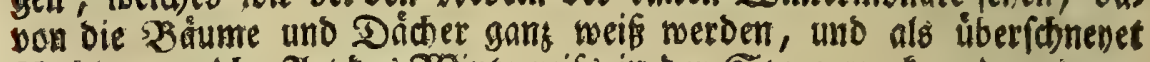
fheinen, weldse $\mathfrak{A r t}$ bes 2 Sinterteifs in ber Stenermark, uno noct ans bern Sberteut (chen \&åndern, Oer Rbeim genannt wird. Dak Die Frúbs lings: und infonderheit bie Scerbftnebel, weldhe fich gerne um bie Şerge aufhalten, auf benfelben fo viel 23 affers abferen, als ein fadjer lang: wieriger ßiegen, Das wiffen biejenigen, weld)e an folden Srten viel berume 
berumgejogen fino. Denn bie ßlaitter ber $\mathfrak{B}_{\text {áume treufen babon, als }}$

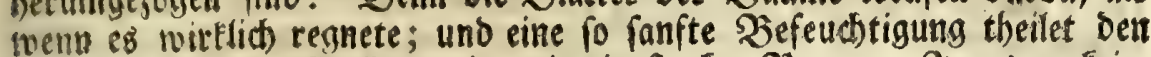

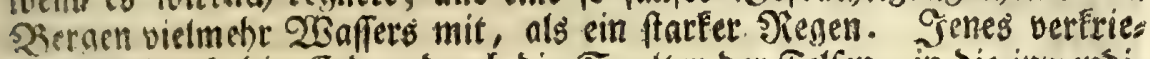
()et fidh ourdh bie Eroe, ourd bie Spatten ber Felfen, in bie inmenoir gen Sietter hinein, wo bingegen basjenige, fo burdh einen farfen Begen betunterfillt, von ben Bergen allentbalben berabläuft, unb nur bie Sluffe auf eine Furze Zeit greffer madyt (ee). Der Schnee if ber britte reidte glenferfd)a der beharrenden brunnen. Denn fein fad)te treufendes 23affer, twenn er jergehet, verlieret fid groffentheits in Den innern Sdjoof́b ocr şerge. $230 \mathrm{eg}$ auf Denfelben umgeidlorfene Siefen gibt, ba wiro ber Sdnee burds bie $2 B$ Binde hineingewehet. 2 senn Derfeibe

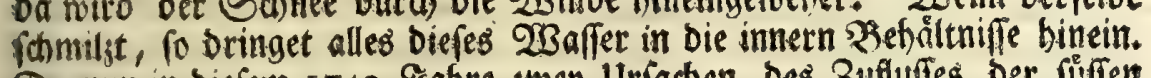
Da nun in biefem 7499 Sabre zwen Urfachen Des Bufluffes Der fúffen 2Baffer gefehlet baben, Der Fegen und ber Sdnee, (Denn bas Mittel und Enoe bes Sommers waren burre, Der yorbergehende 2 Simter batte

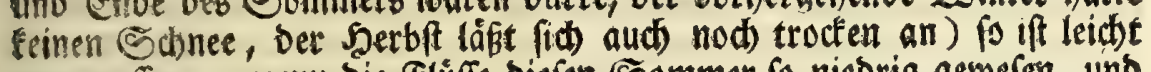
gu ermeffen, warum bie flúfe biefen Sommer fo niebrig gewefen, uns nod biejen Sherbft Die Donau fo flein if, Daß Die Mahls Eages Papiers

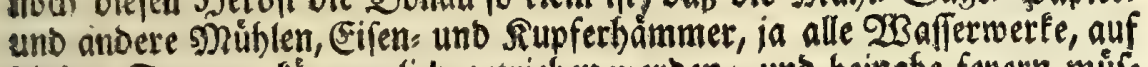
biefem Strome, funmmertich getrieben werben, und beinahe feyern mú; fen. Eg if maht, Das im jpaten Frublinge, went ber Ednee aufs thauet, bie grluffe gewaltig ansuftowellen priegen. 2allein bas iff fein

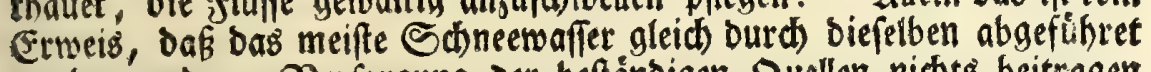
werbe, und fur Jerforgung oer beftánbigen Quellen nidts beitragent forme. Denn man mus bebenfen, bas manchmal fo viele gaan von

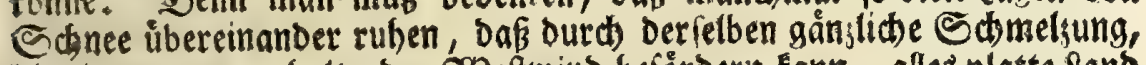

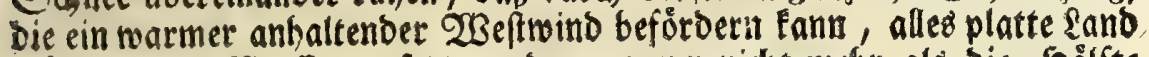
múste unter 28 affer gefést werben, wenn nidht mehr als bie Şålfte bavon in bie Skerge, uno das úbrige (Erbreid), fich entgegen nieberjegte. G\& fommet alfo vom Sdneerwaffer nur basienige ben Slúffen su, twas von nieorigeren Şügeln berabfinfet, audh was von fold)en abhängen bet groffen Berge berunteridhieft, weldhe ihres glatten und mit Srafe bes

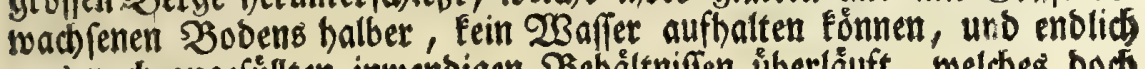

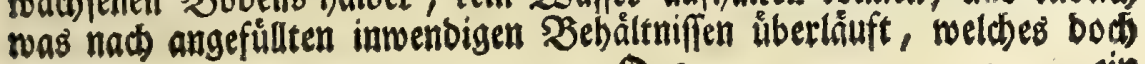

$$
22
$$

eit

(ee) Dos ift abet aud teine allgemeine פ্Babrbeit. Denn exflid) gibt es auf Den Steinbergen úberaub viele mit Sanbe, sics, uns gertrummerten felfer,

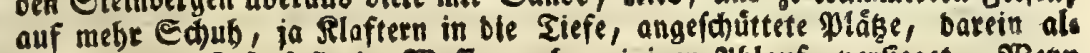

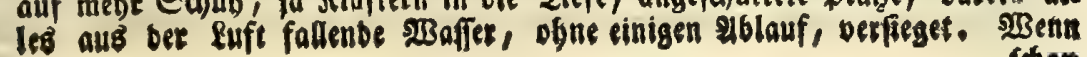

1内0\% 
ein io flarfes Giemåffer ausmacht, baß Heberforwemmungen baraus er: folgen formen. Eg beftehet alfo diefe \&ebre niajt allein wiber alle Ein.

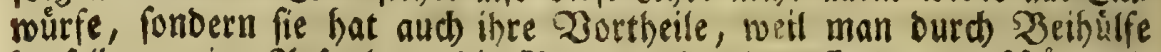
Derfelben enige Aufgaben, Die $\mathfrak{B}$ runnquallen betreffeno, gar idion uno

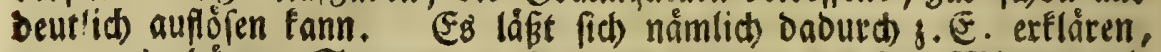
warum in burren Sommern, beboraus wern aud) Der 23 inter mit wenigem Sdnee fich eingeftellet hat, etlid)e $\mathfrak{B}$ runnen feichter werben, anbere aber gar vertrodfnen; ferner warum an ben Bisfeln ber BBerge, fo obenber nid)t platt find, uno bie auf einer meiten Strecfe bes fans bes leine bơbern $\mathfrak{B}$ erge uni fid baben, feine 20 runnenquellen gefunden werden u.f.f. meld)e Uebereinfunft ber \&ehre mit ber Patur, ein Senns

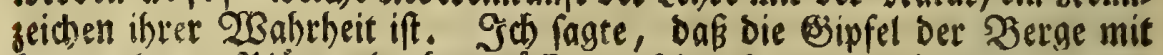
feinen ebenen भylägen obenber múffen verfehen ienn, fo roirb es nach ben Sirunden biefer \&ehre unfebltar eintreffen, Dấ fid aud feine 23 runnen

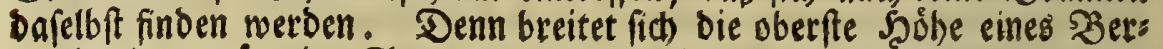
ges in eine geråumige Ebene aus, fo fann biejelbe nidte allein sBrunnen aufweifen, fondern aud ganz moraftig fenn; weld)e Seidhaffenbeit man auf Dem (3ipfel Des Bloctsberges fieht, Bebrens Hercynia curiofa,

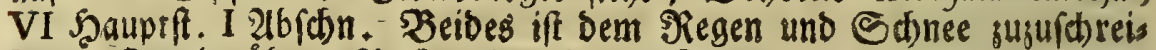
ben. Der berübmte Yader im Diertel Billi, Der zwifden Windird,

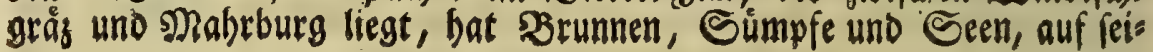

\section{netI}

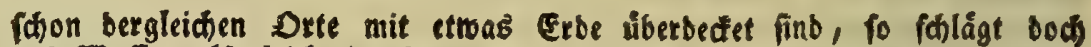

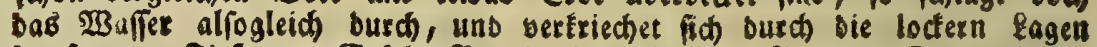
in fernere Siefen. Solde \$ergfiridi) baben bie Mrt Deb Eampanifonen erobobens, von bem \$liniub gan reci)t alfo fadreibet: "Terra ejus ( "Campanis) pulverea fumma, inferior bibula, et pumicis vice filtu" lofa: montium quogue culpa in bonum cedit. Crebros enim imbres "percolat atque transmittit." XVIII, II, Sars. 29. Sernat finb fift alle berge bin uno wieber mit Eefflformigen fidtboren 2usboghlungen vets

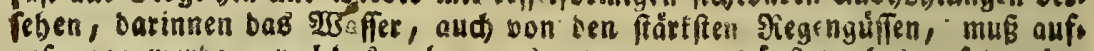
gefangen werben, weldes, obne was entgegen wegtunitet, bis auf ben leg: ten Sropfen in oie innern skrunnenfăften verfinket. Das fid)tbarfe Beifpiel biejer $\mathfrak{B}$ abrbeit fellet Der Berg Soridb bor, ber in bem eigentlichen Wins bichen lande, ober in bem ijigen Diertel żilli, gelegen ift, unb von feiner runden Beftult ben Namen bet; wie Eerongyle (igt Stromboli). Berg unb

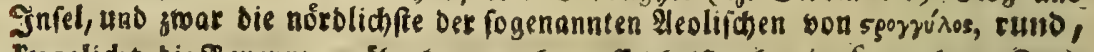
fugelicht, bie Benennung úberfommen bat. Eg beifit aber Lof̂, auch im Seuts fhen, runs, eine Rugel; bolfen, ruits machen, globare, opargô, 5es nifd. Ther. 467,13 uno 14. Sr. Plichen bat in Idiot. Hamburg. Boffel 
nen breiten (Jipfeln, bic in $2 B$ indifü)er Spradhe Roppe genennet were ben. $S_{d}$ ) nufi aber bier groen (sinwenoungen ablebnen, weld)e gegen Diefe sehle fisnen aufgebrad)t werben.

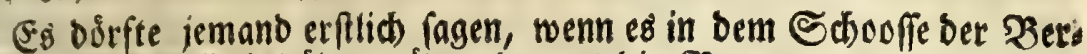

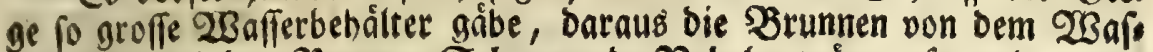
fer, fo burch ben Siegen, Sd)nee und Nebel, wåre gefammlet mors Den, ifren Zulauf bătten; to můsten bie Quellen meit fiérfer hervors brechen, ja Durd) bie (d)eitelrecht ftebenden Münoungen ber flieffenoen

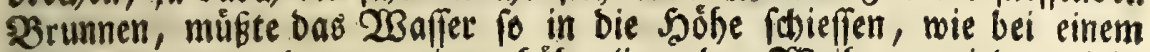
Epringbrunnen, ber son einem föfer liegenden 28 eiher getrieben wirb; folglich hătten bie Wertheibiger biefer Meinung benienigen (Einmurf felbft

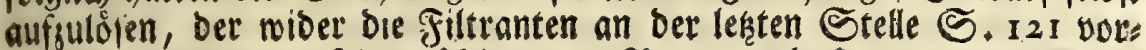
getragen worden. Scierauf bienet zur 2(ntwort, oak man ju unterft an

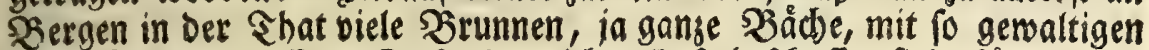
2lusbrudben antreffe. Dak aber nicht alle fo befd affen find, Eơnnen wir leidt begreifen, weil ber Booen Der Behalter, ourd oie Bufinffe mei: ftentheils mit Erbe und Sande beleget wird. Der Jorrath bes 20 af: fers finet nun in Den Bergen, auf 2 etten von Sand unb Erbe. Die Grde wiro burd bie $\mathfrak{B r}$ runnquellen unvermerft berausgeipúlet, Der Sano

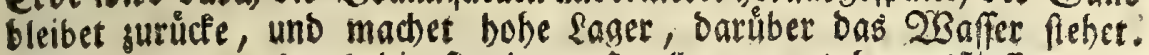

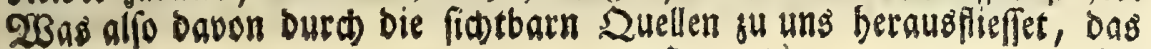

$$
23
$$

wiro

cine segelfugel, bober if boffeln fu Şamburg, unb noch in einigen anbers Seutichen IRunbarten, to viel, als mit Ziegeln fpieleit, weil mit Rus geln barnach gemorfen mirb. Dex granzofen bolje, eine runbe Beule, ein

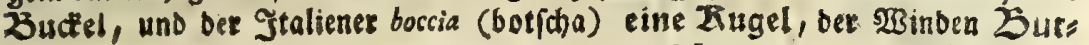

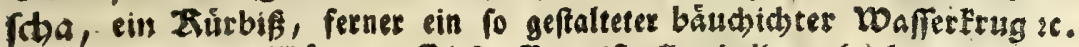
fino baber gebolte $\$ 3 \delta$ ster. Diefer Berg ift allentbalben obenberum, Damit idh auf mein Borbaben Eomme, voll runber gerăumige: Bruben, die feichten

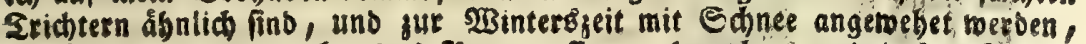
bie úbrige Jabrefeit aber bas Regenmaffer verfammlen, unb in Das Junere

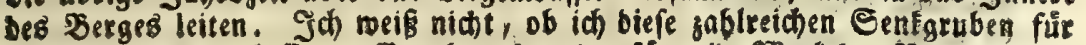
Epuren eines verlaffenen 5 ergbaues, ober für eín 233 ert ber 2Ratur balten foll. Bielleiche Gat ber Brund nach Sertebrung ber Mineralien, ober nach

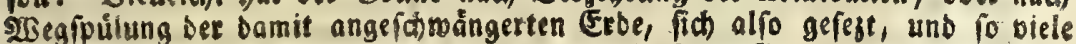

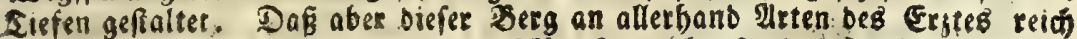
fiv, das befeunen bte rings um benfelben beroorbredjenden Quellen, die von

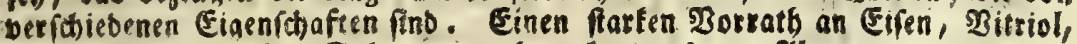
Ethmefel, Eteinfalye, Salpeter, auch nod) etwas von Mllaune, verratben et,

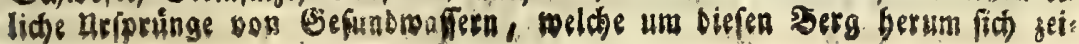


wird mittelft einer Seigung burch ben Sand, von ben inwendigen Geen uno 23 affergruben abgezogn. Daburd aber seiget fid) erftid), marum ber Srieb ber Sagequellen nith fo farf $\mathrm{fen}$, als man eingerwendet hat. Darnach wirb hieourch eine anbere Sommierigfeit geboben, welche bies jenigen erregen, bie nid)t berfteben, warum burd Dieie Quellen nicht in Furfer Beit alles inmend g gejammlete 2 Baffer becauslaufe, fondern es Drunnan yeben fơnne, weldie ourd) Das ganje Sabr inren beftánoigen Buflus baoen. Denn biefen gar zu gáben 2luslauf verbinbert I) Der 3 ug

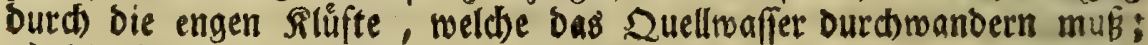
2) Die facte Durdfeigung Durch bie Sanblagen, weld)es bie ß̧es trad)tung eines 2 Baffer: ober Sandreigers begreilich madt. Destos; gen if aud Der zubor geoađte Einmurf nur wiber biejenige Erthlórung ber Filtranten geftellet worben, bie fid) etwa folde frene ben, woburd das 2 Baffet auf die Berge flieffe, wie es Sircher an oben erwebnter Stelle ourd) $2(6 r i f f e$ vorweifet. Die zwente Einwenourg wis

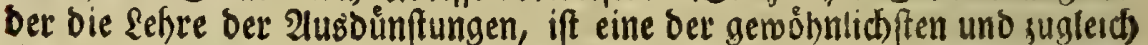
eine ber widstigften. Diele bilben fid ein, es fonnte eine fo aroffe s) nens

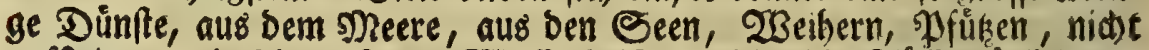
auffeigen, als bie Saft bes 2 Baffers ift, weld)e bie Fluffe tåglich bon ber Groe binwegibaffen, und bem Meere zufübren. 2llein dlefe Sobries

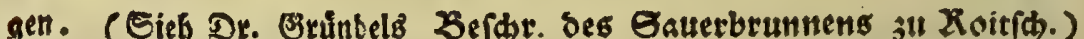
Denn aufier der berủbmten fauen Quelle, welche anberthalb St. von Roitich,

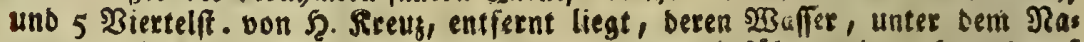
men bes Roitfcherfauerbrunnens, weit uno breit berfúbret mirb, bat es auf

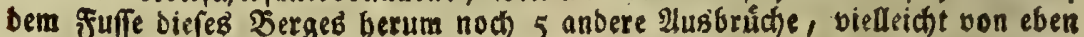

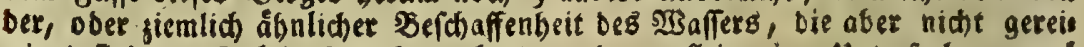
niget finb, aud teinestoegr geachtet werben, allein eine Unterfudung nol verlobnen offften, benn aub ie mebreen ober menigern mineralifhen Irten

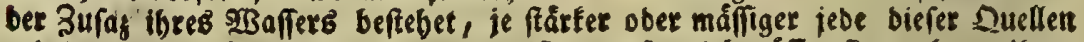
mit bergleid)en Sheilhen bermenget ift, um fo viel muffen fie aud an ifree 2Bitfung unterfóieben regn. Den ftarten Eifengehalt bezeuget ber odergel. be Infas, tomit die 5. Eireuserquelle ben Etein beleget, darein fie igt eingefoloffen ift. Das গ্Baffer, fo bei Zriavija (rufus vicus), aufquillt, und bie Eteine mit einer rothgelben (Erbe überfiefet, foll nach) linter/uchung

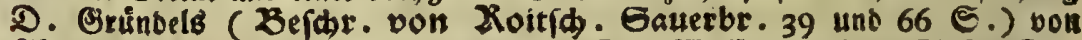
Allaun unb Eifenvitriol Spuren meifen. Dab Waffer, to beim Slofter Stun benis mit vielen beftigen Quellen aufwallet, beim urfprunge einen $23 e i b e r$ macht, bet gebectt ift, und ein 23 afhbaus abgibt, movon bet 24bftus ores

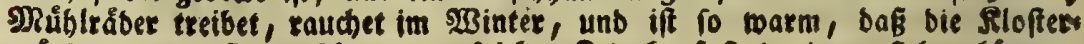
mågpe, twenn fie wafhen, gu foldhet Zeit barfuß barinnen fieben tónnen. 
Sकwierigfeit ift Dur(b) Die Unterfuchungen Der gelebrten (Englånoer uno Franjoien beteits abgethan worben. Diefe baben nachgerechnet, wie viel 2Bafiers ein ganjes Sabr o. E. Die Seine unter ber Fóniglidjen Dructe in Waris ourdfeke, uno wieviel bingegen Regenwaffers ein ganjes gahr auf ben Etrich Degs Eroreid) falle, in Dem biefer Fluf fich fammlet. Die Dergleidung hat gejeiget, bás ber uberficus bes Siegenwaffers fec)sma! groffer (en, Pluche Spect. 1 31 - 1 35 S. 2 enn man nun einen 216 fug madt, wiesiel 2 Baffers burd) bie Fluffe wieber

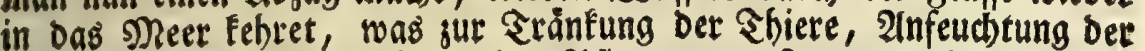
Erbe, und jum 2 adjsthume ber $\mathfrak{P}$ flanjen, mus angewendet werben, fo bleibet gleidfrol nod) ein fo groffer Heberf(d) turkunbiger, in Betrachtung ber nod ungerechneten \$yenge $2 B a f f e r \mathfrak{s}$, meld)es die Sebel auf ben Sergen abjekzen, bie unterirrbifhen Fluffe gu Súlfe nebmen múffen, um ben Heberreft von Der Erbe binwegas (c)affen, Damit Feine allgemeine Heberfobrommung entftebe. Die 2luss rechnung Des SRegenwaffers, welđe von bem D. Engelgrave, Dom. 6 poft Epiph. Luc. Evang. p. I35, beigebrad)t, und von Happelio

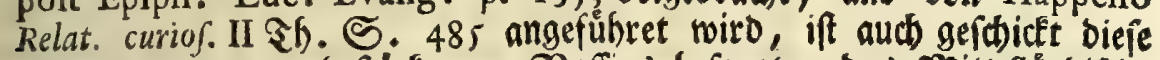

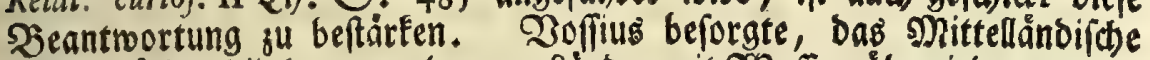
)eer mo̊dte bie Daran gelegenen \&ảnber mit 2 Baffer ủbergieben, wenn es swifhen Afrifa und Spanien feine Oefnung båtte. Die neuern $\mathfrak{T a :}$

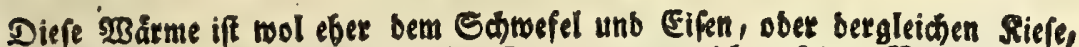
jusufdreiben, als einem wirflid)en feuer, wovon id auf bem Zotid, unb

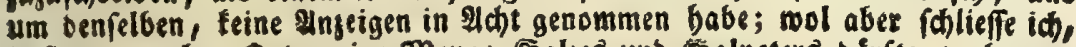

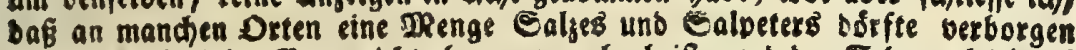
liegen, weil biefer Berg nid)t eben gat ju boch ift, unb ber Sdnee gleidiwol in einigen Gruben bis in Den fpaiten Sommet binaus liegen bleibet, wie in Dex unter bet $\mathcal{S}$. NRicolai Jitche, welde $\mathfrak{w}^{\prime}$ Kaunim, b. i. in Ser 隹bes ne, beigenannt witb. Die 20ern, weldhe teines gebacteer anineralien bes ruiben, geben bas gemeine Trinfraffer, barunter biejenige Ouelle bie vos, tefflidfte ift, welde auser bem Bjarten exmebntes Slofter gemaltig bervors pringet, unb ber Ginabenbrunn beiĝt. Die vielfáltigen oon biejem runben

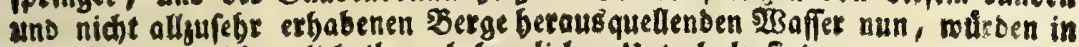
bemfelben wol (A)merlich ibeen bebarrliden unterbal finden, wenn nicht is sftere Rebel, meld)e ben Snnobnetn bes platten Petauer: unb Eanbobens

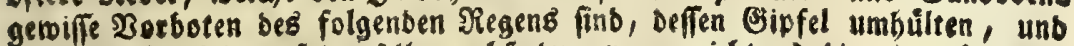
siele Geuchtigfeit auf bemfelben abregten; wenn nidht 2) bie ooen berabies

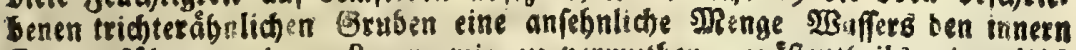
Seen jufíbreten, beret Eager, mie zu ostmutben, groffentoeils mineralifo

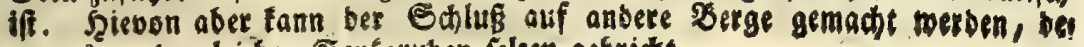

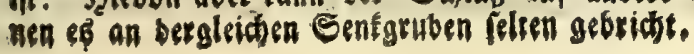


turforfher befurchten bas. Bjegenfpiel; bie feften sheile bes Erobobens

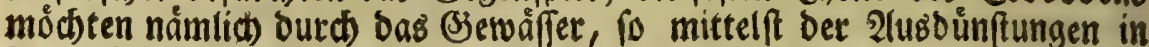
bie \&uft aufgesogen wiro, aus berfélben aber wieber herunterfällt, ers fåufet werben, weil ifhen bie fichtbarn fflúfe, wie audb bie úbrigen 2usfpenoungen, befielben feine sureid)ende Mienge von ber Oberiăd)e ber Eroe binmegråumen. Sllo fann ber uriprung aller füfien $23 a f f e r$

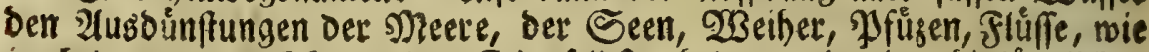

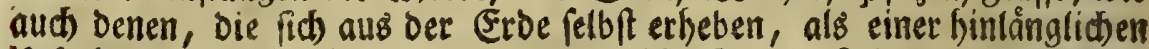
Hlifache, jugeidsrieben werben, und bie $\mathfrak{B}$ erge find ber eigentlidse

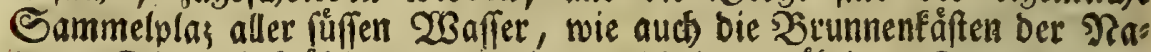
tur. Diefes befråftigen ganse Seen, Die in ungåhligen Bergen, uno aud auf benfelben, allein in foldter sage fich befinden, oaf allemal nod) andere mehr erbabene Shohen um diejelben fteben, oon benen fie ibren Unterbalt überfommen. Der berubmte Unteriperg bei Saljburg ge:

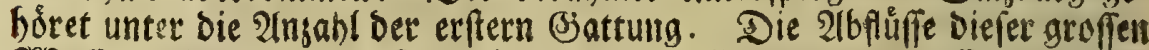

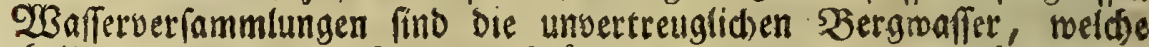
theils als $\mathfrak{B r}$ runnen, theils als 3 jåche, an niebrigetn Orten berborbre,

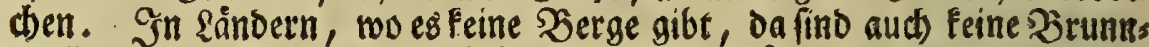
quellen anzutreffen. Illioa fieft man feine SBádbe. Sa foldbe (Seget. Den haben aud Eeine Slüffe, wenn biefe nid)t von entfernten Bergen itg, ren Eauf babin nehmen. Mian betrad)te nur bie platten \&ånoer, als $\mathfrak{Z}$ pulien, Aegupten, und bie Ungrift)en Ebenen, fo wiro man von bies

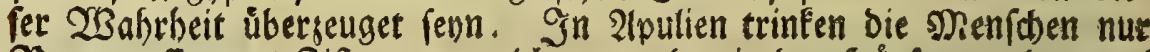
Siegentwaffer aus Bifternen, weld)e entweder in ben Såufern, ober, auf gemeine Foften gebauet, auf Den iffentlichen glärften ftehen. Das Dief) trinket aub Jiegenwaffer, allein aus Bifternen, meiche bie Natur

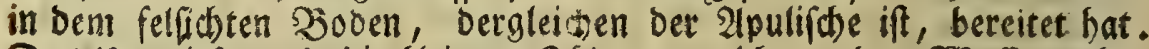
Das Ungejiefer und bie fleinern Shiere, meld)e ju ben $23 a f i e r g r u b e n$

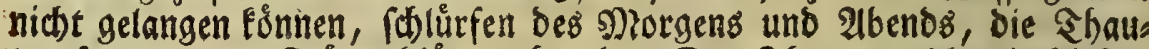
tropfen von Den Fråuterblåttern berab. Der Shau, weld)er in biefem

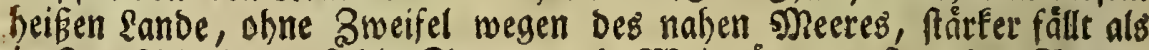
in ₹eutfaland, mußs bie Saaten unb 23 eingårten anftatt bes Regens erquicfen. Die Bartengewåd) fe werden mit Dem faljichten uno finfens

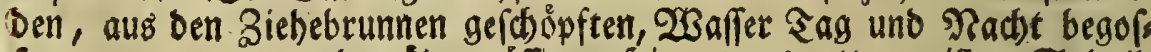
ren, wenn man vor ber übermáfigen b̧ize etwas retten will. Sobalo

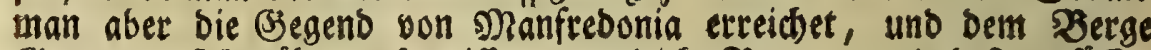
(Garganus fid nåbert, fo trifft man gleidh) Brunnen mit beftem furfen

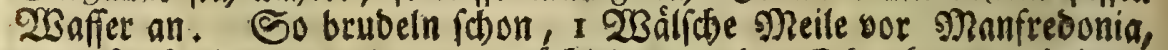

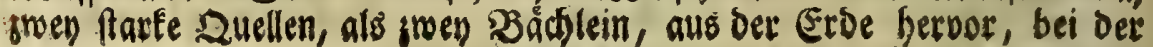
Madona 
Madona di Siponto, an ber Stelle bes alten Gipontum, aus beffen Siuinen erftgemelote Stabt Sganfrebonia erwadjen ift. Sit erwelynte gwen Quellen begeugen burd) ifre Sichtung, baf fie son bem 2 jerge (Siarganus fommen. Dieje orifte gneinung, welche ben Uriprung Det

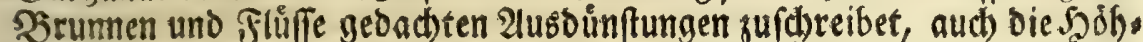
len, bic Silufte und Sandlagen ber $2 e r g e$, fü bie unentbehrlithen

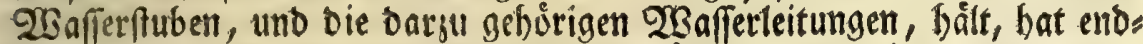
(ich auch bem Siajus feinen Beifall abgendthiget, ber in Den phyficos Qbeol. Betratir. S. 113 , alfo foreiber: IMon wiro ferner fragen,

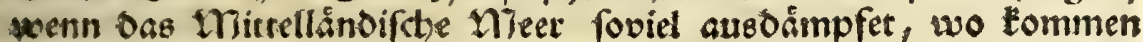
Denn die Dunfte alle bin: It) antworte, fie werben auf die Zerge gerricben, auf ben Seiren uno Spizen Derfelben 34 Waffer ver: bicket, uno alfo ourch die fluffe voieder in oas Meer zurút gee fitbret. Siebe nud bie 162.5 .

\section{$\$ 2$.}

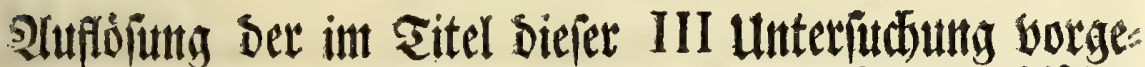

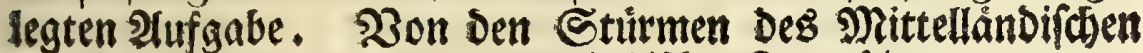
Meeres; won bem unterirrbif(chen Feuer feines \&agers.

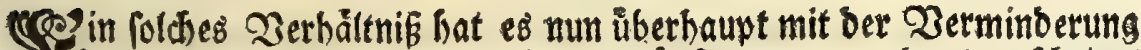

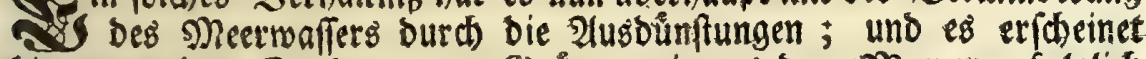
bieraus meines Eradtens zur Gnüge, wie aus ben Meeren, folglid,

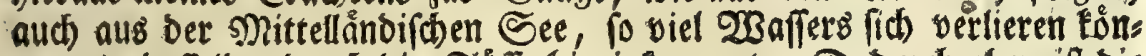
ne, als beffelben burd bie Stuffe bineinfummet. Daburch aber ift bie swente 2 lufgabe, oie id oben (S. 109) vorgetragen habe, aufgelofet, und mein jerfpreden bieffalls erfullet worben. Sch) (t)reite ist gum Erweife bes britten bajelbft yorgelegten Sajes, ben aut Sallen ver. theibiget, wie es aus Raji gebadten Phyr. Tbeol. Zetr. S. 110,

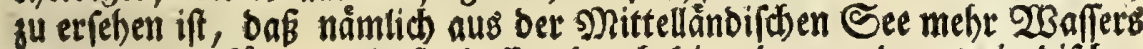
beridsminoen fónne, als fie befien burd) bie obern uno unterirrbificen Stluffe, twie aud) ourd) ben Fiegen empfångt, ber wieber unmittelbar in biefelbe fineinfållt. Daburd) wirb sugleich bie Frage, welde der Begenftano biefer III Unterfuchung ift, unb bie 2luffitrift berfelben aug:

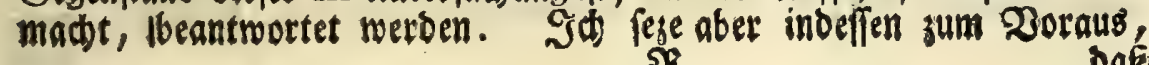


Das es mit Dem reeit ftårfern Einfiffe aus bem Scean burch bie Straffe, nach Dem Berichte bes Jarn. Wrof. Sdwarzen aus dem Jurnerius,

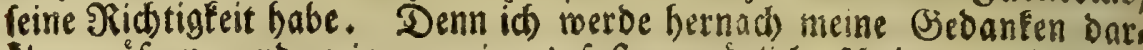
uber erófnen, und zeigen, wie es faft uninuglich (t)eine, bas biefer Eintritt, zu allen Sabrszeiten, in gleidem Maffe vor fïb gehen fónne.

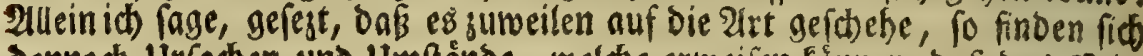

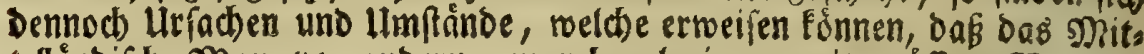
tellånbifhe sheer yor anbern, manchmal einen meit gróffern Vorrath Des 2Raffers, fu feiner Erbaltung vonnóthen habe, als bemielben burds bie Fluiffe sugebrad)t wird. Sh) foreibe foldes erftlich einer befondern

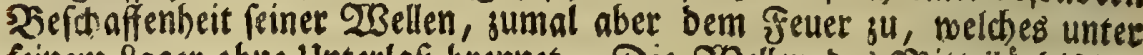

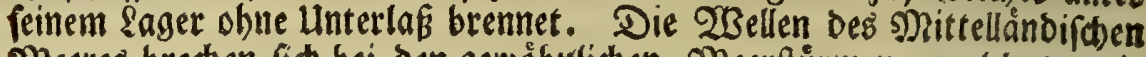

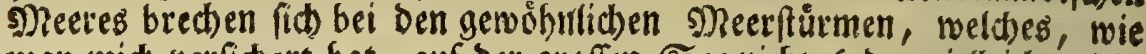
man mid verfichert bat, auf ber groffen See nicht (ooer vielleicht nicht

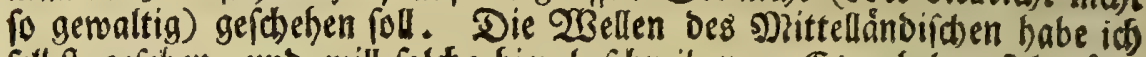
fetbft gefehen, und will foldse bier befhreiben. Es erheben fid nåm. lich bei obwaltenden Inittagstwineen, bie auf biejem meere bie gróften Stủrme erregen, bie Sbertheite beś 2 affers, als toenn jemano eine Menge Shigeld)en fich einbilbete, bie gegen einen Srt fehr fonell und

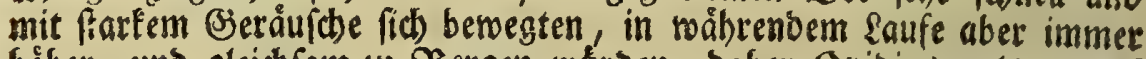
bóber, und gleichfam zu Bergen warben; baber Svioius, als er auf feiner ßeife ins Elend, auf biefem Neete (Trift. 1, 2, 92) einen Sturm ausgeftanden, mit einer ziemlid ertråglidjen Dergrofferung (ibreiben fonnte:

\section{Me miferum! quanti montes volvuntur aquarum!}

ib. v. 19. Allein das \$entametron, und Das folgende Werspaar, ent, Galten eine Sapperbole, weldbe nur Durch bie poetiche Frenheit fann ents f(j)ulbiget werben. 2 Benn nun ein fold er 23 afferberg feine äuserfte Şobe erreichet bat, fo macht er vorwerts einen Bogen, fpaltet noch

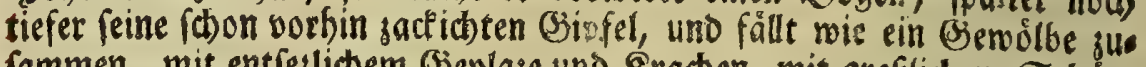
fammen, mit entfeflichem (jeplage und Sraden, mit greflichem Schâs men, und bidstem fowol gerabe auffteigenden Bemoilfe, als gegen ben Ort, wo ber 2 Bind binwehet, Davon jiehendem SRegen von jerfteubtem Wewáfier. 2Beil bemnach bei Seefturmen auf einer Et edfe ces Mees

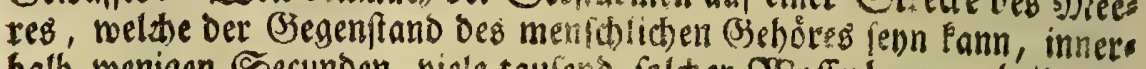
balb wenigen Secunden, viele tauferts folder 2 afferberge, theils wes gen úberwiegender Sd)were, vor fic bin nieberfallen, theils gegen eins

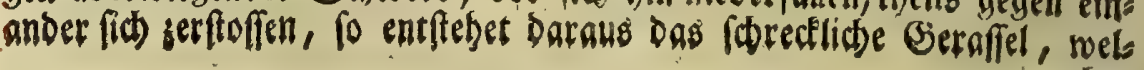


ches zu folder Zeit, auf eine jientliche Entfernung, aus bem Neere bet. nonimen wirb. Daffelbe vergroffert fich, wenn bie Wellen an herbor: ftebende Slippen, an Eteinmende ber Ufer, ober wider ein sgeerges biube getrieber werben, und fich Daran zerifilagen. Co fino bie 25 afs

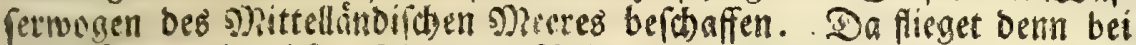

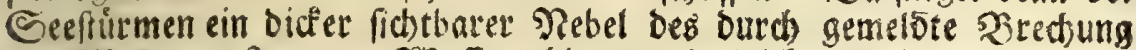

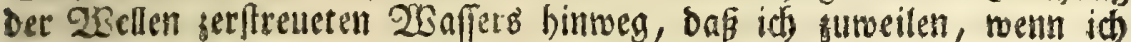
unmeit bes Ufers, me ber 2rind bingog, auf bem sande herumgieng, gan:

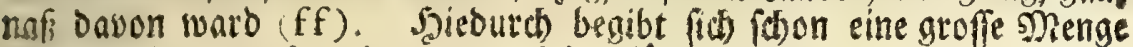
23affers in bie \&uft ; ein anderet Sheil fált allobalo auf oas fefte Eano,

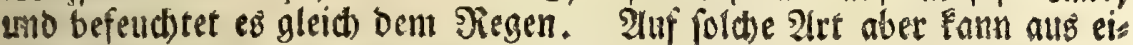
nem Neere fich mebr 2 affers berlieren, als aus cinem andern, bas meder fo vielen, now to beftelten, Seefturmen unterworfen ift.

Die gmente aukerorbentliche Jerminderung Des 2 Saffers ber snit:

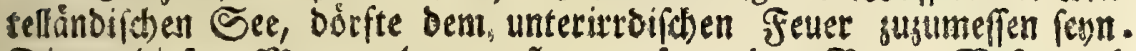
Die an biefem sieere gelegenen flammenipenenben ZBerge, Defuo uno 2letna, bic im s?leere felbft ftebenden, Strongnle (ijt Stromboli) uno

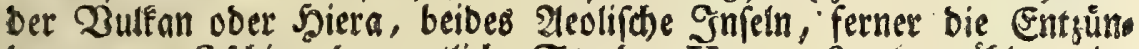
Dungen von Sfotia, Deren etlide Strabo, V, 247 fequ. ergáblet, eitre aber now unter Carolo II fich ereignet, und ben Eroboden, auf eine

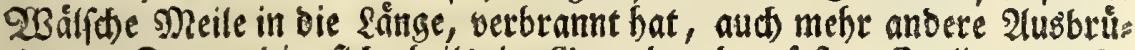
we von Seuer, bie fich theils in segenben bes feften Staliens (gg), theils auf feinen Eilanden zeigen, ia juncilen mitten aus bem Neere

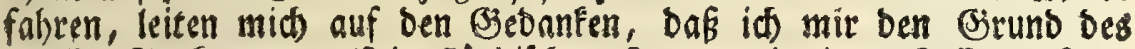

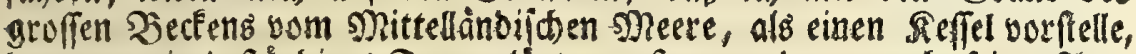
Darunter ein beftåndiges feuer gluet ; weßktoegen benn aud feine $\mathfrak{A}$ luse büftungen ungleid) ftärfer múffen fenn, Denn bei andern sneeren, beree sager nicht to bejhaffen ift. Fine $23 r u n f t$ bie mitten in ben 2 legäis fhen Neere fich ereignet hat, erföhlet Strabo, I, 57: Medio inter Theram et Therafiam loco, e mari flamme emicuerunt per dies quatuor, adeo at totum ferveret atgue arderet mare: exque paulatim elatam veluti infrumentis quibusdam, atque e mafis compofitam ediderunt infulam, ambitu XII ftadiorum (hh). Bunåd)ft bei ber o̊ftichen obern Spize DeE Salbinjel $\mathfrak{R} 2$

cin

(ff) In bem IReete um Epizbergen wirb fur Beit bet Ereftirme biefer auffeigens

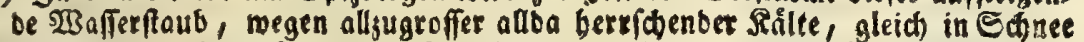
verwanbelt, laut folgendes Beridtes, Der in bem Blichelden Reife nad, Horberl, Reip: $1706,12, \mathcal{E}$. 344, ftebet: Im barten Eturme ftaubet

Die 


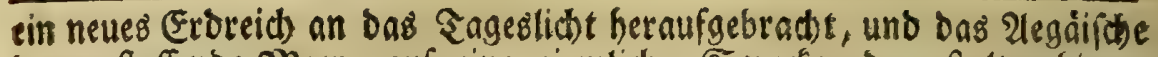

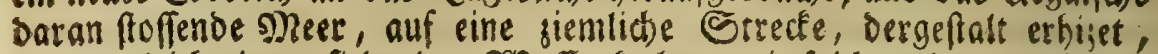
Daß es gleich einem fiedenden 2 affer foshte, toie fol t)es abermal Gras bo mit folgenden 2 Borten angeiget: Circa Methonam porro, in finu Hermionico, terra altitudine feptem ftudiorum egefta eft a flammofa quadam efflatione: locusque is interdiu inacceffus eft ob calorem et fulfureum odorem: noctu autem bene fragrat, proculque effulget et calefacit; adeo ut mare ferveat per Jtadia quinque, $I, 59$. Einen Ausnorf von feurigem Shlams

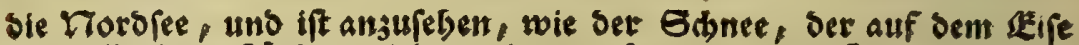
von Winde geftăubet woirs, uno von ferne an ber Luft, wie der Gans ftaubet. WBer fo befhaffene Deerweflen nid)t gefeben bat, Dec fann eir gleiches Echaufpiel bon gebrochenem, und in Nebel verwandelen

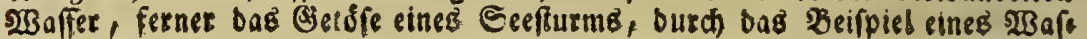

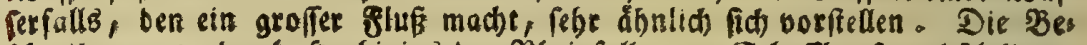

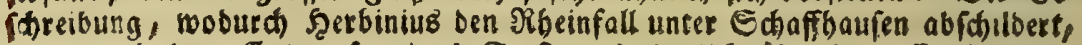
fommt mit bem Entwurfe cines Seefturms ficmith áberein. (Ex fohreibet de Cataraft. p. 214 folgenber (Siffalt: "In has tres rupes altiffinas, in ipfo "Cataract præcipitio, vaftiffimæ Rheni aquæ defuper tanto cum impetu " et fragore boante feruntur, inque eas medias impingunt adeo, ut aqua a ") rupibus quafi repulfe furfum, in modum vaftifinorum maris fuetuum, " afcenclant, iterumque $a b$ aliorun faxorum anguftia repercuffr, et in aerem "2. diffipatæ, craffiffimam nebulam conficiant, ac guttas circumcirca denfiffi"mas fpargant. Hinc ibi æterna eft eritque pluvia, quam protenfa manu, ") et in paludamentis quoque noftris prope advertimus. In quo tam horren2) do Rheni lapfu tantus colluctantium undarum fonitus audittir, ut in riparum 2) anfiractibus eminus confiftentes, boatum quendam murmure coimnixtum, "2 effe attoniti diceremus (mitem alioqui viridantemque ac dulciffimi hauftus "n fiuvium, immania rupium et faxorum obftacula exafperant) trepidique de ") tanto portento exclamaremus: O Domine Dominator! quam admirabile eft "nomen turum in bac terra.

(gg) Dertmutetig ift bie unterirzdifde Entgundung, mit ifren de Pliniuz, $I I, 83$, 5aro. 85 , befhreibet: "F Factum eft femel, quod 97. equidem in Etrufc $x$ difciplinze voluminibus inveni, ingens terrarum porten"tum, L. Marcio, Sex. Julio Cofs. in agro Mutinenfi. Namque montes "duo inter fe concurrerunt, crepitu maximo affultantes, recedentesque, in"ter eos flamma fumoque in cælum exeunte interdiu, fpectante e via Ámi"lix magna equitum Romanorum, familiarumque et viatorum nultitudine. "

(hh) Ene gleiche, oder eben biefe Entguntung unter Dem Megåirchen Meere, bes fciseibet ausfúbrlicher Seneca, Nat。 queft. $I I_{*} 26$ : "Majorum noftrorum "2. memoria, ut Pofidonius tradit, cum infula in $E$ geo mari furgeret, fpu" mabat interdiu mare, et funus ex alto ferebatur. Nam demum prodebat " ignem, nom continuum, fed ex intervallis emicantem, fulminum more, g) quoties ardor inferius jacens, fuperum pondus evicerat. Deinde faxa res roluta, 
Schlamme auf ber Sufel Eubvea beforeibet er, I, 58: In Eubcea ita fe exeruit (terra motus), ut fontes Aretbufa, qua in Chalcide eft, obturati fuerint, qui fons multis poft diebus alia erupit fcaturigine: neque ante dejiit infula per partes concuti, quam biatus terre in Lelanto campo apertus fluvium luti igniti evomuit. Dergleiden Sdlamm, Deffen beifer Bro.

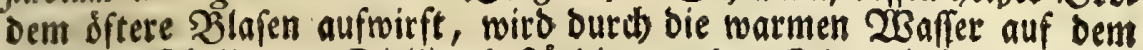
füblid)en Sheile von Sicilien beftanoig aus ber sebe mit bervorgetries ben, wie id relbft gejeben babe. Shier verbienen infonberbeit nod fols I 3

gento

"voluta, rupesque partim illæf $x$, quas fpiritus ante, quam verteretur, ex" pulerat, partim exefæ, et in levitatem pumicis verfæ, noviflime cacumen " exufti montis emicuit. Poftea altitudini adjectun, et faxum illud in ma"gnitudinem infulz crevit., Netuere Brunfen, bie in biefer Begend bes Archipelagi fich von Zeit jue Zeit ereignet baben, werben in Kirch. Mund. fubt. Tons. 1, p. 182 feq. ergăglet. Ith will aus einem bafelbft eingeruid: ten Sriefe des p. Sranc. Jídard, einige Stellen anfübren, weil biefelben

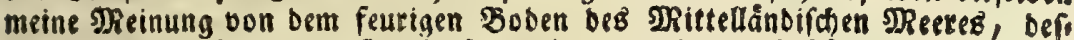

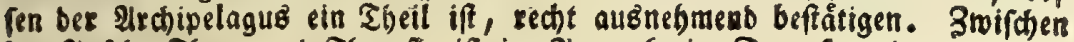
bets Infeln Thera unb Therafia ift im $\mathcal{T} \mathbf{7 2 6}$ ein Dampf, mie aus einem Ofen, vors sReere aufgefabren. Diefes Dúnfen, uno mit fflammen bers

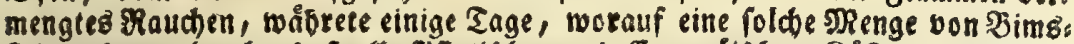

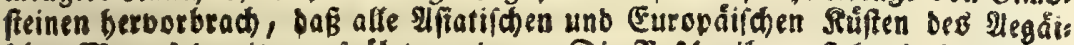

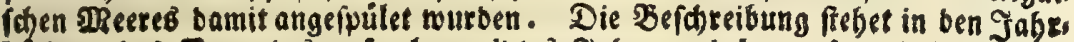
biddern bes Fatonius auf obgemeldetes Jabr, unb lautet fo: "Vapor ex " camino ignis vifus ebullire inter Theram et Therafiam infulas ex profundo " maris per aliquot dies, quo paulatim condenfato et dilatato igniti æeftus in" cendio, totus fumus igneus monftrabatur. Porro vaftitudine terrenæ fub2) ftantia petrinos pumices grandes, et cumulos quosdam transmifit per to" tam Afiam, et Lesbun et Abydum et maritima Macedoniz, ita ut tota fu1" perficies maris his pumicibus effet repleta; in medio autem tanti ignis in3. fula ex terræ congerie facta, infulæ, quæ Sacra dicitur, copulata eft,

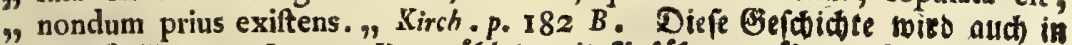
Tournef. Voyage, I, 102 ' $\mathrm{B}$, erfảblet, mit Infúbrung álteret Edriftfelfer,

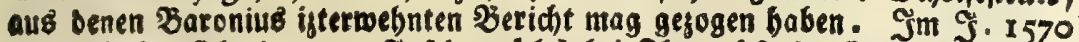
(1573) bat fid) eine neue Jufel gunäh) bei Shera ( fo ift Santerini beift, uns bie Eeftalt eines Şufeifens bat, Tournef. p. 100) aus bet Tiefe bes

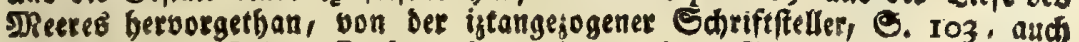
Melbung tbut, Juban. Sircher aber aus gebachtem Briefe bes $\mathfrak{P}$. Richarb folgende $\mathfrak{B}$ efdereibung liefert: "Rurfum alteram infulam huic proximam 9 formatam fuiffe conftat anno $157^{\circ}$, non : minori Santirenenfium terrore, ") cum per annunz duraverit incendium, ut teftantur adhuc quidam feniores, " qui illud oculis confpexere. In medio autem hujus modicx infulæx, quz

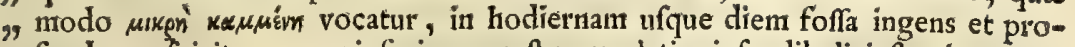
7) funda confpicitur, quæ inferius angurta, paulatim infundibuli inftar in rotung) dun 
getide 20 orte bes Strabo in Setradtung gesogen fu werben, ba ex VI, 274 am Enbe, alfo fatreibet, und meine Zorfellung von bem

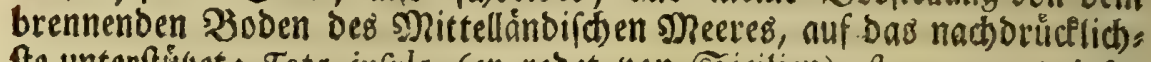
fte unterftúferet: Tota infula (er rebet von Sicilien) eft cava, et infra terram ignis fluviorumque plena, ficut effe diximus Tyrrbenum mare usque ad Cumas. Nod beutlicher ift Das Beugnif, V , 248, To auch gant auf Diejen Sdblag lautet: Probabiliora funt, que Pindarus dixit, ex iis, qua apparent, ratiocinari orfus. Apparet autem, totum maris trajectum, qui a Cumis ad Siciliam usque pertingit, ignitum effe, et in profundo babere cavernas quasdam, et inter $f e$, et continenti conterminas. Soldes fhlieffet er aus ber 2ingabl ber brennenden Serge, und aus ben Ent.

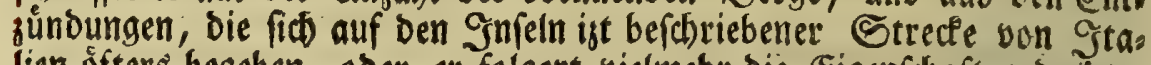
lien ófters begeben, oder er folgert vielmebr bie Eigenfdiaft geonob)ter Szerge und Serter, aus erwehnter $\mathfrak{B} e$ ch affenheit bes Neerbodens: Quamobrem et eam Atna, quam omnes memorant, ofendit fui naturam, et Liparcorum infula, et loca Puteolis, Neapoli, Bajisque propinqua, et Pitbecuse, ib. Eben fo úbergeugend fino folgende 2aorte: Sapenumero etiam in superficie maris, quod eft circa infulas iftas (Eolias), difcurrere flan-

9 dum fe explicat, ex qua tanquan e camino erumpebant ingentia illa faxa ", et fcopuli, qui cineribus comnixti molem illan undis prominentem conftru. " xere. Nunquam auten extingui fubterraneos illos ignes, gui e bitumine g, et fulphuris copia foventur, et interdum impetu maximo erumpunt, con9) Ptat ex calidifimis aquis, qua ad littus maris in extrema auftrali parte in" fulæ reperiuntur, et quibus ut thermis faluberrimis utuntur incol $x$, ad mor", bos ex frigore ortos expellendos. . Mund. fubt. I, I82 k. Die Eiegen nart bes (Eropeche mito biecurd) nidh unfeblbar ermiefen, Denn 2ranfer,

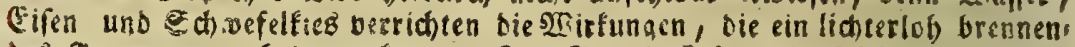

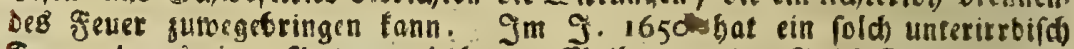
Feuex, ba es einen 2luggang fudte, 4 sieilen von Der. Jnfel Santerini oft

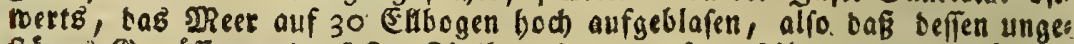
ftumes (serwáfier an bie feften Ibeile austrat, auf benfelben alles verwúfiete, uno fo gat in bem Eeebafen zu Stantia, welcher bed 80 . Meilon entfernt iff, ije Caleren unb andere Ediffe berbrach. Darauf maso bis euft mit eiuem fintenben Diauche, to ben 2ugen facholich war, kiberjegen uno verfinfert;

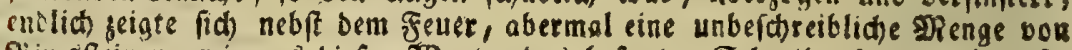

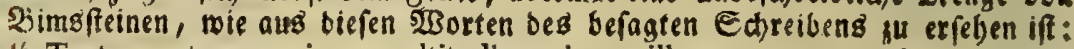
"Tantam autem pumicum multitudinem ignea illa vorago evomuit, ut totam ". pelagi fuperficiem contegerent, ita ut vix wavigio incedere poffet aliquis; "Smyrnas usque et Conftantinopolim delatos fuife, littoraque omnia com29 plevife, certifimum eft. Vis autem hujus incendi prinis duobus menfibus " erat maxima, guandoquidem et bullire vicinum mare infar ferventis ollx , vide- 
fammas animadverjin eft, cum cavernarum, quibus ignis in profundo continetur, meatu aliquo recluso, foras vi prorupit, id. VI, I76. 9) Zarfilius beftárfer enolid burd feine neueften Beobadtungen biefen Berid) Der Alten, uno jugleid) meine Neinung, ber in reidten (S) genden, ober bei ergrúnblichen ३iefen Des Mnittellänoifden Meereg, in Der shat deffen 2 Baffer, burd Deibúlfe eines bineingefenften şermos meters, nach ben SBoden zu, wairmer befunden bat, wie aus reinee Meerge(d). S. 16 , uno Dem Dabei ftefenden (Srunbriffe Der gemadten Dergleidungen, erbellet.

Die befonbere 20 ăme ber Meertuft an bem weftlichen untern Sheile bon Stalien, wo die Pomeranjenbaume an ben ufern fuffe frúcte bringen, weldhe bod tiefer im sanbe fauer bleiben; ferner baf bie (segend des alten \&ucaniens, allwo Đaefum gefanden bat, nod izt juenmal Des Sables 2 lumen erjeuget (biferique rofaria P\&fti, vIRG. Georg. 4, 119) und noch andere biefer Orten angemente Seltenbei. ten bet Ratur, fehe id úberbaupt als 2 Birkungen Diefer getwaltigen un. terirroifwen Defen an, weldbe, beooraus um ben untern weftid)en Sbeil oon Stalien, in fiemlider Menge fich befinden (ii). (Eben fo ur,

theis

"videbatur, et diu no\&uque ingentes flammarum globi, fumique denfifimi 22 acervi, emergebant., Mund. Jubt. I, 183 B. F\& ift auf folche खBeife ber 3̧oben bes IReeres an biefem Drte ein rechte: Feutrfeffel, bef Dab in bemfel,

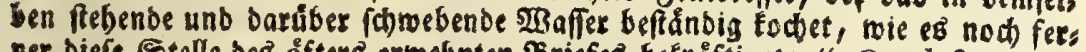

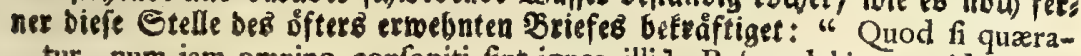
" tur, num jam omnino confopiti fint ignes illi? Redpondebitur, videri ali" quando revivifcere, fiquidem animadverfum eft, multoties illic mare ferve. " fcere, fumumque cum undis attollere, maxime autern hoc anno 1656 , " die undecimo Januarii, et tribus fequentibus diebus. "Stirder an gebach, tet Etelle. Die $23 a b$ beit diefes Beridtes bat eine neue im $\$ .1707$ bei Eanterint ausgebrodene feuersbunft beftåtiget, bie abermal eine neue Snfel

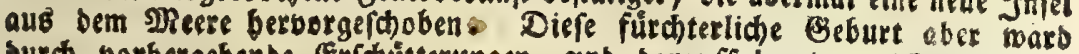
surd vorbergebende Ex[thutterungen, unb Darauffolgenden oicten SRauch),

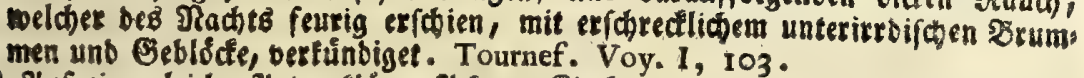

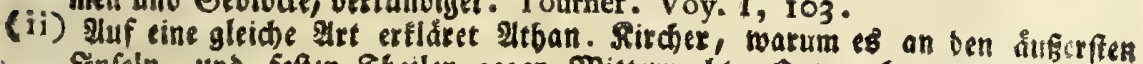
Infeln, und feften Ibeilen gegen Mgitternach, Drte gebe, wo sus Mieer

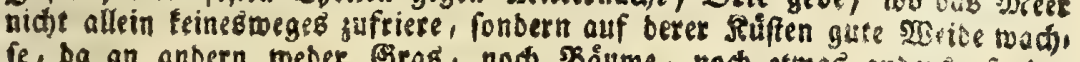
fe, ba an anbern weder Geas, nod) Båume, noch efwas anders, fo bent

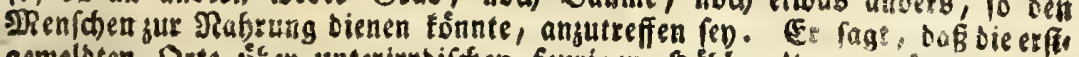

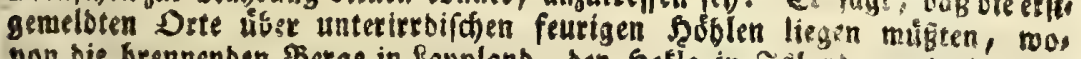
oon bie brennenben Berge in Ravplanb, ber Şefla in Gelano, und ein anbes

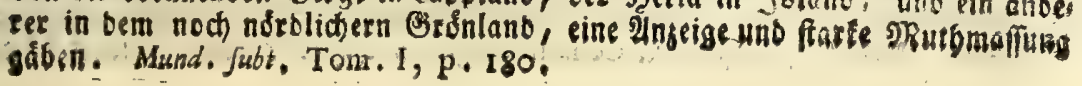


theilet Renbler in bet Sortey. Reuefter Reifen, im LVII Sdreiben.

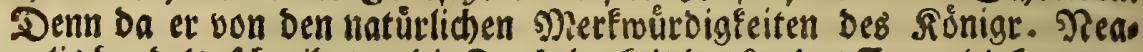

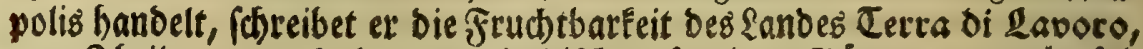
zum Sheile gang red)t ben unterirrbijaten feurigen Biangen fu, mit folo genden $230 r t e n$, welde a. D. 2 I I S. ftehen: Der Defuvius if Dev berumliegenden Gegeno, weegen feines feuers und Erfthútterun gen 3 roar oftmals febr erfatrectlid. Zllein gleidwoie jede Sarbe, fo fthédich fie aud ftheiner, bennodh aud ibren Dortbeil mit fid bringet, alfo trägt oiefer berg ourd die fthwefelithten und falpes trigen Cbeile, tvomit ex bas Lano gleidf fam dünget, uno wegen

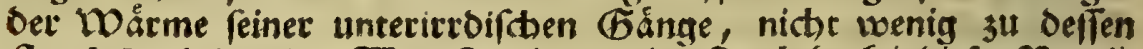
frumtbarkeit bei. Was Rensler von Der FrudtbarEeit Diefer शeaplio ithen (segend melbet, Das weifet ben Seifenden Der Alugerrídein, Das

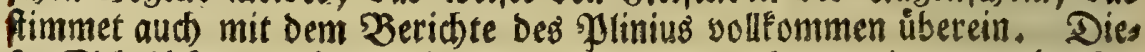
fer Edbriftteller erbebet die Frudhttarkeit von Campanien an mehr Srs ten, wie III, 5, bard. 9: Hinc felix illa Campania eft. Ab boc finu incipiunt vitiferi colles, et temulentia nobilis fucco per omnes terras inclyto, atque (ut veteres dixere) fummum Liberi Patris cum Cerere certamen.

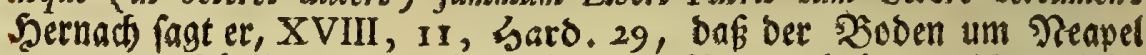

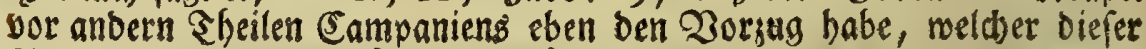
Wroving bor andern \&ånbern gebůhre: Quantum autem univesfas terras campus Campanus antecedit, tantum ipfum pars ejas, que Laborie vocantur, quem Pblegreum Greci appellant (kk). Die Ilriadse ber fo befone Dern Frudtbarfeit bat Rensler fehr wohl eingefehen, weil biefe Biegeno inmendig yoll Shige, und berfelben Eroreid, fo fu fagen, nur eine Schale ift, weldse ourd) bie unterirtbift)en brenmenden (Serovitber, wie auch burch bie feurigen \&aufgráben, to von ienen ausgeh hen, uno roeit

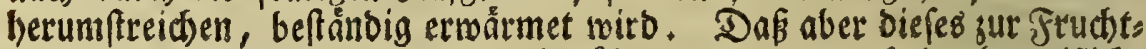
barkeit fein (jeringes beifrage, Deffen ůbergeugen uns, auf eine begreiflidje Ât, Die OBeingåıten, weld)e auf ber mittảgigen und weftliden Seite bes Defubs liegen. Denn die Reben Derjelben faben aufenter ifje Warme von ber Sonne, Das locfere fandidte (Erbreid, auf bem fie fehen, wirb aud) von inmen ₹ag unb Nadbt gebáhet, wie auch mit

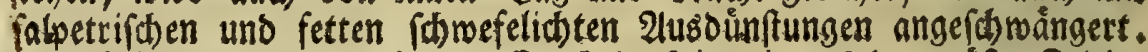

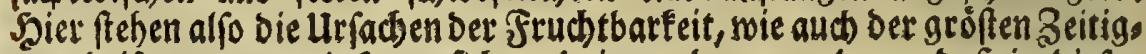
ling beifammen, und fann fich wol niemand verwundern, Dap in biefen

Srati:

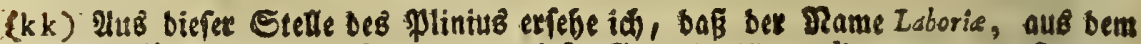
unfeblbar bie seuere Benennung biefer Gegend, Terra di Lavoro, entftanden, fd)on fo alt fen, ấ ex in Cellarii Geogr. ant. eine Stefe verdienet bătte. 
Srauben, weld)e man tor ibermåkiger Súffigleit faum genieffen mag, ber cole Caft augefocht merbe, fo unter bem Tamen Lacrima Chrifi berufhnt ift. 2Senn aber Der feurige 30 oen eines arofien sheils bon

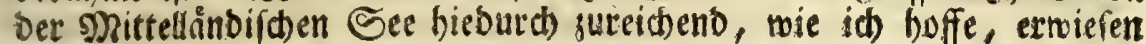

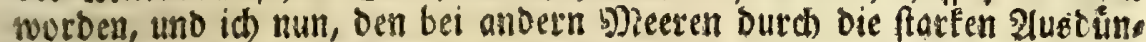
fungen, meldse bie Sonnenbise verurfacbet, wie aud ben Durch bie Win: be beforberten $916 j u g$ Des gneermaffero, mit bargu redye, fo ermefte

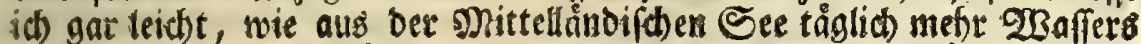
in bie suft verfiegen Fonne, als baffelbe beffen von ben flúffen erfált, und ids verftehe fodann, watum Der Dcean, burd) fein Sereinbringen burch die Strafle, bemfelben einen farten হBeitrag zunemben múfe.

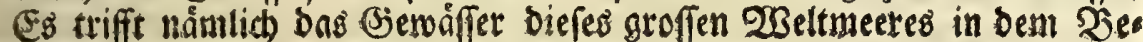

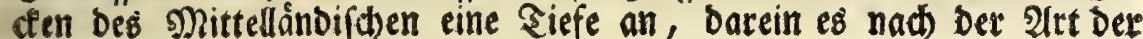
flúfigen Rơrper fo lange rinnet, bis ber 2 bhang aufgeboben, uno bie Sberfiád)e Des 2 Baffers mit bemienigen, fo in ber atlantifót) (See ift, abgegleioet merde.

\section{\$. 3 .}

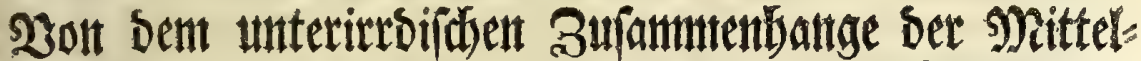
ländiłchen See mit andern MReeren; von Den Seenirbeln. Det Eharnbois bei Sicilien, uno bem SRaelfroom

\section{bei Trorwegen.}

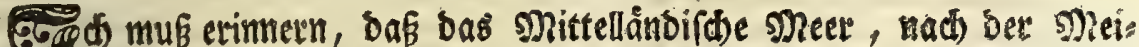

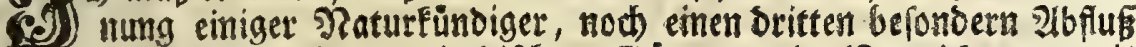
baben foll, ourd bie unterirtbifonen (sainge, mittelf veleber es mit andern Neeren, unb infonderbeit mit bem Dean, furammenbange. Dak es in ben ắlteften Beiten Feine bergleid)en berborgene (Simeinfd)aft múfie gebabt haben, låfit fid faft aus bem Dorgeben bes Brrato ur: theilen, Der beim Gitrabo berfichert, oaf biefeb sneet, bevor bie (Sas bitanifó Defnung entfanben ift, weiter ausgebreitet gewefen, uno Wfügen gemadt babe. Die Stelle ift oben 5.55 angefúpret mote

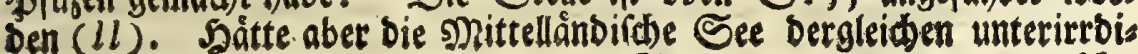

(11) Ein anberes Beugnif befinbet fid 1,52 : "Nam ipforum quoque fenten, tia id abfurdum non eft, ne, fi totum quidem mare noftrum olim lacus " fuit, qui a fluminibus impletus, turgente fuperficie per anguftias apud Calin pem 


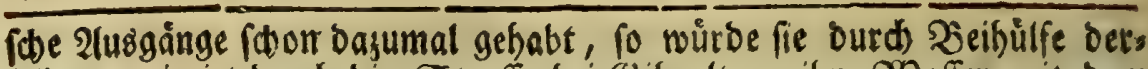
felben, wie ist Durd Die Straffe bei (Sibraltar, ibr $23 a f f e r$ mit bem Weltmeere in gleidbe Soobe gefest, und in eben Dem Stande erfalten ba: ben, in weldem wir biefelbe gegenwártig feben. 2llein ids bin nicht in Abrebe, bak bergleiden unfidatbare Wereinigungen biefes sieereg mit Dem Scean, erft nad) Der Zeit haben erfolgen fơnnen. Denn es bủnft mid) Eeinesweges unwahridbeinlid) zu fenn, Daß Die \&agen ber verbrenn: lichen Materien, Daran bie Feuerfpenenden 2 erge jebren, viele Seut: (d)e Meilen, ja ganje Tagereifen, unter ber Erbe fortlaufen. 2Benn nun eine foldbe \&age, bie vielleid)t mit bem einen Enbe bis in ben Ocean

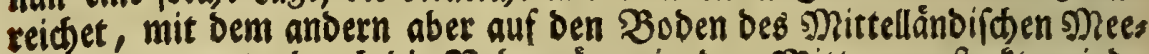

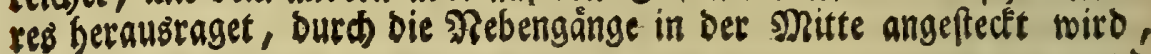

pem eruperit, veluti per catarrąas, ac magis magisque auctus, cum mari 9. fucceffu temporis magis fubinde confluxerit, et in unam concurrerit fuper"ficiem, ac qualitate maris prævalente, ipfe quoque maris naturam induerit $f \cdot n$ 30linius (a)reibet auf gleid)en Sd)log: "Herodoto quidem fi credinus, mare fuit fupra Memphim usque ad \&thiopum inontes: itenrque a planis "Arabiz. Mare et circa Ilium, et tota Teuthrania, quaque campos intulerit

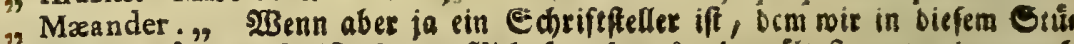

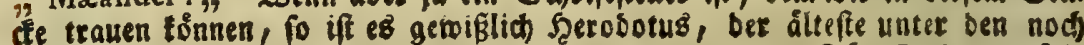

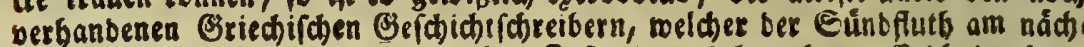
ften gewefen, und alfo von Dem alten Zuftanbe bes bewobnten Erobobens ain grúnblichfen fhreiben fonnte. Daber wird as von Ecaliger bem jưngern gan redit fo abgefdildert: " Scrinium originum Græcarum et barbararum, ", auctor a dockis nunquam deponendus, a femidoctis et prdagogis et fimiolis

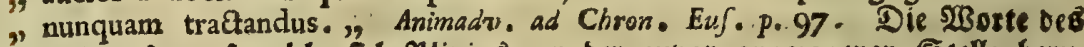
"Serodotus, auf welde fich Plinius an ber juvor angezogenen Stelle berus fet, lauten, II, 10, alfo: "Hujus igitur regionis, qux a me dißa eft, , pleraque pars (ut et facerdotes ajebant, et mihi ipfi effe videbatur) acqui. "fititia eft 2 gyptiis. Siquidem quod inter prædiatos montes, fupra Mem" phim urbem pofitos, mediun eft, videtur mihi finus maris aliquando fuife, ". quemadmodum ea, quae funt circa Ilium, et Teuthraniam, et Ephefum, et 39. Marandri planitiem, ut hæc parva magnis comparentur. "Oaxinnen irect nue 5"

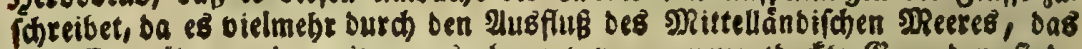
ebebeffen bober unb meiter aug̈gebertet wat, neuentbecte (Eegenden fint. Denn ex fhreibet an biefer Stelle, unb vorber noch ausbructlicher, bas bas ebemals pfüfige 2legnpten eine Babe Srg Filftromes fey: "Primum i) mortalium regnafe Menem, ac fub eo omnem Aegyptum, prater Thebai3. cam provinciam, paluftrem fuiffe; ex eaque nihil eorum; quæ nunć funt: "fupra ftagnum Myrios, extitiffe: in quod ftagnum a mari per flumen fe-
" ptem diebus navigatur. Atque de regione bene mihi dicere videbantur; n ptem diebus navigatur. Atque de regione bene ashi dicere videbantur; 


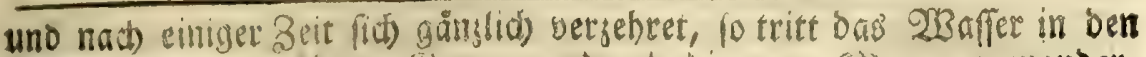

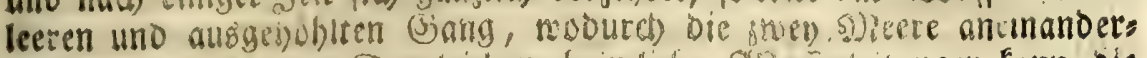
gebinger weroen. Dergleid)en beimlidie 23 ajerteitungen fann bie

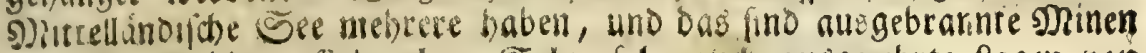
bon Stuntohlen, Eropecte, Sd)wefel, auth ausgejetrte Sagen oon

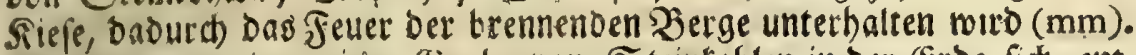
Zienn etwan sine reid)e (Srube bon Steintohlen in oer (srbe fid ents

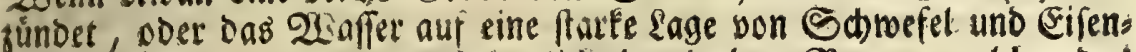

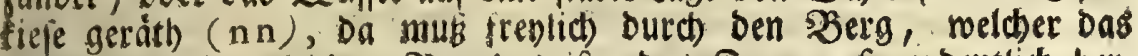
Dampflod eines jotden Dranoes ift, Das Feuer auferorbentlid ber: aus toben. Es boren aber aud $\mathfrak{F e r g e ~ a u f ~ j u ~ b r e n n e n , ~ w e n n ~ b i e f e ~}$

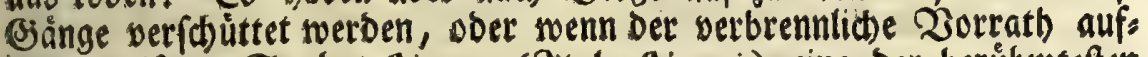
gegebret ift. So bat Lipare (Stal. Lipari) eine Der berúbmteften 2 Aleoli.

2, manifeftum enim eft eî, qui, fi antea non audierit, tamen infpexerit, (mo"do fit folertia præditus) Aegyptum, in quam Græci navigant, acceffionem "effe terræ, ac fluminis donum: quin etiam loca, qux fupra ftagnum hoc "funt, ad trium usque dierum navigationem." Diefes (pred)e id), (Wheinet

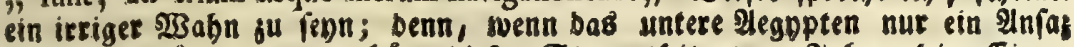
bom Pil måre, marum båtte biefer Strom feit 2000 Jabren feine Eigens

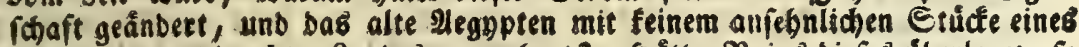
neuen beroorgebrachten \&anbez wermebret? Såtte Rajus biefez úberleget, fo triebe et bie SReinung Det Plegpptiet, DeB Şetodotus, bes Strabo (XII, 536),

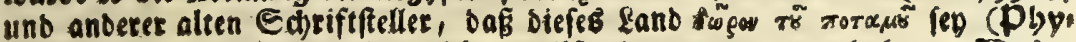
fico, Cbeol. 498) vielleicht nic)t fo eilfertig angenommen baben. S্Sas ex a.b.f. S. aus bes Eeneca Nat. qu. VI, 26 (Diejes uno Strabo, I, 37, aus

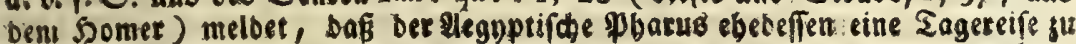
2Baffer, ober nod) mebr, von bem feften Ranbe entfernet getwefen, bas tann

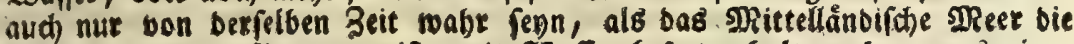
Begeno, wo ift 2legopten ift, mit SWaffer befegt gefalten, bebor es einen 2uøfuß burd bie Etraffe exbalten bat. t Sieb bie $\mathfrak{B}$ etbefferungen am Enbe.

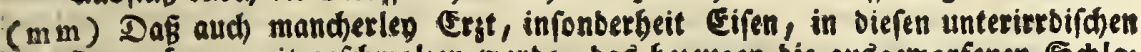

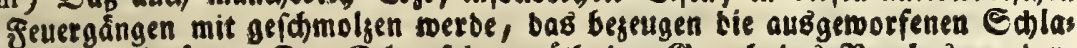

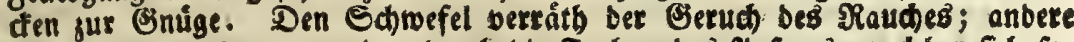
sineralien rerben angezeiget burd bie Jarben bes elnfases, weldher fid for wol an ben felfen ber feurigen Edilüne, als, auf ben berausgef(t)leubers

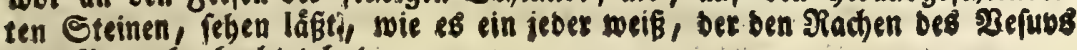
ober Itetna beobachtet hat.

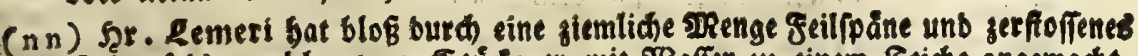

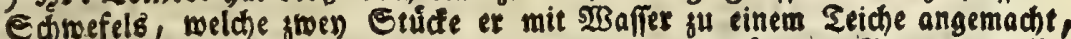

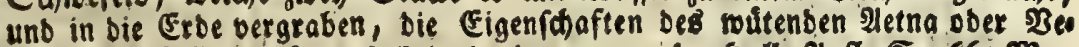

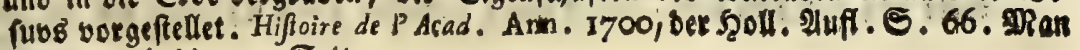
berebe auch bie 133 Erite. 
2leolifchen Infeln, ehedeffen feurige und raud)ende Edblinoe gehabt, weil bie \$yoten biefelbe ju einer 20 ereffatt bes 2 ulEans gemadt, uno (Elaubian, Conf. Honor. 3, 196, nod) (d) reiben fonnte:

\section{Ignifuisque gemit Lipare fumofa cavernis.}

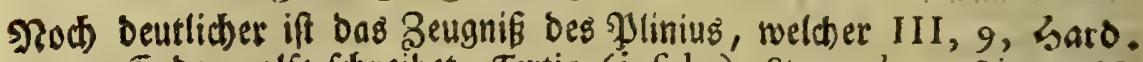
14 am Ende, alfo forecibet: Tertia (infula) Strongyle, a Lipara $M$. paff. ad exortum folis vergens ( 0 o), in qua regnavit Aeolus; que a Lipara liquidiore flamma tantum differt: e cujus fumo, quinam flaturi fint venti, in triduum predicere incole traduntur: unde ventos Acolo paruiffe exiftimatum *. Des Strabo Berid)t frimmet auch) ỉberein, welder VI, 275 , von biefer Sinfel (priø)t: Agrum babet fertilem, et reditum ex me-

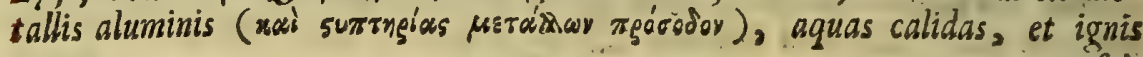
exppi-

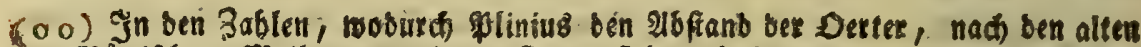
Rơmi(chen Meilen, anzeiget, finben fich now bier und ba unrid)tigfeiter,

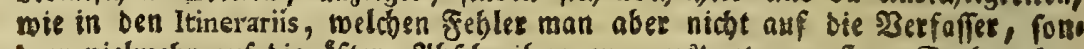

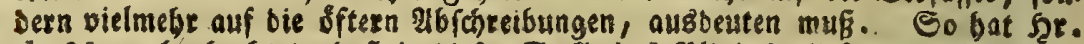
de Marca beobachtet, bafi in biejer Stelle bes \$linitz, " fumen Alba: Em, poriz: - - Flumen Tichis. Ab eo Pyrenza Venus in latere promonto"rii altero, XL. M." (III, 3, Hard.4) Die Zabl Der \$Reilen gu grof angegeben werbe, uno fer vermutflid bas I nach $\mathrm{cem} X$ in $L$ verwandele

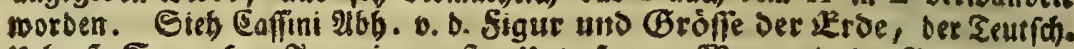
Heberf. S. 206. On meiner erften unterf. vom 刃Reere, in ber Inmerf. (c),

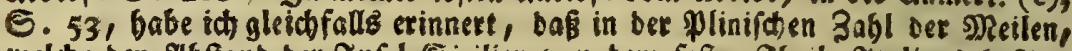
toelde ben Ibftand ber Infel Eicilien von bem feften Ibeile Jtaliens beftim? men fol, ein Caufens weggetommen fey, welches gar leicht gefoben fonn te, ba etwa bas M boppelt geftanden, ober nut ubex einem M. jweb Strichs gen gelegen, anb entweter biefe, ober bas eine M, vermifit worben, weld) Stefle Sarbuin nid) follte ofne \&gnoung borbeigelaffen baben. In ben biet angefúbrten $\mathfrak{B}_{\text {Brten bes }}$ pliniue, Strongyle a Lipara $M$. pafs. fteffet audi),

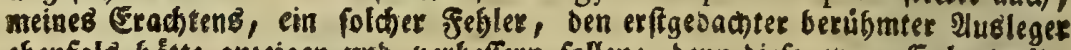
ebenfale Gätte anjeigen und verbefern follen; Denn biefe zwey Enlande lies gen wol eber 20000 , als nue 1000 Echritte, voneinanber ab Buenaro fes

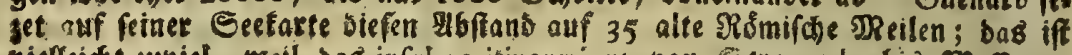
siefleidft suviel, weil Das infulare itinerariun1. bon E trongnle bis sopeffana, mit giemliber Hebereinftimmung oet beften neueen Seetarten, nux C C XXX tadia angibt. Eich Cellar Grogr int in Der Mtbandi. von Den 2leoliphen

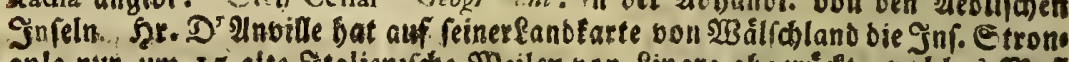

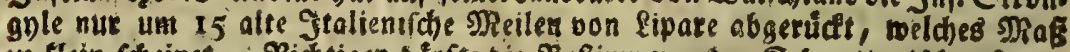

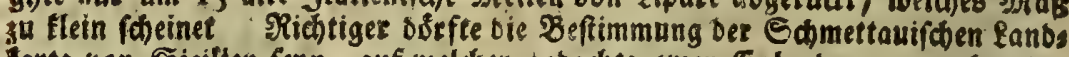

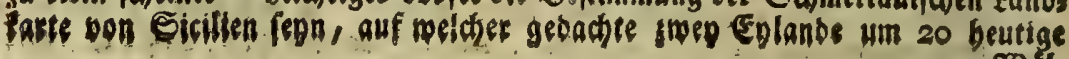




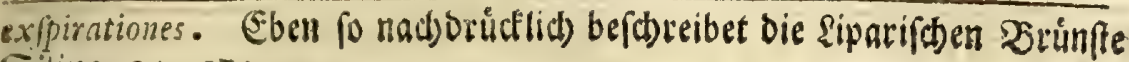
Siliue, 14, 57:

Nam Lipare vaftis fubter depafta caminis

sulpbureum vomit exefo de vertice fumum.

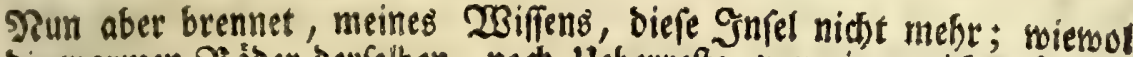

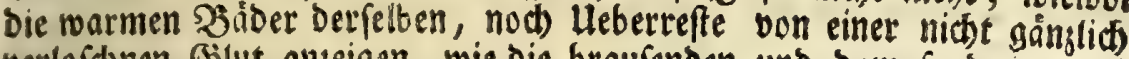
verlofd)nen (silut anseigen, wie bie braujenden und bampfenben, aud wol fiammenden, Defnungen ber Jolfatata úber Dojzuolo ( forum Vuls cani Strab.) annoch beutliche Fennseichen eines ehemals ftårfern,

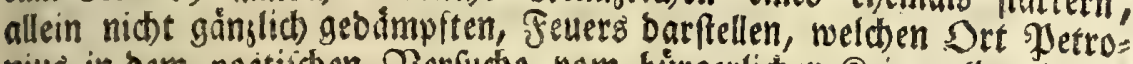
nius in bers poetijhen 2 erfuche yom burgerliden Friege (Der Seips. Iluf. von I73I (5. 147), beffer aber 2tthan. Sircter, Tom. I Mund. fubt. p. 178 , uns Fensler in ber Sortfes. Teuefter Reifen 3

vot

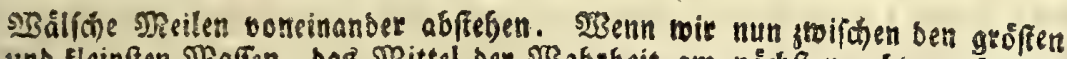

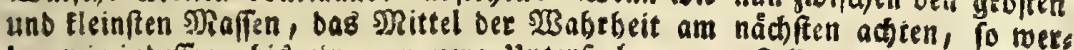
ben wir inbeffen, bis eine genauere unterfuct)ung angefelft merbe, am ficters ften geben, wenn wir ber Deftimmung beg fern. Srognarb folgen, weld)

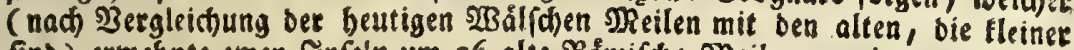

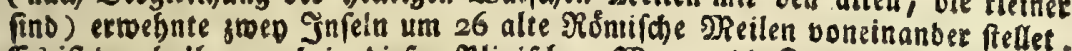

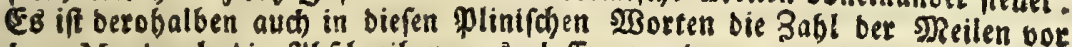

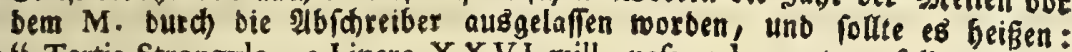
- Tertia Strongyle, a Lipara XXVI mill. pafs, ad exortum folis aefivum "vergens. " Daz eingeíhaltete aftivum muß́ bie gwepte untic)tigfeit biefer "Ërelle, auf eine nod fo jiemlich ertrăglice 2trt, berb effern belfen. Denn eś liegt bie Injel Strongyle von \&ipare eber norboftwerts, ja faft norbnorooftwerts, als gegen SDorgen. Diefe Stellung ift auf Der Eeetarte von Eurenarb, auf bet

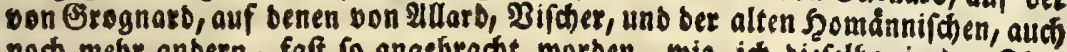
noch mebr anbern, faft fo angebradt morben, wie id biefelbe in Der Sbat

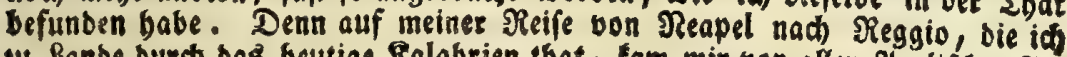
fu Eanbe burd bas beutige Jalabrien tbat, fam mir vor allen शeolif́nen In felin, ber bobe כoerg oon Etromboli, mit feinem raucbenben Sipfel, juerf́

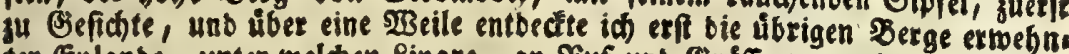

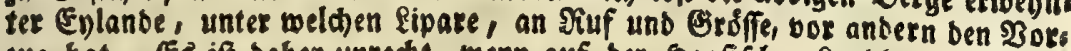
gug bat. Es if baber unrecht, menn auf ber Saafifhen lanblatte von Eus

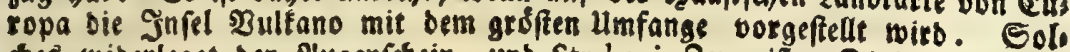

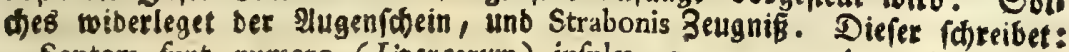
"Septem funt numero (Liparcorum) infula, quarum maxima eft Lipara, "Cnidiorum colonia, VI, 275. "

* Die legtern 23orte biefer Stelle gebogren nicht melte zu meinem Vortrage;

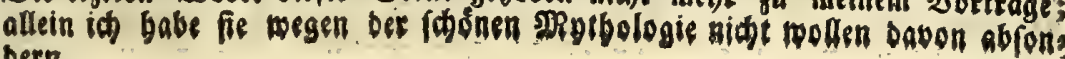
bern. 
bon ber 353 S. an, beforieben haben. Seine beftalt, wie aud bie nodh übrigen Dampf: und Feuerlober, fino gemiffe Spuren eines ehes Deffen weit heftigern unterirtbifd)en Brandes, weldes aud) Der Name campi phlegrai (brennende (⿹勹geno) beftåtiget, moourd) bie Alten dies ren Strid) von Eampanien verftanden baben, wie aus ber Stelle bes Plinius etbellet, bie S, I 36 angefúbret worden.

2tthan. Sircher bat allentbalben auf ber Sberfläd)e biefer \&anbs (t)aft, \$ierfmale einer ehemals weiter ausgebreiteten Ent jưnoung beobs ad)tet, uno mit biefen 20 orten angegeiget: Tota ubique Campania in fu. perficie antiqua ejusdem conflagrationis gerit veftigia, folo paffim arido, cineris et pumicis inftar, et pulvere, quod puteolanum vocant, carbonibus vivo faxio conclufis. MvNd. SvBT. Tom.I, p. 177. Soldes fen aud nicht ju bewunbern, fprid)t er gleid) Darauf, weil cin groffer Striक von Stalien voll Samefels ftecke, beffen lleberflus fich nod alenthals ben, Durch bie vielen Sd,wefelgruben, uno Dergleiden Brunnen, Dar,

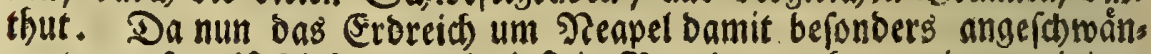
gert geweren, ift biefe Ssegend einft in STrand gerathen, wie bor einigen Gnbren eine Strece bes Eilandes Ifthia, aus gleicher Urfache, bom Feuer ergrifen und verjehret worben. (Sleid)wie aber hier bie Żenents

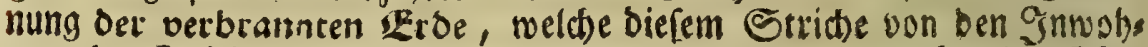
nern ber Gnfel gan; redt beigeleget worden, bas 2tndenfen ber Shat erbålt, fo beutet allbort ber ?Rame, campi pblegrei, unftreitig an, was in ben ålteften Beiten, in einem grôffern Sheile bes umliegenden fefter sanbes mus vorgegangen fenn. शach einem nut to fdlechthin vorges ftellen Entwurfe von ben brennenden Bergen, iftes bod leidt $a b j u f e s$ ben, mie Flammen mitten aus bem Meere berausfahren fönnen. Diefes gefbieft, wenn eine angeftedte zage bon Sdimefel, Stein: tohlen, ober anoern Erbhargen, ihren 2lusgang in Das Meer gehabt,

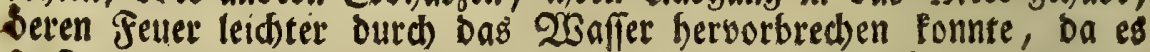
fonft, etroa burdh einen langen Umidweif, nad ber Defnung eines ent:

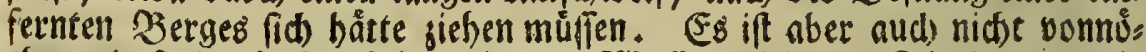
then, bak eine foldbe mine bis zum $23 a f f e r$ reide. Sie fann nur in einer mittelmåsigen Siefe unter Dem fager Der See brennen. Fine plósliche Bermebrung Des Geuers fprenget Den झeerboben fo leid)t auf,

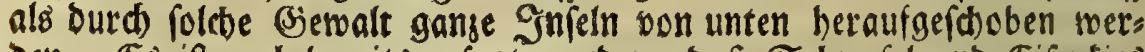
Den. Eg ift audb bereits gefagt morden, Daß Schefel uno Eifenfies

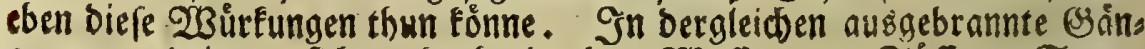
ge nun, oringet fid nachgebenos bas Waffer son Fluffen, Seen, 


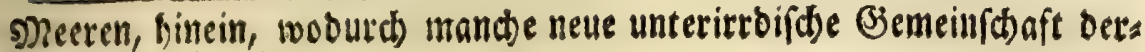
felben entffeben fonn.

Der nambafte Meerwirbel bei Meffina, ben bie 2llten Charybois gebeißsen baben, gibt nach einiger Naturtúnbiger Meinung, (Der i is eben nidht alliufehr anhange, Diefelbe aber gleidnol nicht ganzlich vers werfen fann ) eine Spur foldher beimliden Yereinigung bes mittelläts birdsen NReeres mit cinem andern, und vielleidt mit bem Dcean felbft.

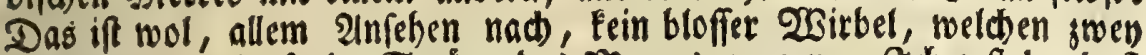
gegeneinanber laufende Stróme bes Meereo erregen. Tot geftebe, Daß eś Dergleichen in Dem Mittellåndifकen meere gebe, wie in anbern, Da

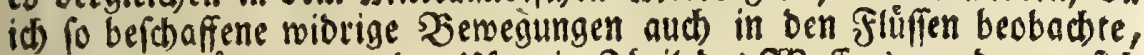
menn bei Srimmungen ber Ufer ein Sheil bes 2 Baffers gerabe bor fich

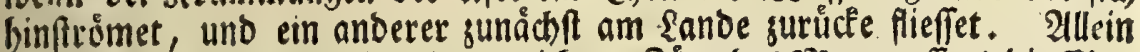

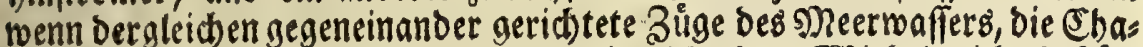
rnbois verurfacten follten, to bliebe vielleidt ber 2 sirbel nicht beftane big an einer Etelle ( $p p)$. Wiele bilben fich alfo vielmefr, an biejem Srte, ein wirklides Sod in ben Meerboben, und einen 216 fall bes 20affers in unergrundiche Fiefen, ein. So wirb uns auch in ber

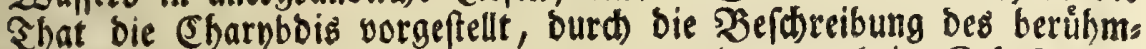

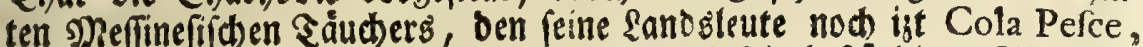
D.i. Den Vielas Sift, nennen, weil er burch jein beftänbiges 2 andeln

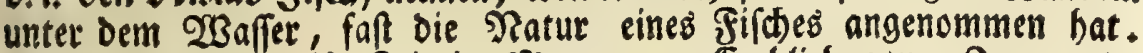
Ex brad)te feine meifte Seit im झeere gu. Er blieb ganze Sage unter bem $23 a$ fer. Er năbrete fich mit Murdetn, und andern roben Fi: (d)en, befand fid aud beffer Dabei, als bei warmer Soft. Eine fers nere 'Nadrid)t von biefem Menfinen fann in Kirch. Mund. fubt. Tom. I, p. 98 , nadgef lagen werben. Er beridtete nun nach ber

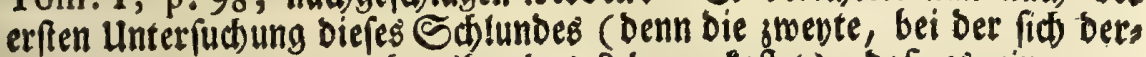
felbe zu weit gewaget, hat inm bas seben gefoftet), baf es ein uner:

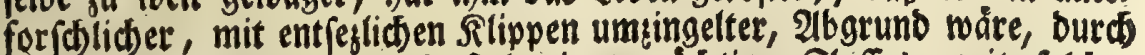
weld)en Das 2 Baffer in Beftalt eines mád)tigen Fluffes, mit polder

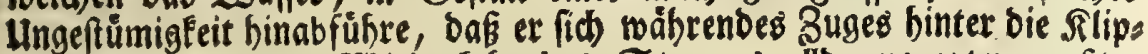
pen legen, unb bie $23 i e b e r f e b r$ bes Stromes alloa ermarten mußte, wollte er anbers yermeiden, in ben 2borund mit geriffen zu werben.

Dies

(Pp) Eo urtheilet aud Mtban. Firder, Tom, I Mund. Subt. in bex Fefdreifung biefes $\mathfrak{B}$ isbels. "Non ignoro, ppridt et p. 102 , multos in contrarios " fieti fluxus fibi obvios, quorum occurfa zqux coscervate in altum extol- 
Diefer (Sserudite bebartet nod) zu Meffina, nidbt nut unter bem gemeis nen Manne, ronbern aud) unter ben Sielefteten, und grundet fich auf bie 2luffage besienigen, welder isterwehnte $\mathfrak{B}$ ef(haffenbeit bes Drtes relbft ange jeben hat. Rircher bejeliget in gedachtem s Budbe, p. $99 \mathrm{~B}$,

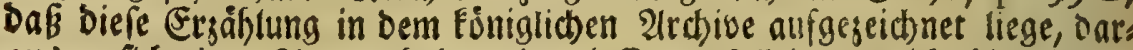
aus er fïh einen 2 lusisug habe geben laffen. Illein was ich bier forei be, bas babe id entweber felbft beobadtet, ober von ben seffinefern múnolich empfangen. Es liegt biefer 2Birbel gleidf auker bem See bafen, vor Der Feftung, uno fönnen bie Sreife, welche bas Neer zur Jeit ber Einfahet bafelbft mad)t, wie aud) Daś 2lufwallen, fo bei bet

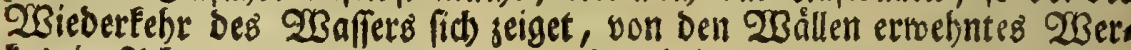
fes in 2 (d)t genommen werben. Slls bei ber vorfegten Belagerung von Meffina, bie Spanier ein mit Şolje belabenes Jabrjeug, Das in

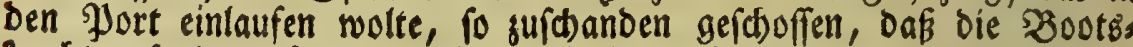
fnedte, to barauf waren, fich auf einem siaden retten musten, fo

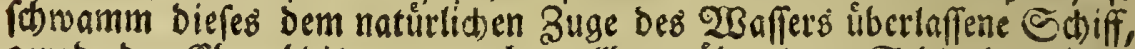
gerabe ber Sharnbois zu, madte alloort über Dem Sdlunde einige

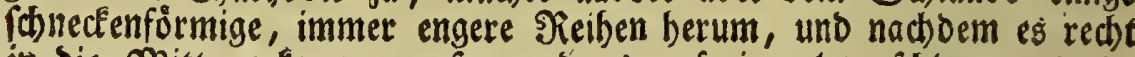
in bie Mitte gefommen, fo waro $\mathrm{es}$ auf einmal verfhlungen (qq). Deffen verficherten mid) fowol bie ₹eutichen Soldaten, als bie şuts: ger von Meffina. Diefe haben aus den Scáufern, weldbe um den Seen bafen liegen, und ein balbes simpfitheatrum oorftellen, istgebadtem reltiamen S

9, lantur, uti in nullis non maribus contingie, effe Qum tam infolentem contu"liffe : fed fi hoc, cur temper uno et eodem loco hujusmodi maris ebullitio? "cur non in alia quavis freti plaga?",

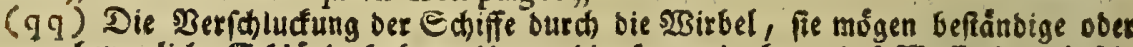

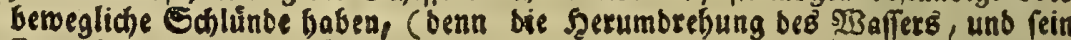

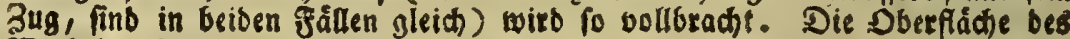
Birbels ift gegen bie 2 Ritte allemal tiefer, welches aud) bei einem groffen

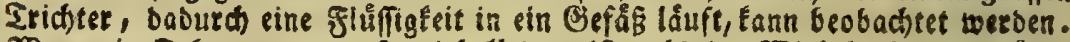

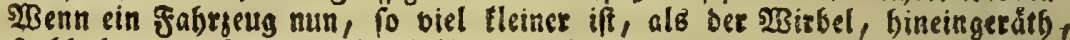

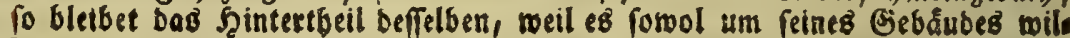

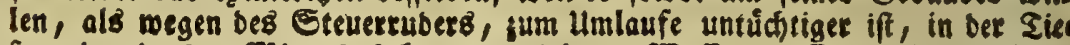

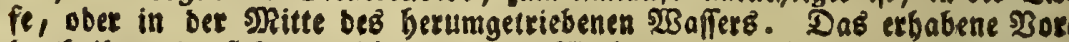
bertbeil wendet fid inzwifhen nod eine Siseile berum, alfein eben baburd be

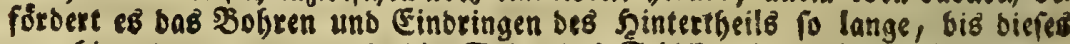
gar binuntergezogen, uno bie: Epize bes Edjiffes. bitumelan geffellt wiso: ba ift bie ganje 2 Berfentung vorganben. Da fánt vor allen ter Eteuermann 
m. Fin foldber Kachen mus nun auch bei eben biefer Snjer, ant fuffe bes yortagenden Berges Saurus, Darauf Saormina (weilano Tauromenium, liegt, offen fehen, weil oas 2 Baffer gu getwiffen 3 citen, eir entfeslid) (Sebrúlle bafelbft unter ben Felfen vollbringet. Finige fino bet Q) Reinung, aud etlidbe unter ben alten baben es allbereit, fich alfo yot: gebidet, bict fáme Das 2 Baffer wieder Gerauf, fo bon der sbarbbo is

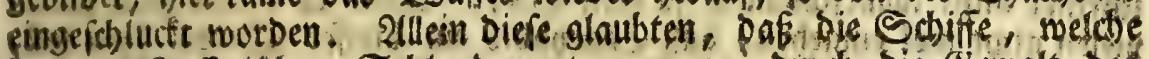

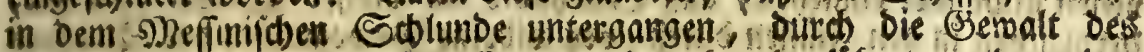
Etramo nur unter bem 2 bafer von oben berabgefubret, und an ben

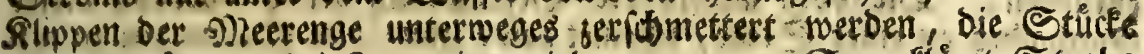
aber fonnaimmen bei sadrmina mieber empor. So ertáret Strabo bie Beforaffenbeir diefes 23 afferwirbels, VI, 268: Demonfratur paulo ante eam arbem (Meffanam) in freto chargbdis profunditas quadam prodigiofa, in quam aftus freti, ob naturam loci, facile abripiunt navigia in verfejcun circumagitatione et fiuctus procella magna; quorum abjorptonom et difipatorum fragmenta ad litus Tauromenitanum devolvuntur (rr). pacatus fidreibet in panegyr. Theodor.c. 26, auf gleiche altes chargbdim loquor? que quum plena navigia forbuerit, dicitur tamen rejeftare naufragia, et contortas fundo rates Taurominitanis litoribus expo-

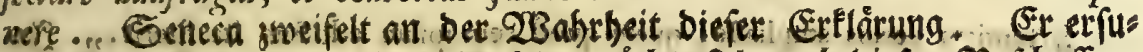

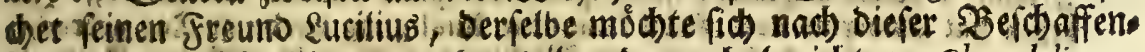
Beit gehauer ettunbigen, und es ifm barnad bericten: cbargbdis an respondeat fabulis, fino reine 2 Borte im 2nfange bet LXXIX Epift. Bew cribi mibi defidejo. Et $j$ forte obfervaveris (dignum eft autem, ut ob-

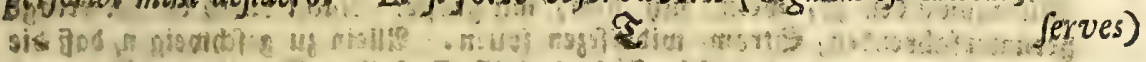
(ก).

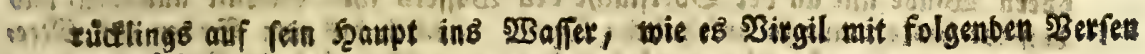
ausocuctet:

\section{Wismatif - - pronusque magifter}

Volvitur in caput. Aft illum ter fluctus ibidem

Torquet agens circum, et rapidus vorat aquore vortex.

Aes. 1, I19. Eine anjiebende Seaft fpuret man fobon bei ben stsiebela it

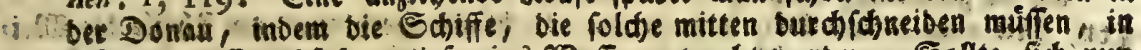

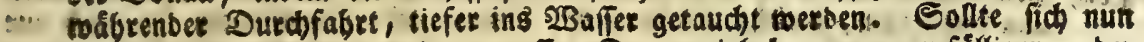
-... ein tleines Jabizgeug in einen groffen Donaumirbel wagen, fufálliger, ober

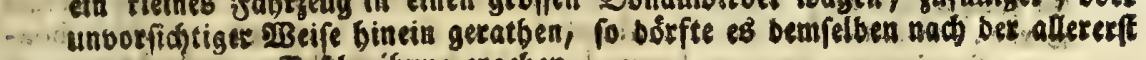
Is worgetragenen 5ef breibung ergeben wi

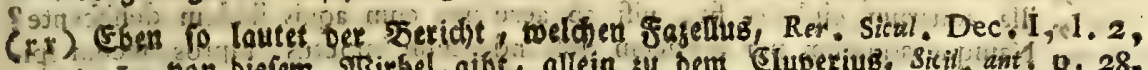

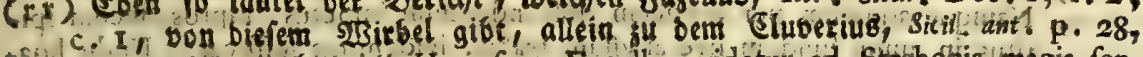
- folgenbes anmarfet "Hæc fane Fazellus videtur ad Strabohis mais fen- nogiti ee 
ferves) fac nos certiores, utrum uno tantum vento agatur in vortices, an omnis tempeftas aque mare illud contorqueat? et an verum fit, quidquid illo freti turbine arreptum eft, per multa millia trabi conditum, et circa Tauromenitanum littus emergere. Das bie 23 inde fur fich, einen to bef(d)afo fenen, unb fo lange beharrenben, 23 irbel follen erregen fónnen, bas

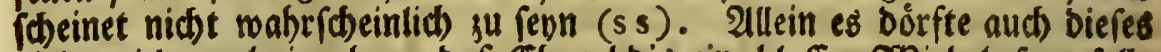
bielen nid)t mol eingehen, bas (Eharybbis ein bloffer 2 Birbel feun foll,

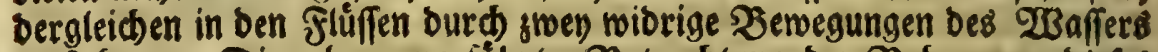

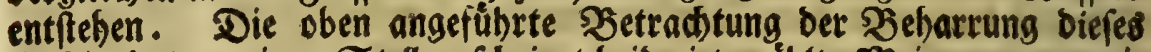

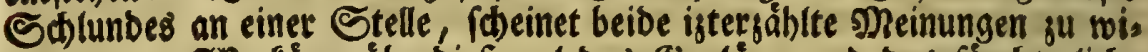
berlegen. 230 fåme úberbieß Brúllen bei ₹aormina ber, wenn DaB $\mathfrak{Z}$ Baffer burd gemiffe Mundun gen nidt wirflid irgend unter bie Erbe gieng, unb an biefem Srte

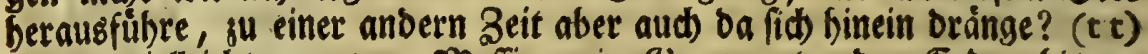
Sollte vielleidht nur von Meffina ein Bäng unter ber Erbe, bis an gebadtes Jorgebirge, fid) erftrecten (u u), ba foinnte man feine urfache bes fo gewaltigen 2lusfalles vom $23 a f f e r$, bei etwebnten Si. cilis

"tentiam verbis ampliaffe, quam quod rem ipfam edoctus ita fuerit. beffen bat (luberius boch feloft feine neue Husilegung babon an ₹ag gebradi)t,

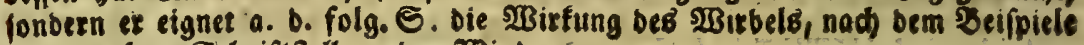
einiger alten Edriftitlez, ben 3 inben gu.

(ss) Eluverius (́)reibet auch, Sicil, ant. p. 29, bie urfache diefes wirbels ben

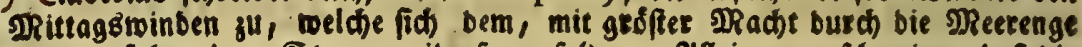

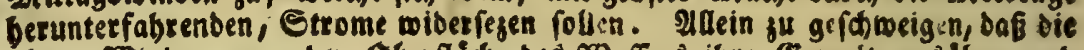

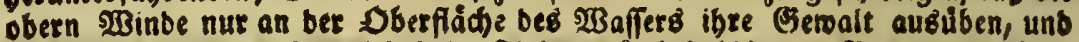

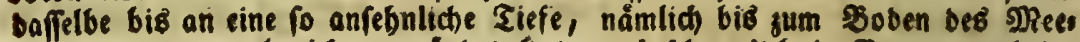
res, ben man nod nicht exgrúndet Gat, nol (đ)wetlia) in 5ervegung brine gen tonnen, fo mirb man aud niemand úberreben, bet ben ungeftumen

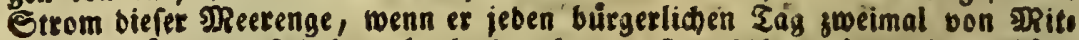

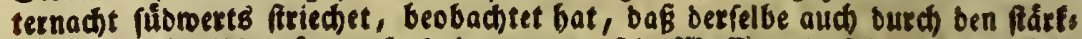
ften IRittagswinb móge aufgebalten, ober fein $W_{3}$ affer mit folder f̧eftigfeit, als eहै gef(c)iebt, berumgetrieben merben.

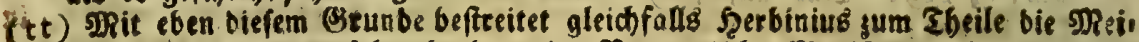

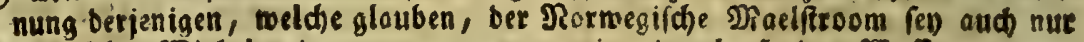

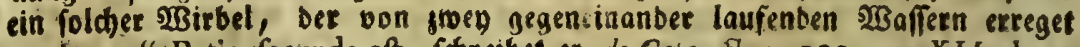
werbe. "Ratio fecunda eft, fchreibef ex, de Cataral, p. 133, n XII, boa,2 tus fremitusque aquarum horrendus. UInde enim fibilus, unde boatus, et "illa aquarum ejulatio fit, nifi ab aere una cum aquis ibidem dehifcente? 19 Namque aquarum per vorticem defcendentium impetus, raptos fecum fpi7ritus in imum fundum five abyffum trahit, ibidemque fuffocat Inde boa
3s tus quosdam undarum navigantes audiunt, exterritigue magnis pelagi denfides- 
ciliidhen Steinmánben, fich einbilben, Denn es ift fein fo ftarfer 2 bbang bis Dorthin. Die zuvor angebrachte Eizåblung bes ₹äuders Ziola Defthe, Der in bem Ebarnboiften Schlunde einen wirfliden Strom

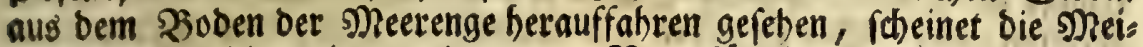
nungen, fowol ber alten, als neuern Raturfundiger ju vernict)ten, und gu ermeifen, baß bie Scerumbrehung bes 23 affers bei biefem 23 irbel, weber eine bloffe 2 Bitfung ber $2 B$ inde, nod) ber wiorigen Ströme fen. Fran fónnte fich bie Zjef(haffenbeit biefes Srtes vielleidt nicht uneben

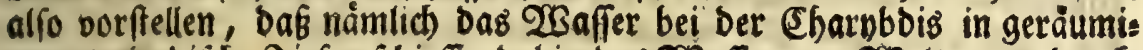

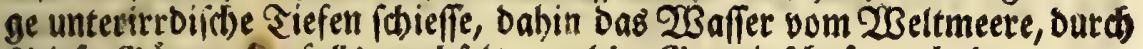

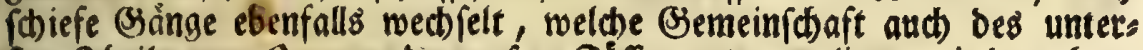
ften Sheils vom Scean, ber unfern fruffen entgegen liegt, mit ben obern

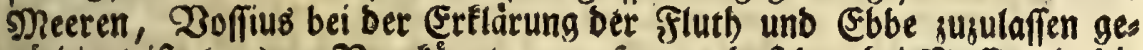
nóthiget ift (xx). Noun fơnnte man fagen, $\mathrm{Da}$ B bas bei Meffina in bie

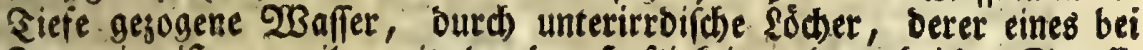
₹normina ift, zumeilen mit eben ber Sूeftigfeit, alö es bei ber Straffe fereinbricht, wieber jurúc beraufgetrieben werbe; wo benn einige ₹ 2 Srúmo

7) fidentis vorticibus, latrare putant undas, quas forbentis aftus vorago illa con10 lidit.

( u u) Diefer IReinung ift 2tban. Sircher, ber Mund. fubt. Tom. I, p. 100 A, fo foreibet: "Præterea totum illud inter Scyllam et Charybdim quinque fe"re milliariorum maritimum fpatium reperi ferventiffimum, omni bolide " quantumvis longa inexplorabile, ac vorticibus formidabile; ubi und $x$ un" dis contrariis obvix frevos movent turbines, modo in abruptum abeunte "freto, modo cum impetu et colliforum Auçuum fragore fuperna facie refi" liente mari, vaftum hiatum et immenfam voraginem conficiunt: quibus in" undationibus miruin in modum, per gyros et contrarios curfus, nat igia et "obvia qurevis interna vi fpiritus abforpta, in imos gurgitis fubterraneos cuni" culcs pertrahuntur , qux in littore Taurominitano, tefte non folum Salluftio 3. et Strabone, fed et Taurominiorum (Taurominitanorum) obfervatione, re"gurgitantur.

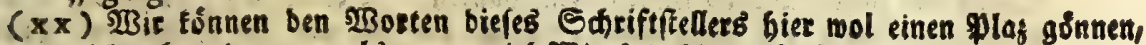
nidht eben barum, als menn viel $23 i j e s$ babinter fectete, fontern um bargus tbun, auf was fứt feltfame Bebanten, ju verfóciebenen Zciten, bie Belefro ten verfallen finb, ba fie bas Eegeimnis ber gluth unb (Ebbe, mie aud) an bere (Eigenidaften bes झReereb, ergrunben wollten. "Non abfurde fortaf") fis, fureibet $\mathfrak{B}^{\circ}$ ffrus (de Idol. II, 69, p.670) hine colligat aliquis, com" pluribus terram locis pertufam effe ac perforatam; non quidem per diame2, trum ac centrum, fed tamen de hemifphario uno in adverfum; perque " gurgites ejusmodi, expertes fundi, agere Lunam in aquas utriusque hemi") Cpherii. Ac probabilem utcunque hane fententiam reddunt voragines non n pau- 


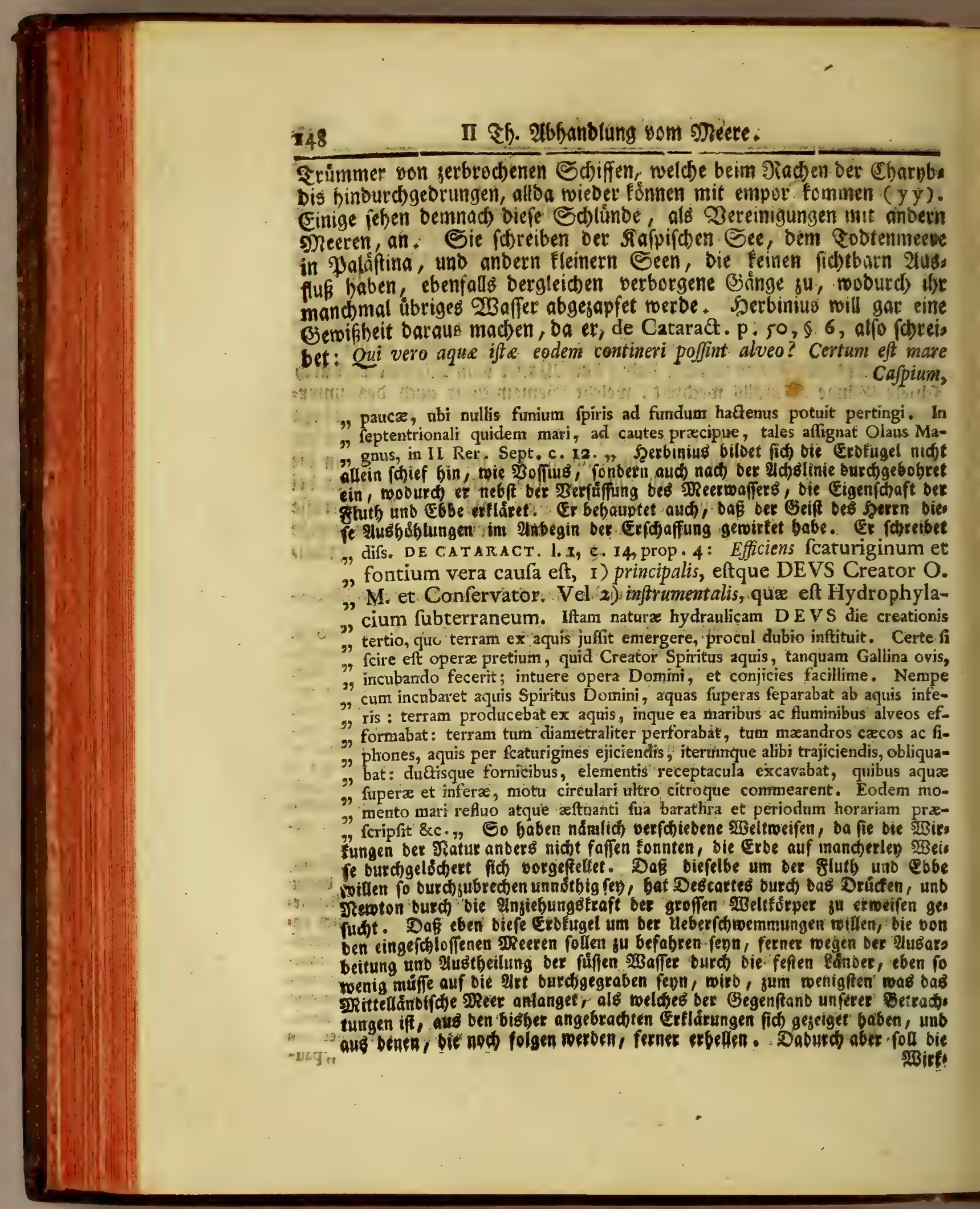


Cafpium, ei alios lacus forbentes minime effe otiofos, fed aquas fuas per meittus fubterraneos emittere. Sic lacus Afphaltites aquas Fordanis gremio fucipit, nec mifcet eas aquis fuis bituminofis, fed per ductus bydragogos fulterraneos in Mare Rubrum transmittit. Nod Oreifter if bie Dెers ficherung bon bem Safpifhen Neere, bie auf Det folgenden $\mathbf{S}$. ftebet. St.tuo, fprid)t Şerbinius bafelbft, egrefjum omnium aquarum, qua in rave Cafpittm influunt tot fluminibus, ita neceffarium effe, ut eodem ipfi denegato, accolis diluvio pereundum brevi fit. $(\mathbf{z z})$

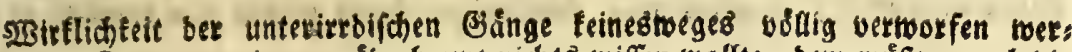
ben. Denn wer bavon liberbaupt nichts roifien nolfte, bem múBten aud) bie unterirebifchen fluffe unbefannt fenn. Diefen fơnnte man fragen, was es won ben ungåligen lagen oon Edymefel, Erbpeche, Eteinfoblen, Rieje, unb andern s2sineralien, weld)e unter bem ErDboben burch beftánbigen \$rano forfglimmen, uno leere Gånge binterlaffen múffen, fich fúr eine $\mathfrak{B}$ orftellung

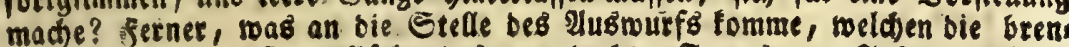

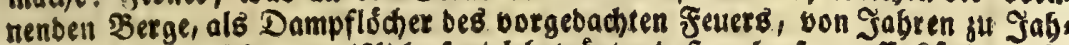

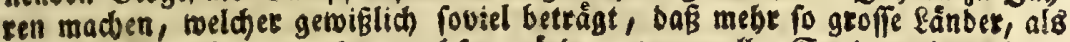
gans Sicilien iff, barauz erwachien wuiroen, wenn aller Sanb, wie aud bie

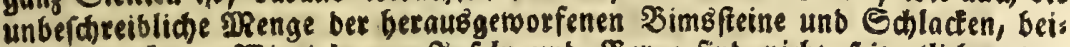
fammen maire. Wieviel neue Junfeln uno Berge fino nicht feit eflichen taus renb Jabren, burd) bas unterierbif the getuer aus ber Tiefe beraufgetrieben

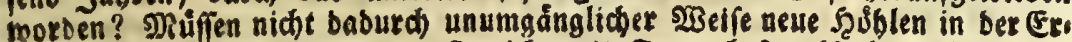
be entfeben, in welche, menn fie nicht mit feuet befest bleiben, Euft ober Safier fich bineinbringet?

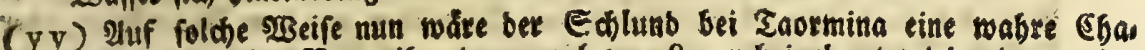
rnbbiB, weldhet গarme ibm benn auds von lucan beigeleget wirb, ba ex cine

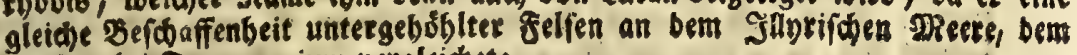
gradien bei Tauromenium bergleidet:

Impendent cava faxa mari : ruituraque femper

Stat (mirum) moles : et filvis xquor inumbrat.

Huc fracas Aquilone rates, fubmerfaque pontus

Corpora fepe tulit, cacisque abfcondit in antris;

Reftituit raptus techum mare: cumque caverna

Evomuere fretum, contorti verticis unda:

Tauromenitanam vincunt fervore Charybdim. N,457:

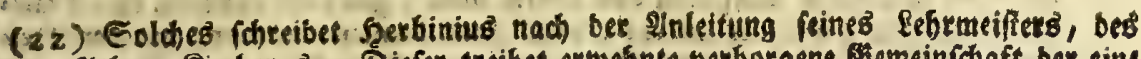

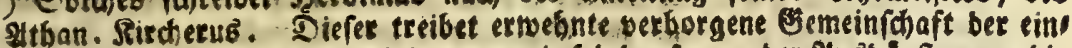

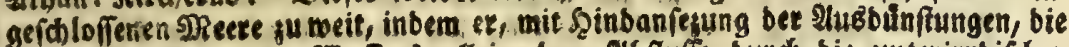

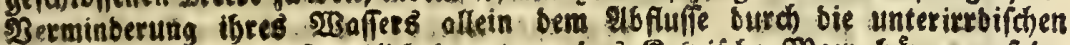

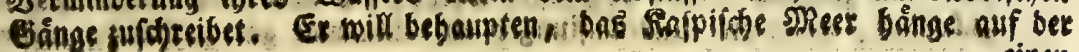


II. Sh. Ifbranolung som Neere.

Der beruibmte Forweglid)e Siaelfroom, unweit Drontheim, (d)eimet mit ber (Sharnbitis einerlen Beidaffenheit gu baben. Sa er iffeine red)te (Charbbois, und ztoar ber groffe unter ben befannten Waffermirbeln, indem er mit feinem Unifange 13 Seutíte sieilen bes greiren foll. Er fübret audb oie Edbitte, melche bas unglúcf baben

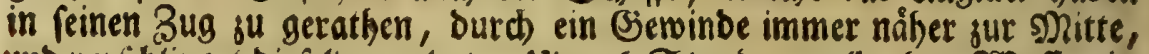
und verihtinget biefelben gulegt. Hoer 6 Stunden roallet bas 230 effer, in

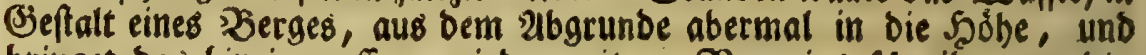
bringet bas bineingerıfiene wieber mit. Yarenius focreibet von bies rem Wrirbel, GEOGR. c. 14, prop. 31: Vorago bac fex boris abforbet omnia, qua illi appropinquant, vel vicina funt, aquam, balenas, naves onerarias, et alias res; totidemque boris omnia illa eruetat et evomit,

cinen Seite mit bem Sdimargen, auf ber anbern mit bem 230 elmeere gufamo men. 2Benn bemnach ftarte Weftwinbe mebeten, fo báufete fich bas Bjewaffer an

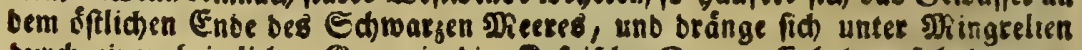
burdh einen beimlichen Eang, in Die Safpifhe Eee. Erbeben fich Dagegen

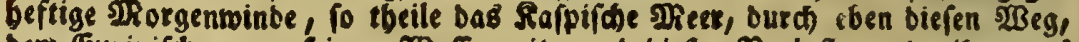
bera Euxinifhen bon feinem 250 fer mit, unb biefer 2 Berluft merde ibm aus bem Perfifhen MRerrbufen exfest, Tom. I Mund. fubt. p. 86, two ex cinen Cruntriß von biefem $23 a f j e r w e c h f e l$ vorftellet. 2uf ber folgenden 5 . fúbret ex bab SRittellantiíde und Sobte MReet in bas Fiotbe, uno entwirft diefe

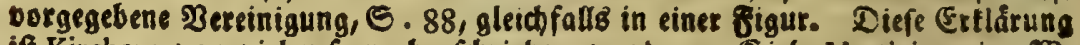
ift Kirchero bon vielen fo nadgefictieben norben. Eieb Martiniere im 23. MER Caspienne, p. 294. Happel. Relat. Cur. ITG. S. 156. Şere

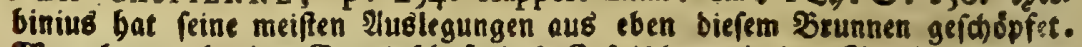
IRan bat aud eine Semeinf(h)aft bes Rafpifanen mit bem Zralifichen obec

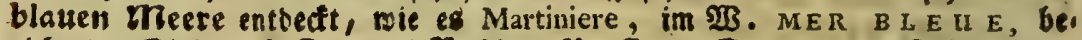
riditet. Eieb auch Dappers Befdor. Perfiens, S. 49; bem Sobtenmeere

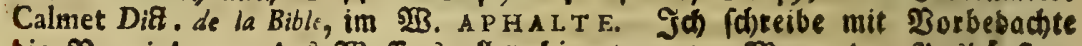

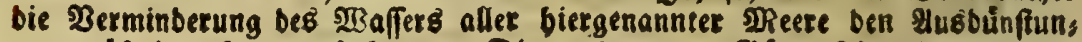
gen, als einer Şaupturfad)e fu. Die verborgenen (3̈ånge febe id), nach vies ler Ueberlegung, fum wenigften von Dem SRRittelländichen IReere fu reben, als tein nothwenbiges . Mittel an, baburd) $\varepsilon_{\text {, a }}$ auf sine unentbebrliche 2ixt,

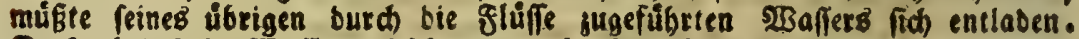

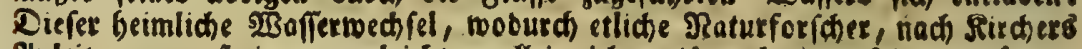

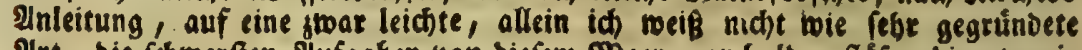

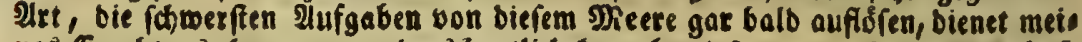
nes (Erachtens (menn ex anbers beutlich tann bewiefen toerten) mit ber Orfo

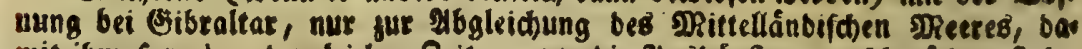

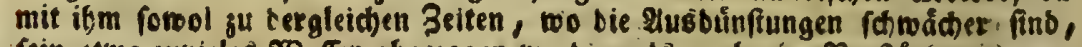

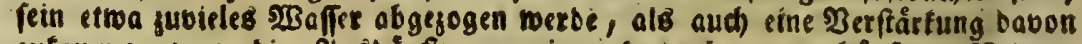

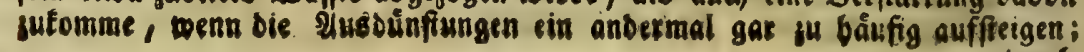
burd 
mit, magna cum violentia, frepitu et circumgyratione agus. Caufa latet (aaa). Einige wollen behaupten, Daß bie mitternádtige See, burd einen unterirrbifben $2{ }^{3}$ g, bon bort aus mit einem anberh Meere fid vereinige, uno burd biefe Defnung bie Fluth unb Ebbe treibe. Diefe Mreinung wirb Daburd im geringften nidt wiberleget,

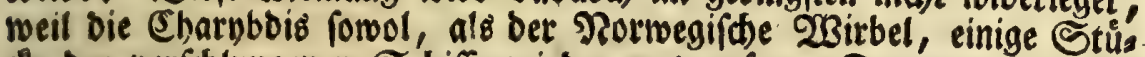
de ber verfdlungenen Sdbiffe wieber auswerfen. Denn oas 2 Baffer Eann burd bie flippidten (Jiange wol burchivanbern, und all einen ants bern Theil ber 2 Belt fid binbegeben, bie Schiffe aber, ober berer Sheile nidbt. Diefe bleiben in bem fobroffic)ten Shlunbe ftecten, (wie Rola pefithe fich binter Den zacfidten Rlippen bes Sgeffinefifonen 2 Bir:

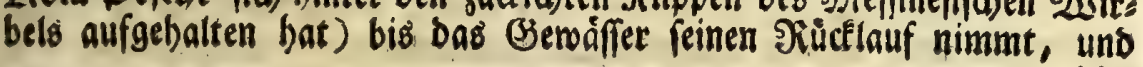

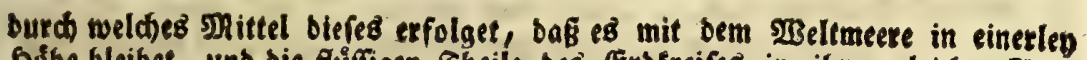
f̧obe bleibet, unb bie fixffigen Tbeile bes Exbfreifes in ibret gleiden Run bung erbalten werden.

(a a a) J̄h merde obne STreifel benjenigen Eefern, welde bes Serbinius 216banb, lung de Cataractis nicht baben, butch) Infübrung einer tweitlåuftigern uns

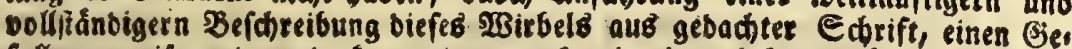
fallen erweifen; benn ba fommet, p. 526 , ein eigenes Sauptftúf, unter dem Sitel, de Cbarybdi. Norvvegica Mufcans, bor, wo gleid anfangs bie verfaties

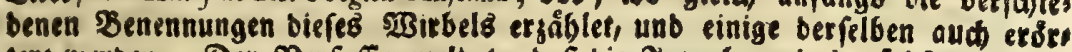

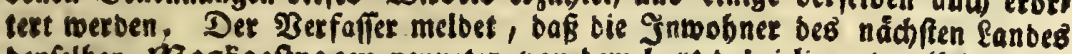
benfelben, mosfoeftroom nenneten, bon bem bart babei liegenten fleinen Eis lanbe mosfoe. Iuf ben Eanbfarten werbe et Maelftroom, von ben Saiffern Zabel ber Eee, ober Geenabel, von ben Naturfunoigern lateio nifich umbiticus maris, nares unb anbelitus Mundi, Cbarybdis Norz'vegica, /eplentrionalis, Mo/ciana obet Muscasa, gebeiß̄en. Uber bie Jెenennung nares Mundi,

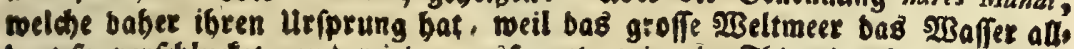

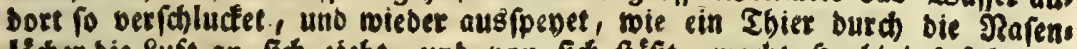

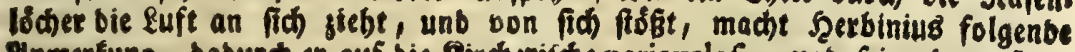
Inmerfung, babutch et auf bie Sircherifhe pericyclofin, unb feine barauf get gruinbete Eefre bon ber Glutb unb Ebbe, abfielet: "Quas autem Mundi nares 3) ego, non iftas parvas, fed immenfas illas fub Polis, aquas ultro citroque 2, vorantes, atque iterum evomentes Charybdes, xftus refiui marini caúas "efficientes proximas, certasque ac veriffimas, effe Atatuo, p. 126. Es

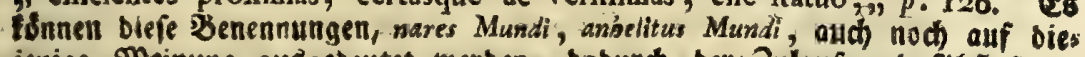

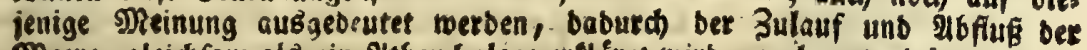
SDeere, gleidh fom als ein 2itbembolen, erflákst mirb, aud) boh eingen neuern Narurfuindigern. Eo lautet in bet 'Tbat eine 2ustigung, weldhe SIBBAL-

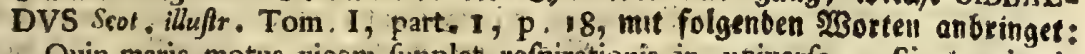
"Quin maris motus vicem fupplet refpirationis in univerfo. Sicut enim in $n$ corporibus noftris commercia funt fpiritialia; ita quoque in profundis vafti "Oceani, 
Diefelben wiebet betaufbringet, ba man benn bie 2risberfefr bes un

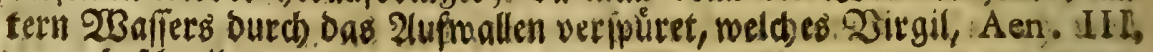
420 , befatreiber:

Dextrum Scylla latus, levum implacata Chargbdis

Obfidet, atque imo baratbri ter gurgite vaftos

Sorbet in abruptum : fluctus, rurfusque fub auras

Erigit alternos; et fidera verberat unda.

Das fidera verberat unda, if eime farfe poetifose somperbole, hos burd

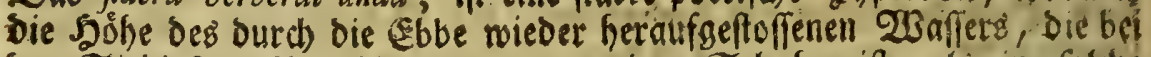

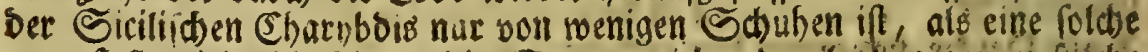
vorgeftellt wird, bie bis ait bie Sterne reidse, bergleid) in gar zu fredte

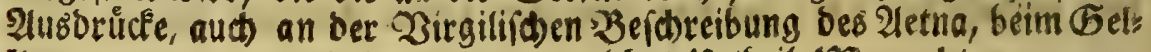
lius, 17, 10, getabelt werden, weldes Urtheil Macrobius, 5, 17, fo nachgeforieben hat. Das ter gurgite vaftos forbet in abruptum fluctus, ber angesogenen wirgilifiten S telle, oorfte ebenfalls rocts eine poetifhe Siedensart fenn, und Das ter fur fapius fteben. Dinn wojers

"Oceani, Nares quafi Mindi conftituta, per quas emifli anhelitus et reducti " modo, efflent maria cum impetu aquas, quo modo effoetze univerfí vires "reftaurantur et exfufcitantur.", Jun win ich aud) bie \$eichreibung biejes berúbmten Mosfoeftrooms mit bes Serbinius 230 sten, melde eine lleber:

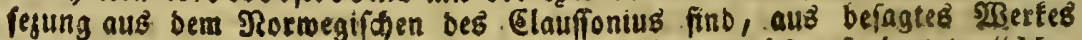
P. 127 , liefern, uno bon $n . V$ ben 2 nfang madien, weldher fo lautet: "Mo") tus Charybdis Norvaregicx duplex eft; Afcendens et Difcendens. : Namque \% crefcente Oceano, aqux ejus fumma vi atque impetu in circulum rapituntur, " in quo per modum cochle $x^{\prime}$ tantundem circumvolvuntur w quoad deorfum ", in barathrum cuin magno et horrendo undarum ftrepitu, vortice haurian" tiir, tanto undarum illabentium, fefeque inter fcopulos Charybdicos ibidem ") collidentium, ftrepitu et fragore, quanto cataradicus fimainum inter fcopu". Los et faxa ruentium lapfus majorem edere non poffit... Qui horrendus " aquarum fragor zeque in malacia funma, atque tempeftate cogrta yehe. 9, menti, obfervatur; fonitus vero earundem cataracticus tranquillo et filente n. Oceano, aliquot abinde milliaribus anditur." Vortices voraginis ea funt va". ftitate ac celeritate, ut incautas naves, etian ampliffinas et, maximas, quo" cunque illæ ferantur ventorum impetu; circulis aliquot prius circumackas, "7. tandem hiantes in medio abforbeant: Et hæ naves, quia os voraginis fco2) puli multi præacuti in fundo circumffiftunt, in affulas franguntur atque conte-

"kendi reliquiæ triftifima . Nam.VI: Corta tempeftate, -aut yolagime ve-

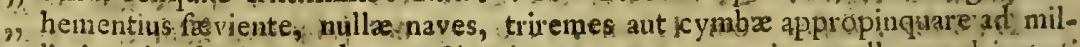

$\Rightarrow$ liaris unius patium audent. Si qui ver $a_{1}$ nautarum, vi procell $x$, yel incauti $\Rightarrow$ in circulum illati fuerint, actum de illis eft, quautacunque vehantur navi : "fiqui: 


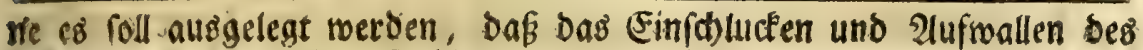
2Saffers, bei biefem Edlunde, orbentlich brenmal bes కages ab: medhsle, wie es Somer, nad bem Beugniffe bes Etrabo, I, 43, 84

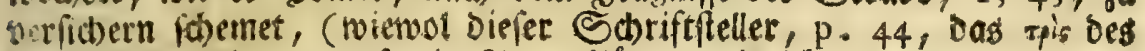

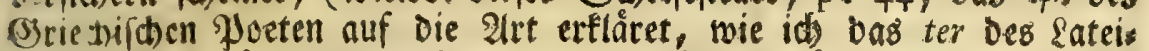

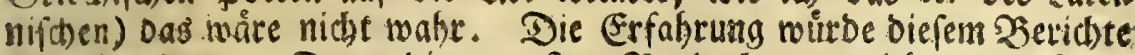
videriprecten. Denn bie neueften Seobadtungen leblen, Daf bie (Sharnbois mandibe Sage fid) ganj fille halte, unb nut bei Sturmmet: tern, juforberft aber bei obwaltenoen befrigen sgittagstwinden, wie es

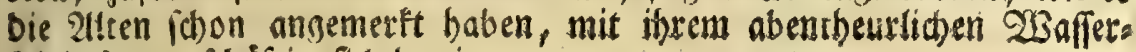
fpiele febr gefdåftig fids bejeige.

Die llrfache fönnte man fich atro vorftellen. Die sneerenge; Dar innen biefer 2 Birbel fectet, if oben fotmal, uno behnet fich mittagwerts auseinanber, weil bie Ufer Siciliens, twie aud bes unterften beuti, sen Salabriens (jwifhen benen biefelbe liegt) nach geoachter (Jjegend, sie bie Seiten eines Srid)ters, auseinanoer geben (b b b). WEent 11 .

nut

7) fiquidern periculum iftud non experientibus modo, verum etian procul viy) dentibus, terribile eft. Eodem fato balænæ quoque forte fortuna ibiden 3) trajicientes, fimul atque in gyrum devenerint, in abyffum, nequicquam cau" da renitentes, fubito rapiuntur. Cui malo inaffueta Cete, ubi fe rapi ac "7 torqueri in vorticem, nec ullum evadendi locum fupereffe vident, tantun ", clamorem aut mugitun potius attollunt, ut tremere terram, fcopulosque " horrore affilire diceres. Iń verticem delata momento ad ima bellua pra" ceps trahitur, allifunique fopulis corpus fruftation conciditur atque conte" ritur." Das ift abet erft ein Thetl bet Befdichte bon biefem $\mathfrak{W i r b e l}_{\text {. }}$ Sisber if nur bas Einfhlucten beffelben, weldse8 6 Etunden máthet, bes

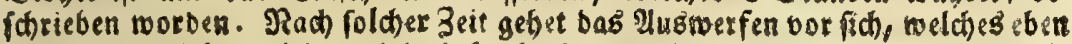
fo lange getrieben mird, und Das ferbinius mut jeren abgeborgten 230 oten ab;

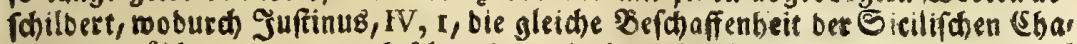

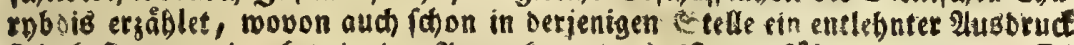
fid) befindet, bie sben in ber \&nmerfung $(t)$ ift angefuibet noeben. EB

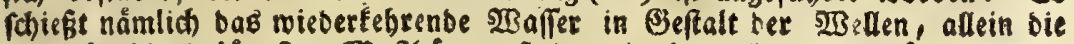

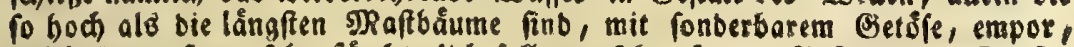

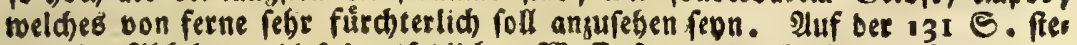

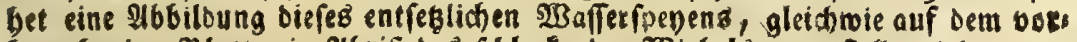

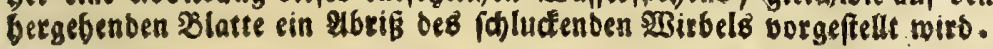

$(b b b)$ "Namaue fretum hoc duobus promontoriis geminoque litore coarlatur: "parvo primum, mox fenfim paulatimque ad meridiem aperientibus fe fe "anguftils, latioris maris intervallo dilatatur." Fazell. R. siCVL. Dec, $I, l$. i, G. I. 


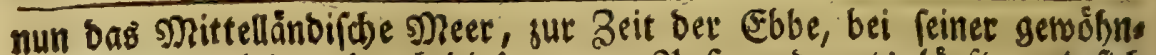

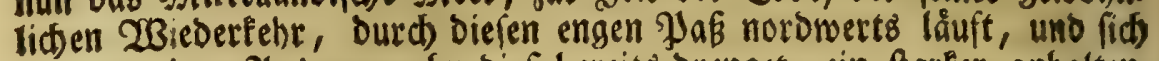
alloa vor bem 2lusgange olynebiéz berei:s orenget, ein ftarker anbalten.

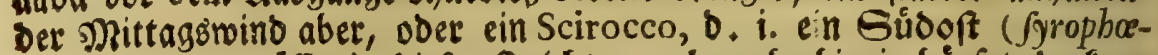
nix), Das (3etwăffer in biefen Yrid)ter nod mehr hinein báufet, ba fann burd bie ftsmale obere munoung, nidbt to viel 2 Gaffers hinauslaufen, als namlits in ben untern weiten 20 ufen, Durd) ben ordentliden Strom bineingefloffen, und nod barsu burd ben 23 ind aukerorbentlich hineins

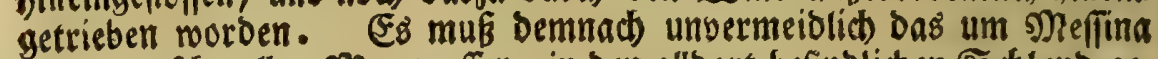

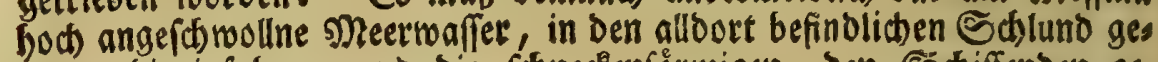
waltig hineinfahren, uno bie fonnecienformigen, Den Edbiffenden ges fåbrlide, Freife geftaltent. Sơoret erwefnnte Urjacbe auf biefer Seite

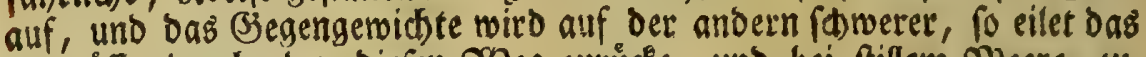

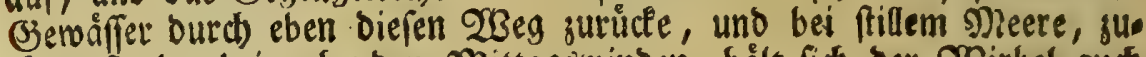

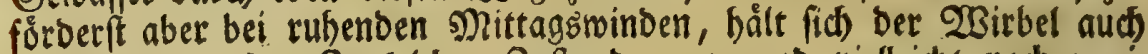

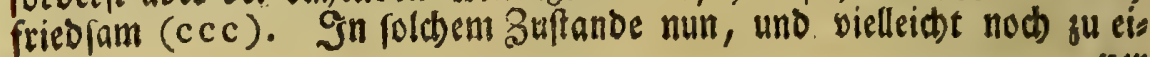

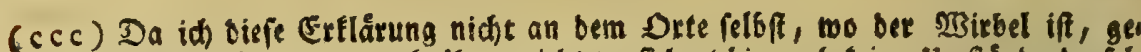
(a)rieben babe, unb oerobalben nicht verfichert bin, ob teine umftánbe berfels

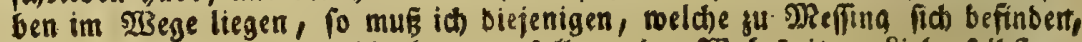
ober bevor, als id), babin Eommen follen, ber $253 a b r b e i t$ ju liebe felbft ex:

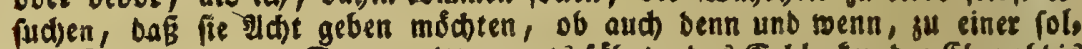

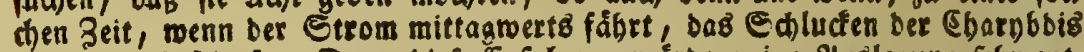
ungemein beftig fev. Denn biefe (Exfabrang tourto meine 2lug̈legung fegr enso

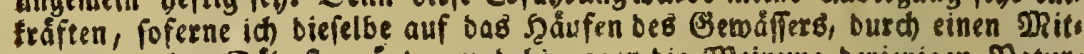

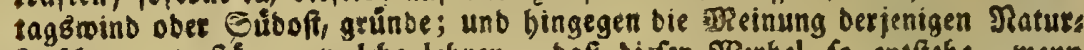
forfher unterftuigen, weldhe lebren, bas diefer 20 irbel fo entfebe, wenn bas פReer obenber mittagreerts ftrómet, zugleich aber ein unterer Etrom entgegen fiebet, bergleichen wibrige Fremegungen in ben Mreerengen, nach

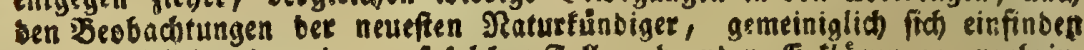

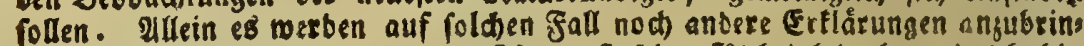
gen fenn, menn es nur mit bir Sbat erft fetre Ridhtigteit bat; ja ich bin

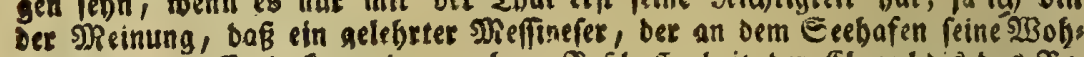

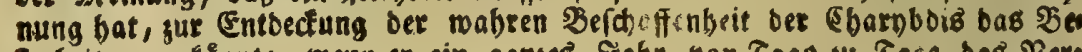
fte beitragen fonnte, wenn er ein ganges Jabr, von Tage gu Tage, bas Vere

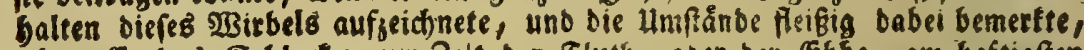
ob s. E. Das Ethlucten zue Belt Det Fiuth, oner ber Ebbe, am beftigften (ev), wie lange es wábre, ob baffelbe allemal nur bei ftúimenben untern 23 in. ben gefobebe, oocr auch conft. Einen fall bat Rircher fojon angemerft, baf

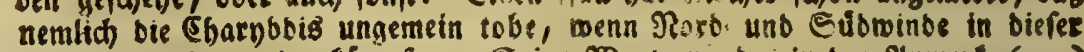
DReetenge miteinanter fámpfen. Eeine Forte werosn in ter $21 n m e r f .(g g g)$ vorfommen. Diefes beftätiget noch meine Aublıgung. 2lfein mebr bergleio

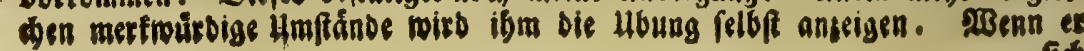




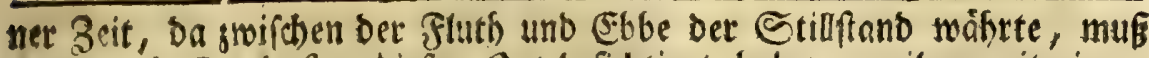
Jouvin de Rochefort biefen Drt befichtiget baben, weil et mit einent fleinen Sahne, obne Bebenfen, Dacuber berumfahien fonnte. Es bat

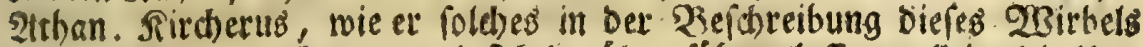
reloft geffebet, nuds swenmal fich Daruber fübren laffen, allein bie ums

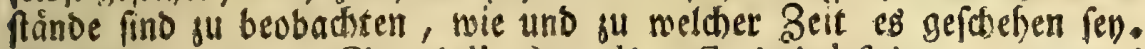
(Sr fpricht: quam (Charybdim) et bis vectoris induftria, et opportuni temporis occafione tranfivi, MuND. SuBTERR. Tom. I, P. 102 A. Das musten aber bie sllten auch foton. Iuvenal zeiget es gar fchón, ba er Sat. 5, 99, fdreibet, Dab bie ffifober fu feiner Beit; bei ruben:

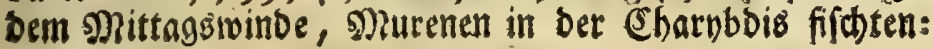

Virroni murena datur, que maxima venit

Gurgite de Siculo: nam dum fe continet Aufter,

Dum fedet, et ficcat madidas in carcere pennas,

Contemnunt mediam temeraria lina chargbdim.

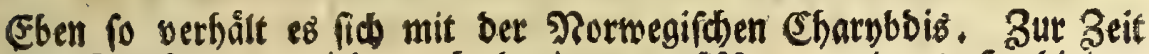
Des Stillfanbes wirb aud Darinnen gefif(het, wie es Serbinius, 112

DE

(id) bereits einen phofifalifaien Entwurf von ber (EGarpbbis gemacht, bas

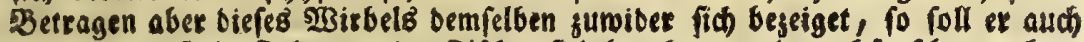
guweilen auf ein Gabrjeug ber fifher fich begeben, unb nachforichen, ob ex teinen untern Etrom roabrnebme, ber bem obern eine wibrige Richtung bas

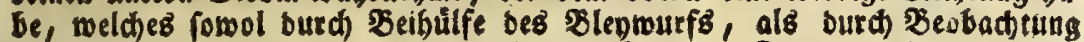

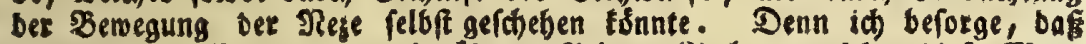

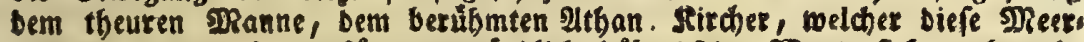

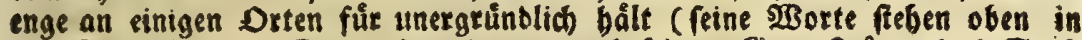
bet Inmerf. u u, $\mathcal{S}_{147}$ ) Die untern beftigen Begenftrôme bas Eanf:

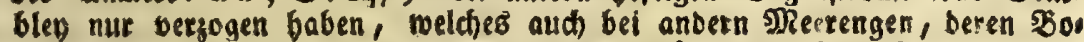
ben man gleich faliz noch nicht bat exforfchen tónnen, auf bie 2lrt, fich bets

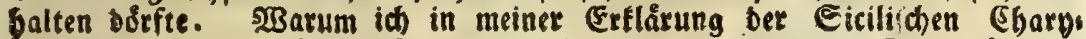

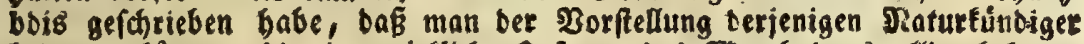
beitreten fơnnte, bie eine wirtlidje Defnung bes JPeerbobeng alloa beboup;

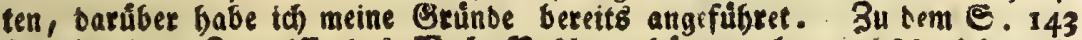
beigebrad)ten Zeugniffe bes Rola pefde gebótet audh, was Martiniere in feinem geogr. Worterb. V. CHARYBDE, p. 528, auB sinem Serich te DeB Jouvin be Rod)efort, bon einem andern Zäuder melbet, bee

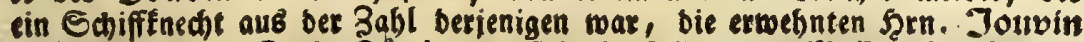
gefúbret baben. Diefer Taudher bat fíh ebenfallz in ben Meffinifhen Wirbel binabgelaffen, unb beftåtigte, baß̉ ex ein roirflides \&och in ben Boben ber Meerenge in Ild)t genommen. Eine lange Ueberlegung noftbiget mid úbri

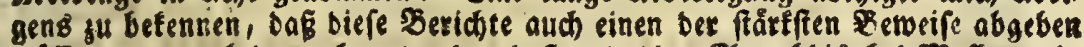
múfer, moburd oargetban soerde, baf́ unter ber Gbarybois bei MReffina eia

mits. 
II $\$$ h. 2lbbandlung vom sneere.

DE CATARACT. P. I30, bejeuget: Motu voraginis vebementiore, tranfitus alvei illius plane impoffibilis eft. Quiefcente vero alveo, quod fit, quando acceßus et receflus maris medio fe modo bahent, navesque impune trajicere pofjunt, ingens ibi pifcium copia, prafertim pajjerum ma, orum, capi illo momento poteft.

\section{Sifte Beilage}

gut III Interfuchung.

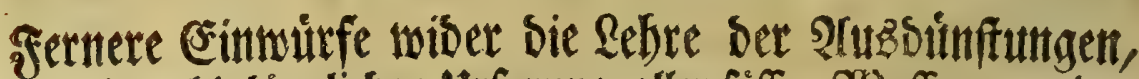

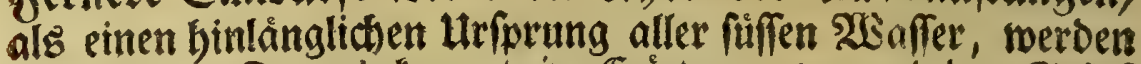
abgetefnet. Darnad fommet eine Eroórterung bor, ob der Einfü Des Deeans burch bie Straffe, im 202inter fowot als im Soms

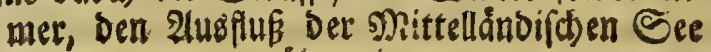
aberwiege.

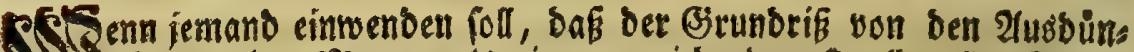
30. fiungen ber Merre, als einer zureichenden Quelle aller $\mathfrak{B r u m}$ nen, Eeen und fluffe, wie aud als einem Mittel, modurd zugleid Das '2Saffer. Der meere táglich vermindert werde; Oamit fie regen ber Einnabme fo vieter fluffe nidts úberlaufen, in 2infeflung ber greffen 2 settfee wot feite SRidstigfeit haben fónnte, weit die Sonne bas ganse Sabr binourdh mit ibren geraben Errahlen einige Sheile berielben bes

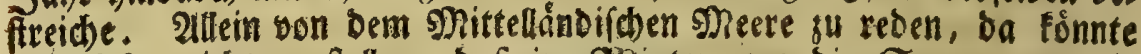
man fids nidht vorftellen, baß im 28 inter, wo bie Sonne nur mit fhiefen, und Daher fomádsern Etrahten, Daffelbe beribrte, foviel bas yon ausbunnften mơge, als im Sommex. 2Benn nun Das 28 affer dies

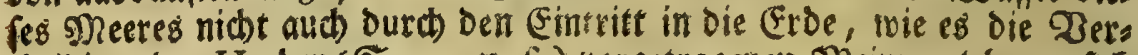

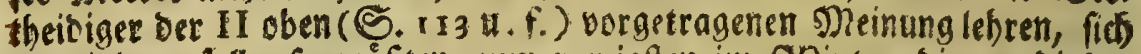
warmindern foll, to músten, sum wenigfen in 23 inter, bie an biefem

Meere

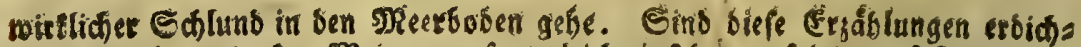

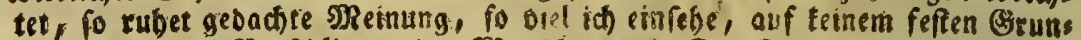

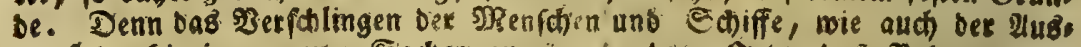
murf bet bineingegogerten Sacten an einem andern Orte, Dob Bebarten teb

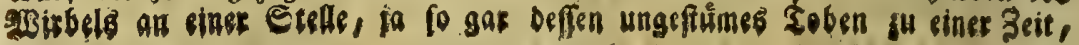


Meere gelegenen fánder überfbomemet werben. Diefen Einmurf,

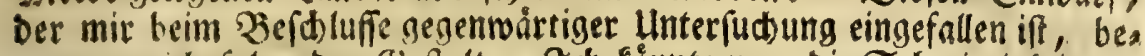
antworte id) folgender Gieftalt. Gd) fönnte gwar die Schwierigfeit am furzeften fo ablehnen, wenn idb fagte, bas g) ittellandif the sieer fer nut

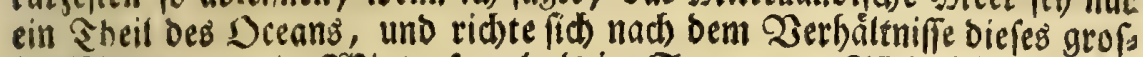
fen 2 Beltmeeres, im 2 sinter fowol als im Sommer. Pllein id fann yon bem Mrittellåndifden nod veridbiebene befondere umftånde anfǘfren, bie nicht allein vorgebad)te Folgetung entfråften, fondern aud) nod) sú

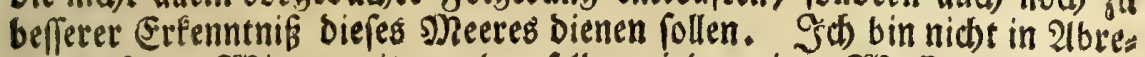

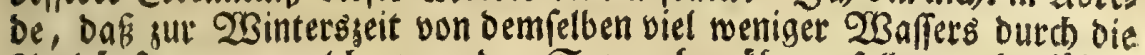
2lusbünfungen, weldbe von. Der Sorme herrúhren follen, abgefüfret

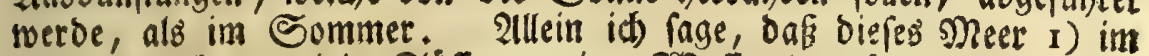

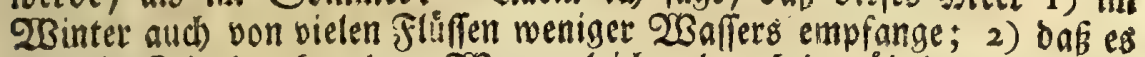

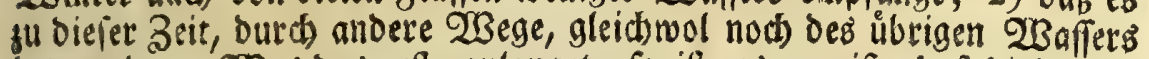
108 werde. Was das erfte anlanget, fo ift es gewis, baß biejenigen Fliffe, welde von falten \&indern berfommen, ober aus hobem Sdnee: gebirge ilgren merften Zumeds zu erfiglten pflegen, als bie Donau, Der

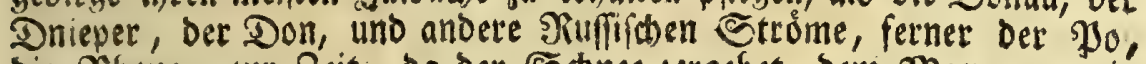

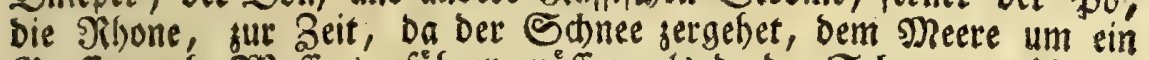

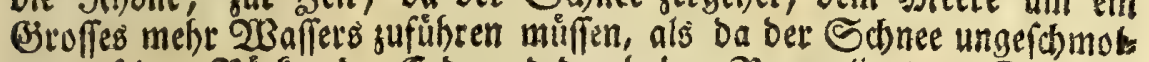
jen auf Dem אưffen ber Erbe und ber boben Berge liegt. Eo trifft

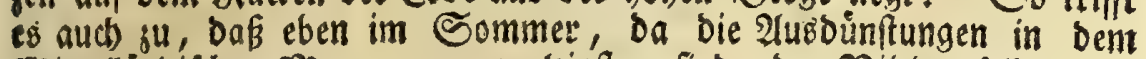

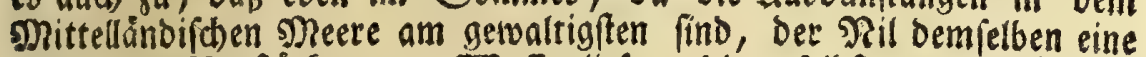
anjehniiche Zerftảrfung von $23 a f f e r$ liefert, bie er felbft son ben båufigen uno beftảnoigen Mittagsiregen erfålt. 2uf bie twente $\mathfrak{B}_{\text {eantwortung }}$ zu fommen, fo Edonte man vielleidst nicht obne (3rund mutbmaffen, Das

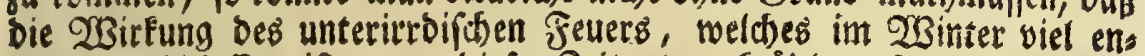

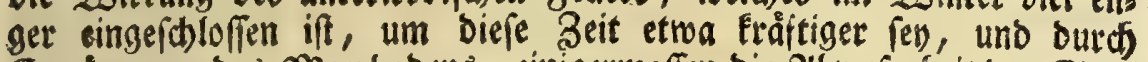

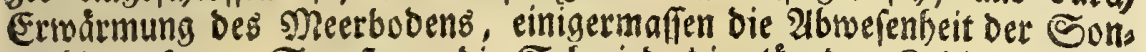
nenbize erfeze: So pflegen bie Shmiebe Die gluenden Roblen obenher zu nejen, um berfetben Feuer ju vermehren. Es dortfte alfo Eeine bloffe 2leffung ber Sinne fenn, wenn Das 2 Baffer bes Mittellănditben Mee: ses im 2 sinter um ein 2 ieles wårmer, als in Sommer, befunden U1 3 wirb.

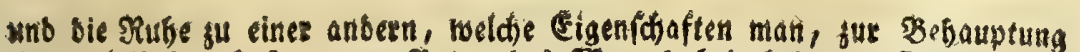
riner wirtlichen Defnung am Boben bes SReeres, beizubringen pfleget, ino, nach genauefter Prafung, eben teine unfoblbatn senngeiden eines 2lborundeg,

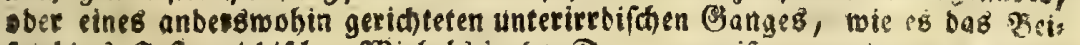
fpiel bes Deferereichirchen 23 irbeld in Dex Donau erweife?, von dem unten eine

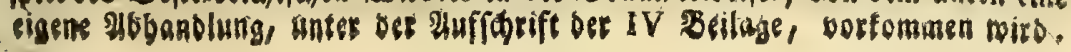


wirb. (jd) mus ferner aus Derhams Pbyficos Theologie, II $\mathfrak{B} .5$ Sauptft. eine Stelle anführen, weld)e biefen (Gebanken befråftiget. Er fohreibet bie 23 årme Der \&uft in \&ånbern, bie an Meere liegen, Den 2uebunftungen beffelben ju. Wie Ulrfacte aber, fpricht er ferner, wober diefe toürme entfpringet, ift, meines Gractens, 3 um Theil oon der Gonne, zum Tbeil aud bie unterirroifthe Wárme. Daf es b:e to årme der Gonne niche gans alleine fey, erbellet daraus, Oaf bie Dinfte eben fo háufig uno ftark, ja nol noch báufiget

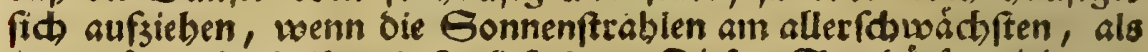
wenn fie recth beiff und fart fino. Diefer Saf bơrfte vielen uns

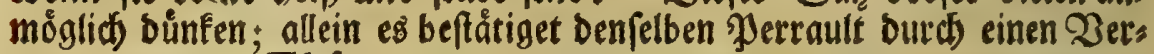
fud). Sieh Thúmmigs tMertw. Zsegebenbeiten Der Tatur

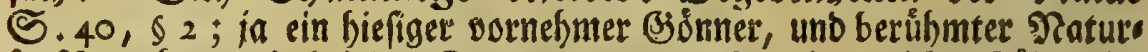
forfder, hat aud bei Der Donau, wenn auferoroenntlide Fålte eins

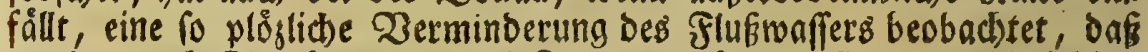
es eber nach Schuhen, als nach Bollen, fu fallen pilege. Sb rolches

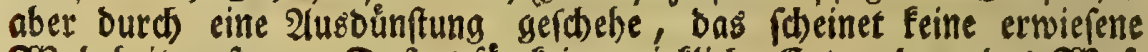
23abrheit zu fenn. Daf es fur Eeine wirflide Entwenbung bes $23 a f_{5}$ fers, , fo bei gåhlings entftandenem frofte in Den fleinern Zufluffen su Eife geftehet, und am Eande figen bleibt, fơnne gehalten werben, Das erfehen wir baraus, weil biefe 3erånberung bes Donaumaffers in ei, ner Nactit vor fid gehet, two hingegen Das Steigen ober Fallen bies fes Stroms, Daran bie oberlánoifhen flúffe Sheil haben, bei Res gensburg erft Den britten sag gefpúret wirb. Sit es vielleid)t eine Ers

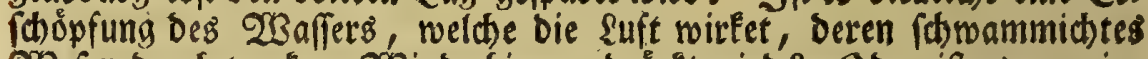

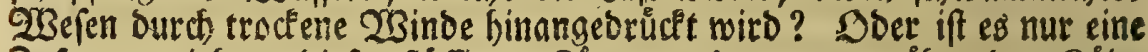

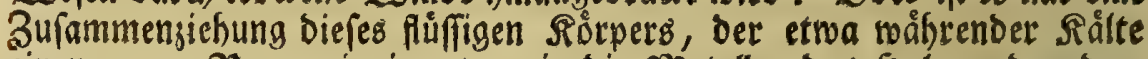

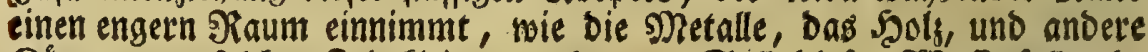
Sórper, zu folther Zeit Eleiner werden. Soll Diefer Wafferfall end:

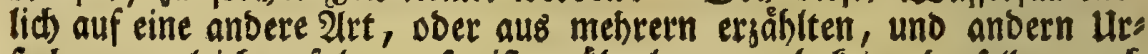
fachen, zugleich erfolgen, fo ift zu überlegen, ob Eeine Derfelben auds

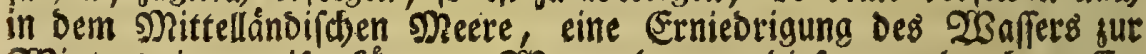
YSintergseit erweifen po̊nne. $23 e n n$ aber von biefen angebrad)ten Ers. Elärungen Eeine beftehet, fondern im 23 inter, weber burch bie 2lusbüm ftungen, nod) Durd eine 2 Birfung ber troctnen fharfen 2 sinde, Das Meerwaffer fo ftare als im Sommer fallen fann, fo gehet Der Ueberreft getwislid zur erftgebacten Beit burd Die oftern und faft beftandigen Seefturme grơftentheils weg, Die in ben brey 23 intermonaten ben See keuten, fo nue fleine Jafigeuge befigen, unamfänbige Jevertage madsen. 
Sollte jemano ferner fagen, meine erfte Urfacte, auf melche id S. I57 bas 2tbnehmen bes 23affers im Winter bei bem

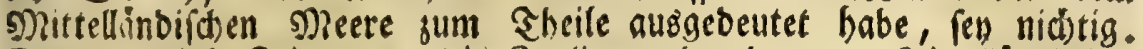
Demn zu biefer Zeit regne es in Stalien, und andern am gittellänoikben meere gelegenen făndern. Die mittlern grlúfe nun, welche aub bieren

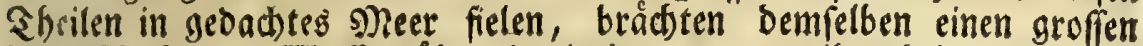
Heber(d)us yom 2Baffer über basienige gu, was ifm bei ben groffen Stromen entgehet, Die im 2Binter fleiner fino, uno gegen ben Sommes

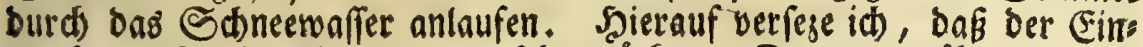

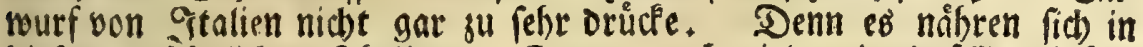
biefem anfehnlichen Sbeile von Europa now viele mittelmåfinge Flüffe aud im Sommer bont Sdunee, ber auf ben hoben (Sipfein, wie aud) an ben fobattichten Seiten bes 2tpennins tiegt, uno belfen zu fold)er Zeit Den Ueberfa)

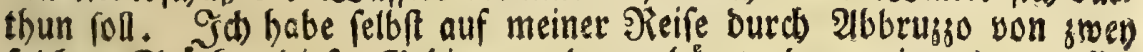
fold)en Stuicten biefes Siebirges reben gehöret, berer eines la Maella, Das andere il gran Saffo d'Italia (Der groffe Fels von 2 älfoblano) - ber il monte Corno, Der bornbera, bon bem gemeinen Manne ges nannt wirb, weil biefer $\mathfrak{e r} g$ auf jwey Backen fich endiget, weld)e wie Scơrner ausfeben. 2luf beiben liegt ber Shnee nod) fpât in ben Som mer binaus, ja er vergebet aud) in manchen Jabren nicht gånilid), wie Denn die umliegenden, auf zwen uno mebr Fagereifen entfernten Stăb. te, wenn ibre Sobneegruben ausgeleetet fino, ober wenn in $23 i n t e r$ in ifre Giegend fein Schnee gefallen, Denfében im groften Som. mer, zur Rúblung Det Sietrăncée, von gebadten Bergen bolen fom: men, unb auf Eafthieren in Săcen, bie mit Spreuern inwendig bers: um beleget werben, Des Nachts von Drte zu Orte fáumen. Die Tes, ftung Destara in 2 bbrugso beoienet fich aud biefes Sdnees und Eifes.

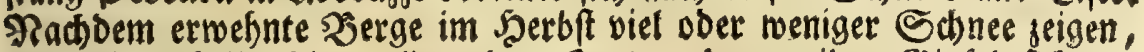
Darnac) urtheilen bie umliegenben Serter, benen ibre (Gipfel fidjtbar find, ob ein ftrenger oder milber 2 sinter folgen werbe. Won biefem Sdnee nun, ber po pär aufthauet, úberfommen in Sommer viele

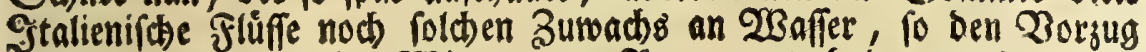
Der andern, welde im 2 inter vom Segen unterhalten werben, um

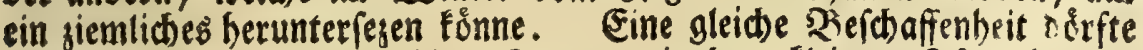
eछे aud) nod mit bem Sebirge Taurus, in bem fleinern Slfien haben.

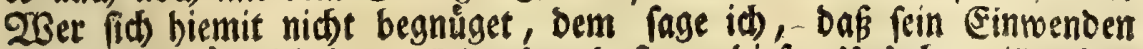
einestheils grundlid fev, allein obne Daß um biefer urfache willen Das. sebrgebăube von ben susbuinfungen úber ben şaufen falte.

Der 
Der \&fters gepriefene Naturforider Sar. \lancus, nunmehr Sienis

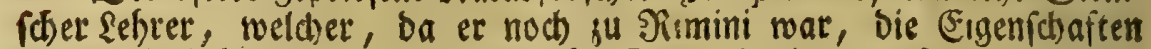
bes 2oriatif(t)en Bufens Durch mefr Sahre beebachtet hat, verfichert

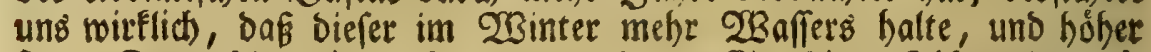
fer). Denn feine Propor. VI (a. D.56 S. Peiner Abhanblung de Aeftu maris) lautet to: "s Mare Hadriaticum in litore Arimi"nenfi (veluci flumina, torrentes, et lacus omnes) plus פ aquarum continent hieme quam xetate., Und Das fónnte aud) auf bem Mittellånbifhen Meere, beffen jenes nur ein $21 \mathrm{rm}$ iff, eben fo fich befinden; ja wem biefes lejtere im $2 B$ inter nur um einige Bolle bóber ift, fo hat es fiton viel fu bedeuten. In bem fcholio jur gemelbten V I Propofition fosteibet $\mathfrak{h r}$. Plancus: Mare noftrum bieme femper magis elevatum eft, et urbi noftre propinquius, quam aftate; idque perpetuo per quinquennium cognovimus ex notis illis, quas muro interio$r i$, et palis exterioribus portus noftri appofuimus. Alii videbunt utrum boc contingat propter majores pluvias, et propter ingrefjum majorem aquarum fluvialium in mare bieme quam aftate; an propter minorem evaporationem aquarum maris a radiis folaribus factam biberno tempore quam aftivo. Noftrum modo eft obfervationes pracipue, et qua patitur mare, referre, non conjecturas declarare, et bypothefes confingere. 2tuf Der folgenden $\mathbf{S}$. nod) in eben biefem fcholio, erflåret istgerůbmter sefrer feine 2ln merfung ferner, wenn er fagt, baß er Das 2(briatifhe Neer bei Neimini im 2Binter um einen Sd)uh hơher beobadtet habe, als es im Som:

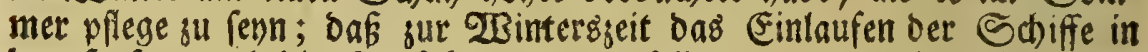
ben bafen, uno bie 2luşfahrt aus Demfelben, um ein vieles bequemer verridtet werde; Dafi bas Neer zu foldher Beit auf 60 Schub Der Stabt naber fomme, ja wo bas Eroreidt nidte erhaben ift, Da breite fich beffen 2 Baffer auf 200 Sd)uh weiter in bas sand binein, als ges wònhlict, und uberfatwemme daffelbe, wie er biefes Prop. X, und im

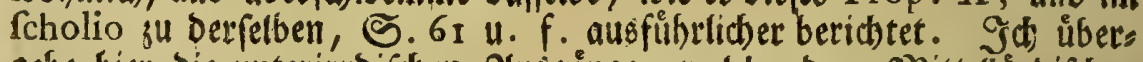

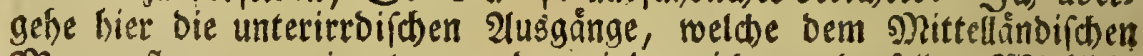
sheere plegen zugeeignet zu wetsen, inbem id) von berfetben 25 irflids Eeit nicht to feft überjeuget bin, als ßird)erus, Soerbinius, Sappelius,

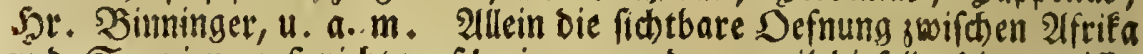
und Spanien mus nid)t veríbwiegen merden, weil diefelbe die getwiffes

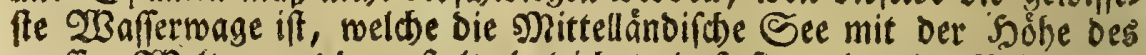

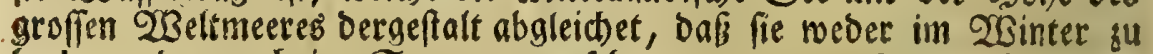
hod merde, nod im Sommer gu fefre vertreuge. Sat biefes meer 
zuniel 2 Baffers, fo wiro es burch erwefnten 2 Beg abgezapfet. Sat es brfien su menig, allo baf feine Oberfiàc) beginne niebrer fu werben, ats Diejenige ift, welche ju folcher aeit bas 2 Seltmeer hat, fo fleffet bems

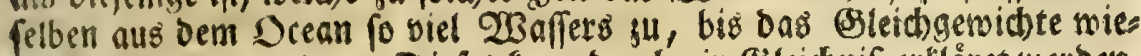
ber bergeftellet werde. Diefes fann Durch ein (Sleidnif erflaret werden. Dent wenn einige 2 Beiber ober Yeiche fo angelegt fino, bas bas 20 afer von einem in ben andern, von biefem in ben Dritten H.f.f. laus fen funne; fo fieffer Daffelbe, wenn bei einem Diefer Seithe eine frarfe Tbjapfung vorgenommen wirb, aus ben ůbrigen in Denjenigen, Dem man fein 2 affer benimmt. (ddd)

Eben defwegen aber balte id) es nicht für ausgemad)t, bas oer Einfluf Surch die Strafe, im WBinter unb Sommer, ofne Unterfocid, gleid

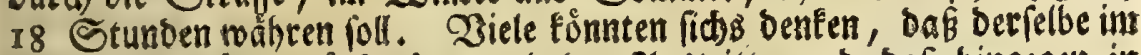
gỉnter (đ) wá̉b)er oórfte fenn, als ber 2(ustritt, unb baf bingegen in

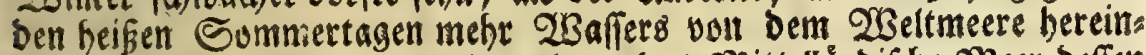
fomme, als binaus, wenn ia anders bas Mittellänifabe Meer befien nidht mebr im $23 i n t e r$ verlieret als im Sommer. Fluf biefe Art Eonnen bie freitenden Beugniffe oon bem 2usfuffe und Fintritte bes Waffers burch gemelote Meetenge, auseinander gefejt merben. Dies jenigen, welde verfidern, es flieffe aus bem Mittellandifonen Meere mehr $23 a f i e r s$ binaus als berein, iren meines (Erad)tens nidbt, allein fie borften in ben falten Monaten, vielleicht aud nach einem lange an: baltenden $23 e f t$ ooer Troroweft, diefe \$reerenge beftotiget, und ince ₹efकaffenbeit unterfuch baben. Sindere, bie mit Furnerio berichten,

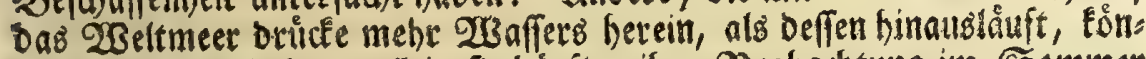
nen nudb red)t baben, allein fie borften ifire Seobad)tung im Sommet angeftell haben; uno bie mit ben alten fatreiben, bas Atlantifite gleer

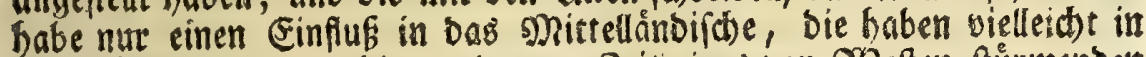
ber gróften Sommetshize, ober zur Beit eines oun $23 e f t e n$ frurmenden

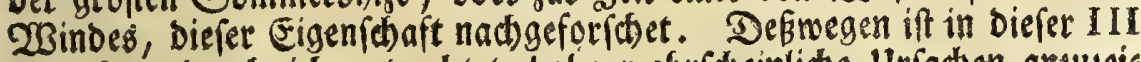

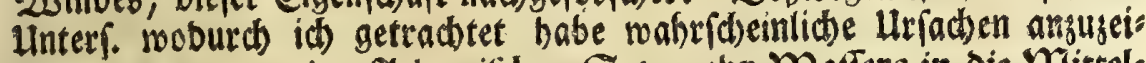

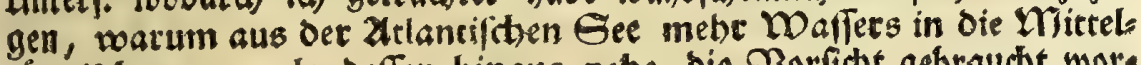
Ianoift)e trete, als oeffer binaus gebe, bie Dorfidt gebraudit wor: ben, oafi ioj gleid anfangs erinnerte, uno jum Doraus fejte, es múffe mit Dem Beridte, welden Der Şr. Derfaffer Der Shrift de COL. $x$ HERC.

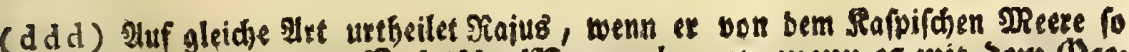

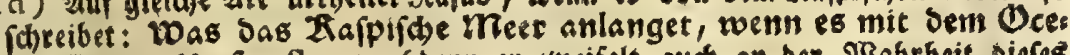
an Gemeinfdaft pfleget, (benn ex jweifelt aud) an ber $23 a b e b e i t$ oiefes 
HERC. aus bes Furneriug syorographie anfúbret, und weld)er bee Gegenftano biefer unterfuchung gewejen, feite Srichtigfeit haben. Denm

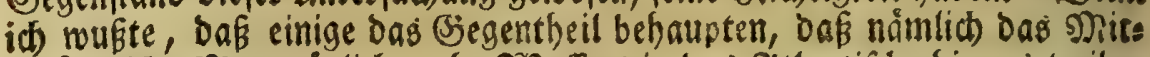

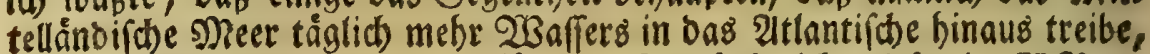
alš es beffen wieber herein empfăngt. Das habe id gelefen im V $\mathfrak{B a n s}$

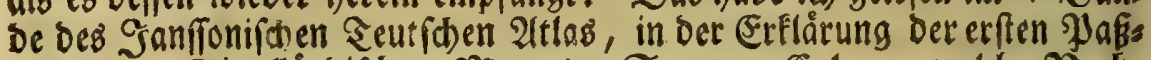

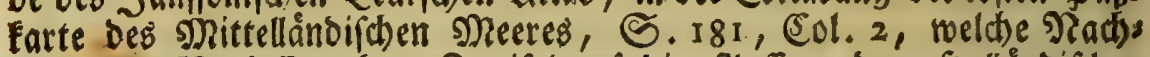

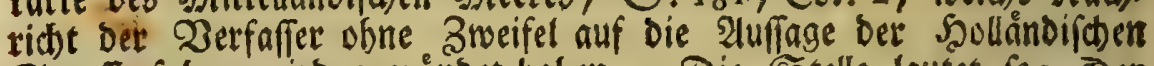
Etraffenfabrer wirs gegrunbet baben. Die Stelle lautet 10: Det Strom laufet gemeiniglict mebr nad) dem riedergang, denn nads 2ufgang, to oaß ex fifkter ourd) die Etraffe binaus, denn binein geber, und wăbret der Znlauf des Waffers aus dem groffen meere in oie Srraffe binein bei gutem wetter 4 Stunden, oer ablauf aber oder Jurtedlauf in die 8 Gtunden; ift bisweilen befrig, uno gefabiebr mic einem farken Gerofe, eben als wann oas Waffer úber Klippen und untiefe Derter binnber rauft)te. 2uf gleid)e 2irt laus

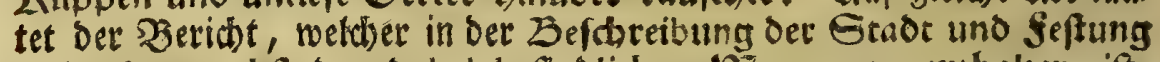
Gibraltar, nebft oer dabei befinolitien nizerenge, enthalten ift.

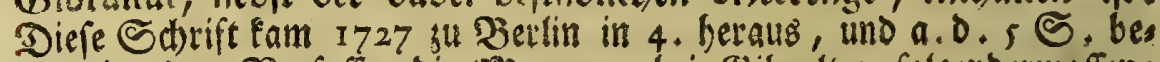
fhreibet der Derfaffer bie Mnerenge bei Bibraltar folgendermaffen: Gie ift tief genug, uno fider $3 u$ befabren. Zei oer Jnfel Cariffa

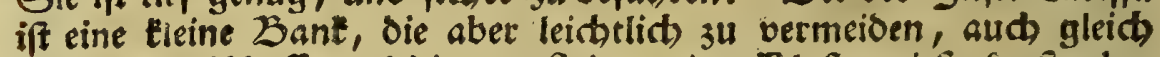
umber oas Daffer 16 bis 17 Saden oder Klafter tief, ronit aber etwas weirer vom Lande fo tief, oaf man nidhe ankern Eann? Jut

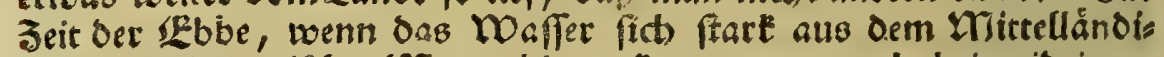
foren ins atlanif he Mier zieber, tann man aud bei wibrigem Winde mit Dem Grrom die Grtaffe berauspalfiren, fedorb bei ans gebender Siuth mus man 2inker verfen, bis oie Q Eboe nad) 6 Gtun=

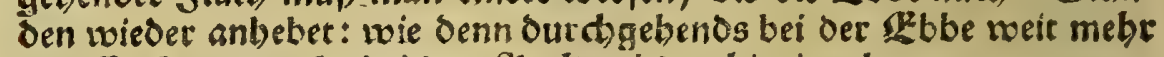
Woffer beraus, als bei oer $\mathbf{f l u}$ th wieber bineingebet.

Diefen owen Zeugniffen miderftebet bes Dlinius meinung, oer

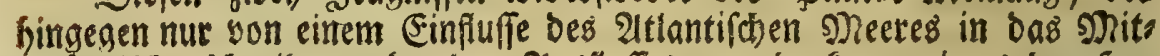

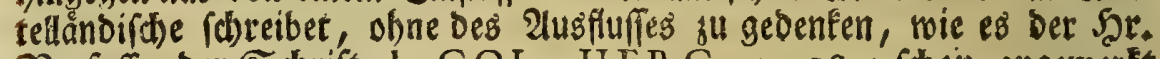
Zerfaffer ber Sthrift de COL. HER C. p. 18, folon angemertet bat, Plinii $290 r t e, I I I$, in procm. lausen fo: Origo (terrarum orbis)

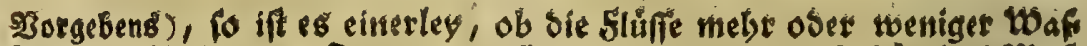

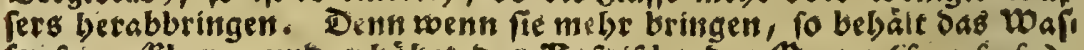

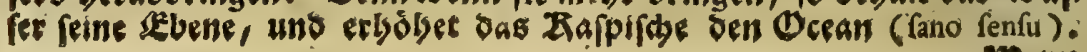

Wenin 
ab occafu folis et Gaditano freto, qua irrumpens Oceanus Atlanticus in maria interior diffunditur. Uno balo Darauf: Oceanus boc, quod dictum eft, fpatio Atlanticum mare infundens, et avido meatu terras, quacunque venientem expavares demergens: refipentes quoque flexuofo litorum anfratu lambit EC. So foreiber aud Inela, 1, 4: Nunc exactius oras fitusque dicturo, inde eft commodiffimum incipere, unde terras noftrum pelagus ingreditur. Eg befräftigen abel aud bie neuern Yaturtunoiger biefen Bericht Det Altets. Zob, Greaves (Gravius) bat ebenfalls nur einen Einflü aus bet 2tlantifo,en See beobadtet, wie in bes Sajus pby. ficostbeolot. Berr. S. 20 , gu erfeben. So find uns nun foldser

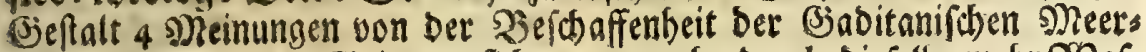

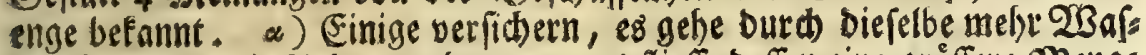
fers berein. B) Anbere geben vor, es flieffe beffen eine groffere ฌenge binaus. y) Wieber anbere wollen befaupten, Daf Das 2 Belimeer nue Gereintrete. \$) Die vierte 2 adbridt, neld)e id bier gum erftennal ans fúbre, ift ber britten gerabe entgegen gefest. Serbinius erjåblet diff: de Cataract. P. 107, bap ber Dcean fo wenig einen ordentlid)en Finflus

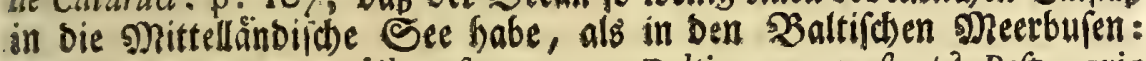
Quaris ex me, cur nobile noftrum mare Balticum non aftuet? Refp. quia Oceanus reptentrionalis incremento periodico in ejus alveum non influit, quod quidem Varenius faljo adftruit; fed aquis maris Baltici per fretum Codanum et finum Fionicum prorumpentibus, eftus influxus Oceani repellitur, quod avrowla in freto Codano, et glaciei in Oceanum inde propulfatio evi. denter oftendunt. Sic neque Oceanus Atlanticus per fauces Gaditanas in alveum Mediterraneum infuit, quemadmodum aliqui volunt.

Es ift aber Feine unfeblbare Folge, Daß eine biefer 4 wibrigen Mei

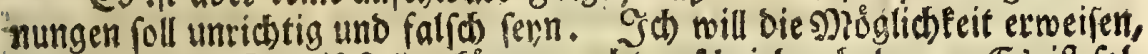
baf alle biefe Sdriftfteller fonnen red)t gefdrieben baben. (Eo ift fol des vielmefr fojon bargetban worden; ich Darf nur bie bereits erftrittes nen 2 Babrbeiten bier wieberbolen und beifammen vortragen. Es Eann nómlich zu gewiffen Beiten, aus bem Mittellandifhen Meere. Durd bie Straffe in ben Dcean mets 2 Baffers hinaus, und ein andermal Deffen eine groffere s)enge berein fiefien. Sa im Sommer, wenn bie Alus:

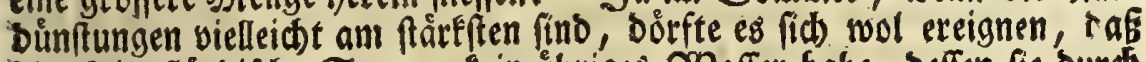
bie Mittellánbifbe Gee gar fein übriges 2 Baffer babe, beffen fie Duré I 2

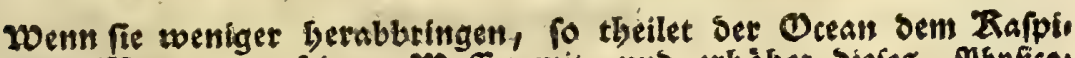
fden meere von feinem waffer mit, uns exbobet piefes. \$byfico! speol. Bett. S. II2 H. f. 
gemelbten 23 eg fid) entladen muiste. Sn biefem Falle wirb biefelbe viets mebr eine beftindige Derftảrfung bon aufen herein begefren, uno ben

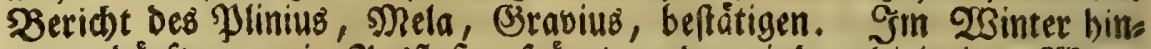

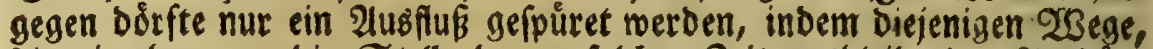
Die wir oben, an bie Stelle ber zu fold)er Beit ausbleibenden 2lusbuns ftungen, vorgef́tlagen baben, Den erforberlichen 2lbt:ng bes 23 affers

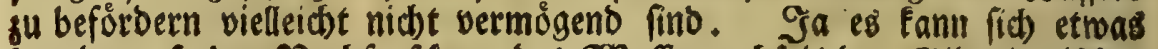

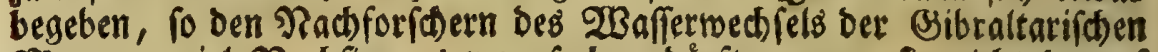
Meerenge biel Maddfinnens verurfaden Dỏrfte, wenn fie nid)t Darauf

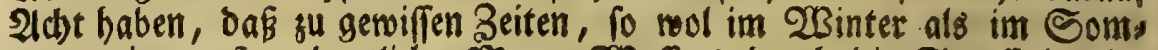
mer, eine auferorbentliche sinenge WBaffers burd bie Straffe bereim

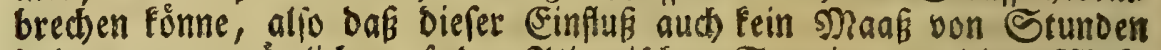
balte, renn nåmlid auf ber 2ltlantifchen See ein gewaltiger $23 e$ eft

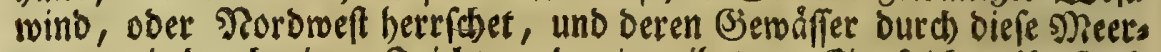
enge, wie ourch einen Frid)ter, bereintreibet. (Ein foldber unftand verurfachet auferordentlicke Heberfotremmungen um Şamburg, und in andern (jegenden an Der Elbe. Zu fold)er Zeit muiffen alle flache నíften

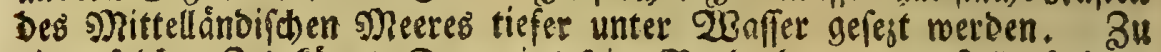
einer folden Zeit fơnnte Furnerius feine $\mathfrak{B}$ eobact)rung angeftellet haben. Wer follte glauben, daß ein farfer abenomino, Der von ben Sanaris

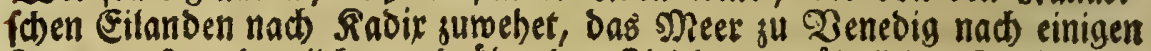
Fagen auferorbentlid, und úber bas Biel ber gewóbnlidsen Fluth, aufs bläben foll? (Es mus gleidwol, nach meinem wenigen \&ebrbegrife von

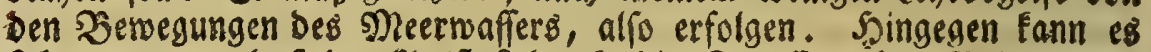

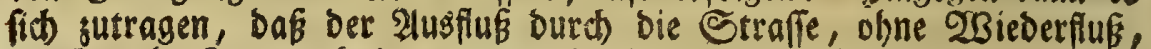
burch meht Fage anbalte, wenn vielleicht langwierige 2 dbenominoe fo: viel (SEemåffers bereingetricben baben, Daß fold)es in einem Sage nid)t

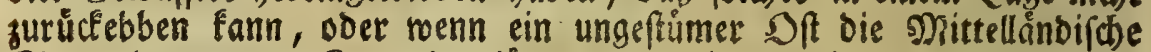
See, einen ganjen ₹ag ober långer, nur hinauszminget. WBenn nun

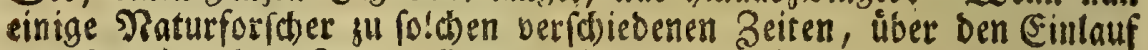
und 2lusgang bes gleerwaffers burof bie Strafie, ifre Unterfudungen vorgenommen baben, fo můffen aud ifre Ergăblungen unumgånglich wiberftrebent fenn. 2illein es ift biefes, wie id bereirs gefagt habe,

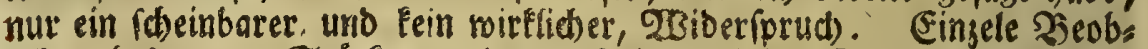

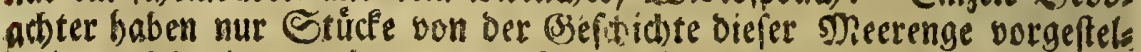

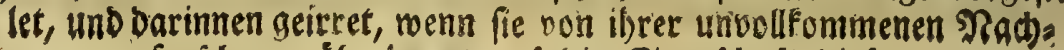
foridhung, úberhaupt auf Die Eigenimoft Diefes Jafles gefdolofien. 


\section{Wevte Beilage}

zur III Unterfudjung.

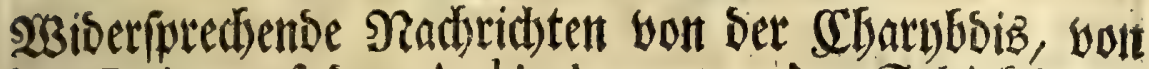
Dem Euripo auf Dem Archipelago, von Der Salgigfeit Des Meerwaffers, werben erflaret, und vom 230 bers pprudise befreyet.

7. Sel Der (Jibraltarifoten Feerenge ausgelegt babe, Eơnnen aud) Die freitigen Seridste von ber (Eharybois, bon bem Euripus, wie aud bie uneinigen 2 luffofungen ber Frage, ob Das sheer oben ober unten mefor gefalien fen, zum wahricheinlichfen entiobieden werben. Zon ber Eharybois ju reden, to fajreiben einige, diefelbe fen ein gefäbrlicher Writbel, ber Sd)iffe, und alles, was ibm su nabe fommet, in ben $2(b=$

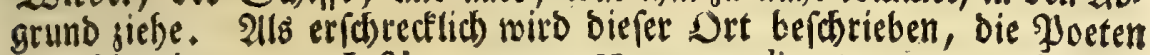
gu gefohmeigen, von Juftino, 4,1 : Nusquam alias tam torrens fretum, nec folum citato impetu, verum etiam $\int_{a} v o$, neque experientibus modo terribile; verum etiam procul videntibus. Undarum porro in fe concurrentium tanta pugna eft, ut aliqs veluti terga dantes in imum defidere, alias quafi victrices in fublime ferri videas: nunc bic fremitum ferventis aftus, nunc illic gemitum in voraginem defidentis exaudias. Mnela hat eine gleiche $\mathfrak{A b}$ bilbung mit etwas fursern, allein nid)t weniger nadborucfliden 290 orten bavon entworfen. Id anguftum et anceps, er rebet von bem freto Siculi maris, alterno curfu modo in Thufcum, modo in Fonium pelagus perfluit, atrox, fevum, et Scylle Chargbdisque fevis nominibus inclytum. Scylla faxum eft, Charybdis mare, utrumque noxium appuljis. Dab biefe Sici lifhe seerenge, zufórberft ber Ecylla und Ebarbbois halber, nod

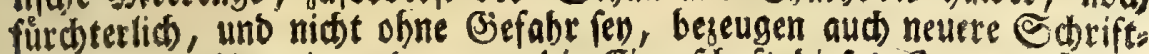
ftetter, wie Cluveriug, Der, um bie Eigenfichaft biefes Srtes grundis:

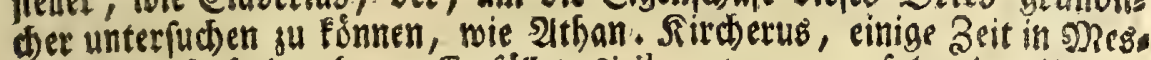
fina fich) aufgefbalten bat. 'Er fállet, sicil. ant. p. 30, folgenbes Urtheil Davon, und beftátiget namentlid) bes Mela aeugnißs von eben biejem

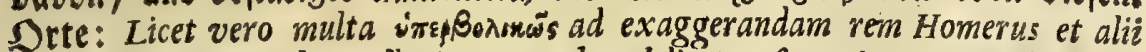
ide boc freto, five de Scylla in eo et Cbarybdi, confinxerint; tamen re vera ocus per fe fatis eft formidabilis, periculofus, et, ut. Mela $l .2, c .7$, ait a 3 
appulfis noxius EGc. Anbete, und gmat etliche Der neuern श्रRaturfunt biger, láugnen alles, was yon ber Sefăhrlicteit ber. Sharbbois vor: gegeben wirb. Diefe berfidern im Sjegentbeile aus eigenem 2lugens. fibein, fie wairen mit geringen Sdiffben, obne etwas wibriges aus: zufteben, barauf berumgefabren, uno bătten an biefem Drte nut eine facte Serumorebung Des $23 a f f e r s$ bemerfet. Daffelbe fúbre fwat ben Rabn, wie burd ein Ednectengetriebe, berum; allein nacboem berfelbe burd immer engeres Siewinde in die Mitte gebradjt worden, oa begegne ifm ferner nid)ts bebenfliches, fonoern man Fonne ourch

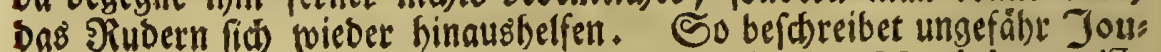
vin de Rodefort ben Sicilifhen 2 Birbel, in Des Martiniere Diq. Geogr. im $2 B$. CHAR Y BDE. -2llein ber $\mathfrak{E}$ eriकt diefer und jener Sdrifteller fann meines Eradtens wabr fenn. Siefes ift nur babei su beobachten, Das beibe Sbeile, einzele Stucfe von Der (s)efhid)te der Charbbois borlegen. 2Senn jemand ibee Sefdreibungen zurammentra: gen, und benfelben nur bie llmftende bon gewiffen Beiten voranjuregen bie snibe fich geben will, fo wiro er yon biefem LBirbel eine volfăn bigere Radididt liefern. Sie erfern, weld)e benfelben fur entfeslich ausgeben, baben ibn gu einet Zeit gefefen, on vielleidt bei obwalten.

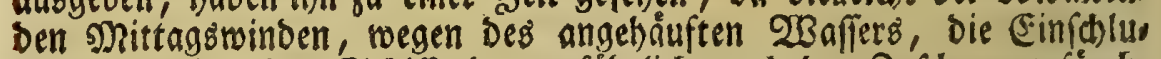

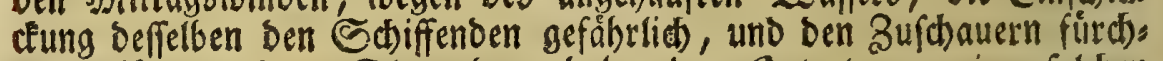
terlid ift (eee). Die anbern baben ben Srt etwa su ciner foldsen Beit befictiget, oa ber 2 Birbel ruhig lag, uno feine fonberlicten $\mathfrak{B} e$ wegungen machte, ober Da fein $2 \mathrm{~B}$ affer furude febrte, und oben her: aufwallete. Denn Rircherus bejeuget, Das Die Cbarybois Damals Den Eeeleuten bei weitem nicht fo gefăbrlion (ev, als wenn bas $23 a f i e:$ bineingesogen wiro: Cujus (Charybdis) natura eft, quod nunc, veluti fubjecto igni cacabo, perpetuo bulliat, nunc vortices veluti turbinibus agitatos agat, qui tanto navigantibus funt periculofiores, quanto ebullitiones minori periculo cosdem exponunt. Siquidem per ebullientem syrtim (fff) impu-

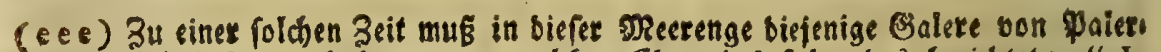
mo fich befunden baben, von tolcher Eluberius folgenbes beriatet: "In ng quem locum quum auftro flante Panormitana incidiffet triremis; in orbem " circumactam ac pene abforptam fuiffe, vixque ingenti omnium remigum, ") quibus inftructiffima fuerat, adnifu periculum evafife, narrarunt Cluverio " Meffanæ quidam Hollandi, qui eadem triremi yecti fuerant " Sicil. ant. p. 29. (fff) Das $\mathfrak{W}$ ort Syrtis ift bier, wie an mebr anbern Stellen, in untechtem Ber, fanbe angebradt; wie benn Sirdherus aud bos Euripus, unb andere 238 orter, jumeis 
impune, non item cum vorticibus agitatur, tranfeas. MUND. SUBT. Tom. I, p. 102 A. (ggg)

Die berfhiebene Beit bebet ebenfalls die wiberfprechenden Berids: te bon Dem Euripus auf, fo eine fehr fdmale, swifhen Euboea uno

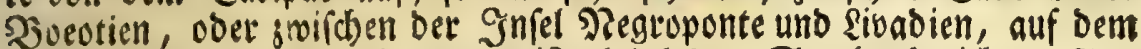
Archipelago gelegene meerenge ift $(\mathrm{h} \mathrm{h} \mathrm{h})$. Strabo berichtet, IX, 403, mit einigen alten $\subseteq$ briftfellern, der Euripus flieffe fiebenmal beš รages auf und $a b$. Diefes befráftiget aud snela, 2, 7: Eubca - angufto freto diftat a littore. Euripon vocant, rapidum mare, et alterno curfu, fepties die ac fepties nocte, fluctibus invicem verfis, adeo immodice fuens, ut ventos etiam ac plenis velis navigia fruftretur. So auch Se: neca, Herc. Oet. 779 :

\section{Euripus undas flectit inftabiles vagus,}

Septemque curfus flectit, et totidem refert,

Dum lajsa Titan mergat Oceano juga.

Des Suibas 2 orte lauten aud niфt anders: EURIP HS, anguftum mare, vel aquofus locus inter duas terras, boc eft inter Baotiam et Atticam. Septies autem quotidie ejus aqua mutatur. Sivius miberleget, XXVIII, 6, ro, biefen $\mathfrak{V}$ eridit, und meldet, Euripus fieffe gan; un: rid)tig auf und ab: Fretum ipfum Euripi non Septies die, ficut fama fert, temporibus ftatis reciprocat: fed temere in modum venti, nunc buc nunc illuc verfo mari, velut monte precipiti devolutus torrens rapitur. Es vet bålt fí aber mit biefer Mreerenge, nad) Den neueften SBeobad)tungen, folgenber (Seftalt. Sie bat ihre regelmáffige, wie aud) ifre unrichtige Fluth uno Ebbe. Som Peulichte an bis jum erften Diertel, uno vom bollen Monben bis zum lezten Diertel, ftrontet Das 2 Baffer in berfela ben orbentlich fwenmal bes ₹ages auf und ab, wie bie Sicilifose Meerenge, nach Anzeige ber Grfabrung, und nad Derficherung Des Strabo t, ibre Fluth und Gbbe innerbalb foviel Beit su treiben pfleget:

gumeilen miabrauchet. Die llrfache verformeige id gerne. Eg if biefelbe eine unftreitige, allein bittere 230 abrbeit.

$(g g g)$ (58 verbienet autc) eine Innterfung biex beigebrach) ju merben, marum man

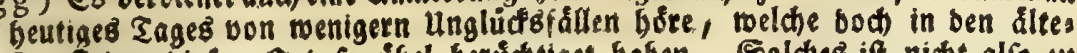

fen Beiten biefen Drt fo úbel betúdthtget baben. Soldes ift nidht alfo ju

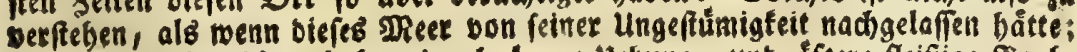

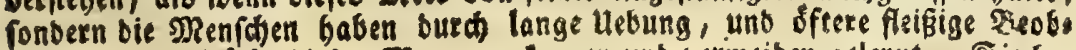
adtungen bie Sude biefer areetenge fennen unb bermeiben gelernt. Sie bas 
Ein Erweis istgeoadter $\mathfrak{B}$ eíhaffenheit bes Euripus, if aufer ber $\mathfrak{B} e$

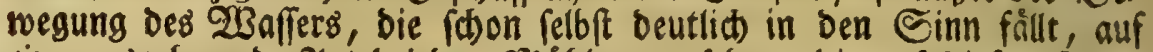

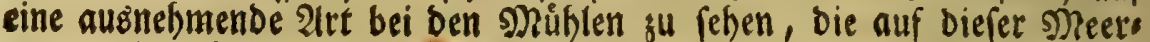
enge, wie auf einem Stuffe angelegt fino, weil Derfelben Siōoer, zu ben

\begin{abstract}
ben 8. E. eingefeben, baß ciue Itrfade ferner Befäbrlidfeit ben barinnen wis ber einanber laufenden Eseftrơmen fuzufhreiben fed. Da nun bie Eeeleute zugleich finb genabe rooben, baß biefe Etróme cine gewiffe Orbnung balten, fo baben fie aud angefangen fid) barnach gu richten, uno wiffen buroth ge:

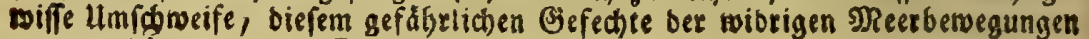
gu entweichen, wie es Rircher, Mund. Subt. Tom. I, p. $100 \mathrm{~A}$, mit biefen 230 rten anjetget: "Atque hæ quidem fævæ et immites procellæ non fem2, per (quemadmodum menftruo fpatio data opera Meffanæ commoranti mihi 2) innotuit) fuas ferociz (cenas agunt, fed tum vel maxime, quando venti 21 partim ex Jonio, partim Tyrrheno mari contrariis fluctibus angutti maris "fauces exagitant. Cæteris temporibus, etfi quoad fuperficiem tranquillum ") videatur, nequaquam tamen a confuetis fibi interioris machinationis tumulti"bus ceffat; led ita ad lunæ afcenfum defcenfumque fluxus fuos moderatui", " ut vel ipfi nautæ, a puero huic freto affueti, currentium rationem vel ad 2) primum lunæ afpectum prædicant; luna vero nubibus obduata; ex curren") tium fluctu ejus in coelo ftationem cognofcant; quæ omnia fumma fimul et " curiofitate et admiratione a me comperta funt: unde infańe olinı nanfragiis , fretum modo tam facile tranfitur, quam quodlibet aliud, horum nautarum " peritia; qui naves per varias ambages fine ullo periculo ita deducere folent, " ut devitatis contrariis currentibus, vicinum mox recta tendentem aufpicen" tur, donec tandem terminum affequantur. Si vero neglecto horum nau"g tarum conductu, inconfiltius fretum aliqui ingrediuntur, certo certius uti " abditas currentimn rationes nefciunt, ita manifelto quoque fe naufragii periculo exponunt, nifi mox auxiliari conductorum manu a periculo liberentur.", wenn es fit) zutahgt, Dafi ein groffes Ediff an einen foldten Ort biefer

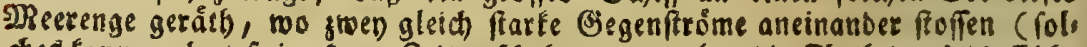
ches fann aud) auf eine furfe Zeit gef́cheben, wenn eben die gluth ourch bie (5bbe abgelơfet wito, meldes allema! úber 6 Stundert erfolget) (o bleiben auch bie Echife unberweglidh fteben, wie id es felbft gefeben babe, SRirderus aber an vorgemeloter Stelle mit nachgelejten Worten befeuget: "Eft Religionis "noftræ Meffanæ tyrocinii domus in edito loco fita, ex qua totius freti lon"gitudo obtutui patet. Ex hac non fine adiniratione fubinde notavi, naves 2) etiam prægrandes et onerarias, expanfis etiam velis omnibus', ad inultas ho9. ras ita hæfiffe, ac fi trabalibus clavis affix $x$ detinerentur; quæ mox tamen ") mutatis currentibus, et peritia duatorum emerfæ, curfum occeptum conti-
\end{abstract} 9 nuarunt.

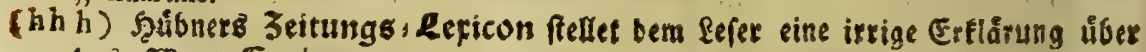
bas Wort Euripus bor. Es wiro bafelbft gelebret, (Euripus fen ein meerftrubel ober Wirbel im Meer, melder Das waffer fiete in form einet 
bemerfen stoentlichen 3riten, des sages jmenmal auf bis eine, swev:

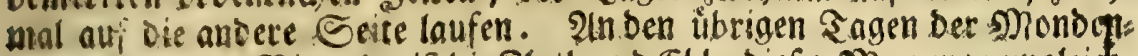

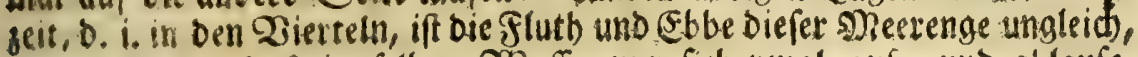
aber nid)t to, Dab Derfelben 20 nffer nur frebenmal auf: und ablaufe. (3)

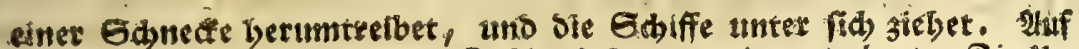

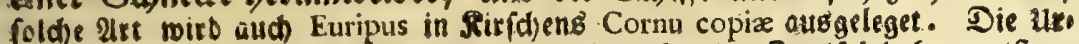

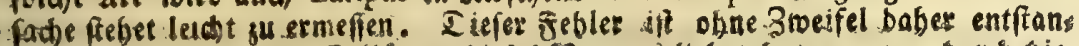

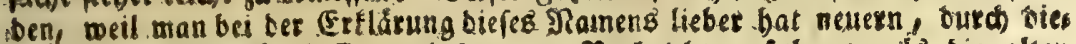

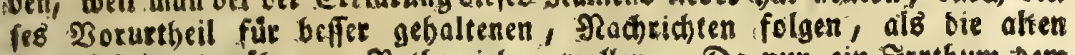
carifteller baruber ju Fiatbe tieben sollen. Da nun ein Irthum bern anbern u Keiner Sied)tfertigung bienen fann, fo entidultoiget borgebachte uns

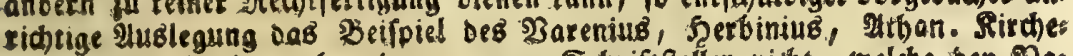

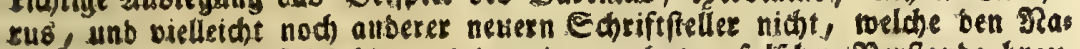

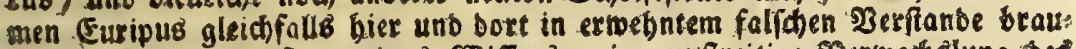

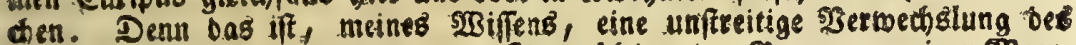

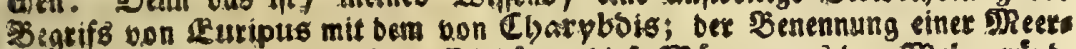

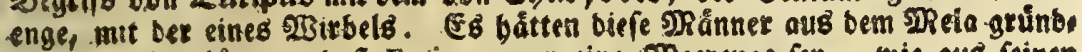

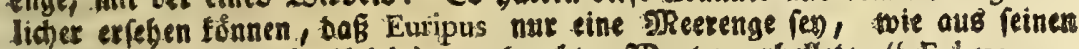
in Serte gleid) nad) ( $\mathrm{hhh}$ ) angebrachten 230 orten exbeflet: "Euboa - angufto freto diftat a littore. EuripoN vocant, II, 7. Suibas forretbet auc): 66 EuR IPVS, anguftum mare, inter Boeotiam et Atticam., Nidht

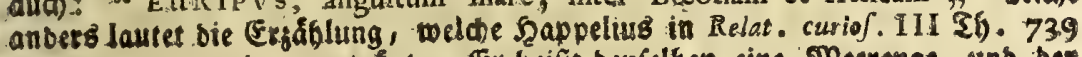
S. ben bem Euripo vortrăgt. (Ex beifit benfelben eine Meerenge, unb bex Bericht von feinen Gluthen ift nad ben neuern Beobastumgen gefeflet. Mllein ex hat ridhtige uno unxidhtige Sachen zufammengebracht, baburh et

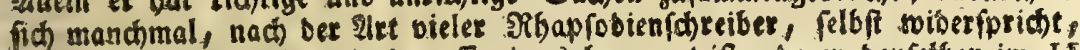
nie es ibm ebenfalls mit bem Euripus begegnet if, ba er benfaiben im II

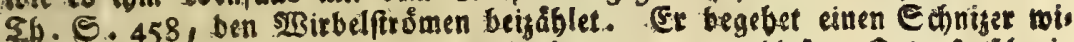
Der bie Ratinitat uno Raturlegre sugleid, senn er an biefem Drte fo fatecis bet, nie \$areniuళB, geogr. c. 14, prop. 31: "Nautæe vocant hosce vorti, ces et gurgites Maelftroom, latini etiam Euripum., NBeiter unten lieft man 10: "Vortex et Euripus ad Norvegiam omnium celeberrimus et maxi70 mus, etenim tredecim milliaria habere fcribitur in circuitu., Diffes iff

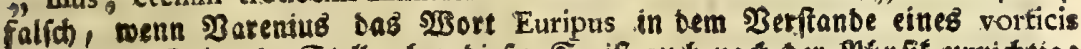
braudet. Golgenbe Stelle eben biefer $S$. ift aud nad) ber \$onfif umxidtig: $₫$. Chalcidicus Euripus feu vortex celebris eft prope Græciam, inprimis proptex , fabellan de Ariftotehs morte et obita, benn Diefer (5uripus ift tein $23 i t$ bel. In biejen Etellen wirb Euripus mit Vortex vergefellifor) aftet ( fo aum in Herbin. diff. de Cataralt. Sfters gefdieht) ba foldhez 230 ort nur mit fretum fid verbinben lägt, ja Plinius fezet baffelbe mebs alz einmal fdjlechtroeg ani

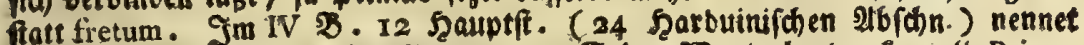
ex bie Meerenge von Saflipoli euripum. Seine SBorte lauten fo: " Primas 12 anguftias Hellefpontum yocant. Hac Xerxes Perfarum rex conftrato in nan vibus 
Es fliffet baffelbe in einem buirnerliden sage, eiffs swostf: brenzehene bis biersebermal, und nods ofters, auf und ab, wie es ber Jejuit

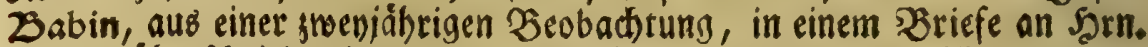
pecoil úberíchrieben bat, wovon man Spons Reifevefths. T. 2, p. 193,

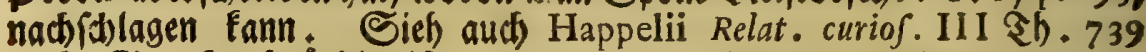
u. f, S. Merfwurdig ift Der Beridt, welden Paul Rucas, Voyage

9, vibus ponte (confrato navibus pontó) duxit exercitum. Porrigitur inde te"nuis euripus LXXXVI mill. paff. fpatio ad Priapum urbem Afiæ, qua

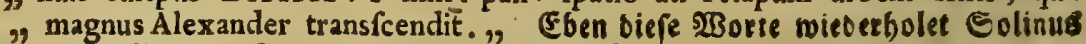

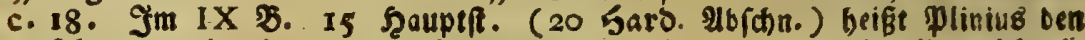
Bofphorum Thracium fneymal earipum. "Eft in euripo Thracii Bofphori, "quo Propontis Euxino jungitur, in ipfis Europam Afiamque feparantis freti "2 anguftiis, faxum miri candoris \&c., lunb gleid barauf: "Itaque omnis is captura Byzantii eft, magna Chalchedonis penuria mille paffuum medii in") terfluentis euripi., Sn einem mit bet theerenge vermanbten 2 erfan De gat plinius, VI, 23, 5aro. 26, Das $2 B$ ort euripus gefegt, ne̊mlich fút einen foiffbarn Ranal, melcher burch untiefe Dre bingebet, Dergleichen

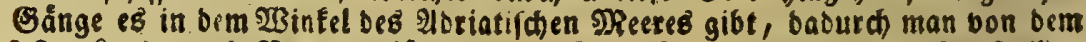

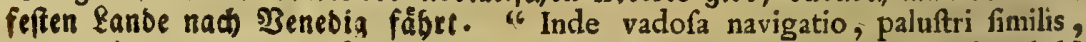
per euripos tamen quosdam peragitur. $"$ In ber Bebeutung eines $23 i r b e l \hat{B}$

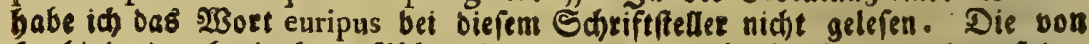
- Seerbinio in obgebachter 26banblung, p. 130 , befhriebene, und auf bet

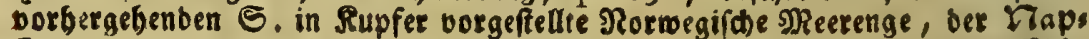
froom genannt, ift cin mabrer Euripus, auber bas bie fluth und Ebbe

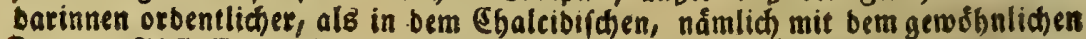

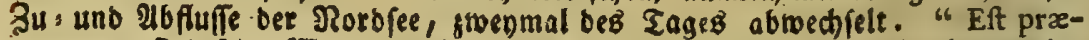
"terea, fino feine 230 orte an befagter Stelle, alius alveus verfus feptentrio"nem, accolis Napftroom dickus, tantze violentix, ut flantibus coro vel ze" phyro, maximas quasque pifcatorum naves convellat atque opprimat . Re" cedente mari curfum convertit, inque Oceanum occidentalem effunditur; "2ccedente vero rurfus in alveum voraginis illabitur ac refluit., SBenn aber $^{3}$ ein Irrthum, bee bei einer bloffen Erfăblung be zangen wiro, fhon zu tabeln ift, befto exbeblidbet mirb er, wenn man in Exflátungen, baburd bem - Jus

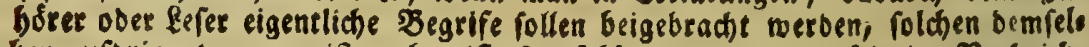

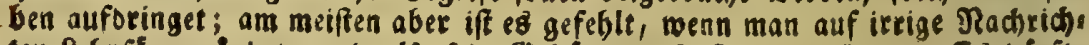
ten Eibrjăfe gründet, und alfo fein Bebáube auf Eand binferet. Ez dófte

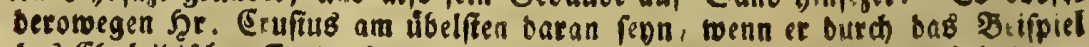

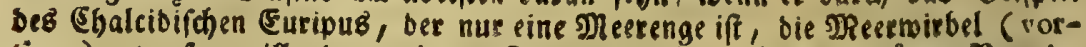
tices) erweifen mill, ba ex in II Th. frimer anl. íber naturt. Begeb.

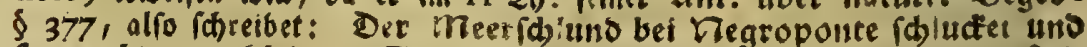
ip yet bis 7 mabl in 24 Stunsers, Cbarpbois aber binnen fo virl 3eit sreymabl. Gcyila uns ansere folucten fets wafier ein. \$387 am

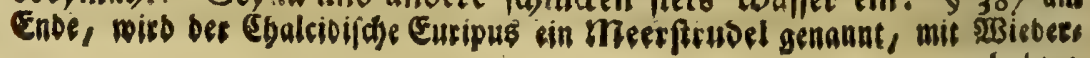


dans la Grece \&c. 17I 4, T. I, p. 220, von biejer Meerenge ertheilet. Er fagt, bafi diefelbe in einem sage nid)t nut 12, 1 smal, foildern bis zomal ibren Eauf veraindere. Er felbft babe fie in einer Etunbe fiebene mal wedfeln gefeben. Einen andern Eag blieb er 2 Stunden babeifte ben, und ward nut einer Zeránberung gerwabr. 2luf foldbe berfocies bene Beiten nun múffen bie ungleid lautenden Erjåblungen von biefer (3) 2 berons

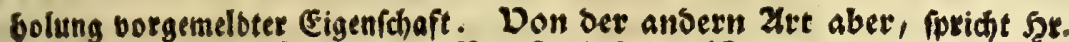
Erufüs oufelbft, foónute Der Meetftubel bey Regroponte feyn, wels doer th ungefelye 24 Stunoen 7 mall labludt uno fpeyet. Die exfe Stel le entbălt überdieß nod) andere pobfiffalifche unridtigfeiten. Der Someri!

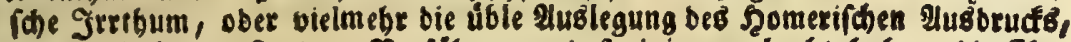
unb bie baber entftandene Berfübrung, oaß einige geglaubt baben, bie Sbas

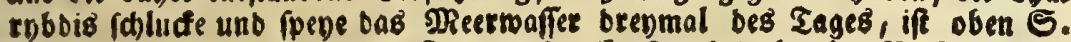
I52 u. f. abgetban morben. Die bon Scr. (Erufius beigebrad)te ßerficherung,

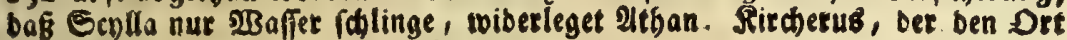
unterfutit bat, und beffen beiche. Mund. fubt. Tom. I, p. IOI A, fict mit biefen $230 r t e n$ anfángt: "Jam Scyllam ordiamur. Patitur ea, perenni ex9, perientia, fingulis diebus fuos affluxus refluxusque, qui hoc pacto contin"gunt \&c.," Эक wollte aud), Daß ber auf eben biefer Eeite ftehenbe Ext weis mit Dem Delpbine, bet in bas Rotbe SReet getworfen, unb bei Damias ta in bem Mittellänoifhen, wieber gefangen worben, von biefer phnfífali

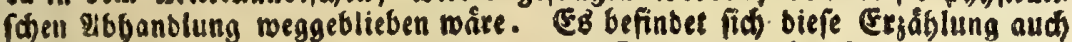
in Kirch. Mund. fubt. Tom. I, p. 87 A. Sie fauget aber beffer in Happelii Relationes curiofas, unb in anbere Peifebefdreibungen, um bas 25 unberfas ine, berfelben zu vermebren, und Den Riebbabern vorgultellen, als in ein Werf, barinnen bet Eefer wichtige $\mathfrak{B}_{3}$ abebeiten ber Naturlebre fuchet. Denn id febe nicht, wie aud nach Einråumung einer baburdh vorgetragenen biftos

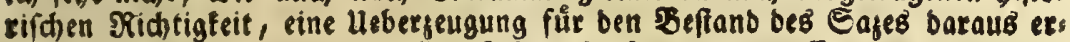
folge, ben man bebaupten will. İh mug aber von bem (Euripus noch exin,

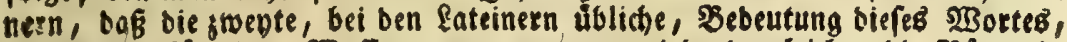
ba foldes fie einen Waffergang genommen wirb, bergleiden bie Romer in ibren Båten batten (in welchem Berftanbe euripus beim Eiceto, Eeneca,

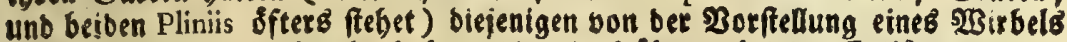

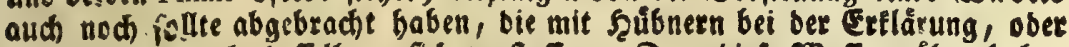

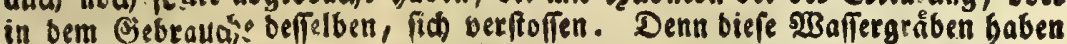

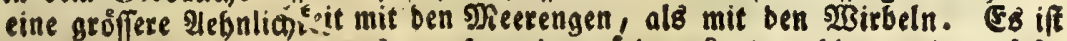

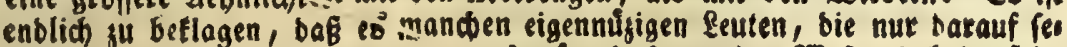

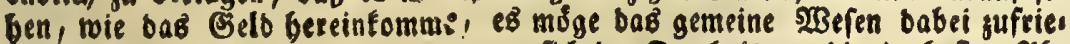
ben renn ober nidt, geftattet werbe: fid ber grenbeiten, bie in befter 246 . fid)t ertbeilet merben, allein babin ju besienen, baß̈ fie beffere Iluflagen von foldhen $w_{3}$ erfen bintertreiben mogen, bie nuť ebebeffer gut genug getwefen, nun aber in vielen Stuicten zu verbeffern waten. Einer befinbet fid nol babei, bingegen mebr taufeno betrogene IRenfd)en leideri baburch, und pet, 
befonbern smeerenge (bem (Efateibiftyen Euripo) ausgebeutet werben; wenn einige fagen, es fróme bas 2 Bafi: barinnen viermal bes Sages bin und wieber, andere aber behaupten, bas foldses fiebenmal ober nocts

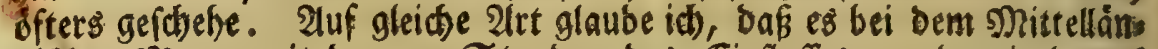
Difict Meere mit Den 18 Stunden bes Einfluffes, uno mit ben 6

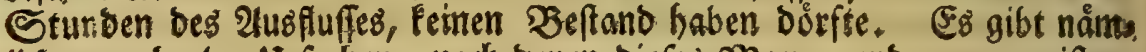
(id) mancberley Itrfacten, nach benen biefes Seer, uns zwar meiftel: theils qu gar untidtigen Beiten, mefr ober weniger 2 Baffers bat, Dets gleiden erfitid bie Flúffe fino, wefde ifm beften batb viet, bato weris ger jufufyen; barnad ungleidse, fowol von bem abrech felnben 20 ets ter, als verfobiebenen Sabrgzeiten abhangende Ausbunfungen, fernes bie 2 Binbe, bie Stróme, das unterirrbifase Feuer., andere Umfánde, und juforberft bie Monosverånberungen nidgt ungeredsnet zu laffen, mit benen auch oas 2 Sad)itfum ober ber Fall bes meermafferg, nad Der Eebre Der atten und meifien neuern Raturfundiger, eine (Semeins. fibafe bat, wo benn nach foldser mamnigfaltigen Sewanotnif Der Uria d)en, bei bem Saupteinfluffe ober 2tustritte diefes IReeres, $D$, $i$, in be: Straffe, eine Ungleidheit muf gu fpúten fenn. (iii)

Don ben miberfprectenden gleinungen, ob das obere ober bas

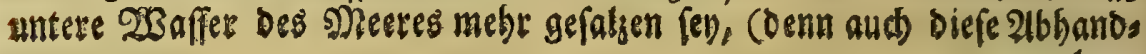

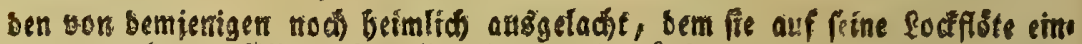

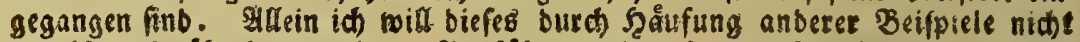

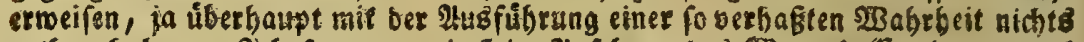

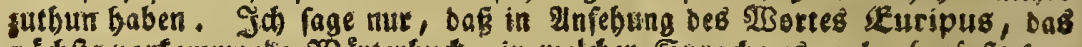

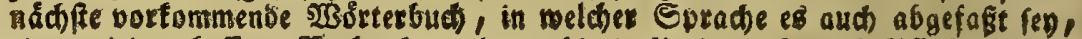
einen jeben beffere Siacfricht gebe, afi Dasjenige, fo aus Pfict, babon

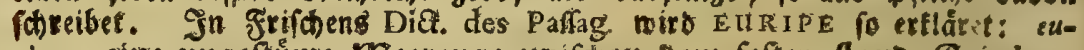
ripus, eine ungeftume meerenge zwifonen sem feften Rano Briedsen Lanses unt Ser Iniel Tegropont. Das Did. du Voyag. gibt es po: eine ungeftume Wherenge, oie ab: uns julanft, euripus. "Eg ift gemifis

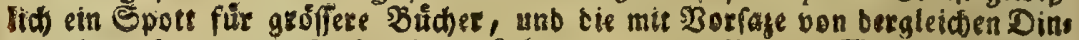
gen Ganbeln, werin gleidtwol bex fefer aus einem fleinern stserctden, einen

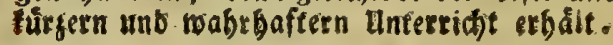

1 Hanc eandem ob saufam euripos quoque effe fluctuofos; maxime Siculum " fretum, quod eodem, quo Oceanum, modo xftibus agitari dicit: bis enim 7) quotidie mutare fuxun, ficut et Oceanus quavis ajie ac nocte bis exundat 3) atque in fe refluit, Strabo, I, 54. Eo auch a. b. folgenben Seite: De fretorum Aluxu et refluxir hoc pro inftituto noftro dixiffe fufficiat; non y) unum effe in univerfin modum aftus fretis omnibus: alioqui non Siculum "bis quotidie mutaretur, Chalcidicum (Euripus) fepties, Byzantinum nun-

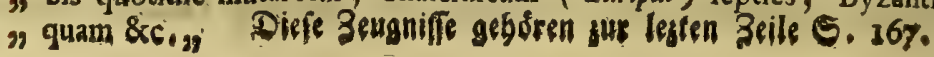




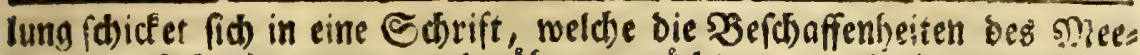
res unterfubet) etroas su berubren, módte man glauben, baj ber: bloffen Betraditung nadjugeben, weldse main úber Die (sigenfdift $n$ Der Sơrper anfellen fann, je tiefer bas Ineerwaffer ift, je mebr eo auch muste gefalzen fenn. Denn bas gefalzene $23 a f f e r$ ift fanerer. 230 . ferne biefes nicht waire, fo befámen wir fein füffes und trinfbares $23 a$ fs fer, bermóge ber 2lusounftungen ; indem nămlich Das Kegenivaffer

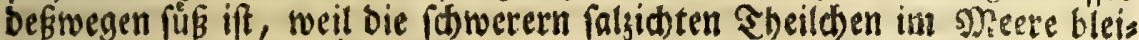
ben, uno nur die ráfferidten, bie leidter fino, Durd bie Sraft bet Sonnenbize, ober der $2 B i n b e$, ausgeboben werben; was aber nod modte forol vom Salge, als von Der flebricten uno fetten Bitterteit, mit aufgefiogen fenn, bas wiro nod in ber suft, im Suffeigen bis ;ut Dberften Soble Des Euftereifes, abgefonbert. Won Dem 2 baffer ber groffen gleertiefen berfichert in ber Sbat Mrarfillus, Das daffelbe fowerer (bift.de la Mer, p. 24) und aud mefie gefalien fen, p. 36. 2tlein Darenius behauptet, bietaus wăre feineswegs zu fhlieffen, baf Das obere Neermaffer nid)t eben foviel Salses balten fonne. Denn er lebret, geogr. c. 13, prop. 12, Daß das Meerwaffer gwar (bowerer lev, als ein gan füfes; und baf aud ein Neerwaffer bor bem andern

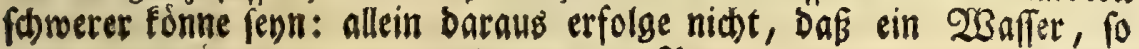

(2) 3

mebr

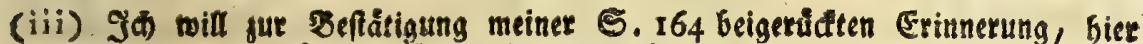

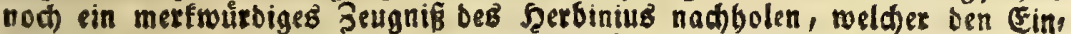

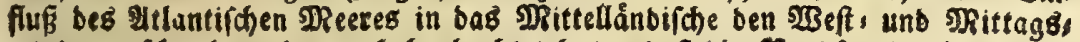
winden jufdretbet, ber aud beobachtet bat, Daß̧ bie Norbfee ourch mittera năd) tige अinde in ben man fonft nue einen 2 tusgang guleget: "Obfervaban hoc ano 1670 pro", ximo, in freto Codano, quod quoties non trajeci, et de induftria quidem. "Flante enim tum Coro, alio tempore Borea, Oceanus in mare Balticum 93 fummo cum impeta irrumpebat. Sic flantibus Zephyro et Africo Oceanus 3. Atlanticus mare Mediterraneum petit. "De Catarad. p. 93. Eben Der IReis nung iff atich Feuillé, Der bei Belegenbeit einer im füblichen sbeile von 21mes vita, bei Raguimbo, gemachten Inmerfung úber bie flutb unb E્bbe, von

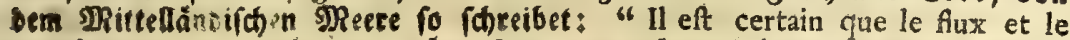
9 reflux que nous obfervons dans la mer Mediterranée, n'ont pas d'autre ") Caufe que les vents, puis qu'on remarque que dans cette mer les eaux " font pleines dans la faifon des vents d'Oueft et de Sud-Oueft; parce " qu'ils pouffent alors les eaux du grand Ocean; et les font entrer par le " detroit de Cibraltar dans la mer Mediterratiée, d'oǹ elles ne fortent qu'après " la ceffation de ces vents, ou lorfque quelques vents oppofez venant 1 " fouffer, obligent ces eaux à rentrer dans POcean. of Journal des obformat, $p .579$. 
mehr gefalsen ift, befiwegen nut) am Siewidte das andere úbertreffen múfe, weil eine beftigere Sddárfe bon einer grơffern Nienge fúdbtiges Salges berrubren fónte. So urtheilet aud Sircher, Mund. jubt. Tom. I, p. 165. Darnach geíest aud, bas bas unterfe Meerwaffer

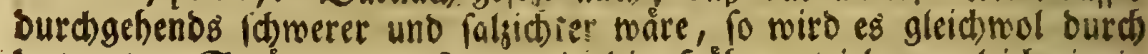
bas untere Stròmen Des sneeres in bie Shöhe getrieben, gleid)mie in Iopfen, bie beim Feuer fod)en, bie כ̧rủbe im råhrenden Sieden oben falsichter ift, als am Booden; ja man fieht, bak foldhe Sachen bie viel fówerer find, als bie Suppe ober 2 ruthe, im Sieden Durds Das Slufwallen empor gebradt, und im Topfe berumgetummelt mers ber. Es Eann also aus ben bloffen Segeln ber Naturlebre nicht beftimo

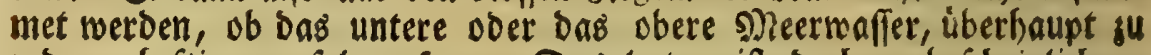
reben, beftiger gefalzen fey. Daz leztere ift bod mabricheinlider, reil bas burd bie 2lugbunftungen zurúcfégelaffene Sals auf ber Dber: fiåche bes sneeres bleibet, wegen bet befiàndigen 2 enegung bes $2 B$ af.

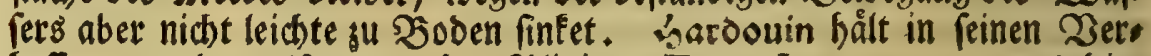
befferungen ber Hift. Nat. Des łlinius (Tom. I, p. 132, n. 84) bies

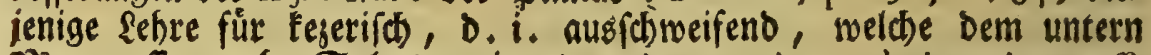
Mleerwaffer mehr Saljes zueignet: Scio recentiores plurimos in ea effe berefi, qua marinas aquas in imo falfiores effe pertendit, quam in fuperficie: quoniam aqua falsa, quam dulcis, ut Arift . ait, multo eft gravior \&ce. Warenius befauptet, bas das untere 2 affer bod nidt meniger gefal ien fê, als bas obere: Falfum eft aquas Oceani eo minus falfas deprebendi; quo fundo funt propiores, c. 13, prop. 8.

Meines (ract)ens wird ber Sas von ber groffern ober minbern Salgigfeit bes sneerwaffers eben fo renig überhaupt fid entid eiben

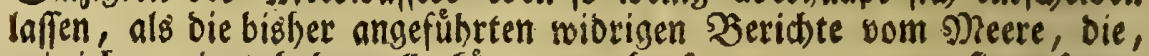
wie id) gezeiget habe, alle fơnnen wahr fenn, wenn man fie auf bers Thiebene umftande und Beiten bringet. Eine folde Betwanbtnif Dorfo te es ebenfalls mit bem Salse oes Meerwaffers haben. Denn bas obes re $23 a f f e r$ ift rüffer als bas untere, nach ftarfen Meer fallen, ferner bei ben 2lusfiuffen ber Strome, ia aut) nact) einer sweiten Strecte bes Neeres, wo ein groffer fúffer flus oben barúber

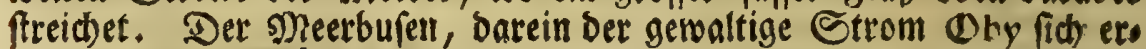

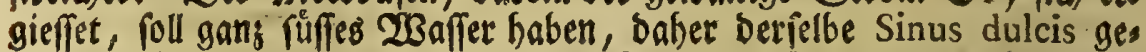
nemnet mird, Reife nach Torden, $\mathfrak{S} .510$. Das untere Meerwafs fer ift finfer an folden Srten, wo es fuffe Srunnquellen am Doben 
bes Meeres gibt, (kkk) ober gat füb an anbern Drten, wo ganje Friffe, bie ungefalienes 2 Baffer fúbren, am 20 oben bes meeres aus bet Erde bervorbrecten. Silfer ift bas meerwaffer, nac) ber unterfuchung Des Mrarfilius, bei mittelmáffigen Siefen; gefaljner aber, wie allbereit

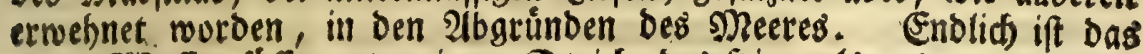
- bere $2 B a f f e r$ fîffer unter einem Strid)e bes Simmels, als unter einem

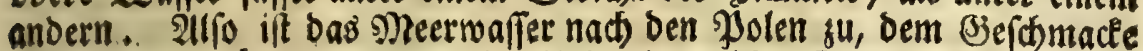

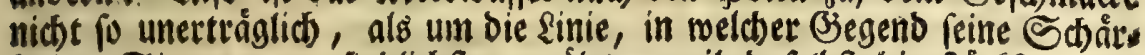
fe ben Sinn am empfinolichften quálet, weil bajelbft bie ftártfe 2lus: bunfung gefdiebt, uno bie zurúgégebliebenen Salgtheil(t)en bort in

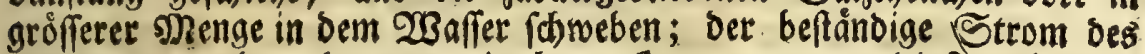
Weltmeeres aber, ber an gebadten Drten am genaltigfts ift, bas Sals oben etbait. Iuf gleide Weife ift bas WBaffer in einem szeere nidbt fo gefalgen im Xinter als im Sommer, Kirch. Murd. fubt: Tom. I, 1. 3 hydrogr. c. 4; Varen. geogr. c. 1 3, prop. 8, 9, 10. ga) febe biefe verfabiedene limftande, als fo viele Quellen ber wiber:

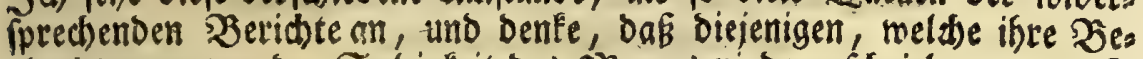

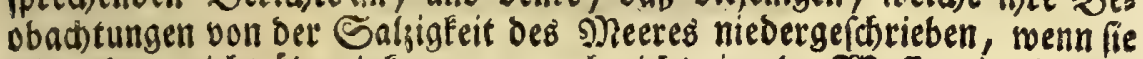

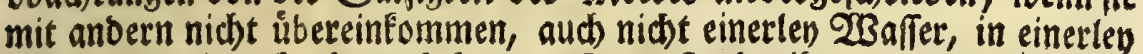
3eit, Begend, Siefe u.f.f. zum (Segenfande ibrer Unterfuchung ges babt. Das find alfo auds nur fobeinende, und feine wirffiche 2 Bibers

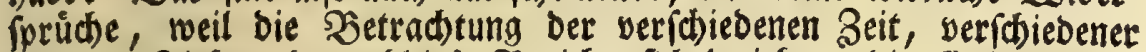

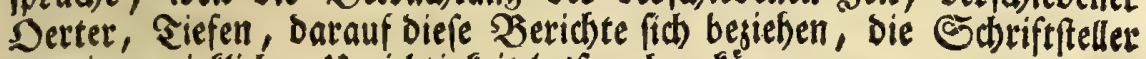
bon einer mirfliden Unridtigfeit losfprechen fơnnen.

Da id von ber Salzigfeit bes Meerwaffers rebe, wirb es nicht unbienlich fenn, bafi id aud von bem Urfprunge bes Salses meine Meis: nung lage. Sinige ber beutigen शaturfunbiget behaupten, SDST babe bas sneer fकon gefalsen erfक̄affen; andere lehren, Daffelbe babe erft mit ber 3eit Durd 2lbfpulung Det Saljberge, bie auf feinem $\mathfrak{J}_{0 .}$ ben fit) befinben, biefen (Sejomact angenommen; und erfalte fich ben: felben noch beftúnbig auf gebachte 2lrt: Denn bie oritte umgereimte

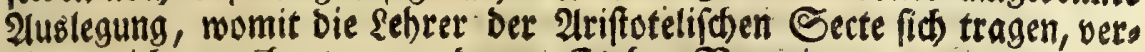
bienet nidht erwēhnet ju twerben. Es hat Darenius, c. 13, prop. 8, beren lingruno loon bargetban. S山 fimme bem Srn. Pluche bei, ber Sped.

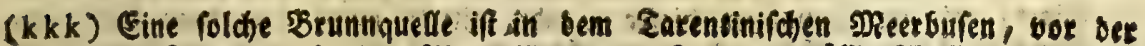
Stubt Taranto, fo bet 2liten Tarentum ift, beren fuffes $2 B a f f e r$ main, wie

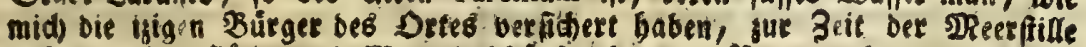

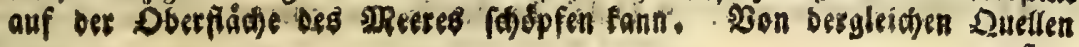
nusiten 


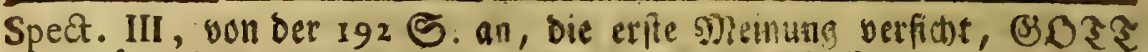
babe námlich bas soermaffer idson gefalien erfer effen (111). Lunter feinen Brrünoen gefált mir defer am beften. Er jagt, ber Edobjer babe gleid) in sinbegin ber 28 alt auch bie Eeefficte erfatifien; aljo má.

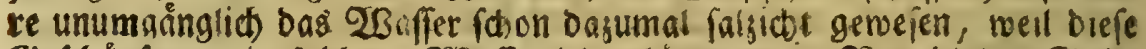

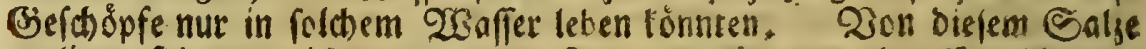
verlieret fich nun nichts aus Dem Neere, aufer mas Dhe Nienid)en zu

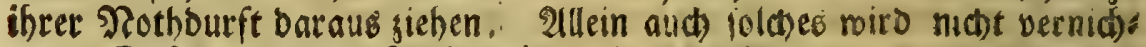

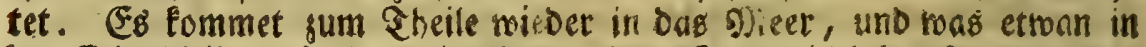

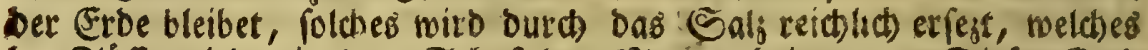
bie Flúffe mieber in Den Shó bes Meeres bringen. Diefes Sals übernehmen bie rirnenden $23 a f f e r$ von Den $2 u e l l e n$, relcte úber \&agen von Steinfalse binflieffen, uno bur(⿻) 2ibfpůlung berfelben faljict)t wers ben. Der Unrath, fo von snenichen und Shieren abgehet, und

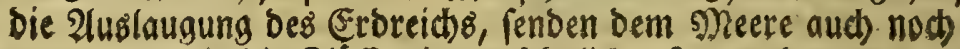

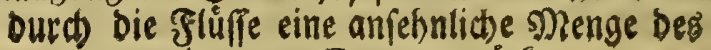
geborgten Salyes gurúde.

\section{Dritte}

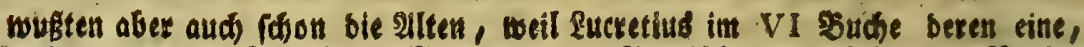

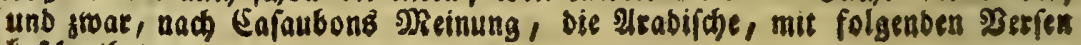
befóreibet:

Quod genus endo mari fpirat fons dulcis aquaİ

Qui fcatit, et falfas circum fe dimovet undas.

Et imultis aliis præbet regionibus zquor

Utilitatem opportunam fitientibus nautis,

Quod dulcis inter falfas intervomit undas,

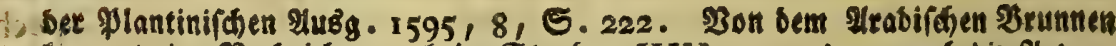

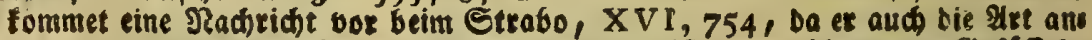
seiget, mie bie Intwobnet biefer Stabt, mittelft eines blenernen Giefáfiez,

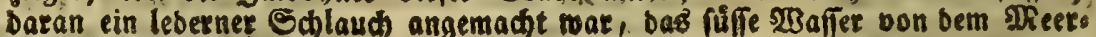

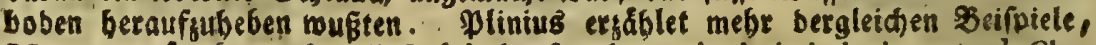
1., 103 , 5ar5, 106: "Dulcis hautus in mari plurimis locis, ut ad Che"lido. 


\section{Serte 3 eilage}

zur 1 II Unteriudung.

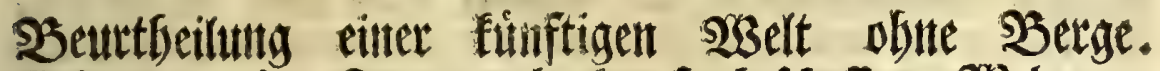
Eroprterung Der Srage, ob eine fo befthaffene 2 Selt von bergnügten Menichen fonne beroobnt

toerden.

Sele

er Franjofifhe Joete D. Kapin bat bie stwente, oben S. I 3 U.f. vorgetragene, sebre vom litprunge ber fuffen $23 a f f e r$, in lateinifde

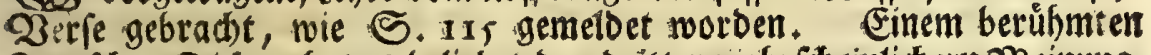

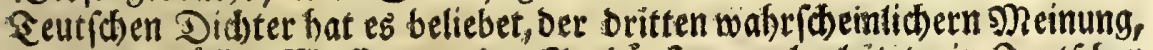
seltbe bie fuffen $23 a f f e r$ on ben 2 lusbunftungen berleitet, in ₹eutichen Beimen fu gebenfen. Denn in bem Sefange son ber Dberpfals faceis bet er im 9 Abraje folgenoermaffen:

Der fteilen Berge Reib, Die Deutralands Mitte trennt; Und Dogtland, Jrantenlano uno Dberpfals ourd)rennt,

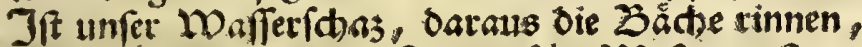

Wodurd fo mander Strom fein Wejen muß gewinnen.

Diefes låft fid zwat nod auf bie erfe unb swente oben angefübrte Mnei: nung auşbeuten; nåber erfláret er bie Seinige in ber XI Strophe, allwo

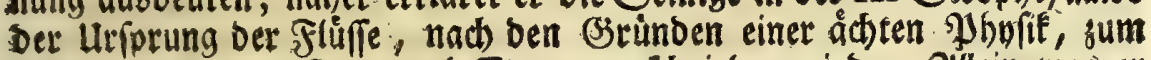
Sbeile aud bem thebel und Cbau jugeidrieben wiro. 2llein was et 3

"lidonias infulas, et Aradum, et in Gaditano Oceano, zu meldfer Etelle "Sarbouin folgenbez anmerfet: "De mari certe, quod Aradum alluit, id "Strabo diferte affirmat $1.16, p \cdot 754$, modumque idem aperit, quo ex " ipfo maris fundo dulcis aqua peti ibi foleat: qui modus hodieque in ufu "frequenti eft ad Ormuziam infulam, ut Furnerius refert. " L. 9 Hydrogr c. $26, P .358$.

(111) Was bie Zeit bet entfanbenen Salfigfeit bes sReermalferz anlanget, ent:

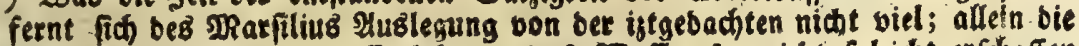

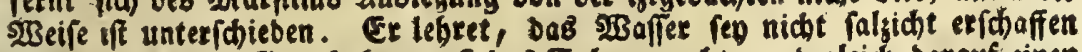
sorben, foubern ङुott babe juerfit bas Sals gemaht, unb gleid barauf eineu

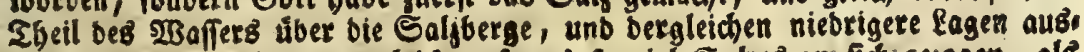
gebreitet, wo biefes bennt gleich anfangs po viel Saljes an fich gejogen, als eb Deffen ju feinet Erbaltung bonnsitben batte. 
in bem XVI, und ben barauf folgenden bren 26 fåzen, finget, bab fdeeinet fowol wiber feinen enft vorgetragenen eigenen Sas, als wiber bie ges

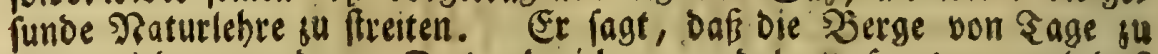
Fage niebrer werden. Das gebe ich gu, und begrelfe es gar wol, oaß erfitich 3. (E. Durd) Das Tegenwaffer ein Sheil ber Eroe von ben bohen

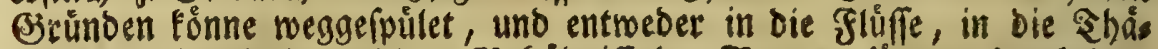

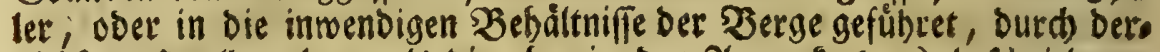
gleid)en Quellen aber als Die oben in Der 2(nmerf. (cc) befdoriebenen

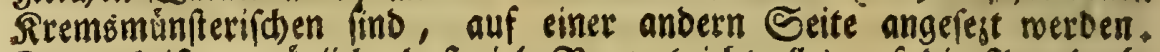

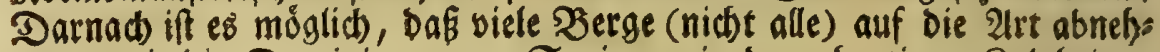
men, mie bie Dominicaner zu Soriano, in bem heutigen Salabrien, Den norblicben SEerg abtragen, Daran fie iffr Slofter bauem. Sie lafo fen von einer hoben SRinne Das 2 affer an ben Set fallen, wo fie, ju funftiger Erreiterung ibrec Sebảube, bie Eroe wollen weggernumet baben. 2 Benn biefelbe meggefpult, uno bie Felfen entbloffet worden, ridten fie ben 23 afferfall auf eine andere Stelle; fie laffen Da gleiders maffen bas 28 affer, ohne ferneres Sandanlegen eines Menfohen, bas Ero. reid hinwegfübren, uno brechen alsbenn bie Felien, roourd fie einen Doppelten Zortbeil erlangen. Sie úberfommen, ofne groffe Roften, in

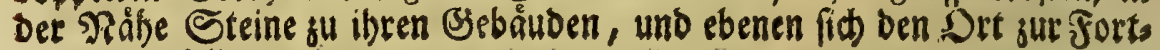
feģung berfetben.

Eben fo macte es auch bie Ratur. Der Negen fobremmet bon Deri Biipfeln und gåhen Abbången mander Serge, bie Erbe herunter, uno bectet oie Felfet auf. Diefe twerben ourd) bie Sonne, zumeiten audb Durd) Das inwenoige feuer, erfigt, uno wenn es oarauf regnet, múrbe gemad)t, ober aufgeriffen. Diefes lestere thut nud bie ăußer: lide Ràlte. Die Donnerfabläge machen ebenfalls mandbe Sluft. Die gerpaltenen Theile löjen fid entweber burdb bie eigene Edwete, ourd SBeibülfe ber hineinfriect)enden 2 Burgeln ber $\mathfrak{B}$ åume, uno anderer (Ses

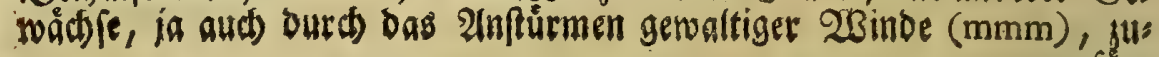

( $\mathrm{mm} \mathrm{m})^{6 t}$ Quantum ventis adjuta vetuftas impulit, Valer, Flase, 2, 528. Dies pe llefacte erfennet auch Rajuz, ba ex in Den Plyyfico: Cheol. Betr. S. 497, fo foreibet: Diefem lejten mag, fatt einer feruern rladidot,

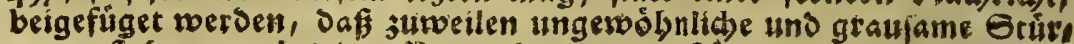
me entfeben, wobei ber Kegeil eurd ungeftume winde mit rolder Bewalt an die Gpizen uns Seiten ser Jerge getrieben unto angeidias gen rours, Jaf fie Jurd abbredung, Jerreifung uns Serunterwer, fung Der Jellen uns Bteine in wenig Cagen mebt, Sbaden verurias 
forberft aber burch bie Exfdutterung ber Erobeben, wo foldte herr: Fitben, bon ben Felfen ab, und fiursen fich bis auf ben (Stunt ber Sbá. ter hinab. Die unter fteinidten $\mathfrak{B e r g e n}$ liegende, mit foldtem Sctutt

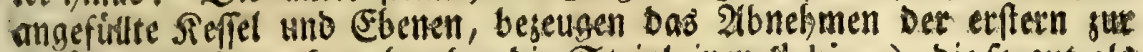
(Bninge (nnn), not) mehe aber bie Steintainen (labinx), bie fo gut als bie Sd)neelainen, in Rergländern nidbt allein ringele Săufer, fondern. sool ganje Doorfer verfobutten, wie gur Sebjeit ber Pliniorum, Ziverina

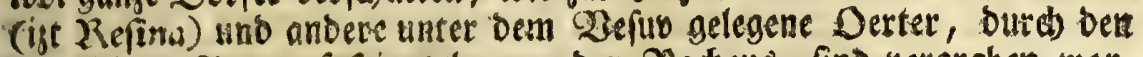
gewaltigen 2ustwurf feines bennenden Sindens, fino nergraben wor:

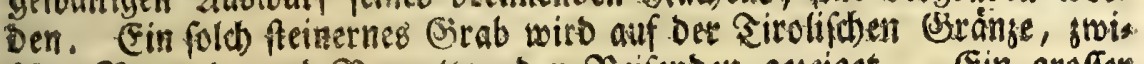

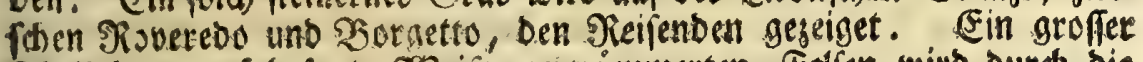
Theil ber, auf befagte 23 eife, ferrrummerten Felfen wirb Durd bie reibenden sjergwaffer in bie Fluffe gebradt, in benfetben ferner zu Ries uno Sanoe jermalmet, wovon fehr viel an ibren ufern selaffer, nidbt

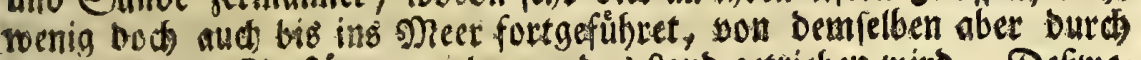

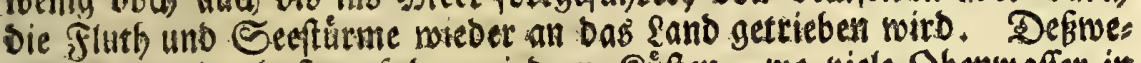
gen fehen wir, bafi auf ben niebern Süfen, no viele Dbenwaffer itt

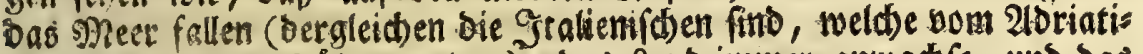

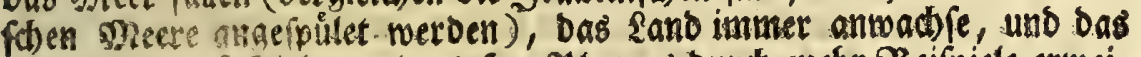

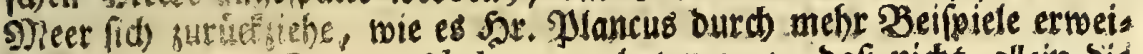
fet. Er zeiget, 5.69 , fchol, 2 zur lesten prop. Dap nidt allein bie

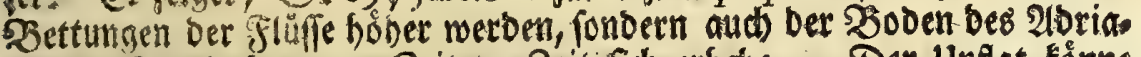

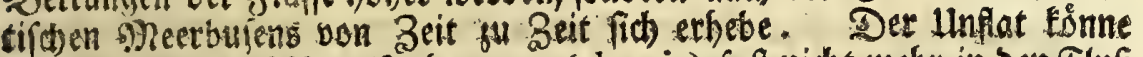

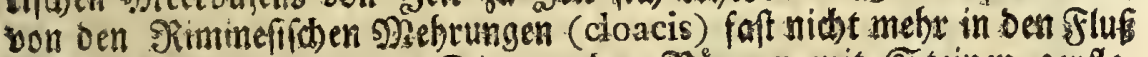
maricta ferausfinten. Die uon Den Fiomern mit Steinen gepflas flerte Straffe, uno vie mofaija)en Sbóben ibter Şåufer, werben nun mebr thef aus ber Erbe herworgegraben. Sal 3 fchol. a.b. 7 I unb folg. $\mathcal{S}$. bejelliget er, - baj ber Dainm beb alten Seehafens (Der bei ber

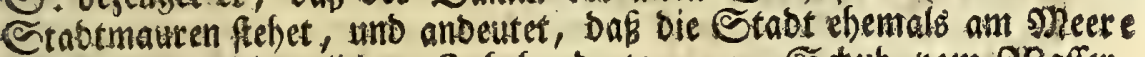
gelegen mar) fett etliden Sabrbunberten 1300 Sdub nom 23 affer,

$$
32 \text { unnus }
$$

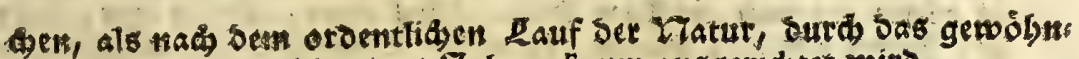
lidbe wetter in viel bundert Jabren Eaum ausgeridtet wiro.

(nnn) Diefeb etweifen einize Begenben im Betglanbe 230 altez in Englant, wie

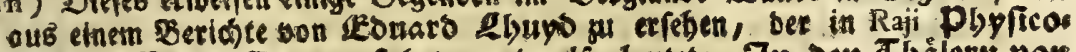
Clyeol. Betr. E. 495 ferbet, und alfo lautete In Den Chatern von

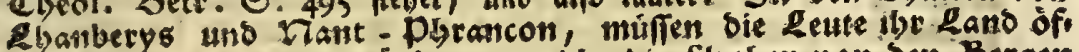
ters von ben Eteinen (ärubern, weldbe die Slutben von bels Bergen berabbringen, uns sennods buffen fie, siejer Gorgfalt ungenditet, mans 
unnủzer Weife auf bem feften sanbe fich befinde, weil námlidt bas

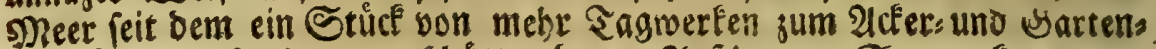
bau tủdtiges \&anoes angefdiuttet bat. 2fuf ber $72 \mathbb{S}$. merfet er an, Dafi bie Stabt Ravenna, die zur Beit ber Rơmer und Borben, in Dfüen ftuno, welde som 2lbriatifden meere allda gemadt wurben,

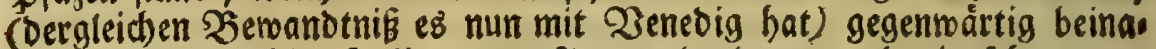
be bren Gtalietrifobe Meilen vom Meere abgelegen, und ein fehr unges funber Drt rev, ber bod nach dem Zeugnifie bes Strabo (o o o) ehes mals bie befte \{uft gehabt. Nadh Diefem Beifpiele bejorgeten bie $\mathfrak{Z}_{e}$ netianer, (weldbes auch fidon SRajus, pbyfico= Tbeol. 23. S. 500, und vor Demfelben Jof. Slancrnus, ein Jefuit aus $20 l o g n a$, im $\mathfrak{B} u(b)$ de fabrica Mundi, angemerft haben) es módbte auf eben bie $23 e i(e$ ihre Staot mit Der Beit auf trofnes \&ano gejest, nie aud berfelben gefunde \&uft

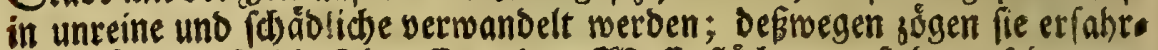

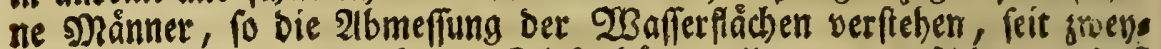

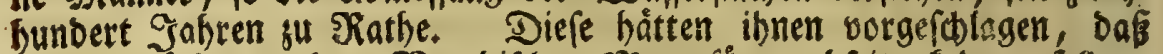
fie bie Fluffe von Den Zenebifden Meerpfugen abfeits fehren follen. Der zuvor gerübmte Şlautanus bejenget, Dafi auch bie siauren von

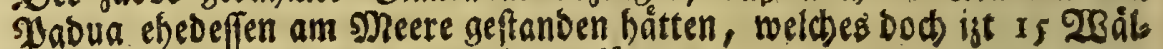
fide Meilen von biefer Stadt fid) befănoe:

mandue anfelonliche Etŭde Lanses ein. Manlefe aud bie Ergäblung, welde auf eben biefer Eeite n. 4. angefúbrt mirb. Die Etabt Silli, ber

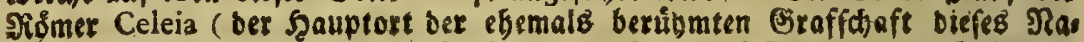

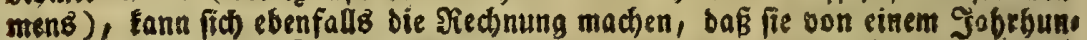

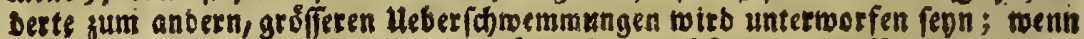
Die Bettung Dex oren bereinigten fluffe, Ean, Rotbing und Boglain, fofers

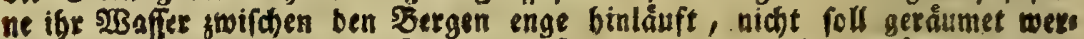
Den, inbem biefelbe mit unjăbligen Stứcten zerfallener Eteinnainde, weldje

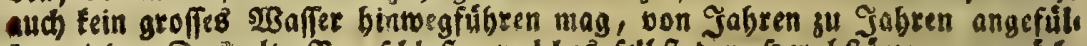

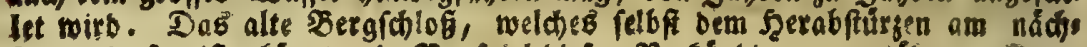

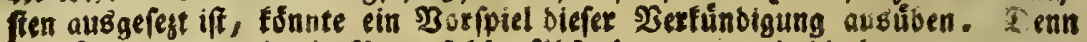
es ofefen nue noch ein Paar foldhe 2lbfpaltungen, wie bie lejte, vor toenis gen Saheen exfolgte, gewejen ift, an Der Etrinwand fids exeignen, tarauf

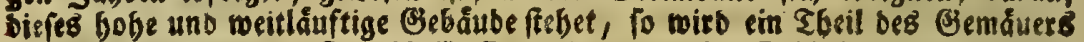
mit berunter fallen. Die bloffe Betrad)tung biefes SchloffeB, wie man $8 B$

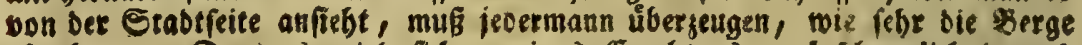
abnebmen. Denn es witb fich, Mtrines Erad)tens, mol fatwetlid jimans glaubrourbig borftellen fơnnen, bas ez den \#lten folfte in ben Einn gefoms

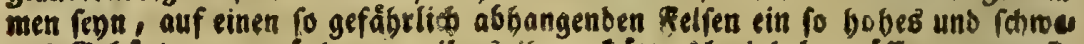

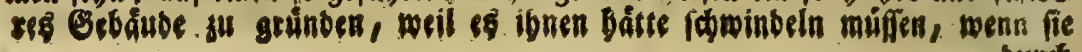
buxd 
Dá̧ es aber mit ben Deeren uno Strơmen auf ber ganzen 23 elt

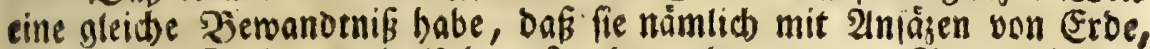
Sano und Steinen, als Ueberreften ber abgetragenen 2 erge, bie fes ften Sheile bes Erobodens von ₹age zu Sage wirflid vergróffern, ers weifet Sajus in einer eigenen 2lbbanolung feiner Pbyfico. Tbsol. 23etr. (in ber III Betr. s Shauptft.) too er bie Frage erortert: Ob etwas in ber Welt fey, fo cine sutunftige Dertilgung serfelben wabrfibeinlid verurfachen, ober 3 ut ertennen

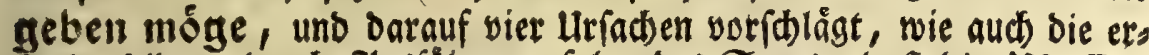

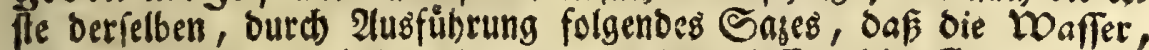
wenn GUบ位 Welt fo lange fteben lieffe, die Eroe wieder úberftivemmen uno detten twirden, son ber 483 . S. an, vorftellet.

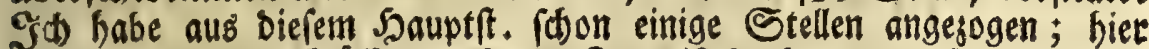

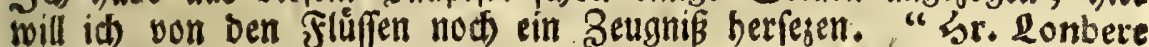
"(fprid)t er a. D. sos S.) hat auf feiner legten SReife nach Siam an. "gemerlet, bas bie Sanbbänfe uno feichten Srte um bie 2lus:

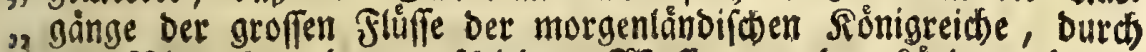
3. Den Niederiaz, ben verfhiebene $23 a f f e r$ von - ben Eăndern berabs

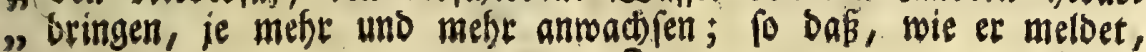
33 Dié

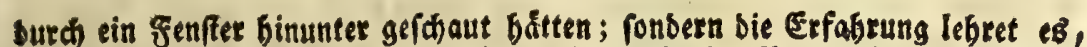

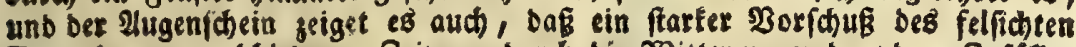

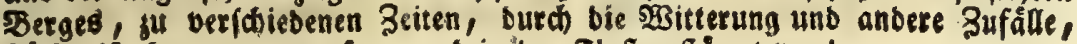

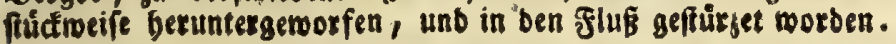

$(000)$ "IIrbium in paludibus fitarum maxima eft Ravenna, tota ligneis conftans ") xdificiis, aquis perflux, quare pontibus et lembis viz expediuntur. Non " exiguam maris portionem affluxu zeftus recipit : quo et a fuminibus co" nofa omnia cum eluantur, aeris vitio fit medicina. Itaque locus adeo fa"lubris eft, ut ibi gladiatores ali atque exerceri jufferint principes Romani. "Mirabile igitur hoc locus ifte habet, quod in palude aër eft innoxius. " $V$,

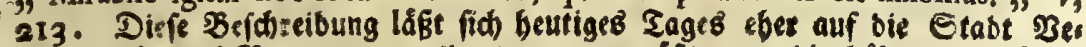

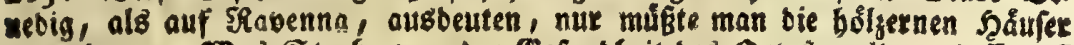
ausinebmen. Was Strabo von Det Sefunbbeit bes Drtes melbet, befien iff nun bas Esenfbetl wabx. Das fann id) burd) eigene Erfabrung begeugen. Denn a!s id 1728 gut Seerbftzeit in biefe Stabt fam, unb miz Bals in einet

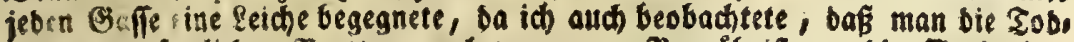
ten nur auf etlichen Brettern noch warm gur Begråbrifi bor bie Stabt bin:

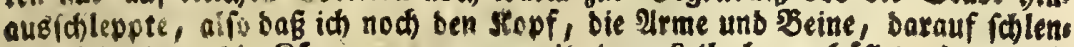
tern jab, o nn bie Sistper maren nut mit einem Reilache verhiffet, fo erroects

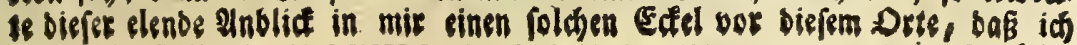


" Die Sthiffahet auf erwebnten Fluffen je länger je befdowertictiet "fålt, und mit der Beit gánglut bờrfe unterbrodien werben. (Ebent , Diefes ift, meines Eractens, bei Den meiften groffen Fluffen in Eus "ropa wahrsurefmen, als worinnen neue Sanolager aufgeworfen, "und die alten ermeitert merben. " So fduterbet aud Jof. Blancas nus, in fabr. Mundi, beim Baius S. 5 I5: "Eben biefes, (find feine "Worte, eteignet fit aut) um das skeet. Denn Da bet Srund "Deffelben niebriger ift, als bie Dberfląhe ber Erbe, und alle groffen "Fluffe fich in bas Meer ergieffen, bie eine anfebnlid)e Menge Sano "und Solamm mit bimeinfübren, fo múfen nothmendig groffe Sand. "bánle ober Frobaufen, um die sheerufer, bei ben 2lusgangen bet "Slúffe entfteben, woourd die Strände fehr ausgebreitet, uno immer " weiter in bie See bineingetrieben werben, oa benn biefe weiben,

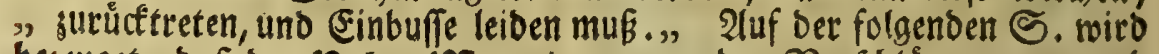

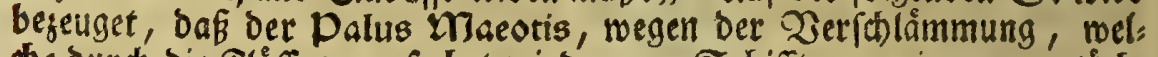
क) burd die Flüffe berurfadet wiro, zum Sdifftragen immer untúd: tiget fíd reige.

Bis bieber bat alfo bes seutfon Didters Durgeben, bon bet Derminterung ber $\mathfrak{Z}$ erge, feinen (Sirund in oet Naturlebre, unb bie

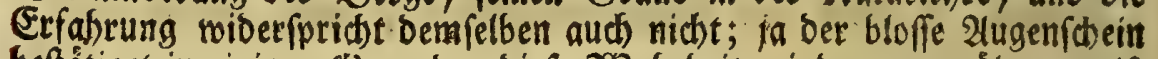
befátiget in einigen S3egenben diefe 23 abrbeit, indem man über gewifs re Sơben anfángt Sirchthurme, ober anoere unbewegliche- Sadben, oie jenfeits liegen, zu entbeden, welde Dod vormals unfictibar gemejen

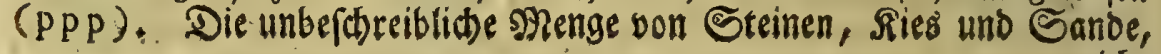
nelóse

teine Euft batte tnidh vill batinnen nach ben gltertbümetn unb Eeltenbeited umzufeben. J(t) eilfe bei einem anbern Thore binaus, uno bem Seebafen

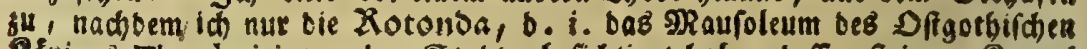
REniges Theodorici bor ber Stabt, befidhtiget babe, beffen feinere Suppel baxum mertwuirbig ift, weil fie aus einem Stuite beftebet, unb gletdjool 114

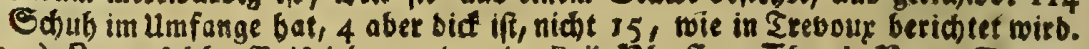

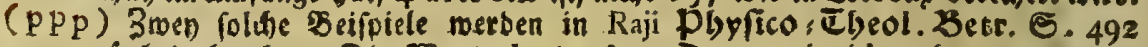
u. f. Beigebradt). Die 530 rte lauten fo: Denn wie id andersmo anges merfet babe, bin id von einem glaubwirbigen uns vorneimen sreun De verfichete worben, Daf Det Cburm ju Craid, auf oer Epize (peak nicht park) von Derbyshice, foviel etliche Reute, Die Samals ( 1672 ) nod) gelebet, gesenfen fonnten, bon einem gewilfen Sügel, ber jwis (d)eh sopton uns wirfiporth liegt, nidu babe fonnen gejeben wer Sen; Da man boch ijt nidht nur Den Clurm, fonsern aud einen Cbeil

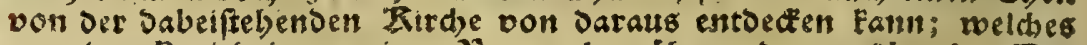

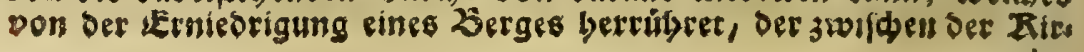


welige wir in ben Fliffen, und an berfelben ufern, fehen, fommet von

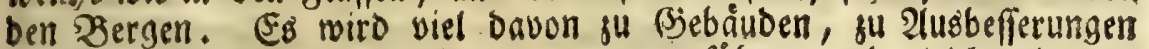
Der Girafi:n, uno andern शiuzungen, weggefúbret, uno gleidwol mans gelt eg niemals an neuen eben fo reiden Infpulungen, fo baß nod) ein anfehnlid)er Sheil bavon bem झreere jufommet, weldses baburch biet und bort an bas fefte sano neue Infäge madht. Ungeachtet aber Sar.

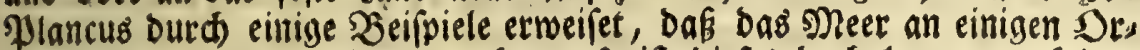
ten aud vom Eroreidbe wegnelyme, fo ift biefes bod lange bon feinet

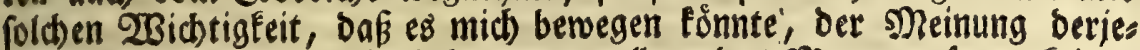
nigen beizutreten, weld)e behaupten wollen, bas Meer empfange Feinen neuen Sanb. Fó gebe nur einigen (Segenben, mas̀ es anoern abgejwact

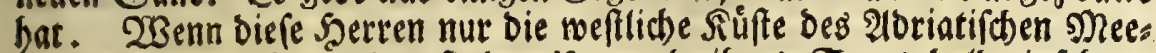
res betradten, fo werben fie ben llngrund ibres Sares bald einfehen. Denn ber Зumađs úbertrifft bier gewislid) um ein (Sitofies ben Derluft. Jon Dem, was biefes Neer bei Rimini, Jabua uno Savenna, ange: fert hat, ift bereits gemeloet worven. Go münithe aber ferner, baś

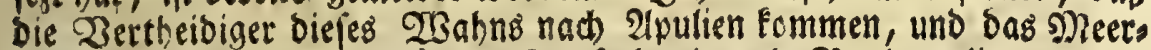
ufer, fo zwifeben ben Stábten Mianfrebonia uno 2 arletta liegt, anfes

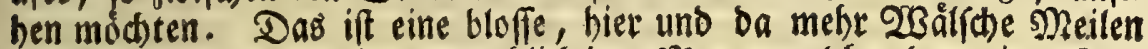

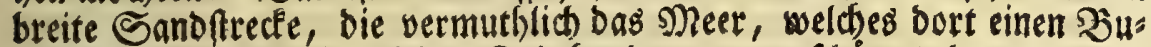
fen madt, innerbalb etliaben Sahrbunderter angefduttet bat ( q q ). $_{\text {. }}$ In Dem Sarentinifion nod weitern Meerburen fieft es eben fo aus. Da gibt es aud breite, obe und unbewobnte Seegegenden, die aus

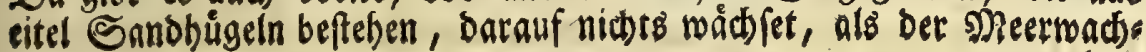

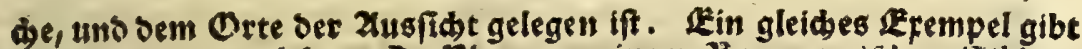
uns auch Des gelebrte D. Plot von einem Zerge jwithen Gibber toft uns Gegleby in Forthamptonshite, in feinet Hift. nat. Stafford. 113. Eben diefes bat \$lancanus, in bem Buche de fabr. Mundi, bor

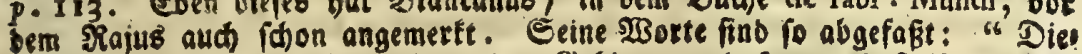
" Fę betråftigen alle Einmofner ber Bebirge, unb fagen, baf̧ ibnen biefe "Erniebrigung Dex Berge fhon långf betannt gemefen; well ebebeffen Die

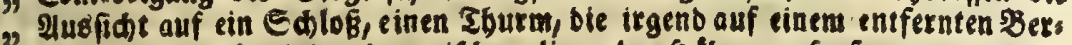

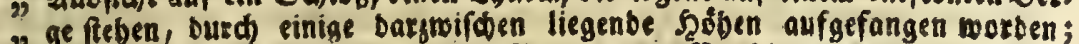

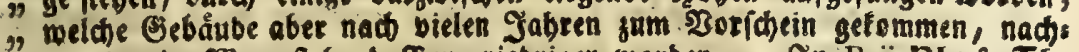

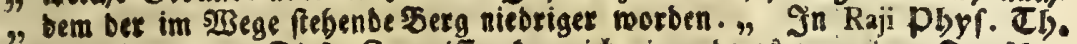
3ett. 5 . SII. Diefen Zeugniffen tann id ein anderes von einer seutí(en Segeno beifúgen. Der gelebrte Scr. Tobias MRaver, MRathematicus uns

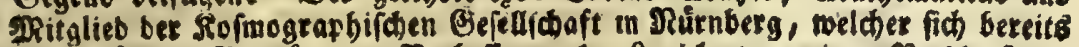

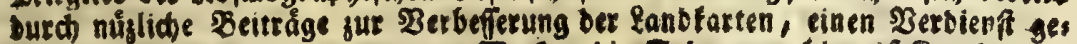
madt, nun aber an sinem neuen soerte, bie Gelenographis auf Rugeln vors ouftel. 
bolber mit rothen Beeren, fo ber $\mathrm{V}$ und lefte funiperus Turnef. ift (Inttit. 589), nebft now) einigen, alletir fehr werigen. anoern Stråuchen

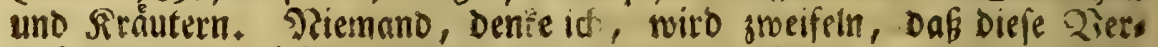

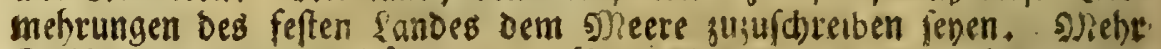

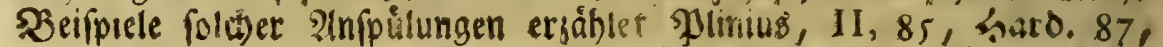
uno wie fold)e verridtet werben, Strabo, I, 53. Sieftüfen aber bie vielfăltigen isuinen, we! the in Jlanbern und Sollano bie Lfer Der \$Tord. fee Dåmmen, nicht auch bieje 23 ahrheit? ailerbings. (So fiel)t aud Der ganje wefticbe Strano von 2 Balles aus, nad) Der 21nmerkung Des

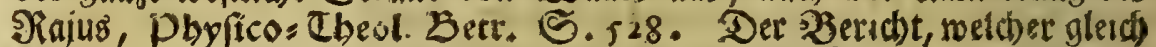
vorbergehet, ift ebenfalls nod) cin 3eugnif, was fúr cine groffe menge Sanbes vom Meere ausgeworfen merbe. "Ferner fann auch, ficheis

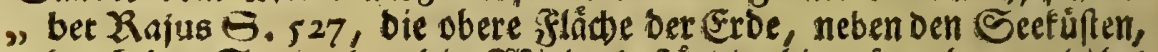

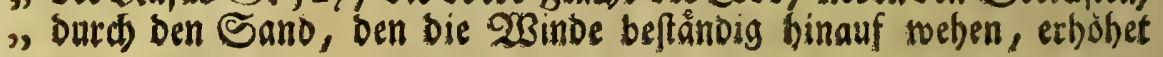

toers

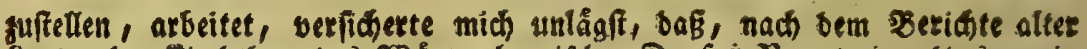

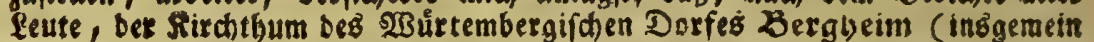

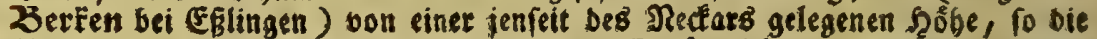
Recfarbalten beiBt, auz Dem fo genannten Echügenbăuslein, megen beb bat:

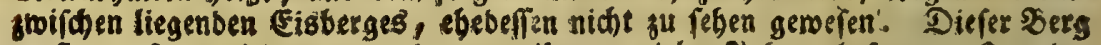
muß nun fenn niebriger wotben, weil oor vielen Jabren befagiem Orte ber

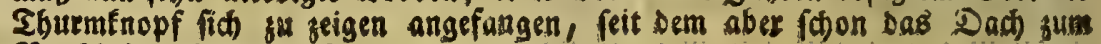
Borfwein getommen ift.

( 9 q q) E8 liegt bet Sanó an sintaen Orten viele Slaftern boh) Hbereinanber,

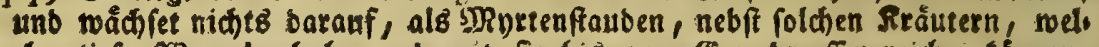

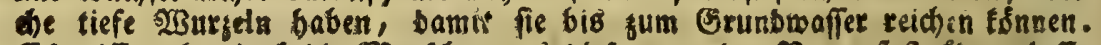

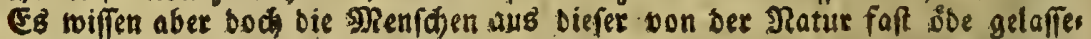

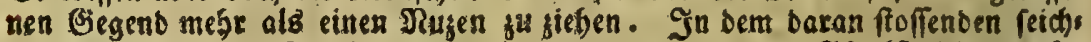

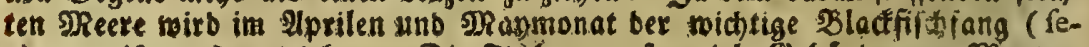
piarum pifcatus) getrieben. Die fircher nerfen biele (Sebúnte von Mipkten:

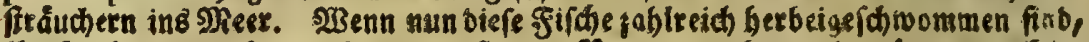
ibr faid) baranzufejen, (o merben fie mit \$ejen umgeben und gefangen. Dier habe id fureft gejeben, mie ber burte Fuffelfoth ben Dienft bes Sorfg ober Solfes vertreten tônne. Die ffifber fammlen benfelben auf biefer Sarbfé. fe, unb braten fich bie gifine bamit, inbem seit und breit fein betoofnter

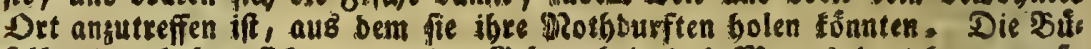
felbeerben balten fich segen ber Belegentheit bes Meeres bort berum auf:

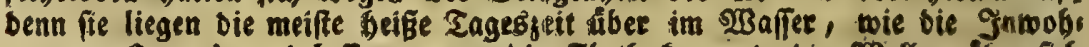
ner von Drmus, unb Iaffen, wenn Die gluth fommet, bie अrßellen uber fid

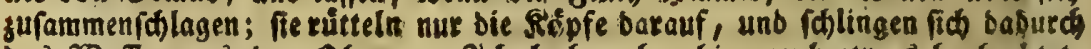
bas $\mathfrak{B}_{\text {Baffer }}$ aus ben Dhren. Iक babe aber bier aud etwas beobachtet,

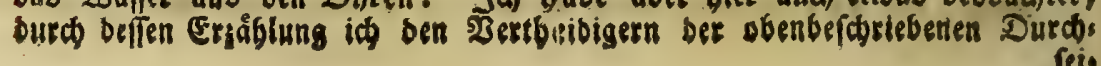




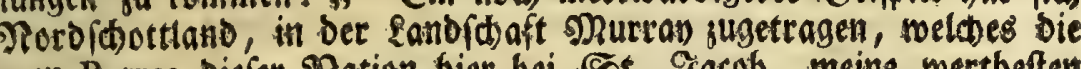
erren Patres Diefer פRation bier bei St. Sacob, meine wertheftert

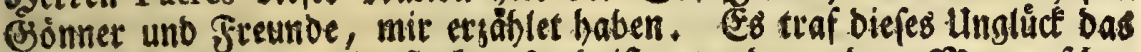

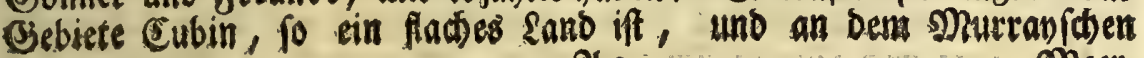
24

figung bes Mectwaffer, einen angenebmen Dienf gt etweifen boffe. Cs find námlid in biefer panbiabten Gegenb, infonbetbeit nad Barletta gu, aud

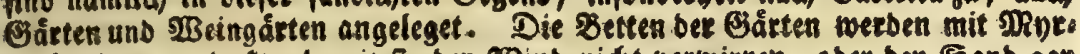
tenftauben gugebect, bamit fie ber 223 inb nidht bermirten, ober ben Sanb gar

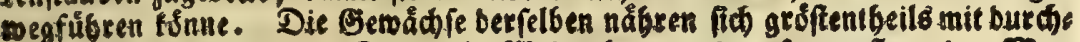

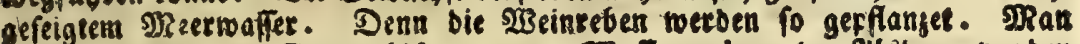

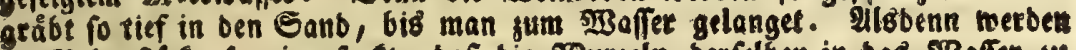

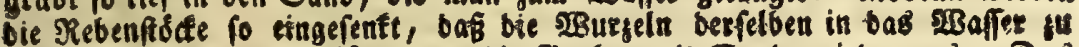
Reben tommen; barauf füfet man bie Cruben mit Sanbe roieder aus. Das Waffee, in weld)em bie Beben fieben, if gefaljen, benn wegen ber Nabe bes sReerez gat bie furse Durdifeigung burd ben Sanb baffelbe nidgt bets riffen finnen. Bon ben Gartengemódj fen phanjet man alloa nut foldhe, bie

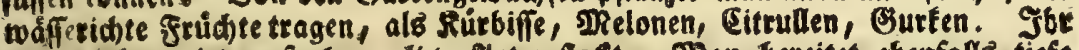

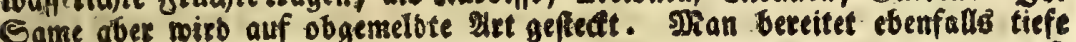

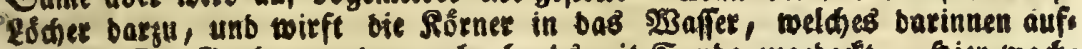
quillt. Die Bstuben werben nadgebenos mit Sanbe fugebedt. Sgier toads. fen bie esfliden Baffermelonen, bie bis Deapel beefubet werben, unb in ben beifen Sommertagen eine trefflidje Erquidung geben. Der aulbier ges

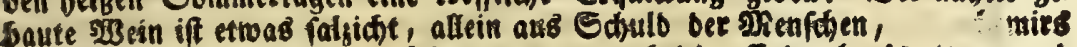
borftelle. Denn bie Rebenftse werben gan bei ber Eebe abgefanitten, unb furt getogen, Deret aber viele twen eltme die finb. Die úbertommen teine

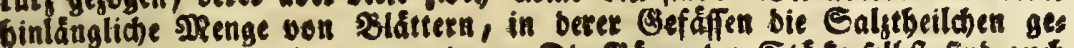

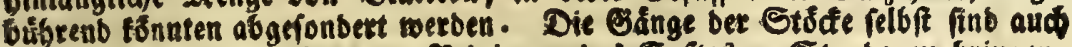
cut furs, um eine vollommene Peinigung bes Safteb ju Stanbe gu bringen.

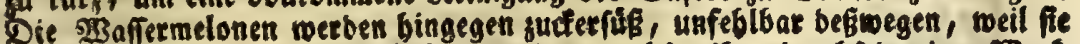
lấngete Stenget unb mebe Blätter baben, welde ibre burd)feigenden 2 Bert: fátte fins. Des if ein Ermeis, bas bie Ratur, burd bas filtrien bes

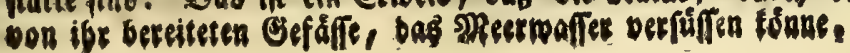


Deerbufen liegt. Diefes bat ein Dftrino vor ungefågr 22 Gabren ber:

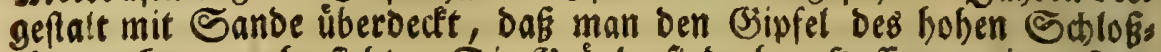
thurms faum mefre fieft. Die Brrunbe find ofine Soffnung einer Shers - fellung veróbet, und bem Sefifer baburd ein Schaben von taupend Yy fund Sterling, Doer 9000 Bsulden, zugefüget worden. Mefr Dergleis ゆen Beifpiele von Sanoflutben befareibet Sappelius, Relat. curios. III ₹b. S. 679 u. f. Diefe faft unfáglide menge von Sand ift ein Flarer $\mathfrak{B} e w e i s$, um wieviel bie $\mathfrak{B}$ erge allbereit abgenommen haben. Denn wo wir einen Sand fefen, ba múffen wir benfen, baßi es einmal Steine gewefen, bie Steine fino Stúcke zerbrod)ener F̂tren, von bies fen aber ift bereits gefagt worben, Daß̧ fie verfechiedene Sufálle von ben Siergen abgeriffen, uns beruntergefturget haben. (Es fino aud nod)

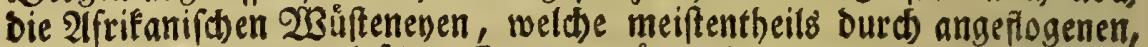
ober vom seere angefpúlten Sanb, veróbet liegen, uno viele ₹agereifen in bie fánge und $\mathfrak{B}$ reite fid erftrecten, unverwerfliche $\mathfrak{B}$ etweife, Daf unzăblige Şơhen begs Erofreifes bereits abgetragen und vernidtet wor: ben. Sa aus bem Brunbe ber Erniebrigung ber 3 erge, Fann erflaret werden, warum man in Den Flúffen ůberhaupt eine $\mathcal{B}$ erminderung bes Waffers yerfpure, wie es einige, nad) etlicben, feit taufend Jabren ber angemerften umftánben, wollen berednnet haben. Denn, wenn bie $2 \mathfrak{B a f f e r b e b a l t e r ~ ( D i e ~} \mathfrak{B} e r g e$ ) abnebmen, fo muß aud Des 23 affers weniger werben ( rrr). Das gibt in meinen Biedanfen einen unfehts

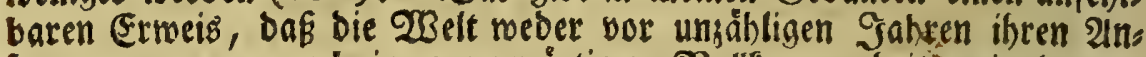
fang genommen, now in gegentårtiger $\sum_{0}$ dlfommenbeit emig Dauern fonnte.

2Ilein

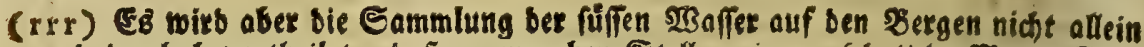
baburch bebortbeilet, bấ an mandien Etellen eine anfebrliche Nienge Sans

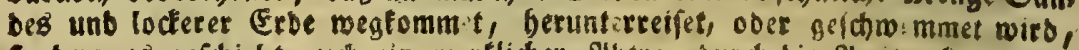

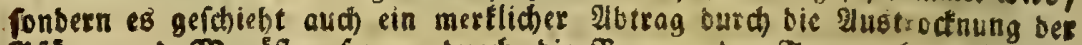
Pfifizen und IRoráfte, ferner ourch bie Baung ber Fergwerfe. IJanche

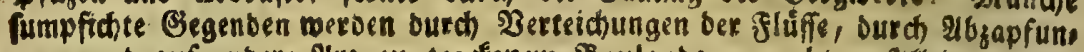

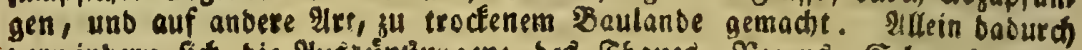
berminbern fid bie 2hostunturgen; bes Thaues, Siegens, Sthees, wito meniger. Die Rebel falingen fich (parfamer um bie nổifigelegenen Serge

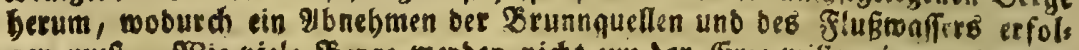

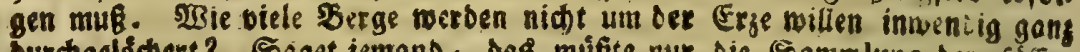
burchgelódsert? Eaget jemano, Das múste nur die Eammlung der fúfien Waffer befortbern, will baburd groffere Defnungen innerlid gemadit wer,

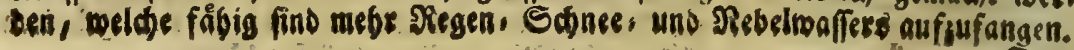


2llein eben Darum beftehet bas folgenbe nicht, was ber oben ges rubmte Woet ferner verfindiget, unb bat foldes einen fdilecten 3u. fammentang mit feiner eigenen furf vorber vorgetragenen febre. Dennba er fareibet, oaf enolid, die ganse Welt wito eben werden ( 10.

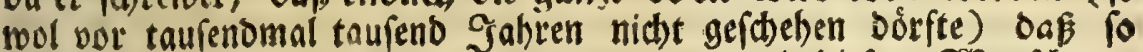
oann ein neues patadies entiteben foll, und biefen 20 unich ans bringet:

Romm, angenebme 3eit, beft)leunige oen Lauf!

Matb alle Qánber glatt, beb alle búgel auf! (sss) ba halte ich es mit biefem 2 Beltweifen nidt. EB foll wol niemanben geliffen, auf einer fo befकaffenen 2 Belt gu wobnen. Diefe fúr glúcf: relig aus่gegebenen, allein naक einer grüblidern शaturlebre febr elenben Ehiliaften, werben fein anders, als Bifternenwaffer trinfen. Auf biefer

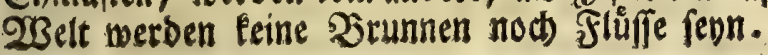

Aud Gemfen werden oann auf Keinen Klippen wobnen,

Ilno felbfit ber Jaget wiro fie mit oer Jago verfdonen.

Das if wabr, benn es merben gar feine bergleid)en Shiere auf biefer fladben Erbe leben; fonbern entweber aub Mangel Der geborigen ఇabs rung, mit anderm ふ̧ergwilbe und ben Alpenoogeln, vor Şunger ums fommen; oder genoiflich in beipen Sommern, mit allen übrigen wilben Shiecen vor Durft verfidmathten. Sum Blucte melbet ber Derfunbi: ger biejer ruen Sd)laraffentelt, oâj gefunoe reine Ruft biefelbe umgeben, uno das Leben oer Leute fo bauerbaft feyn wird, als es bei ben ITienfiden vor ber Gunoflutb gewefen (ttr). Er bilbet \& 2 .

fid

Das ift eine irtige Borftellung. Denn bură bie Schådte ber Bergmerfe werben bie Reitungen ber füfen $\mathfrak{B}_{3}$ ffer nut tiefer gegogen, und viele taufent Suellen, bie oben biek uno ba einen 2lusfall gebabt, fenfen fich unter ben

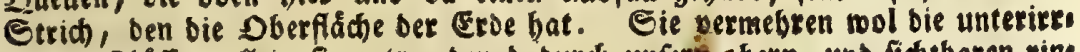
bifden fluffe, allein fie entwenden baburch unferti obern, und fidjtbaren sing

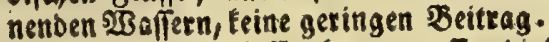

(sss) Der f̧r. Berfaffer bat Dergeffen biefe Meinung in einer beigefegten Inmets

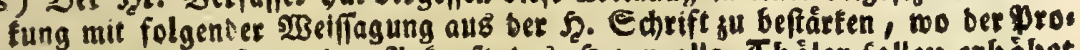
phet foridht, Daß́ vot ber Antunft bes Serrn alle Chäler follen erbóbet (boil) twerben, uno alle Serge uns. Sügel follen exniebriget werben. Эัย. 40,4 ; Ruc 314 .

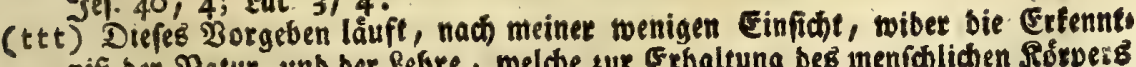

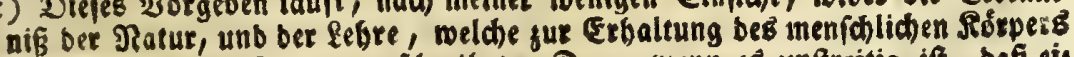

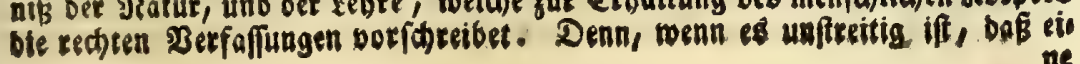




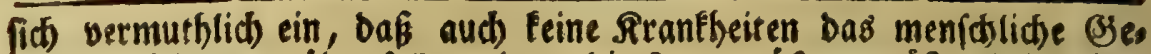
fibledbt fooann quailen follen, benn bie feute múften grofftentheils ohme

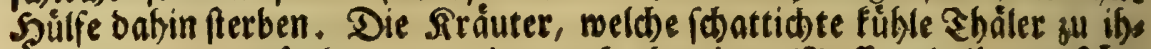
rer Erseugung erforbern, werben nach eben bem Maffe, als ibre anfăn. bigen Iagen, über Dem Erbboben berfoswinben; wie bie Fifhe in Den Sibiriften Seen, nach Dem Beriate bes Scrn. Dr. Smeling (in ber Qorrebe sur Slora Sibirica) fich verlieren, wenn ithe füfes $23 a f f e r$ in gefalsenes verwanbelt wird. Es ift befannt, Dak ein anjebnlicher Sbeil ber beften 2rzneyfråuter und 2 Burzetn, aus ben 2llpgebirgen fomme; bie aber bei biefer abgefकilderten neuen 23 elt ebenfalls alle werben bergan: gen (enn. Der Dicbter wirb aus Der Naturlefre, uno aus ben গiad)=

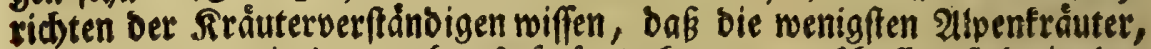
(weil foldse nur in ber rauben \&uft fortgufommen eridaffen find) in ber

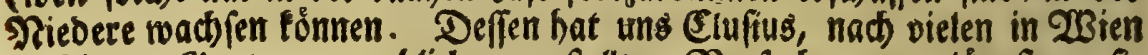
in feinem Barten vergeblid) angeftellen Jerfucten, Dorlångf berfis (b)ert.

WBitb aber (3) Ott bielleid)t, jur Eribaltung ber anfangs erfd)affenen

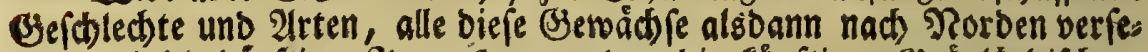
jen, uno bie bürftige Slora Lapponica, bie fünftigen Brrónlänbifonen,

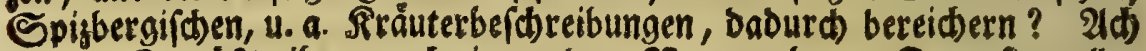
nein. Er múste ifnen auds eine anbere গPatur geben. Denn fie wollen

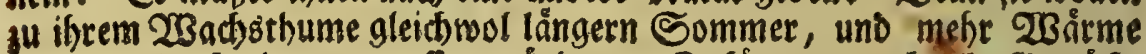
baben, als fie bort antreffen rúrben. (Es fónnten aud) alle (sewád: fe in benfelben Esegenden nid)t fortfommen. Die abnehmende Sirdfie

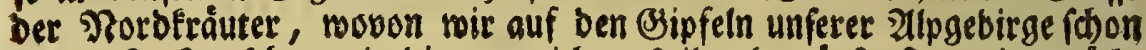

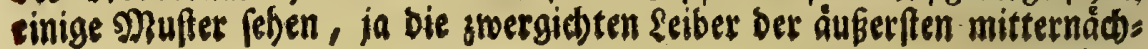

tigen

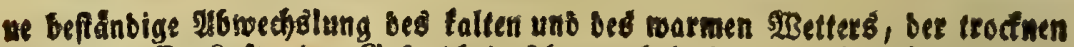
uns bee naffen luft, ber Sefunbbeit febr nattbeilig ren, fo geben uns bie Serge, untes bielen alloen roigtigen Dienften, aud biefen Bortbeil, DaB fie

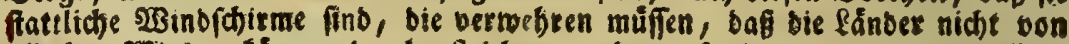

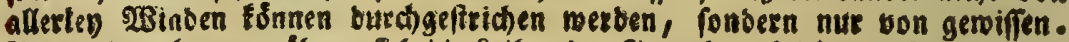
It wenige aber genodbnen fich bie seiber ber Inwobner leiater, alo an biele, fie mogen rarm ober fall feyn. 2Altein, wenn es auf bem Eroboben feine

betge folf geben wirb mandiet eirich fo toiberweirtige, unb balo aufeinana

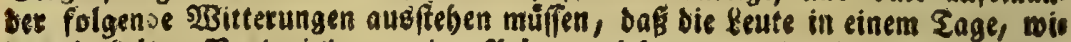
ber die Eultin Dorbminde, merben Pelge angiegen, renige Stunben barauf,

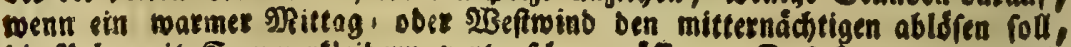
lie Pelse mit Eommertleibern bertaufden müfen. Das begegnet benjenis 


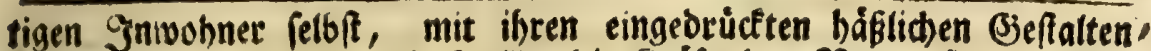

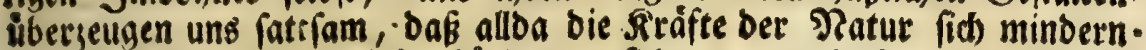

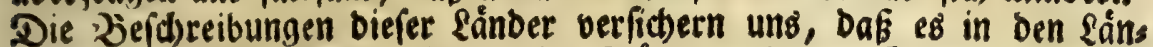

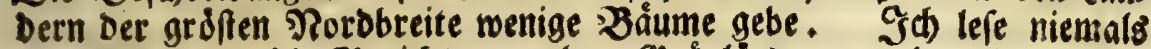
obne Erbarmen die Berid)te von ben Brónlänoetn, und anbern mits

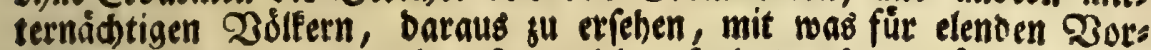

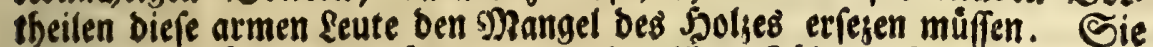

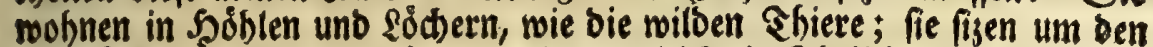
angefunbeten Firíththran herum, ber zugleid) ein Theil ibrer Speife mit

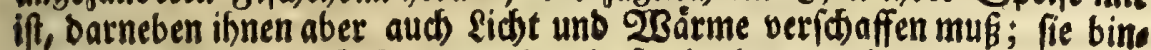
ben ifre \feile an Sd)nuren, bamit fie ia bes wenigen Solges nicht

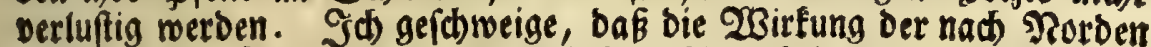

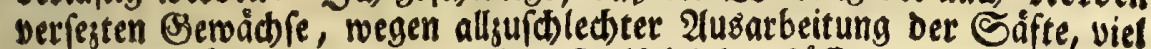
Fraftlofer múkte fenn, wie es das $\mathfrak{B}$ eifpiel bes Eóffelfrauts (Cochlea-

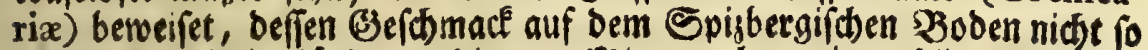

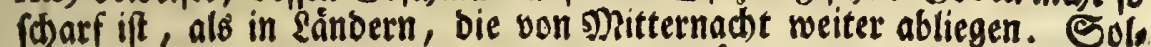
Фes lel)ret eine $\mathfrak{B}$ ef ben, $\mathfrak{S} .355$, ftebet, und fo lautet: "Intwendig (it) verftibe in me"diterraneis) find, mie man am Stranbe fiefet, nur groffe mit Sodnee "bebecfte Berge, feine Bảume, Stráude ober Frúdte, aud nicht

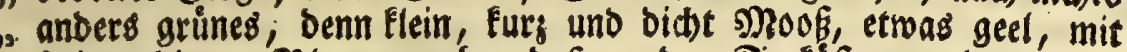
"Fleinen blauen SBlumen, ofne baß an Den Seefúften, uno auf Den "Silippen, bie uno Da \&óffeffraut wåd) fet, Davon im Dảnifchen Sas

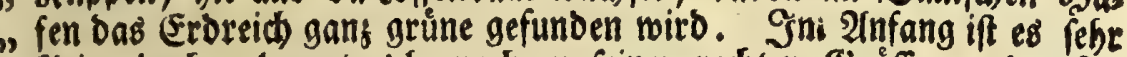
" flein; boch gelanget es bernach zu feiner rewten Sirófe, uns trágt "im sionat Sulio feinen Saamen. Es haben aber feine $\mathfrak{B l a ́ t t e r}$ " wenig Sodarfe, beswegen man aud baffelbe als einen Salat in " roenig $\mathfrak{A a}_{3}$ "Spiss

gen in ben Bergherten, bie aus einem talten Bange, batinnen 23 affer ftes bet, lafuft, ober berabetreufet, in eine ttoctne Esrube tommen, bie mit Sabwes felounften angefüket iff; obet wenn jemand an einem beizen Sage im Ilugufto monat, auf Dem Bipfel eines Edjneeberges, in eine fópattichte Ednneegrube

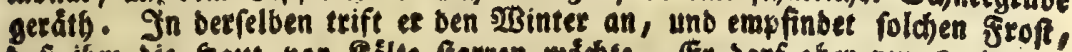

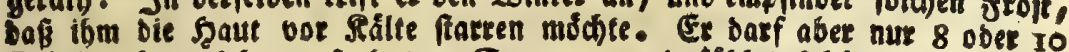
Edritte beraustbun, fo bat et Eommer, und füblet folde hige, bas ex

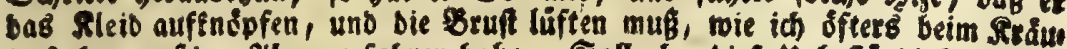
terfuchen auf oen 21 pen erfabern babe. Soll aber biefe Unbeftänbigfeit, unb biefe immerwåkrenbe Unorbnung (eine unvermeiblide folge ber flähen ổeft)

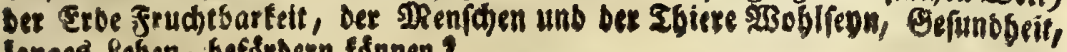
Ianges feber, befósoern Esnnen? 
"Spibergen zur Erfrifoung iffet ( u u u). , Der Did)ter fonmet alfo am fúrzeften bavon, wenn er fagt, biefe fünftige gefunde 28 elt wird Feine Alerste brauchen, fie mơgen Baleniften ober Chymici fenn. Denn mit ben mineralien wurbe es eben Diefe Scbwierigkeit fejen, weil man billig anfteben Fann, ob es aud fonoerlid viele Sergwerke auf Diefer flachen WBelt geben werbe. Befegt aber, baf es beren geben foll: múrbe es wol móglid) fern, bas Ers aus bem Sdjooffe der Erbe hervors

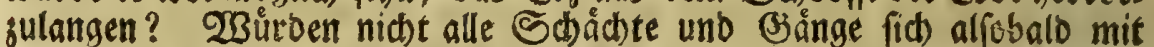
Warfer ausfüllen? Man Eónnte es mit Pompen uno Bieheimern her: aubidaffen: Diefes ift wahr ; rolches ware su bewerffelligen. 2ullein

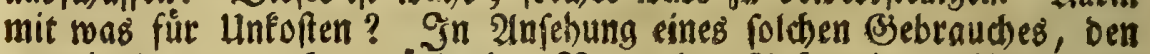

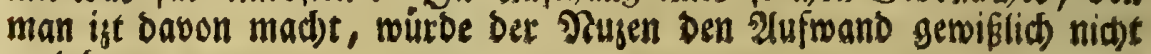
verlobnen.

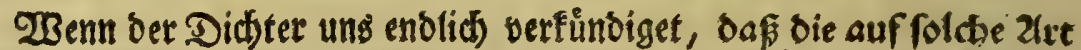

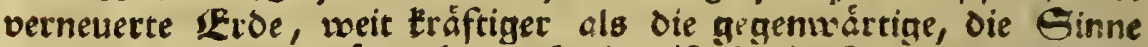
Dex-Menfthen vergnigen foll: D! Das ift eine im Sraume borgeftelte Wer:

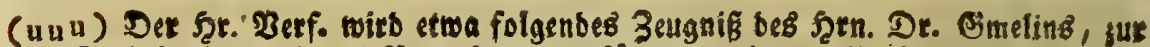

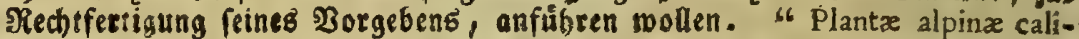

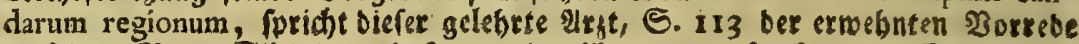
fu feiner Stora Gibirica, infeptentrionalibus pratenfes funt. "Ex beweifet

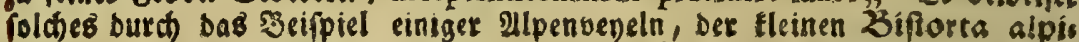

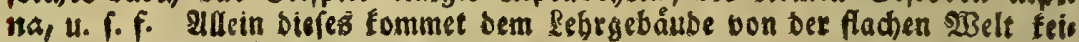

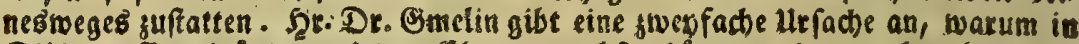
Sibirien SBergtråter auf ben (Ebenet toad) fen tónnen, beren aber feine auf

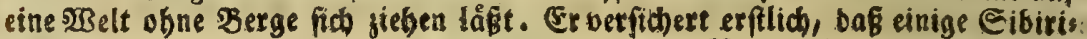
face Ebenen, mie biejenige, bie jenfeit bes Eees Zaifal liegt $\left(\mathcal{C}_{.82}\right)$ it Infebung ber Oberfiḱche ber Mecreb, fo bod) fich befinben, alo mandse Eusopaifhen serge. Die tronte Urfache ift bie gtimmige Rálte (dirum frizus, $\$ .80$ ), bie in Sibirien berrfdet. Diefelbe befareibet et $\mathbb{E} .67$ mit folo

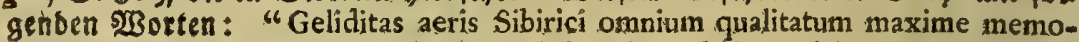
3) rabilis eft. Ea fluvii maturius congelafcunt, et ferius refolvuntur, nivesque "jam feptembri menfe non rarz funt, nec Majo menfe infrequentes 8xc." "Eind aber bie Sibirijhen fladben Eegenden fo hoch und fo talt, als unfere

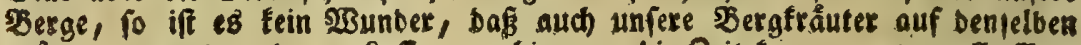
mogen eryeuget merben. Raffe man bingegen bie zeit fommen, wo alle 5 bes ge, bie Petucenbalter Der Winbe, follen abgetragen fenn; laffe man gefdes

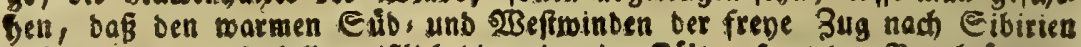

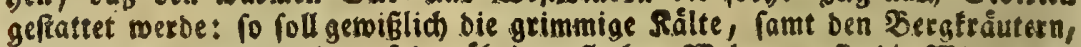
allba ber/h)winben, wie auf ber úbrigen flachen $23 e l t$, wo fie bie 23 itterung, bie tu iber Ergengung exforberlic ift, nicht antreffen merben. 
Dergningliú) feit $(x \times x)$. Denn was ift anyenefmers, als in ben fobnu:

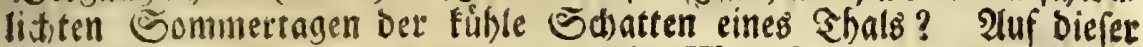
gun; anders geftaiteten (Frbe wirb foldse 230 luft nid)t ju finden renn. Die jnwohner ber beiken fänder werden fich fu Derfelbell Zeit ver,

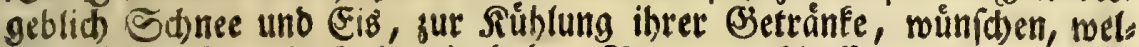
de \&abung ifnen bod ift Die bohen Berge verichaffen (y y y). Ein fobones 2luşfeben auf eine anmuthige sanorevier geboret auch billig mit unter bie Ergeflichfeiten ber Menjchen. 2(llein Diefes Zergnugen

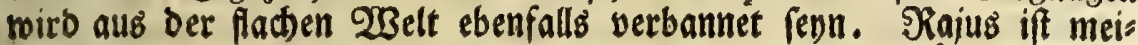
ner Mleinung. Er lejet biefes leztere unter bie erften Srünbe, womit er bie 2 ollfommenbeit einer 23 elt, bie obne 3 erge wäre, beftreitet,

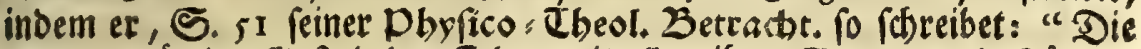

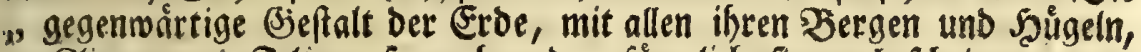
"-Rlippen und Felien, fo raul) uno unformlich) fie aud (d)einen, (voie "Die Oberpfaly bem Dertbeldiger und Lobredner der flachen welt "gef(tienen bat) fommt mir als ein felst fotoner und luftiger \$ros

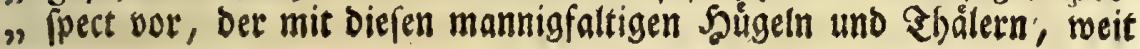
ange:

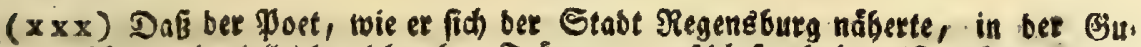
tíbe, unb viefleicht nicht obne Irăumen, gefdalafen habe, if mol gu vermus tben, weil Jas raube Pfäljerlants, beffen Golperidbten $\mathfrak{W}_{\text {ege }}$ ign ju einem unfreundlichen Silageliebe aufgebracht, fenen leib po derfte abgemattet baben,

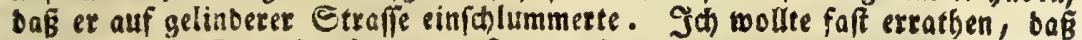
bie zroangigfte Strophe eben bie exfte geroefen, bie et ici feiner Ermunterung verfaffet bat; benn ber 2 nfang Derfelben lautet fo, wie aufwadenbe शRen fóen ju reoen pifiegen:

Was fel id von ber $50 \% 5$, wo mid Der Wagen ttágt?

Ifts nicht Der Donauftom; Ser fid vor Zugen legt?

Jit Sas nidbt Kegensburg $2 c$. ?

Eoll ber Sct. Berfafiet mid) etwan einet Inmifiengeit befdulbigen, unb mit

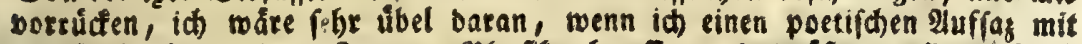
bet Stidtifdnut einer frengen PGofit abmeffen uno prufen moute; ob ich

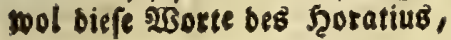

- Pictoribus atque Poëtis

Quidlibet audendi femper fuit aqua poteftas,

niemals gelefen ober gebóret bátte? To babe ic) bie Ebre, barauf gu melben,

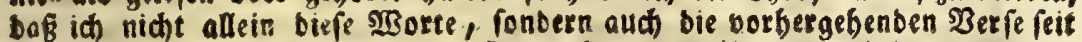
bielen Jabren aubmendig miffe. Ja id) tann benjelben aufridtig verfichern, baß orefe vortreffliche Stelle bes lateinifhen Poeten fich in meinem Sebåd)ts niffe benfelben 2lugenblick bargeftellet, als th bie Mbichlloetung biefer neuen, sbne 3meifel fur bie Ebiliaften beftimmten, sobelt zu lefen angefangen babe. 
" angenefimer in bie Plugen făltt, als eine gans platte und ebene fanos " f(c)aft (zzz):

Es foll aber biefer neubejwaffenen 28 elt nidbet allein an vielen 2 in. nebmlichleiten ber gegenwártigen gebred)en, fondern eB werben aud) Die Şnwobner berfelben wirklidbe neue unertråglidbe Ungemádb)lid) feiten auss ftehen múffen. Nad) Dem Segen, Deffen 23 affer obne 2lblauf fenn,

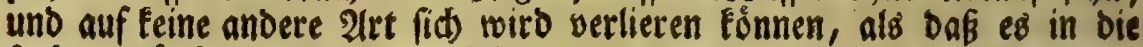
Ruft verbinfte, ober in ben Erbboben verfinfe, werben bie \&eure in fol: कen Siegenden, too fette Girunde find, fpannentief im Sothe herum waten ; bie vornefmen Şerren werben auf hohen Farten mit vorgefpan. ten Ddfen fpasieren fabren; bie Eein Jubrwerf vermogen, auf fehr boben

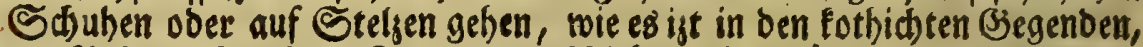

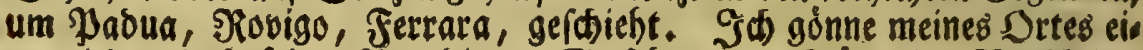

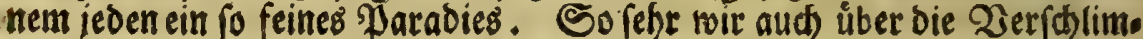
merung unferer Zeiten Hlagen, wie es bie \$Renf́t)en bereits vor taufeno und swevtaufend Sabren mit Den ifrigen gemadbt baben, fo ift bod uns fer gegenwårtiges 2llter ein gủlbenes, in Dergleichung mit bemjenigen,

wele

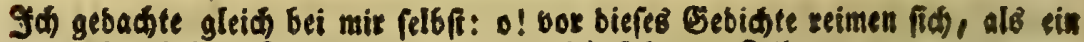

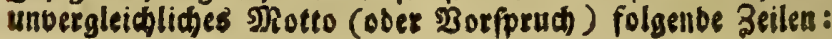

Humano capiti cervicem pictor equinam

Jungere fi velit, et varias inducere plumas,

Undique collatis membris; ut turpiter atrum

Definat in pifcem mulier formofa fuperne:

Spęatum admiffi rifum teneatis amici ?

Credite, Pifones, ifti tabulze fore librum

Perfimilen, cujus, velut ægri fomia, vanæ

Fingentur fpecies. Horat, de Arte.

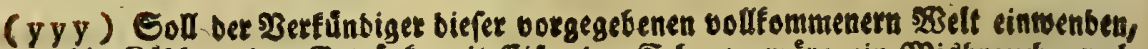
bie Rüblung bet Settånte mit Eife ober Sđnee, wåte ein SRisbrauch, mels

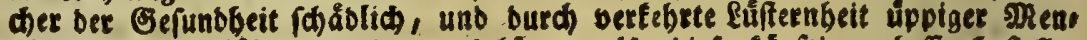

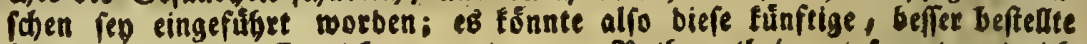
Belt, bergleiфen Erquicungen mit gutem Ratbe entbebren: 10 antworte id barauf, baf in Infebung bet beifen Etride bes Erobobens biefe Gefunbbeitל,

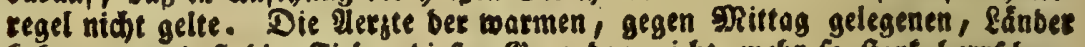
bebaupten, Daßj bie fieber biefer Begenben niche mebe fo fart beerfden, nacbern man bie Gettanfe mit Sdinee gu tüblen angefangen bat. Plemi pius verfídert in feinem 23 erfe de Togatorum valetudine tuenda, bafi iu

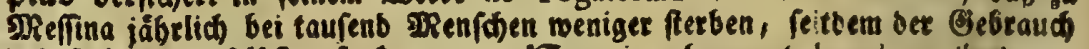
bes Ednees bajelbft aufgetommen. Ronnius besenget, 1.4 de re cibasta, c.

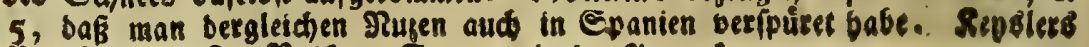
sortes, neuefter Rieifen, 5. 229, in ber Pnmerfung. 
welches die vorgegebene flache 2 Belt erleben foll. Diefe Menidjen

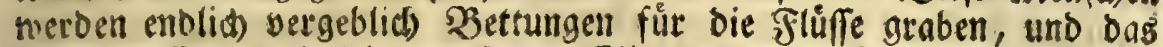
Siegenmaffer Darein leiten wollen. Sie werben, gu iflem nod groff rn Sibaden, und Derberbung iher (Selunbbeit, fid) Daburth bie fánoer nur průgicht madsen. Das 2 Bafer biefer Sraben wiro in feinen \&auf zu bringen fenn, Denn fold en Srieb geben ben beutigen fiuffen Die von Den-Bergen, oder gewiflid Don bỏbern Drten, fallenben Såt)e, und unterbalten benfelben befanoig. (5o ift leicht zu ermeffen, mieviele

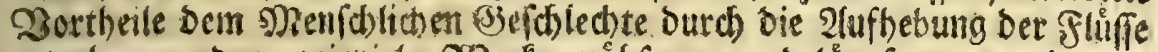

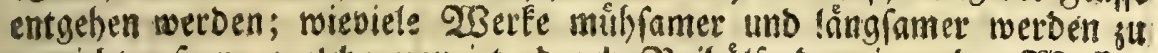
vertichten fenn, welche man ijt, burd) 2 eifulffe ber rinnenden 2 Baffet, mit getingen foften zu Stande bringen fann. Gd) bente nol, Daf (3) D t unferer 2 Belt, bevor fie follte eine ganj ebene (Sieftalt überfon. men, oorfte ein (Ende mad) on, Damit bie Men(d)en über fo ausneb) menbe Linoolfummenterten berfelben, feine Urfache zu tlagen baben; ja Damit fie nidjt, wiber Das (Sjottliche Deripred)en, nod einmal et: faufen. Denn Fajus bat in Dent oben angejogenen Şsuptft, feiner $\$ 3 b$

Dby:

(zzz) (5een fo urtbeilet aud) Derbam in bet PLyfico, Cheol. obet Viatur,

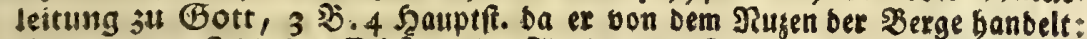
Was nun erftich Die Gdonbeit, כieroe uns Anmutb betrift, fo fanit

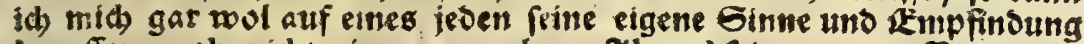
bertiffen, ob nidyt eine argenelyme 2 bwedffelung von Berg une Chal, arimutigiger uno luftiger fey, als Jie grofe immer fortgebene De Lbene. Id will oie Sabe Dem Urtbeil Derjentgen überlaften, be: rer Chun if Sie welt ju be(d)auen, bie jur Luft west uno breit bers

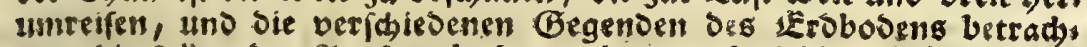
tell: Die follen Den zusfprud thun, ob es wol viel ber Mube werth feyt móde, bie alletentlegenften ebeile ser Melt 3 u befuden, bas ferne bie dEibe allentbaiben nides als eine gleide uns platte Kun:

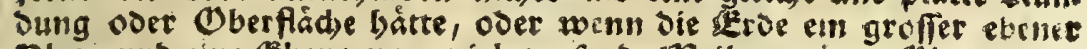
plaj, and eime Rbent von viel taufeno Meilen ware: Ob es nidat Dem Huge weit anmuthiger, von ben Bipfeit Ser Zerge berab auf

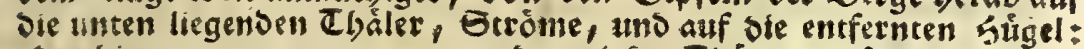
obix Gingegen bon unten, aus Sen tiefen Elsălern auf Die berumlie: genoen Serge ju felgen? Rajus, ber im II Sh. von Ser weigbeit Sottes in E Erichaffung ser Welt (Wisdom of God - - ) aud) won bem গTuzen ber Berge rebet, uno bierinnen Şrn. Derbam vorgeleudhtet bat, berus

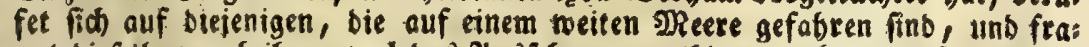
get biefelben, of ifnen wol bas 2usfeben anmutbig voxgefommen fey, ba. fie nichts als eine tunbe Scimmelsbecfe úber fid, unb um fich eine fo erídeiten.

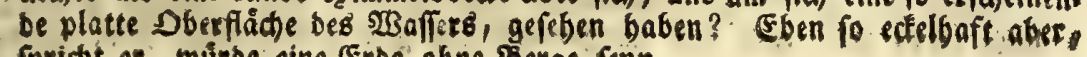
fpridt er, mútoe eine Eroe obne Dorge fepn. 
pbyficos Ebeol. Betz, Dargethan, bak bie Feerge in ber That immet

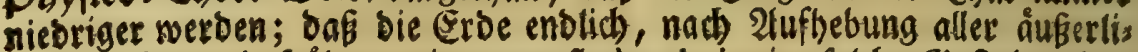
den Tiefen uno Saóben, eine gans flache, D. i. eine fold)e Beftalt erlan gen wúrbe, bergheiben unfere groffe Ebenen ist haben, alleit oub bas

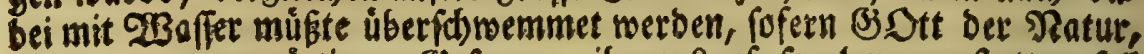
nad Den gegentwartigen oseresen, ibren fauf to lange geftatten foll (a a a a). Denn er fagt, bie \&ånoer nåfmen inmer su, uno trieben bas

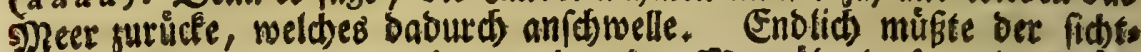
bare Sheil ber Erbe gant eben werben, bas meer úberlaufen, ein Stúc

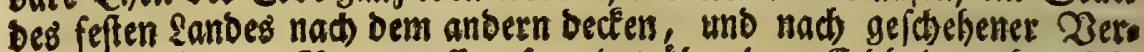
einigang mit bem Fegenwaffer, fo julejt uber bemt Eroboben ofme 2 tbs lauf fethen rourbe, ein allgenteines gReer qusmadben; baraus benn biefe

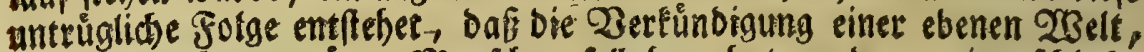

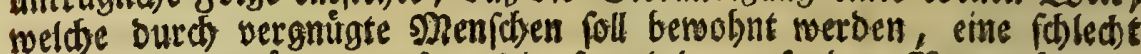
úberleate Sdwármeren fen, bie fowot ber gefunben ó Bemunft, als

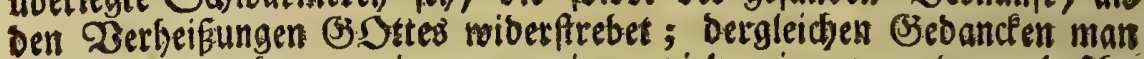

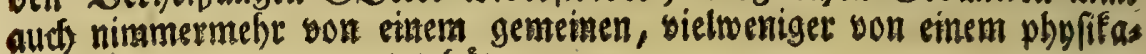
firchen \$oeten + erwartet båtte.

Der Sar. Derfaffer bes conffeirten Erefanges, baraud id bie Stef, ten vou biefer neuren 28 eft onme Berge entlefget habe, fragte mich neulid, bei feiner Durdseife áber PRegensburg, ob ith fubirt babe.

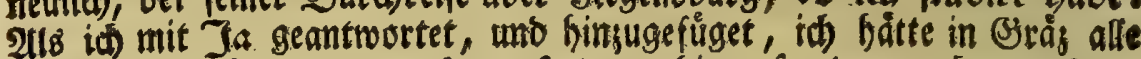

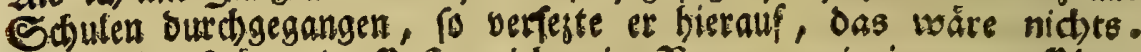
Die Univerfitaten in Defterceid), in 2Sayern, ja in gan3 Ober,

teute

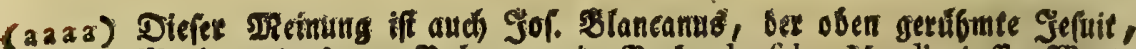
unb Matbematicub yon Bolognta, im Bube de fabr. Mundi, beffen Worte $^{2}$ in Raji pbyfico: Ebeot. Zetr. S. 508, fo vorgetragent werben : Jds Goffe, es roerbe bem Refer nide mangenebm feyn, wenn id ism et, was entoecte, welder gas mol wertly tit angemerte 3 w werden. Id

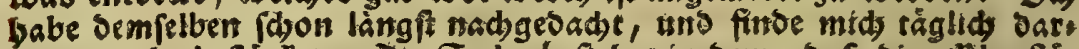
inmen mebr befarfet. Die Gade befebet in sem, oaf die Oberflä

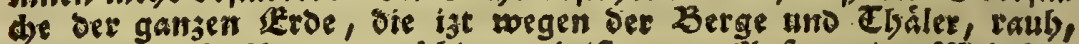

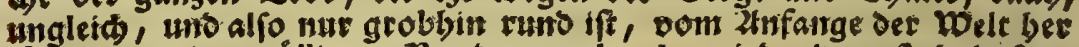

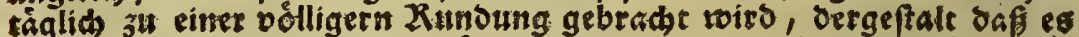
naturticher weífe gefduelsen fórnte, Saf́ fre bermafeins von bef Gee müfte úberfduenmet weroen, who unvewobnt liegen bleibert. Die

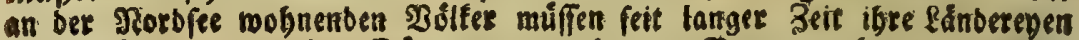
unb Etåbte, mit bober Da hmmen berwabren. Bejengen aber diefe eingele Beifpiele von gewaitigen Einbríden bes IReeres laber niedrige Etránbe, nidgt fdon its 
teutfobland waden febr folledt belfellt. Gr mollte mir ofne 3tweis fel baburd) ju verftehen geben, id müfte voa neuem anfangen ju ftus

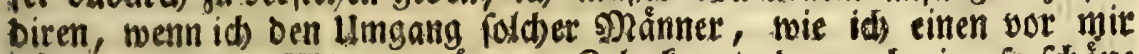

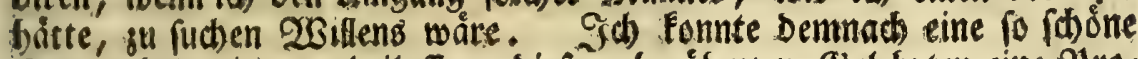
(j)elegenkeit nict vorbeilaffen, biefem berúhmten Belehrten eine Jiro.

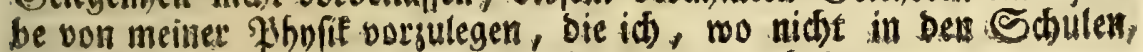

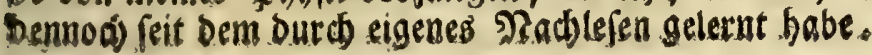

\section{Sierte 3 Silage}

sur III Unterfudfung.

\section{3olt Den 2 Birbeln in Der Donath.}

2.

$a$ id in biejer III linterfudutring son ben Seenirbeln gefandelt bas be. futfer mid Der Zufammenhang auf Den befannten Defterceis

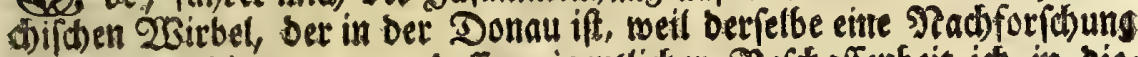
feht wol verbienet; von beffen eigentlicter SBefdaffenbeit id in bies

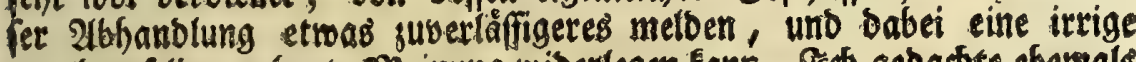
bon b.emfelben gefregte sleinung miberlegen fann. Tot gebadite efemals mit vielen anbern, Daş biefer eine balbe Stunbe unter Ejrein auf Der

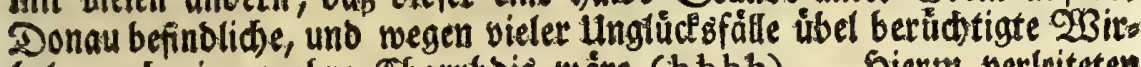
bel, aud) cine wabre (Sharybbis wáre ( $\mathrm{bbbb}$ ). Shiergu berleiteten $\mathrm{Bb}_{2}$ mich

went alle Jreetufex auf bem ganjen Exbboben follten bon gleidet Sefdaffent beit merben?

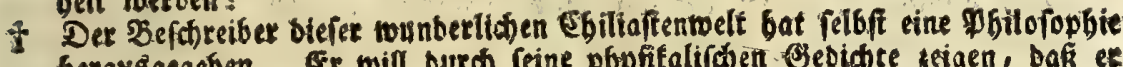

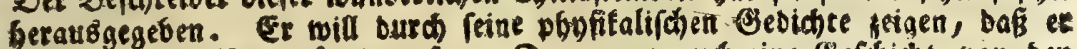

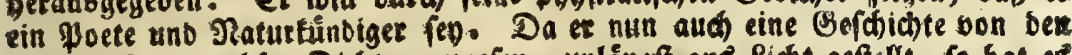

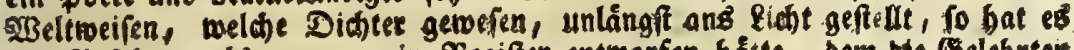
bab Infeben, als wenn et ein Fegifter entmorfen båtte, bem bie Eelebrteit feinen Ramen einverleiben folten. Bieleidte thut et es nod felbft benn feis ne thátige Sittenlehte vermirft ben Eigenrugm niфt.

( $b$ b b b ) DaB ift, ich bilbete mir ein, baB ein Tbeil bes Donaumaffers aflba bured

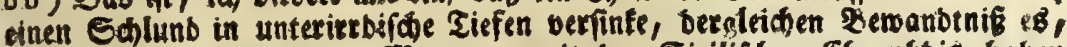

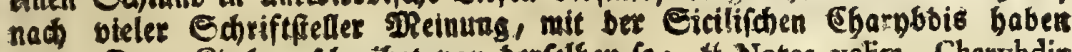
foll. Denn Rirder fareibet von berfelben fo: "Notes velim, Charybdin " hanc nihil aliud effe, quam ingentem voraginem feu abyffum, qua per cæca " terræ vifcera, tanquam per vaittos telluris fiphones, ebulliens illa aquarum " moles certo tempore regurgitatur, et ceflante regurgitationis caura, aquan grece: 


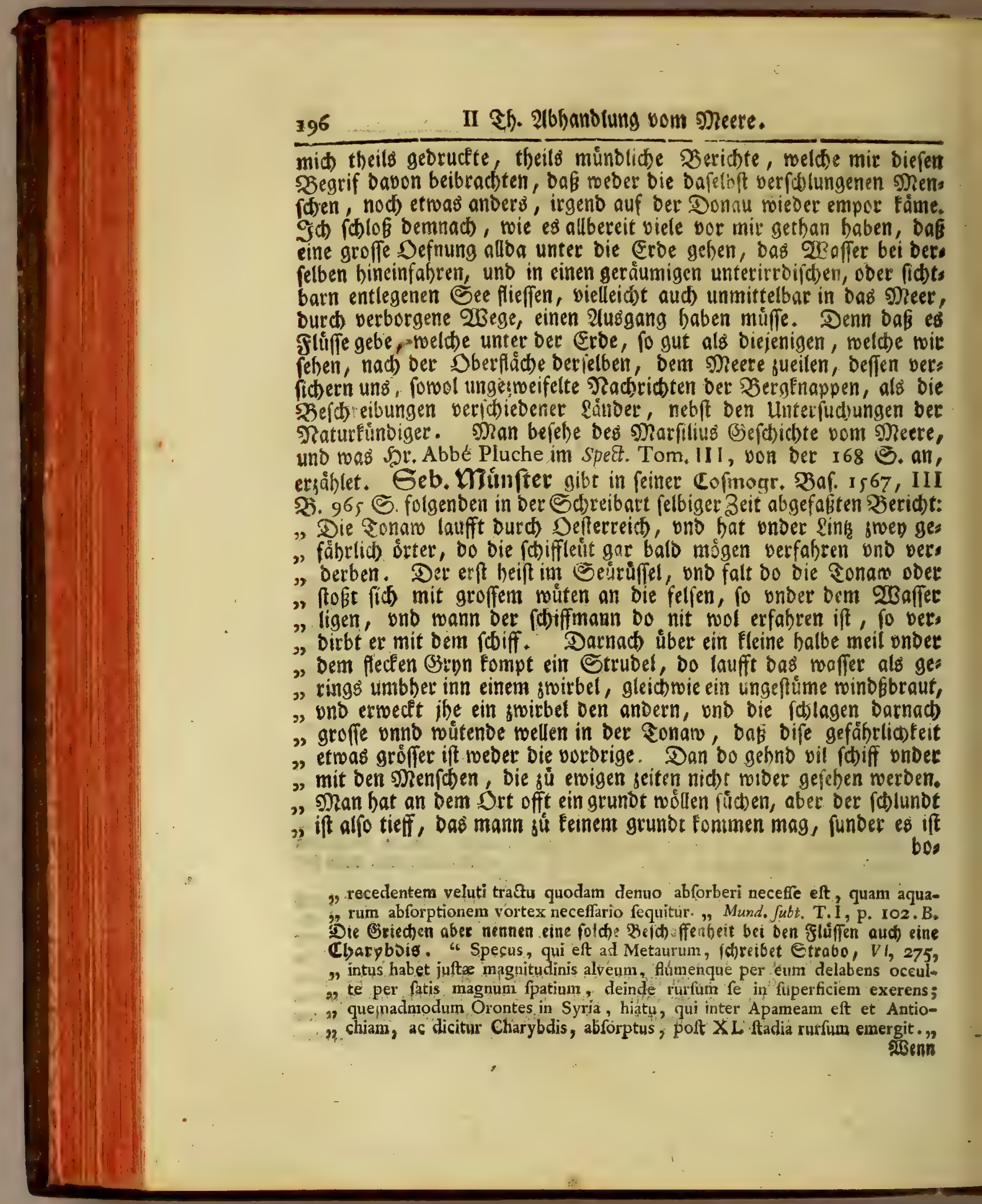


hodenlós do. 2Bas do bineinfalt, bleibt do unden, unno fompt

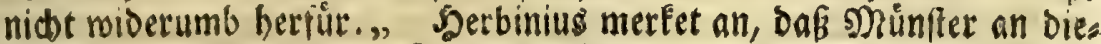
ret Stelle ben 2Bitbel und Strubel zufammen, als einen Drt, befdreis be. Sappelius unterfacibet fie Durd nadsgefeste 2 bjobilberung: Der andere Fafl ift bei bem Stãotlein (Sreina. Den nennet man Den Strubel, weil bie Donau Dafelbft úber einige verborgene Felfen

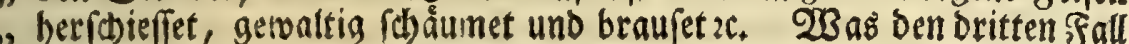
" anlanget, fo if berfelbe befannt unter bem פamen eines cBurbelo " in oer Donau. Diefer ift nur 200 Sdritte von bent Strubel, " unt jiehet eine groffe shenge 2 Baffer binunter in ben 2 bgrund, famt

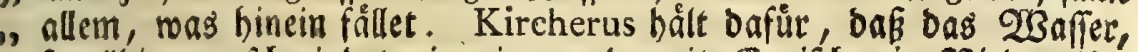
"fo allbier verid)mindet, in einem ofnweit (5anifha in \$rieber= In: "garn gelegenen See (Zalaton, Blaitenfee) wieber ausgeftoffen "werbe; Danu es ift gewifi, Daß bie Donau an diefem Drte viel von , ifrem $23 a f i e r$ berliehre, fo baf fie unter bemielben nach 2 Bien binab "lange nict)t fo viel 2 baffer bat, als úber bemfelben.",

Das Seugnif Kircheri, auf weld)es Sappelius an biefer Etelle (i⿱亠⿻⿰丿亅八阝 bejiefet, ftebet in Mund. fubterr. Tom. I, l, III bydrogr. p. I 50 , in Confect, 2, uno lautet 10: Hinc quoque patet, cur nonnulli Vortices aquam femper abforbeant, nunquam evomant, uti fupra de Euripo Africano oftenfum fuit. Hujus generis quoque Vortex Danubii eft, qui quas aquas abforbet, illas per fubterraneum meatum intra lacum Hungarie prope caniffam, uti fertur, deponit (cccc).' nem Curieuren Antiguario, bie gefábtlichen Drte in Der Donau, wis Sappelius, aufer Daß er bei ber Inzeige ber (Szegend, in meldber ber Wirbel fich befinden foll, einen geographifwen Jebler begebet. Eeine

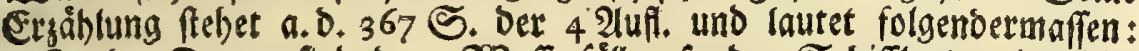
"In Der Donau find Dren 2 Bafferfálle, fo ben Sobiffleuten jiemlid)e (j)efabr bringen. Der erfte nabe bey Sinf insgemein der Gaus "Rúffel genannt, wegen eines alfo geftalten Felfen, Der fich weit in $\$ 363$

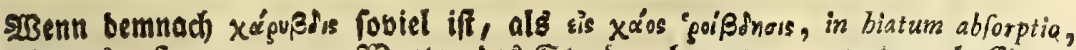
wie aus exft angejoganen $230 r t e n$ des Strabo abjunesmen, uno aud Slubes

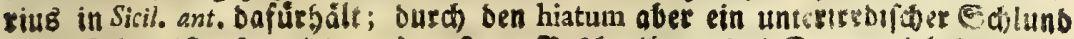
zu verfeben ift, fo mirb aus unferer befthreibung bes Donaumitbels erbel

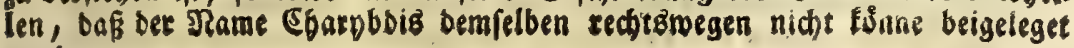
merben.

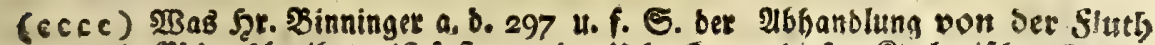

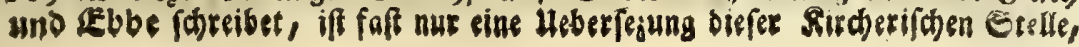




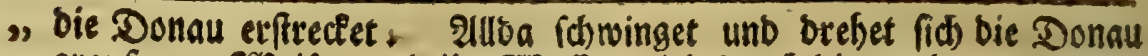

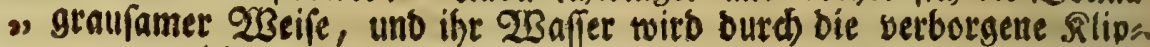

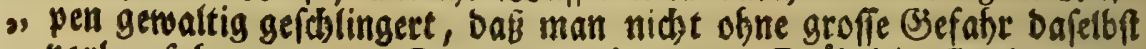
"vorbey fabren mag. Der swente ben Dem Stäbtlein Sirein, Der "Ettudel genanne, weldier nod gefäbrlidier, als ber vorige, weit " Die Donau bafelbft zwiraben graufamen Felien lauffet, Deren etlidse " oberhalb, etliche aber unter bem 23 affer ftefyen, an welden Felo

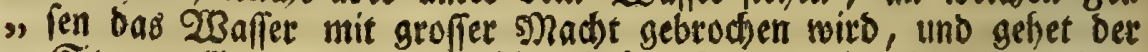
"Strom allbar, weil er swifden bohen Bergen eingefdoloffen wirb,

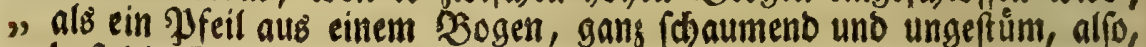
"Daf bie Sdsiffe, to oahin berfallen, auf und nieber getworffen wets "Den, Dannenhero an biefem Orte nod groffere (Befahr als an bem "vorigen iff. Der britte unter Erems, uno niro der $\mathfrak{B}$ úrbel ges " nannt, ber gleid) als ein brefgenber Schluno angurehen if, allwo fid "Das $23 a f f e r$ mit groffer (s)ewalt umbrefet, und an feinem geraben "Eauffe burch einen groffen entgegen fehenden Felfen verhinbert nirb.

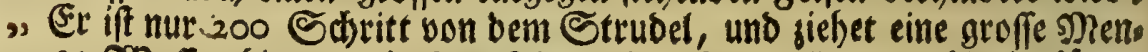
" ge $2 B a f f e r$ binunter in ben 2lbgrunb, famt allen was binein fállet,

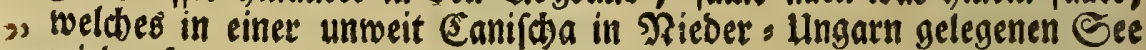
"s wieder beraus fommen foll." Strablenbergs Beridfet fommet mit Den bisher angefúfrten ùberein, benn a.b. 429 S. Der Befbr. von Ruff. fteket folgenbe Erflärung: Wirbel ober Gtrubel, latein.

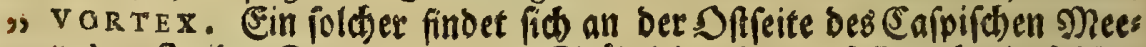
"reb. In ber Donau bei bem Stábtlein (erems foll auth ein foldhet

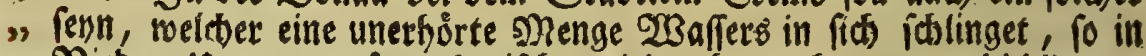
"Neieber : Ungarn unfern Canijoa wieber berworfommet. (dddd)

unb beffet, was borbergebet, foviel in mich exinnere, benn id babe sizs

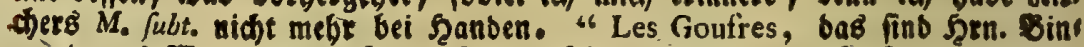
") ningers Borte, font de plufieurs efpèces. Il y en a de fi petits que la " diminution des eaux fe fait peu remarquer par celles qu'elles engoufrent. "Il $\mathrm{y}$ en a qui engoufrent les eaux fans jamais en rendre, ou plutot fans " qu'ils régorgent. Tel eft le Goufre énorme du Pole Artique; tel eft auf12 fi celui d'Afrique dont j'ai parlé ailleurs; le Goufre du Danube eft auff " de cette efpece. "Der Ungrunb bes bier vorgegebenen ungefeuren $23 i$ bels unter bem Norbpole, wie aud bie flare Unwabrbeit Des Edhunbes in ber Donau, laffen uns urtbeilen, baß fre. Dinninger arich polde Dinge, bast auf er feine Rebre von ber glutb unb Ebbe geúnbet, für exwiefen bofrfte ane genommen baben, welde bod bon bet Ridigteit nod febr entfernt gimes cen. 
इd) wollte fdon bor einiger Beit bie fiebbaber ber Geltenteiten ber SRatur erfudien, oak fie die Grforfdung biefes 2 Birbels unternebmen, uno eine anfehnliche Sinjabl Borfftucle bon allerley Bseoffe, mit einet: aufbabenben, auf tupfern 2 led geftodsenen 2tufforift, su verfobieber nen Seiten móchten bineinwerfen, um su fef)en, ob einige babon auf ers wefhntem Gee berborjdwimmen werben. Sot wollte ferner eintatben, Das man bie 2 efdaffenbeit diefes $23 i r b e l b^{2}$ beobadten, Den etwan alls ba fid) jeigenden Sacten, bei fleinem 2 Baffer, mit Bleiwurfen abmeffen, uno burd) Derfenfung eines barsu gebauten 2 Berfes verfalieffen móch: te. Denn baßj biefes gut getbau bátte, wenn eine wirtliche Defnung

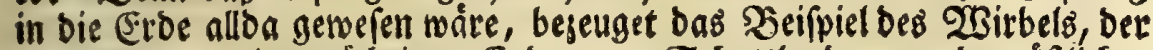
unweit bem mitternåd)tigen Ende von Shottland, an Der offtictien Seite ber Drcabifden Eleinen Gnfel Souna, fid befinbet, beffen Xas ben mit einem alten leeren Faffe, ober mit einem (siebunbe Strob, Eann jugethan, und bie Serumorefung bes 2 Saffers baburch gebemmet rerben, bis sur Wieberfebr Des unten beraufwallenden Stroms, toels

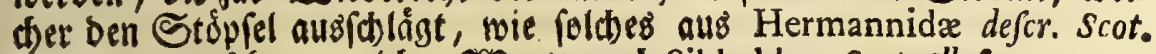
p. 540 , fu erfeben, weld)er 2 (Sorte aud Sibbaldus Scot. Illuftr. part. 1, 1. 1, p.19, fid beoienet. Det $\mathcal{B}$ ericht lautet fo: Ad Orientatem insule (Sunæ) partem, fluente a Deucaledonio five Occidentali Oceano eftu, tam borrendum in modum marina circumgyratur aqua, ut, $f i$ vel grandior oneraria aliqua navis in Sunenfes bos gurgites incidat, trocbi inftar flagello a pueris agitati, circumferatur. Horum periculorum gnari tum Orcadum incole, tum Cathanefii, multis maris obviam eunt incommodis. Dolium aliquod, quod nullius jam fit ufus, accipiunt, alii ftramineo experimentum faciunt fafciculo. Hac in gurgitum injiciunt fauces. His immifis, ubi abjorpta

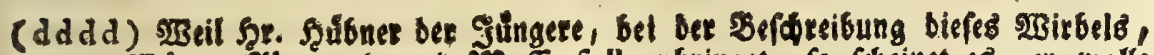

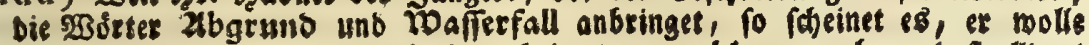
gleidfalls ber SRetnung berienigen beitreten, welche vorgeben, baß alloort bas S\$affer burch eine Defnung in bie Exbe fin verliere. Denn ex fidrei bet im III Th. ber vollft. Geogr. S. 134: llm diefe Gegens (um Erems) jit auf ber Donau ber berủbmte Wafferfall, ber sBübel genannt, wels ben bie Ediffer vermeiben muffen, wenn fie nidat in 4 bgruns wollen gezogen feyn. Dabero fiel et auf der Gpige eines boben Selfens ein grof fes Creus, Danit man fid bey. Zeiten in adt nebmen Fan. Daš Zets

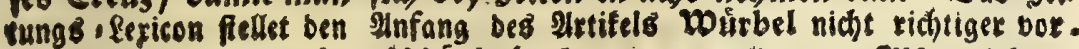
Derfelbe ift fo abgefafit: Wu urbel, lat. Gurges, Vorago. 2llfo wirs ges nenht ber Wafferfall in ber Donall unter Crems ic. Das ift aber ein mater, uno theils irriget linterridat. Denn erftlid ift anba fein eigentlicher

Maffe: 
abforpta fuerint, biantes occluduntur fauces, et quietior complanatur aqua, vectoribus tranquillum faciens tranfitum. Da nun bei ber Sonnu fein

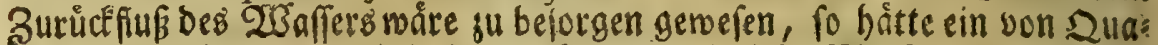
Derfteinen gebautes , uno in die Defnung verfentes 2 Berf, nimmermebr Fonien ausgeboben weroen.

\section{Allein}

20afferfall, fonbern nure eine limbrelgung tes 2 baffers. Darnach befintet (itc) ciefer Drt nidit um Exems, biel weniger unter Erems. Er liegt in eis

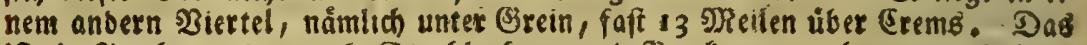
if ein Srrthum, ben aud Etrablenberg uno berctenmever begangen baben,

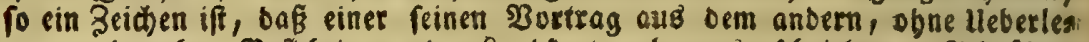

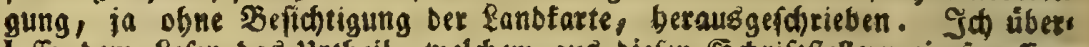
laffe sem Refer bas urthail, weldiem aus biefen Sarrifteftelern ein fo offen:

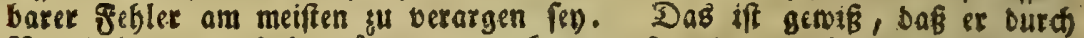

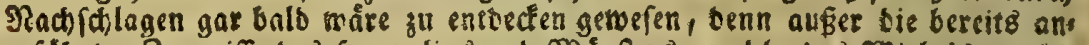

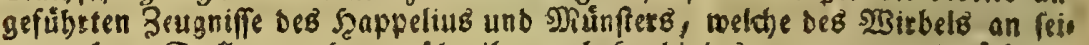
ner rechten Etelle errobenen, (d)reibet aud J̨erbiniuz, p. 235, ausbrúctlich: "Sed majus longe periculum damnumque fecunda catarąta fub oppido Grei"na, minitatur. Nautæ et accolæ eam a Atridore, voce Teutonica Detr "Etrubsl appellant. Nluf. ber nachtommenden Eeite: Tertia cataracta, "plus minus ducentis paffibus a Strudelana, longe naxima navigantibus inten", tat pericula, quæ eo majora fint, quo minus oculis obiter afpectantium ob-

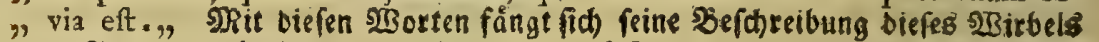
an. Mventinus berictet, Ann. 1. 5, c. 7 , feat. 28 (ber Bundingiraten \&uzs. gabe, Reip. 1710, S. 503 ) ebenfalls, Daß́ ber Strubel unb ssirbel bei Srein vorfommen, unb ift mar gu ben \$\$SOrten: "Teutones hunc locum in"famen perniciofumque navigantibus, a ftrepitu aquarum Strudelon nuncu-

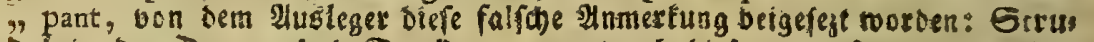
Jel in oer Donau bei Gtodterau, modurd biefe fiben Drte nod meiter.

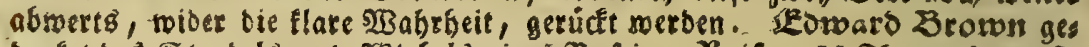

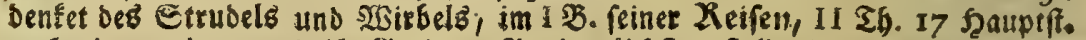
aud) ein menig unterbalb Srein. Im beutlidfen fteltet bie eigentliche lage Diefer zmen Drte Enerians Beforetbung on Eefter. S. 10, mit biet fen 30 rten oor: SEine balbe meil von Srein liegt Srrom, ein altes Slectein uns wefen, famt bet Maut obex 5oll. Dabei nabend, this alfo aud) unterbalb Grein, adbthalb Meil unter Linj, uno oritha!b

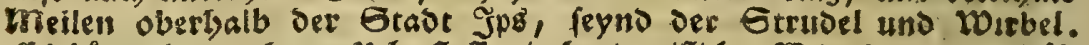

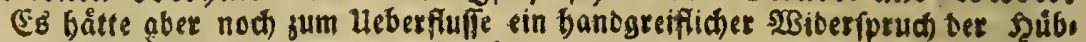

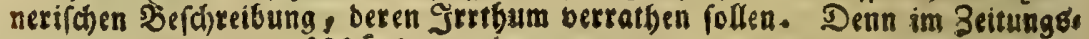

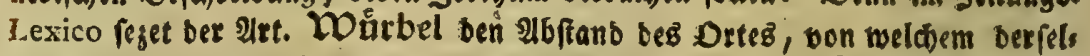
be banbelt, nut auf 200 Stritte vont Etrubel. Der Strubel witb in

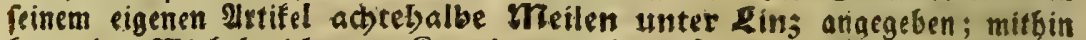

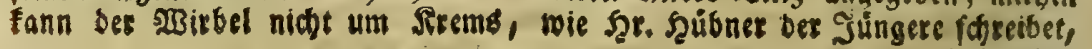




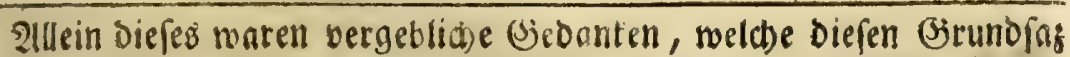
'zum Siegenftande batten, unter Dem Donatuitbel befinde. fich ein

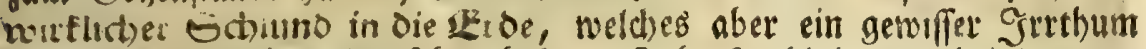
ift, ben ith nachber eingefehen babe. Joh. Saerbinius vertbeioiget von

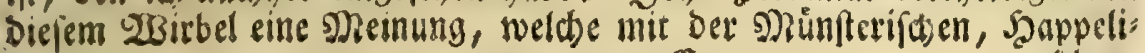

(c)en,

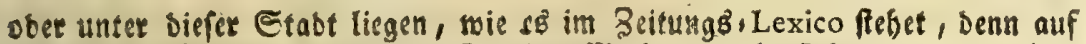

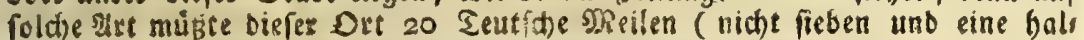

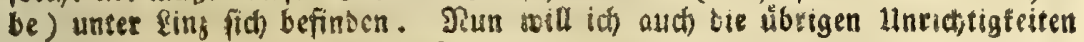

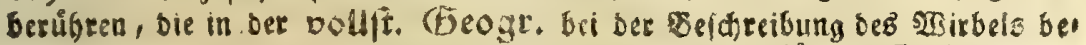
gangen worben. EB follte jum oritten an ber obenangefübrten Stelle boifien,

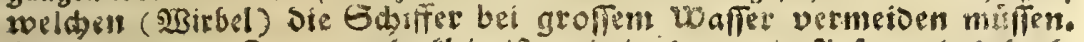
Denn, wenn die Donau rect flein if, wie izt 1749 im Anfurge bes berbs

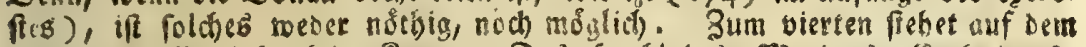

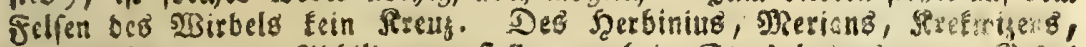
bon Sirfens, u. a. 2bbilbungen ftellen nur beim Etrubel cines sor. Bs:pest

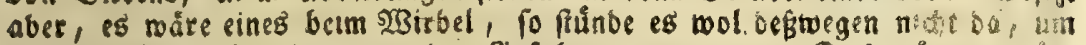

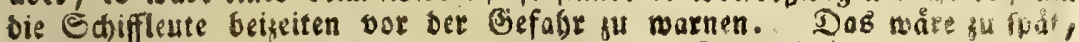
wenn fie auf foldhe Erimnerung warten follten. Diefe Begent if ibnen oor: hin fhon fo befannt, baß̃ ein jeber auş ignen (von cen Regengburgern tann id es aus ber (Exfahrung verfictern) von bem 2 Brbel unb Erubel, obre bieles Dechliaten, einen fobrographirgen Entmurf mit ber Siribe auf ben Tlid) ju geichnen weip, und folches viel genauter, als bort ein Brichricher Selo einen Srunorí̄ von Troja vorfellet, Ovid. Heroid. 1, 16. Dent ber Ediffmann wito in feiner albichilberung biefer Drte, nicht einen einjian Etein vergeffen anz̧uozuten, Der ibm auf feiner f̧abrt Ulegelegenbeit mad):n fónnte, weil er fowol bie eigentlid)e Eage, als Giffal, ber allort thet!s vorragenten, theils im $23 a f f e r$ ftedtenden gelfen, wol im Einne baben mus.

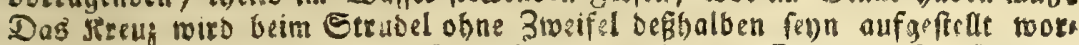
Den, um bie Sdiffenben zut 2noadjt zu ermabnen. Denn bei 2nnăbecung su diefen zwey geföbrlichen Orten, pflegen einige. Ediffmetfer ben aufbabens Den Reifenben, menn fie Diefeiben mu folden Dingen butháftiget fehen, wels dhe man bei edntretung ber Befabren trinesweges gutreiben sfleget, eraftlich anfutúnbigen, fie módten vom Spielen, Schergen $2 x$. aufboren, unb lieber jum Betben fich anfithiffen, weldtes binitg ift, weil ta bie Reit antúcfet, welate burch ein Eleines Berfeben ber Ediffleute, oder Dutch eineli unvermciolis d)en Lnfern, ibrem Reben gar balo ein Ende manten Eann. Denn bas $\mathfrak{B}$ orges

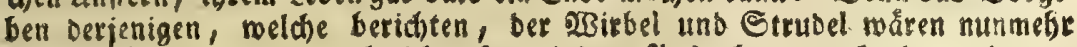
nicht gefäbrlid, fann nol nid)t obne einigen Alaznabmen wabr fenn, basuns

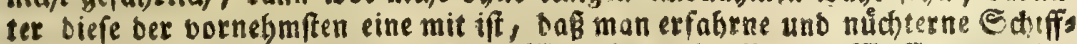
leute baben múfe. STernad) ift Der Wirbel nur bei fleinem $\mathfrak{W}_{\text {affer, }}$ uno oet Errubel bei groffem nicht fut beforgen, two aljo bei bem einen, ober bei bent anbern, bie Eefabr allemal unumgănglid) ift. WBenn ber Etrutel und bel, tiberbaupt zu reden, fichere Drte fino, wasum perben alldort noch gu 


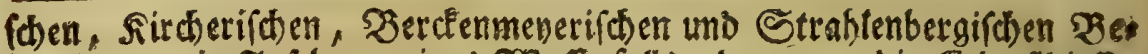
(d)reibung, in In[ehung eines 2 Bafferfalls, ber unter die (stoe fhiefie, ubersinftinumet. Er bemủbet fid) in einem eigenen Şauptftúcfe (de Cataracta Danubiana, p. 232) ourd eine Sotufrebe zu erweifen, baf at Diefem Drte ein wirflicher Soluno múfe vorbanden fenn: Erit autem opere pretium inquirere accuratius in penetralia Damubii: num Gyrus ille Danubianus, fit Vorago proprie dicta, aquas Danubii in fundo bauriens? Affirmo id argumentis iftis. Primo: Libi eft Vortex continuus, ibi naturalis aquarum ingluvies, five Vorago aquas bauriens. Aft in Danubii tertia Cataracta circumflexa (e eee) eft Vortex continus: ergo in Danubio etiam eft ingluvies five Vorago aquas abforbens, de Cataract. fluvial. p. 238. Serbinius bilbete fid) ein, beite Säze diefer Solufrede wåren ridstig, uns begefre Feiner berfelben fernet bargethan gu roerden. Denn bou bem exfen fagt er balo Darauf: Hac autem affertio certifima eft: ub: gyrus cum vortice perpetuo atque injectas res forbente circumagitur, ibidem etiam vorago aquos in abyjum trahens, aut per meatus fubterraneas alio trdnsmitters eft. Iflein bie Erfahrung verfichert uns, daf beibe igt ans gefübrte Såge fafor fino. Die Beugniffe auf bie Serbinius, als ben Jonten (sirund feiner Dreinung, fid berufet, fino ebenfalis unridtig. Er foreibet alf ermefnter 238 Seite: Secundo; accole omnes fundum illius Cataracte nulla arte explorabilem effe, adeoque funda carere, omniaque ibidem baufta non amplisis emergere, communi experientia docti, teftantur. Exiftino autem aquas voragine illa abforptas, non in abyjun fubterraneam defcendere, fed cunculis alio derivari: et quidem naute experti, nec non curiofi rerum talium fcrutatores afferunt, Danubium abfor-

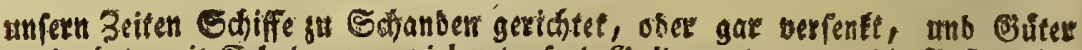
verberfet, mit Shaben bon bielan toufend Brulden, Den nur bie Befiget leis

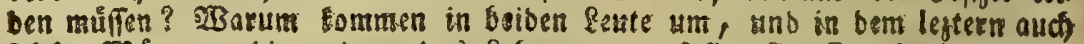
folche SRånner, bie andern bas Reben retten foltert? Dergleidhen fanfte sorftelungen baben the urfachen, vie id) nicht verwerfen mill; allein fie. metben von ben 2 ergten curationes palliative gemannt. CEs find aber nicht alle Schifleute einerley Sinnes. Inbere feigen ben Sieifenben, wenn biefe aud fagen, bergleichen gefäbrlictie Drte bosfeglich nidst an. So lätert Herbi-

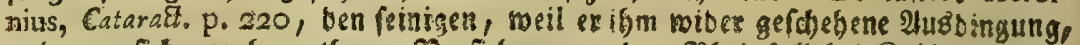

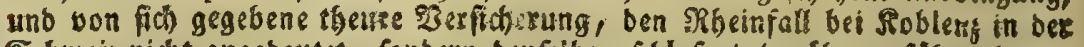
Edymeiz nicht angebsutes, fonbern benfelben follofeno daruber gefübret bat.

(seee) Durch biefen Ramen verfebet ex Den Wirbel. Denn ber Gauruffel if peine erfíte cataracta Danubiana, Der Gtcubel bie zmente, ber wirbel bie britte. De Catarati, fluv, po $234 \mathrm{fq}$ 
ptas prope Lintium aquas et res leviores, intra lacum Hungarie prope Cavifcham evomese. Diefer alleg, (preche ich), ift faljh). (ffff)

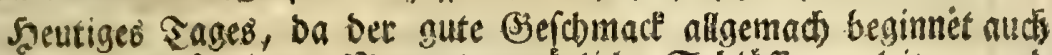

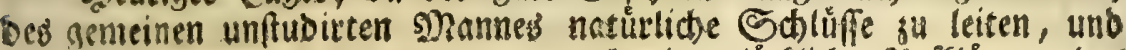

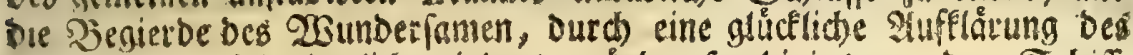

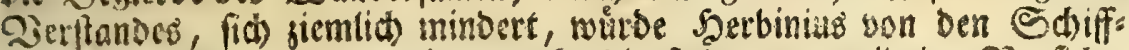

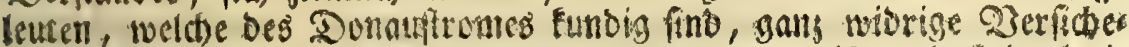
rungen empfangen. Folgende steuere Beridyte etweifen, Daf Dasienis

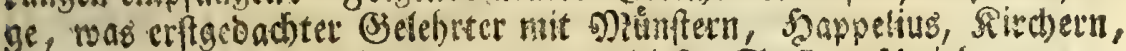
Sercenmevern, Strabtentry, u. a. an biefer Stelle geforieben, mge: grunder fen. (Es ift vor ungefábr 8 Sabren ein plattes Sdiff (nad) ber Siegenburgiften fifcher Munbart ein Sabrm, 0 . i. wie id glaube,

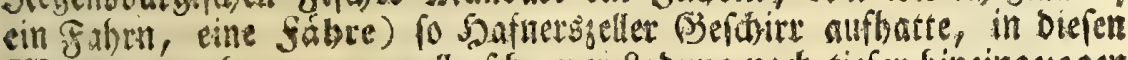

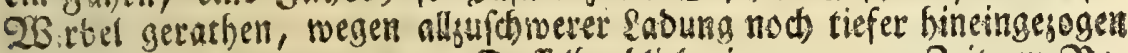
twordell, uno untergangen. Daffelbe blieb eine geraume Zeit an $\mathfrak{D o s}$ ben bes 23 irbels figen. Die Seute, fo bei fleinem $23 a f f e r$ barintet fifoten, follen bas Dad) babon gefehen haben, bis ber Strom eins: mals angeroadten, bas Fahrseug umgefturzet, und bas (Sefd)irr aus: geleetet bat. Da fdswamm senes empor uno davon, ward aud enige Sttunder 2 Beges unterbalb aufgefangen. 2Benn jemand einwenben foll,

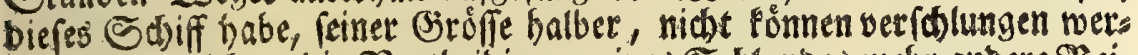

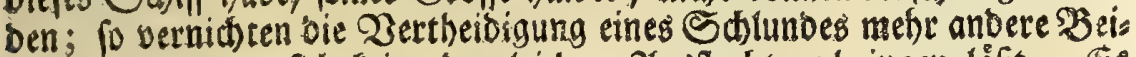

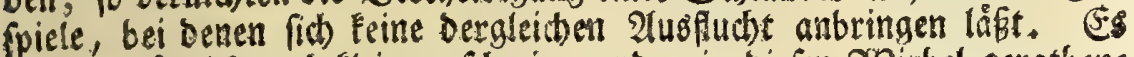

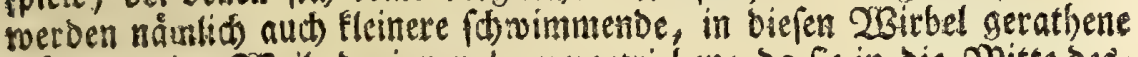
Sorper, eine 2 Beile barinnen berumgetrieben; Da fie in Die glote bes: (6) 2

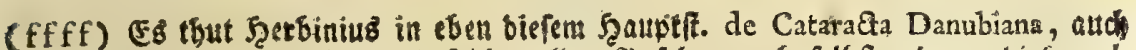
bem Strabo uncedit, uno feblet allem Sufeben nath felbft, ba er biefen als

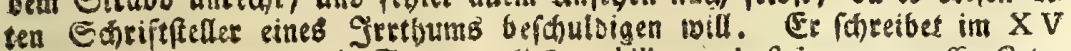
Sauptft. de Catar. Danub. S. 233: "In nobili per Auftiam progreffu Cataractis tribus horret fi. Danubius. Strabo Catarakas Danubii nomen mutare 7) in Iftrum demonitraturus, collocat eas inter Dacos et Getas; qua in re ta7, men falfus eft; namque illa in Auftria Germanix ferociunt, non in Dacia, "2ut inter Getas, nec Budam usque, Metropolin fedemque olim Regune "Hungariæ, ulla in Damubio vifitur Catadupa, adeoque non ifter volvit Ca-

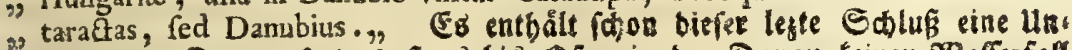

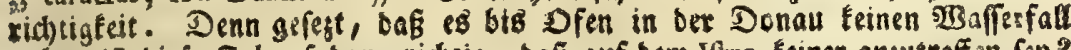
gebe, if biefe Folge fobann ridtig, bas auf bem Iftro feiner angutreffen feg?

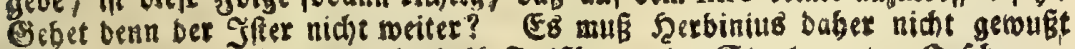

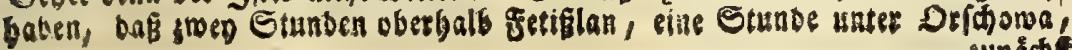


relben fommen, himabgejogen, und über einige Beit an einem andern

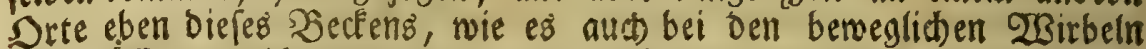
Der Fluffe zu gefdehen pfleget, mieber herauf gebracht, bis fie endich ein feitwertiger Sdivall (Strom) gat negfúlyret; fo wol nidt gefdes

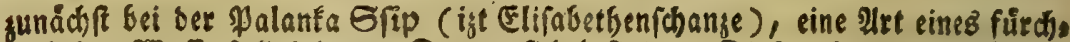

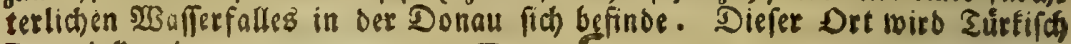
Demictapi, D. i. Sas eiferne Cior, genannt, weluben Die MRéllerifde von Jo5. Sapt. Scomann beraügegebene, forol bie fleine, als bie grofie

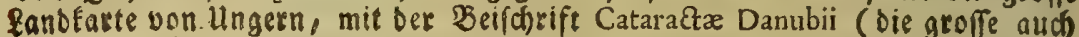

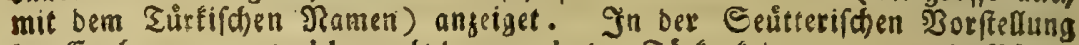
Der Eroberungen, welde nach bem borlegten Túténtriege, 1718 oie 9 forte

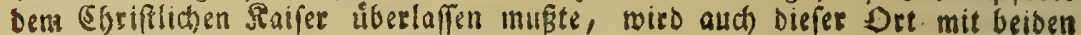

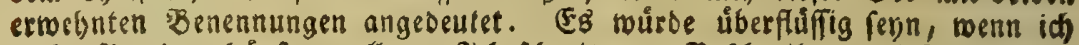

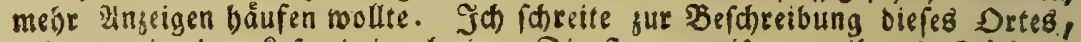
uno vermeine bem Eefer Dabuch sinen Dienft ju erweifen, weil er in búd)arn,

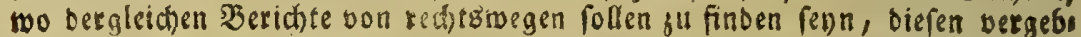
lid) fuchen roisb. Es ift an bem angeregten Drte eine felfichte Enge, frois fchen belberiests ftehenben Bergen, burch toeldie ber gange ungebeure Donau

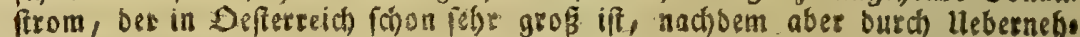

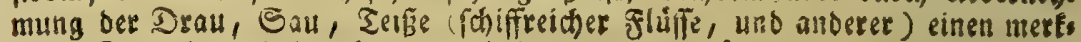
liden Zuwachs exbalten bat, mit befonderer ungeftumigttit, uno entfejlichem

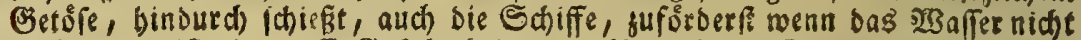
boch genug ift, in groffe Befabr bringet, alfo bas bie Raufleute ober andere

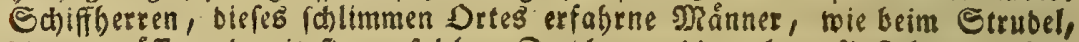

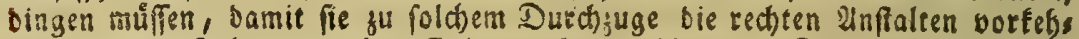
ren, und bie Fabrgeuge obne Edjaben binourchleiten. Denn moferne eines Dem vollen Strome fich úberlaffen molte, fo mište es unfélbar fu Brunde geben. Frålt es fich aber, ofjne binlångliche Rundrchaft, zu viel auf bie eis ne ober bie anbere Seite, mo bas $23 a f f e r$ nicht fo reißeno flieffet, fo begibt

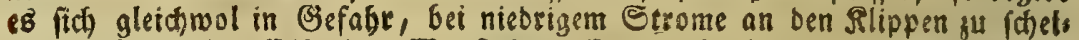

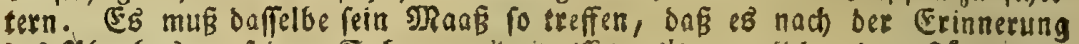

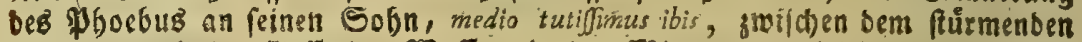
unb bem gelinber flieffenden $\mathfrak{W}_{\text {affer, }}$ in ber. Nitte, uno gleichrol bem Ser: virken ufer nåber, bleibe. In biefem engen Paffe merden bie feaufen th eis nem 2 Berfe von Stacfeten gefangen, melched in ber Serben, Siązen, und

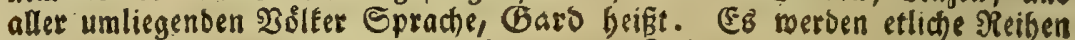

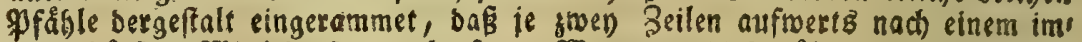

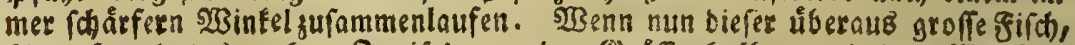

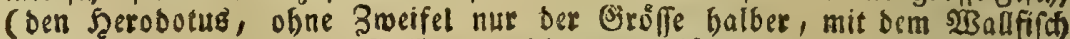

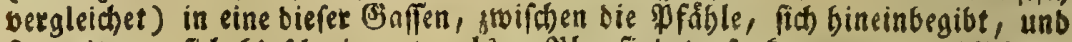

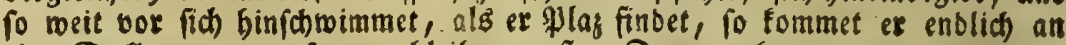
eine Stelle, wo er gefangen bleiben mús. Denn er fann weder vormertż, noch aud zutúcfe, meil et fid nicht menoen mag. Diefer Drt båtte in Setr. 
ben wuirbe, foferne bas TSaffer alloa wirflid unter bie Eroe gieng: Dor vielen Gabren ift ein biefiger Edhiffmeifter, Martin Deyer, in biefem Wirbel umgefommen, und bei Rlofterneuburg aufgebract wor: Den. Die in Stein gebauene Sirabldrift zu Salenberg, benn bort ift CS 3

Sưbnet vollf. Geogr. mol eine furge Erwefinung berbienet, anftatt vielet abgefomacter und aufierft partheniface Anmertungen, beren Berfaffer beis nabe auf allen Blåttern, audj ofne bie geringfte juvermuthenbe Belegenbeit, ben Satbolifen in bie Scaare geräth, unb fich mebr als sin theologifcher Şas bergeilt, als ein red)tfd)affener Geograpbus, auffübret. Jich neis abir nidit,

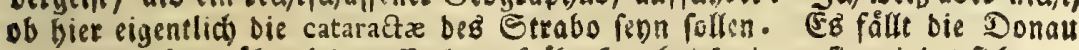
an bieferm Orte tiber teine offenbare feóbe bereb, fondern fie nindet fich nur, eine ganze Biertelfunde in bie fänge, nit gefchlungenen Rrümmungen, ưber einen Elippidten facte abbangenden boben, ztoifhen beiberfeifछ febenden

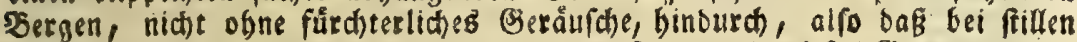
Sådten, auf eine Etunbe in bie $2 B$ eite uno ferner, ein tiefes Bemurte, wie

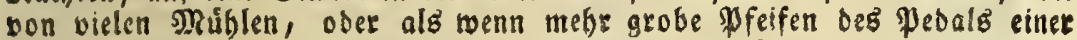

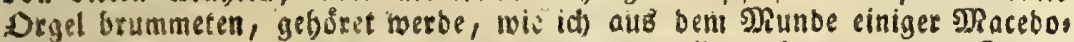
nifden Raufteute, to mit Schaf, und Baummolle nach ber gangen Donau

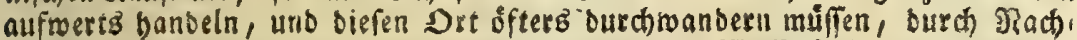

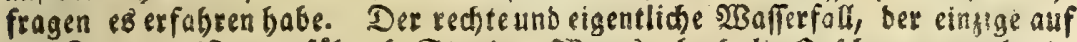
Der Donau, ift ungefăgr 6 Etunben 2 beges oberbalo D:fhowa, noch ein

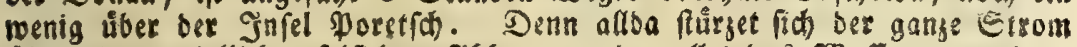

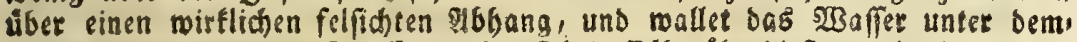
felben gleich mieber auf. (Es brebet fich Daffelbe uberbir B, nach biefem ents

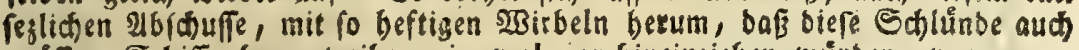
groffere Sdiffe berumtreiben, ja rol gar bineingieben wurben, wenn man

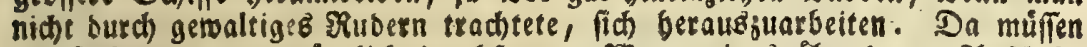

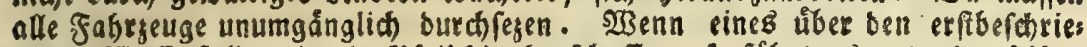

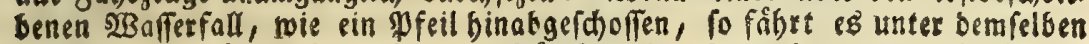

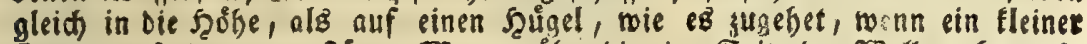

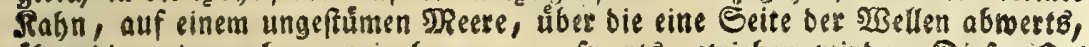
úber bie andere aber, nie betgan, aufroertb getrieben witb. Diefer Det beift in ber Túfen, Siąjen, uno anberer bort berummobnenten, bermeng: ten B\&lfer, Eprache Cactrali. Er wirb auf ber De l'Jlif(ben, nach) Des Natfilius Seobach)tungen eingeridteten, fobann auf ber aroffen und fleinen

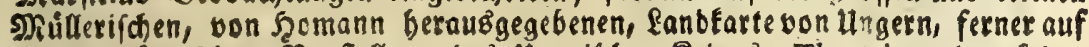
Der Somånnifhen Borfteflung bes lingrifden Rriegż, Theatri, uno auf ber Eetiterifchen 2 bichilberung ber gegen bie \$forte, im vorlezten Surtfentriege, gemachten (Eroberungen, mit ber \$Bsifhrift, Dahtali, vortices Danubii, (auf

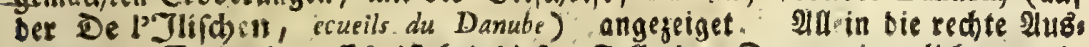
pradje ift Cudstali. FB ift bei biefem Falle ber Donau eigentlich nue eit

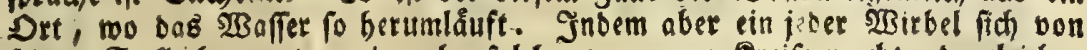
feiner Stelle berweget, uno mebr foldhe vergogene sireife madt, oergleidjen Sinien 
et bon ben feinigen gut Eroe beftatfet worben, geiget die Art feines So bess an. Dar neuefte Exempel bat fich Diefen Gommer (1749) ereig: net, als ber Sdiffmeifter Sreioenberger von Jjaffau mit feiner Sod). ter in Dem 2Birbel ertrunfen, weld) \erfonen eine (id) weißs nicht et,

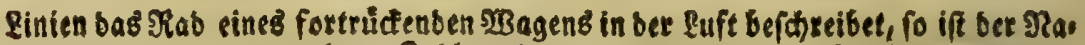

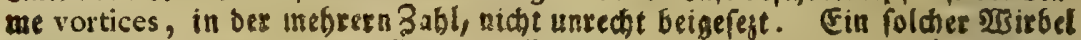

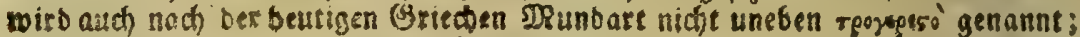
id Denfe bon rpoxhòs, volubilis inftar rote. Siefer Det ift mit Demirfapi, note auch mit Dem Strubel und 23 itbel in Defteresia, Der gefábrlichfte auf bem gan. zen Donauftrone. Ez múfien bie Schiffe, ble abrerts fahten, einen Conrens

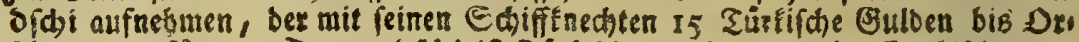

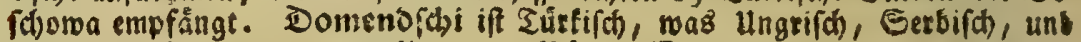
in anbern Eprachen Der umliegenoen 3 élfer, Kormanofh, ned) ber beuti

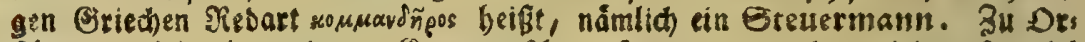
facto mirb ein anderer fiozmanofón aufgenommen, ber wieber fo viel

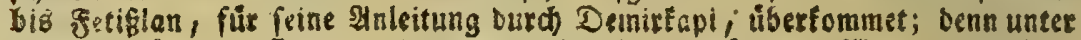

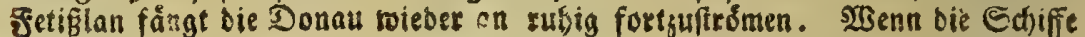
aufwertb fabren, fo mirs ein Eteuermann ju fetiflan gebungen bis Orichor na, unb bier ein anberer bis Tachtali. Da nun ber Durch zแg Des Etror mez burch bie (Enge Demirfapi, to renig als ber Etrubel, eire eigentliche cataracta ift, fo wollte id) unmagegeblich) angeratben baben, bafi man auf bet Sanbfarte biefen Det fo andeutete: Demirkapi Turc. fauces Iftri fcopulofe. Det liber Dríchowa gelegene Doneufall follte billig fo befátieben merben: "Táh", tali Turc. catarąze Danubii cum vorticibus. Hic fecundum Strabonem Da", nubii et Iftri divortium." Denn biet finb meines Erach:enह, Die xแrap-

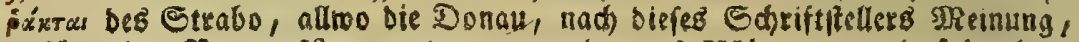

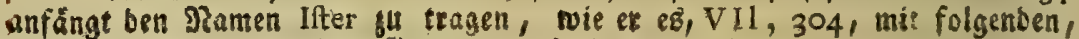
bon bem freebinius obne Brrunb angefodtenen, ŞJorten begeuget: "Per 32. Getas Marifus fluvius in Danubium labitur, quo Romani res ad bellusn ne3" ceffarias fubvexerunt. Etenim fiuminis fuperiores partes, quæ verfus fon"tes funt ad catarąas usque, Danubium dixerunt; qux maxime per Dacos " feruntur: inferiores ad Pontum usque, quibus Getæ funt vicini, Iftrum ap-

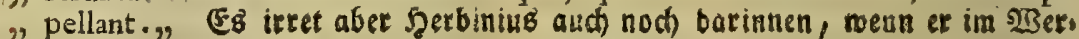

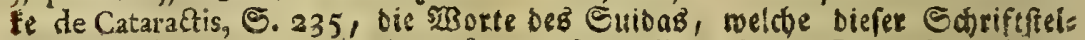
ler, V. KATARPAKTAI, vorträ, auf Den $2 B i r b e l$ unb Errubel bei Sirein in Defferreich augleget. "CATARACTAE, fpricht Euibas, rupes funt in Iftro "f fumine montis inftar, quam latus is eft, fub aqua enati, in quas fluvius in") cidens cum maximo ftrepitu regurgitat, et in rupibus murmurans, easque fu " perans, vortices et xftus et charybdes, in orbem agitato fuxu, efficit. "Denique fluvins is in locis non multum diffimilis eft Siculo freto. $\%$. इक

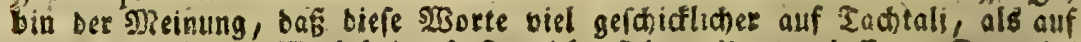
Den Strubel uno soirbel in Defterteid, fich ausbeuten laffer. Denn bui

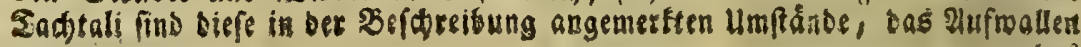


boer fie) wieber gefunden, bie rutfdye aber, barinnen beibe auf bem Rebenfoiffe faffen, nod eher aufgefangen worben. Es bat dennads mit biefen juen gefábrlicben Sorten folgende Bewandtnif́. Der Durds. jug burch ber Strubel ift mistich, wegen ber vielen alloa unter bem

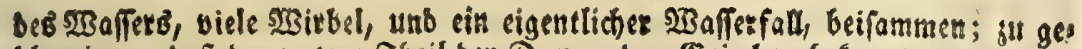
fdoweigen, bafi ber untere Sheil ber Donau ben Estiechen befannter taot, als ber obere. 2rsienol id) geftehen mus, baß̈ biefe Befdreibung fidh nodj eben fo gut auf DemittFapi fieben laffe, wo es aud sirbel gibt. Id tiberlaffe eB bemnach ben Ejelebrten fu fernerer Betrachtung unb Entítheibung, ob nidit auch bie Cataractre bes Strabo, unb ber Infang bes Iftri, vielmebs bis auf biefen Drt gu verforicben feven.

IJeil bie um Drfhowa in biefer Inmetfung einigermafien entworfene Begenb,

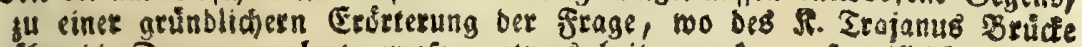
siber bie Donau angelegt geweren, etmos beitragen tann, fo wifl ith bieroon auch etwas melben. Es follett gleid unter getiglan, an beiben Eeiten bes Etromb, Ulefertefte von gemouerten $\$$ feilern einer Brutce, mit Spuren einet an

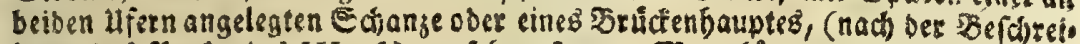
bung bes Protopius IV, 6) ju feten fegn. I2Ran Eơnte muthmalten, Daf es eben bie rudera pontis Trajani wáren, wenn uns Fiphilin nicht irro macj:

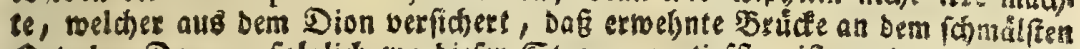
Orte ber Donau, folglid) wo biefer Strom an tieffen if, und an fonntls ften fitefiet, (Cellar. Grogr. Ant. I, P. 46r, n. 49) geftanden babe. Denn

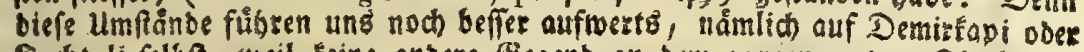

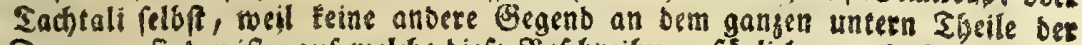
Donau ju finben ift, auf melche biefe Sefdjecibung füglicher auģulegen wáe,

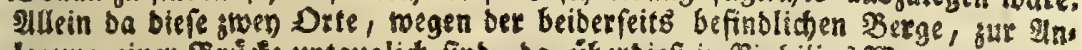

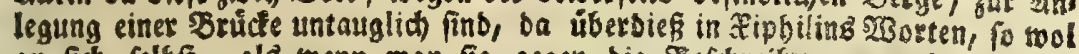
an fich felbft, als wenn man fie gegen bie Sefchreiburngen anderer aiten

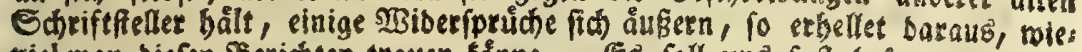
viel man biefen serichten trauen tonne. Eg foll uns faft befremben, wie

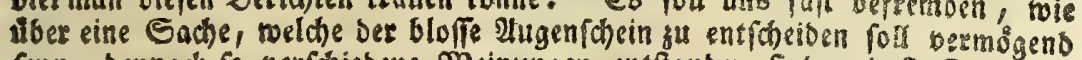
fenn, bennod) fo verforiebene Meinungen entfanben find, Das Cellarius a. o. folgenben $\mathcal{E}$. n. 5I, fareiben fonnte: "Locus pontis incertus et maxime " dubitatus. Vulgo ajunt rudera ad Severinum oppidum exftare : fed vereor, "ne decepti a Paullo Jovio fuerint; ipfe vero a rumore vel fabula: quod et" iam Lipfius de Jovio cenfet, lib. III Magnit, Rom, cap. XIII. Ferner: Nec " de Severini oppido iden omnes judicant, quod in Servia alii longe fupra "Moravam collocant; alii prope Alutz confluentem in Bulgaria. Quo fit, 2. ut disjunctifimis locis pontem eumdem in diverfis chartis poni videamus. "Quum ergo ab recentibus nihil fit fubfidii, ex antiquitate repetendum eft. "Procopius frepe diato loco, pontem Trajani longe infra Viminaciun ( quod "Widin putatur effe) et poft Cuppas ac Novas recenfet. Ergo falfi funt, qui 3. fupra Viminaciun, feu media via inter id ac Taurunum ponunit. Job tama 
agaffer ftehenden Slippen, bie, wenn ber Strom klein ift, auch hervoes: fehen. Der 2 Birbel ift wegen ber Serumorehung beg $23 a f f e r 8$, uno eines babei unterwerts gerichteten Zuges halber, gefåhrlich, alio daf Fleine, oder auch groffe, gar ju ichwer belabene Fabrjeuge, Eonnen ges trånft, oder wol gar verjenft werben. 2Senn der Strom grob ift, fo hat es beim Strubel feine गoth, denn das 2 saffer gehet alsoenn hod über bie Slippen binaus; ; allein Dajumal ift Der 23 irbel oefto ungeftumer und gefáfrlicter, weil beffen limorehung, wie auch fein Schluden, fobann frårfer uno beftiger werden, zu weld)er Zeit benn aud ber

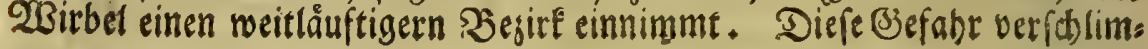

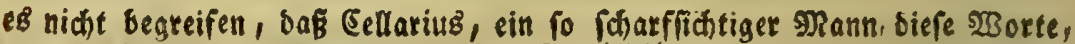
VIMINACIUM, quod Widin putatur effe, felbff foll geforieben baben. Tó balte foldhe füe eine Einfothalting eines naferesifen Correatoris. Eellatius fann fich felbft nidhe fo fáenblidh noiserfprecten, ober ben lefer, ourch eine fo itrige Inmerfung, von feinem $\mathfrak{B}$ ortrage ableiten, Da ex fomol Das Viminacium, in Det Erúrterung Diefez Drtez, an feine rechte Etede, Dem beutigen Sipalanfa gegenúber, als auch) bie Trajanifhe Brutate in bie Eegento bon Demirfapi, im Texte uno auf ber Ranofarte, geftellet bat. Dabi sie neuern

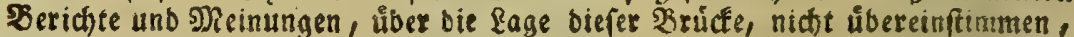
Das ift aus ben Ingeigen verfchiebener Randfarten, roelde zu bes (Eellarius Sebjeit berfertiget worben, leicht abjunebmen, uno bierinnen bat et bolltoms

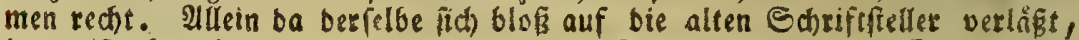
ba neis id nidjt, ob er eben bie fictierfte Eeroffe mantere. Denn ein to groffer Seograpfus, ale (ellariug auch war, fo bat ex bod in Der beftim: mung ber Beftalt bes Safpiffien 5Reeres, mit feinen Dlten geirtet, Geogr. ant. II, p. 674, n. 3 . Wrie unrichtig bie Beugniffe ber 2llten, in 2urehung

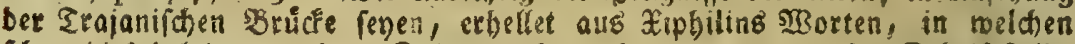
fhon biefes keinen redien Burammentiang hat, wenn biefer Edfriftefllet

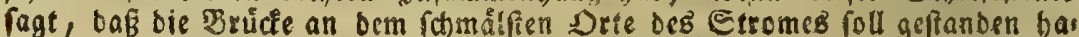
ben, uno gleichnol tiber vierthalbeauseno fup lang getwefen fonn. Eie nar alfo in Demirtapi nicht gebauet, wo biefelbe feine folde Range haben fonns

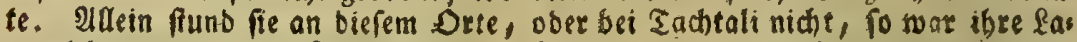
ge nicht an bem famålften Drte ber Donau. Fiphilin feyreibet feener, bie כrufice fen an einer foldien Etelle geweren, wo ber Sirom nidht bat tónnen abreitz geleitet merben, Cellar. p. 461 . Aluf Der folgenden Eeite mirb bod) aus bem Procopio ein Zeuaniß angezogen, welches melbet, baß bie Donau,

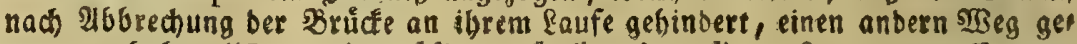
nommen habe: "Procopius addit, ruderibus impeditum flumen mutaffe curfum, fubindeque alveum repetiiffe. ". Eelle aber nol ber Raifer, ourch

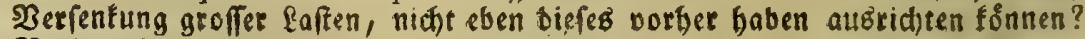
Rach metner wenigen Einficht hat es mit ber Unterfuchung Dec Rage, to bie

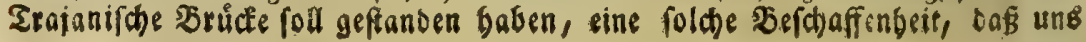


mert oamalo nod sin (Siegenftrom, fo red)ter Sand vom sodse (g g g g)

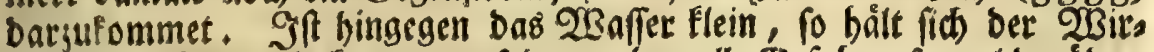
bel ganj rubig, uno fann man fooann obne alle (Sefahr, fo wol barúber, als Darinnen berum, faffeen; allein Damals ift es beim Strubel, wes gen Der betborragenden Felfen, befto übler burdjufommen, uno mü fen fu foldser Beit won ben Sdbiffleuten Des Drtes nol funbige Manner fu Sirein geoinget werben, die wiffen, wie weit man fid einem jeben

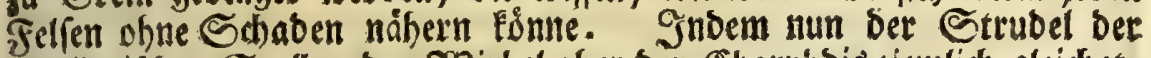

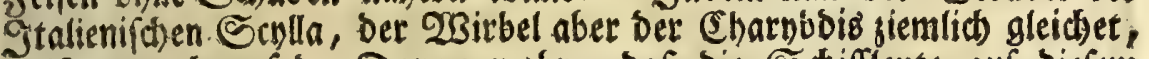
To ift es aud auf ber Donau tbabt, dap die Shiffleute auf biefen D 8

Stro.

neute einbellige Betuniffe, aud ungelebtet leute, fo gut aub betn Sraume belfen fönnen, als bie Sefdjetbungen ber Mlten. Weil ja Uleberrefte bon biefem Gebálide nod) follen vorbanden feyn, too ftegen diefe? Bon Birfen feret a. b. 100 S. feines Donaufrandes die Heberbleibfel bet Irajanifhen

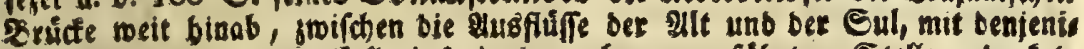
gen Bielebrten, berer Erllarius in ber oben angefübrten Etelle gebenfet. $\xi_{\text {d }}$ glaube ben Rauffeuten, benen alle Drte an ber Donau, wegen ber bes flanoigen Befhiffung febe mol befant finb. Diefe fagen einftimmig aus, baf unter Demirtapi, uno nod) ein menig unter fetiflan, to bie Donau miebee anfóngt breiter uno factere ju flieffen, lleberbleibfe! bon gemauerten Pfeilern

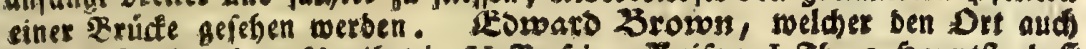

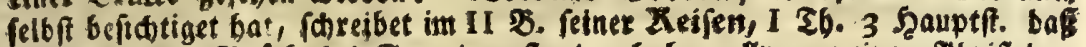

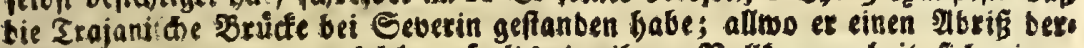

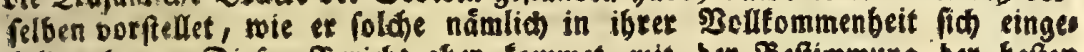
bilbet bat. Diefer Beridit abet fommet mit bet Beftimmung bet beften canbearten wiemlich überein, auf benen Severin, am linfen ufer ber Donau,

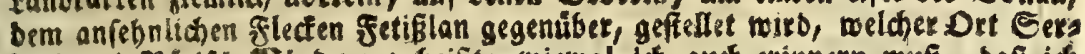

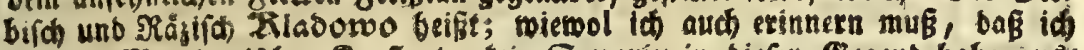
bei ben Macebonifhen Raufeuten Eein Geverin in biefer Gegenb babe aus: funb/d)aften fónnen. So viel ftebet in meinem $\mathfrak{B}$ ermógen, gu biefer Erơte: rung bon bem 2 Reinigen beifutragen. Dielleidst bat ein S̈elebrter, obne

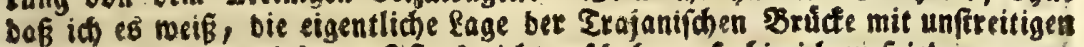
Grunden idjon erwiefen. Iff es nicht gefcheben, fo bin id) gis frieber, soent

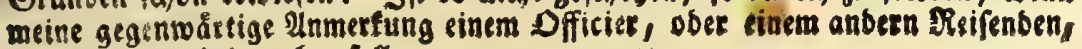
barju Eelegenbeit geben foll.

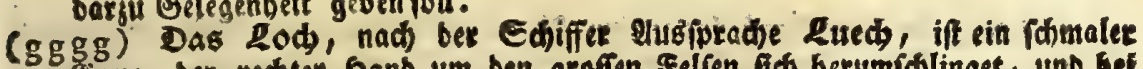
Gjang, bet redter f̧anb um ben grofen felfen fid berumidhlinget, unb bel

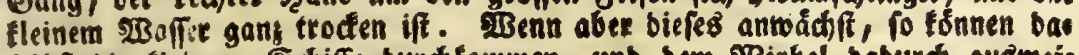

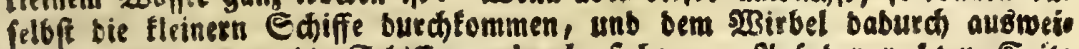
wen. Das nennen bie Ediffet gelued fabren. 2luf bee redten Eetie bes Ėtrubels gebet aud cin foldhet tleinet Plem bet Donau berum, jum Bes fen ber fleinen unb mittern grabeteuge; benn, wenn ber Strom mobe $203 a$ fa fere 
Strome allema! eines aub beiben, entweber die Scylla, ober bie Cha rnbois zu befürdsten baben. ( hhhh)

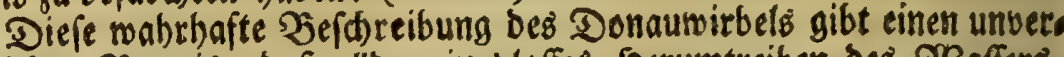

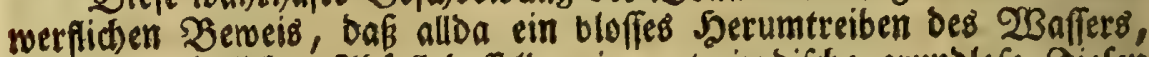
und fein wirflid)er 2 bfall beffelben in unterirroifase grunblofe siefen vorhanden fenn fơnne. Denn wenn biefes legtere wáre, fo múfte ber 2sirbel, renn ber Strom niebrig ift, viel fiditbarer werben, wo aber bas Bregentheil erfheinet. Darnach, wenn ein jiemlider Sheil ber Donau, wie es Scappelius und Strablenberg erjäblen, allo w wirtlits unter bie Eroe fúbre, to würbe bei fleinem 23 affer, zwifhen bem 23 ire. bel unb ber Stabt Woien, eine merflidhe Werminderung befferben zu furen fenn, wie es in ber That Sappefius (oben S. 197) verfichern mill. Die 23 afferwerfe wurben fobann auf biefer gamsen Strecke yon

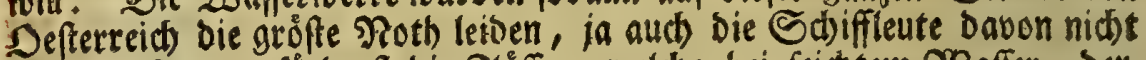
befrenet fenn, juforberft bie Flófier, melche bei feichtem 20 affer, bets gleid)en fie biefen \$erbft uno ben verwidienen Sommer batten, ourd the SRingen mit ben Sanbbånten viele ₹age länger jubringen, efre fie nad) 2 Bien fommen. Denn ber Rachen des 2 Birbels bliebe alleseit gleid tweit offen, uno wurbe in einem burren Sommer eben fogiel 2Baffers idstueten, als in einem nafen. Sold)es aber miberftrebet abermal der funbbaren Erfafrung, und vernidtet gänjlid ben 23 ahn aon einem Dafetbot befindliden 2 bgrunbe, ober einer 2tbapfung oer Dos

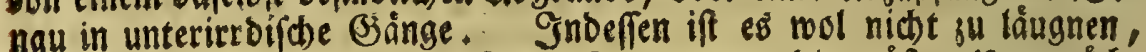

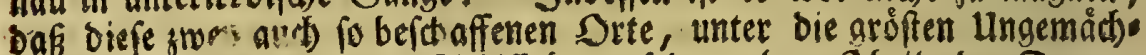
lidfeiten ber ro midtigen Shiffabrt auf bem obern Theile ber Donau, mit zu zâblen feven, uno màre es allerbings hơdeft billig, baß biejenigen, bie ein berrliches (Einfommen von berfelben iånrlid) jieben, bie aud) fein

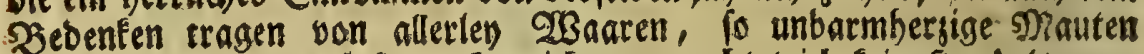

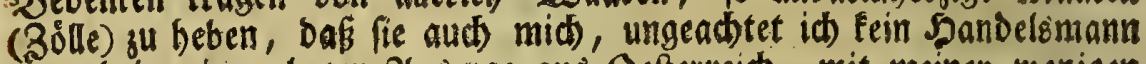
bin, bei meinem lesten 2uş̧uge aus Defterkeid, mit neiner menigen Gelebrtenware, bie an Den übrigen Srten bon Teutfoland gollfete ift, nidit

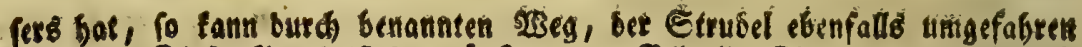
merben. Diefer Irmbeist Jer 5efgang. Soei allen figuren, bie id nod bom Strubel und 2 Birbel ben Şudtern einverleibt gefeben, b. i. Denjenigen, bie Serbiniuz, Rectwis, Merian, von Birten, ibren Bejobreibungen beiges füget babes, mird bie lage biefer stoen Drte vertebrt borgeftellet. Eie find

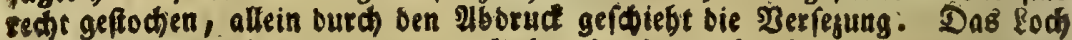

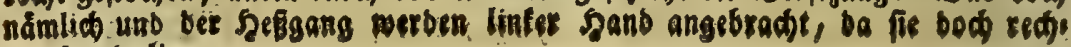
ter Sond liegen. 


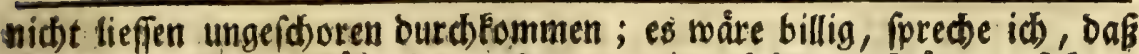
biefe Serren feine shübe fpacen follten, mit erfabrnen s) Rainnern fich su beratbidslagen, wie auch ¿jorficlagen nadsulimen, wie biefe Sinber: niffe am beften aus bem 2 sege zu ráumen wären, Da eś gewif ift, baf fie nicht unúberwindlich fino, fondern nut groffen Aufroand erforbern. Denn fo viel ich onson urtbeilen fann, fo wäre ber WBirbel burch eine ganjliche Berfiprengung bes grofen Telfens, baran fich Dab Donaumaf: fer ftóft, reie audb ourd 2lusfüllung feines gar ju tiefen uno gar zu geráus migen SBecfens ( weld)es legtere ztwar ber Strom nabgehends felbft thun wurbe) obne Btweifel ju bernidber. Det Strubel abet Esnnte fider gemadt werben, wenn man burd) Serausiptengung einiger Silip. pen, ben Gang ber gewóbnlichen Durd fabrt erweiterte.

So) geftebe gerne, baf biefeb , fo ich allhier mit wenigen 2 borten anjeige, mit folden Soften mingte ausgerichtet werben, bie nur bie

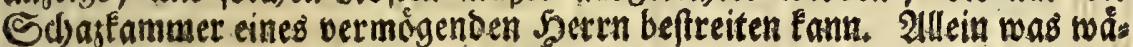

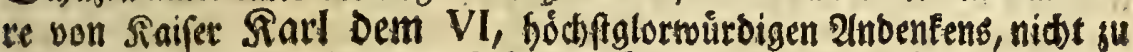
erlangen geweren? Sat ber bobe (Beift biefes Sertn fid nid) immer nut mit folden grofien 2 Berfen befóntiget, oie ewig bleiben, uno berer rufmwórbigfte Ausfübrungen ein beharrenbes Beugnifi abgeben follten, das bie widtigften und Eoftbarften unternefmungen der erfen Siomifhen Saifet, vor ben Sbaten ifrer fätern Nactommen, feinen Borjug haben, ia biejen in einigen Etuden nod) weiden múfen? Sch fage obme Sdmeid)eten, Saifers Rarl Des VI Maiefát;

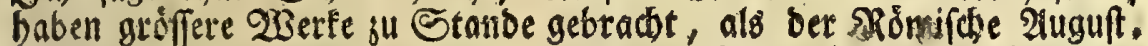
Soldbes will id) gieid) erweifen. Diefer shonard fonnte mit feinem

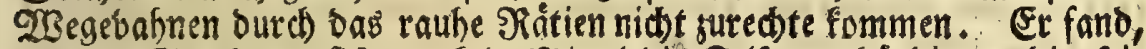

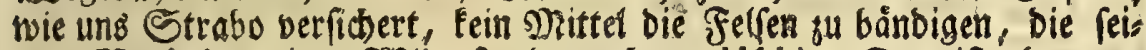
nem 20 orbaben cinen 2 Biberftano madten (iiii). Das ift aber bon unferm Rayfer ofters bewerffefliget worben. Der über ben Semering

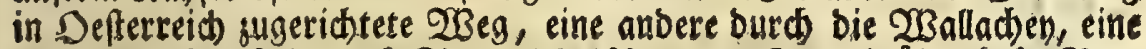
britte bon Sarlfabi nad fiume (St. Deit am flaum) über bobe Set: Do 2

(hhhh) Den beften Nadfridten, bie id vom Strubel unb sroikbel bex Dontau ans geteoffen babe, verdienet unfteitig biejentge beigefdblet fu weeben, weldge Siretris in defcr. R. Hung, auf bet 826 S. babon ertbeilet.

(iiii) "Auguftus Cæéar viarum ftrueturam adjecit, quantam omnino licuit per"fici. Neque enim potuit ubique vi perrumpere naturam faxorum, "et ingentium praruptarum rupium, alias viæ impendentium, alias fub" jacentium, ita ut vel leviter e via egreffi in periculum venirent inevitanbile 


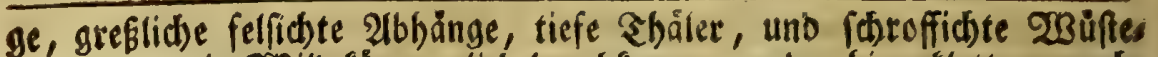
neven, wo ein WBilo fummerlid, burdfommen, oder binantlettern mod), te, gefúftete und in fo guten Stand gefezte Strafien, Dap man reit bem mit Sutichen und \&aftwágen bequem Darauf fabren fann, ermeifen ja zur Bnnige, saß̉ 2luguft uno Trajan nichts gleides gethan baben, uno

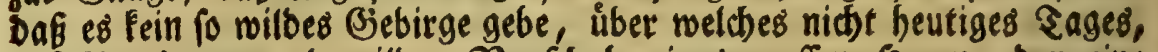
auf Anorbnung unb milloen Yorfaub eines groffen Soerrn, ben eine eble Ebrbegierbe su Berwerffelligungen erbabener Borídläge antreibet,

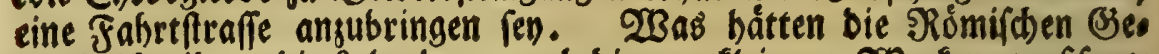

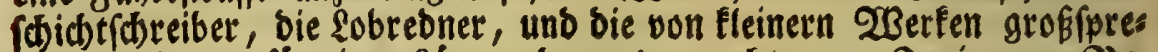

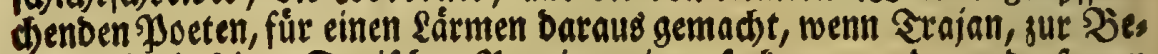
quemlid Eeit feiner Dacifden $\mathfrak{g r o v i n}$, einen fo fursen uno runderfamen OBeg burd Dannonien angelegt båtte ? WBas Saijer Sarl Der VI, bem gemeinen 20 efen zum $\mathfrak{B} e f t e n$, vollbradt, bas cutbmen bie auf ers wehnten Strafien aufgeftellten Denfmale. Sch will nur bie 2lufíbrift Desjenigen anfuhbren, meldes (Sraf Steinuille auf ber Straffe Durd bie WBallad)en nad) Siebenburgen, bie unter feiner 2luffidt gebahnet worben, Diefem Raifer zu Ebren bat fezen laffen. Sie lautet fo: STA. VIATOR, VBI. NATVRA. STARE. IVBET. ET. VIRTVS. TRAIANI. STETIT. HIC, SVB. AVSPICIIS. CAROLI. VI. IMP. CAES. VERE. AVGVSTI, SVBACTA. BREVI. BELLO. SED. FORTI. ANIMO, EVGENIO. CAESARIS. VICARIO. DVCE. RIPENSI. DACIA. VT, MEDIAE. MVTVIS. COMMERCIIS, IVNGERETVR. ALPESTRIS. EFFRACTIS. RVPIBVS. PRAECIPITIIS. IN, PLANVM. DVCTIS. ALPIBVS. PONTE. IVNCTIS. XI. HORARVM. VIA. VEHI, CVLARIS. APERTA. EST. Das Ende biefer Aluffortift ift fo abgefaft: IAM. VADE. PROSPERE, ET. MEMINERIS. VIRTVTI. CAROLI. INVIAM. NVLLAM. ESSE. VIAM. QVAE. DVM. ALPES. EVISCERAT. ET. FLVMINA. DOMAT. BELLVM. SISTIT. POPVLOSQVE, MONTIBVS, NVDATOS. IMPERIO, FRAENAT. OBSEQVIO. FELICES, VIA. CAROLINA, HAEC, EST. M. D. C. C. XVII.

Da nun biefer groffe Saifer bie Funft befeffen, wie man bie গRa tur bejwingen, unmeglame Srte wandelbar maden, Steinberge zers

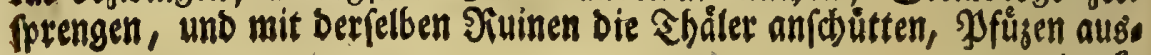
troces:

„3 bile, cum in fundo carentes valles effet decidendum. Ibi quidem alicuor bi ita arcta eft via, ut et peditibus et jumentis non adfuetis vertigo "oboriatur." IV, 204. Mit biefen 2 sorten fobrinet Et:abo ben úblen

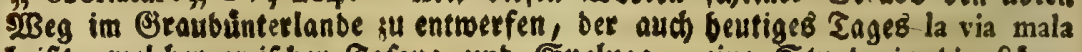
beifi, meldet tmifhen Sofana und Epeluga, cine Stunbe in bie fange 
trcefren, bie gerăumige Striche von \&and faften boe, uno bie \&uft ungefuno mad)ten, wie aud ben Fluffen ncue Sertungen graben, uno ibren Sauf Darinnen einfdránten foll, fo wurbe biefer boderleudtete Monard, wol aud beim Strubel und 2 sirbel, ja noch viel efer, und

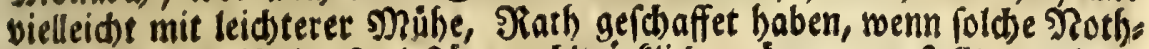
burft Sr. Raiferl. Majeftát nadbrucflid) waire borgeftellt worben.

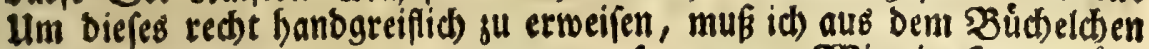
Augufta Caroline virtutis Monumenta, fo 1733 gu 2Bien in Octavgroffe georuct tworben, eine Stelle anfübren, weldbe bartbun foll, bas auf Diefes preismúroigften Raifers Deroronung, in ber zlte, welwer Flü

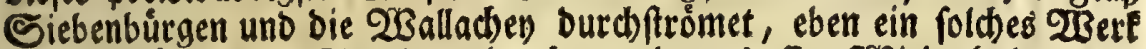
bereits glucelid) ju Stande gebracht worben, beffen Wieberbolung ben 2æirbel aufheben, und ben Durdjug beim Strudel hătte ficher maden fơnnen. Ad Alutam Dacia fluvium progrediamur. (So fängt fich Diefe Stelle p. 64 an) Ortus in Carpaticis montibus, et fubinde bauftis pluribus minoris nominis torrentibus auttior faltus, Daciam totam et Wallacbiam percurrit, Pafjarovicenfi nuper in congreffu limes Cafaream inter et Turcicam Wallacbiam conftitutus. Ad Rubram Turrim (fic anguftum ex Wallacbia in Daciam aditum appellant) adeo faxis fcopulisque borridus, ut navigari fine periculo baud potuerit. Sed purgavit et boc flumen, bactenas intractabile, Augufti-noftri fortitudo, opera Excellentifimi D. Stephani Com. a Steinville, fui in Dacia Legati et Prefidis, qui indefeffa induftria, ET RARA RUPES INFRA AQUAS EFFRINGENDI ARTE, SCO. PULOS EXCIDIT, PETRAS IN AURAS EIECIT, FLUVII IMPE. TUS cOMPES CUIT. Won bem berrliden ist beidriebenen, Durd $\mathfrak{R}$. Sarl Den VI ausgeführten 2 Berte zeuget eine anbere in Stein ein. gebauene 2uffichrift, meldhe auf Der vorgebactsten, und von biefem Serrn beigenannten Straffe, neben ber alt gefegt worben. Diefelbe făngt fid folgendermaffen an: OVO. TRAIANI. VIRTVS. AVSA. NON. FVIT. ADVERSO. ALVTAE. FLVMINE. EODEM. SECVNDO. CAROLVS. VI. ROM. IMP. ADMIRABILI. FORTITVDINE. ET, CONSTANTIA. PENETRAVIT. HANC. VIAM, ILLE, PER. IMMANES. ALPES. DESPERATVM. ROMANIS, OPVS. INVENIT. ET, HERCVLEO DVORVM. ANNORVM. LABORE. PERFECIT. cetera. Einem fo groffen Raifer nun, fprede id, ber bie DO 3 Mòg:

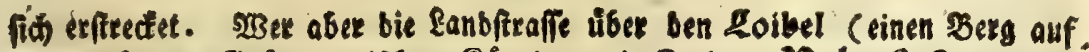

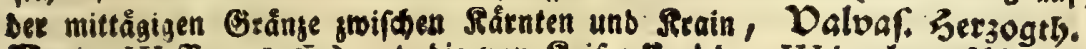
ZTrain, IV \$. 558 S.) und bie von Saifer Starl bem VI burd) verf(tiebene

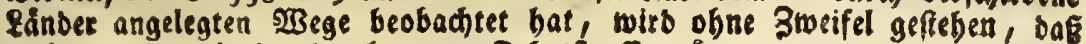
aud) bie via mala in eine bequeme fahrtftraffe wăre gu berwanbeln gemefen,

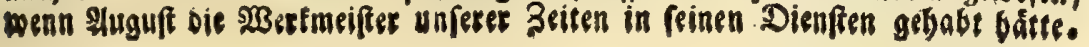




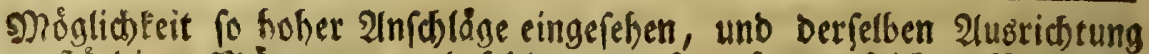
verftåndigen soảnnern anjubefehlen getwukt ; ferner foldten $23 e r f m e i s$ frerm, Derer (Befchicfliebfeit Durd) lange Hebung gleicher Arteit nod) grods fere Bolfommenteit erlanget bat, wade es rol keine unuberwinbtiche Sobrierigfeit gewefen, Dem ungemad)e bes Etrubels und 2 Birbels, burd) Shinwegraumung ber im 20 ege ftefenden Jelfen, abzubelfen.

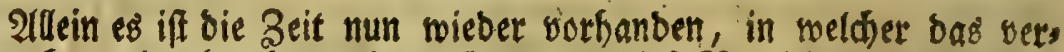

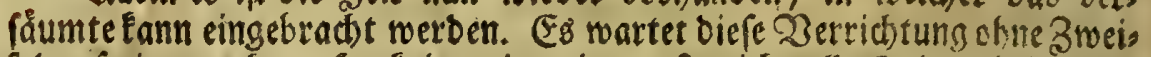
fel auf einen andern Scerfules, Dem ber erfte nidt alle (Selegentyeit, feine Stårfe gu uiben, bat entzieben wollen. E\& baben Seine Siómifotse,

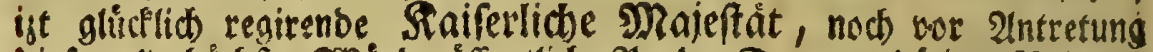

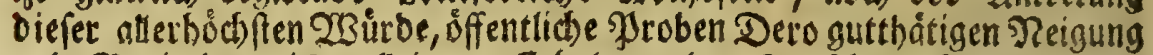
uno Begierbe, nicht allein jur Erfalrung ber Menfichen, fondern aucb gu Derer Vergnigung, an ₹ag geleget, und fabren now immer fort

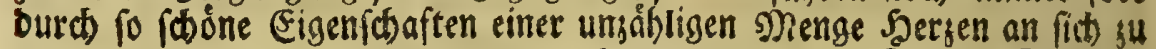
sieben. WBir fino ferner Deutlid übergenget, baf Seine Saiferl.

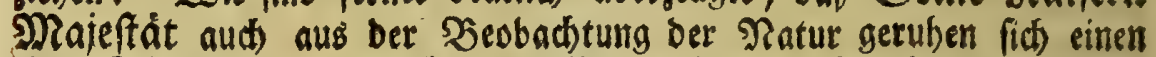
eblen Beitbertreib fu machen. Wor meinent 2lufbrudbe aus Jefters reic) babe id) mit grofter Freube etfabren, saß Seine Siaiferl. Majeftåt einen jungen Mann, welder vorber burch einige \$robftu. cfe in ber Mathematif fich befannt gemadt, ins Defterreid uno in bie umliegenden fänder mit Dem $\mathfrak{B}$ efehle ausgefchicht haben, Dá̧ er allers bano Derfwurbigkeiten, infonderfeit allerlen Seltenbeiten ber Natur,

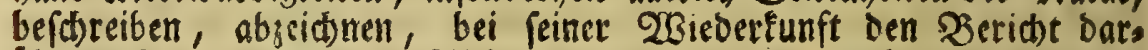
über abftatten, und feine Siffe varweifen foll. Es ift $z$ hoffen, bas biefer fo rufmmurobige Srieb, Eeine Saiferl. Mateftát now su

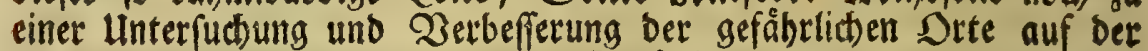
Donau veranlaffen borfte, weil Diefelben babura) vielen taufend sieniden ben fumner benefimen, einige barunter vom sode erretten,

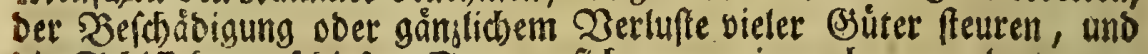
bie Sdiffahrt auf Diefem Strome fidferer, wie aud) angenebmer mas

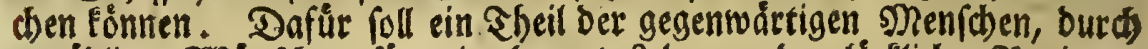

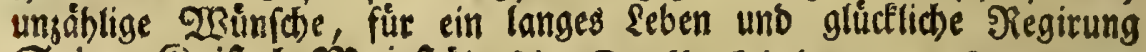
Geiner Siniferl. Majeftát, feine Danfbarfeit begeugen. 2ndere, bic gleiben 2intheil an biefer 2030 lithat gu nebmen Urfache haben, werben auf bem groffen Felfen beim Strudel, ein anfethnliches Denfmal mit 
Bierte Interfuthung.

ber 2uffarift hinfezen laffen, welde Seiner Saiferl. Majeftát

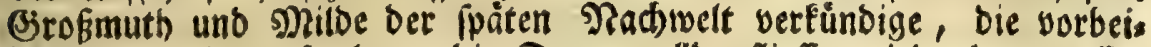
jififfenden aber, fo lange die Donau allba fieffen mirb, Des groffen Beforberers ifrer Sidnerbeit erinnere.

\section{Siette Sinterjutumg.}

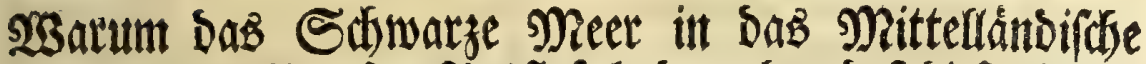
cinen immerwaibrenden 2usfluf babe, obne Daßs Diefes Durd)

Die Ebbe wieder in Daffelbe zurúctrete, und wie es, ungeaditet ber Einmabme fo vieles fúffen $W_{\text {Baffer }}$ gleidwol ges falgen bleibe.

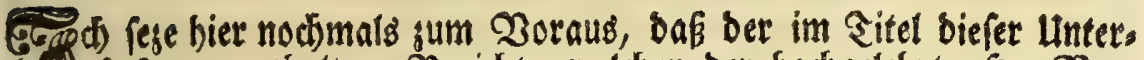

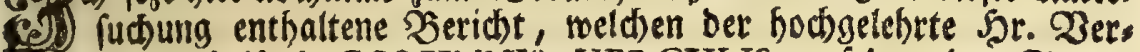
faffer ber Sdurift de COLVMNIS HERCVLIS, auf ber oben S. 108 angesogenen Stelle aus bem Furnerius anfübret, wabr (ey). Tlad) folo

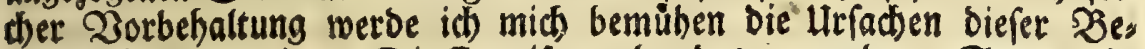
fit)affenbeit anzugeigen. Die Erroeifung aber Des angegebenen Sajes nebo me in Eeinestweges auf mid, (onbern id werbe vielmefr, an einem ans Sern Srte, meinen Zweifel über Defien Bsemißheit vortragen, uno ben

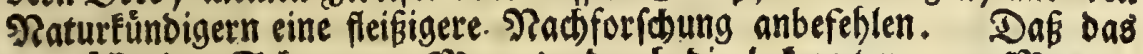

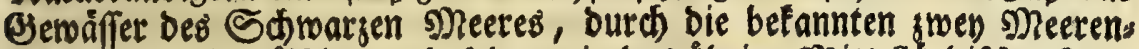
gen, in Das 2legáif he, und fobann in Das übrige Mlittellandifhe Meer immerfort, obme einigen WBieberflus, nur berauştróme, bas hat, nad

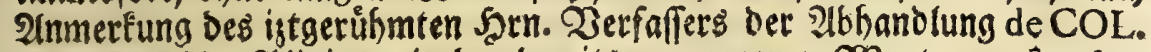
HER CVLIS, Ðlinius mit Den bereits angesogenen Worten, eftus femper e Ponto refluens nunguam reciprocatur, IV, 13, an Sag gegeben. Diefem Zeugniffe Esonnen folgenbe beigefellet werben. Jim II $\mathfrak{B u}^{2}$ be,

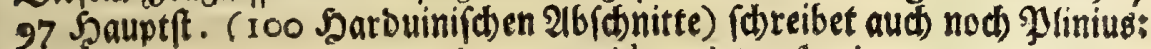
Et Pontus Semper extra meat in Propontidem, introrfus in Pontum nunquam refluo mari. Die erfte Đlinifbe Stelle hat Solinus faft mit eben ben 20orten abgeid)rieben. Omnem illum fluorem (fprid)t er im 22 Şauptit.) mjunt a Ponticis faucibus inundare: idque fulciunt argumento non inani, quod

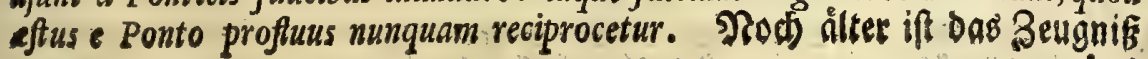


Des Strebo, I, 55: Byzantinum (fretum) nunquam fc. mutart: : id enim folum femper e Pontico mari in Propontidem effuxum babet. Soldies

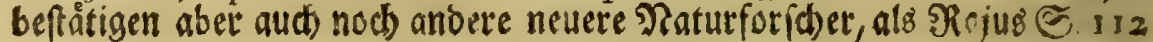
feiner Dbyficos Tbeol. Betr, mit biefen 23orten: "Das Somarse " N)eer nimmt mehr ein, als es ausbünftet; weil ein beltántiget "Etrom burd Den Sbracifden 30 ofpborus uno Sellefpont bavon ", ausgehet, ,"

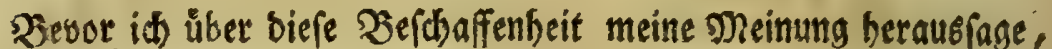
und sur Ifuflofung ber borgetragenen Pufgabe fidreite, will ich oon ber swevten uns britten (oben in ber II Unterf. \& I erllärten) Jewegung Des Mittellånbifhen Sneeres, D. i. bon beffen Etrome, wie aud von feitrer Fluth und Ebbe, nod etras zurudgelaffenes nadjfolen. Th erinnere nămlich aub cigener Erfabrung, baf in bet פleetenge gridoen Eicilien und bem beutigen Falabrien, melde insgemein, il Fore of Vleffina, bon ben Meffinefern felbft abet il canale genennet wiro, bie fluth uno (Fbbe fefr getwaltig fey; beim faro aber ( $\mathrm{kkkk}$ ), wo bies fe Meerenge am fdimalften ift, am feftigften beobachtet rerbe. Sus forberf verdienet hier Diefes eine Inmertung, Daß ber Strom bes গjees res weit ungeftimer fev, wenn es von bien Gerunter, uno nach (Siries

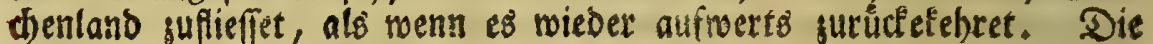
Urfache biefer Figenfdaft ift meines Etadtens folgenbe, weil ber geras be 3ug, nad meldem das 2 Baffer bon bet Altantifden Gee berein forieft, auf biefen Theil bonasalabrien fich ridstet, mitbin feine grofte

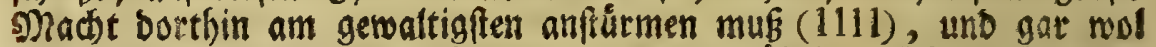
ehebeffer die stbfonberung Siciliens oon bem übrigen Sheile Statient hat verurfadien fonner. Eben biefer gerabe Inlauf Des 23 affers an bie Siffe oom beutigen Salabrien bat bor alters bie Scylla fo ubel bes

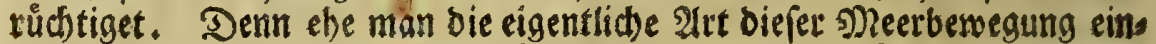
gefeben, uno gemerfet, wie gefábrlid) es (et), bem naturtichen Zuge bes Stromes fich su úberlaffen, wurben bie Sthiffe an bie Steinmañbe oon Salabrien, too sas promontorium Scyllaum bervorraget (Daran ift die Staot uno Feftung Sciglio ftebet) mit (Semalt angefdimiffen, uno ofne

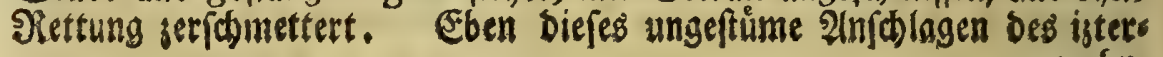
webin:

(kkkk) Wab Saco bei Menina Tev, wirb unten am Enbe biefer IV Unterf. in bee I Sugabe, exláutert weeben.

(IIII) Diefes bejeuget aud elthan Rirchet in bet Reforeifung ber Ecylla, Mund. fubt, Tom, I, p, IOI A: "Infinuante $f e$, abdita urgentis lunx vi, Oceano nimera 
wehnten Meerftromes hat, meines (Evad)tens, bas bohe felfichte Nas labrifche Ufer unternaget, und foldbe Saoblen in Demjelben ausgefreffen, Dafi zum ofteften Dab binein uno beraugfabrende 2 baffer, ein feltfames

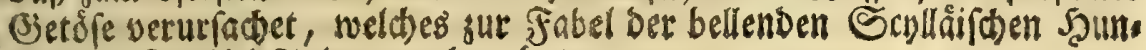
be obne 3roeifel 2 inlab gegeben bat.

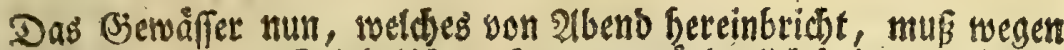
biefer, gegen befagten Salabrifơ

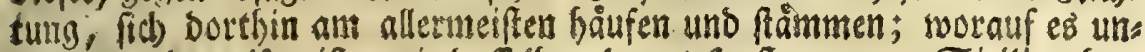
forwer fu begreifen ift, wie baffelbe, ba es fonft um gan; Sicilien bers um bie Reibe nehsmen follte, burd bie meffinifbe gleerenge mit fo beftis

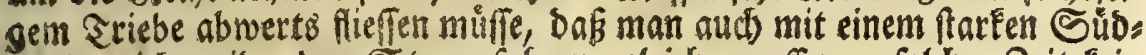

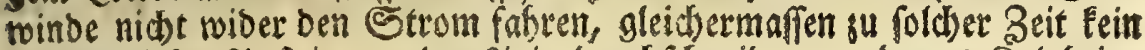

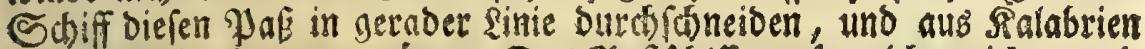

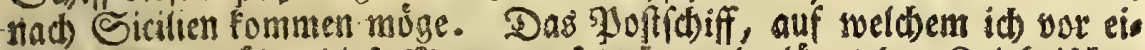
nigen Sabren über biefe meerenge ferte, wurbe längs ber Salabriftsen Rufte, burd) ange(pannte Dd) fen, ein ziemtid) Stude Eanbes gegen ben Strom aufwerts gefúhret, bevor es hinuber fegetn fonnte. Es ift alfo bier Eeine látherlidte Sadje, wenn einer mit Sđ) en auf ber Woft făbrt. Eben fo muifen bie Seeleute fich behelfen, wenn fie längo bem Sicilis diden ufer, gegen sgeffina, wiber ben Strom fegeln rolten. Sie lafs

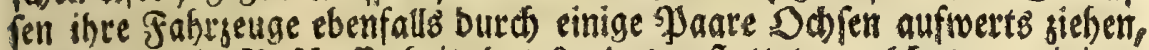

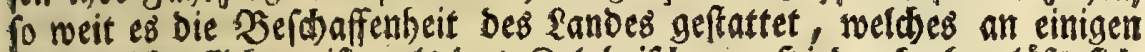

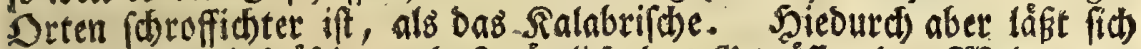
faft bet Sał befráftigen, bás nåm!ia) Das Gietwaffer bes Weltmeeres burw bie Straffe weit ftärler in Das. snsttellándifde fineinoringen mulfe, als biefes binaus. 23 arum bie fo beftige, und ber Ebbe febt

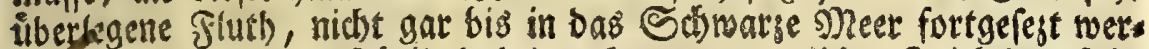

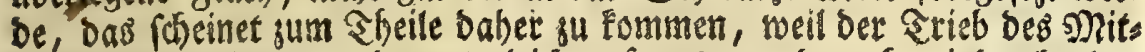

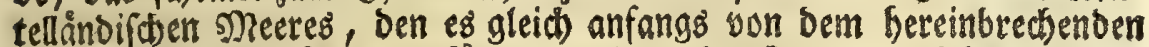

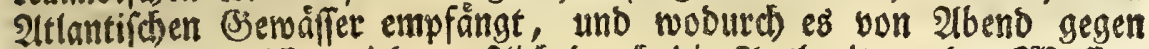
Morgen fortgeriffen wird, erfflich Durch bie 2lusbreitung Des $23 a f f e r 8$ viel von feiner Rraftuertieret; Darnad) meil biefer Strom anden $\mathfrak{B a l e a r i}$ (id)en Snfetn, an Sarbinien, Eorfica, unb bauptfåchlid) an ben ufern Staliens felbft, babin istgebadter Flü gerabe fortfreichet, enblid an Ee

ben

" intra mare Mediterraneum per fauces Gaditanas, derepente tota illa maris "longitudo, ex occafu in ortun exporrecta, impetu Oceani percita, ad recta " fibi obvium Cujatium finum magna aquarum mole, veluti agmine facto, illi" ditur. ", 
ben Peolifhen Eilanden, und an ben obern Fúften von Sicilien, Thom iefre unb vielfältig gebrodoen wirb, wie foldbes baraus erfeltet, weit

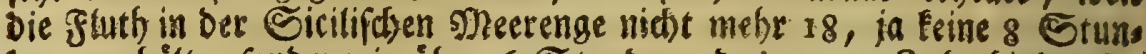
ben, anbålt, ronoesn je úber 6 Stunden, das ganje Saht hinourds,

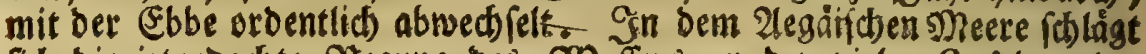
fid) bie istgedadte Siegung bes $23 a$ affers an ben vielen Snieln zulest gênzlid ab, nadjoem biefelbe vielfeidt fonol burds bie Entlegenfeit von Dem erften Sriebe, als wegen bes fósiefen Fintrittes in biefes speer, fijon fefre gefdroddst worben. Daburd) wito es nun begreiflich, wie bas Sdswarze speer, roetches burd bie Einnabme fo vieler (Eutopäi

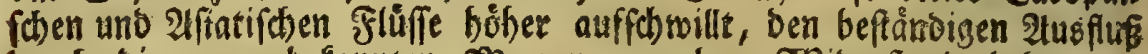

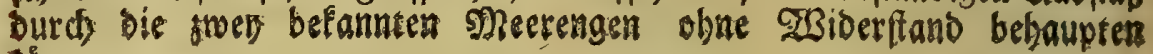
lonme.

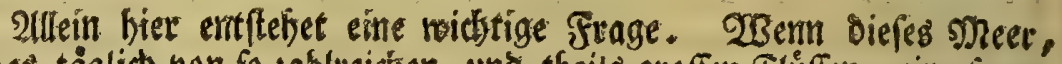
noelches tảglich bon fo tahlteichen, uno theils groffen fluffen, eine fo ans fefntiche ş?

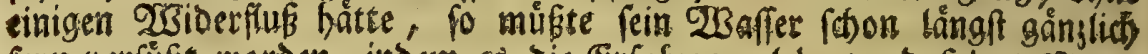

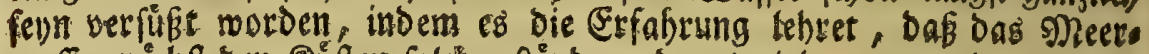

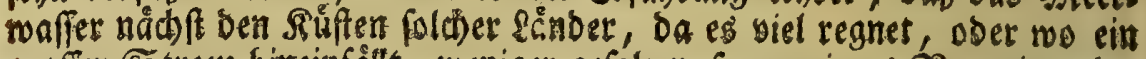
groffer Strom bitreinfâltt, meniger gefalzen fey, wie es 3 areniug bes zeuget $(\mathrm{mmm})$. Es if aber biefes ein Einmurf, ben ich mir felbft made. Ich will gerne glauben, baf andere foldse Schnerigfeit fidon werben erortert, unto vielfeidst entichiegen baben; allein mir if nod feis ne Dergleiden 2fbfandlung. Sa Sanden gefommen. Des Marfitius Sdrift von ber Eonftantinoptifthen meerenge, Deren et in feiner Hift. de la Mer, p. 2.8 anfangs etwehnet, uno Darinnen vielleicht eime 2tuf, lófung biefes Brweifels dorfte enthalten renn, habe id nidt. (Es betrifft aber biefe Shnwierigfeit weder bie Raipifhe See, nock bas Tobte Meer in Waläpina, ez mơgen biefe stwen groffen Wrafierbehalter einen

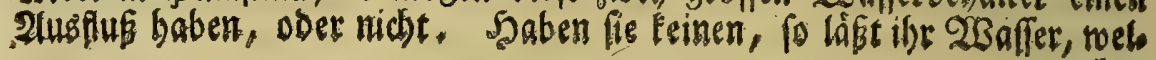
काes

(m mm ) "In locis Zonæ Eorrídæ, menfibus plavíafibus, açua Oceaní ad litg) tora minas falfa eft. Imo ad Malabarici Indiæ littoris plurimas regiones "Ogeanus dulcis eft menfibas plavialibas, propter magnam aquæ copiam, 29 qua e jugis Gatis defluens in mare fe exoserat, Cap. X11I, prop. IO, n. 4. Num. 6 mirb folgerber SEerid)t angebrishl: "Nautæ affirmant, Ocez37 num ad littus Brafiliz, ubi argentéus fuvius fe exonerat ; falfedinem amitभ tere, et dulces latices præebere, quindecim milliarium a littore diutantia. Idem " de Oceano Africano ad littora Congi, ubi Zaire Auvius fe exonerat, atque a aliis plurimis anzotatum of, $y$ 


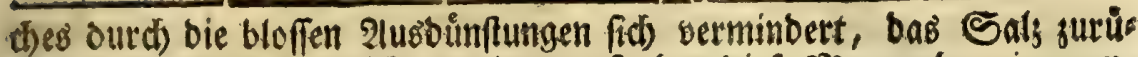
de, und wird Deffen nid)t weniger. Şaben diefe Neere aber einen uns

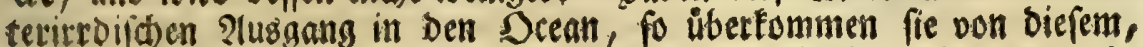
wenll er fein 2 Baffer zurioffendet, wieber genug Saljes mit (nnnn).

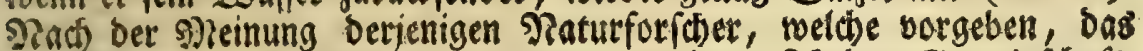
Rafpiche s)eer babe mit bem Sd wargen eine unfichtbare (Semeinfort, wito bie juvor aufgemorfene Schwierigleit wegen ber 23 erfuffung bes Scbwargen Meeres nidht abgethan. Denn es läit fich wieber fragen,

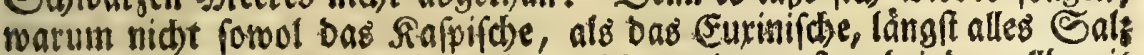
verlobren baben. So will es in Infebung bes erften bei ber allbereit

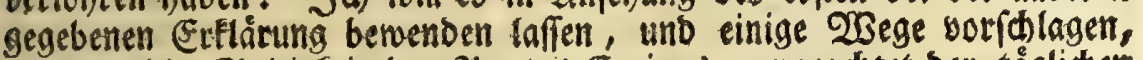

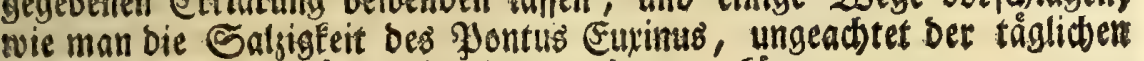
Cinuabme fo vieles fuffen 2 Baffers, bebaupten Eonne.

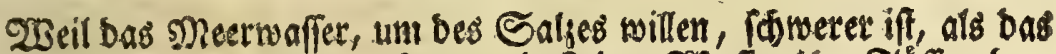

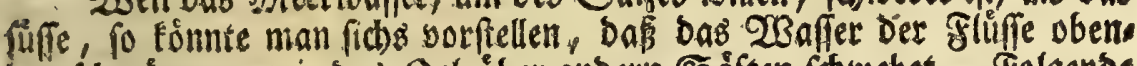

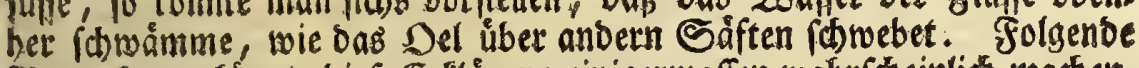
Setrahtung fónnte biefe Ertélárung einigermaffen wabriobeinlio machen,

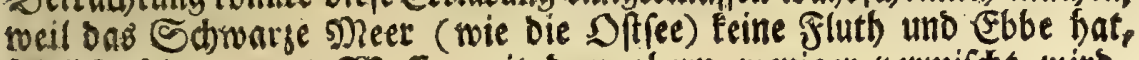
folglich fein unteres 2 Baffer mit bem obern weniger bermifot wito.

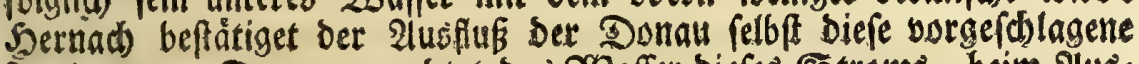

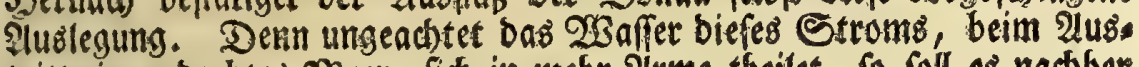
tritte in gebactes Mieer, fich in mebr Intme theilet, fo foll es nadber ood wieber. fich bereinigen, uno, ofne mit bem Euxinifden 2 baffer fich gu vermengen, nad ber Dberfiádse bes Meeres, gegen bie Meers enge von (Eonftantinopel, feinen 3 ug fidt)tbartio) fortfesen (oooo). Siet

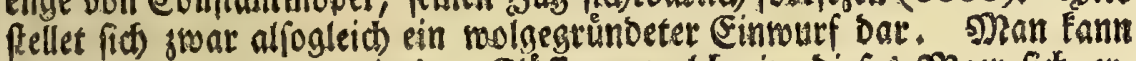
cintwenten, wenn es mit ben Fluffen, weldse in bicfes Meet fich er: gieffen, auf foldse Art jugienge, Dab ibr 20 Baffer obenber bliebe, to múte oer obere sheil biefes sneeres um ein Dertides fuffer fenn, als (E) 2

eift

(annn) Biele wotlen bebaupten, bie Rafpifaje Eee babe feine beinlidje Bufans mentunft mit bem ${ }_{3}$ iltmeere. Diefer Reinung (d)einet folgende Betrachtung zu fatten zu formmen, weil ibr 23 affer im Sommer, bei ubermåffiger Dús

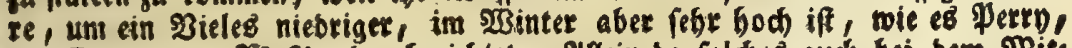

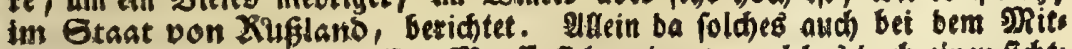

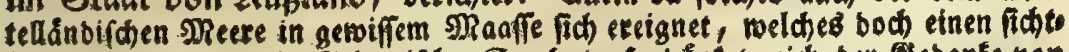
barn Jusaang in bie Mtlantifde Eee bat, fo buinfet mid) ber Eebante von

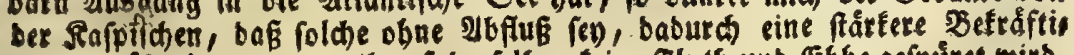
sung ju úberfommen, weil auf berielben feine glutb unb Ebbe gerpuret wirb,

wie 
ein ander gefalsenes Seewafter. Sa in ber Meerenge bei Conffantis nopel, woburd, nach biefem Entwurfe, nur fîfies $\mathfrak{Z}$ Baffer feinen 2 lus flus nefgmen wurbe, múgte man vom Salje gar nichto verfpuren. Şiers auf fonnte stoar erfllid) geantwortet werben, bap von bem 23 affer bet

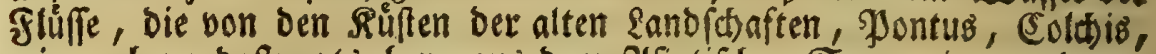
wie aud norboftwerts ber, aus bem 2lfiatideden Sarmatien, und von bem Bebirge Caucafus, in biefes sneer taufen, nichtó biš zu gebadbtem 2lusfluffe, ber bei Eonftantinopel if gelange; Denn von allem biefem

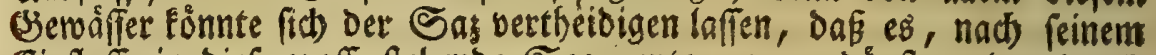
Ginfluffe in biefe groffe frehende See, entgegen wegdurnfe, ober Durch bie Fraft ber 23inde ausgeboben werbe, bebor es zur erwehnten Nseers enge fommet. Dá aber Das $2 \mathfrak{B a f f e r}$ biefer See auf ber Dberfåche gleid)wol füfer fen, als bei anbern Neeren, Daran ift gar nicht zu glveifetn, wenn man bie in ber Ilnmerf. ( $\mathrm{m} \mathrm{m} \mathrm{m} \mathrm{m}$ ) angeführten Zeug, niffe Des Zarenius erwáget. Llm roldbes von dem Ponto Euxino bars sutfun, will ich auf bent Berid)t bes (Curtius mich nicht berufen, uns

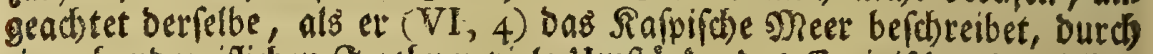
einen fanogreifichen Srrtbum viele Umftände Des Eurinifosen Demielben

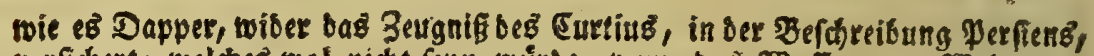
verfichert; melches mol nicht feyn wúrde, wenn bas 230 ffer vom SBeltmeere

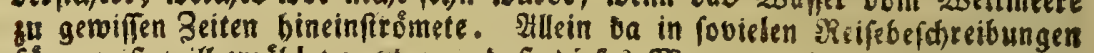
- fúr gemís will ergåblet merben, bafi diefes Meez an einigen Drten groffe

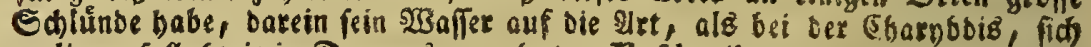
verlieren foll (wie in Dapperz ernebnter ZBefdreibung Perfíns, aus dern Oleariuz berichtet wito, wie ferner auz Martinieres Diat. geogr. in ben $\$ 3$. 20. MER CASPIENNE, und MER BLEUE, wie aud m. a. Fưdern

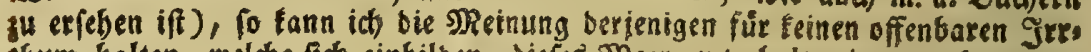
thum balten, weldse fich einbilsen, diefes 刃oeer unterbalte einen verborgenen 2YSedfel mit bem Scean, unb vielleiche noch mit andern Reeren. Sievon

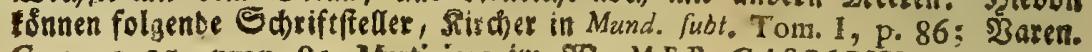
Geogr. c. I5, prop. 8; Martiniere im 5B. MER CASPIEN NE, p. 294;

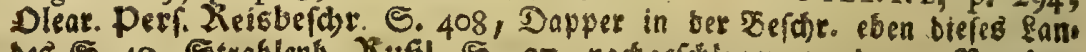
DeB S. 49 , Strablenb. Kuffl. S. 27, nachigethlagen rerben. Bon bem Sodten siReete (lacu Afphaltite), beffer $23 a f f e r$ am meiften falyicht iff, babet

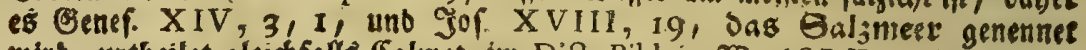

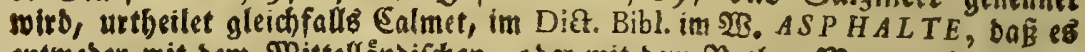

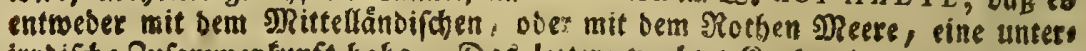
itroifhe Sufammenfunft babe. Das legtere traditet Setrd)er in fubor angegor genem Suche, p. 87 , burch Angeige einer groffen 'Jienge Juberpeds barju thun, fo an einem gemiffen Drte auf bem Sotben Reere empor fobmimme,

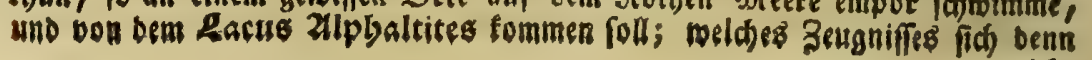
niф)t 


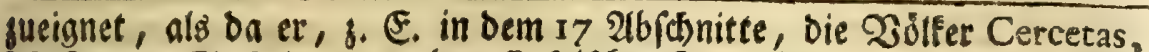
Mofynos, Chalybes, an Das Rafpifoe Nleet fejet, Die nur um bas

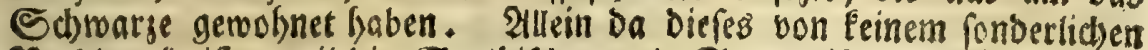

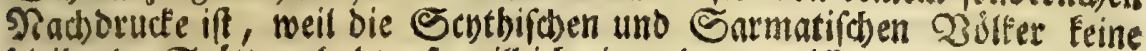
bleibende Státte gebabt, fo will idj ein ander gewiffeces Derfeben bies

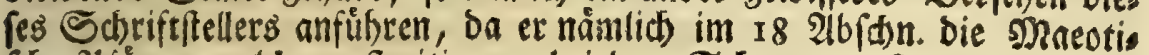

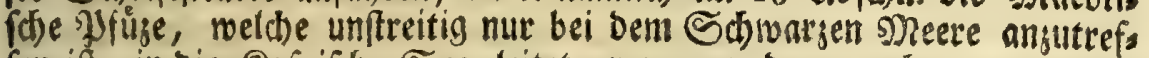
fen ift, in bie Sajpifhe Eee leitet, wo man benn aud), was et von

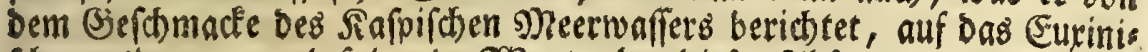
fobe ausbeuten, unb folgende 2 borte eben biefes 2 lbjajes, mare cajpium dulcius ceteris, bon bem leytern Meete betfefen Eonnte.

Sib) mill, fprecte id, mit feiner fo weit bergefudtein, und nodf überdiěs nicht allsuwol beftehenden I) Juthmaflung auftreten; benn Stra.

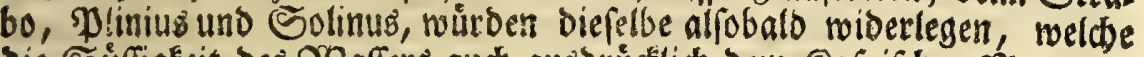

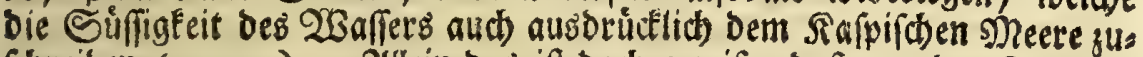

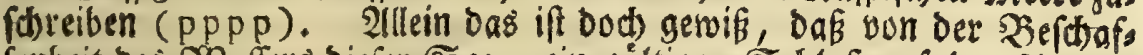

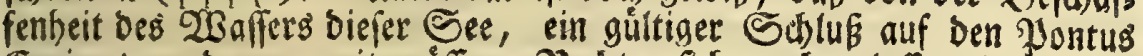

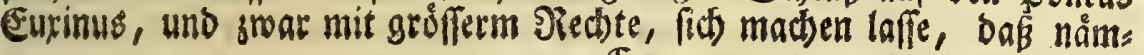

$$
\text { Ee } 3 \text { lid }
$$

nid) alfein viele in ibren Reifebefareibungen, fonbern auch anbere in ibren phofitalifenen abbanblungen, bebienet baben.

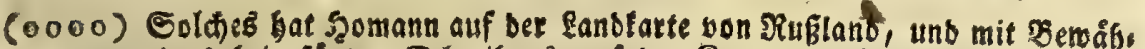
sung eines beigefugten Schreibens auf Der Rarte Dez Donauftems, anges zeiget. Das Das Donaumaffer auf eine jiemlid)e \$Reerftrecte mit Dem Euxis nifchen fich nicht vermenge, beftätiget auds bie Hift. Orb. Ters im I I Saupte. bet bydrogr. mit folgenben 230 orten: "In Pontum Euxinum evolvitur (Darusbius), ut in X usque milliaria aquam ejus dulcem percipere liceat. $D_{a \beta}$ eह

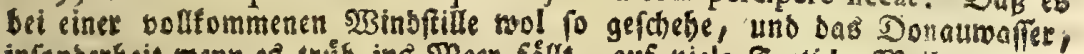

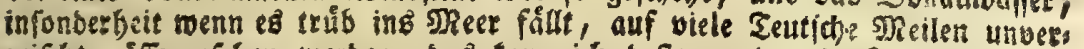
mifdse muffe gefeben werben, bas fann ich befto reniger in stoeifel sibben, als ich eben biefes bei anbern glüften sffters gefeben babe, oie irgent ourd cinen See geber, mie audh bei bem \$o, Ironto, Pefcara, uns andern Titas

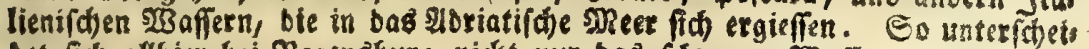

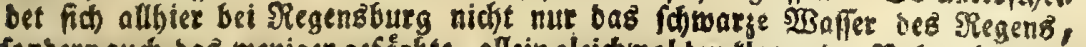
fonbern aucb bas weniger gefäbte, allein gleidwol buntleke, ber Rabe, bei bem Eintritte in die Donau; fie vermengen fids nidit alrobalo mit bicfem Gellen Stro:

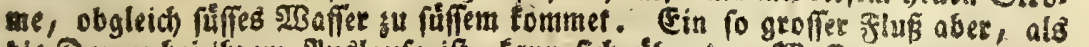
Die Donau bei ibrem Mralaufe iff, fann fid) úber bem 2 Baffer bon einer ans

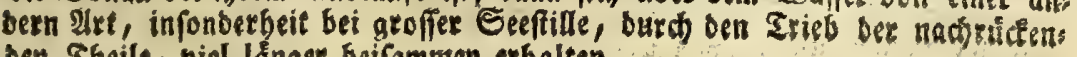
bes Sgeile, viel lenger beifamuen erbalten. 


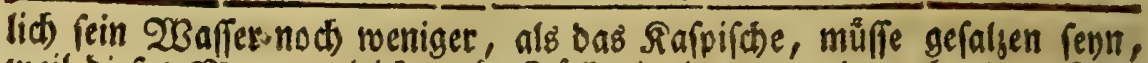
meil biefes sieer ungleich mefir Fluffe einnimmt, und nods einen fidts

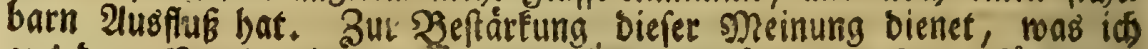

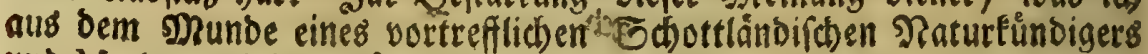
uno Mathematici, uniongft vernommen habe, weldber vor einigen Jabz ren aus Damig nach Dem Finnifđen Meerbufen eine Fafort borgefebret.

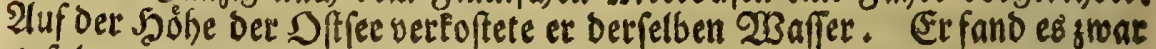

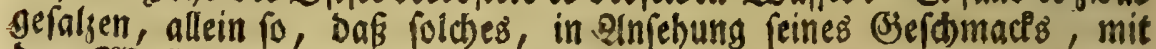

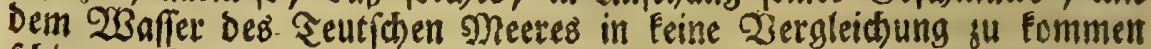
fhien. Se mehr nber berfelbe aufwerts nad gedadtem Sinnisden Meerbufen fubr, je fúfferes $23 a f f e r$ traf er an. So ift das Safpífde Meer in ber slitte stor gefalsen, allein bis auf einen gerwiffen 2 bftand von feinen Sortanden, ift Defin Sthärfe febr leiolid); ia an ben Riuften ber sandibaft Rillan gibt cs" Drte, wo bas WBaffer biefes sneeres ebet fing als gefalgen befunden wirb (Martiniere Dia. geogr. im 23 . MER

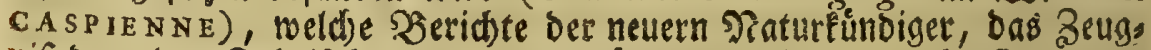
nis ber alten Sdriftiteller, yon bem füflichten 23 affer biefer See, volls fommen beftátigen und bewáben; denn bie 2liten fegelten gróftentheils

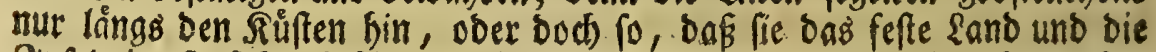
Sinfeln im (siefidte befielten; fie wagten fid nicht leidttich auf bas bos be Neer. Eie kofteten alfo bas Safpiface nur unweit bes Lffers, wo es noch públidtes 20 affer fübret. 2Ulein wenn eime nenigere 2insabl Der Fluffe bie $\mathfrak{R}$ afpirdse See gleidjwol bergeftalt berfúffen fann, befto eler ift ia foldses von Dem Eurinifionen ju glauben, barein ein anfehnlis der Sheil bes Siewåffers bon Europa uno alfien fâtu. Sieh Strab. I, 50. Sobiel Pann ich gegenwärtig gur Dertheibigung diefer erften Meis nung aufbringen. 2⿺lein Der Einwurf von Dem gan füfen 24usfluffe bes Sdbwarsen Neeres Durd bie Neerenge bei (Enftantinopel, ift fo mids): tig, Daß berjenige, welder bie Salsigfeit bes গুontus Eurinus auf befage te 2 Seife befjaupten mollte, entweoer biefe Folge julaffen, ober eine ans

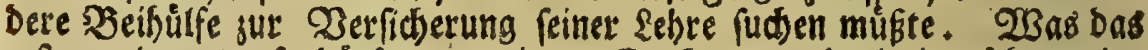
erfte anlanget, fo boirfte, meines (Erad)teng, Derjenige fehr unbes fonnen banbelm, Der in reiner Stubirfube, auf Redonung eines nid)t alljus

(PDPP) Strabo XII, 509, am Enbe: "Polycletus etiam argumenta profert, " quibus fidem faciat, Hyrcanum mare paludem effe: quia et ferpentes edu"cet, et aquam habeat dulcem." Plinius VI, 17, Hard. 19: Hauftum ipfius " maris dulcem effe et Alexander Magnus prodidit: et M. Varro, talem per" latum Pompeio, juxta res gerenti Mithridatico bello, magnitudine haud "dubie influentium amnium vido fale." Eben fo foreibet Solinus, S. 22: "Mare 
allsufeften (Srundes, eine Sache ju bejahen fich unterftunde, weldbe

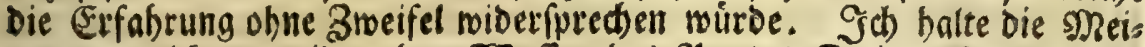
nung, welde vorgibe, das 2 saffer bes \$ontus Euxinus fen weniger

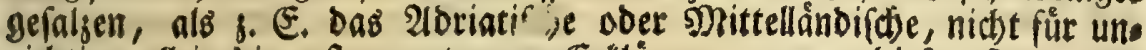
riebtig allein bie erft borgetragene Erklảtung, warum biefes gneer nidbt

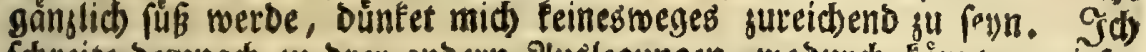
(d)reite benmad) ju brey andern 2luslegungen, rooburd fonnte erwiefen

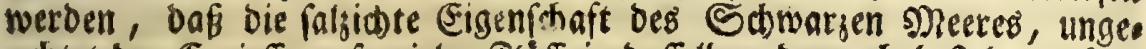
achtet ber Ergieffung fo vieler Sluffe in Daffelbe, Dennody befteben móge.

Die erfe Diefer bren Erflarungen bunfet mid) jwar nod), twenn id biefelbe gegen bie ztwey andern halte, weniger alo biefe gegrundet su feun. Sob will foltibe aber gleid)wol nicht zurúctelaffen, bamit id alles vortrage, was zur 2uflófung einer 'ctweren 2lufgabe aufsubrin. gen gewefen, oder was mir zum wenigften als id) ber Sache nad) famn, eingefallen ift. Es mơdte alfo jemano nach ber Rirdserifonen febrart

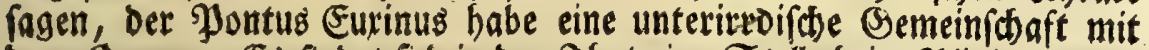
Dem Scenn. Es finbet fich in ber Shat eine Stelle beim Plinius, wels

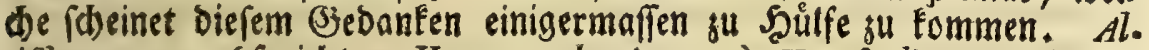
tifimum mare (fprid)t er, II, 102, 5ard. 105) XV ftadiorum Fabianus tradit. Alii in Ponto ex adverfo Coraxorum gentis (vocant Bag'ea Ponti) trecentis fere a continenti ftadiis, immenfam altitudinem maris tradunt, vadis nunquam repertis. Man fonnte fidos nun vorftellen, Daß̧ biefer 216 . gruno vielleid)t eben eine foldse Siefe fery, weldse bas 2 affer biefes Neeres burch einen fohiefen (Sang unter ber Eroe mit Dem Dcean ver, einige ( 9 q q). S'nbem ₹ournefort nid)t begreifet, too eine fo úber: groffe snenge des Serwáffers binfomme, melches nur allein bie Donau

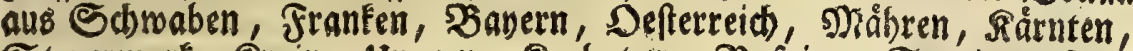
Stevermart, Rrain, Itngern, Rrabaten, Zbopinien, Servien, Sies benburgen, aus ber $233 a l l a c h e n$ 26. an fich giefet, unb bem Edwarzent

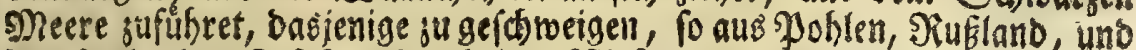
Dem \&anbe Der Fofalen, Durd) Den Riefter, Boog, Nieper, Don, uno

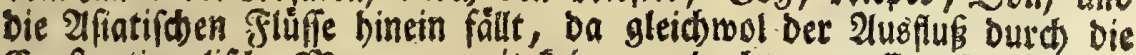

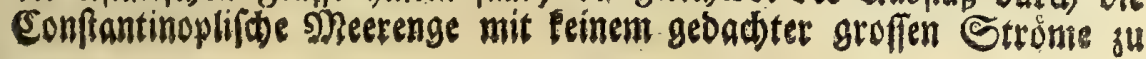

2 Mate antem Cafpium ex altero Ponti latere ultra Maffagetas et Apelizos 9, Scythas, effe in Afiatica plaga dulce hauftu, Alezandro Magno probagr tum eft: mox Pompeio Magno; quí bello Mithridaticó, fictit commilito " ejus Varro tradit, ipfis hauftibu's perichitari fidem voluit. Id evenire pro. " dunt e numero faminum, guorum tanta copia ibi confuit, ut naturam nas. g) tis vertant, $y$ 


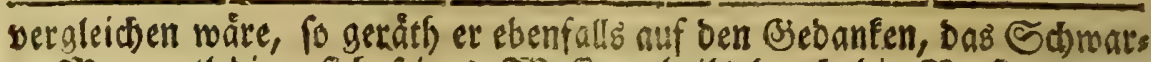
ge Aneer entlebige fin feines 23 nffers theilo burd bie Derfiegung in bie Erbe, theils burd unteritrbifd)e (sainge, bie vielleidt unter 2ifien und Europa firftreidsen ( $\operatorname{rrr}$ ). Diefe meinung foinnte endid) ba burd unterftuset twerben, toeil auds in ber Sffee, unb infonberbeit in beren norblidtent sheile, ober in Dem Sothnirdsen Meerburen, berglei c)en 3ufammentiang mit anbern Neeren foll fern entbeclt worben (ssss). Ez hat aber biefe See mit ber Eurinifonen eine grofe lleber. cinfunft. Sjeibe empfangen burd) bie Flüfe ungleid) mehr $23 a f f e r s$, als man bei ifren 2lusgángen bavon siefsen fieft. (Es ift auch bie Bals

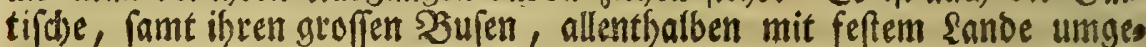
ben, uno hat nur brey fdomale Oefnungen, námlid ben Sunb bei Fop. penfagen, wie audb ben gloffen und ben fleinen $\mathfrak{B}$ elt, an beiben Sriten

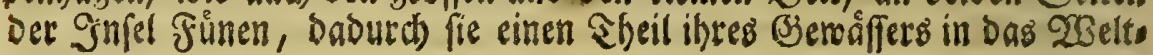

neet

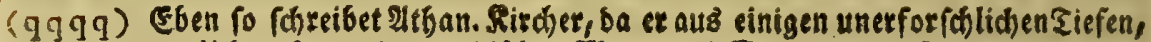

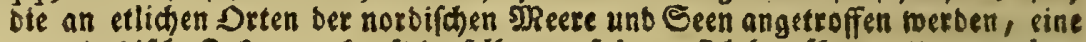
unterist bif he Bufammenkunft berfelben ju folgern fich bemúbet. "Notandum in fecundo, fino feine 230 orte, M. fubt. Tom. I, p. I47 A, rion tantum lacus "Norvegix, fed et Suecix, quos Venner et Vetter vocant, inexplorabilis 3. profunditatis effe, idem Olaus fcribit, ita ut funes, çui yel integram nai) vim onerent, ad fundum penetrandum non fufficiant; et idem experti funt "Hollandi in dictis Norvegix littoribus, qui bolide 130 orgiarum fundum re$\%$ perire non potuerunt, quemadnodum in navigatione ad Arcton referunt; is gux quidem inauditx profunditates aliud non arguunt, nifi fubterraneas im"menfe amplitudinis abyflos. Notandum tertio, ex tanta fubterraneorum 3) meatuum abundantia facile inferre poffumus mutuum circumvicinorum ma" rium cum Oceano Norvegiam allambente abditumque commercium; et id "variis exemplis oftendit Olaus \&c.

(rrr) "Neanmoins le Bofphore de Thrace n"eft comparable à aucune des gran" des rivieres dont ont vient de parler. Il eft certain d"ailleurs que la mer "Noire ne groffit pas, quoiqu' en bonne Phyfique un réfervoir augmente "quand fi décharge ne répond pas a la quantite d'eau qu'il reçoịt. Il faut " donc que la mer Noire fe vuide et par des canaux fouterrains, qui traver$\because$, fent peut-être l'Afie et l'Europe, et par la dépenfe continuelle de fes eaux, ") lefquelles s'abreuvent dans la terre, et s'écoulent bien loín des côtes. "Cette efpece de tranfpiration répond à celle du corps des animaux, "laquelle, fuivant la fupputation de Sanctorius, eft beaucoup plus confidé"rable que celle qui fe fait par les évacuations les plus fenfibles.n. Voyage du Lev. Lettre $X V, p .63$ B. Diefer Biebanfe ift nidit ofne allen Erunb, Denn

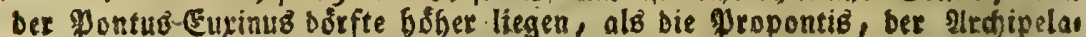

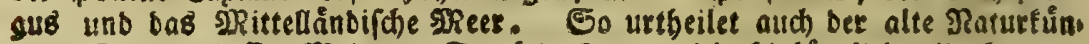

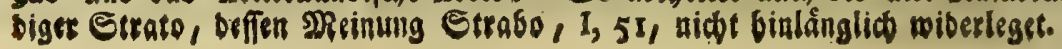


meet ausleeren fann. Go if bie erfte bet oben verfiprodenen bren (Ere

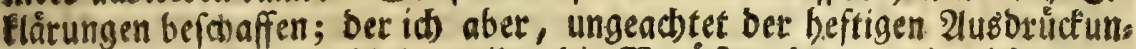
gen, mit weldben Scrbinius wiber bie Derád)ter ber unterirbid)en (S) meinf(haft ber Meere losfäbrt, nidst allsufehr anbange. Denn su ges

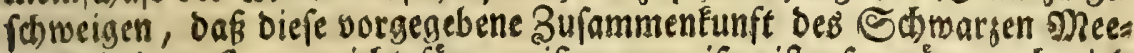
tes ntit bem Dcean nicht fur gemif zu erweifen ift, fo wäre aud viels leidst unbermeiblid), Daf in fold)em falle eine Flutb unb (Fbbe in bem erftern müpte gefpuret werben, weld)es bod bie Erfabrung wiber: leget.

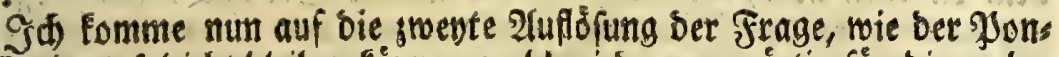
tus Euxinus faljidt) bleiben fóne, weldhe iti gegenwártig fur bie wabs: fdeintidfte balte, jeood) fo, Dafi auch bie an bet alleretften Stelle an gebradte 2uslegung, und bie britte von ben lestern Drenen, Die nod) foll angefubret werben, nicht gänglich ju verwerfen, fonbern cinigers

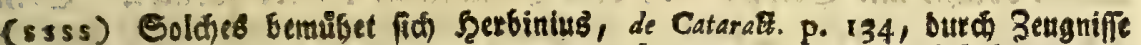
bargutbun: "Conftat jam, non terram duntaxat in genere, fed fingulariter "totam Scandinaviam regionem fub terra effe cavernofam. Probat hoc pri" mo occultum Sinus Bothnici et Maris Albi (Mofcovitarum lingua More Pe"3orke dicitur) aquarum cum Mari Norvegico commercium, quod fere ad , oculuin patet, fi modo quispiam rationem fanam adhibere velit. Ita cum " incomparabili viro Ath. Kirchero, ego in feptentrione toto jam quinquennio, " maribus et fretis toties transmiflis, fentio: nam profedo inexperto has " in re fapere non licet. Levinus Algotius hif. reg. Septentr. Objerva"tum, inquit, eft a peritis barum partium ultro citroque commeanti"bus viris; poftquam Norvegicus vortex aquas abjorpferit, alterume "in Botbnico Mari vorticem denuo eas per fubterraneum finum Norve"gicum ad evomendas, quas abjorperát, aquas cogere. Quod fi toi. tam Scandinaviam effe cavernofam verum eft, quid prohibet, quo minus 1. inter latentia charybdis Mufcanx faxa, foramina in abyflum fubterraneam, " per occultam naturæ ingluviem aquas trahentia, atque iterum inde eruatan 9. tia, dentur? hoc ipfum enim fana ratio et avirofíx demonfrat. Secundo idem 1" comprobat horribilis littorum Sinus Bothnici et Finnonici, tum etiam lacuum Weneri ac Wetteri fonitus, quem quibusdam in locis tantum effe fcribit Olaus, ut homines propius accedentes furdos et veluti attonitos, fubinde " etian exanimes reddat, nifi tempeltive fe fe a funeftis Charontis antris fub" duxerint. Imo et fub glaciebus feptentrionalibus Weneri, Wetteri ac Me"leri, horrendi mugitus, vaccarum inftar audiuntur, qui procul dubio a ca"taduparum fubterranearum motu funt. Profedo experientia ocularis, in " tam reconditis naturæe rebus, magiftra eft optima. Idem Olaus, $l_{0}, 2$ bifl. "Septentr. f. 6, tradit, Sinum Bothnicum innumeris fcopulis intricatum, mon. , tibus- 
maffen gefdicft feven, ber allbier folgenben beigefellet zu werben. Diefe

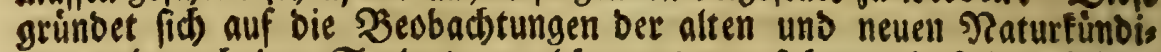
ger, wie audb der Seeleute, welde uns Derfichern, Daß bei einigen Meerengen, wo bie Bewegung bes 2 Baffers obenber nut nad einer Seite gefpuret wirb, baffelbe unterbalb feimen \&auf, gegen ben obern Strom, auf bie anbere Seite nebme. Rajus bejenget in feinen pbys fico, Ibeol. Betr. S.117, Daf diefer in ber sheerenge bei Conflat. timopel, unb im Sunde, beobactet toerbe, allwo bas obere (Seroaffer, Dem 2 ńfeben nad), beftánbig bon ber innern See nur berausflieffet, als lein ba lefre es bie Erfabrung, baf bagegen bas untere 2 Baffer beftins big bineinftóme. Don bet seerenge bei Conftantinopel verfidsert fols des aud Marfitius, ber verfdiebene Unterfuchungen oabei angeffellet

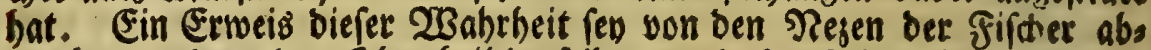
junebmen, benn bas Obertbeil berfelben werbe burd ben obern Etrom, jad ber jropontis, ober bem ijigen Mar oi Marmara, gejogen; bas übrige bringe mit (Seroalt nac) Dem (Eurinifकen श)eere surucle. (Eben Diefes bat ex bei bent Senfbley in $216 t$ genommen, und oabei anmers fen fonnen; wie tief ber obere Strom fen, ober wieviel $25 a f e r s$ aus bem Sळwargen Meere beraubflieffe. Denn wenn er geoactes Maab nut auf 5 ober 6 Sめub ins 2 Baffer gelaffen, fo warb es nad) ber Pros pontis berausgefúbret. Şat er es tiefer eingefenft, fo wurbe er ges mabr, Dá̧ Das untere $W_{3} a f f e r$ Daffelbe einwerts, nach Dem Đontus Gurinus, furúctetrieb. Sidt weniger merfwurbig ift, was er von beat ber\{diebenen (Senid)te und (Sejकmade bes obern und bes untern 2 Baro fers biefer meerenge berid)tet. Er hat befunden, baf bas obere leiuter

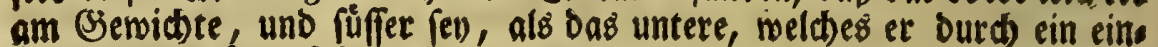
gefenftes (Sjefás erfabren; Denn fold es war mit einem Dentile verfeben, Dab er nad Selieben in berfdiebenen siefen erófnen fonnte.

Shieraus twirs es nun erftlich flat, wie bem Eurinifden sneere; burd ben untern Strom, bas Sals erfezet werbe, meldes burd Daś bere 2 Baffer mit berausfommet. Darnach ermeifet diefe פharfilifice Interfuchung, baf bie allererfte Auslegung, welche vorgab, Das fúffe

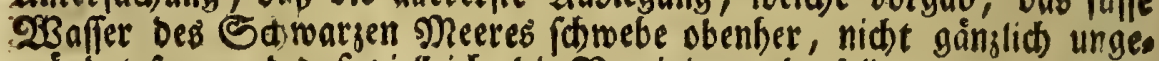
grundet fev, uno Dafi vielleidft bie Deteinigung berfelben mit Det gegent wåcs

"t tibusque altiflimis perpetua nive candentibus circumdatum, intra quorum 2) radices, mare per immenfas voragines, cum horribili ac intolerabili fono, 25 munc abforbetur, nune iterum revomitur, "D Dis 230 orte Ath. Kirchers, auf vildie 


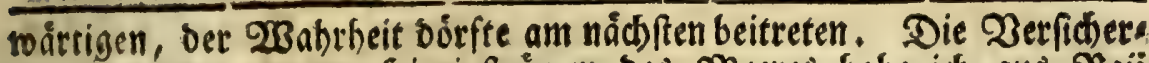
thng von bent untern Shineinftrơmen bes Neeres babe id aus SRaji plrfics: Cbeol. 3 etr. (oben erwefinter S.) entlefnet, weld)er biefe?acha rid)t unfehlbat aus ber Marfilifonen

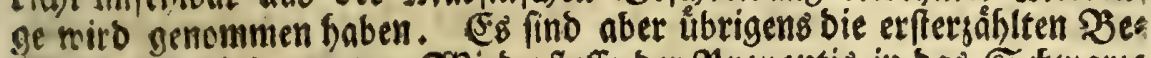
Hure, ben biefem untern 2 Sieberfiuffe ber Propontis in bas Sdjwarje Nieer, trine gang neue Entocfungen Des s)arfilius. Denn Drocopiug,

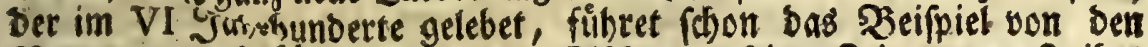

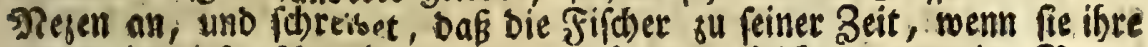
Obarne in biefes fomale sneer geworfen, an folden swenerlen Szewes gungen in 2 (cht genommen baben. Der obere sheil Derfelben warb bis auf eine gemiffe Siefe bon \$nitternad)t mittagwerts gejertet, ba inbeffen as tibrige berfelben, fo yon gebaditer siefe an unterwert's bieng, auf bie nibrige Seite fich frummete. Diefer Sd)riftfeller beseuget aud', Das bie zuvorbefagten gegeneinanber laufenden Stróme, weldje biefé

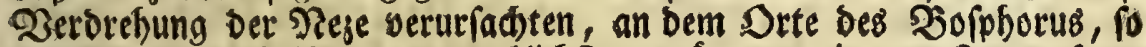
ber 21 bqutuno beist, am merf́lidfften wåren, wie aus ₹ourneforts Voyage du Lev. Lettre XV, p. 63 A, zu erfehen, allwo biefer Franjofe aud melbet, dás Marfitius fid swar viele mühe gegeben, Die wunbers

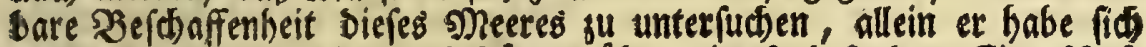

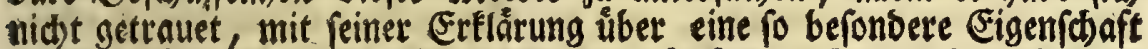
beraugzurücten. Sournefort meinet, es ftecfe am 20 oben Der oben ets wehnten Siefe, woruber ber Strom aus bem Schwarzen \$leere fers ausfährt, ein ausgeföblter und mufhelfórmiger Fels, an ben bas uns

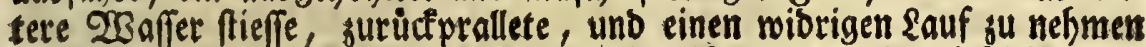

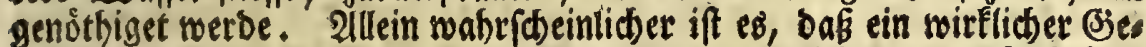
genfrom, zu eben ber Zeit, als ber obere beraussiehet, unterhalb bin

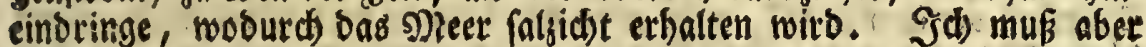
nidbt vergeffen zu erinnern, Daß̧ ber gelehrte Rajus, ben id in biefen Blättern fo oft anfübre coem aud Sournefort, Ifagog. 53 , mit allem

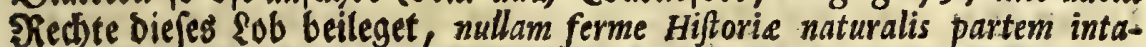

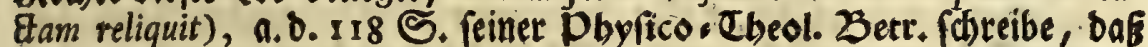

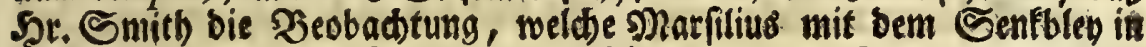
ber Neerenge bei Conftantinopel verrichtet, in bem $B a l t i j$ en Sunbe angeftellet babe; allein anftatt bes SBlentourfó båtte er eineb Eimerb fid If 2 bebies

meldje Serbinius an biefer Stelle fid betiebet, fieben in M. fubt. Totn. I, p:

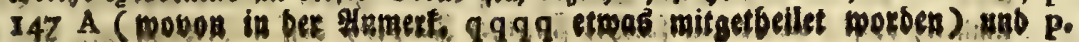
148 B. 
bebienet, ben er mit einer Stúdffugel gefchweret. Mnittelft beffelben befano ex biefe Meerenge von eben Der Befdbaffenfeit, welde Mas: filius ber bei Confantinopel zuleget. Denn bis auf eine gewiffe siefe fかrwamm ber Eimer auswerts. 28 enn er Denfelben aber tiefer binums ter gelaffen hat, fo warb et in bas Baltíche. Dieer hineingejogen, und je tiefer er foldben binunterfenfte, je getwaltiger rib denfelben ber untere Strom eintwerts.

Diefe ErElarung ber Salgigleit Der Mneere, bie nur airen fojmalen 2usfius baben, bưnfet mid) siemlid wol su beftépes. (Es erbellet auds Daraus, warum fie feiner fluth und Ebbe unterworfen fenen, tweil nåms lich ber 2lustritt uno bie Einfahrt ibres ejerwáffers nicht wedbelweife. gefdehen, ronbern gugleith fich ereignen. Dieles 2 lus: und Eingieben Der wiorigen obern uns untern Strome in Den Meerengen, (d)einet übers bief bie oben (in ber II Unterf. $(.1$ ) vorgetragene SBefthreibung ber

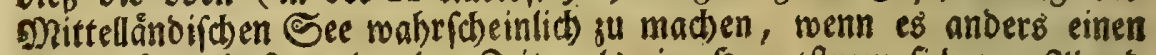
(Bruno bat; bás zu eben Der Zeit, als ein Sauptftom fic yon 2abeno

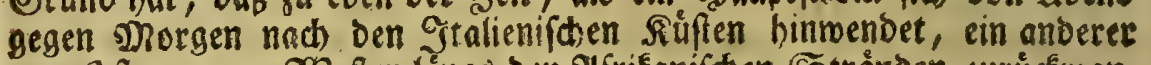

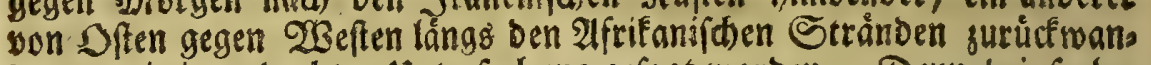
bere, wie in gedachter unterfuchung gefagt worden. Denn bei fo bes

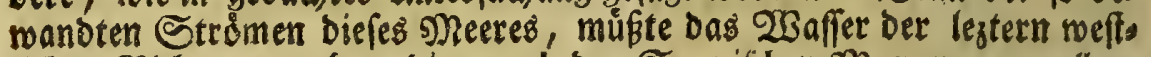

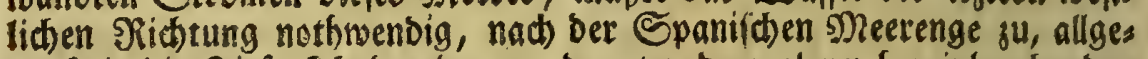
mad) in bie. Siefe fid begeben, unb unter bem obern bereinbrectenden Etrome binausfabren; fonft murbe an bem Srte, wo Diefe zmen mis brigen 3úge obenter aneinander ftieffen, ein beharelid)er Sturm uno Fluthentampf auf bem Meere gu fehen feun. Wenn bemnad) Der gwev:

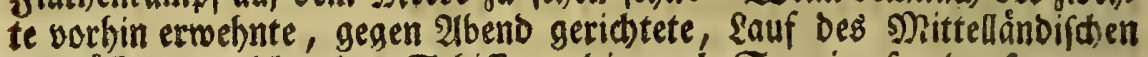
Bienáfiers, weld)er ben Schiffen, Die nach Spanien fegeln, fo guten Wortheil berídaffen foll, nid)t etwa nur bamals beobadtet wirb, went biefes Meer burd) bie Etraffe binaustritt; fonbern auch jur Zeit bes Cinfluffes bor fich gefbet, fo múften wir un bie Stróme der mittellán: bifden See, nact) ber Straffe ju, in Der Beftalt vorbilben, bie ein Bimbfaben haben wurbe, beffen Ende man to úbereinander legte, Das

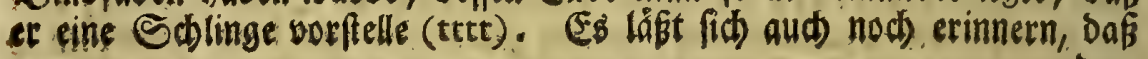
gul :

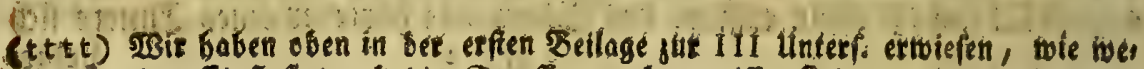
nig ber Einfü ourds oie etraffe, nach gewifien 3eiten, esee nach ei em

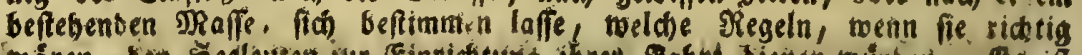

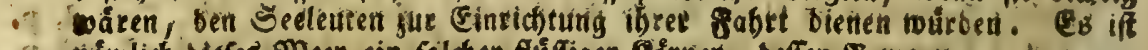

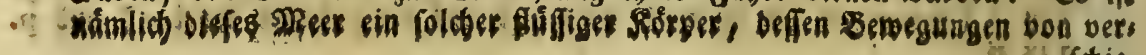

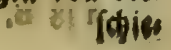


Dem (Entmurfe ber fu gleidher Zeir fiusmos uno bereinwech felnden Strds me ber greerenaen, bie ungsuleine Tiefe berfelben úberaus wol suftats ten fosust. Der zooen ber Straffe foll, wie Jerry berfichert, an mand)en Drten nid)t gu etforichen fevn. Wei ber ß̧efdreibung bes Bofphorus 3hracius ift aud eines 2lbgrundes gebacht worben. Saus will biefen Ertáblungen Feinen volfommenen SSlauben beimeffen, fon: bern verlanget, Daf man gemeloter $\mathfrak{B}$ ejchaffenbeit ber wibrigen Strome genauer nadbforfden foll. 2 Bas mid anlanget, fo rollte ich auf bies fes einjige 2 cht geben, ob es mit bem untern 2 Biberftromen ber sneers engen, foferne feine Richtigfeit babe, Daf Das Neer wirflich bei ben gundungen berfelben in Den innern groffen $\mathfrak{Z} u f e n$ bineinlaufe. Dent

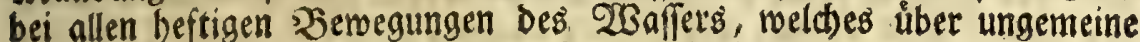
Siefen hinfibieffet, wird on fold)en Drten fich ein (Siegenfluf einfinben, wo bie ufer in eine Jiunoung fic ausbreiten, wie bei Der Jropontis.

Die Urfache ift meines Erachtens diefe, weil Das obere 2Baffer, weldes ber Sibfang, nebft Dem engen Durchjuge, in fonellen \&auf gee

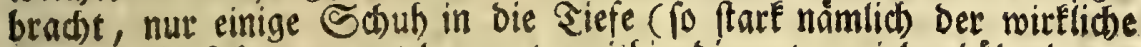
Qusflus ift) fth borwerts beneget, mithin bie untere vielmal úberlegene saft bes 2 Baffers feinestoeges mit fich fortfubren, ia aud felbft reinen frengen 3 ug mit gleidber Sceftigfeit nicht beftandig fortjejen fann, weil enolich oie urfachen Des gewaltigen Sriebes aufboren: (o ftoffen fich eis nige sheile bes obern ungeftum flieffenden 2 Baffers an bie vorbern láng: famer fortrúcelenden, uno bequemen fich gar leidt erftlic) su einem feits wertigen Sange, nacbem aber, Durd ein neues 2 infoblagen an bas. Sieftad ber runden Bucten, zu einem mibrigen \&aufe, infonberfeit an

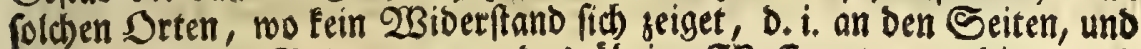
unten nach bem 20 oen zu, wo Das úbrige 2 Baffer etwas rubiger, uno su einer jeben Beroegung gefdicfter ift. Gin Beifpiel biefer Er: flórung lábt fich albier auf Dem obern 2 Bert, bei Dem fogenannten Yehrtode, beobadsten, roo der beftige sinfall eines alms der Dos nau, welder bei Staot an bof vorbei freidset, Das getwaltig fro: menoe 2 Baffer einer meerenge, bie gleich unterfalb aber, infonberbeit auf ber Saperifकen Seite, ausgebreitete Bettung biefes Sanges, baš

$$
\text { If } 3 \text { VIar }
$$

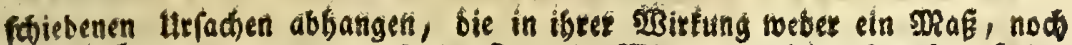

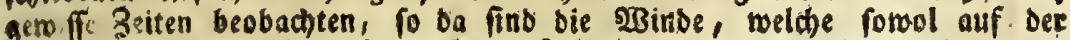

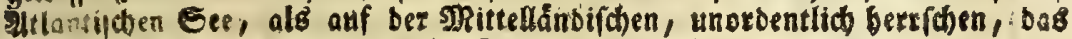
unckech brennenbe unterirzbifabe gieuer, to bas bager bes lejtern biget, Die

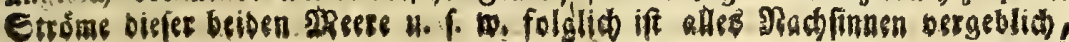


War of Marmata, oder vit Wrapantio, einigermaffen borffellet. Da

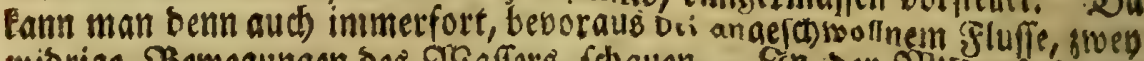

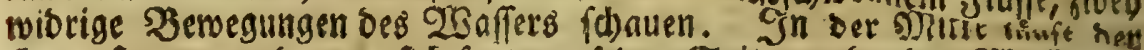
Saatpeftrom gerabe vor fich fort, auf ben Eeiten gehet bas 2 affer bus

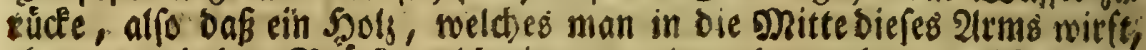
abwerts und ber Bructe jufdowimme, ein anbers aber, sweld) ho man nóber beim Ufer bineinwirft, aufwerts D. i, nach bem Einfalle, zurúcts getrieben swerbe, auf bie strt, mie Tournefort (Voy. du Levant, Lettre XV, p. 62 B ) mit bem গarfilius, bie 2éftaffenteit ber Meerenge bei Conftantinepel abfdifbert, too ebenfalls oie Schiffe auf ber Mitte beg

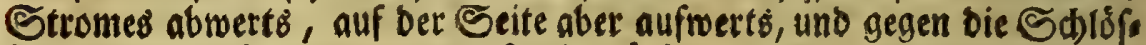
fer, ofne baf fie rubern ober fegein borfen, blok burch Den Irieb bes

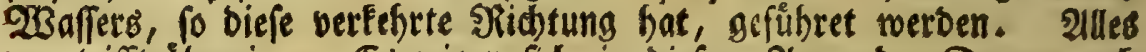
nun trifft überein. Es zeigen fid in biefen Slrme ber Donau aud wirflidje Spuren von einer untern rúcfwerts gefefheten Bewegung Des $23 a f f e r 8$, bergleichen ?ournefort und Marfilius in befagter meerenge

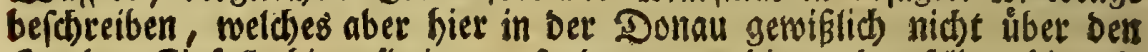
Ort bes Einfalls binauforinget, fondern nut bis zu bemjelben bin: fo beforge id, Das in ben meerengen, bei benen mibrige obere und uns tere Sitróme angemerfet werbeli, es nur auf eben biefe $23 e i f e$ suges ben bórfte. Diejes verbienet eine genauere Unterfucbung.

Wenn es aber mit biefer wirflicben Einfafot bes untern Seewafo

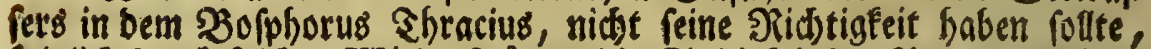

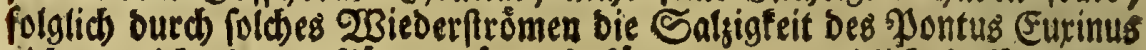

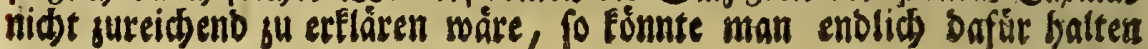

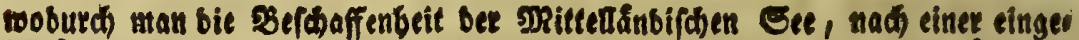

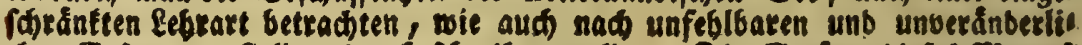

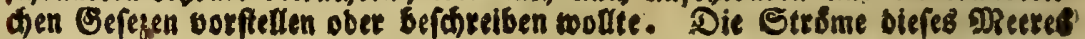
geben uns eine neue luebergeugung biefer $23 a b e b e i t$ an bie sanb. Es if a. b. 7 S. bee Recenfion, unb im II 56.2 Unterf S. 68 unb 8I, eines Stromes.

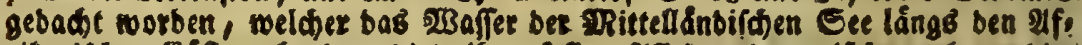

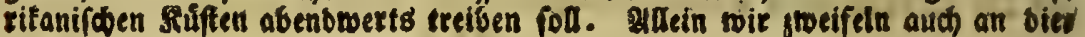

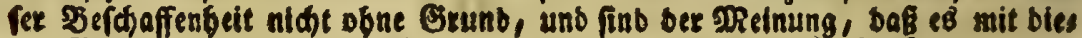

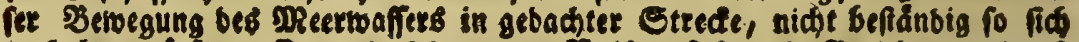
berbalten boffte. Detn in Monconys Keifen feber ein Berid)t, woburd begetget mitb, baf bas IRtttellanbifaje MReer zuweilen aud bon ber Strafies nach ber Eegenb bon Eyrien ftóme. Die eigenen $2 B$ Borte biefeb Edsiftitel. lers lauten fo: "L'aprèsdiné nous nous trouvames à quatre heures à deux " lievës de l'isle d'Arboran qui nous etoit a l'EAt. Les pitotes en furent 
(bas if bie britte verforodene 2luslegung), bak biefe See ben Derluft Des Salkes, weldben ber luberfiußs von fíffem 23 affer bei berfelben veruro facben Ddrfte, fid Durch bie Bef(taffenbeit ihres gagers felbft erfese,

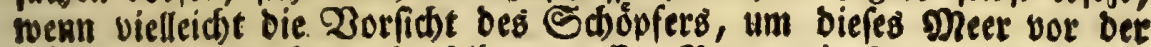
fáulnis su verwabren, berfelben groffes Bette mit \{agen von Steims falbe, Steinfoblen, unb andern 21rten ber untetirrbif̧chen Şarse, reids: liber bepflaftert hat, baraus, zufolge ben Entbecfungen ber neuern गas

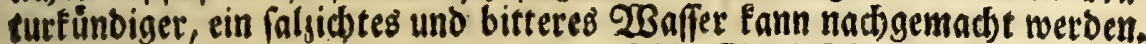
Oatenius meinet (c. 13, prop. 8), Daß bie Salsigfeit bes গneerwaffers

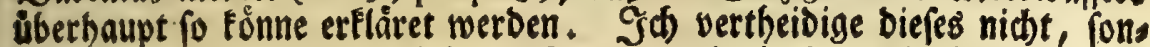
betn fage nur, baß in einigen Neeren, als in Dem Eurinifhen, wie aud in ber Offee, es vor anbern to zugehen Ponne. Es zeigen fith

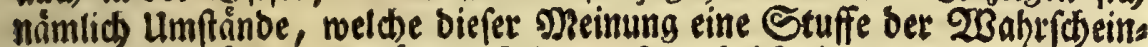
lid)feit beizuricten vermógent fino. Man bridst in Lngerm eine groffe Menge Steinialzes. Marfilius befdreibet a. D. 12 S. peiner meer. bift. Die \&agen bes Steinfalzes in Ungern, Siebenbưrgen, in ber \$Nol,

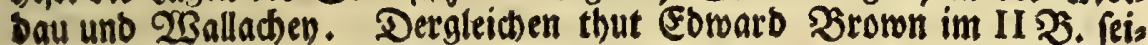
ner Reifin, I Th. I Sauptff. Zon Dem Ungrif́chen Salbergwerte if

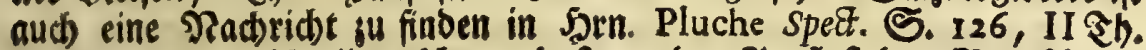

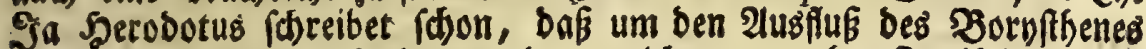
überaus viel Sals gefunben werbe, weldhes man obne Zweifel jur Ein: falsung bes Saufens wiro gebraudit baben. In bujus (Boryfthenis) quoque oftio ingens vis falis fua jponte concrefcit. Prabet idem ingentia cete ad falfuram, spinis carentia, que antaceos appellant. IV, 53. Es

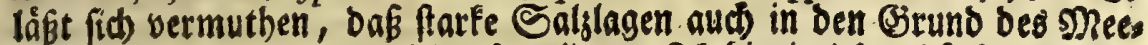

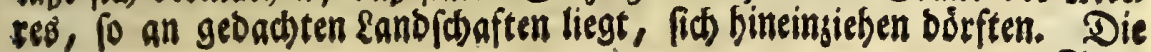

7. etonnez; parceque n'ayant pú gagner depuis le detroit que 9 ou Io lieuës, 31. les courans nous en avoient fait faire 40." Fournal des Voyages, P, 78. 28ic

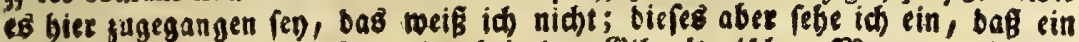
Sbeil ber 2irlantifden Eee, bet bei ber Gibraltarifoen Mreerenge bereins

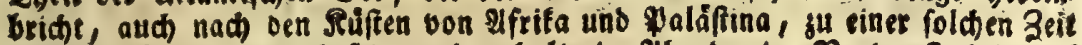
frómen fónne, wenn beftige unb anbaltende 2ibend: ober Rordmeftwinbe auf

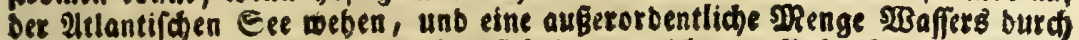
bie Etraffe bereintreiben, weld)es fid foobnn nidt nut linfer şand nach Stas

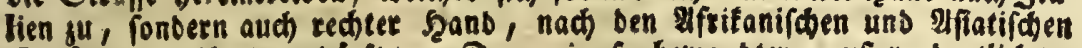
Etránben ausbreiten boffte. Denn ein fo betoander, auserorbentlicher,

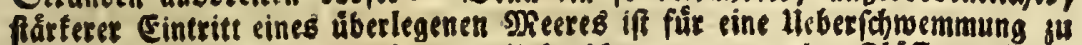
balten. soir fegen aber bei ben lleberfobemmungen der fluffe, boß ber

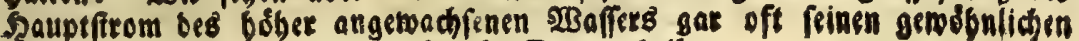
cang verandere, poet fid auf mege Seiten thelle. 
Strecle bes alten Shraciens, weldyes bun einer Seite Das Schtwarje seer berúbrte, mus mit Eagen von Eropeche verfehen feun, weil bees gleiden Silumpen auf ben baranitoffenden s)eeren, fu allen Zeiter, her, umformimmend angetreffen morden. Die Altem baben bergleither Sars um ben Serg 21thos (Der heutiges ₹ages il Monte Santo genenret wirb) auf bem 2legäichen झुeere gefelen, wie es Euboxus, uno aus bemfelo ben Eallimađbus Enrenåuś, im 2Berfe von ben Seltenheiten des \elos ponnefus uno Staliens, aus biefer Schrift aber 2intigonus Sarnfthius,

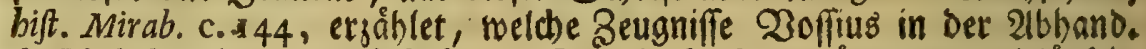
de Idolol. zufammengefaft bat. Dás foldhe gagen überaus weitláuftig fenen, wie aud) ben (Eroboben febr tief Durdffreiden můfen, Eönnte man bacaus abnehmen, weil Das gneer bis auf Den beutigen ₹ag immer

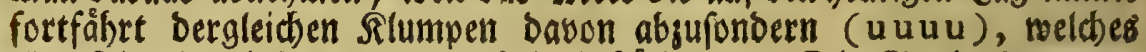

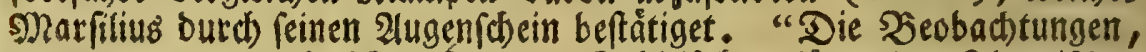

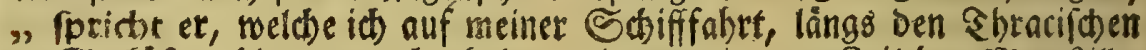
"Seefuften hin, gemadbt habe, jeigten mir, zur Deit Der Meerfille, "in benfelben Siegenden, auf bem 23 affer lorwebendeb Eroped)." Meergef(t). S. 28 .

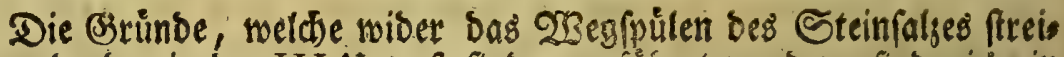
ten, uno oben in ber III Unter find angefubert worben, finde it. in

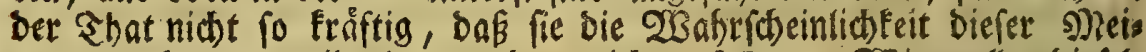
nung volfommen wiberlegen und vernichten follten. WSir wollen biefels ben ein wenig überlegen und prúfen. Der Einwurf bon Der foleimid), ten Shaut; romit bie gange Sberfiădbe bes Sneerlagers, folglid) auds

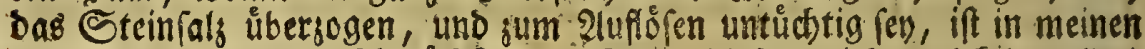

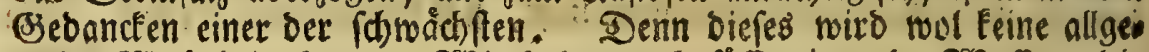

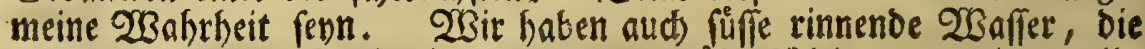

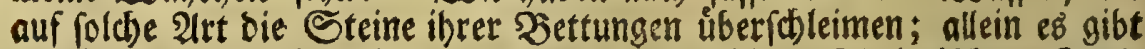
mefrere, bie es nicht thun. Sob bin viel auf bem Abriatifon, Sonis idien

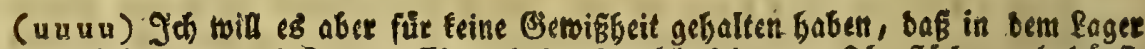
biefez ober bes Tobten IReeres (auf neld̄es leztern Dberflädje nod) báufio

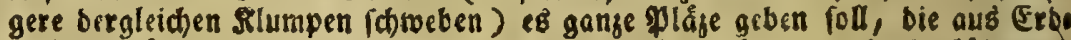

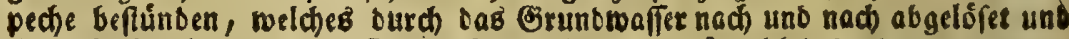
beraufgebradit werbe. Denn id febe feine unmogglidjett barinnen, marum nicht vielmebr Das unteritrbifche feuer, io etwan unter bem Soben biefer Dreere beennet, unb bas gefalgene, wie auch Das bittere, SBaffer tochet, bie slidjten bittern sbeild)en beffelben mit ben irrtifhen, barunter befindlidgen, verbinber, fu einer \$erbictung bringen, unb enolid groffere Snolen baraub biloen tốnae. 


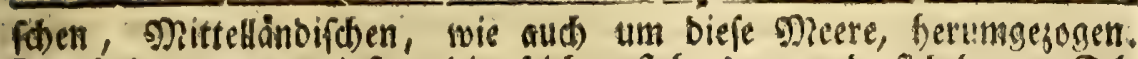
Gd) babe sum wenigften bie feidste ftehenden und fichtearen jelt

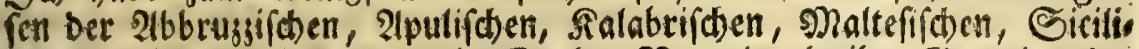
fden, wie aud ber, um die Etabt Neapel und ibre Begenden bes

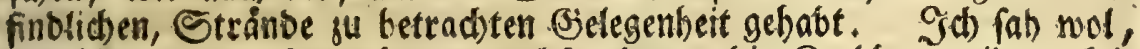

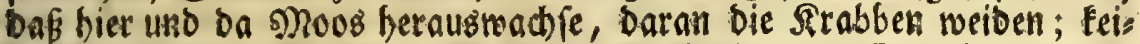

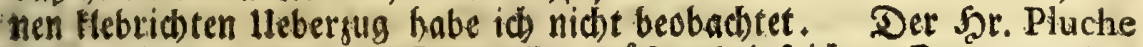

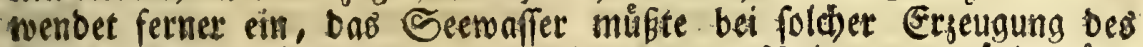
Neerfalges, on theils Srten ungleid) gefalzen erfotheinen; es murbe nám.

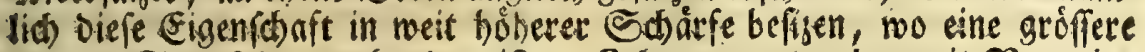
Nenge Stenfaljes bothanden ift. Sh) antworte aber mit Warenio, Dafi fold)es bet Erfahrung nid)t entgegen fev. Diefer Naturkunbiget beftâtiget nicht allein bie ungleide Salgigfeit bes sneermaffers, fonbern

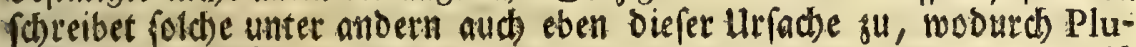

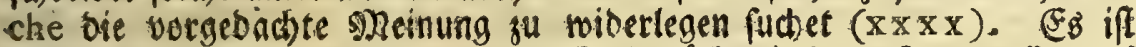

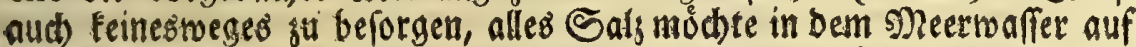
einmal zerfieffen. Denn die Erfahrung bejeuget, Dấ bas $23 a f f e r$ nue

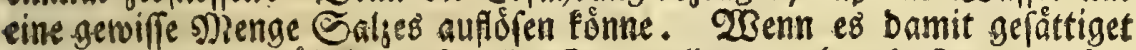
ift, fo bleibet baỏ ủbrige auf befen 20 oden fiegen, obne bab es jergehe.

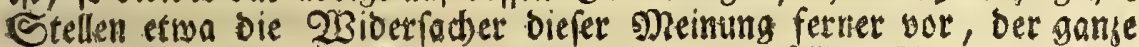

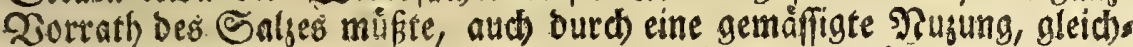

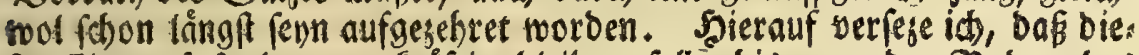
fer Einnurf fo lange unfręftig bleiben foll, bis man ben $\mathfrak{B} 0$ ben bes

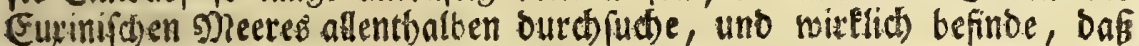

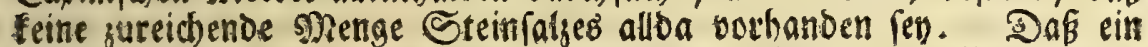
groffer Heberfuß von folthem Salje in mefre Sfeilen ber 2 selt gefun Den roerbe, erbellet aus folgender Stelle bes \$linius, XXXI, 7 , 5ard. 39: Sunt et montes nativi falis, ut in Indis Oromenus (oab lautet wie (Ormus), in quo lapicidinarum modo ceditur renafcens: majusque regum vectigal ex so, quam ex auro eft atque margaritis. Effoditur et $e$

terra,

( $\times \times \times \times$ ) "Tertia caufa (inequalis faljedinis) eft copia major vel minor falis in di"verfis alvei Oceani partibus. Etenim ficut non omnibus terræe extantis par" tibus deprehendimus ineffe fodinas falis, neque ubi funt, ibi eandem effe " copiam falis; idem quoque de parte terræ, quam Oceanus tegit vel alluit, " hoc eft, de alveis et littoribus afierendum effe, nemo ibit inficias. tlbi " itaque major falis copia vel minera, in alveo vel littore Oceani eft, ibi " aquam magis falfan effe, quoniam majori copia falis imprægnata eft, facile ") eft concipere. Sic infula. Ormez tota fale conftat; itarqe vicinus Oceanus ") admodum falfas habet aquas." Geogr. c, 13, prop. IO, n. 3. 
II S6. 21bfanblung bom Meere:

terra, ut palam eft, bumore denfato, in Cappadocia. Ibi quidem ceditur specularium lapidum modo. Pondus magnum glebis, quas micas vulgus appellat. Gerrbis, Arabie oppido, muros domosque maffis falis faciunt, aqua ferruminantes. Don Den Hammanientibus (einem Plfrifanifiden Dolfe) fo nach bem Urtbeile Harduini, bie Amantes Solini fino, foreibet ebert: falls Plinius, V, 5: Domos fale montibus fuis excifo, ceu lapide, confruunt. Serobotus erzåblet im IV $\mathfrak{B}_{\text {ud }}, 181$ abfonitte, uno in Den bren folgenden, von mebrern Afrifanificen Salghugeln. Diefe Etellen bátte Sar. Pluche anjefen rollen, bevor er gejabrieben, eb ftecte nirgeno fo viel Ealzes in ber Groe, weldes binlänglid näre, ben Meeren ben faljidten (jefhmad fu geben. Darnach munfobe id, baś biefe Serten, weldbe in ibren Stubirftuben alles gar gettau wollen aubgesiss felt uns berechnet baben, aud blob auf Diefe ifre theorifoen Seroeife,

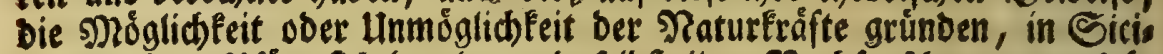

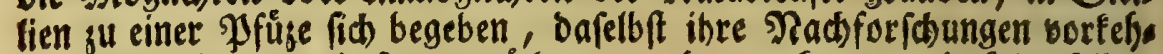
ren, und alsbenn mir fagen mód)ten, woher es fomme, bafis berfelben Sal; nimmermefr erfí) ơfet werbe, ungeadtet eine nambafte 2njab! Iaften jăbrlid binweggetragen toerbe, beren 23 affer aber gleidnol feis nen andern $3 u$ flus bat, als was vom SRegen binein fommer.

Es liegt Diejer fleine See auf Der mittăgigen Sỉfte bet Gn(el, nidjt gar toeit von Capo Paffaro, ber füboffticten Shauptecte bon Sicilien, am nåd)ften aber bei ber úbelbefdaffenen Sdifflánde, sold)e la Marza beift, Daber Diefes eingefoloffene 2 Baffer, la Salina della Marza, Der Galzteich von triarza, genennet wiro. WBenn diefes ftebende Waffer im Sommer eintroctnet, fo binterláft es foviel Salzes, Dafi bie barzu geftellen seute es zu Saufen follagen, wie bei Srapani, wo oaś fơnis glidbe Salywert non Sicilien ift, alfo baß eine Saft beg vorgebachten Salses, foviel ein Efel tragen fann, nur mit einem Sicilianifíten Sar. liin, b. i. mit 5 Sreusern, und was auf einem smaulefel mag binmegges fthafft werben, mit einem cari, ober mit Io Rreusern, Dem furften von Spaccaforno, als (Srunoberrn, bezablt wiro Scierbei ift diefes obne Zweifel bas mertwourbigfte, uno meld)es eine Uleberlegung wol verbienet, wenn man ben Urfprung biefes Salges unterfuchen will, námlid bie ungefünfelte 2 Beife, nad meld)er bie Juffefer viefes Saly. werfes fid berbalten, wenn fie bie verlobrne Frudtbarfeit befagter गjüze wieber berfellen wollen. Denn fobald fie merfen, baj diefelbe ibre gewoóntidie 2 lbgabe bon Salze nid)t liefere, fo untafern fie nue ben Soben berfelben, wenn fie eingetrocfnet ift, fobann überfommen fie nieber foviet Salzes als norbin. Diefer Derfabren fobinet uns zu inbes: 


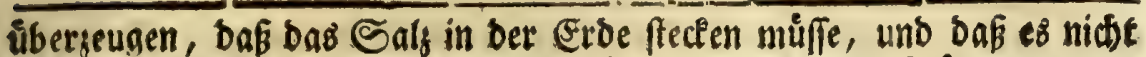
von bem 2 saffer anberswoher gebradbt, ober aus ber suft angejogen

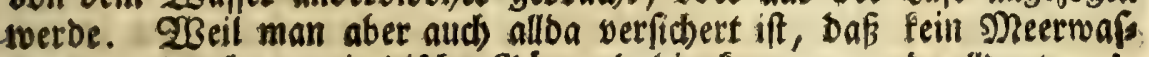
fer etwa burd) unterirrbirdoe (sảnge bahin fomme, und alloort ausos breche, wie bas fuffe Waffer beim Birfnizerfee in Srain, fo bitte ic biefe saerren, weldbe befahren, baß Sals Dorfte ermangeln, wenn bas Neerwaffer foldes oon feinem sager empfienge; ich erfuche, (pred)e id, biefe Şerren, fie midaten mir fagen, was bemn bei ber Salina bella

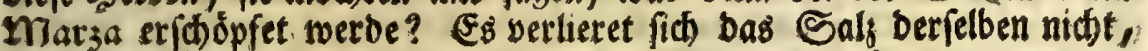
unb man fpuret aud fein abnebmen ber Erbe ( у y y y).

23eiter gegen 2beno, 623 äljhe Meilen vor Serranoba, ift ein. anberer See, ber nidt gar breit, aber lang ift, bet etlid)e groffé Frummungen madte, uno Daber ùber 3 Stalienirhe - Meilen im Besirte betragen foll, wie midh bie Syerren erwebnter Stabt berfictert bas bert; benn ourd) Den bloffen Augenf(hein fonnte id Den Umfang nidht fo genau beurtbeilen. Er heift il Beviero di Terranova, b. i. Der See von Cerranova; benn beviero beift ein Eee, nad ber beutigen smunbart diefes Eandes. Str. 2ratino Daioone, ein Sicilianer, aus ber Stabt

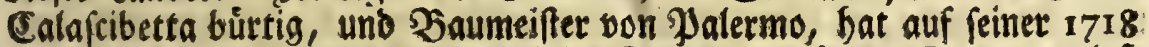
berausgegebenen sandfarte von biefer Infel, erwefnten See augigelaf: fen. Soldes wiro vermutflich aus Ulebereilung gejheben fenn, weil er begierig war, bie Freube feiner Sanbegleute, über bie neuangetretene Serrichaft ibrer fo fehr geliebten Spanier, burd ein óffentlicbes Merts mal zu bejeigen, laut ber 2 Uuffiditift: Data in luce dal medefimo in vccafione della commune allegrezza per lo ritorno di quefto regno fotto il Dominio del fuo Piifimo Monarca FILIPPO V. RE delle spagne. Es ift abet feltfam, onß auf bet Sdymettauifden groffen sanofarte von Sicilien, weldje bie Saiferl. Ingenieurs bren Sahre fpäter verfertiget haben, uno bie in Wien auf 4 Silattern Gerausgefommen ift, biefer See aud nid) entwarfen worben; Daraus es benn abzunehmen, baf biefe Serren nicht: allemal bie Srte befidstigen, bie fie in itren SRiffen angeigen. Die

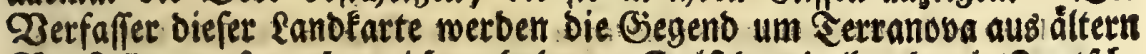

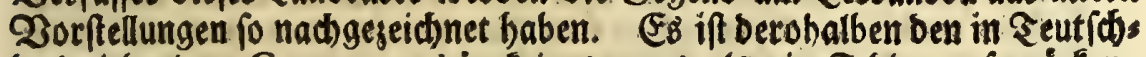
lanb lebenden Cosmographis feinesweges alo ein Jebler aufjurúden, (3) 2 wenil

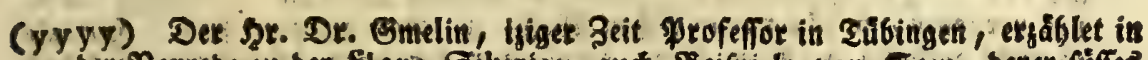

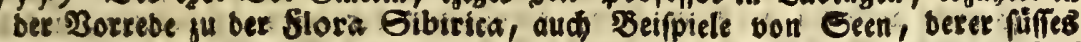
SBaffer, feit IDRenthen Bebenten, in gefalyenes verwanbelt worben. :2uf

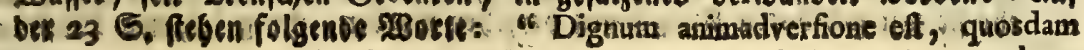
nlacus 


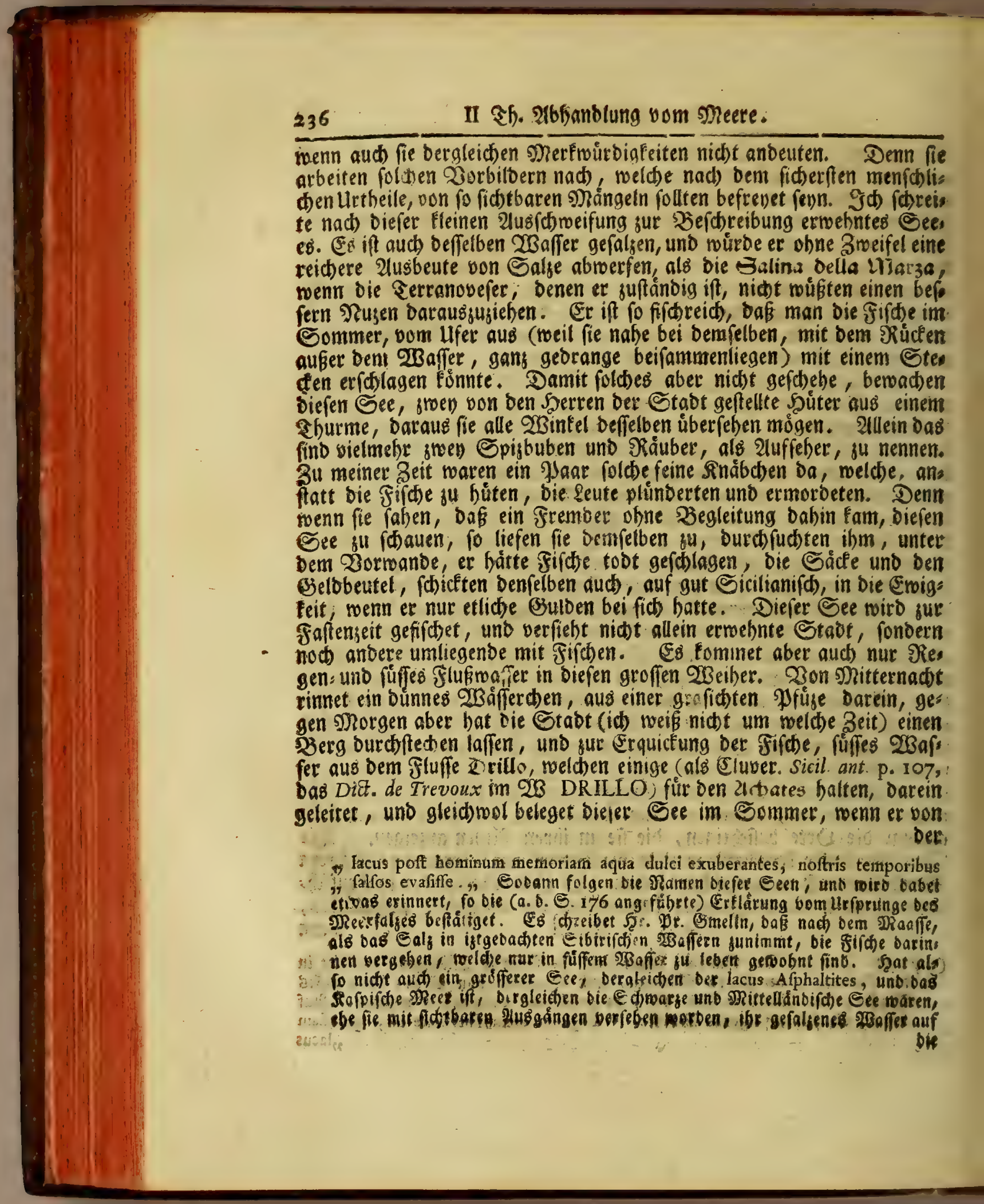


Det Sonnentige etwas eintreuget, fein ufer mit Salge (zzzz). Diefe Beifpiele erweifen, meines Eractens, fur (Sinuge, baß bie oritte 2us: legung, warum das 2 affer bes Jontus Eurinus, burd feinen beftón bigen 2lusflufi, niche berfuffer worde, feinesweges su bermerfen fev. Denn gefest, baf, nach beobachtetem (3leichmaffe, burd) ben \&uslauf

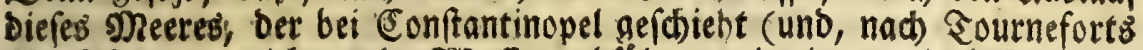
Derficherung, nidjt mebr. 2 affers abfübret, als ein gemeiner (Strom), poviel Saljes demielben entwendet werbe, als burd) daś Saljmact)en bei ber Salina della :7zarza von biefem fleinen See wegfommet: fo fann bod Das vielmal groffere \&ager Des ’ontus (Eurinus wieber foviel

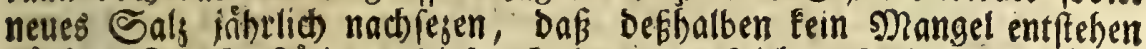
borfe. Zut Beftátigung biefer Neinung muß id nod cine merfwuro: ge Stelle aus Sourneforto Mornenl. Reifeteftr. anfuhren. Diefer Franjofe bebauptet aud, Daf bie (Euxinifde See burd) Saljlagen, bie in ifrem 2 ette ftecten, Das vermifte Sals wieber be: foimme. Dies Serftellung ber Bitterfeit fobreibet er einer andern Urfa: de zu. "Eg ift gewif (fpridt) er, Lettre XV, p. 65 B), Daß ber " Wontus Euxinus um ein Dieles leiolicher gefalsen ren, als bas " Waffer unferer meere. Uebrigens ftecten bie \&ander, welobe um ges bachtes Meer betumliegen, voll Eteinfalses, weld)es burd Deffen ", Waffer beftánoig aufgelófet wirb. Diefes Salz vermenget fich mit

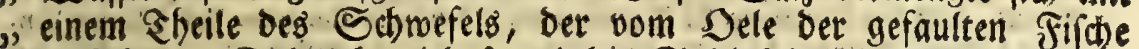
27. entftebet. Daburd) wird fowol die Saljigfeit diefes 2Baffers ges 2? (c)arfet, als aud oie zugleid beimobnenoe Sitterfeit Demfelben s. mitgetbeilet.,

Siemit befdlieffe ich meine 2 ettadtungen, bie ich uber bie (si, genfofaften bes. Seeres anjuftellen, mit vorgenommen batte. I\$ fdumeidbele mir zroar nidt, Daß ber Sefer geftehen wird, er babe font berlid) viele neue Entbectungen bier angetroffen. 2Bol aber wirb bem: felben eine fiemliche Anjabl bon Zeugniffen, ber alten uno neuern Sothif: (s) 3

fiele

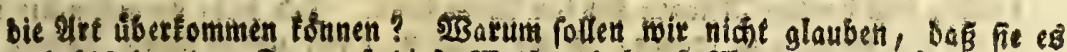

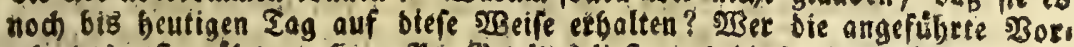

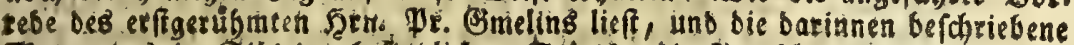
Denge beß in Eibirien befindichen Salges, bie Ingahl Der Salgbrunnen, und ber geralgenen Seen, erwåget, wirb leiajt ertennen, bas Sibirien, wenn

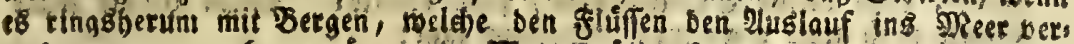

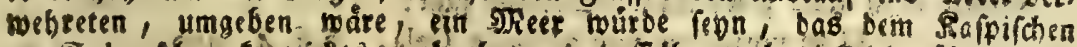

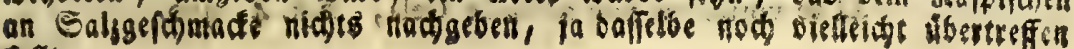
s): polte. 
fteller, vorgelommen fenn, Dawan id) einige ertlåre ober bertheidige, an,

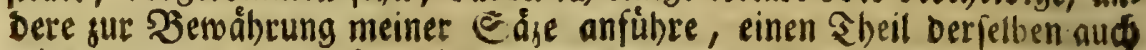
widerlege und verwerfe. Zeei vorfommender Sjelegenbeit unterließ i申 nid)t, aud Derbefferungen ben etlichen verberbten Etellen vorsus raflagen. Es mirb aber boffentlich Diefes von niemanden getadelt wer:

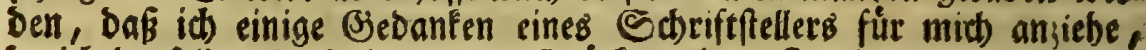
ba ich benfelben bod in andern Stúcten eines Srrtbumb bejdulbige:

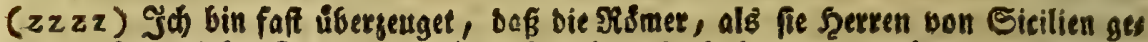
mefen, biefen Sze zum Salgmerfe gebraud)t baben, unb Daß er einer Derjenis gen jwen Eeen bõefte fenn, Derer Đlinius, XXXI, 7, 5aro. 39, mit diefen \$Bokten gedenfet: "Sal omnis aut fit, aut gignitur: utrumque pluribus mo2) dis, fed caufa gemina, coakto humore, aut ficcato. Siccatur in lacu Tro "rentino xeftivis folibus, totumque ftagnum in falem abit, modicum aliogiwin, 9, altitudine genua non exceders. Item in Sicilia in lacu, qui Cocanicus vó ") catur, et alio juxta Gelam. Horum extremitates tantum inarefcunt \&ce a

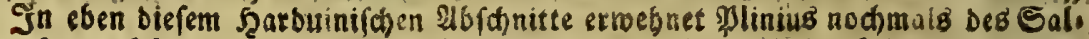
jeb, welळeb man auş bem lacu Cocanico erbielt:" "Adulteratur Siculo (Saie), quem Cocanicum appellavimus: nec non et Cyprio mire fimili." Das Gelifhe Salz befdreibet er, baß eb gleich einem Spiegel glänge, in bem $4 \mathrm{I}$ Şarbuinifhen 26f ()nitte: "Circa Gelam in eadem Sicilia tanti fplendoris,

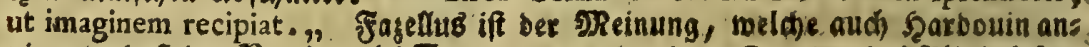
nimmt, baj dee Beviero di Cerranova, dee lacus Cosanicus bes \$liniug feg. Deb legteen $\mathfrak{B}_{0 \mathrm{rte}}$, bie als eime Inmertung, zur erften oben angefubrten Plinifhen Stelle, angebradt werben, lauten fo: "Stagnum Cocanicum haud procul oftio Dirilli amnis, latere Sicilize meridionali.," Fazellus Decad. I, 1. 5, c. 2, p. I19. Die De l'Ilipaje alte Randfarte von Eicilien, nense

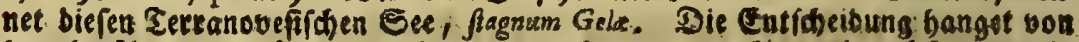
bet betifimten Exơterung $a b$, beren ober in bet 2tnmett. (dd) gesacht

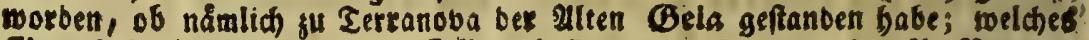
Cluberius, Sicil. ant. p. I05, Eellarius Geogr. ant. 1, 792, bet \$. Bincent. Coronelli in feiner Iorografia, $u$. a. m. befaupten mollen. Die פBerfaffer

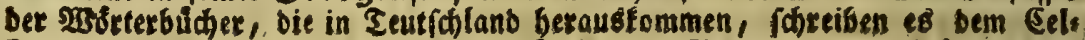
Iarius fo nach). Sgarbouin bagegen bâlt, in ber 2/nmert. gu ben $2 B$ órtern Ge-

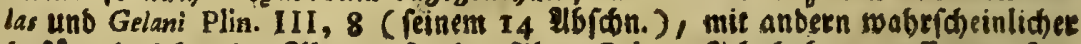

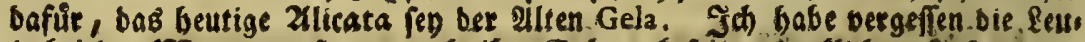
te bei bee marza fu fragen, ob ibe Salgroerf feit unbenflidoen Jabret ges trieben werbe. Denn to oferne es fo fid verbielte, fo gäbe biefes einen 2us:

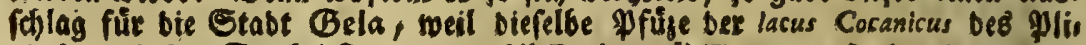
niub, unb bet See bei Ierranoba (il Beviero di Terranova) Det lacus juxte

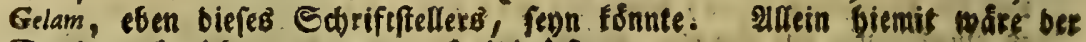
Etreif nod) nidit getwonnen: Doibius fagt:

Et te vorticibus non adeunde Gela, Eafi, 4,479 


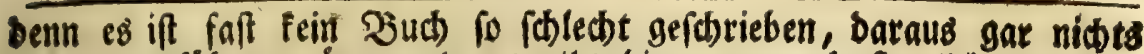

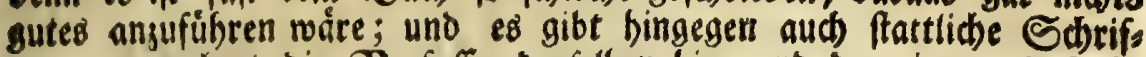
ten, ungeadstet Die $\mathcal{B}$ erfaffer Derfelben bier und ba seigen, baßj fie

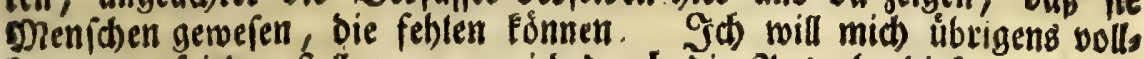
tommen zufrieben ftellen, wenn id Durd Die 2lusgabe biefer geringen

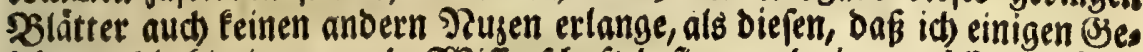

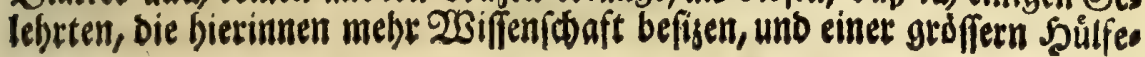

lein

Diepe Etelle fann auf Terranowa nidjt gefogen werben. Denn ber bort sors

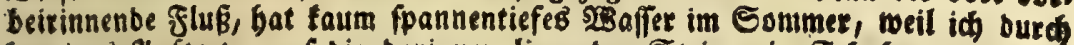
burtiges Iuftreten auf die darinnen liegenden Steine, in Sduben, obue bie Etrumpfe zu nezen, baruber fpringen fonnte. Die Doibifoen $\mathfrak{S B}_{\text {Borte reis }}$ men fid beffer auf ben gfluß bei Jlicara, fo einer ber groffen in Sicilien iff. Es bat aud Birgil, ba er am (Enbe bes III Bubes ber 2leneis, gefdrieben:

Immanisque Gela fluvii cognomine diaa,

Bas immanis obne 3meifel auf fluvius, unb nidit auf Gela, getidhtet; babet ich su ben f̧erten bon Illicata gefagt, baf man ibnen ben ఇirgil nid)t recht etflaret babe, toeil fie, um ibren 2Inipruch auf bie Stabt Gela sffentlich zu Debaupten, auf ibre gerid)tliden urfunben forne anjufezen pflegen: IMMANIS GELA, NVNC LEOCATA. SEemiffe, fomol auf ollicata,

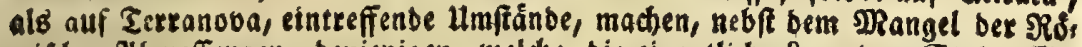
mijhen Mbmeffungen, benjenigen, weldhe bie eigentlidbe Rage ber Stabt Bes la aubforfiden wollen, ein arges Epiel. Bei Bela befand fidh ein flus. Sei Terranova unb bei Ellicata ift einer. Die Serranobefer bebaupten, bet

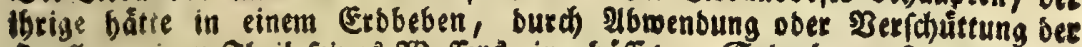
Quellen, einen Tbeil reines $\mathfrak{W a f f e r}$ eingebúffet. Bela lag auf einem Bet. ge. Die Epuren einet alten Stabt geigen fith auf einem $\mathfrak{B}$ exge bei glicate unb bei Terranova. Der Raum geftattet mir nicht, bie beiberfeits aufget bradten Ërúnbe bier alfe gu esgåblen. Eben fo ftreiten bie gelebrten Sicilias net um die Rage der Stoot Selinis. 3mev Derter, Majara und $\mathcal{C}_{a f t e l}$ Deterano, santen fich Darum. Die Hrfache biefer Ungenifibeit rübret bas bet, weil oie alten Etåbte ber mittågigen Ruffte von Sicilien, vorlångft find

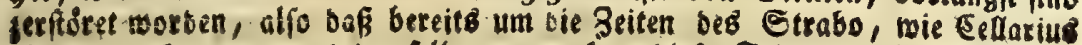
Geogr, ant. 1, 793, aus bemfelben anmerfet, biefe Seite gebacbter Infel ro

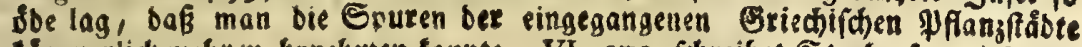
fummerlich mebr nonebmen fonnte. VI, 272, fabribet Strabo fo: "E re" liquis Sicilire lateribus id, quod a Pachyno ad Lilybæum pertinet, prorfus "defertum eft. Veftigia duntaxat antiquorum quæedam oppidorum reftant: \% ut fuit Camarina Syracufanorum colonia. Agtigentum Jonica colonia, et " navale ejus, ac Lilybxum adhuc fuperfunt; alioqui cun hoc Siciliz latus n maxime Carthaginenfium ditioni effet objectum, longis as continentibus bel") lis pleræque urbes ejus funt deletæ." 
leiftung fic rufbnen fömen, als ich, sinlas gebe, sen bier vorgetras genen Sachen ferner nach)fuforfitien. Sa es foll mid nidt verorieflen, wenn jemanto etwas ober alles toiberlegen miro, wenn wir mur lein eitles

Sejånte, folloern 2lusfinourgen bon núglidern ober gewiffern 2 abrbeiten, daraus su gewar:

ten baben.

\section{igaben.}

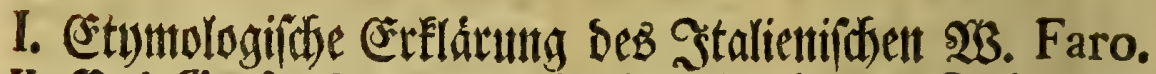
II. DeE Grafen Marfilii, und eines iztlebenden Raiferlicten

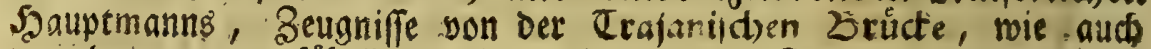
bon Den fivey gefábrlid)en Drten ber untern Donau, Jadtali uno Denireapi, wodurd) Derfelben, in Det Inmertung (ffff) vor: getragene, Ḋefdreibung erláutert uno beftåtiget toiro. III. Erinnerung von Studenis.

I.

ie meetenge zwifden bem beutigen Salabrien uns Sicilien fobeinet ifren 2 ålichen Pamen, Faro di Meflina, wan eirem am Juffe bes Jorgebirges Welorus ftebenden Shurme su buben, welder Stal. Faro (pharus) beipt. Dort if Ralabrien oon Sicilien nicht gar Dren 2Bälfche Meilen entfernt, wie in ber sumerfung (c) S. 53 oiefer 2 b. banolung, gemeldet worben; baher fefreibet Dirgil, ber in Det 2uss bructung Der Ratur ein Neifter gewefen, ganj red):

Ecce autem boreas ANGIST $A$ a sede Pelori

Miffus adeft. Aen. 3, 687.

Suf biefem Shurme wirb bes গRad)ts in einer saterne sidt angeftect, Damit bie Scbiffe im Finftern Den Fingang ber Mgeerenge treffen, und bem noch igt gefábrlicien Orte Scylla, nach beffen Steintwánden uno Silippen Das sineer, aus oben angeregter Urjacbe, ziehen mus, entgehen formen. Scylla, weldser शrame nod in ber beutigen Stabt und Feftung Sciglio erbalten wiro, liegt Dem Faro gegenubet in Calabrien, und als fo zu 2Infange ber Mneetenge, nid)t mitten in berfelben, wie in Sorn.

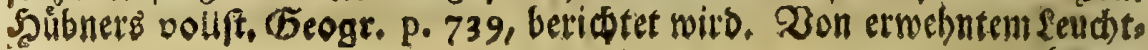




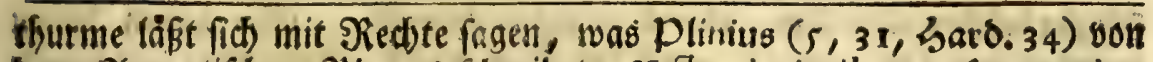

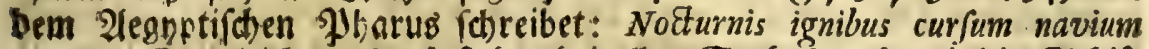
regens. Dergleidhen phari ftehen bei allen Seehafen, bamit bie Sdjifs

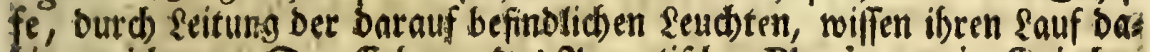
bin zu ridten. Der Erbauer bes 2legyptifhen Phari war ein (Sriec)e,

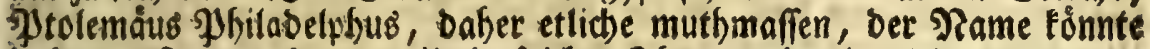

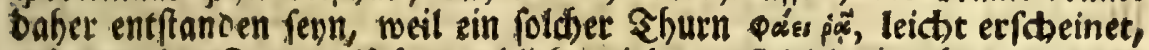

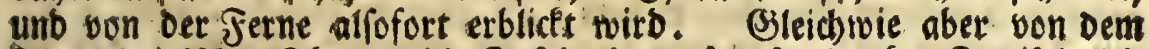
2leranorinifhen Shurme bie Infel, Darauf er ftunb, ofne Zweifel gleis Wen Ramen überfommen bat, fo fd einet ex, als wenn von bem Sicilianis

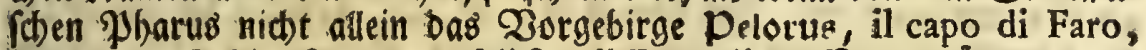
ronbern aud bie sheerenge felbft, il Faro di Meffina, wåre genannt worben. Solches aber foll obne Nactstheil berienigen nidbt minbet.

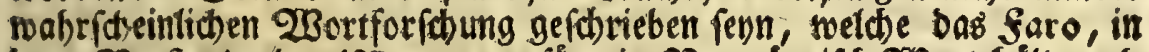

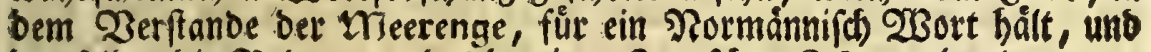

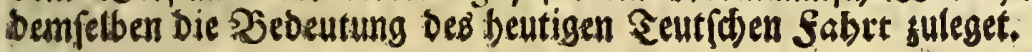

\section{II.}

(6) Bis eben ber Druce biefes WerEd)ens zu Enbe gieng, finb mir swev

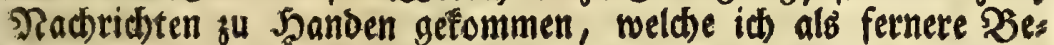

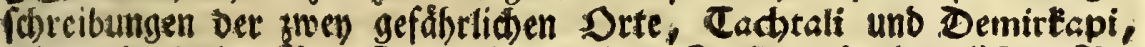
mie aud) als bewabtrte Beugniffe von ber Stelle und eigentlicten $\mathfrak{B}$ es,

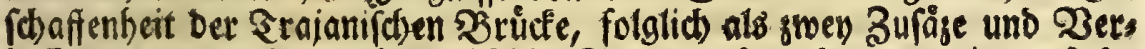
befferungen zur 2inmerfung ffff (S.204 u.f.), bem geneigten Eefer

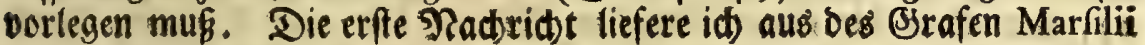
groffem Werfe von bet Donau. Sd) habe S.209, in istgebadtet 2nmerfung I) geidrieben, baß́ Setiflan in ber Serben unb Săsen

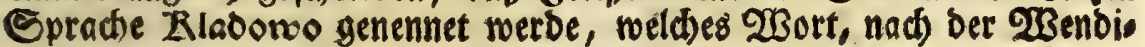
(c)en Munbarf, einen bammer bebeutet. S) Sarfilius unteridbeibet Flaborwo von Setiflan. Er eignet ben erften Namen, welden ex

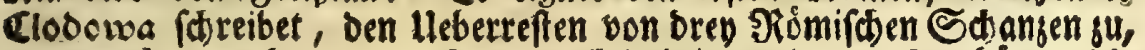
Topograph. Danub. p. 22. Den gleich Dabei angelegten Drt bátten bie Burten Setiflan (a) genennet. 2) 2(n eben biefer Stelle batte in

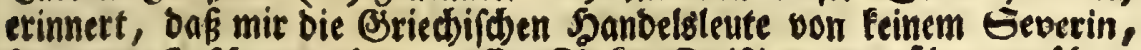
fo unter Drfasowa, bem groffen flecten Setiflan gegenüber, auf bem S马 gsals

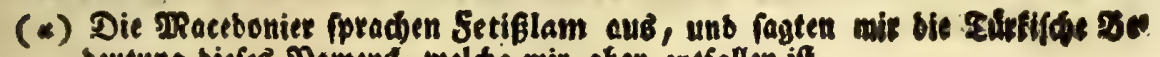
beutung biefer Rramend, welde mir aber entfallen if. 
2ablachifhen ufer låge, etwas gu fagen gewuft. Sie baben leinen fo genannten Srt gefeben, aud bei ibrer sftern Worbeireife, in befags ter (Segend Diefen Mamen nidjt geforet. Mraritius bericbtet, Tom. II, p. 22, Das Seberin eine Stătte fen, wo man abermal Spuren bon brey Sómi then Sdanzen fieht, mit bergleidten 2Berfen, bie er auf feiner Eanofarte bon bem untern Strid)e ber Donau anjeiget, beide ufer biefes Stroms didte befest waren. Daf Seberin ein alter Drt gewe en, betwáhret Marfitius in bem I Sh. Oder in Topogr. Danub. p. 22,

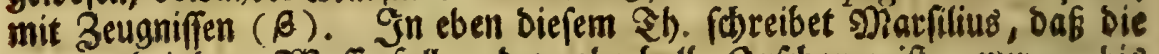
Donau bei Dem 2 afferfalle, ber sberbalb Drichona ift, nur 30 bis?

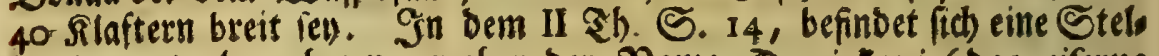
le, Daraus abjunefmen, woher der Name Demirtapi (oas eiferne Cbor) Eonnte feinen Hriprung baben. Die Sage gebet allda, fpriøt Nharfitius, wie id es yon alten feuten erfabren habe, dás vorseiten biefer enge pas mit einer eifernen Sette (ober vielleidjt mit einem Bits tertbore, wie die Aetín zu Zerona, und mefr Fluffe anderer Srten) gefperret gewejen. 30 oer 25 S. an befhreibet er bie Heberrefte ber

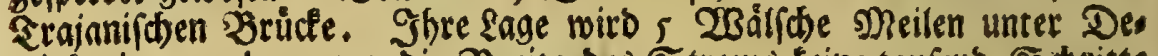
mirfapi angegeben, wo Die Breite bes Stroms feine taufeno Sdritte betrage. Shieraus erfellet bie Nichtigfeit besjenigen $23 a h n 8$, oa eimge bebaupten wollen, biefe 3 rúcfe fer beinabe 4000 Sd)ritte ober faft eine ₹eutiche SReile lang getwefen. Er rebet nur von zmen gemauerten Sodjen ober Yyfeilern, bie an beiben Ufern nod) ftünoen, allein bei nieorigem und flaren $23 a f f e r$ finnte man bie úbrigen in Strome auth fehen. 2tus dem 2ibftande der jwey erften, weld)er $17 \frac{1}{3}$ Silafter aus. madt, foblieffet Marfilius, wieviel berer múffen gewefen ievn, nàmlid 23, woraus er bie ganje \&ánge ber $\mathfrak{B}$ ríle von 443 Rlaftern, burd bie 'Berectinung, betausbringet. Er verfichert, Das bas Bemáner ber Dfeiler aus gemeinen Baufteinen beftunde, weld)es aber aufenber mit \$Bacffteinen ober Ziegeln (nid)t mit Quaberfúcten) wáre überfleibet ges wejen. 24us bren, an jebem Yfeiler angebradten, Reihen ter Defnume gen ober \&ơder, urtbeitet פNarfilius, Daß̧ bie 22 Bogen, famt bem

( $\beta$ ) MSEVERIN, Ortelius habet Severianum. De hoc Bonfin. 1, 1, dec. I: 9. Ad pontem Trajanum in ulteriori parte Danubii, Sevexinum eft oppi. " dum, a Severo Imperatore conditum. Item dec, 2, 1. 10: Tunc "Ludovicus rex, ut Valachis tutius imperaret, Severinum oppidum, " a Severo olim Imperatore edificatum, ac vetuftate collapfum, in: "Sauravit."n 
ganjen Dbertbeile ber $\mathfrak{B}$ rúde, aub eidenem Solge mügten fenn berferti-

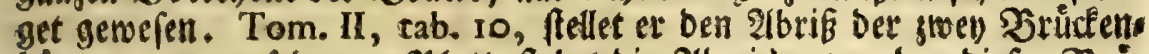

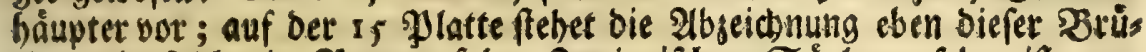
ae, wie foldbe in Siom auf ber Srajanifhen Saule ful feben ift, two bas obere 2 Betf aud als follzern angezeiget wirb.

2Benn aber biefes gegrunbet ift, barm nidt gu groeifeln, fo etgibt fich faft eine neue Unridstigfeit in ben Belkniffen oer Alten, welde uns bon biefer Bricfe hinterlafen worben. Denn es fonnte jemand fagen, auf foldhe 2lrt beftunden ja bie in befagter anmerf. ( ffff) S. 208,

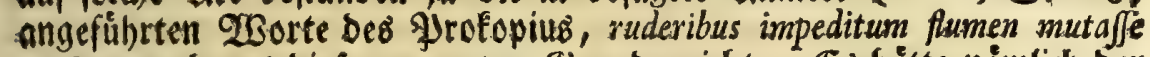
curfum, aud aus biefem swenten (Sirunbe nicht. (Gs båtte námlich bet R. Sabrian, wenn Das Dbertbeil ber Bructe wäre bolgern gewefen,

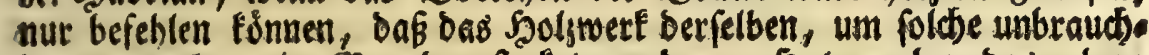
bat ju maden, in Brano geftectet nerbe. Sat er aber Das obere Sebaube burd Simmerleute abtragen Infen, fo ift es als Birennbols verbraud)t worben, ober bat man ia bie Stucle (vielleicht gur $\mathfrak{B}$ es foleunigung, bei einer andringenden (Sefahr) nur ins $2 B a f f e r$ getwors fen, fo fino fie babongefotocmmen, uno baben ben Strom aus feinet breiten Bettung nidt binausteeiben fónmen. Sक febe aber boch ein

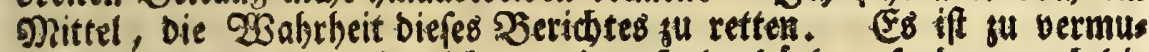
tben, $\Re$. Sabrian twerbe nicht nur bas Solzgebáube, fonbern auch bie im Strome fiebenden $Y$ feiler bem 23 affer gleid baben abroerfen laffen. 2llein biet fonnen wir eine andere mertwurbige $\mathfrak{B}$ eobachtung machelt,

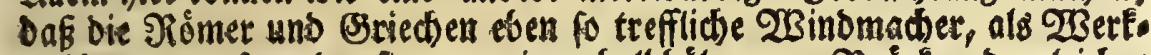

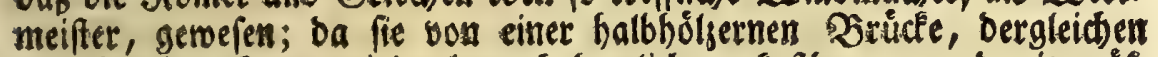
nod beuriges rages viele, ia nod berrlidsere, foftbarere, und mit grofs ferer Befdwerlicheit, gebauet werben, ein fo großs (Gefichen, als von

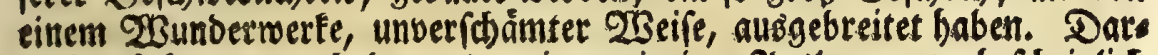

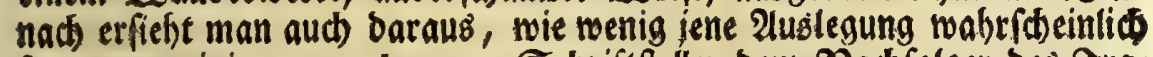
fet, wenn cinige, zumal neuere Sd)riftfeller, bem slad)folger beb ₹ras ianus biefe शriebertrádbtigfeit anbidren twollen, er habe aub̉ Rleinmuth,

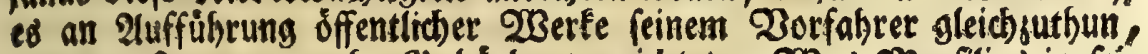

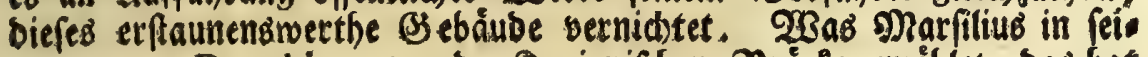

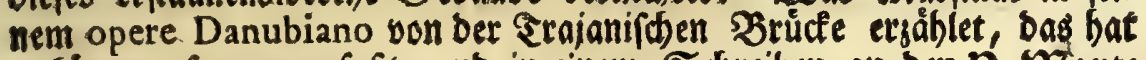
er Eúrjer zufammengefaft, unb in einem Sdreiben an ben $p$. ITtonte faucon vorgetragen, welć)es in Thef. Antiqu. Roman. Sallengr. Tom. II (ber Denebifden 2ufl. S.990) ftebet. Sn Demielben wirb erftich gemeloet, Dafi bie tweo llfer Der Enge Demirtapi fo nabe beifammen funben, Daf sin श्रenich bou cinem Ranbe auf bas andere fónne tobe कb 2

sefooflen 


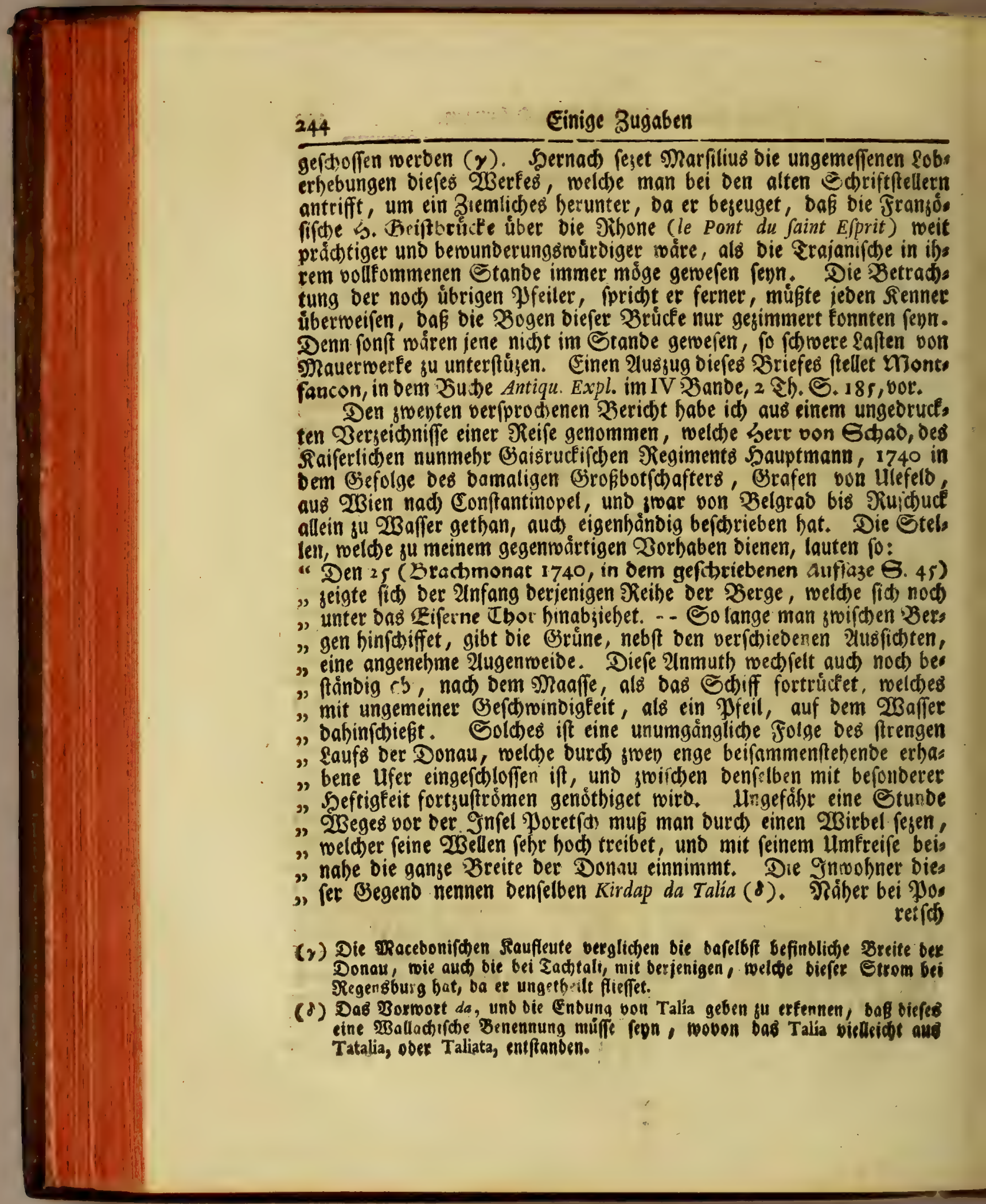




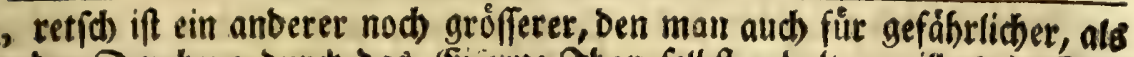
Den Durdjug Durd, bas Elierne Shor felbft, balten will. (s) Daв "ift ein Sgerumorelfung beg 2Baffers, bie blok burd bie Befchaffens beit ber swey Ufer berurfactset wird. Denn bon bem Servifden et: frecfet fich ein bober Felo weit in Den Strom binein, an deffen Spije die ₹eutfothen ein bofljernes Rreus aufgeftellet baben, po nods , vorbanoen ift. Das $23 a f f e r$ lauft an biefen unbeweglichent Giegens ftano mit aller Gervait, uno mit foldem (Setófe an, Dak man bafo felbe lange borber vernimmt, ehe ber Srt gejefen wirb. Won bies , Fer vorragenden Steinwand prallet der Strom zurúcfe, und wirs Tehs ungettumig an bie Telien bes gegenúberftebenden 2 Ballachifhen "Llfers angetrieben, weld)es fdbiefe uno unordentlid)e Stromen gleid ", unter Dem $23 a$ afferfalle, und nodh weiter unten, groffe $23 a$ allungen " uno 23 irbel erreget, allo bas ein Sdiff, to bie gerade Straffe vers "feflet, Daburds umgefturzt und verfenfet wirs. Shinter ber iftbef(d)ries benen Ecte, weldbe bie Schiffe gang nabe beftreichen muiffen, breitet , fich Die כettung Der Donau in eine geråumige Bucbte aus, Darins tten bas 23 affer mieber anfángt gemadjam fortuffieffen. In bie.

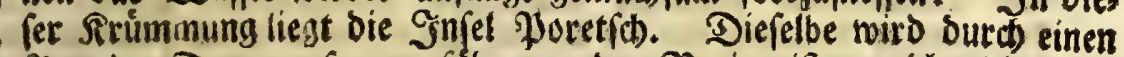
21rm Der Donau, to ungefábr von ber Breite ift, reldbe die Sau , bei Betgrab bat, (ober fo weit ein farfer frlintenídub reidet) von "Dem Servifchen ufer abgefondert.",

2uf Der 49 S. gebet bie Befareibung von Demirtapi, ober bon Dem Eifernen Ebore, nit bieien $230 r t e n$ an:

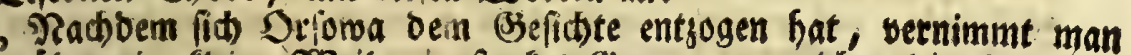
" über eine fleine $\mathfrak{B}$ eile ein ftarfes Semurre, welches bie Sthiffen. "Den von ferne in Sorecfen fezt, unb Daher entftehet, weil bie Donau

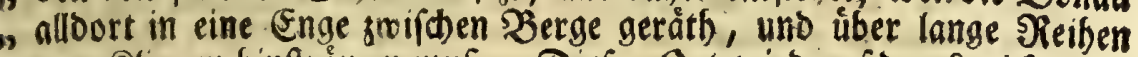
, von Rlippen hinftromen mußs. Diejer Drt wiro auf Den fanbearten, , Cataraete Danubii, inzgemein aber oas eiferne Tbor genannt. Bur - Felbigen Zeit war bas 23 affer fo boch, baß es alle Spizen ber Fels "Ren beclte, welde bod fonft bis zwey sannslången aus bem Stroe. " me bervorragen. Der Steuermann muf fein. Sabrgeug mit groffer Shb 3

(B):

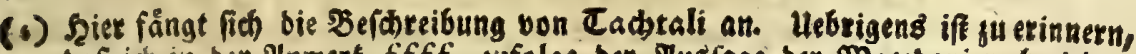
baß id in ber Anmert. ff ff, zufolge ber Musfage ber $\mathfrak{M R a c e b o n i e r , ~ b e r i d ) t e t ~}$

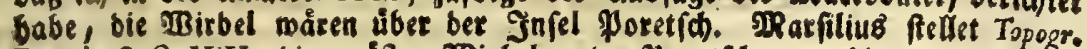
Danub. Sea. XIV, bie gróften TrBirbel unter \$oretín, um bie zmen Infeln,

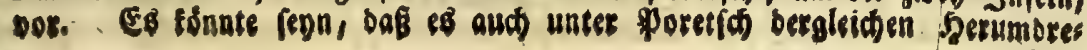
buns. 


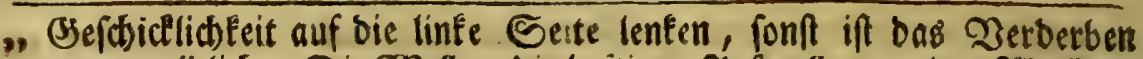
" unvermeiolid). Die 2 Bellen, Die beftigen 2iufwallungen bes 23 afferb, " Die 23irbel, fo burch bie Bjewalt bes vielfáltiglich gebrodsenen Stros ". mes erreget werben, \{d)mingen und werfen bas Scbiff bin uno her, auf ") und nieber, als wenn es auf ber ftúrmenden weiten See mit ben Flutben

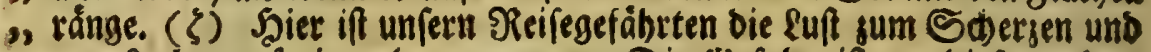
2) sum \&ad)en auf einmal vergangen. Die Befabr ift an biefem Srte ". Dod groffier, wenn bie Sdiffe aufwerts, ober gegent ben Strom, " fabren; weil pold)es nur Durd) Seibúlfe ber Segel gefकehen Eann. "Diefes hat aud 1737 unfere Sdiffhauptleute babin gebrad)t, Daj "Diefelber ibre Friegsichiffe, auf Denen fie to lange wider Den Jeind ") fí gewebret, alloa verjenten musten, weil fie aus sRangel bes 23im

Gungen bes $23 a$ affets gebe, fo oft nåml ther Strom, an tiefen Orteth, eineth barten Segenftand finbet, woburd fein geraber lauf gebeochen roirb, meldes

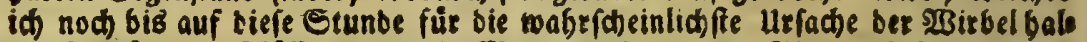
te, fie mógen in fluffen, ober in MReeren fid) zeigen. 2llkein id bin, bei mei nem Durchblättern ermegnter Marfilif̣en Sopograpbie, getwabe noro

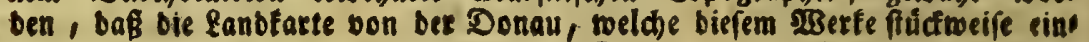
verleibt ift, nidt eben bie ridtigfte fen). Diefer gelebrte Sraf wiro fie ourd feine untergebenen İngenieurs baben feichnen laffen, bon benen aber nidht alles mit gebúbrenbem fleiß̈e vollbradt worben. Eo weiß id mich gu exin. nern, baË \&. E. auf einem Etude berfelben, baz fleine 2 Baffer, fo bei bem groffen

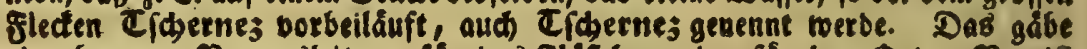

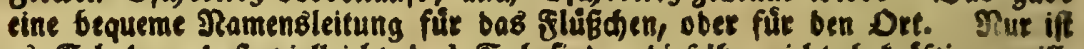
es Edabe, baß̧ vielleidjt bas Sobefinden biefelbe nidht befraftigen mill.

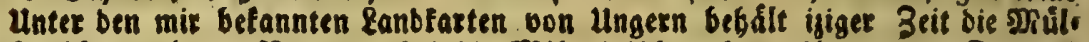

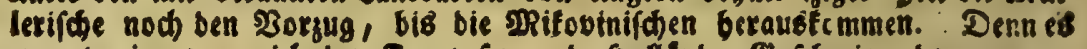
grauet mix, toenn id bet granfofen unb frobanber Eefdjmiere bagegen ans

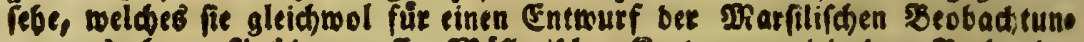

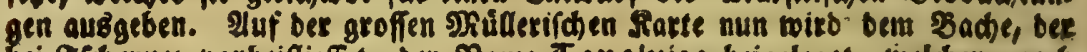
bei Ijocenes vorbeifieffet, Der Rame Copolnija beigeleget, welder, nad oes $23 e n b i f h e n$ IRunbart, wie Xe(penbad), lautet. Id babe bei meinet fứctigen Sefidtigung ber IRRarfilifonen Sopographie ber Donau, aud Epus

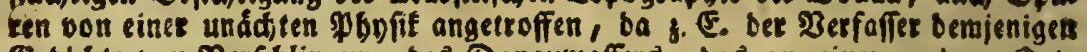
Gebla)te von $B$ erf́hlingung bes Donaumaffers, Das an einem anbern Drte

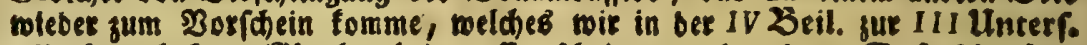
miberleget baben, Glauben beizumeffen (h)einet, unb a. 0. 84 S. To fhreibet: "Inter alios (vortices) famofus itie eft, qui afpicitur-fub Lincio. Creditur "vulgo origo effe lacus Neufidel in Hungaria Cis-Rahabanti. Afpicitur etiam " alter, fed hoc minor, prope pagum Almas, infra Comnsaromium; qui per" hibetur effe origo lacus Balaton, pofiti in Hungaria Cis - Dravana inter non" ", tes," Die beige(ejte Rilberung, creditur (perbibetur) vulgo origo effe, 
Winbes nicht weiter aufwerts fegeln fonnten. Es ift wabr, baj roit forvol als bie ₹urfen, einige Stute bes groben Sefhúges an bies - fem Orte bernach wieber aufgebracht baben; allein diefes ift unges "grunbet, baj Der Feino eines ber alloort Derienten Rriegsidhiffe gans " aus bem 2 Baffer gezogen, welches man fobann fu 2 Bibin mieber aus. geriftet gefeben babe. Das if eine unwabrbeit, welcbe bamals "burd bie Beitungsfobreiber fo in Der 2 Belt ausgebreitet morben." Sier erimnert ber $5 r$. Zierfaffer, Daf er biefe Enge abgejeichnet babe, gleidwie aud Drfowa (n), und fábrt (ङ. so) fernet fo fort:

-3ur Beit, Da wir Serren vom Sande waren, fielten die Bauern an "Diefem Drte Pferbe in Sereitfđaft, jum Dienfte Derjenigen, wela)e "befagte (3efabr zu vermeiben, lieber ourd einen Lmmeg die Sieife zu isane

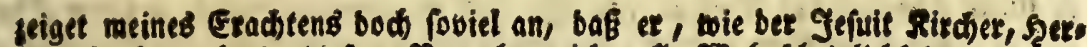

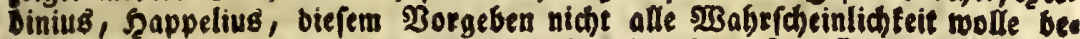
nommen baben, weldhes aber nod ein milbet Strtbum ift. Denn bie sobibers

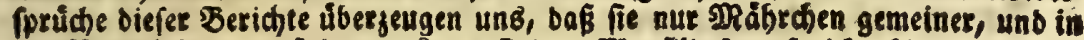
Der Naturlebre unerfabrnes, feute finb. NRarfilius berfpridgt biebon cine efo nene Nobanblung, bie id aber nidbe gefehen babe.

(3) Det Setr f̧auptmann verficherte midh auf meine. Infrage; baß bei Demirtapi bie Donau úber feinen mirtliden felfid)ten fid)tbaren Mbbang fid fturge, wie bei Sachtali; allein ber Rame Cataracta fónnte biefem engen \$affe ooch ges

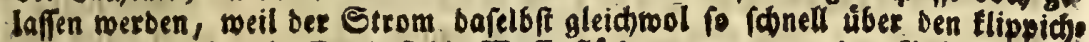

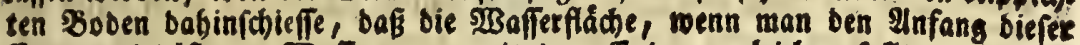
Enge, mittelfit ber $2 B$ affermage, mit Dem Enbe bergleichen follte, oberbalb

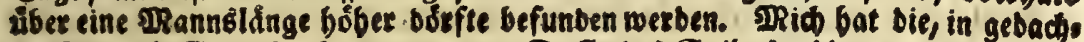
tes Inmert. S. 206, oben angezogene Etelle bes Suibas, bie von einem છerge rebet, ber fid burch bie ganje Sreite ber Donals. (quam latus is [Ifter] eft) quer Ginuberziebe, anfangs auf ben Cebanten gebracht, baÉ biefelbe auf Sachtali abjiele, weil allba ein mirtlider felfichter $26 f_{a g}$, melder burd ben baruber fohieffenben 2 Bafferfall merflich mirb, über bie ganfe Donau fich Gine iberftectet. MUlein Die Errodgung ber folgenden $230 r t e$, bof ber Strom at

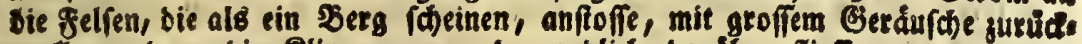
pralle, uno um bie Rlippen murrenb, endlid baruber flieffe, tooburd ein

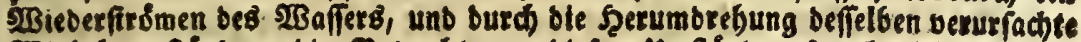

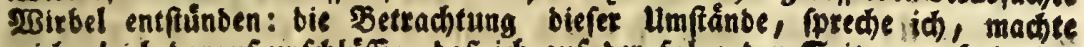

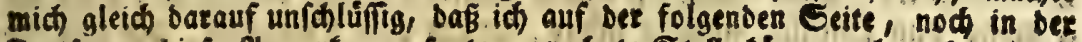
Sortfejung biefer Inmerfung, fagte, etwebnte Stelle fsnme auth nod auf bas Eiferne zbor aubgebeutet werben; nut fab i申 biefes babei ein, baß bie ßeer gleidung ber Dernirtapifden Slippen mit einem \$Eerge, fobann nicht allyu nabebaft fabeine

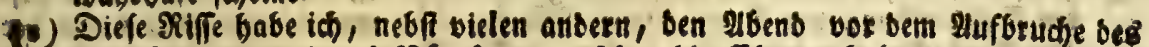

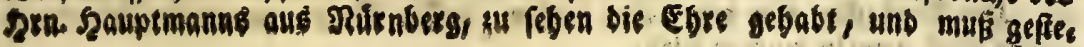




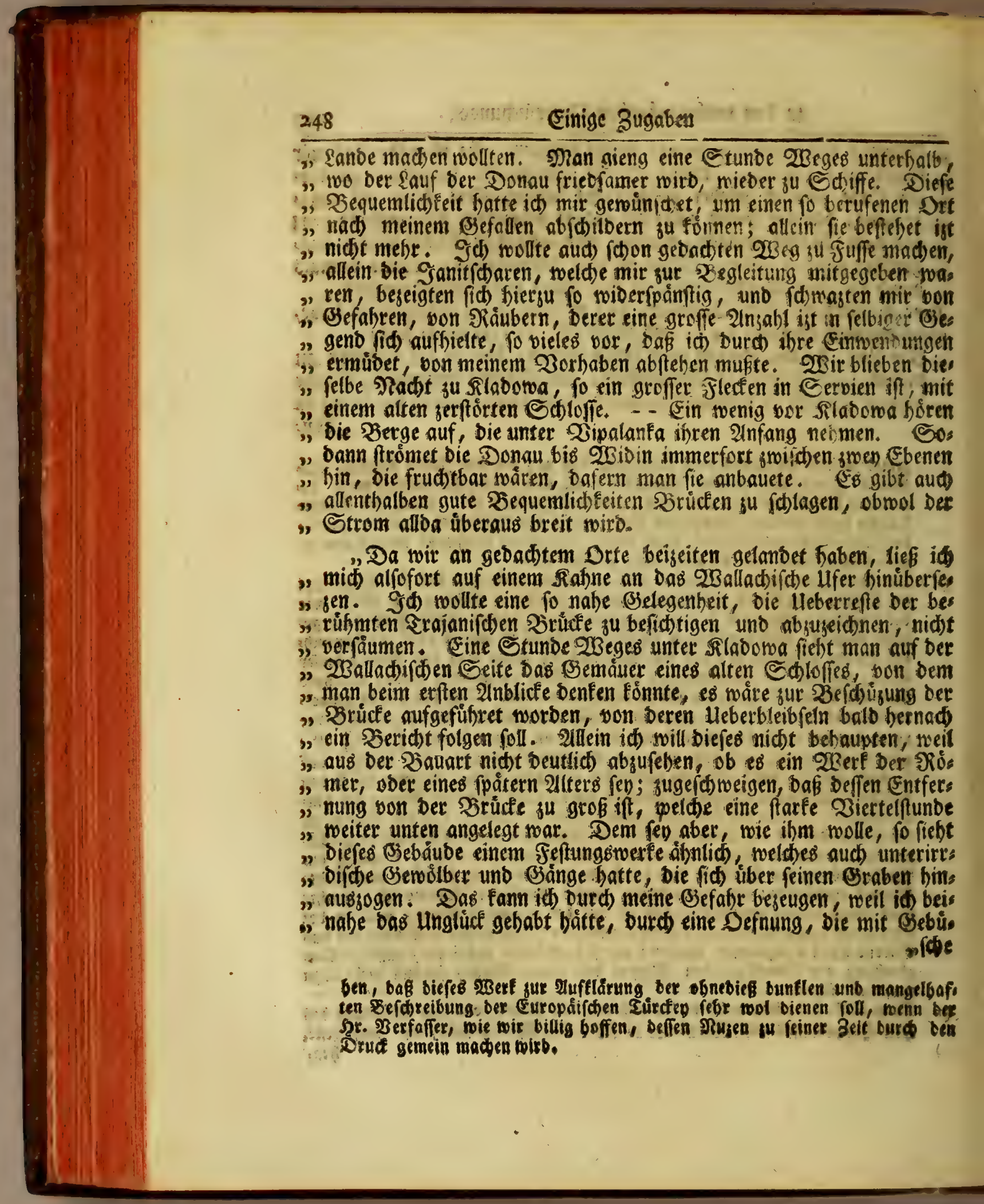




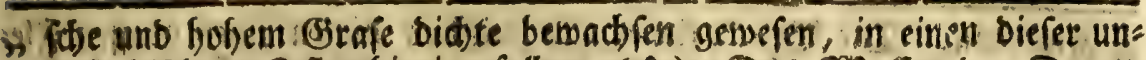

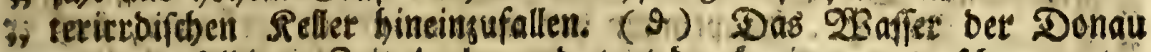
7. mar sur felbigen Zeit bodb, uno trat burd einen auagefdwetrinten

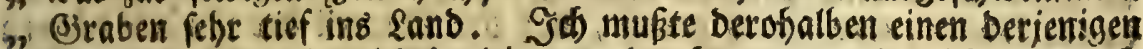
"Ganit(d)aren, Die mich begleiteten, Durdjwaten, uns mids, mie auch

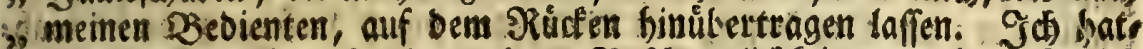

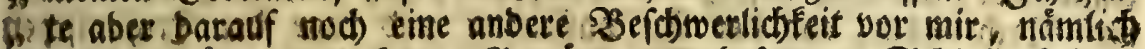
"auf bie Şobe, barauf bas Gieméuser von befagtem Scbloffe ftebet.

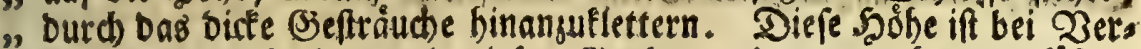
"fertigung bes breiten und tiefen (Brabens, Den man ferumgefúbret

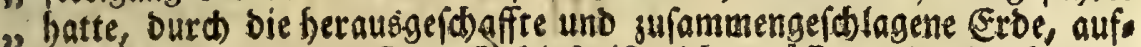

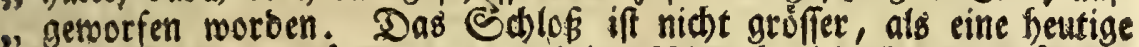

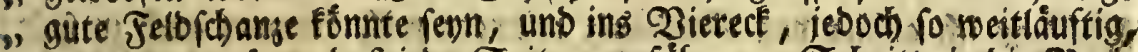
"- gebauet gewejen, baß jebe Seite ungefófre 100 Sdritte in bie 23rets "te módbe gebabt baben. Stus ben nod ftelenden Sheilen ber 2 Bär. "be ift abjunelymen, Dafí es ein Shurm von methr Stoctwerfen getwes " Fen, Derer serwólber aber ju Stúcten jerfallen fino (1). Das úbri "se ift unfennbar.

Eine Diertelfunde nun weiter unferwerts trifft man ben erften " Wfeiler Der Bructe an. Man fieft berer nod mebrere in einer Fieis " be hin, "wenn bas 23 affer ber Donau diefelben nidte bectet, wie bas " mals. Thl fonnte feinen anbern beobahten, als ben lejten, bet "gegenuber, auf bem recten oder Servifhen ufer, ganz auber bent

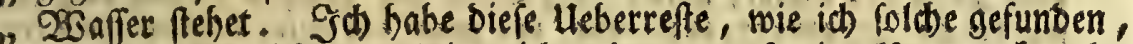
" in. Eile abgeseidnet, allein nidbt obne mandserley Ungenach, ba " mir forool bie Sommerbige, alo bie um mid) farmármenden ftébens

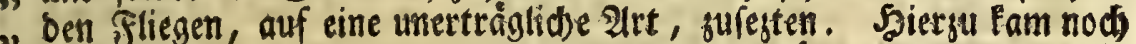

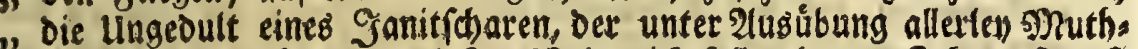

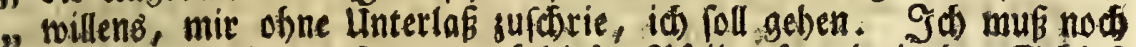

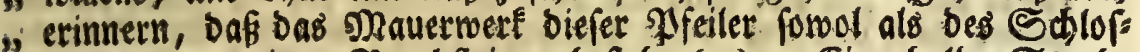
") fes, aus gemeinen Sorudffeinen beftehe (x). Eine halbe Stunbe * beffer unten, atlein etwas abjeits von Der Donau, liegt auf ber $23 a$ alo

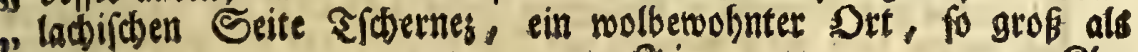
Si Pla

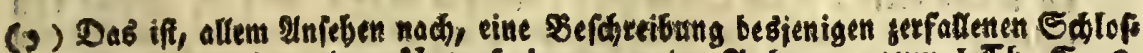

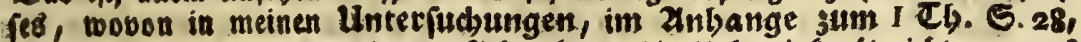
cine s)eloung getban worben. Tht erfenne bie Uebereineunft nidhe nuk aus

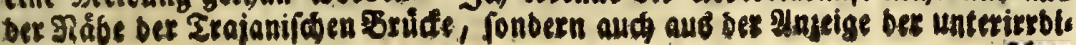




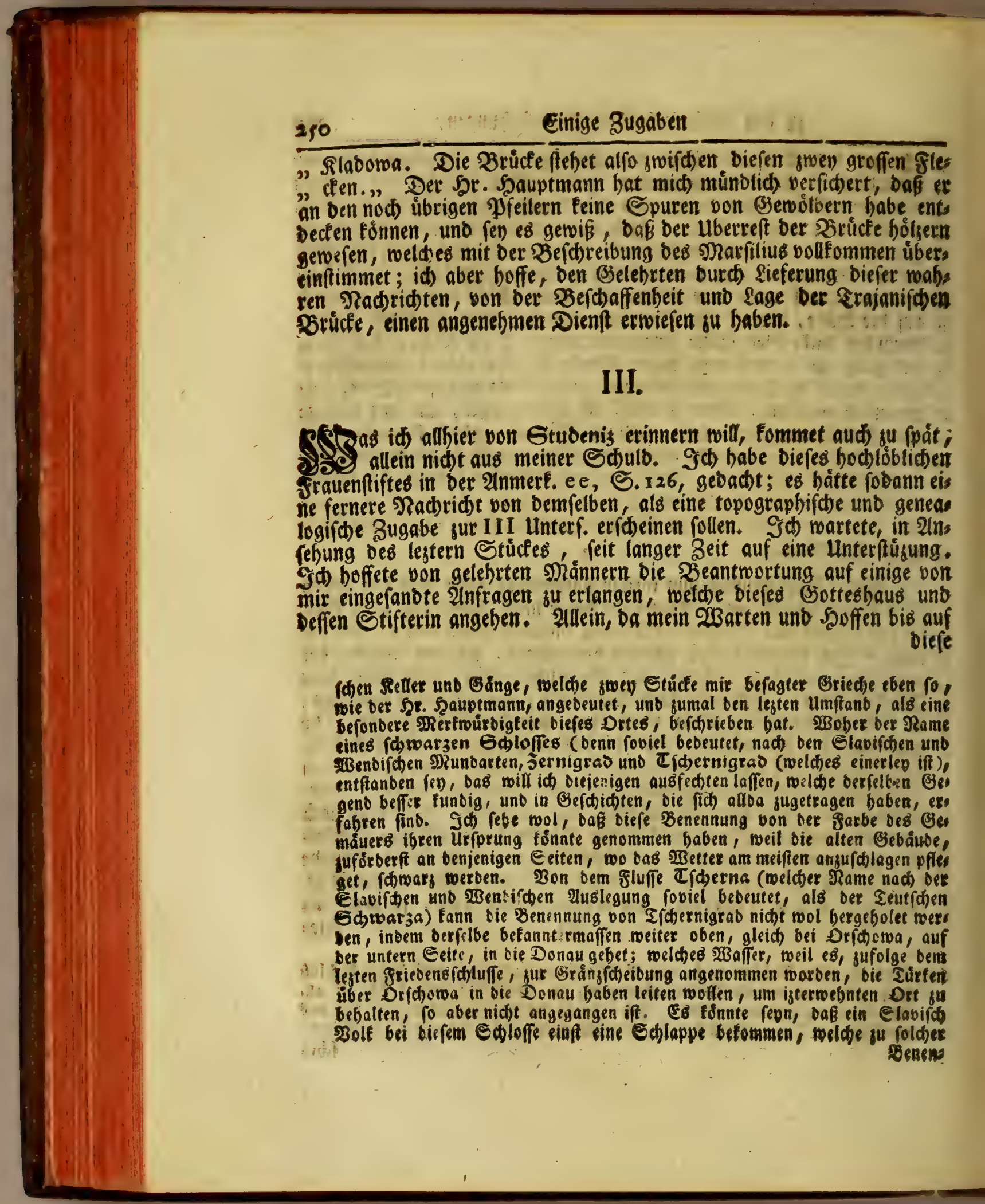


Diefe Stunbe veraeblich sewefen, fo muf id mit meinem trocfnen uns unoollommenen Berichte betoorrucien, nur Damit anbere (Sstebrten baraus 2Inla ju vermebren. Sie werben barinnen 2ufgaben fu genealogifwen Hebungen antreffen. (Es bringet mid) aber, nebft bem istgebadten, nod ein jwepfacter Antrieb gu bem Entfdiffe, von Stubenis bod lieber etwas in fohreiben, fo gut id fonnte, als bavon gar ftillsufd) weigen.

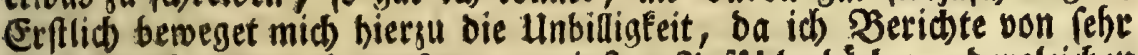
geringen Dertern, in unfere gemeinften 2uffolagbüder, bergleident bas 3eitungs : Lexicon ift, eingetragen finbe; wo bingegen biefes in bet Rieberftenermarf, infonberbeit aber in bem 2 Binbifdien sanbe, fo bes rübmte Stift, ben Selebrten fo wenig befannt ift, baß (Martinieres Dict. geogr. gu gef

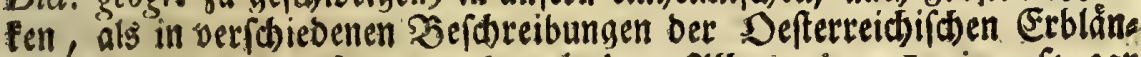
ber, in bem suftoriftben Lexico, in Dem 24 gemeinen Lexico, fo gat fein Rrane nidt ftebet. Eben biefes bat ein vornefmer (Selebrter, eis ner ber groffen ijt in seutioblano lebenben, weldsen id unlángft um ei. nen Beitrag zur abbanblung von. Stubenit, múnbliक und foriftlich

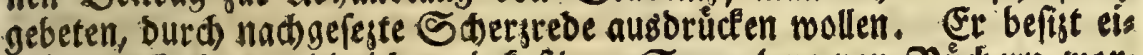

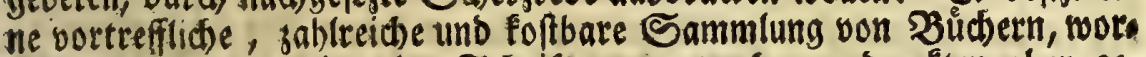
unter aud ungebructe alte Shriften, unter ben gebrucften aber gea

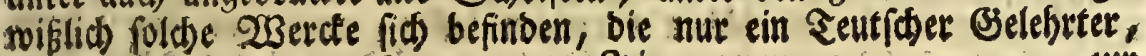
of $\mathbf{i} 2$

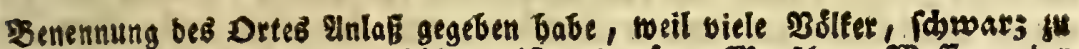
nennen gewobnt finb, was fhlimm iff, es mogen Menichen, 3 affer, ober Derter feun. Die Túrten fprechen fo. Es wat aber biefe Rebant aud) bet

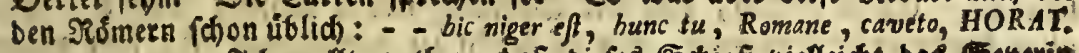

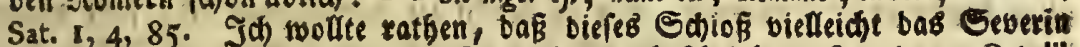

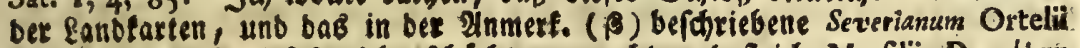

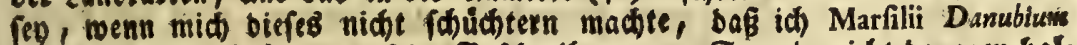
nid't yur Şanb babe, uno feine Bef́dreibung bon Seberin nid)t bagegen bale ten fann. Eo vill weib id) midh 34 eximnern, dak in Danub. Tom. II, p. I9. (welches id allein bei meiner eilfertigen Durdblätterung aufgegeidnet babes)

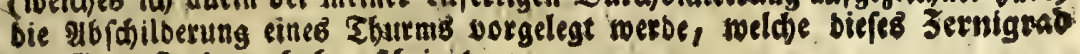
fum Esegenftande ju baben fळeinet.

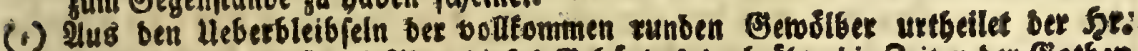

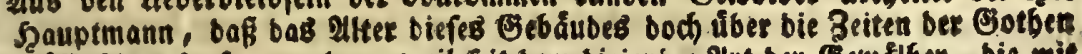
múfe binaudgefeft werben, weil feit bem biejenige Hrt ber Ëew\&lber, bie mit einem fogenannten Gfelerúcten gebroden fins, unb von bem istgebadten. Bolfe bie Gotbifchen beifen, in bie saufunft eingeffifert topeben.

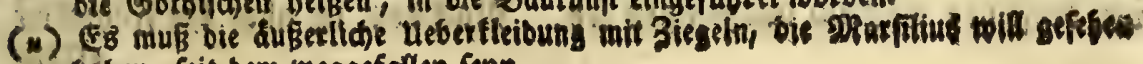
baben, frit bem weggefallen feph. 


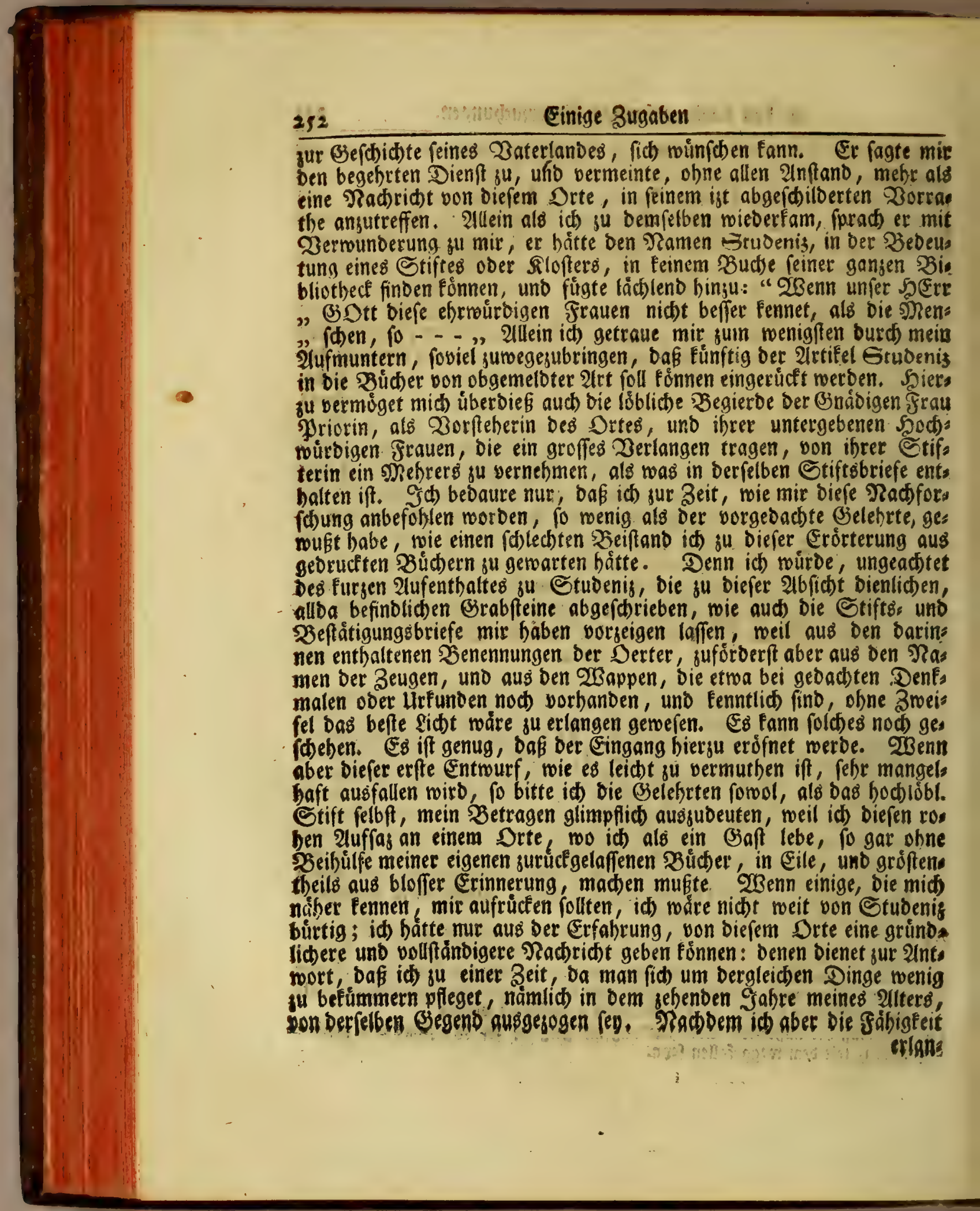




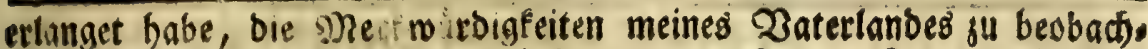
ten, nufsuzeidonen, uno aniern betannt gu maden, geftattete mir mein

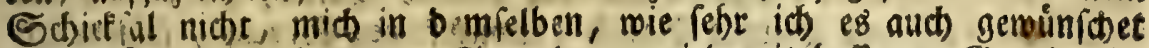
bistte, lá ger aufjuhalten 19 Ein anderer wiro mit befferem Grunde fas gen, ich hâtte bie (S)elegenbeit ju irren, ober etwas unoullemmenes vor. zutragen, vermeiben follen; bie 2ibhandlung von biefem Stifte wåre ohnes

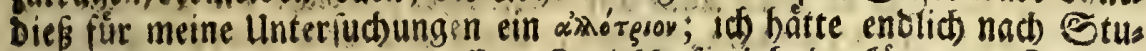
benis felbft fatreiben, uno beffere Sunojhaft einbolen fónnen. In $21 n$.

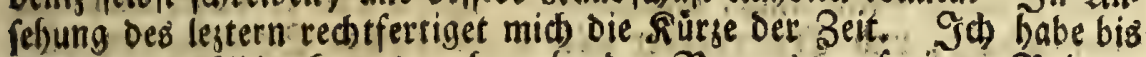

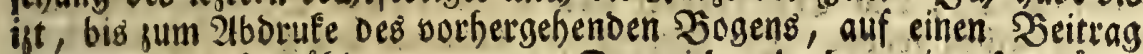
von Srn Wrof. Robler gewartet. Denn ich gebadte, eine fo grúnd. liche 2llearbeitung von bem Befhledte Der Stifterin Sophia, welde

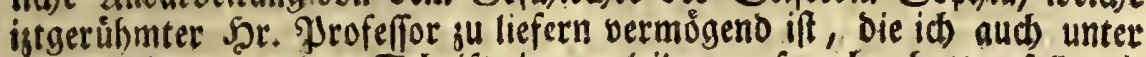
feinem Namen meiner Sd)rift einjuberleiben verfproden batte, foll meinen ZBeriate von Etubenis fo erheben, Daß id Damit fítherlid merbe auftreten finnen. Denn bie Ertåuterung biefes genealogirdben Stưcles

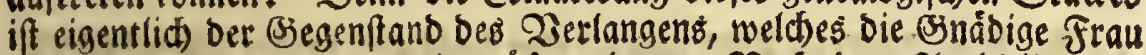
famt inten untergebenen mir ecofnet bat. Rad bem 2 (usbleiben et: webntes Bbeifandes aber, waro id) erft genơthiget, mids aufsumachen, uno jelbft ju thun, was ich surwegebringen fonnte. Die Unoollems menteit biefes 2luffazes nun muś, nåb)t meiner untúchtigfeit, baupts

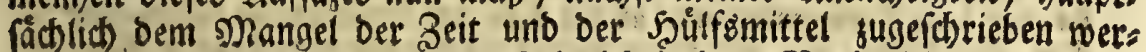

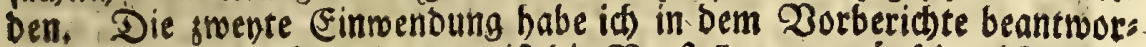
tet. 2Baв bie erfte anlanget, ift bie Dorftellung vernunftig, id) geftes

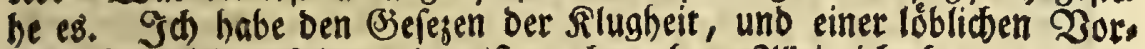
fidtigfeit nid)t gefolget, $b_{a s}$ ift aud wahr. 2Ullein id that es vorfes:

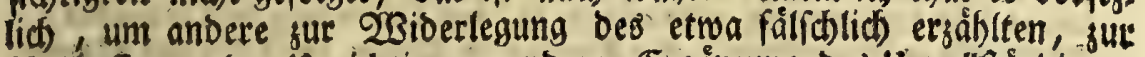

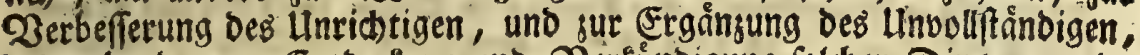
Daburch aber zur Entbectung uno $\mathfrak{Z}$ ertúnoigung foldher Dinge amulo:

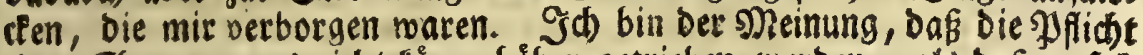
cires Sfjrenmannes nidbt fönne hơher getrieben werden, als bas er fich

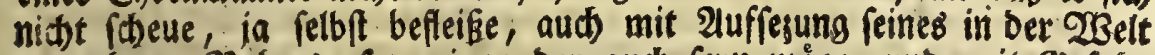
erworbenen SRubms, to geringe ber aud fenn móge, uno mit befabt

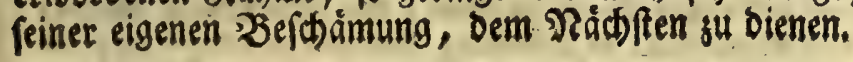

Es liegt oas Srauenfift (ober Silofter) Sttubenij, 10 balb su भnfange bes erridbteten Dominicanerorbens, unter Deffen Siegel, geftiftet worben, jenjeit Der Drau, und alfo unter bem geiflichen Giebiete bes Pyatriarchen yon Pquileia, in Den eigentli fogenannten 23 inbifthen fande (Vindia gi 3 inter. 


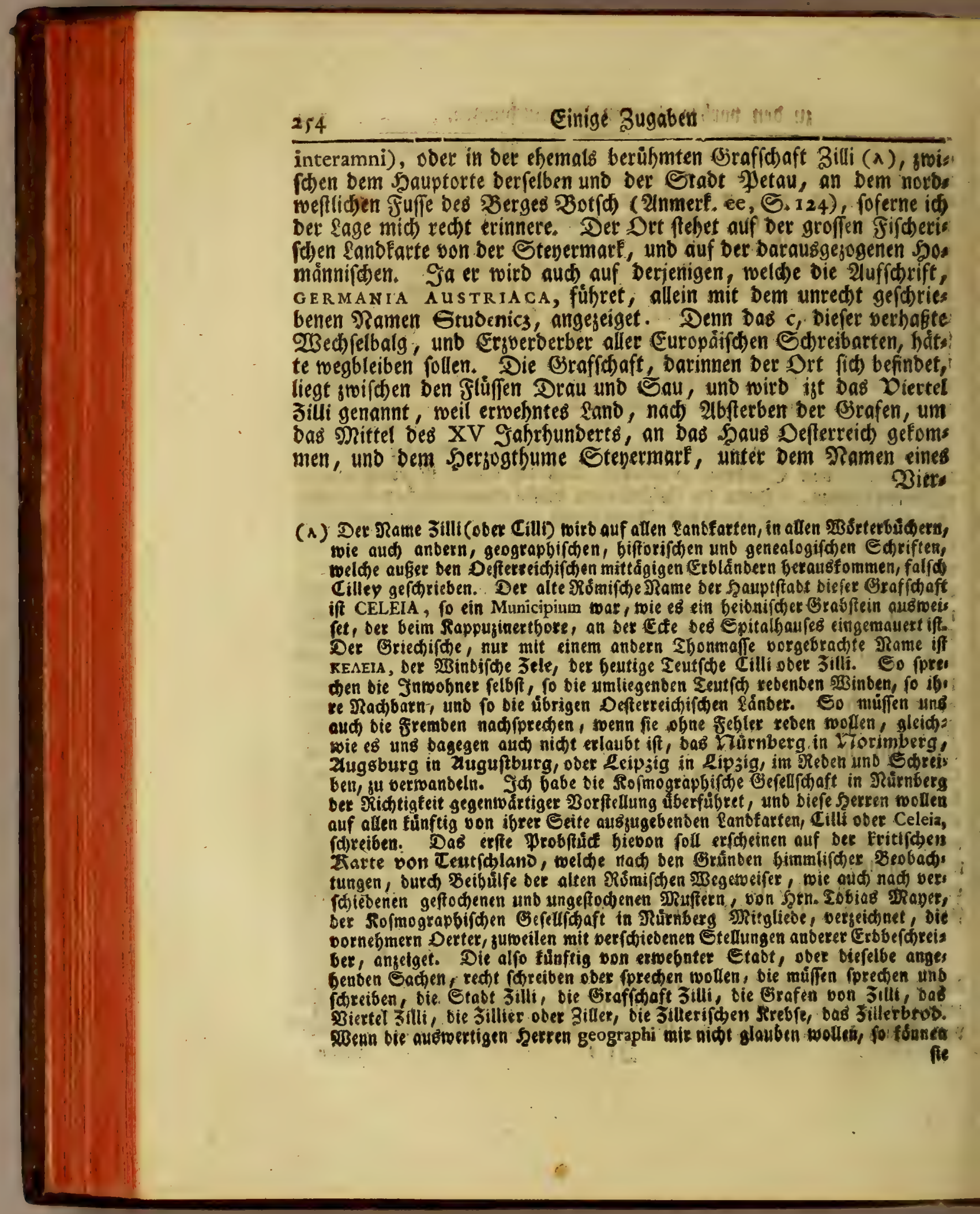


Siertels einverfeibet worben. Die Jnwohner biefer (3raffdaft fino alle 28 enden, oder, nact ber Defterreichif hen Mundart gu reden, 28 ins

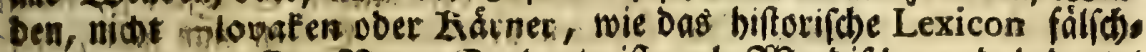

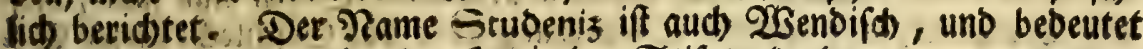
eine 2 runnquelle, oaber Der Drt in ber Stiftsurfunbe Fons GRATIARUM

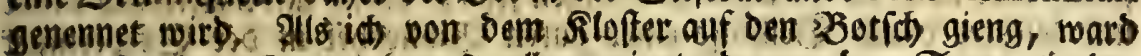
Mir auser bon Gantem jene Quelle geseiget r beren oben S. 127 in bet 2(mpert. gedadts morben Derfelben $23 a f f e r$ fommet auf bie Fafel ber Frauer. Man fagte mit, Dab einftens aus biefer 26 ber 23 ein follte alls flatt beg 2 Baffers gefloffen fenn, welthes bie Erbaung bes. Slofter vers anlaffet babe. शRad 2lusweifung be Stiftungsbriefes, ber im 9 . 1263 , Den 25 Mrav, gegeben ift, hiéB Die Etifterin Gophia, welche nad) bem Tobe ibres Ebebertn Richeri von Gunegk, biefes milbe $23 e r$ vollbracht bat. Sie wat eine Sodter Alberti von Robats, roie es

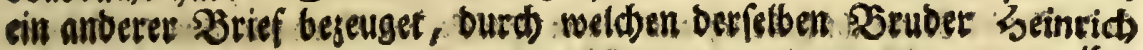

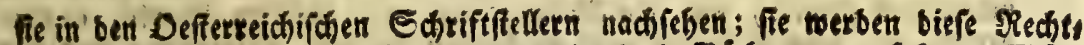

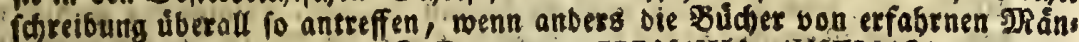
nern fino oerfobe worben. 3. E. in bem GERMANIA AUSTRIACA; welcheB

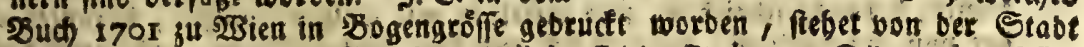
Cilli, S. 39, folgenber \$̇eridt: "Plinio Celeia, Ptolemieo Cetia, vulgo Cilly, antiquifluma inferioris Styrize urbs ad Sanam amnem, non multo poft Savo in-

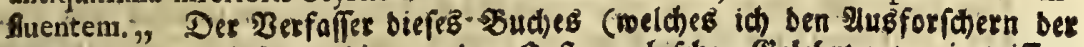
anonymorum, und jenen, bie bon ben Defterretcif́ten Eelebrten wenig miffen, fu etebe melde) if P. Carolus Granelli, a b. Befellfhafe Jefu, ein fattlidete isntiquarius, melcher Damale Prof. Math, fu WBien gewefen, bernach aber ber verwittibten Raiferin Imalia Feid)toater worben (Topogr. Styr. art. RECKERSPVRGVM, p. 65), bei weldher Sebienung et sisittel, Zeit und Belesengeit

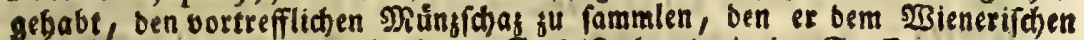
gefuiten. Collegio geichenfet bat. Sas ift eben berjenige Stoff, bataus bie powol aufgenommenen פRunjoerfud)e ibren uriprung genommin, melche, un:

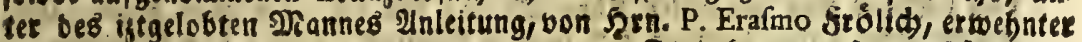

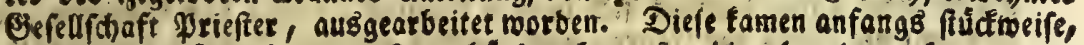
alB Erabusbúd elden, in Dctabbanben beraus, bie aber barnach von bem

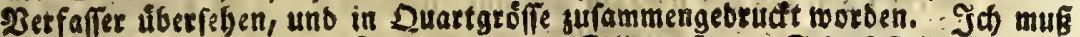
now erinnern, bafi aud diltere, und von Biffi entfernte Sdbiftftellet, Diefen SRamen recht gefdrieben baben. In Bothonis Chronico (LEIBN. Script. rer. Bruinfv. III, 370) befinbet fid) biefe Etelle: De verde (Docleter) heyt Anna, de nam Greven Frederick to Zily. Uluf bex 396 Eeite: Do nam he vedder des Greven dochter van Zilli de heyt' Barbara. Derjenige bat fich nun einen (chlediten 2 ecbienft gemacht, Dem eg juerfi in ben Sinn gefommen, Cilley ju (checiben. Das if ein Ermeis, baf bie Deuerungen nicht allemal Berbefies rungen fint. 


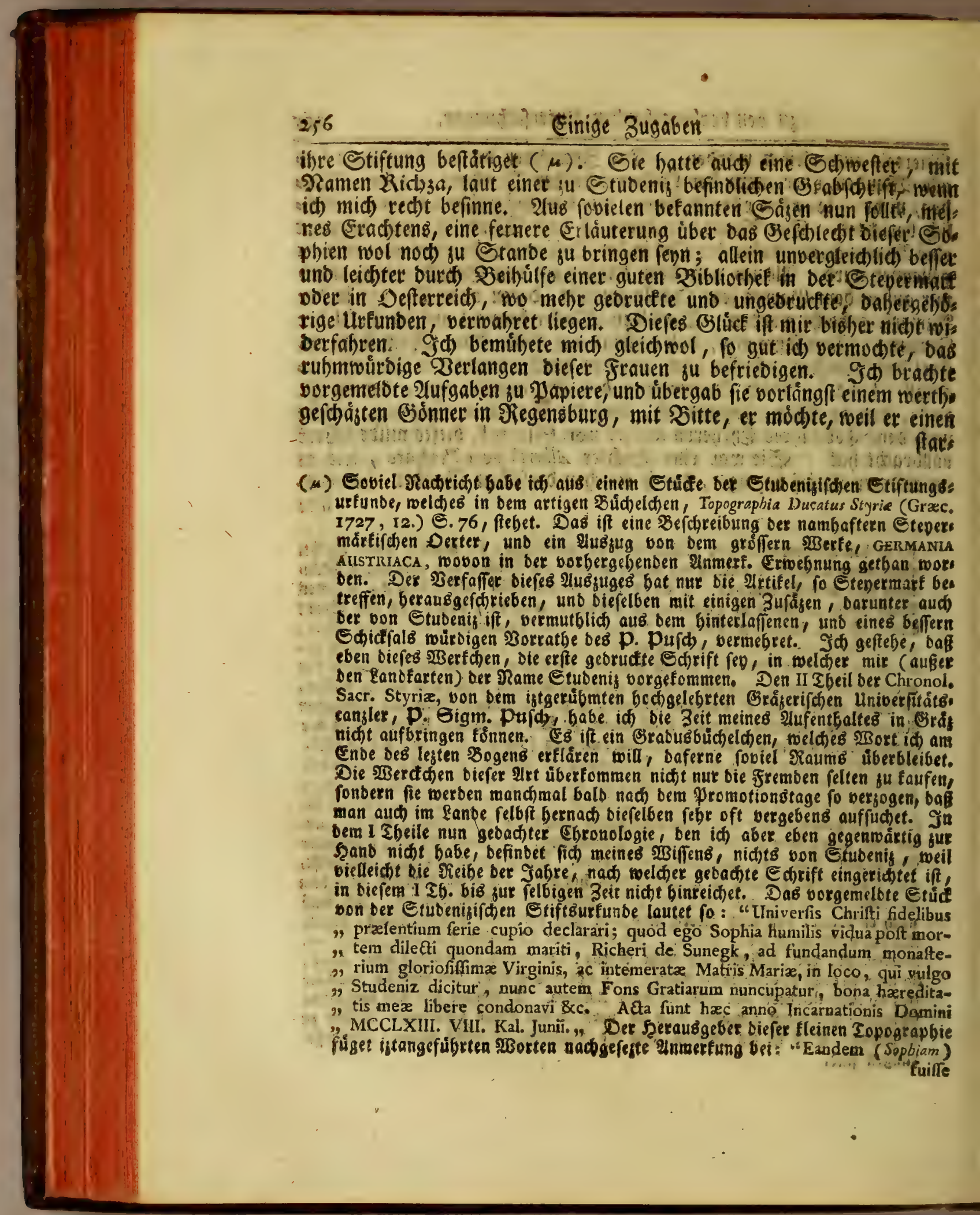


ftarfen Sriefwedbfe! mit vielen (jelefrten in Seutfoland unterfielte, biefelben einem fold)en Manme gufertigen, bon bem man verfichert wä.

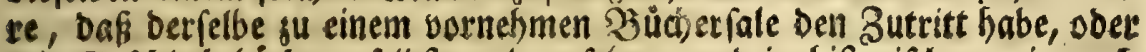
mit (sefds)ed)tbuidhern felbft wol verfehen, und in hiftorifhen, wie aud

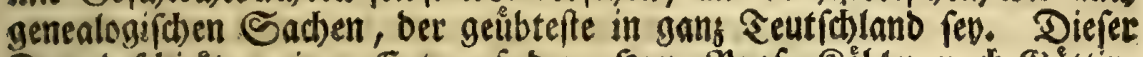

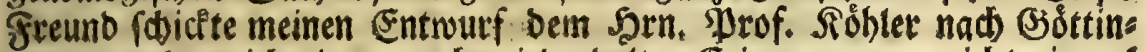
gen; von bem id) aber, nach wieberkotten (Erinnerungen, nid)t einmal

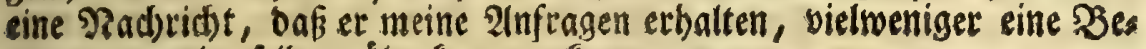
antwortung berfelben, liberfommen fonnte.

S由) babe Demnac sin grofferes Dertrauen su Dem gelehrten, unb in ben 2llterthümern yon Sberteutfid) land rolerfahrnen, wie aud) burd

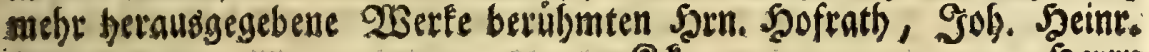
SE Shert

fuiffe Alberti de Rohats filiam, ex alio diplomate patet, quo Henticus frater

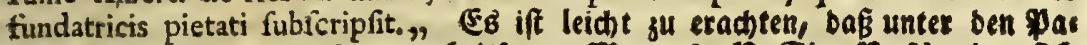
pieren beş juvor gepriefenen arbeitfamen Mannes, D. Sig. Dufd), Der fí) um bie firchengef(hid)te von ber Stenermart fo febr betummert, und fu bem Enbe von allen geiflichen Stiftungen bie N6phriften burd) viele Jabre, mit unermibetem fleise, aufgefucht bat, vielleicht eine gange Ilusfertigung von Stubenis, ober gum wenigfen baber cinfhlagende Rachridhten oofften anju: treffen fepn. Es brictet aber iftermebnte gelehtte Sammlung bas ungeteकte

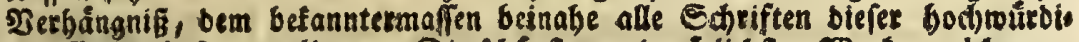

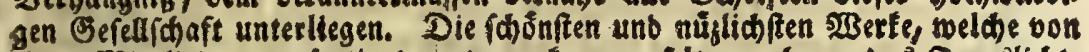
ibren MRitgliebern berfertiget werten, fommen felten mebr an Dab Sageslid)t, menn folde bie nod lebenden Berfaffer niđ)t felbft berausigeben, es múste nut Theile betreffen, Die ein boebergebenbes 23 erf ungang mact)ten. 2uf bies

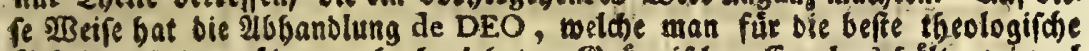

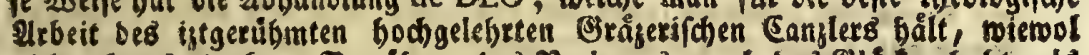

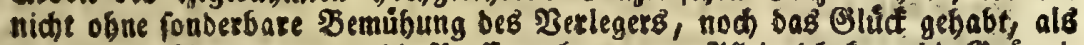
cil opus pofthumum, unter bie Preffe zu fommen. Mltein iđ tann bie Crâgerio fकen Sceren gefuiten verfichern, baß̂ fie nidht allein bie auswertigen Geleber

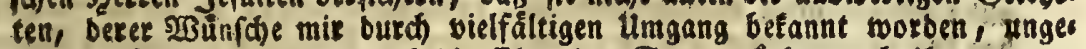
meir verbinben, fonbern aud bie (Egre ber Stepermåter, nad ifrer unum!

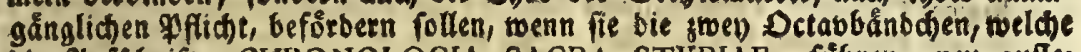
bie Sufforift, CHRONOLOGIA SACRA STYRIAE, fúbren, neu aufies gen, aub Dem binterlaffenen $\mathfrak{B}$ orratbe fortfezen, wie aud bie übrigen biftos rifhen, genealogif(t)en unb geograpbifhen Sammlungen bes vorerwebrs

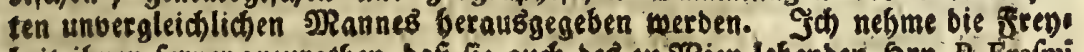

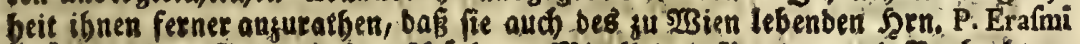

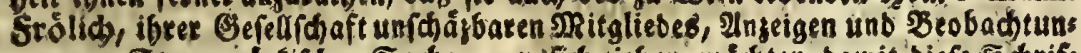
gen bon Etepermárfifden Saden, an fít jieben módten, bamit biefe Sdrifs ten niकh ald bermaleinft bie Zagl bet IneEoten bermebren belfen, menn bie 
Serrn von Falfenftein, ben id fu Shrwabach gu fpreden bie Elye ge: habt, uno bem id ebenfallo bie Angelegenbeit son Stubenis anbefohten habe. (Ev veriprad) mir bei einer finfrighin auszuarbeitenden 2 tb hand:

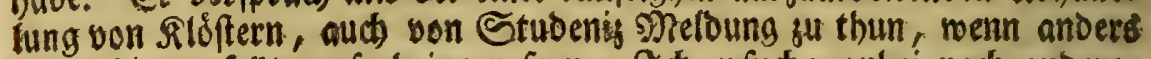
etwas bievon follte aufsubringen fenn. S.d erfude anbei nod andere,

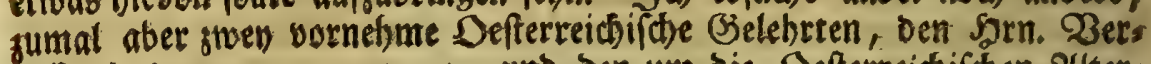
faffer beB GERMANIA SACRA, unb Den um bie Defterreidgif(i)en Alters

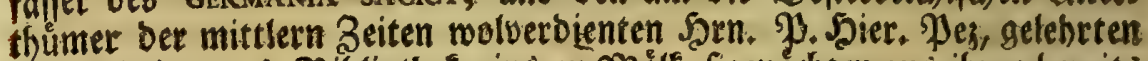
Senebictiner und $\mathfrak{B}$ ibliothefarius zu Mölf, fie moditen aus ibren bereitg vorbanoenen Sammlungen, ober nod jumadbenden Entbectungen, bie

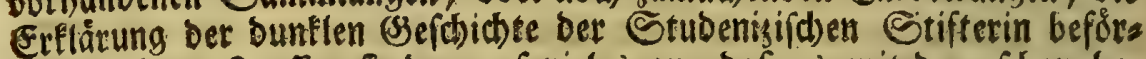

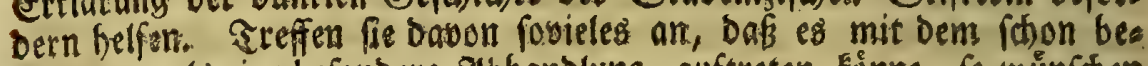
fannten, als eine befonbere 2abhanblung, auftreten finge, fo wunforen

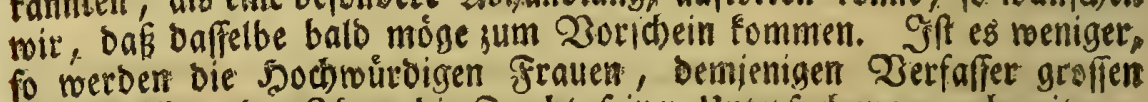
Dane wifien, ber Signen bie Frudt feiner unterfuehung, aud mit wes

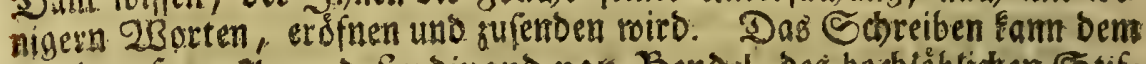

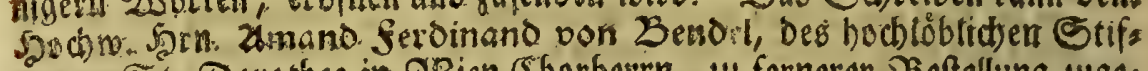

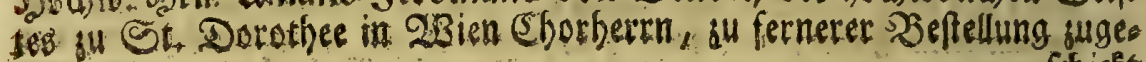

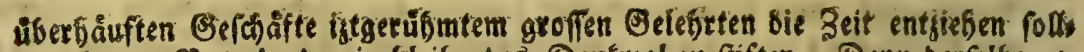
ten, feinem Baterlande ein Gleibender Denfmal gu fiffen. Denn Derfelbe ger

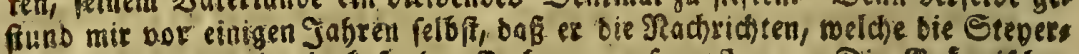

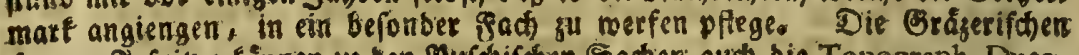

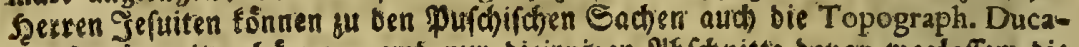

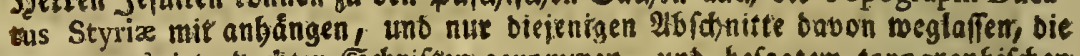

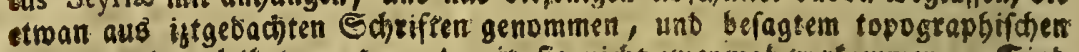

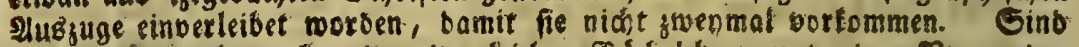

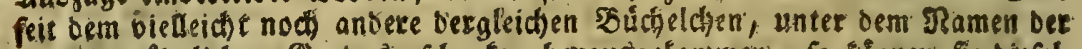

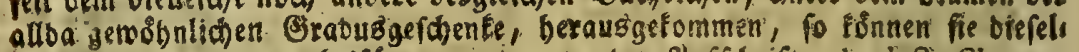
ben ben vorgenannten beifuggen, uno unter ber 2luffichrift, Analecta Chronelogica, Hiftorica, Topographica \& \&c. res Stiriacas illuftrantia, ober unter einet

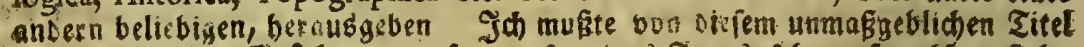

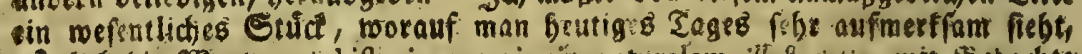

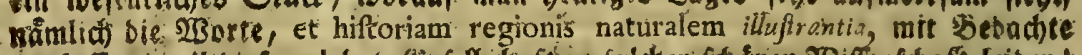

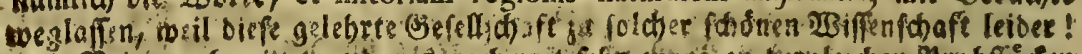

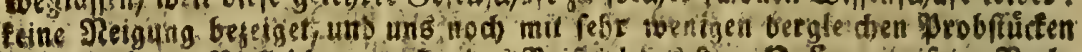

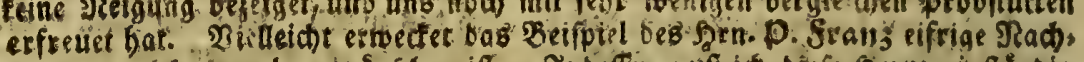

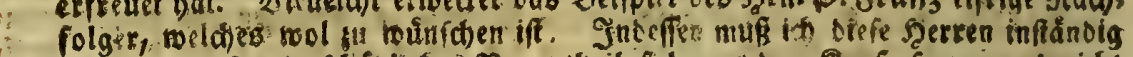

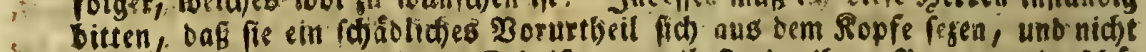

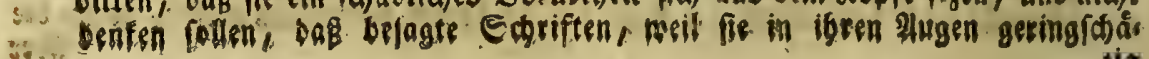




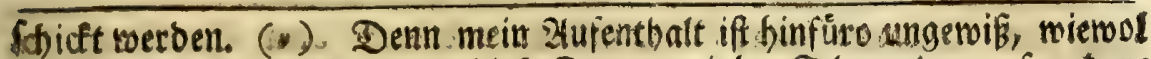
id) úbrigens bereit bin, gegen biefe Grauen mit ber. Feber, ober auf noere

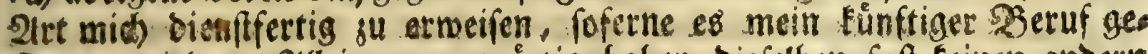
ftatten miro. Allein gegenwartig baben Diefelben faft feinen andern

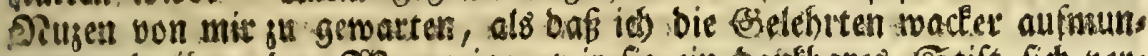
tere, unb ifnen ben $23 \mathrm{eg}$ zeige, wie fie ein banfbares Stift fich vel,

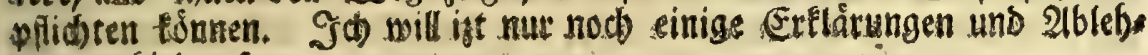
sungen fieber fejen.

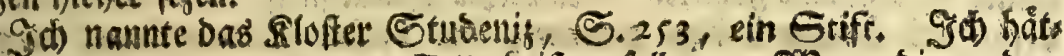
te es vielmeftrein abelides Stift heisen follen. $23 e r n$ bie anber

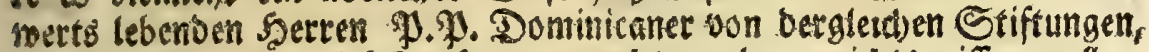

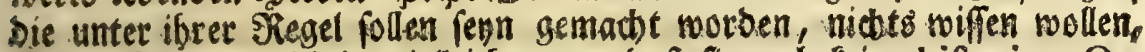

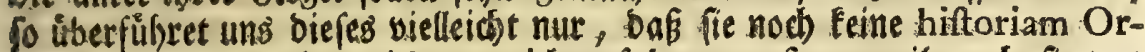
dinis haben; werches nicter nur id erfahren mufre, weil aud fie vou feinem Rlofter Stubenis ifeces Sordens mir einen S3eridbt geben fonnten,

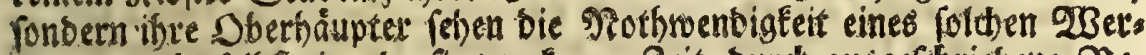

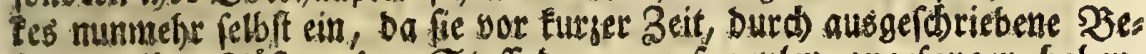
feble an ibre Silofter, Den Stofí bactu zu fammlen angefangen baben. J中 bitte fie, ia oas Stubenis nid)t zu vergeffen, fonbern biefes Etift,

$$
\text { SF } 2
$$

natb

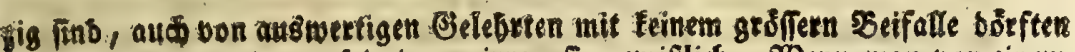
aufgenommen werben. Siecinnen irten fie gemiglid). When man bon einem

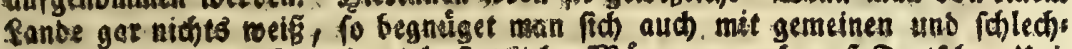

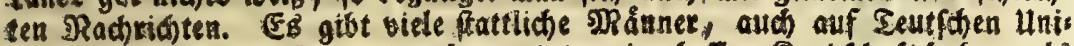
serfitáten, bie nom Lande ber scottentoten eine beffete Sundfhaft baben, als̉

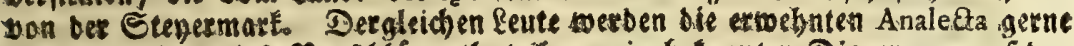
Faufen. - Ildein biefe Borfólnge tbut innen ein befannter Diener nur auf ben Fall, enn fie wallen faul feyn. Denn fie finb im Stante, fie befifen bie bes

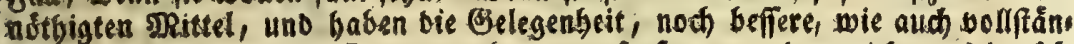

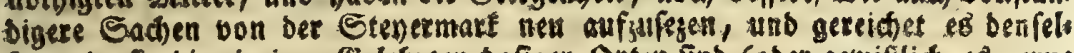

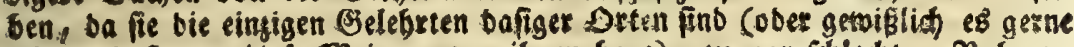

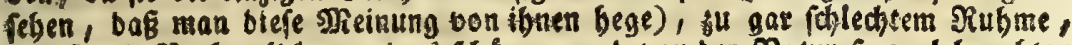

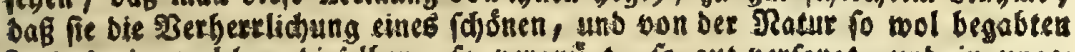
lanber, in weldiem biefelben, fo vergnügt, to gut berforgt, unb in unges

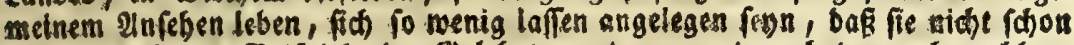

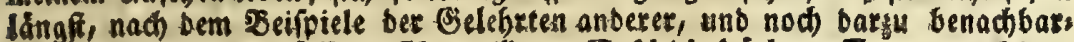

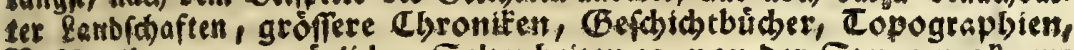
Jefdreibungen natuelidger Geltenbeiten $2 c$. von Der Gteyernatf, jue

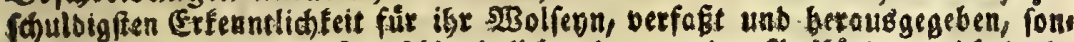

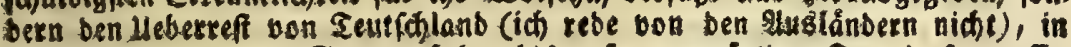

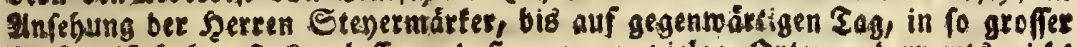

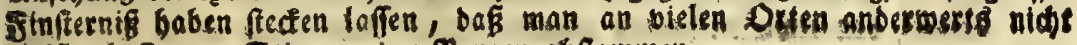
veigh ob fie bon Stieren ober Bergen abfemmen. 
nad Dem Yorguge feines 2llterthums, uno nach bem 2 erbienfe feis neB, burd) fo viele Sabre, mit erbaulid)er 2uffübrung ber (5'emeinbe,

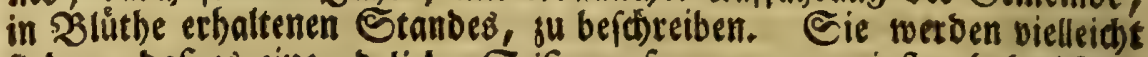
finden, $\mathrm{Dap}$ es eine abeliche Etiftung fev; jum wenigften babe id es to gefóret, uno bie Erfabrung fiteinet es zu beseugen, weil man alloa

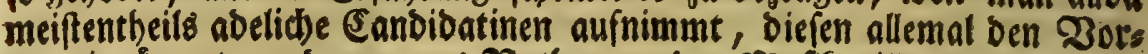

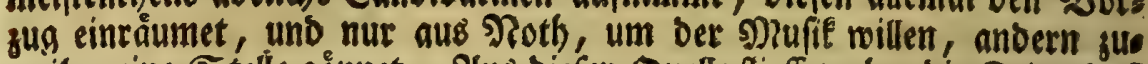
weilen eine Stelle gonnet. Fus biefer $2 u e l l e$ flieffet aber bie Folge, oas

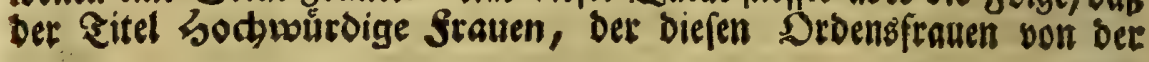

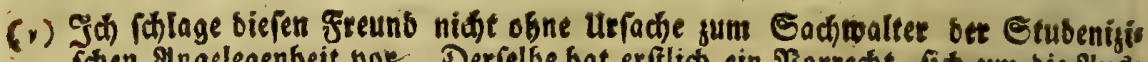

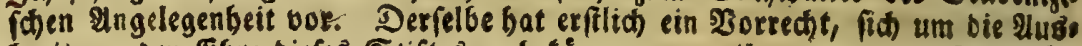

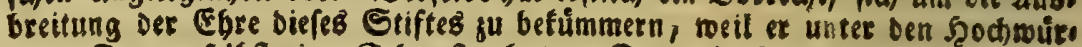
bigen frauen felbft eine Edwefter bat, Darnach ift er nidit fo bejd)affer,

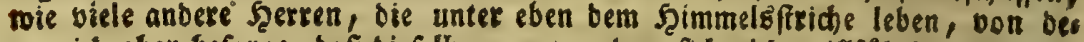
nen id aber beforge, baf́ biejelben gegen anbere fid) nide minfętriger bejeigen ớrften, alṡ gegen mich; ba ich in gleichen ulmftânoen, nåmlich in Eachen,

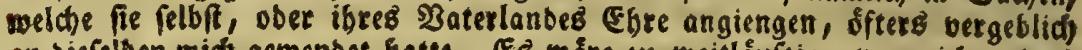

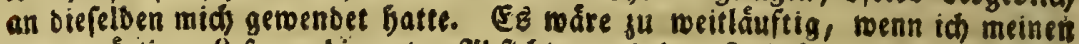
gegentbártigen fefern, bie guten $2 b$ fichten und den Inbalt meiner fruchtlofen

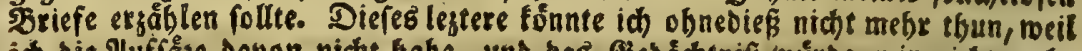

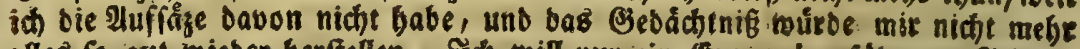
alles to gut wieber berfellen. Ioh toill nur ein Exempel anfübren. Job bas be vor bet, zu meinem groffen Ungemade, mir abgenótbigten abreife aus Deftereich, von bem Lanbe ober ser CEng zmey lange Sriefe bon sines Dotanifhen Reife, in bab untere Ranb gefdrieben. Jot fieng meinen Zug bei Edjieferftein jenreit bet Eng an, und burchftrid) bie Berge bis Epidąl, von

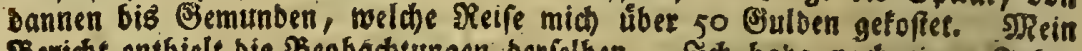
Dericht entbielt bie Beobadtungen berílben. Id) babe nach einem Jabre exfabren, baßs meine Briefe bon groffen Serren mit Bergnúgen gelefen wors Derr, alleín mid lieffen fie niche miffen, bấ fie cinen von mir empfangen,

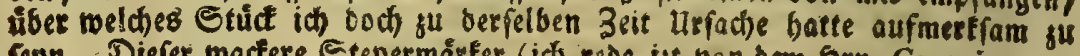
feyn. Diefer wactere Etedermårfer (ich) rede igt von bem fern. Canonico von Benbel) bat mix auf mein exftes Echreiben, barimnes id benfelben um eit

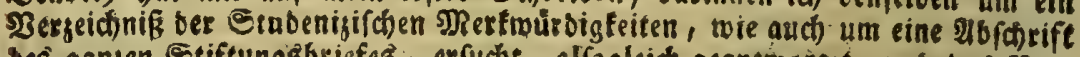

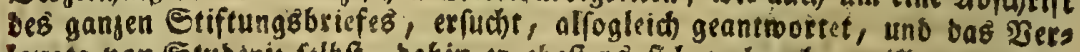
langte von Stubenis felbft, bahin er eheftens fid ju begeben willens ferg, am

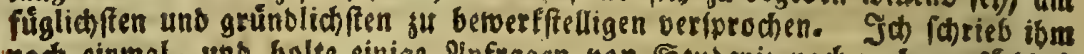
nod einmal, und bolte einige 21nfragen oon Etutenis nach; bauptféchlid aber gab id batinnen gu erfennen, wie mir feine Reife in biefelbe Segend

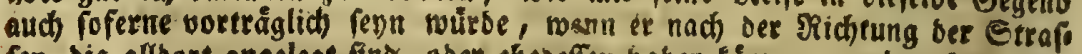
fen, bie alloort angelege find, ober ebebeffer baben E⿺辶nen angelege feon, fers

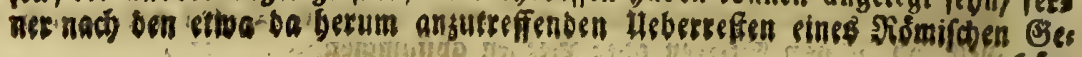


gu bell vorhergebenben unterfudjungen.

ganjen Nachbarfdafit, uno von \$erfonen allexley Standes gegeben wiro, ben iffnen bei biefer abbaniblung aud ids julege, und ben fie retbft unter cimanber gebraudsen, nicht ubertrieben ober garju anfefnlich

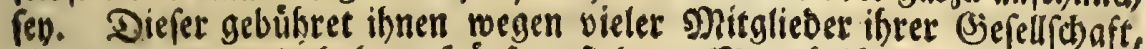
Die von guten uno boben Şåufern fino. Man beift Die Eborberren

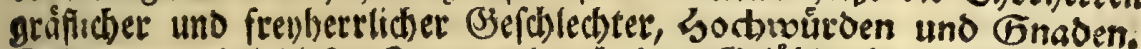

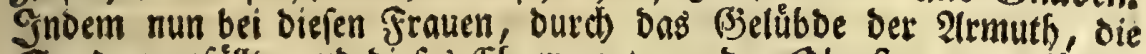
Enube wegfállt, und diefes Effrentwort nur ber Dberfen unter ifmen, als eigenthumlid gelaffen mirb, fo iftes billig, Daf fü bie úbrigen, ju eis If 3

net

båubes fich gu ettunbigen, unb bas 2usgeforfhte an mich fu berichten bie

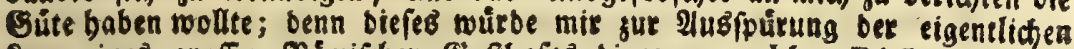
lage eines groffen Siómifhen G̈aftbofes bienen, welcher RAGANDO ges beisen, uno in berílben Segend muf geftanden baben, weil id zu sterfeach

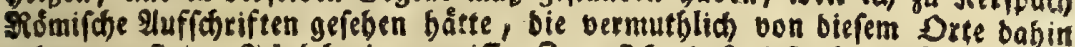
getommen finc. Id) lebe ber gewiffen Suberfid)t, bas biefer bochmuirtige Sere mir auch birfes Echreiben beantworten, ober, weldiez idh bielmebr berlange,

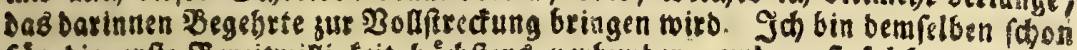
fút Die erfe Bereitminigfeit bơdftens verbunden, uno muB folds: unter die Seltenbeiten zåflen, bie mir fit meinem obbemeloeten 2ufferuche begegnet finb; weil aus vielen an meine furudgetoffenen Gónner und freunbe gefdriebes

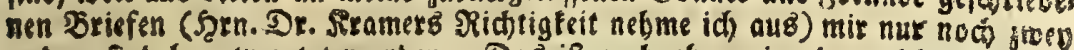
andere finb beantwortet worben. Das ift aud eben eine ber withtigften ut. faden mit, warum ich mich entichlieffen mufte, folche Drte zu verlaffen, ba man fich nicht entblobes, fo garinge und leichte Dienfte folchen Reuten ju ver: fagen, bie fîh aus eigenem Sriebe, aud (nád)ft góttlid)em Beifanbe) aus ei

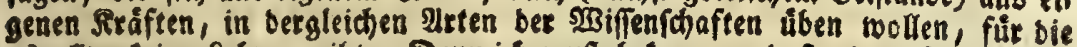

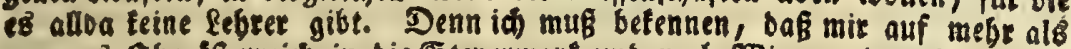

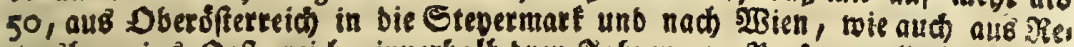
gensburg ins Defterzeich, innerbalb brey Jafren, an Betonen allerlicy besె uno \$erufв, gefandte Sriefe, bie fu meinen vorbabenten 2ubfertigun. gen benỏtbigte, gang gemeine Infragen entbielten, bie Intwort fo gut aus,

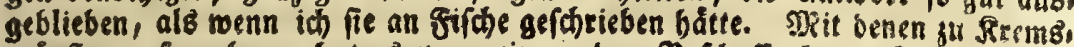

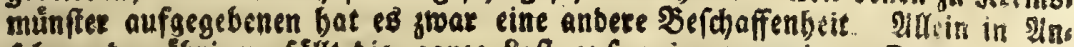
febung bet abrigen fátt bie gange laft auf meine betmeinten fitcunbe, unb

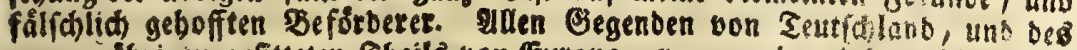
gangen úbrigen gefitteten Tbeilb von Europa, wo man ber einbeimichen Rins Der lebrbegierbe niche beffer einfiebt, weber iben von felbft erlangten grorte gang nacborudticher unterftuget, noch berfelben múbfam erworbene Gerdicks lichteit ju gemeinem Beften anjumenben meis, foll diefer unvermislid). Şobn

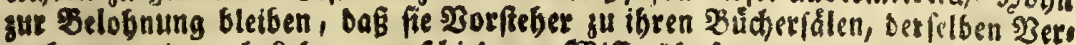

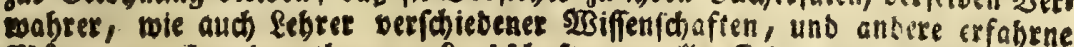

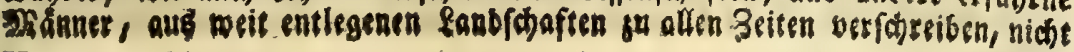

menis 
net fleinen jeitlichen (Ergelidfeit, uno Decgeltung fur bie abgefd)normen

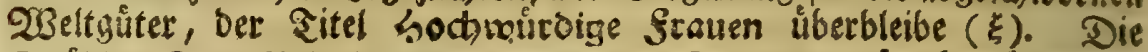
(Snåbige frau Priorin befommet in Der Zufdrift, Sod)wuroige, Sod, uno Wolgebobrne, Ensógige Srou, senn fie gráflides Stanbes ift. Die Sodtourdigen Frauen wăhlen fid felbft eine jrio. rin. Diefelbe wiro von geiftliden uno lanbesfurftlichen Detoroneten; bie allegeit bei ber 23 abl muffen zugegen fenn, beftátiget uno eingefest.

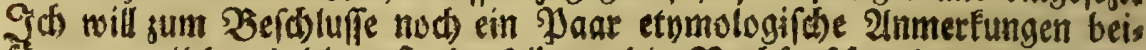

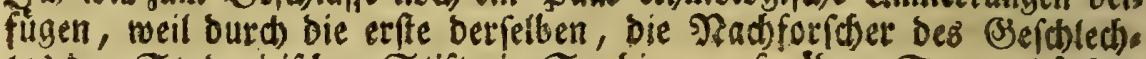
tes ber Stubenizifoen Stifterin Sopbien, auf nảbere Spuren dórften geleitet werben.

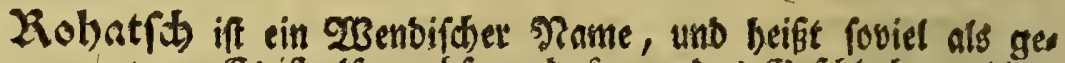

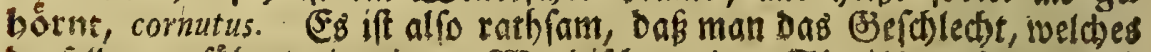
benieloen gefühet, in einem OSenbifben ober Elavijhen Ranbe auf: rudse. Soun finden fich swat in Sóbmen uno anderwerts Familien, bie alfo gebeifen haben, oder bie now befteben; allein bas serfommen

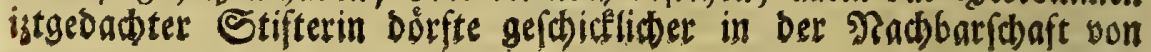

Stu.

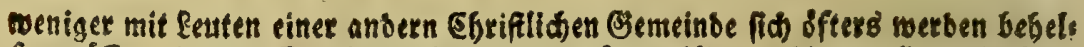
fen múffen; ba inbeffen einige ibrex eigenen Ranbegitinber, bie fu allen gebachen

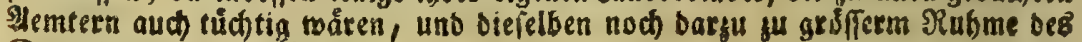

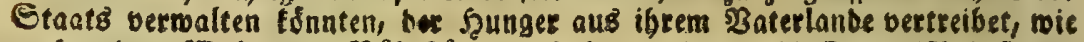

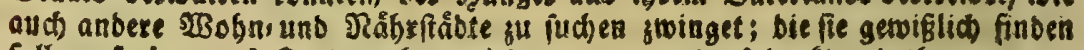
folleit, fo lange es Derter gésen miro, wo man anders benft und thut.

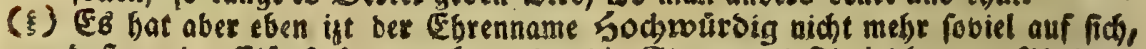
Daß́ er eine (Eiferfucht etrocten, ober bie Sittens uno Titelrid)ter fur Ubnoung

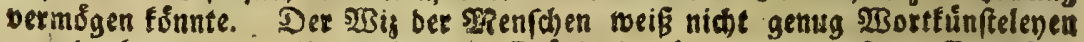

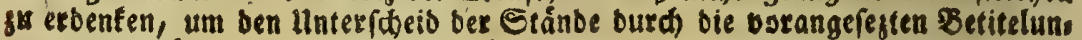

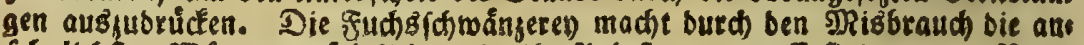

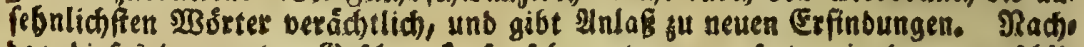
Dem biefes bem guten Befd)macte fo fefte entgegen gefegte, ja bem menfalie

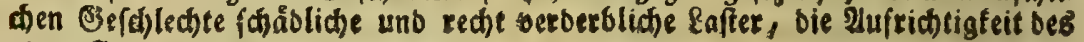
alten $D$ u, aus bem umgange anfebnlicher leute verbannes, uno foldses nur

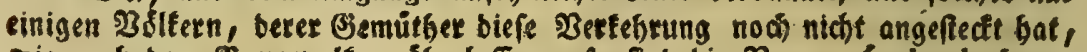
mie aud bem Sauterodfe, uberlaffen; fo fino bie Ramen $50 d$ gebohrn,

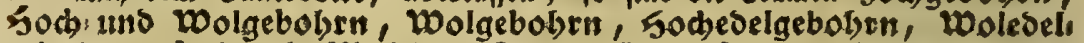
gebobri, 5odbebel, wolebelgeftreng, Keselgeftreng, wolebel, wols coel uns Deft, Roel uns Deft, Rbrenveft, Kerbar uno Deft, Erbar uns Doolvornelgm, 㐾ebar uns Dornelsm, KExbar uns Kinftreid,

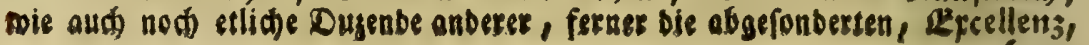


Stubenis felbft nuzjufpiren fenn. Diejenigen, weld)e (jelegenteit ba: ben, atte tretunbent bon Siobitin) (einem unweit Stubenis getegenen

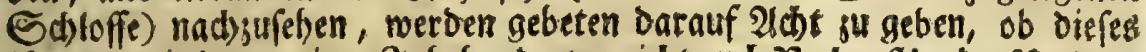

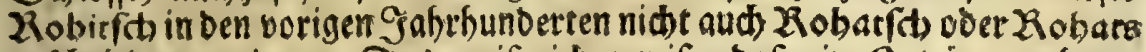

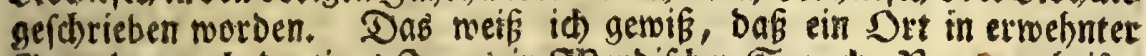

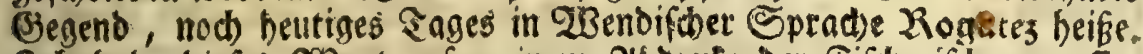

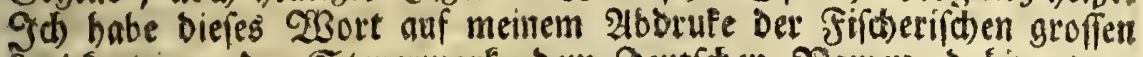
Eanofarte von Der Steverniare, Dem ₹eutid)en Tiamen, bahin es ges bóret, beigejest, allein diefes Stúct babe idh nun nicht bei mir. $28 \mathrm{sen}$

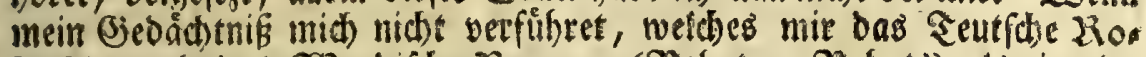

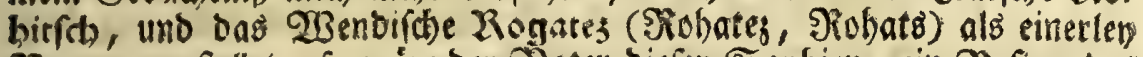
शamen vorftellet, fo wáre ber-sater biefer Sophien, ein Befizer Des

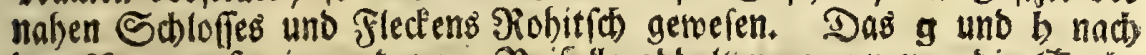
bem Ro, nuf niemano vom $\mathfrak{B}$ eifalle abhalten, wenn nut bie $ミ a d)$

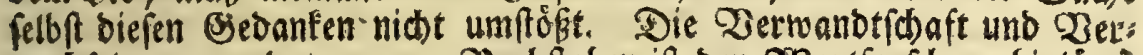

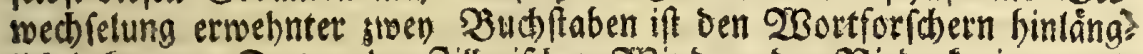

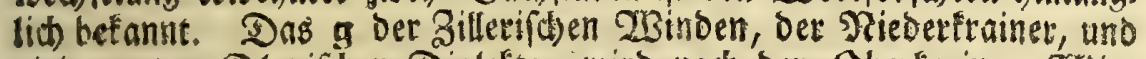

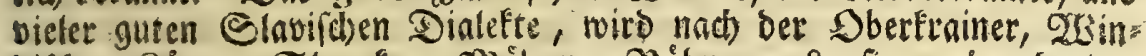

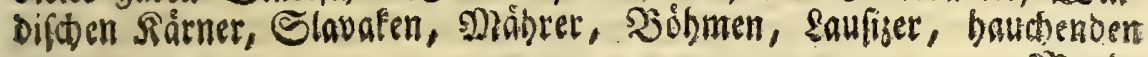

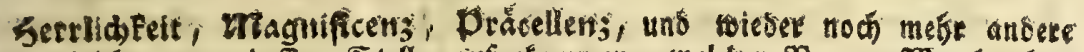
Dergleichell, an Deffer Etelle aufgefommen, weldjer Namen $23 e r t h$ aber,

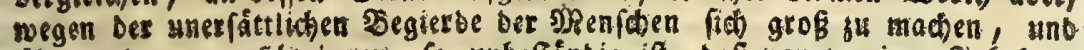
úber anbere fu exfotiningen, fo unbeftándig ift, Dof vor wenigen Jabubun. Derten bie legtetn Eftenbenenmungen ber erfen vorgemeloten Claffe, fovisl ges

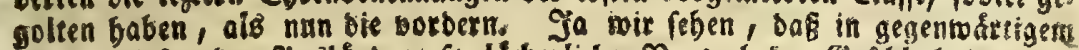

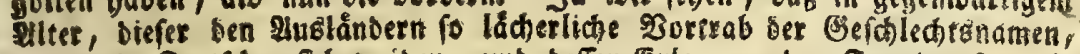
baran bie Teutfhen fid) beiben, und beffen Erlernang ben fremben fo vide.

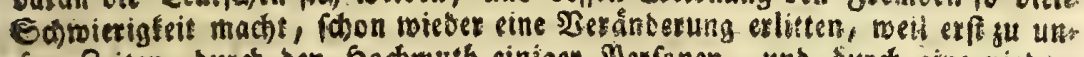
fern Beiten, burch ben fgodtnuth einiget Petonen, und burd eine nieber,

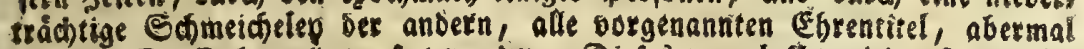
un eirre Etuffe herunter gefegt worten. Diefes weranlaffet bieber frifche fer

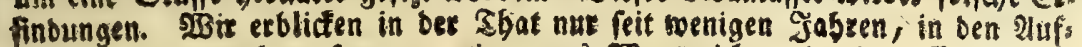

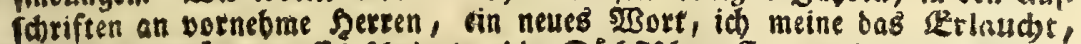

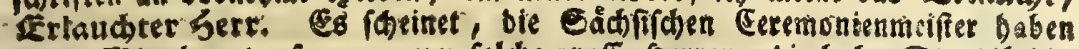
Diefes SRittetwort erfonnen, um folde groffe ferren, bie bobe Etaotsbedies nungen befleiden, bor andern gleich) bober (Bebust gt unterfeciocn, uno gu Dem Júrflidjen Stande nåber binanjurúcten. Diefe Henderungen geben aber auch in ben geiflichen Ebrenbenennungen eben forol bor. Ith fitrosige bon

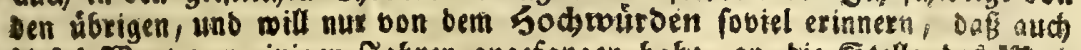

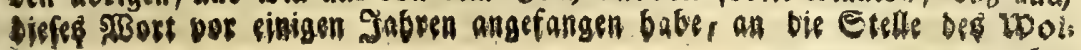
the; 


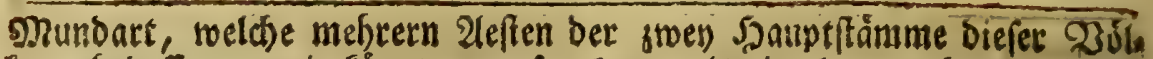
fer, efjebeffen gemein Eoonte gewefen fenn, als ein b vorgebradtst. But

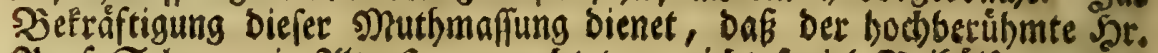

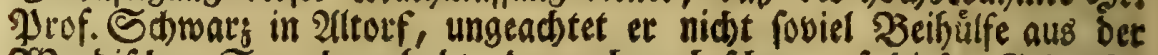

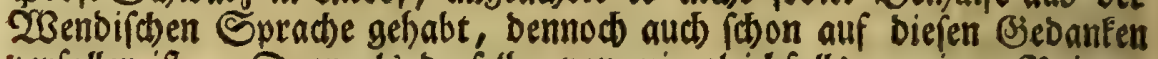
verfallen if. Denn als berfelbe von mir gleidfalls um einen ßeitrag zur unterfuctung bes (S̈efhlecttes biefer Sophien angefprod)en worben, fo (ah) et eben aud) einen Zufammenbang bes Naments Robats mit Robitfth ein. Die befte Entfocibung aber werben bie chriftlichen ju Stubeniz noch erhaltenen Lrffunben, und zufơroerft Der Stiftungs̈brief felbif, an die Saand geben, baraus fich alfobald seigen mus, ob biefe Eretärung einen Sirunb babe ober nidjt.

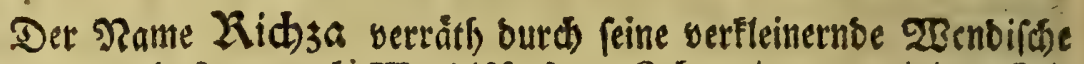

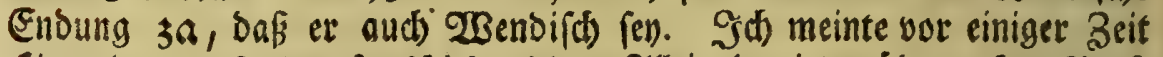

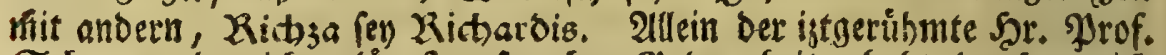
Sd)rars, ben id) unlång?t ju (prect)en (sielegenfyeit gehabt, bradbte mid yon biefem Zegrife ab, Da er mir aus ben Scriptoribus Rer. Germa-

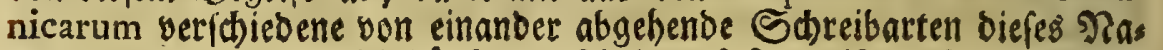

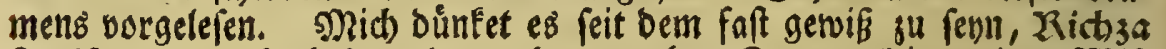
fen) Regina. EB haben aber mehr vornefme Frauen (Die meines 28 ifs

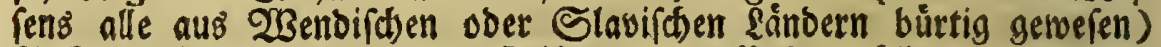
Sidsen geheifen. Fine war Faifers Lotharii Bsemahlin, eine anbere

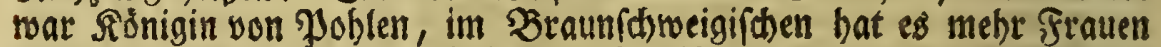
Diefeg Nameng gegeben, swie in bem Segifter Script. Brunfv. Leibnitii

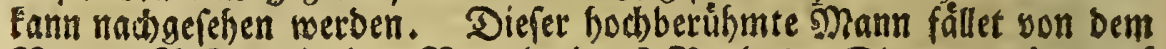
Namen Sichsa, in ber Zorrebe bes I Bandes, Gignatur d 2, auf Der umgefefrten Seite, folgendes Urtheil: De Rikefa vel Richfa, Regi-

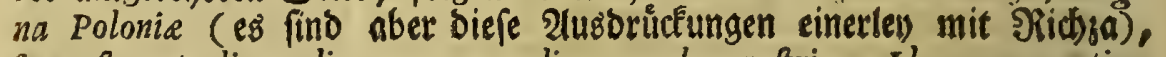
fupereft, ut aliqua dicamus, non aliena a rebus noftris. Idem nomen etiam gefit Imperatrix, Lotbarii Saxonis uxor, cui dotalem attulit Brunfvicenfem

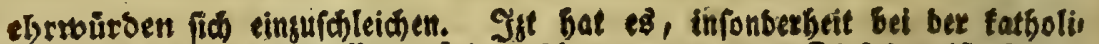

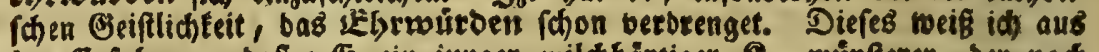

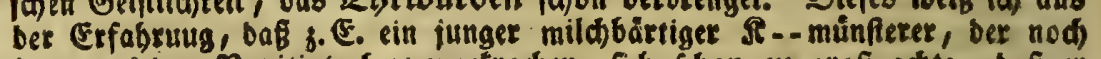
faum aus bem Sovitiate bervorgetrodgen, fich fdon gu groß adjte, bas et

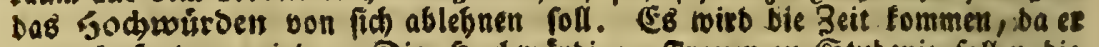
es nod forbern wirb. Die Şodmurebigen frausen fu Etubenis follen bies feg 2 ort als eigen bebalten, uno fich nach ben verânberlichen Xeltmoben niकt befunmers. 
fem ditionem. Sufpicor ex REGINA (quod non inufitatum eft nomen) faEam Rekinfam aut Rikinfe: fic enim fape babent diplomata et veteres fcriptores. Da nun ber Drame Rich;a unterfotiedich vorgebracht wirb; in Chron. M. Sereni Richfa, beim Alberto Stadenfi Rikenza, bon Dem Annalita Saxone Richenza und Ricbinza: fo überzeuget mich bie nod beftehende Sprad)e ber mittágigen 2 Benden (Der gegenwairtigen Sin. nohner eben biefer (biegend, wo bie গichza, gebachter Sophien Sowes - flet, gelebet bat), bas bie allerlezte Sdbreibart Kichinza am wenigs fen verftumimelt fev. Denn unter ben itgenannten 2 Benden, ober ben

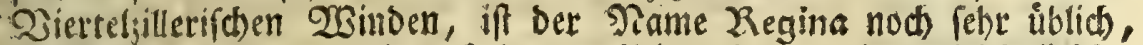

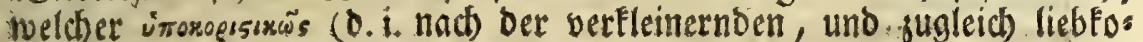
fenben (snoung), Der (Eigenfwaft biefer Spradie gemǻ, Reginza vors.

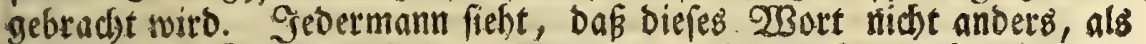

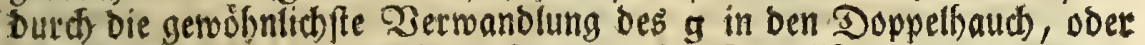
in Das verwanote $\mathrm{k}$, bon Dem Rithinza bes Innaliften, ober von $\mathrm{Ri}$

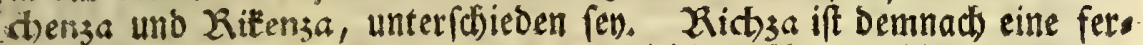
nere Derfleinerung aus Ridtinza, Dergleid)en Ramenzbiloungen aud im sateinifoen, im Seutf(ben, und anbern Spracben gebråuchlich finb. Denn 5 . E. tenellulus fommet bon tenellus, biefes bon tener. Aus Dem 23. 2uth nacht ber Stenermaiter, ber Defterteidser, uno andere Dberteut(t)en, Diud)el; biefes verfleinern bie Sad) (en nod) ferner, oa

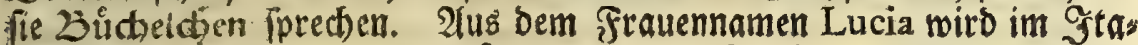
lienif (sen, Durd) befagte Derónberung, Luciuccia. Diefen פamen wollen die (Satanefer in Sicilien, famt ihten $\Re a d$ barn, nod) artiget und fomeichelbafeer borbringen, menn fie einer sucien Ciuccia surufen: Dar

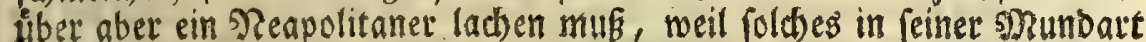

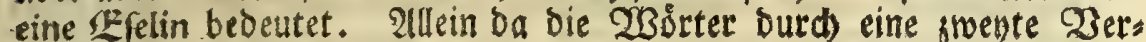
Fleinerung nur pflegen lónger zu werben, to ift Ricb3a vielinehr burch eine Burammentiebung (Suntope) aus $\mathfrak{R}_{\text {is }}$ thinza entfanden (eb. (o) Das Richiza, weld)es auch in alten Sdriften gefunden wito, ift gleidfam eine Mittelfuffe swifden Ridsa und Ri=

$$
\text { I! cbin3a }
$$

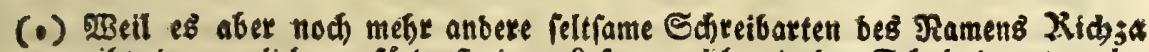
gibt, beren etlidje, zuforderft einem fefer, weldher in ber Sd)ule bet etymolos

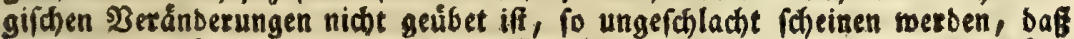
ex anfeben borfte, ob fie nol bon Kegina baben tơnnen bermaffen verftume

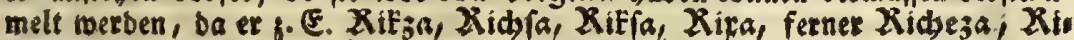
defa, Xifefa, Kifeja, Xidejeja, (mit Kictejen); uno Kibinja, Kibinia, Xifenfa, Zefinfa tc. gefdrieben antrifft: ber nolle bor allem biefes in 


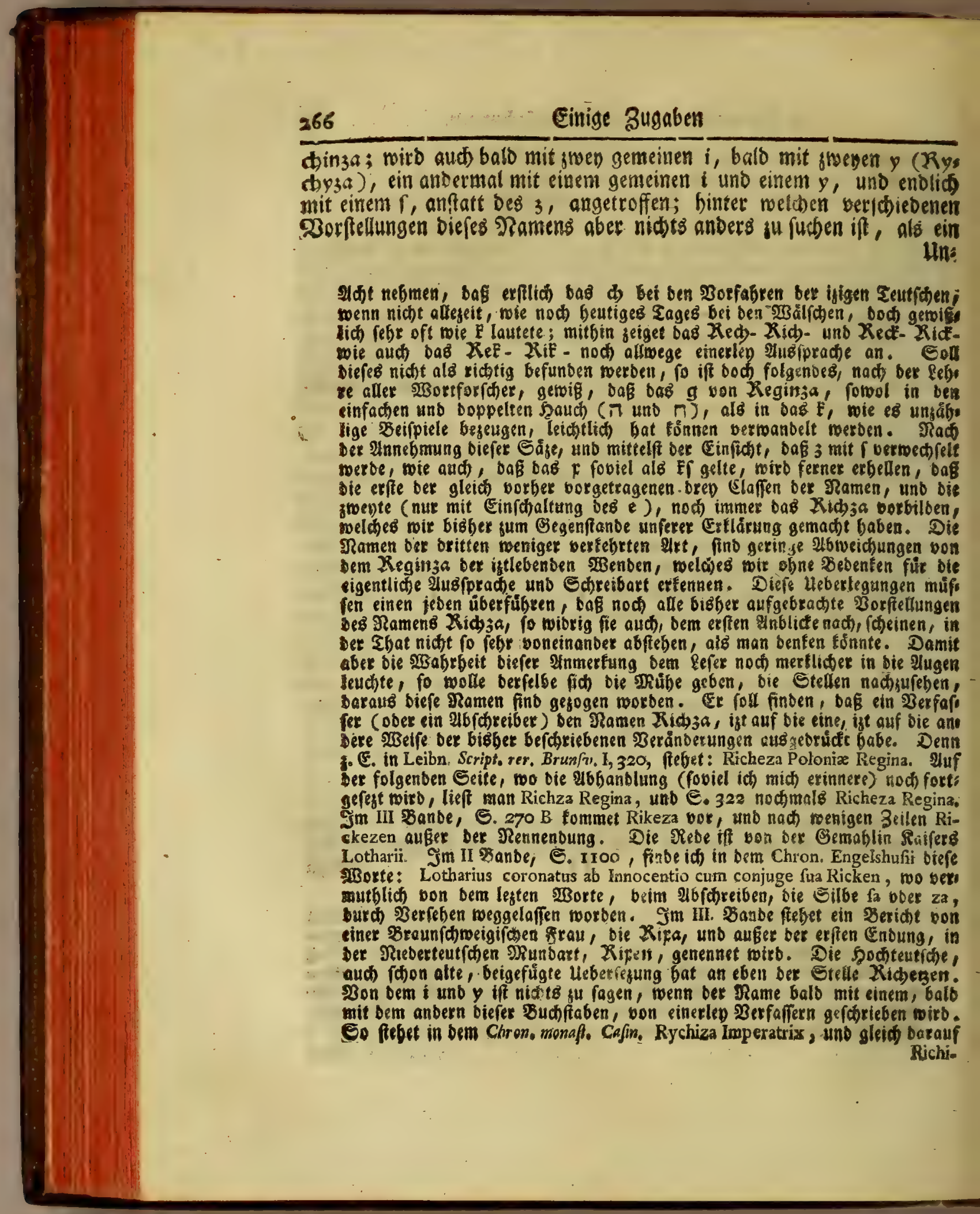


Unfeif ber 916 fdeciber, ober biefer Fehlet, Daf fie bie Sdireibatt nads

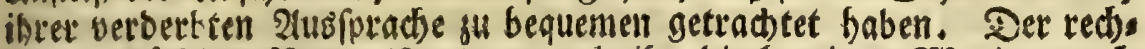

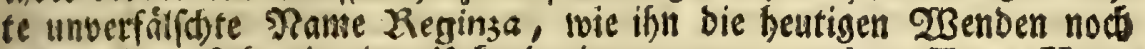
gebraudfen, ftefet in ciner luffunde in uGHELLI Ital. S. Tom. V, p. \&2

755,

Richiza Augufta. Die Stelle bat Sr. Pr. Jol,. Seumann, Dipl. Imperatr. p. 218 , Qus Dem Muratorio angejogen. Diefe Beifpiele, bie ids nur in Esile anfgebrad) babe, torben gleichivol zulånglich farn, ben fejer fu überfeugen,

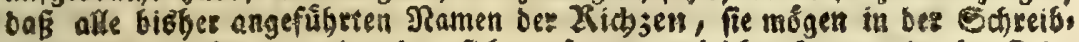
art now fo refte von cinanber fid entfernen, gleidiwol nue cinerten finb. Die Bilbungts Richenfe, Rikinfe \&re. finb batbarifobe genitivi, für Richenfe \&c.'

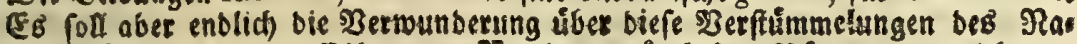
mens Richa, und beffelben bon Zegina, gạnlich aufbóxen, wann id bem

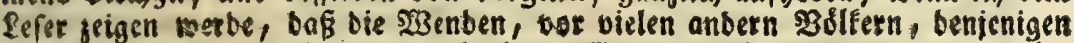

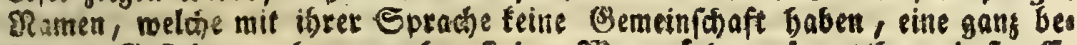

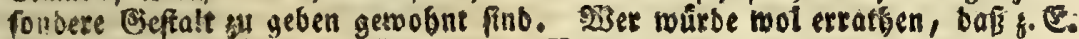
Int, Jerney, Wijia, Epsla, bie Ramen Georgius, Bartholomzus, Ma-

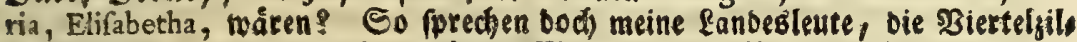

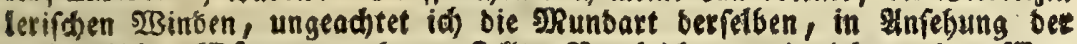

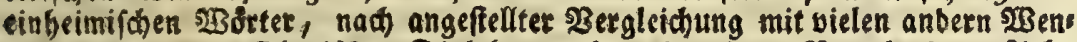
bifden, nie aith Slabifan Dialeften, obne es meinem Baterlanbe gu fiebe

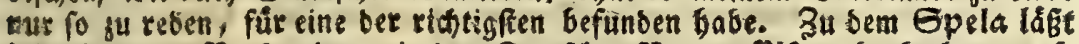

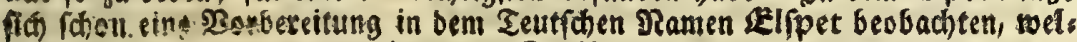

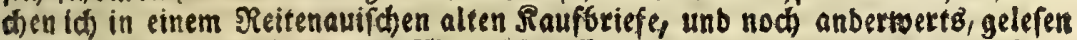

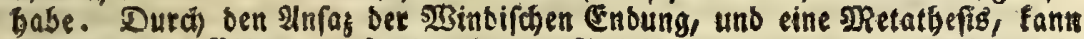
Gpela aus gelppet entfanten fenk. Hus maxis toirb butch bie (a)meid).

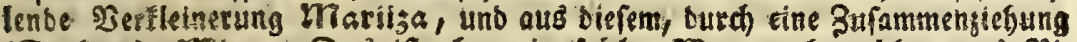

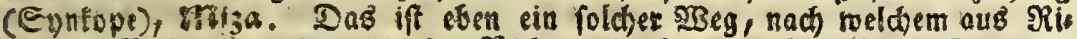
chinga, Kidjiza, atro aub biefem Kidja abgefommen ift. Einet Sigmunb beisen meine lanbeslcute Gigh, pine urfula nennen fie Hrfdia ober whes

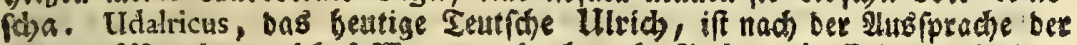

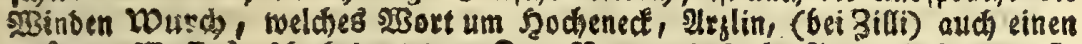

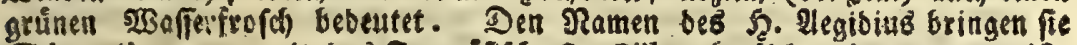
Edjentil vor, tomit Das Srattoffithe St. Gilles fiemlic nabe verwanbt ift.

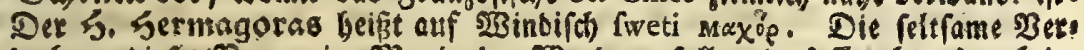

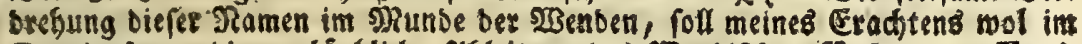

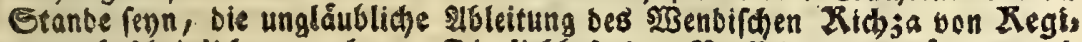

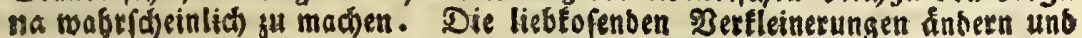

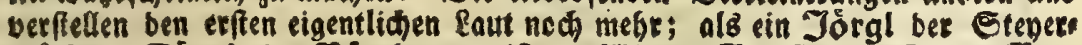

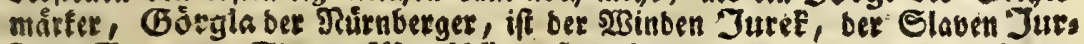

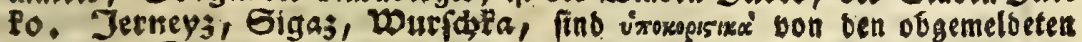
Jerney, Biga, wuefdaa. 2lus Catharina mirb Catra, unb aub biefemt burd) Die ßerkleinerung, Cátrza. Ein fleiner Antonius, eine fleine Barbara,

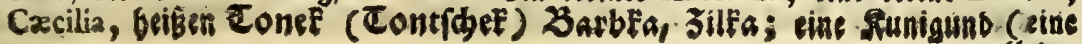


755, und aus bemfelben in 59rn. Job. Sheumann Dipl. Imperatr. p. 222. Nebft Dem 2luśprub)e bes groffen \{eibnis, berfich, re gefagt worden, fúr biefe Meinung, Rich 3 a jey Regina, erfläret bat, Fann ich Diefelbe aud) Durd) Den 2 eitritt bes hodbberübmten altorfifden febrers

Heine unb grofie) Riunja ; welder Name mieber nach bent Befdmade von Zidja gebilbet ift. Agnes wirb in ZeuJa berwanbelt. Eine fleine beifit

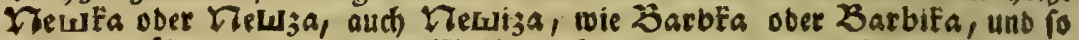
bei aften úbrigen, wo eṡ ber 2 bolflang leibet; benn bas $i$ mirb bor ben bys

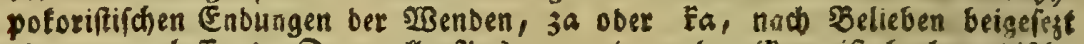
ober neggelaffen: Der volle 2lubgang, t3a ober if a, ift bodtoencifot;

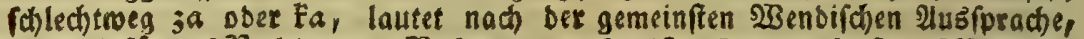

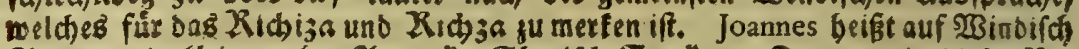

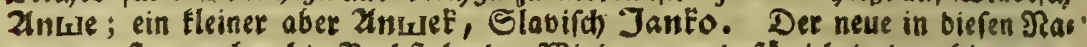

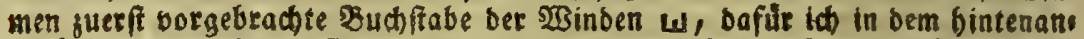

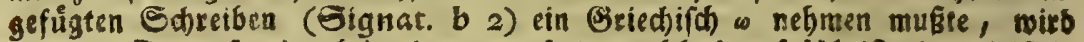
von ben franjofen burch je ober ge erfezt, weldjes exffalid ift; benn $j$ ift $i$,

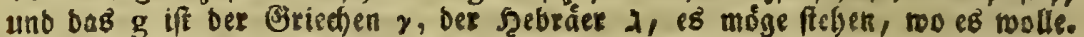

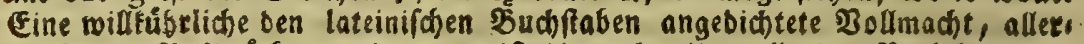

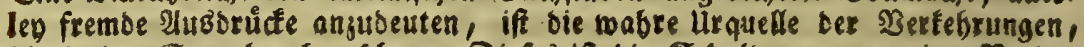
bie in ben Spradjen berrítien. Diefes ift bic Schulo, marum eine গation nicht einmal bie notbmenbigften slamen ber andern lefen fann. Das ift ein fposttlicher Uteberzeft bes sRomifhen Tod)

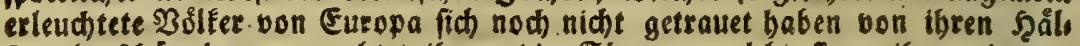
fen abzufthutteln, trageadftet ibnen bie Slaven, welche fie zu ibrer eigenen

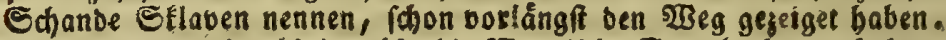

soseil man izt, mebe als jemals, bie 2 Benbifde Sprache bervorfuchet, uns nach beren Beforaffenbeit fich erfunbiget, fo will ich biefen liebbabern bei gegen maxtiger Eselegenbeit nod fagen, Daf bie $\mathfrak{B}_{\text {enben }}$ auth nomina vituperativa, roie bie graliener, in ibser Sprache baben, bie aber jugleich indignativa

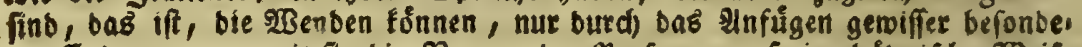
rex Enbungen, momit fie bie Ramen ber Perfonen auf eine bofbnifhe șseife

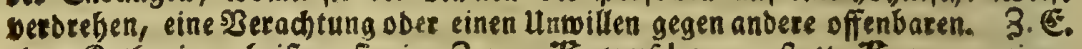
eine Ratbarina beifien fie im Jorne Katruidga, anftatt Katra; einen

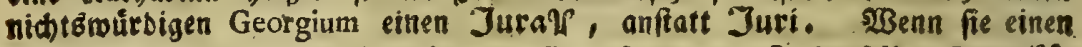
Sanns fhelten, ober geringad)ten wollen, fo nennen fie benfelben zntuix.

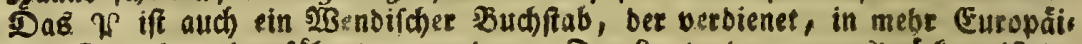
fhe Sprachen eingefúfret ju merden. Der faut, Den et ausbrúctet, if im Seut(d)en, ungrifisen, Stalienifhen, Englänbifhen; aflein eine jebe biefer

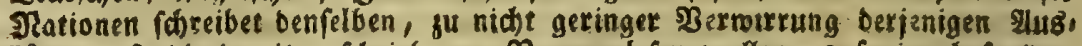
lånber, fo bie bamit gefariebenen शamen lefen mollen, auf eine befonbere

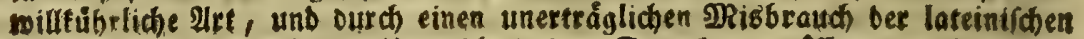
Suchfaben, woburd ber Unterfarto ber Eprachen gesffer gemacht roirb,

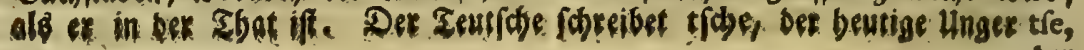
$\therefore$ Der 
Sin. Ehrift. (Sottl. Scbmalgen, befraftigen. - Denn nadbem ich bem: felben meinen Stuffas gefanot, um zu zeigen, mas icb aus ben verffoie. benen Sdreibarten Des Ramens Rich) $3 a$, für einen (Jebraud) gemacht båtte, fdrieb er mir fo jurúcfe: Memini in Balbini Mifcellaneis rerum \&1 3

Bobe-

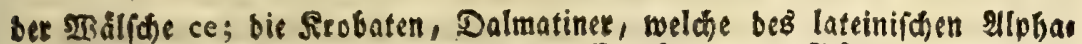

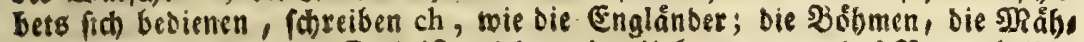

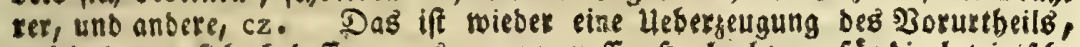
weldhes man fich ebebefin, aus gar gu groffer hadjachtung fưr bie lateinifhe Eprad)e, in ben Ropf gerejt, unb varmeint bat, Derfelben Mllphabet wake

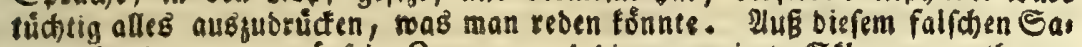
fe makse jener unverminftige 3 wang, unb bie ungereimte Eflaberen notfwen.

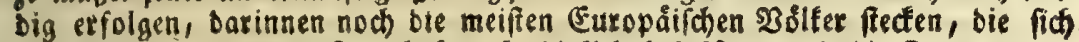
bis auf ben beutigen Tag lieber elenbiglich bebelfen, und bie fremben bon ber Erlernung ber Spraden abbalten, alš vermilligen, baß̃ einige neue uns

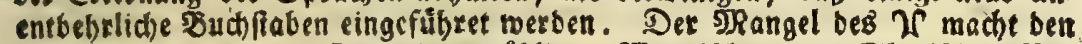
Jtaliener fo tumm, ba

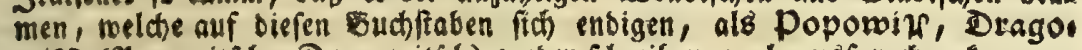

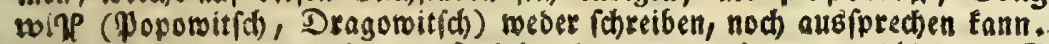

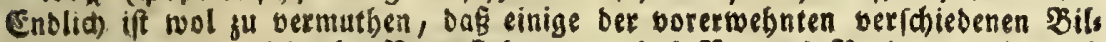
bungen, ober vielmebe $\mathfrak{B}$ erunftaltungen, bez Nameng Regina, auch Dusch. eine Eajulb ber 216fareiber, bie anbere Sprachen gerebet, oder an andere sRunbartent gewobnt waren, in bie Fúcher getommen, ja jurvetlen audh uns ftreitig und augenficheinlich) feblerbaft abgeidkeieben worben. Fon biefer lefs

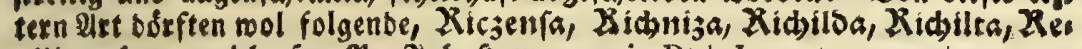
giliza, fenn, welche Scr. \$r. Jo6. Settmann, in Dipl. Imperatr. pagg. 2191223 ,

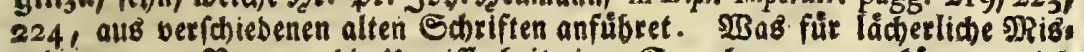

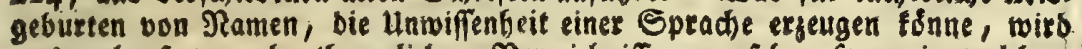
ous nachgefegtem abentheuerlichen Verjeichniffe ju ex feben. fegn, in welchem ein $\mathfrak{B}_{3}$ alf her, bie Derter Durch) Srain uno bie Stenermarf, Raubad) (Labacum ), Sranj, Jilli, Seiftis, Marburg, Elyrenbaufen, wolloon, Grá; zc. Die ifm ein Teutfher genennet, fich zu feiner vorbabenden Deife nach $23 i e n$ folgenbermeffen aufge(a)ricben bat: Prima fi viene alla Bocca, poi nella Franzia, a Cecilia, Feisdrec, Mariaborgo, Aranausi, Belladona, alla Grazia, u f.f. Ioh ftelle mir aber einen alten 'iơmer, alB feinen grơffern Sinffler bor, menn ex bie fremben, ober (nach) feiner glet zu reben) barbari

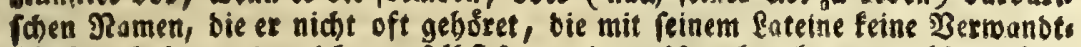
f(j)aft gebabt, tho melohe er felbft fo renig aus(prechen fonnte, als ein bets

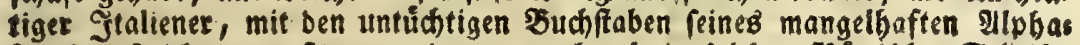
betes aufyeidinen muBte; wo benn mand)mal ein foldher sRómi(d)er Echrifts

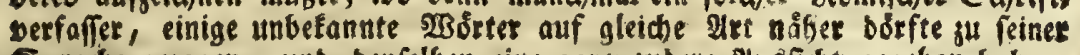
Sprache gegogen, unt benfelben eine gang anbere 2usfidit gegeben baben, mie eg ber vorerwegnte Staliener mit cen Etegermarfi id en Benennungen bex

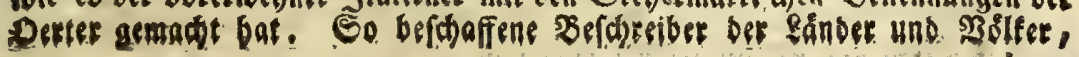
berex 
Bobemicarum legere, audorem bunc nomen RICHENZAE per nomen $A M A L I A E$ feu $A M A B I L I A E$, interpretari: unde mibi aliquando in mentem uenit, an is fortaje duxerit boc nomen a uerbo Germ. reizen; quafi fuerit, die Reizende, aut Liebreizende. Sed nunc fententiam tuam

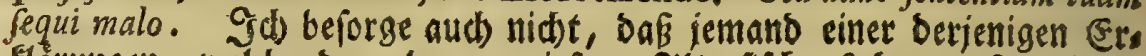

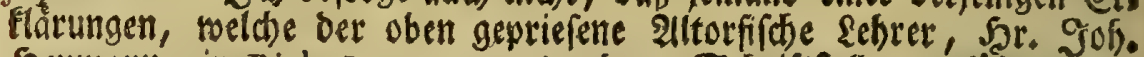
Setumann, in Dipl. Imperatr. aus anbern Sdififtellern anfúbret, als Rictza fey Rebecca, Doerberfelbe Pame bebeute reidsen Gegen, bot ber seibnigifonen unt unferer, eimen 20 orgug suerEennen foll. $(\pi)$

Weil ich oben $(5,255)$ bie 2 ebeutung oon Gtudents, neb/t bem Urfprunge biefes হamens, gezeiget babe, fo folgert fids von felbft,

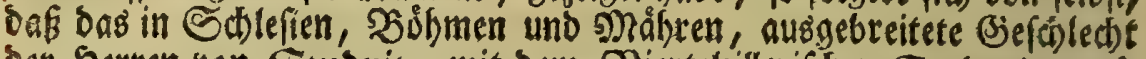
Der Serten oon Etuonis, mit Dem Diertelifllerifoen Studeniz, auf fer einen (3leidlaut bes Samens, weiter feinen Sulammenbang babe.

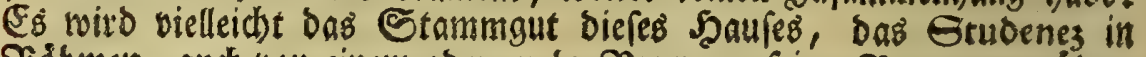

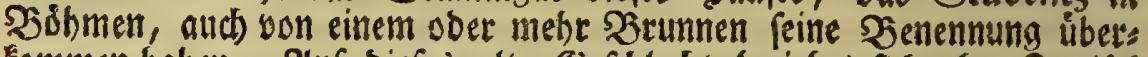
Fommen baben. Iuf biefes alte (Sefoled)t bejiebet fich obne Zweifel folgende Stelle Balb. Epit. rer. Bobem. p. 224, Da biefer Soriftels ler yon Boleslai I, uns Wladislai II, Sfiaten fo foreibet: Clatovienfis coenobii aedificatio abfoluta eft $A$. I I 58 , et inducta religiofa $S$. Benediti familia. - Blabovvidus quidam Studinezkiana, feu Fontinorum (quod S. Adelbertus iis nomen dedit) gente, religiofam vitam Clatoviae amplexus, boc coenobium locupletavit. S. Amabiliae, Theobaldi (Ducis Boh.) fororis, corpus bic fitum effe tradunt. Su Den Worten, inducta

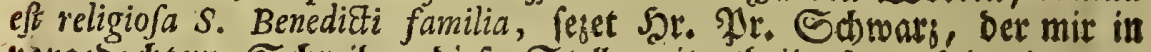
vorgebad)tem S\$reiben biefe Etelle mitgetbeilet bat, folgende gute Erinnerung bei: "Errat Hagek, qui Praedicatorum ordinem S. Dominici

berer Eprache fie nid) berfunben, berer शamen fie aud (weil ignen bie bes nơthigten Budfitaben feblien) gar nicht cusbeuffen tonnten, ferner fo unget

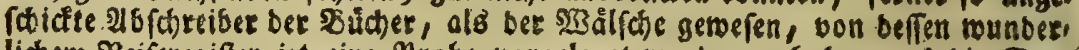
lichem Reiferegifter ift sine probe vorgeleget morden, Gaben uns bie Grys

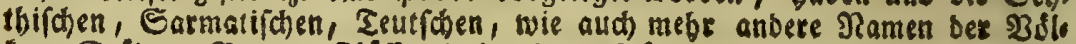
fer, Etábte, şerge, Glúffe (wie es bie Buther Ammiani Marcellini, unb bie (Erbbefdreibungen ber Alten leiber! begeugen) bergeftalt verbunfelt, Daf

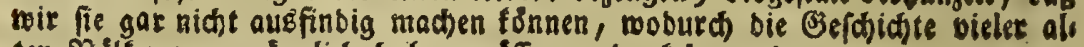
ten Ş\&lfer unumgånglich baben múffen berbunfelt werben.

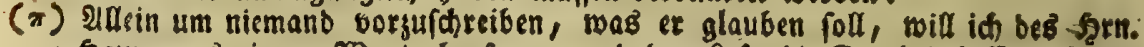
Srumannz eigene $230 r t e$ berferen, unb dem fejer bie Grenbeit laffen, feinen

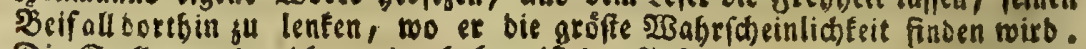
Die Elefle bon ber id gerebet babe, iff ber 2unfang bes CXXX \& ermefins 
nici uocauit, cum S. Dominicus nondum ratus effet. 213 ad ben esemafl ber Stifterin Sophien anlanget, fonmet mir ebenfalls nidht roalyerdheins

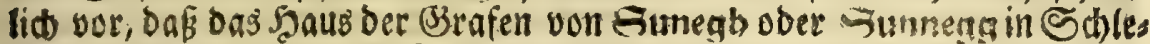
fien, weldes aus Ingern ftammet, mit bem (S̈ejd) led)te biefes Richeri von Guneak eine Berwallotidaft habe, bafern, wie ich niche sweifle, ber Emmurf bes Serchenifhen Stammbaums ridtig ift, weldier in Des zllgemein Lex. XLI Şande, S. 281, vorgeftellet mirb. Die 5̧०d). wirbigen Frauen fagten mir zu Stubenis, fie båtten Spuren, Daß

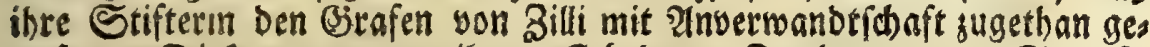
wejen. Diefe waren vor ihrer Erhebung Frenberren von. Sanece. Sie behielten bie oren Sterne aus bem Sternbergif

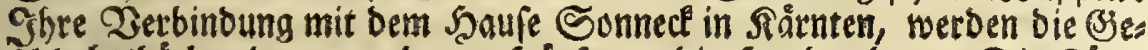

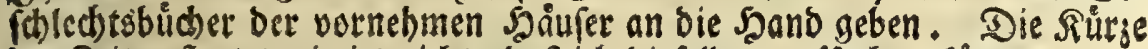
Der Seit geffattet mir ist nid)t, oafid biefelben auffuchen fornte.

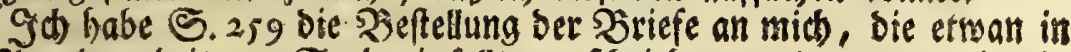
Der 2ingelegentheit von Stubenis follten gefwrieben werben, von mir ab: gelebnet, weil ids) felbft nid)t weis, an weldem Drte mein funftiget SEeruf mir einen Stand anweifen wirb. So muste befswegen an et: wefnter Stelle, Den allda genennten, zu 2 sien lebenden (Shorbern vors foblagen (bitte aber fehr ntir biefe Frenheit nidje ubel aufsunefmen) weil id) von ber Sinábigen Jrau Priorin ju Stubeniz, weldbe mir bie offters geoachte Unterfuchung vor einigen Sabten aufgetragen, weber

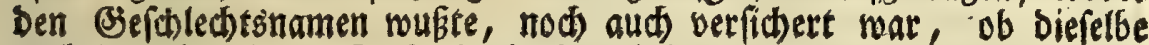
nod) im Seben fen. Dap ich bieffalls befutfam gebandelt babe, erfebe id) aus ber eben ift erfaltenen Beantwortung meines swenten Sdreis bens ( $t)$, Das ich an befagten Sherrn Canonicum von Zendel abgelafien babe; Denn ich erfabre, Dap Diejenige Bnådige Frau Jriorin, bie id

yot

ter शlbbanblung, ftelset p. 217 , unb lautet fo: "RICHENZA, Henrici co. g) mitis Nordheimenfis filia, in Lotharii manum venjebat. Nomen illius et g, RIXA et RYGHYZA exprimitur. Henrico Meibomio in not. ad Hiftor. 3. Bardeuici, p. 32, RICHENZAE vox fignificare uidetur reicher Segen. Leib. ") nitius rectius forfan eam a nomine Reginae haud diuerfam effe putat, in Inv) trodua. ad Tom. I Scriptor. Brunfuic. n. 27. REGINWIZ mulieris no27. men legimus apud Meichelbeck. T. II biff. Frifing. p. 73. In Pontan. REB. " GELR. diplomati Lotharii haec formula inferitur: juuante et presante pia Re"gina et conjuge Rebecca. Inde Gundlingianorum audor P. XXX, p. 49r, ") huic Auguftae verum nomen Rebeccae, quod Saxonice Rickigen enunciaretur, "fuiffe exiftimavit.,

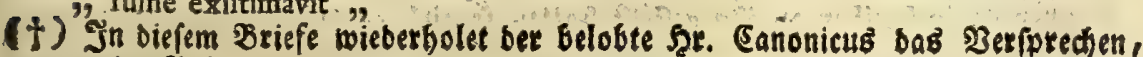
meine Infragen megen Stubenis unb Ragonbo, melche if in bem erfer unb stope 


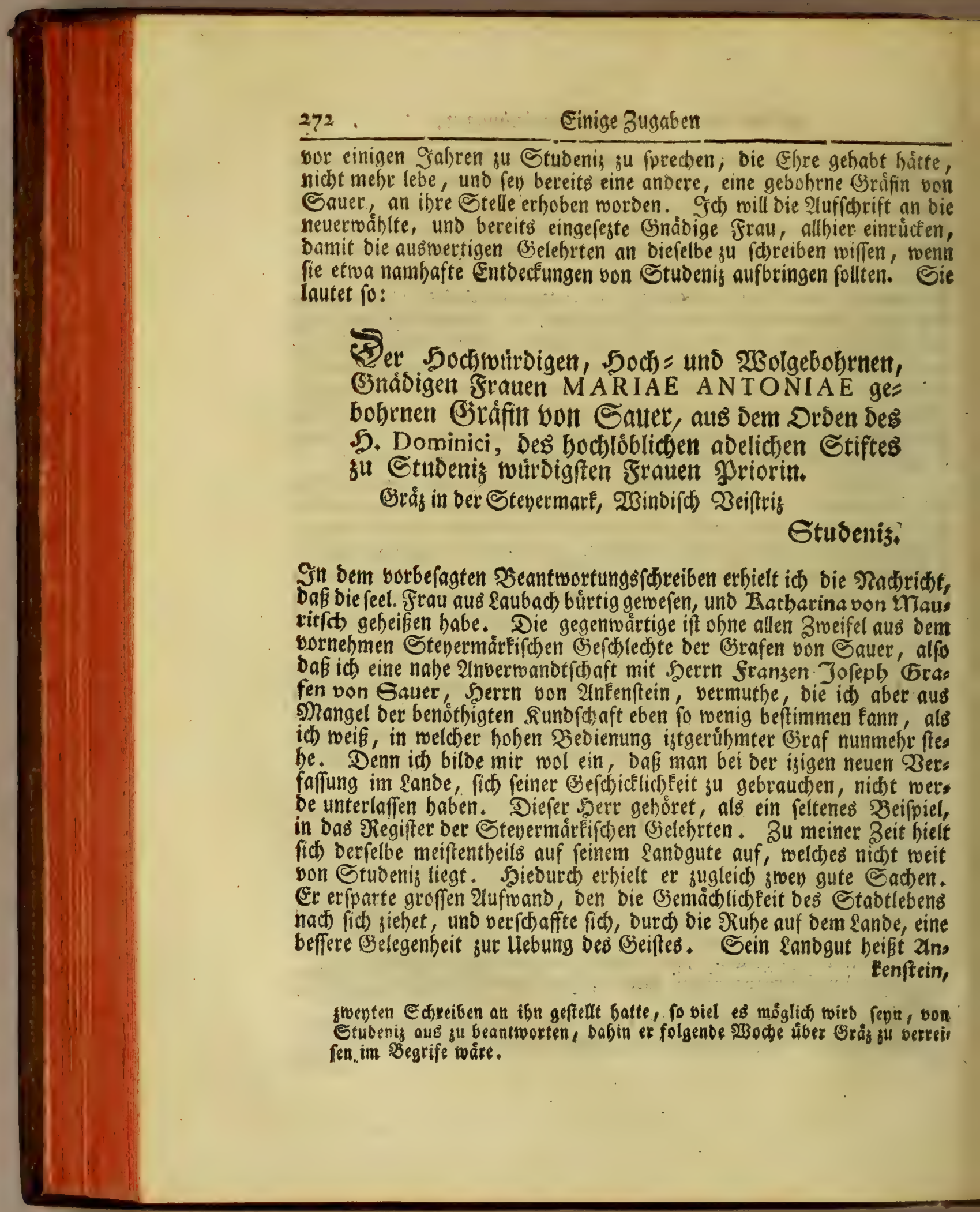




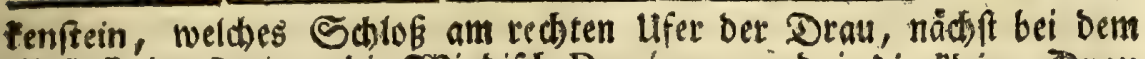
Eimflufé ber Drán, bie 2 Sinbifh DRA'W INA; $b$. i. oie Eleine Drau ( wie oie San, Sáwina, D. i. oie tleine Gau) beift, auf einer felfit), teas Scobe liegt, unb in bas facine Pletauerfelb, wie aub nadb ben ums liegenden Bergen, bie anmuthigfte 2(uşifht bat. Diefe Bjegenb ift,

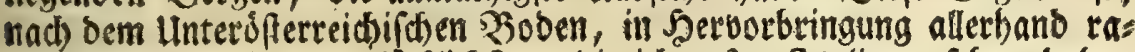

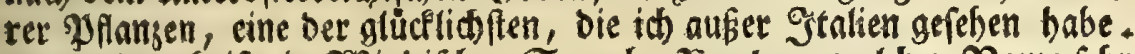

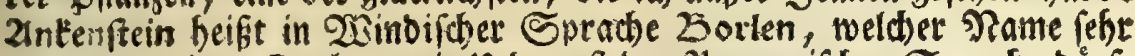
alt, und meines Eradtens ein lleberreft ber Wanmonifthen Spracte borrf: te (evn, in weld)er id), Durb) Betradstung ber Denennungen ber Det.

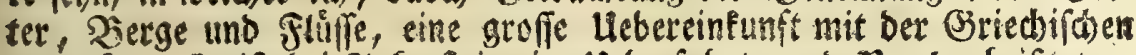
entbecte. Es if bei Anfenftein eine Leberfainet, uno Bocten beift trajectus fluvii; Denn rópos ift rine Uleberfart, und. Ilyn bebeutet in ber

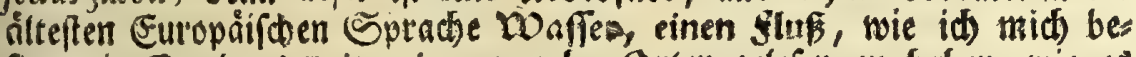
finne, in Eamoens Britannia an mebr Srten gelefen zu haben, wie es

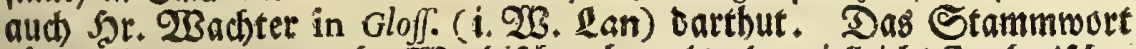

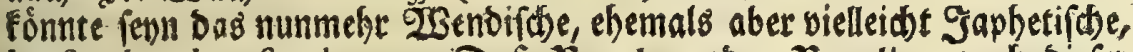
ly funde, lyt fundere. Dấ Sorslen ober Sor:lin, nach Diefer Zufammenfegung, feine vox hybrida fen, betoeifet bie \&efobichte bet. zwey Sprachen, baraus iळ gebadten Namen berführe.

Diejer gepriefene Sraf nun verbringet feine Zeit nicht mit Saftes renen, Bsejelliafaften, mit Spielen, Spajierfabrten, unb anbern \&ufts

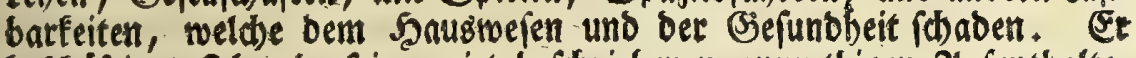

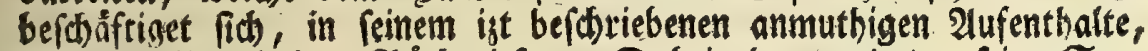
meifentheils mit bem $\mathfrak{B}$ údberlefen. Dabei aber nendet er feine Sor ge von bem gemeinen $\mathfrak{B} e f t e n$ nidht ab. Er warb fajon vor einer geraus

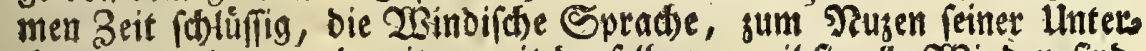

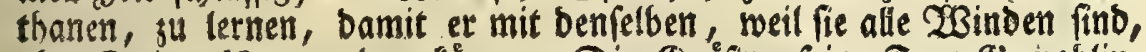

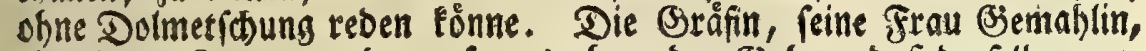
eine junge Dame, und von fo ausinehmenden Ejaben, Daßj Derfelben twe.

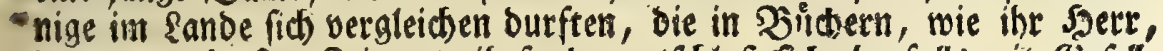

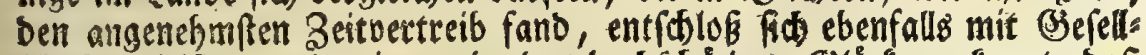

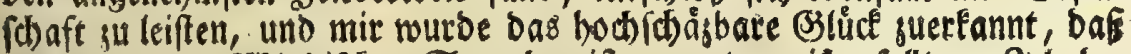

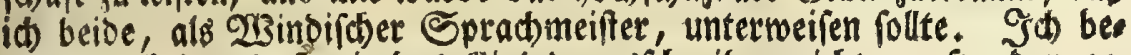

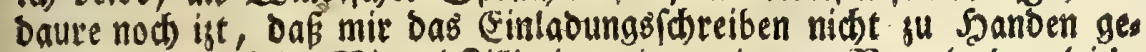

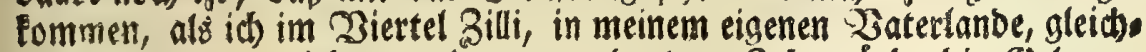
fam als ein Vertriebener, herumwanberte. Th) mürbe bie Bjelegens beit, ein fo rúfmlid)es Oertangen zu befriebigen, nidbt nur willig ets grifen haben, fondern i屯 wåre nod) red)t frob getwefen, obne meinek Mn

Sei: 


\section{Einige 3ugaben su ben vorthergefent en Linterfuchunger.}

SBeitrag eine Ebre zu erlangen, nact meldier id, auf bie minbefte ges

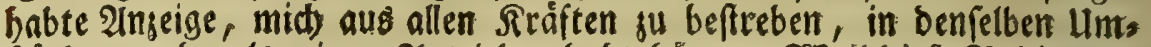

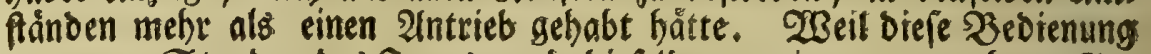

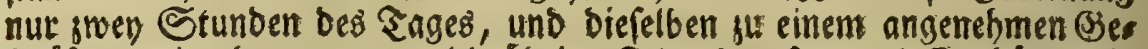
fhåfte, mir abgenommen, bie úbrige Zeit aber frey gelafien hátte, po

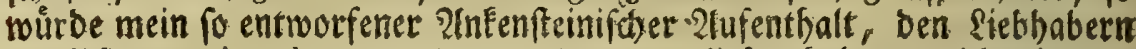
Der Pflanzen eine Floram agri Poetovionenfis getiefert baben, weid)e, in SEe. tract)tung der Seltenfyeit Der (Setwåd) Fe, nach Der Defterreidifonen, eis

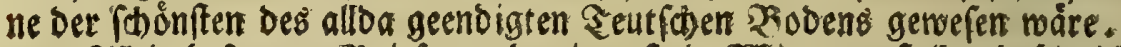

Altein bejagter Brief ward mir erft in Wien jugeftellt, bahin ids mit einer groffen saft meiner $\mathfrak{B u b h e r , ~ b i e ~ i d ~ u ́ b e r s l l h i n ~ m i t f u ̈ f r e , ~ w i e ~}$

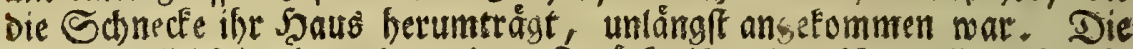

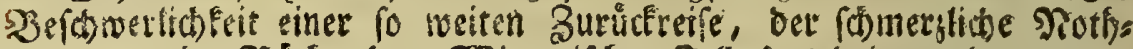

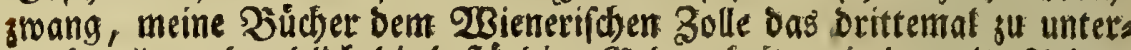

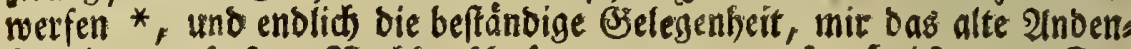

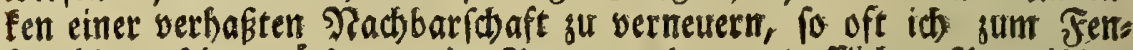

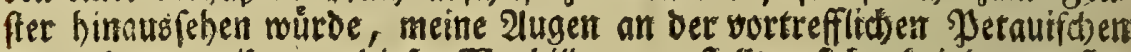
Siegend fu weiben: bieje Dorbiloungen ftellfen fidt, bei bem 'erften Anblice befagtes Unternefurens, als Sinderniffe Defferben, meinem Bses

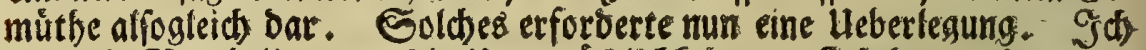

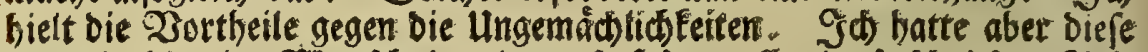

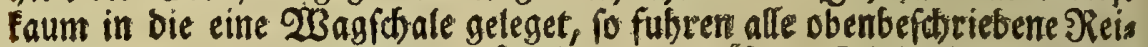
zungen auf ber anbern Seite plogtid in bie 5 gohe. Diefes bewog mid,

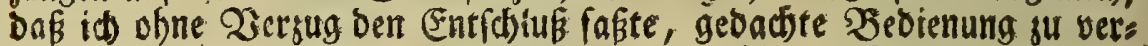
bitten, weld)es bur

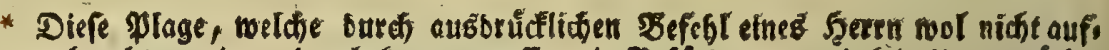
gebracht morben, ber befanntermaffen ein Beffrberer, unb fein untesorúctee

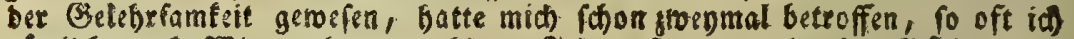

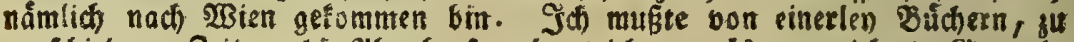

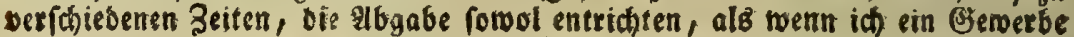

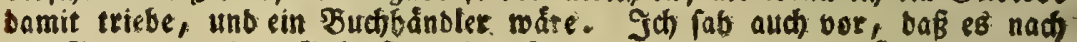

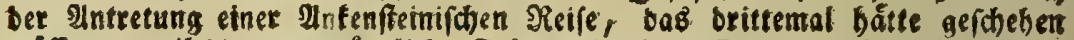
múfen, weil bie unumgainglidie Folge mik beoorfint, mad bollbractitem

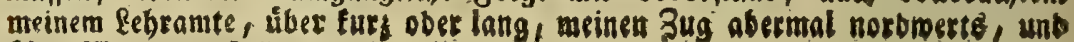
über șien anzuftellen. 


\section{ritter silocil. Sreacileje \\ von etlichen $\mathfrak{Z}$ ula $\mathfrak{a} \mathfrak{j}$,}

Die fich bei ber Berfertigunt Des Regifters gefantmilet Whaben; Daburch einige Stellen Der vorbergebenden grwey I beile ergánzet, andere erláutert QDer verbeffert werden.

\section{1.}

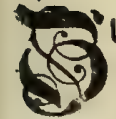

u bem Auşuge bet Sकrift de COL. HERC. S. 7, geboret bie: fe Ánmertung, baj biejenigen Dåmme, burch weld)e Sertu les, nac) ber feltfamen Meinung bes Sicilifwen Diobors, bie Defnung fwifben Spanien uno Afrifa foll enger gemadt baben, bon

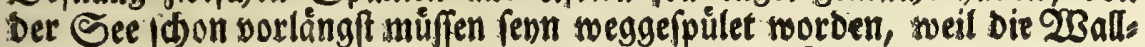

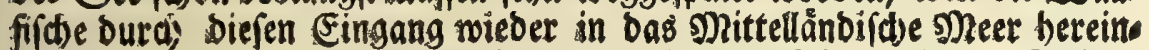

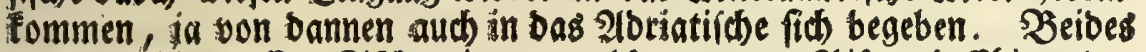
erweifen bie groffen Fifibgerippe, welde man gu Wifa unb Cbioza bet Fremben feiget. Scerr Sauptmann von Schab verfichert mid), Dafi um Sicilien und bas Sơnigreid Teapel, infonderbeit aber in Dem ge:

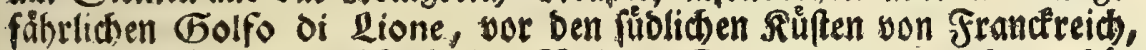
bie groffen Fifde, weld)e in ber Dulgata Cete genenmet werben, febs gemein wắren. Die Seefabrer befămen siejelben in erwebnter Bjegeno

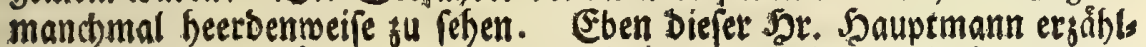
te mir, baf ungefábr im S. 1723, in bem gegrabenen Safen ju Wes faro, ettid)e fundert Schritte vom Mneere, ein foldser ffifd geftrandet babe. Man forof anfangs mit Flinten bon beiben Ufern auf Denlelben,

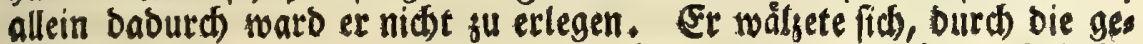

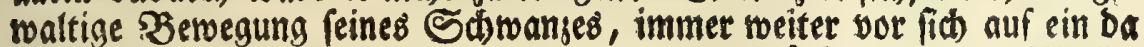
befinolicbes Sanobete, bis er mit bem ganjen $\Re$ Rucken aus bem 2 Baffer fam. Sobann fubren die Fifoter mit Safnen berbei, fletterten auf ben fijd binauf, und biebell inm mit 2lexten fo oroffe Etúcte aus Dem seibe, bis er ourd bie beftige Slutlaffung entfrăftet (melwes nicht

$$
\text { Min } 2 \text { obne }
$$




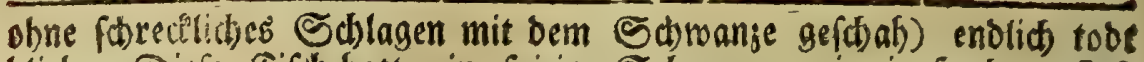

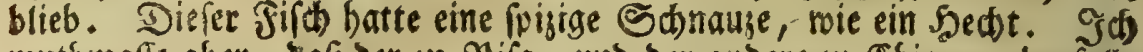
mutfimafie aber, daf ber zu Pifa, uno ber andere zu Ehio;a, ebenfalls nur Durch Strandung ibr \&eben eingebiffet haben; weil die Fifich ir bee

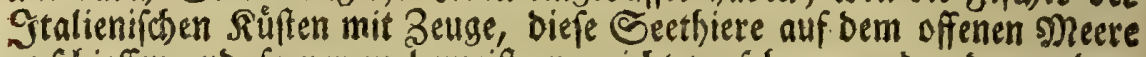
ju fhiefien und ferner zu bemeiftern, nidt verfehen, reber baju abges richtet find. Das fehr groffe (seburtsogtied, reldtes man zu Chioza weis.

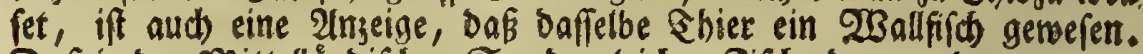

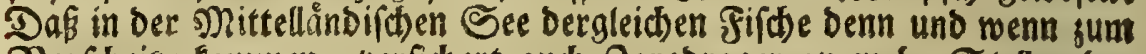
Qorfibeine fommen, verfichert aud Borgbrager an mefr Stellen ber Frónl. Filcheres ( als S. 135, 142, 153, Der 24usgabe von 1723) Durch Dog Zeugnifí Frieb. Nartens, Der im angefenden Frúflinge, in=

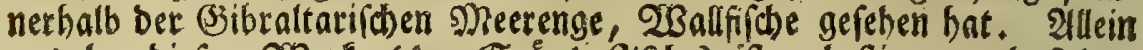
aus eben biejem 2 Berfe (sec (Fronl. Sift).) ift gu beffimmen, baf bas groffe Seethier, to in bas ijtgenannte, uno bie baranhangenden meere fich begibt, nidht fơnne ber eigentlid)e 23 allfifh) (balana vera) fevn; fowol, weil biefer fein 2 las (meld)es in fleinen Snfecten befehet, S. 137 u. f.) alloa gar nidt, ober getwistich in foldher menge nicbt wurbe fin. ben, weldbe zur (Grbaltung feines ftarten Sidrpers zureidbeno máre. Dars.

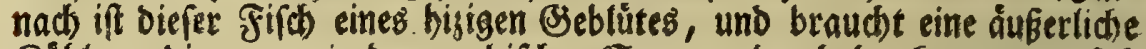
Süblung, Die er nur in ben norbifthen Seegegenden baben fann, wo er fich Denn aus biefentwenen Urfachen aufsufjalten preget. In ben beifen Dreers

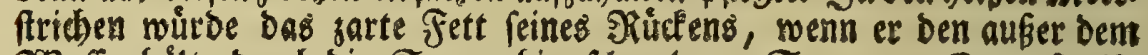

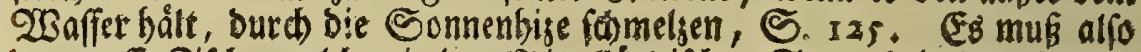

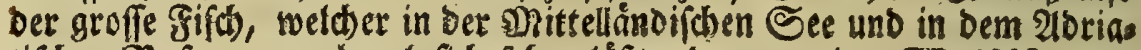

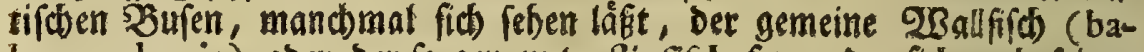
lena rulgaris) ober ber fo genannte Sinfifh fepn, Der fid nad feines

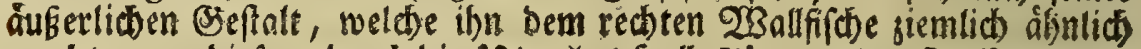
macht, yon Diefem burm bie Din * (Joll. Vinne, eine Floffe) unters

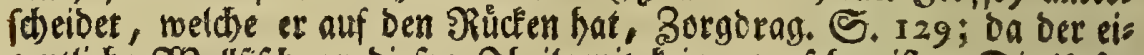
gentliche 2 allfifs an biefem Sheile mit leiner berfehen ift. Die lltias

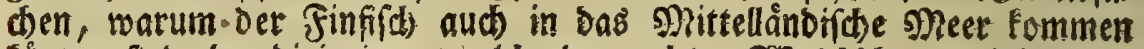
fonne, fino eben biejenigen, weldse ben red)ten 2Balfifich von biefem 3us

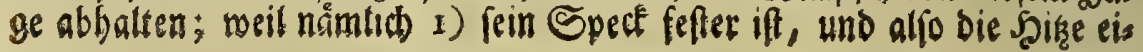

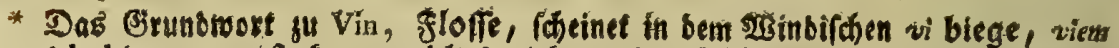
id) bisge, zu frecten, melches viele artige 2ubfammungen in iftgebacter Eprache bat. Denn bie floffen finb partes flexiles, biegige und froetartis

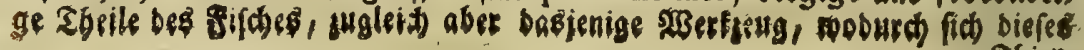


ner mårmern Suft wol ertragen fann; 2) weil biefer fifd fowol, als bet

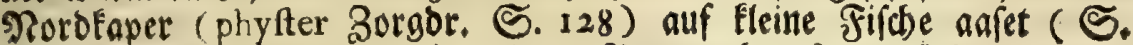
142), weld)e शrabrung er in andern Meeren eben fo gut findet.

S(d) bole biefe Inmerfung nach, um fu erweifen, dab biejenigen Religionsfpotter irren, welche bie (Sefthichte bes Sonas aus ber llrias

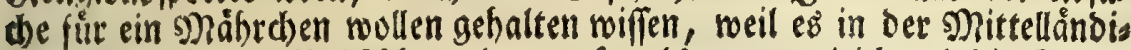

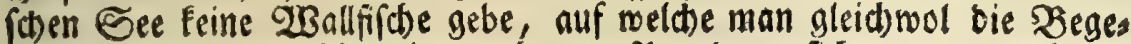
benheit ausbeutet, bie mit erwebntem

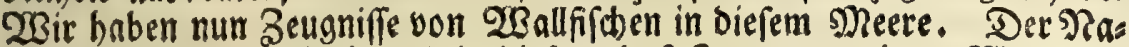
turgefthidte wiberftebet allein biejes, baß Sonas von einem $\mathscr{W}_{\text {Ballifhe }}$ foll wirflid fenn verfdsluct morben, weil bie Reble biefer Seethiere fo

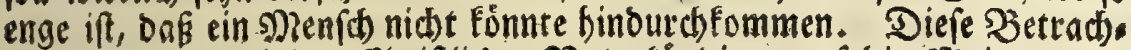
tung bat Denn einige Ebriftlid) Naturfundiger auf bie Mreinung ge:

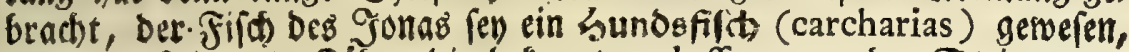
Deffen verfeinerten Bobne bie betannten glofopetræ oder Steingungen fino, welthe man in ben Steinbrúden um bie Strot Lecce in bem Terra d'O'tranto und andernertò, am båufigften aber in ben झूaltef: fhen, antrifft. Der Sळlund biefes Fifdes (menn man einen groffen verftebet) ift smar fo geraunig, baf er einen menfchen gar wol eimiteb: men uno verfablingen fann; tweil aber ia ein 23 unberwert unumgånglid mus jugelaffen werden, fo da gebindert babe, bafs der carcharias den

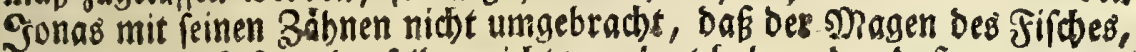
weldber es auch fen, Denfelben nidut verzebret babs, ober Dafier zum we: nigften in Diefem ouftern Serfer niфt erftictet fen, rorum balten wis

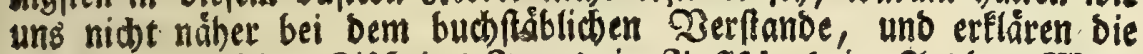

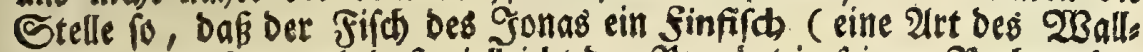
fifches ) geweren, uno bas vielleidt ber Jjrophet in feinem Pachen ober

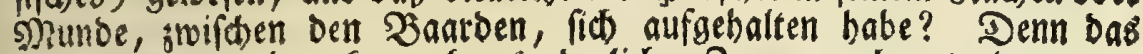

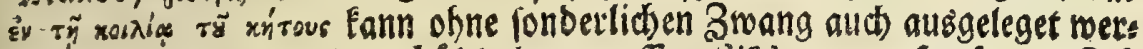
Den, Daß̧ Gonas in ber Soble des greffen Jifhes geweren fev. Ga

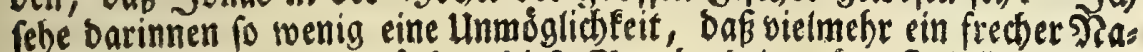

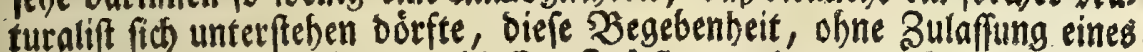
2Bunberwerfes, auf einen bloffen 3ufall auszubeuten, wosu ifm ber groffe Spalt, welden Der finfifd auf bem obern Sbeife Des Sopfes S) in 3

bat,

Sbiet minbet unb lentet, wo ez bintommen will. Bon gebactetem vi fann auch abgefúbet merben bas Echwebifde WIKA biegen, Erummen, baber WIK (flexun, curvum litus) cine 26leitung if, welches ich in Den 20 orfalligen an die Rofmogr. Bef. S. Lil, fu erinnern vergeffen babe. Zu biefer Ber panotichaft gebdret das lateinifó vieo, es. 
bat, baburd er bas 2 affer, twie ber red)te Walfifa burd bie Sprüs getód)er, ausmirft (3orgor. S. 143), wie aud bas Stranben, bem

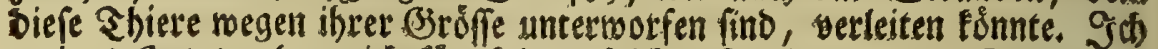
meines Srtes gebe miđh für feinen fold en 2lusleger aus. Denn weil

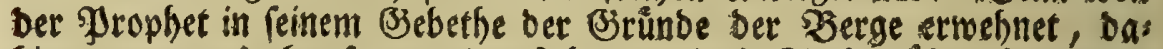
finunter er gejunfen (ev), uno geftehet, Dob bic Fluthen ủber ihn gegans

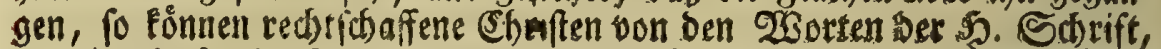
auf eine fo frenbenfente 2lit, fid) nidbt Gintwegbegeben. 23ir nuffen in ber (Jejechidte Des Gonas ein 23 unberwerk, ja Derer mehrere, ers fennen, uno glauben, Diefer Mamn feu Durb eine befondere Sdickung

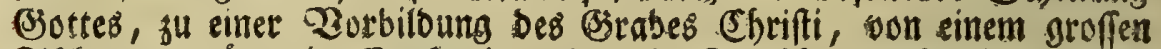

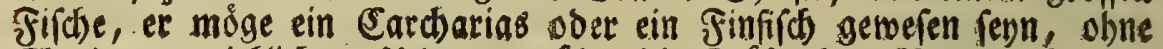

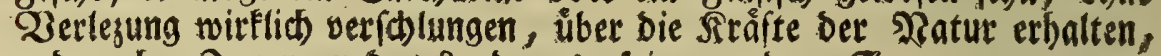
und nad) 3 ?agen an bas fand ausgefpien worben, Jon. $2, x 1$.

\section{II.}

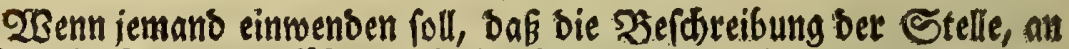
weldber bie $\$ .24$ angefúbrten Meilenfteite ausgegraben worben, gar viele Rleinigfeiten, und unnuge Ulmftảnbe entbalte, fo werben folgenbe Zeugniffe biefe Weitlăuftigteit entfhulbigen. Sn ber allookt genannten İbhandlung DE viIS MILITARIBVS ROMANORVM PER GERMANIAM, ftebet S.

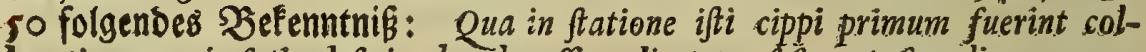
locati, proprie fatis definire baud pofis, licet prefeferant finguli numerum VI. bafi fue infcriptum, qui baud dubie totidem pasfuum millia defignat, et ad oppidum majus quodpiam erit referendus. Dás biefe Stabt bas als te CELEIA fev, båtte ber Sar. Y3erf. aus Raym. Duellii EPIST. ad D. de Boxadors Comitem de Cavella, erfeben Eonnen, in weldbem Sdreis ben befagte Steine um einige Gahie eher, als in Den Deronefiften Offervazioni Letterarie, befannt gemađt) t, und von ber 26 S. an bes fabrieben worben. Der Sinfang lautet fo: Addi bifce 'omnino merentur $V$ lapides miliares (milliarii) in commemorato fuperius Celeiano territorio detęti. 2llein bas ift feine fo beutliche Anzeige, baß meine SBe(chreibung bes eigentlichen Ylajes, too diefe Denfmale aufgebractst worben, befss regen foll als überfiúffig, ober bie fernere Slage bes Sch. Stegers für ungerebt zu halten fenn, bes in ben Inmerfungen zu bem funften Neis

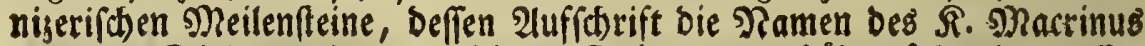
uno des Diabumenianus, feines Eohnes, entfålt, folgendermaffen fhreibet: Cave tamen a nobis expectes penitiora iftius (vix) indicia. Ex seftebet, er miffe nidt, welder Straffe \$reilenmaak biefer Stcin 
foll gewefen fenn, uno fäbret weiter fort: Nibil nos illorum babemus compertum. Nibil bac de re fufpicionis fubminiftrat primus columna bujus

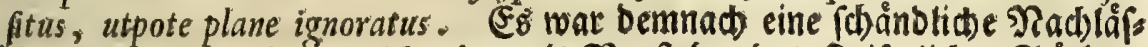

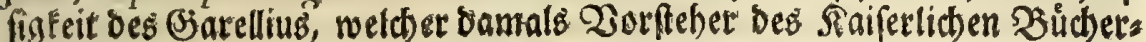
fales gewefen, dafi ex bie Stelle diefer Steine, die er not genust, reil inn meine sandesleute darauf herumgefúbret, anjumerfen unterlaf́ fen bat. WBie et bei andern Denfmalen, bie auf fein 2Ingeben, bon bem Billerifden Sathbaufe, von anoern s) auren, beruntergeriffen wors

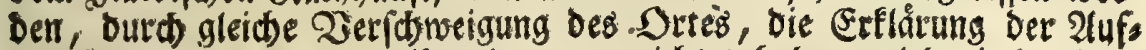
fobrifter, foviel es an inm lag, betnithtet babe, wird eine andere 2lbfanolung zeigen, Dalaus zugleids erbellen foll, wie feht bes Detos

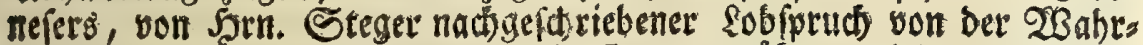

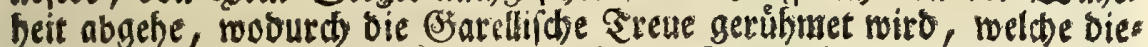
rer (3)lefrte bei ber Sammlung erwelnter Steine bewielen babe. Die Worte lauten ungefäbr fo, Denn id babe biefe Sobrift nid)t bei San: Den: cue mandata, quanta fide executus fit Illuftris Garellies, copiofius exponit eruditifimus obfervationum literariarum Veronenfium auctor. Das ift getwif, baf einem, ber bon ben Umftånden gebadter Steine beffere Sumb fobaft bat, bie istangezogene Stelle allerbings ectelbaft vortommen múffe.

\section{III.}

Die 230 onte, Jllein find nidt, Surd gar su groflen $26 \mathrm{~b}=$ frand ber Jeiten, mebt wabrbafte Gefibidte deg grauen 2ltertbums in Sabeln verwandelt worben, (11.1Interf.

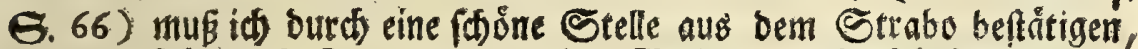

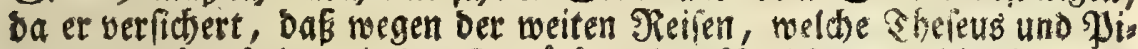

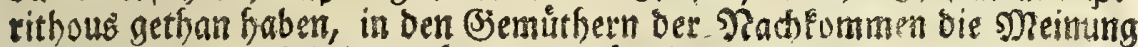
entftanden fen, biefelben wáren zur Sgifle hinnbgeftregen. Die vertreffe fiden mytbologifhen 230 orte diefes Sdbrifftellers verwienen ganj biefer gefest zu werben: Si de iis loquitur, quorum ad nos perlata eft memoria, equidem nibil verear dicere, antiquos longiora terra marique confeciffe itinera, quam pofteros, fiquidem biftoriis fides adbibenda eft. Rerbibentur enim Baccbus, Hercules, et ipfe Fafon: tum ab Homero commemorati ulyffes et Menelaus: Thefeum quoque et Piritboum trobahile eff propterea, quvd longinquas fecerint expeditiones, banc de fe opinionem in animis bominum reliquife, quod ad inferos defcenderint: eademque de caufa Caftores maris effe procuratores diatos, ac navigantium fervatores \&x. I, 48.

IV. వut 
Dritter \$beil.

IV.

But S. 67 nad) ben 230 teten, Utebr beiondere Gtróme, die auf verficiedenen Theilem ber groflen Gee beobadtet

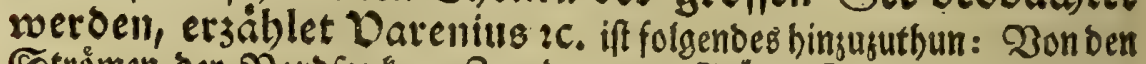

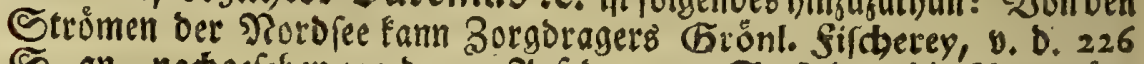

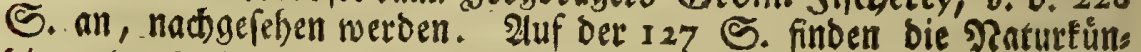
biger eine 2ufgabe, warmn in allen falbrbaren Geen bont $\mathbb{K}^{\mathbf{Z}}$ ropa, peit so Jabren, die Gtrome 3to eymal f

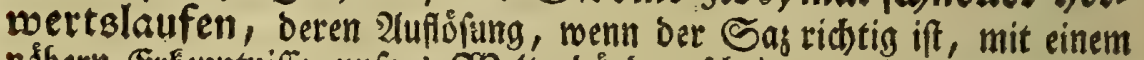

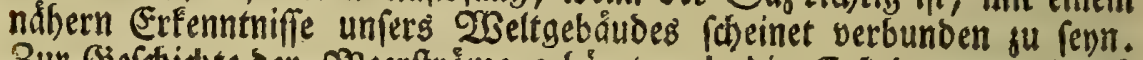

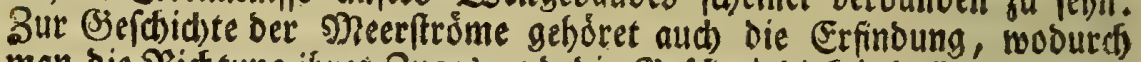
man bie Piidtung ihres Buges, und bie Befditoindigfeit beffelben, erfahs ren fann. Das if bie Entbeçung zines Jrancifaners yon Dourbeaup, Göt. gel. Jeit. I750, XLIV, 349.

Das ift eine Zugabe, rooburd id eine S. 73 u. f. votgetragene Zerficherung befraftigen will. Ith fagte bafelbft, Da ber ber Rirderi

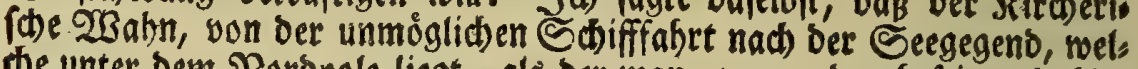
the unter bem Norbpole liegt, als ber man, wegen ber beftigen bahin: fiehenden Meerftróme nid) beifommen fơnnte, burd bie Zeugniffe ber nordichen Seefabrer miberleget werbe. Meimes Srtes hege id von biefer (Segend feit langer Zeit folgende Đ) einung, baf in Derfelben, soenn

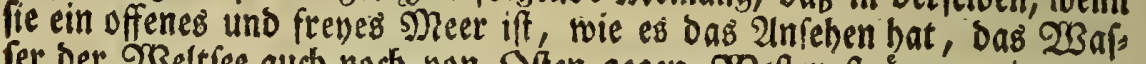

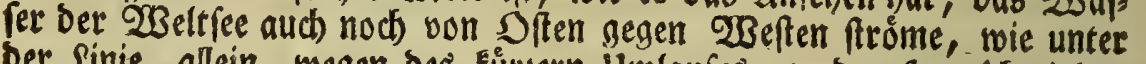
ber sinie, allein, wegen des furrjern llmlaufes, weoer fo gef(t)winbe, now mit foldher Macht, weil bie Rreife, weld)e bie umorehung bes Neeres allda macht, gegen ben 90 Srao hin, immer Fleiner werben, wie bie \$arallelen auf ben nad)gemadsen Erofugeln; und unter bem 90 Brabe muß̧ bie See, bei einer 2 sinoftille im Sommer, in vollfom: mener Rufe fteben. Diefer Sagen habe id bei Jern. Probirector ber

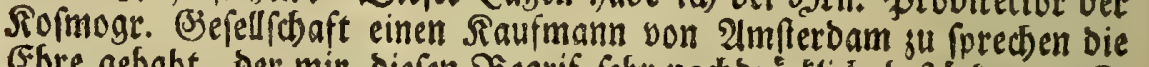
Ehre gefabt, ber mir biejen Segrif fefte nacboructlid) beftarte. Er

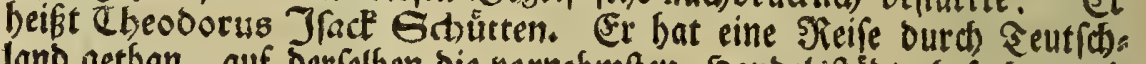
land gethan, auf berfelben bie vornefmiten Sandelsftibte befudbt, uns gebet ist wieber nach 2lmfterbam zurúce. 2ills ith mit Demfelben úber

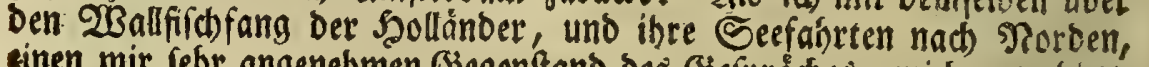

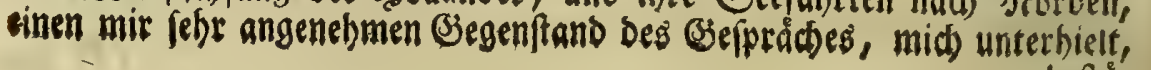
beftå: 
beftirigte er meine 23orftellung von bem auferften norbliden Sheile un. ferer Erofugel, burd folaenden Beriat. . Er betheuerte, Daß̧ ber zu 2imferoam noch lebende Conmandeur eines Stratbavisichen Schiffer, Dutman Kor ames im S. 1737, um auszufunbfhaften, ob es beffer

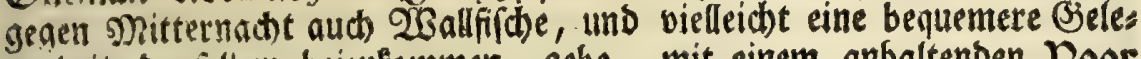
genheit benjelben beizueommen, gebe, mit einem anhaltenben Door $^{2}$ Winor (was bie Jatalienifacn Seeleute vento in poppa, bie Jrangos (en vent en poupe, nennen) immer gegen গlorben forgefegelt fen. (5t Eam endich) auf eine (siegend bes Meeres, oa er wahtnabm, bas bas

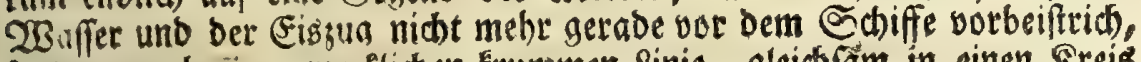
fondern nad) einer merelichen frummen \&inie, gleidf fäm in einen Sireis berum, fith ridtere. (Ex rah nad) ber Seefarte, und befand, bafert aufer ben brgher befafrenen (Siraben, auf ber cuserften Norbfee ware; et fehrete looann wizoer zurücte Diefe Ersählung gebỏret ju-Den

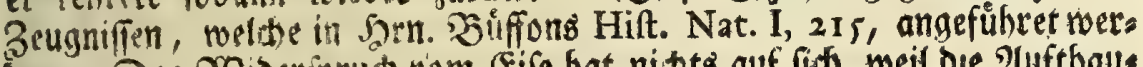
ben. Der Wiberiprut nom Eife hat nithts auf fith, weil bie Alufthaus ung nicht alle Gahre rinerlen ift. Die Naturfúnoiger, welche vorgebact): ten Eeefabrer ;u forechen (3)elegenheit haben, werden obne Zneifel nod)

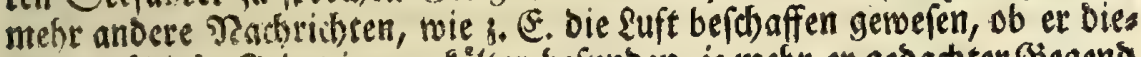

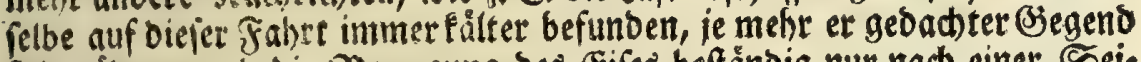

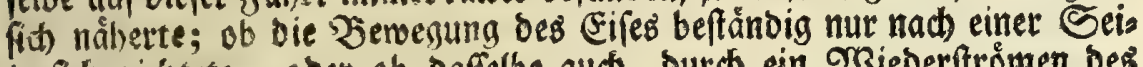
te fí ribtite, ober ob Daffelbe auch, burdh ein 2 Bieberftrơmen bes

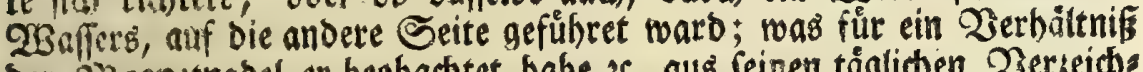

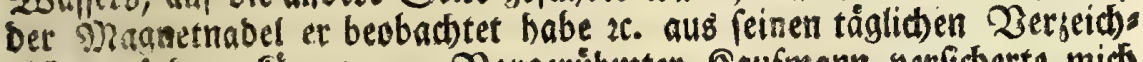
niffen erfahren fönnen. Sorgerubmter Saufmann verfid)erte mids

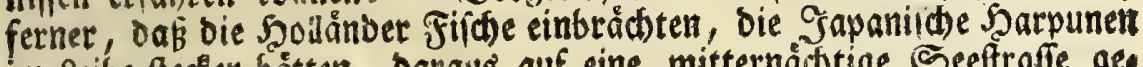
im seibe ftecten hátten, baraus auf eine mitternådtige Seeftraffe ges faloffen wirb, baburd man in bas Dftindifhe meer fommen fơnte. (Ex

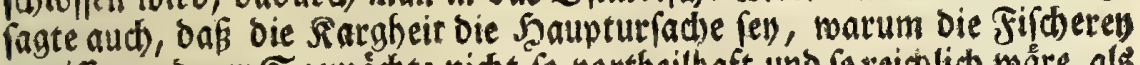
gewiffer anderer Seemáchte nicht fo vortheithaft uno foreichlich toare, als

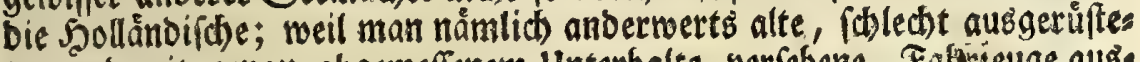
te, unb mit genau abgemeffenem Unterbalte verfehene, Fafageuge aus:

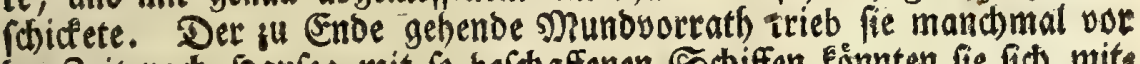
ber Zeit nad) Shaufe; mit fo befhaffenen Shiffen fornnten fie fid mits ten in bas grofte (Fis nidt hineinroazen, Da aber eben bie meifen Fiifhe

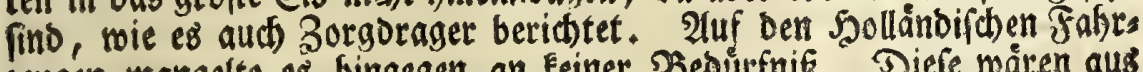

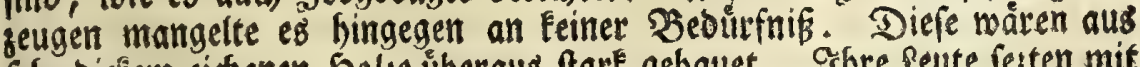

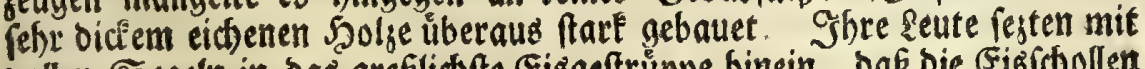

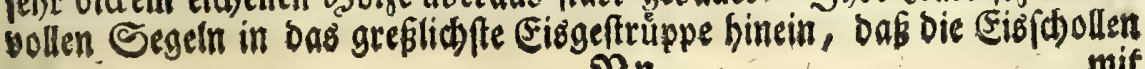
Pn 


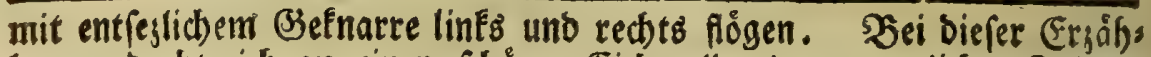
lung gebachte id an einen (t)oinen Eidbwalo, ber vor etliden Jabien in einem Sefterreidifichen \&anbe, nicht obne 2ibnoung oes Scofebs, Durch

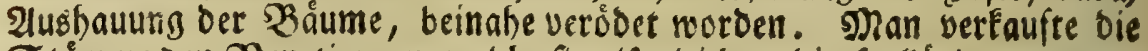

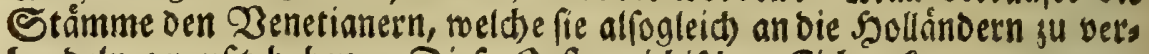
banoeln gewufst baben. Diefe Sefterreidifonen Eichen freusen nun um

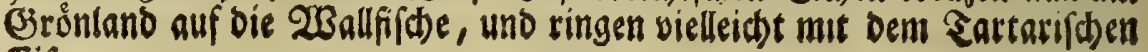
Eife.

\section{VI.}

S. 74 Kabe id bei bem Sberidte, bap bie Seeleute bas Welts

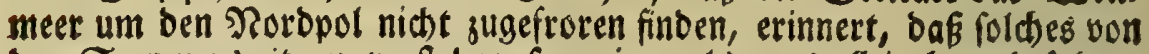
ber Sommerszeit zu berftehen fey, in welder es allein fann befahren merden. Denn Daß im $23 i n t e r$ bie See um ben Norbpol auf 25 Bras De mit Eife gant gefeblofien fen, erbellet aus Borgbragers Grónl. Sis

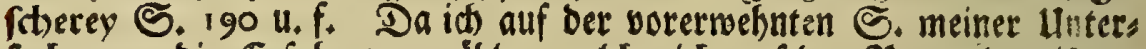

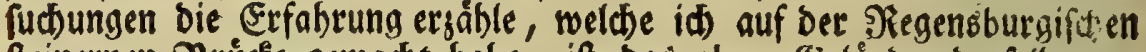

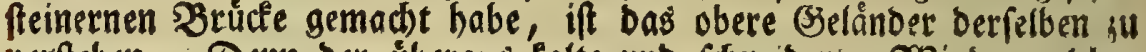

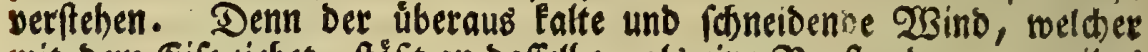
mit Dem Eife ziebet, ftogt an baffelbe, als eine $\mathfrak{B}$ ruftweht, an, weil es eine gante 2Band ift. Er bridht fid an biefem 2 siberftanbe, und fábrt etwas hober Daruber nach ber STichtung bes Stromes abwert', Daß̧ als

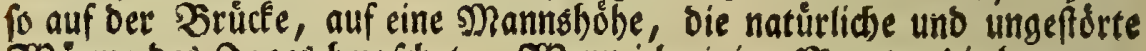

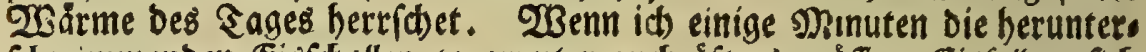

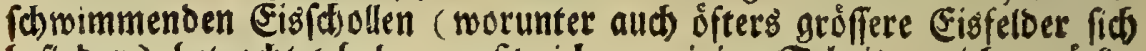
befinben) betrad)tet habe, mufste id um einige (d)ritte mich suruefes jiehen, unb auf ber Brücte wármen, wo es, in Wergleidung mit ber Rálte, bie ich an bem Bjelånder empfand, fo watm war, als in einer gehigten Stube. Neine Kegierde biefem Eisuge beizumohnen, war fo gros, bas ich an einem 1)re, Den id mit Zufatauern am bidsteften belest fand, einem saglóbner feinen झlaf abfaufte. Diées bat, als ein das felbft neues Exentel, einigen Serren von Regensburg, meinen Bön

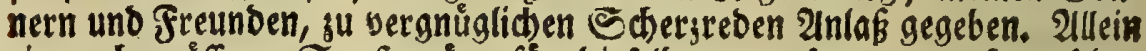
ein now) grofferer Spaß wåre fúc biefelben gewejen, wenn fie gejehen båtten, wie id) in bem Bruberwerb vor bem (Eife bie Flucht nebmen muste. Denn alloa thurmet fít) Das úbereinander uno an Das fand gef(t)obene (FiB, wie bei allen Srúmmungen ber Donau, auf bie Art auf, mie an ben Spizbergifđon Seúften, nur bak bie Eišberge Der Donau fleiner fino. Hm nun beffer in Denjenigen Arm bes Stromed, weld)er 
ben Bruberwerb vom llnterwerb abiondert, fineinfehen su fónnen, flets

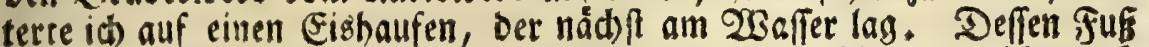

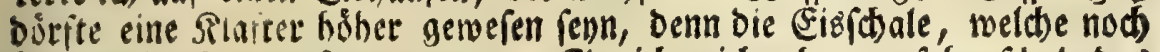

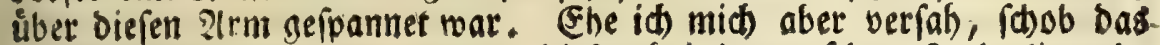
natifommende Eis baś vorbere, biefes hob bas auf bem sande liegende von ieiner Stelle, mein Şaufe ward rege, bas ploglidh aufgefdwollene 2raffer fiens an mid von allen Seiten umburinnen, ba mufite ich laufen, um nidst wiber meinen $2 B i l l e n$ nad 2 Bien gefúhret gu werben, unb rets tete mid nod) fümmerlid auf ber $\mathfrak{g l a n f e}$, mit welder berfelbe 23 erb aingefangen ift.

\section{VII.}

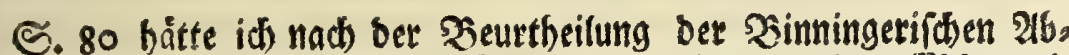

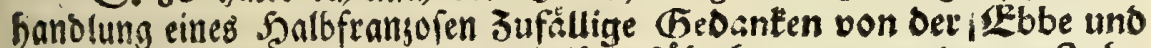
Flurb anfübren follen, weld)e Sd)rift ju sủbeck vergangenes 1749 Jafkr, auf zwey Bogen in Sataugróffe herausgefommen. Der Yerfaffer wäs: met bie Meinung ber 2 liten auf, bie id von ber 110 S. an, aus ver. fohiedenen Sbififtellern entworfen habe; weldbe bas Strómen bes Neeres, fo aus bem Gnnerften beffelben nadb bem Umfreife, ober nads feinen kukerften sheilen geidsehen foll, bem umlaufe bes SSeblütes in Den Fórpern ber Shiere vergleidhet. Er meloet aber nicht, twer ifm . fu bies

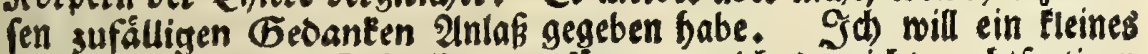
Mufter von feiner Sd)reibart anfugen, weldes mid)t redt)tertigen wirb, Daß iఉ Denfelben einen Şalbfranzofen genennet babe. Er lefret, " bás in ber Zeit, als ber Mond einmal bie Tour um bie Erbfugel " macht, bie Marée zwenmal erfheine; bas ibr Effect an ben \$leerlü. "ften in groffer Etenduie zu fehen fen; Daf fie fich Durd bie Embouchu"res ber Fluffe aufwerts communicire, jebođ mit Diminution. $\mathfrak{E r}$ "Fejet eine Proportion jum Fundament, und fupponiret auf eine sheit "einen Fus Diminution; Denn man fehe, Daß bie Extenfion ber Ma"rée in einen Sinum ober groffe Embouchure, in horizontalem Mou"vement, auf eine \$neil cinen Fuß diminuire. Ev formiret bernad " eine Tabelle, aus weld)er man agnofciren fonnne, wie viel bas vehe" mente Mouvement vom Centro Terræ bis jur Circumferenz obet "Peripherie bes Globi in ber Force verfiere, woraus er bie Jyóhe ber "Marée determiniret. Er nimmt aud bie Origine ber Fontainen in "Confideration. Er examiniret, wieviel $\mathfrak{Z}_{3}$ affers ber $\Re$ Regen fournire, uno expliciret, wie baffelbe in bie Eroe penetrire, wenn biefe "Darsu difponiret ift; wie es bernad unter bem Niveau qusbreche, 


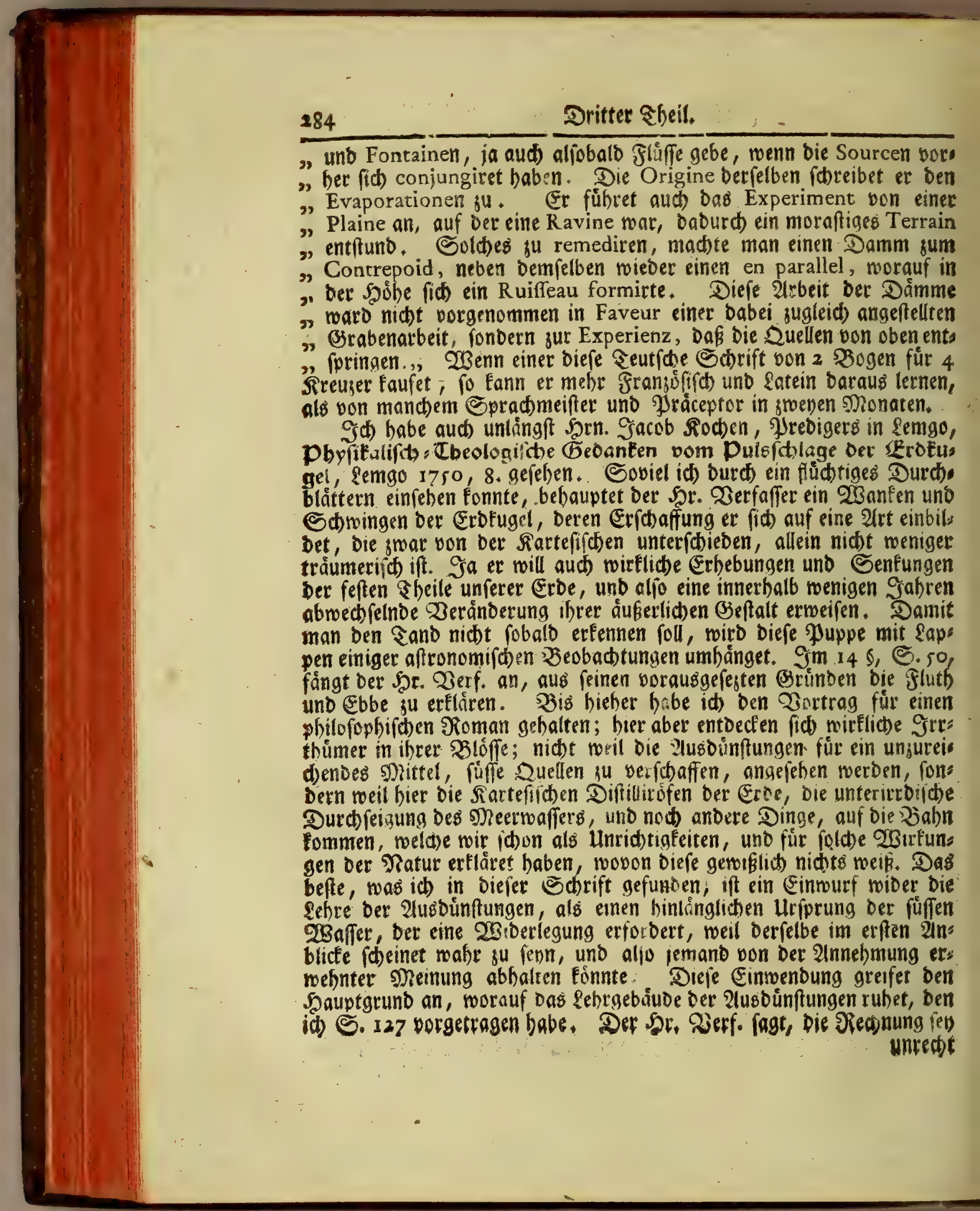


शadilefe von Bugaben.

unredt angeftellet morben. Shan habe bas Siegenwaffer fo auf eine ganze Jjegend, Deren Bierge uno Ebenen, fállt, in Die Piectnung ge: bract, und baher frenlid nidts allein auf ein jureichendes, fondern nod)

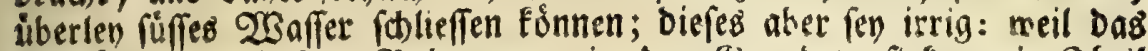
Semáffer des flachen Bobens nur in Den Brunb verfintet, ein Sheil Deffelben aber von ber Oberflåche Des (Erbreichs in bie Trtiffe fállt, alios gleị̦ binwegftrómet, bem Meere zueilet, und gu einem beftänoigern

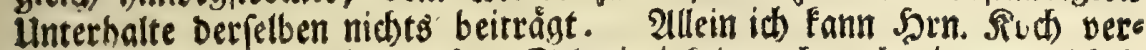
fichern, baş feine aufgeworfene Schwierigfeit aud now einen unrid)tis gen $\mathfrak{B}$ egrif jum Grunde babe. Denn bie Tliffe, Die úber Ebenen hin: freidien, liegen gleidbwol nod) um einige S(tub) unter Der Sberfind Der (Eroe, und werben nid)t allein burd) bas Siegen. ober Sd)eewaffer vergroffert, weldbes bon oben bineinfétefst, uns Ueberfchwemmungen berurfacbet, fondern Das ylatte Eroreich felbft Eann biefelben nod Durd) viele Quellen ermảhren, biefe aber werden burd Das Segen: Sonnees Shau: und Rebelwaffer unterhalten. Soldhes bejeugen erflid) bie SBrunnen, die am Kande Der $\mathfrak{B e t t u n g e n ~ D e r ~ F l u f f e , ~ m a n d m a l ~ n u r ~ e i n e ~}$ Spanne über Der 2 Safferfiche, entipringen, und zwar in folden Stri: den von fảndern, wo es weit hrrum feine Şerge ober Shügel gibt.

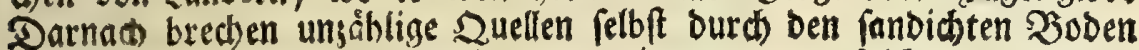
Der Fluffe unter bem $28 a f e r$ beraus, wie man es an folden Surten bes obact) ten fann, wo ein Flus einen andern \&auf entweber felbft nimmt, ober burd) eine albftedung uberfommet. Denn ba if zu fehen, wie an vielen Crå̀tten bes verlaffenen Banges, Das 23 affer nit Ulmtreibung Des Sanoes, artig aufwalle, als menn es fodete; und folches bergeftalt, baß malt nidbt nur eine Defnung, fondern beren wol funfsig und bun. bert, von allertey Sireffen, wahtnimmt, bic alle an einer Stelle náber beifammen, ober in manduerley 2 bftanbe voneinanber, ibr anmuthiges 2Bafferpiel treiben; und foldes wahter fo lange, bis burch den Ders Jauf einiger Sahre, Das fandichte alte sager Des Fluffes, burch einen Heberzug von Erbe, Der fich von Gabren zu Sahren anjezet uno erbo: bet, allenthalben jugeithloffen, und ju einem 2 aufeloe gemacht mird. Diéer Einwurf fiteinet aker gleid)mol folgenden Nuten ju baben, baf et uns argmohnen láfit, melchermaffen ber Heberíbus des berechneten

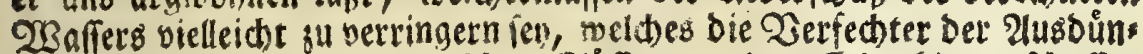

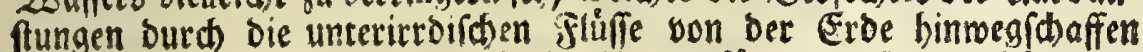
múffen; meil Dasienige, fo auf bie Ebenen făllt, gleidnool nicht alles

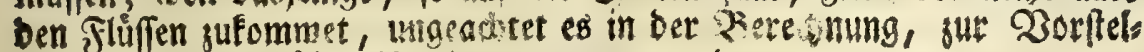
lung Def Şauptgro̊fle, if mitgenommen norden.

श口 3

VIII. \$3ei 


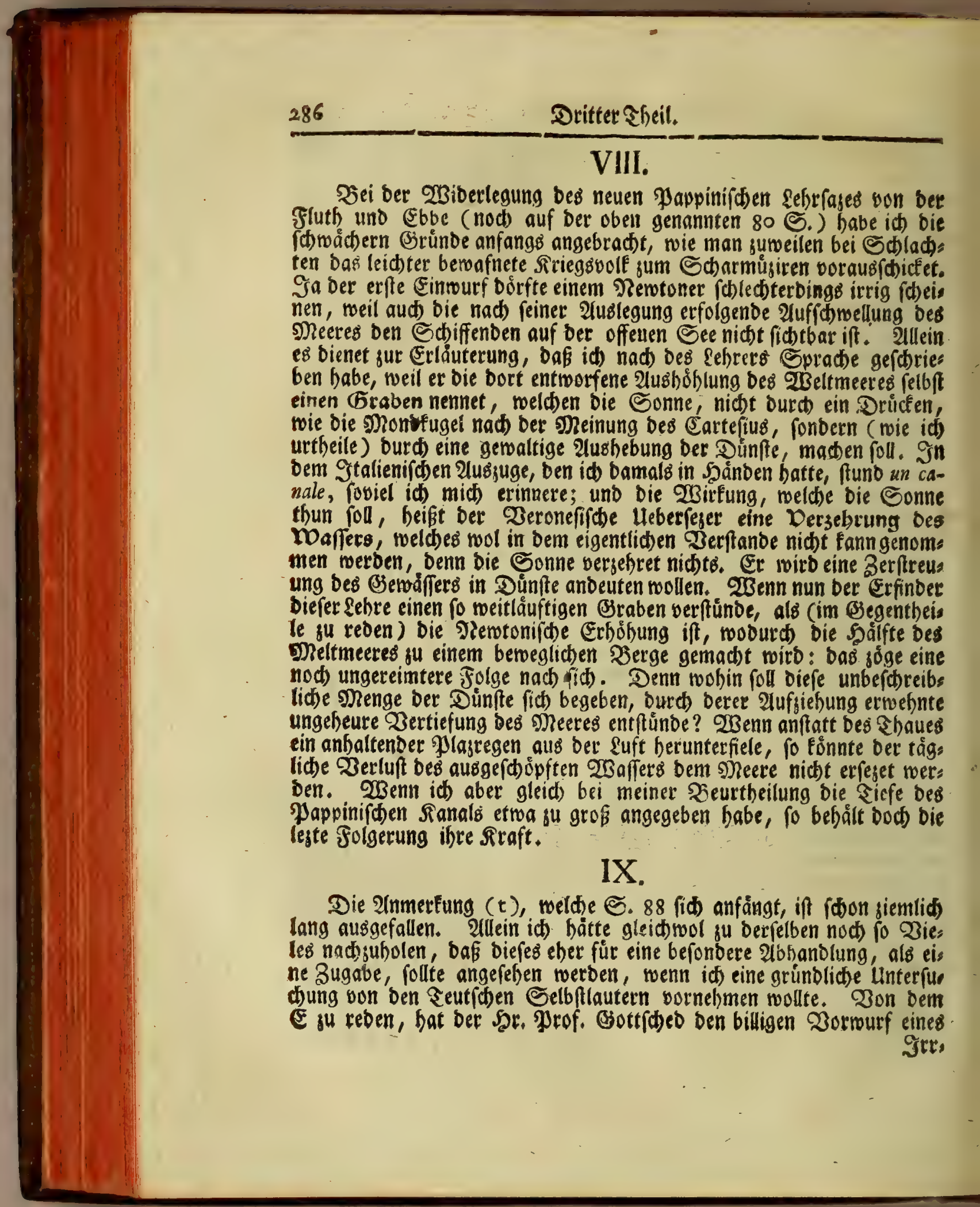


Grrtfums fid jugezogen, oa er bas lateinifhe E mit bem Franjófifiten in Zergleidjung leset, alö wenn bie Fransofen nur eintes, wie bie $\mathfrak{E} a s$ teiner, soer bieje berfélben fo viele bätten, als bie Frantoren. Denn bie lestern haben, roie bie Syebråer und bie Slavonifhen 2 beller, ein viers fached e. $25 e n n$ ber Spradjlefier bie Seutfoben e nur mit Den Fran. jófíf den verglid)en bătte, fo getrauete id mir, jum renigften aus der Stenermárfipthen \$nundart, denfelben gu redtfertigen. Denn biefe bat exftlic) ein (क)arfes $e$, wie in frellen ponere, weldes aber nicht fo

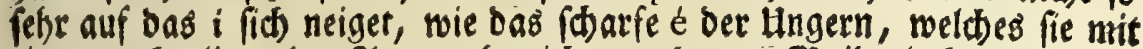

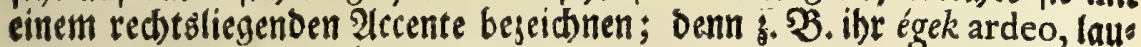
tet faft wie iget, mit einem bunflen 1, Das ég aer, ather *, ( Pariz 230 ora terb.) Gringen fie beinahe fo vor, rie bie erfte Sylbe in bem lateinis foben Worte ignis. Ferner hat bie Stevermårfifate Munbart ein bis cles $e$, wie bas erfte in fteblen furari, wie audh ein balb fummes in graben, und allen Enoungen Der Zeitworter. Dem vierten Franjofie

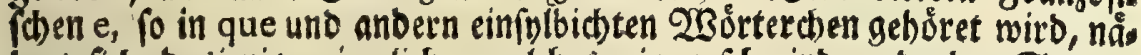
bert fid basjenige jiemlich, weld)es ein gejtwinde rebenber Stener.

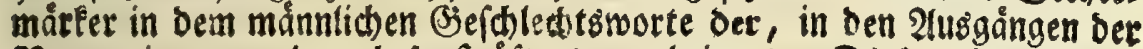
Namen in er, und now ronft ofters, vorbringet. Dieles vierte Fran zofifithe e, von bem in \$lepliers Sprad)lefire mit feinem 2 sorte ges

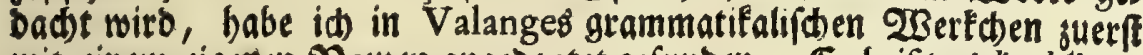
mit einem eigerten Namen angedeutet gefunben. Er beiftes l'E bêlant,

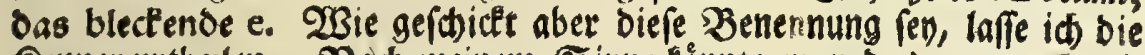
Fenner urtheilen. Fads meinem Sinne fơnnte man bas e ouvert mit

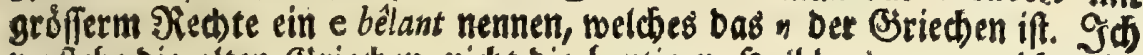
verftehe bie alten sriecten, nidts die beutigen Salbbarbarn, weld)e Dies

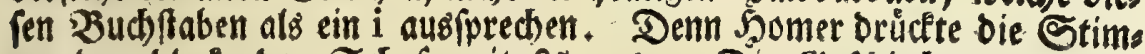
me ber bleckenten Schafe mit Bỹ aus. Die Befdilectronamen ber

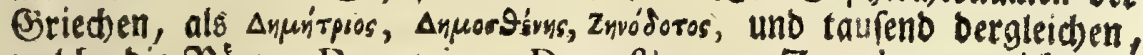
welche bie IIdmer, Demetrius, Demofthenes, Zenodotus, nich)t Dimitrius, Dimolthenis, Zinodotus, gefatrieben, ja now mehr annere Brunbe, befreiten bie ungereimte 2usfpracte, bie Peudtin von ben beus tigen (Sriect)en gelernet, unb mit foldhem $\mathfrak{B}$ eifalle in ₹eutfhlans auss gebreitet bat, Dap wir Daraus erfennen, wie febr bie rafende Şegierbe

bet

* E'g if ein Scntbirdes Etemmmort fonol gu bem ungtifchen tgek ardeo, als fu bemlateinifain ignis, unb ein leberreft bon bet Eepthifhen Pbilojophie,

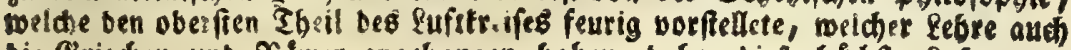

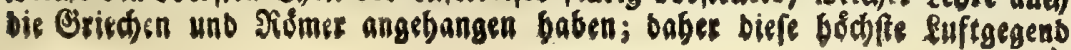


Der Neuerungen ber Bernunft überlegen fen. Tab habe bas vierte

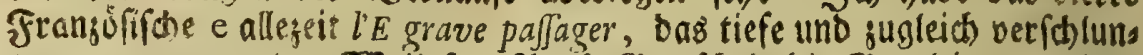
gene e, genennct. Weil Srr. Yloof. Gottiched bie (Sirundegung einer Deutichen Sprad) funft aut fur bie Gtaliener unb Fransofen gefories ben, fo follte er nol bei ber Eneflárung bez e eine 2mmerfung fur biefe

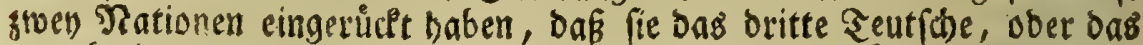
nut halblautenoe $e$ wol in 2 (d)t nefmen, unb fid huten mónten, in Den Enoungen ber Seitworter, wie aud) in ben mannlitien Ramen, welche in er alsgefen, bas e lang ober gebefnt auszufprechen, wie fie es zu thun nflegen. Man mus ihnen die Stellen biefes halbftummen e zeigen, Denn fie bringen alleseit loben, 300 ér 26 . heraus, anftatt ben FGon auf bie erfte Solbe gu merfen, und dab Eno: e zu verbeiken.

Mein Berid)t von bem Sbetteutichen a (S. 89 4. f. in ber 21

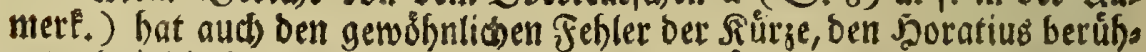

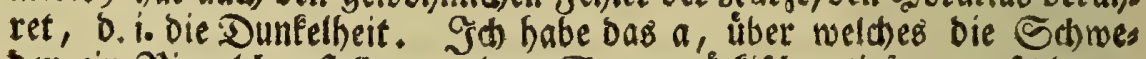
ben ein Pingelden ftellen, zu Dem Stevermårfifben tiefen a gefitlagen, meld)es bod, nach genauer Yrúfung, Davon muß abgefondert werben. Es gibt in ben Europaifchen Eprachen aut) viererley a. Die Miund: art ber Stenermårfer, Defterreither, und anderer umfiegender. Feus

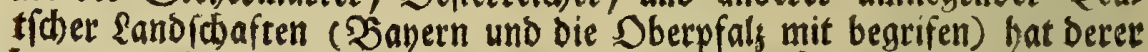
orev, weldse burd unterfsiebene Bilbungen múfen angedeutet wer:

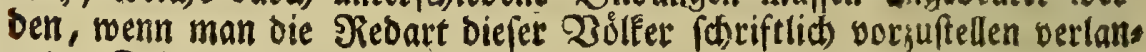
get. Das gemeine a berfelben bat einen Mittellaut zmifhen a und o,

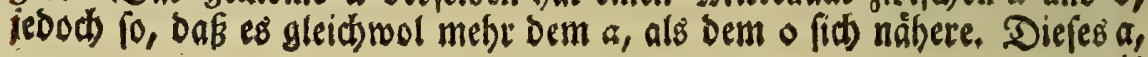

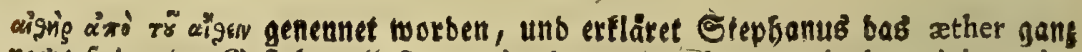
recht folgenber B̈efialt: "Sunt qui stberem pro elemento ignis accipiant, inter quos eft Anaxagoras. "Die Sonne und alle Eterne bildeten fith bie als

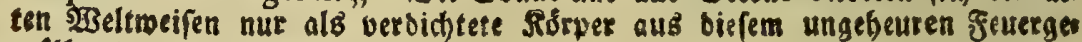
poflbe cin, wie uns (sicero, Nat. D. 2, 36, berfithert: "Hunc (aerem) rur" fus ampleatitur immenfus xther, qui conftat ex altiffimis ignibus. Uno "gleich batauf: Ex xthere igitur innumerabiles flammæ fiderum exiftunt; 23. quorum eft princeps fol \&c., Von bem 23 etterfteable mahten fie fich folgen:

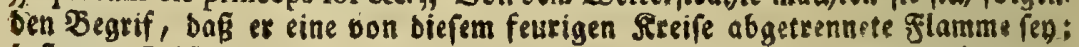
befinegen VAL. Argon. 1, 616, ppridt: ". - Vafto pariter ruit igneus æther Cum fonitu., Shiereus etfebt man auch, wie burd) nad)gefigte Erefle: "Arces attigit igneas, HORAT. Od. III, 3, 10, bet feimmel fu berfeben fen. Dies

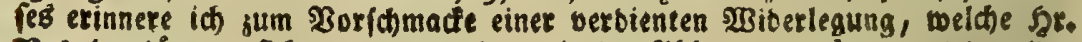
Bel ber jungere fich jugefogen, oa et in ber $26 b$ andlung de peregrinitate ling. Hung. bas ég, mit vielen anbeen sof́rtetn, unter biejenigen gefeje gat, bie 
als bas gewoinglid)fte, uno welches gum ofteften vortommet, bebarf feis nes Merf geidents. Daz gwente ift oas belle $a$, weld)es fich mit bem $N$,

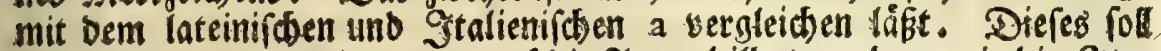
mit einem Sd)nerfel, etron auf bie 2 art gebilbet werben, wie bie Stas fiener bas a seid)nen, wenn es bas lateinifote 2 sorftellen rofl. So wirb bas helle a im 2 Bendif

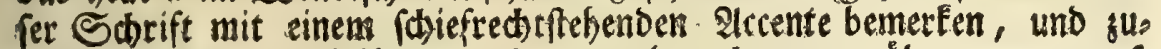
weilen nur ein lateinifhes a barku gebrauden, worủber man gegor. fene bergleiden Stridhelden hat. Das bellefte a Der Stenermárfer uno ihrer Epradiberwanden Dberteutid)er (weld)e ein Mittel

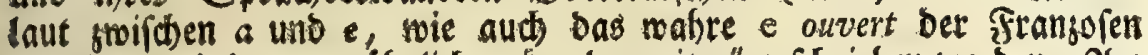

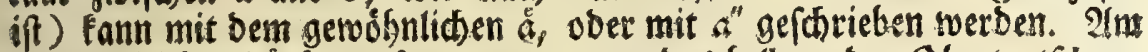

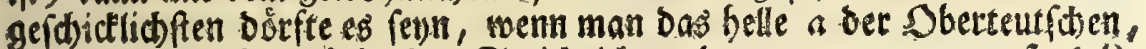
mit einem (t) iefred)titebenoen Strichelchen ober accentu acuto, fo $\left(a^{\prime}\right)$, unb bab \& mit jwewen bergleidsen Strid)elden $\left(a^{\prime \prime}\right)$ begeidsmen wollte.

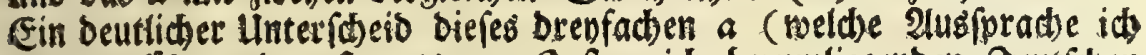

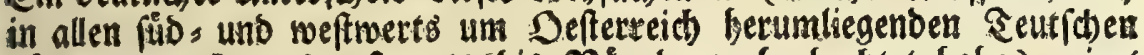
eanbern, aud norbweftwerts bis siurnberg, beobad)tet babe) jeiget

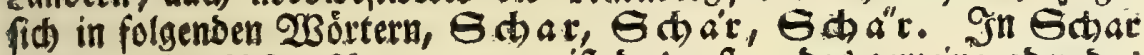
rurma, obee Dflugftar vomer, if Dab erfte, bas gemeine ober bas tiefe $a$; in Eक $a^{\prime}$ forfex, Das swente ober a as belle $a^{\prime \prime}$; und bas brits

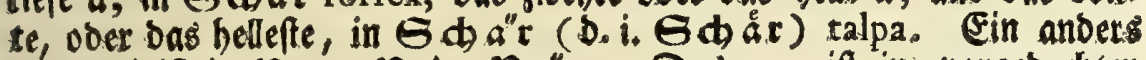
Beifpiel ift in $\mathcal{p} a r, \mathcal{p}^{\prime} r, \mathfrak{p}^{\prime \prime} r$. Das par ift in vorgebadtett

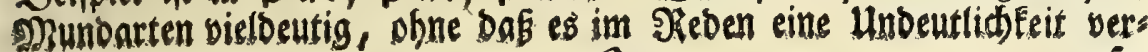
Do

urias

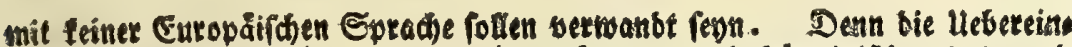
sunft bes Ungrif́chen ég ether, beß ég es brennet, bebl lateinifłen ignis, unb bes SBendifhen oign, po aud Seuter beipt, liegt an Sage; wie von bem une grifhen tüz (tús) Sas feuer, toldhes eben cin Ecythtfdes Etammmott ju fenn fdeinet, in bem freanfoffifoen attifer Semer fdurren, tifon ein Zrano, ja fhon in vem lateinifoen titio ein brennendes Gdjeit, Epuren vorbane ben finb, folgliç baffelbe aud) unredt benjentgen 2 sórtern beigejáblet wirb,

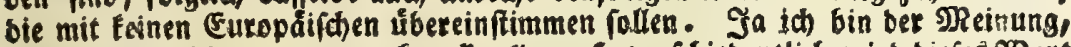

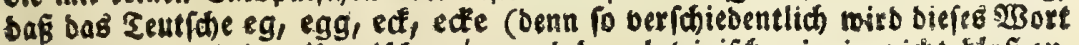

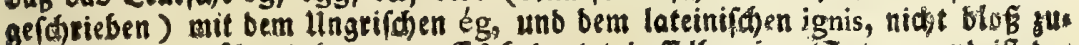

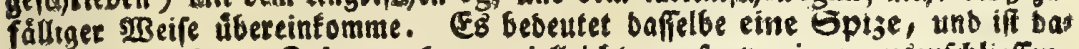
ber won erwehntem Bufammengange vielleicht um fo weniger ausifuichliefies, weil biefe 5 eftalt bem feuer eigentgúmlich ift; um weldher Urfache millen in

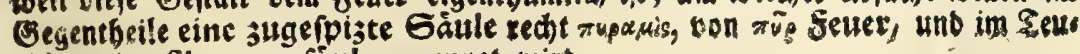
th 
urfacte, mie es die Exempel barthun werben. Erftid) ift es ein Beis wort, als par Gelo, repræfentata pecunia; barnach eine Enbung

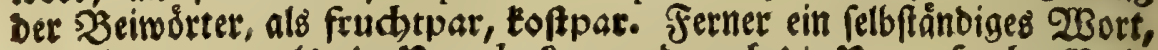
oas Pat, par, als ein Par bofen; uno now) die Par, Şedt. Babo re, feretrum. Wenn jemand aus ben 230 rtern biefes gwenten Mufters urtheilen foll, bie Defterteichifde smundart, und biejenigen alle, welche mit berfelben einftimmen, wåren unrichtig, weil fie bas $2 \mathfrak{b}$ und $p$ nid)t soústen su unterfheiben: Der wirft ifnen bas 2llterthum, als einen Febs ler vor. Das ift bie månnlide 2llemannifhe 2luśprad)e, welde in als len vorbenannten sånoetn nod) vollfommen berrf(bet. Nach Detrelben lautete aber bas 2 nfangs: 25 als ein $\mathfrak{P}$, und pold ess wieber burch feis ne Berberbung. Die Unterítheioung bes 25 uno $\mathfrak{D}$ if Eeine uralte

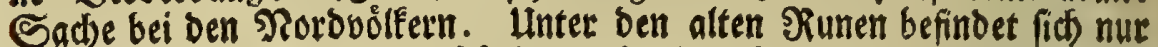

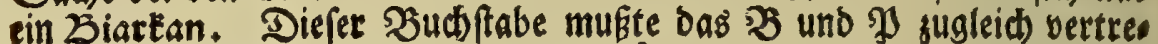
ten. Das ftungen Ziartan (Dab getúppelte Siartan, ober bas heus tige $\mathcal{D})$ if eine neuere (Erfinoung, wie baf ftungen Ron Dber Das $\left(b_{1}\right.$,

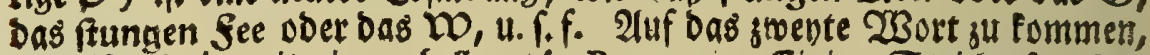
to beist $\mathcal{D} a^{\prime} c$ mit einem bellen $a^{\circ}$, Bavarus Einige Stride fprecten Do a'r, unb zerzerten bas a a in einen Doppellaut, weldbes id aurd) nod) fur feine $\mathfrak{Z}$ erberbung balten fann, weil es vielleidbt nur eine Zurammens

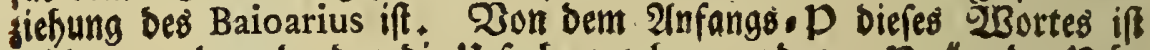

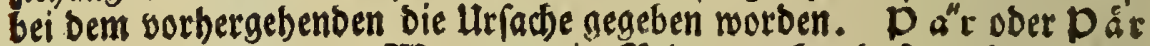
beist verres und urfus. Wुenn man im Sieben merfet, baß aus bem 2 Jors trage eine Zmendeutigfeit entftehen fơnnte, fo ipricht man mit einem 3us fase, Gaupáx verres, Caspara urfus.

Das betle a' ber Stenermaำfer, und ifrer munbartgenofien, fin, Det fich I) in ben fremben 2300 rtern, bie aus bem fateinifasen ober anbern Spradjen genommen worben, in weldsen bie bellen a gemeines

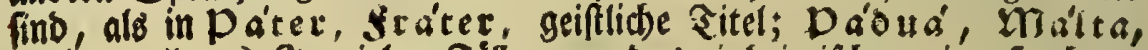

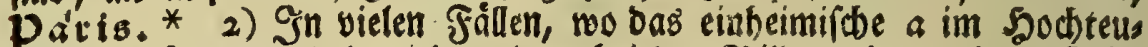

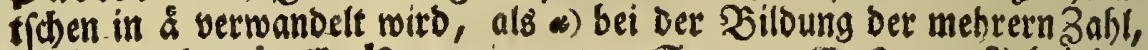
Ga'rten horti, Ka aifen arce, von Garten, Ealten; $\beta$ ) bei Det

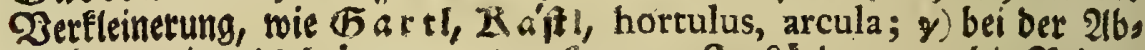
leitung, Ia'p pifd ineptus, von Rapp. SI Rănbern, wo bie Rebart

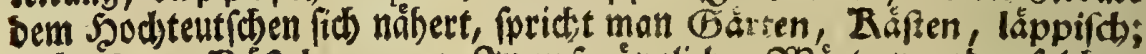

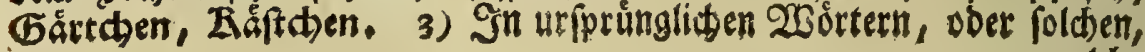
welde

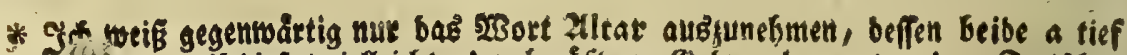

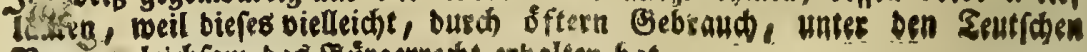

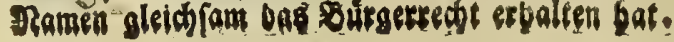


soldbe Dem urfprunge náher beitteten, too benn bie Stenermårfifóc Munbart ein vortreffitides Mittel ift, bie Stammmórter aušzuppuren. 3. E. Der Sndbfe fridte fitwer, gravis, difficilis. Das ift ein ounfles

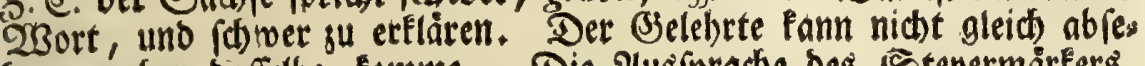
hen, woher baffelbe fomme. Die-2luşfpradbe bes Etevermärfers, welther biejen siamen mit feinem bellen a'vorbringet, und fit wo

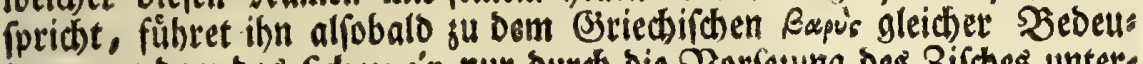

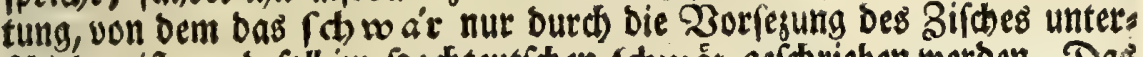

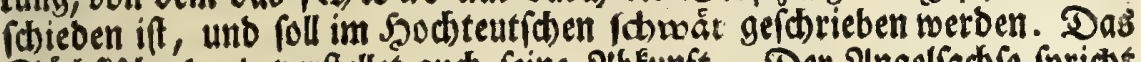

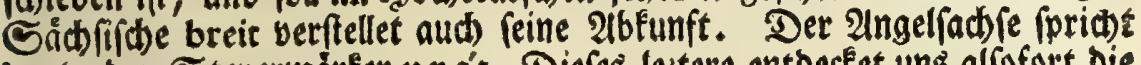

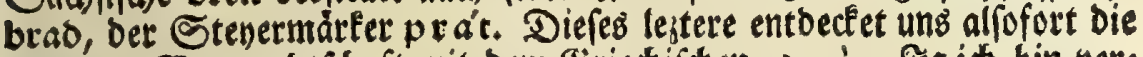

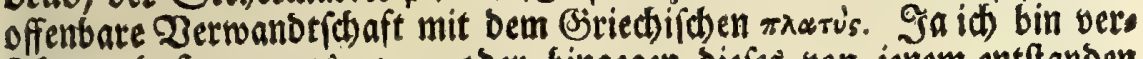
fífiert, Daß $\pi$ par aus $\pi \lambda a \tau$, ober bingegen biefes von jenem entftanden

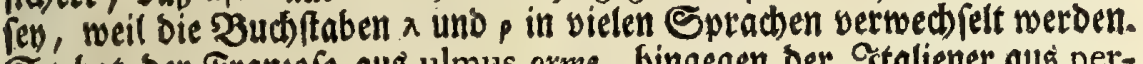
So hat ber franjofe aus ulmus orme, hingegen ber Staliener aus peregrinus pelegrino gemadt. Der Sdweiger fagt Kild fur Rird. Sith

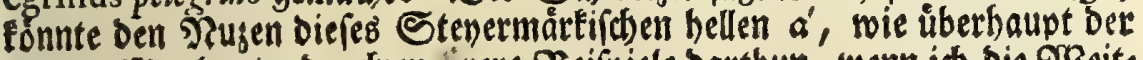

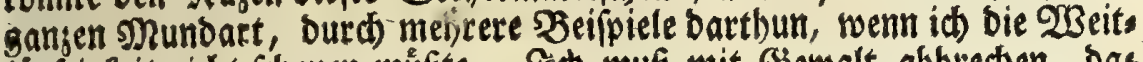

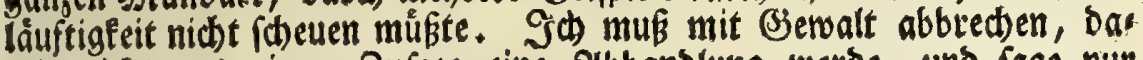
mit nid)t aus cinem Bufaje eine abhandlung werbe, und fage nur Eurf, baf biefe von bem Zwitterfareiber Blaurockelio gerabebrecht

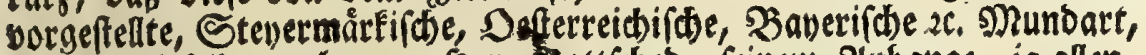

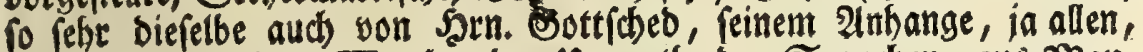
bie von bem red)ten 23 erthe ober Unwerthe ber Spradben, aus Mans gel ber Einfidts, nidbt zu urtheilen wiffen, beractet wirb, ein Sdass

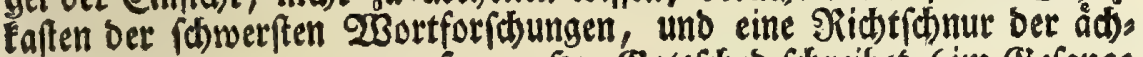

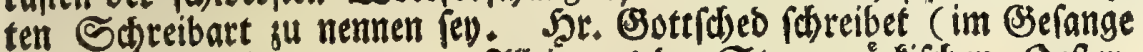

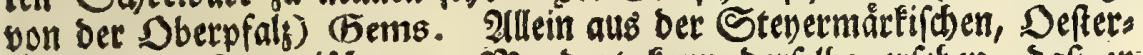

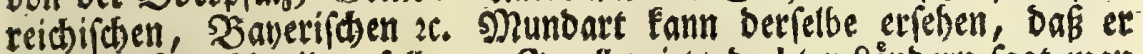
Gáms bảtte fidreiben follen. Šn allen istgebad)ten \&åndern fagt man

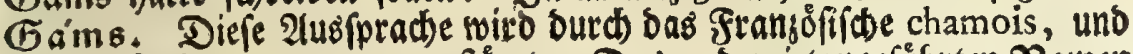

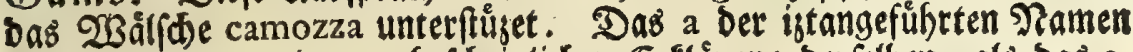
leitet uns eber su einer wahrffbeinliden Erftårung berfelben, als bas e.

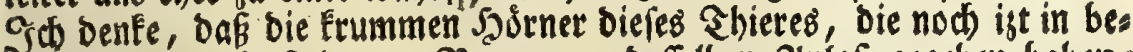

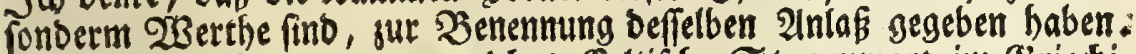
Denn tam beift krumm, weldes (Eeltif

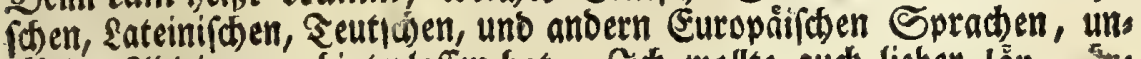

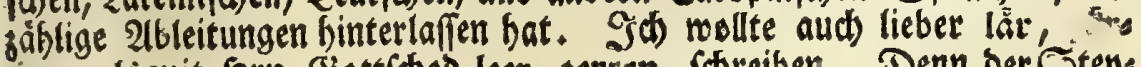
ren, alo mit Šrn. Jottided leer, zerren, fhreiben. Denn ber Oten: D० 2 crmáts 


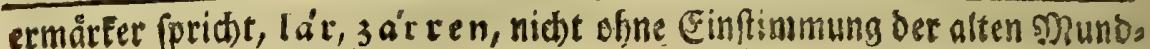
arten. Die Aitfranten und alemannen fprachen aud) (ar, 3uten, uns vielleidst eben mit einem bellen a', weldsen Uniteridsero man aber surch

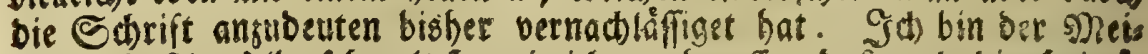

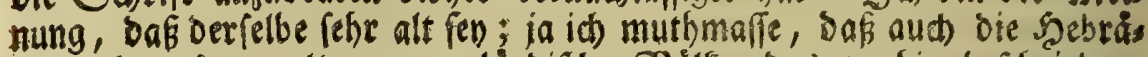

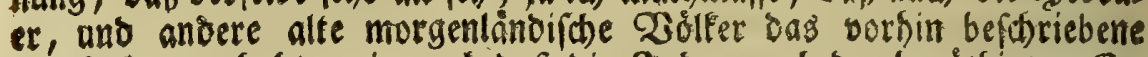
orenfade a gebabt, roie audi Daß bie Juben nadh Der bendethigten (Ero

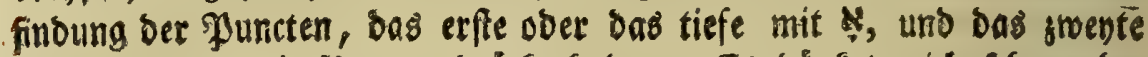

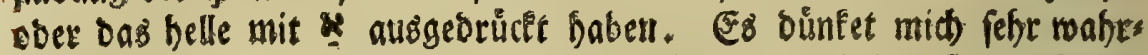

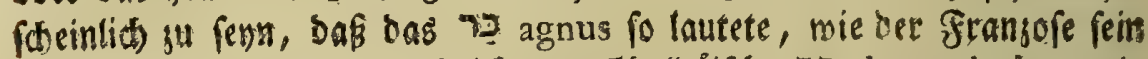

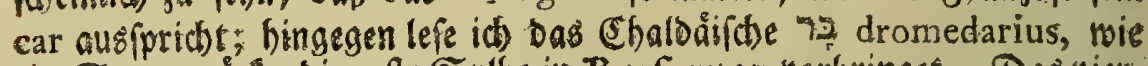
ein Stenermarfer bie erfte Sylbe in Karfreytag vorbringet. Das viets

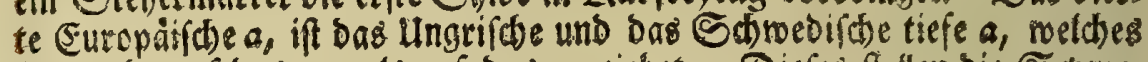
fich mebt auf Das o, als auf Das a, siehet. Diefes fellen bie Schwe. ben mit einem barứber geftelten SRingeldsen bor; allein es fỏnnte, unt andern babei vieleidht mit ber Zeit anjubringenden Itcenten SIlaz gu ge: bell, beffer mit einem queren mitten Durd)gezogenen Ctriche bemerfer werdet.

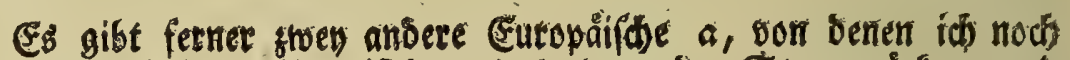
nidts gefagt habe. Eines ift bas nieslende a der S̈tevermåreer, wets

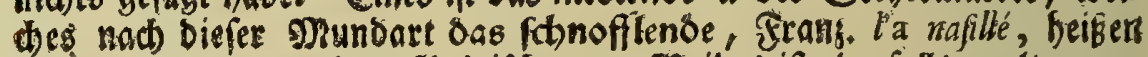

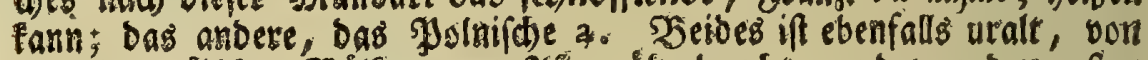

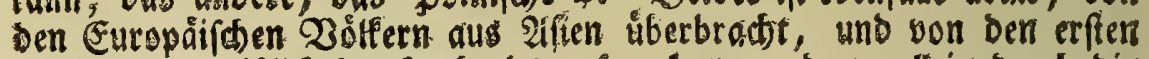

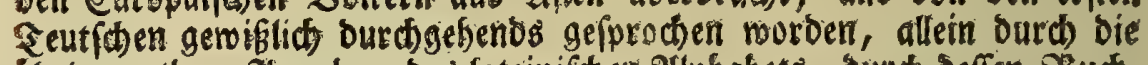

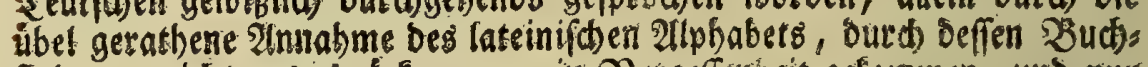
ftaben es nicht ausigubrücken was, in Dergeffertheit geformsten, uno nur

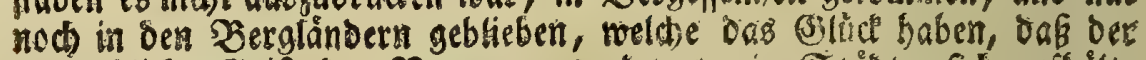

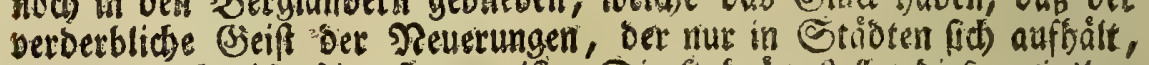

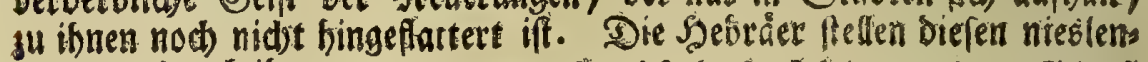
Den \&aut burd iff $y$ vor, welder Budbfabe fonft Eeinen anbern Dienfit

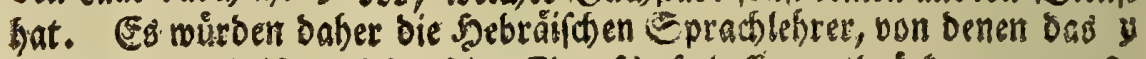
ein bauds gebeifen roirb, feine Eigenfth aft beffer audobricten, wenn fie benfelben einen Zafenhauch nenneten. Eg kann auch das (Eurovãifobe

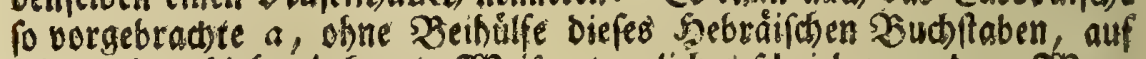
frine andere bigher befannte $23 e i f e$, tauglid gifdrieben werben. 23 enn

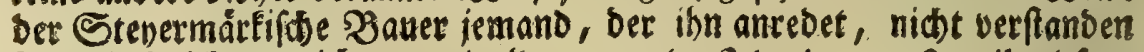
bat, fo feridit er nidit was? ober was loggt ou: was fagt ibs: font 


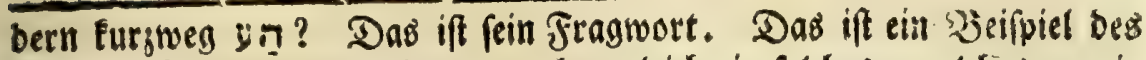

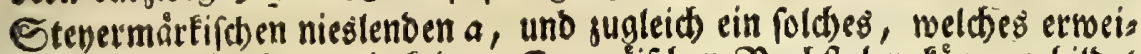
fet, Das biefer \&aut mit feinem Europdifthen Bud)ftaben fornne gebildet merben. Des Stevermárfers taan facere, wofür man igt im Soctbtels.

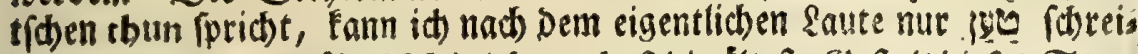

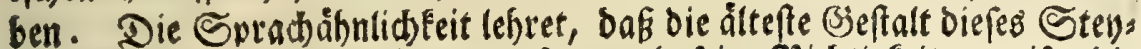
ermàrfifchen Zeitworteg taa gewefen, uno feine S̈ithtigfeit ermeiren bie

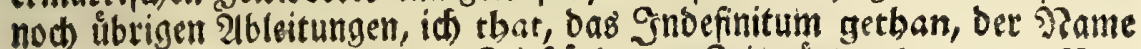
bie That. Afle unridtigen Beitftånbe Der Beitwoirter (tempora Verborum), alle unrid)tigen Enoungen (cafus) Der Namen, fino lieber. refte bon ridjtigen 2 (bwandelungen, die ebemals gebráud)lich gervefen, weld)e 2 sahrfieit id Durdi) fo viele Beifpiele, nur aus ber lateinifonen

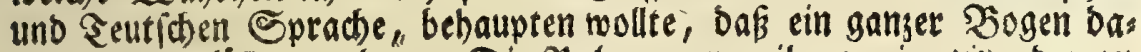
mit foll angefullet werben. Die polen nennen ibe as ein lis ober iz (mit einem Rames d)atuph, Demman auch swey Plunctcten forme beis zufesen pleget), weldes beinahe lautet, wie ber Sranjofe bas 230 rets d)en on (man) vorbringet. Das̉ Polnif́che maka thehl, farina,

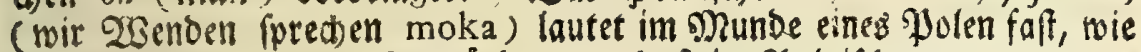
ein Franzufe monca lefen wurbe; nur bas im Polnifichen etwas vom a

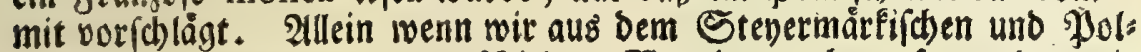

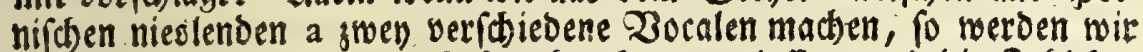

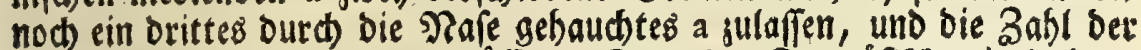
Europáifcten a, auf 7 resen múffen. Denn oas franjófifde nieslende a, wie bab erfte und leste in bem 230 orte franchement, ift wieber ein alls bers a nafillé, und forool von bem Polnifosen gar zu tiefen, als von bem Etevermárfifoten gar gu boben uno bellen, abjufondern.

Sieruber urtheile id) fo. Sक fage, bas man feine lirfacbe babe, bie niesilenben a für neue Selbftlauter zu balten, uno bie 3abl ber Euro.

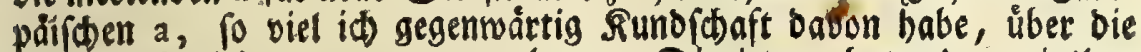
bisber befabriebenen 4 gu vermehren. Die isterwehnten bren nieglen.

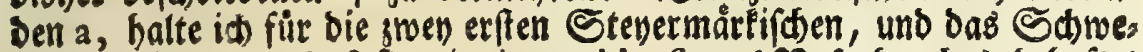
oifhe tiefe a; nur oás fie mit einem rhinefmo ( find, Der aber nid)t nur auf bas a, fonbern aud auf bie andern Selbpts lauter, auf bas e, i, o, u, ö, $\ddot{i}$, uno nod auf bie Doppellauter, fált, weld)e befruegen leine neue 2 ocalen oder Diphthonge find. Det rhinefmus ift nur affectio vocalium ac diphthongorum, (ein netuet

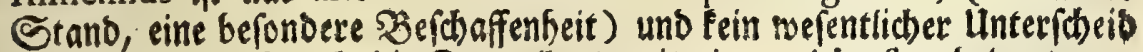
serjelben. Das aud bie Doppeflaute mit einem rhinefmo beleget wer: DO 3 ben, 
Den, erbellet aus ben 230 rtern, Maubel, wo ain vinum, wie biefes lestere ein Stevermåreter cber Sberơfterreider ausfiprid)t. 'Maudel if

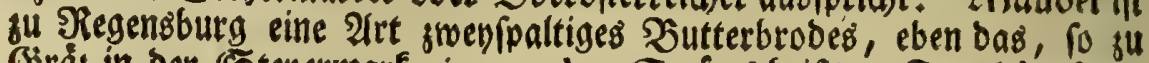
B̈rås in ber Steyermart tin marbes Etrúzel heißt. Dir rhinefmus

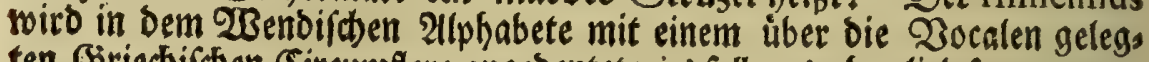
ten Briecbifisen Circumflere angebeutet; es foll uns aber lieb feyn, wenn

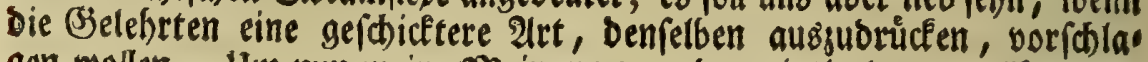
gen wollen. Um nun meine skeinung von ben nieslenden a vollfommen

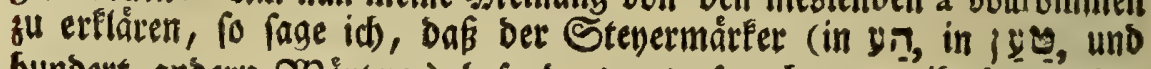
bundert anbern 2 oirtern) befonbers ausgefprodene $a$, ifre belles ober

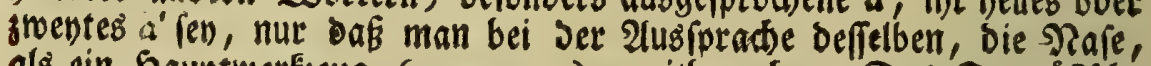
als ein Shauptwerf $z e u g$ (organum), mitbrauthe. Das' Frangoffiché nieślende $a$ in franchement, ift Das erfte Stevermártifíbe, ausgenom. men, Daf es von ben Framojen ebenfalls geidnuffelt wirb. Das Wo6 nifate $z$ if $b a s$ Stbwebifhe tiefe, allein aud mit einem rhinefmo bes

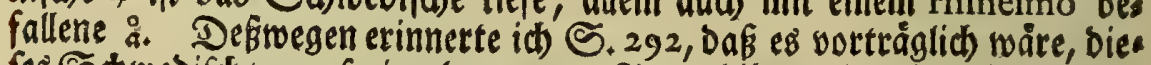
fes Sarwediche a auf eine bequemere $2 \mathfrak{n t}$ zubilden, bamit andere babei anjubringende Beidjen, wie fier Der accentus rhinefmi, barúber Pla baben fónnen, wenn man etwa funftig Den in gegentårtiger Sdrift ans

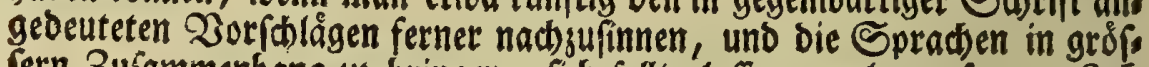
fern 3ufammenhang su bringen, fio follte laffen angelegen febn. S\$

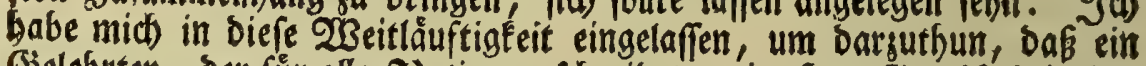

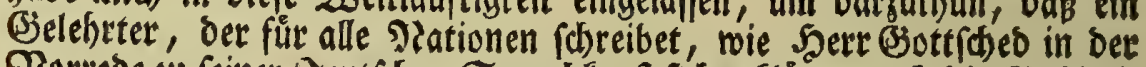

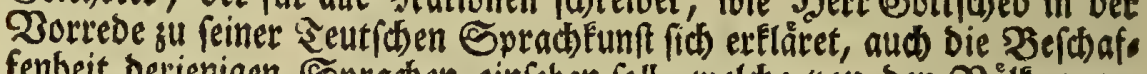

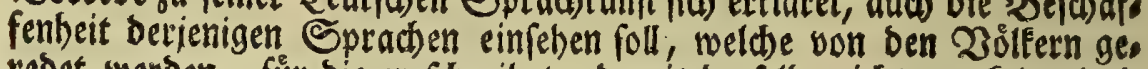
rebet twerden, fü bie er foresber; bamit berfelbe nidst nur feine itris

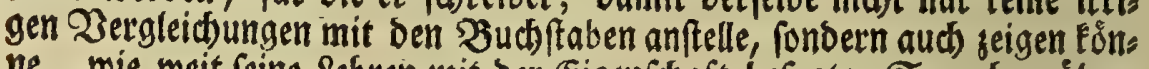
ne, wie weit feine feffen mit ber (Eigenfidaft befagter Spracten über: einpimmen, oder bovon abgefen, wobures ein unterridst erft redit beuts lich wirb. Pluf folde Alrt wode es nicht vonnothen gewefen, Die frem: ben suerfucten, baf fie ifm vorber bie lleberfesungen feiner Spradlefre zufenden modsten, samit er febe, ob fie ifn verftanden baber. SSefest aber, baß fie biefes thun; fo will id glauben, Daßs er mit ben J̈talienern, Epaniern, Jransofen, Engländern, fison wiro juredte fommen fons

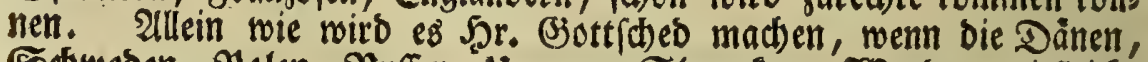

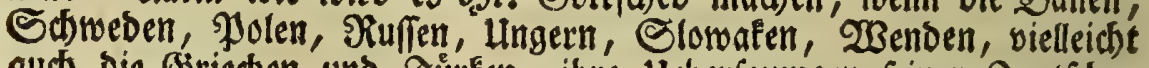

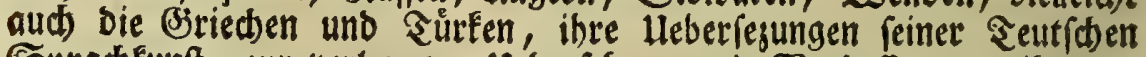
Spradjeunf, jur berlangten Heberiefung und Derbefferung, ifm su* 
fertigen werben?" Derftehet er alle biefe Sprachen? WBirb er fid

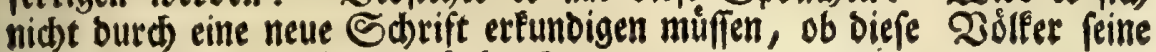
Derbefferungen verftanben baben?

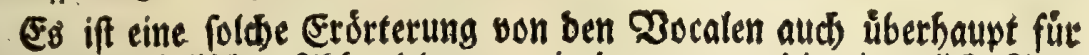

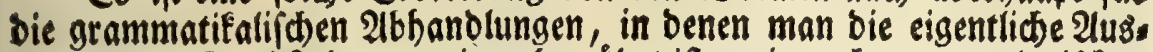

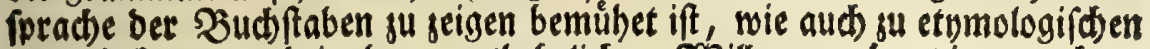
Interfucjungen, beinabe unentbefrelid). 2 sill man aber einen redsten Nusen Daraus baben, uno bie Spradben fo fobreiben, wie fie gerebet wers

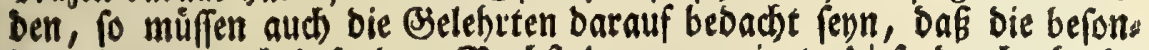

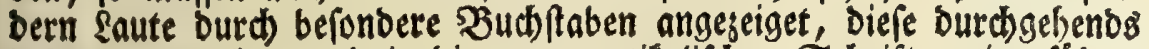
befannt gemad)t, und in bie grammatifalifchen Sd)riften eingefübret werben. Denn will jemand bie Steyermårfifden Namen, $\mathcal{Z} a^{\prime}$ 's cafeus, 々a'rn crus, Tráo frumentum, nárrif b fatuus, wa'd mol-

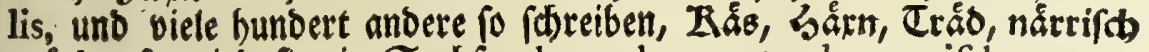
wåd, fo wirb fie ein Sad) fe, kæs, -hæxn, træd, nærrifch, wæx, folgliđ nid)t, wie ber Stencrmátfer, ausfpredoen. Sdreibet man bins gegen biefe 23 orter nur mit einem bloffen a, fo lieft fie ber Stenermårker mit feinem tiefen $a$, und abermal falfít). So Fann ber Name bes Billeris fiben Fluffes, welcher aus Dem Sulsbadifít)en (Sebirge (wo brey săn

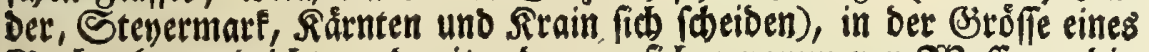
3adbes bervorbrid)t, und mit anbern fu fid genommenen $\mathscr{W}$ affern, bie

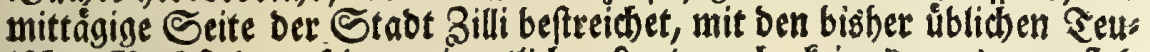

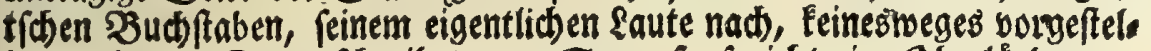

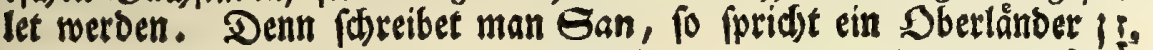

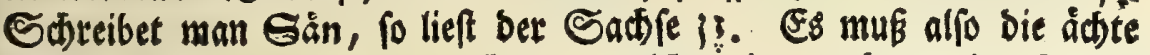
2usipradbe is burd) ein Teut(क)es a, weld)es einen anbangenden Eleinen Sdbnerfel babe, ober mit einem accentuirten Seutfhen a ( $\left(G a^{\prime} n\right.$ ) ges (A) rieben, und im Jorberidje, ober in einer Sprachlefre, erinnert wers Den, was bieje zeiden bebeuten. Sol habe felbft bisher Gan ges

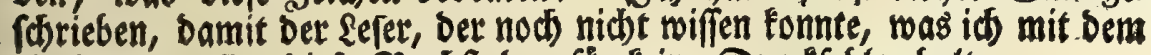
$a^{\prime}$ ober á wolle, Diefe $\mathfrak{B}$ udffaben für feine Drucffefler balte.

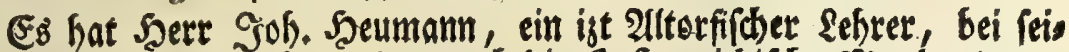

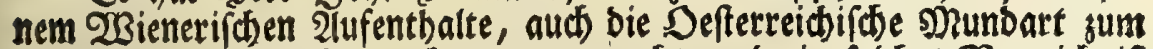

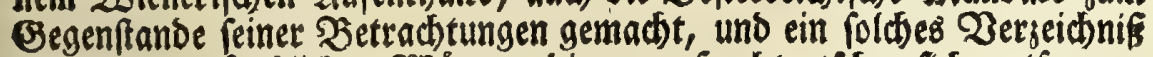

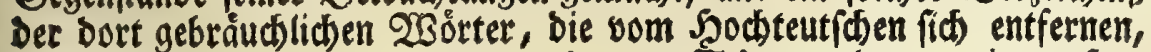

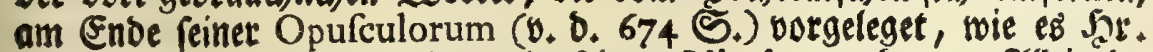

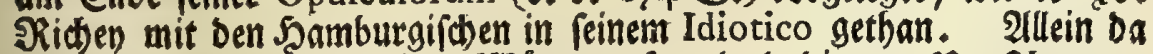

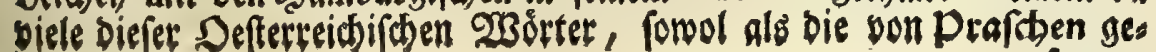
famm: 
fammleten (welde Şr. Sceumann vor ben 23 ienerifden barftellet) gros

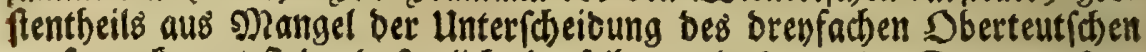
$a$, fo verlappet fino, bas etlidse berfelben, als zemmel, Saemer, ftar, aud ein gebohener Defterreicber ober Bayer nidit verftehen wurbe,

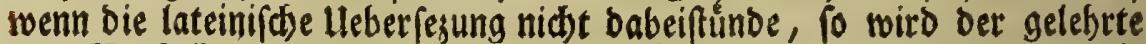
yr. Werfaffer, bey einer vielleid) benóthigten grweyter Tluflage, bie Gute faben, bie Sdreibart uno einige Erflårungen bejagten 230 orter, auf folgenbe 2 eife zu serbeffern. J出 werbe aber, um bie 23 eitlåufo tigfeit zu vermeiben, meifentheils nur biejenigen, welde burch eine uns redite 20 orfellung bes a unvernefimlich find, und nod von biefen nidst alle, anfüben fơnnen. Das beigefügte Sterndten zeiget bie 2Bieneris

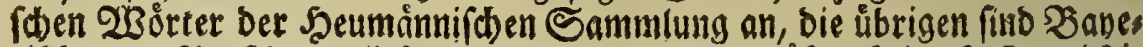
rifche von Jrafthen gelieferte, allein aud) nod) groftentheils Defterreidis fibe, 230 orter. Diejenigen, Denen id ein Sreujajen beifezen werbe, fino gemeiniglich pơbelhafte neuere 2usbrúcte, bie feine 2ufmerffamfeit ju

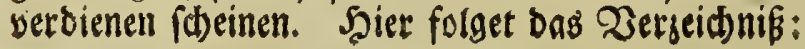

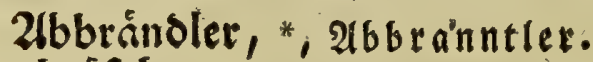
abtáfeln, t, mit einem a: 2ld'eram *, glans fagea, Şuđăcterm.

Zlebnl, avia. Allein werm biefes 230 ort ein Sadfe ausporidt, po verftelyet ein $\mathfrak{2}$ ayer, ein Sefterreid)er $2 c$. avum, niđt aviam. Avia beift $2 a^{\prime} n l$, ober vielmehr mit einem o euphonico X'noel; uno avus Zen ober izosopistxẅs 2lendel. (a)

Zlemmel, nutrix, zímmel.

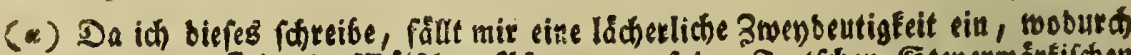

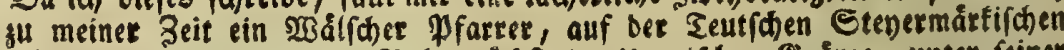

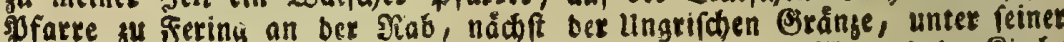
Pfarrgeneinbe allemal ein (j)låd)ter erregete, fo oft er biefe 230 orte in ber Rirche borbringen mufite: Sudbs (fo beigt ein Dfarrmann zu gering) lafte bitten fît

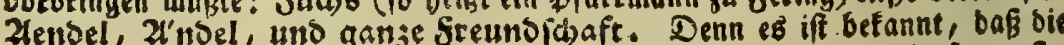

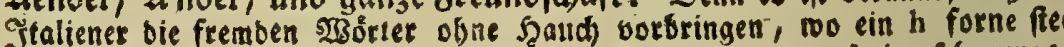
het, und im Giegenfpiele bie anfänglidhen Eelbftauter, auf eine pebr unge facicte 2urt, mie bort bet Eatullifide Arrius (Sciop. GRAMMAT. PHILOS

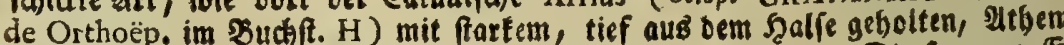

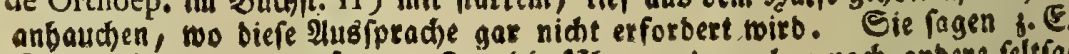

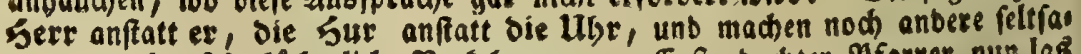

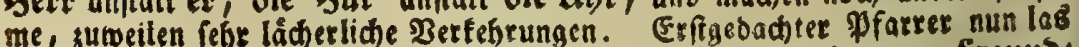

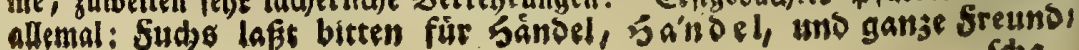




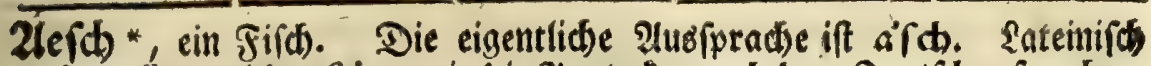

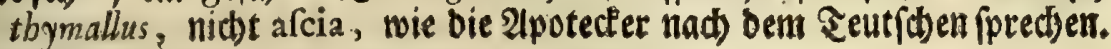
anuábmlen $t$, mit einem a', annámeln.

2tnzen*, eine boppelte Deid) fel bei einem einfpånnigen Fubtwerfe,

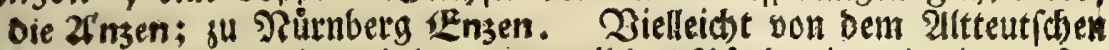
einnis, weldbes mitten bebeutefe, weíl Das̉ Đfero mitten barimen fies het. 2renoifs heift biejer Fubrmannşeug Woinza.

2lugens 2 ramen * fupercilia, bie $\mathfrak{A}$ ugenbrám. ( $\beta$ )

2 befonetin *, Defefnerin, mit einem lautenben $\mathfrak{b}$, von befeben infpicere.

Oćmelin, am Daumen foltarn, ocimeln.

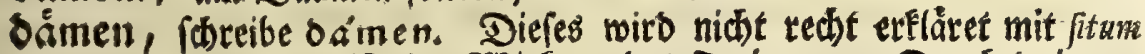

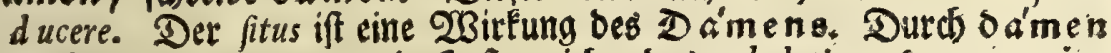
verftefen bie $\mathfrak{B a v e r n}$ unb Sefterreicher bas exbalatione (evaporatione) bumere. Das fitum ducere geben fie mit anlaufen, fo bie Sor: $^{2}$ bereitung fum Sdimmel (Deft. Ghimpel) ift. Son oa'men Commen Die $2 B$ órter, Dampf, Othmpfen 26 .

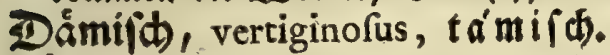

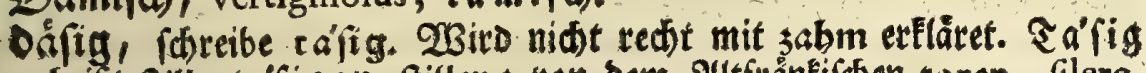
beibt ftll; táfigen, ftillen; bon bem alltränfifben tagen, filere.

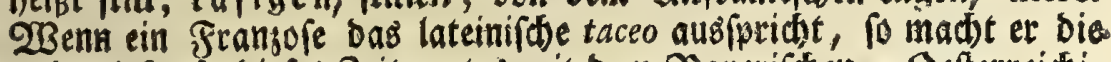

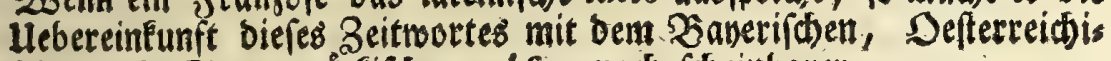
fhen und Stenermárfifien $\mathrm{e} a^{\prime}$ fig nod (h)einbarer.

LEbul avus. So fönnte man bas 2 Bort gat nid)t vorbringent. Die Defterreidjet (preden mit einer Epenthefis, Zlendel, Zendl.

$$
\text { Yo }
$$

İlter

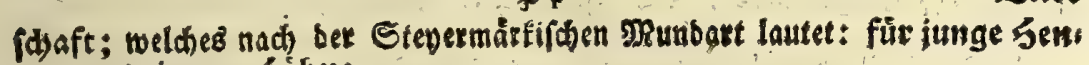
nen uns junge Sábluse.

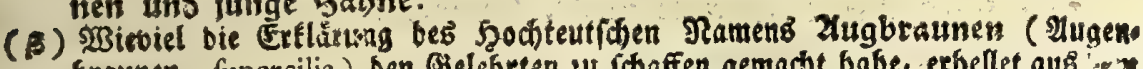

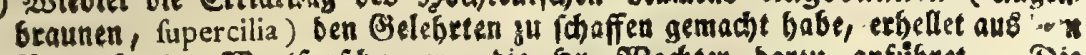

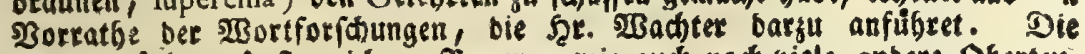
Stepermerfer, Defferreider, Bayern, wie audh nod viele arbere DGertents

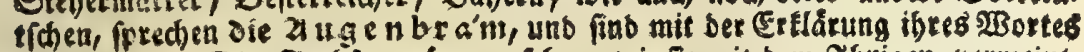
balo feetig. Die Gadisen mógen fupehen, wie pie mit bem Jhrigen, vermeints

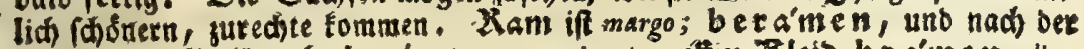

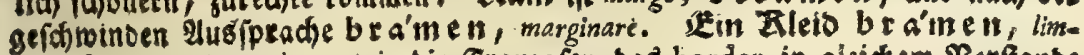

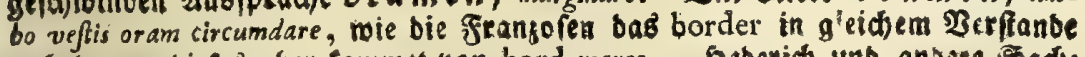
antringen, tiefes aber fommet bon bord wargo. Şeberict unb an'ere Sadis Fen, bie bremen, verbremen, fabeiben, entfernen fid von her Quede.

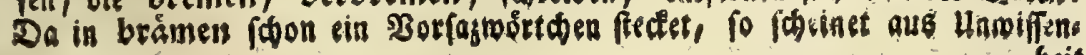


SyIter * fenium, bas Zelter.

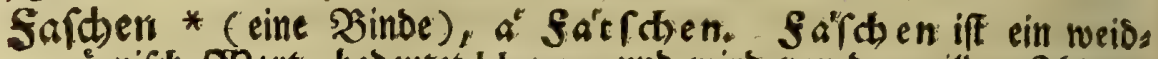
mänifक 230 rt, bedeutet bluten, und wird von ben wilben Shieren

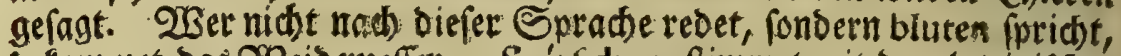

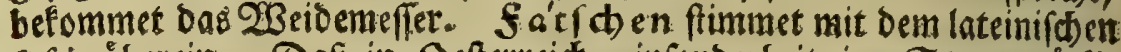
fafcia úbereir. DaE in Defterrerch, infonderbeit im Stevermåntiz

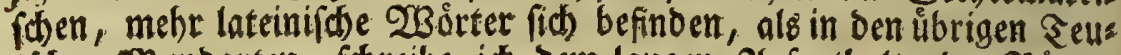

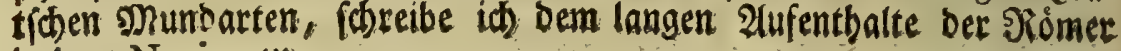
in bem Norico fu.

Seim puma, faim Nach ber Mrunbart bet 2ungelfadjen aud

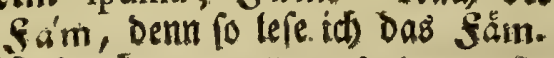

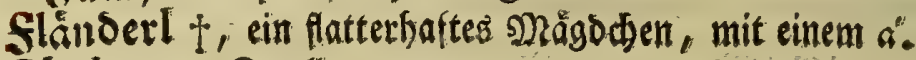

Sócben *, Forelle, trutta.

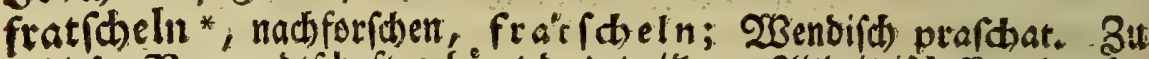

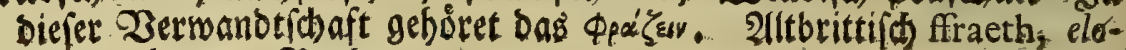
quens, difertus, $\mathfrak{B} 0 \mathrm{xh}$.

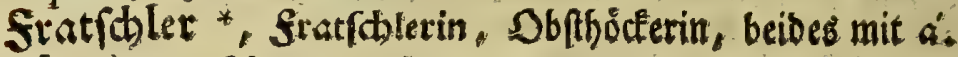

gámejel ofcitare, g a"me:en.

Gejait venatio, Geja's, von Jago, mit beat Dorfagmórțen. Die Sodteutfhe Munbart liebet bas go und gt, Die Sberteutide mirft

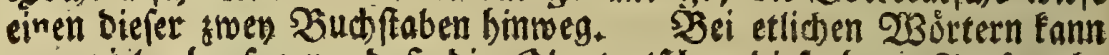
man vielmehr fagen, bap bie Sberteutjhen biefe barke 2usiprache nod) nicht angenommen baben. Eine niago beift von Sberofferrei

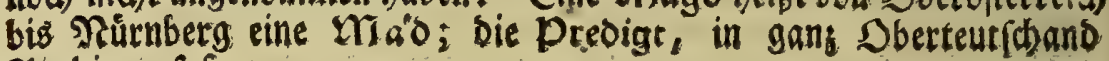
Yrebig u.f.f.

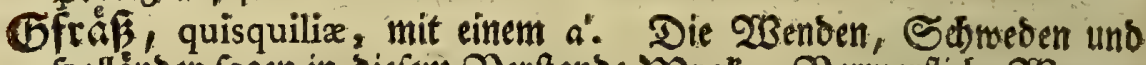
Şolländer fagen in biefem Werftande $\mathfrak{W r a t}$. Zerwerfiche 2 Baaren nennet Der Sdwebe worat gods. 20oher biefes Wrat fomme, Fat Scr. $23 a$ chter geseiget.

gnấchig ( genăfchig) mit einem a:.

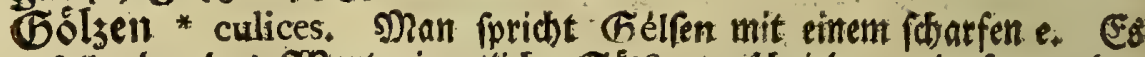
foll aber bas WBort eigentlich (Gälen geftrieben und fo getedet werben. Die Sdmacte ift ein fingendes ungejiefer. Gala beift in

beit bet Mbleitung nod) ein ber baborgefommen gut fevtr, wenn man berfed mert pridt. $2 \mathrm{ra} m$ limbus, ift ein verbale von bra'men. Das atu gen bra'm if limbus ober margo: oculi, wie e8 Her fharfinnige felonit

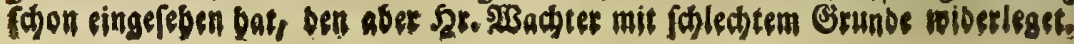


Verelii IND. fingen; von weldhen (Eeltifchen Stanmmorte nidt nue

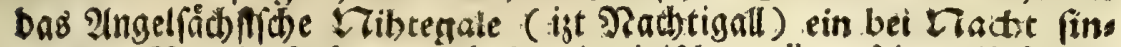
genoer 2 ogel, fonbern auth bas lateinifose gallus, feinen Hrfprung bat; wie bas 2 Bendifthe petelin, fo aud einen babn bedeutet, bou pét fingen, bettommet. $(y)$

grándig morofus, grántig. Angelfáchfifon gtam, furor. Grónil $3^{*}$ limes, Jránib.

gfbunppig loquax, mit einem ả. 5̧ollånd. fnappen, garrire. guánden veltire, gwanten.

$\zeta$ ádel

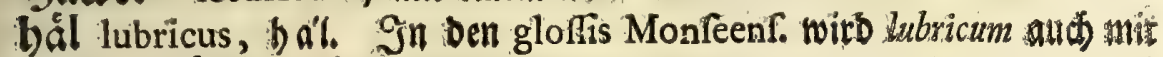
bali ertlåret.

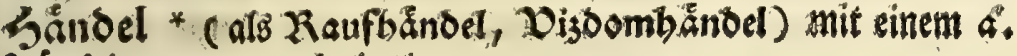

bíndig amarus, bántig.

Jântl parva manus, mit einem $\mathfrak{b}$.

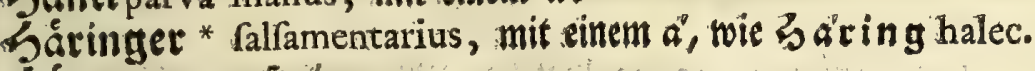

b́axen coxa, Shân.

Semb uno Gátten, alfo foll man in Das $23 a b$ geben. * Fs poll

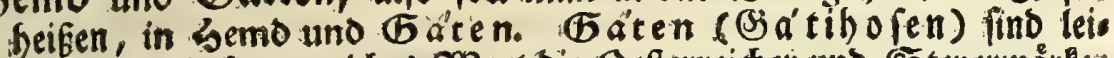

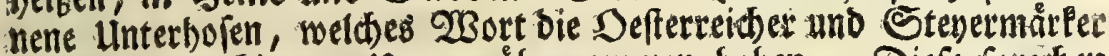
bon ben benawbarten ungern übernommen baben. Diefe fprechen gatya.

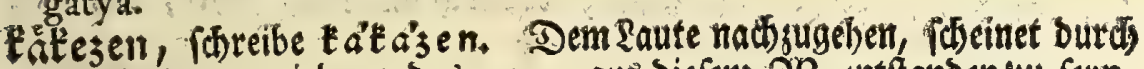
eine Zufammenjiebung das garen aus biefent $2 \mathcal{3}$. entitanden ju fenn. Das ङSloffarium Rab. Mauri fat (h)abazen für gaken. Ifllein bie

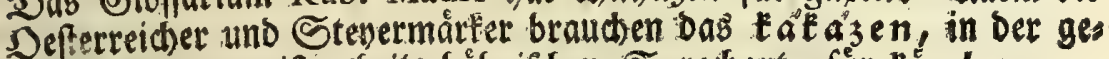

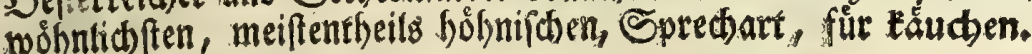

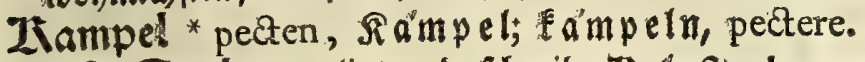

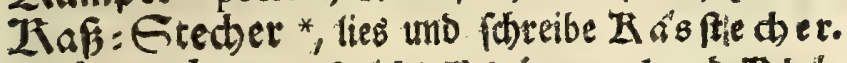

Zlímperl. Man foride Zilámperl uns Zlámp ferl. Jemand cin Љ lámp ferl anbănten; cavillari.

Pp 2

Żoy,

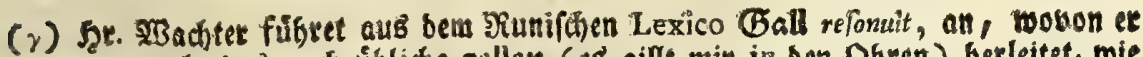
ganj rect) das noct úblict)e gellen (es gillt mit in ben Obren) berleitet, wie bas Satredifhe Gilla refonare eben bajer genommen ift. Ermebntes Gall

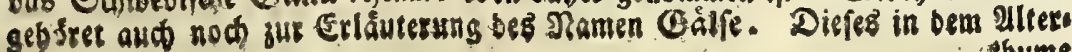

toume 
Koy, Kober unter dem 2Sart, paleare*. Diefes muf fo aubeinander gefezt werben:

a) Koy (Die) mandibula, von Foyen mandere, Såd) kăuen. In bem Sodteutiden 28 orte Kinnbacte febe id feinen 5 Begrif bon eimem Beine.

B)Zlooer (ber) palear, nidt paleare. Diefes ift beim Joanne Januenfi ein Gpreuboden. Indere ipreden Goder.

Kráxul xrumna, fbreibe Zirárn.

Zirec)seln * (Flettern), krápeln.

Zrestsen * corbis dorfuaria. Diefe $\mathfrak{B}$ ebeutung if bie getoóbnlidse;

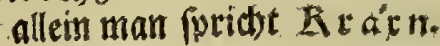

Laxel *, ein poobelfaftes Sdimpf unb Sderzmort, mit a:

Mrandel * , ein Şaufen Garben, Mándel. Mandel ift amygdalum.

Mráxgarånt * malum granatum. Einige fprechen Mairgárant, andere Margatant.

HTafbe, bie Móf $n$, nodus ductilis. Hud eine coquarde.

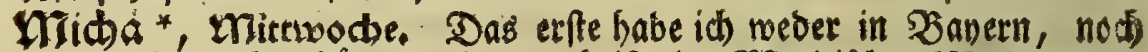

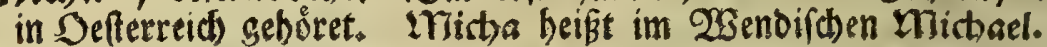

Zabing * terebra, Tábinger. Etlide fprecten aud Táber. ב J heifet etrans hohtes, Durdjgebohrtes, uno die trabe ift das grofo

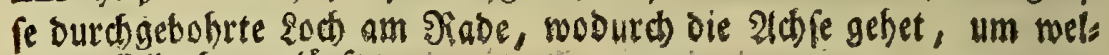
We baffetbe berumlåuft.

rTárb,

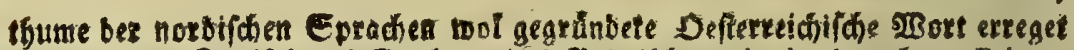
einen billigen Zmeifel, ob Bopborn bas Frittifche gal, in bem Lex. Britarnico-Latino, mit fanguifuga redht úbericget babe. Sol c8 nicht vicleidt culex beifien? Dir Gâlfen faugen aut) Blut. Gharade, tat Dbetrbeinifhe

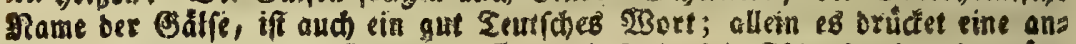

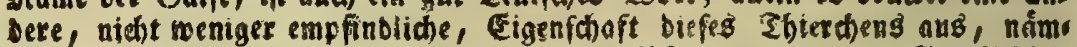

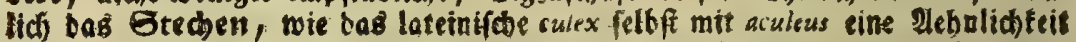

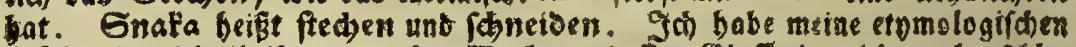
* gen babe, erflázet weber (Belfe, nod) Ednadte culex. Sch exinnere midh aber

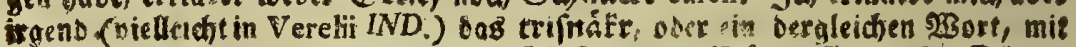

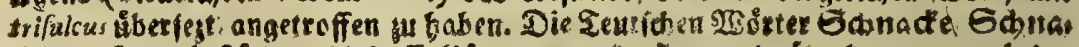
denr

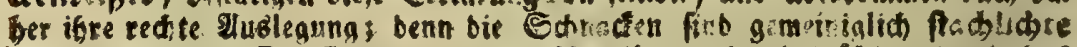

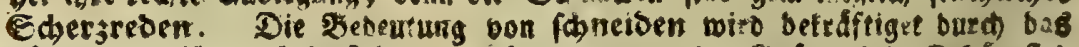

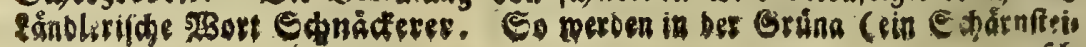




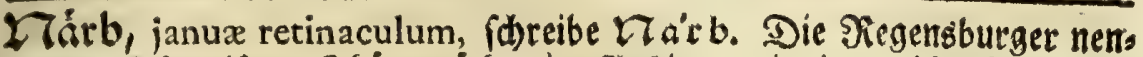

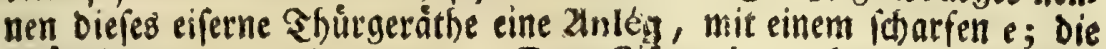

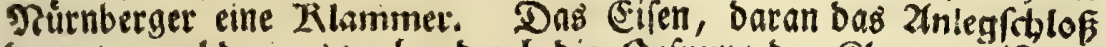
hanget, nadbem es vorker burd bie Sefnung ber Slammer ift ges ftectt morben, heipt ber Ziloben, weil es getloben, b. i. gefpalten ift.

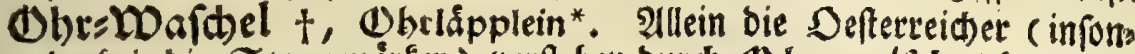
berfeit bie Stenermårfer) verftehen burd) (O hr wa a (rt) el bas gan. ze Ohr, und werben von andern Seutiden meiblich ausgelact, wemn fie for reben.

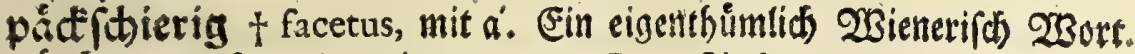
páplen t (zárteln) pápeln, vom Papáaiufen ber Rinber.

párzen faftuofe fe efferre, fid $p a^{\prime} r$ ent.

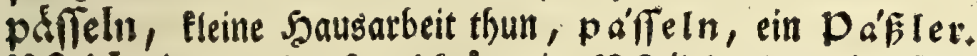

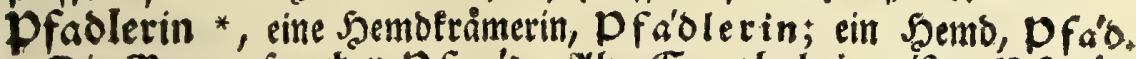
Die Bautern precten $\mathfrak{D}$ foa'o. Zlte Gewobnheir, eifern $\mathcal{D}$ fo $a^{\prime} 0$.

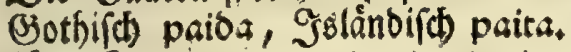

Pfanzel, Đifannenfud)en, mit einem $a$ :

Praixen * brama, Dráren, 2urt eines Fif́ches.

Rámel in ber \$fanne, im Fodtiegel, im Fopfe : Rain ell.

Ránffitl von Brod, Ránftl.

rántig, ftol ; mit einem á.

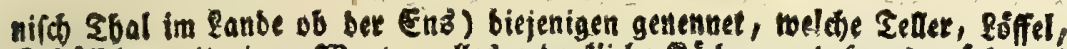

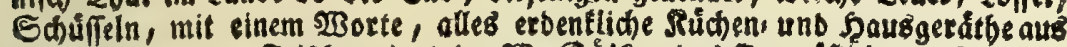

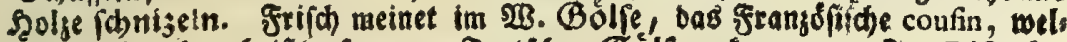

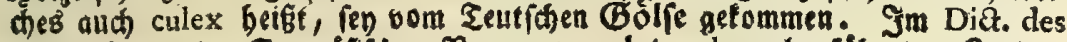
Paftag. bat er ben Frangofifichen Stamen vom lat. culex abgefíbret. 3u bem Komár (

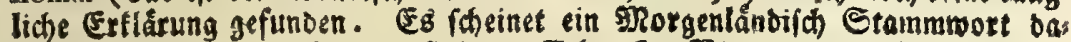
binter fu fteden. Hebrigent finb sie Sdinaden Blu svernande (confanguinei) DeB̃ $\Re$ Renchen, wie

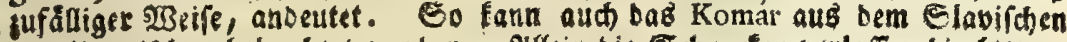

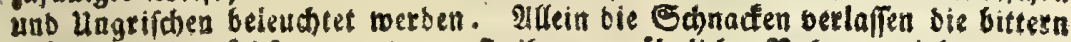

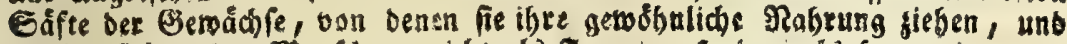

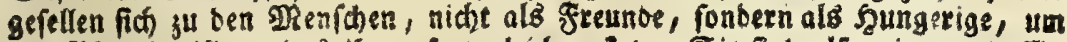
bes Flutes willen, bas ifnnen fo mol idmectet. Eie fint alfo etn vortreffli, Ges Einnbilb berienigen, bie fich um anbere \$Renfihen bienftertig berum، famiegen, benfelben fdimeichelbafte Rieber oorfingen, allein uur fo lange, als fie etmas gu fougen fincen. 


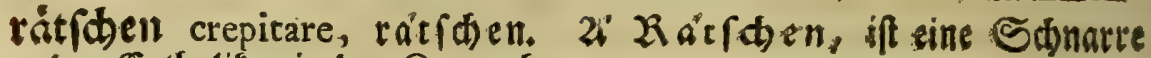
Der Catboliten in Der Rarwodbe.

rátítben *, im Sieben fonnarren, $\mathfrak{r} a^{*} \mathbf{f}(\boldsymbol{t})$ en.

Red̂bánctel qur Tortur ${ }^{*}$, mit einem $a^{*}$.

Robat * fervitus rufica, Rioba't.

Gábel, acinaces, Sábel.

Gaemer * clitellarius, Sa mer. (d)

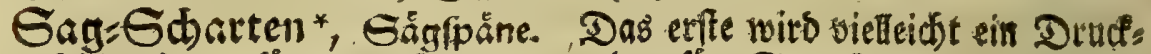

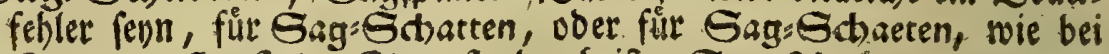
Gaemer, Zareferl. Es mus aber beifen Gagfoba"ten.

Gamemett:LlaeferI * cicindela. Die ridtige Sdreibant uno

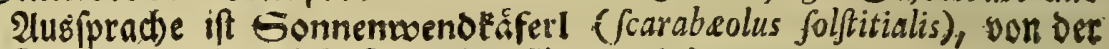
Beit, in weld)er biefe Shierd)en fliegen. ( $E)$

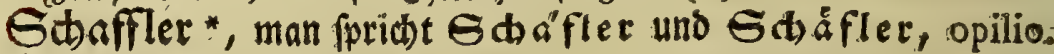

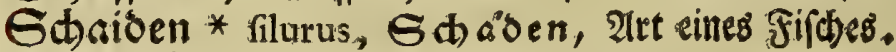
Gdlaipfen (bie), traha, S 4 lop fen.

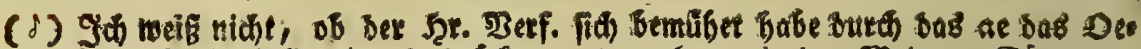

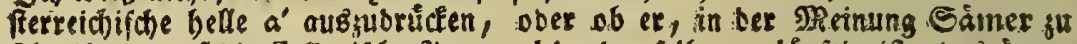

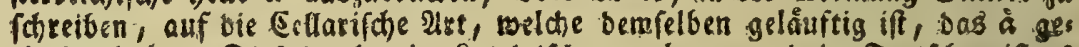

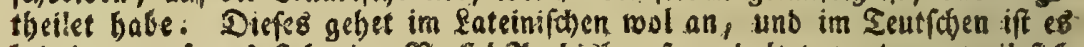

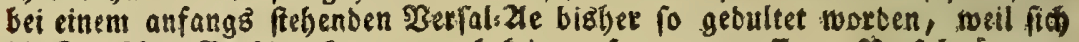

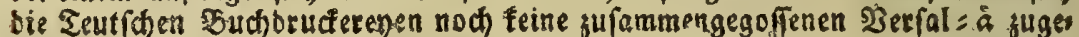
leget baben, wie bie Estreobijhen; aflein anbere Eprachen for in bamit ver:

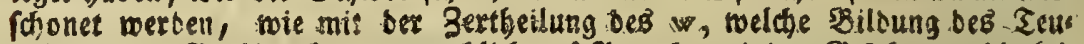

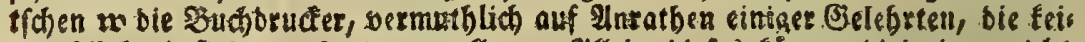

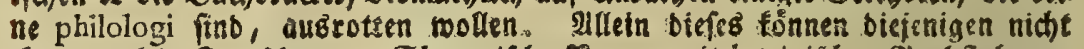

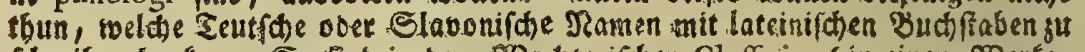

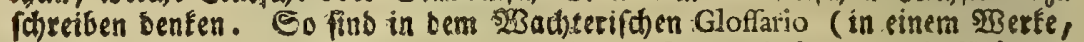

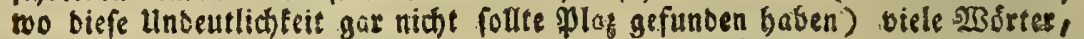

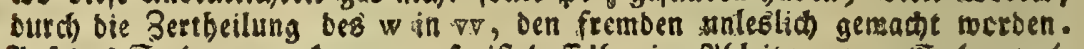

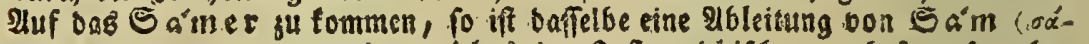

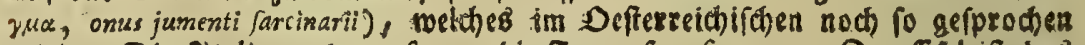
wiro. Die Jtaliener ragen foma, bie freanjofen fomme. Der Efel ift bas befanntefte Ea'mtbiex, Daber berfelbe nut Jitalienifiden, von fnma, redit

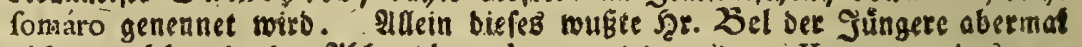
nicht, nelder in Der $26 b$ andlung de pergrinitate lingue Hungarice, bas von

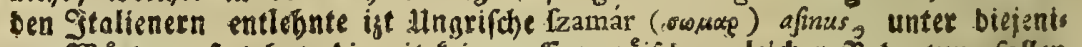

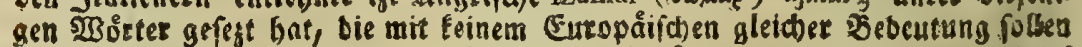

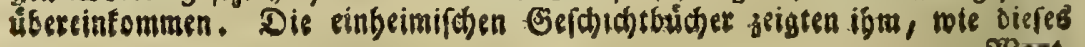




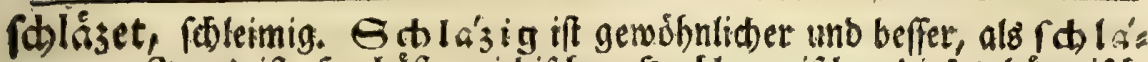

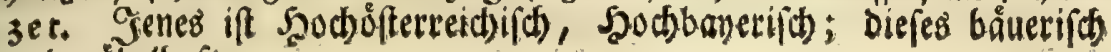
und pobethaft.

Shmadterl * fingultus, ber S.4nácfert.

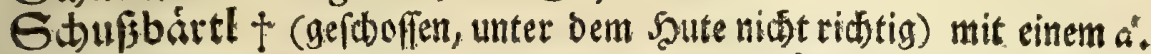

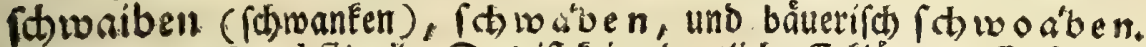
- Geffel; Eenfte, lectica*. Das ift feine Deutlide Ertalarung. Es foll als ro beifen:

a) Seffel, ein gefütterter Stubl, fella. Die Mrieberfadfen unterfळei Den bie Seffel nidst won Den Gtublen.

B) Cragfeffel, fella getatoria, oder lectica folectitweg.

y) Gánfte, vom fanften sragen, lectica jumentaria.

Stángel MTezen, * mit einem $a$ :

ftat *, langlam, fill; fát.

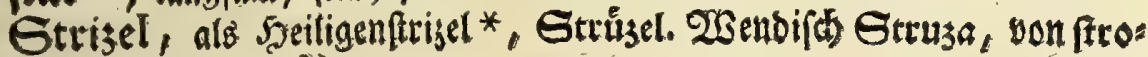
3en turgere. (S)

Cacten

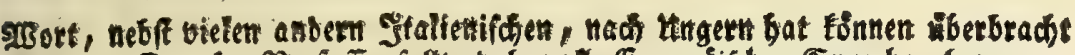
reeben. Der STr. Berfalfer follte vaber alle Europáifchen Sprachen beoor ges lernet baben, als ifm in ven Einn getommen, ein $23 e r f d b e n$ mit einet fo

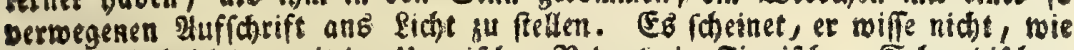

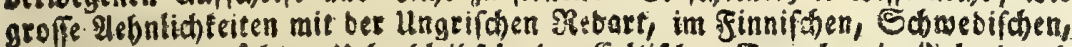

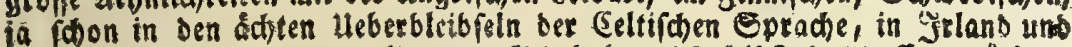

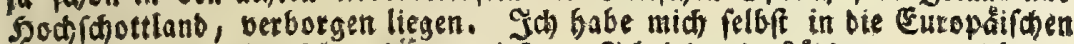

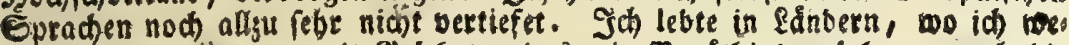

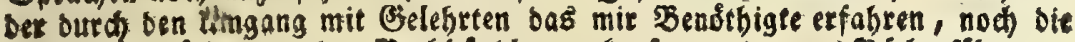

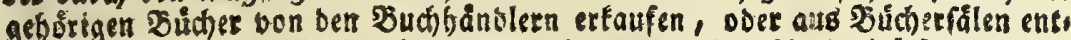

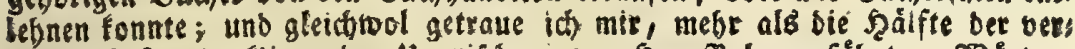

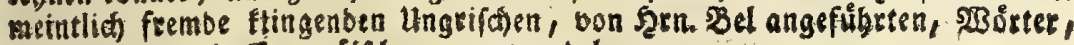
ofne fectered in Europdifbe gu varmandelt .

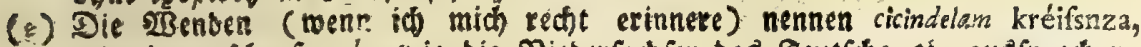
mit einem fharfan é, mie bie Rieberfachfen baz Teutfhe ei, ausfiprechen; bon kréifs, Jobannisfeuer:

(3) Die $2 B$ enoifchen Feauen fino gerthidte Brobsactertnen. Bon ifyen baben sie

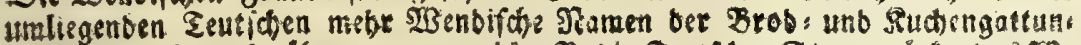

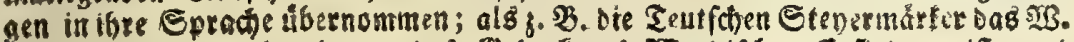

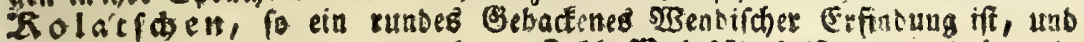

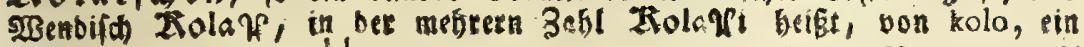
Zias, unb biefes von bל $\lambda$ volvit, rotavit, bavon auch bas \$ormort okóli

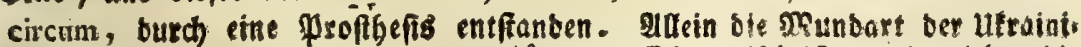
ichen Solafen, bie ein alt uno ungefalchteg Slavonifon ift, aus welcher bie

25 ent 
Caten * ftorea, Táck en; bon bem Altfrånf. und Ilem. tactien, wels

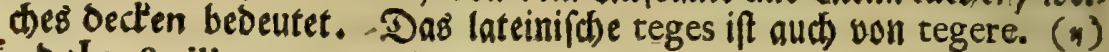
tåndeln futilia agere, tainoeln, von tano.

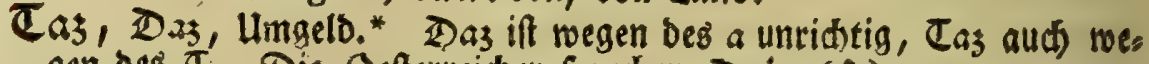
gen bes $\mathbb{C}$. Die Deferreider fpreden Daj. (\$)

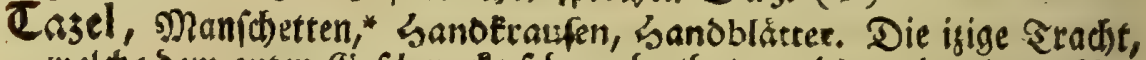
melche bem guten (S) fommade fefr wehe thut, veroienet ben lesten PRas men mit allem Siedte. Die Steyermärker, Defterreidier $2 c$. Fipes

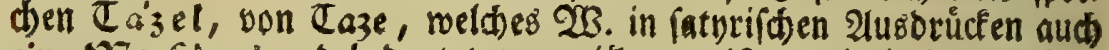
eine NTenfitienbard bebeutet, von ráks" greifen, wie in ber vorber, 2inmerfung ift gefagt worben.

trósen, irritare, trázen.

Cremel, ein Finúttel, groffer \$rŭgel; Trämel, verfleinert bon đram trabs. Die Stevermåter (pred)en Drămel.

verbaint (verfocte), verba'nt, ober verbánnt, o.i. burd ůber

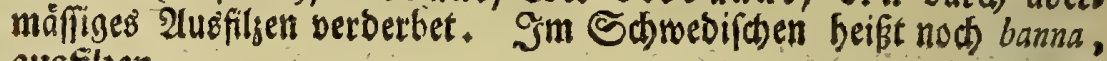
ausfilien,

Waserl *, flabellum; Wo a berl, von bem Altfrånfifhen waben, beutiges ₹ages weben. Es follte aber wäben gefdrieben werben, Denm Das Stammwort ift $\alpha^{\prime \prime} s v$. Die Stenermoirfer fpred)en, mit ftar,

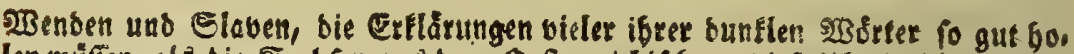

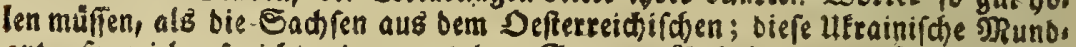
ort, fage id), fprid) reinet, und bem Stamme abnlidber, kolo fút okóli, toie

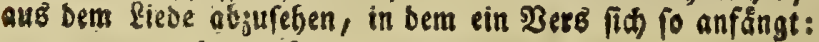

Kolo wodi, kolo mlina, Sakwitla kalína,

b.i. Um sas waffer, un bie müble,

Gielst man $\Xi$ कwelfenftauben blübn $2 c$.

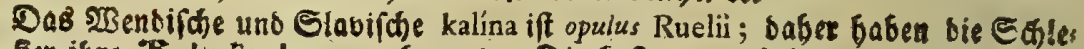
fiet ibre Zialnfenbeere geborget. Sie beften uno befannteften Suchen bet

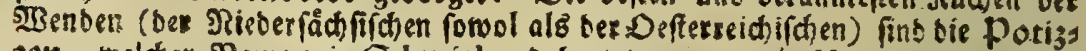
3en, nelder Rame mie 6 dimijbrod lautet, bon potit fdbmign, weil jie

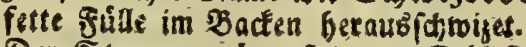

(n) Der Etammoocal muE in Der Ealefiftien Drunbart nod) gebråublich reun,

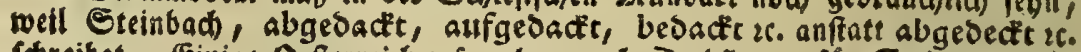

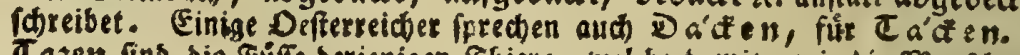

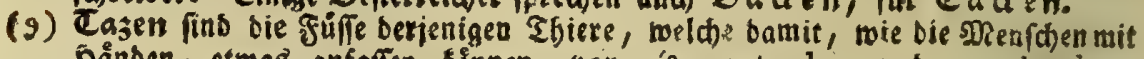
Tånden, etwaz anfoffen Eśnnen, von rá\}乡y extendere uno apprehendere. Die Razen, fudje, baren, baben Tazen: Daber fagt man in Defterceich ein 
fem Syaude, und sugleich einer Werfleinerung, welde bie gefámino bere und oft wieberbolte $\mathfrak{B}$ ewegung aubbrucfet, waidseln. (s) scánseln (bátrabeln) mit einem á. zártenl, vexare; zárten.

Sc) babe ist leine Beit, weber meinen geringen etymologifiten 20 re

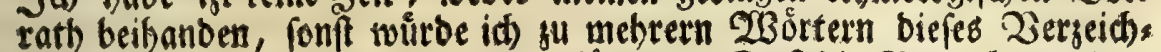
niffę 2inmerfungen baben madsen fơnnen. Daß bie B̧etrad)tung Ders felben nicht unfrudbtbar (ei), will id burd) ein Beifpiet, nåmlid burd

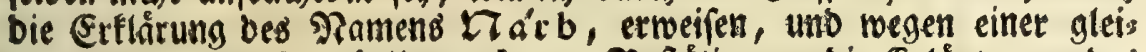

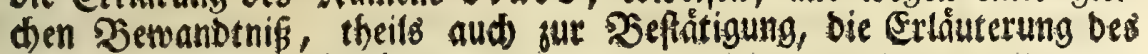
Worteb Tatter mitnebmetr.

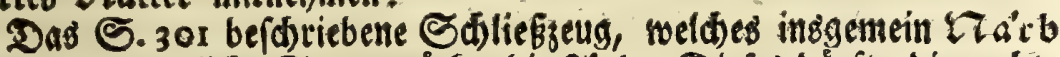
beibt, nennen etlide Steverntårfer bie a'rb. Diefes borfte bie rechte

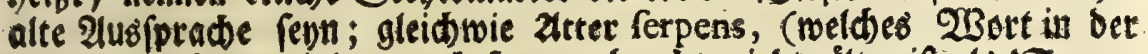
Stenermact von einigen nod) fo vorgebrad)t wirb) ålter ift als Vatter. Sth will biefes vorker barthun, uno bernad burd) Beifúlfe ber Eprad):

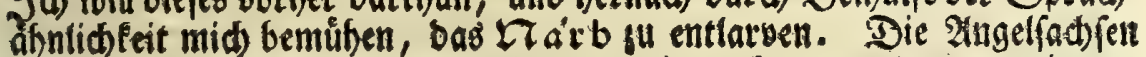
(prabben atter (Etym. Angl. Eoder), ja aud) atter Serpers, wie aus

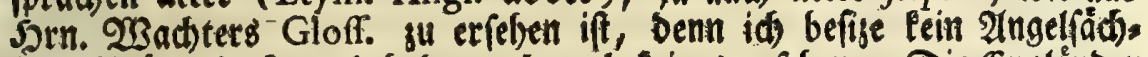

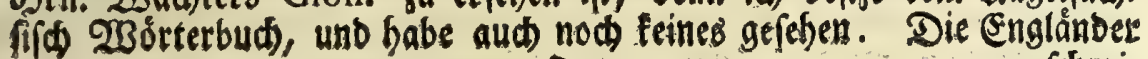
Q9

forteis

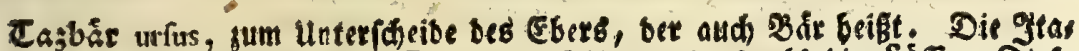
liencr nennen ebenfalls bie Cajen ber Thiere anbers, als bie Süfle. Diefe beigen fie piedi, jene zampe, unb prúfen bie gremben, ob fie ibrer Sprache

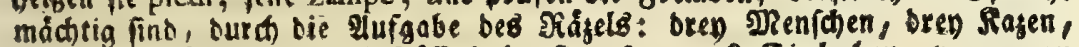
und oren) Fáren, mie viel fuiff baben fie fufammen? Eie lachen, wenn man 30 lagt, unb beantworten bie grage po: 6 piedi, e 24 zampe.

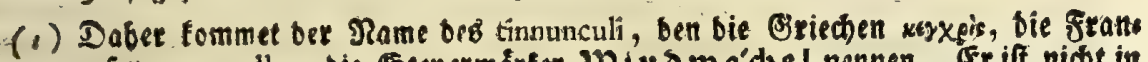
zofen crecerelle, die Etepermárfer 10 ins wo a'd) 1 nennen. (Er ift niơt in

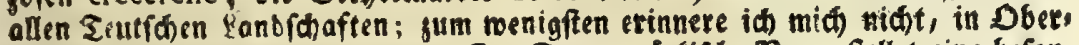
sfterreid einen gefeben ju baben. Der E teyermärfifhe game fieflet eine befon

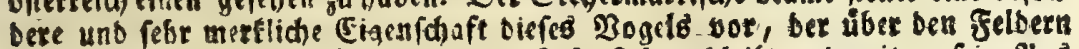
3u fiegen sfleget, und sfters in bet fuft fteben bleibet, bamit ex fein 2as befier aubipuren fšne. Um fich aber an einet Stelle fut erbalten, wåbet ex mit ben flígeln. Daber finb bie Şodteutfden Namen, ein Wannentwes ber, eine Toiegrwebe, auch beffer als folgenbe: Toandwebe, Gtein idinas, bie ibm beigeteget morben, weil et auf ren Thuirmen unb boben \$2auren niffel. Im Elovonifaben bat biefer Boget aud gute-Benennungen.

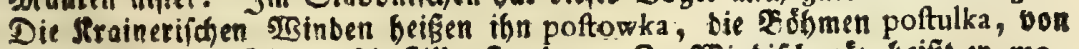

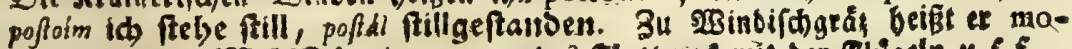
kodewka, eine meblffeberin, wegen bez glatterns mit ben glügetn u.f.f. 


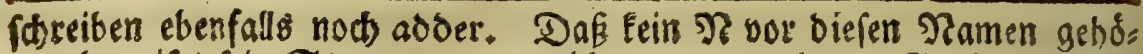
re, bemeifet fein Stammmort, welches von erwehntem Budbftaben fids

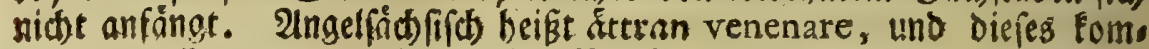

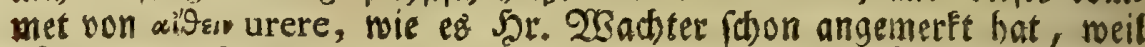
nåmlich bie Stiche und Biffe ber giftigen ₹biere Entzúnbungen verut:

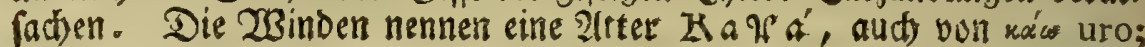

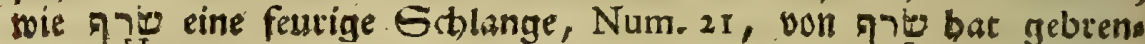

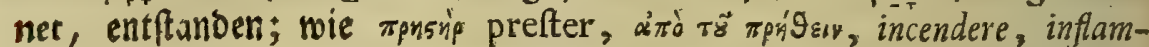

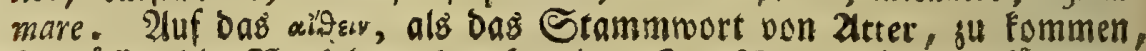

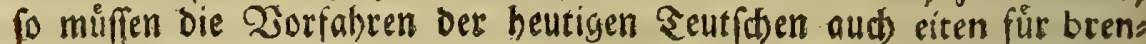
nen gefagt haben, weit Eirerneffel eben bas ift, mas Erenneffel, wie urtica von uro fo genann worben. Sheutiges ₹ages heif́t die urtica urens, minor C. B. Kiterneffel, meld)er Fame von benen, Die ber alten Sprad) nicht funtig fino, unredt beiterneffel gefdrieben mirb. Sie geben Demfelben Diefen Sinn, Daper ein Rraut bebeute, weldoes

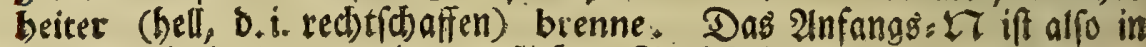

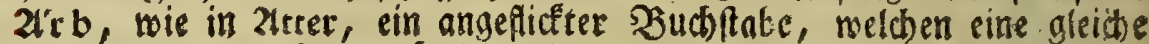
Derlernung Der ehemals úblichen Siebart batangebradbet hat. Ein brits seb $\mathfrak{B}$ eifpiel eines eben fo angefezten, und zu Den Stammbuchftaben nid)e gehorigen $\mathfrak{H}$, if vielleidbt in Dem Defterreidbifd)en, imfonderheit

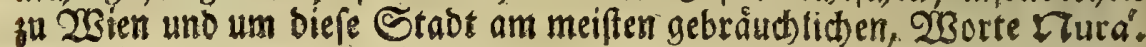

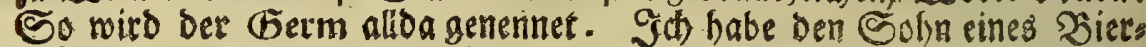

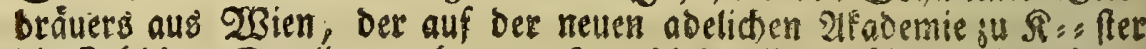

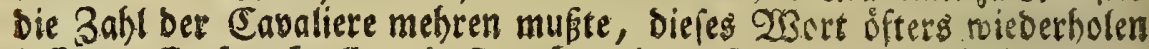
lafien. Er (prad allemal riurá, und verficherte mids, Daf man ju Wien fo rede; er babe zu Saufe Belegenteit gehabt, diefen गramen offters zu horen, wenn bie Miágde famen Nura von ifnen zu faufon.

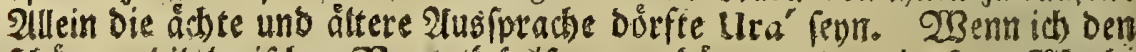

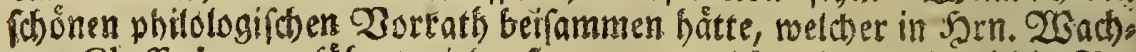

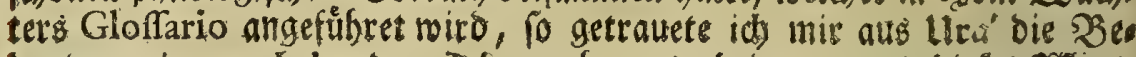
beutung eines ethebendan Dinges ferauszubringen, und biejes Wrsert,

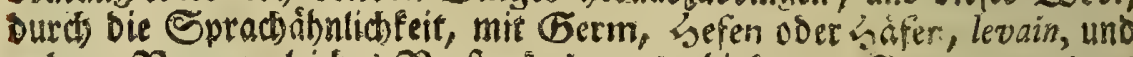
anbern Ramen gleiches Werftandes, zu berbinder. Fetm (voralters

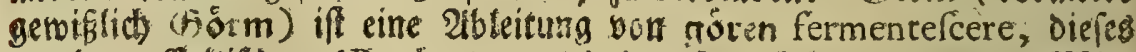

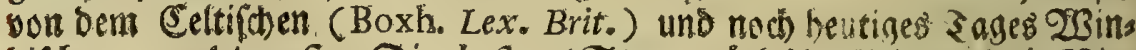

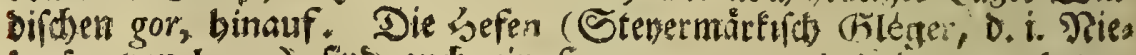
Derfat von Irgen) (ind audb ein fermentum, uno Daher von beten (Edwedifo băfina) elevare, fo getrannt worden. Das Franjof. levain Germ, bas (Engl, leaven, find befantermaffen aud von levare 
(heben) entfandene 230 rter. 23enn bemnach bie 290 ortforther bei einem Namen, Der fits mit Dem $\mathcal{L}$ anfängt, feinen tauglithen Urforung

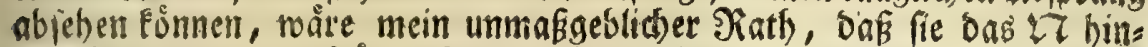
sweathun, und nachfouren follen, ob Das 230 ort nidst etwan unter biefer (jeftalt feine ?htunft beffer serrathe. Soldies mus man aud offers

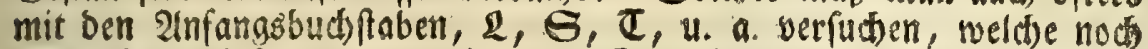
articuli prafixi aus veridiebenen Sprachen uno Munoarten fins.

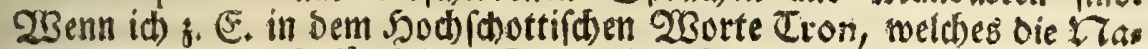
fe beocutet, Das $₹$ fur feinen Stanmbutbftaben, fondern fur ben $2 r_{s}$ tifel halte, erfotecinet alfobald stwifhen oem úbrigen ron, uno bem (jiries

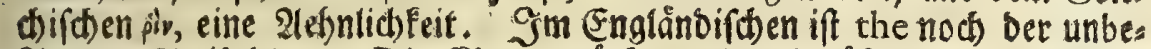
flimmte 2irtifel Der. Die Stenermårter und Sberofferreidjer fprechen

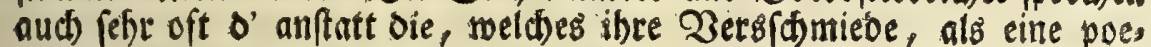
tifche erlaubre frenheit, bier unt ba wiffen anjubringen. $23 e n n$ ein

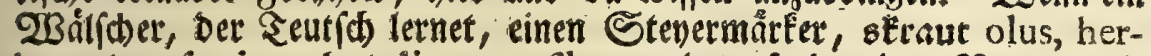
$\mathrm{ba}$; sfeur ignis; sbolz lignum, filva, und taujend andere ग?amer, mit einem Oorface von s, vorbringen bơret, fo wirb er ebenfalls meinen,

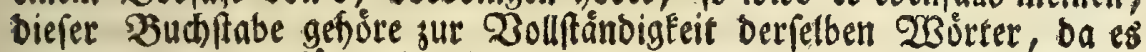

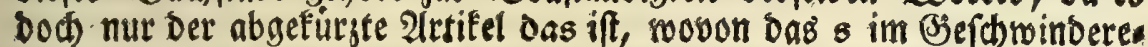
ben an bas Scauptwort gewoorfen wirb; welche alte Sedart aud nod

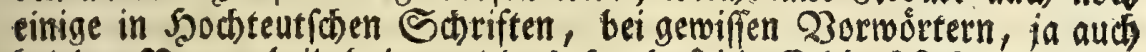

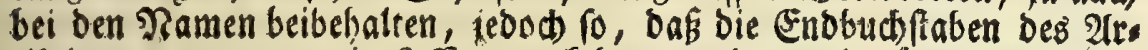
tifels, $6, r, m, n$, in fuffixa berkefret werden; als firts erfe, $\mathcal{B}$ el

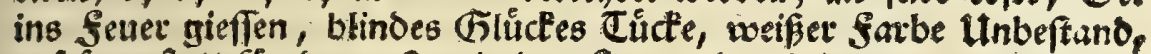
u.f. F. anftatt für das erfte, in bas fener, des blinoen, oer weipen, selebes bie reutfoben Spradhmeifter ben articulum poftpofitivum

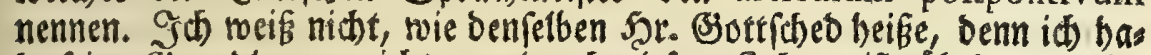

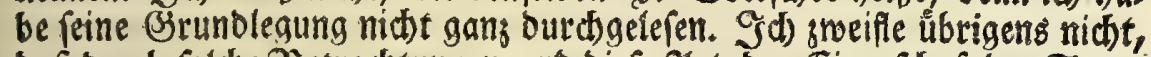

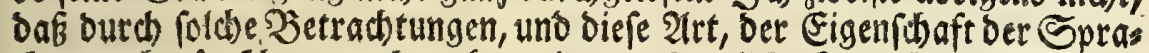

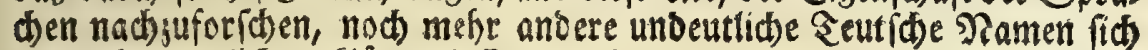

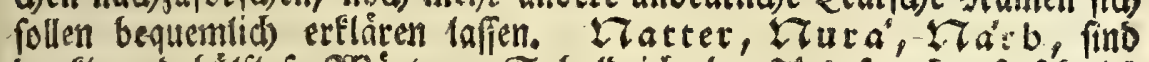

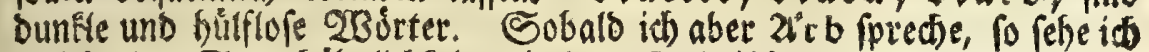

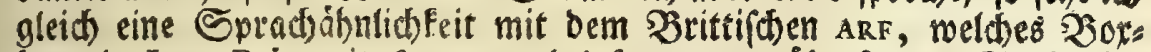
born in Lex. Brit. mit ferrum uno inftrumentum úberfejet. Sobiel foll

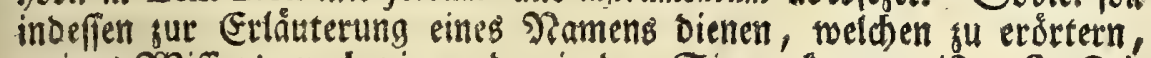
meines 2 Biffert, nod niemanoen in ben Simn gefommen ift. Gn Fri,

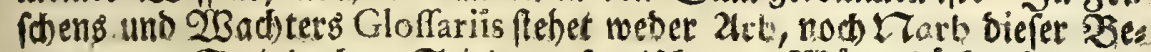

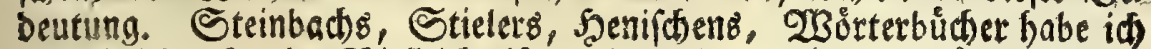

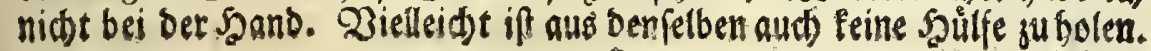


23enm mid aber jemand fragen foll, wie bas $\mathfrak{n}$ vor biefe 230

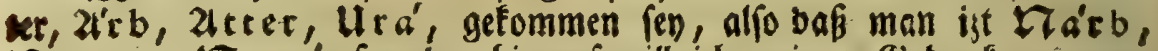

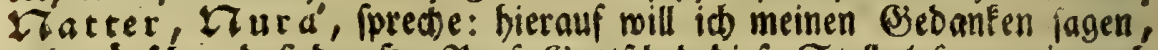

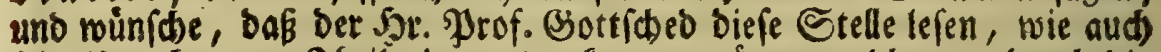
fein unrect)t zum sheile daraus exfennen mogge, welches er burch bie Dethobnung ber oberläroifthen Mnundarten bisher begangen hat. Denn

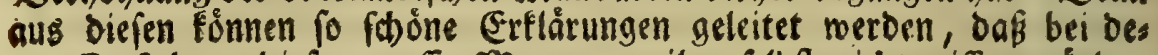
ten Entfehung biefer groffe פRann zuweilen felbft nid)t wiffen wirbe,

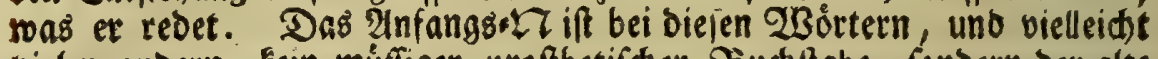

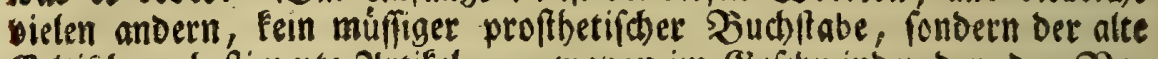

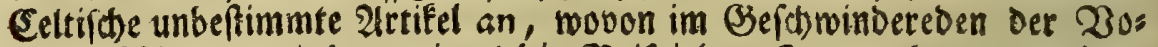
eal verínlungen worben, wie es bie Sheifpiele, s feurer, s bols, bon bem

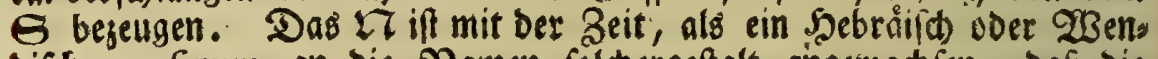
birch prefixum an bie Namen foldbergeftalt angerwadien, on शadbeommen, weldhe bis auf heutigen ?ag fortfabren, bie Sprache ihrer Worfabren mutbwilliger $23 e f f e$ und vorfeglid zu berlernen, nidte meft gewufit baben, Diefen $\mathfrak{B} u d$ fraben bavon abjufondern. 2 (llein bie fleifige

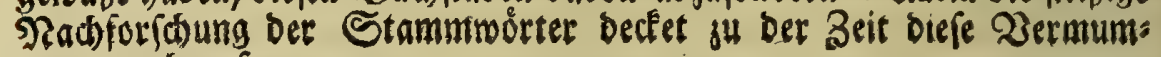
mung noch auf.

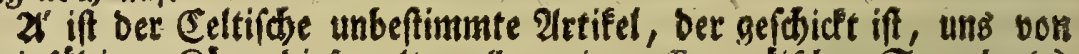
Der einfältigen $\Re$ ürze biejer alten allgemeinen (Europairchen Sprache $(x)$ tine gute Jorbiloung gu geben. Denn fơnnte man wol Eúrser ein fwres

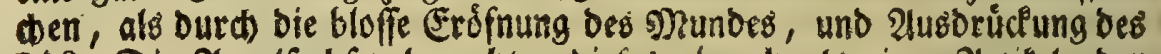
2'? Die 2ngelfadfen braudten biefes a' noch als cinen 2lutifel, ben Die Englánoer bon ihnen geerbet. Die Stevermårter, Sefterreidher, Bavern, Sberpfälşer, baben geoadbtes a, als einen 2irtifel, nebft ancern lleberreften ber Eeltiicten Sprod)e, bis auf heurigen ₹ag ebenfalls nody bebalten. Es bleiber biefes a' unveránoert vor allen Pamen, bie fid von einem shitlauter anfangen; uno beife id es darum lieber einen 2tre

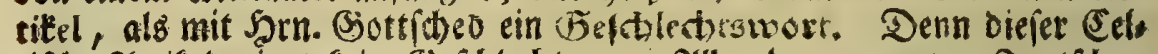

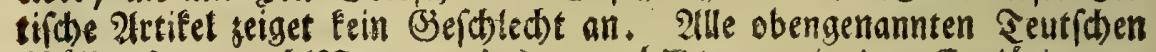

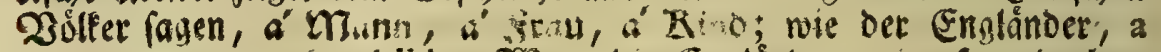
man, a woman, a ehild.. 2Bern bie Englônter, eine fo erleuchtes

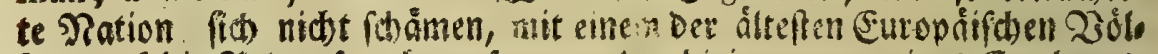
fer, auf bie Atrt gu fprechen, fo verrather bieiengin, meines Eradtens, nur ifre Unmoifenteit, retibe bie fo recenden Srevermärfer, uno inre Eprad)genoffen, ausfipitten. Escim jemand einen Sberländer aublas d)et,

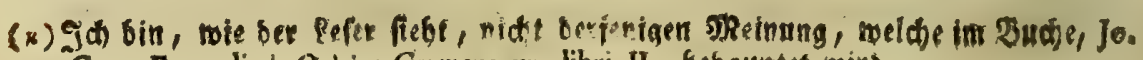
Geo. Eccardi de Origine Germanorum libri II, Gebeuptef mied. 
Wet, ba er ifh, $a^{\prime}$. Singer, $a^{\prime}$ fifch, $a^{\prime}$ Firtl cingulum, $a^{\prime}$ Glas

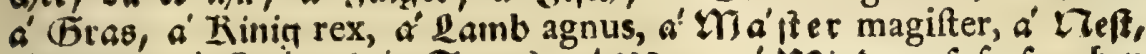
a' Sact, a' Sa'm (ein Saum), a' war, a' tWind, u. f. f. (prect)en bidret: ber mus vermuthlid nicht wiffen, baß die Englänoer euds, a finger, a fish, a girdle, a glafs, a grafs, a king, a lamb, a mafter, a neft, a fack, a feam, a wax, a wind, (h)reiben, und obne 3weifel ebedeffen alles auch fo ausaeprodhen haben, wie es hier gefdrie: ben ftehet. Wor bie meiblithen গamen fommet eben biefer Arrtifel a. Der Englánder fprid)t a mother, wie a father; eben 10, wie ber Steps ermárfer, a' Muerer, a' fater. 2lifo aud Engl. a loufe, Stenerm. a' Laus; a moufe a' Maur, a fow a' a tavern a' Tafern, vom lat. taberna. Die 2Ingelfadfen rebeten eben

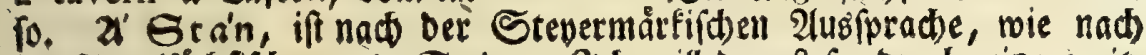

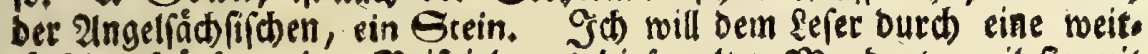
lăuftige Şâufung ber Beifpiele aus biefer alten Mundart, weil fie mit

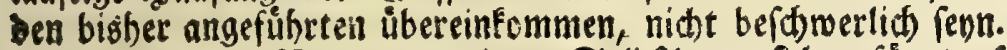

Wenn ber Pame bon einem Selbftlauter fich anfángt, fo nimm ber baborftefende 2 rtifel $a^{\prime}$, um bas ungereinte Bjábnen ju vermeiben, ein euphonifdes n ju fied, und wirb an, als: án altar altare, án Oren fornax, a'n zirm brachium, án Zefpen ober án zlefpenba'm

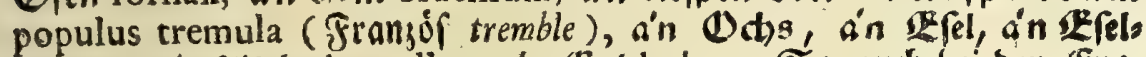
treiber, a'n 2'r(t) thymallus, a'n 便ul bubo. So aud bei ben (Eng: laindern, an altar, an oven, an arin, an afp ober an afpen-tree, an ox, an afs, an afs-driver, an ash, an owl. (Eben fo fipracten aud bie Pingelfachien. Diefer euphonifde Artifel bleibet in Anfebung ber Bjes

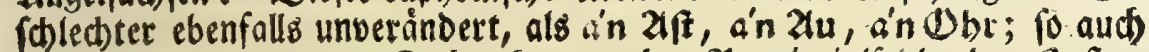
in ber vierten Enoung. Dafer fommet ber Provinjialfehter ber Defter: reicher, menn biejenigen, bie Scudteutid) idhreiben wollen, ofme fies vorher in ber Grammatie diefer Sprade gebúfrend umgerében ju bas ben, ein Infel, ein zrffen, anftatt sime Inft, einer afren, fejen; - weil man nad ibrer Mundart redtet fo (pridbt: án I ll infula, infulam; a'n 2uff fimia, uno an 21ffen fimiam. Das fino aber im

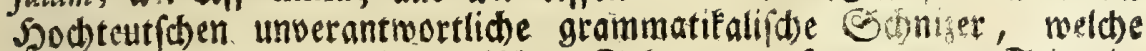

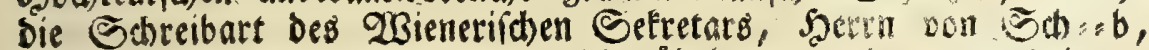
bemacteln: $(\lambda)$ Nian befebe bie ubrigeng lool auṡgearbeiteten

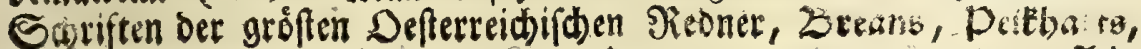
293 Dit.

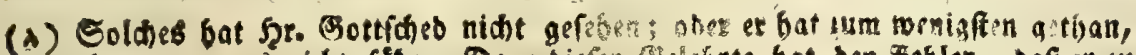

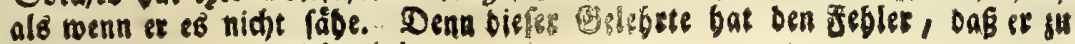
biel lobet, ober fu viel tabelt. 
Dittermans, fo mirb man finden, oas biefe 23 abtheit aus allen Seiten ifrer gedructen 23 erfe hervorleut)te, fie baben fith um oie Regeln

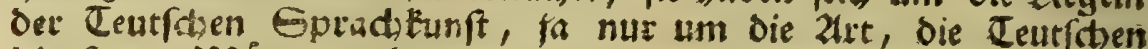
biegfamen too orter redt) 34 declinicen und zu conjugiten, wenig bes

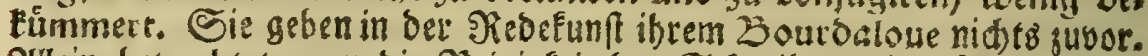
Illein berradtet man bie Rzinigkeit ber Sdureibart, fo múffen fie bies fem Sranjofen fo weit nachgehen, als ifre Untuft, oas Şod)teutfitse

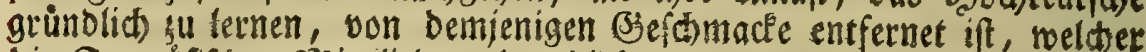

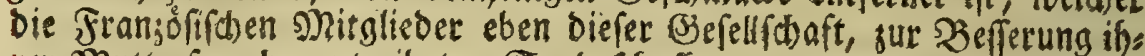
rer Mutteripract)e antreibet. So befthaffene grammatifalistoe unrith;

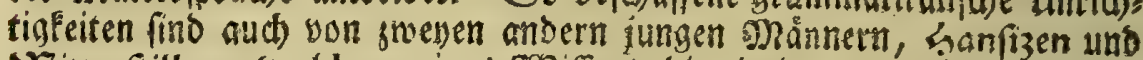
iritterftillern (welde, meines $2 B$ iffeng, Die einjigen geweiheten Defters reicher find, Derer ₹eutfibe \$oeterenen man obne (Ectel lefan Fonnte) nidt vermieden worden. Diefe baben burd) etlide in ifrer Gugeno beimlich verfafte Seutidite (Sjedichte Dargethan, bas es ben Sefterrei:

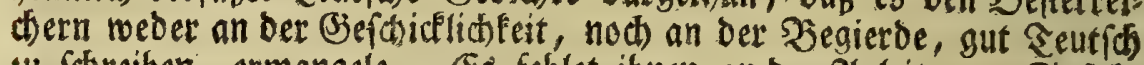
gu fobreiben, ermangele. (EB fehlet itnen an ber Anleitumg, (Einfid)t

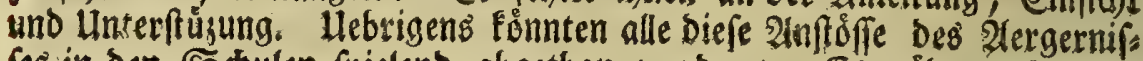
fes in ben Shulen fpielent abgetban werben. (EB găbe aud, um biefes einjuriditen, eben feine $2 B$ eitlauftigleiten, wenn man fich nur ent: fidlieffen wollte, die Sand an bas 23 erE zu legen, unb einen fo fehr in

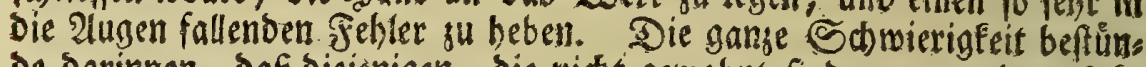
De barinnen, Daf biejenigen, bie nidjt gewohnt find, yon anbern ₹efs:

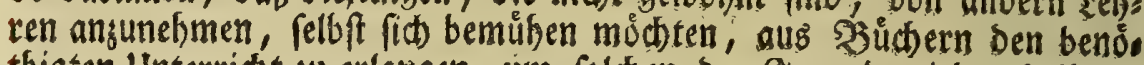
thigten unterriot) zu erlangen, um folchen Der Jugend wieber beibrins gen ju fonnen. Snnerbalb menig Jahren wâke bas (Eis gebroden, und eine fo wiberfpanftig faseinende \&lbeit in bie Hebung gebract).

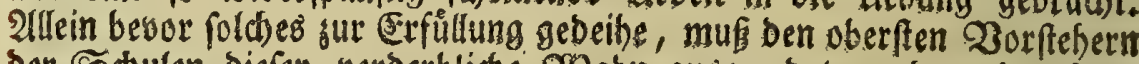

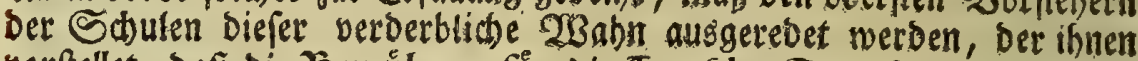

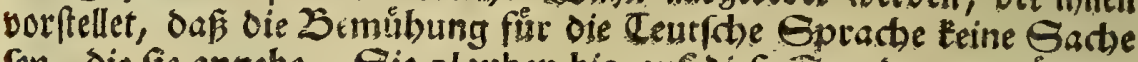
fey, die fie angebe. Gie glauben bis auf oiefe Stunde, es werce ein Jeitvertreib, ben fomd fie felbft, als ibre Sthuler obne trathetheil entratben Eonnten. Fin patriotifoser Defterreid)er foll fid) fu Fobe

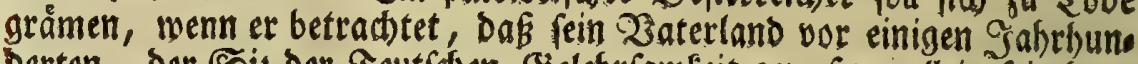

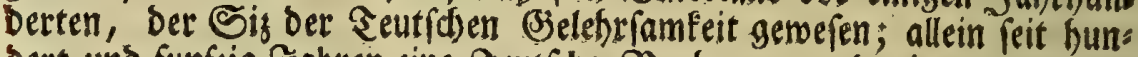
bert und funfsis Sabren eine ₹eutipe Sarbaren, und ein Biegenftand Der Sberfádfif́ten Spo̊tterenen geworben. Wie lange wirs es aber nod) fo róbren? Meiner halben now greubunbert Jabre, Nein Ders.

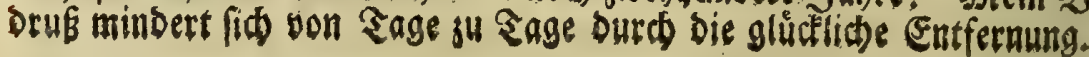


Der Stenermárfer nun (id) fomme auf ben (S)tuf meiner (Fror: terung) (pricht aud) a'n 2tter ferpens, Der Englinnoet an adder. WBeil Der erfe aud) an $2 a^{\prime} \mathrm{b}$ fagt, fo feben wir, wie burd ben oben befdrie:

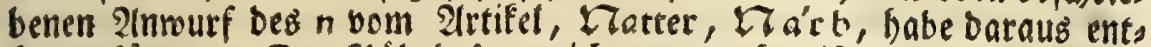
fteben fonnen. Der Jóbel, Dem nidt fujumuthen ift, Daf er bie $238 \mathrm{r}$ ter nach ifrem rechen Serfommen beurtbeilen foll, bot enolidf nod Den beftimmten Artifel vorangefest, und die Datter, oie $27 a$ rb, zu

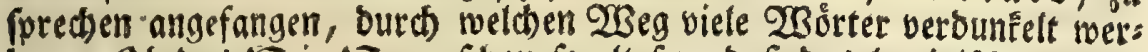

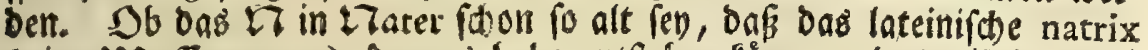
( eine Waffernatter) Daraug habe entftefen fonnen, Das mill id), we:

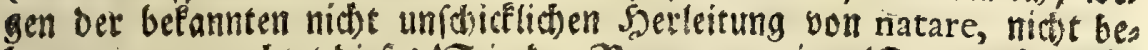

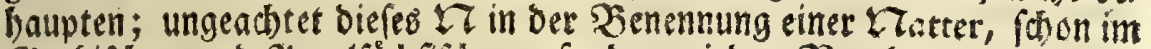

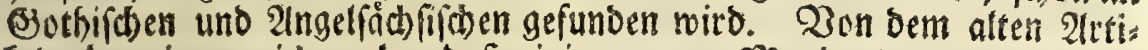
Fel cin erinnere it nod, Daf einige neuere Munbarten en oder een

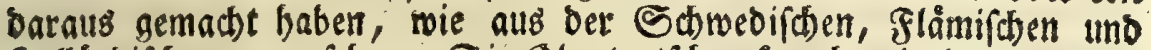
Sollånoifaen, qu erfefen. Die Dberteutfoten (prachen in oen mittlern Jeiten, ain. Diejenigen Stenermåtfer und Defterreicher, bie fid fod. men mit bem gemeinen Manne a' und án ju fagen, foredoen nod) ain;

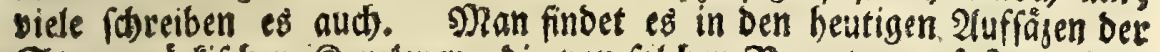
Stevermárfifchen Santlesen, bie von fold en Benmen verfafit werben, Denen bie Schreibart ibrer Altwäter beffer gefällt, als oie neu eingefúbr te. Det jüngfte, ausgepujte, und burds bas viele fegen gang binne ges madte, Scochteutide unbeftimmte Irtifel, if ein. 2llein fo fid ơn oets felbe aus dem Mlunoe eines Niederfactien Flinget, fo barf er fic ber furgen, uno vielleict) gefbiçtern (Einfalt feiner alfnen nicht fodmen.

Soviel ju einem Mnufter des Ctenermårfirden ober Defterreichi: (chen Gloffarif. WBeil aber nid) nut ein foldes 2 Berk, fondern fobon

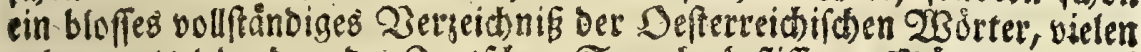

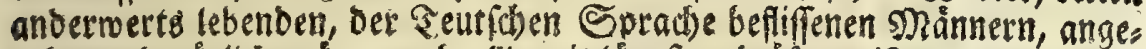
nefm uno nủglich wáre, auch allbereit längf uno of ters ift verlanget roor Den, fo mogen die einheimifd)en (s)elebrten zurehen, wie fie Den gereds.

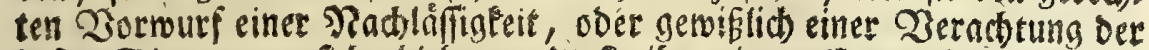
beften Dinge, bon fith ablefnen, Da fie ibre eigene snutterfprache burd Fremoe fartftich oerfaffen laffen, gleichrie ifre 30 rfafren auf bie

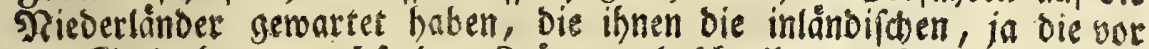
ben Stabttboren mablenoen Sråter, befibreiben musten. 2Biewol

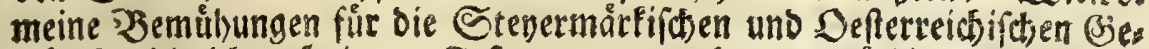
soádble, bie id) auf eigene Foften zu unternefmen genóthiget warb, nut

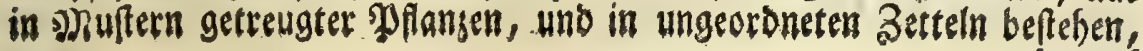
oarauf 
Darauf id einige 3 lumen und Samen gezeidnet, wie auch basjenige,

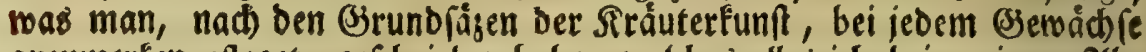
anjumerfen pileget, gejdrieben habe, weiches alles id bei meinem $\mathfrak{A} b s$ zuge in bie Siften zufammentwerfen muste: fo bebált bod) biejer nur po beidaffene Zorrath biơ auf gegenwårtige Stunbe feinen $2 B e r t h$. Eg ware mir aber, auct) in 2(nfebung einer Sammlung ber Defterteictis

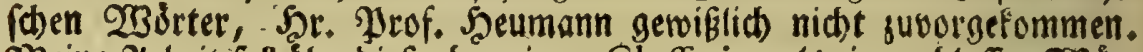
Meine Arbeit fol úberdieß efer einem Gloffario, ats einem bloffen $2 B \delta$ rs terbudbe ábnlid ausgefallen renn, wenn ich -zu berfelben nur fo groffen

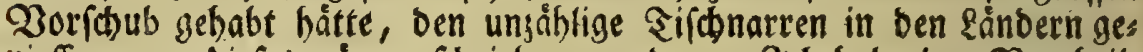

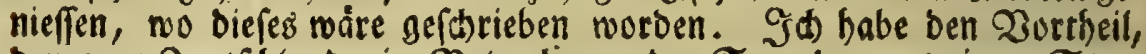
Den gan Seutifhlano, in Betractitung ber Spracte, aus einem Steys

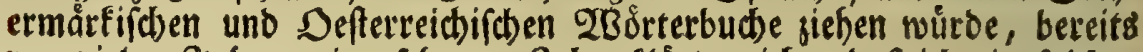
vor vielen Sabren eingerehen. Sid) erflärte mich, baß id ein folches

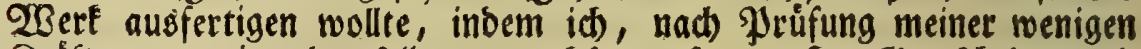
Fråfte, vermeinte bemfelben gewadefen zu fenn. Shr. Bjottided, welo der burd) einen groffen Şerrn aus Sadbien, meinen bohen Goinner, biebon Nadbridt befam, und glaubte, id) wurbe eine Teutide Sprads.

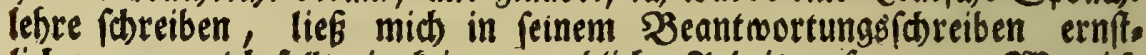
(id) warnen, id follte ja feine vergeblicbe 2irbeit anfangen. $2 \mathrm{Bas}$ id

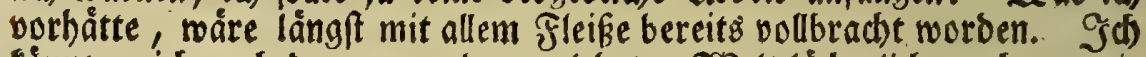
fonnte mich noch Darsu vor Der gelehrten Welt lód)erlich nadeen, wie

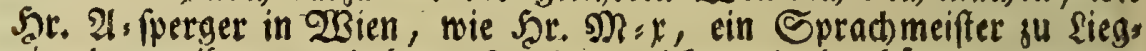
nis, benen ihre angebohrne Munbart niđt erlaubet hätte, etwas ges

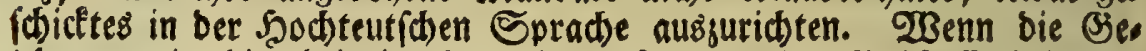

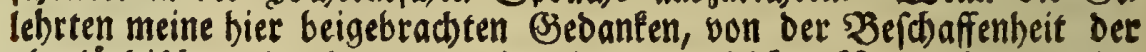
oberlåndichen Nhuno arten, und andere bergleicten Nachridten, getne eher erfahren bătten, weil ifhnen vielleicht folche $\mathfrak{D}$ orftellungen zu ferneren

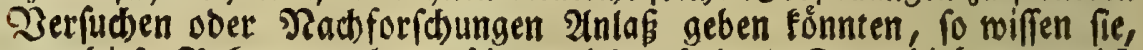
wer biefe Sefanntmacbung bintertrieben habe. Denn bisher war id nod) furdstfam. Nun aber baben wir bie glúctlid)e Beit erlebet, in

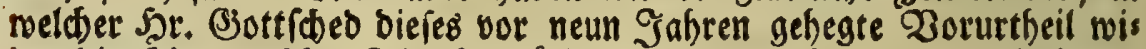
Der bie Soberteut(f)en Dialefte, sffentlid) wiberrufet, und als irrig ero flîret, in ber Grumolegung einer Deutfthen Epract)tunft, in ber Dorrebe jur erften 2tusgabe, a. D. lezten und vorhergehenden Seite.

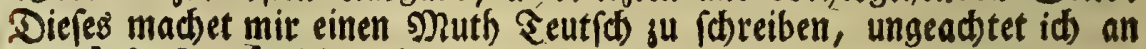
Dem äußerften fübliden Enbe von ₹eutfhland, und aus ben 21 then ges

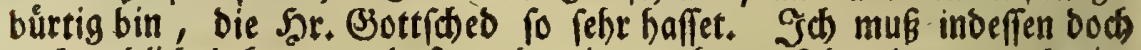
aud) reblic) befennen, Dak su ber isterwefnten 26 mabnung now eine 


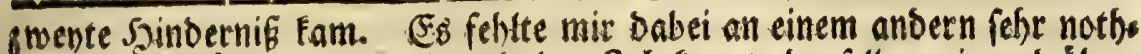
wendigen Stúcte, an bem llnterbalte. S(t) fonnte benfelben nirgend úber fommen, ungeadtet id) einen fo geringen Borfhtib nur auf 2 Sabre

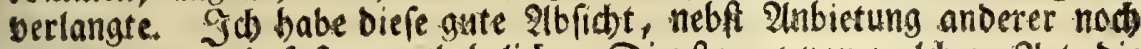

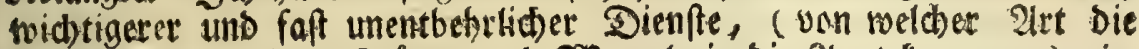

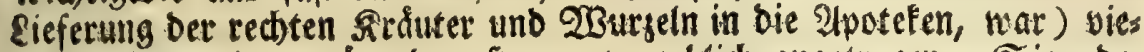
Len reidsen uno vermógenoen Scerren vergeblid) angetragen. Sie reber ten alle aus einem Shone. (Es hię, id foll einen fobon erridoteten Dienfi annehmen, wenn id Brod baben wollte. Dir gu (Befallen wurs

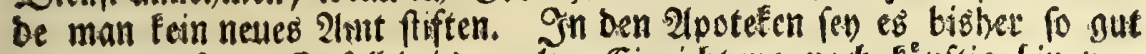
genug gewefen. E⿺辶 foll bei Der alten Einrid)tung nodh funftig bin vet bleiben. Diefes fam allen überaus ungereint bor, bas fie einen Mens

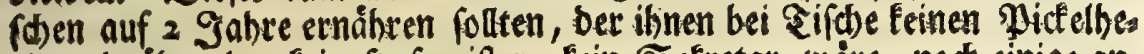
ring abgåbe, ber fein 5 ofmeifter, fein Sefretar, wäre, nod einige ant bere innen befannte Stelle verfáthe. Diefe Arbeit watb alfe, nebft ant bern bem gande nod núglidseren, auf Die Seite gefejt. Selbft batte

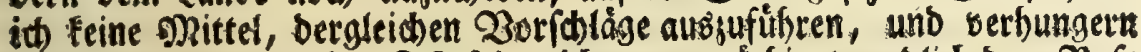

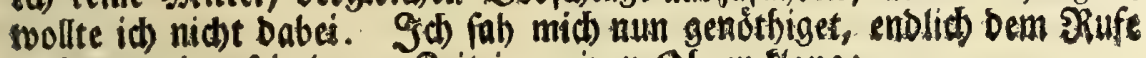
6u folgen, Der feit langer Beit in meinen Sbren flang:

Heu fuge - - terras, fuge litus ávarum. ( $\mu$ )

Die abbanblung bon ben Pocalen ift burd) bas bisher biefagte

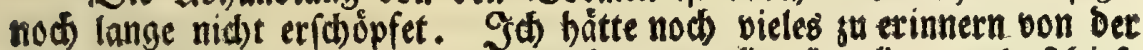

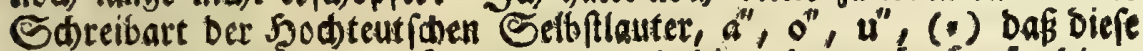

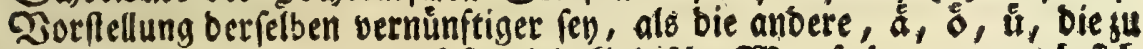

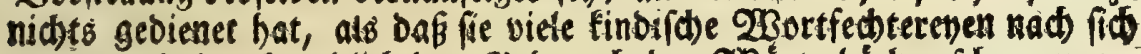

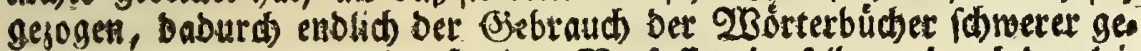
madt worben, wenn eigenfinnige Derfaffer berfétben, ourds berglei: d)en albere Eppisfiti igfeiten, bie alphabetifhe Dronung ber 20 orter verworren haben. Die Schranfen, weldie mir ber 23 olftand reset, bamit bie 3uråze nidbt lănger werben, als bie 2ibbandlungen; unb bie Zeit, weld)e meine Feber gur $\mathfrak{B}$ efanntmadbung anberer Sadben abrufet,

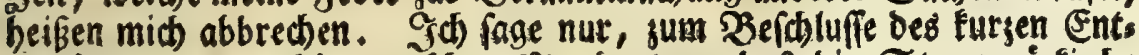
wurfes von ben Dberteuriden slundarten, bas bie Stegermáttiche Ii

mit

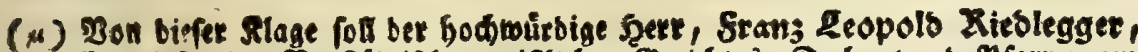

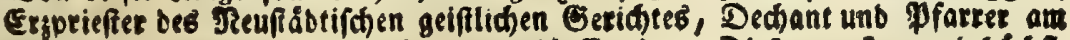

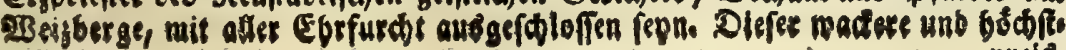


mit ber Defferteidifhen múglich, wie aud) feht gefoidt fen, bie wabren

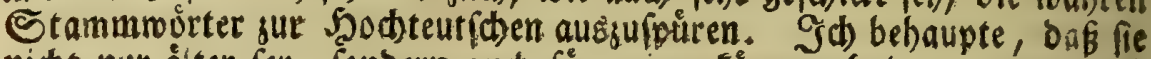
nid)t nut åler fen, fonbern aud fur reiner fönue gehalten rerben, als die $\mathfrak{S}$ chteutiche, menn man bie Reinigfeit fo beftimmet, saf fie feine

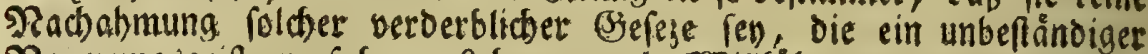

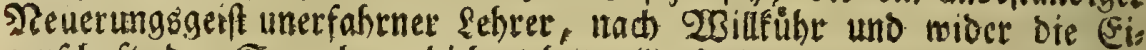

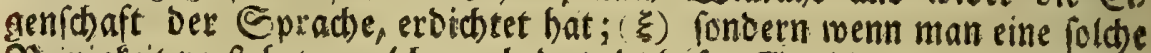
Fieinigfeit verftelset, wetche nod das lebhafte Ebenbilo der einfåltigen, furzen und nachorúclichen, babei aber aud wortreichen, Sebart bé

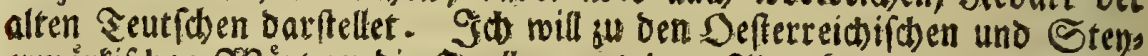
ermirtfifden 230 ortern die 2 uellen aus bem Altertbume Der Sprad)en

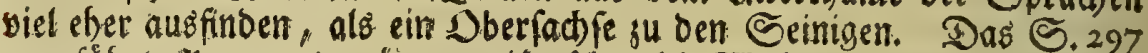

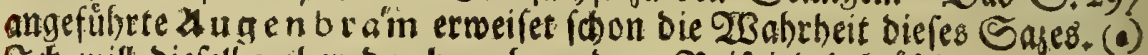
Sob) will biejelbe aber burd mebr andere Seirpiele befråfrigen.

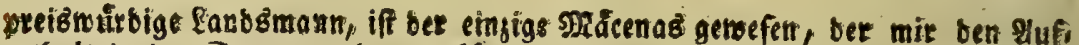
enthalt in ber Etepermart gu verlángern, unb mid), fo lange id molle, obs,

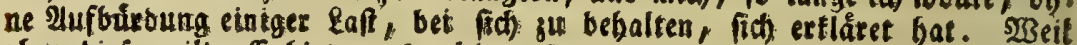
ober biefe milbe Erbietung (weld)e alleroings verbienet unter bie feltenften Exempel bexienigen Sirgenten gerechnet zu werden, mo man ben Esubirenben

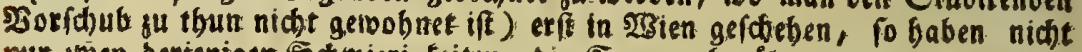

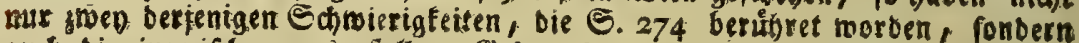

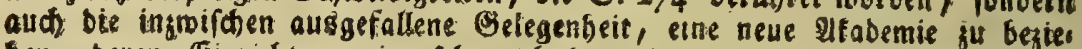
ben, beren (Finrichtung einjufehen id) begierig mat, biefe 3uricfreife bin tertrieben. Die foulbige Ertenntlidkeit für eine fo aubnebmenbe Büte, vere bittbet mich, folches bier effentlich und mit allem gebúbrenten Dante gut ea wefnet.

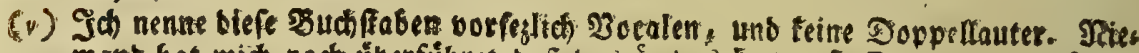

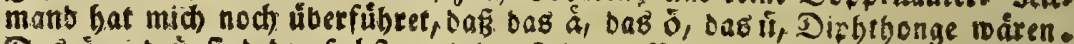

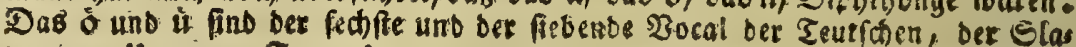

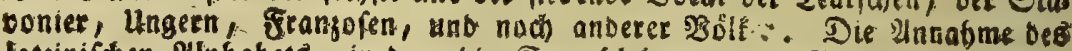
Iateinifich Mlphabets, in Dem die Sprachlebrer nur 5 Bocalen gefunden, mufite nefft bem 3roange, baffelbe, als eine unverbefferliche Erfindung ku bals

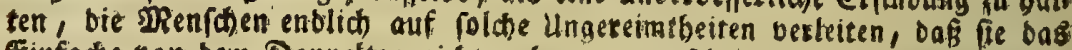
Einfadie oon bem Doppelten nicht nethe sut unterfobeiben geroufit babett.

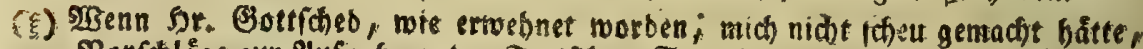

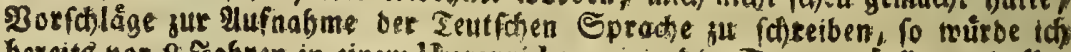

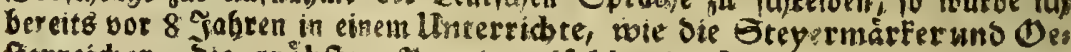

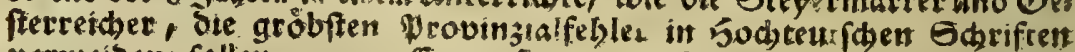

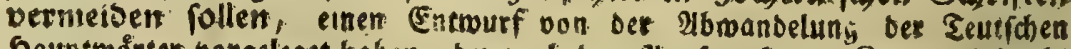
Şauptworter vorgeleget baben, ber nach bem Ilusfpruche Der Rentret vielleid)t bolffandiger, uno den firemben beutlidher, als oer vermorrene, ist ans Jas 


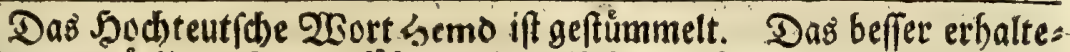

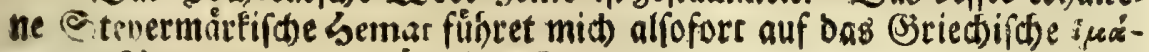
sıov veftimentum (vermóge ber Endung ein teringes Kleio), welches bon eipas, uno biefes von ber alten Urquelle sis induo, Fommet; wie bie Siomer aแs induo indufium gemaht baben. Das. Unerifhe imeg, to auch das bemo beocutet, (h)einet ebenfalls, Durch bie ehemals Aleos.

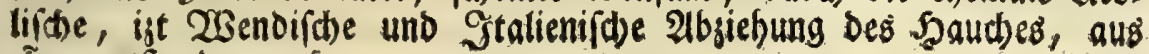
cípeas entftanden gu feyn.

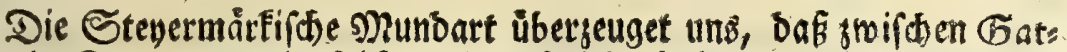
ter und Gitter nur ein folcher Unterficheb bafte, weldben biejenigen Sprad)eúnftler, obne 2(blicht auf bie Stammmórter, eingefübret bas

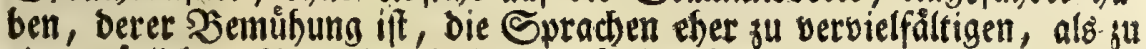
einer núglidben Einigfeit, poviel es moglid ift, wieber zu bringen. Tht) bebaure, Daß $52 x$. Wadter, meldber in feinem Gloffario offere 3 jele: OP $2 \ldots$

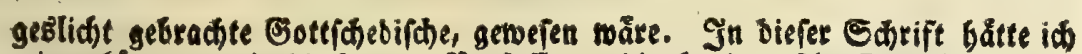

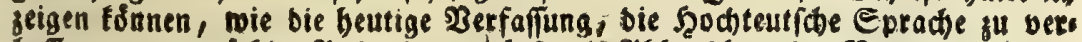

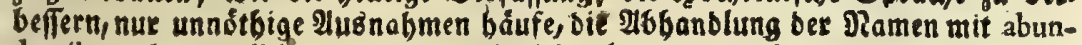
dantibus, heteroclitis, unb anbern linridhrigfeiten vermebre; io wie exft in bies

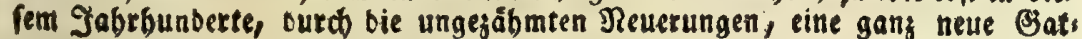
tung ber 2 brandelung ber Namen (Declinatio Nominum) aufgebradtet wors ben, uno becen now mebrete nad)folgen bórften, Daf es billig zu beforgen fey, man werbe $D_{a g}$ Seutiche endlich burch Regeln faum mebr lernen tünnen, menn nicht rechtichaffene. Belebrten zufammenfteben, um eine vernünftige, analogif

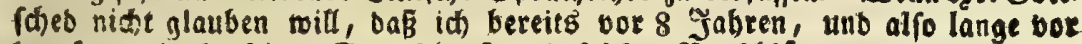

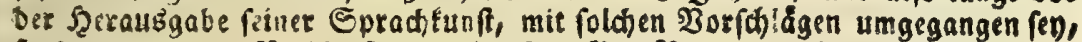
fondern, um ben $\mathfrak{B e c}$ ienft eince fo alten Bemúbung, Durd bas befannte, inventis facile eft addere, nieberzuf(y)lagen, etwan vorgeben foll, ich bátte aus feiner Brunblegung Dos Befe berauspegogen, unb baffelbe in einen anbern Sortrog eingefappet: fo berufe id mid erftid auf ben (S. 312 gertibm

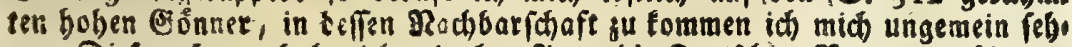

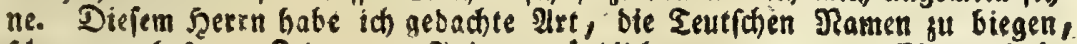
fhon vor befagter Żeit von 8 Jahren mutnblid voręutragen bie Egre gehate,

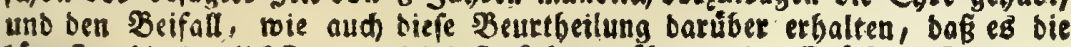
firyefte, bie beutlichite unb richtigfte Rebrart über biefes Gtúct ber Seutichen

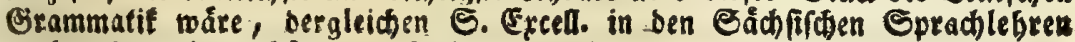

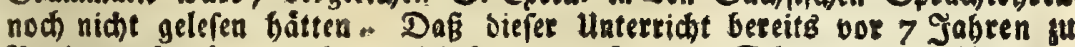

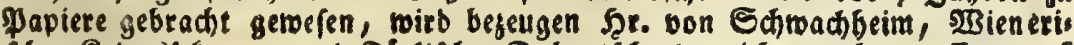
(d)er Rerieggifefretar, unb Túrfi(cher Dolmetfi), bem ich gemelbeten Entwurf bor meiner 2 breife nach Rermsmunfter, beren Etifter Derfilbe getwefen, auf

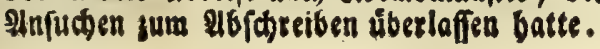


genteit gefabt, biefem unfuge fich mit aller (serond gu miberfesen, fots wes nidst nur forrfam gethan, fondern oas llebel an gar vielen andern

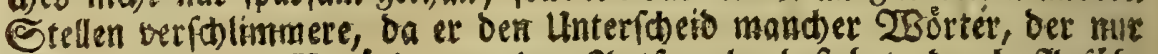

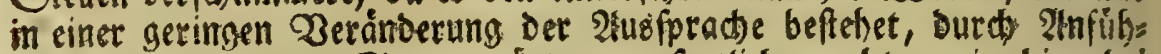

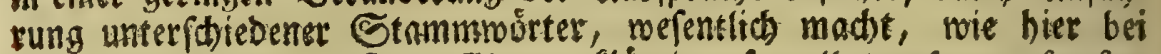
Gatter uno Thitter. Das Gitter erfláret er fo: "tranfenna, feneftra reticulata. Differt a GatTer feptum, quod non profpiciendi, fed cuftodiendi et muniendi caufa factum eft., Diefer (Gitter führet er, ofne ben gerimgften Sdatten eimer $23 a$ hrefdeintich feit, von dixtu rete, $a b$.

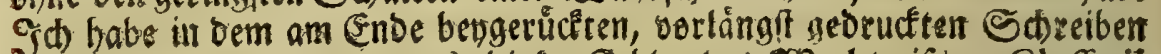

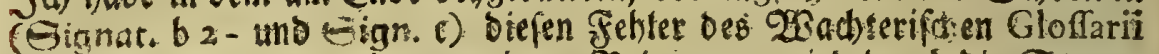

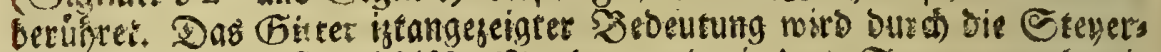

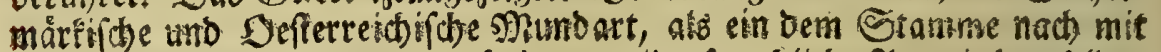

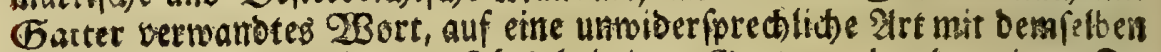
berbunden. Eim gegittestes i hor bei einem (Sarten, ober bey einen fyso flungerwerfe (Heal. un raftello), nennen bie Stenermårfer und Sefter: reidber einen Gatter. Gben fo lautet ein Jallantter bei einem Stadts thore, cataracta. Fin Bitter vor eimem Fenfter heise in erwehnter Munbatt $a^{\prime} \widetilde{G}$ atter, nur mit, einem bellen $a^{\circ}$. Sn oerfelben if fein Gits ter ober Gegirtet. Die Sade ift ba, allein diefe wirb Gater ges nennet. (Es if demnad) mafricheinlid, Dâs Gitter, wo man alfo fpridte, aus Garter entfitanden fen. Biefe Bermandelungsifufen, Gatter, Gätter, Gátter, Getter, Gitter, find in ben etymclogis

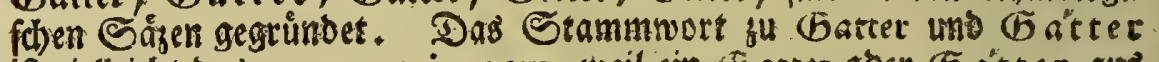

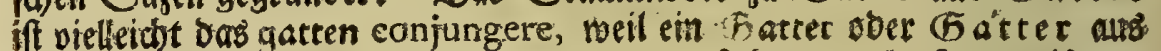
satten, Stáben, ooer eifermen Stangen beftebet, meldbe freusmeife ans cinanber gegattet ober gefüget fino. WBeit aber bie Şauptabficht Dez

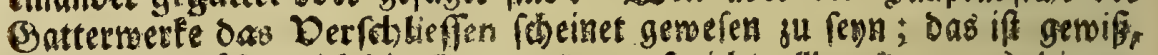

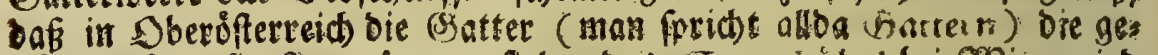

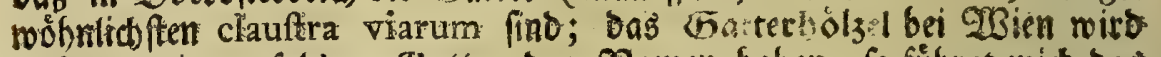
aud) nort eirrem folden (Sacter Den s?amen haben: fo fúthret mid) Das

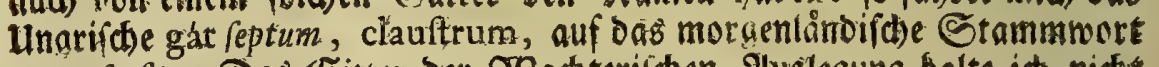

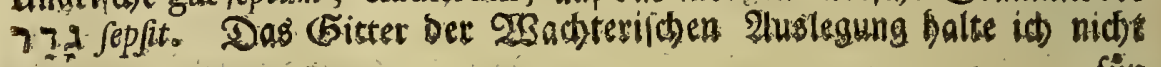

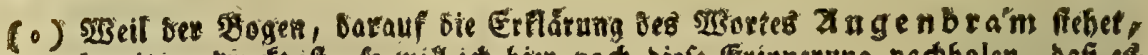

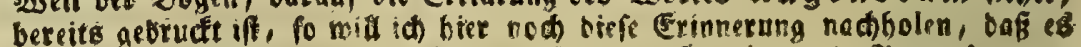

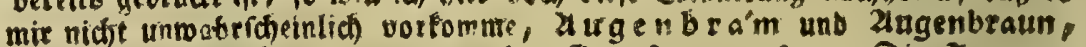

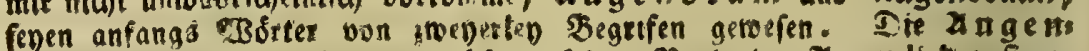

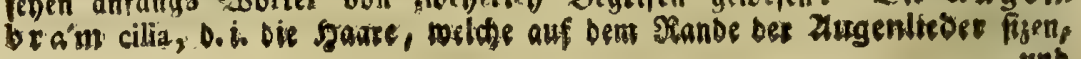


Nablefe van 3ugaben.

fir fo ale, baßs es von ber oben angegogenen ungerdalachten 2 Surzet

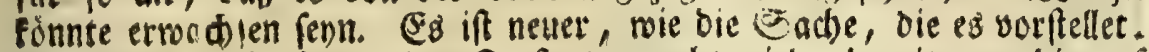
Ein şlenbmere, fo yor bas Fenfter gemacts wiro, bamit man bie auf ber Estraffe gehenden \{eute badurd betrachten und beurtheilen mo is, ohne von ihnen gefehen fu werben, ifi ein Unterhalt bes fünbhaften Mui: figgange8; eine Enfinduing (wie es ber (Sefithmact seiget) neuerer Zei.

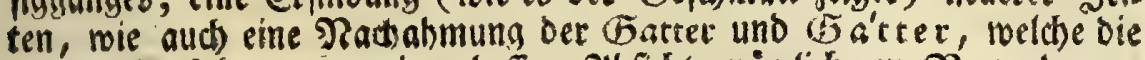
flugen Worfabren, aus einer beffern 2ibficht, nämlich jur Zerwabrung, aufgebratt baben.

Sambucus beift in bet Stevermarf, in Deferreid ac. Soblet,

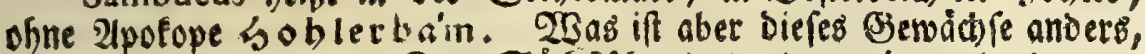

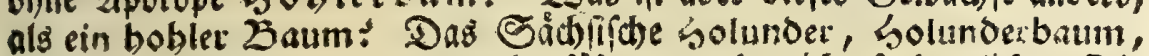
ift von biefer Quelle weiter abgefübret, und nicht fo beutlich. Die

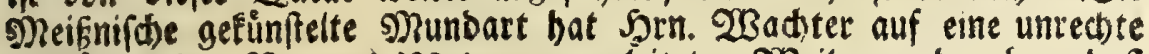

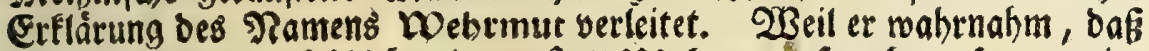

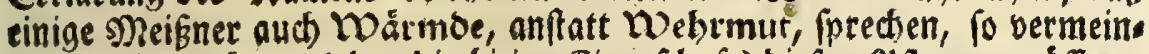

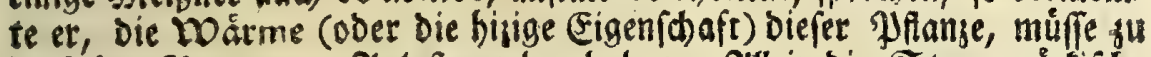

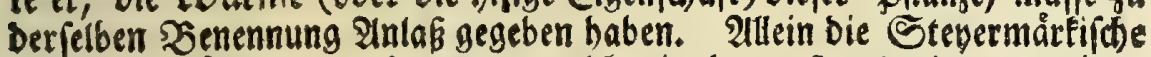

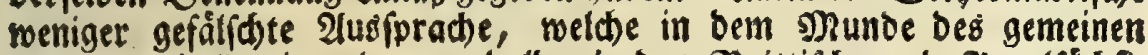
ManneB, balo wie wermat, bals wie ons Frittiche und 21ngelfádbfis

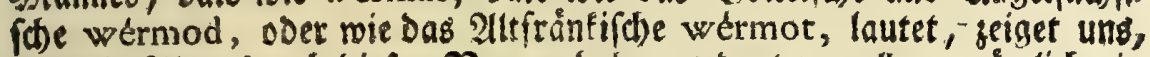
was bie Alten burd) biefen शramen haben andeuten wollen; nämlia) ein Sraut, fo dem lingeziefer uxebret. Der vordere Theil fommet von webren; benn die Stevermårfer preden das erfte e in Webrmuth idarf aus, wie in webren. Marba, Maoo, Mooo, Maden, Horo

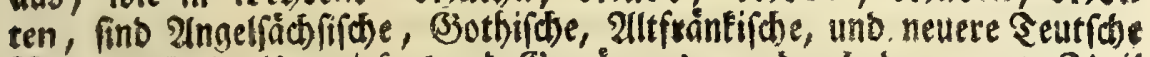
Namen allerley Ungegiefer und Gemurmes, woburd ber jweyte Sheil von Wehrmur erflaret mirs. 2Beil Diefes Rraut Der झlage, die von

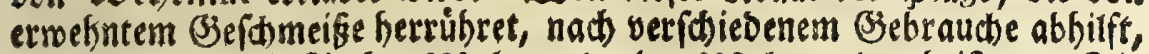
fo hat man es mit \$Rechte webrmas ober webrmos geheifen. Die ungleiche heutige Sdbreibart liegt .Der 23 abeheit nicht im $25 e n e$, fons bern bejacimet, meines Eradtens, nur biejenigen, weldie biefétbe aufs gebrad)t haben. Shan bat angefangen wels mit sinem zu (d)reis

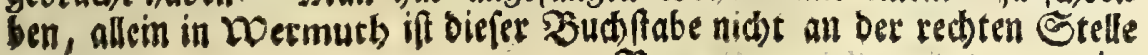
Rr 3 cino

unb biefelben gleidfiam br a'm en. Die Zugenbraumi fupercilia, eigentlich) minentie oculis insumbentes. Engländifi beiget fupercilium brow, ober vodifiann Big eye-brow. Eye if Das Zug, brow etwas erbabents, bie Sóbe eis

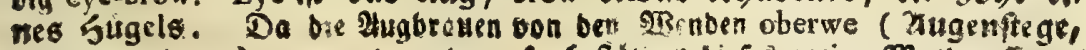

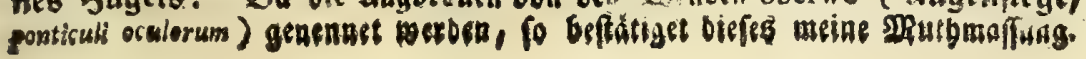


eingefdoben morben, weil man nicht mehr wufte, baß biefes von jenem herftamme $(\pi)$. Dás Der 23 ehrmut ein bewáhrtes ssittel wiber als lerlen Ungesiefer fen, wiffen bie 2lerjte. Das ift bie gewoobntichfe 2irs.

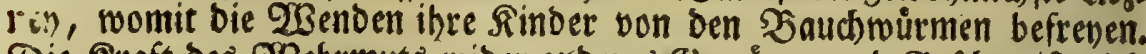

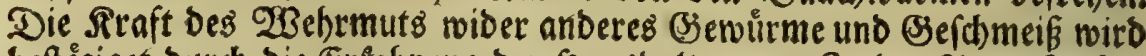
beftåriget burch bie Erfabrung ber \$̧aushaltungen. Sn Den 2lpotecten fat man ben Samen einer \$lanje, weld)e bie 2liten unter bas Bjef(ledtst bes 28 ehrmuts geredtnet baben. Eafp. Bauhin nennet biefes Fraut nat) Sautwolfen (Franff. 1582, S. 456) und anbern, abfinthium

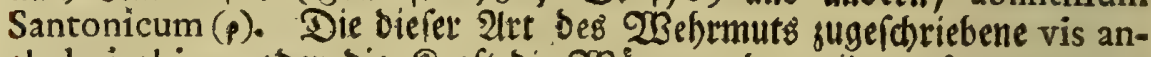
thelminthica, ober bie Sraft bie 2 Jurmer absutreiben, ferner andere Fenennungen biefes Frauts uno feines Samens, melde insgefamt bie 2lusbeutung auf Wourme baben, als Wurmeraut, Wourmfamen, lumbricorum femen Jo. Bauh. III, 180 ; Fram. la mort aux vers, b. i. der wo wes mer Loo, find fo viele Beftátigungen meiner 2luslegung von Wobrs mut, und folches um befto-mefir, als aud ber gemeine 23 ehrmut bies fes alles wirfet, und bie ist angefúfiten Ramen eben fo wol verbientet. Die Englånber, weldhe wórm-wood anftatt webrmut fipredsen, bes

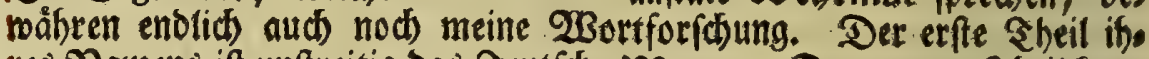

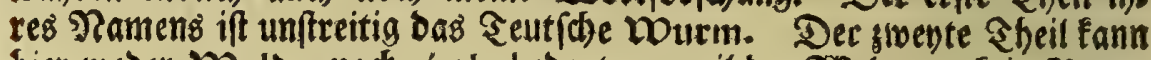
bier weber $\mathfrak{W}$ alo, nod solz bebeuten, weil ber $2 B$ bhrmut fein $\mathfrak{B a u m}$ ift. Wodim beift in ber 2 sendiften Sprache ducere. $23 e n n$ biefe ErËläs rung anftefet, fo wåre wórm-wood nach berfelben planta vermes educens.

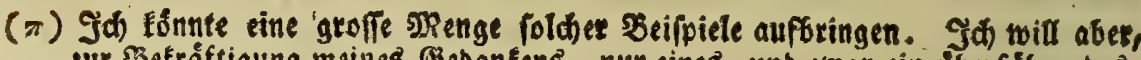

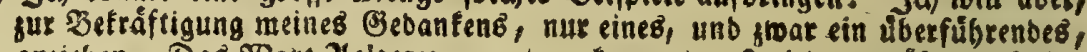
anjieben. Dab 230 th Zeltern parentes, fommet unftreitig von ältern fenio-

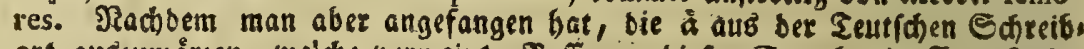
art aนB̧jumårien, weiche vermeinte Befferung biefer Eprache ein \$aar Jabr: bunberte getrieben, unb burd ben Beitritt einer groflen (Sefellf) aft beftáti

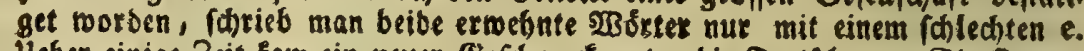

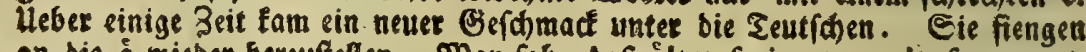
an bie á wicber berzufteflen. SRan $\{a h$, bas álter fenior oon alt fenex ent

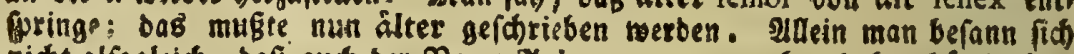
nid)t alfogleid, Daß́ aud ber शame Zeitern parentes eben baber burtig fen);

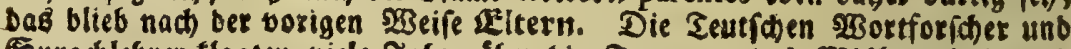
Eprad)lebrer tlagten viele Jabre úber bie Intanney bes MRisbraudes, und rietben, man foll Zeltern (parentes) fateiben. Pellein bas QEltern blieb feft fieben. It beth legieen Jabren gegenmártiger Rebjeit brauthen bie Bies lebrten Biewalt. Sie famifien gang erboßit ben Gebraud) vom Sutbeber ber.

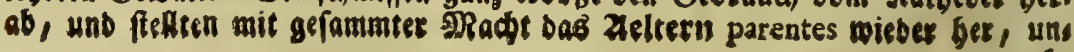


Tadilefe von Zügaber.

Die Stenermárficte gmundart meijet mit bet Defterreichiften, und allen benienigen bon Sberteutichlano, weld)e buth die fo genann

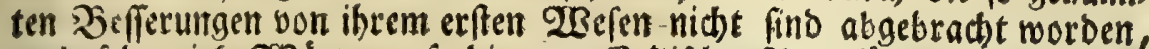

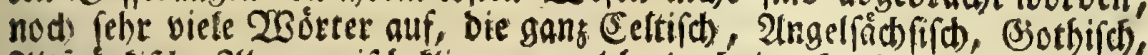

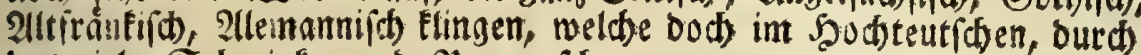

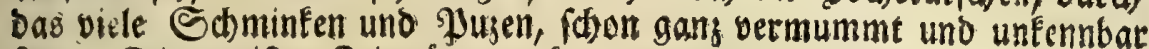
fino. Die meiften Bettwơrter gehen, nach bet Spredjart bes gemei. nen SRannes in Defterreich, now in a aus, wie im Elandifhen, und

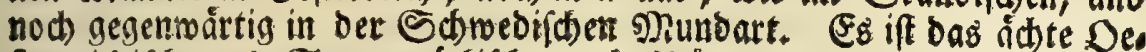

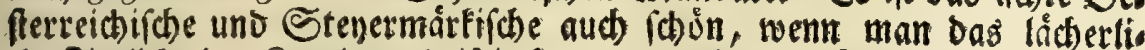

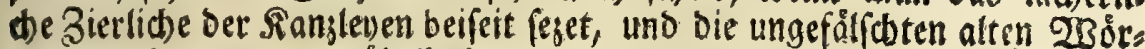
ter von ben neuern pobethaften zu unteriheiden, bie guten rectit zu

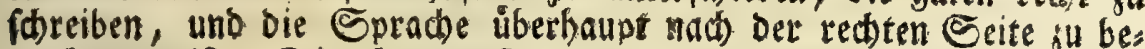

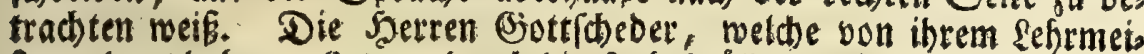
frer gelernt baben, alles nur burds oie Şohnbrülle anjufehen, finden freys

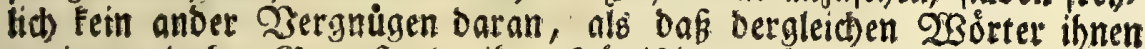

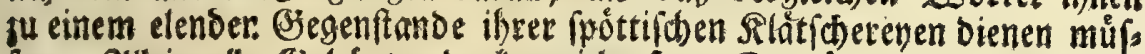
fen. 2llein alle Gielefrten bemen niche fo. Eg märe aud ein groffes Hebel für ₹eutidlano, wenn Diefer (Stefthmat weiter einreisen follte. Denn bie alte Sarbarey, bie ist nur in einigen $\$$ egenden now einen 2ufenthalt gefunden bat, befóme fobann gewonnen Spiel, Durch folde

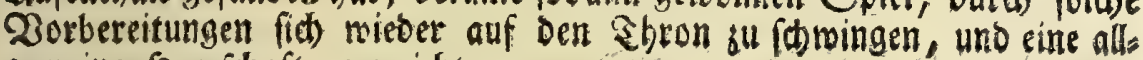
gemeine Sherridant zu erribten.

X. 3

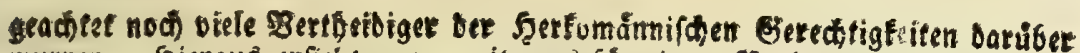

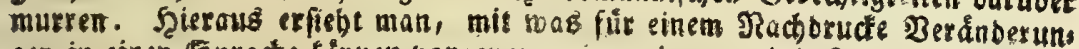

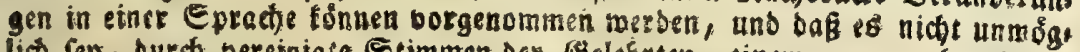

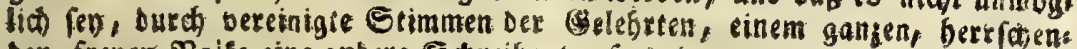

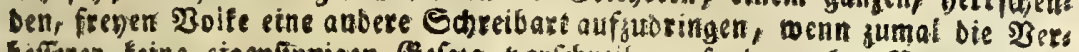
befferer feine sigenftunigen Befere borfctreiven, fondern the Borfellungan mit Der Anologie bewafirat find, unb ouf folche Regeln fich grüben, ornen

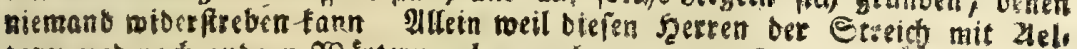

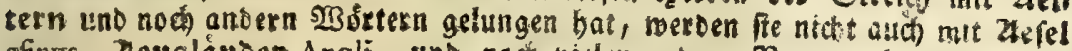
afinus, Brngláner Angli, und noch vitlen andern Namen, bei berten bas a, nact 2lustueifung bet alten Epradien und झRunbarten, ein Etammoocal

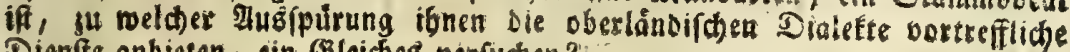
Dienfte anbieten, ein Sleidhe verfuchen?

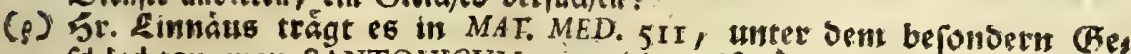
fidedetenamen SANTONICVM vor; id weif aber nids, mir twas fur

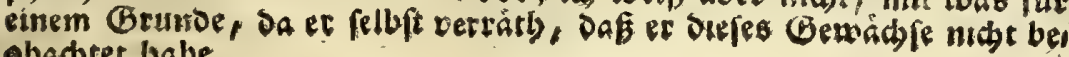
- badotet babe. 
3u ben Beugniffen son bet groffen norbifaten Eeeflutb, bie 1717 in ber (Shriftnad)t fid ereignet hat, Deren traurige 23 ürfungen v. 0.94 (5. befá)rieben werben, gehoret der funfte Wers bes XXXIX (Befans $g e s$ in bent Rerne ariftitier uno lieblicher Lieber, fo bas belannte

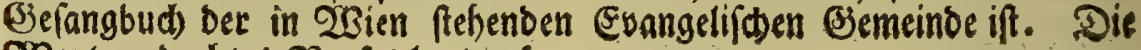
23orte gebndtes Derfes lauten 10:

Doir gedenken izt oer Riutben,

In bie fturvere Jammernact,

Da bie tharbe oee wafferflutben

Dieb uno Menf(ben umgebrad)t:

Mouren, Dakmin uno bobe Deid'

Wurben all ber Erben aleid);

Die Oas Cbriftefit wollten balten:

Hiviften in ber flutb extalten.

\section{$\mathrm{XI}$.}

2Benn jemanbeth, bei Durd)lefung ber 102 S. biefes nidit anftes

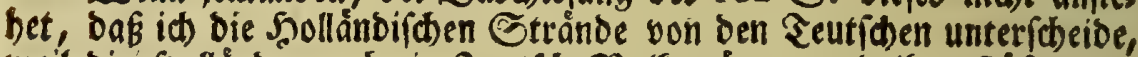

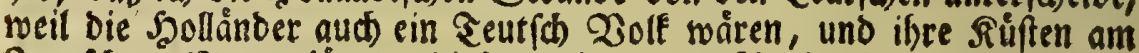

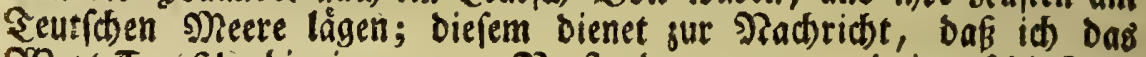
$\mathscr{2}$ ort Teutftie bier in engerem 2 erftanbe genommen, b. i. auf bie 3 res

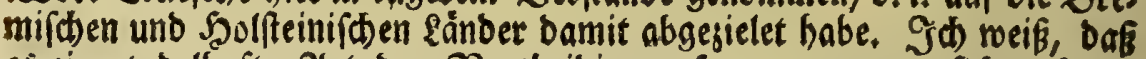
es eine tabelhafte 2 ntt ber Zertheibigung (ê, wenn man fid) auf bas Beipiel eines gleid)en unrid)tigen 2 lusbructes berufet, beffen ein anbes ret fich bebienet hat; fonft murbe id) eine eben fo lautenbe Stelle aus bet erften Jorrebe fu 3orgbragers Grónlánio. Sift). S.2, anführen

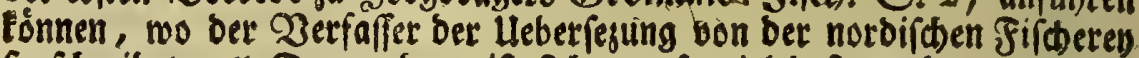
fo ihreiber: "Damnenbero ift fich um fo viel befto mefr zu verwuns

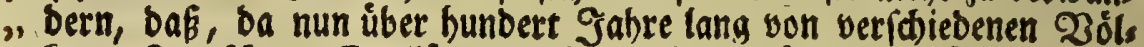

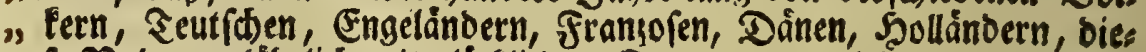
"Fe Rabrung iăbrlich mit glúcflichem Fortgange getrieben worben $2 c$.",

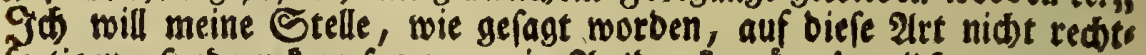
fertigen, fonbern fur fagen, mein 2lubbeuct wáre beutlicher gewefen,

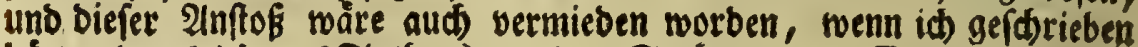

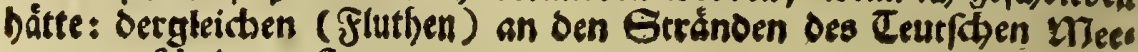
ree zu erfibeinen pefiegen.

XII. 2Bean 


\section{XII.}

2Benn meine Erflärungen einiger Platteutfher 2308 teter, bie S. 103.107 vorgetragen worden, jemanden veranlaffen follen, etwas volls fånbigeres von biejer Ât gu liefern, Demielben norb, außer Dem S. 1o7 erwel)nten Idiotico Hamburgenfi, Dasjenige SRegifter einige Beitråge

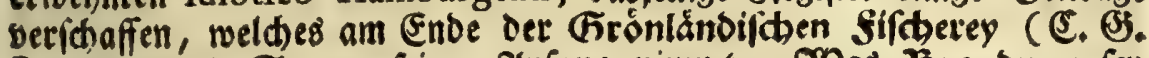

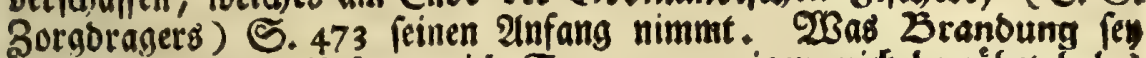
(weldes शamens uriprung ich $\mathcal{S}$. 104 anjueigen mid bemúhet babe) wirb in erftangefúthrtem $\mathfrak{W e r f e}, \mathfrak{S} .474$, mit folden $W_{B}$ orten anges

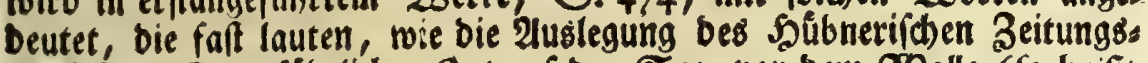

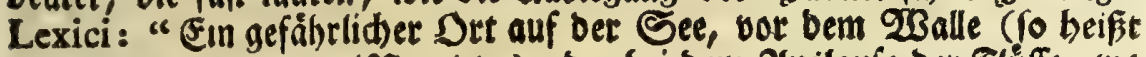
"Oas Rano von oer Meerjeite) ober bei bem 2tusilaufe ber fluffe, wo " Dав 2 Baffer úber verborgene §lippen, quf feichtem Brunbe braufet,

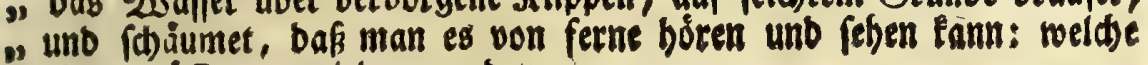
is Drte múffen bermieden werden.

\section{XIII.}

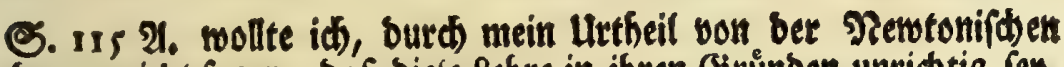

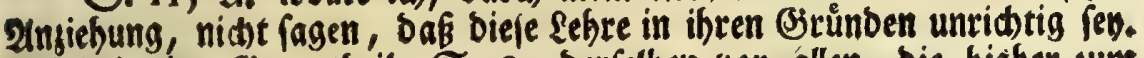
Sd) habe im Esegentheile S. 81 berfelben vor allen, bie bisher sum Zorideine gefommen, was bie 2Aufófung ber widtigften 2ufgaben det

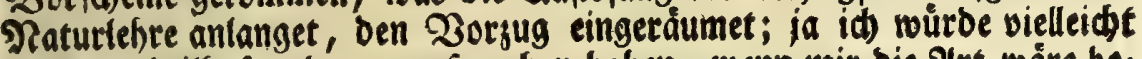
nod) vortheill)after bawon gefprod)en haben, wenn mir bie Art wáre bes

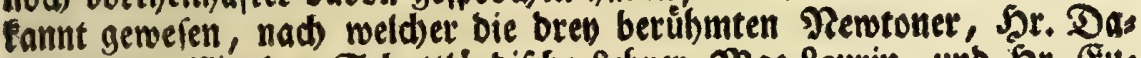

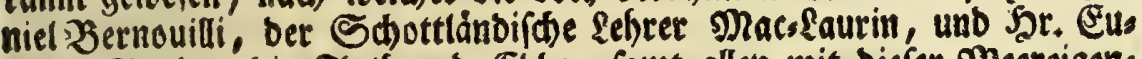
ler fu Berlin, bie Fluth unb Ebbe, famt allen mit biefer MReereigens (

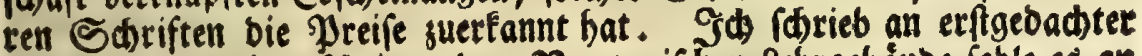

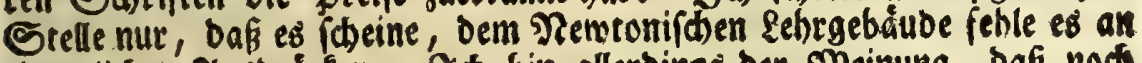
eigentlid)en Aub̈brúcen. Sक bin allerbings ber Meinung, baß nod grånner fommen borften, gu unjern ober in ben folgenben Beiten, wels

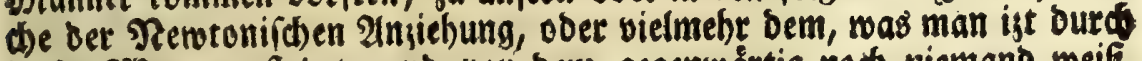
biefer 230 ort verftehet, uno von bem gegenwártig nod) niemand weif, to verítiebener (Erít)einumaen mit folden $230 r t e n$ vortragen werben, bie

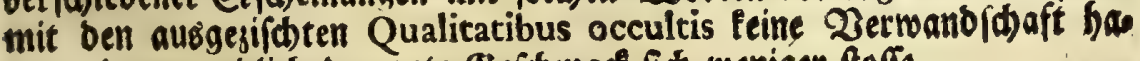
ben, baran endid bet gute Eseidmact fid weniger foffe. 


\section{XIV.}

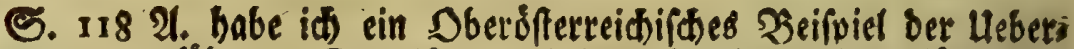
fteinerung angefübret. DaB̉ ift aber bei ben beutigen Raturfúnbigern feine Seltenheit. So befthaffene 2 gaffer findet man in ve:foriebenen

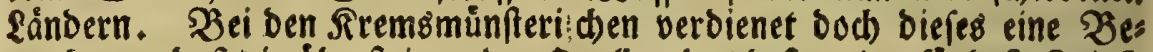

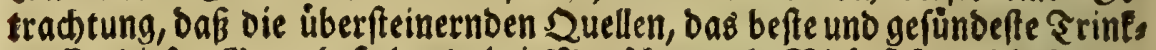

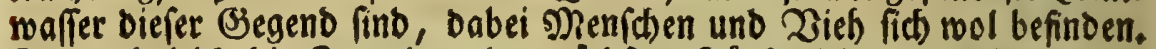
Denn obgleid) bie Inwobner ber nádbften Şåufer lebenslang feinen ans

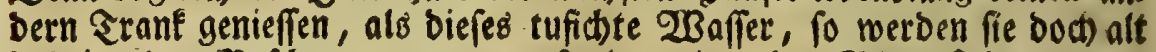
Dabei, ohne $\mathfrak{B} e$ fatwerungen vom fendengries ober $\mathfrak{B}$ !njenfteine zu em!

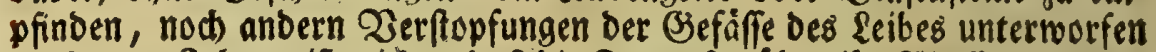

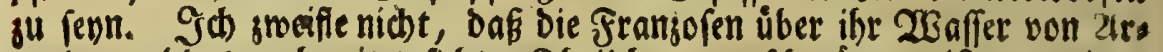
cueil, tweldes auch mit tufidsten \$beilden angefdswángert ift, womit es feine Эinnen ůberffeinert, und gleidwol in $\mathfrak{Y} a r i s$ getrunfen wiro, eben Dergleiden Anmerfungen und unterfucbungen werben gemact) baben.

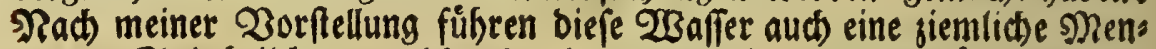
ge von Salstheildsen, welde eben bie lleberfeinerungen befórbern. Die falinifhe Sđårfe treibet ben Nieberfas ber tufidsten $23 a f f e r$ mit aus Dem 乏eibe, uno hinbert bie Derbinbung ber aufgelofeten Erbe, weldse

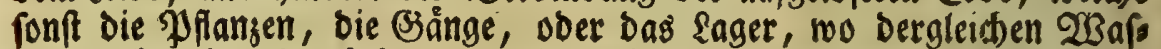
fer Durdhlaufen ober ftehen, mit einem fteinichten Uebersuge becfet. Meis ne Muthmaffung von istgedachter Sewanbtnis biefer Quellen, wiro

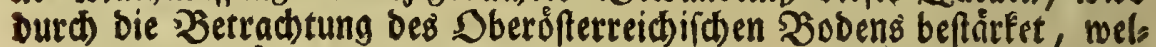
her nid)t nur úberaus falperticht ift, ronbern aud voll Sals fteclet, wie es bie ftattliden Salsmerfe, ia nod anbere an mehr Srten hers vorbrecbenbe Sulgen ober Salsbrunnen bejeugen, als einer bei Spis tál, ein anderer bei Şall, weld)er legtere, nact ber gemiffen und burd

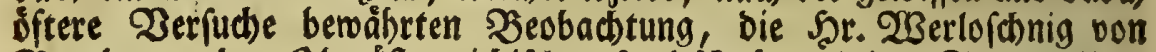
Bernberg, Der Sberófterreichifchen \{andíthaft uno ber Stabt 2 sels

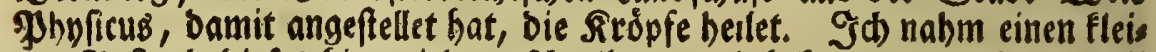
nen 2Inftano biefes bier nieberzufdreiben, unb befannt zu maden, weil

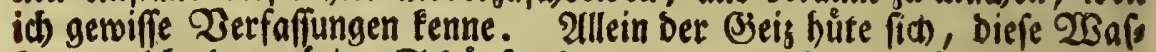
fer ( welche ber gutige Sd)opfer bem armen \&anomanne hier unb bort, zu vielfältigem (jebraude, aufquellen lǻpt) auf meime 2(meige, burd) ein und)riftlid)es Unternebmen, zu verlegen, weil fonft ber gottlid)e Segen anderer Srten, zur billigften Strafe, gerwißlich ausbleiben mirb. 
Die wabefrafte Werfeinerung (petrificatio) verurfad)et ben ijtles

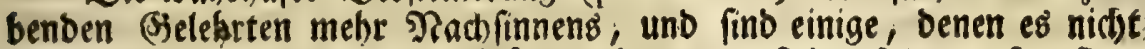
eingeben will, Daß nach ber Sưnofiuth neue entfeben follen. Sor. Des

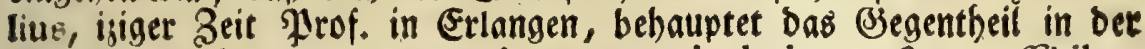
Sd)rift, Rudera terræ mutationum particularium teftes poffibiles,

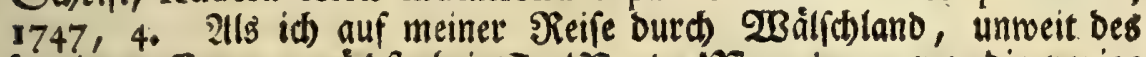
beutigen (Eapua, nåd)ft bei 3 . tharia Maagiore, wo bie vorige Stabr biefes Namens geftanden hat, bie berrliden Meberrefte bes Amphicheatri betrad)tete, weld)es fúrwahr ein Neifterftucf ber alten $\mathfrak{B a u s}$ funft, uno bas prid)tigfte in gan; Stalien gewefen, fano id eine mens ge Arbeiter barinnen, weldbe nid)t nur bie heruntergefallenen und in bie Erbe verienften Strine ausgruben, fonbern auds aus Den Birundfeften bie Quaverfincée herausbrac)en, um biefelben ju ben Stadtgebåuben ju

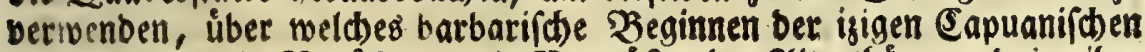
Zauherten, als Zerád)ter unb Werwúfter ber Alterthumer, berer ibre Dorfahren mit allem Fleiß̧e geidsonet, Mazochius in Ampbith. Camp.

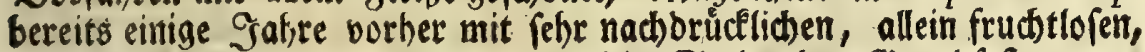
230 rten fid beflanet hat. Da nun bie Steine ber Grunbfeften, wes Der aneinander gefúttet, nod mit Salfe zufammengefúget geweren, uno gleidtwol an mantben Sorten, wie aus einem Steinbrude, mit gewsons lidem 25 red)seuge musten gefprenget uno ausgehoben werben, fo glaus

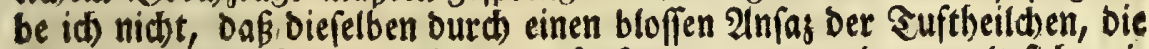
etwa burd Das \$egenwaffer baraufgeftwemmet worben, und fid jwis (d)en bie Fugen modten bineingeleget baben, fo fefte fonnten aneinans

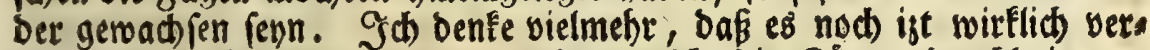

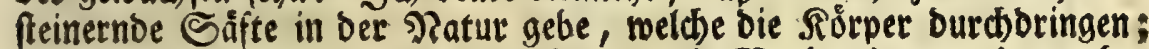

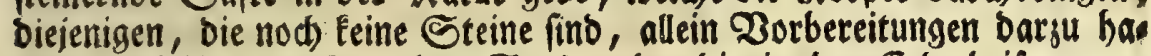
ben, zu fol(b)en mad)en; ben Sand, ober bie in ber Eroe beifammens liegenden ober gefpaltenen Steine, aneinander fügen und gang macken Eönnen. So felle id) mir bie Entftefung Der Marmelfteine, ber Sanbs teine, uno anberer $\mathcal{A}$ rten bes Steinreides vor.: WBenn aber bie $\mathfrak{Z} e r$ feinerungen, weldbe nod) fu unfern Beiten in ber Groe gefdeben, auds nod) vielleidst wenigern 2 infechtungen unterworfen find, fo will iक ben Eiebhabern biefer unterfucungen ein artigeres Exempel einer úber bee

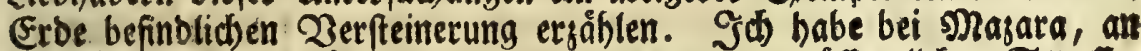

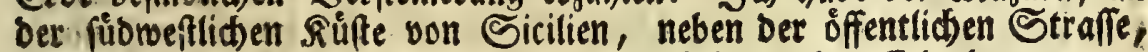
ein Stude einer Ziegelmauer, Deren Sbertheil au ber Erbe berborrages te, nidbt erhärtet, (weld)es bei alten (j)ebåuben ju geíhehen pileget) fonbern famt ben Biegetn und Salfe in wafgen Stein verwanbelt gefes 
ben. Es lagen audb bergleichen Stúcfe baherum, bie bermuthlid) um ber gradforfdung willen, von ben Zorbeireijenoen heruptergeidlagen worben, benen etwa bieje 2 Sirfung ber Ratur, wie mir, felram vors sefommen.

\section{XV.}

3u ber abhanblung von bem unterirrbifhen Feues, beffen theils bes

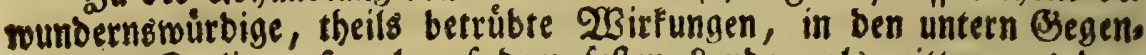
ben von Gtalien, fowol auf bem feften sanbe, als mitten aus bem meere, fith offers feigen, wovon id v. D. 131 S. an, einige Rieippiele

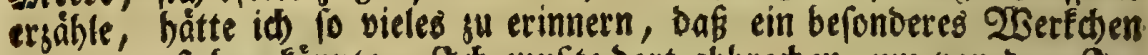

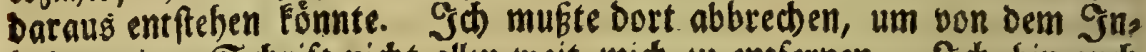
bale meiner Sdrift nid)t allsu weit mid) zu entfernen. Sab bin aud bier nidbt gefinnet, mids in viele $2 B$ eitláuftigfeiten ein\}ulafien. Sch fas

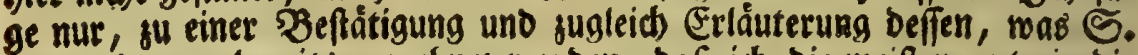
139 und 142 bereits ermebnet worben, Das id bie meiften unterirrbio

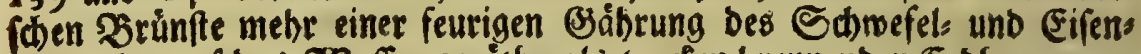
tiefes, barauf bas 2 Baffer geráth, alö troden brennenden Erobarzen jus fareibe; weil es bie Erfabrung begeuget, Das fowol burch Den Qejuvis

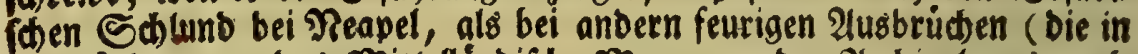
ben \&åndern um bas̉ Mittellándifhe Meer, um ben 2(rchipelagus, uno auf ben Ginfeln beffelben, infonberbeit zur Beit ber farFen Erobeben,

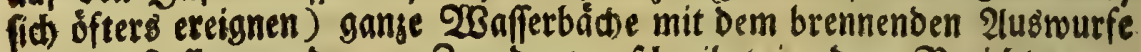

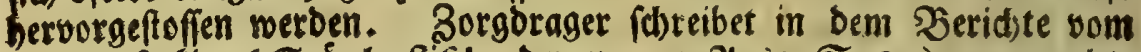

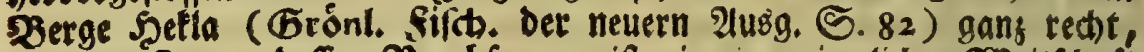
Das Das Feuer, beffen Saudfang er ift, in einer ziemliden WBeitfouft berum brenne, und bie Sdwefelabern auf roldhe Ant burdjiudbe, wie

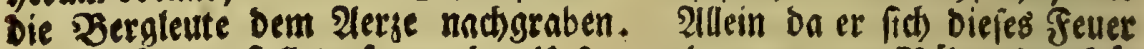

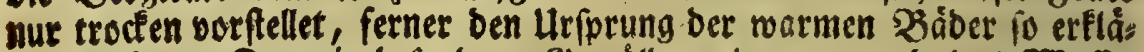
ret, Daß bas Jeuer in betondern Bemótbern brenne, und das $23 a f f e r$

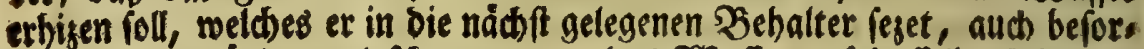
get, jentes múroe verleficen, wenn bas $23 a f f e r$ auf Daffélbe fiele, ba

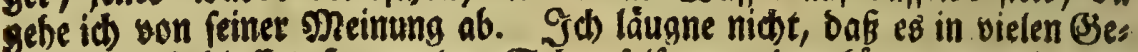
genden aud bloffes Saras ober Sdwefelfeuter geben tónne, uno in bet: Shat gebe; allein alle 2usbrübe fommen nicht von folden \$Brănben. Tis bitbe mir an ben meiften Orten das $23 a f f e r$ und Das Feuer beifams.

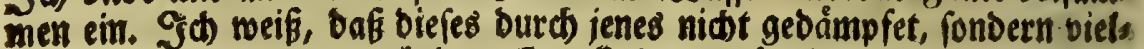
mehr unterbalten, uno nad) bem smaaffe bes vorbanbenen Riefes vermefs. eet werbe, Die feneripenenben Ferge beift man aud, in meinen Bseo. 
Danfen, unredt brennende berge, als wenn nur ibre inwendigen $58 \mathrm{~s}$;

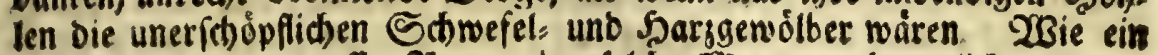
nidh eben gar ju groffer SRam eine foldbe s)enge verbrennlidję Unter: baltes in fich faffen tonne, weld)er jureidend fen, ein beftánbiges Feuer auf taujend und nochmals taujent Sabre ju ernábren, bas begreife id eben fo menig, als ein anders Bebeimmís, soarum námlid) ein fo enge beifammen liegenber Borrath niकt auf eimmal follte angeftect, ober geo wislid in einer fürsern Zeit aufgejebtet werben. Diefe\} nad) meiner Dorftellung, nur \&uft: uno Raudblöwer bes feuers, wel' d)es vielleid)t weit von biejen Defnungen, in einem andern \&ande, ober unter einem entlegenen Sheile bes Meerlagers, brennet. Es baben

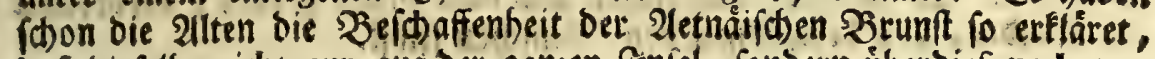
Daf biefelbe nit)t nur aus ber ganjen gnjel, fondern überdię nod) von

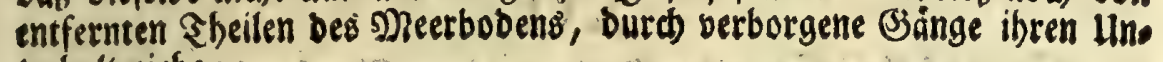
terbalt gief)e.

Watum ein folteb feuer nur auf ben Bipfeln ber Berge peinen 2lusgang fübe, ift eine leid)t begreiflid)e Folge fo bejofiffener unters irrbifher Entgunoungen. 2 Benn aud anfangs ein feuriger fluf bet

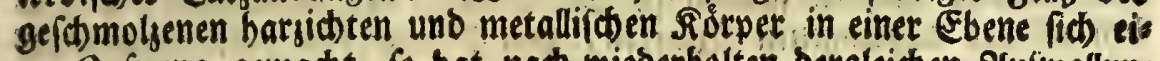
ne Defnung gemadt, fo hat nach wieberholten bergleichen 2(ufwalluns gen, aus bem 2luswurfe, ber gleid) 34 Steine erbartet, nothwenbig ei. ne şóbe entiteben, biefe burch ófteres Heberlaufen immer anmadhien, uno zu einem Berge múffen werden. Es låkt fid gar leidt behaupten,

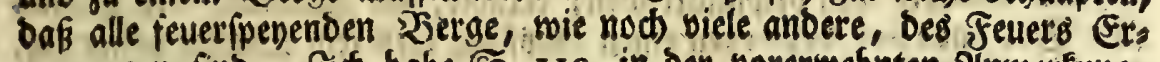
seugungen fino. Sid babe $\mathcal{S}_{\text {. }} 119$, in ber vorerwebnten 2inmertung, erfläret, wie ourd tufidte Quellen, ebenfalls erfabene Bjưnbe unó Şúgel, wiewol långlamer, erwad) fen Eosnnen. Wenn bie Stalieniphen ふ2erge, Der Wefub, 2letna, Etromboli, und bie zmey andern 2 ulfas

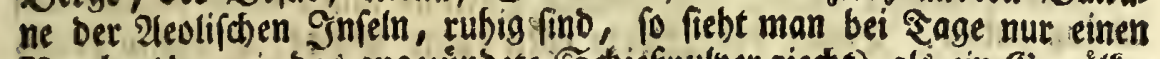

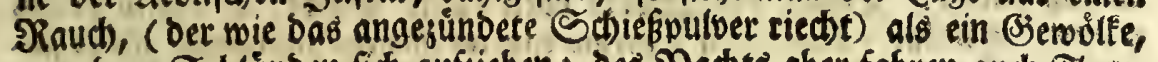
aus thren Sdtunben fich auffieben; bes, Tachts aber fahren aud Flam: men baruntem mit beraus, wenigere ober băufigere uno fărtere, nađ Serd)affentheit ber $\mathscr{W}$ inde. Wenn man eigentlich reben will, fo if ber

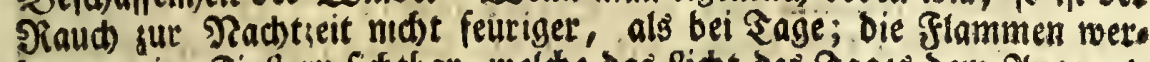
ben nur im Finftern fichtbar, welde bas sicht bes ₹ages bem 2uge ents fiebt. Berlanget jemand von einem ber bisher beidhriebenen Berge fid eine gute 20 orbiloung su mad)en ( $b a s$ ift ein $3 u j a s$ sur 2inmerfung $n$, S. 139) ber thue in ein jilinorifo, (3)las frif eben fo viel Sdorefelblüthe, uno idjutte einen gleiden Ebeil 23 affer S. 3

bave 
baran; fo wirb er bei ₹age, in einem bellen 3immer, nur einen भauds,

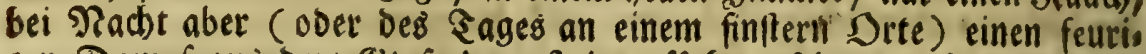
gen Dampf aus bem (S!)afe bergeftalt auffahren fehen, Daf er audi ein fleines 28 actslitit foll Dabei anzunden Éonnen. Diefés wirfet ber fpiritus vitrioli ebenfalls, wern er auf Eirenfellpaine behutiam und rads: te gegoffen wirb. Diefe Jermiftung gibe aud bei ₹age einen ßaud, und flammet bei ber Fadt oder im Finftern; Denn Der $\mathcal{B}$ itriol ift Det Sauptbeftand theil bes Sd,wefels. Td fagte aber, baß man mit bent Sugieffen bes 2 itriolgeiftes vorfidtighi umgehen foll. Denn ift man Damit gar su frengebig ober ju gábe, fo erfolget eine gar su gewaltige Bjábrung. Es fpringet bas Feuer aus bem Slafe beraus, verbrennet

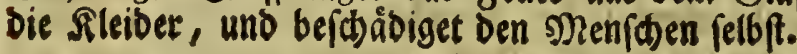

\section{XVI.}

S. 139 habe id su einet Stelle aus bem Strabo, bie im 2nfange ber 2(nmerfung (il) Phefet, eine (Erflårung verfprod)en, weil ich) in ber Correctur beffelben Zogens, bei welder Arbeit man ben Wortrag mit grófferer Infmerffamfeit zu lefen pfleget, exft rahrnabm, baß es ben alloort angejogenen $230 r t e n$, aus Mangel bes Zufammenhanges mit ben vorbergehenden, an Deutlidfeit fefle. Denjenigen nun, wels

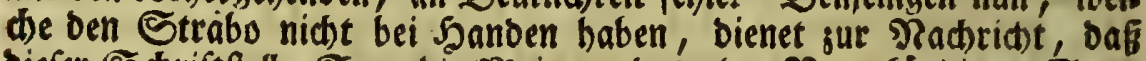

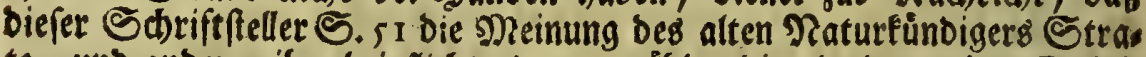
to, und anderer ifm beipflidstenden, ergåble, bie glaubten, ber Eurini,

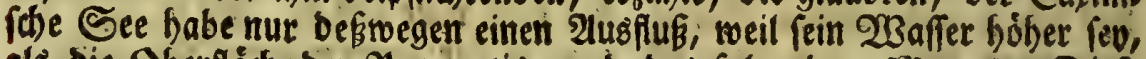

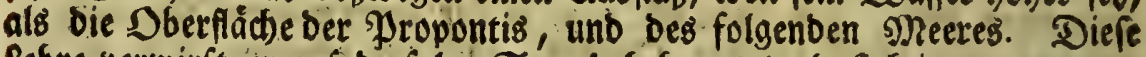
Eefre betwirft er auf D. folg. S. unb behauptet, Daf Eeinesweges un einer hobern \&age willen, fondern wegen ber झ̈enge bes 23 affers, weil ber buflus groffer wáre, Der Pontus Eurinus múffe einen beftinoigen 2bflus baben. Daher bie 230 rte eben biefer Seite: ut non in fundis

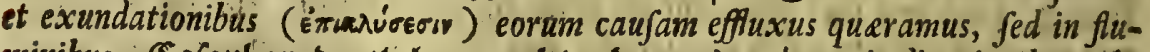

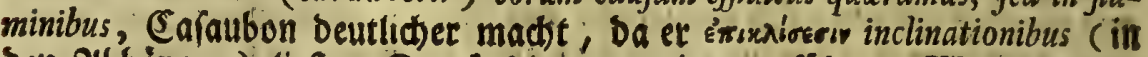
ben 2(bbängen ) lieft. Durd bie bon nit angefúbrten 2Borte: Nam ipforum quoque fententia Ëc. will Strabo fagen: "Denn nach ibrer " (oes Etrato, und berer, oie, wie er, oenken) sleinung ift biefes "nidt unwahrfidseintid ober vertwerfich, menn man audb fagen follte, " Daß̧ Das Mittellánbifhe Meer vorgeiten ein See gewefen, beffen "Oberflåd)e burd) bie Einnabme vieler fluffe enblid) fo bod gewors "Den, Daf fein Serwáffer bei bem Berge Ralpe, wie burch eine Sthleufs " fe, binausgebroden; weldes ruted feine Dermengung mit bem 20 af 
" fer bes groffen 2 seltmeers, uno burd bie von bemfelben erbaltene "Werftarkung, aud in gleide Scoibe gefest worben, baburd aber mit "Der Beit bie Eigenichaft eines recten Meeres angenommen babe. „,

\section{XVII.}

Die in ber 2 nmeré. (ss), S. 146, angeführte Eluberifbe Erflå:

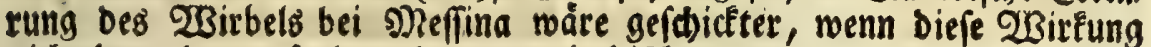
nid)t ben obern, fondern ben unterirrbichen, von bem sheerlager hers auffahrenden, und mit dem gewaltigen Seeftrome fåmpfenden 2 Binben, ware sugeforieben worden.

\section{XVIII.}

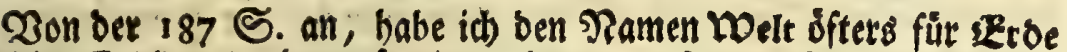
ober bie Erotugel, barauf wir wohnen, gefegt. Seederict bat in Promtuario biefe $\mathfrak{B}$ ebeutung strar nicht; allein biefelbe wirb burd) vies

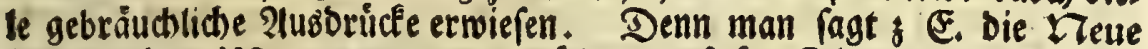
Welt, bas Weltmeer, weltberúbmt u. f. f. Die welttinder find aud) sgenf(h) unferer (Erbe, Feine Monoenburger, ober in bem gans gen weitlauftigen Umfange, ben man fonft die Welt beist, berumichwes bende కsefoidpfe.

\section{XIX.}

S. 192, in ber 21nmerf. ( y y y) ift nut ber 2 (uşug einer Stelle

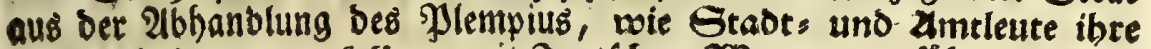

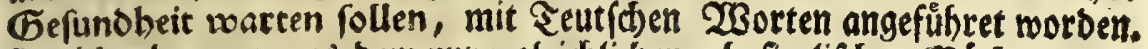
Da id aber nun aus bem unvergleichlichen phpficalifhen sBúchervortas the bes Syerrn Scofrarhs ?rew, Der allen Stubirenden offen frehet, bies fes But jelbft babe, fo will id) bes Zerfafiers 2 Borte bier nachbolen. Die 2tufichrift lautet fo: VOPISCl FORTVNATI PLEMPII de Togatorum Valetudine tuenda commentatio, Bruxellis 1670 , 4. Die Stelle (meldbe E. 249 ftehet) ift fo abgefafit: Pofterior etas frigidum potum laudavit; narrantque Medici Siculi, poft ufum nivis in vino refrigerando invectum, rarius, quam folebat, peftilentiam id regnum invadere. Id ipfum confirmat BALTHASAR PIS ANELLVS Medicus Bononienfis lib. de efculent. fac. Siculos, inquit, memorant ante introductum nivis ufum, cum in aere degant ferventifimo, ac tepidifimis utantur aquis, quotannis aftivis menfibus maximo numero febrium peftilentium tyrannide e medio fublatos. Ducebant autem bi morbi origitutm ex obftruetione primarum bepatis 
venarum, ob pravam calidi potus concodionem factam: quod malum ferocire defiit, ex quo primum nivis ufum in potu admifcuere, annis circiter abbinc viginti. Diligenti namque obfervatione exploratum eft, in urbe Meffana quotannis mille numero pauciores, quam ante ufum nivis, interire. De Hifp.rnis fimilia refert $L V D O V$. NONNIVS lib. 4 de re cibar. cap. 5 , minus illos malignis febribus tentari; quia frigus illud nivati potus vifcerum fervorem temperet, et putredinem bumorum cobibeat \&c.

\section{$\mathrm{XX}$.}

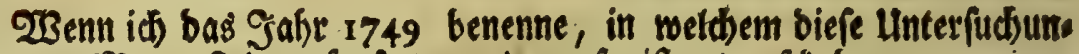
gen vom Meere fino aufgefest toorben, fo ift eb gefideben, um einen

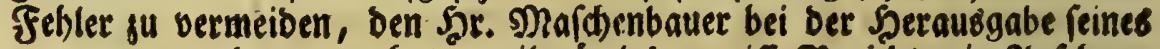
REFERENDARI begangen hat, meil nåmlid gemiffe Beriøte, in 2infehung ber Jabrjab!, bie auf Dem Sitelblatte ftelbet, nid)t wabe wáren. Dena

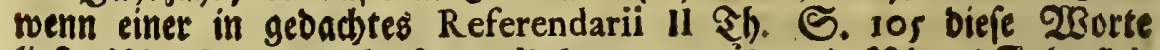
lieft: Woir baben in biefigen Jlubren nun uber ein Diertel Jabr Eeio nen Landregen, aud yar wenige Stritbregen gebabt - . - weldhes

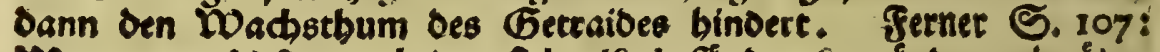
Wann nun diefes noch fezo fidb alfo befánde, fo wurben wir úber

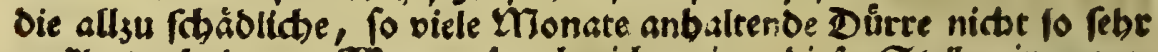
34 elagen baben. Wenn, ipredbe id, einer biefe Stellen in gegens mårtigem I750 Sabre lieft, und aus bem Titelblatte erfieht, Daß bas

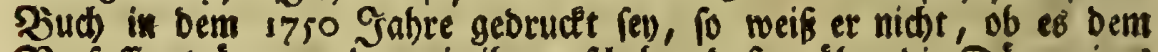
Oerfaffer tråume, ober wie îm gefdehe, Daßs er úber bie Dúrre eines naffen Sommers Elaget. Die \&efer ber fünftigen Zeiten merben bas

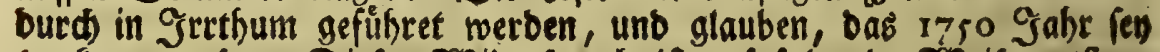
trocken gewefen. Diefer 2 Biber(pruch ift auf folgende 2 Seife entflans ben. Die 21bhanblung warb i. $\$$. 1749 aufgefest, weldbes ein burres Sabe war. Das Bu(t) ift aud) in Demielben Jabre gebruct toorben. 2llein bamit es långer neu bleiben foll, hat $\mathrm{SCr}^{2}$. Marhenbauer ben bes

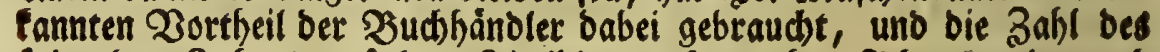

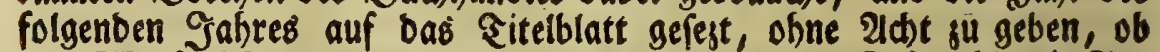

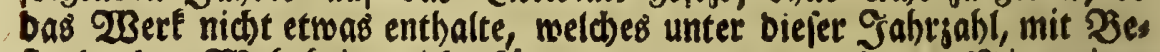
ftanbe ber $23 a b r h e i t$, nidht eơnne vorgetragen merben. Nit meinet Sd)rift ift ế verfefrt gugegangen. Der 2luffas ift um bas Enbe bes abgeroidtenen Sabres gemad)t worben, allein burds 3ufálle uno gewiffe Umftånbe, berer Ersăblung ben fefer wenig vergnứgen wúrbe, exft in Diefem 1750 Jabre beraubgefommen. Dei einigen \$̇eridten (als S. 
207, (5. 123) muite id in ber (eorrectur Det gebructen Pogen bie Jahrjabl des 2lufajes beifúgen, Damit man mir nid)t ebenfals vors werfen Esme, was i内' an anbern ist getabelt babe.

\section{XXI.}

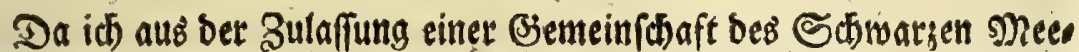
res mit Ber offenbaren $\mathscr{W}_{\text {elt }}$ ee, $S .225$, eine Fluth unb Ebbe in bem er.

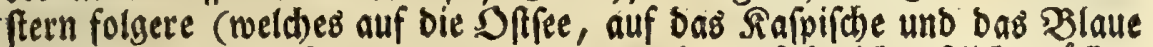
Meer, gleid falls fann gejogen werben) to berftebe ich erftich groffere Defnungen, uno bie nicht alfu tief oie (Froe burd)ftereiden; benn burds engere und tiefere (3ange fonnte Das 2 Seltmeer, wenn beffen Dberià:

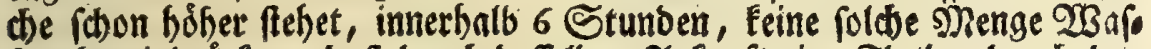
fers bereinbructen, bafi burळ beferben Intunft cine Fluth, burd bet I্blauf aber bie Gbbe erfolgen múfte.

\section{XXII.}

5. 231 babe iద bas̊ a'y ङ. 204 in Der Inmert. mit ben 2 borten, Der groffe fift, Den bes roborus, obne క̌weifel um Der Grófte willen, mit bem toallfifthe

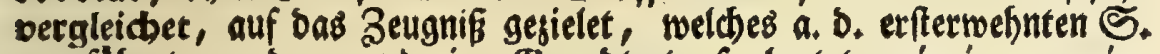

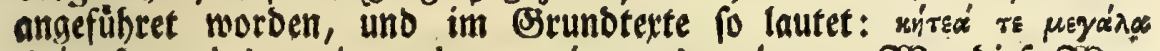

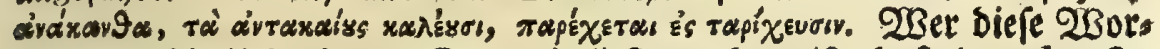
te ( oder bie lleberfejung S. 23I ) lieft, aud reiß, baßs oer Jaufen

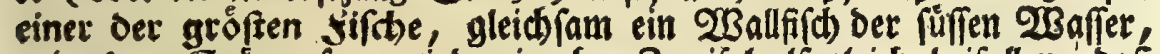
und obne Graten fen, wiro mit oftue Broeifel alfogleid beifallen, Das Serodotus an bet igtangefubrten Stelle ben baufen verftanden babe.

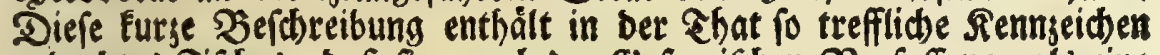

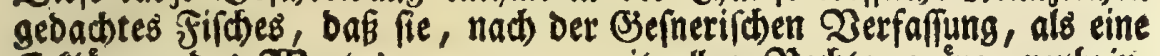

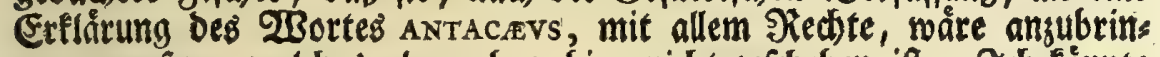
gen gewejen, weld)es aber eben bier nicht gefकeben if. Ģ fónnte biefe 2ublegung, Daf antacaus oer Saulen fen, Durds viele Seugniffe befátigen, wenn. es sonnơtben wåre. Eines will id bod anfúgen. Dillugbbey liefert in bift. Pifc. S. 243, zu Dem Titel hvso GerManoRVM, folgenbe $\mathfrak{B e f d}$ reibung: Pifcis eft Danubii, nec reperitur (inquit Albertus) in aliis aquis, quam in Danubio, et influentibus in eum. Diefe Stelle berbeffert Sajus 10: Nos et in Borythene, et in Pado reperiri putamus; Boryftheniten quippe antacaum, et Padanum Attilum, non alios effe quam Hvsones, fufpicamur (a). Der Pame felbft St

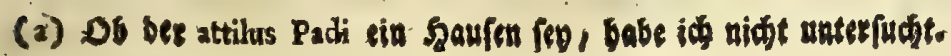




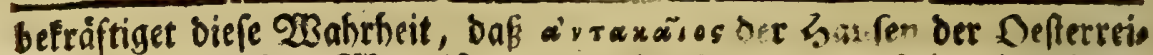

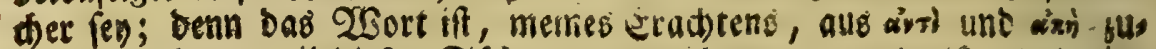
fammengefest, weil biefer Fifh vormet br:alis refpizt ift, D.i. eine jugefpizte Sdnause hat, wie ber 3 tor, beffen latemifoter Tame aci-

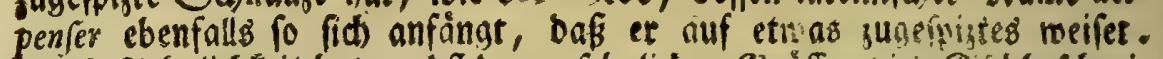

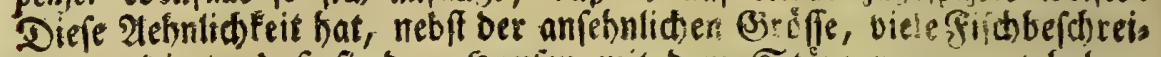
ber verleitet, daß fie ben Shaulen mit Dem Store vermenget baber. Soldes fann man ben Franjofen nadbethen, bie feinen Scaulen in isten

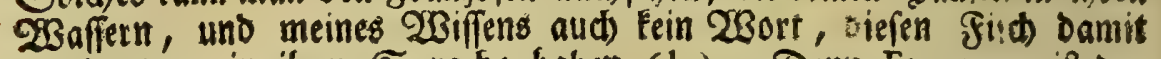
anjubeuten, in ibrer Spradbe baben (b). Denn Eturgeon if oet

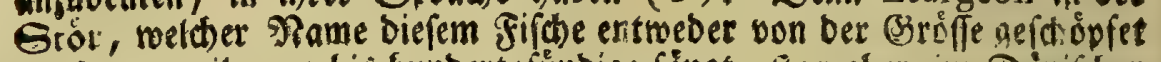
worben, weil man biš hunbertpfundoige fängt, ftor aber im Dänifher

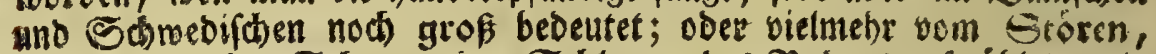
weil er mit ber Sdnauje ben Sdlamm bes Sobens aufnublet, wié

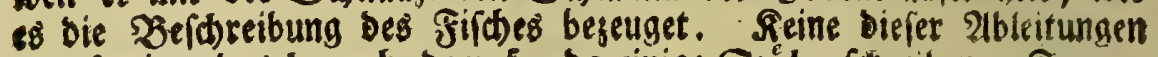
rechtfertiget $D_{a s}$ b nah Dem \&, Da einige Stóbs fatreiben. Fernere

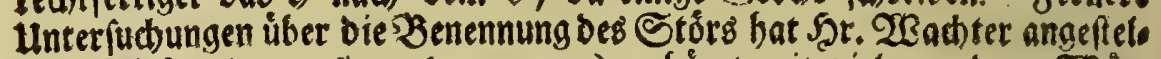
let. Diefes áv

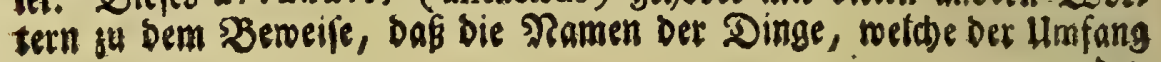

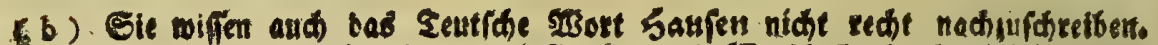
3um toenigften in Martiniereb Dit. Geogr. i. 23. MER CASPIENNE, mets ben bei bet \$brhilderung besjenigen fifhes ber Safpifhen Eee, ben die

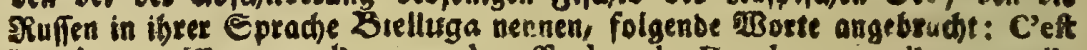
Ie même poiffon que lon prend auff dans le Danube, que l'on appelle HANSEN en Autriche. Diefes fann ein Drudfeblet fepn, bie man bei ben

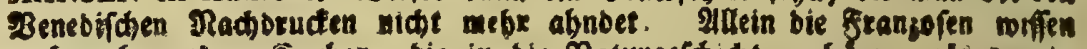
nod) mebr anbere Cachen, bie in bie Raturgeforidjte geboren, als ben in Zeuffकlanb befannten Bogel, ber LOXIA Aldrov. iff, reidjer im Defterteio Wifhen und in Bapern ber Erummignabel, in antern Munbarten bet

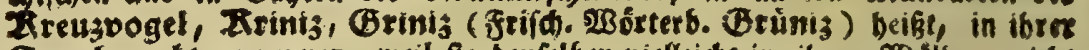

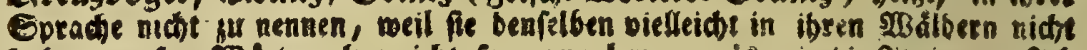

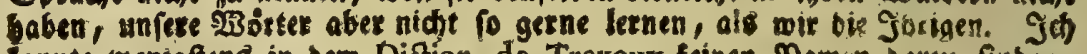
lonnte menigftens in bem Diation. de Trevoux feinen Namin carju finben,

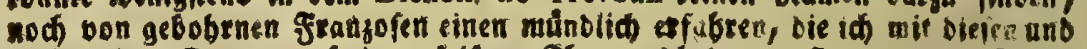
nod) anbern fragen auf cinen leifern Ibon gu'bringen pfiege, menn fie mit

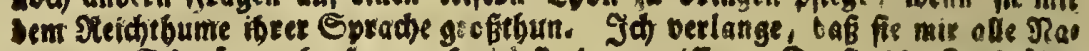
men ber SAwarmme berjagen, fovtel fie berer miffen. Da fie die Zabl äber

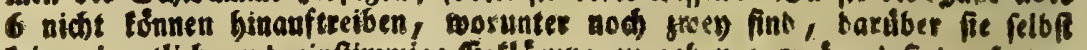
leine eigentliche unb einftimmige Erflárung tu geben vermogeno fino, fo tras

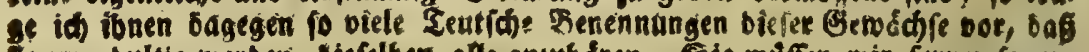

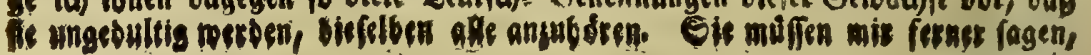




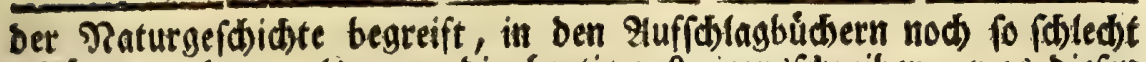
etfláret werben, als wenn bie beutigen \&exicondict)reiber, was biefen Sheil ber lateiniften und Bried)iften Eprad)e betrifft, noth Barbarn waren. Soederict hat in bem ponft wortreichen, aud ftattlich ausgears. beiten (bie istgeoacbten Ramen aubigenommen ) Lex. man. Græco,

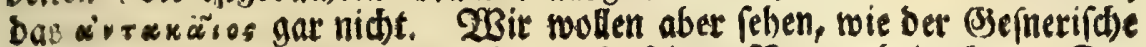
Thefaurus Diejen fifin befdreibe, und feinsa Ramen beleudste. Det bollpánoige IIrtifel lautet fo:

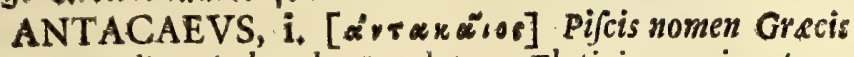
familiare inde ab Herodoto. Elatinis nominant

Cafiodorum.

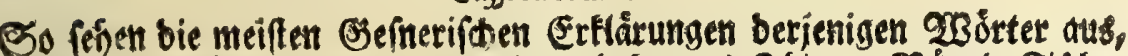
woburd vierfüfige (nid)t einem jeben befannte) Shiere, 30 ỏgel, Jifher stáume, Stauben, Sräuter zc. berftanben werben, bie bod einen fo

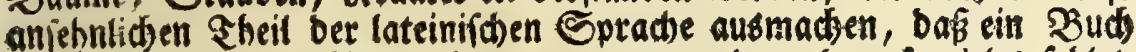
fein Thefaurus mit Ped)te lann genennet werden, bem fo vieles fehlet.

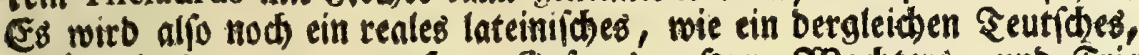

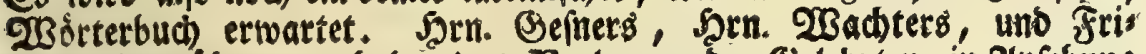

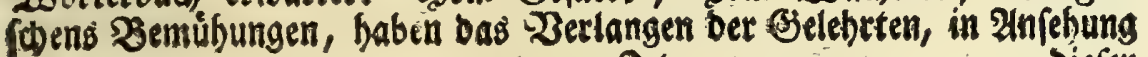

$$
\text { St } 2
$$

Diejer

wie fie auf gut grangfifid ben Ireerrettid, eine Aeid)e (thymallum), beif

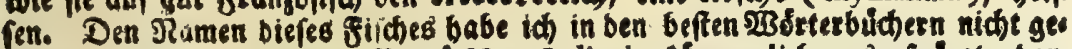

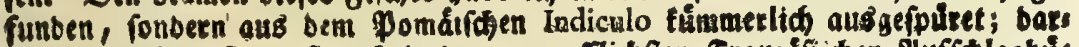

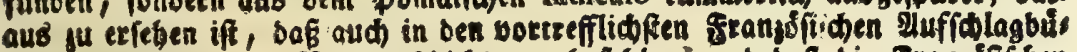

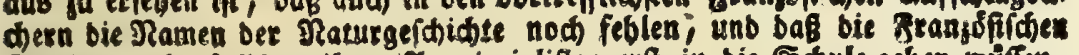
Gelebrten ebenfalls ju ibren Provingialiften exft in bie Saule geben múffen, um von ibnen viele sojster ju letnen, aufoaß fie ibre gelebrte Sohfrangó.

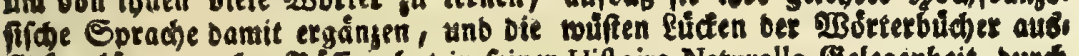
fiden fonnen. \$at. Buffon bat in feinet Hiftoire Naturelle Eelegenbeit, burd

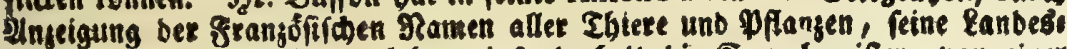
leute, bie in Feutichlanb leben, infonberbeit bie Spradjmeifter, bon einet

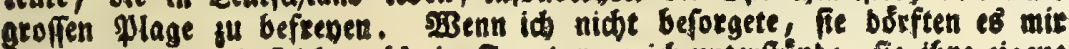

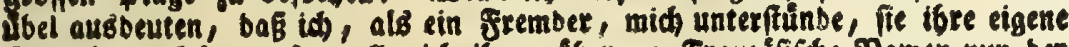

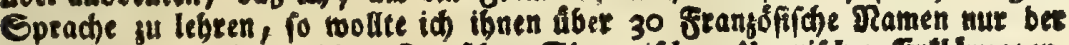

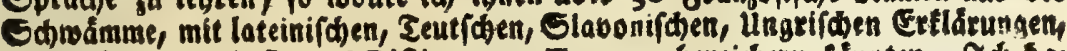
mittbetlen, momit fre bas Dietioss. bon Trevoux bereidern fónnten. Ich bes be Diefe शamen tbeils aub ibren Probinjialfhreibern, theils ous gemeinen uns fubtrten fransofen munblich ausigefor (chet. Solten fie biefes nidht fahon vots

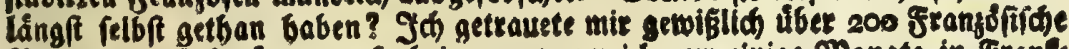

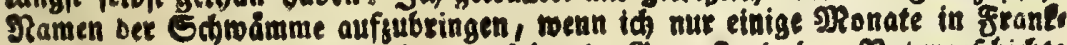
reid berumecifte. Die Saden, weldie ein Segenfanb ber Raturgeididite fino, soben in allen Eptaden ibre Ramen; allein bie Selegrten finb bisbe an nachlâfing geweron, biefelben ausjufunbíhaftet. 
biefer swen Sprad)en, nod) nid)t geftillet. Dempelben foll nur ein (Bes núgen geftheben, wenn bie 2lufficlagbúd)er gemeldeter Sprad)en, nad Dem Mufter ber Crufca, ober nad) bem noch beffern Zorbilbe bes Dictionnaires bon Trevoux, werben ausgearbeitet fenn. Der Manget einiger 230 orter verichlågt ben 23 erth biefed red)ten Sranjofifden

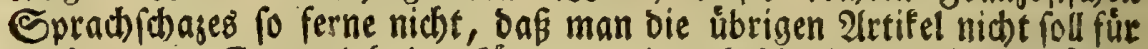

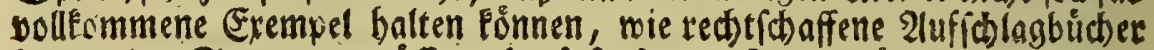
in allerlen Spradsen múffen abgefät fenn. Sei 2 sortern, bie roldbe

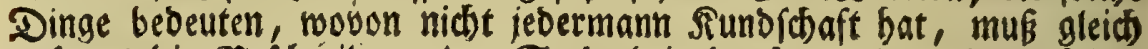
anfangs bie Bef́ctreibung Der Sacbe beigebradbt werten, barauf Das 2 Sort fich befiefet. WBas bilft bem sefer ber bloffe Rante, wenn er nictet weis, roeld)em Dinge er benfelben beilegen foll? 280 er bes grò.

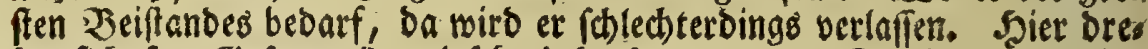
bet fich Shr. Serner allemal refre befutfam aus Der Sollinge, und bes

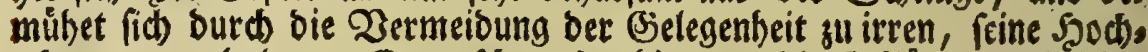
adtung su erbalten. Er verfotwendet hingegen bie Erelarrungen bei fols wen Stellen, bie aud ein Fnabe ohne Unterrid)t berfehet. Wenn jea mano eine lateini(a)e Sdrift zu verfafien bat, unb fid) bas (Sefmerifose

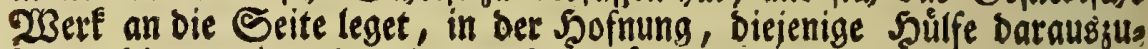
bolen, bie man in andern bergleiđen $\mathfrak{B}$ úd)ern fudbet uns antrifft; 3 ll feis ner Zermunberung aber allenthalben auf folche 2luslegungen geràth, wie bie von antacxo ift, und bie Eobfprüđ)e Dagegen bălt, woburd bie.

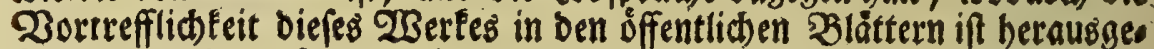
ftrichen worben, fo benfe id, Dak aud bei bem gelafienften snanne bie

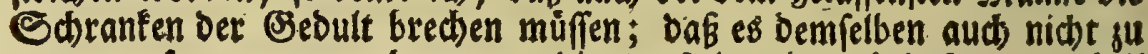
verargen fen, menn er bem unberbienten \&obe ein wahrbafteres urtheil entgegen reset. Die Stelle von antacao ift nun eine berienigen, wets

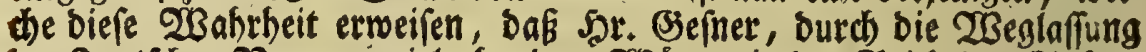

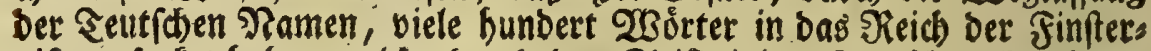

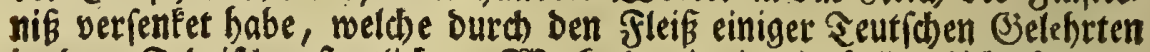

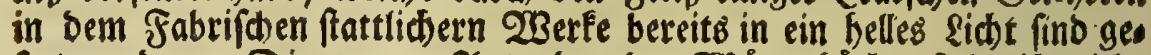

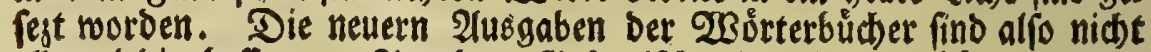
allemal bie beffern. 2lub bem Befneriftien Thefauro erbält ber Refer

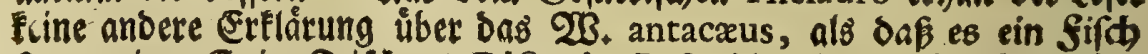

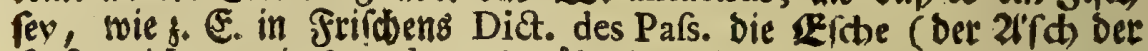
Defterreidber) mit forte de poiffon úberfest mirb. Das wuste aber ber-

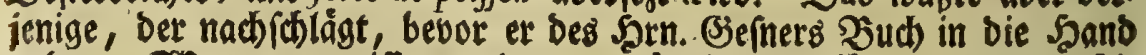

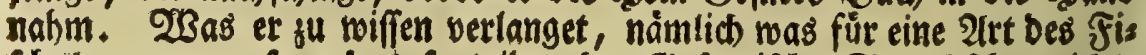

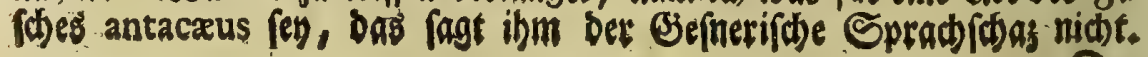


Nadilefe von Zugaben.

Der Fabrifac Thefaurus, bas Sceberidjifde Detablericon, ia bas nod) Heinere von Garthio (mehrere fonnte id niđt nachichlagen) vers

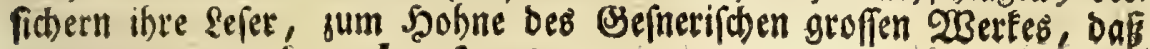
ANTACAEVS ber 万auren rev.

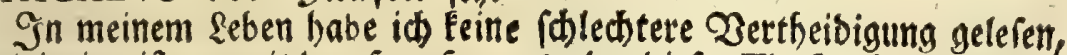

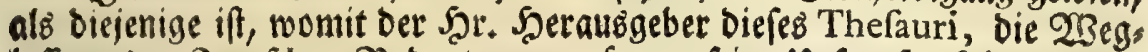

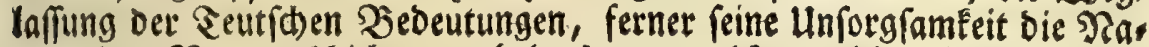

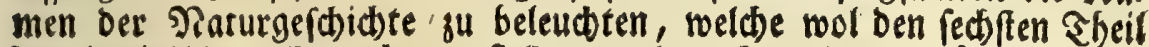
Der lateinifben Sprache vorftellen, und now andere mangel peines

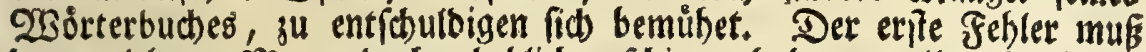
bem gelehrten manne boch erbeblich geichienen haben, weil er benjelben

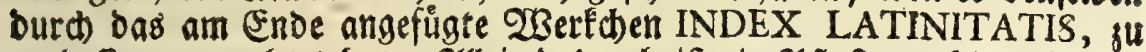
verbeffern getractet bat. SAllein baburd) ift ein $\mathfrak{P}$ flafter auf ben Schuh geleget worben wiber bas Siopfroeh. Die నamen, weld)e ber Erlåutes eung am meiften bedurftig fino, ftethen fum unglücte nicht in biefem

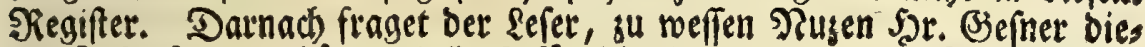

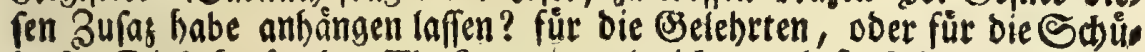
ler? Diefe faufen ben Thefaurum wol nidt, und fie finden basjenige, womit ibnen $\mathcal{G}$ r. Eiefner etwa zu Dienen vermeinete, in Cellarii PRIMI. TIVIS. Sft biefer Index zum $\mathfrak{B e f t e n ~ f o l d b e r ~ \Re a ̊ n n e r ~ g e w i o m e t ~ m o r b e n , ~}$ bie weit uีber bie Sdjulen hinausfehen, fo erweifet Sct. Seiner benfels

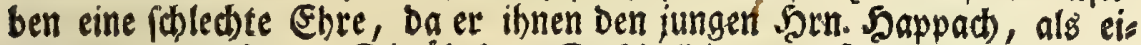
nen \{eister, vorieset. Die ǔbrigen Entf(juldigungen find nid)t beffer ges grundet. Daraus erfennet man auf eine bandgreifliabe Art Das offenbas

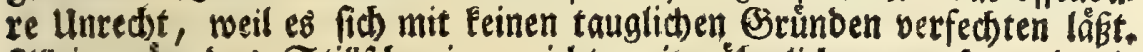
2llein wäre bas Stillidsmeigen nicht seit rübmlider getwefen, als bie bnmeidtige 2 ertheibigung eines tabellhaften Werfahrens? Sch will gar nictet fagen, was id von biefer Yorrede benfe. Es ift aud biet Der Drt nicht zu bergleichen Anmerkungen. Eines mus ich Dodb erins nerli, un es mit dem antaczeo zu befthlieffen, von dem id biefe Zugabe

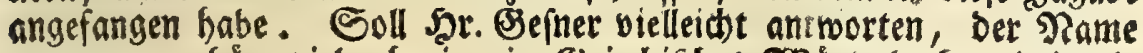
antacxus gefjore vielmehr in ein Briectifhes 20 orterbuch, als in ein lateinifhes ; fo verfezet Der Sefer: Sff antaczus von ben \&ateinern in ibre Sprache übernommen worben, båtte es ber Shr. Zerfaffer in ei. nem $23 e r f e, ~ b a s$ fúr einen latenifonen Thefaurum ausgegeben nirb,

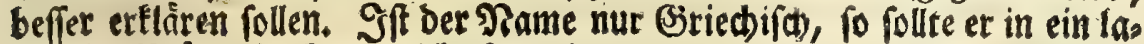
teinifक Wörterbuch gar nicht fenn eingetragen worden. AVT CAESAR AVT NIHIL, if ber W3ablfpruch groffer Månner. Jn ber Worftela

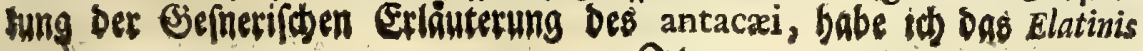
it 3 yok 
borfextich fo gelaffen, wie id es in biefem neuen Thefauro gefunden has be, um barzuthun, wie idbledten Dienft Derienige (Sichülfe su Diejem 2Berfe beigetragen habe, bem bie articuli biftorie Naturalis, bermuths

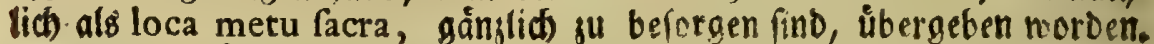

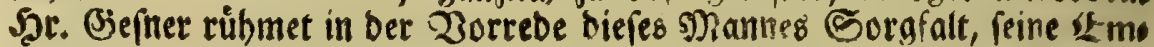
fiater, feiners Fleip. Allein bie meiften Etellen, bie it m jur 2lusare beitung gugetheilet worben, find fo viele Mufter bes fleipes, ben Sar. Mrathia in bem Manuali locupletifimo Der gelehrten 23 elt vorgeleget bat.

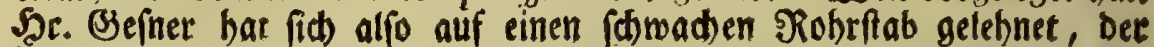
ihn vor bem isalle und vor ber Sdanbe nitht fonnte bewahren. 230 biefe Stức hátte bienen follen, serbrach fie, uno Durdbobrte bie șanb bes unvorfidtigen.

\section{XXIII.}

Bu ben 2Bouten: It) mutbmaffe ferner, dak bie Celten obne Doppellaut hab fiur hod derften gefpreden baben (Edreiben a. $e_{\text {. }}$ vornehme Bel. in seipsig, Gignat, a 4 -) erinnere id, Daf bie Raau ern im Sanbe ob ber Ens, in beten Nundart viele Ueberrefte ber Eels tif(t)en Eprad)e vorbanben find, noch ba für bods pred)en. Sie fas gen :. E. bie bo'leiten anftatt bie borbleiten, alta crepido. Ein

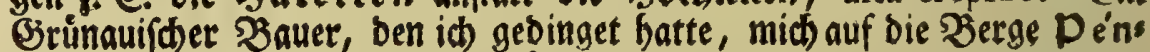
nog (c) uno Ka'sbetg ju fúbren, redete gu mir unterweges eine

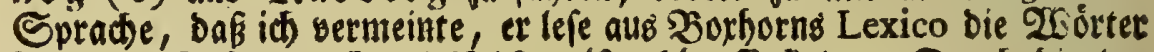

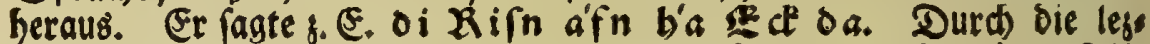

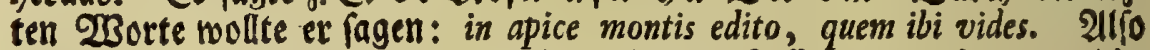

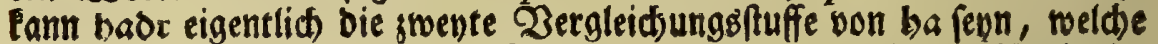
burd bie Einid)altung eines euphonif(ben o gebilbet worben. Nad) Dies fer Anglegung wåre badr mor in ber Munbart ber $\mathcal{S} e$ elten fuperius mare, (d) das obere Meer, wovon bie Siómet Hadriam uno Hadriati-

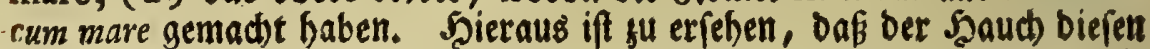
stwey 230 ortern nur burd) biejenigen 2ib/dreiber entrogen worben, bie in ibrer sutter(prache feinen batten.

Was

(c) Diefer Mame lautet' ganj Eeltifich. 2luf beiben babe ich nidit nut befonbere

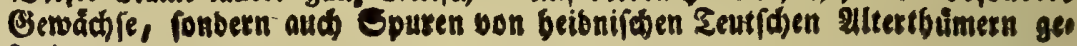
funben.

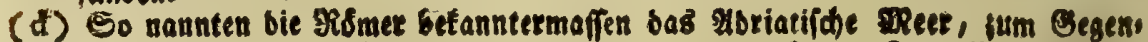

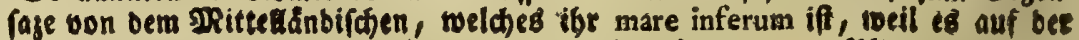
untern Eeite bes Ippennins liegt, wis foldes livius unb Plinius an més Stellen beteugen. 
Nadblefe von ăgabeu.

TBag a Rifn in ber vorerwehnten Fede bes Brrinauifhen $\mathfrak{B a u}$ erś bedeute, werben vielleicht, nebft vielen Bergmoittern, diejenigert (Selehtten nidt wiffen, bie nur siebhaber und gobreoner ber Ebenen find. Pllcin aud) Diefe meiftentbeils alte 2(usbruidfe gebören zur Dolls

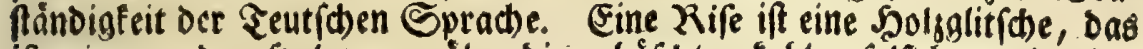
ift, ein getader Solsgang, uber bie gebdfichte, fable, felfichte und glats te Seite eine B̉ergeb́, Darauf bie $\mathfrak{B a u e r n}$ bie bebauenen Ståmme von B̉ómen, fúrzere Stơde, ober audh Scheiter, berunterrifen lafs fen (e). Die Sifen erfennet man von ferne, weil fie reife gerabe Streife find, bie nad ber Shalhänge ber $\mathfrak{B}$ Berge fid) berunter erftrecten. Diele muffen von Menfidsen unb Shieren vermieber werben, wenn fie

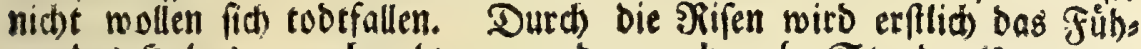
ren bes 5ुolies, mand)mal bon 2 und 3, aud) mefr Stunden Limmeges,

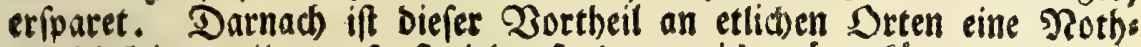
wendigfeit; meil man fonft vieles 5013 gar nidt nügen fơnnte, wo Dems felben mit feinem Jubrwerte beizutommen ift (f).

\section{XXIV.}

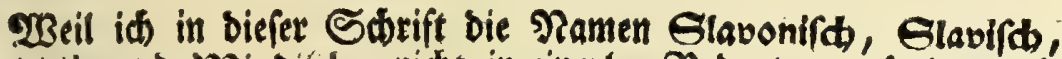

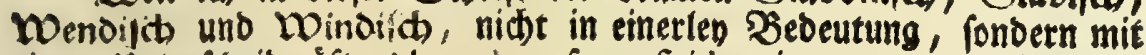
cinem unteríheibe offers brauche, fo mus id erinnern, was id Damit anbeuten wollic. Durd bie 2 oinoen verftebe id benjenigen Theil ber Wenden, ber fid in bie mittágigen \&ånber von Teutibland gezogen bat. Die Defterreibifichen Wenden nennet man winden, wie if in bem bintenangefúgten St)reiben (Eignat. b, in Der Inmerfung) bar. gethan habe. Das find bie Winidx bes Jornanbes, von benen Vindobona jelbft ben Namen ju haben fheinet, wie in Der I 2(nmerf. gum

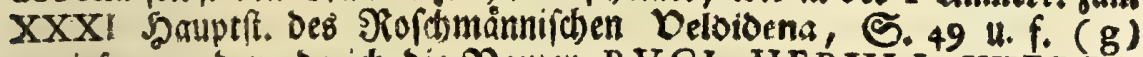
gewiefen worben, da id die Namen, RVGI, HERVLI, WERII,

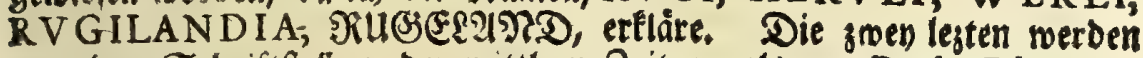
von ben Sd)riftttellern Der mittlern Beiten, als von Paulo Diacono, Eugip-

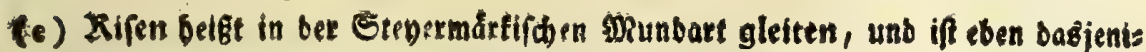

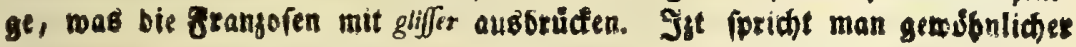

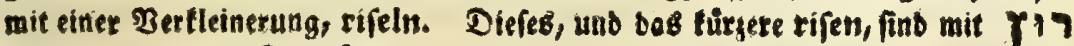
murrere, verioanbte 3eitworkter. Illein von biefen Stamme tommet bas ande

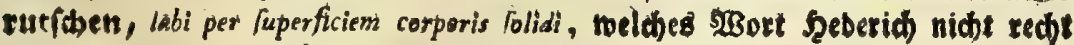

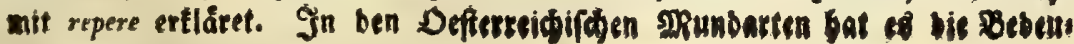
ung, bie id unforieben babe: 
Eugippio, Dem úber ber Donau, 2Bien gegenúber, gelegenen \&anbe sugeeignet, meld)es man ist Das 2 iertel Untermanhartsberg beift.

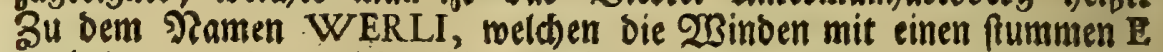
vorbringen, erinnere id allhier, baß Deffen Stammmort wer fen, wels

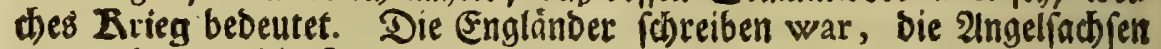
war uno wer, bie Frantofen guerre, wie fie aus Wallis, Woilbalm

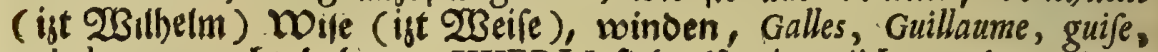
guinder, gemadts baben. WERLI find alio eigentlich su reben, tries getilde Reute, bellicofi, barnach frenui, egregii. Der Name HERVLI ift túdtig eben biefe 2luslegung anzunehmen. Das 2ingelfäbfis

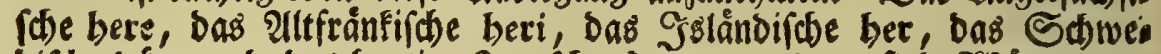

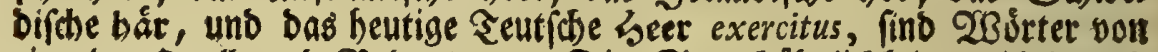

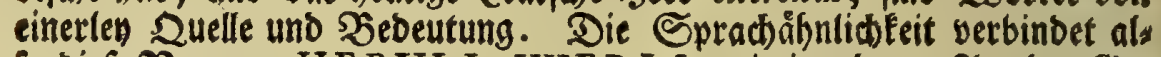

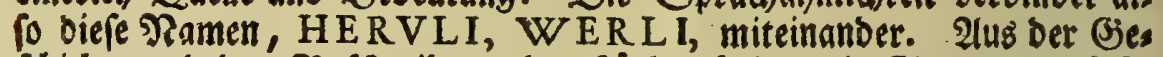

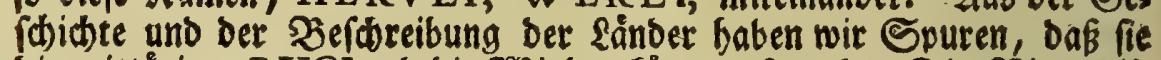
Die mittågigen RVGI und bie WBinben Eònnten fenn (h). Die Yiertelgif. ler, Die Rrainer, bie Nieberfắrner, unb nod ein Sbeil ber Stever: marefer, weld)e yon Draburg und ben zwey Si a'beln, auf ber linfen Seite ber Draz (Drau) bis . Detau bin wobnen, find 2 sinben. Um

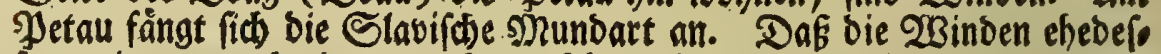
fen weiter ausggebreitet gewejen, erfehen wir aus vielen Namen ber Ders ter in Niebers uno Dberofferteich, im Salsburgifiden, in Savern, bec

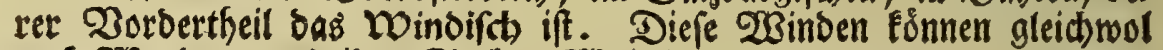
auch $\mathscr{W e n b e n , ~ u n d ~ i b r e ~ S a d b e n ~} \mathscr{Z}$ endif genennet werben; Denn fie geforen jum șauptftamme ber 23 enden.

\section{Die}

(f) In ber Stener unb Ens in Dberofferreid wirb bas f̧eu von ben Fergmiefen auf eine Irt berunterge(c)afft, weldbe ber borergábiten Erfinbung gleidhtoms

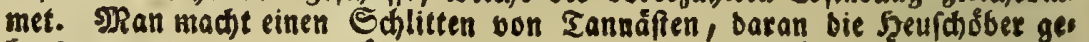
Gunben werben, bie man úber bie grafichten glatten 2abónge, mandimal auf

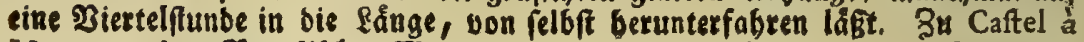
Mare; an bera Meaplifonen NReerbufen, babe id) nod cine anbere Runft ges. feben, bas ßrennholf von bem nádhen \$erge obne groffe Roften bis zum Sabife, bab im IReere ftunb, berunterzubringen. Man fonnet ein langes

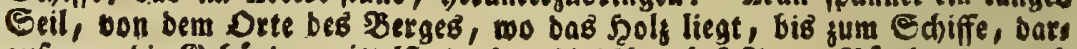
auf man bie Giebunbe, mittelft eines an biefelben befeftigten $\Re$ abdeng, bued bie Ruft berunterlaufen láBt.

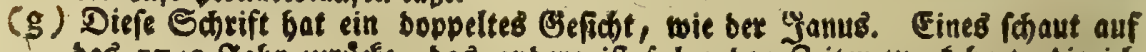
- Das 1749 Tabe zuructe, bas anbere if folgenben 3etten jugefebret, bie id

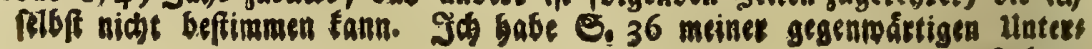


Die slaven unterfaciben fid von ben 2 Benben burd eire bejon:

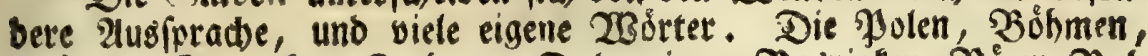
Mibrer, Slowafen, Rrobaten, Dalmarimer, Bosniaten, Kåzen, Zul garer, bie eigentlid) fo genannten Clavonier, welde von bem Jiertel Bil, li an, mifhen ber Gau uno Srau, bis an bie Donau bin wobnen 2c. fino Slaven. Die g)unbart ber Suffen, uno vieler anbern zu dies

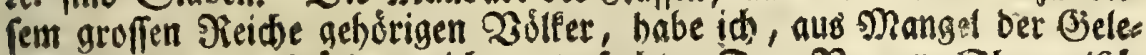

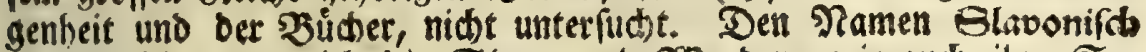
braudie id, wenn id bie Slaven uno $23 e n b e n$, wir aud ibre Sa. ben, fugleid) anbeuten will. Denn bie Suffen, Polen, 2006 men,

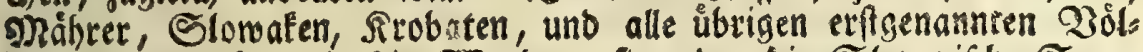
Per, fagen felbft, wie die 2 Benden, fie reben bie Elabonifhe Spras de. Meine Eanbesleute, bie Bierteltillerifden Winben, nennen fith Slowenzi, und ihre פmutterfpradbe to Slowensko, weldte Enbung gan:

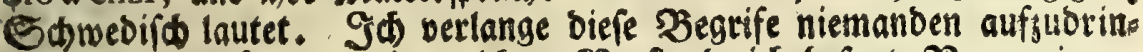

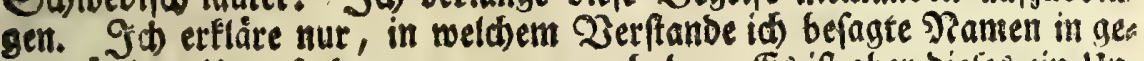
gentoártigen Unterfuctungen genommen babe. Es if aber biefes ein un cerfocib, ben in felbft erft faum feit einem Gabre beobahte. In bent

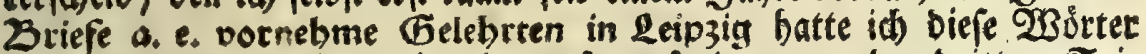
nod nicht fo beutlid) auseinanber gefegt, fonbert oon ber britten Sei: te an bes Ramens Slavonift) fur Slavifd, uno alfo als eines (ses

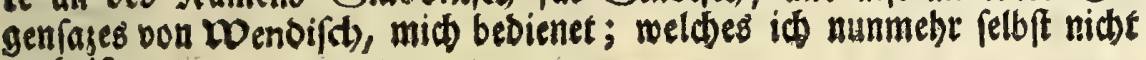
gutbeifie.

$$
\text { Uu XXV. Sit }
$$

fudjungen erinnert, baß bon bett vorgebachten Inmertungen bereits 9 Fogen

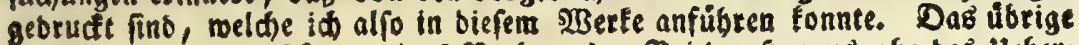

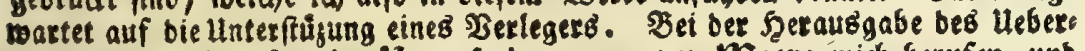
reftes werbe ich auf meine Unterfushungett pom meere mid berufen, unb eine Ş̧rift bie anbere anfúbren fónnen, von ber fie felbft angefübret wirb.

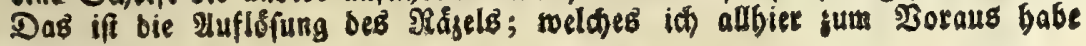
melben wollen.

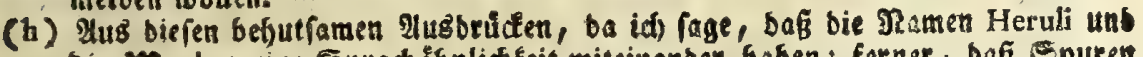

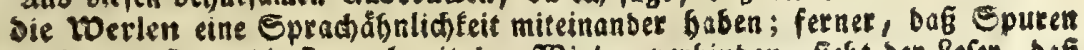
vorbanden find, die fie aud mit ben 3 inben verbinber, fiebt ber Refer, bas toh nichts beftinme, fondern nue ben Gelehrten Inla geben wolle, genaute

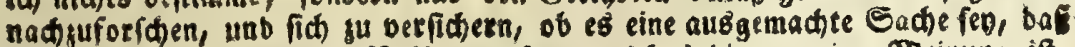
bie Heruli ein Teutfídes Bolf geweien, weldjes bie gemeine SReinung ift. Dean id finbe in ibren Eitten unb Erefegen, bie Procopius de B, Goth. II, I4, befóseibet, f. E. ta fie ibre betagten sblutsfreunbe umbracten u.f.f.

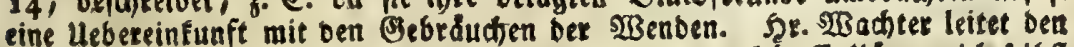
Pamen Heruli toon bem Efanbifden, Ger altus, ab, weldoe Erttlérung id felbf 


\section{$\mathrm{XXV}$.}

Ein gelefuter Bsonner, beffen werthet Rame in ber Borrebe fres

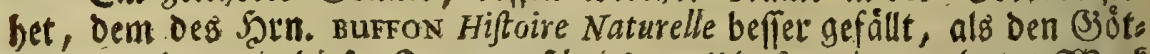
tingern, hat mir biefer Sagen gefdrieben, "Daß́ er isterwehntes 23 erE "überfommen, uno ben erften $\mathfrak{Z}$ and bereits durctgelefen habe. Er ges

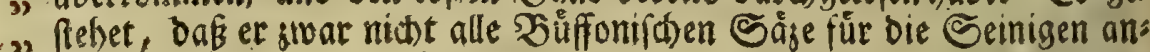
nehmen fờnte; ia er berichtet, bas er auch offenbare, wienol ges ringere Fethler in biefem SBudse angetroffen habe. Allein bie Sd)reibo art wiefe allenthalben beutitche Merfmale eines erhabenen (Sieifeo, wethes ihn vermodbt hơtte, bie fleinen Fehltritte zu überjeben; melches aud alle unparthenifhen Fidater beroegen follte, biefem 2 serfe Das Fed)t einer yortrefflichen 2irbeit nidbt abzufprechen. Dre \&ehre de animalculis fpermaticis, von deren 28 abrheit man nod burd Feine Deriuche eine rechte lleberseugung habe erlangen fơnnen (i) ; an welcher bie (Göttinger aber Dennoch fefte flebeten, bătte von dem Ştn.

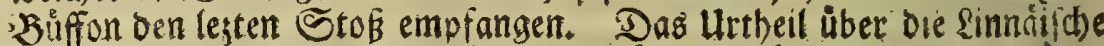

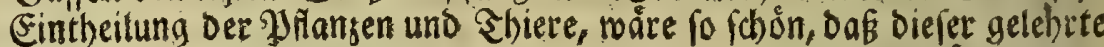
(Sionner Davon nichts metben mollte, um mir Das 2 ergnúgen nid)t su veroerben, Daffelbe bei itim in feiner uriprunglichen Schontheit zu

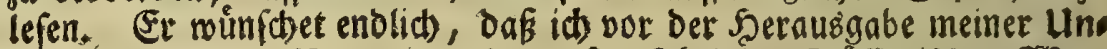

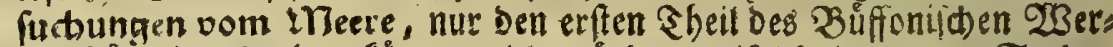

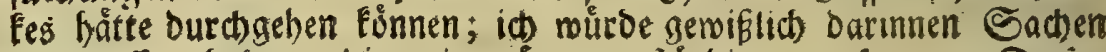
angetroffen haben, bie mir mären anfländig gewejen. „s Diejen

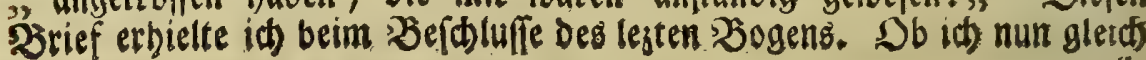

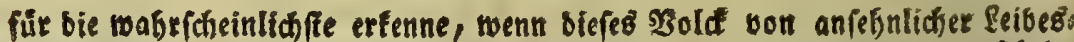
långe gervefen, tooourd) aber eben bie 2lebnltatert mit ben wenben verftártet wirb. WBenn beffen ungeachtet bie Heruli ein anbers 20 olf fino, als die Wero lett unb toinden, fo hat bielletcht eine foldhe Bielegenbett biefe Derwedtfei lung verurfachet, woourch bie wanbaln mit ben. Wenten, auch bon ben gelefreteften $\mathfrak{R a ̊ n n e r n , ~ f i n o ~ b e r m e n g e t ~ w o r b e n , ~ w e i l ~ n a ̆ m t i d ) ~ b i e f e ~ b i e ~ D e r t e t ~}$ und Esegenben eingenommen baben, barauk jene aubgejogen find.

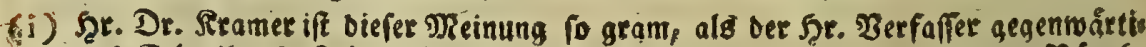

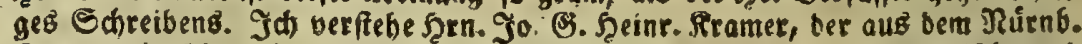
Commercio Literario, burd feine befonberb beraużaegebene meticinifche unb botanifde 2 Berfe, wie aud burd) feine Dienfte, melche er ben Deftereidifden Itrmeen geleiftet, befannt iff. Diefer arfeitfame MRann befifet aber nodg

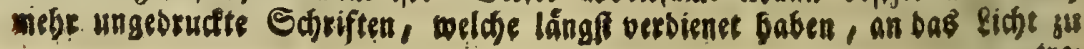


alle Simberniffe qu-vermeioen trad)te, weld)e bie Syerausgabe biefer Sothrift nod) ferner aufistien fónnten, ro entlebnte id bernod con

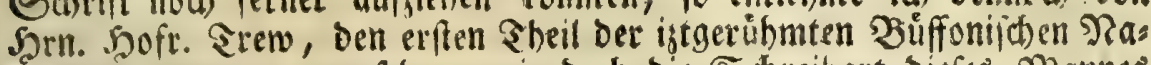
turaefobitice, um ju felen, mie Dod) Die Edreibart oiefes J?anneb minfe bejchaffen fenn, weldbe su io miorigen Litheilen habe 2inlaf geten

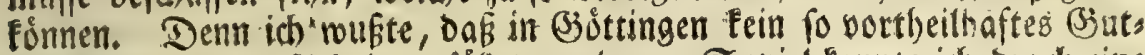

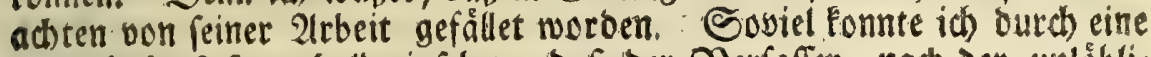

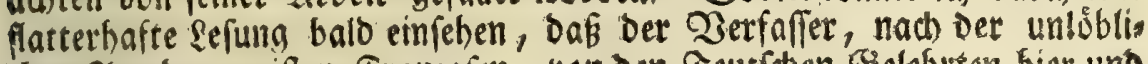
then 2irt ber meiften Franjofen, von ben Seurfden Bieleficten hier und ba mit Zeradtung (d) reibe. 2(llein baburd) erreget er bie billige 2lyns

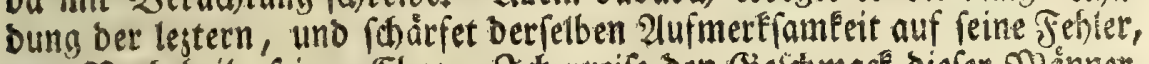

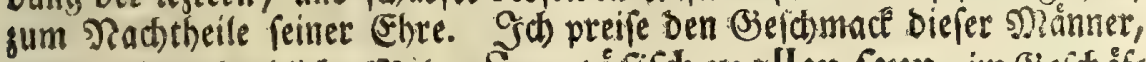

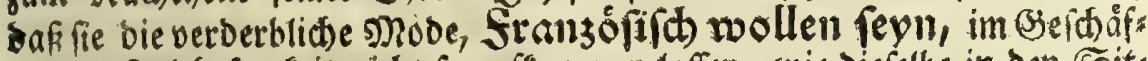
te ber Bjetefrramfeit nid)t ro auffommen laffen, wie diejelbe in ben Sits

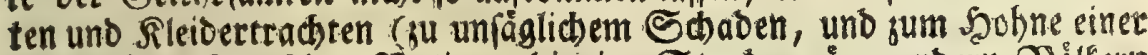

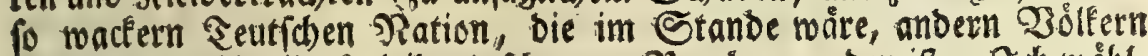

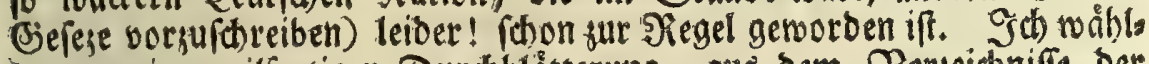
te ;u meiner eilfertigen Durdblîtterung, aus bem Derjeidniffe Det Abhandlungen, Die 2Artifel VI, XI und XII, bie bom Meere bandeln,

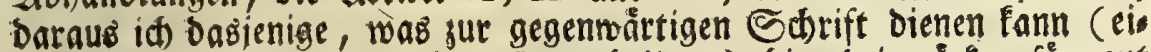

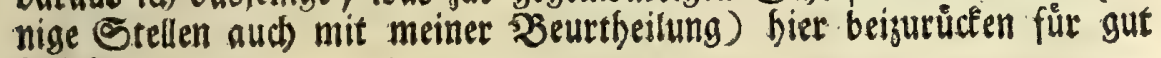
befinbe.

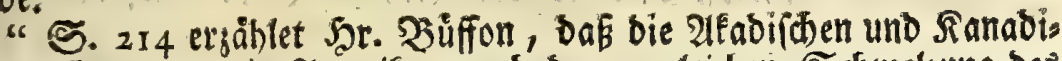
35 fchen Snwobner in 2lmerifa, nach ber ungleithen Schmelfung bes " SReereifes, bie 23itterung bes Sahres vorhersufagen múkten. 2Senn " im N. 2lpril, unter ben Sraben 67 und 68, Das Eis auf Der See IIน 2 . m nicht

rreten; allein es frehet ibnen eben bas Chicfial entgegen, weldies mir bas Súcherfhreiben cofelbaft mocht. Unter biefen 2lusfertigungen if feine FLORA AGRI VINDOBONENSIS, cum ORNITHOLOGIA filii. Diefez ift eine

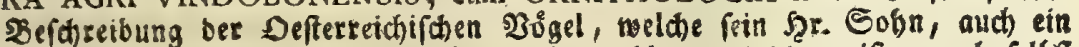
Dr. Det Irgnenfunft, nach Der ఇatur abgimablet, und die meifien aud felbit

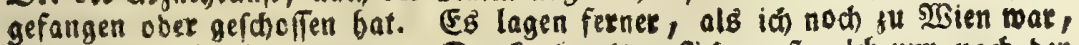

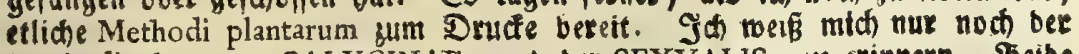
Methodi plantarum CALYCINAE, uno bet SEXVALIS, fu exinnern. Deibe find auf bie 2ut eingeriditet, wie Deffen Methodus Rivino-Tournefortiana, in beren Einleitung et meinet sfters gu gebenten bis Girte gebabt. Sein Ealg:

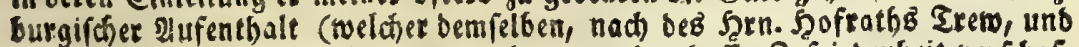
meinem berilichen 23 unithe, bic angebotene und geboffte Zufriedenbeil beridaf:

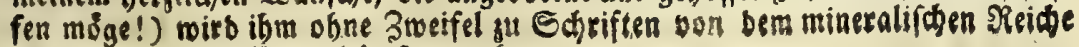
sulaß geben, weil ex nicht fepern fann. 
"niकt aufthauete, to pflege ein falter uno regnerifher Sommer barauf g zufolgen. Sm 9. 1725 warke gar fein Sommer gerweren. Sgan " bátte nod) im ßradimonat unter dem 41 Brade Eis angetroffen. ". S. 218 beridtet er Daf Der Plontus Eurinus ginglich zufries " $r e$, fowol wegen bes nielen E:fes, das bie Flluffe in biefen Eec brid). ". ten, als reeil beffelben 23 affer fuffer wáke, Dean ancere gzeere (*).

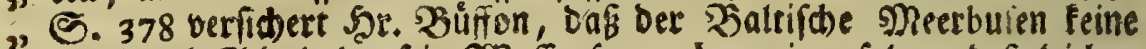

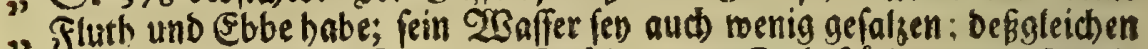
"Das 23eife \$neer, S. 379. 2luf ber 414 $\subseteq$. befătiget er nodmals

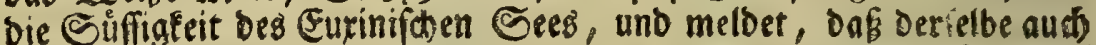
truiber fey, ats bie rechten meere. Die Sturmmetter máren auf

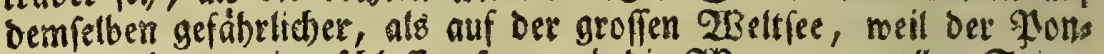
tus ringsherum eingefwloffen fen, uno bie 230 gen von allen Seiten an bie Shiffe amidtagen (k ). S. 390: In bem Werfifhen Meers bufen, uno in Dem Sothen Meere, ware ber Anlauf bes 2 saffers zur Beit Der Fluth rehr groß, weil erftich Diefe zwey Mreere bem Dittags:

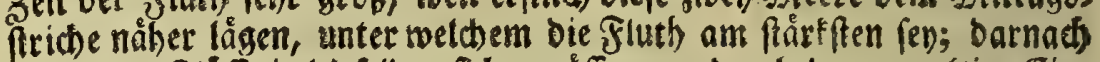
weil feine Flüffe in biefelben fíh ergöffen, woourch Der gewaltige Ein.

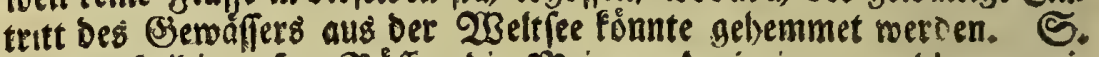

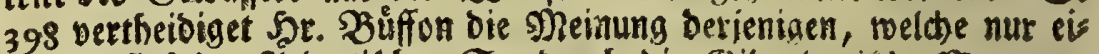

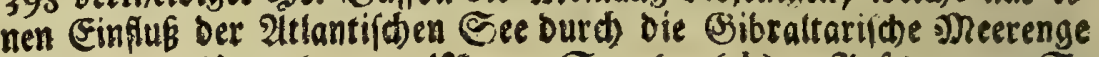

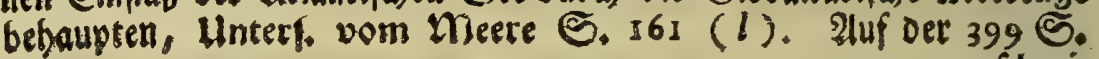
" fobreis

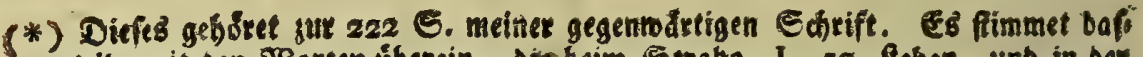
lelbe mit oen 2 Borten úberein, She beim Ettabo, 1,50 , feben, unb in bet Unmert. ( $p) \odot .342$ fo den angefubret werben.

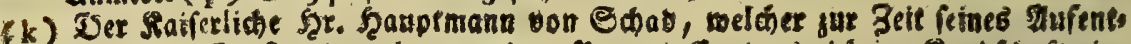

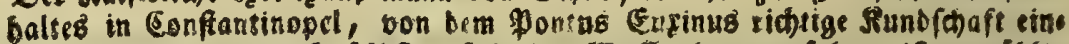
zieben tonate, ber aud feloft oxf diefem 5Baffer bezumgefabeen iff, ergabite

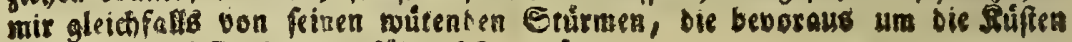

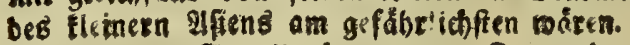

(1) शluf ber $4: 1$ E. miberieget es ben Sourncfort, melcher nach bex febre eiriges

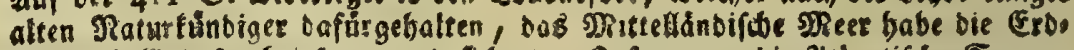

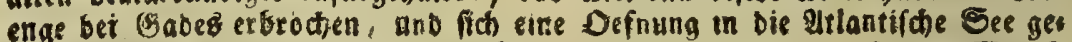

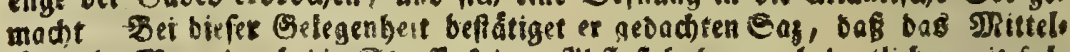

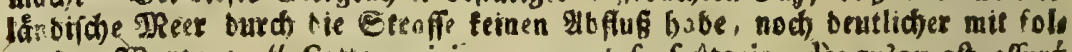
genber 20 reten: "Cette opinion ne pent fe foutenir, des qu'on eft affuré n) que c'eft Pocéan quá coule dans la méditerranée, et non pas la méditerra-

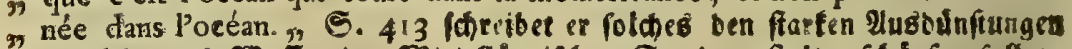

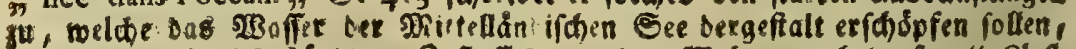

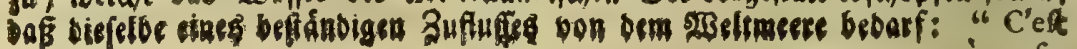
ì caufe 
Whieibet er, baf in ber Mittellåndifden See bie Fluth und Ebbe " nicht merflich fen, wol aber in bem 21briatif(t)en meerbufen, no ber "2 21nwachs bes 2Baffers, wegen ber Enge bes Seelagers, Fưnnte ge, " Spuret werben $(\mathrm{m})$.

"2uf biejer u o. f. S. berwirft Shr. Büfon bie Meinung berie, nigen, bie lebren, bas in ben \$neerengen (in ber Bsibraltarifonen, " in ber (conftantinoplifhen, im Sunde) es untere Strdme gebe, deces "SRichtung Der obern 2 erwegung bes Deeres mibrig len. Er fagt, oies " fer Sas wáre offenbarlich falíc); es lieffe fich berfélbe mit ben જ̧e.

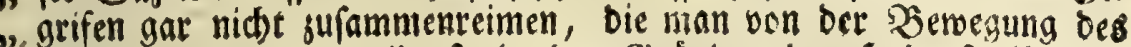
Waffers habe; er miberfrebe ben (Birimoen ber şudroftarif $(n)$. S. 400 erófnet er feine Meinung ůber Das verlohrme alte Birơnlans.

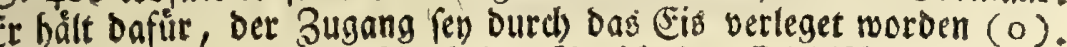
S. 410 redtfertiget ber Zerf. Den Berid)t bes Sicilifhen Diobor: welder vorgibt, das Sdwarge sheer fey borjeiten ein Spe obne

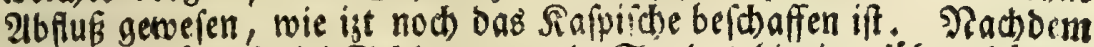
aber bie Flúfe poviel Solamms und Eandes hineingefúhret háttin,

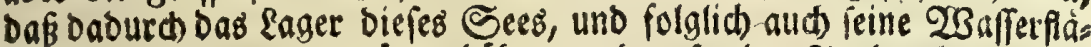
()e um ein Merfliches wäre erhóbet worden, fen ber 2usbruch erfolget, uno ber $\mathfrak{B} 0$ sphorus entfanden; befreegen fareibet er auch, S. 412 , Sounnefort batte fich obne Uriade uber bie \$neinung bes Đolnbius

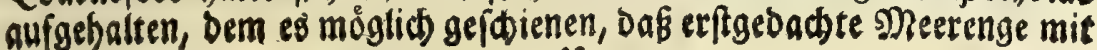
$\mathfrak{H} u 3$ „Det

9) à caufe de cette grande évaporatión qui fe fait fur la méditerranée, que "l'eau de l'océan coule continuellement pour y arriver par le détroit de "Gibraltar.,

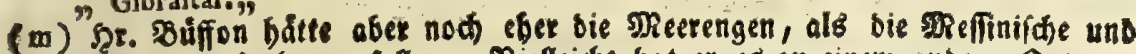
andere, aubinebmen fotten. - Dielleicht hat et er an einem andern Drte bes

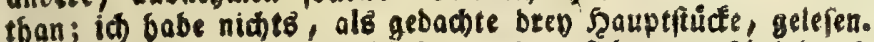

(m) Diefer wollte id) unmaßgeblich etras vorfichriger gefchrieben baben, um nich

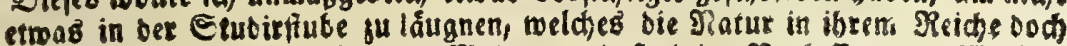

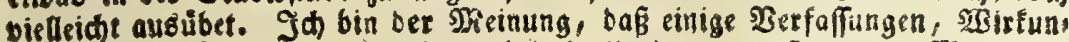
gen, uno Edrife berfelben, infonberbeit tasjenige, roas fie in bem sRere un

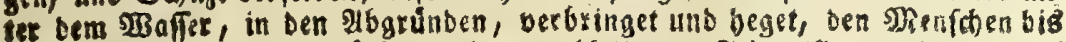

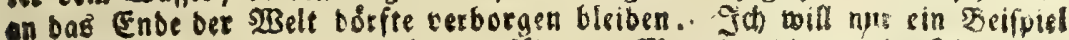

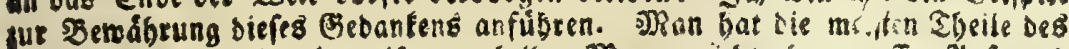
Crofreifes bereits burdogcreifet; aud ibre Desze, niost ofne groffen 2lufwans

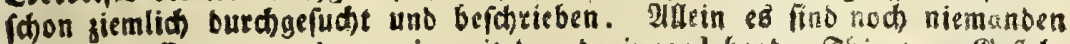
nur bie groffen cornua Ammonis, mit bem Darinnen lebaben Tbie e, fu Bsfids: te aefommen, oie man bod in ben Berfeinerungen, in Beller Hno Sctuffis srifie, auch an manden Drten fegr băufig antrifft, wie auf bem SRotw 
"Der Beit mieber konnte verfhủttet, und aus bem Cdwwar'sen sneere

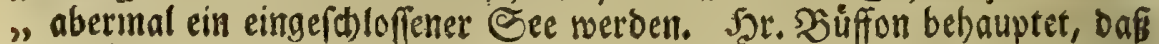

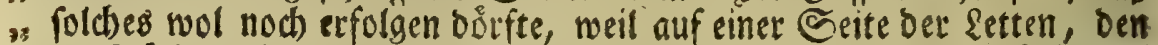
" Die fluffe nebft bem Eanoe bineinfthremmeten, fid mieber häufe; auf

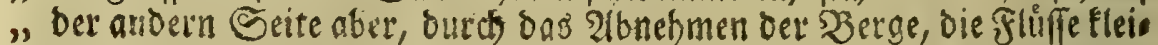
"ner werben ( $p$ ).,, S.414 fommet eine Erinnerung an bie Allgebraiften vor, Die fich einbitben im Stande su fenn, mittelft ifrer Berednum. Ben, die 2lusbuimftungen ber Neere bis auf etlide Sropfen beftimmen

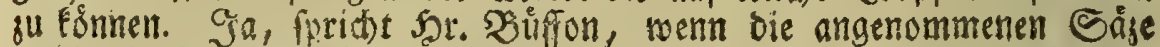
fo richtig find, als iffere Fedinung. Er ithreibet an gedadter Stelle,

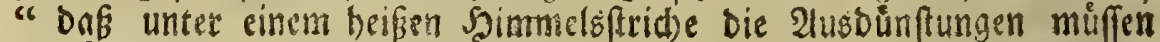
" ftärfer jeyn, als unter einem Falten ( $q)$; Dấ ein rubiges Woffer, "Doer

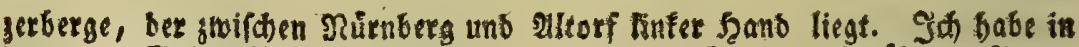

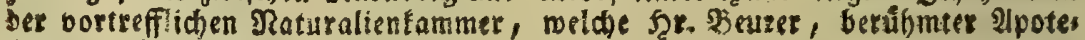
fer zu Narnberg, mit ungerninen Stofer zu bereidern fid befleifet, jowey foldie verfeinetre Stúdte gefeben, Dis ex auf gebadtem berge gefunten. (5is nes ift von 2, bas anbere von 3 Spannen im Durchiónitte. (58 gibt abes

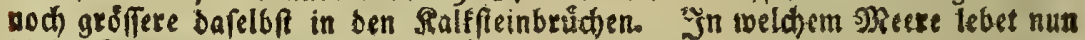

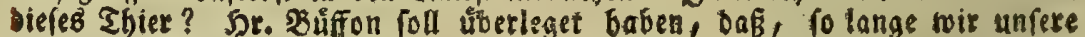

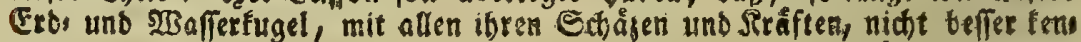

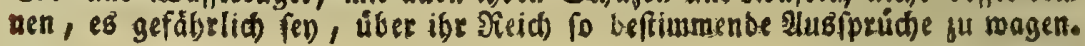

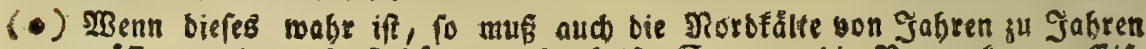

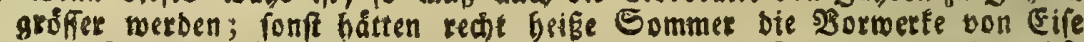

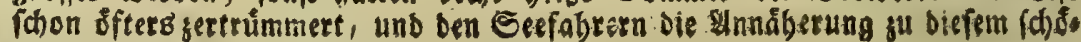
nen lanbe mogglict) gemadt)

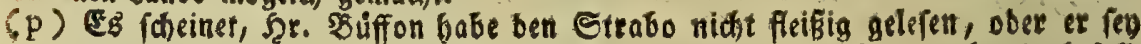
zum renigfen nidht gleidjes Sinnes mit bemielben, weld)ez ex aber boá) foll

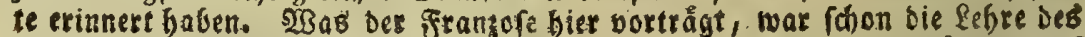
alten Naturfundigers Etrato, weld)e Strabo, I, 50 uno 5 I, exjåblet, auf

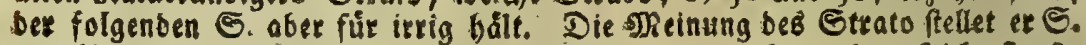
50 alfo oor: "Pontum porro effe omnium minime altum (am feidfeefen); ") profundiffima, Creticum, Siculum Sardoumque, maria. Cum enim maxi" mi $2 c$ plurimi fluvii a feptentrione et ortu fuant, Pontum coeno impleri, 2. cetera autem maria manere profunda: ideoque dulciffimam effe Ponti aquam, "fierique effluxus is locis, ubi inclinatar fundus; putatque fore, ut fi hujus3) modi affluxus fluviorum perduret, aliquando totus Pontus aggere oppleatur 2, terre: nam jam nunc in paludem converfam effe finiftram Ponti partem, 3) ubi eft Salmydeffus, et quæ Stethe, id eft, peffora, a nautis vocantur, circa 21ftrum et Scytharum defertum. "S. 52 wiberleget Strabo ben Strafo uno

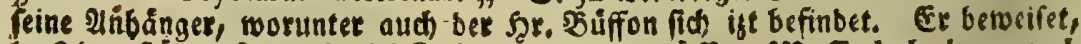

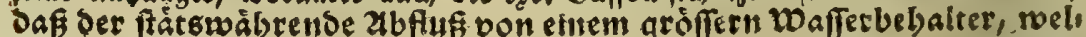
ben ( 
ober eincs, fo mit Salis uno Saritheilchen angefonmoingert ift, fic lónglamer in Dúnte aufjiebe, als ein erregtes oder ein fuffes. Der "Unterid)eid ber Siefe babe aud einen (ntbeil an bet ungleid)en Wers " minberung des 2 Baffers, uno fhlieflet fooann, bas es fober balte, "Den Betrag der 2 lusoinftungen genau ju beurtheiten, toeil bor einem

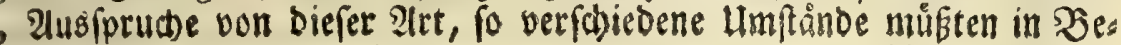
"trad)tung gegogen werden. ",

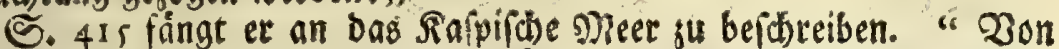
"Sften übernáhme daffelbe feine Fluffe. Stuf biefer Geite lăge ein obes Sandlano beruin, Davon man vor Zarn Jeter bem Siroffen "nichts gewust bátte $(r)$. Dureh die Unterfuctungen, weldbe biefer "geprefene Shert angeoronet bătte, roaice nicht nut die rectste Geftalt "Des

sem bŏbern Rager seg Becfens abbange, savon gesadter abjug ge fhrebe, fortsern sem lleberflufe feines waffers jujufdreiben fey. Dee

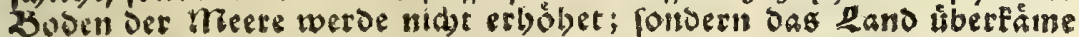
voll Denfelben immerł netue Znläje, bevorsus um bie Zusgånge Det

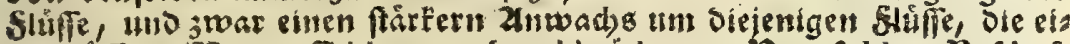

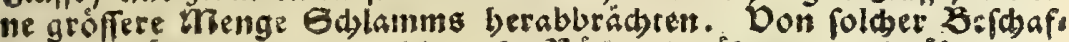
fenbeit wáren dielengen, die melse $\mathbf{3}$ adje amábmen, und tiber net. be Grinse binlie;

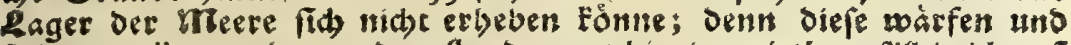
fpuleten alles roteder an Jas Ranb, was bineingerietbe. Allein ich muß bee bem fern. Búfion einigarmafien bas 20 ort fprecten, unb fage, baß̉ bies

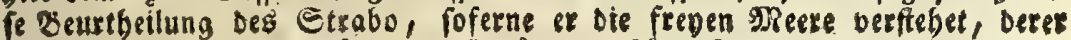

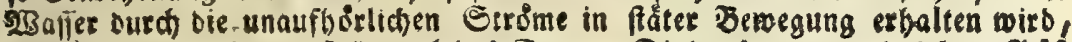

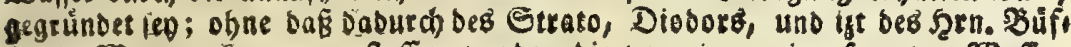
fong, Nutbmaliung umgeftofien werbe, bie von einem eingefperten S2Baffers

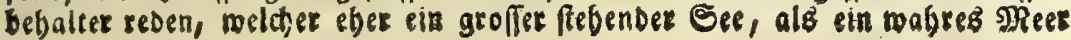
3u nennen ift.

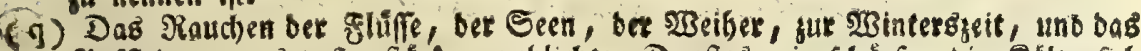

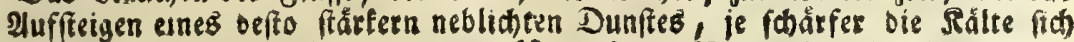
zeiget, ferner einige S. 158 meiner Unterf. v. Meere, beigebrachte midrige

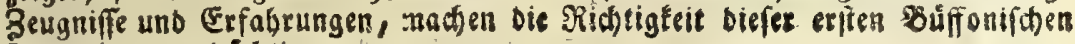
Innertung verbådtig.

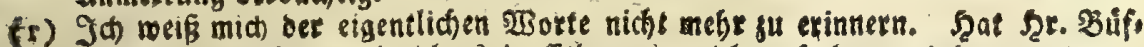

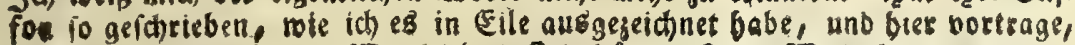
fo ift fein Beriht falfh. WBena ich bie Beit bestte erft cine $2 B$ eile berumbugenen, um bie Hiftoriam Byzantinam irgeno in einer Bibliotbef gh erfragen; oarnach auch Soffnung bătte, einen Zutritt gu Derfelben ju etlangen (Denn ber fer.

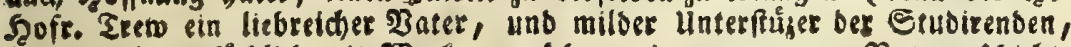

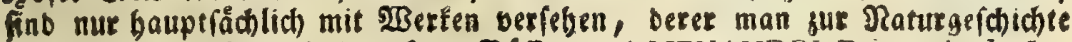
bebarf): (o wolte id bem 5̧rn. Búffon aus MENANDRI Excerptis de Legationibus, ben Hngrun der iztgedachen Berficherung exmeifen. 


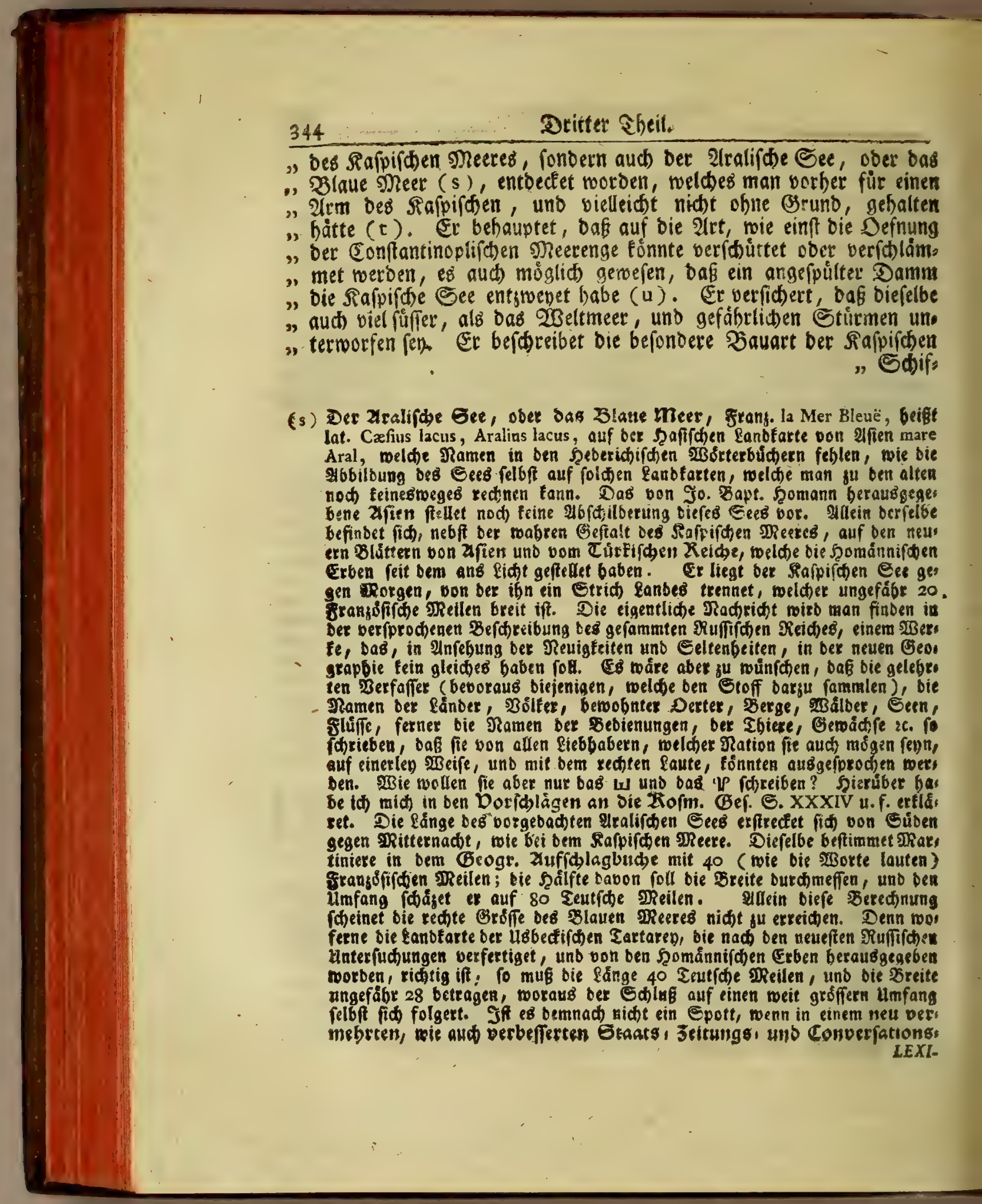


- Sdiffe, bie breiten platten Bjoben múkten boben, meil nur bergleio " ten auf biefem $23 a$ fifer, wegen feiner Seichte, braudbbar wären, u. f. f. S. 426 ศ

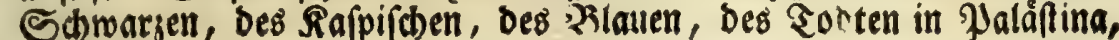
ben Flúfien su, welde befagten $23 a$ fferbebaltern viele Salztheildsen zufubreten. Diefe bliebeil Darinnen, weil nur das fúffe Wुaffer ver:

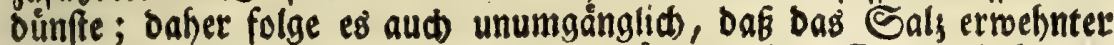
- Neere je mehr und mehr zunehmen múkte $(x)$. S. 427 beftreitet

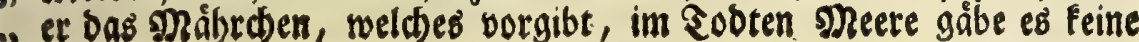
$\mathfrak{X}$ ". Firíbe,

IEXICO, bet letten 2luffage, io gat bet Dame eines fo anjebnlicen Sees now nidht ftebet? So merben bie frepbeitsbriefe nicht geebret. Diefe mers ben gewistios in ber glbfid)e nidt erebeilet, bamit anbern berboten feD, bet \$selt mit beffern פachridten gu bienen.

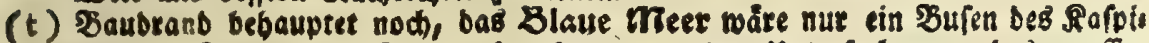
(क)en. Ecaliger bet gleltere bat lange bot ben unterfuchungen beg groffen Beters allbereit Sunb/haft gebabt, baß́ bie fänge bes leftert शReeres nicht von IRorgen gegen Q15enb, fonbern bon SRittage nach Mitternacht fith fiebe; babes twasb ex, megen biefer 20 peirung, als ein Reueret angepacte. Cels

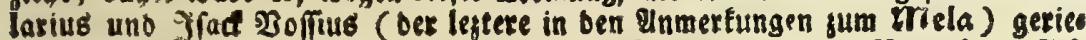
then bemielben in bie Saare. Dleariub beftátigte Scaligers 2 orgeben. Jof muś úber diefen Etreit eine artige Stelle aus Martinieres Diq. Geogr. Die i. $\mathfrak{B}$. CASPIENS ftebet, hier anfügen: "La côte meridionale de cette Mer " (er fohreibet von ber Rafpichen See) eft aujourd'hui fi bien connue que "les préjugez anciens font entierement détruits, et qu'il n'eft plus queftion 9 de raifonnemens pour favoir qui a raifon, ou de Scaliger, d'Olearius et " des autres, qui prennent la longueur de cette Mei du Nord au Sud, ou de "Voffius, de Cellarius et de quelques autres, qui fe foulevant par une pré"Ocupation déraifonnable contre l'experience moderne, entaffent mille rai" fons pueriles pour foutenir une ancienne erreur. En fait de queftions de ") cette nature un homme qui dit de bonne foi jai vî, eft plus croiable " que dix mille favans qqui difent j'ai lú dans un Auteur qui en avoit lit "d'autres.

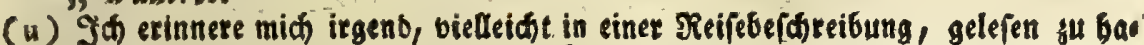

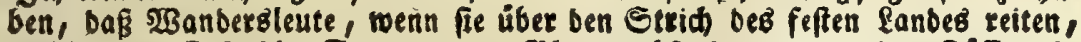

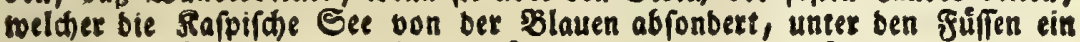
\$olteen vernábmen, bergleiden geboret toirb, wenn man über boble Derter

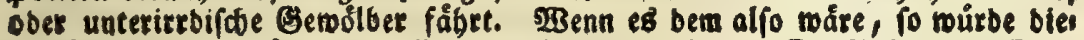

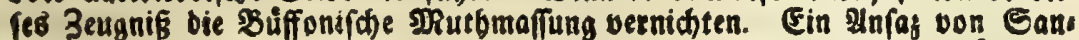
be tbofnet nidht; et múgte nut feon berfeinert morben. 2ullein mer båtte feif

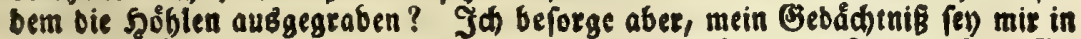
biefem Etticte nidit treu, fonbern fetle mir bas iztbenannte lanb anfatt BSes orgiens ober einer anbern lanbfareft oot, bie jwif由en bem Edwarten unb Sem Rafpifchen meete lieğt. 


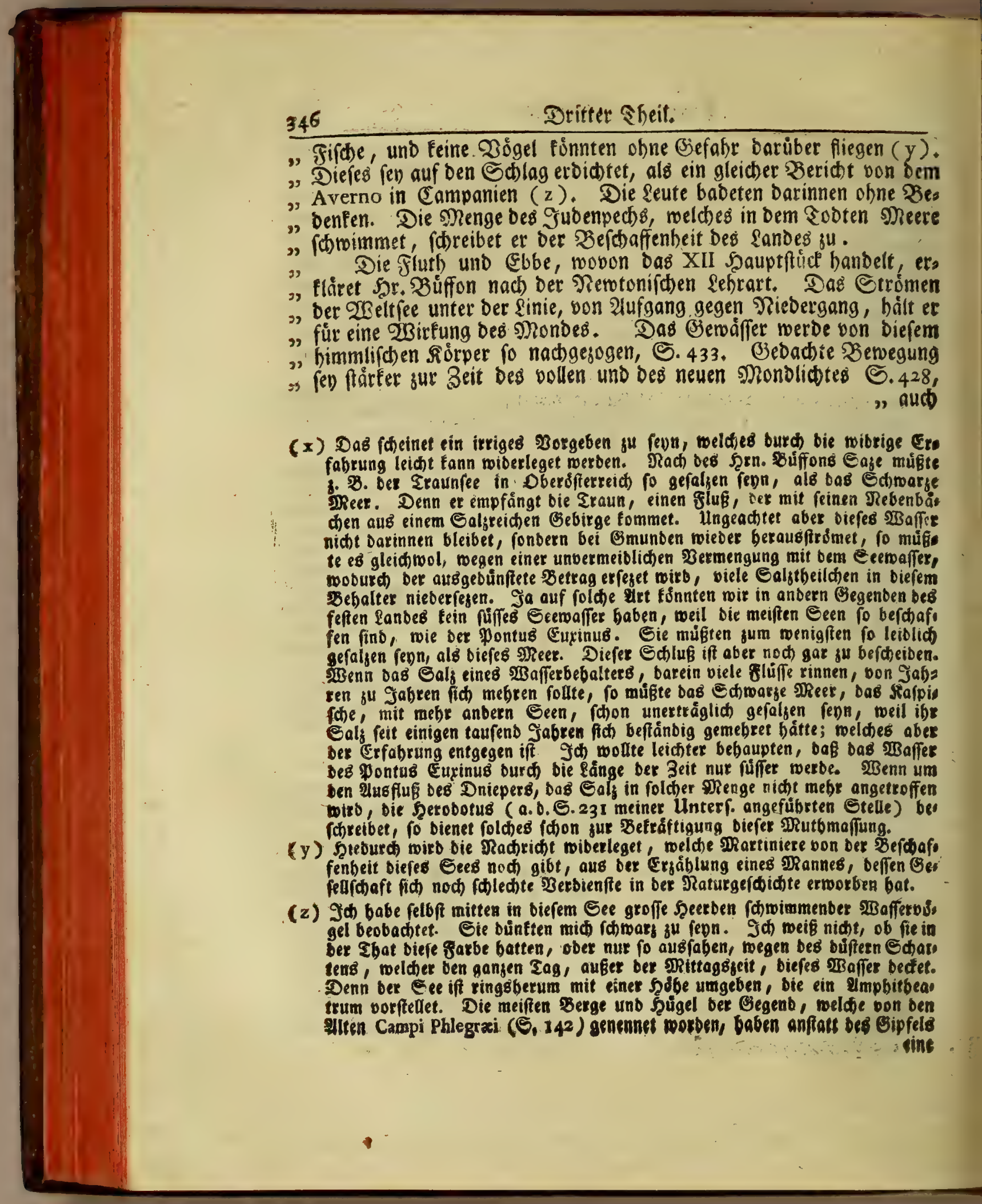


auch) รur Frublings: uno Serbfteit, S. 429. Wenn bie Fluth Fome met, werbe das 2 saffer aus Dem (Srunde berauf erreget ( a a). In "Der Magellanifonen meetenge erbebe fid bas Waffer in ber Sluth "bis auf gwanig Sकub, in bem 2lusfluffe bes gnous bis auf orenfs

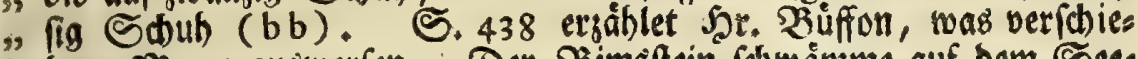

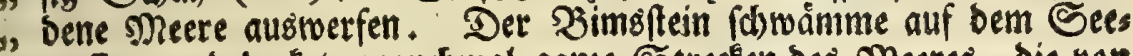
waffer, uno becfete mandimal ganze Strecfen bes smeeres, bie von "ferne, wie felbet ausfáben ( c c ), Hift. Naturelle, Tome I, p.439," Soviel habe id aus biefem $\mathfrak{B}$ (c) erwebntem Derseidniffe, bas forne fefet, nod mebr anftandige 2lufo foriften, bie mid) fur fefung ber baburd angejeigten Sauptfucte ane reigten; allein aus shangel ber Beit fonnte ich bie 2lbbanblungen felb/t tx 2

eine foldhe feffelförmige baß eहै auggebrannte Serge fino. So fiebt bie Jolfatara aus, von ber E. 14I Eewebnung getban morben. Dex serg S. Salvatore if aud) fo befdaf: fen. Seinen Seffel beift man il campiglione. (Fine anbere Şo̊be am sReere, bie linfet Şanb gelaffen wiro, wenn man oon Dojjuolo nach) Cuma ( $\mathrm{Cu}$ $m x)$ gebet, ift ebenfalls auf biefe girt obenber eingebridt. Das bodhliegen be Felo vor bem gemauerten Fogen, arco felice genannt, baburch ber Weg von bem See Averno fu ben Heberteften ber (Eumairhen थltertbümet fúbret,

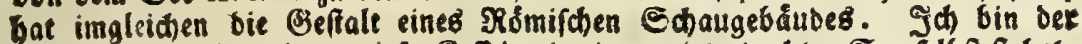
פReinung, Das auch ber tiefe Reffel, Darinnen istgedacter See felbft ftebet, eine Ergeugung bes Feuers fev, burch welches ber Berg fo nach bet Tiefe burchgenaget unb aubgejebret morben. Der unfreundliche einbltef diefer ab:

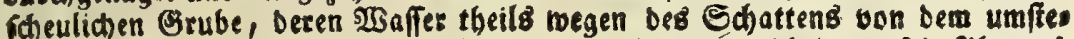

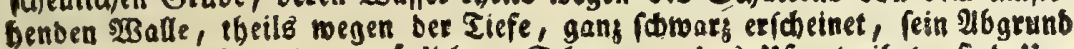
felbft, unb weil es einen gruinlichten Edhaum an bas ufer treibet, finb ums

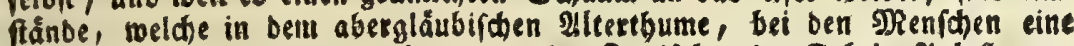
Fusd) vor biefem See erwectet, unb ofne 3weifel zu ben fabeln Ainlas geges

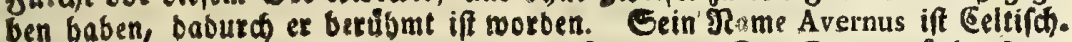
Denn aben beifit defcendere, von ab deorfum. Die Etenermárter fagen abe. Daber tommet bas 23 . Zbens, tempus diei, quo fol defcendit. Man

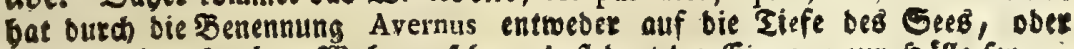

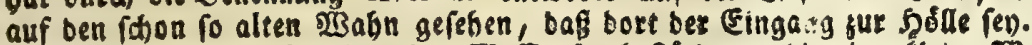

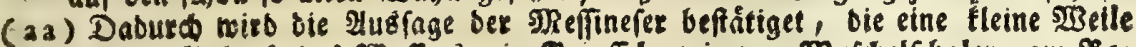

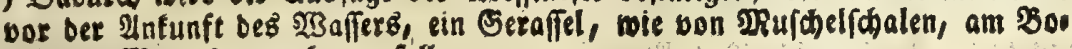
Den bes Reeres bernebmen follen.

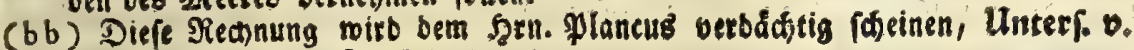
meere S.100 u. f.

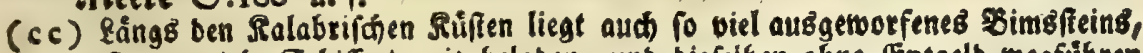
bas man viele Sdiffe bamit belaben, und biefelben obne Entgelb roegfúben

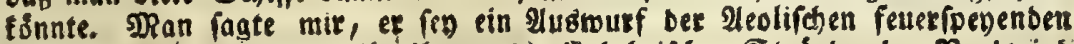

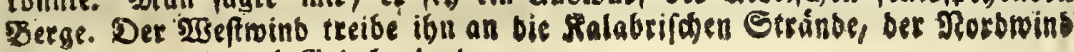
aut Eicilien und nad Ëriechenland. 
auf biefe Art nicht burchgeben, um bas mir bienliđe, fur Bewåhrung meiner Meinungen, baraus anjuführen, anbere Sảze und Beridate aber zu miberlegen, ober für ungewoís zu erflären, wie id es in meinen unterfuct)ungen mit mehr anbern 23 erfen vorgenommen habe, Derer Berfaffer bem Sarn. Bủfon an Derbienfte gar nicht zuvergleichen finb. ÖBenn mur jemand befrwegen basjenige vormerfen foll, was Strabo an Dem Eratofthenes fodon getabelt hat, Da er fítreibet: Id quoque non reEte Eratofthenes, quod crebram facit bominum memoria indignorum mentionem, modo reprebendens, modo corum utens teftimoniis, ut Damafte et aliis fimilibus. Nam etfi aliquid ii veri dicunt, tamen iis id teftibus comprobandum, aut propter ipfos credendum non eft, I, 47. Diefes babe id $)$. 238 u. f. beantwortet.

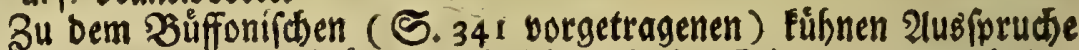
bon ben wibrigen Meerftoomen, will id nod) eine Erimnerung nachbolen,

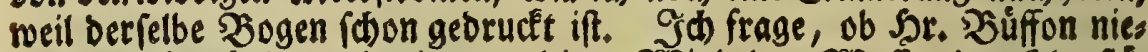
mals gefehen habe, wie ein gerwaltiger 23 ind das 2 affer ber Sberfias We, gegen ben \&auf eines Fluffes, aufwerts treibe, ba inbeffen bas uns

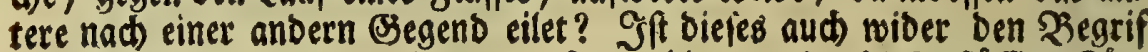
ber $\mathfrak{W a f f e r b e w e g u n g ? ~ W B e n n ~ e r ~ f a g t , ~ h i e r ~ w e r b e ~ b i e f e r ~ f i u ́ f f i g e ~ S o ̛ ́ r . ~}$ per Durch eine ảuferlid)e Fraft genóthiget, einen unnaturlichen (Sang su nebmen; fo lage id, baß man aud feineg'weges behaupte, bas Meer laufe von fï felbft aus Der Propontis in Den Eurinishen See. Es lann revn, Das Daffelbe ebenfalls nur burc eine frembe Serwalt bineine gebructeet werbe. 2̧senn ber Franjofe biefes låugnet, fo muß er alle Triebwerfe der Natur fennen, die unter dem $23 a f f e r$ verborgen find.

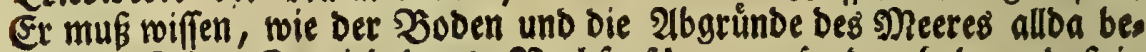

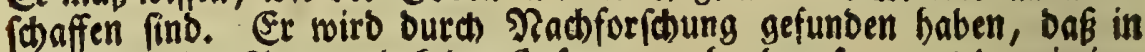
bem fager ber Yropontis feine Sefnung vorbanben fen, aus ber ein im. merwábrender $23 i n b$, wie an mefr Srten bes feften \&andes, herausfabs re, und das ruhige $23 a f f e r$ ber ₹iefe in Den Pontum jage. Er muś

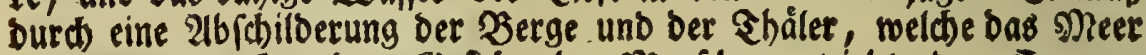
an gebadtem Srte bem Befidste ber Meniden ent;ieht, Den Saf von ben wibrigen $\mathfrak{B} e$ wegungen beffelben $34 \mathfrak{B} 0$ ben merfen, und fobann iff ex einer ber gröften fehrer, Dégaleichen nod) Der Erbboden feinen getragen

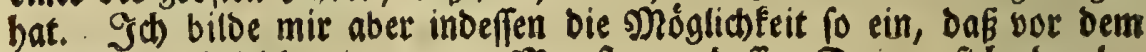
Bofphoro vielleicht ein unterer Meerftrom, beffen Daienn fid eber bes

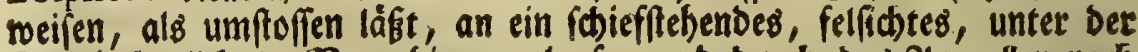
See befindiches, Dorgebirge anlaufe, unb burch bas 2inprellen nach Der sneerenge getrieben werde, Da indeffen ber Heberfins bes zugefüberen Flufis 
Nadilefe von Bugaber.

Flußrwaflers, bas fich mit bem gefaldenen vermenget bat, aus bem Euxino beftänoig oben heraugftro̊met. Die Siefe Des $\mathfrak{B}$ ospborus trågt zur 203abríchetntich)eit ber 2luslegung vieles bei.

Das im enfange biefes XXV Zujazes, S. 338, angefühtete

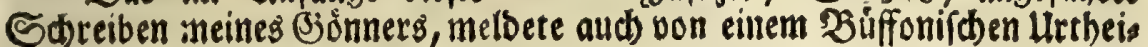

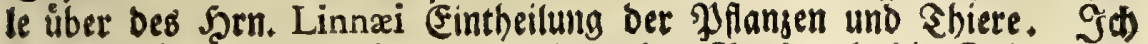
batte bie Beit nicht nact)sufuden; Denn ber Band und bie Seite murs

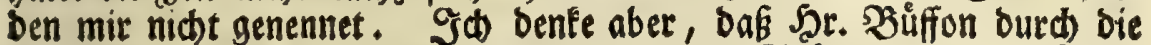
fieferung biefes 2 rtifels Feinen fonberbaren STufm erlangen Dörfte, wenn nur foldhe 3 eurtheilungen hochgeadtet werben, badurd man fd)were Sadben auseinanber feset, ober bie gelefrte 2 Belt bon Srrthü. mern abbringet, bie entweder ítson tiefe 23 urgeln gefakt baben, oder

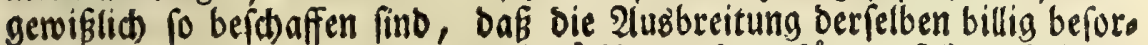
get niro. WBiberlegungen ber simnái(d)en \&ehren fơnnen fid biefe 20 ors

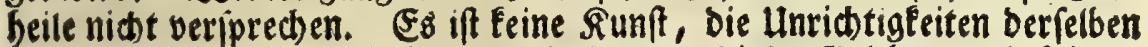

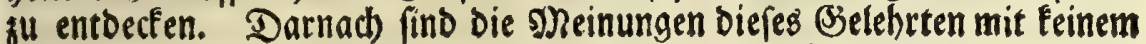
io allgemeinen $\mathfrak{B}$ eifalle aufsenommen worben, Dak man grofie Urfache bátte, bie 2Belt vor benfelben zu warnen. Eś ift oiefes aber zum Ueber: fluffe, und zwar burd groffe månmer, fhon gefthehen. Die Miángel,

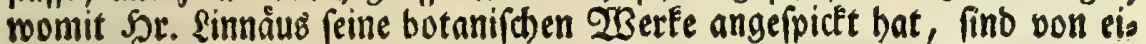

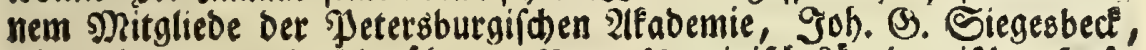

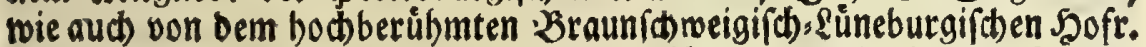

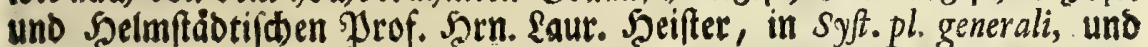
beríchiedenen andern Jyrobidsriften, bereits angezeiget worben. Wer Die botanifhe Bef(hid)te im Sopfe hat, und von bem neueften 23 erfe, PLANTAE SELECTAE (fu Deffen Şerausgabe auf Smperialpapier, mit gemabiten Rupferplatten, in Dielem i 750 Sabre Der 2 nfang gemaché

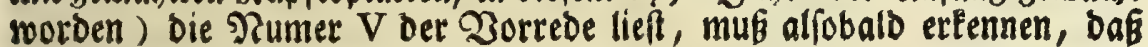
Der Şr. Şofr. Irew, Urbeber biefer Unternebmung, Sammler ber prácbtigen Abbiloungen, welcbe bie शatur trosen, mie aud Detr

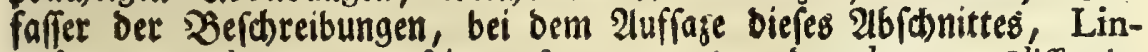
næi Genera plantarum, fein Syftema Nature, ben bortum Cliffortia-

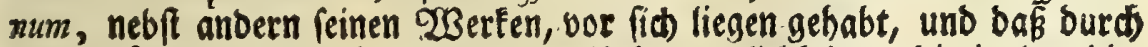

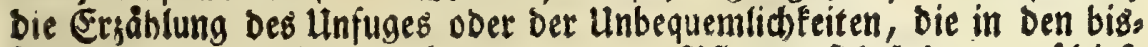
ber befannt gemadten 216 hanblungen von $y$ flangen fich finden, auf biefe

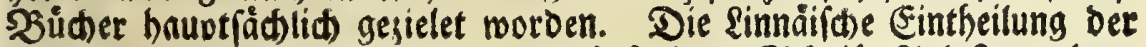

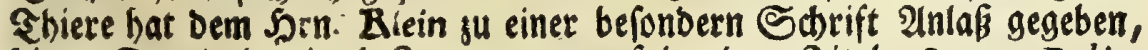
bie ju Danzig bereito i. \$. 1743 unter folgendem รitel, Summa Dubiorum circa Clajfes Quadrupedum et Ampbibiorum in LINNAEI STSTEMA$\mathfrak{X} 3$ 
TE NATVRAE, in Quartgróffe herausgefommen. 2lls der erfte simnåis

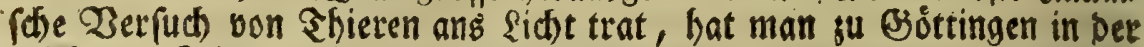
gelefrten Zeitung biefen ungereimten Bjebanfen nidbt obne Urfndbe ges

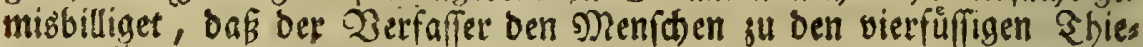
ren gefellet, uno mit bem 2lffen gleichiam in einen (Stall eingefd)loffen bat. Diefe finnäifhe Episfindigfeit gibt eine feltfame 2 lusilegung tu ben lateinifoten 2 Borten der Wulgata, III Şauptft. Des Ecclefiafteg, 19, und folgenden 2 Zerfen. Wenn bei ber Eintheilung ber Shiere biefes die Sauptabficht iff, baf man ibre Pamen in gewiffen Fäd)etn

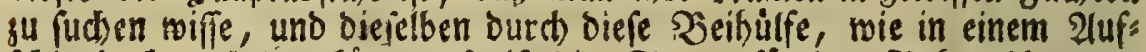

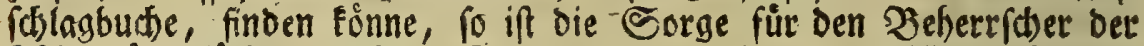
Thiere überfiuffig getwefen. Der Saner und ein find wiffen, ofne bie

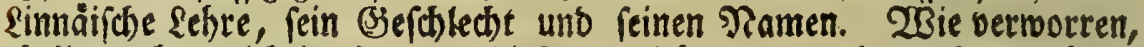
theils au(h) unridtrig, ber bon biefem (B)elehtten yorgelegte Entwourf bes

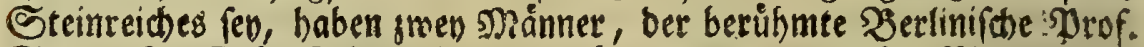

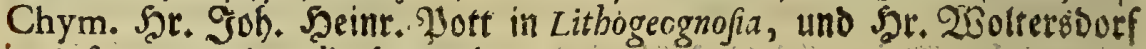
in Syftemate. Minerali, Dargethan.

Эक) geftehe aber offenbergig, bafi id, aufer der angegeigten Stelle ber 20 orrebe zu den P L A NT IS S E LECT IS, Die mir vor dem 2borus

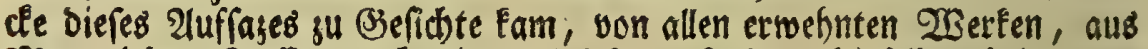
Mangel ber Muffe, nod) nidutb gelefen, fonbern biefelben bei guten

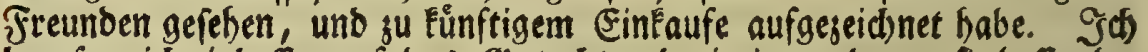
berufe mich inbeffen auf Das (Sutad)en berienigen, Denen fie beffer bes fannt finb, und fage nut fo viel, baf ich ein neibifher ober auf andere

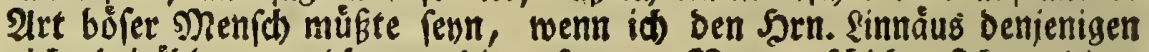

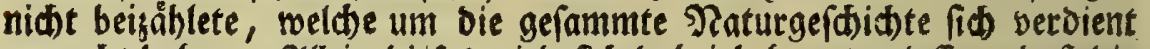
gemadtt haben. Allein biefes wirb fich oabei behaupten laffen, baf bie sefung feiner 2 Serfe nüglicher, angenefher, unb deffen Siubm tweniges ren Inftófien unterworten wåre, wenn bie allju beftige $\mathfrak{B}$ egierde, Neus igfeiten zu lehren, benfelben nidfte auf befondere, munberlidbe, freche,

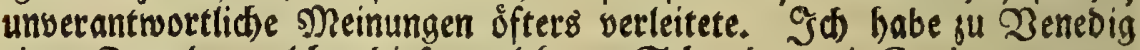
einen Freund, welcher biejen gelefrten Søweben mit Cardano gu ber, gleiden pfleget. Er fagt, Cardano a fcritto molte belle cofe, mà egli a fcritto ancora molti.jpropofiti. Utm ben \&efer wegen bes entgogenen $\mathfrak{B}$ üfs

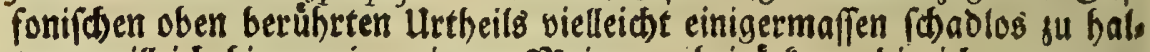
ten, will id hier meine eigene sneinung beirúcen, bie id) vor zwen Sabren, bevor nod) ber Entwurf bes befagten Framsoffifthen 23 erfes nach ₹eutratlanb getommen ift, über bie simäifhen Einleitungett,

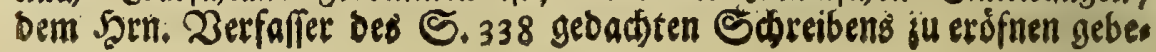


Padlefe yon Zugaben.

ten marb. go verlange mir aber baburd fo menig einen Serbienft qu maben, ais ich bem Scr. B̉uffon einen, in 2(nfishung einer fo funfto. fen Arbeit suerfannt habe. Szein Jorbaben ift, Denienigen Refern,

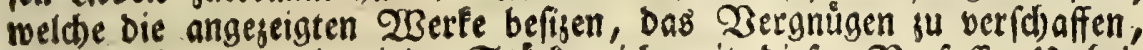
bas fie feben, in wis vielen Studen id mit biefer Derfaffer Urtheis len, Die id nidt gelefen babe, ubereinftimmen meroe. Iक fagte Dem ơfters gepriefenen (3onner vorher Das (3)te, wethes ioh allhier nid)t wieberbole. Es ift Daffelbe von ben sinnaifosen sobrebnern, nur mit allju groffen 3ufäzen und Dergrofferungen, bereits ausgepofaunet

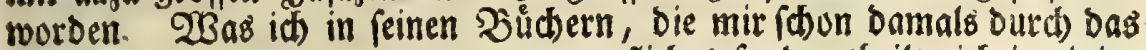
Pachf(blagen befannt waren, berwerflides fand, theilte id in einige Ab/dhnitte, bie aber ftarfe Dermebrungen leiben, uno erwies vorges rúbmtem freunbe nacfolgende Săje:

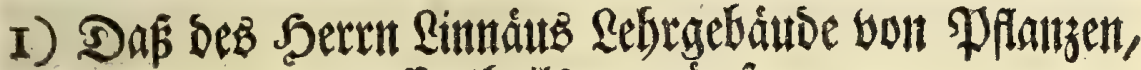 groffentbeils untury fery.}

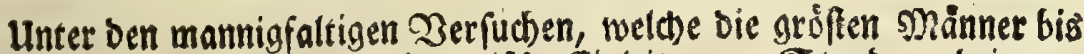
ber angeftellet baben, um eine botanifoe (sinleitung zu Stande ju bringen, welche ben sernenden beutlich fen, und fugleich biejenigen mefentlid)en

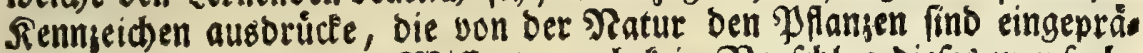
get worben; hat meines 2 Biffens, nod fein Dorfalag diefes gwenfache Derlangen etfúltet. Sa es borfte Der isige Bau ber 2 Belt bebor zer. fallen, als eine febrait ausjufinoen fenn, weldbe bes lezten iftberubrten Dorsuges fich follte rúbmen fonnen. Der weife Sibopfer, welder bes

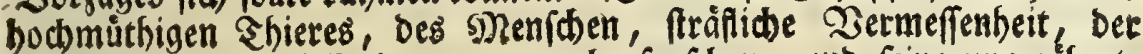
Wabrbeit feiner Dffenbarungen nachfuforfacen, uno feine ungesábmte Begierbe, aud nidt geoffenbarte funftige Dinge gu exfabren, vor ber (Fr: f内affung Deffelben getoust, legte ifm, ju feiner Demuthigung unb $\mathfrak{B}$ es

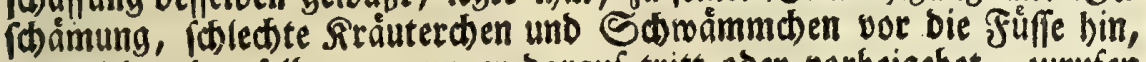
berer jebes bemjelben, wenn er barauf tritt ober oorbeigebet, zurufen foll, mir grubele nach, mi $\phi$ fergliebere, mic nenne mit meinem rechs ten 'ramen, und fage qu weldem (Serdflechte id gebóre; lebre fooann aud beine গ̇ebenbruber, marum mid) (Sott erfoaffen babe; unb wenn

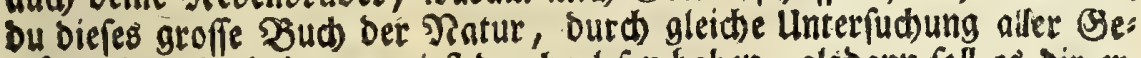

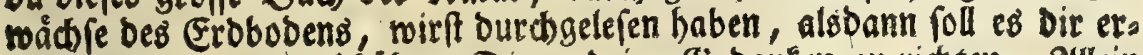
laubet fenn, aud auf hởere Dinge beine Siebanfen gu richten. Alllein wir werden nitht iren, wenn wir bebaupten, Das ber groffe, ber fürh: terliche Sag, Den Soel abldildert, vorber fommen foll, als eín Eterb. lid)et 
fider bie befdriebene eigentlide Erfenntnis ber forperliden Dinge, bie er fieht, riecht, fofter und greifet, erlangen merbe.

2Bas foll nun aber Der Menif thun? (Sott verfichert ben elben, baf er alle Shiere, Giewåche und leblofe Dinge, auf bie Erofugel, oie er bewohnen wirb, gu feinem Dienfte gefejt habe. Soll er biefe fút

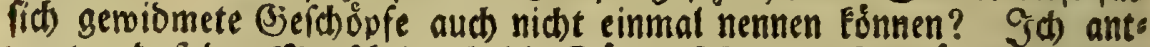

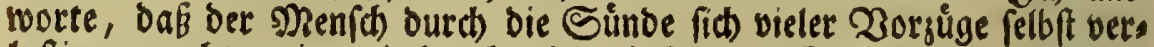
luftig gemadt, wie aud burd bie unbefonnene Begierbe, redtt grofi und uber feine Nothourft weife zu werben, Die er gleid anfangs an Sag legte, in biefen Stand ber unmiffenheit gefturset habe. Sebod

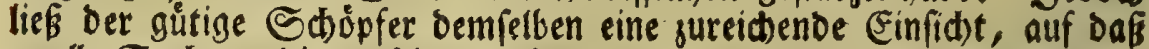
er alle Sacben, bie zu feiner Erfoltung, ja aud zum 20 olfeyn bienen, in ber Sprache besienigen fandes, in bem er lebet, nennen Eơne; uno

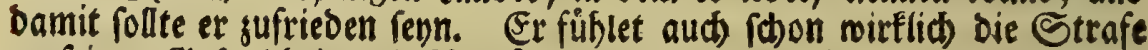

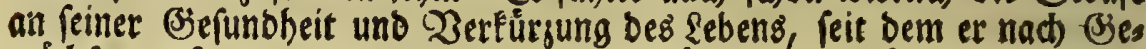
wåd) fen entfernter unb anbers gearteter sănber, bie fủr ifn nidit bes flimmt waren, if lúftern getworben. Er weis nun aud ben Sebraud

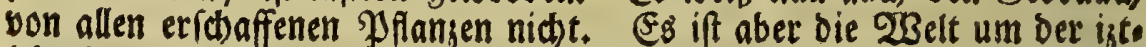
lebenben senfiben willen alleine nidht gebilbet worben, fonbern aud wegen berienigen, bie bor taureno und mefr Gabren vorgegangen fino, und fur biejenigen, bie nodh fommen werben. Wrir fehen, Das ber tweife und vorfichtige Bjott, in einem jeben Sabrjunderte, Die Sräfte ans berer (Serwådbre, nicbt nur Durch) 2(noronung vermeinter zufálliger $\mathfrak{E r s}$ fabrungen, fonbern auch Durch aubbructliche Eingebungen ben gienichen entbecle. Man Eann biefe $23 a b r h e i t$ f由on baraus erfennen, weil viele

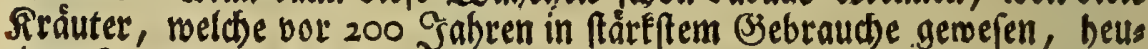
tiges ₹ages zum Dienfte ber 2 (potefen Faum mehr gefammlet werben, fonbern anbern ihre Stellen baben abtreten múffen, von benen man zu

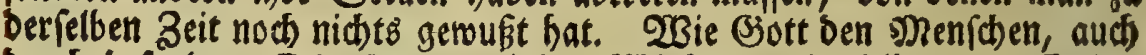
Durd befondere Erleudtung, einige 2 sirfungen berfelben $3 u$ offenbas

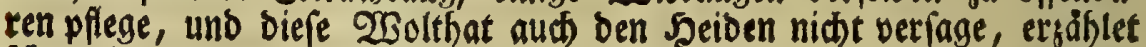

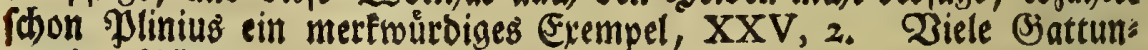
gen ber $\mathfrak{l}$ flamsen baben ifren Dienft bereits vollbract)t, unb ben Mene fiben v iget Deiten genuset. Sie bleiben aber bennod), zum Sdimu. cle ber Erbe, fteben. Eetlide werben erft bei ben sufunftigen siells fhen berưhmt werben, bie wir igt nod) mit Fúffen treten, alo Unfraut aus bem $23 e g e$ ráumen unb ausrotten. (Es (h)einet bemnach, bas

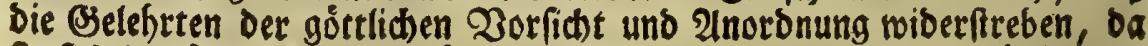

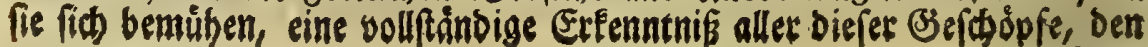


Sgenftien ifrer Sehseit auf einmal beigubringen; und barum gebet ibnen

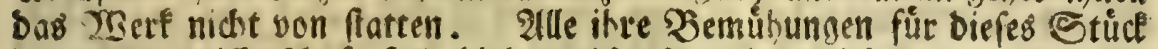
ber ?aturwiffenidhaft finb bisher nicht fo meit geoiehen, bafs fie nut

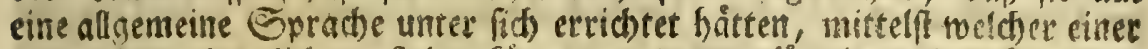

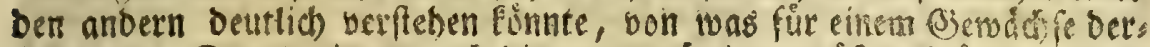

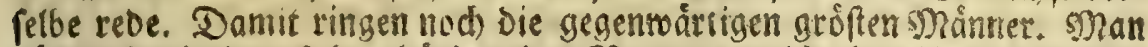

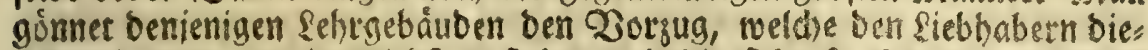
fer Hebunnen am beutlichfen find, uno bie ficherfe 2ltteitung an bie

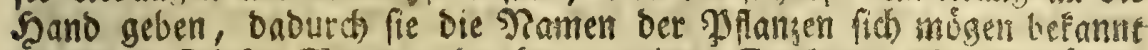
macben. Diefen Jorjug aber bat, meines Erachtens, Der Einnáiche Entwutf nitht.

Seine Cruptogamie betråth fhon bie Unoolfommenfieit beffelben, and madt biefe \{ehrart für einen groffen Sheil Der (Setoritbre undienlich, sumal ba fie aud) bei ben fichtbaren Stucfen ber $\mathfrak{B}$ lumen ben vermein.

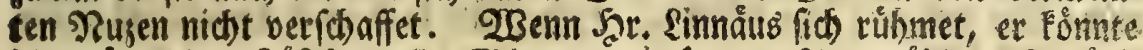

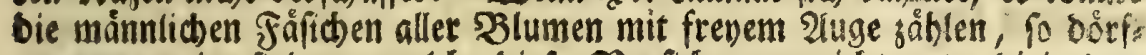
te man wenige finben, weld)e biefe Derficherung nidst unter bicienigen redhnen werben, bie etliche burd Das হieilnerfen, andere mit bem 2 uf: (d)neiben ertácen. Jab babe mir felbft vor einigen Gabren ein gin renglásic)en geidslifen, Deffen Riennhero nicht gar won cinem balben Bolle ift ( $d d$ ). Mnit bemfelben fonnte ids alle Sbeile Der $\mathfrak{B l u m e n}$ und Der Samengefâfe, nad) ber ?urnefortifden Einleitung unterfuden, ob:

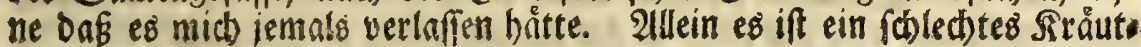
()en, momit bie Betreibefeloer im \&anbe ob bet Ens, bie um झriffes ning bei Regensburg $2 c$. Didte bewad) fen find: id berftebe bas KNAwEL

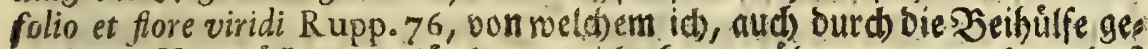

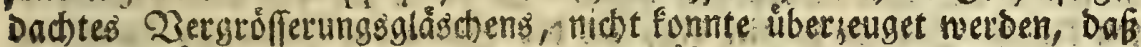

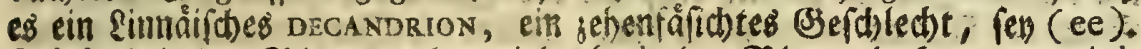

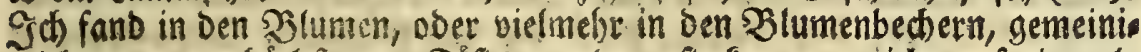
glid) nur $5,7, b 0$ d)ftens 8 jơficisen; Denn fie fommen nidht auf einmal; fonbern einize fino nod) nieorig und unfichtbar, ba man oie ubrigen mit

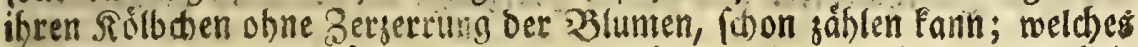
bei mefr anbern (Semoidblen aut) fo porgehet, uno, als eine (Belegenbeit bet 2 erfubiung, biefem sehrgebabo nachtheifig if. Darnach verbienet

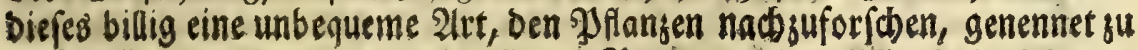
2) wer:

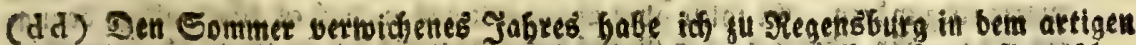

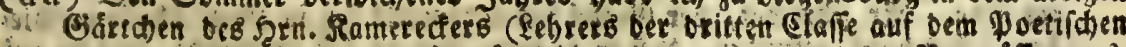

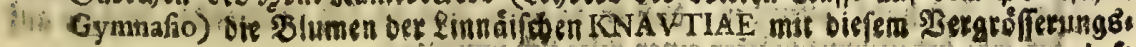
glafe 
werben, wenn ber Siebbaber zu einer gewiffen Safrogeit, in cinem gewiffen g)onate, ia mancomal faft gu ciner gewiffen Stunde, muß sum Fraute bin

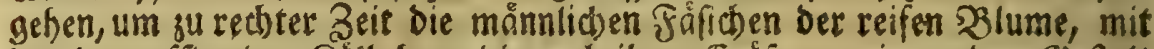

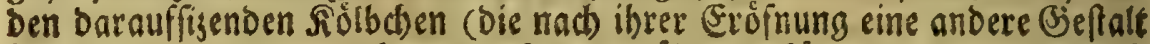
ǔberfommen, oder balo berunter fallen ) zăblen gu fónnen, morauf er nod ofters mebr ratben mus, als fiobertich uno beutlich erfåbrt, toas es fü ein (3ewådos fev. Sine Srăuterfrau beftoimet einen Sinncianer, menn fie ifn

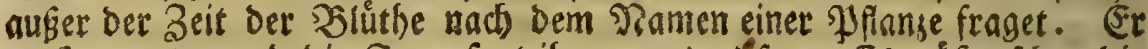

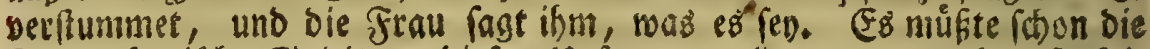
Sournefortifd)e Einteitung Diefem Unfuge unterliegen, ungead)tet fie feis ne 10 frenge $\mathfrak{X}$ eobachtung ber Sleinigleiten ber Slumen erforDert, menn man fich nach bem $\mathfrak{B u c h}$ ftaben an biefelbe binben wollte, und nidst bat

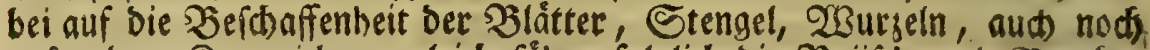
auf andere Rennseict)en zugleich fábe, folglich Die Siajifiche uno Roerfan

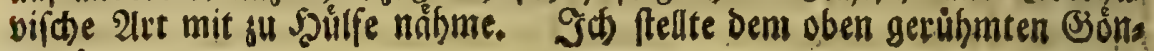
net ferner bor,

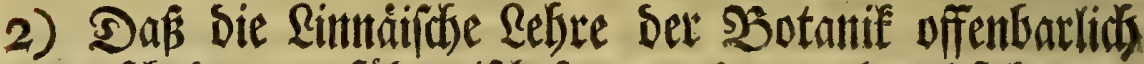

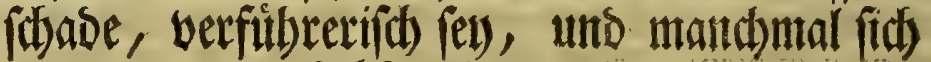 ferloft wiberlege.}

Die erfte Wabrbeit leuct)tet einem jeben redtbenfenden und forarfs fidtigen Fenner bon fich felbft in bie 2 lugen, wenn er betrachtet, wie Sr.

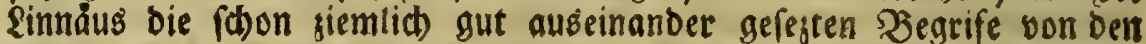
Pflanjen mieber verountle, oa er bie ßabl ber Arten minbert, und viele berjelben nur. Deränberungen beist. (Er biloet fich auf Diefen vermeins ten flugen Streich fo biel ein, als ber Sobn ber 2llfmena, ba er ben Stall Des 2lugias ausgemiftet bat. 2Allein bie Derftånoigen fönnen Das gegen befaupten, bafi biefes, nebft ber unertråglichen Derwechelung

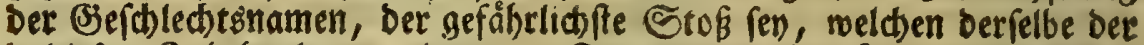
in biefem Sabrbunderte mit gutem Jortgange aufgellárten Siraterwifa

fents

glafe betrachtet; moburch id faft bon ber $23 a$ hebeit ber Betficherung bin úbers

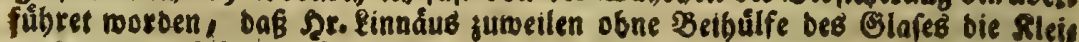
nigfetten ber Pflangen beobachte, und vielleid)e eben befirwegen nicht allemal am

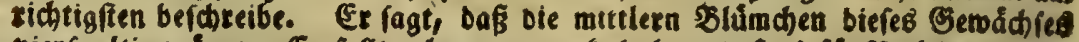

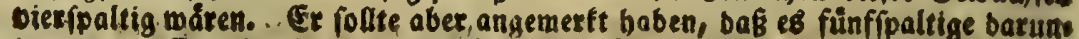

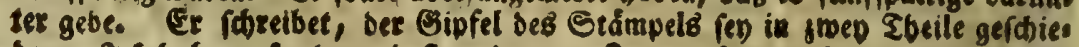
ben. Iक babe gefunben, bab et in oren 3unaen fin ausbreife, wetche aus?

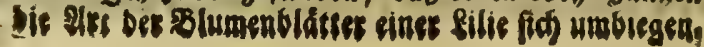


fenfchaft anjubringen borhat, wenn ber gute (3)efd)mad nid)t beharret, feiner Eebrart bas 2luffonmen abjuiprechen. 2luf Den Zorwurf Diefes

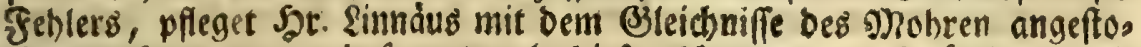
wen zu fonmen, unb fraget, ob biefer ldhwarse, grofinalichte uno plattnáfige 2Ifrifaner, eine andere 2irt bes Mienfchen fen, als ein (Euros päer. 2Allein burth) biefe eingebildete Spisfindigkeit yerrăth er nur einen anbern Grrtbum, ba er bie getúnftelten airten von ben naturtichen nidht

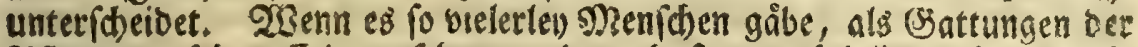
Pflangen auf ber Erbe gefehen werben, bap man folglit auf eine 216 .

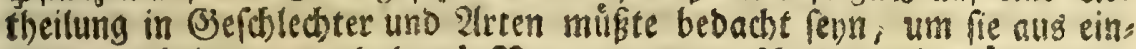
ander zu bringen, und burd) Namen zu unterídseiden, fo murben ber

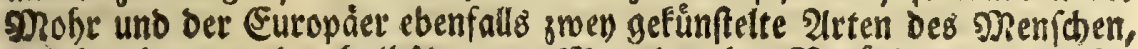

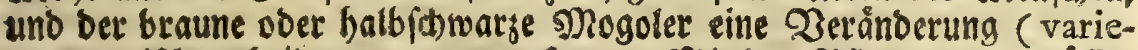

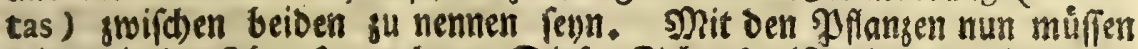
wir es in ber shat fo maden. Diefer Sd)webe ift mit aller feiner (Bes fóctefid) Eeit nicht im Stande (er fiebt es felbft wot ein) zu allen feinen

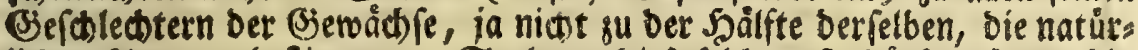
lichen 2irten zu beftimmen. So lange bieje fehlen (fie bórften feblen bis an baf (Enbe ber $23 e l t$ ) muk man fid) mit getúnftelten behelfen. Da er aber biefe abidaffet, uno jur (Erteid)terung des (Sedáchtriffes fein bes

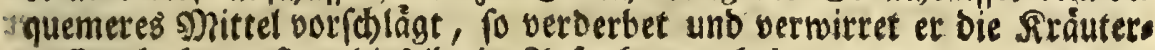
wiffenid)aft, anffatt biefelbe in 2 (ufnabme su bringen.

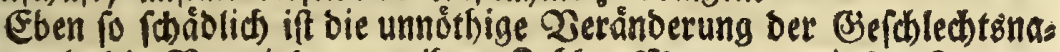
men, und bie Detminberung ibrer 3ahl. Man war mit ber ₹ournes

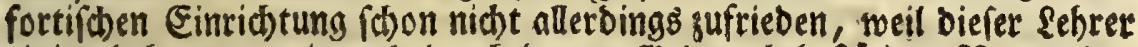
einige befannte, roie aud) ourd) tangen (Sebraud) beftátigte Pamen oer

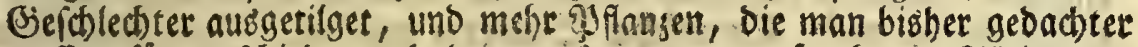
maffen fure entfobieben gebalten, jufammengetworfen bat. allein man

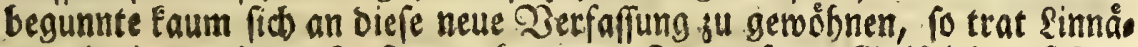
us mit einer andern Mlufterung hervor. - Fourneforts SBeifpiel verficter.

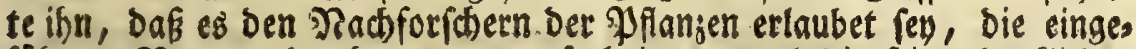
fübrten शamen abjutfun, neue aufjubringen, uno die feit undenflicben

$$
\text { (2) } 1) 2
$$

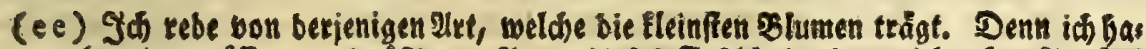

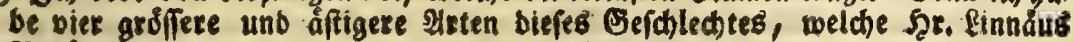

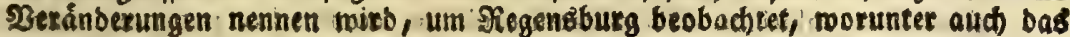

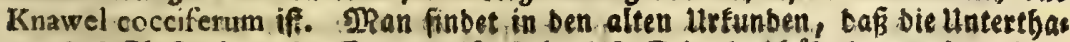

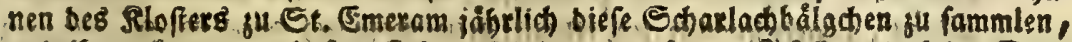

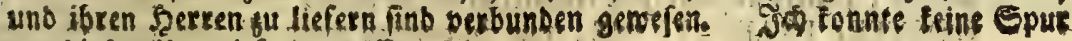
vor bieferm ungegiefer antreffen. 
Tafreen erfannte 2rten eines (अefdlectes, cinem andern juzutheiler. Diefe Frenbeit ermunterte if n, aud) ein foldes 25 erf zu unternehmen. Die \$ahn fano er Dazu gebrodien. Die áltern Sdrifteller, Den Theos phraft, 叉linius, u. a. zu gefch weigen, haben ibm unter den neuern Suns gius, Malpighius, Slud. Jac. Eamerarius, Der vortrefflidie Dr. Joh.

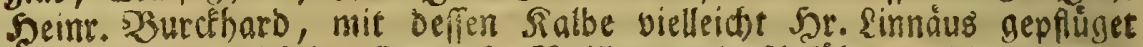

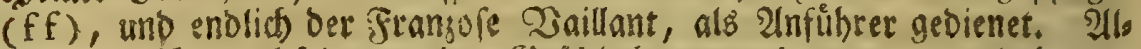
lein mit Derwed)felungen Def (jefdsled)ter macte ex es toeit bunter

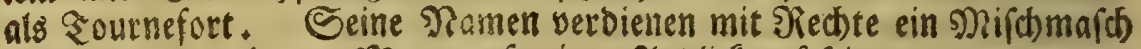
genennet ;u sorben. SRan werfe cinen 2Inblicé auf feine genera, PYRvs, TEVCRIVM, ORIGANYM, THYMYS, ANTIRRHINVM, ARTEMISIA, VICIA, uno nod) andere fimnåifthe Şúlfengeidled)ter, fo wirb man nidht ofne

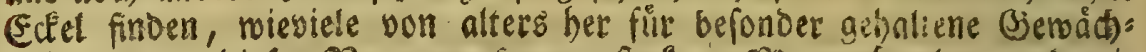
fe, er unter biejen Mamen fufammenftecte. Mlan gehe aber audt mit

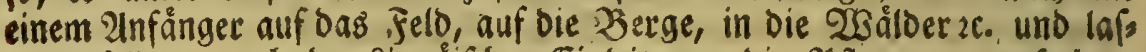

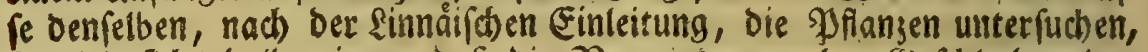

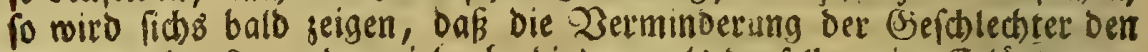
fortgang Der Rernenden vielmebr hindere, als Denfeliven eine Ertáuterung

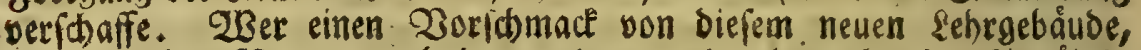
uno beffelben शasen, ju Saben verlanget, Der betrad)te Das \&innaiidje Be(wledt PYRVS. Der Zírnbaum, der 2lpfelbaum, uno bet Uuittenbaum (gg), find 21rten (fpecies) Des sinnáiichen PYRI. Der Apfelbaum ift ein simnaifcher pyrus. Der 2 uittenbaum if aud nod rein pyrus. 2Benn einer ist fagen follte, er habe auf Dem siartte. Zlepfel uno Zirnen gefehen, ber múrbe, nad der ginnåichen neus en sebre, eben fo feblerhaft reben, als wenn er vorbråd)te, er habe

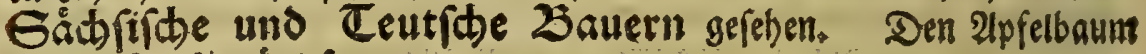
nennet Şr. 2innåus fo:

$$
\text { PTRVS folis jerratis, pomis baji concavis, Cliff. } 189 .
$$

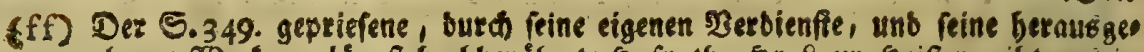

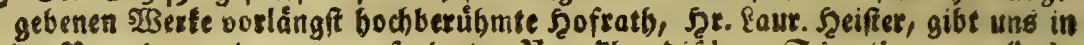

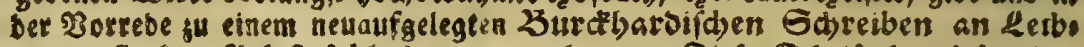
ntjen, farten 2lnlä folches gu argnobnen. Diefe Edjrift bat folgenben Sitel: Epiftola ad GODOFR. GLIL.LEHBNITIIM, qua charadterem plansarum naturalem nec a radicibus, nec ab aliis plantarum partibus minus effentialibus, pluribus difcriminandi capitibus conftitutis, peti poffe oftendit, fimulque in comparationem plantarum, quam partes earum genitales fuppeditant, paucis inquirit JO. HENR. BUIRCKHARD Med. Doctor: Cum LALIR. HEISTERI PRAEFATIONE; gua de origine methodi plantarum hwjusque in- 
Den reciten SBirnbaum folgenber Beftalt:

PYRVS foliis ferratis, pomis bafi productis, Cliff. 190.

Det Quittenbaum ift fein

PRRVS foliis integerrimis, ib.

Man hat in ben Sefterteidbiftien (Erblänern, und nod) in Babs

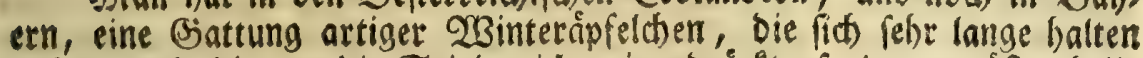
laffen, uno bie um bie Stiele nid)t eingeorlidêt, fondern groftentheils voll uno platt finb. Man beift fie in Deferreid Brinerlinge, gu Ses gensburg uno anderwårts Zrunercipfel 2c. 2Benn nun jeniano biefem Sebrer einen Sorb ooll folder Ilepfel sor bie Fuffe binfeste, ober wenn

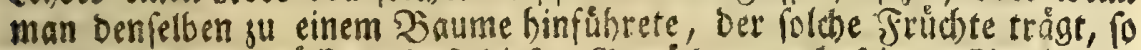

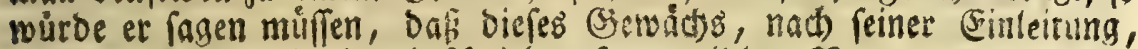
nod) unbefannt uno nidst bei(h)rieben fen, reil Der Name, PXRVS foliis ferratis, pomis bafi planis, in feiner כerfaffung nicht flehet. 2Hllein wurs. De er fid Dabei nicht ein wenig entfärben, in Betractung, Daß̧ ein Snabe ober ein Mangoden von fünf Gabren, biefe in gebacten sản,

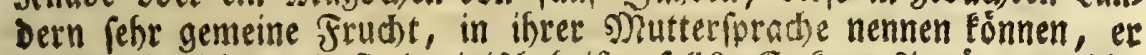
aber wiffe nicht, wie fie lateinifh heífen foll? Es Eann sinnåus aus bies fem Fallfricte, ben er fid felbft geftellet bat, auf folgende 2 art fidi) Eeis nesweges losimickeln, wenn et etwa lagte, Der Brunerling fen Eeine

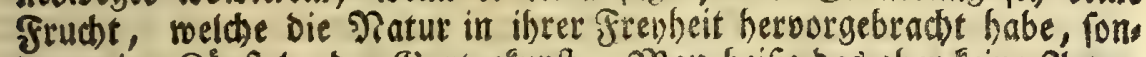

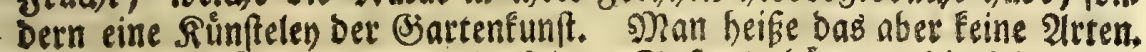
Es fenen Derånderungen, bie Eeinen Zeftand hătten, Die feine Zabl

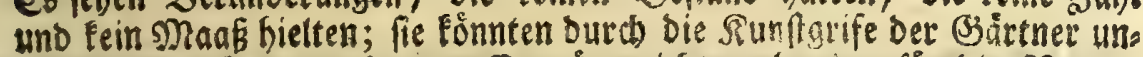
endich vermebret werben. Er wäre nicht verbunten für bie Namen

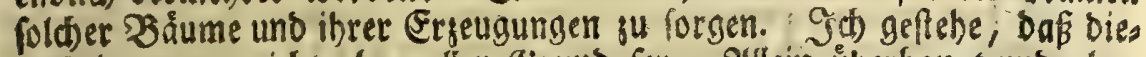
fe Erinnerung nid)t obne allen (srund fert. Aluein uberbaupt unb obne 3) 3 ในง

ventoribus, de methodis ipfis earumque veris auctoribus agit, et quod auctor bujus epiftola inventor fit metbodi Sexualis, oftendit \&c. Helmftadii MDCCL. 22 Bogen in Duartgroffe. Im LX. u. f. 2ubphn. ber Borrebe, rie aud

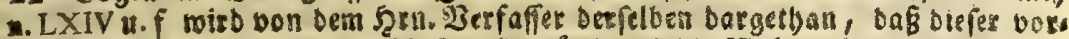

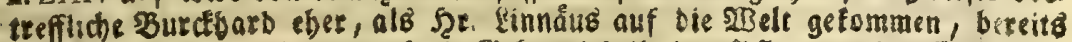

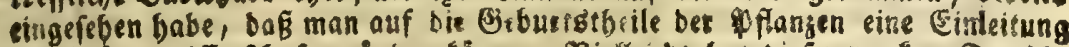

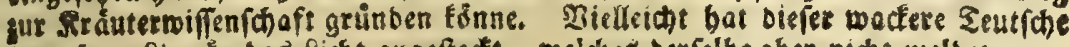

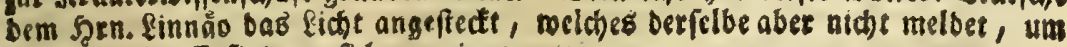
bie Egre bes Erfinoung fị juzueignen.

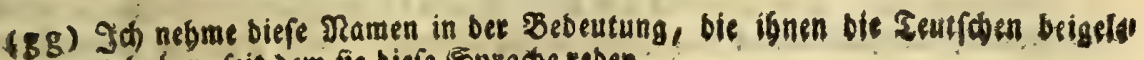
get baben, feit Dem fie biefe Spradie reben: 


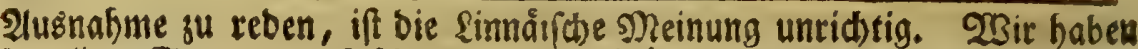

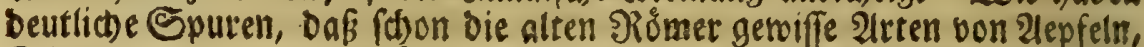
Birnen, und andern Srüdten, gefiabt, bie bis auf heurigen ₹ag nod unverånbert beftehen. Den in ₹eutfoland befonnten Porforfer, melo

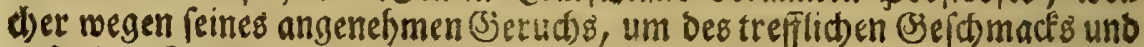
gefunden fleifthes willen, gepriefen roiro, ben (Corous unter biefem $\mathfrak{R}$ as

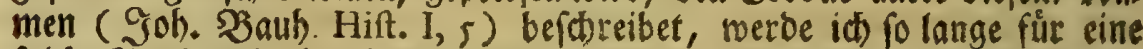

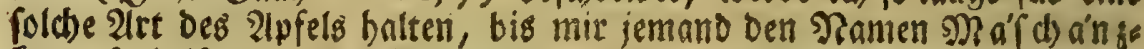
Eer (fo beifter in Defterreich) aus einer anbern, als ber lateinifosen

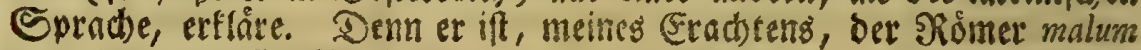
Scantianum, beffen \lunits, XV, 14 , gedenfet ( $h$ h). Datuach fann

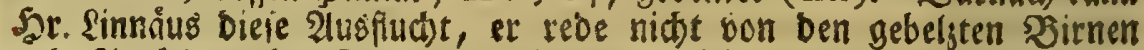
und Aepfeln, obne fich ju wiberfwrechen, feinebroeges ergreifen. Shat er benn nidbt felbft bas wejentlide Remmeidben ber swenten Art feines PYRI, ocn Dorfduuf um den Stengel, von Den Bsartenbirnen entiefnet? Die Solgbirnen baben feire forden bafes productas.

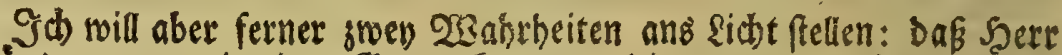
Sinnăus, wenn er in einen (3arten fonmet, Die swente 21 rt feines PYRI bon ber erften (b.i. bie eigentliden Zirrnen von ben 2lepfeliu) burch

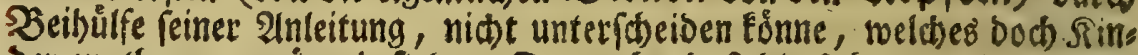
ber gu thun vermógend fino. Darnadi), oná bie \&efre von ben atrten feines PYRI widerfpredend fey. Den erften Sa erweife id fo. Es

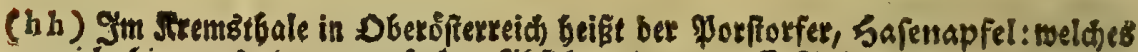

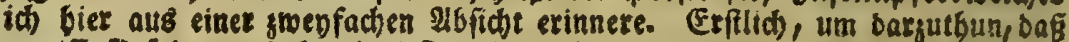

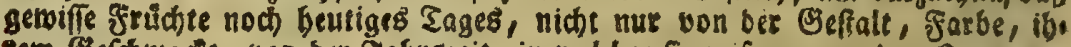

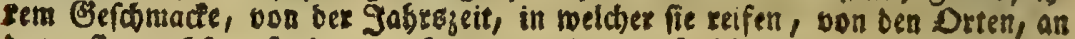

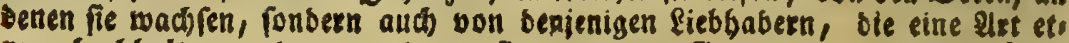
wan bochbalten, ober von benen fie aus einer Gegend in bie anbere tibess

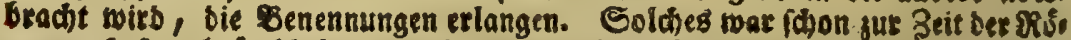

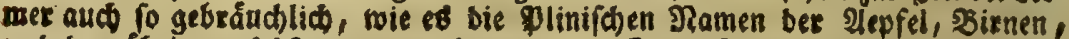

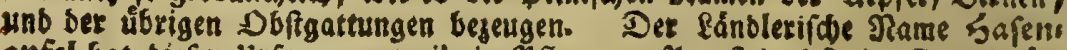

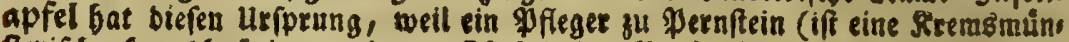

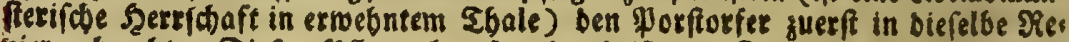
biet gebracht. Diefer Pfleger bat Saaś gebeiśen. Daraus aber fieffet Die

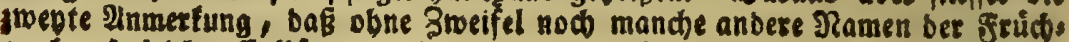
te eben fo leidte Ertlårungen baben werden, allein bie ist unerforfahlich finds, meil uns ber MRangel ber Eartenge(d)idt)e bie Edalúfiel zu beret Erófnung

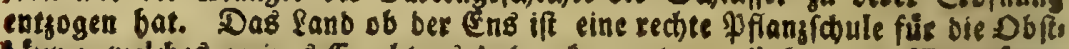

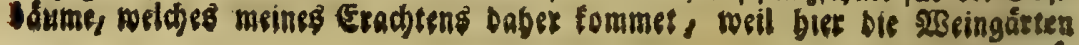


gibe in 28 åtbern eine siattung fleiner 5 delgbirnen, bie eine niebrige soer jufammengebructere Seftalt haben, weldies bie Eareiner mit fefilis

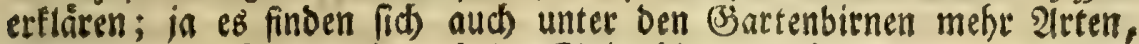
bie gegen ben Stiel nid)t auf eine Spise binauslaufen, fonbern auf bies fer Seite gans ftumpf, und nod Dargu mit einer (jrube verjefen find.

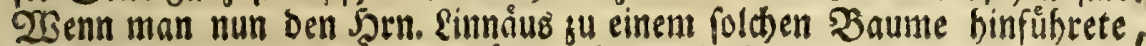
und benfelben erfuct)te, et mód)te ibn nach feiner Einleitung nennen,

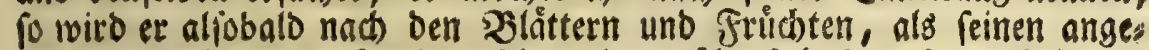
nommenen Scauptmerfmalen, fehen, barauf berfelbe ben unteríbeio der

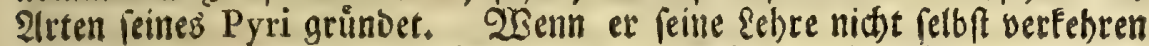
will, to wiro et nach eingeholtem slugenifieine, und befundener biefer

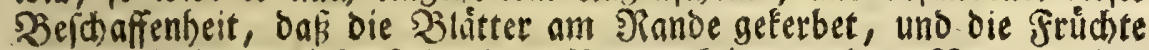
um oen Stier bertiefet fino, Dem SBaume feinen anbern गanten geben fónnen, alo folgenden, PrRVS pomis baji concavis. Das ift aber feille

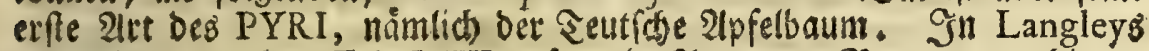
POMONA werden Tab. LXII u. f. mehr $\mathfrak{A r t e n}$ von 2 bergamottenbirnen vorgeftellet, bie alle nad) Des șrn. Simäus \&efre 2 epfel find. Die ges meine Sergamotte (common Bergamot) Tab. LXV, ift ein ausges

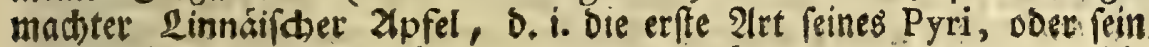
erftgedadtet P $R R V S$ folits ferratis, pomis bafi concavis: nooraus bie.

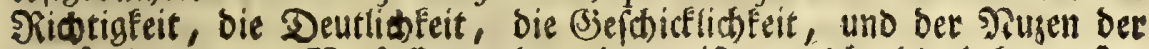
sinnairiten neuen Derfafiung abjunebinen ift, welche bie betannteften.

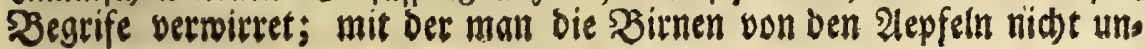

teto

auffören, unb biefes bas exfe Bierlanb ift, wenn man aus Unterffertech nach

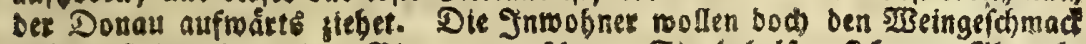

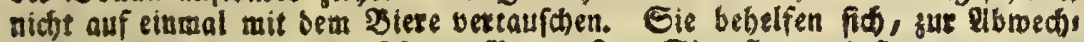
felung, farf mit bem \&epfels uno Bitnmofte. Sie pflangen befigegen eine uns berdretblid)e Dienge Doftbiume, benen ber feuchte Zooen, uno bie fühle

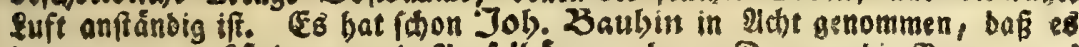
in ben marmen Ränbern wenig Elepfelbaurme gebe. Da nun bie Raatern auss

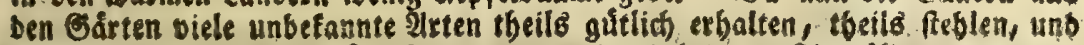
ben auf Die leste $2 B e i f e$ úterfommenen (wie es bei ben finbelfinbern gefties bet) nicht wiffen bie rechten Ramen zu geben, fo beisen fie ibre

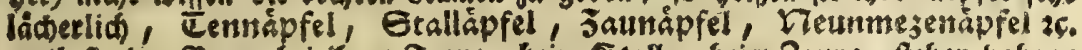
weil fie ben Daum bei ibeet Tenne, beim Stalle, beim 3aune, fteben baben; - Der weil Dex Baum einmal 9 sRejen fritide getragen bat. 3weige andern mittheilen, fo verbielfáttigen fie bergeftalt biefe feltfamen $\Re_{a}$

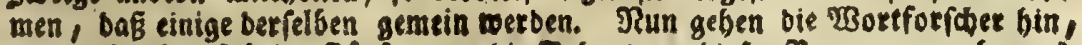

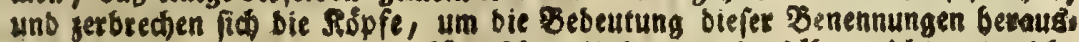

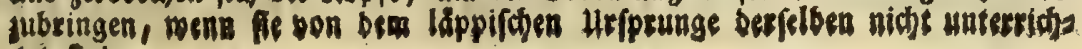
sit sibs. 


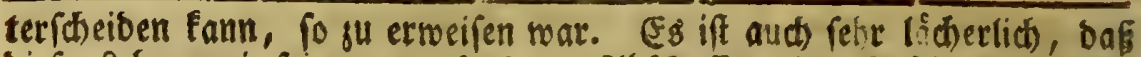
biejer sehrer mit feiner neuerfunbenen 16 fd affung ber (Stefdeledter, MALVS uno CYDONIA, fid nod) grofi madjt, als roenn er ber ganzen menfdhliden (Semeinbe baburds einen Dienft ertwiefen bätte, ba er einen fo lange gehegten uno nicht rahrgenommenen Jrrthum entoecter. Mi-

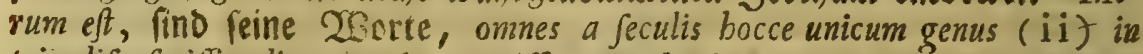
tria difpefcuifje, licet omnium notiffimum, Species vocantes genera, et varietates species, GEN. PLANT. 481. Allein biefe Anmerfung verbies net allerbings auf folgende 2irt umgetelyret su werben: Ridiculum eft. Linnaum in componendis generibus, qua omnes a feculis bomines difpefcuerunt, adeo ineptire, ut ipfe deinde Species corum a se conftitutas diftinguere nequeat, cacutiatque oculatifimus in rebus difcernendis, quas ancillule puerique nullo negotio, fola ope fanorum fenfuum, valeant internofcere.

Der 2 siberiprudt) feiner \{efre bon ben Zepfein, Zirnen unb Quito

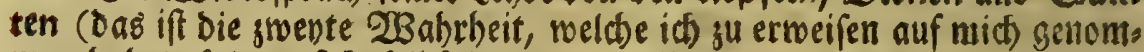
men babe) folgert fich felbft baraus, weil ex nur eine Ant feines s well: ten PYRI erfentet. (Er berufet fid bieffalls vergeblid) auf Raji Zeug.

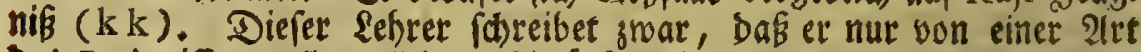
bes Pyri wiffen wolle; allein er fabrănket feinen Pyrum nidbt fo enge ein,

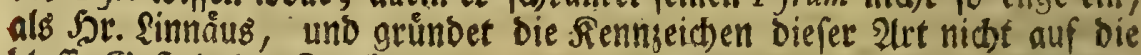
bloffe Beftalt ber frudte. Raji Pyrus ifte eine fpecies naturalis; Linnæi II Pyrus, eine fpecies impoffibilis. Raji Pyrus ift ein $\mathfrak{B a u m , ~ D e r ~}$

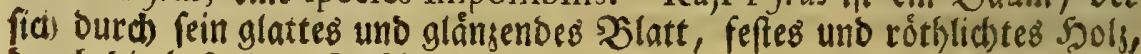

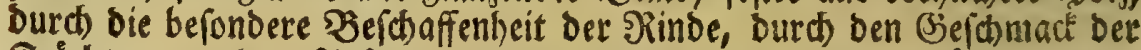
Frúchte, bon bem 2lpfelbaume fowol, als yon andern Gewád) fen unter. ideibet. Fur yon Dem (sefdimade feiner Frud)t zu reben, fo if Ders felbe to fonberbar, bas mittelft beffelben allein, ein Slinber, ober ein

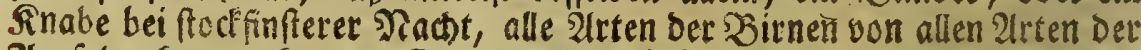
2lepfel erfennen Eam. Der Befdmade ift alfo bei Der Şirne Dasjenis

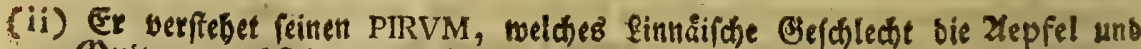
Ouitten, nebit ben eigentlión fogenannten 3 irtren, begreift. Ee neunbert

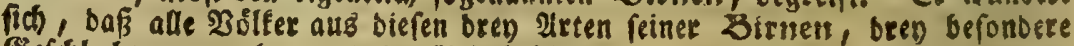

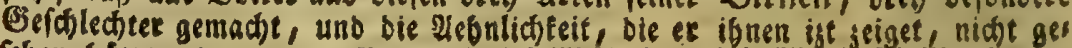
reben bätten.

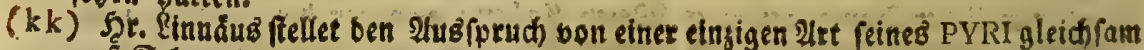
auf Edreauben, Da er fo foreibet: LIt Mali, ita et Pyri unam duntaxat fpe-

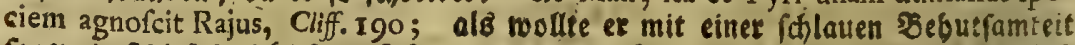

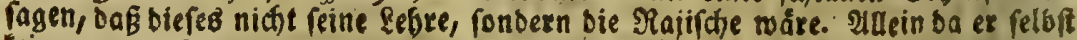
teine andere 21 rt von feinem zmenten PYRO anfübret, fo gibe er baburch beut

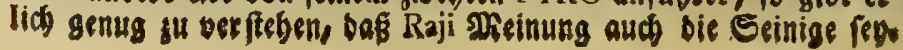




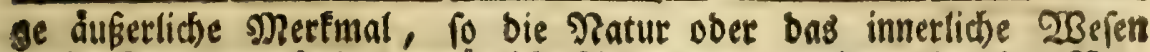

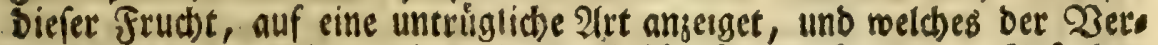
vechfelung Derfélben mit andern (jeffolechtern fteuret. 2tuf Den

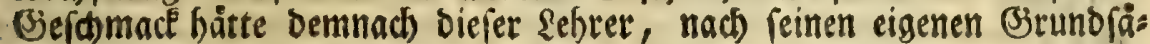
sen, weldse bie 2luffubung und Benenmung ber leidteften, wie auci) ges wiffeften Siegel ber Yyflanien anbefehlen, ben wefentlichen Unteritheib feines II Pyri grunden follen*. Die Bieftalt thut bier ben berlangten Dienft nic)t. Der (3efd)mace ftellet mit benúbrigen borerwefhnten Fenms

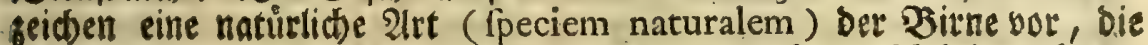
fid) in bundert uno mebr gefunftelte Arten (fpecies artificiales) fernet

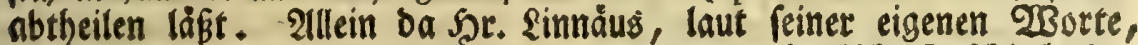

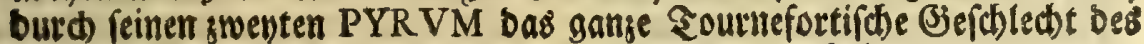
Pyri verftehet, Deffen einige 2Arten um bie Stiele erfaben, andere auss geboblet fino, fo mus biefes neueften \&ebrers blóf auf bie Bieftalt bet frudbt gegrundete jwente PYRI SPECIES VNICA, um ben Gtiel er:

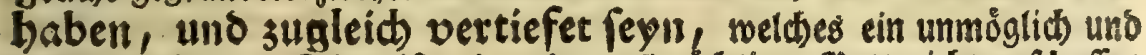

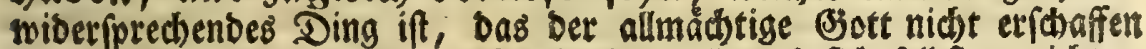
cann. Eine foldbe 2 inleitung ift alfo eine tolle und fich felbft berniditents

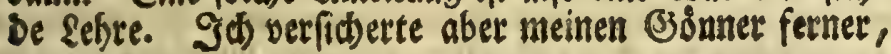

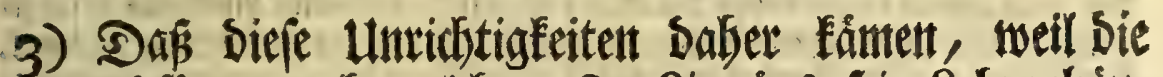

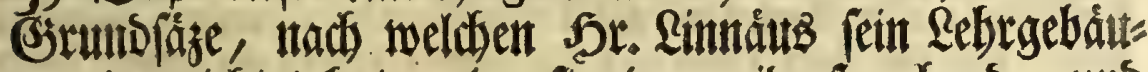
be eingeridjtet bat, eigeninuig, wiberipredsens, tmo nidht nad Dem beften Beschntadfe abgefapt

\section{waitent.}

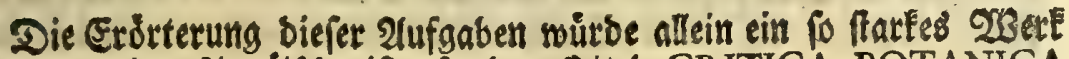
geben, alB bab simmáifhe ift, fo ben sitel CRITICA BOTANICA 38 füls

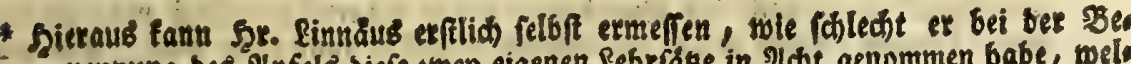
nennung bes 2 ip fels diefe zwen eigenet Rebrfäse in 2 iat genommen babe, wels de gletch auf einanber folgen: Nomen fpecificum plantam ab omnibus congeneribus diftinguat, Fund. Bot. 257, benn Det Rame feines Iipfels tann aud eil nigen Mrten bet Birnen, mit Beftanbe ber 230 abebeit, gugeeignet mexben. gerner: Nomen fpecificum primo intuitu plantam fuam manifeftabit, cum differentiam ipfi planta infcriptam contineat, Fuxd. Bot. 258. So trăftig ift aber det

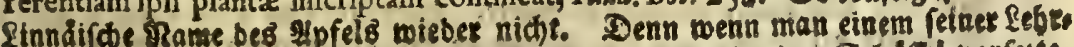

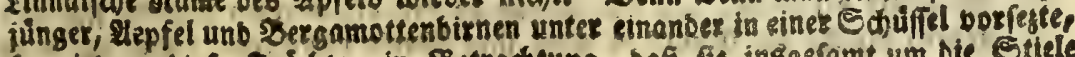

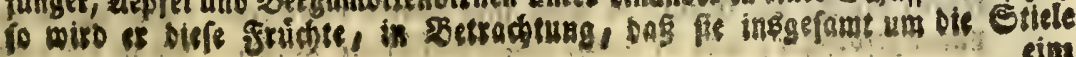




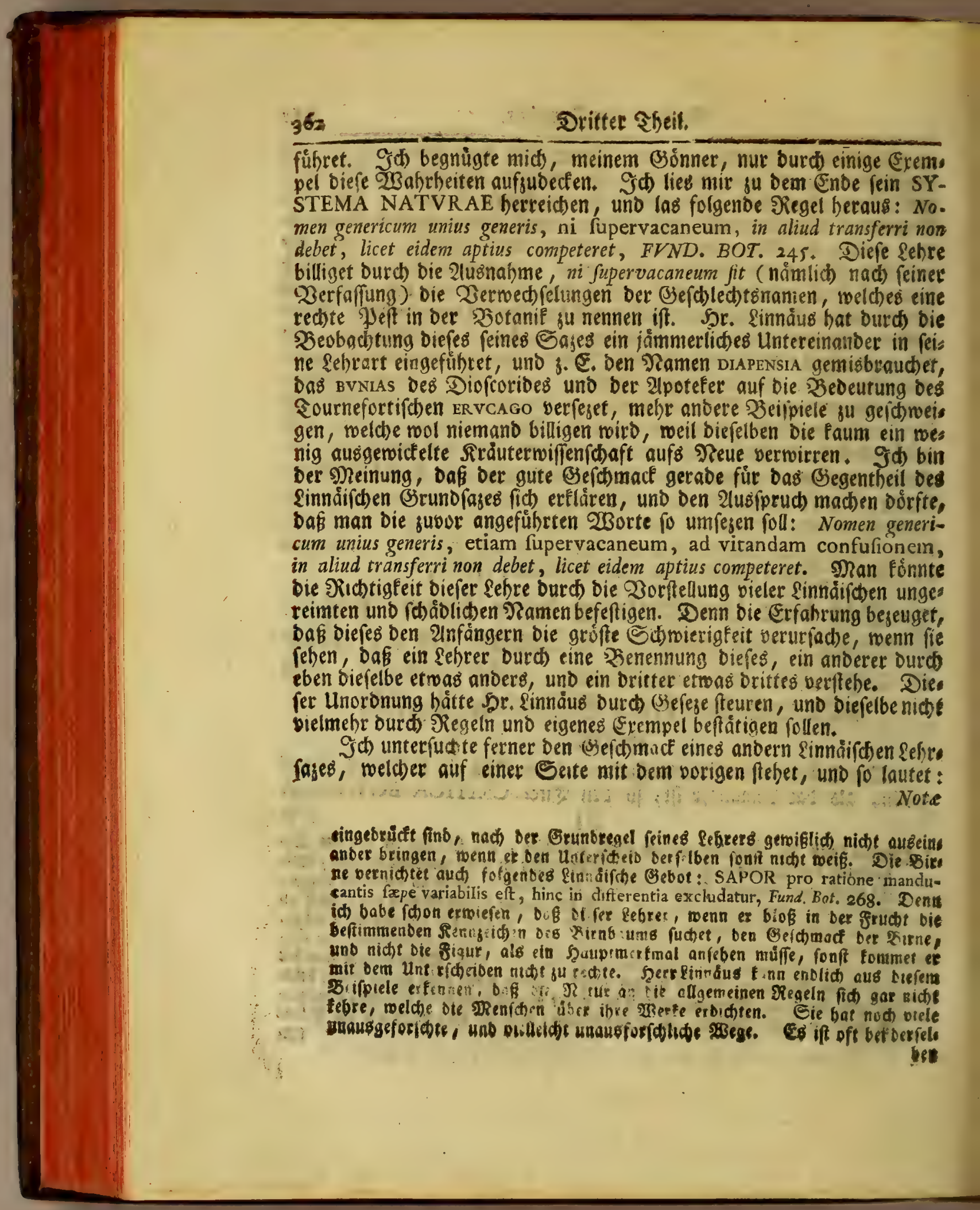


Note collatitie cum aliis speciebus diverji generis falfe junt, FVXD. BOT. 261. Saburch gebietet er, Daß man bei ber Wenennung ener Pfanje'

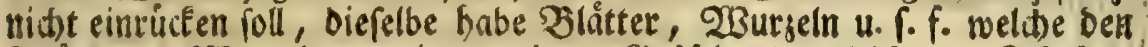
Silåtern, 2Burgeln $2 c$. eines andern Seidjlestes gleiden. Sol fags: te erfflid, Şr. Sinnaus múffe biefon Sprud) nidst wiffen, omnis fimilitudo claudicat; uno gleichwol bedienen fich alle szenchen bet (Gileid).

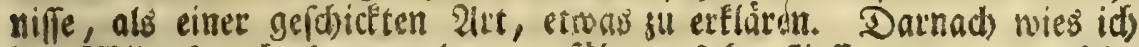
ben 2Biderforud), Der aus ber engefubrten sefre fleffer, wenn man bies felbe gegen folgendes Rinnåtfoe (Sebot bălt: Similitudo omnis, in nomine Specifico ujurpata, dextra manu notion erit, licet et bac minus placet, FVND. BOT. 299. Durd Dicfe 2 Borte oultet Sar. Sinnáus fum wentigften bie 23ergleichungen, Die er in ber zuoor angezogenen Siegel fur feblerbaft angibt. Er bultet alfo Strthumer. Deun man mơge bie gyflange verglet hen, mit was man wolle, fo ift baffelbe, nomit fie vergliden mitb, boch

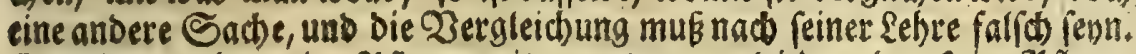
Srlaubet er aber, eine Jflanse mit etwas zu vergleiben, Das feme Jflange ift, warum niởt aud mit einer anbern 引flange? Sann ein Bewåds cis nem anbern nicht fo dibulich, ia nod difnlidber fenn, als ber Sano bed Drenichen, ober einem anbern eben fo befannten Dinge? Sक berief mich enblich auf bie Erfabrung, um aus Detfelben barzuthun, Dap bet 26 I

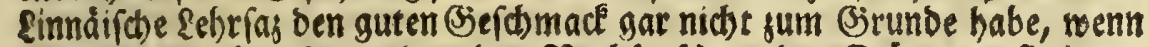
er benfelben ofne susnabme ben शad) forfdern ber Reăuter auforingen

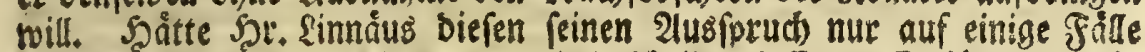
geridjtet, fo fonnten roir uns bamit beforben laffen. Es ift o. E. nid)t redt, wenn man eine befanntere Jilanje mit einet nicht fo befannten, ober weniger gemeinen, bergleidet. Diefen Febler bat Der sourmefors tifche হame bet Sanne, Abies taxi folio, Inft. 585 ; tweil bie Sanne it ben neiften falten Eánoern gemeinet ift, als die sibe (ll). Unges

$$
\text { B: } 2
$$

reint

ben etwas mefentlid, wie bei ber Birne bet Befdhmacf, mas bie gRenjohen

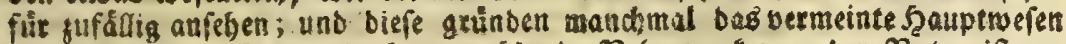

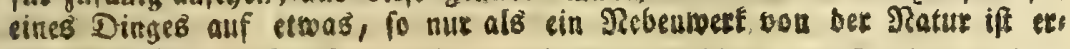
geuget worben.

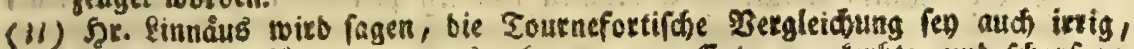
neil bie Eibe lăngere, etwas gebogene, am Enbe ungeferbite, und fijarf fus gefpig̨te Sangeln babc. Diefe wåren untenber gelbgkủn, obenber bunétgrun, unb ouf biefer Seite mit einer keifte berfeben, welohe Diefelben mitten burdos:

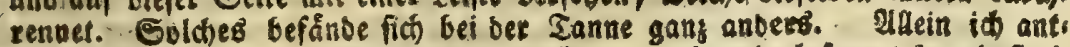

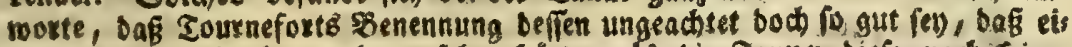

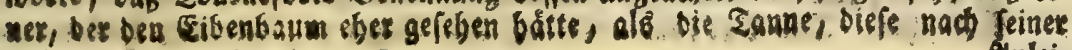




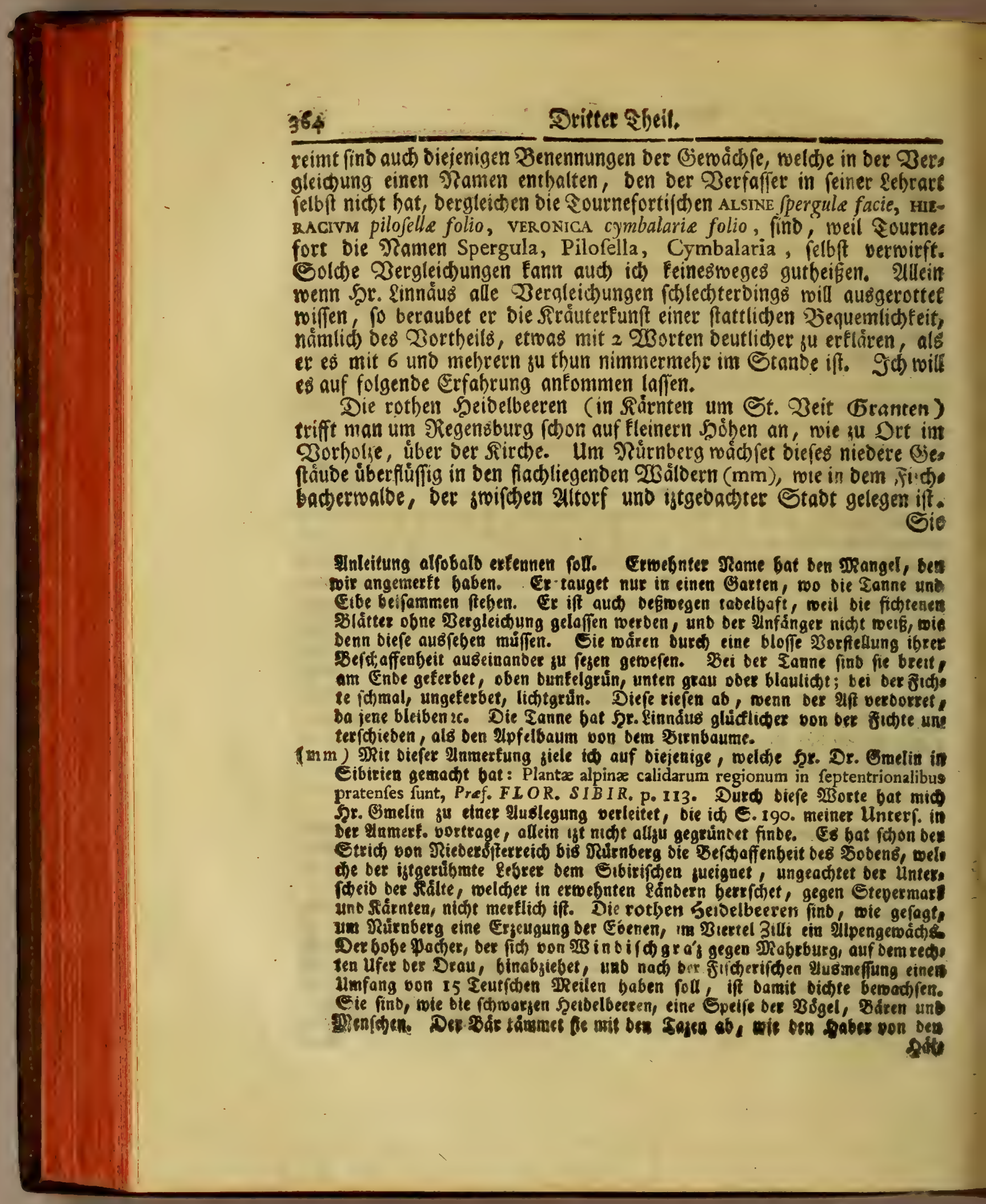


Sie werben in biefer Siegeno, wegen ibrer Wirtung, Greinbeere ges nennet, wie aud) zur Speife forool als gur arzney vertauft, wie in Sárn.

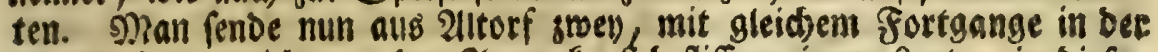
Sotanif unterridtete, ber Argnenfunft befliffene junge seute, in biefon 2Ralo, uno trage benjelben auf, fie follen einen Zneig bon bent (Ses. wád) folen, weldes man ihnen nennen wirb. Man fotreibe aber bent einen oiefe \&innåif b) Benennung, vaccnNvM foliis perennantibus obverfe ovatis Clift. I 48 , Dem andern folgende, vaccinsvi folit buxi, femper virens, baccis rubris Rupp. 39, auf einen Bettel. So will metten, baf bet lejtere mit feinesn s) nur Diefe Worte, foliis obverfe ovatis, wirb verftanden baben, wold), wie nod) bunbert andere sinnäifhe 2 Börter und feltfame Sprúche, git oerfeben, ein befonbers $23{ }^{\circ}$ rterbud, uno eine neue lateinifo Spradj: lebre erwartet wirb. Eine gleid)e \$efdaffenheit bat es mit feinem Chaerophyllvm foliis lanceolato - ovatis ferratis Cliff. $\mathrm{IO2}^{2}$, weld)es

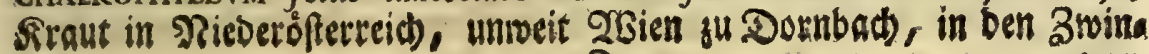
3: 3

getil

Salmen, wie ber Bauter bem flach/e bie Samentolten mit bent siffel abi nimme. Det exfte CRA T AE GVS Linn. Cliff. 187, if in gebachtem tleinem

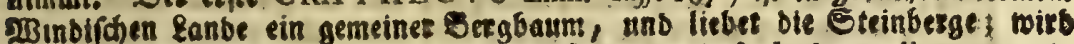
bon einigen T̈talienern, wegen bet. Sárte feineB Solzes metallo genannt.

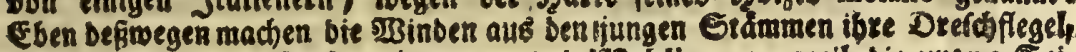
ben Saum aber beifín fie mókowna, b.i. Meblbaum, meil bie umtere Seis

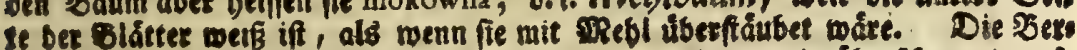
ge, auf benen folde ssálber feben, feben von ferne mie úberfobuepet aub. get bet exten \&ugigabe bex Floræ Jenenfis befinbet fid oon biefem Baume noch feine Ermebnung. In ber zwenten wiro ex S. rog. unter bem Ramen, CRATAEGVS alpinus (e\& foll alpina beinen) alni folio incano, ooxgeftellt,

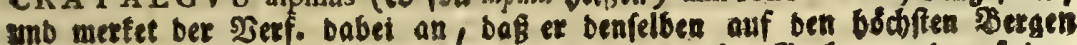
(montibus altiffimis) als auf bem Rnfelsberge bei Sotba, uno auf bem Chüringerwalbe, angetroffen babe. Iin SRiebersferteich begniget fid biefer Doum mit ntebrigern Stugeln, wie in ben SBalbern binter KaDaun. Im fanbe ob bet Gas febet of bet Girninghofen nach Dera feinidien ufer bex Btepes. 3u Drt bei Segeneburg auf teine bobern Rage, am 23 ege, wenn

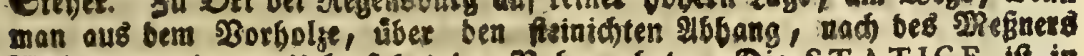
Sobohnang unb fur Ueberfabrt Dat Nabe gefet. Die ST A TICE if in

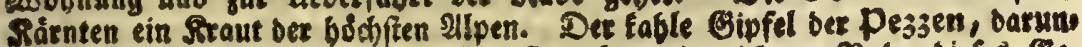
tet Blenburg liegt, ift an mandhen Strecfen mit bidbem Rafen biefes Ges máchies, wie an anbern mit bem Sournefortifiben IIVA VRS1, mit bem DRY A S Linn \&ce. gebect. Im Rúrnberg babe in oie Sratice juerfit in ben Cbenen gereben. Es ftebet biefelbe băufig um bie Stabt berum an ben 2 Beget,

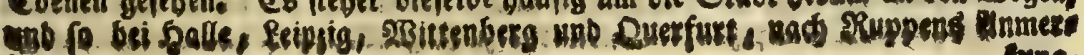
bust. 
gern und Båcten, unter ben Dbfbåumen, in leberfluffe angetroffen wirb. Diefer Rinnáifbe Rame if ein Dunfler uno matter 2lusbtucf; folgen ber, MYRRers podagrarie folio. Riv. iff furger uno fo lebbaft, Dab einer,

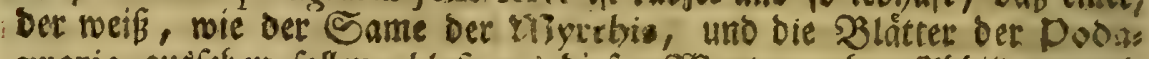
araris ausfejsen follen, blob aus biefen 230 rten, obne 2 bbiloung uns

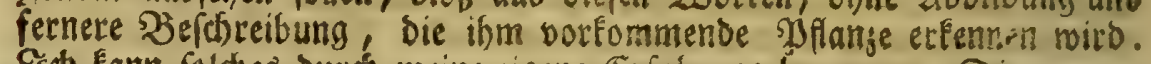
Sob Eann foldses burd meine eigene Erfabrung beteugen. Die vrticia maxima, racemofa, Canadenfis Inft. R. H. 535 , weld)e id in bes Sarn. Sofraths Trew (barcen bas erftemal gefeben babe, toire viel fürer un Seutlid)er abgefdilbert, wenn man fie VRTICAM viburni folio nennete, als menn fie, vRTICA folits cordato-ovatis amentis ramofis difticbis eredis Cliff. 440 , beift. Meine SEenennung ift nad) Diefem \&efrifaje Des Srn. \&ınnọus, Nomen specificum, quo brevius eft, eo etiam melius (FVND. вот. 291) abgefafit, feine niфt. Darnad babe ich zu 2Bien untef Dem Eubenifich Sarten bei St. Mark, auf einem ungebauten-2lcer,

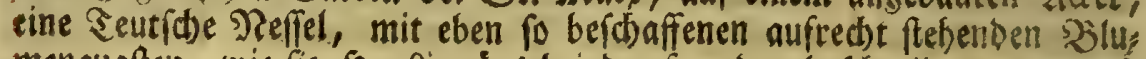
menquaften, wie fie Sor. \&innåus bei ber fremben befdreibet, angetrof:

fen;

fung, Fl. Jen. 76. Die Beobachtungen, wie bie Ståuter buth bie Lånbet zieben, redone id unter bie gxoffen Innebmlid)feiten meiner Reifen. Defter.

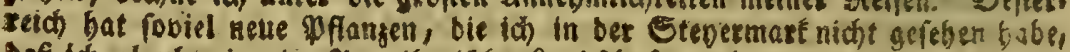
Dafi ich glaubte in cine Imerifaniōje Land (d)aft gu fommen, als ith oufen

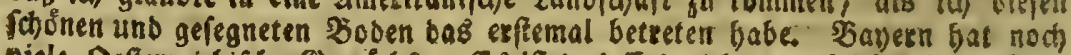

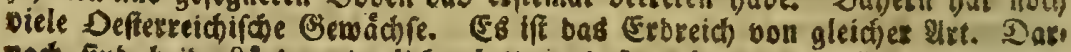
nad, fino beibe \&anber ziemlid) platt, unb fo gelegen, bas fie bon einerle

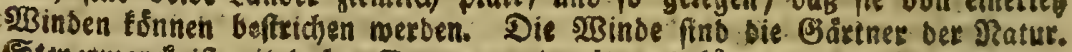
Stegetmarct ift mit boben 5 ergen umfingelt, uno fornten bemnach bie Defte? reidhlichen Samen niche binein getragen werden. Da\& \$etauerfels bat oftwerts

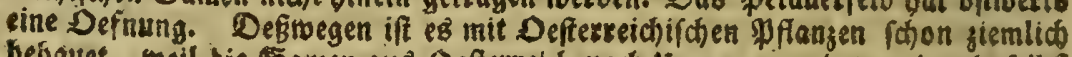
bebauet, toeil bie Samen aus Defterteth nach ungarn, uno von ben bafelbfi

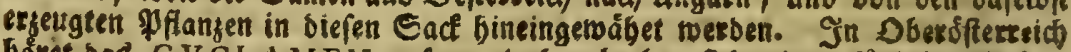
boret bas C Y CLAMEN auf, uns beurlaubet fid mit unfäglidem Heberı fluffe. Un Regensourg unb weitet nach Docben bin wähfet teines mebr, sie ith aub ben. Floris erfebe. Die B̈egend unt Regensburg bat nod eine

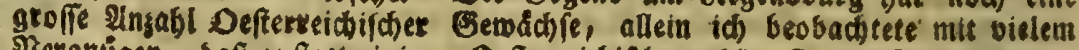

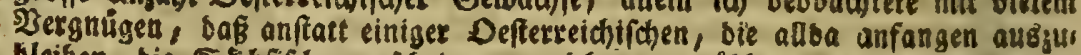

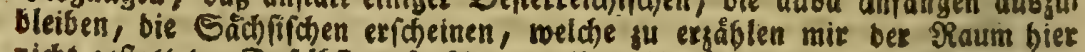
nidbt geftattet. Dafelbft mus alfo eine fleine Desanderung bes Exbretchs unb ber fuft bor fich geben. Das PEVCEDANVM zeiget fic bereits unter

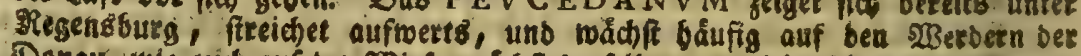

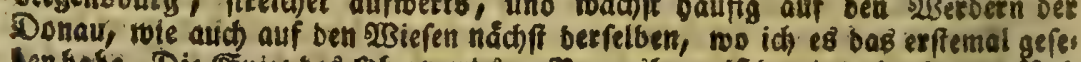

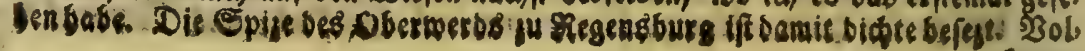

damiet 


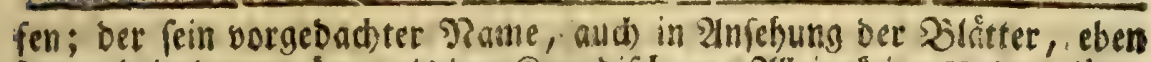
fo gut beisulegen warre, als ber Ranabifdsen. Sillein feine Vrtica viburt

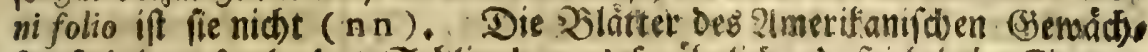
fes find bem \&aube bes Sdlingbaums fo shintich, bas ich teim Eingam ge in Den (Sarten, ben Şrn. Shofr. bei nahe gefraget bătte, wor; burnum in Dem (Bjartentopfe ergogen werbe? ob Keines un गairnberg mad)fe? Denn id fah, Daßs gleid gegeniber audh bie Cerinthe in eis nem fold)en Befâffe ftund, bie um saturnberg nid)t gefunben wirb, in Defterreid aber, in ber Stenermart 2c. ein allgemeines . Rraut iff (Ed

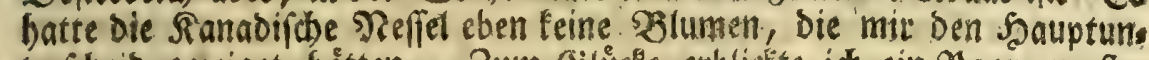

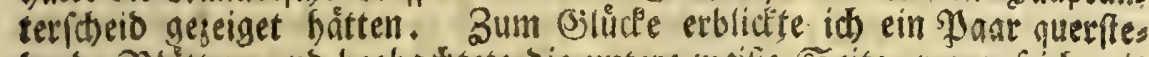
benbe 23 tătter, und beobact)tete die untere weige Seife, worauf ict) mit Der Anfrage yom Viburno jurúcéfbielt.

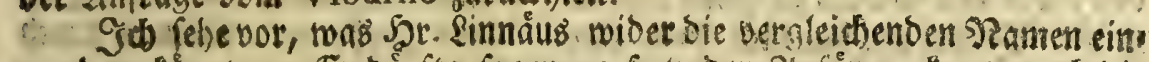
menben foonnte. Er oórfte fagen: gefegt, Der sinfanger fenne nod bie Surblåtter, Den (Seisfü (podagrariam) unb den Sdlingbaum nidt,

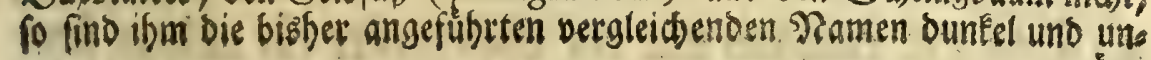

nùge.

damet batte alio nåbere Bsebuttellen biefer Pfange fonon aus Clufi Hif. CXCVI angelgen fornen. Wo ber Sanbooben eiter unfarg nimint, bet fich

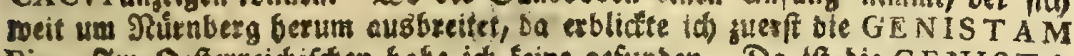
Riv. Im Defterreidifdoen babe id feine gefuaben. Da tf bie GENIS T A humilior, Pannonica In,$R_{0} H_{0} 643$, fér gemein. Uuf bem Tegelbarge bel Diegeneburg febet fie not băifig. Soldtamet bat fit unter ben Sartenges

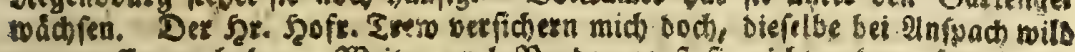

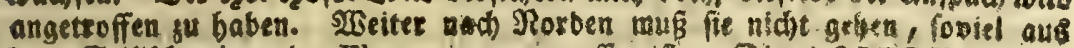
bem Etiafomeigen bet Florarum ju exmeffen iff. Die ASPER V GO be Heibet bie MBienerifchen und Regentbutgthon Etostmeuen. Die SHERARDIA Dillen. flattert von ben felbern um Slegenskurg fo gar in bic Etakt fist,

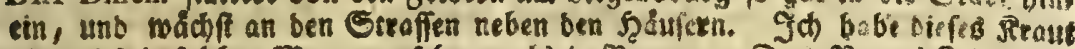
nizgends in foldjer Menge gefoben, als in Bapern. Das Piettel Billi beges

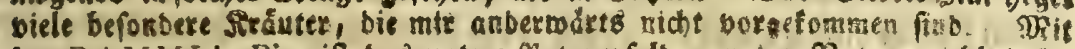

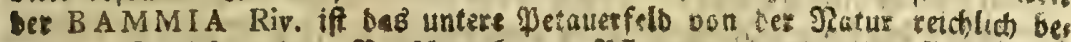

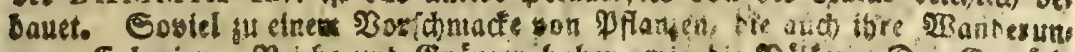

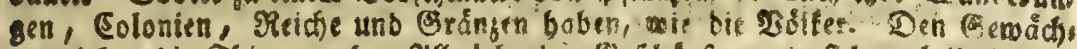

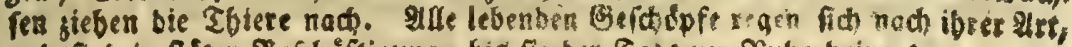

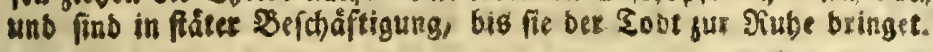

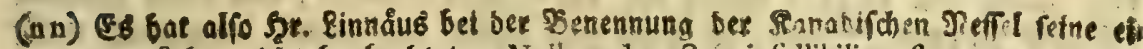
gene Regre nidit beobadtet: Nullus character infallibilis eft, antequam fecundum amnes fuas fpecies diretus, FVND BOT 193. E ein sfume fereitet auch miter biefen eigenen (stunefag: Nomen fpecificus plantam ab omnibus cpngeneribus diftinguat FVND. BOT. $25 \%$ 


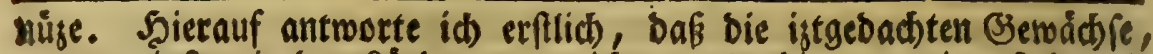
gum roenigften in ben sảnbern, too id) geweren bin, gemeiner finb, als bie andern, bie mit ifnen vergfitben werben. Der sur ftebet in allen,

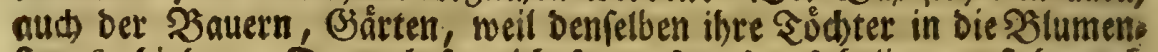
freaufe binben. Darnach fage id) 10: gefest, ver fefrling verftehe nocb fein Eatein, fo must bu ibm entweber eine Teutfhe Einleitung vorlen gen, ober er muß vorher bas \&atem, und fobann bie Fråuterfunft let. nen. Ulm fo oortrefflid)er 2(usbrúcke mat)t verluftig zu werben, als bie

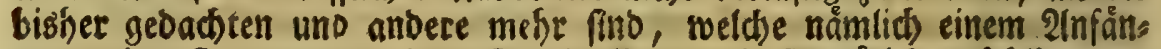

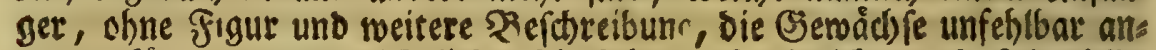
zeigen fónnen, wollte id lieber bie \{efrart fo einridjten, Daß berfelbe biejenigen 引flangen, mit benen eine Dergleidung foll angebradbt wer, Den, vor ben andern zu fefen befåme, weldbe verglid)en werben. Das

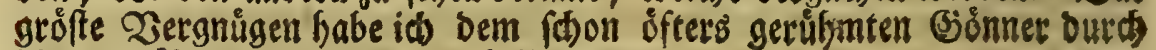
bie Sewågrung folgendes Urtheils gemadt:

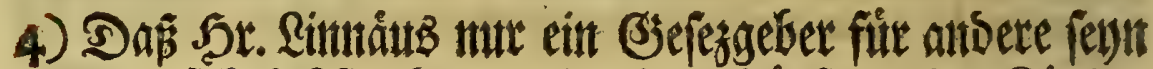

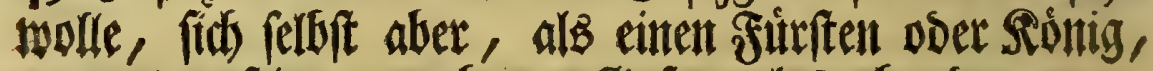 bon feinen gegebenent Gejegen losgebundent aditite.}

Soldes fonnte iđ nod aus dem SYSTEMATE NATVRAE bato thun, Darinnen feine FVNDAMENTA BOTANica ftefen. Er fagt f. E. «) Nomina generica, que ex graca vel latina lingua radicem non babent, rejicienda funt, FVND. Bот. 229. Das ift erftlic) ein eigenfinniger (B̈runos

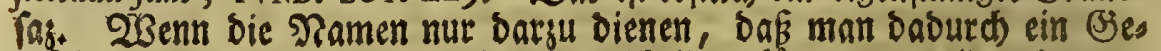

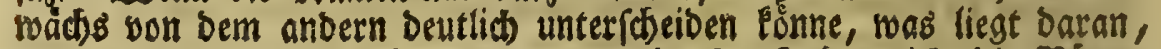
aus weldoer Spradbe fie entlebnet werben? Shaben nicht bie Srónter felbft, wie aus bem Plinio su erfeben, barbarifhe Namen ber yllanzen

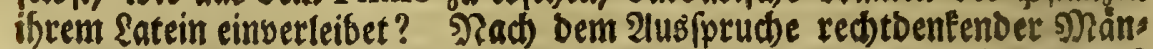
ner follen bie botanifóten গa amen vornemtlid biefe ßebingung baben, Dafs fie nid)t fo wiberlid lauten, als bie Eimnaifden befaltenen ober neuers ridteten, JVNGERMANNIA, SCHEVCHZERIA, SIEGESBECKIA, TILLANDSIA, $u_{*} a_{*}$ bie et felbft burds bie erftangerogene Bstunbregel verwirft. 20 enn et

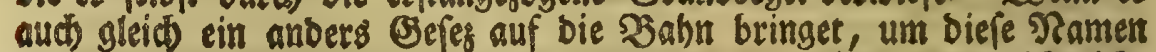

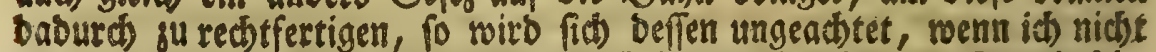

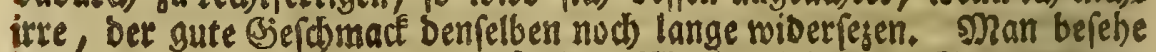

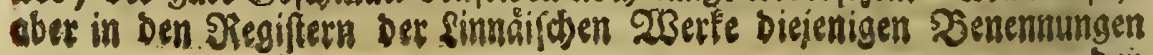


Der Yflangen, welce biefer \$nann zuerft aufgebract ober angenommen bat, fo werben nod einige anbere barunter vorfommen, bie nidht bon

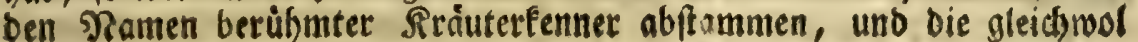
meder aus ber lateinifden Epracbe, noch aus Der (Striechifinen gebor, get worben. $\beta$ ) Nomina generica fimili fono exeuntia, anfam prehent confujionis, FVND. BoT. 228. (Er bat aber Dod BVNIAS und BVNIVM, unter ben. Zojgeln OTIS und OTVS, PICA und PICVS. y) Nomina generica Adjectiva, subftantivis pejora funt, FVND. вот. 235 . Daburd tabeit er bie शamen, welche butd) WSeglaffung eines barju gehörigen Sauptnamens, aus Secmortern ju Sauptwoirtern gemacht weroen. Sirio nber, Imperatoria, Parietaria, Pulmonaria, Pedi-

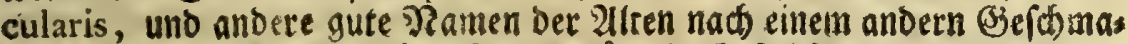
de gebilbet? Darnach) bat $5 r$. Emnáus Dod) felbft die (Sejchledtsna. men, GLORIOSA, IMPATIENS, MIRABILIS, unter ben Dógelt CANARIA. Sein ERYTHRONIVM, SANTONICVM, fino aud (o befchaffen, tweil bei bem erften fatyrium, bei bem grwenten abfynchium, oarunter verfanoen miro. Seine BADIANIFERA, ELEMIFERA, INDIGOFERA, PERVIFERA, TOLVIFERA (ber im voriger Gahre berausgegebenen Materie Medice [o o], Dacaus aud bas Santonicum ift) muffen naw (einer eigenen sebre fur folechte शramen gebals ten roerben.

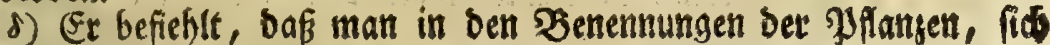
reiner ?lusorúcfe bebienen foll: Termini puri elegendi, FVND. BOT. 200.

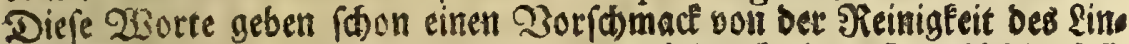

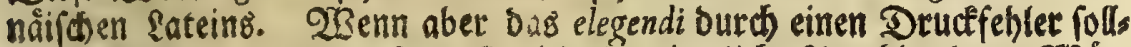

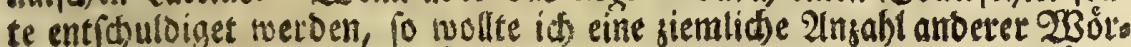

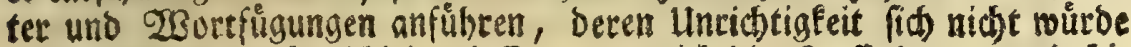

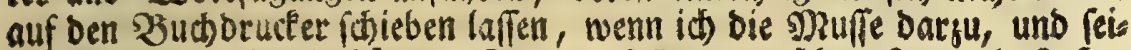

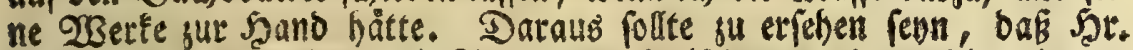
sinnóus fich fo wenig an bie Jegein Des Yrifians, als an feine eigenen binbe. Der 2 orteag folgendes sebrfajes ift aud noc) ein silfet von Rinnåifdjen \&atein: Claffes et ordines nimis longæe vel plures, difficillimx funt, FVND. BOT. 207. Die (Gefeze bet \&ateinifden 2Bortfüs gung, beipen bas Beiwort mit bent nådften obet vornehmilten Şaupt: श्वित

morte

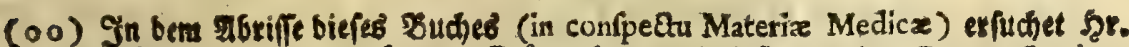
Sinnåus S. 4 bie auşwårtigen Rrâuterfznner, bafi fie von bem Dauco Cretico, befien Same in ben Ipoteten gebrautht nirb, gute 26bilbungen unb Defकesil

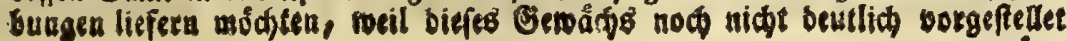




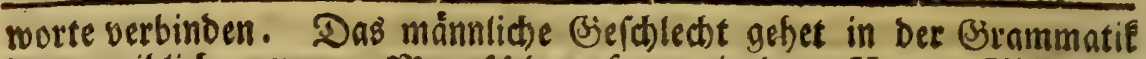
Dem weibliden vor. Man fiblage ferner in bem Horto Cliffortiano nad, uns beobad)te, wie oft Şr. \&innảus bei Den Benennungen Der. Planzen, weldbe nad) feimer eigenen 2trmeifung in auberleienen 2Bortern beftefen follen, Das terminatrix, als ein Beimort, außer bem meiblidben (Sefdlect)te, ofne alle Noth angebrad)t babe (PP). Saert wan Royen fatreibet ihm biefe Sdnizer fleifig nact.

8) 5ू:.

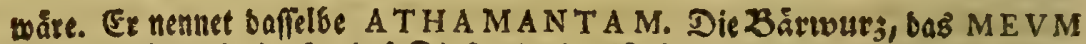

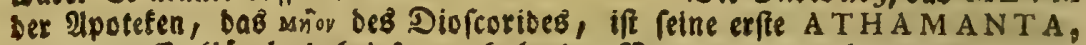
Cliff.93. Er flúgelt babei fo; ex babe ben ఇamen Menm abgefdafft, bamit

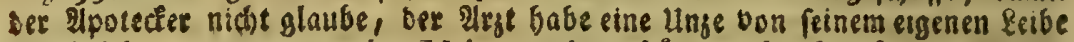
serfobtieben, went ex unciam Mei verorbnet båtte. Ser. Einnåus mad)t bell 2lpotetern burch Diefe Inmerfung wenig Ebre, ba et ignen etme fo (a)lechte

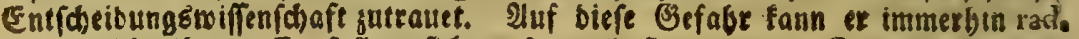
Mei verfabreiben. Er foll verfichert fenn, bafi weber ber Rrante, nod bet Ipotefer, eines feiner Blieder verftummelt gu feben verlangen werbe. Seine gmente A THAMANT A ift ber bisber fo genannte D A V CVS Creticus. Ş. \&innåus båtte aber mil leibliderm unfuge ben pferfichbaum, ber fein Manbelbaum if, mit bem Tharillenbaume (nalo Armeniaca),

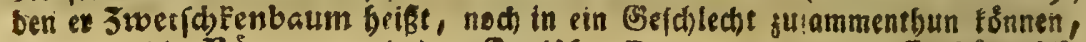

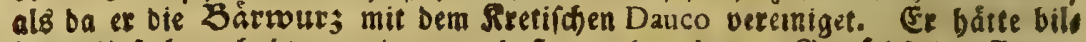

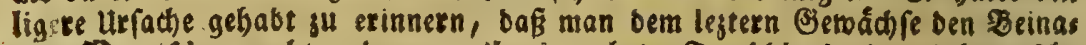
men Ziretifh uneedit zulege, neil es aud) in Seutichland eine eingermifhe

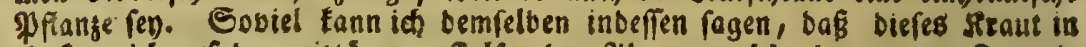

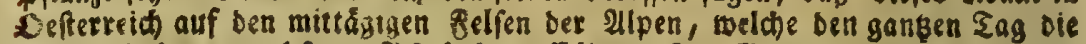
Eonne Gaben, madfe. Joh habe baffelbe auf 3 Eergen im lande ob bee

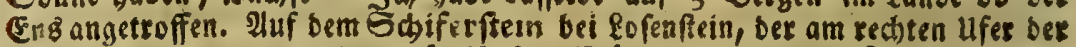

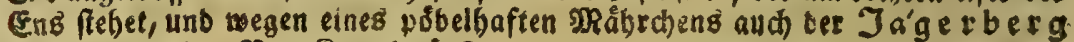

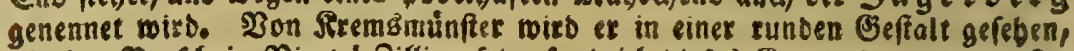

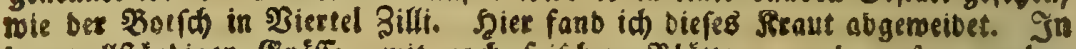
ber volftănbigen Broffle, mit nod) frifchen Sblăttern, uno retfen rauches Samen traf id eB auf Set Durn an. (Diefer Berg liegt am linten llfes

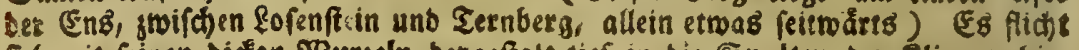
fid mit feinen biden 23 urgeln bergeftalt tief in bie Epalten Des Rlippen bin

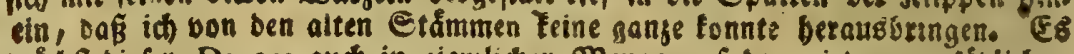
mådit Diefer Daucus aud in tiemlicher Menge auf Den nieorigesn fiblichess

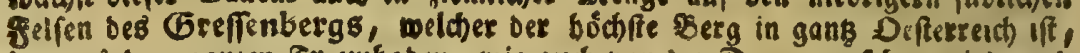
Der aus bem ganjen Truunboben, wie auch von ber Donau gefeben miso, uns in ben Ranbfarten fallichlich der priel beift. Der Pricl (ich rebe yon bem groffen Priel bes Innobner bes Stoders uno $\mathfrak{B}$ in o if ch $g$ a'rftentbals) if viel niebrigek, unb bat meines (Erad)tens bon bem vielen Bebuifche biefe

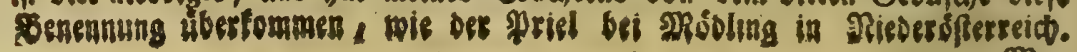


8) Srr. Sinnius lehret an mebr Drten, baßi man bie guten altent शamen in ibrer 2iedeutung beibehalten foll. 2llein bat er nicht bei bet

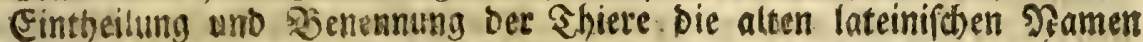
goinglid) verfectret? Mlub nicht ein gan; befonberes 2lufícla!nbuch ges

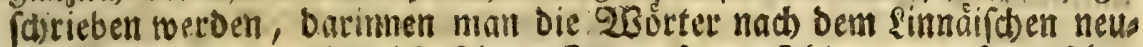

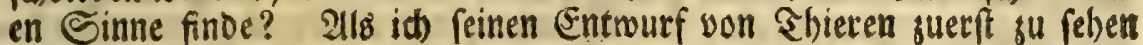
befam, fo vermeinte id nicht anders, alo man habe mit ein SRegifter 21 a 2

Det

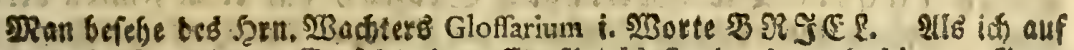
bem oberfen platten Sipfel bes grofien Priels fturb, ber mit feltenen Irten

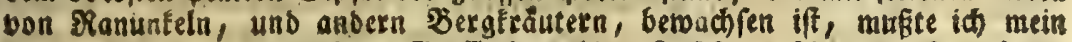
Saupt exbeben, um auf Den Brreffenberg binauffuregen, alह benn iक nach bet Spise aines Dadjes bătte fhauen toolien. Diefer bobe Felsberg banget mit ber fidoweftlichen Seite in ben Stoder bincin, uno bat ben Oftrorvis unites

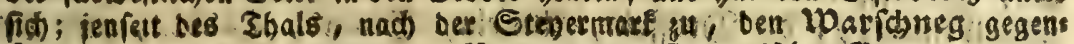

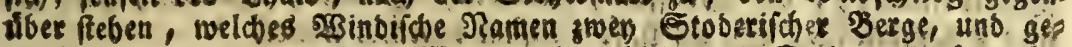
miffe Inzeigen fino, baß̉ bie MBinden ebemals in bern Stober getwofnet ba

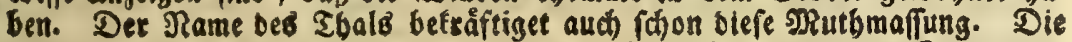
anbere Scite bes Greffenbergz ift nach bem Traunboben unb Der Donau get febret. \$Benn id) an einen Drt fomme, wo id) meine getreugten Reáuter auspocten fann; fo mill ieh bem Sen. Linnxo einen ganten Stengel diefer Dail-

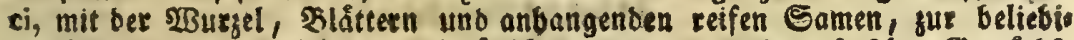

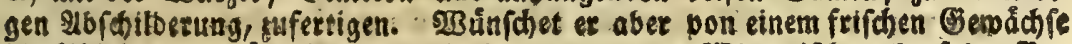

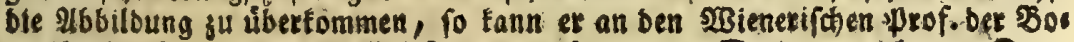
tanif fajreiben, uno ben Brief nur an Srn. van Broieten ridhten. Denr ben Ramen bes exfern toeis ich nidst. Diefer bat ibn, wie th vernebme, aus Paris ver/drieben. Det Etrangre miro, auf meine exft vorgettagene

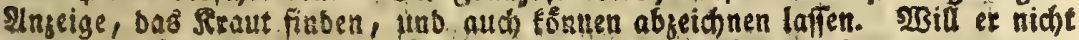

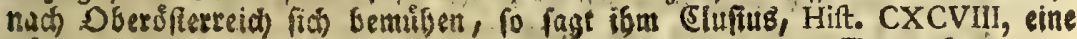
nábere Stelle an. Dar Same teifit bom 2uguft bis in ben Eeptembet.

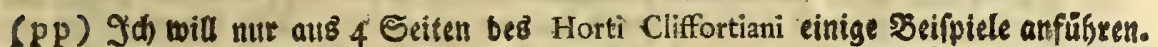

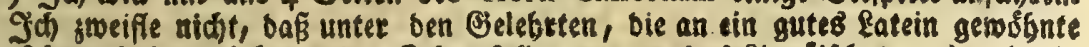
Obren baben, fít menige finbet follen, benen bas finnafifhe terminatrix in folgenben sencrnungen ber \$fhangen sidjt miberlich tlingen werbe.

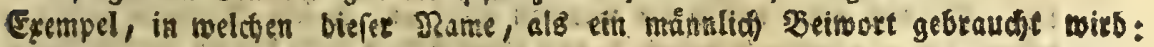
ASTER foliis ovatis angulatis dentatis, calyce terminatrici foliofo patente. Cliff: 407 :

A STER caule fuperne ramofo ampliato, foliis amplexicaulibus integris, calycibus laxis terminatricibus, io.

ASTER foliis lanceolato linearibus plternjs integenrinis femiamplexicaulibus, fioribus capitato, terminatricibus, $P \circ 408$.

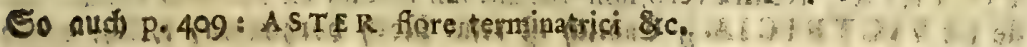

... A TEK foliis ovato-oblongis alternis felfilibus, corymbo terminatrici \&ce.

Exempat 
Dee Ovibifd)en Dermandelungen vorgeleget. Die Sausfasen und Die Saushunbe, find nad ber bon Linnæo verbefferten sateinifaten Spras We, FERAE Syjt. Nat. p. 35 feq. Die Bjiber, bie Scafen, bie Sias ninđen, die Stachelføroeine, finb GLIRES, S. 38. u.f. Die Spizo

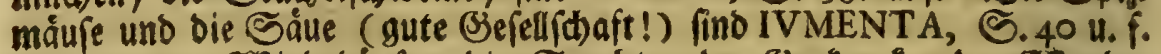
Die Siaben, 2Biebehópfe, bie Spechte, ber Bjuckgude, Der 2Bendes bals (in Deft. Natterwinoel) find PICAE, S. 44 u. f. Die Enten, bie Sthmåne, bie ihtwarzen SRobrhúner ( fulicx), fino ANSERES, S. 46 (q q). Die Sperlinge ( Spazen) bat er in Finfen verwans Delt. 2llein bie redoten Finfen, Die Bimpel ber Defterreic)er (fonft

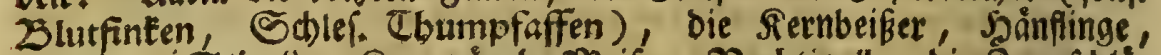

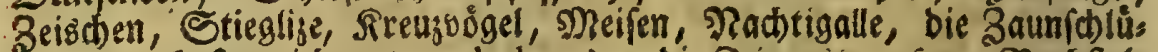

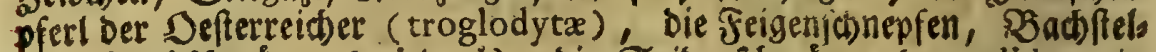

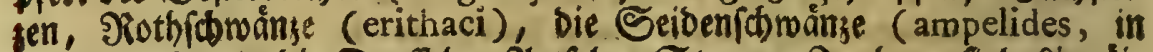

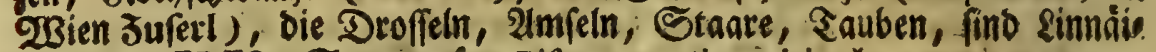
fife PASSERES, S. 48 u.f. Rifum teneatis amici. "

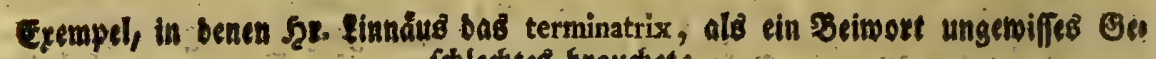
(iकlectites brauchet:

AN THYLLis folis pinnatis, foliolo terminatrici majori, p. 371.

ANTHYLLYS folis quinato - pinnatis, foliolo terminatrici maximo, ib.

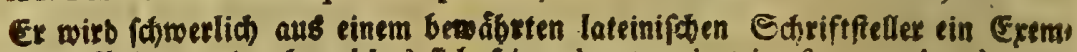
pel aufbringen, burd meldes fid fein calyx terminatrix, flos terminatrix, corymbus terminatrix, fơnne zechtfertigen lafien. Die giamen, vierix, ultrix, bienen ifm aus mebr Uzfechen gu teiner Entichuldigung. Diefe finbot man

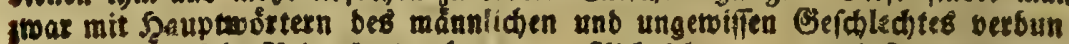

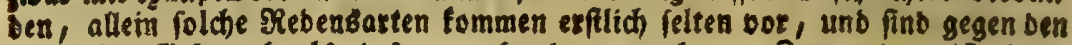

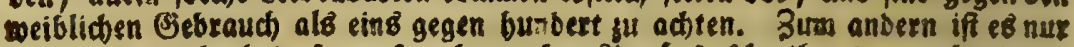

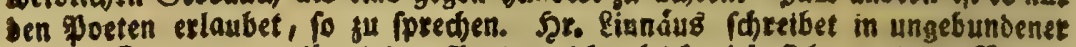

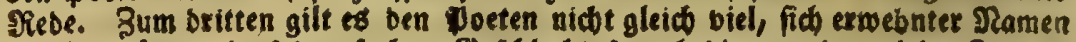

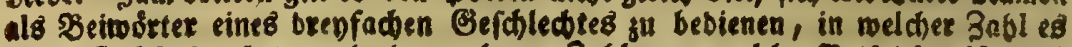

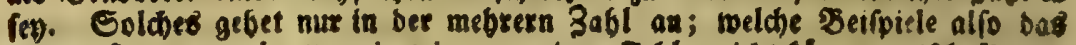
alyx, flos, corymbus terminatrix, von einem Eeblex nidt fonnen entídulbigew. Ditgil rajecibet:

Res Agamemnonias, vi@riciaque arma fecutus, Aen. III, 54 .

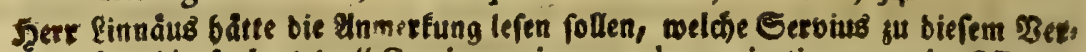
fe madit, bie fo loutet: "Omnia nomina a verbo venientia, cum in $O R$ ex3. eunt, maffulina funt ut VICTOR; cuma in TRIX, foeminina funt, ut 3) VICTRIX Neutra vero non faciunt nifí tantum ex Numero Plurali: um $\rightarrow$ de eft VICTRICIA. 2 , Enolich is feine Rot6 vorbanden, weldse biefen 


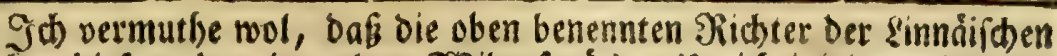

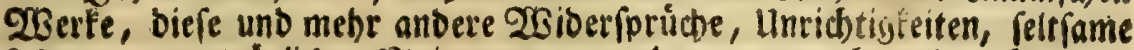
Sebren, unertrágliche Neinungen, werben angemerft uno aufgesogen baben. Denn weldsem sefer follen fie nicht in oie 2 dugen fallen? Tht babe nichts aus andern herausger dorieben, fonbern bas bier ?ingeseigte

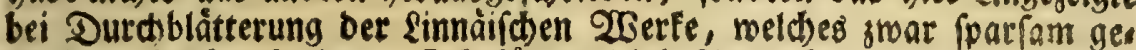

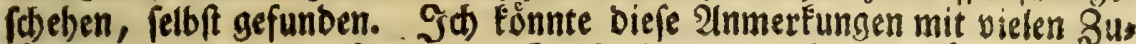
fízen vermebren, roferne eine Frudt baraus zu boffen wåre. Eines

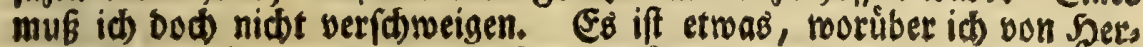

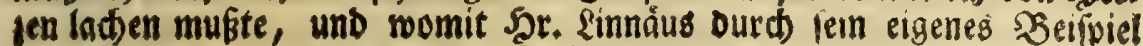
Dargetban bat, baj es lange nidjt fo leid)t (ev), die Bereje zu beobads ten, als biefelben andern nufjubuitben. Er ermafnet bicjenigen, weldbe

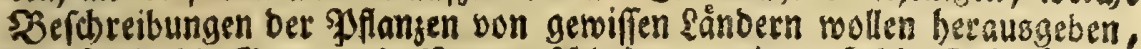

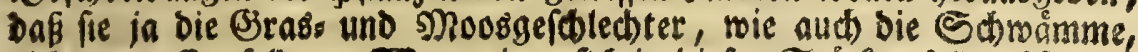
nicht vergeffen follen. Wenn einer fich in biefen Stúçen foll zu fithroach finden, bem ráth er freundlid, Daß Derfelbe mit feiner Flora lieber zu Saure bleiben mởte. Denn, fpricht Sct. Sinnåus, wenn er miteinem

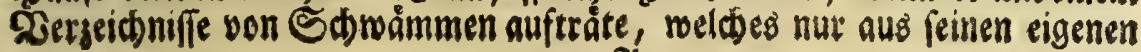
มิa 3 शas

Celehrten angetrieben båtte ein neues seimort su exbioten. Das if einer

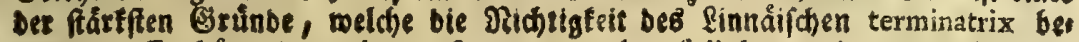
meifen. Ex bătte ja, calyce, flore, corymbo, foliolo terminante; calycibus, foribus terminantibus, nad ben beften lateinifhen IRuftern, unb obne allen

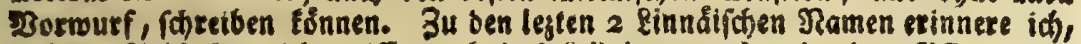
bas bet elebbaber nicht miffe, ob Das foliolum terminatrix einer Yflanje, bie ibm vorfonmet, majus ober maximum feg. Ex lefret felbft: Similitudinis notam, ni dextra manu notiorem, character non affumiat, Fund. Bot. 198, unD: Similitudo in nomine fpecifico ufurpata, dextra manu notior erit, Fund, Bot. 299: allein ift eine unbeutlide Ingeige ber Groffe nidht eben fo mangelbaft? Warum bat ex nicht DaB IRaẩ beigefezt? Darnach entfernet ex bie Eroffe von bet Interfobeibung ber Irten. MAGNIT VDO fpecies non diftinguit, Fund. Bot. 260; btet wirb boch bie unbeftimmte B̈:ffie beb folioli terminatricis, als

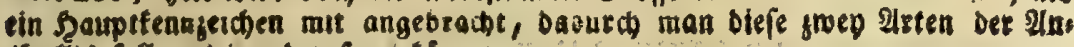
thollis foll arbeinanber fejen tónnen.

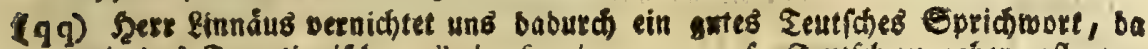
mie das zerentianifche, aliud refp'ndes, ac rogo, fo Setrifh ju geben pflegen:

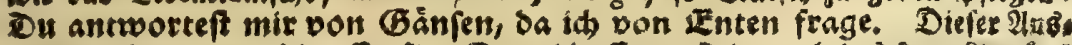

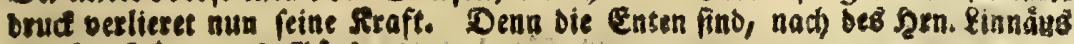
neuefter febee, auts Shanfe.

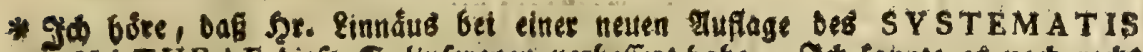
NATVRAE biefe Solipferegen verbeffert gabe Tot tornte ibesfominen. 
Pranten beftúnbe, ofne anjubeuten, wie biefe (jemåd) pe bon anbern

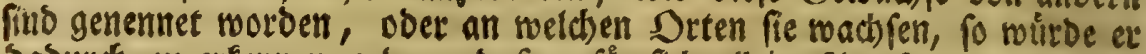
baburd gu erfennen geben, baf er fur fid alleine flug fenn toolle, baßs et andere Sdariftfeller nid)t verftehe; nientand fomte ertathen, non nas el rebe; Furs, feine Unmiffenbeit rourbe baburch an $2 a g$ fommen. Die sinnairichen 280 orte lauten fo: Qui boc tempore in Floris fuis Gramina, Mufcos et Fungos non recenfet, vili aftimatur, licet a veteribus ef ante Dillenium fcriptoribus, ficco pede communiter transgrediuntur *. Omnes, qui ejusmodi Floras, nominibus plantarum propriis, fietis, et fine teftimonio auctorum eorumque locis fcripserunt, fibi ipji fapuere, alios audores non in tellexere, unde demum nulli eos intelligere poffunt. Si quis noftro tempore tali modo fcribere velit, eum ( $\mathrm{rr}$ ) amice fuaderem, ut ab opere vano defifrat, ne nimis prodat ignorantiam fuam. BIBL. BOT. P. 84. Der arme Str. Sinnåus wuste nicht, als berfetbe biefes fahrieb, bas et fich felbft

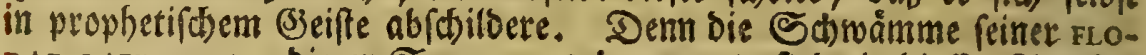
RAE LAPPONICAE, Die er S. 354-358 bernemnet, fino ein bloffes Siegifter

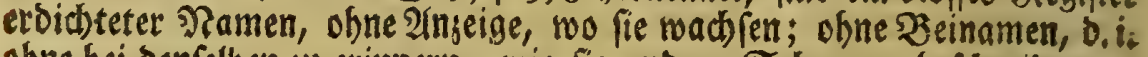
obne bei benfelben ju erinnern, wie fie andere Sdjnammbeibreiber ges

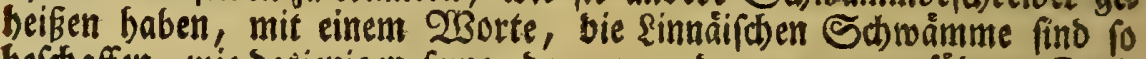
befthaffen, wie besienigen ferne, dem er an Der guwor angefübrten Stels le råth, zu Saufe zu bleiben, bamit et feine Inmoiffenfeit in biefem

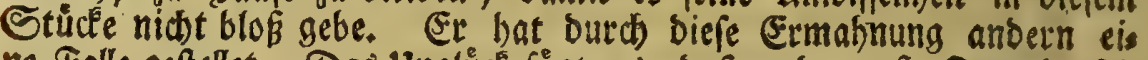
ne Falle gefteltet. Das ungluce fügte es, bas er ber erfte Fang beriels

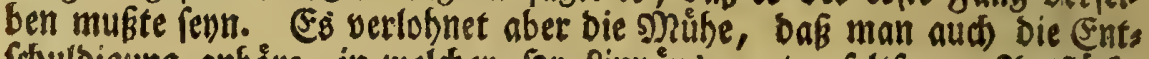

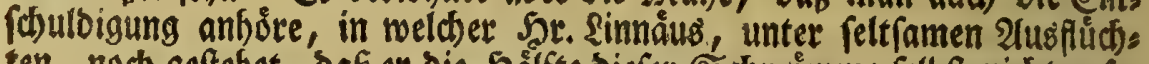

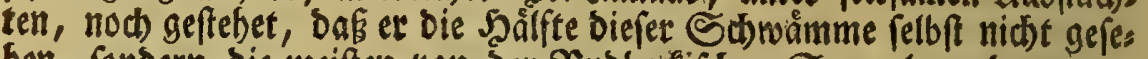
ben, fondern bie meiften yon ber Fubbectiphen Sammlung berausges forieben babe. Seine 230 rte lauten fo:

1. Excufabit me facile lector benevolus (ss), quod fynonyma bic non adpofuerim. Is certe, qui confiderat, fungos non ut berbas facile exficcari, in parvum fafciculum compingi, domum duci, fervari poffe; dein libros Botanicos, qui bic, fi alicubi, requirebantur maxime, mecum ducere per deferta, per rupes scopulosque adituque carentia faxa, quaque erat diffecilis, quaque via nulla ( $\mathrm{t} t \mathrm{t}$, impojgbile fuiffe mibi, qui folus per devia

\section{* Tattes Ratein.}

ince-

(rr) Das mus ein Duucfebler feon, füt el, wenn bie Itumertung \&) nid)t gilt.

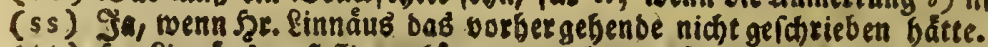

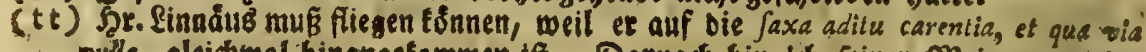

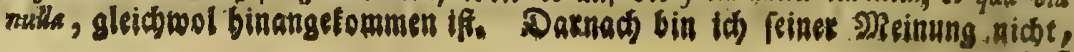


incedebam, unico cum comite feu vie duce Lappone; tum quod poft exficcationem, que bic difficillima erat, vix eundem liceat dignofcere fungum, tandem quod autumnus, eo quo in Lapponia verfabar anno, fuerit valde calidus, ut omnes bos, quos recenfeo, ipje videre non potuerim fungos. ( $\mathrm{u} \mathbf{u}$ )

2. Celcberrimus Rudbeck, dum fuum iter inftituit Lapponicum, et focios et pictorem secum babuit, preterquam quod ipse in arte pictoria excellue. rit, ex profefjo fungos collegit, vivis coloribus delineavit, eosque in bunc diem fervat. Hoce injpiciendi fepiusque examinandi licentia ab eo benevole mibi conceffa, ex quibus felegi omnes iftos, quos quoad partes fuas rimari manifefte licuit, eosdemque meis interpofui, ut fere duplo plures invenias cnumeratos, quam quos ipfe viderim. Flor. LAPP. p. 352 .

Das if ein furgweiliges Exempel, woburd Sar. Simno̊ auf eigetre

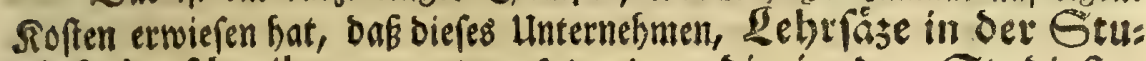
Sirftube fitreiben, von Dem folgenden, oie in oer Etubirftt: be geidriebenen Lebrfäze auf oem feloe, im Wolbe, zur

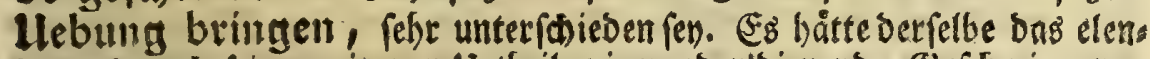
De, uno nad feinem eigenen urtheile niemanben'bienende, Befefimiere von 47 Agaricis, womit er funf Seiten feiner Flora beflecter bat, tortíses, wie er felbft befennet, ber Sefer nicht verftehen fam, fider veglaffen

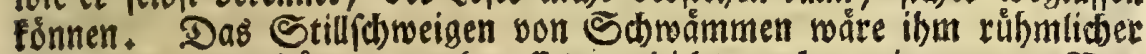
gewefen. Man batte gemuthmaffet, er bidbte nod an einer neuen Dets

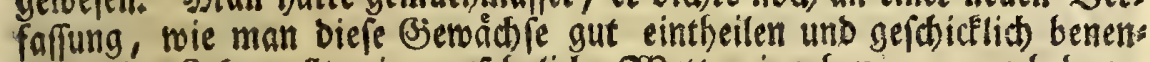

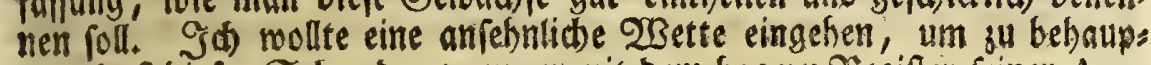
ten, bás biefer Sd)webe, wenn er mit Dem hagern Piegifter feiner Agaricorum wieber in \&applano fid verfugte, nicft ber Sälfte Der Arten feine eigenen शramen wurbe beigulegen miffen, wenn ifm Sct. Rubbeck bie gemablten figuren nidit wieder lehnete. $23 a$ bienen aber Diefe bloffen $\mathfrak{B}$ enennungen andern fefern, welche weber bie barzu gefórigen

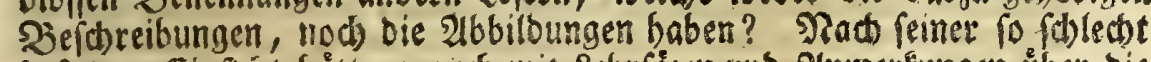

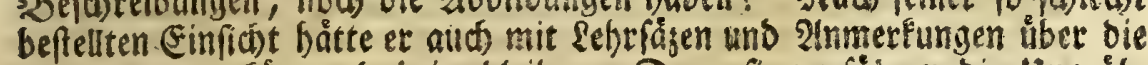
Sdwamme, Eơnen babeim bleiben. Denn fie berfübren bie ungeib.

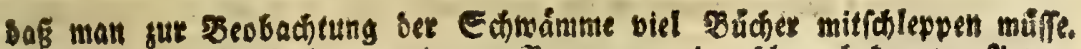
Eine bequeme Eintbeilung, und gute Benennung Der fotor betannten Arten, nebf ben 266 billungen im Sopfe, thenn man fie auf bem saplere nicht babew

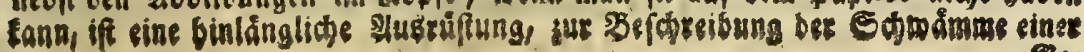


ten, und benen, bie es beffer wiffen, maden fie fein Vergnuigen. Fr fagt z. E. mekn ber Eame einer Dilleniiden 2lmanita auf bie Eroe fált, to werbe eine 2manita barauş ; fält er hingegen auf einen \$̧aum, fo erzeuge er einen Dillenifichen 2garicus. W Wie beneifet er diefe 23 abt, beit? Scat Şerr \&innáus ein einziges Somenftáutden bon einem Cowamme iemals auf einem Saume erblicte, uno erfannt, baßs es von einem Erofomamme, von einer Dillenifoch 2Imanita, binaufgeflos

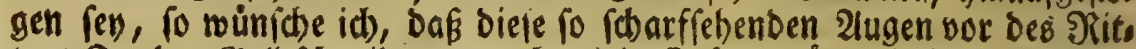
ters Saylor (Belofinneiberey noch viele Jahre mogen befrenet bleiben. Durd) Die Infúbrung, baß man auf bem Eroboden Sdwámme finbe, reld)e benjenigen ålbmlic finb, bie auf ben ร̧åumen erzeuget werben, läkt fich bie WBahricheinlichteit reines Sages fo wenig Dartfun, als menn einer vorgeben wollte, oaß ein weiker $\mathfrak{B o g e l}$, ber auf bem 2 ffte

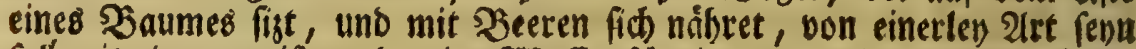

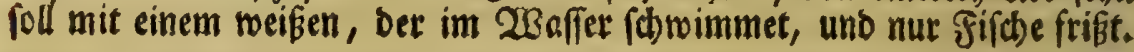

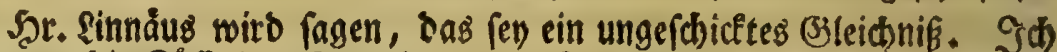
follte nur bie Füffe bes 20 gels, ber auf einem 2lfe fisen fann, betracbs

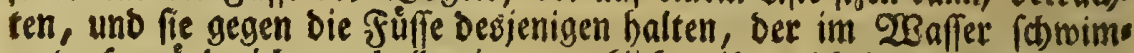
met, fo murbe id) gar bald einen merfliden unterfareio fwirchen biefen Bbieren wabrnebmen. Allein id) antworte, Jar. Sinnåus foll aud bie Fuffe ber Erofobámme beobadten, und gufehen, ob er an ben 2 autm, (4) wämmen, was biefen Sheil anlanget, nidt eine gróffere Unàbnlids feit antreffen werbe, als diejenige ift, moburd bie g wey erwebnten $20^{\circ}$ get fid) boneinander unteríteiben. Die wenigften Erof(d)wámme fint

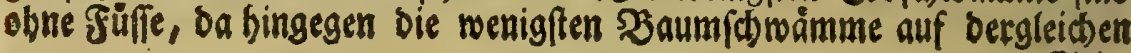

Cegent. Rann man gemablte figuren liefern, fo gefien biefe ben 5e(d)eibum

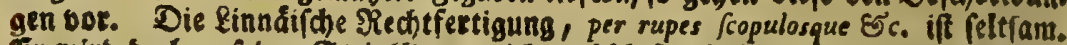
Er mirb bod) auf ben Eteinflippen nidht gefhlafen baben. (Er fonnte fid bie

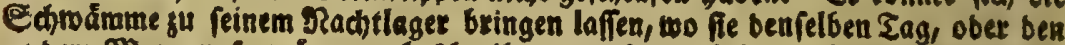

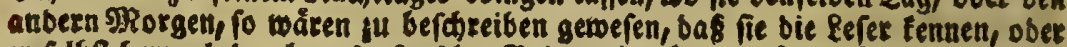

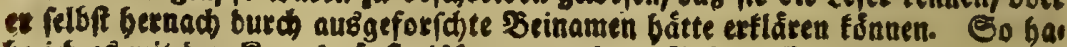
be id) es mit ben Ritembimunfterifhen gemad)t. Iuf ben Stetntlippen mactien

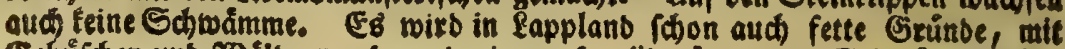

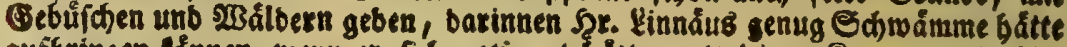
auforingen tơnnen, menn et fí getiauet batte, mit feines Rroptogamie bin einugefget.

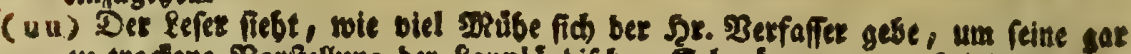

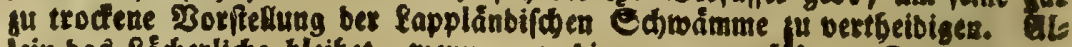

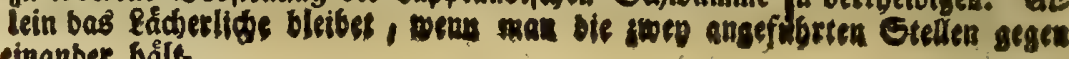
cinanbet bålh 
Stielen wad) (en. Die Erofdroimme fino íberhaupt obenher runb; bie

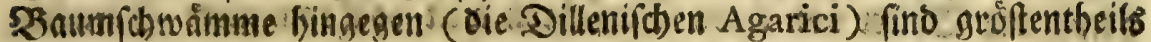
nur wie ein balber soond geftaltet, alfo ba p fie mit berienigen Seite, ber es an ber Siunbumg fetlet, ben Stoct oes Baums anfaffen, uno

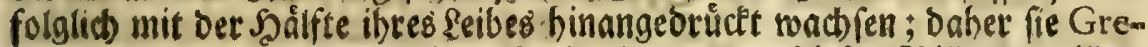
vin, nach Der פ)?undart feiner Eanbesleute, um biefer Sildung willen, riffoles (xx) nennet w? Die Sergleidjung ift ofne ₹abel. Denn ju

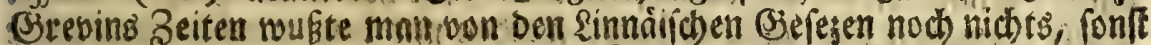

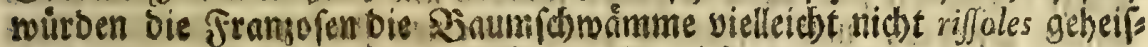

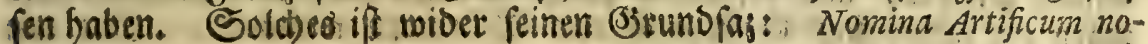
menclaturis communia, omittenda erunt, Linn. FVND. BOT. 23I. Diefe wichtige Segel mirb nodb einmal miederbolet: Terminis artis loco nomisum genericorum abuti inconfultum eft, FVND. BOT. 250. Es iff alfo nad

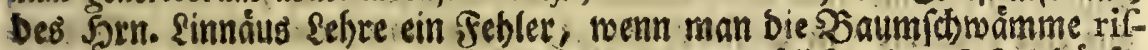
foles, गुafteten, nennet. (Er beforget vermutblid, ber sejer borfte

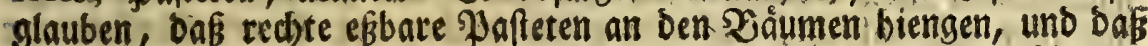
ein armer Sropf leidt fơnnte verführet werben, in ben 23 alo binaus:

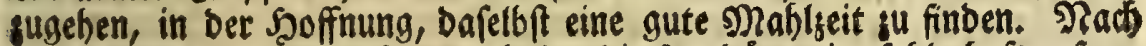
biefes Sielefrren Beurtheilung haben bie \&aceoảmonier fehlerbaft gefpro. chen, ba fie bie Siúben, wie Âthenáus beriđbtet, yos'spes nannten. Denn bie Siuben fino feine 2 åuche, fonbern fie haben nut báuchid)s te Wurzeln. Ein ftarter Theil ber alten Spraden mübte, ben \&ins náifden (Strunbfäsen zufolge, ausgemuftert uno verbeffert werben. Fs if Sdjabe, baßi biefer zwente Dioscoribes nicht vor Dem erften geles bet; und bas die 23 elt nicht bereits vor ztweys oder andertbalbtaujend

$$
\mathfrak{B} \cdot 6 \mathfrak{b}
$$
Saho

( $x \times)$ RISSOLLE ift nac) Ertebins Crtlårung cinte Wolloprātpaftete. Die beutigen fransoffif

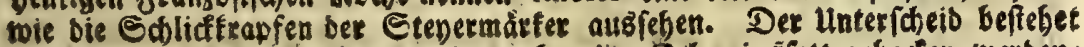
baxinnen, baf́ biefe gefotten, jene abet in Echroeinbêfett gebacten merben.

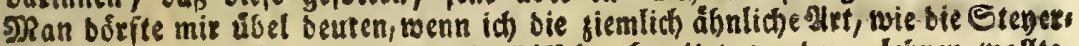
mátifhen Gatidfrapfen unb bie Riffoles bereitet merben, legren wollte. uns otenet bie Betraditung inger Beftalt. Die Riffoles baben auf einer Eeite

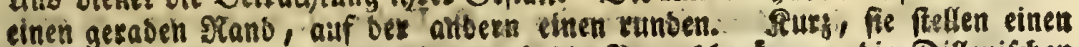

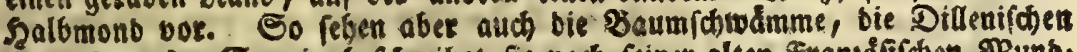
Ágarici, aus. Grevin befdreibet fie nad) feinet alten frangéfichen \$unb, art folgenbermafien: "Entre les "arboriens les uns font nommex Aureilles de Güdas pourautant qu'ils fónt faits èn façon de aureilles, et les autres font - auff nonimet Riffelles pour la fémblatice fin'ils ort avec des riffolles, les-

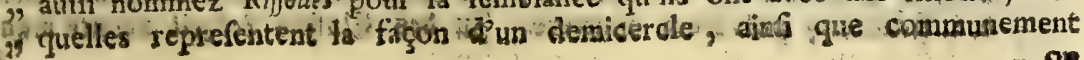




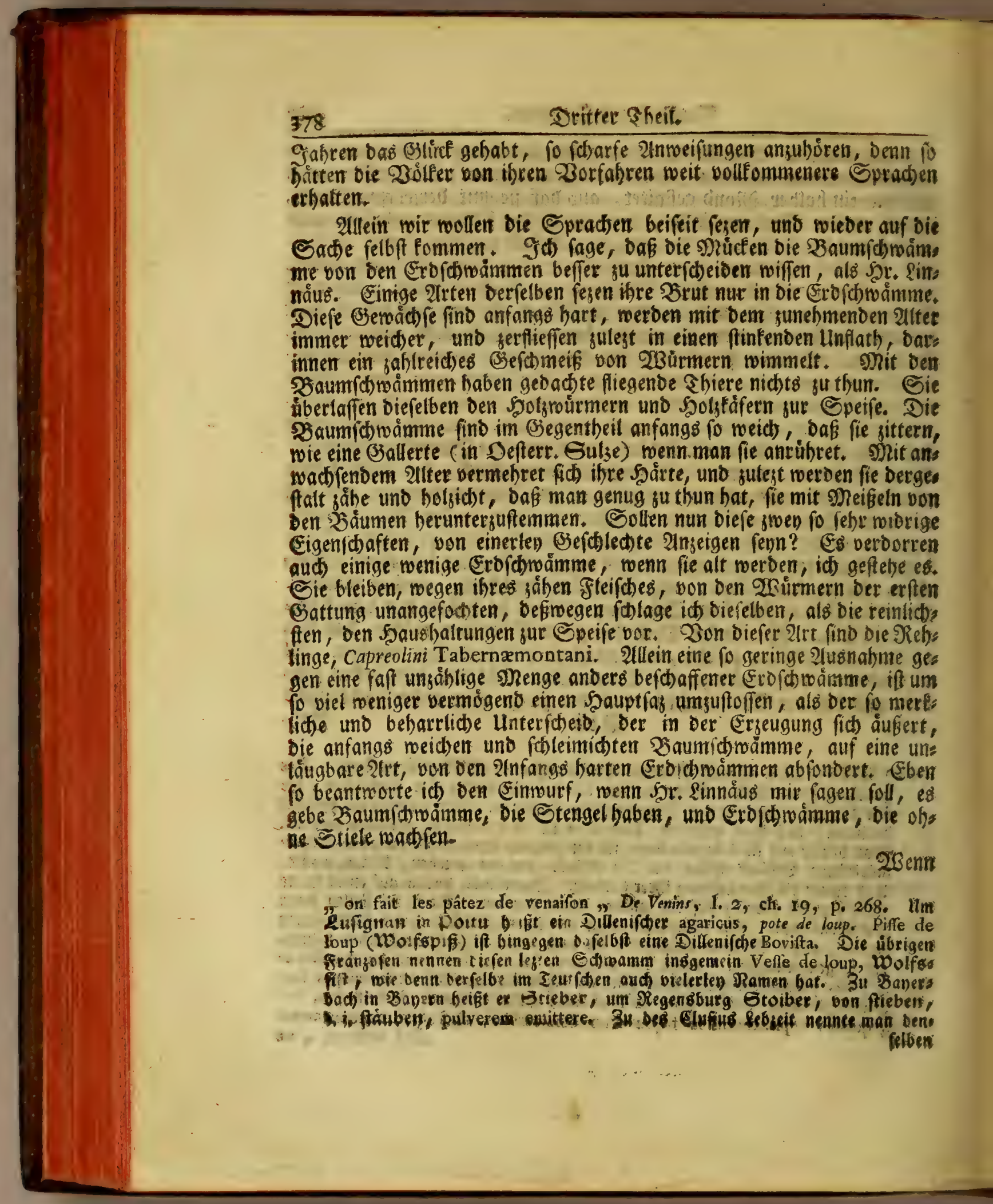




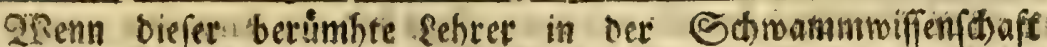

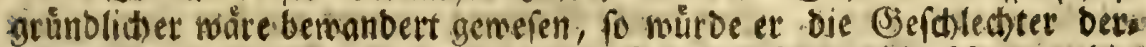
felben eher vermehret, als semindert haben. Da er bie faton worhin

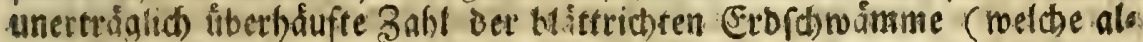

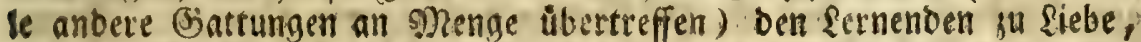

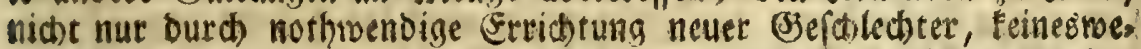
ges auseinander gefejt, fondern ourd bas unbefonnene Einmengen Det:

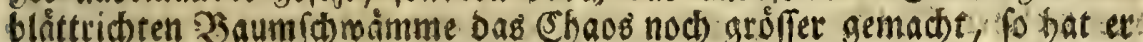

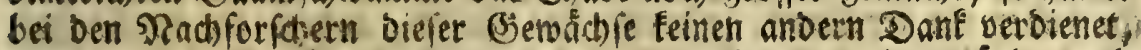
als ben ein anderev butch folgenden 2 infolag fith erwerben rourbe, wele: ber bie Namen, Rabe, Apperling, 25atitelse 2 . atforaffen, uns anrathen nollte, man foil Funftig lieber, ein fthwarser Dogel, ein brauner Dogel, ein weifjgrauer Vogel u. f. f. fpredben. Q QBBeil bie

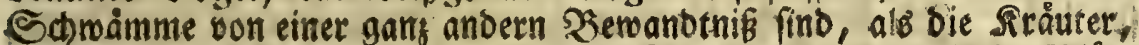

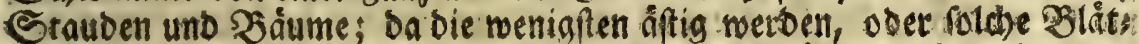

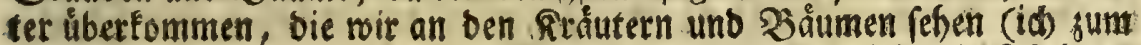
wenigften fenne nur einen biefer $21 r t)$; oa fie fernet Feine fo fítbarn

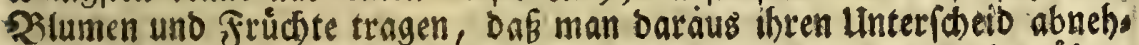
men fơnnte, ber zur beutlidben SBenennung Derfelben, regen bes úbets groffen Shauferis, uneritbef)rlid) if : fo muif man auf bie Bjeffalt ibret

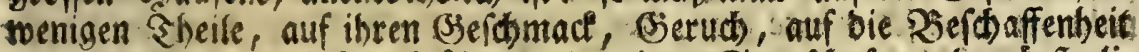

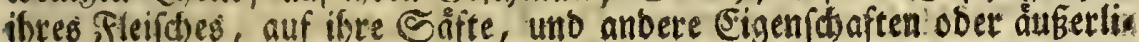

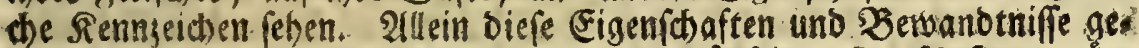

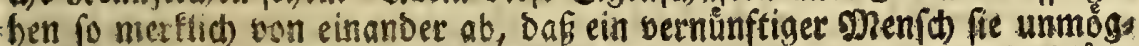

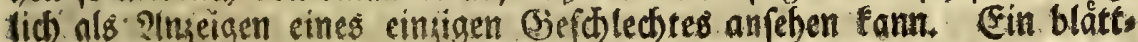
ridber Schwamm ift rufs, uno fann roh genoffen werben; wie id bent

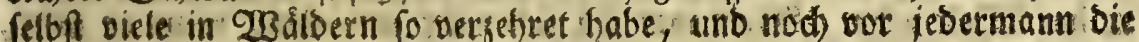

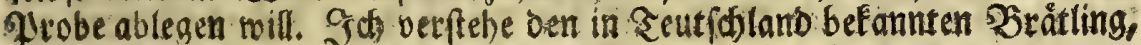

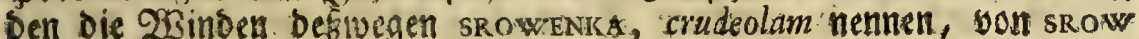
crudus... Das if ber fungus pileolo lato, lateum et dulcem fuccum fundens C. B. (YY) Ein anberer blätrit)ter Sdwamm ift bitter, mie meie

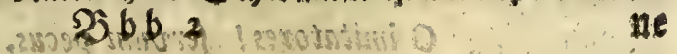

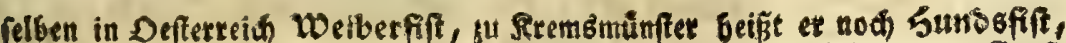

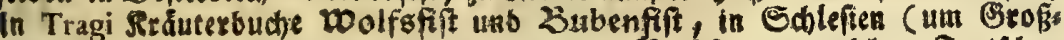

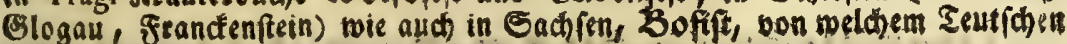
Ramen Diflenius feir Bovifta geriadtet bat.

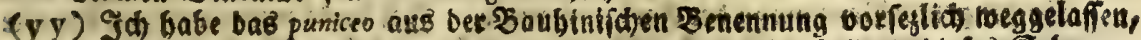

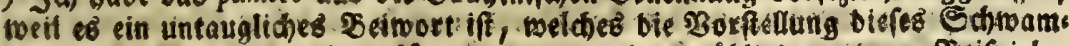

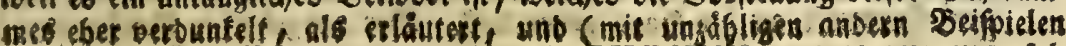


ne STELECHIDES lamellis olivaceis. Sar fino bie Amanitæ noxiæ fafciculof $x$ DILLEN. $(\mathrm{zz})$. Sine Dritte Battung brennet auf ber Zunge, wie Der Yfeffer. So ift befwaffen meine PIPERITIS, ober ber fungus piperatus, albus, lacteo jucco turgens 1. B. Den bie Seutfden Stevermatfer beftoes gen Pfifferling, Das ift, Pfefferling beifen, wie Cordus. Fernet

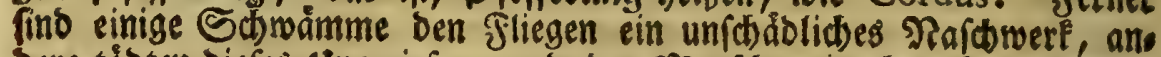
bere todten biefes ungegiefer, uno ben genld ben madben fie unfinnig,

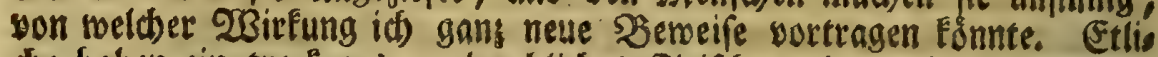

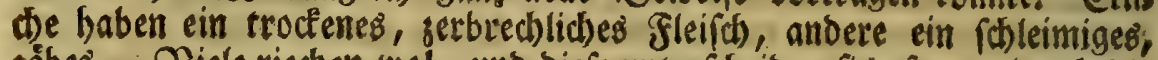

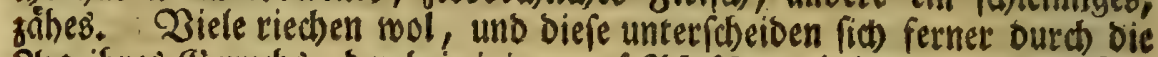

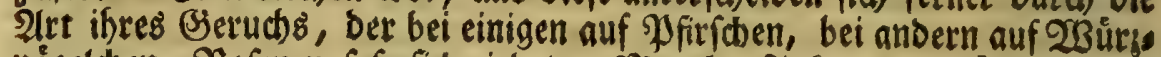
någelden, Rofen u. f.f. fich jiebet. Sand) frinfen unertråglid, wie Der Nonosvs, welden Sळramm id nur su Fremsmuniter angetrof:

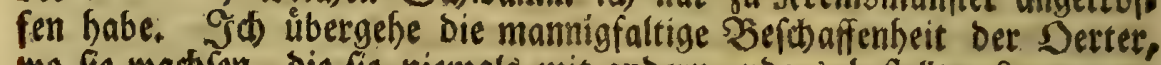
two fie wadbren, bie fie niemals mit anbern anbers beftellen \&agen bers

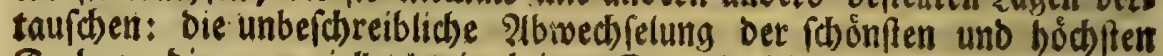
Farben, die man bielleid)t in Feiner Sprache bisher fu nemnen grmuft bat, beren viele auch fownertich ein Mahler nach ber \$atur treffen mur be, und nod) andere fonberbare smertmale zu gefchweigen, die uns ubet führen, Dafi berjenige ein srăumer, ein unfinniger ober im (jehurne uns

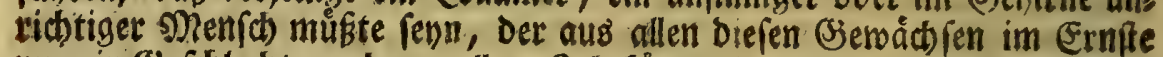

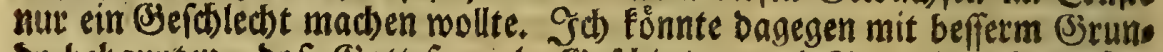

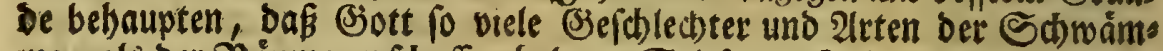
me, als bet 2 áume, exforafen babe. Seltfnme Meinungen eines einjis

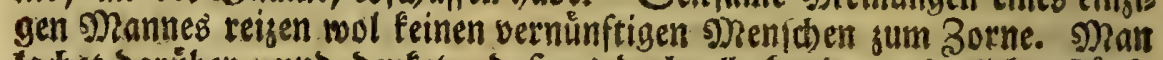
lachet Daruber, und benfet, Das es Dod) allerbano wunderliche Fiopfe in ber 2 Belt gebe. 2 llein wer foll fid nidt entruften, wenn er fiebt, Dafiein fo tadelfafter Befomad bei seuten cines beffern Sinnes ben Beifall, und ein fo gearteter Sonberling Pachfolger finbe, Die fich nict entbloben, ibm feine årgertichlten Sdbniser, als Sobonbeiten, nad)รu(d)reiben, twie esి ein Sollánber madjt.

O imitatores! fervim pecus.

[XXVI.

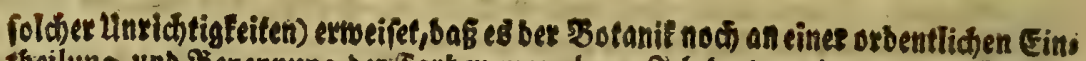
tbeilung unb Benennung ber farben mangle. Sidh biete meine toenigen Dienfte

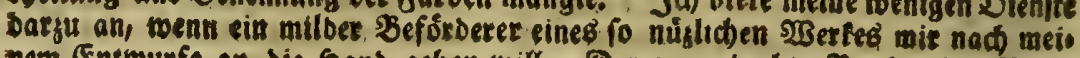

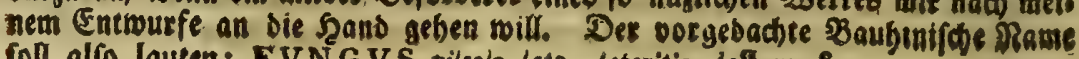

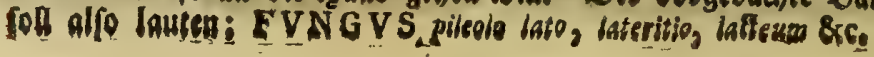


XXVI.

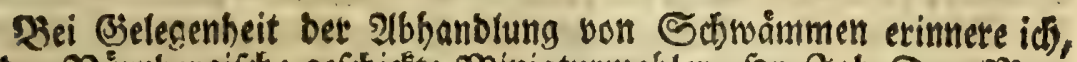

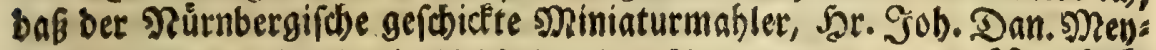
er, von beffen Şand bie \&iebbaber ber Naturgef(hid)te bie Dorftels lunten ber triebenden, fliegenden und fhwimmenden Cbiere, mit ibren Gerippen ober 3 cintérpern, empfangen, von freven Stứfen fich erboten habe, meine Sammlung bet Oberofters

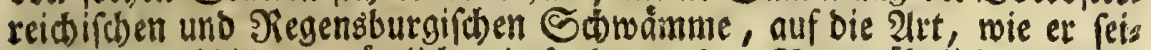
ne Shiere abbilbet, no̊mlich mit faubern, Der Satur ắnnlichen illunti: nirten Supferfticten, herausisugeben. Sich melbe foldes allhier offents

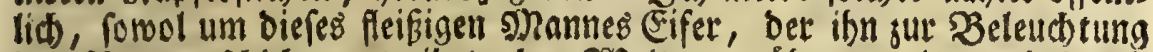

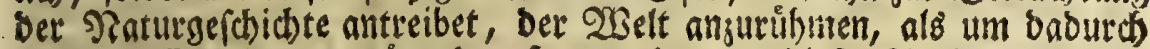
einen groffen ober vermo̊genden Şerrn, ber aus biefer 2lut ber Erffennts

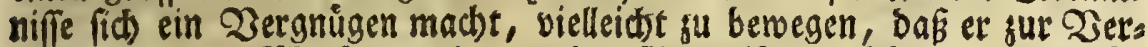

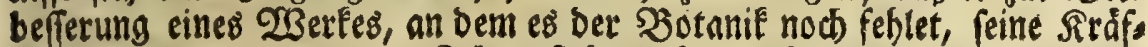

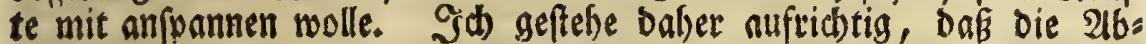

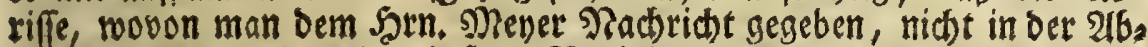

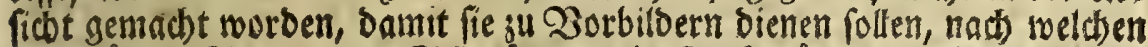

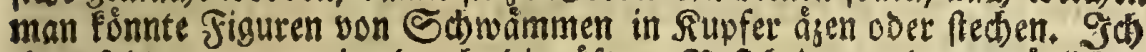
that foldes, um mir, burd bie offere Befid)tigung Des naturlioben

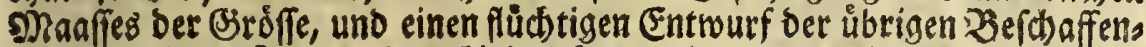
beit bet Sdbroamme, Den Einbrute von einer jeben Gattung bergeftaft

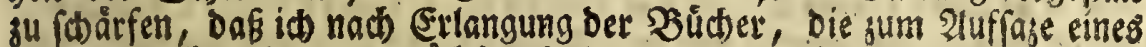

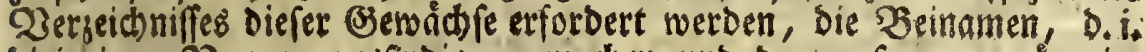
biejenigen sramen ausfindig zu machen unb barjugufesen, móge int

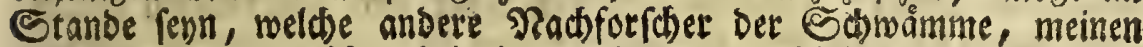
beobachteten 2trten finon beigeleget baben; wenn biefe anders mit túcb. tigen $\mathfrak{B}$ efobreibungen ober Figuren begleitet, ober zum wenigften gefotidet abgefaft fino, D. i. gute Sennzeidsen enthalten. Denn alle Sobwamms regifter, Denen $e^{8}$ an biefen Erftärungen burd Beinamen, wie aud) an

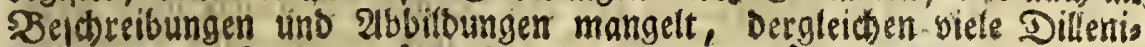

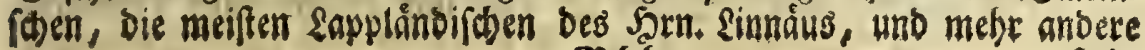
$\mathfrak{B}_{6} b_{3}$

fino,

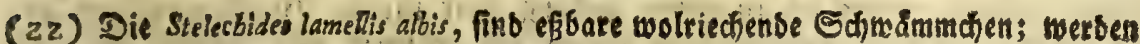
gu Regensburg 5 to d (d) to a'm m e rl genennet, unb in groffer NRenge bet: ipeifet. Sinb Amanite fafciculof $x$ efculentr Dillen. In ber Eprade ber Billes zifhen 2 inben beifien fie Stórowke, pon. Stor, truncu, weil fie auf ben al sen Etoften unb um biffelben wachjes. 


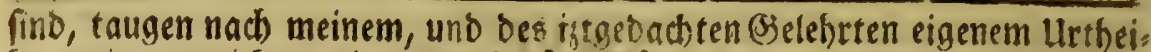

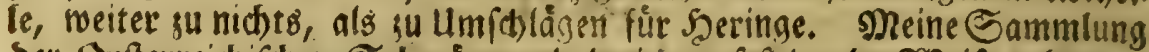
ber Defterreichiften Sdmåmme habe id auf folgende $23 e i f e$ erhalten. Mlein abgebrungener 2lufbruch aus ben Erblånoern meiner aller: gråbigften Frau, warb auf ben Frühling beg 1746 Sabres feft gefest. \$) ne Greunde riethen mir aber, wegen Der ciblen Straffen, melche bie 2lufo thauung gu berfetben Zeit grundlos madte, nod) einen Monat zu berzies ben. Die \&aftrågen, weldbe meine Bzüber führen rourben, fơnnten fonft

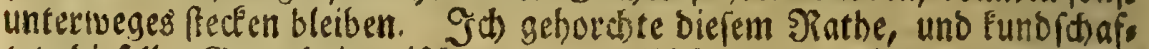

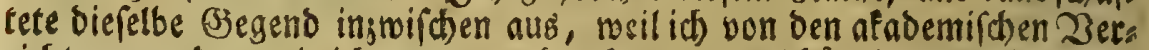
richtungen eher, als id) es vermuthen fonnte, vollftänoige Muffe hatte.

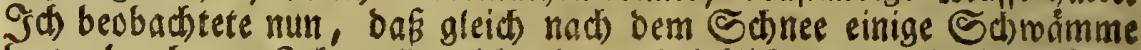

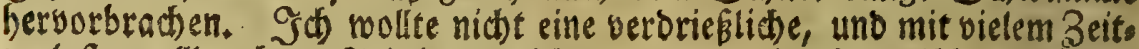
verlufte vollbradte, Alrbeit vernid)ten, um meine botanifhen $\mathfrak{B u t h}$ er

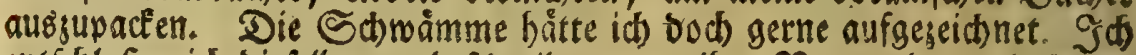

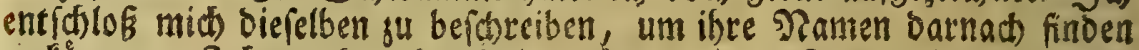
gu Eonnen. Sab merFte aber balb anfangs einen Mangel ber notbwett,

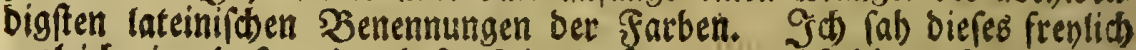

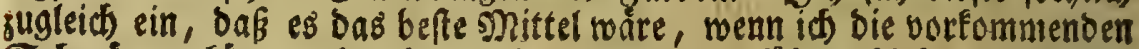

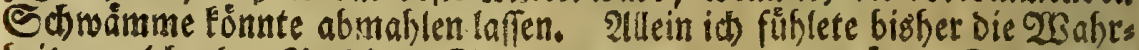

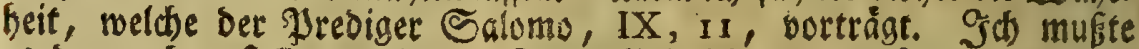
es bemnach anfellen, wie bet Franzofe ipridt: Le riche fait comme il veut, et un autre comme il peut, oer Reidhe thut, wie er woill; ein ander,

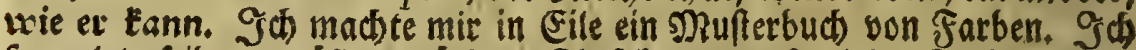

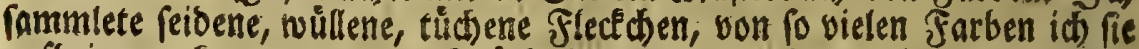
aufbringen fonnte, aud) Stide von geber und gearbeiteten Fellen. Diefe theilte id nach ben Werwanbichaften und (Sattungen ber Sarben ab. Die sưfen fülte id Durch gemahlte eingefhaltete Felber aus, bie id) mit Murchelfarben auf Sopier vorftellte. Die Namen fezte id in las teinifher Sprache bargu. 230 es mir an biejen gebrach, ba madte

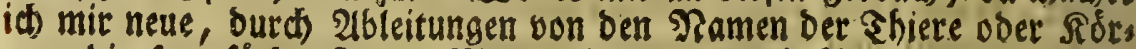
per, bie fo gefárbet finb. WBenn id gute uno beftimmenoe ₹eutí(be, Frangofifiche oder Statienifte wufte, po ftellte id diefe indeffen bin, un

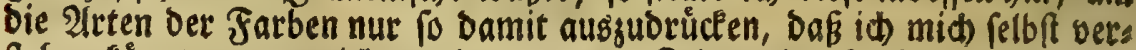

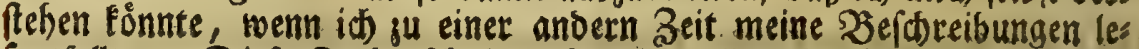
fen follte. Diefe Farbenidule nabm id allemal mit, wenn it auf Sd)wåmme aubigieng, uno besog mid) bei ber 2lnoeutung ber farben guf bie barinnen entbaltenen \$rufter. WBeil aber je über 8 ober I4 2 as 
se neue Sdwo amme berborfamen, bie ich nicht wollte in Sefterteich unbeidorieben zurúctlafien, fo wurben aus einem \$nonate meines verícho.

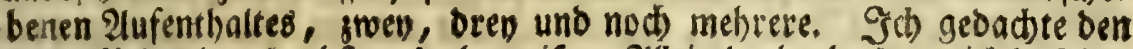

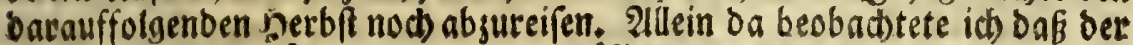

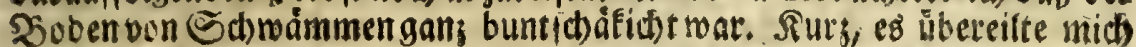
cin neuer 2Binter in meiner Sd)manmbef(d) reibung, uno fo habe ith

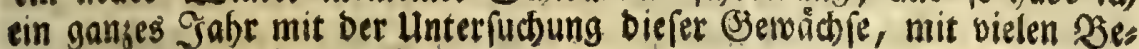
fohwertidfe eiten zugebract. (a)

2siemol id aber ist erwebnteg 2 sert obne allen Unterrictit anges atifen, unb nut bie शatur zut \&ehrmeifterin gebabt babe, fo erlangte id) bow, ourds bie llebung einer fo langen Zeit, eine jiemliche (Einficht,

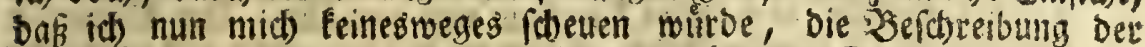
Sh)wamme in einer jeden (Jegend vorjunefmen. Zu SRegensturg bes

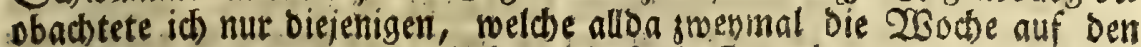
sharft gebradst werben, uno fano, baf bie Snwohner ebenfalls nur un.

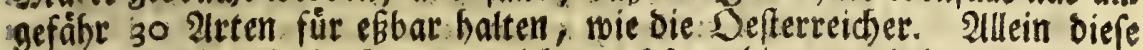
baben etliche, bie in :Banern nicht wad) fen; bingegen bringet $\mathfrak{B a n e r n}$ wieber einige befondere ȩ́bare Sdwámme tereor. Ulm Regensburg

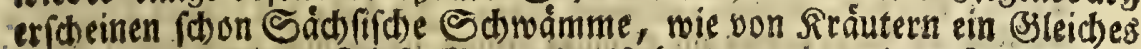
erwehnet worben. Diefe Bzewandenis hat es mit meiner Sammlung yon Sdfwónmen, Die uber 200 21rten begreift (b). STun will id aud bie Vortheile berfelben ergåblen. Einige, Die mir baraus erwads.

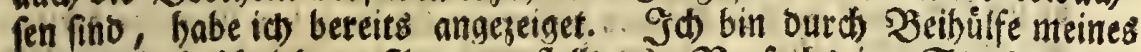
(auf bie beforiebene ant angeffelften). Berfudbs im Stande, alle

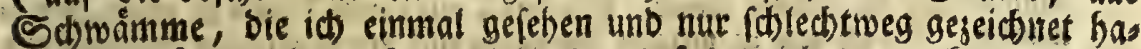
be, fie mogen mir vorfommen, wo eb fer, wieber zu erfennen; und benfelben meine erften शamen zusuftellen. Das ift ebenfalls fein geringet

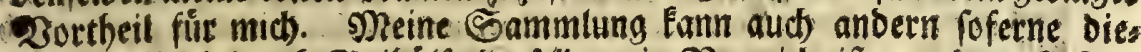
nen, weil id) Durch Beibúlfe Derfelben ein Dergeidnif́ yon Den Defters

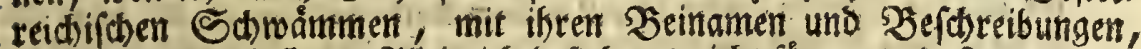

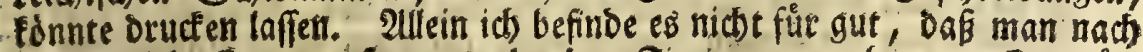
meinen Abriffen ene Serausgabe Der Figuren vornelyme. (Es woere Schabe fúr bie muibjame 2libeit, welche bod) nid)t ummittelbat bet श2atur nadbgemad)e waite, uno in vieten Sticfen mangelhaft ausfallen múste.

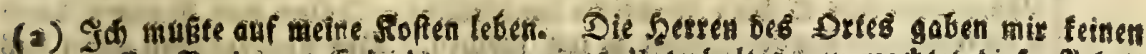
Q

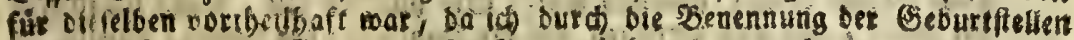

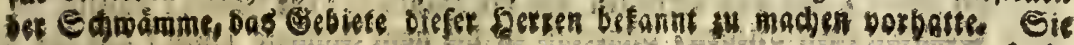


múste. Die Menge ber Scwammarten, und bas seib, fie in meiner

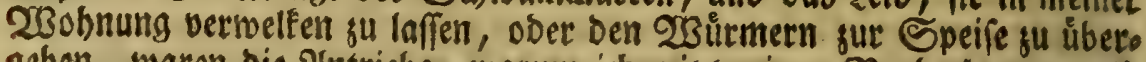

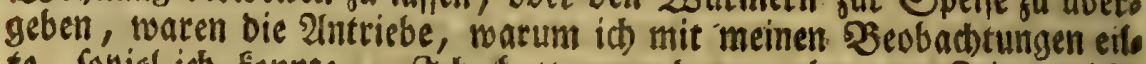
te, foviel ich fonnte. S'b batte nur benn und wenn Beit; etlid)e Sd)wåmme, mit foldhem fleife zu zeidsnen, bap fie aud in meines

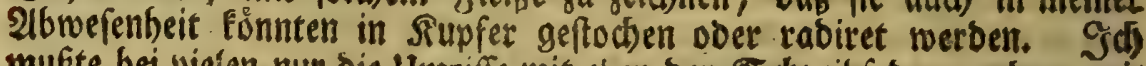
muste bei vieten nur die Lmriffe mit eben ber Sareibfeber madben, mit

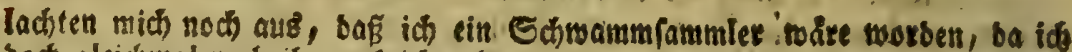
bod) gleidhwol nad) ibrem (nidt) aber nad bex Serken Sefuiten, meiner beften frreunbe) Lrebrile, noch beffere Dienfte ju tbun vermidite. Dex Mangel bet

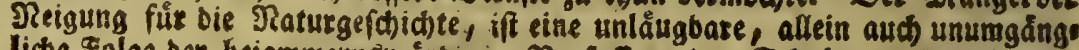

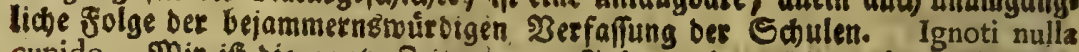
cupido. Nir ift bie ganke 3eit von 13 Jabren, in meld,er io athe Schulen surdhronbert babe, fo gat ber Name hiftoria naturalis niche gu Obren getoni

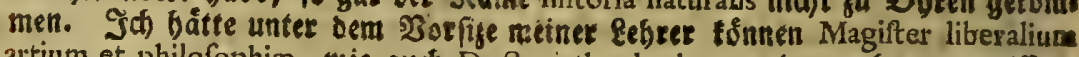
artium et philofophix, wie aud Doctor theologize werben, ofne fu wiffen, baß Erben, S̈ffteine, IRetalle, erfennan fonne. Ja babe ben Namen So otanif, uadjbem id) lange vorbcr alle Sdjulen meiner univerfitåt butdftubirt batte,

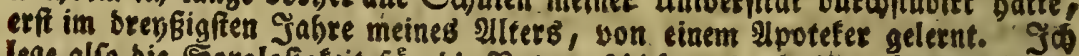
lese alfo bie Sorglofigteit für bie Naturgefaid)te, benjenigen Serten, is bes

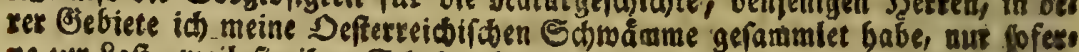

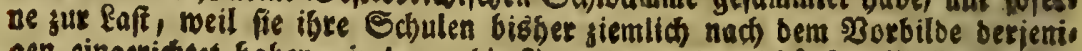
gen eingeridotet baben, in benen bie Jugenb von ben ihunften $23 i f$ enfojaften

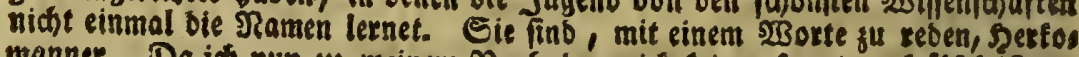

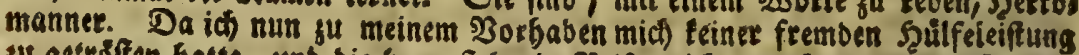
gu getroffen batte, unb bie bevorftebenbe Sieife midh ermabnte, meine 2lubgas

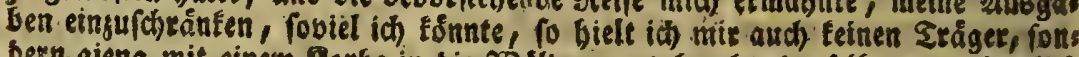
bern gieng mit einem Rosbe in oie 23 ślbet, uno brad)te benfelben gemeinigilo

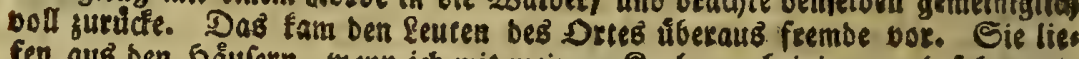
fen aus ben $\mathfrak{f}$ ăfern, roenn ich mit meinem Rorbe vorbeigieng, unb faben mit

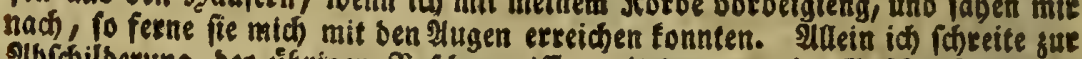

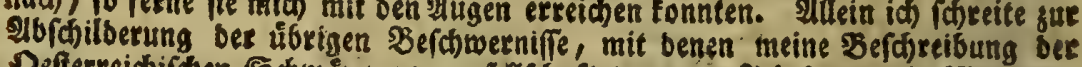

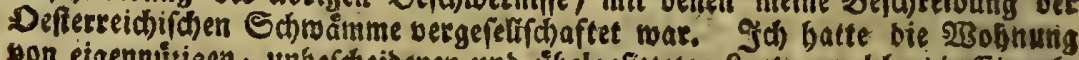
bon etgennugigen, unbefbeibenen uns úbelgefitteten Seuten, weldie bie Finnabs

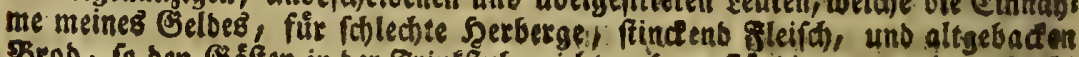

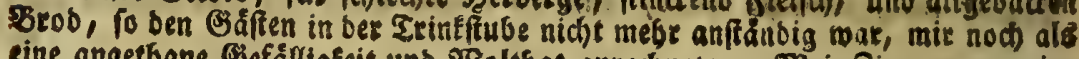

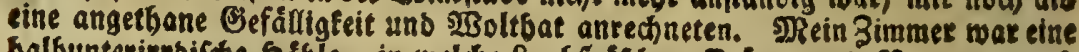

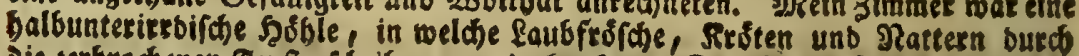
Die zerbrodenen grenfterfheiben ju mir frodsen. Den Eaubfesfden gefiel bas

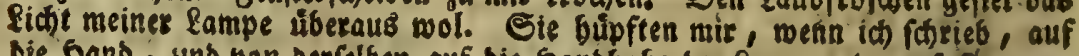
bie Scand, uno von Derfelben auf bie Sanobabe bet Rampe, Dacauf fie ganje Stumben fizen blieber, blinjelab in bie nobe flamine faben, unb ibe artiges 
meldber idf bie Befbreibungen gu jeber (Jattung auffeste, uno biefes aus mel)r ?(bficten, bie id angebeutet und glúctich erteicht babe: Um aber Den Siebbabern bie rechte Zorbiloung einer jeben meiner gejehenen ars

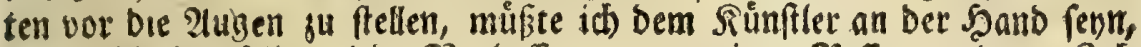
Damit id Demjelben die כjerbefferungen meiner Riffe angebe. Sob múpte aud) zu ben gut gezeichneten, bie red)ten Farben aller Sheile aus

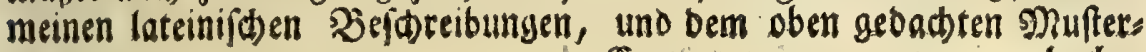

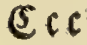
buめe,

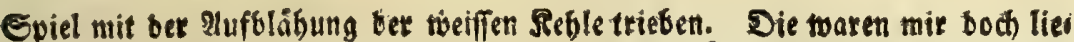

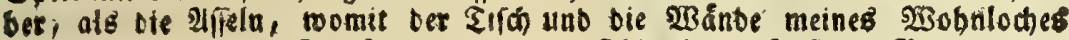
wimmelten, wie bie SBettfatt mit andern Sbietden. Shuf ben Brettern bes GuBbobens mucts eine feltene $21 \mathrm{rt}$ DeB Agarici, weld)e biefleicht nod nicht bes (h) rieben ift. Diefer Edwamm exfúllte meine 20 obnung mit einem burdjorins genben, nidte ftinfenden, allein to:gen bet Şeftıgkeit unertråglid)en Beruct)es

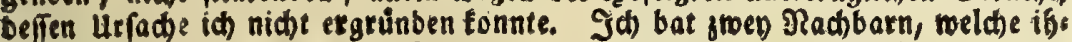
re Simmet gleio') neben Dem Reinigen batten (einet mar ein $23 e b e r$, bet ans

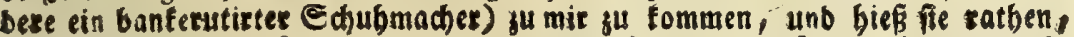
wober bet (Serud) tåme, Den id feit einigen Zagen verfpurte. D! fagten fie

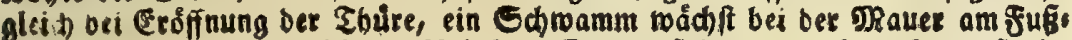
boben, uns fanben benielben atrobald. Sie berficterten mids auds, Daßj biee

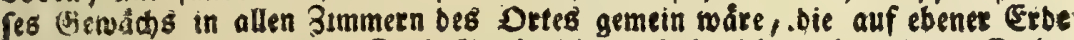
angelege unb feudt finb. Diefe \&usforfdung babe id bod meinem setfet

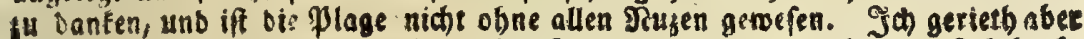

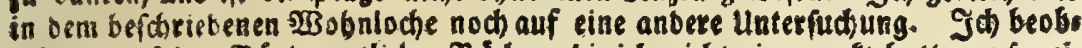

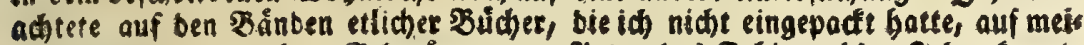

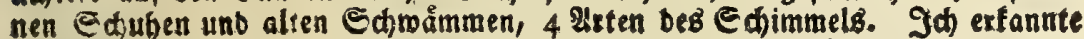

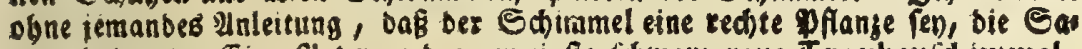
men bringet. Fine Alt war ber gemeinfte fidwargraue Traubenidimmel

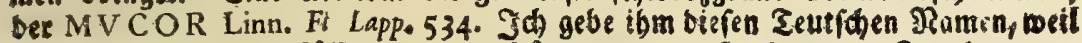
bie runden Eamengefälie, uno oie Gäben, bakan fie bangen, Trasaben bots

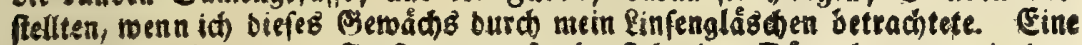
anbere 2hrt bilbete einen forft von aufred)t ftebenoen Băumden vor, in bem

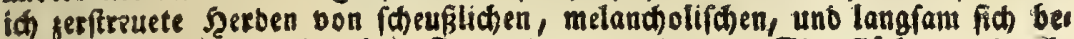
negenben Thieren wabrnabm. Die reibeten barinnen. Sie pflúdten nicht obs ne \$ुabl bie Samenbólldell ab, unb fraffen diefelben. Sie faben über uns

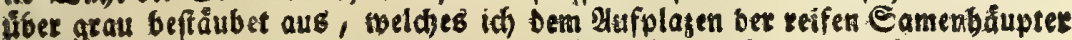
jufdrieb, bie grauen Etaub enthalten. Mit bloffem 2luge fab id nidhts oox

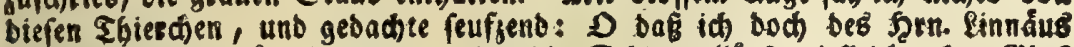

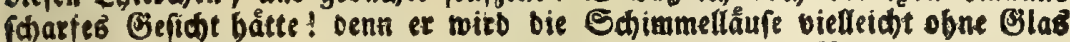

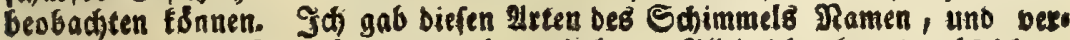

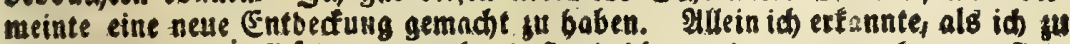
Regensburg meine Butcher auspactite, Dấ mir f́chon anbere juoorgetommen finb.

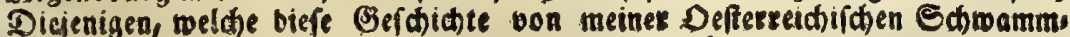

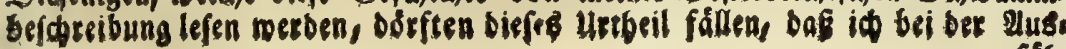


budbe, anfagen, ein und anders auch aus ber nod frifden Erinnerung beifügen. 2Allein es ift einem Jerleger nidt zuzumutben, Das er mir auf ein ganjes Sabr ben Unterfalt beridaffen foll. (Da id nun mein funf:

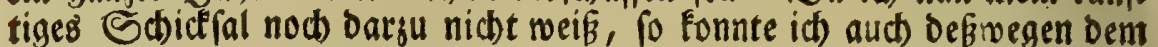

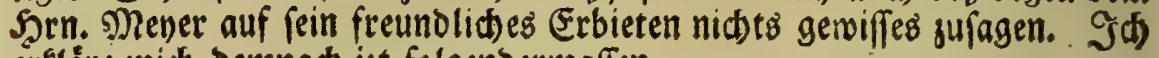
erflare midh demnach igt folgenoermaffen.

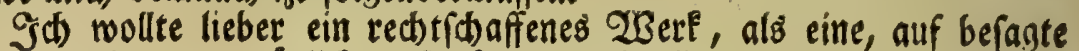

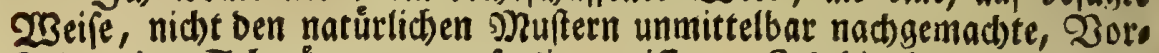

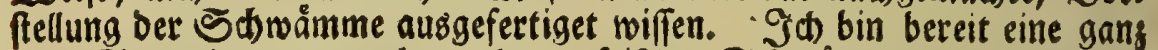
neue Sammlung su madsen, Deren frift)e Sdiwamme von erfabrnen Runftlern alfofort nach ber গatur follen mit lebbaften Farben abgejobil bert werben, um nad biefen 2 orbilbern illuminirte Supferfiche zu er: balten. Die Eintbeilung foll gan neu erfocinen, allein mehr auf bie Erleidhterung oes 2luffuchens, als auf bie Ratur gerichtet fenn. Eine

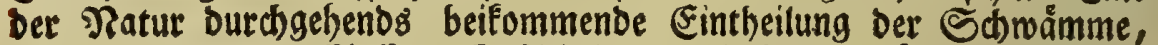
uad) Oromungen, Slaffen, (Sefd)lechtern und Arten, überfeiget nicht nur meine Iråfte, fonbern aud ben Begrif einer Móglidfeit. Sm

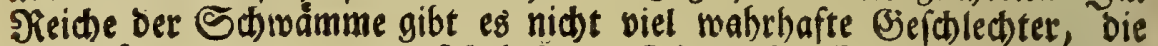
red)tmåsige 2irten unter fich baben. Die meiften find befondere felbfts ftebenbe (Sattungen, bie auch Defivegen eigene शamen erforbern, wenn

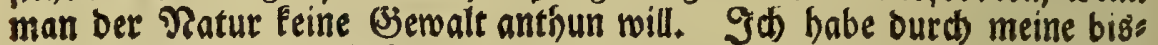
ber angeffellten Unter(ud)ungen uno Betrac)tungen ber Бd)rámme fos biel erfabren, daß̧ (oon ben bloken शamen nichts zu gebenten) bei ben meiften Die $\mathfrak{B}$ efdreibungen, bei vielen aud oie Figuren frudjtlos fino, wenn biefe bie Farben nid)t jugleid anjeigen. Der einjige Anblick cis nes gemahlten Sthwamms berichtet uno lebret ben siebhaber Deutlider

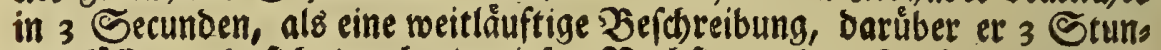
ben fåfe, uno fich ourd ein tiefes शadfinnen ben Sopf zermarterte.

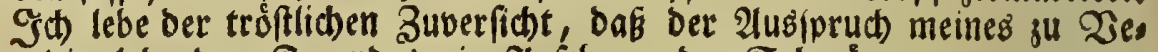
nedig lebenden Freundes, in Anjebung Der Sdwámme, von unpar.

teys

füheung biefes nigen find, Durch Deren Erjăblung Şr. finnåus Die Hnterlaffung feiner Pficht

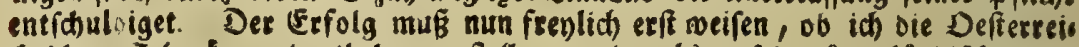

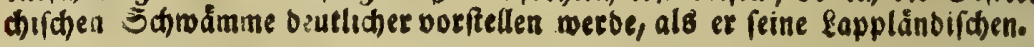

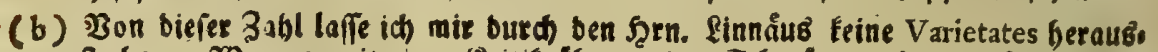
frechen. Wenn er mit einet Jitritif úber meine Étbwámme betaubitúcfen folf, fo merbe ich benfelben gu einer gruinolichern unterfuchung ber Sache, worúber

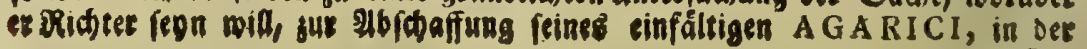




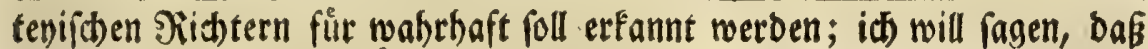
man Dasienge Urtheil für eine (Earbanifhe $2(u s$ f

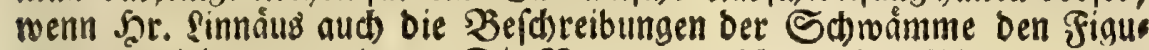
ren vorjugiehen vetmeinet. Die Namen, weldhe er ben झylanjen gibt, find eine Alt furger $\mathfrak{J}$ efhreibungen; nllein fie verbienen wol ben ges

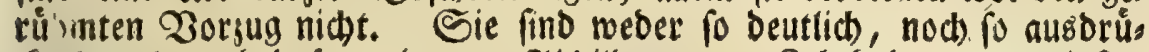
c'eno uno wabrhaft, als gute abbiloungen. Sch habe gum wenigften

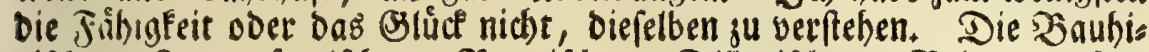
nifhen, Sournefortifthen, SRuppifchen, Dillenif(t)en, Beinamen fmo

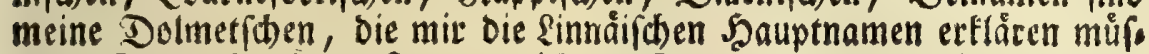
fen. Sene leje id juerft, wenn id die $\mathfrak{B}$ ebeutung biefer einfehen will. Shene Die Beinamen wúkte id) vielmal fo wenig, von was Sht. Sinnảus rebe, als id aus feiner FLORA LAPPONICA abmehmen fann,

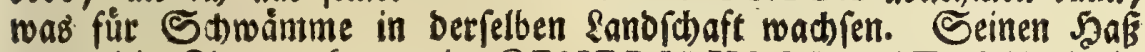
gegen bie Figuren hat er in GENERIBVS PLANTARVM, in RATIONE OPERIS, n. 13, mit folgenden 260 orten an ?ag geleget: Icones pro determinandis generibus non commendo, fed absolute rejicio, licet fatear has magis gratas effe pueris, iisque qui plus babent capitis quam cerebri. Niemanden wiro es, meines Erad)tens, fu verargen (eyn, weld)er bei Durdilefung biefer Stelle fo denEen foll: Denn Der $5 \mathbf{r}$. Verfaffer bier wabrgefbrieben, fo muf er entweoer feine Sdrif:

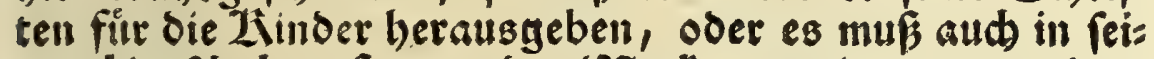
ner Sirnfकale anfangen ses Mrarkes weniger $3 u$ werben, oa er feinen Werten felbft siguren cinfot)altet. (c)

Darnach habe id burds meine Unterfudungen biefe $23 a b t 5 e i t$ ers Eannt, baßs bie Abtheilung Der blåttridten Sctwodmme, wegen ber Nenge foldher Arten, Dem Derfaffer einer beutliden uno gefwicten Einleitung Die groffe Sd) wierigfeit verurfab); ferner, bas bie Eins theilungen, oie man auf bie Jiroffe der Sdmamme, auf bie \&ănge

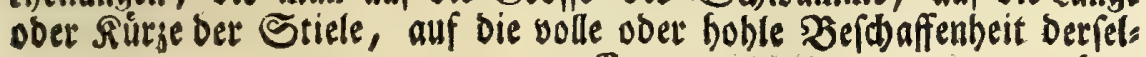

$\mathfrak{C} \mathfrak{i c}{ }^{2}$ inil,

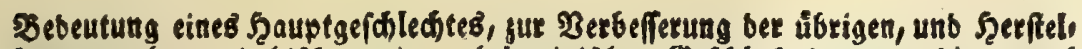

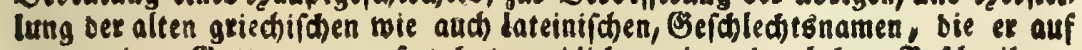

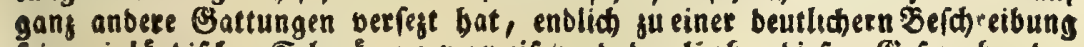

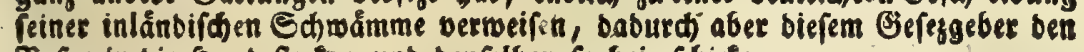
Sefen in bie Şand ftecten, unb benfelben fo beimichicten.

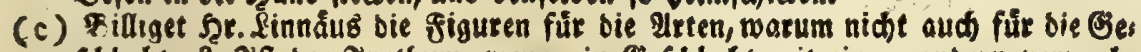

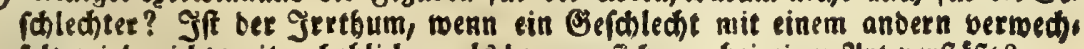

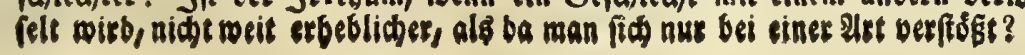


betr, oder auf Die Farbe ber Fęute uno Der Samenblätter gruinbet, alle irrig und ber ?atur zumider finb. N)ian mag eine biefer Derfaffun. gen erwåhlen, weldse man wolle, fo wird fids bei bem 2 erfolge und Der 2lusfúthrung finden, baß eine jebe berfelben ben naturtlichen Bufam. menhang vieler wabrhaften 2 irten trenne (d). Td halte gegenwártig bie åüerliche befondere Beftalt Der Schroamme nod für bas leichtefte Mittel, fie auseinanber zu bringen, obne baß man bie Ratur zu viel

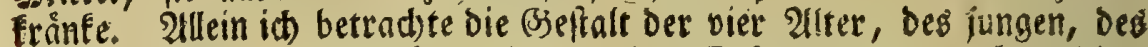

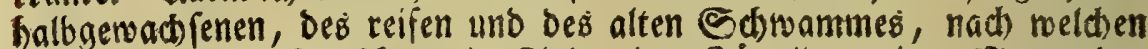

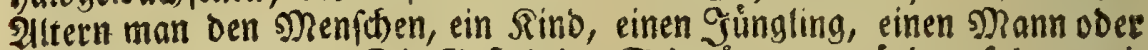

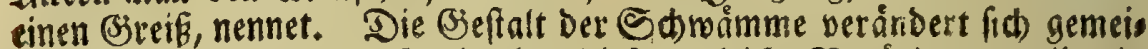
niglid nab ben Altern. 2llein eben biefe ungleide Zerwinecrung gibt ein Mittel an bie Scand, fie ju untericheiben. S(b) wollte meine Einleitung

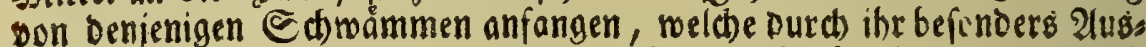
fehen, yor andern fennbar find, und biefés zum $\mathfrak{B} e f t e n$ berienigen, mets

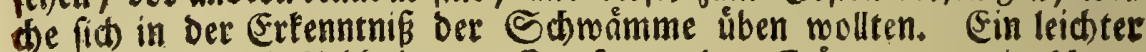
2miang reizet ben siebbaber fur Fortfesung ber Erơnterung; ein fotwes rer fitrectet senfelben von ber gångliden unternehmung ab (e). Tat getraue mir aber gleidsod, nad biejer Eintbeilung bundert und mehs 2irten

(d) Die FVNGI umbilicum referentes C. E. obet bie lin Teutidlans wol

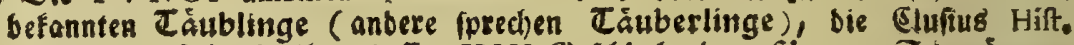

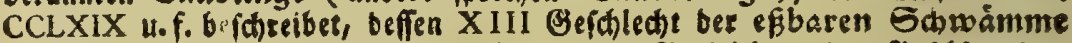

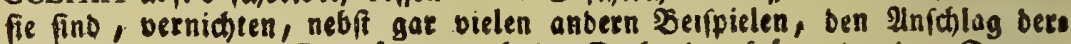

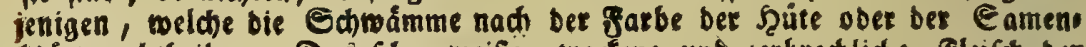

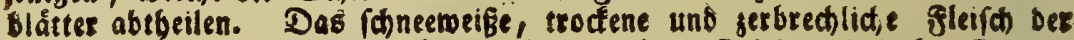

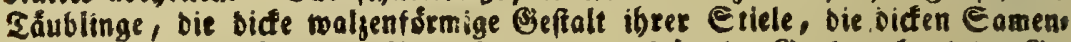

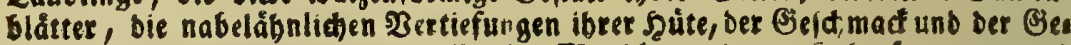

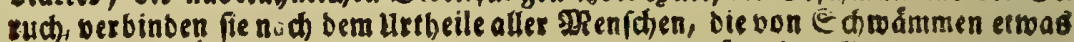
miffen, unter ein (E) als ein getúnfteltes nennen. 280 olte man aber in Infebung ore farbe ber $E_{a}$ menbtätter eine Eintbeilung vortebren, fo mỉBte eine Irt Der Táublinge uns ter bie (Elaffe LA MELLIS FL A VIS, bie úbrigen unter biefe, LAMELLIS ALBIS, geworfen, mithin bie naturelid)e Berwandtich aft gerriffen merden.

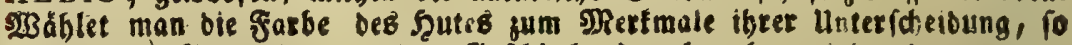
werben Dieje 2 trten eines einjigen (E) Denn bei einer ift ber Şut leberfárbig, mit Puspur untcemenget; bei einet anbern grau, bei bet deitten blutrotb. Diefe Met ift nid): efbar; beifit in Dberofferreid) Speibtäubling, o i. ein Cóubling, Jer (peyen madbt. Die

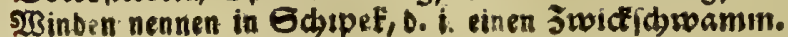

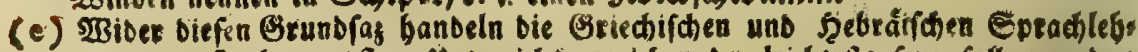

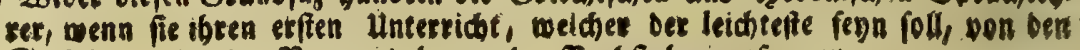

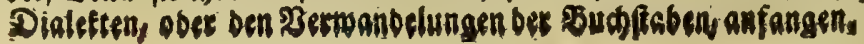


Irten ber Edbåmme fo deutlid vorguftellen, bas benjetben jedermann meine $\mathfrak{\Re a m e n}$ foll beizulegen wiffen, bem eine biefer 21rten irgenbwo zu

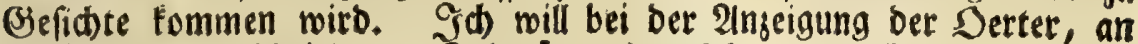
benen meine beidriebenen Shwämme wadfen, es nidjt machen, wie Sct. Sinnáus, weld)er allein biefes beifejet: Habitat in Lapponia, babitat in fylvis, babitat in pratis \&c. (Ex nemet nur bas \&and, und zum bơ ften die unbeftimmte sage ober bie Stelle, ob es ein $23 a l b$, ein

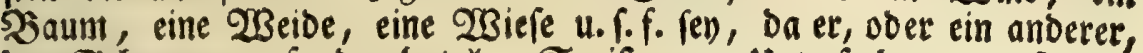
Den Shtwamm gefunden bat*. So ift er vor unterfuchungen gefitbert,

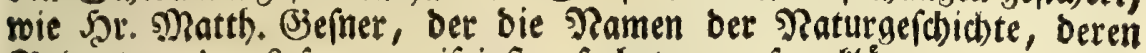
Reobutung ber Eefer am eifrigften fud)et, nur fo erfláret, avis genus, picis genus \&c. Soldbe Şerren fobreiben mabr, allein fie unterridten wenig; uno bie ß̧egierde, mit eigener (Sefahr andern zu bienen, balten

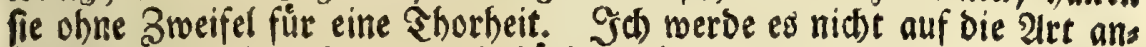

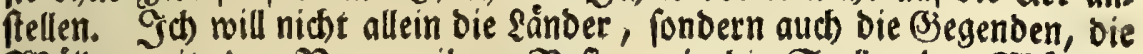

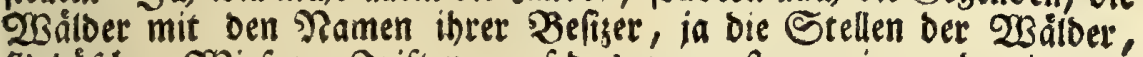
Gebưfhe, $23 i e j e n$, Triften, auf bas̆ genauefte anjeigen, Damit man auf meine Indeutung bie benannten Schåmme finde, und bie Siebha. ber, weld)e vielleidt Daberum wobnen, fid) an bie Derter verfuggen fón. (SCC 3

nen,

Ja) babe geftern bei eittem guten freunde bes şen. linnäi FLORA M SVE. CICAM juerft gefeben, und beobachtet, bẩ et in Schroimmen fich ein wes nig gebeffert babe. Denn bei ben Echmedifhen tonnten ibm vie Ent(d)ulbie

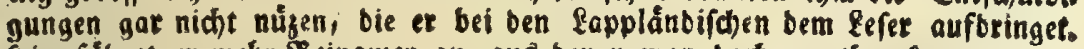
Şet fứbret ex mebr seinamen an, aus betnen man bo() exratbent fann, was ex burch feine vermummten AGARICOS exfebe. Mdeen sie Inzeigen bet Seburteofrter lauten mut fo: Habitat in fylvis. Habitat in Lapponiz fylvis, ober in Lapponia fylvatica. Habitat in fylvis Dalekarlix. Habitat in pratis, Habitat in pratis fylvaticis ober fylveftribus. Habitat in pratis et pafcuis. Habitat in pratis Weftrobothniz. Habitat in Norlandia, Habitat ad domos et

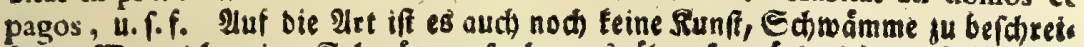

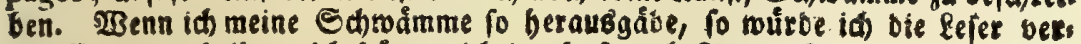
anlaffen zu urtheilen, ich båtte mich Durd) to unbeftimmte IInzeigen vor शach) foridhungen vermabren mollen, ober ith bátte meine Echnơmme aus anbern Floris betauggeforrieben , uno nut Das habitat in pafcuis Stiriz, habitat in pratis Cremifanenfibus, habitat in filvis circa Ratisbonam jacentibus, Daxfugefeft.

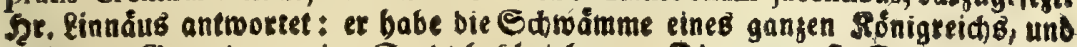
nid)t ber Eegent um sine Etabt befdrieben. Die genauefte Fenentung bet

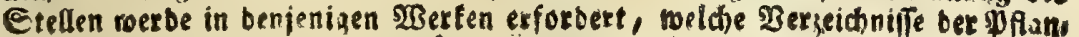
zen von fleinern tridjen dex fánber, ober von Feviersn ber Etäbte borftels

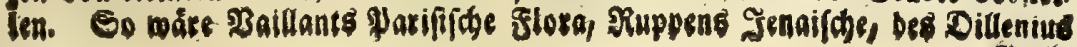
Giefin: 
nen, forol um bie Urbilber ber Supferftiobe ju betradten, ob fie nadts ber Satur gemacht fino, als auch um $\xi u$ unterfuchen, ob id meinen $2(x:$

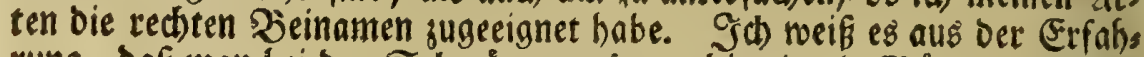
rung, bas man bei ben Sd) wammen rogar Die eingeln $\mathfrak{B}$ ñume nicht ob:

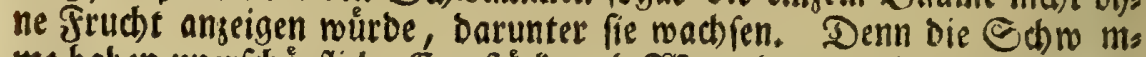

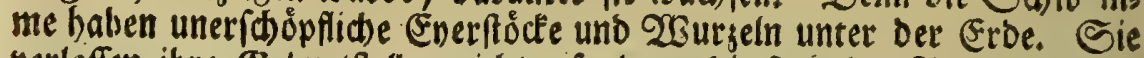
vertaffen ibre Beburtfellen nicht, to lange bie \&age bes $\mathfrak{B} 0$ bens, und Die Heberfatattung Deffelben Feine Derånderung lerbet.

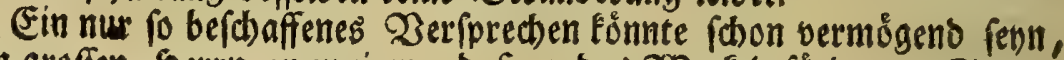
einen groffen Sherrn anjureigen, Dás er Das 2 BerE befórbere. (Fin ans

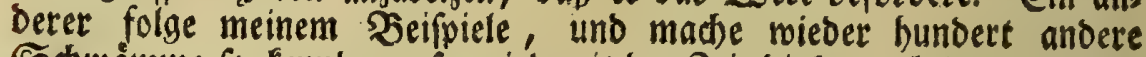
Sc)måmme fo fennbar, fo wiro mit ber Zeit biefer noch Dunfle Sheil

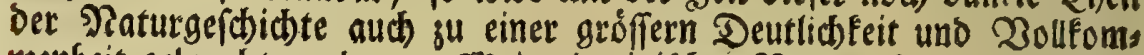
menheit gebradbt werben. Freine lateinishen Namen follen wegen bet Nenge ber erridteten (jechlecter, furser fenn, als bie bisher aufges bradjten. Die alten will id alle bebalten, und fie ihren rechtmáfigen Arten suftellen; allein ibre 3 abl muß mit vielen neuen vermefret werden.

reine

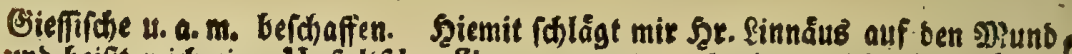
unb beift midh eine Upfalifbe Slora ermarten, barinnen id alle $\mathfrak{B a t b e r}^{2}$ Seftáube, Wiefen, Inger zc. um biefe Stabe bei ben Sthmámmen wetbe bé nennet finben. 2Allein bamit id) für biefesmal nid)t gånglich febl gef(h) offen bas

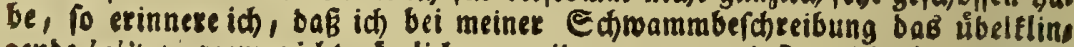
gende babitat, wenn nid)t gånglich vermeiben, gum menigften nidist fo oft fezen,

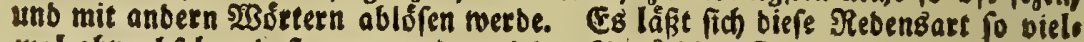

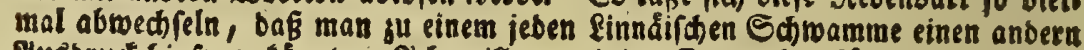

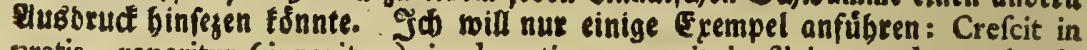
pratis, reperitur (invenitur) in dumetis, provenit in filvis, gaudet umbrofis faltibus, occurrit juxta femitas, amat aprica pafcua, fectatur querceta, faliata \&c. frequens in pinetis, non rarus in coryletis, occupat numerofis gregibus filvarum areas, nafcitur in fterquiliniis u. f. f. Slufius, unb anbere, brau! c)en aud bas emicat, profilit, oritur, in filvarum marginibus \& 8 .

golgenber füge ich allbier an, weil bie $380 \mathrm{~S}$. Fhon abgefeft ift, weldhe Stelle fite

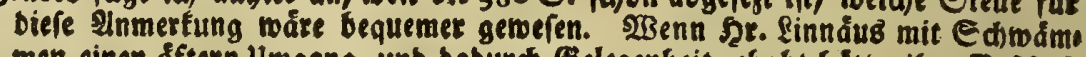
men einen fftern umgangr unb baburd) Gelegenbeit gebabt badte, ibre Befobaf fengeit beffer einjufeben, fo wirbe ex anfatt feiner unmisen Riryptogamie, 6. meldhe eben foviel exfláret, als bie QVALITATES OCCVLTAE,

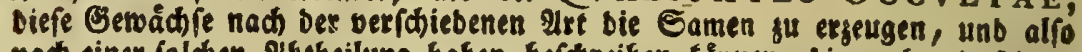
nad einer foldhen 2lbtbeilung baben befdreiben E\&nnen, bie nod) mit feinets Syftemate Sexuali wåte verwanbt getwefen. Er båtte bie Sdmadmme in belele Oronungen, in Fungos LAMELLIFEROS, FISTVLARES, CIR- 


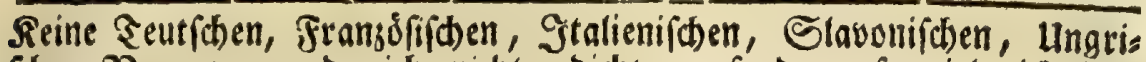
f(t)en शamen, werbe id nicbt erbidten; fondern fo viele id bers felben weiß, ober nod) ausforithen fann, bie follen alle mit ber 2 inseige, in meld)en \&anojhaften ober ifren (Begenden, fie gebråuchsich find, fu ben lateinifoten gefest roerben. Piurnberg fabeinet fur P(usfültung biefes $2 B e r f e s$ ein tauglider und vortheilhafter Ort ju fern. Es liegen allents balben weitlïuftige Bebstge um bie Stabt; in berfelben gibt eg eine

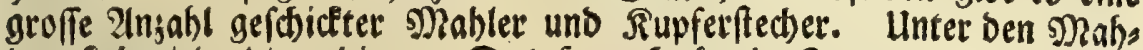
lern find viele, Die rabiren. Des Shrn. Szoftaths Srew auserlefene und bollftandige Sammilung der botanifhen $\mathfrak{B}$ údber wåre ak Det Sand, gu yelcber mir ber zutritt bergeftalt offen ftebet, Dak mir aud in ber

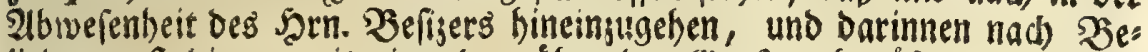

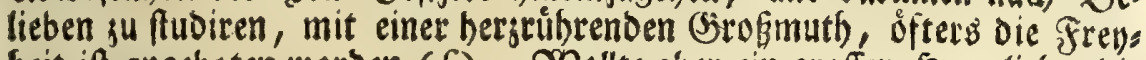
beit ift angeboten worben (f). Woolte aber ein groffer Şerr lieber bie Sdwåmme feiner Begend fo abgefthiloert, und alle 2 Binfel feines Bjes bietes, wo fie roachfen, benennet niffen; fo bin ich bereit úberallhin zu

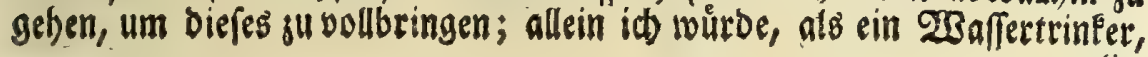

RATOS, BRACTEATOS, CLAVATOS, RAMOSOS, TVBEROSOS, LV T VLENTOS \&c. untericheiben, und Der etfen Drbs nung biefen ritel geben fónnen. FV NG I femina e lamellis radiatis emitten. tes. Das find bie blåttrichten Sđhro̊mme, Die ins̈gemein fungi lamellati

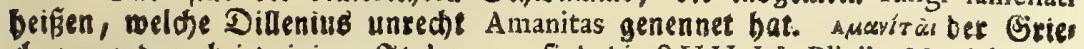
chen, uno nod) ift einiger Staliener, fino oie S V ILLI Plinii, Martialis \&c. b. i. unfere Fil3e. Die úbrigen Italiener fprechen mit ben fateinern ba fie bie Pilje porsini nennen. Die grente Dronung bátten begogen bie FVNGI femina e filtulis ejaculantes. $\mathcal{D a s}$ finb bie fungi porofi ber Ed) wammbefchrets ber, ober alle 2rten ber Dilje, weldhen Rupp unb Dillenius unred)

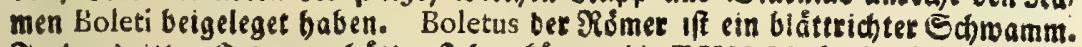
Iñ ber Dritten Oronung bătten fteben fơnnen bie F V N G I femina in cirris pro-

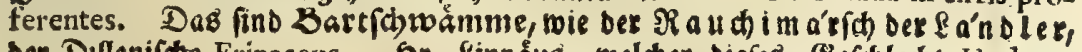

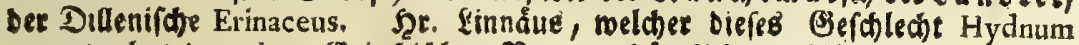

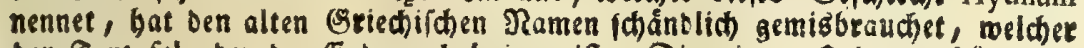
ber Tartufel ober ber Eromordjel eigen ift. Die sierte Dronung bătte Scr. Einndus einråumen fơnnen ben FVNG IS femina e toto corpore brąeato fpargentibus, Dergleichen find (d) on r) Die Morchellæ Dillen. ober - Die eigentlid) fo geuannten Mordeln ; Der Sayern, Defterteicher, Stenetmårfer, Matra. den; 2) Die 5erbjtmord)eln, Der Regensburger Pfafrenbite, Der oritte Siuppifac Boletus, p. 302, ober ber fungus velut apex flaminis Plinii Menzelio; 3) ore Dill nild)en Pezizæ. Wenn eine Jeerbftmordbel, odor bie Peziza miniata major Dillen. ju etner gemiffen - Zeit (einen Sag nad) Der Eammlung) angerúb̆

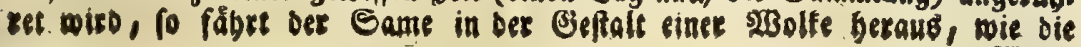


tieber in ein warmes fand, als in ein Faltes; mit grofferm Dergnigen nach Stalien, ober in bie füblichen Eandfctaften von Franfreich, als in

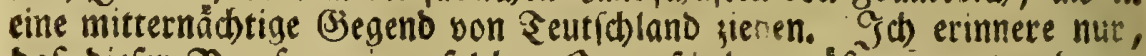

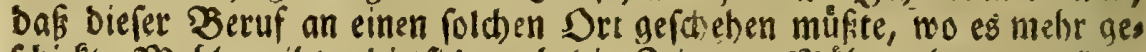

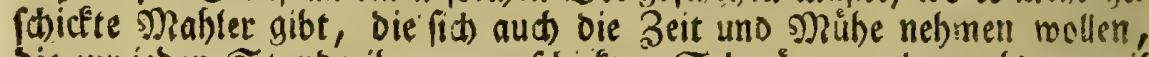

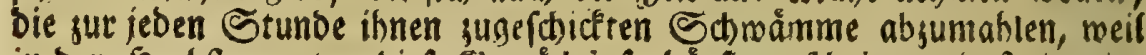

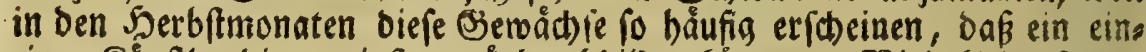
giger Rủnfter bie wenigften wưrbe abbilden fơnnen. Biele fleine Arten wad) fen in einer Padt) aud) unter biefen fo zarte, baf fie in einer balben Ninute zufammenfals len und verwelfen, wenn man fie abbrict). Die Farben verảndern ober

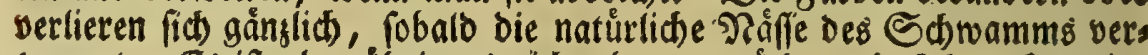
treuget. Es ift aber úbrigens nid)t eben vonnothen, baß Der Srt eine Stadt fey, Deffen Schmámme follten befbrieben werben. Man fann biefe 2irbeit noch mit grofferer (Semád)lid)eeit, was bie Sammlung bes langet, um ein Sdblop vornebmen, weld)es in einer walbreiden (B)egend liegt, und bahin man bie Mabler, ober junge unberbroffene \&eute, wels de bie Mablerkumf verfteben, fơnnte Fommen laffen. Es wáre auds

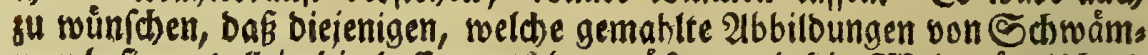

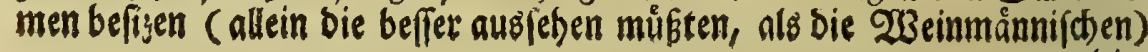

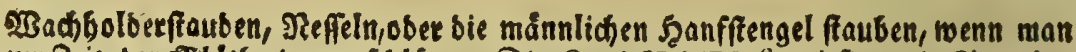

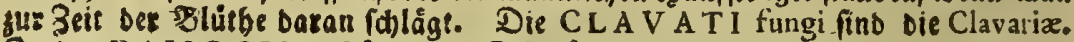
3u ben RAMOSIS geboren bie Sdinåmme, bie nad bem Untericheide bet

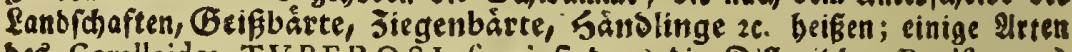
bes Coralloides TVBER OS I fungi finb 1) Die Dilleni(d)en Bovifte; 2) Tubera, bie Cartufeln; 3) Das Lycoperdaftrum Micbelii, fo ber Defterreicher 3runftruge!, unb mein Aphrodifion iff, aud) nod) anbere (Jattungen mebs. Den

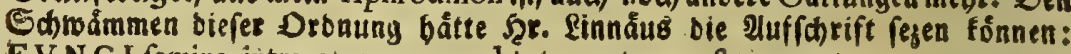
F V N G I femina intra corpus, quod totum uterus eft, gerentes, eoque rupto illa diffipantes. Die LVTVLENT I fungi finb bie Gidntmordeln, Phalli. Diefe friecten aus einem Ev bervor, wie bet Boletus ber Piómer, allein bas

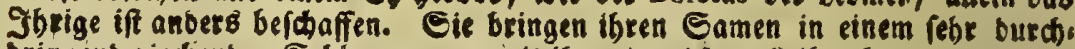
bringenb riedienben Eablamme, womit ibe gitterichter feib, bei andern Bats tungen abee bas Scaupe úberfleiftert ift. Jih úberlaffe es Dem Urebeile Des Peferz, of nicht blog ein folder Entwurf, bet mit feinet anbern Beifúlfe,

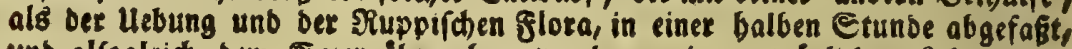
unb alfogleid) bem Eejer übergeben toorben, eine extróglidere febrart ges wefen máte, als bie Rinnáıfhe Sityptogamie.

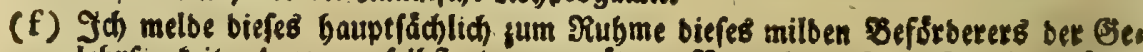

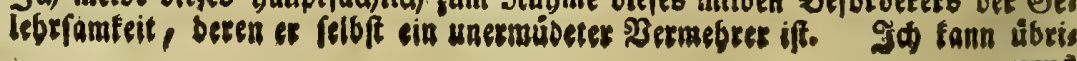


biefelben, bei einam vorsutebrenben 28 erte von S\$brammen, sur 26

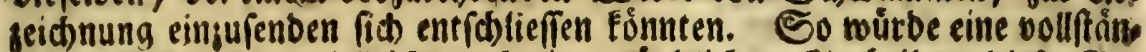
bigete (Sefdid)te, bielleid)t aud eine grúnblid)ere (Eintbeilung biefer (Ses sód) fe su berfertigen fenn. Enblich wáre baraus abjunebmen, melde Sdbrodmme allen fándern gemein, uno weldbe bagegen einigen berfel, ben eigen fino. 2Bill ein anberet bie bier entworfene 2lrbeit auf fios nehmen, uno nad msiner, ober einer beffern Derfaffung, ins $23 e n f$ cidsten, bem uberlaffe id) von Sserzen biefes (oluef und Vergnugen. Sa i i) will bemfelbell nod mit einer Inleitung bienen uno ratben, Dẩ et nach Dberofterteid sefien foll, wenn er eine redte Comamme fd) ule, in cinem engen Saume, beifanmen zu feben verlanget. Das if aus allen so̊nbern, bie id) betreten babe, bas frudtbarfte an Sdroàm:

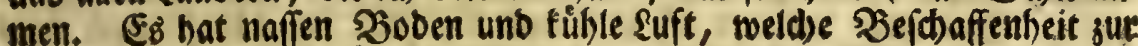
(Erjeugung ber Sobnámme exforbert wiro ( $g$ ). Ulebrigeng mus id ben guten spann, Der in Diefe Begend gu fommen, unb bie Sdorómme berfelben zubeid)reiben suft bat, als ein Freund marnen, baj er auch (Belb mitbringe. 2luf biefes Deripred en, Daf er die शaturgejoidte zu bee fordern millens fen, muß ex fid feine Rechnung mad)en, bafi ibm je: mano einen $\mathfrak{B}$ iffen $\mathfrak{Z}$ rods reidjen werbe, es fey benn, baj et zu einet gluctlidern Stunbe bie 23 elt crblictet babe, als ib; ober es múften DOD

nut

genb ben Refern nid)t betwebren, biekaus, unb aus bem, was id in bet शots rebe berichtet babe, bielletht ben Shlus gu machen, bas id auf meinen

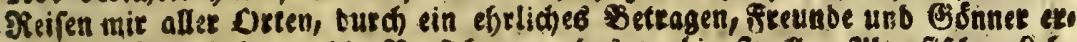

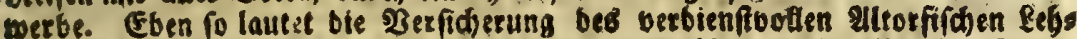
rexs, beffen bohfdabbarer Ramte auf bem Titetblate biefes 2 ertes febet. Er fónceioet mix in leinem lejten: Si Altorfii commoratus fuifres, totos dies, etiam me abfente, inter libellos meos defidere tibi licuiffet. $\mathfrak{N B}_{\mathrm{B}} \mathrm{B}$ et biet libellos nennet, if eine Sammiung von ouberlefenen uno toftbaren Sühetn, bie etlidhe 3immer cinnimmt, unb bie Bugånge ju benfelben enge macht.

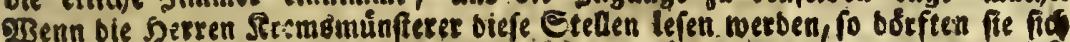

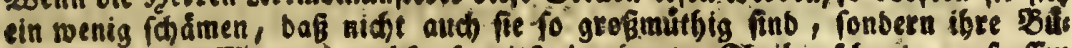

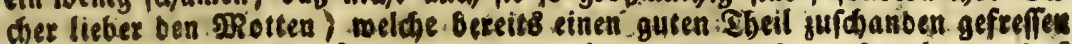
Gaben, als Reuten vergónnen, welche verlangen etwaz barauв gu lernen, bas bod tbeer ilfabemie wieber guftatten fâme. O bet defabemie! welche bes 2ufbelfens bebirftig if ober....

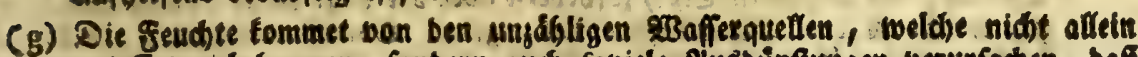
bas Erberid benejen, fonbern aud fobiele 2lusounfungen verurfachen, baß

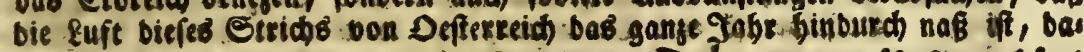

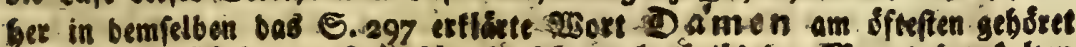

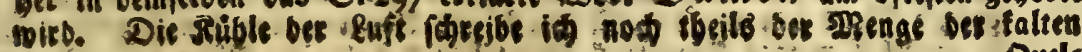
i. Quels 
nur gewiffen feuten, auf meine bier gefübrten Slagen, bic Scisuppen exft yon ben 2lugen fallen.

Wenn ber meltberúfminte Boerhave nod lebete, uno erfabren bàts te, bas id im Stande fer in Sabảmmen etmas vorsunefomen, fo bin id berfictert, baß ex mir fehr würbe angelegen haben, ich mód)te bie Schrammgefdiledter bes Elufius in ein grófferes \&idbe fesen. Er mar ein fonberbarer Derefrer biefes Pieberlónders, unb ich meí, wie febr Derfelbe ben Dr. Baffand feel. mit abforderungen Der Defferreichifet)en Samen geplaget habe. Er befimmerte fíd) ungemein um oie Pllangen, welde (Clufus in Oefterreid beobad)tet und befodieben hat. Igtges rúhmter Dr. Faffand (Damals Srobberzoglicher Tofennifd)er Seibmes bicuß) (agte ofters zu mir: Si Boerbave vivoit, vôtre fortune feroit faite. Boerhave bebiente fich in feinem INDICE ALTERO aud) farf

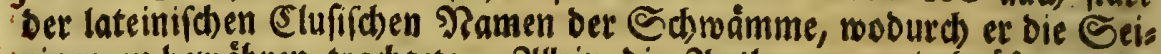

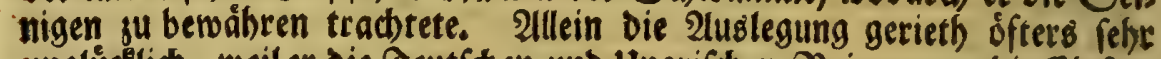

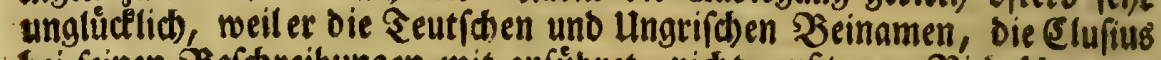

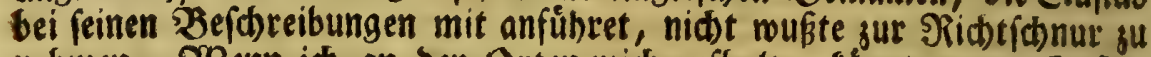
nefmen. $23 e n n$ ich an ben Srten mich aufbalten fơnnte, wo Esufius

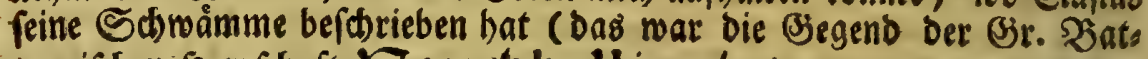

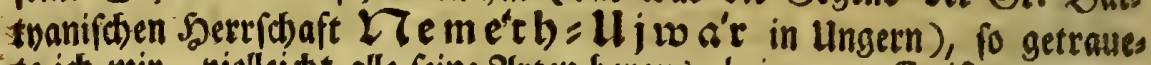

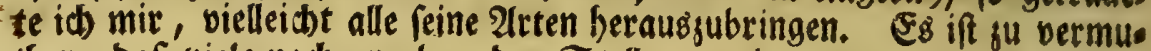
then, bas viele nods an eben ben Stellen werben anzutreffen fenn, wo fie vor anderthalbhundert Gahren gewad) ien fino. 2allein wem máre bamit gefolfen? überfäme man burd biefe 2lusforfdbung gute 21bbilo

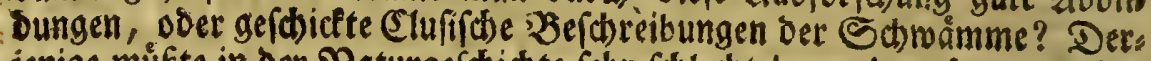

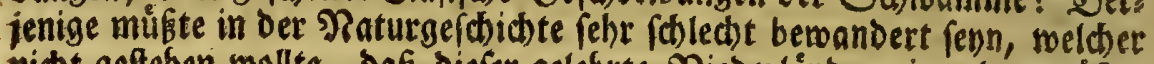

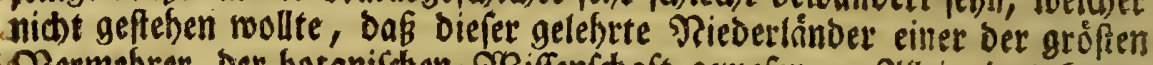
Wermebrer ber boranifhen. Zsiffenichaft geweren. 2llein bas fann, nnch meiner wenigen (Einficht, auch babei nicht gelăugnet werben, oás bie abfandlung von S Shwámmen einer ber gerinaften Werbienfte biefes

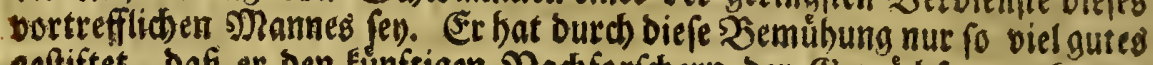

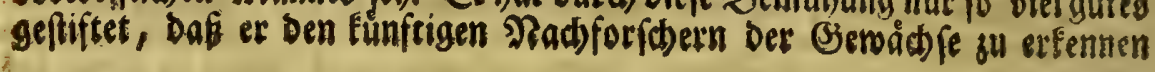

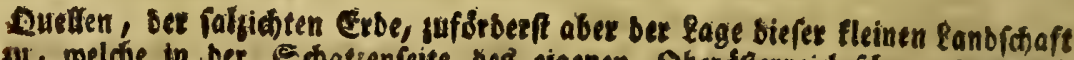

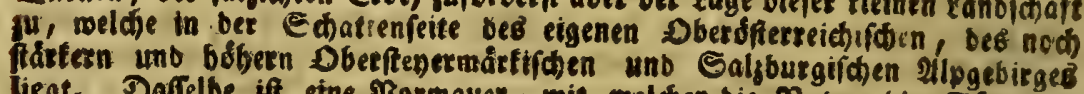
liegt. Daffelbe if etne Bormauer, mit welcher bie Vafur bie Sib. uns

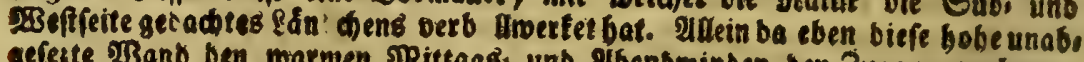

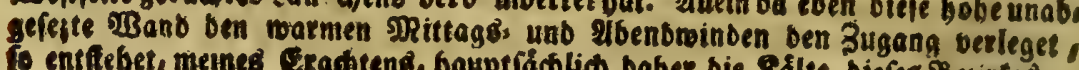

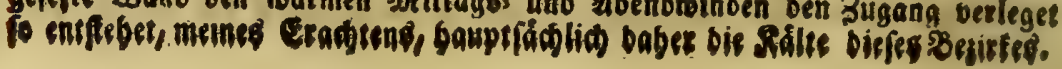




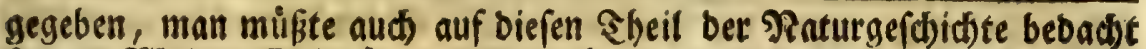

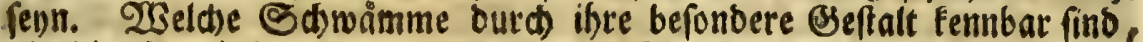
al6 bie grordhel, ber Raiferling, ber Ziegenbart, bie Bidtmordel, uno nod) einige andere, bie fudt) man nidbt vergeblid) in bem (Slufifhen 2Berfe auf. Fllein wie viele anbere find, ungead)tet bet barjugeftel.

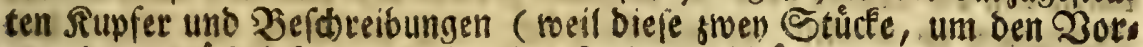
gug ber Untuibtigfeit mit einanber ftreiten) bisiser unausfindich gewes fen? 2Benn feine gemah) (ten Figuren nod) vorbanden fino, und biefe ies manb auf bie 2irt herausgeben wolite, wie man feit einigen Jahien ver. fobiebene Stucke ber Paturgefchid)te gu Plugsburg, Nournberg und ans

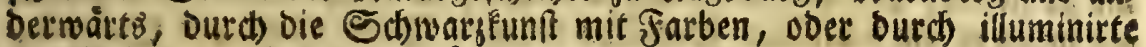
Supferfiche vorftellet: fo wurben biefe mit Farben gemadise $216 b i l$ ume gen, nebft ben blofien beigefesten श्amen, Das mievielfte GENVS Efculentorum ober Pernicioforum fungorum Des Clufius jebes Stưce fey, mefo nusen, als feine ganje 2lbhanolung von Schnåmmen. Seim groffer Soonner, ber zu berfelben Zeit lebenbe Şalthafar Seer von ß̧ats

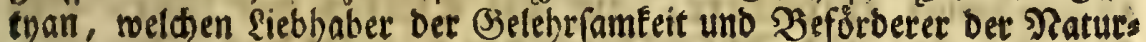
gefdid)te offters zu rübmen er ben billigften Intrieb gehabt, (dhergete

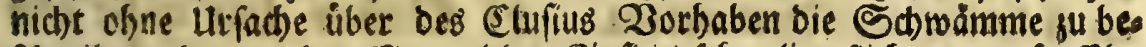
fdreiben, bem er ben Mangel ber (Einfid)t felfr glimplich vorwarf. (Elue. fius geftehet es felbft, nach) reiner betannten und beliebten 2tufridbtigfeit, Hif. CCLXXII, in ber ssefhidte Des Raiferlings $(h)$. 2Benn id

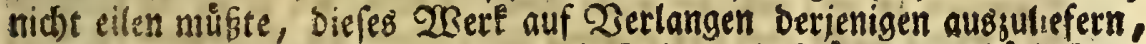

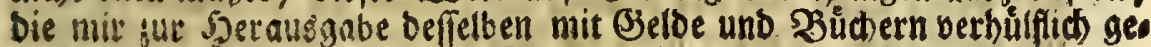
wejen, fo wollte ith nod) einen Bufas madien, unb in bemfelben von bee hiftoria fungorum bes clufus folgende Saje etweifen:

a) Die Clufifhen Zcinamen ber Ghwámme, welde bie Radforfher serfelben bei ibren Zeftreibungen sur

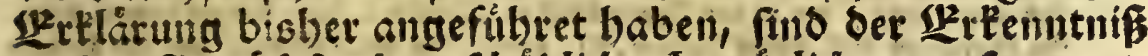

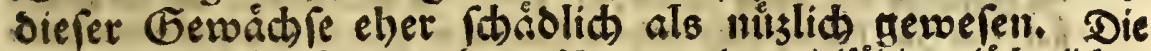

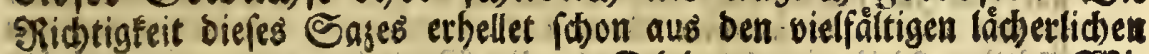
DOD 2 श्Sis

(h) Das if bas XVII Genus efcul. fung. Clufit, bet bextifnte BOLETV S bet alten Foomer, ben SRartialis fo febr berausftreichet, ber bie legte Epeife bes Ratiers Elaubius gemeren. Sein Rame ift (Eelti(́), bott bol rotundus, meit

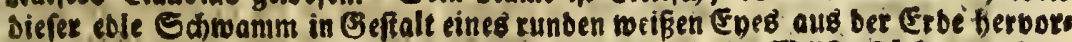
brifit. Die Ratur mollte butch feine Erfeuaung ein IR eifterfticf von ibter

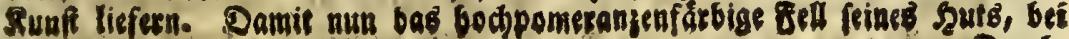


2Biberiprúden, wenn bie Beifbreiber ber Edomåmme hier swey) Elus fifhe (Sejhled)ter auf einen einsigen Sthwamm ausbeuten, 3. E. fein

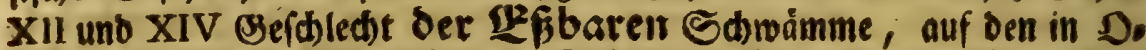
berteutítland, unter bem Namen Fehling, befannten Capréolinum Tabern. ben bie शRatur bod to beutlich geseidnet, und von nilen anbern

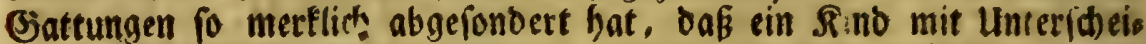
bung beffelben fich nidst verfterfen follte. Man beobaste aber bingegen aud),

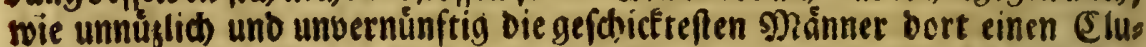

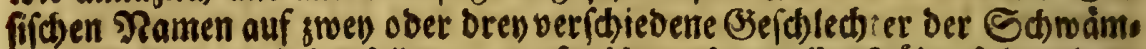
me gu sieben, uno benielben augizuforiden, fo groffe shibe fich geben,

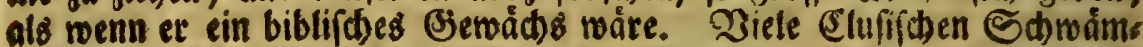
me fosnmen von benienigen, bie weber ungrifh nod) ₹eutich verftehen,

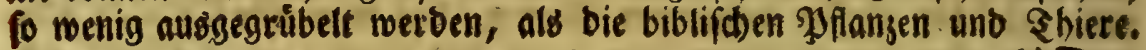

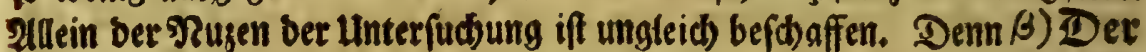
Dortbeil wurbe febr geringe feyn, wenn man aud alle Gdwónme entoedete, auf die Clufius mit feinen $\mathbf{3 e}$ : fdreibungen und 2abfólderungen gesielet bat. Die urias ae if bereits angefúbret worden. $\gamma$ ) Clufius bat nidt alle Gdwåms

Durbbobrung bet Exbe, nicht befdobiget metbe, fo bat fie ben jungen Edmamm in eine aufienber raube meife Edjale, wie in ein Ev verfoblofo

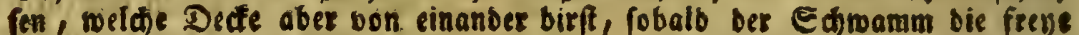

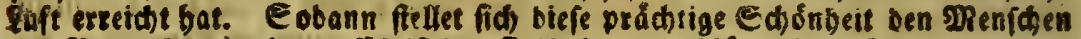

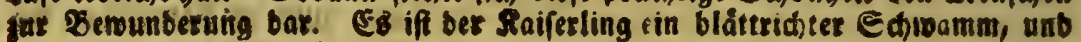

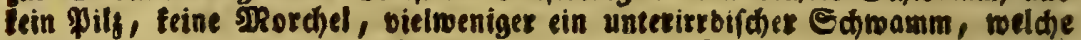

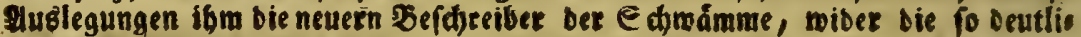

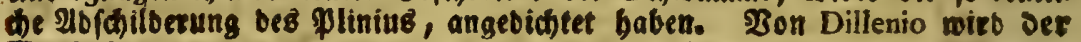
Ziaiferling genenner, AMANITA plana, orbiculata, aurea, Giff. 179.

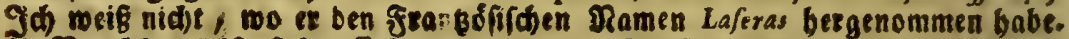

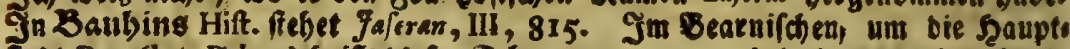
ftabt Pau (lat. Palum) beišt diefer Ehroamm oronge, uno in bet gemeinen fanbs.

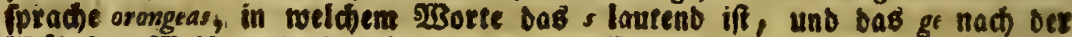

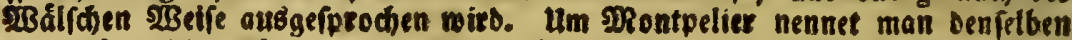
jaune d'iou, Magnol Bot. 103, man mill Daburdh jaune d'ouf fagen. Im Itar lienifhen-beifit ex boleto, su Reapel ovolo uno boiocciolo, nach bem Zetrgniffe bes Sorta; im Florentiniraben, um (omo, unb noh) anberwärt8, cocco. Det

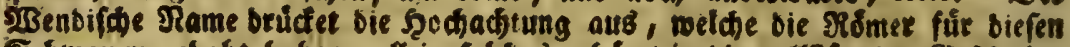

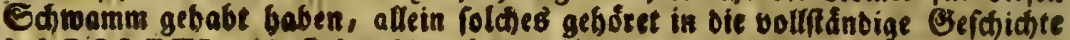
bes B OLETI, unb finbet biet feinen plas. Eetne 2lebnlidfeit mit bem Fungo mufeario miniato Sterb. fo bet rotbe Sttegenfdawamm if , bat in

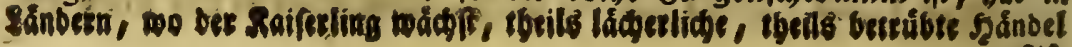
gepifi? 
Gdbrómme, die ex befdoreibet, felbft in ben rwálbetn ge: fammlet, fonberw einige aus ber Battpanif(s) Shicbe erbatsen, wie

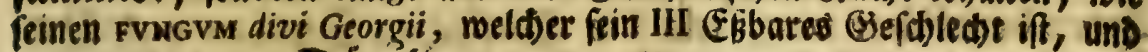
in Dberofferreid Dórnling beift. 2Benn er ibn felbft gefunben haitet te, fo wurbe er ben Stiel mit abgejeidsnet, und nictst abgeidonitten

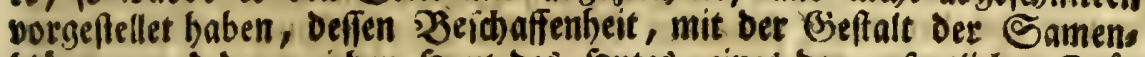

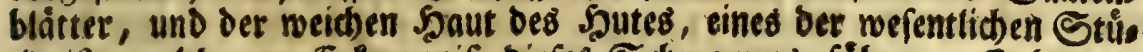
cle in, weldse sur Erfennenis biefes Sdhwamms fübren. Er hat eie

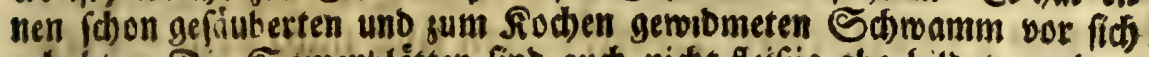
gehabt. Die Samenblätser find auds niche fleisig abgebildet worben. Die शatur hat fie viel feiner unb enger gemact. Tht fómnte argwobs

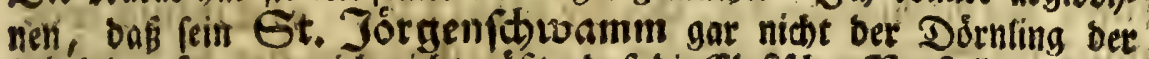

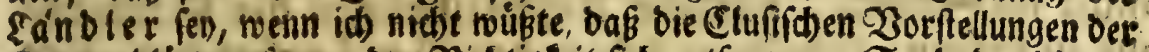
e antenblätter of von ber Fiidstigfeit fíb entfernen. So haben bie gat 3u weit auseinanber ftehenden groben Streife, monnit Glufiub bie Sa menbláster feines XIV Gen. efcul, anseigen woulte, viele Schroammbes.

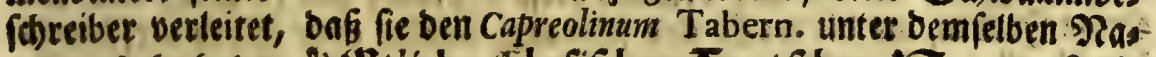

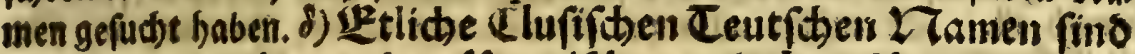
etoidtet, uns aus ben llngrifiten geoolmetfbet, nelder DOO 3 . les:

seftiftet. Diefe Eleidbeit verfẗbret úbxigens nue fold) Menfofen, bie in bet Unteríheibung bet Edhmámme nicht getibet fins, bie aber weber in bie

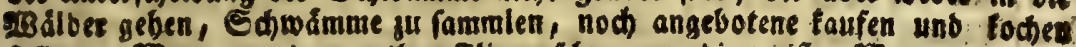

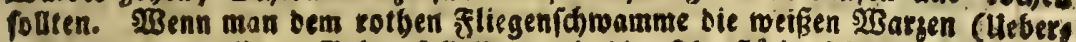

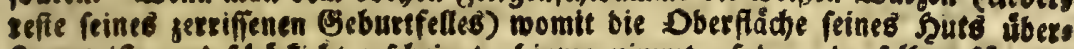

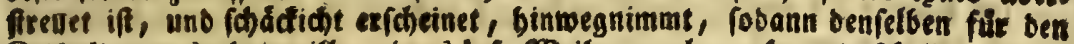
Raiferling aubgeben will, wie eb lofe $\$$ beiber machen, fo unterfheibet et fid bod turd bie farbe ber Samenblátter unb bez Etengels po bentlich boj bein

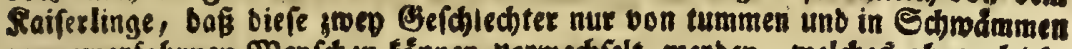
gans unerfabrnen soenfiben fơnnen verwechfelt werben, weldeb aber gleido. wol sfterd gef́ciebt. Der Raiferting bat golbgelbe Samenblätter, uno einen

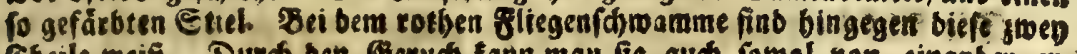

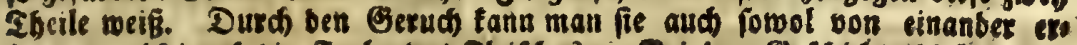

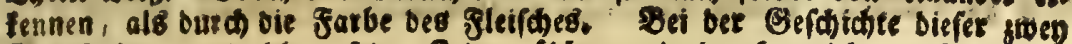
Eeid)ledter merbe id) ju feiner Beit ergáblen, rote in abgemichenem Jabre bie

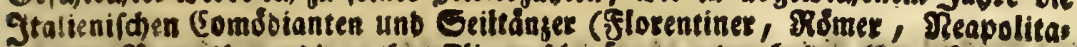

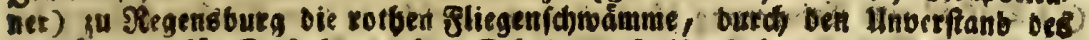

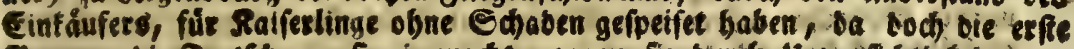

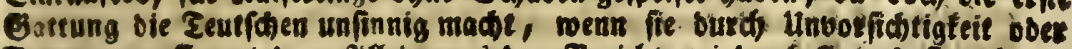

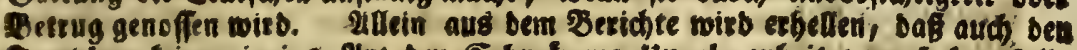

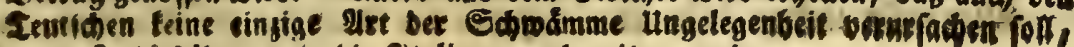
wenn fie biefelben, wie bie gitalienet, aubereiten merben. 
Iejtern aber felbft einige nidts ridtig fuilo. e) Die Ungri:

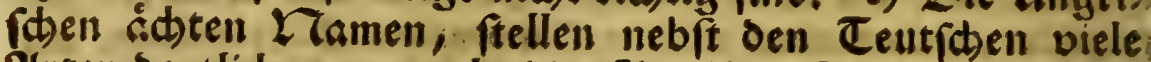
2rrten beutlicher vor, als bie Clufificen figuren und 25 : foreibungen. Surd Beibulfe berfelben, infonderheit ber Ungri.

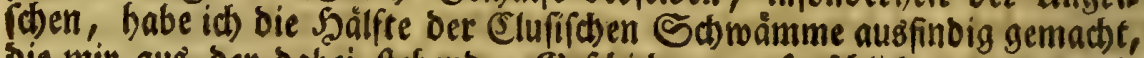
bie mir aus ber babei ftehenben Bsefdsidyte unerforfdolider waren, alö

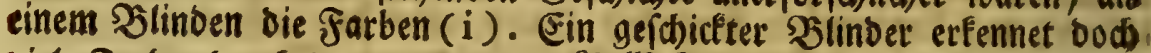

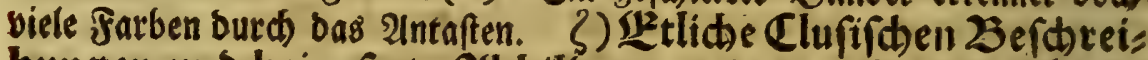
bungen und beigefe3te 2lbbiloungen find nad bein Sorens fargen, und nidt nach ben Dorbiloern ser Fatur, abges faf́t, wie bie (sictmord)el, oder ber PHALLVS. ") Clufius wat

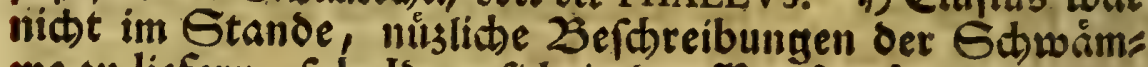
me su liefern, fobals er fich in Den Llopf gefest bat, ibre Sarben nur mit alten und bewåbrten lateinificn Worten anzuseigen, an weld)en Namen biefe Sprad)e gar-zu arm, uno fü einige Farben, als bie weife und fd)warge, wieber obne Sath verratwents berifs ift. Er muste aud zur Benennung foldber Farben, bie fút

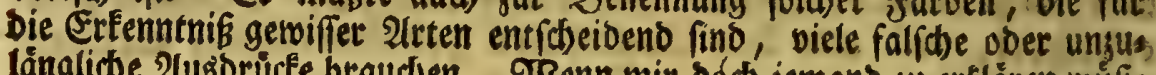

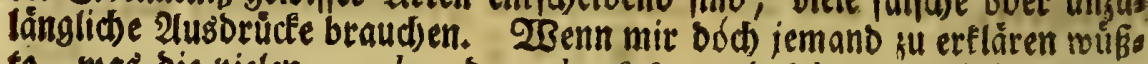
te, waB bie vielen macule, bet color fufcus und fuliginofus, bei ben (Elu:

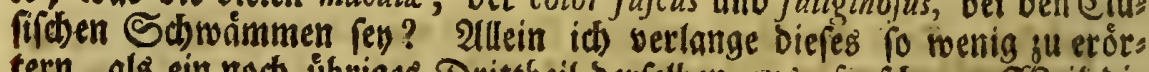
tern, als ein nod úbriges Drittbeil berfelben aussuforínen. 2⿺eil bie

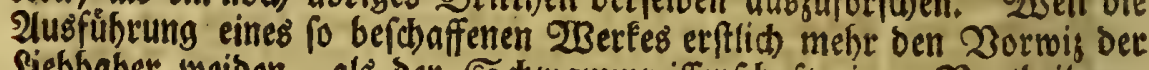
Sieblaber weiben, als ber Sdwammwiffenf haft einen Zortheil vers (đ)affen wúrbe, barnad) aud) nod mit andern lumftanden verfnupfet iff,

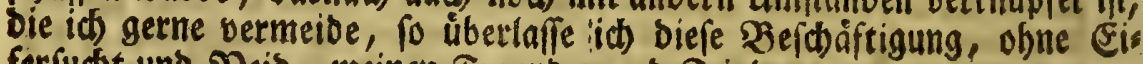
ferfudt) und शeid, meinen Freunden und Feinben.

\section{XXVII.}

Die 2bfict biefes Bufases ift, einige Serren oot bet llebereis lung fu marnen, Denen vielleiø)t gegenwàrtige Sđbrift wenig gefallen miro.

(i) Das if eine Exinnerung fuir biejenigen, welde in bem $323 a b n e$ ftegen, bie ges meinen Epradien toáren fein Dittel, fur Evelefrefamfeit ju gelangen, unb fid etnbilben, eB fey nod beuttges Tageb móglid, alle Sadjen mit Rateinifhen unb

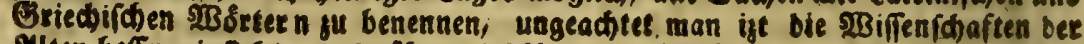

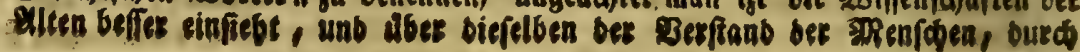




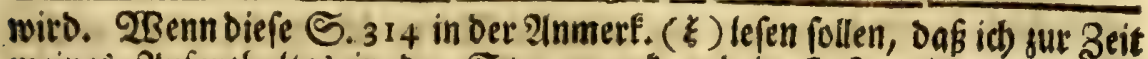
meines 2(ufenthalteg in ber Steyermart uno in Defterreich, eine 2in. weifung babe verfalfen mollen, wie man in ₹eutfoen Sdriften, bie in gebact)ten \&åndern aufgefegt werden, bie ftiriacifmos und auftriacifmos bermeiden foll; fo werben fie vielleidst fich freuen, uno vermeinen, id babe itnen baburd bie Selegenbeit bargeboten, mid auf folgende Art mit meinem eigenen Barne ju fangen. Sie bortten nur bie łros vingialfebler aus meinen gegenwårtigen. Unterfuchungen fammlen, und Das Zerseichniß berfelben mit biefen 230 oten ichlieffen: Sehet, wie gut ber febrer felbft fabreibe! Illein biefe Şerren übereilen fich nidbt, ronbern lejen vorber folgende Erinnerungen.

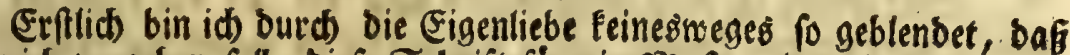
id mid vergeben foll, biefe Sdrift für ein s)ufter einer jierlichen oder reinen seutfhen Sd)reibart zu balten. Shb will fie auth Den Defters reidern sur Padbahmung nidjt vorlegen, ungeachtet mir viele, vermuthe

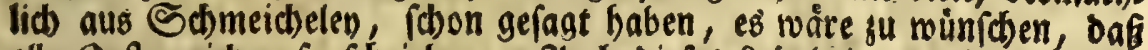
alle Defterreicher fo fótriebent. 2luch biefés sob bringet mid von ber mabren Erfenntnís meiner felbft und meiner Sråfte nidbt $a b$.

Mecum babito, et novi, quam fit mibi curta fupellex.

Tं) babe bei ber Verfertigung bes Segifters, ůberfehene, angeseigte uno nicht berbefferte, ja neugemactite Drucféleler, aud) nod anben re llnoollommenheiten gefunden, bie aus meiner Sandichrift find $a b$. gefejt worben. Eine urfadse biefer Unridstigeteiten habe id a. b. 10 uno folg. S. Der Worrebe bereits angemerfet. Darnad) mus id bes fennen, Daf idh zur 2(ufófung vieler Sd)wierigfeiten, bie mir im

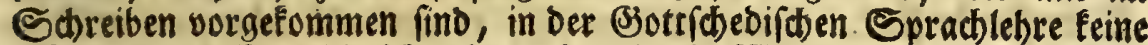

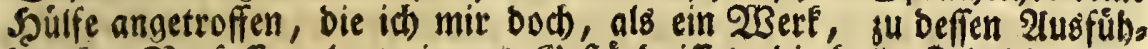
Der Jar. Zerfaffer, laut eigenes Beftänoniffes, bie halbe Zeit feines ses bens den ذorrath gefammlet, für mein Srafel vergeblich zur Şand ges leget habe. $23 e b e r$ ber Faum now bie Zeit erlauben mir, meine Zweifel bier alle vorzutragen. S(b) will zur Beftátigung biefer 2 Gahte beit nur bie 230 rter, mebr, viel, wenig, anfübren. Das mebr

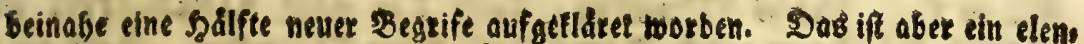

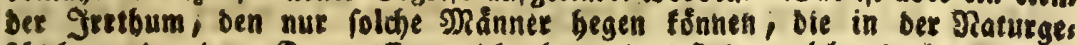
(d)iche unb anbern Senntuifen, nicht bewanbert finb, melche bod berienige

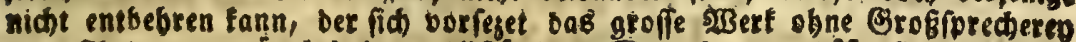

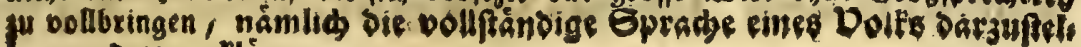
len uns зu exfläten. 
if erftid ein शrebenwort, als in biefer Rebe: id gebe nicts mebr.

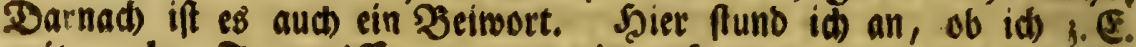
mit mebr Jeugniffen, ober mit mebreren (mebretn) Zetrge

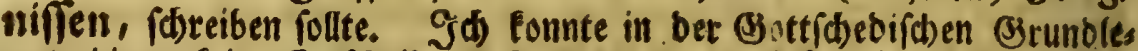
gung hiersu feine (Ent/beibung finden; gum wenigften bat mein eilfertis

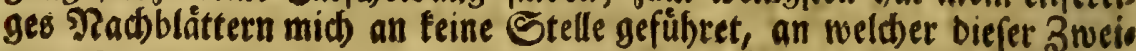
fel måre beruihret worben. Die 238 inter viel, wenig, berurfadten

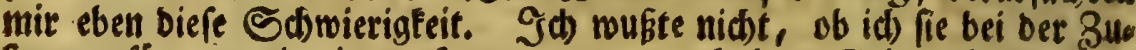
fammenfügung mit einem Sauptworte, nad bem (Jebraudse ber ges meinen Sefterreidhirchen snundart, unveránbert laffen, ober biegen folls

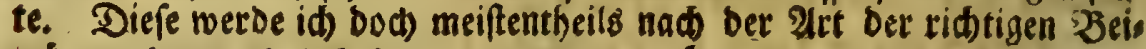
todrter abgewandelt baben; : allein bas mebr if mandmal obne ßemeo gung gelaffen worben, offers merbe id es gebogen haben, wie in ben Dorf́chágen a. 0. Kofm. Gef. S. XL. i. b. Lesten Zeile. Dies fes borfte irrig, und eine Nachabmung ber Eanglenen fenn, in benen

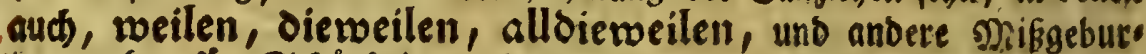
ten mefr, fúr Sdjònheiten, oder eine erbabene Sdbreibart, gehaltent werben. Sb ber Sar. Orof. (Jottiched hieruber eine Эegel gegeben habe, ober eine wiffe, ift mir unbefannt. Das fann ich mit $\mathscr{W}$ abrbeit fagen, baf er felbft balo fo, balo wieber anders foreibe, als wenn auth or nod) zu feiner feftgeftelten Sd)reibart fich entidiofien bătte. S) ir ift biefer Tagen feine Lobrede der Zuborudert. in Sanden ges

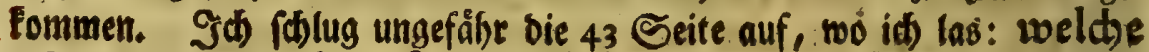

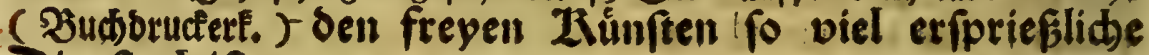
Dienfte leiftet. Şiet gebad)te id): es wirb alfo feblerbaft gef(b)ries ben feun, ba id in bergleiđen Fållen, viele exfpriefflide Dienfte, gefest babe. 2illein als ids in erwelinter sobrebe fortlas, fanb its meht Stellen, weld)e mir meine Angft foferne benabmen, bap id bod vers fidert bin, mit einem groffen Manne geirret zu baben, wenn meine Sdbreibart unteutid beifen foll. S. 45 (d)eibet Sat. Sottibed fo: Die viele Interorídungen Ses póbels, wie viele Vers

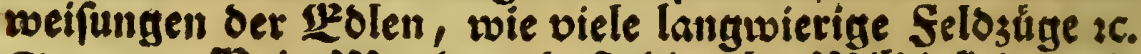
S. 49 fo: Kein Wunder, Dafs bie alte Wiloigteit in fo

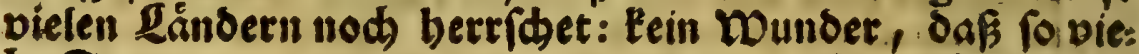
le Etaaten 2c. S. 52 , in bet lejten 3eile: nad weldem gans Ruropa fo viele Jabebunderte gefeufset bat. 2uf ber s4 
S. fand iđ Das viel in einer Stelle unveránbert uno abgewanbelt. Sie ift fo abgefapt: Wie viel fośoliche Debren, twie vit neue Secten, wie viel alte Shuarmereyen find nitht wieber: hervar gebradt worben, uno wie viele weroen nod in Eunftigen Jeiten :C. Das mel)r betweget $\mathcal{S}$ r. Sjotticheb, als bei nebrexn 12rfindungen. Th hatte bie Beit nidst nadbulefen, um gu felsen, ob er foltbes bei diefem 2Borte beftandig beobactite. Das

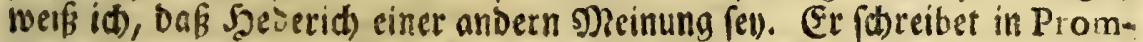

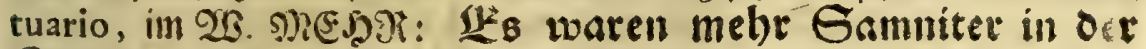
Staot, mit mely Dorten anfubren, mebr Jengen baben, mebr (Geifel baben soollen, in füf uno nidst mebr Cagen, cin wenig mebe matrofen find verlobren gegangen, mie er eben ba geforieben bat: Oreynal fo viel Subren, triplo plus fortorum. 2Benn ran bie Seerten Sachen über biefes Stuct bet Seutfonen Spradlebre, und andere mefr, nicht nur unter fich, fons bern aud mit fid) felb/f, nod) nid)t einig finb, fo berbienen bie Defters reicher un fo viel eber eine Siadsfidt uno Dergebung, wenn auch fie nid)t ricbtiger fdreiben, weil es ibnen an ber Infübrung mangelt; bie auch nod) auf einet Seite burd bie gemeine, ju Sad)teutiden 2üfägen

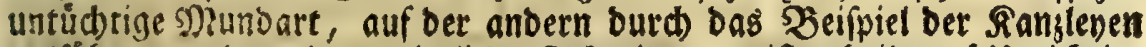
verfubret werben, beren zierliche Sobreibart meiftentbeils auf Unridig. Eeiten fich grúnber, uno diefes wieber nidjt aus Sc)ulb ber Sarren, weldse bieje Stellen verwalten, fondern twegen Sntftehung bes Unter. ridtes. Denn weit man innen in ben Søulen feine Anweifung zut Sechtforeibung vorgetragen bat, fo erdichtet fich ein jeber feine eigenen Segeln. So viel anore Sinne nts Fopfe, bringen to viel neue, zumeilen wunberticbe Brunofáze Der bermeinten Secthtibleibung beraus. Stes ben die Erfinber ber ijtergåblten Derbefferungen in bơbern Aemtern, fo

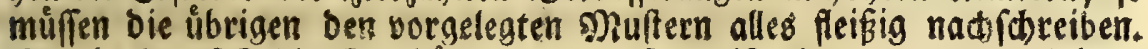
So breiten fich bie grthumer aus. Das ift bir Quelle bes Uebels.

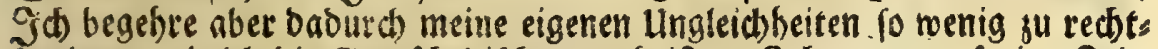
fertigen, als id bie (jottichebifben gutbeife. Sch roarte auf eine Beit,

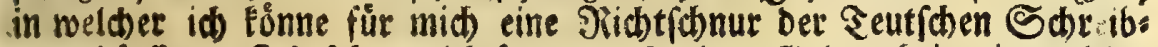
art abfaffen. Sob refne mid ferner nad einer (Selegenbeit, in welbet

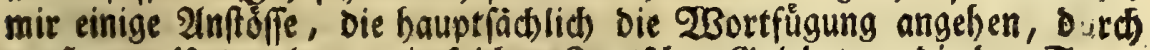
gepflogene Untertebung mit folden seutfden (Selebrten, Die ber ङ. vra: we mådtig fino, aus bem $23 e g e$ gerăumet merden. Sn Anjeljung ob. Fee gebuto: 


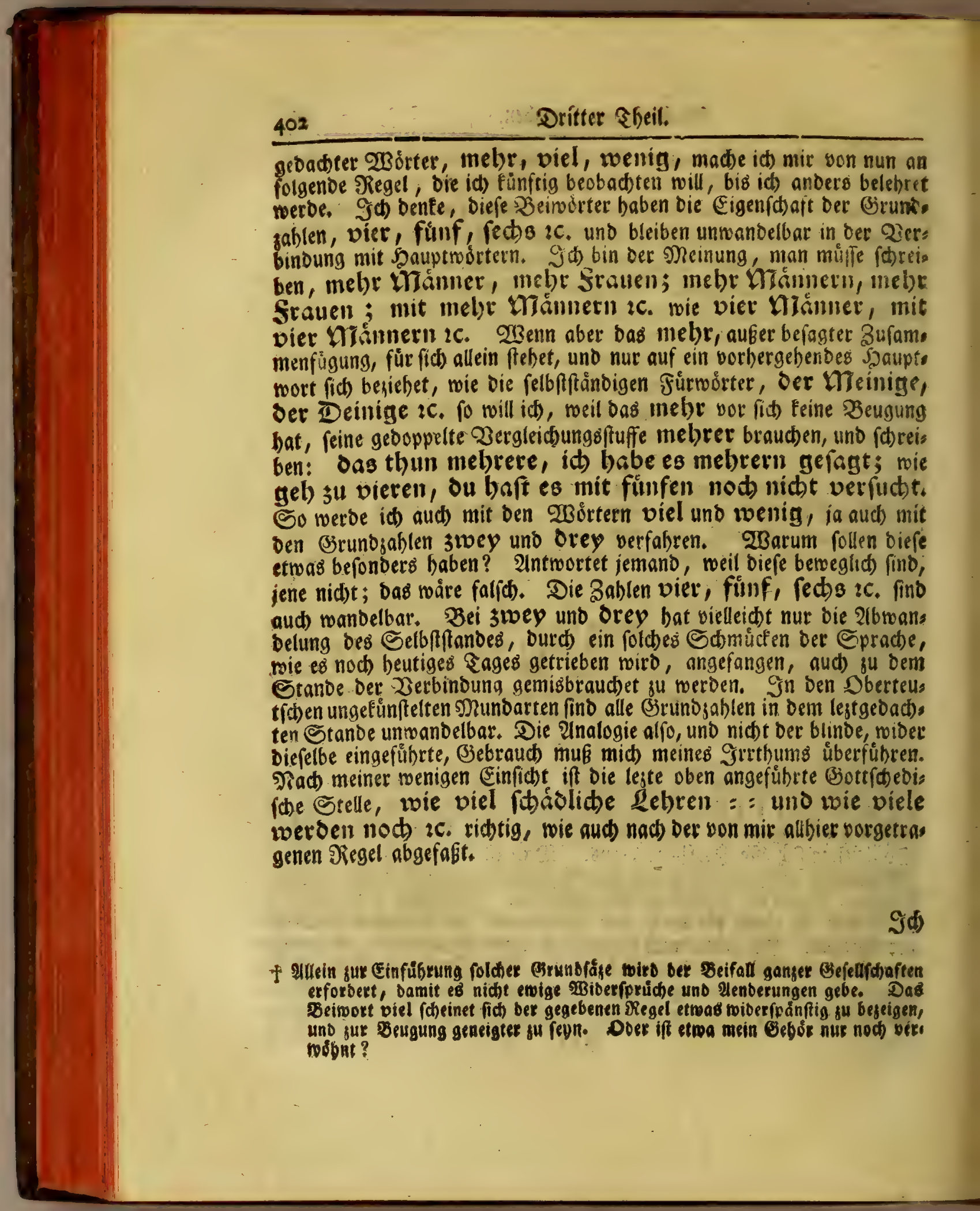




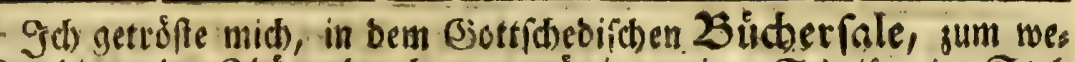
nisfen hinter bet Ebure, ourch gegenmårrige geringe Sctrift, eine ¿telo le ju verbienen. Wenn mir in biefer geoffen Berbse uno. Miufte rungsftube bie hidugen Seutf(ten Sitniser follen vorgewoifen werben,

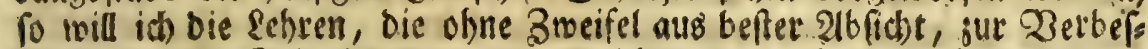
ferung meiner Sdbreibart werden gerichtet fenn, fo Derbe fie aud Dem gewiffeften Bermuthen nad, lauten follen, mit Danfbarem Ssemúthe

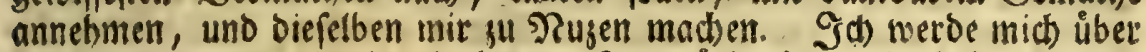
bie harten etwa mit eingeflodtenen 2lušbrúcte to menig beflagen, als̈

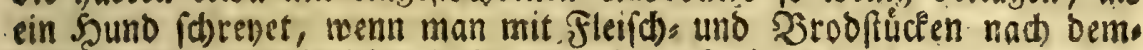
felben rirft. 2lleill id will fobann mieber fo fres fenn, und ben Sarn. ঐrofeffor, nidt in alten $\mathfrak{B S e r f e n}^{*}$, fonbern in ben neueften, ${ }_{3}$. E. in ben - Erflárungen feiner Brrundlegung, wiber bie Siegeln eben biefer (3rund: legung, gemachte Uebertretungen aufroeifen. Da úbrigens nteine Jicuns

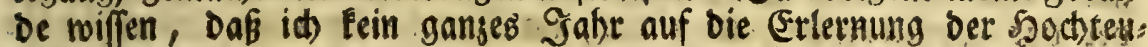

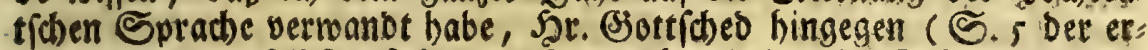
flen $230 r r e b e)$ felbft geftebet, Dafi er mefre als brenfig Jahte Damit ju: gebradt, fo babe it) meine Buverfidst zur Billigkeit Der \&efer, uno boffe, fie werben mir zum menigften allemal brenfig begangene Fefler,

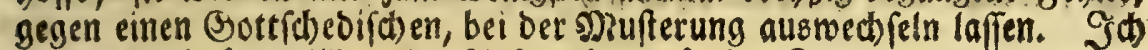
begebe mich frenwillig alles 2 (n)prud) s auf eine Sugabe, bie man mir,

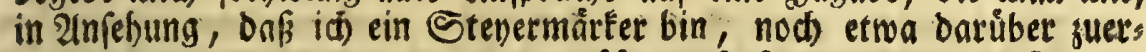
Eennen wollte. Biei bem 2lufiage ber llnterfuchungen vom meere habe id) metre auf bie Sadjen, alb auf Die Schreibart gefehen. Tin.

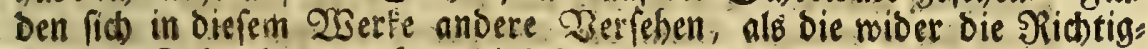
leit ber Sdreibart lnufen; biejelben liegen mir alle jur Saft; biefe find unverantwortlid). Denn ein 3erfaffer, bet unnủze ober irtige (Sebans

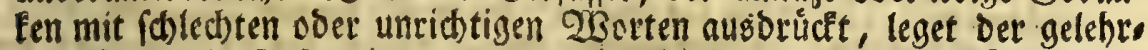
ten 2 selt ein Bjefalmiete vor, welthes biefe bes \&efens untoútoig ach), tet, und in die Baffe verweifet, bie, Soratius am Enbe Des erften Bries fes, in II Bunche, umict)reibet.

Darnach follen dic anfangb erwehnten Sperren verfithert fenn, baf

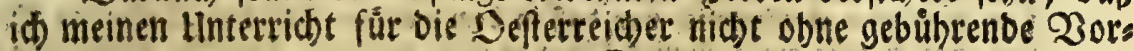
cee 2 bereis

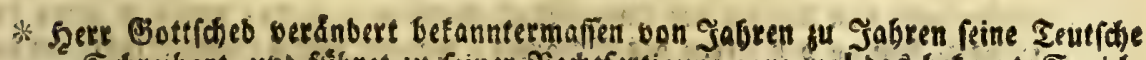
Edreibat, uno fitbet ju feinet Diechtfertigurig gens wol bas betannte Spricts

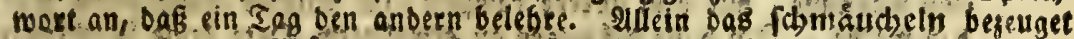

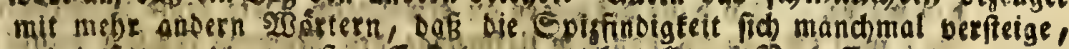

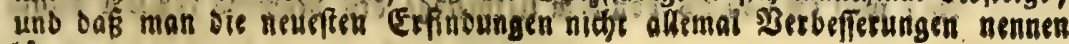
isne. 


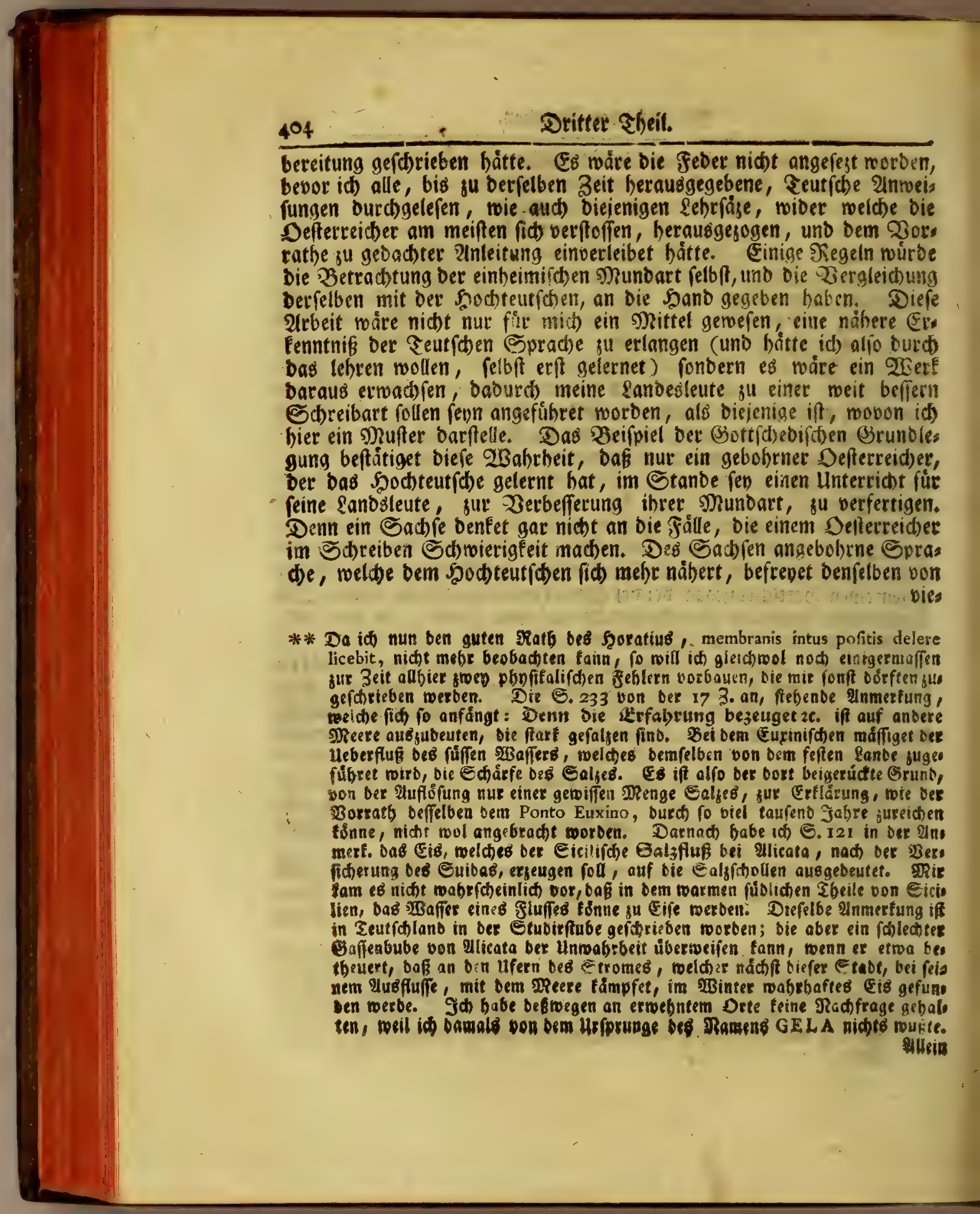


Nadhlefe von Bugaben.

vielen (Selegenheiten zu irren. Des Defterreid)ers feime Fenret er nid)t; folglith weî̉ er auds nid)t, Den. Fehlern Deffelben vorgubauen. (E. Pann nidht beoadt feun, feinen Broeifeln ourch Siegeln ooer serflärungen abjubelfen.

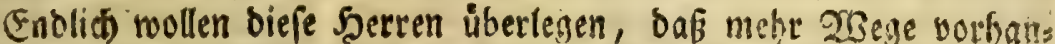
ben fenen, bie gur Zerbefferung ber Sod)teutfden Sprabe finiten.

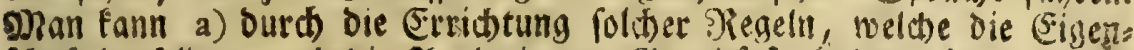
fthaft berfelben, und oie Inalogie fur (Srunbfefte baben; ferner bur Unterfucungen ber üblichen uno ungewónnlitben 2 Borter uns Siebenss

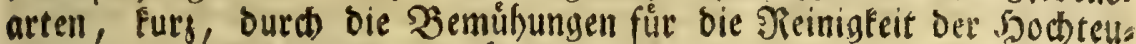
tfiten Gprache, Derfelben nújlid feun. b) (Sieteidset es ibi ju unge, meiner Uufnahme, wenn man bie 2 Borterbid

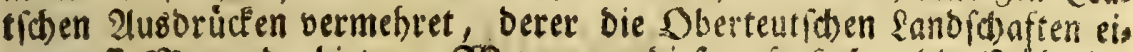
ne groffe gnenge barbieten. 2Senn man diefe aufjufuden bie grube fid geben wollte, fo würben gar balo bie frentoen, aus Proth entlehnten,

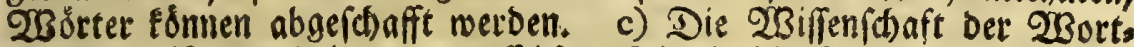
forfichung ift Das oritte vortreffliche saittel, bie Nollfommenbeit bet Sodteutfben Sprache zu befordern. Daburds wiro nicht nur ein Sbeil ber nod ounflen 2 Borter beutlid) gemadt, fonbern aud bie rectite (E) 3

Sdreib:

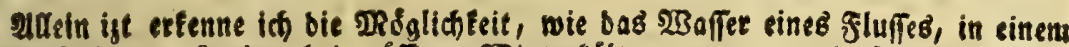
fonft bizigen lanbe, bei måffiger Wintertảlte, wenn man biefe mit ber nor:

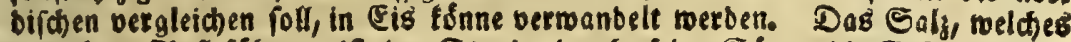

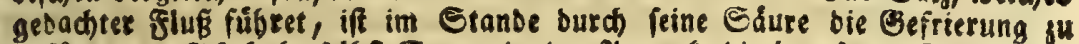

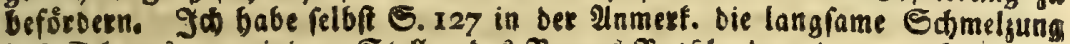

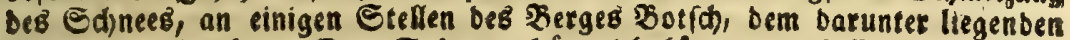
Ealge zugeichrieben. Den Ealpeter batte id) tơnnen meglafien. Diefer ifl zwar aud ein Sals; allein ex túblet nid)t. Die feidten Edncegruben ber Sicilianer fommen einem Teutidien wunberbar vor, ber bebenfet, wie feine

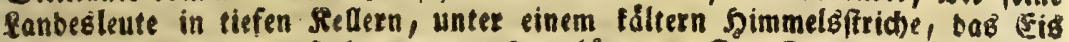
bor ber 2ufthaung oft loum berwabren tinnen. Die Sicilianes graben uns eet frevem Simmel nur einen io groffen Raum in ber Erbe aus, realdo: ben

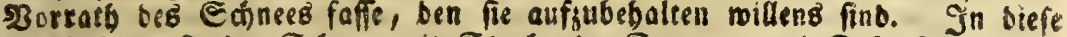
Srubelegen fie ben Ednee, mit Etrob ober Epreuern umb Ealy, faichtmeife binein. Julezt mirt bie auggegrabene Exbe juz Brtedung roieder baruber get fhaufelt. Wenn fie im Sommer fur Rủhlung ibres Tronts einen Eanec bas ben mollen, fo graben fie nut ouf einet Eeite ben Erdboufen ouf, nehmen

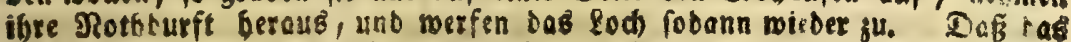
Sals kum grieren etroos beitrage, if aus folgender Erfabrung gu crebson.

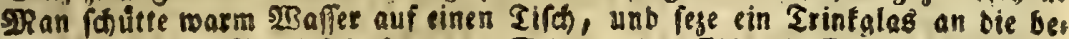
goffene Stelle. In biefes thue man Eannee ober Gig mit Ealje, und rúgre: fo mits bas Ğlas an den Sifch anfriesen. 


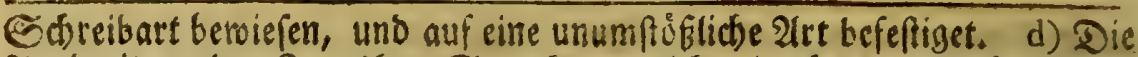

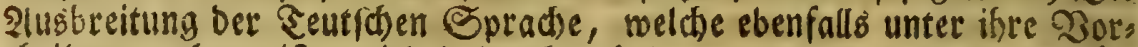
theile z"l reçnen ift, wiro baourd) crhalten, wenn man bie sirunofäre

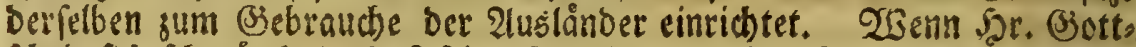

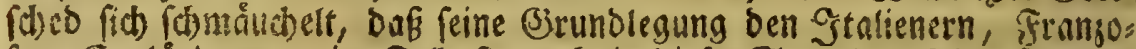
fen, Englänoern 26. im Falle fie aud in biefe Sprachen folte uberfejt werben, auf einerley Irt bienen fơnue, fo ift biefe Shofnung fo irrig,

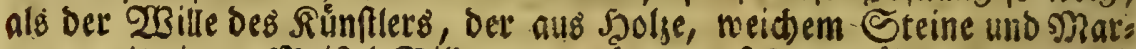
mor, mit einem Meifel Bitber zu berfertigen fich vornaibme. \$Db aud) id im Stande (en, burch einen biefer WBege, jur 2lufnabme ber ₹eutichen Sprache etwas beizutragen, Das uberlaffe id bem Urtheile berienigen, bie mich nåber fennen, oder aus biejer Ëbrift fennen werben.

\section{XXVIII.}

Diejer lejte Zujas enthält einige ß̧erid)te ủbet bie Shreibart Des 2 Berfes, und über einige Drucfelyler. Şei ben 3 ablen bie ich of: ters anbringen werbe, weifet bie erffe bie Seite bes ein S. (ro die Seite bedeutet) Davorftehen ober nid)t. Die stwcyte Zabl bemerfet bie Zeile ber benannten Seite. Das beigefugte 2. jeiget bie zeilen ber Anmerfungen an, weld)es zur Erreidhterung dienet, Damit Der Sefer weniger zu zählen habe, wenn er eine Etelle nadbidblagen wolls te. Die Rómifhen Bablen besiehen fidh auf bie Seiten ber geographis.

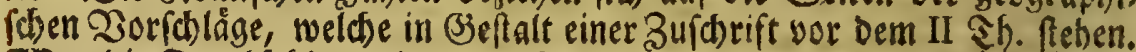
$23 a s$ bie Drudfebler anlanget, Fann id) wol fagen, Das bie meifte uns richtigfeit in Den swen erften Sogen, uno in oen geographifchen erftges

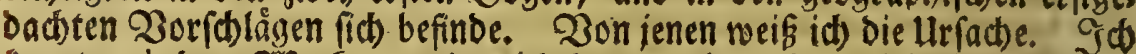

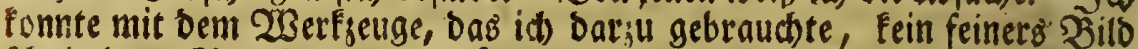

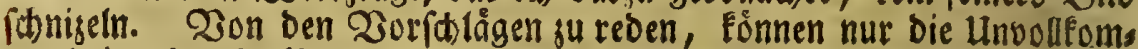

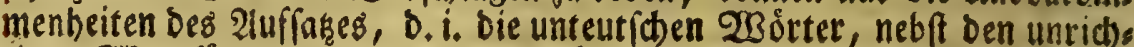
tigen $230 r e f u g$ ungen, Durch Die Rürge Der 3eit, weld)e auf Diefelbe Sd)rift verwandt worben, und ourd) ben MRangel ber benothigten $\mathfrak{S}$ ()er, entfouldiget werben. (Etliche Drueffehler baben fid baburda) ges mebret, weil id vieles nach ben berwábrteften siuftern ber istlebenden కeutfiben (Selefreten fibreibe, Datan aber bie Seser nod) nicht gewóbnt find. 3. E. id) fese nach bem $n$ und $r$ fein $c^{k}$, ronoern nur $E$. Die $\mathbb{E}^{\mathrm{B}}$

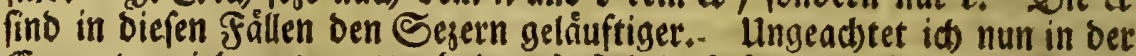
correctur viele ausgerottet babe, fo find bod folgende fteben gebfieben. Mardtfleden S. 118, 2. 7. Getrónde S. 159,25 . Бes 
Nachlepe von వugabelt. 407

Ounden 194, 16; und 232, 26. Ciuté 248, 21, 2, Werd's

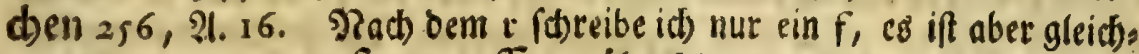
wul S.7, 2, bas anfgervorffene überichen worden. Die Endung

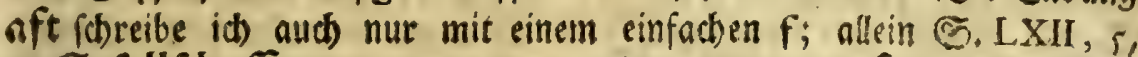

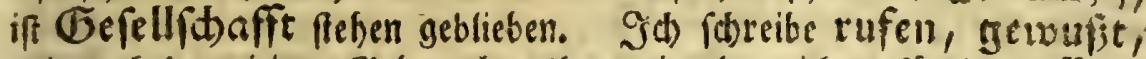
uno nad) bem ijigen (Bjebraud)e (ber mir aber nicht gefáltit) wollte foónte, follte. Es find gleidwol folgente Drucfelser, beruffe 14, 29; gewuft 6, 23; wolte 144; 14, nidht ausgemariset worben.

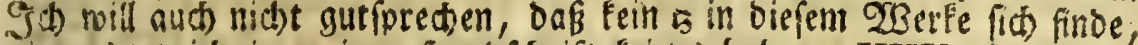
wingestetet id) in meiner Saanoftrift feines babe. XXV, 6, if ons

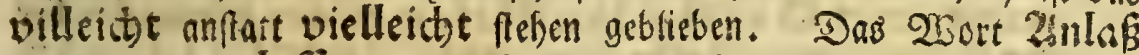
Eomnet von anlafiell. Es ift alfo das geboppelte $\bar{s}$ in bemfelben ein Etammbudftabe, den now barzu das (G)ehờ beftátiget, wenn man bas 23ort, nach Sjóbifers ?tnleitung, beweget. Denn man fónnte nid)t

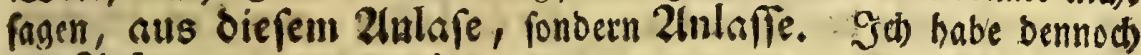
Das 2Anlas hier uno bort úbergangen, als 7,$1 ; 11,16 ; 240,1$, und vielleid)t nod) ofters. †

Etlide Drudfebler find erft nad) meiner lefeten Correctur begangen morben. So ift bas bein, weldes auf ber 9 S. Der Recenfion am Enve ber I 7 Beile ftefet, ein eigentlid)er Drudfefler, b. i. ein folcher, ber nid)t im Sezen, fonbern im 2aborucfe gefdlehen. Es frecite cin m in ber Forme, wie aus ber niobt ausgefülten Belle abjunehmen. Man fieht audh bei benienigen 30 gen, bie nod in feine झtreffe gefonmen, weder gefalagen worben, bie Scharfitung ober ben Eindruce ber britten \&eifte von. bem in. Diefe ift burd) eine Ecfe bes Siñhmonens, aus luns ad)tfame eit bes Drucfers, verbect geblieben, und boburch bas $m$ in ein

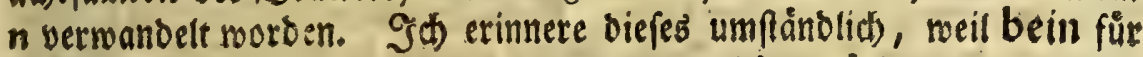
beim ein ftiriacifmus ift, und id nid)t gerne feben wurroe, bas man mir

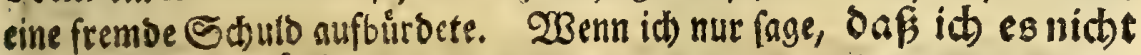
gerne feben wirbe, to begefe id feinen Fehler miber bas Ehriften thum. Ferner ift S. 171 ; in bem Notencuftos bas $n$ bei Einbebung der Forme berauggefallen. Eben fo menig begreife id, wie in bem झetits orus

† Diefer Znlas geboret gu einer Edreibart, bet idh febt abbold bin, weldhe bas boppelte ff, beinabe vezbrången wia, unb eine neife Grau von einer tweifen (fapientem ab alba), die mafen maculas, von haffer menfuris, und viele an 


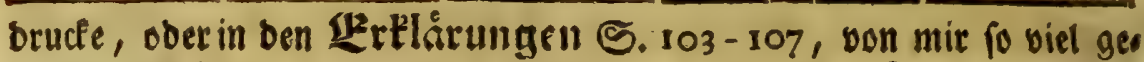
fpaltene 28 orter follen fenn uberfehen worben, als zufammenge fes: tell 104, 43; geor udeten ro7, 13; in ber 32 Zeile einl eimishen.' S. I65 ift on exfte l ber lezten Beile zur obern hinaufgerúcflt worden, welder Fehler Das erfte 280 ret beider gebacbter Zeilen verftellet; allein: nicht bei allen 2 boructen. Denn es fino einige folde Mångel in wábren: Dem Drucke verbeffert worben. 3. E. S. I I I, A. 5, ftethet nur in einis

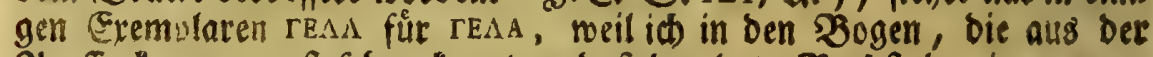

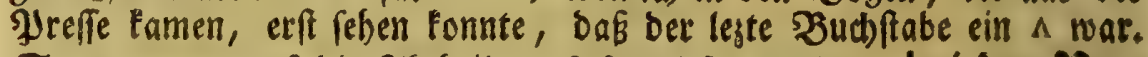
S. 290, 33, muß die Abtheilung $\beta$ fo gelefen merben: bei ber Ver: Heinerung, wie Ga'rtl, Ka fal $2 c$. in welden Exemplaren bes an biefen Etellen hervorftebende Spief eine undeutlidfeit verurfact)et. S. 352, 3, mirb in einigen 2 borucfen ftehen ben elben, fúr benfel: ben. S. 365 verftellet ein ander Spieß bas 28 ort iungen, in ber funften Beile ber 2nmerkung. Es foll beißen: aus ben jungen

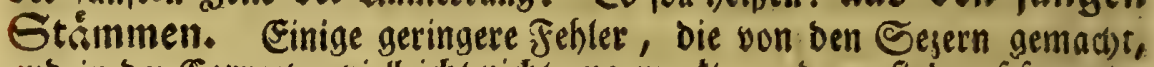
und in ber (errectur vietteid)t nicht angentertt worben, find auf foigente

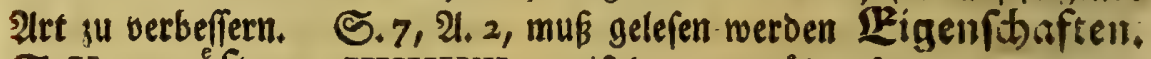
S. V, 18, \&ffters. XXXVII, I 7 , if bas vor ůberfúfig. S. 91, 2. 4, foll fehen: nat) Dem Urtbeile diefes Gelebrten. 14I, \%.2, mianfen, weil id biefes 200 rt fonft fo gefdrieben habe. 146 , A. ss, 3.8, 3mevmal. 17 1, 2.8, 5ri1. 334, 26, 2luslegung.

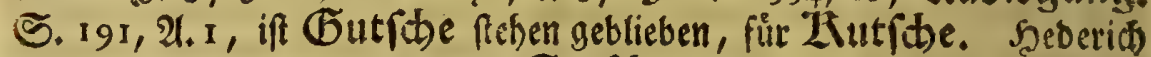
hat in Promtuario, swat nod) Futide, allein bie wahridseintidften

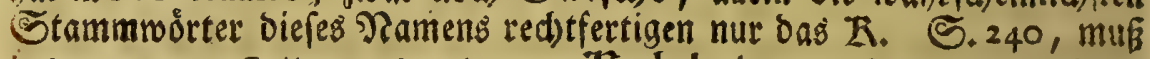
in ber jwenten Zeile vor ber lejten, Kalabrien geleren werben; bemt i屯) babe, meines Wiffens, biefes 230 rt allemal po gejdrieben. S. 57.

थ. 3,

Dere פBofter, nid,t unterfheibet, baburd aber mutbrillige 3meifelbaftigfet:

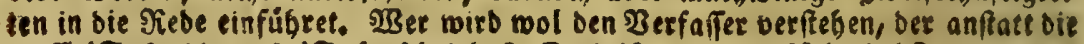

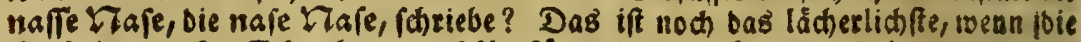

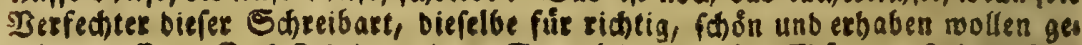

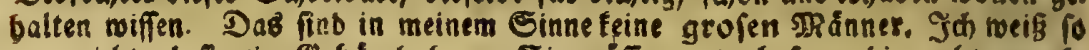
gar nicht, ob fie ein Gebdr baben. Eie múfien la taub feon, bie niche vernetis.

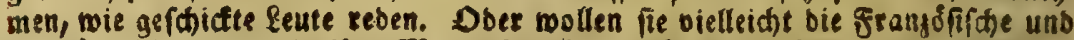

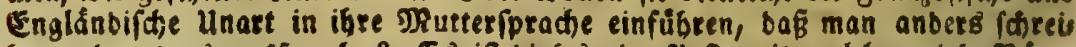

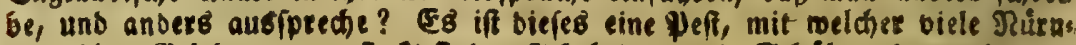

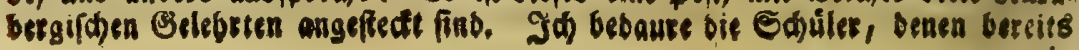


2. 3, werbe id obne 3weifel aus ber sournefortiften Seeifebefdr: ben Tramen les Palus Meotides, to berauggefdrieten baben. E8 toáre aber vid)tiger le Palus Meotide. Sar. Buffon (d)reibet, wenn id mid red)t ets, innere, auf bie leste 2art. Fulgende Etellen bitte fo gu verbeffern. S. XXII, 18, anflatt bátte kommen follen, lies tommen follte. S. XLIIl fann bie 24 Beile fo gelefen merben: Oaff cine Eprridbe fir oefto álter 34 achten fey, je mebr $2 c$. LXXI ift bie 2nseis ge von ber 6 zeile an, twegen eimer andern unentbefrliden Zerbefe: rung, unoeutlid getworben. E⿺ bat in meiner Sanbidstift geftanden, uno foll nod) alfo bergeftellet werben: wie id aus ber ungeorudt: ten Ehrift, Status \&c. erfeben babe, bie von Gr. Krer.

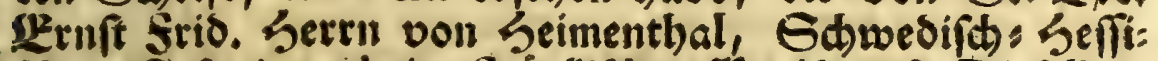
fiben Gefondten beim Srinkifhen Zreife, als Diefelben ebmals in polen fich sufbielten, verfaft toorben. ‥ 60 , 6 , ift bas ztweite es úberfíffig. 158,30 , wåre ber Werftand fo beut: licber: aus einigen ber ersáblten, und jugleid andern, Urfaden erfolgen :c.

Benn ber lateinifhe Doppellaut $\mathrm{AE}$ nur mit einem seutiphen ă, wie in 2legaifi, phocaifich, ift ausgebrudt morben, fo folgte id

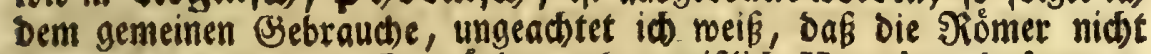
fo gerebet baben. Eg murbe aud gewifistich Horatius, Daferne et aus bem Sote, wo er ist ift, ju uns fäme, fid nidbt umfeben, wenn ifm ein seut(b)e Sorajius, ober ein Franzofe 5 oraffi in's zurufen

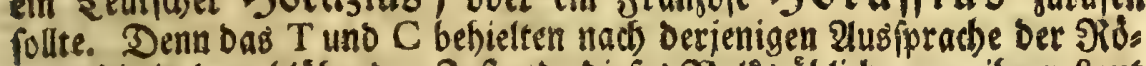

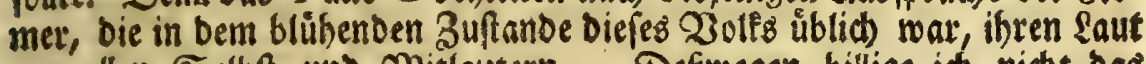
vor allen Selbft: und Mitlautern. Defmegen billige id nid)t bas Soraz ber Derbefferer ber Seut(d)en Sprad)e. Jub balte biefe

$$
\text { Sff Sdreibs }
$$

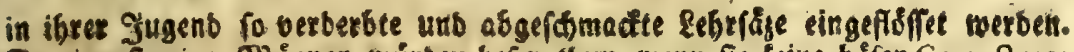
So eigenfinnige jiånner muitcen befet tbun, wenu fie titne bofen Correctores

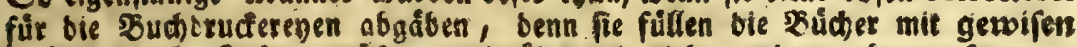
sobstern, als ftofen, mufen, unb uiberaus bielen anbern, bermafen an, bas fie an eine ridhtigere Sdreibart gewobaten Refern gang edelbaft merben.

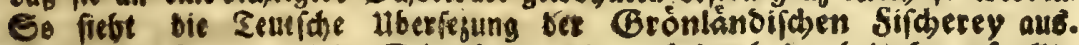
Durch bie Ilngeige biefer Ed)reibant, mie auch burch ben beinabe auf allen Eeiten angebradien Eprud, ju 6 dulben fommen, uno nod) einige andere noricifmos, fabe ith jus Bewurbeznng berjenigen, Denen meine Spuren unbes

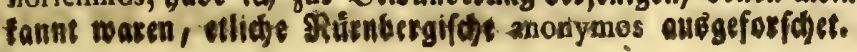


Sdreibart für einen Sdnizer, Der miber bie 21rdbóologie begangen

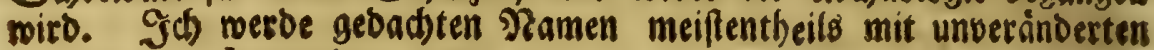

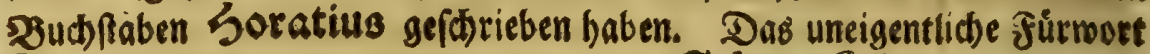
Jebermann wirb in bem 2 briefe a. e. Fel. in Leips. Der vor ben Linterfuct)ungen gebrudit norben, fich now mit einem einfacten $\mathfrak{n}$ finben. I由) folge ist ber neuern Sctreibart, melde bentelben ein boppeltes in gibt. Seb babe nod anoere Unridtigfeiten verberbten Muftern nads:

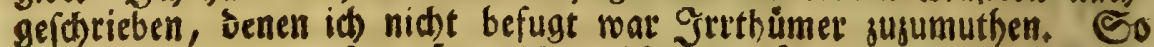

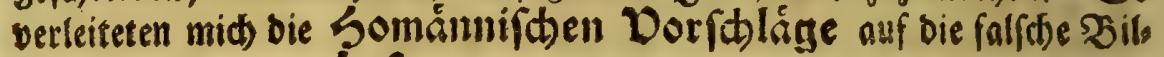

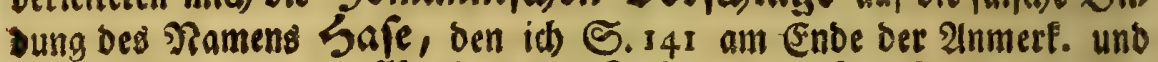
in ber Zufhrift an bie Klofinogr. Gef. S. X. Saafe fdrieb. 9a)

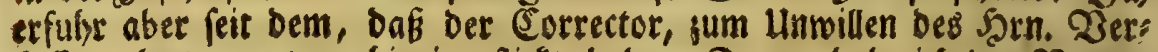
faffers, Das zwente a bineingeflicft babe, Ferner babe ich Den Namen Gefiner, S. 38 , aus einem $\mathfrak{B}$ úberregifter, mit einem $\mathfrak{B}$ untichtig

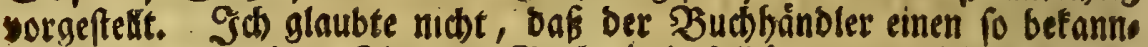

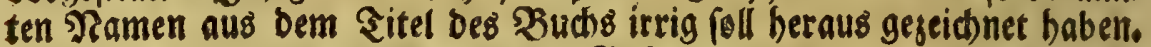
Allein biefer (S)efefete fibreibet fid) Gefiner, wie id) aus einem 28 riefe

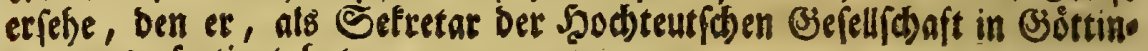
gen, aubgefertiget bat.

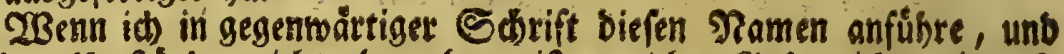
aus ben umftánben nidt abzunefmen ift, roslcben (seftrer ict meine, fo

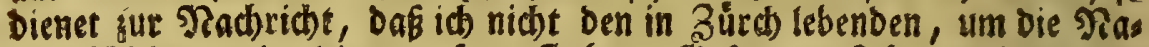

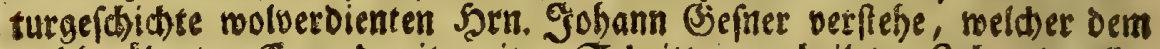
reltberihmten Conrad mit weiten Scbritten nad)eilet. Sath reoe alles

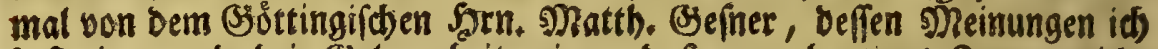
befreite, und bei Sjelegenbeit seige, daf man beutiges ₹ages nicht methe, nie ehebeffen, alle 28 iffenifhaften aus Der lateinifon unb Bries diftien Spracbe holen fornne. Fein, Das Blat hat fid) feit etlic)en

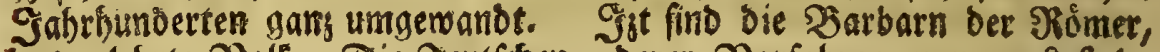

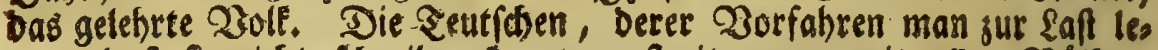

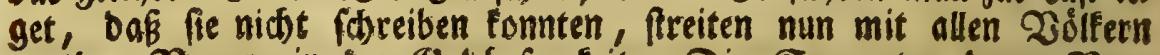
um Den 2 Jorjug in Der, Belehrfamfeit. Die Sarmaten, berer Dors

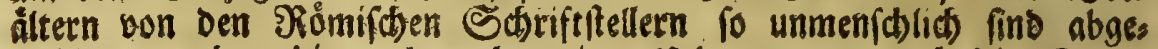
fchilbert worben, bie auch nach meiner Heberzeugung nod Die Spras te berjeniger alten Sarmaten reben, die Den Pismern befannt waren, liefern mun foldse getebrte Tradbribten, auf weldse gans (Europa mit $\mathfrak{B}$ egierbe wartet, wenn fie einige verfprecben. Sie baben eine Alfabemie erribtet, barein bie alten Fioner, wenn berer etlidbe aus

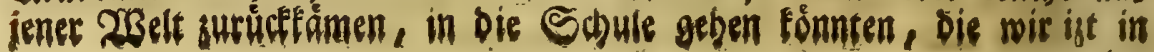




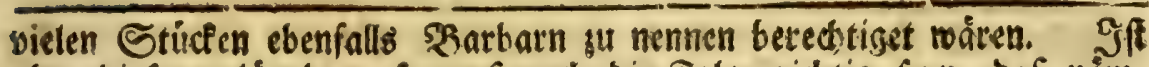

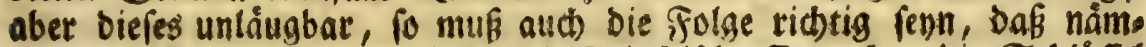

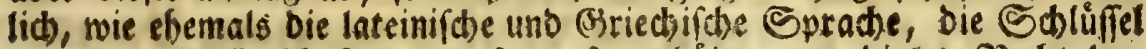
iu allen gsiffenfibaftell gewefen, fo gethibre num bieres. Siectit ben

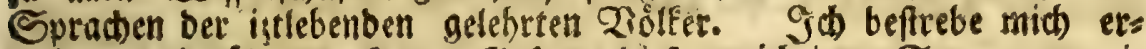

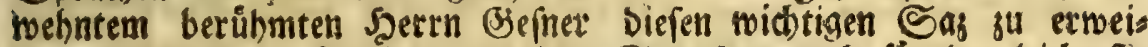

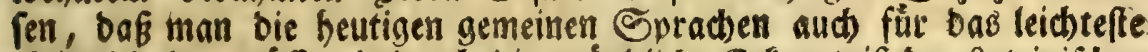
s) felbft gu erlangen fen. Diefes lïßet fict) auf bie (Briectif(c)e ebenfalls zies hen. Id) sum wenigften bin meines Srtes fråftig úberzeuget, Daß̧ bie

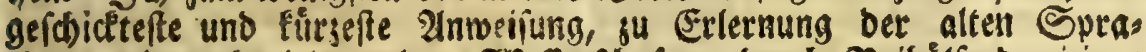

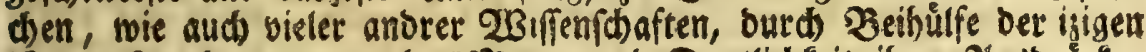

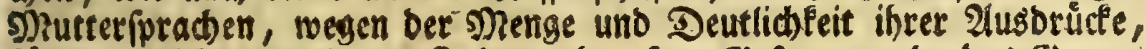
fónne vertidjtet werben. 'Inbem aber Şr. Giefner gerade bas Bjegen theil biefes Sazes, ber nad meinem 2 egrife ridtig if, burd fein Dettagen gu behaupten focinet, to bat er midh zu einer 2 biberlegung aufgebracht. Эक) ermarte, ob er fich grund(id)er verantwoorten wirb, als in Der 2 orrede zu feinem Sprad)idsase.

2 senn ber \&efer in meinen unterfubungen ein lateinif(t) a ober eit ₹eutfobes $a^{\prime}$, in einem ₹eutichen 2 sorte, mit einem 21 ccente finbet, fo if $\mathfrak{e} \dot{B}$ fur feinen Druffefler gu halten. E\& ftellet baffelbe bas belle Dbers

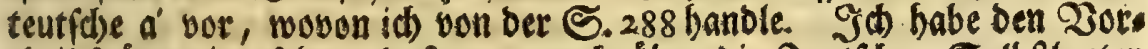
theil parter eingefehen, Daß man aud über die Feutfden Eelbflauter 2lccente fejen Eunne, wenn faton feine Daran gegorfen fimb. Sorber

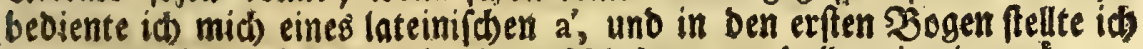
erwebntes belle $a^{\prime}$ bald mit einen foledten $a$, balo mit einen á bor,

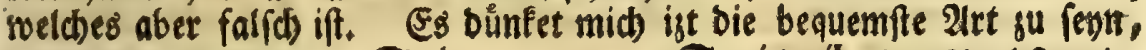

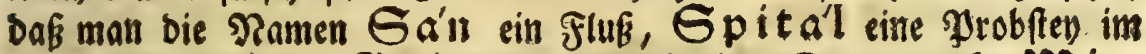
sanbe ob ber Ens, Gra's Sauptfabt in ber Stevermarf; W in:

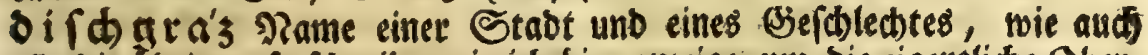
alle bie übrigen, fo (d)reibe, wie id bier anjeige, um bie eigentlide Dbers

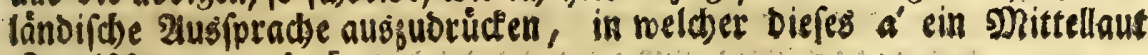

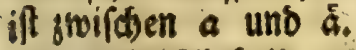

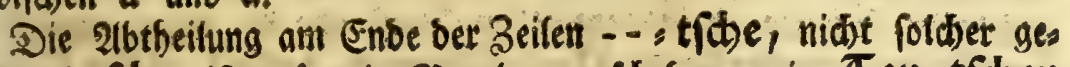
ftalt --: ts f LIII, 13; Ceu: trder LXVI; 9; Rieserten: tid e LXV, 22 u. ..F. Die Sid)tigfeit biefes Bud)ftabicens will id) gegen alle biejenigen wertreten, bie niळt miffen, baf bas zeutide tfd einer einfaden \&aut $\mathfrak{F} \mathrm{ff}_{2}$ Dot 


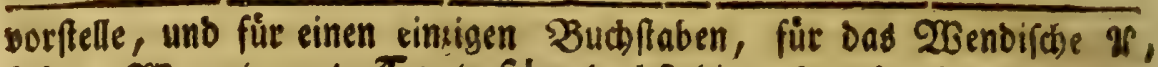
Pehe. Wenn jemano Ceut : fche budffabiret, ber thut in meinen (Bes Danfen nid)t beffer, als wenn er bas Dáter fo zerglieberte, $\mathcal{V}_{a}=$ eter. Eieb bie Dorfal. a. o. Kofin. Gef. S. XX.u.f.

Die Besworter, bie von ben eigenen Ramen (nominibus propriis) abgeteitet werben, fatreibe id mit cinem groffen Alnfangsbudfftaben. Die

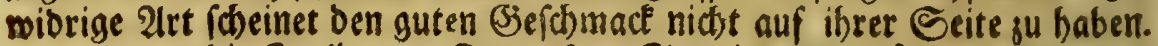
Saben benn bie Statiener, Franjofen, Spanier, Englånder, fein (Jies

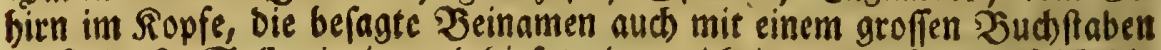
vorftellen? Soll mir iemano biefes als unrichtig vorwerien, Daßs id bie

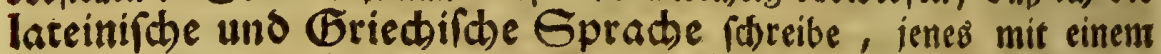
fleinen, biefes mit einem groffen 2nfangsbudfftaben: fo bienet zur शRad): rid)t und meiner Redtfertigung, Daß ber Beiname lateinif(,), wenn er fich auf bie Sprache bejiehet, nicht auf bas 23018 , ourd) Den gar gu gemeinen Bebraud, längf bie Art eines gemeinen SEeinamens ats genommen babe. Ifter mit biefem Beideibe nidt) zufrieben, fo gebe id biefen., baß́ groffen \& zu fareiben, als bem Dertheibiger ber fleinen 3 ud ftaben bie Sonwierigfeiten zu beben, ober bie ungereimten Folgen zu entíbulbi. gen, bie aus feiner Sd)reibart entftehen. Sd) poll aber bei nod) mehe andern 2 soortern etwas erinnern, unb von ibrem Bjebraude, von ifs.

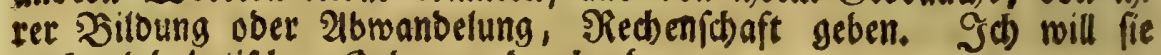
nad) alphabetifdjer Sronung burchgeben.

Ș habe bisher andere gefdrieben (mie bie Defterreid)er fpres

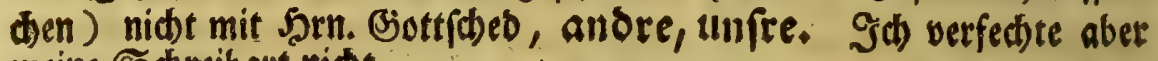
meine Sdbreibart nicts.

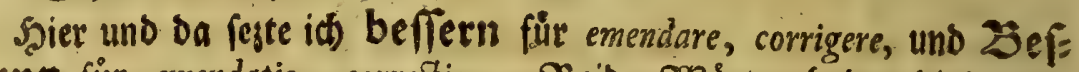
ferung fur emendatio, correctio. Beibe 2 Boorter haben biefe Bes beutung. 2Ullein oa fie nod mels andere Begrife ausbrüden, und of ters von bem febenswandel ober bem 3uftande Der Gefundheit gefagt werben, babei aud nod) mit Zermehren und Bunehmen fid ausles gen laffer, fo bătte idb in bem erften Werftande bie enger eingefobránfs ten $23{ }^{\circ}$ rter, verbefieri, Derbefierung, bafü brauben fónnen.

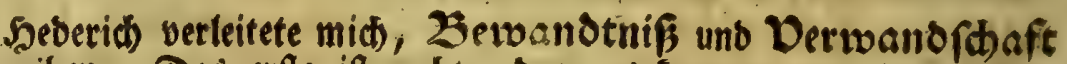
zu refreiben. Das erfe ift recht; benn es fommet von be wandot. Die Sad)e ift fo bewandt; b.i. befdaffen. Das zmente lauft wibet 
Nacjlefe von Zugaben.

bie Spraळăbntiðfeit; Denn Derwanotfhaft fammet aud von ver:

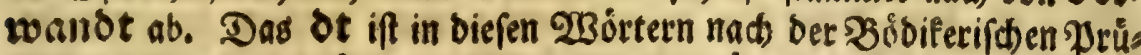
fung ridtig unb gegrůnbet. Frifh fobreiber bewandt, verwandt,

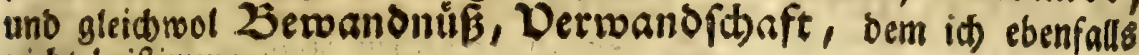
nid)t beiftimme.

Sheberid finreibet bauern und tauen, bedauen und be: tauern. 2Benn idb bemfelben bielleidst irgend (wofü iक nicht gutfes ben will) auf bie ztoente Art nachgefdrieben babe, fo bin id in bas ur: theil berfallen, welches Frifक, im $\mathfrak{Z}_{\text {Brte }}$ osuren, bon biefer Soreib. art fallt: Die es mit einem $t$. fhreiben, fint feine 2 Borte, baben Eeinen 2 eifall, als bei etlid)en von sem blinsen Gebrauth - Der sem Misbraut. Daj Dauren rect geforieben fen, er, bellet aus bem lateinifhen durus, durare, bon bem bas Yeutfoe Sauren nid) anoers, als burd ben groben Sotbifhen Doppellaut au unter: foteben if. So ift Maur, aus Mrur (Boxb. Lex, ant. Brit,) entfanben.

Swifden benn unb bann, weln unb wamn, madbe id

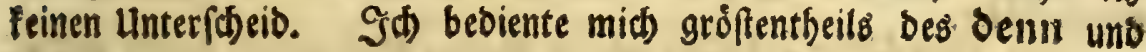
weisn.

Den Namen Driefter und Dnieper babeids vielleidt irgens,

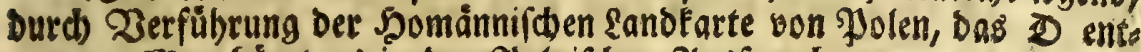
jogen. Man foret es in ber Joonifden 2lusprache.

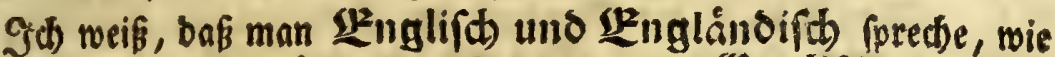

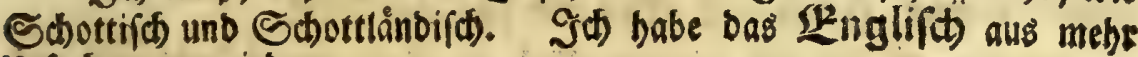
Urfachen bermieben.

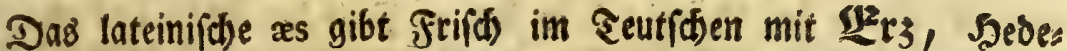

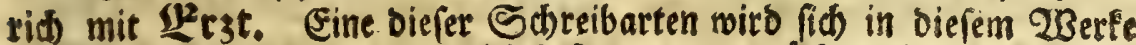
finven, vielleid)t beibe; benn id) beforgte, man modt)te midh einen Peues rer nennen, wenn in 2lers gefest b́atte, meldhes ridbtig ift. Die Sbers

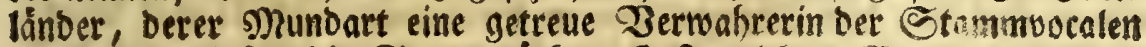
iff, zum menigften bie StevermárEer, Defterreiber, F̧anern, prechen

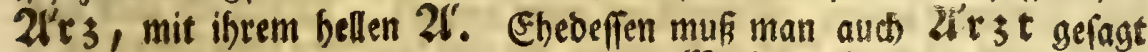
habell, weldes ber Rame bes Srtes L2ifena'r $3^{t}$ in ber Sber: ftenermare bezeuget. 2ille aften Europair(c) an munbarten haben ein ze in Diefem 230 orte. Im fateinifकen iff bie stwedte Zablendung von æs, Sff 3 aris. 


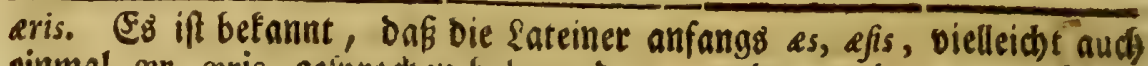
cinmal, $x$, xris, ge(prod)en baben; Denn $s$ und $r$ werben verwed)felt, mie aus Fufius uno Furius, arbos uno arbor, honos unb honor, auś ben Feuribln frieren und friefen algere, wie auch unjähligen ans

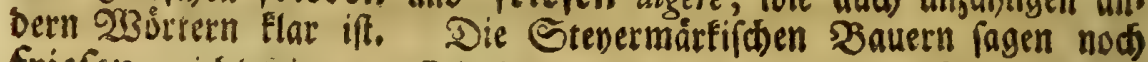

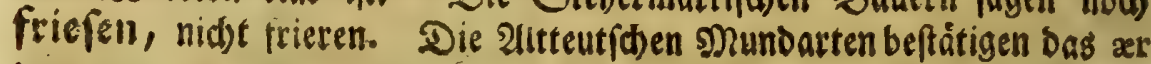
ber Eateiner. Die 2ngeliachien (prad)en 21r und 2ler, fü 2lers.

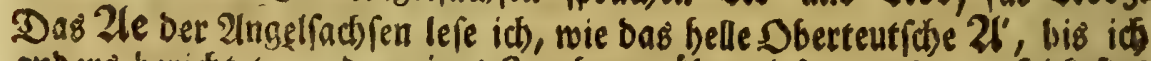
anbers berifitet, uno meines Jrrthums überwiejen werbe. Shicfefius bat eine Angelfáchfifche (Srammatif gefdrieben, meinen Sweifel abee

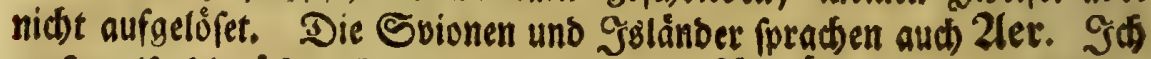

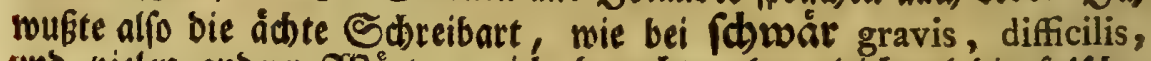
unb vielen anbern 230 rtetn; ic braud)te aber gleidhwol bie falfhe. ufum fcribendi populo concefl, fcientiam mibi fervavi, fagt irgent cicero.

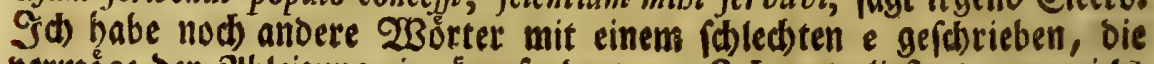

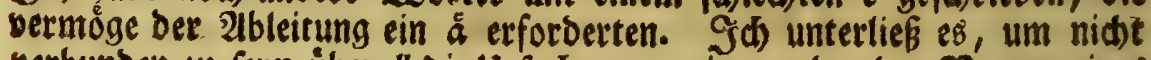

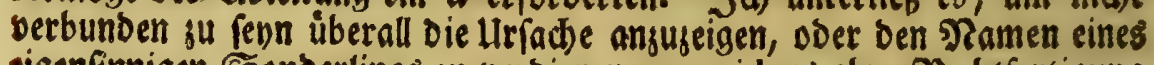
eigenfinnigen Sonberlings zu verbienen, wenn id) getban hătte.

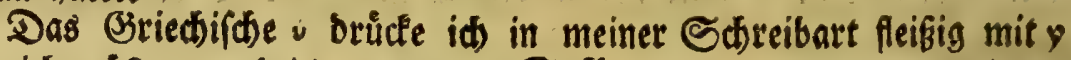

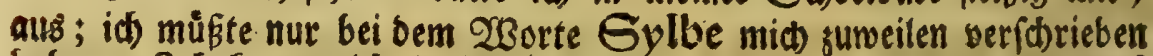
baben. Эक Eann mid beffen Dod nid)t befinnen. Diefes aber weißs

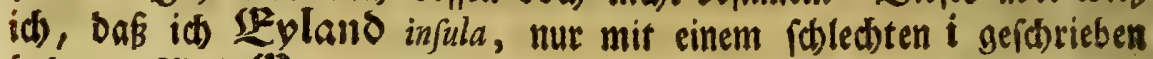

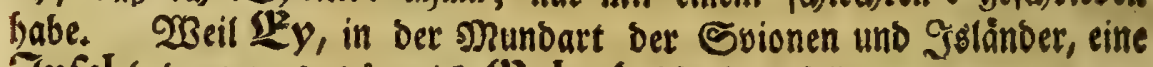

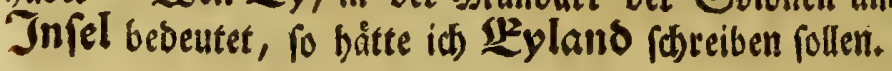

In bem $\mathfrak{B}$ riefe an einige Gel. in Seipzig. befinbet fids auf ber legten Seite bes Bogens $b$ in ber ro Zeile ber Gedanfen. Sn

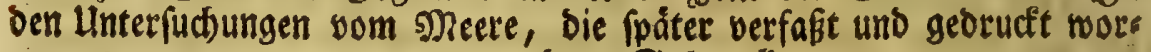
ben, habe id), miewol ungerne, Ser Geonite gefdrieben, wie aud ber Tame, ber Ellaube 2 . Damit bieienigen Serren, welde feif einiger Beit mit ben Sberteutfaten in beftánbigem Feberfriege leben, mir nidjt vorwerfen fơnnen, id bátte bie von ifhnen beliebte, uno naç iffer Meinung beffere, Schreibart nidbt gewuft. WBenn ics aber bas

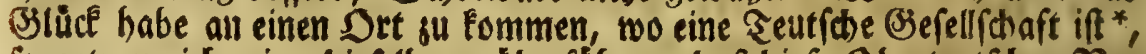

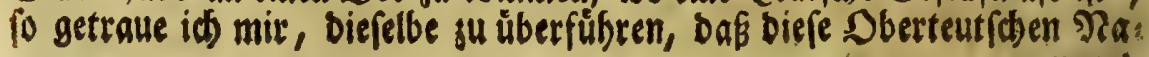
mens,

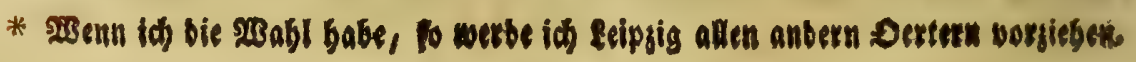


mensbitoungen, ber Gebanten, Der 2 Tamen, Der Glauben, ber Srieben, ber Willen xc. ådt, regelmáffig uno fpracbåhnliđ, bieje bingegen, Gebante, Tame, Glaube, Friebe, Wille :c.

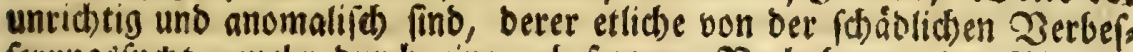
ferungsfuct, , mebr burd eine unbefonnene Nacbabmung ber 引latteus

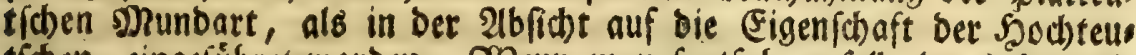
tíden, eingefúbret worden. 2 senn man fort fabren foll, ourd) Derglei, then abgebiffene Enoungen ber Namen, und noch andere vermeinte

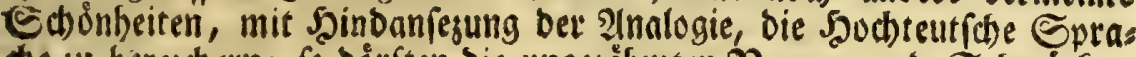

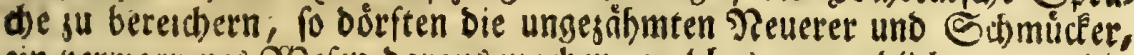
ein verworrenes 25 efen baralls madben, weldses man endlid, wegen bet

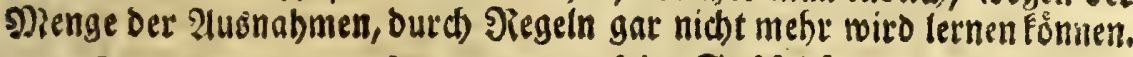

So habe id mit groffem 3wange sie (Gefdid)te, in ber mehrern 3afyl, fúr hiftorix (arum) geítrieben. Diejenigen, welde behaupten

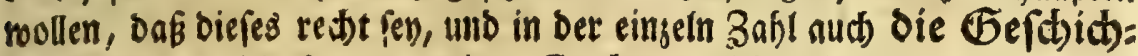

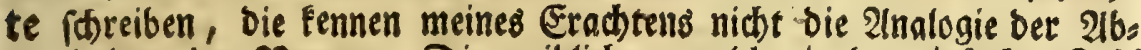
warbelung ber Namen. Die meibliden, welche in ber einfadsen Babl in e ausgeben, ober fu biefem 2lusgange zum wenigften túbtig fino, baben alle in ber mehrern Zabl bie Enoung en. Die Dberteutjoben fprechen regelmåffig sie Gefchichten.

Seberich erflåret im lat. 2Bo̊rterb. bab penultimus mit biejer tthy fdreibung, der lezte obne einen. Die Sadhen fpredien burthges benos 10. Die Dberteutíthen, berer 2lusbrúcte ungesroungen, furz uno

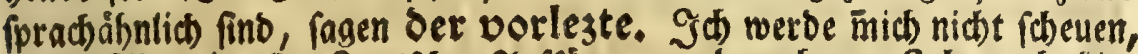
biefes 230 rt in allen รeutfhen 2 uffájen ju gebraudben. Sक mache hier ben 2infang. 2luf ber vorlegten Ceite ** meinez SBriefs a. e. Bel.

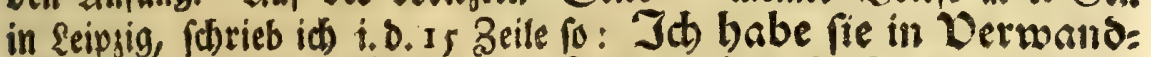

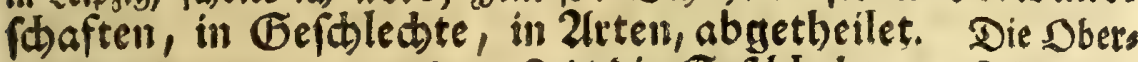

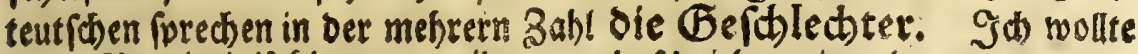
einen Provingialfefler bermeiben, unb fobrieb, mienol gans ungerne,

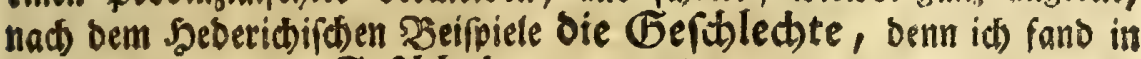

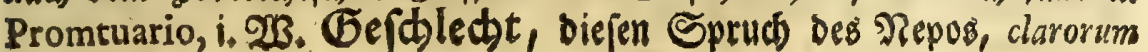

viro.

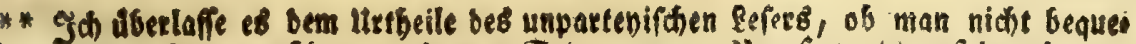
mer to fage: auf bet vorlegten Geite meines Strefeg, a!s alif Det lezten Seite obne einet meines 2 tefefes. Das̉ antepenultimus erflăren Die Deferreicher mit porporlezter, welder Rame aud apd oer Eigem 
virorum propagines cognofcere, fo ủberfest: berúbmter Seute (Б):

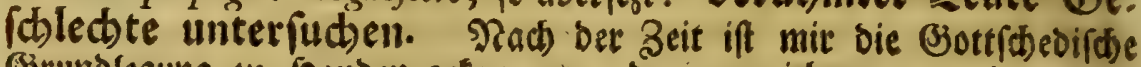
Grunblegung su Sanden gefommen, Dasinnen id) zraar aus Dem (Ent,

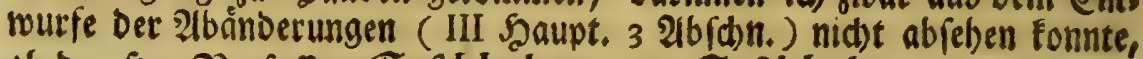

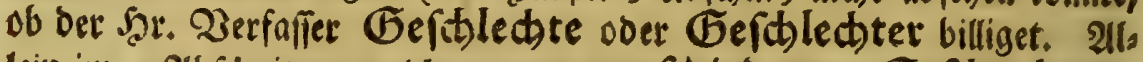
lein int 2 Ibidnitte, reld)er von verfaiebenen (Eefhled)tern ber Sauptwotter hanbelt, und Das-2Bort Gefolecter ofters enthált, waro ich überjeuget, Das Die 2lbmandelung ber Dberteut(c)en

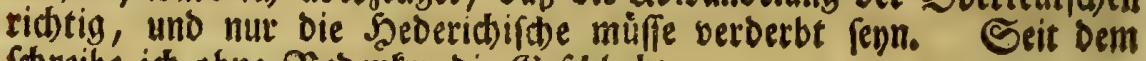
forreibe ich obne S3ebenfen bie Bjefdledter.

Das Eommen bewege ich in bem gegentaantigen Beitfanbe regets måfig, ich Komme, ou Kommeft, er Kommet, Wenn id miф

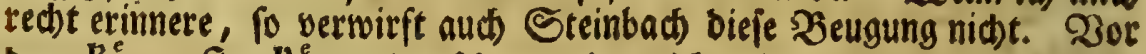

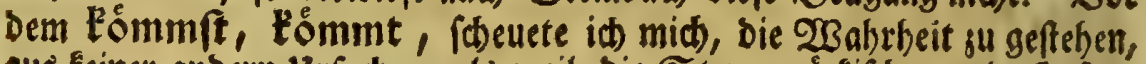
aus feiner andern Urfacte, als weil bie Stenermårfifónen und Defters reidhifhen Bauern fo fprecten. Die Stabtleute fagen Ou fommft,

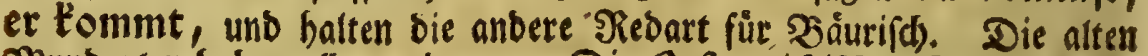

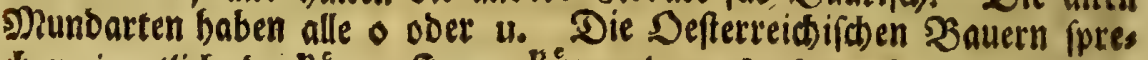

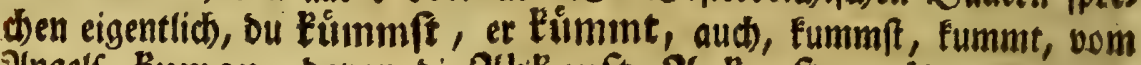
Ingelf. Fuman, Daoon bie 2lbtunft, 2lnkunft zc, úbrig fino.

Die Ramen La'ndler, Eánd lerifd, welde ofters in gegenmårtiger Schrift fitb befinben, mus ich aud erklären, weil man anberwárts nidbt wübte, was id baburd fagen wolle. Erftlich erinnere

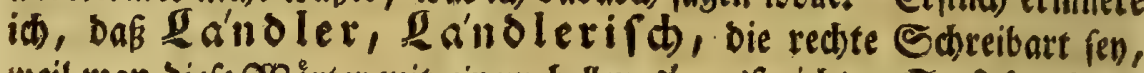
weil man biefe 280 orter mit einem bellen $a^{\prime}$ ausfpridbt. So ftehen fie in

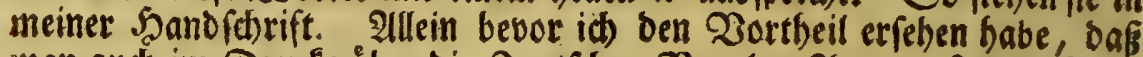
man audh im Drucfe ůber bie Seutifien Docalen 2lecente ftellen fónne,

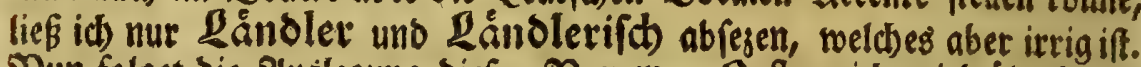
Nan folget bie 2lustegung biejer Namen. Defterreich wirb uberthaupt ill groan Theile abgefondert, welthe in भinfehung ibrer Giroffe fehr uns

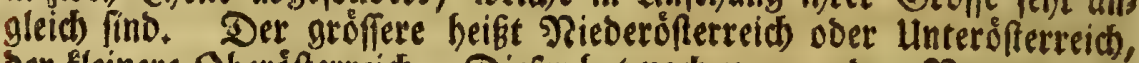
ber fleinere Oberofterreich. Diefer hat nod swed andere Namen. Ev

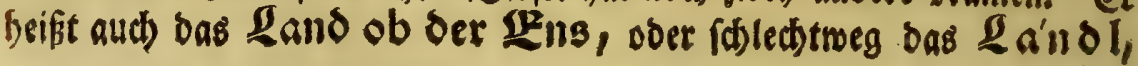

D. i.

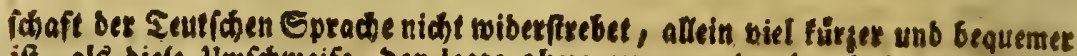
iff, alBi biefe Umictweife, oer lejte obne jwey, ober ser britte bon bin, ten berein, wie Sebcrich bas antepenultimus augbrúden mus. 


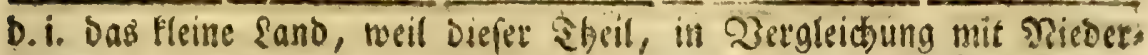
ifterteid), felye flein if. Die jnwohner beift man bafeer die Bans lex.

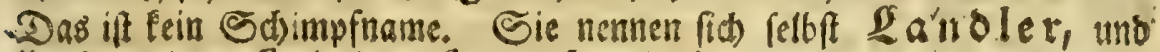

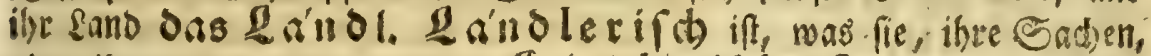

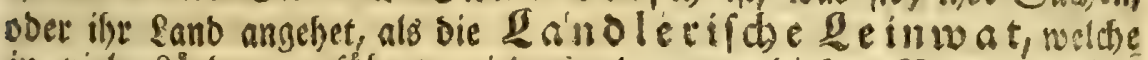
in viele fånder berfubret wirb, und unter biefem গamen in Den Defterteichifonen Erblándern tool befannt ift. Die Eprache ber Inwoh:

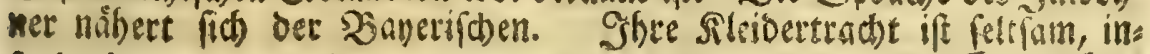

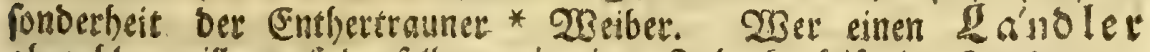
abmablen will, mus benjelben mit einer Sobackspfeife im \$nunbe yors frellen, beren Stiel aber nicht linger fen, alb ein Safnftodser. Det

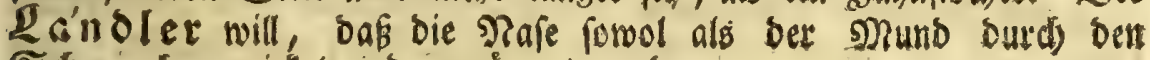
S๙bmaud erquictet und gewarmet werbe.

Das meinethalben babe id S. 310 , in ber vorlesten 3eile, als einen vermeinten auftriacifmum, vermieber. Es rdbreiber aber aud

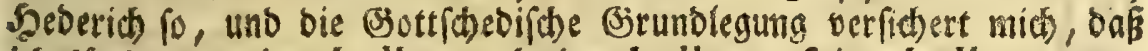
id) Eunftig, meinethalben, beinetbalber, feinetbalben, uns rertbalben, eurentbalbenz a meinstroegen u.f.f. forreiben fönne.

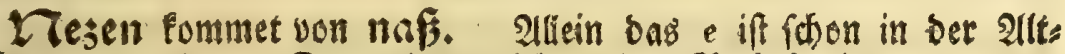

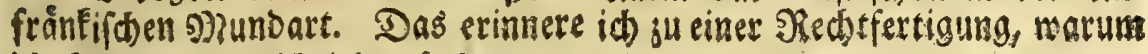
ic benezen gefutrieben babe.

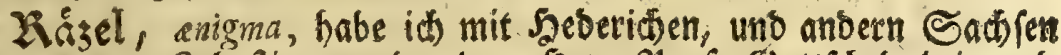

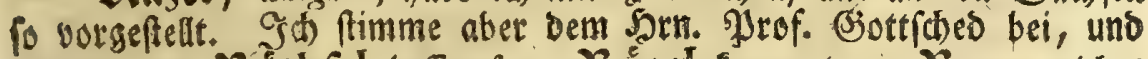

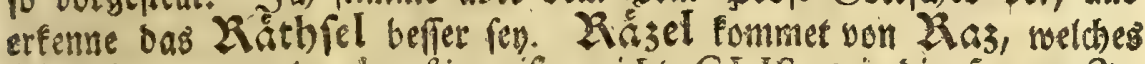
Shier oet mus major domefticus iff; nicht GLIS, wie bie Şerren Ses fuiten lefien $t:$ Sathfet (anigma) if eime 2toleitung von ratherr.

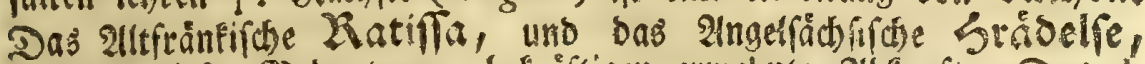
ginaten Diefer Bebeutung, befråfrigen ertwehnte 2lbfunft. Das bo

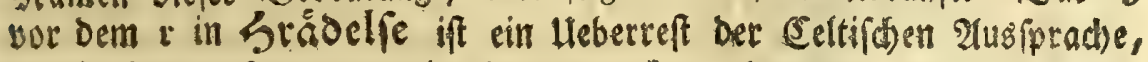
meld)e Das 2tnfangs: 1 mit leinem Scaude vorbradte. Diefe Gewohns beit if im sande ob ber Ens nod in fo farter Hebung, als bei Den alten (jiiecher.

\section{CS9}

Det:

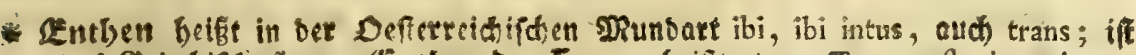

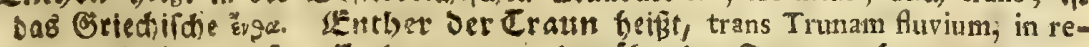
gione Transtrunenfi. Entbetteuner, ber áber ber Sraun mobnet, Transtrunenfis; wie Transclanubianus; Transrhenanus, Transpadanus. 


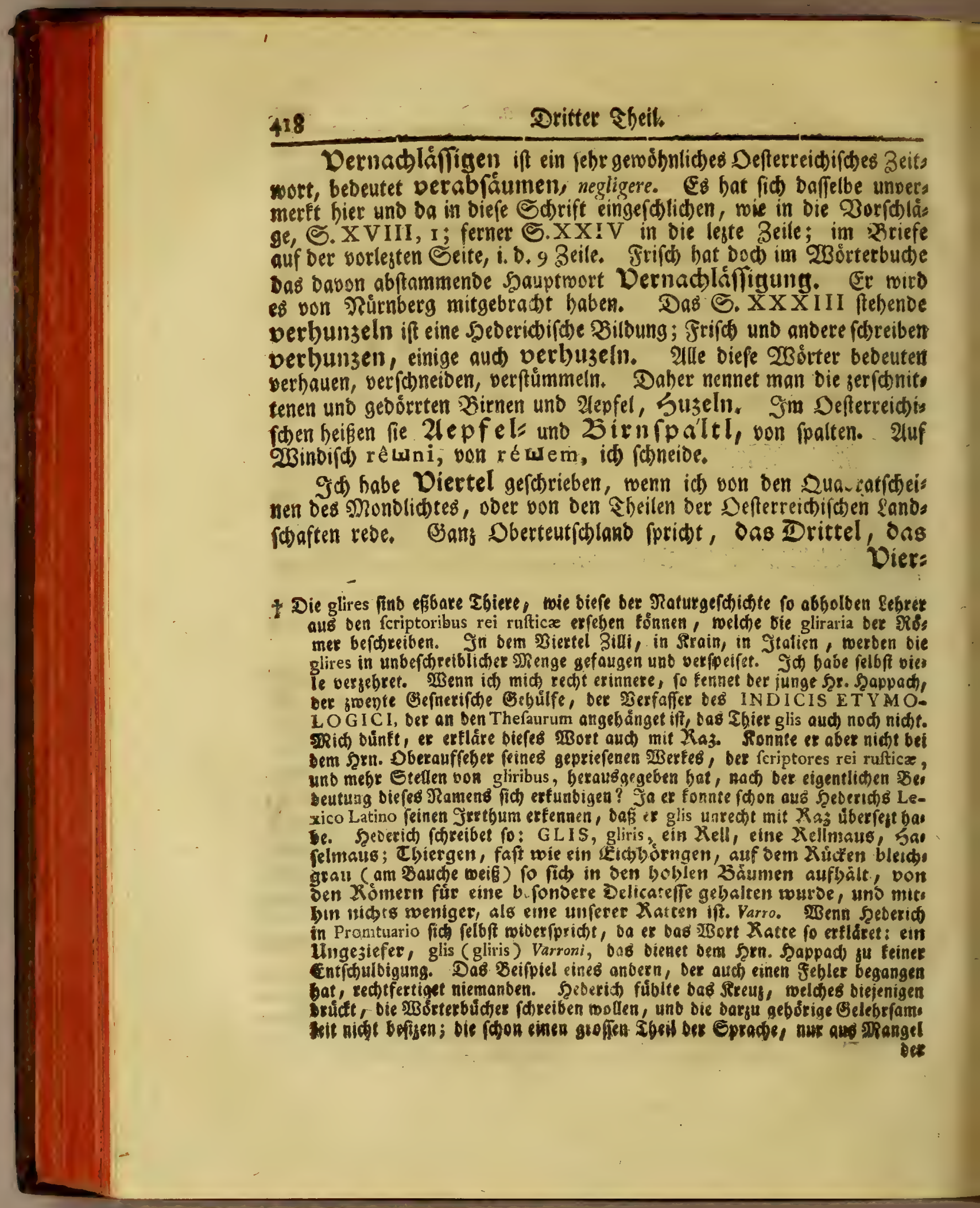


Diertel, Das funftel U.f.f. Diejenigen, weld)e bie Enbung biefer 2Borter mit theil wollen gefdrieben baben, wert:n int Biebraude

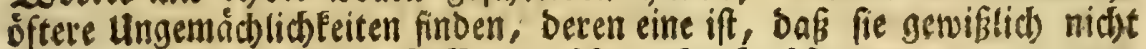
fonnen in Viertbeile Jilli, in Viertbeile Dorau u.f.f. fdyesis

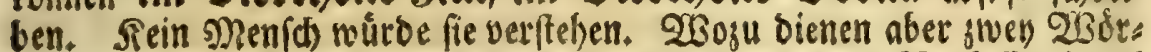

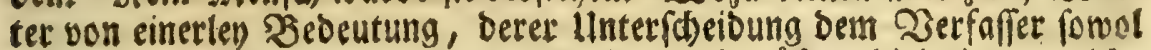
als bem fejer ungelegenfeit madts? Darmad) mü̈ten biejenigen, weldbe bas theil vertheibigen, ein Dritttbeil forreiben, weil es für Drit:

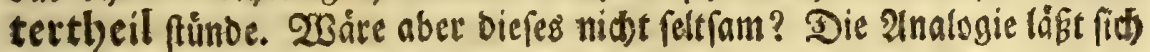
bennodh, wegen einer wot entbefrlichen Siegel, ein $t$ nidht abnehmen.

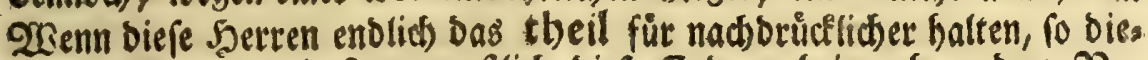
net qur 2ntwort, Daß man erflich biefe Enoung bei mefir andern $\mathfrak{P a s}$ men aud nod mit tel gegeben finbe. In ber Defterreidishent

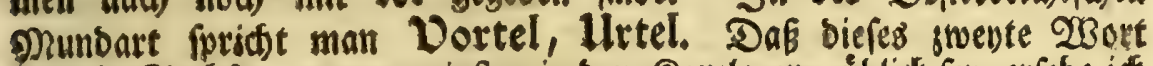
aud in Sadsfen, sum menigften in ben Rangleven, ublids rev, erfehe id aus Syebericts Lex. latino, weldbes i. 23. SENTENTIA folgende Erflârungen enthált: "Jententia confirmatoria, woburch bas vorige Hrtel (c) $g \mathrm{~g} 2$ beftars

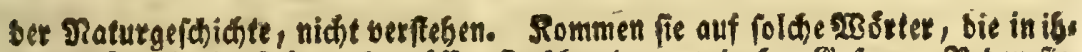

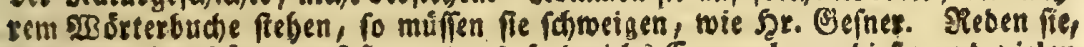
fo warten Jurthümer auf fie, wie es Feberichs Exempel, an biefer unb bieles

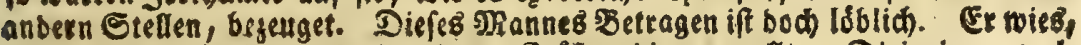

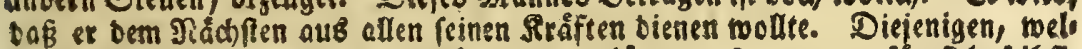
dhe bei ben 20 ostern feine Ert!ärungen anfigen, forgen mar für fich felbp. Eie verbuten, Dafi man ibnen mit ser Beurtbeilung nidht beifomment Ešnne,

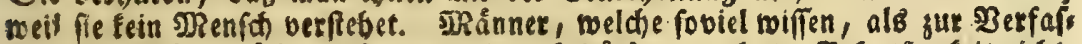

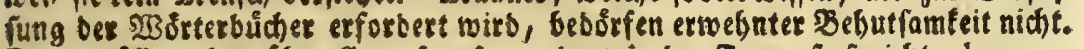
Diefe múflen aber úberall ju Saute, unb, wie bet frangcfe fpricht, hommes

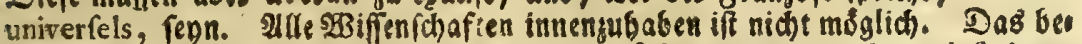
gebret man aber aud nid)t. Die Jtaliener bruefen biefes mit theem infarinato

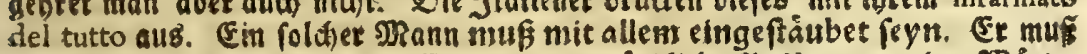

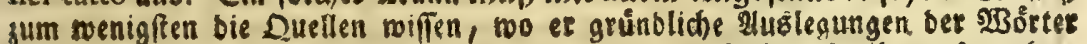
ju fuchen babe. Secterich bat fein Yromtuarium oreg Jaber eber beraubgegeben, ale Dab lateinifche Lexicon. Jinnergalb bren Jagren ift er fitiget unb geleges ter geworben. Er if injwifhen anf beffere Bachrichten von gliribus getatben. Er bat in bem Varrone nad)gefdiagen, ben ex in Promtuario angefulbret, abet nicht gelefen bat. Fr iff fo ebrlid); baf et feine falfone, in gebachtem Euthe ges

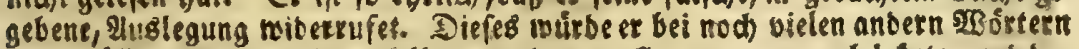

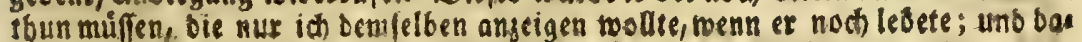

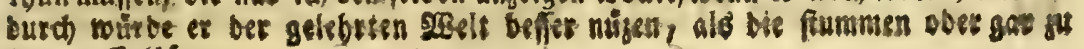
jungen Erflárer. 


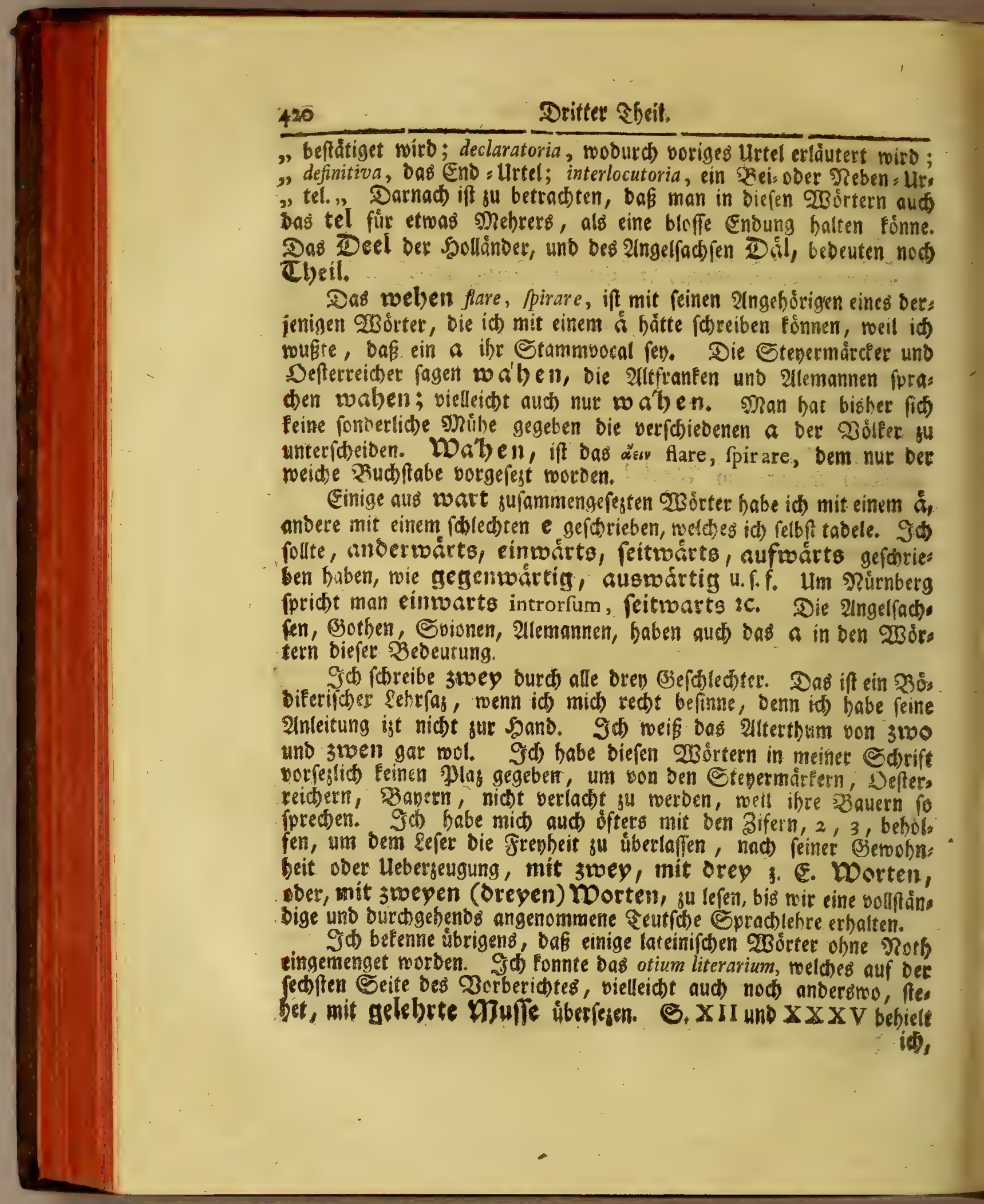




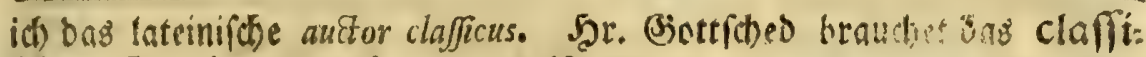
(ib)er Ecribent Dafur. Das if nur um ein halb Quntchen beffer.

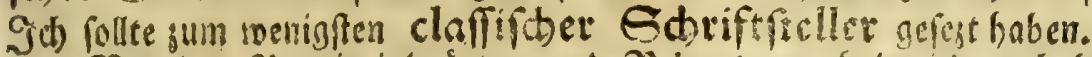

Don ben Wrovinjialwortern uno Siebensarten babe its noth ores Stucfe fu erinnern. Das erfte ift, Daj̧ bei eineth Derfafter, oer in

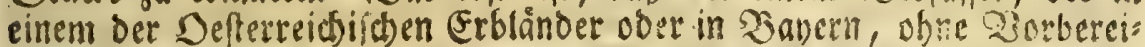

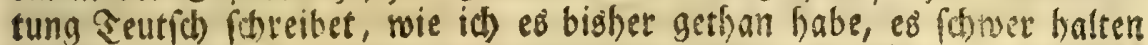
borfte, ben Yrovinjalfehlern gu entgeben, bevoraus bei der Zufanmen:

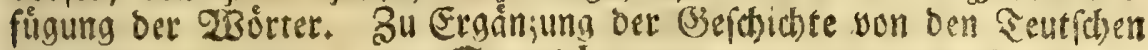

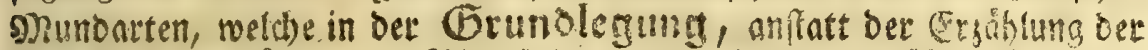

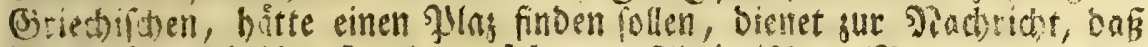

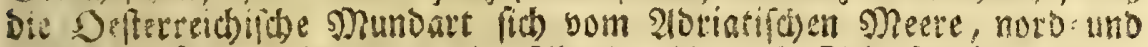

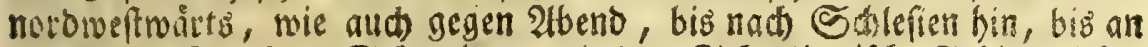

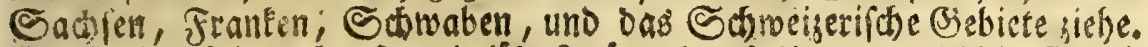
Gie breitet fich aud oft: und fúboftrånts burch Ungern uno bie Slavi: fob en fander aub Die Siebenburger und (Sotfdeer in Irain bejeugen butef ifre gan befondere Rebart, bas fie frembe (Solonien find. Das Sauptween ber Sorad) ift in allen übrigen iftbenamenten scindern einer.

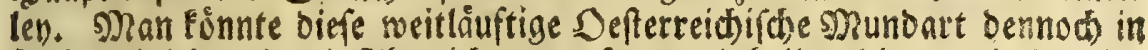
Rebendialefte, ober in 2 broeidsungen, ferner abtheilen, die man in den bes

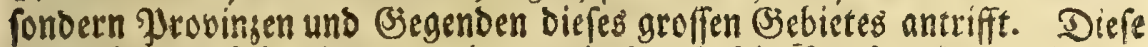
unterforiden fid aber nur ein wenig burch bie 2 tusfpradse, und eine geringe Babl eigener 20 órter. Der Särner verrátb gleich Dabur d) (rin Daterlano, da er s. (E. wol anfatt ia fprictst. Der Dbenftenermár. fer lagt in biefem Derfande leith ne't : Er will fagen, viel. leidt nitht? Det Saner uno Sberơfterceid)er fagen nicht ja, fonoern ia, wie ein gewiffes Sbier forenet. Die Tărnerifonen Detfleinerungs. worter, infonderbeit nad bem Flitio bin, und in Demfelben, genen in ele aus, roie die गrurnbergifónen in ala. Die úbrigen Seftereider bilden fie nur mit einem Eno:I, bem adh gewiffen Mithutern ein

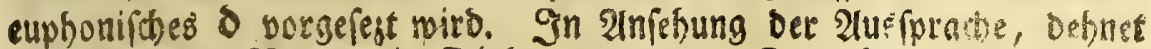
ber Wayer bie Docalen in Diphtbonge aus. Das thut aud now bet

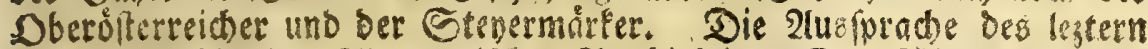

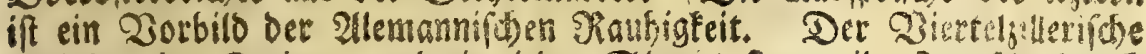
OBinde, bet Srainer, und ein iroer Slave; fingen ihr Seutfo, burd)

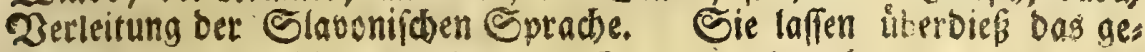
meine Defterteidifo, bon ber 288 (5. an, befthriebene a nod tiefer rauten. Sie bermandeln es in ein Somedindes a doer beinabe in (3) 993 ein 


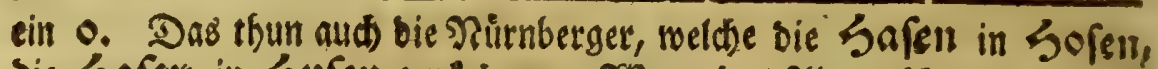

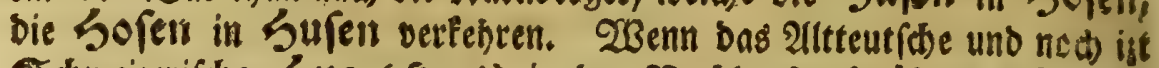

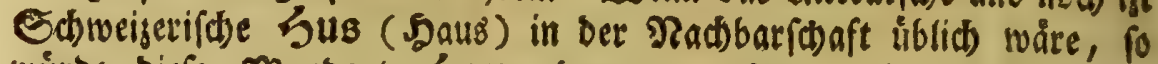
murbe biefe munbart Ђous baraus madjen, wie aus folgenoem Exempel gu erfehen. Denn man fpridt gu Rúrnberg: gei sou, Sous oer! Det $250 u b$ bat gnoug. I moun a was Gouts

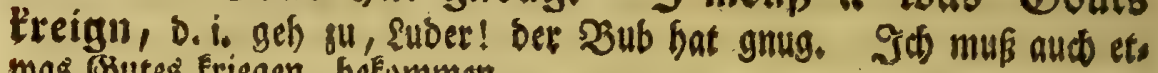
was Esutes Ériegen, befummen.

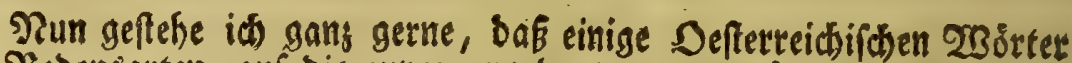
unb Redensarten, auf bie juyor angebeutete unumgénglide 23 eife, in meine Seutibe Shreibart werben gefommen feun. Unter andern fălle mir biefer 2usbrude, fids senten, ein. Der Sefterreicher, Stens ermáter 2c. fpredi)en id (bab gemeine Doff i) bent mirs, ans ftatt, id bilbe es mir ein, id) feelle es nite vor, und fo von mebr ans Dern Bufammenfügungen zu reben, weldbe einem Sach jen nod) frember Flingen werben; Dergleiden abweid)ungen von einer Eprache, bie fü fith on gehalten miro, man foloecifmos nennet. $23 a s$ aber bie einjeln,

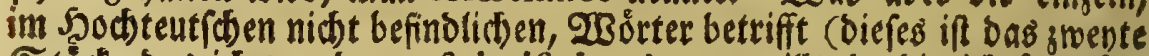

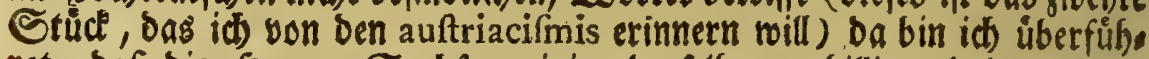
ret, Daß bie Serren Sachen einige berfelben unbillig tabeln werden.

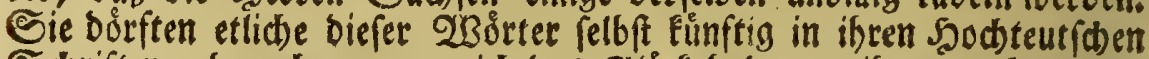
Sdriften gebrauden, wenn id bas Ellick babe, ju ibnen zu Eommen, und benfelben bie nach ber Eigenfdaft ber Sprade geprufte Biute,

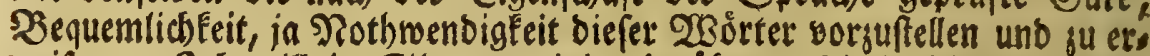

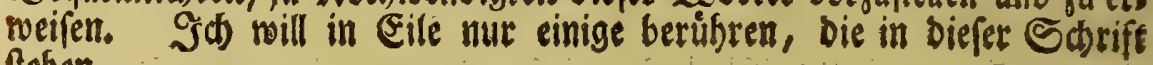
flefen.

Zefabren beift nach bem gewofinfidffen sebrauche vereri, befiirchten. Şeberid)o Promtuarium bat nur biefe 2usilegung. Ė if aber bas befabren auc ein Funftwort berjenigen, Die etwas zu 2̧affer ober ju Eanoe fúbren. Das $23 a f f e r$ miro mit Sthiffen, das fand mit $2 a ̈ g e n$ befahren. WBenn man som 20 affer reber, 10 meis id) gmen gleid) viel geltende 230 orter, befdiffen und befegeln. Sch båtte alfo $5.281,13$, anftatt biefes 2tusbrucfs: aufer ben bis: ber befabrmen Graben, befegelten ober befhiffen fesen fón. nen. 2lllein wie foll man biefes, Pirus (Name eines Sefterreichifinen Derges) bodis plauftris et carpentis teritur, in Sgodteutide überfegen? 
SRadiepe bon 3ugaben.

J山) fabe S. VIII, 27, gefdrieben: Diefer $2 \mathrm{erg}$ wird beuti: geo Tages mit Saftwagen uno Kutichen befabren. Wenn ein anberer bier gefabren gefdrieben båtte, ben laffe id bei feinem 2sillen und bei feiner Neinung. Ith werbe ihm nid)t nachfolgen. Doas falsen, in oer mirlenben $3 e b e u t u n g$, für fübren, habe ich biz. her für einen noricifmum gehalten, weil id biefe Rebensart yon bem sRürnberger Sboten, ber mich von sing nach Regensburg gefüfret, su: eeft gehoret babe. Er fagte z. E. Diefen Serrn babe ich offers aefalyen, anftatt gefubret. S(d) horte feit bem, Daf au'b anbere

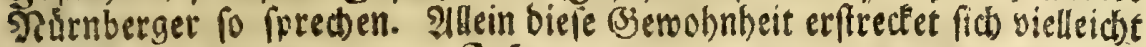
meiter nath Sachen bin. Fabren ift und bleibet ein Zettwort Der gnittelgattung, ein Verbum Neutrum. Der אutidher, oer Fubrmann fályrt; fie fülyren seute, 2 aaren. Das fabren fann nidtet ans Ders sur wirtenden Bebeutung erboben werden, als burd bie 2(nfügung

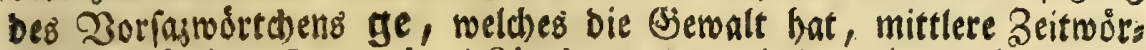
ter in wirfende (Neutra in Activa) zu verwandeln; wie aus ben Beis fpielen, befibiffen, befegeln, und hunbert andern su erfeben if.

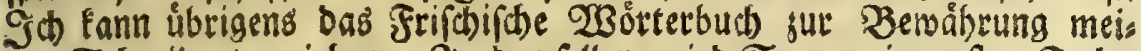
nee Schreibart angieben. Sa bempelben wirb S.240, im erfen Fadbe,

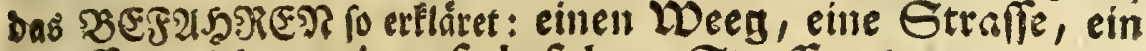
Daffer befahren; eine oft befabrne Gtrafle, via vehiculis frequens; ein uie befobrnes Mteer. Wie man in ben Jergwerfen anptatt geben, fteigen, allemal fabeen fpridt, fo bat aub ons befabren in benferten eine gleidjmåffige şebeutung, und wirb fü begeben, befidtigen, gebraudt. Diefes und mebr anbere bers

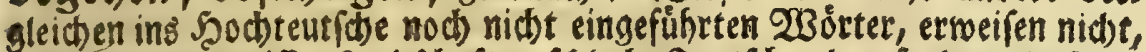

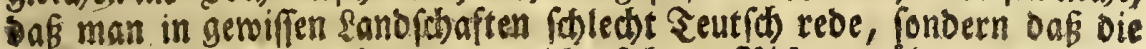
Eadfen und andere Serren, welche fid ju SRidtern uber Die Sodb:

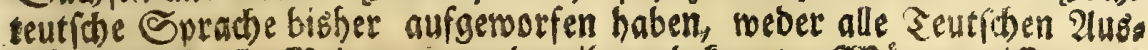
orucfe, noch alle $23 e b e u t u n g e n$ ber ingen befannten 280 orter miffer. S.h habe fernet S. 122,27 , gefthrieben: Wir nennen bie Derfammlungen der Dofferdunfte Wolken, wann fie bod in ber Lufr fibeben, Zebel aber, wenn fie in oer Tie: bere ftreichell. Sollte id in ber Ciefe geforrieben haben? Dies

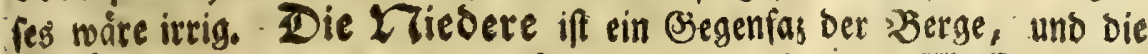

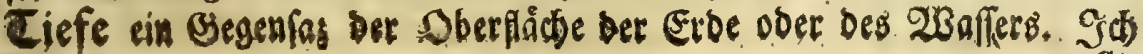
mollot 
molle den erften כoegrif, uno nicht Den giveuten gu verfteben geber.

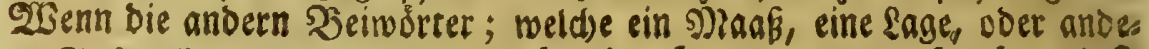
ie Beichaffenbeit bebeuten, als breit, lang, weit, boch, tief, eben, naf, troden, Surr, weif, fownars zc. ifre abgefürs ten Shauptworter haben, die 25reite, die kinge, die Write,

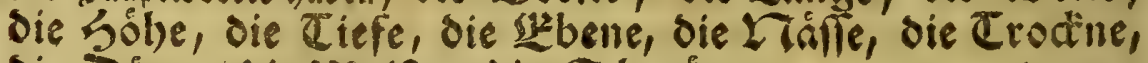
Sie Dirre, die Deiffe, die Gitwairse u. f. f. warum foll man bas nieber feimes SRectes berauben, oa bas von bemfelben abgeleites te Shauptmort die Z7edere etwas ausorủclet, was man burd) Eein anders andeuten Eann? Mnir föllt jum menigften Eemes ein. Sob babe S. XXXII gleid) anfangs gefdrieben: follen fid vielleidst Gpuren von Rómiftsen Febauben in Der Niedere finden.

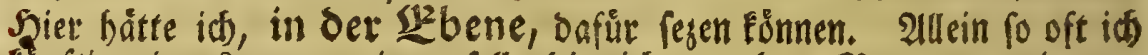

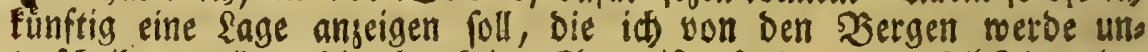
terfateiben wollen, bie aber feine Ebene ift, fondern nod) felbft in erbas benen Abwedfelungen bes (Eroreidbs beftefet, biefe will id) oie Lies

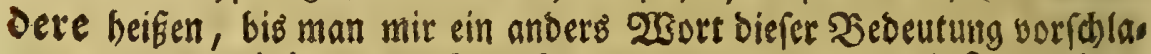
ge. Sft bas nieber nid)t überfüffig, ba wir foon bab tief uno eben

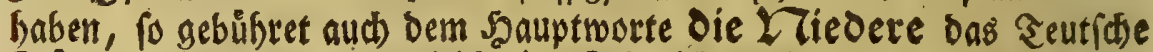

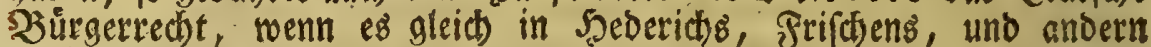

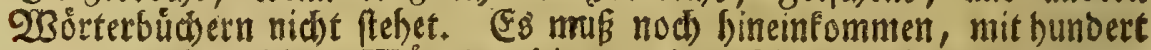

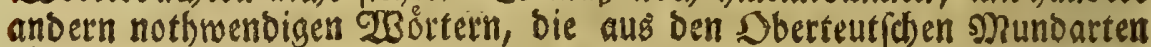
Fo̊nnen gebolet werden. 2Benn mir bie Efhre, nach feipzig ju fommen, noch) vorbebalten ift *, fo will id) biejenigen, welche fur bie Alufnalsme Der Seutiden Sprabe forgen, bon Den unnusen Grubeleven, wie man malen son mablen, weis von weiff, mus yon muf́, ben Gdládter von ben Gefdlechtern **' ze. unterfaciben foll, burd

Beis

* Jab) babe smar cinigen alfba lebenben voruebmen Gelebrten, meinen 5efuch ơffents lid) angetunbiget. NHein bie flingel, womit id mid zu ibnen foroinge

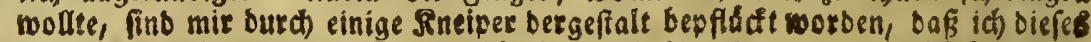

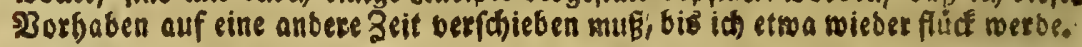

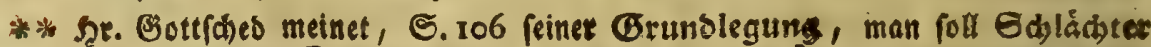
lanio, unb sas Befdjled)t genus (jenes mit sinem ă, biefes nit einem gemel,

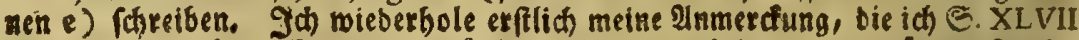

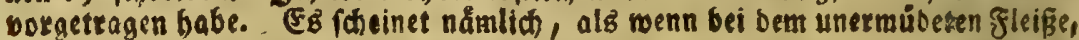

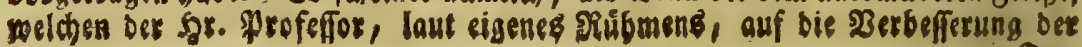




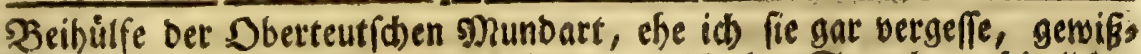
(id) auf anbere Unterfudt)ungen bringen, weldbe Det Sprache anjebnlides. re Dortbeile verichaffen bórften.

Der Name Kuno bebeutet in bet Deferrechif then sunbart, was Die Franjofen burch ibr chaland anjeigen wollen, nảmlich benienis

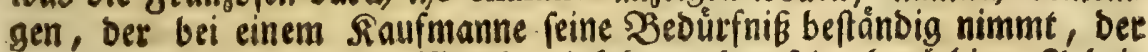
immerfort nur bei einem $23 i r t b e$ eineehret, Der feine benơthigte 2Arbeic bei einem gewiffen Şanbwerker verfertigen láft, und nidbt balo bu ei.

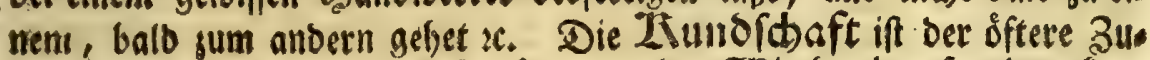

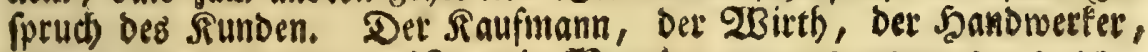
fagen: biefer ober iener ift mein Klund. Der Şandwerfer fpridst, Seere, id mache es elld, Der Faufmann, Sherr, id gebe es euch, um

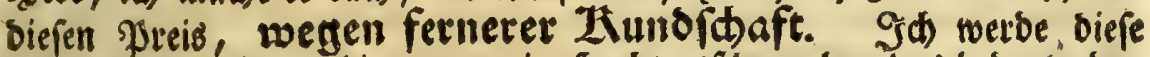
2sorter braudien, bis man mir 5̧od)teutít)e, eben bas bebeutende,

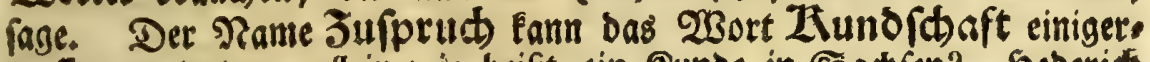
maffen vertteten: allein wie beift ein Sunde in Sadsien?. Sceberid

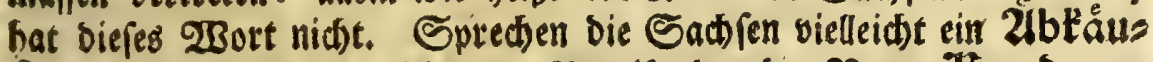
fer, fo beftimmen fie nid)t ben 3 egrif, ben ber $\mathfrak{P a m e} 2$ Zunbe ans

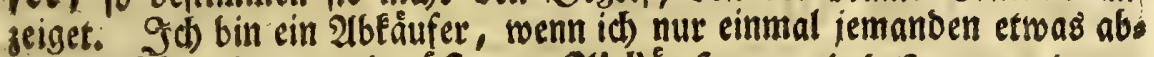

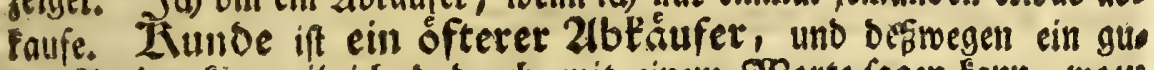
ter 'Aušbruce, weil id baburd mit einem 230 rte fagen fann, woju bet andere swey braudiet.

S(t)rofidt bebeutet roub von felfen. Frifa (d)reibet im 23. Shrofe 10: ein Wort, fo in ben Gegenden, wo Eeis ne Selfen fins, wenig bekannt iff. Deswegen entgehet einem WBorte nid)ts an feiner Siute, wenn es nicht befannt ift. Sar. Botts

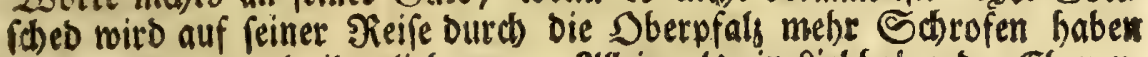
fennen gelernt, als ibm lieb war. 2Ullein alö ein Siebbaber ber Ebenen, 565

unio

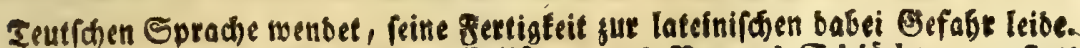

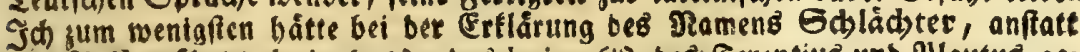

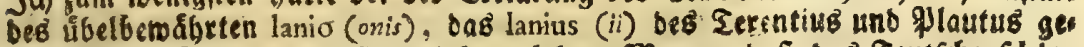

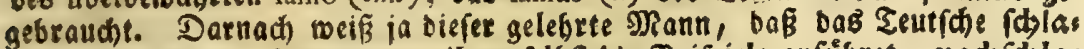
gen auh generare bebeute, weil er felbft bie Feipiele anfübret, nadídblas

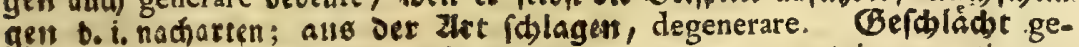
nus, generatio, Eommet bemnad) von (d) lagen generare, wie generatio bon genero; wie genus, gívos, bon zsivo, $u x i$, nafcor, procreo: warum geiget ex alfo, anflakt einer nidgtŝa

cine 


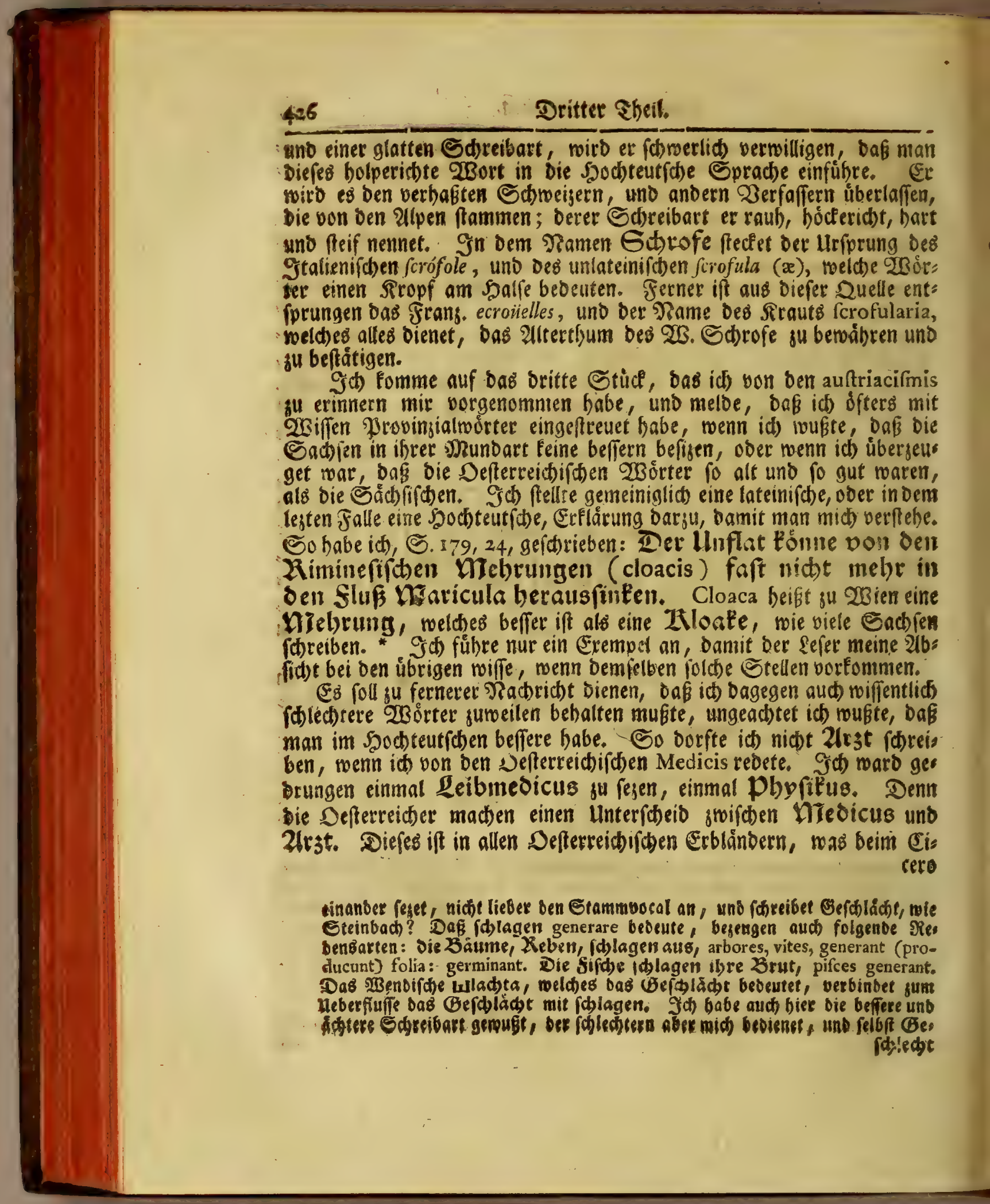


cero pharmacopola circumforaneus, ein Martetichrever, Quad'fal: ber, Der bem leichtglåubigen $\mathcal{Z}$ olfe Das (jelo offentlich aus ben Zeusi

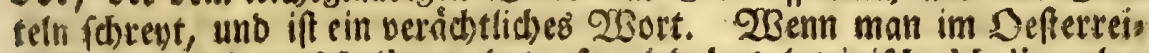
bifchen von einem Medico rebet, fo wiro bas latemifáte Medicus be balten, und in ben 2(uffabriften ber SBriefe mit Phyficus abgewed)fert. פ)?an fagt ein Seibmedicus, Felomedicus, Stcotplyyfitus, Lanopbyfitus U.f.f. Die gemeinen \&eute (aud) ber aloel uno bie

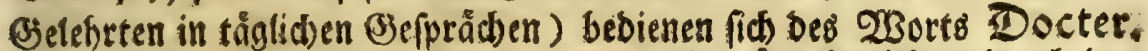

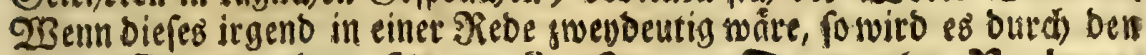

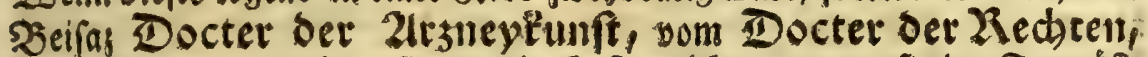
unterfotieben. Daber pflegen bie Defterreid)er, wenn fie im Trangefis fhen nidht fef find, ibten auftriacifmum aud in biefe Spradse su brith gen, ba fie le Docteur, anftatt le Medecin, fpredsen. Es muifen alfa

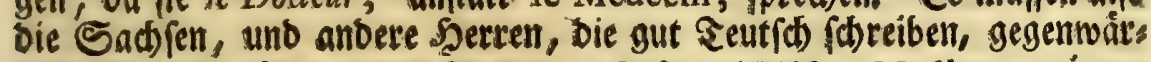

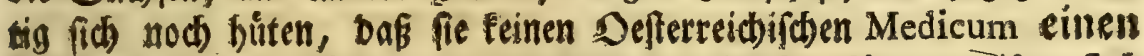
2trst nennen; fie wurben ifm baburd eine foledte (Ebre erweifen. I\$ fage gegentwartig, bis etwa ber Bjefornace yon einer beffern Sprai

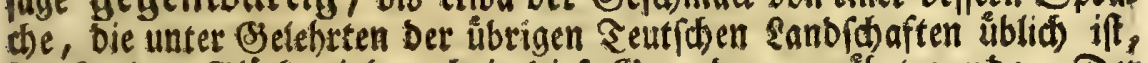

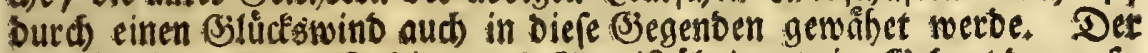
Unterf(heib swifhen spebicus und 2irgt ift úbrigens eine (Beburt ber nafes soifen Unmiffenfyeit, weldbe aud ben Marillen uno 2 bricofen,

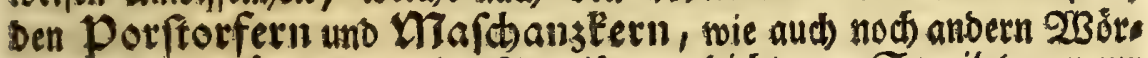

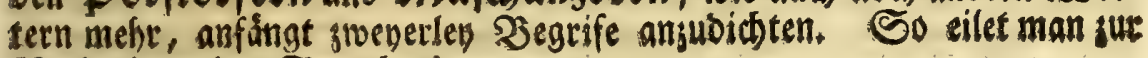
Werberbung ber Spredien!

Shiemit gebact)te id meine Bufäge zu befhlieffert. 23 eil aber auf bieferm lesten $\mathfrak{B}_{0}$ gen nod) ein Paum überbleibet, fo will idh, anftatt bee S. 256 in ber Anmerfung veriprod)enen Evelärung, bie mid) wieber in 2Beitlåuftigfeiten bringen Eonnte, fieber nod) von einigen 280 ortern meis ner Sdreibart Siedenidaft geben.

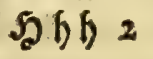

Die

(d) ledst gefdrieben. SDan wirbe eB alb eine Dermeffenbeit auggebeutet baben, wenn ein Etenermárter fich) uneerftübe, Reuerungen in bie Teutiche Eprache

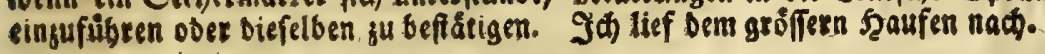

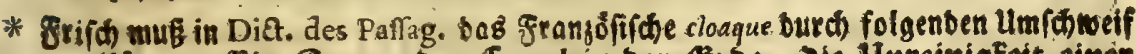
ertláen: Ein Bang over Canal in Ser Eroe, Die Unreinigfeit einer

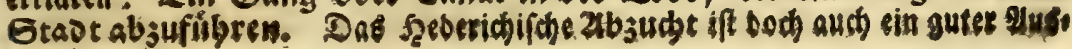
orut. 


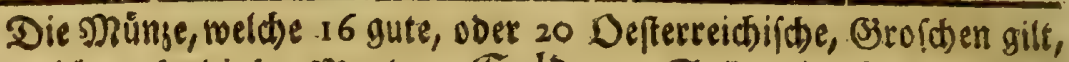
nannte id) nach biejer Mundart (G)

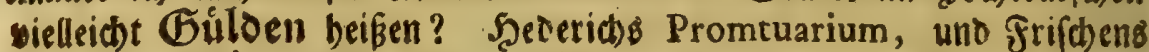

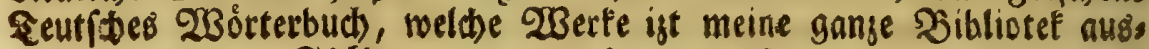
machen, baben Gúlben. Zu Niurnberg fångt man an Bsúlben su fprechen.

Seberid) (d)reibet Partey, parteyifh, unparteyifd); Frifi mit enem $b$. WBenn fid beibe Sdreibarten in meinem 2 Serfe befins ben, fo verwerfe id bie jwente. $23 a s$ foll bas b Dabei thun? Es fommet Partey bod) vom lateinifden, pars, partis, wie bie Franjo: fif́den গamen parti und partie.

S(b) (c) reibe bieten, offerre, liceri, mit ben abgeleiteten obet Damit zufammengefezten Beitwoirtern; nid)t bietben, wie Sat. (J)ott:

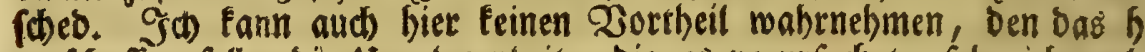
veridbaffen foll; bie ungelegenteit, bie es verurfactset, fehe ids mor. Mann foll bie unumgånglid fich einfindenden Schwierigéeiten vielmebr tractiten abjutfun, uno nicbt die 2 njabl ber unnotbigen, ourd willtibre.

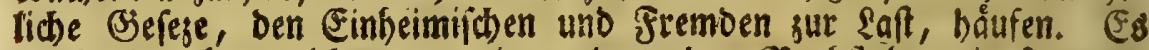

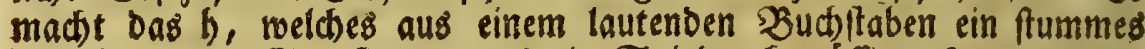

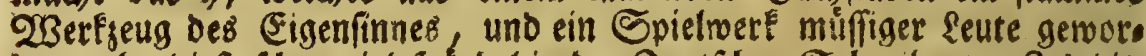

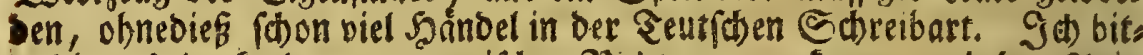

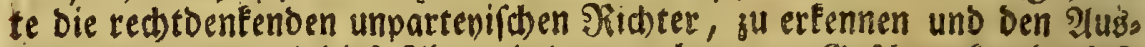
forud) 3u thun, ob biefe 2tbwandelung nach gutem (jefdomacke abgefaft fen: Id bietbe; ou beutfi, er beut. Wir biethen tc. in einigen yerfonen sfre h, in andern mit bemfelben, oa es ood weniget nuist, als cas funfte SRab am 2 agen.

Sth foreibe nit 30 obifern; Saf wir feyen, ut fimus; daf

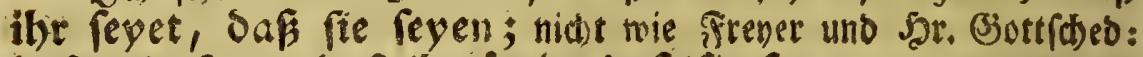
baf wir feym, caf ibre feys, onf fie feyn, welche burds bie anbere Perion den verbindenten 2lustruck bon Dem anseigenten, uns burch bie zwen ủbriaen perionen, Die beftimmte 2irt von ber unbeftimms

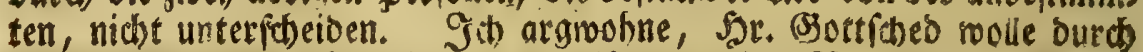

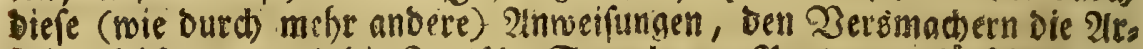

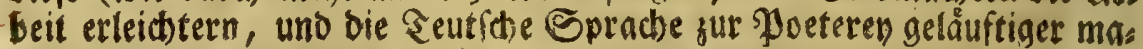
wen. Denn feyn ift gefticte einen Bers zu fwlieffen, feyen ift bars tu untúdtig So fino biefe anten ber Derfe gefwladter, als andere, unfere, wie bie Dbers 
Padlefe von 3ugaben.

teutfden fprechen. Wliein bie Didtfunft ift nicht ber Şaurtzroed ber Epradjen. Sie iff ein Rebenwert. Sie mus fich nad ben Spradsen ridjten, nidst biefe nads Derfelben.

Zei ber Seugung ber 2 eiroorter, wenn fie in ber mefrern 3 abl nat) ben eigentlitben ober uneigentlidben Surwörtern zu fehen fommen, babe id), wenn mein (jebád)enif midh nitbt verfübret, mit einigen geidjidten Sad) fell, feine Sauptregel, fondern bas SSebor , jut Rid)tichur genommen, uno daffelbe befraget, ob id) bejagten $\mathfrak{B}$ eimor:

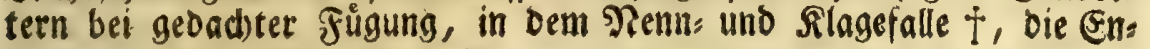
bung e Deb-nachgefejten Irtifels, ober bie Enoung en geben foll, rels

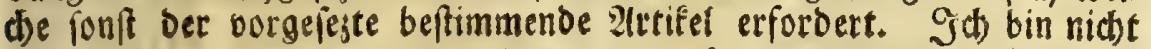

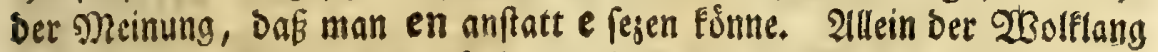
und die Deutlidfeit zieben oft oas e bem en vor. So babe ich s. (E.

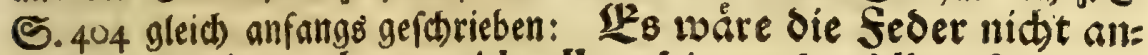
gefest worden, bevor ith alle, bis 3 berfelben Jeit bes rausgegebene, Ceutfhe 2nmeifungen ourbgelefen bátre; nich alle berausgegebenen Ceutfonen Jnveifungen. S. 410 in ber vierten Beile von unten berauf: liefern nun folthe ge:

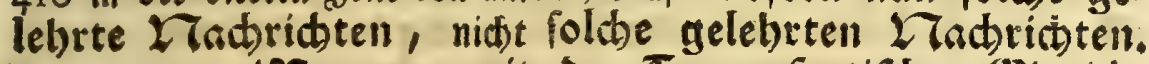
S.355, 24: M7an war mit oer Cournefortifben 1Zinrid): tung f́bon niकt 3ufrieben, weil oiefer Delser einige be : Eannte, uns ourch Iangen (Bebraud beftatigte Zamen austgetilget bat. Im Ende fo: die feit unbentlionen Jabren ertannte arten eines Gefblechtes einem anoern zuzutbei: len. Sier bebet die Enoung erfannte eine Jweifelbaftigfeit auf. Denn, wenn es fünde erkannten, fo mufite ber sefer fid befinnen, b biefes Jeinort auf Jabren, ober auf Zreten fich bejiebe. Soll aber unumgånglid eine allgemeine Rege! fu beobad)ten febn, uno biefelbe von allen Seutionen Sielefrten für gegrübet uno bewábrt befuns Den werben, fo will id mein (Sebor nach berfelben verbeffern, wis meine Meinung nat ben mebrern Stimmen ridhten.

$$
\text { Sפb) } 3
$$

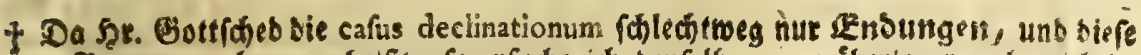
Benennury bequem betst, fo cxfuche id benfelben, zu tiberlegin, of midt je:

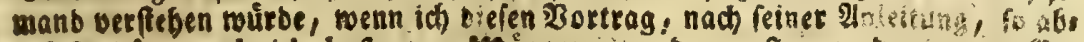

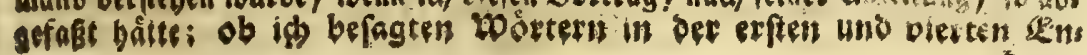




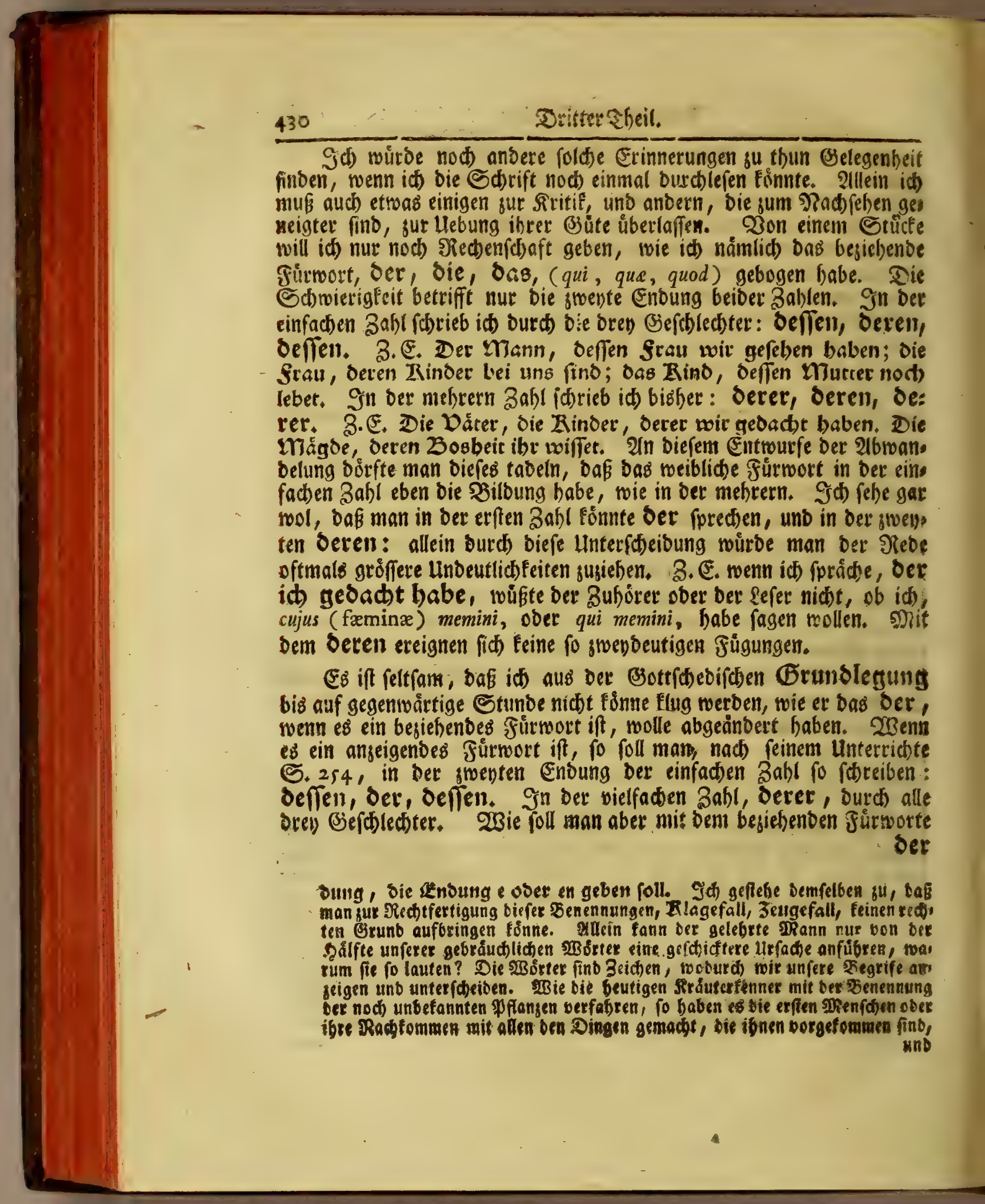


ber verfabren? Zun biefem handelt er S. 258, allein von ber 26 bin. berung meloet er nidst's. Sollte es eine nnoere erfordern, als bie ifm juftehet, wenn es ein anjeigendes Fúrwort ift, fo wirbe et mir, und ohne Zweifel auch anbern Sberteutichen, eine (jefälligfeit erwiefen has ben, wenn er foldses angebeutet hätte. WBåre aber in biefent falle bas

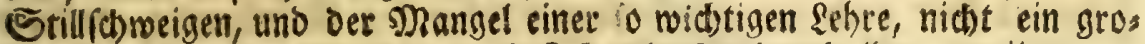

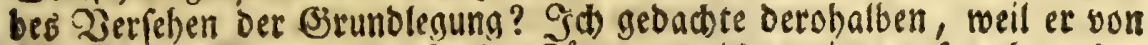
ber Abuanbelung bes befiehenden Tourworts nictes erinnert, fo gebe er Das burd) su erfennen, Daß es auf Die 2lrt gebogell werbe, wie in bem vorber abgehanbelten Falle, oa es die anzeigende Bebeutung hat. 21llein ex madise mich irre, als ich erwelyntermaffen (S. 400) vor wenig Tagen

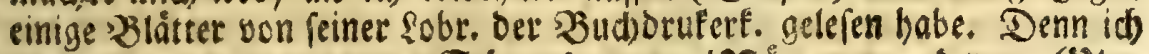
:fano S. 37 Diefe Stelle: Id rebe vor Mianmern, oeren $\underline{L}_{\text {in: }}$ fict)t bem L Zamen oiefer Gtad feinen alten Glans erbålt.

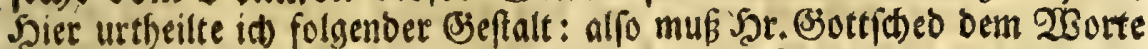
Ser eine anbere dusbilbung feiner Enchngen gueignen, wenn es ein bes jiehenoes, als wenn es ein anjeigendes fứrwort ift. Da id aber jus gleid betrad)tete, saf gebachte Sebe bereits vor ro Jabren verfafit worben, fo fam mir wahrfiteinfich vor, biefer shan fornne mittlerweile

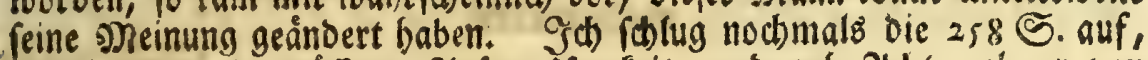
las biefelbe mit grófferer 2(ufmerfiamfeit, und gab $21 \omega t$, ob ef von ber abánoerung bes begiefenden frurmorts ber, alloa gar nidts erins nere. $\Im$ (b) fand abermal nibts , mol aber ein Exempel, melches nicht

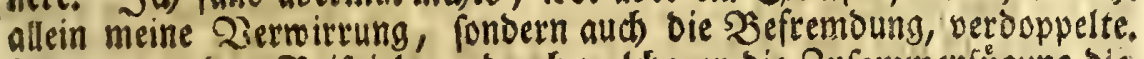
Denn unter Den $\mathfrak{B}$ eifpielen, Durd welde er bie Zufammenfügung bies fes begichenden Sürmortes lebret, jft aud biefes: Selens, um beren willen Croja serftoret worben. Nach peiner eigenen 2nneis fung miste es in bem oben angefúfrten erempel beifen: vor mán: nerii, Derer :ce, in Diefem abek: Selena, un ber willen ?c. șiet

4hb obne Ramen waren. 2Bas fü cinen Ĵfanmenbang baben bie Tantent

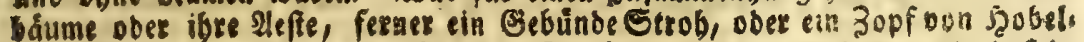

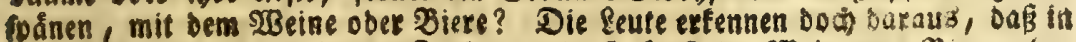

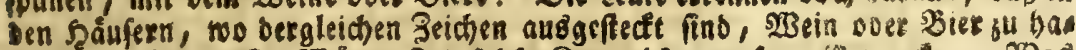

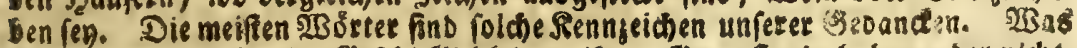

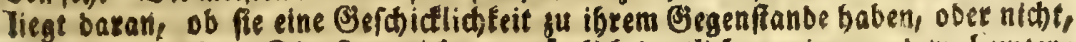
senn fie nut thren. Dienft vertidten, nămlich beutlit) angeigen und wol unters

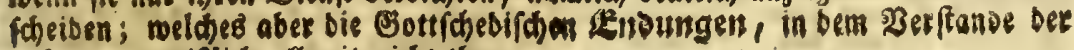
cafynen, semiflich allereit nint thun. 


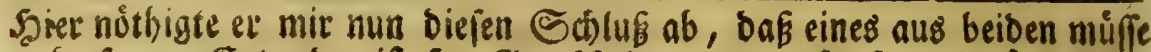

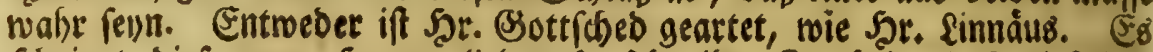

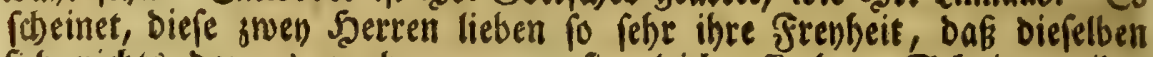
fich nidhts baraus mad)en, wenn fie gleid offenbare Sdjniser wiber

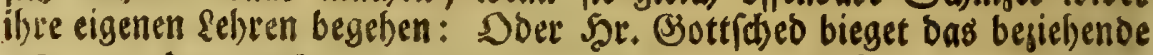
Fürwort Der nach einem befonbern Mufter Der 2 bånderung, welches er aber noch, als einen gebeimen 2 ortbeil, verbelet.

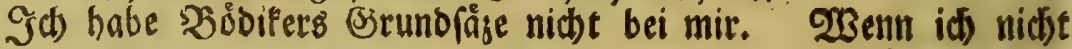
irre, to ift ber (Entwurf, nach) weldbem id) bas befiehenbe Furrwort oet biege, aus biefem 28 erfe entlehnet. Diefes will id auch zu meinet

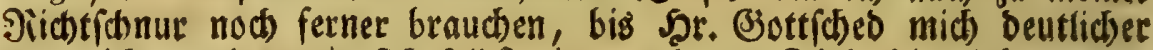
untertichte, ober mit fid felbft eins werbe. Sins feine sefren viels leidft ro bod, ober fo fein, baß nur id fie nid)t verftebe, fo ift bie

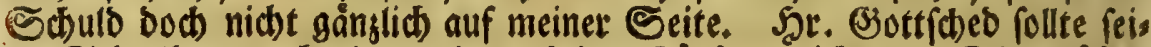
ne Sd)reibart aud) ein wenig nach ben నảufern richten. Die gróften

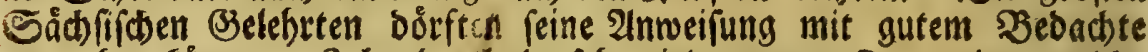

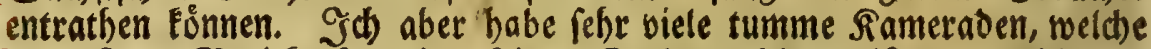

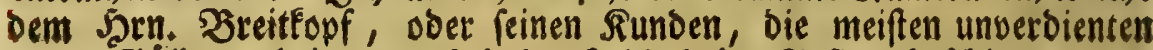
(Sútben zubringen, und baburd) bie britte 2Aflage beichleus nigen werden.

Sthreiben

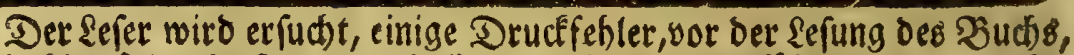
auf bie bier folgende Airt zu verbeffern. 2Bie bie Anfúbrungen zu verfte ben fenen, ift aus Dem $\mathfrak{B}$ eridjte, oer vor bem Segifter ftehet, zu erfehen.

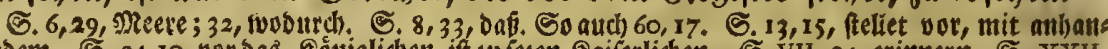

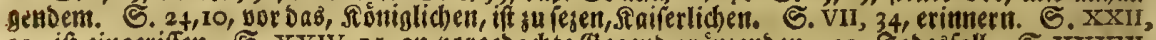

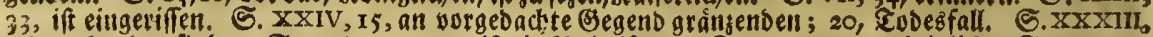
26 , vorbanben fino. S. XLVIII, 4, For if cin 2robaifnus. S. LIV, 26, gemeiniglich. S. LXI, 30, foggiornare. S. Lxin, 12, anberer abbangenben. S. LXXIr, 17, Ilyone. In bet britten áeile

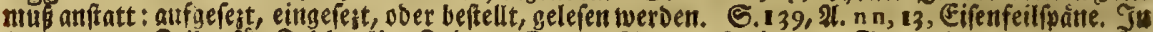

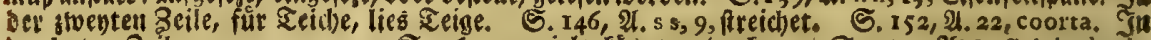

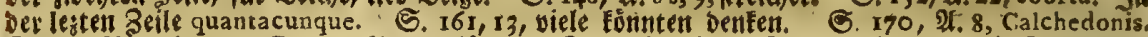

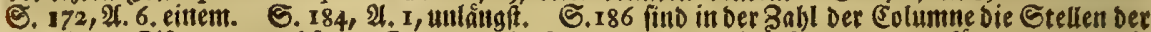

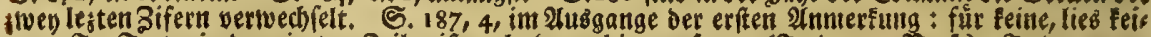

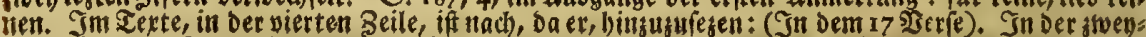

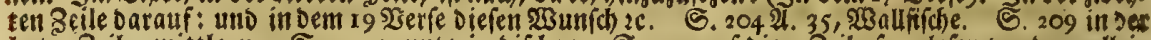

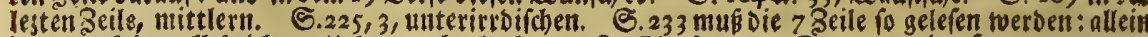
id babe Eeinen flebrichten lleber:th beobachtet; Sr. Pluche ic. S. 445 , 3, eine Sermmorehung.

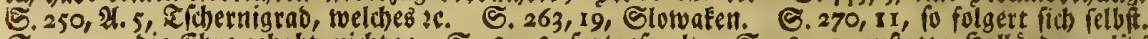
S. 272, 1, bie Ebre gebabt, nidbt 2C. S.28r, 8, fortgefegelt. $ं .282,5$, anfatt: Sollandern, lies

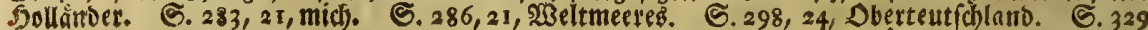
int Enbe, Padanum attilum. S. 33I, 5, ausgearbeiteten. S. 333,23 , bie übrigen Ënt (bulbiguns

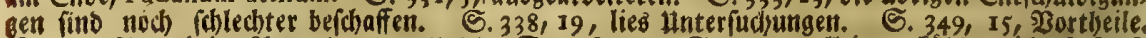
S. 392, $\mathscr{H}$, 5, einige 2 reten Deß Coralloides Turnefortii. $\mathcal{S} .405,8$, allein er fuiblet nidbt fo ftarf.

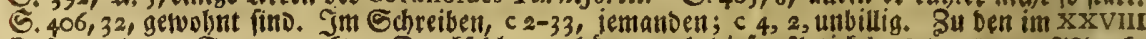

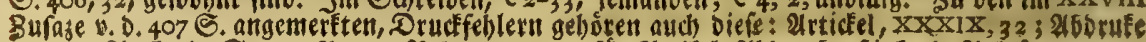

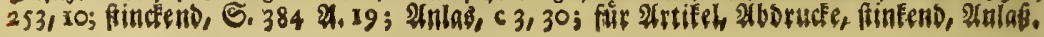


ifitidit DeB Berfafferb

vorbergebender $\mathfrak{A} b$ bandrung

an

Seinige vornebme elebrten in Scipzig. 



\section{Denen}

\section{MAGNIFICIS,}

Sodbuirbigen, Sadbedelgebobrmen, Beften, Soderfabrnen uno \$odigelefirten Serren,

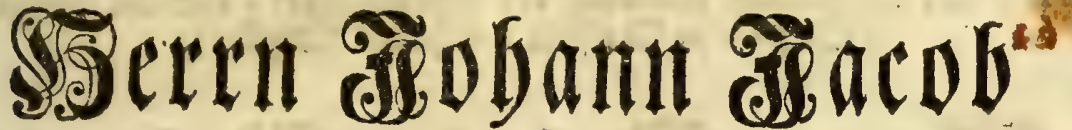

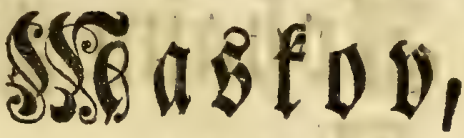

Geiber Siectite Doctorn, Sr. Rónigl, פRajeft. in

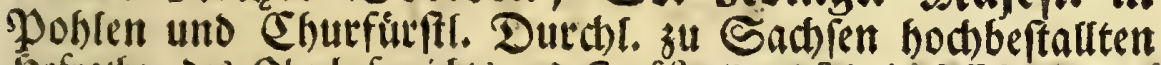

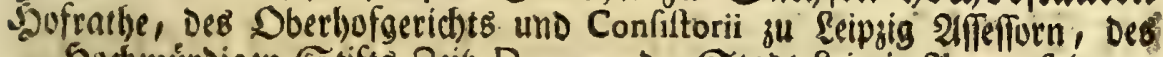

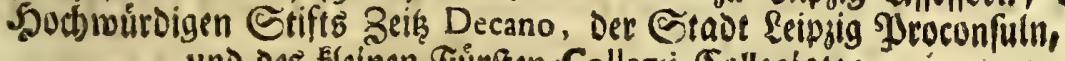
und Der Eleinen Furrften,Collegii Colleginten,

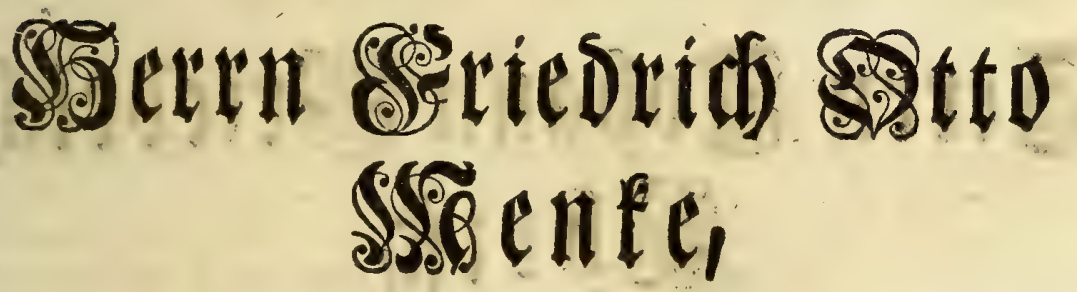

Geiber Stectite Doctotn, Gt. Ronigl. Majeft. in Poflen uno Ehuefiutft. Durchl. zu Eadden foctbeftallten Soufratbe, und godjaniegniliden Eenatorn. su Eeipsige

Setrtt 


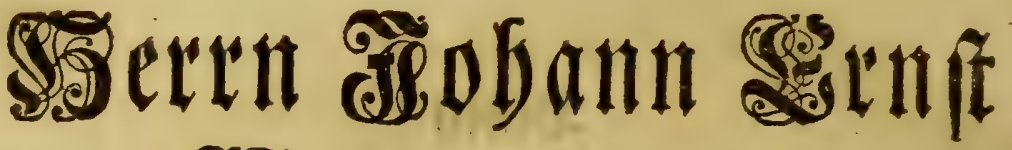 S5ebenfteit,}

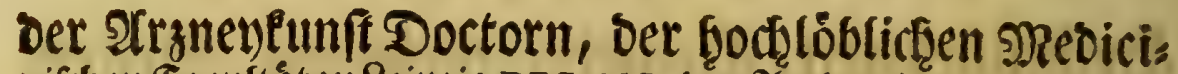
nilchen Facultát zu \&eipzig DECANO, Der 2 cademie DECEMVIRO, Des gruffen Fúrften. Collegii Eullegiaten, Der Staot \&eipsig ordentlicten

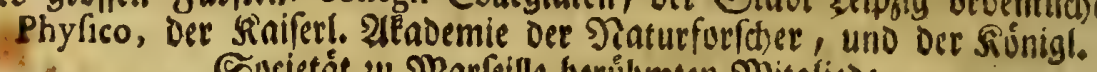
S. Sucietát ju Marfeille berúlbmten Mitgliede,

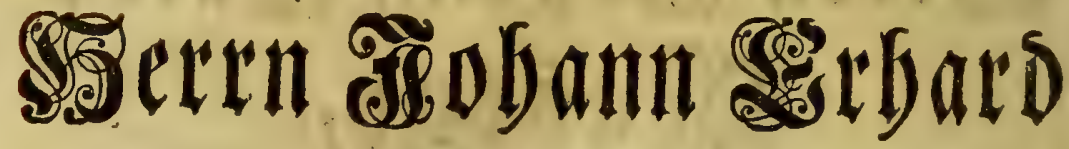 Fappe,}

Det Setedfamfeit orbentlicten sefrer auf bet gohen Shule zu Reipzig, Des groffen Guriften = Collegii Colles giaten, und der atadermie DE CEMVIRO,

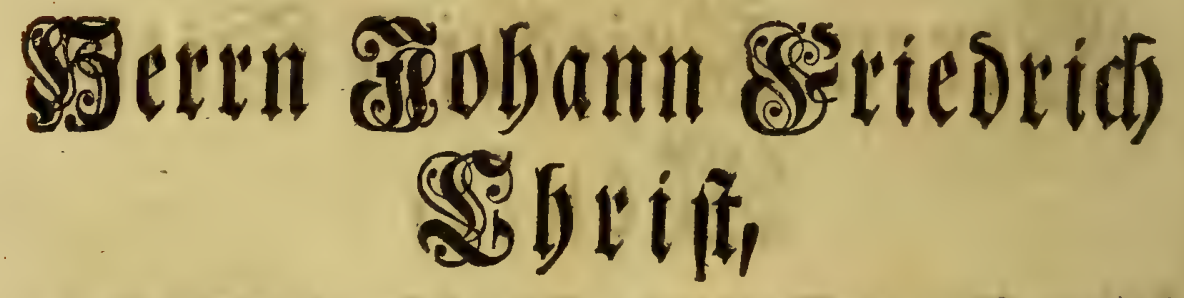

Der Didttunft orbentliden, uno ber Seffoidte auferordentlidsen $\mathcal{E} e$ frer, Des fleinen Fủ fren=Collegii Cols tegiaten, uno higer Zeit Der altademie Srubprubfren. 


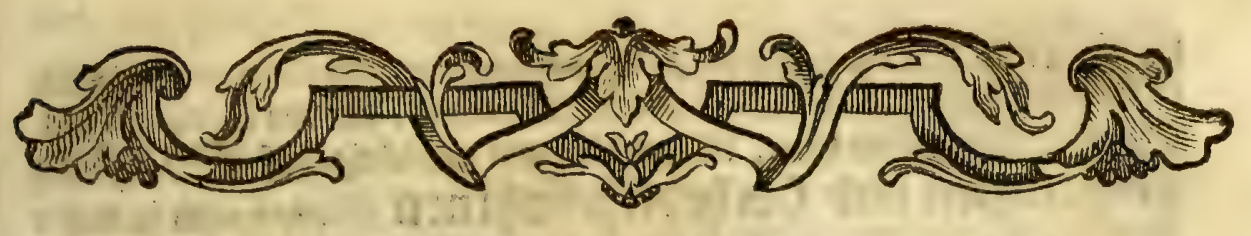

\section{MAGNIFICI,}

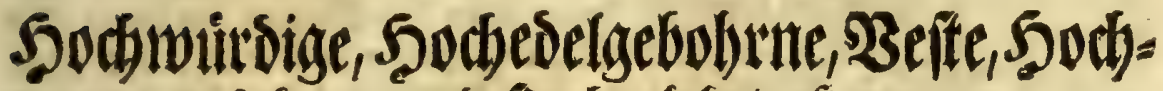 exfabrne, uno Soodgelebrte serren,}

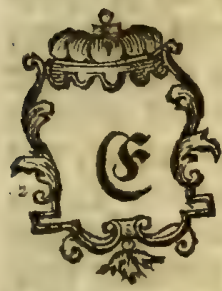

w. Magnificentien unb Socゆedelgebofrnent

Deroienfte fino fo grofi, dafi das (Sserúdte Dero Siramen auch Den entlegenften Sándern oun Seutfdilano vorlángft

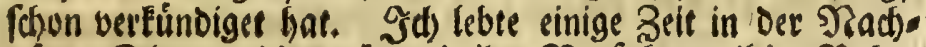
barfdsaft Der tapferen Slaven, Die nod), wie ibre Durfabren, ibren Siubm vielmebr ourch friegerifobe Sbaten, als ourd) Erlernung uno 2usubung anderer griffenfdoften, fuchen. Sie baben aud gerwifich in ben leztern Beitlauften ibren Bwecf crlanget, als fie mit Den gleid falls ftreitbaren Un.

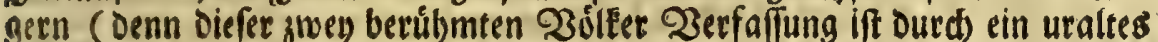
ß3and betfnúpfet) Dem fo plóslids entitandenen, und fajon gegen ifre (Srán. gen fich ausbreitenden siriegesfeuce, unerfdrocten entgegen gezugen fino, auth Daffelbe fo gludflich geoámpfet baben, Dab man ibnen, bev Dem $23 e r$ Fe Des wieder bergeftelten und befeftigten (SJleichgenvidbtes von Europa, mol einen anfefnliden Sbeil Dee Ebre mit allem Siect)te zuertennen mub. Gederman fiebt, Daß̧ nebf Dem martialifben Sriebe, Der fie alle Ergezlidj. Feiten, auser welche im Felbe zu finden, verachten beift, aud nod) ein an.

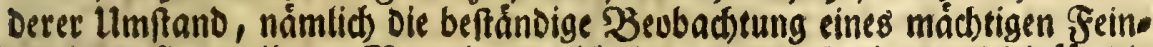
Des, Den fie von ibrem 23 aterlande abbalten, oaburch abee jugleid fur die Sidjerbeit bun seutfbland forgen muffen, unter die llefadjen mit ju zấb 


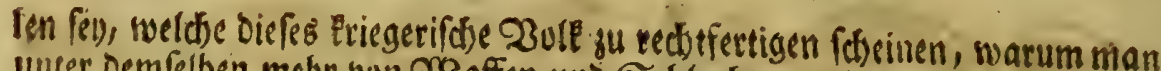

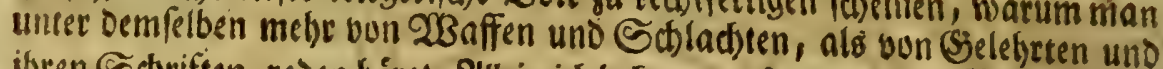

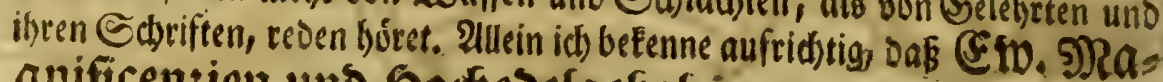
gnificenzien unt Sorfebelgebofirnen פamen aud) in diefen Eándern, wo die gelebrte 23 elt ein Ende zu nefmen foseinet, allbereit bee Fannt find. Denn eben Diefer Эiuf, Der úber Dero treffilicte \urzúge bis Durtbin erfotollen, nóthigte mir ben Entrabluß ab, Dem Drte Deto 2ufa enthalteš mict) zu nábern, ia felbft nach) Seipsig eine Sieife vorzunetymen, nicht in Der Şuffnung alld a niein Giluef us finden, Denn es twáre ein feltfamer Ein.

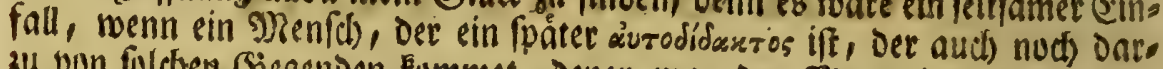
3u von foldber (Sisenden Fummet, Denen man Den Rangel Des guten (Ses,

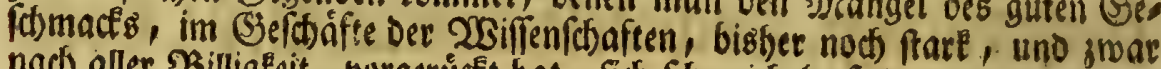
nad) aller Billige eit, vorgerúct bat, fich fomeidseln follte, Durd) eigenen Zerdienft ein bleibendes Unterlommen an einem foldjen Orte fide su bereiten, weldser feit langer Beit Das Siedte befizet, gelebrte (Eolunien nads ganz Seutfeblano auszufenden. Sch nalim mir vor, nacl) Seipig zu gel)en, nide

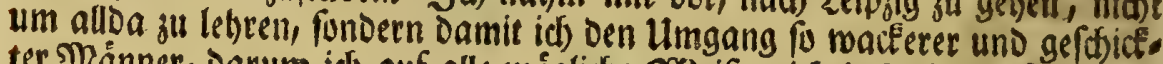

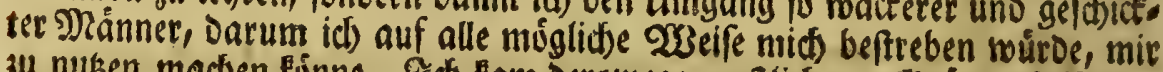

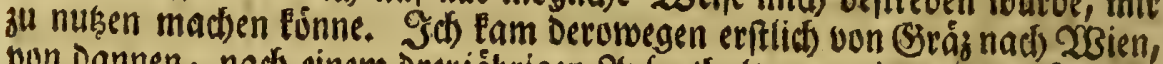
bun Dannen, nach einem orevjábrigen 2ufenthalte, zu einer neu aufgerich)

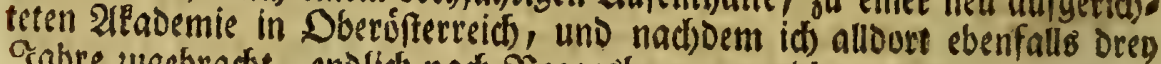

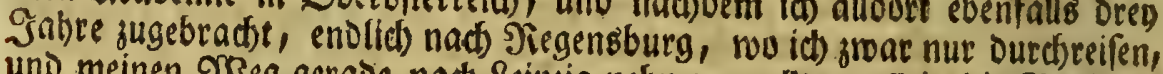
uno meinen $23 \mathrm{eg}$ gerade nadb \&eipgig nehmen wollte; allein Die Begierde

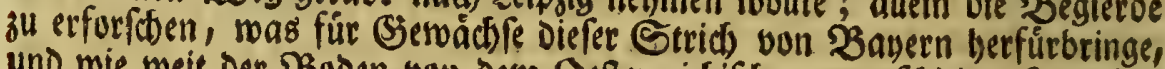

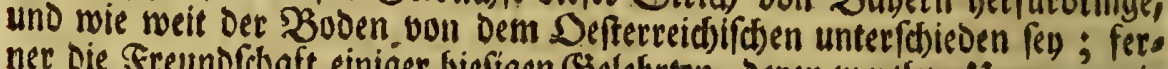
ner die freundfhaft einiger hiefigen Sjelebrten, Deren werthen Umgang mir

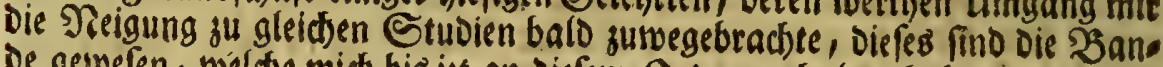
De gewefen, wél(d)e mid) bis izt an Diefem Drte angebatten baben.

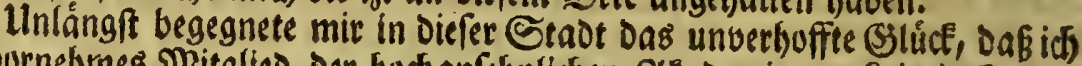

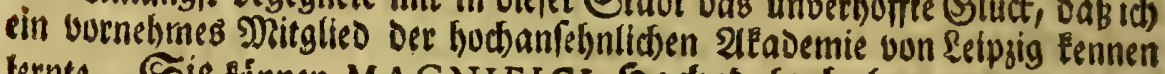
lernte. Sie eśnnen, MA GNIF ICI, Şođedelgebohrne, leidjt abfes hen, das idf oen berúbmten Jerrn Drofeffor Gortfdeo meine, Dee mit feiner gelebreen Frau Semablin aug Dem Rarlebade biether fam, um fodann ferner feine Sieife nad) 23 ien furtzufegen. Den Sarn. Jurofeffor fonnte ich) nue

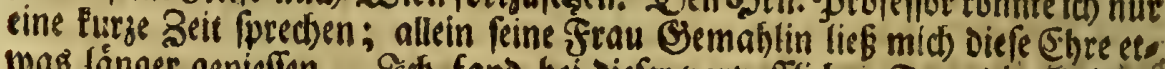
was lánger genieffen. Sas fano bei diefer vortrefflichen Frau Die Ṡetebrs

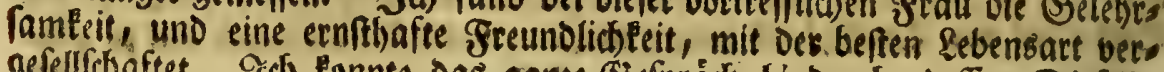

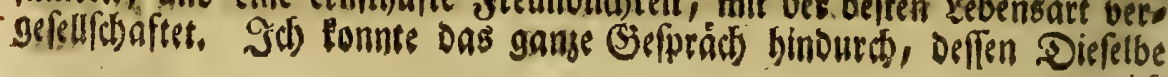


mid) eine balbe Stunde wurbigte, niфt Dle geringfte Epur einer Deract).

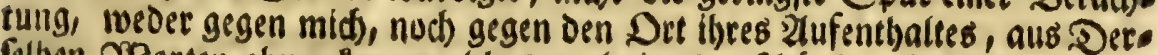
felben $230 r t e n$ abmerlen; weldbes wol eine der fdiunfren Eigenfd)aften ifts novourd) eine gelebrte Эerfon vor anbern fid) lobenswouroig macbt, indem

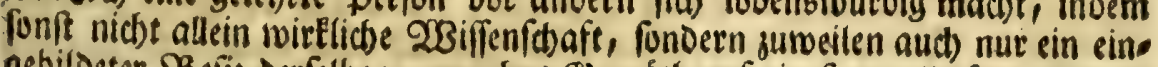
gebildeter $\mathfrak{B}$ elij Derfelben, mandbes (Semuith) auf ein fo tadelhaftes, als ver.

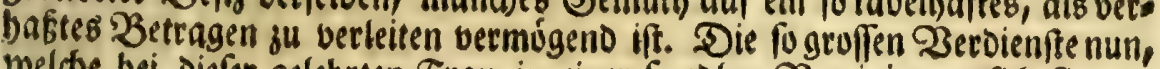
reldbe bei Diefer gelebrten Frau in einer fo eden Oereinigung fidb finden,

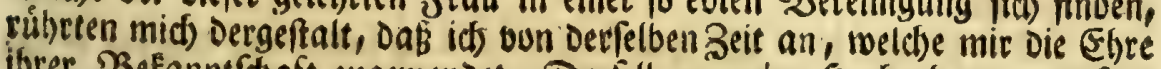

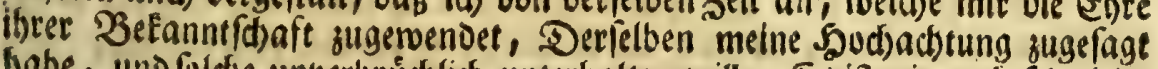
babe, uno foldse unverbrichlich unterbalten will. $E_{\mathfrak{g}}$ ift nir audb febr leto,

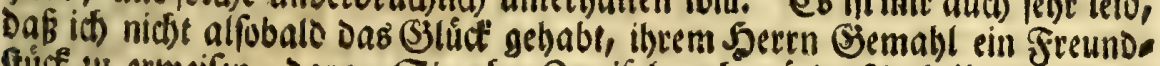
fincf ju erroeifen, Daran Gie ohne Zweifel auch wurbe Antbeil genummen haben. Denn nad Der abreife Diefes gelehrten Jjaares verlautete es in

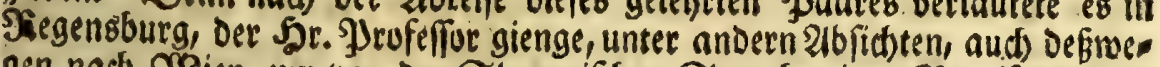
gen nach $23 i e n, ~ u m$ von oer Slavonifosen Syrndbe einen $\mathfrak{B}$ egrif allo

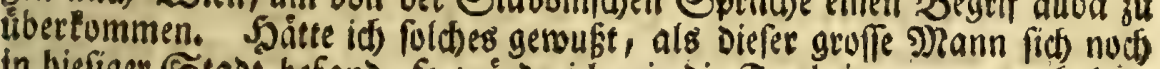
in biefiger Stade befand, fo tourde id) mir die Freybeit genommen haben, Demfelben mit wenigen $230 r t e n$ Darzuthun, was fúr ein $20 r t b e i l$ fúr Dié seutfere Spradje von der Slavonifoben zu gemarten fey.

Denn ids vermeine im Stande zu feun, bieruber eine Nadjeidje Iu geben, oa ich exftlith ein gebubrner $233 e n d e$ bin, Darnach die Eis

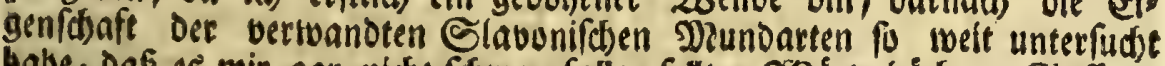

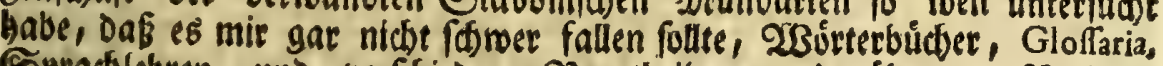

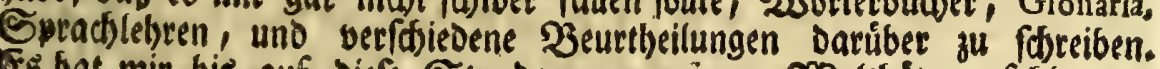
$E_{b}$ bat mir bis auf biefe Stunbe nur an einem 203 ulthater gefeblet, Der mir die Foften zur $\mathfrak{B}$ eftreitung zweyer neu zugieffenden Alphabete verf(c)affit bátte. Denn es Eann die 23 endifbe Sprache mit Den gemeinen latetni. fiben oder Seutfojen Sdbriften nicht ausgeoruct t merden. Sie bat einige felje

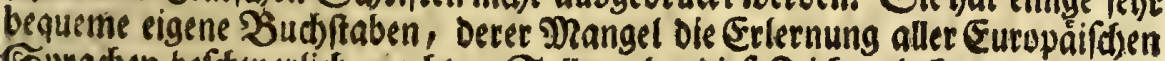

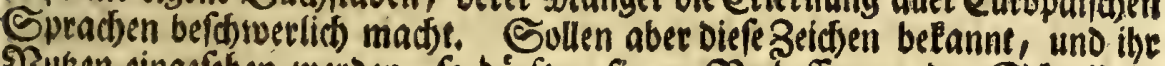

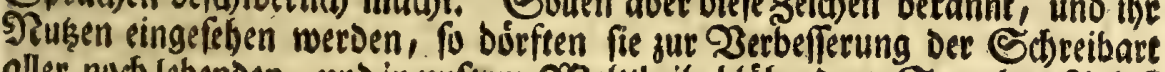
aller nud lebenden, und in unferm 23 elttheile blúbenden, Sprad)en 2 nla geben. Shátte id) Das Zergnúgen baben Eúnnen, Den Sarn. DProfeffor etwas lánger, etwann auf ein \$yaar Sttunden, zu unterbalten, fo tourde Derfelbe, nact einer Eurzen toon mir angeftellten Bergliederung oer 20 Bendiftben Spra.

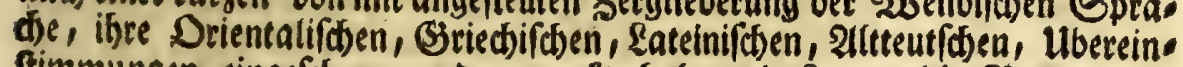
ftimmungen eingefeben, uno gemerlt baben, Daf nut oie Betradjtung Derjenigen 28 surter, fo aus Derfelben entlebnet fino, einem seurfiben nisilich 


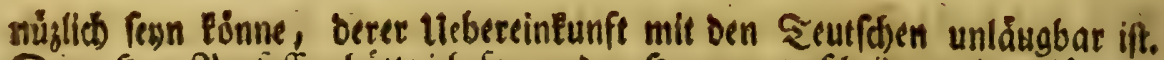

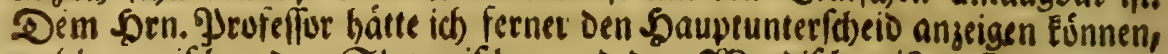
selcher zwifden dem Slavonifden uno Dem 23 endifden ift. Jenez jiebet

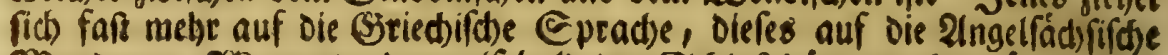

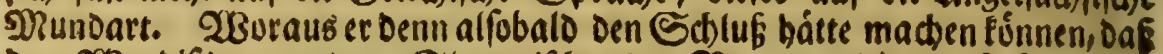

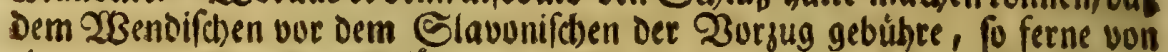
einem aus beiden, zur Erellarung uno Befferung DeE Seutichen, eine Frudbe iu boffen ift.

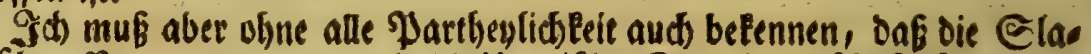

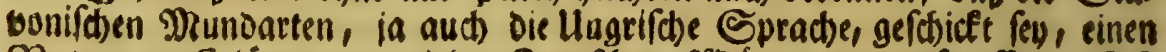

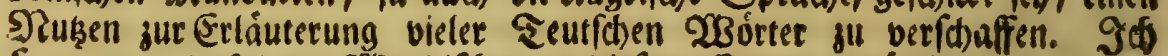

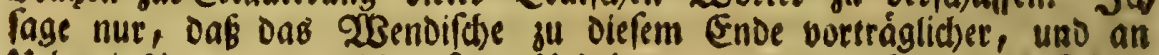
Ulebereinftimmungen reidber fey. Ulebrigens werden aud in ben Slavlo

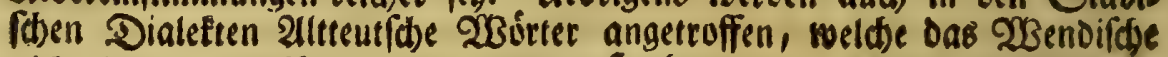

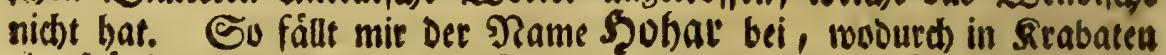

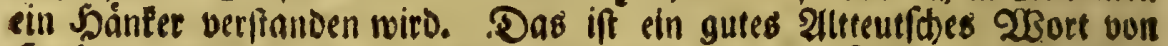
Soban, exaltare, furfam tollere. Dtfrio fobreibet Şaball; alo ufant Eruzi baban, 0. i. auf oas. Kieus bänken 3, 13, 10. Die 2ngel fachfen bradteen diefes Beitwort bean fur. Sead bedeutete nad) diefer Mundart exaltatus. 2(us Derfelben ift in Das Englándifhe bead, Das 5aupt,

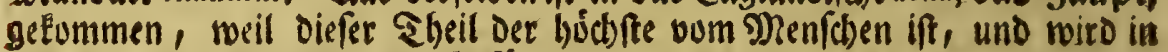
übertragener $\mathfrak{B}$ coeutung auch für ein Dorgebirge genommen, wie aus

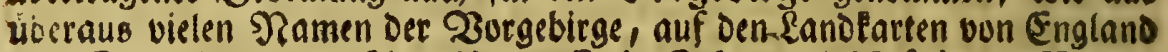
und Edjuttlano, zu erfehen iff; 3 . $E$. in Edjuttlano Nofe head, Hoburn head, Faro head, U.f. f. 100 Das vorbergetgende 230 ort, fo um Des untere

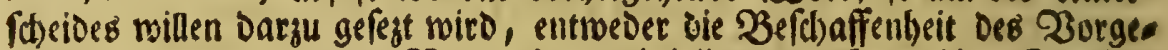
birges andeutet, oder Der Tame eines Dabet liegenden Drter ift. Die Cele ten múfen baan voer haa, für bohan, exaltare, gefproden haben, wos

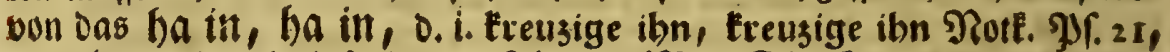
14, als ein lleberbleibfel in Dem 2llemannifben Dialette erhalten worben. Э屯) muthmaffe ferner, Dak die Eelten obne Doppellaut bao für bod, uno baor fúr bòber, voer audi) nod) fúr bod, Dórften gefagt baben, weil Hadriaticum mare, felbft nach Der Siśmer Dolmetfdung, Dab̈ obere UlTeer,

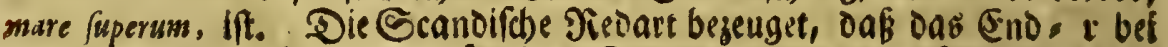

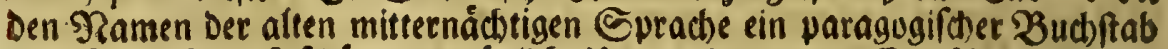

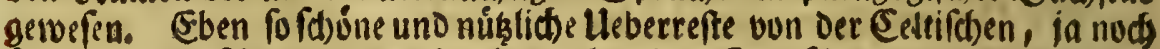
ältern Seytbiffsen, und Doch mit Der beutigen Seurfithen jiemlich verwande.

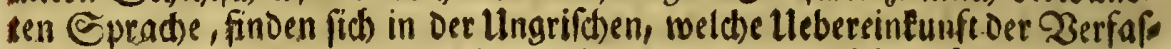
fer Dur 2(bhandlung de Peregrinitate lingua Hungarica, nicht gefeben bat; Die 


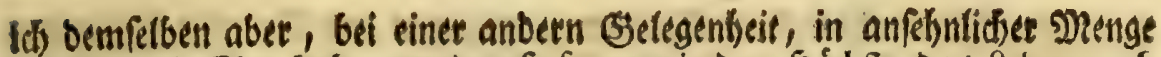

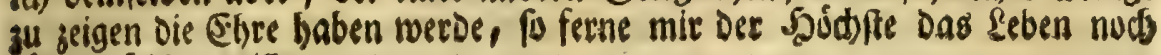
lánger friften will.

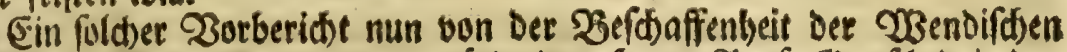

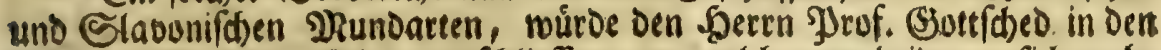
Etano gefezt haben fid zu entfotieffen, um veldse aus beiben er fid) melge

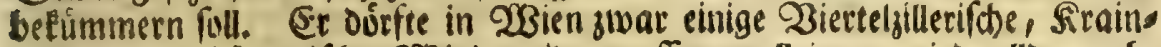
erild)e und Särnerifde 23 inden * antreffen ; allein er wird alloa mebe zeute finden, melde Slavonifd fpreden. Son Denen tann er ternen, nach folden \$Rundarten einen guten Sororgen, eine ruhige 9iad)t zu múnfd)en,

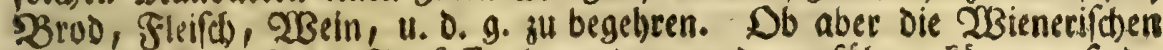
Gelehten Dem Şeurn Đrofeffor jemanien werden zufúliten Eusnnen, fo oa wiffe Das zu Deffelben 2 bfichi bienliche (Sjute aus gemeloten Nundarten ju

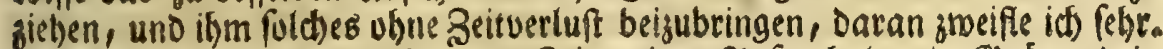
Mir if zum renigften, oie ganje zeit meines 2lufentbaltes in (Sirág und in 2raien, niemano vorgelommen, oer fich auf Die Unterfuctung, uno infone Derbeit auf Die (Sef(d)idte Diefer (Sprad)en geleget babe, Darauf id) Dudf vies

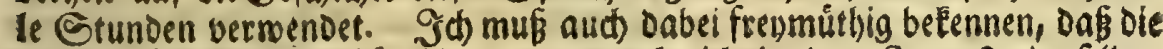
bloffe grunolidbe Siachforid)ung, woourd) id) in Das Sinnerfe Derfelbent hineinorang, nad) meinem Urtheile Elar jeigte, mie renig Dasjenige beftehen

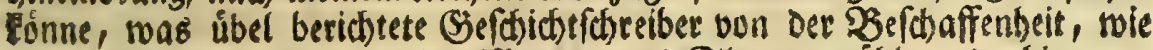

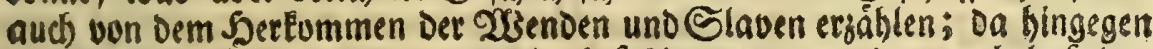

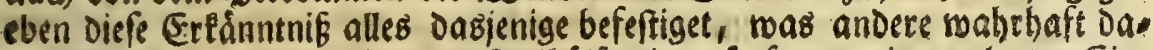

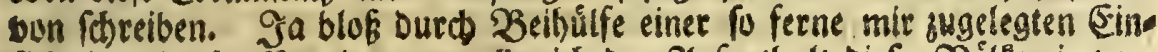

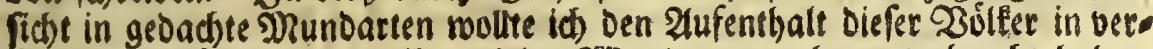
ichiedenen Eándern, uno ithre vielen Crzanderungen heraurgebract haben,

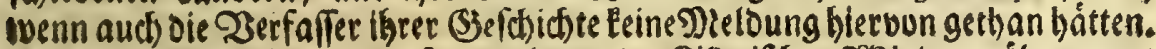
Die Epradje meiner Eandegleute, Der Billerifhen 23 inden, úberzeuget

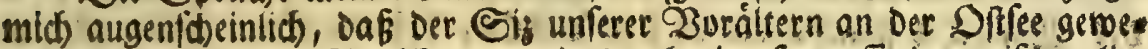
fen, Davon Dod Die Radtemmen izt Durd eine fo gruffe barjwift)en lies gende Strecte von Zeutfallano abgefondert find. Denn wir baben úber.

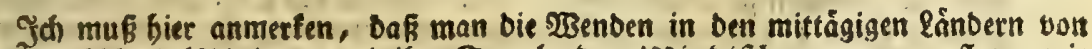
Teutfdhlano Tointen, uno ibre Sprache Sas bo insifde gtt nenner pflege, wie

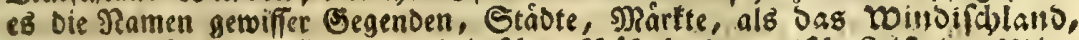

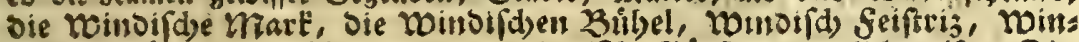
bifd) (1)

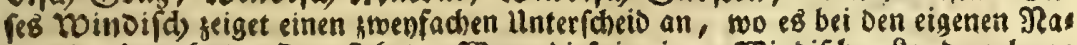
men Der berwognten Drte ftebet. WBenn Diefe in einem Mindifhen Eande gelegen

fino, 


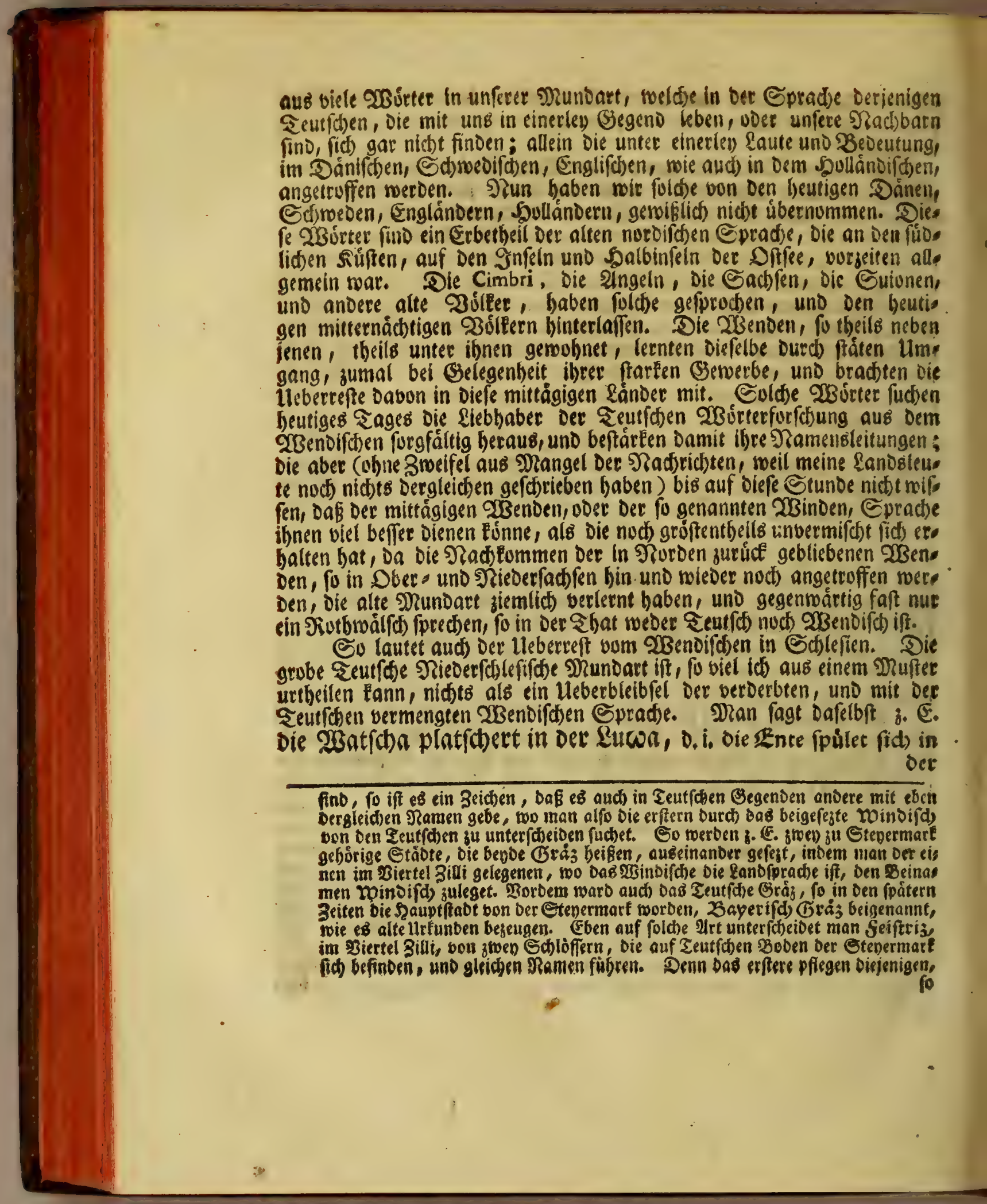


Der Pfüse ab:- Das $\omega$ mus bier, wit bas frangufriche ge voet je, aus, gefprocten werben, fo ein Mittellaut zwifhen Dem 0 und 10 iff. ** Das

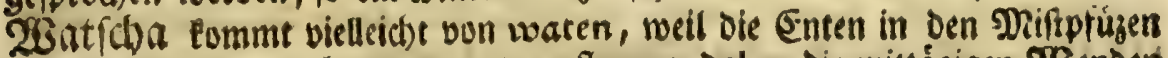
uno im Schlamme berumjuwaten pflegen; Daber Die mittágigen 23 endent gleidfallg bon biefem 20 gel fprecben: Ka

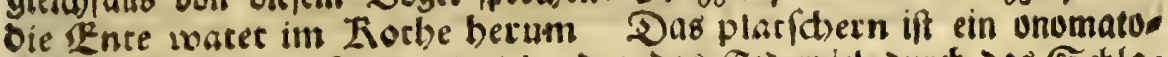

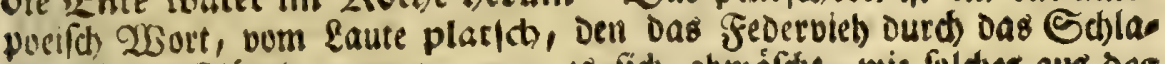

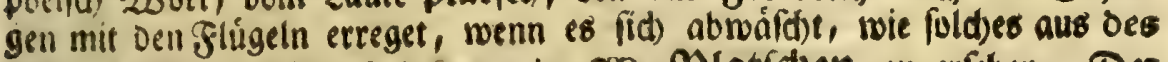

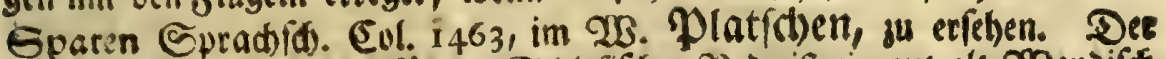

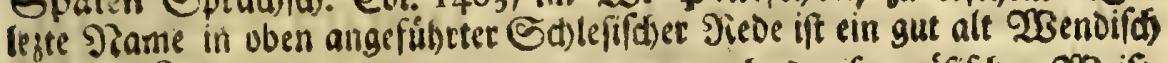

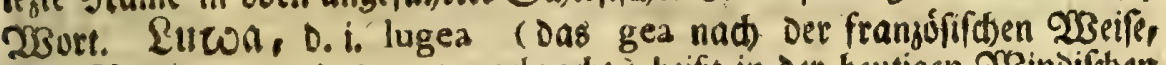

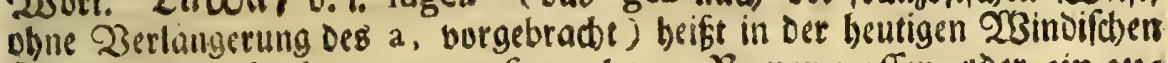
Epradte eine ladte von verfammletem Regenivaffer, voer ein 3 H. formmengelaufenes trúbes Waffer. Das Stammwurt ift LVG, no. von gleid) foll gefagt werden; Denn Das g verwandelt fich in Den 2 Bendi. folen uno Slavifthen Nundarten bei Der 2lbleitung beftándig in $\boldsymbol{\omega}$, wie Das k in Das Elavifthe und 23 endifde Cfaterf $(2 r)$ oder in Das seutfche

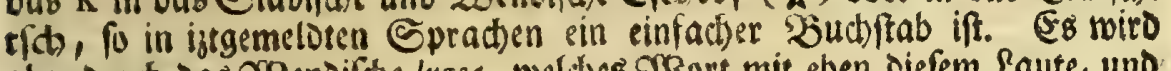
aber burd Das 23 Bendifthe lugea, weld)es 2 Sort mit eben diefem \&aute, uno

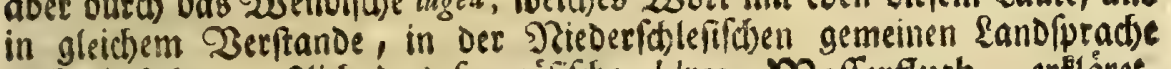

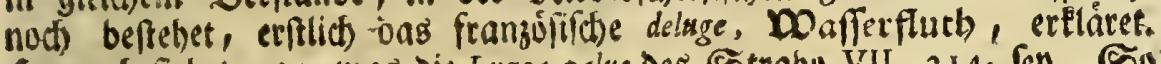
Sernach frehet man, was die Lugea palus des Etrnbo VII, 314 , fey. So nennet diefer Ed)riftfeller, unfeblbar nad) Der Fiedart Der Celten, Den

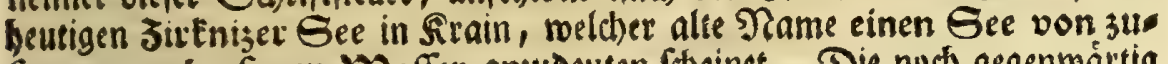
fammengelaufenen Wa fifer anzudeuten focinet. Die nob gegenwártig

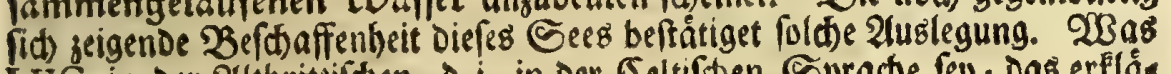

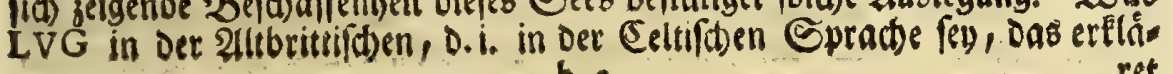
b 2

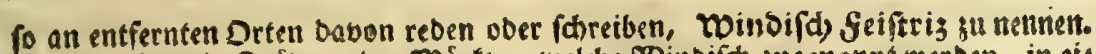

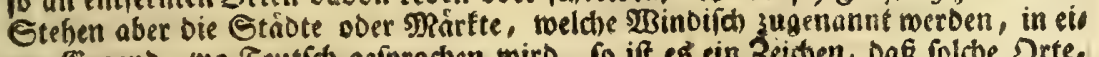

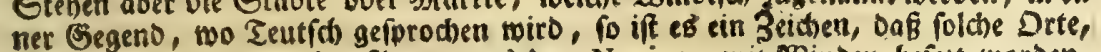
nach Der 3 ertreibung ber 2 barn aแs Dem Norico, mit Winoen befegt worDen, no man Detm Diefelben von Den Teutichen umliegenden Drten, Durch Dorfezung Des seinamens toinsifd), zu unterf(heiben angefangen bat. (Ein folther Fleden

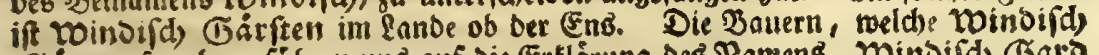

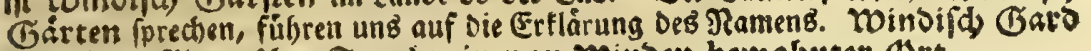

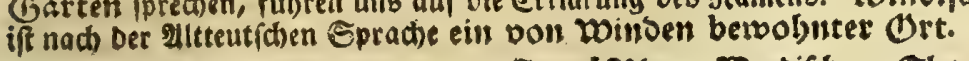

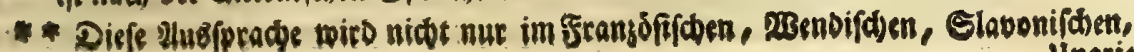
Ungriv 


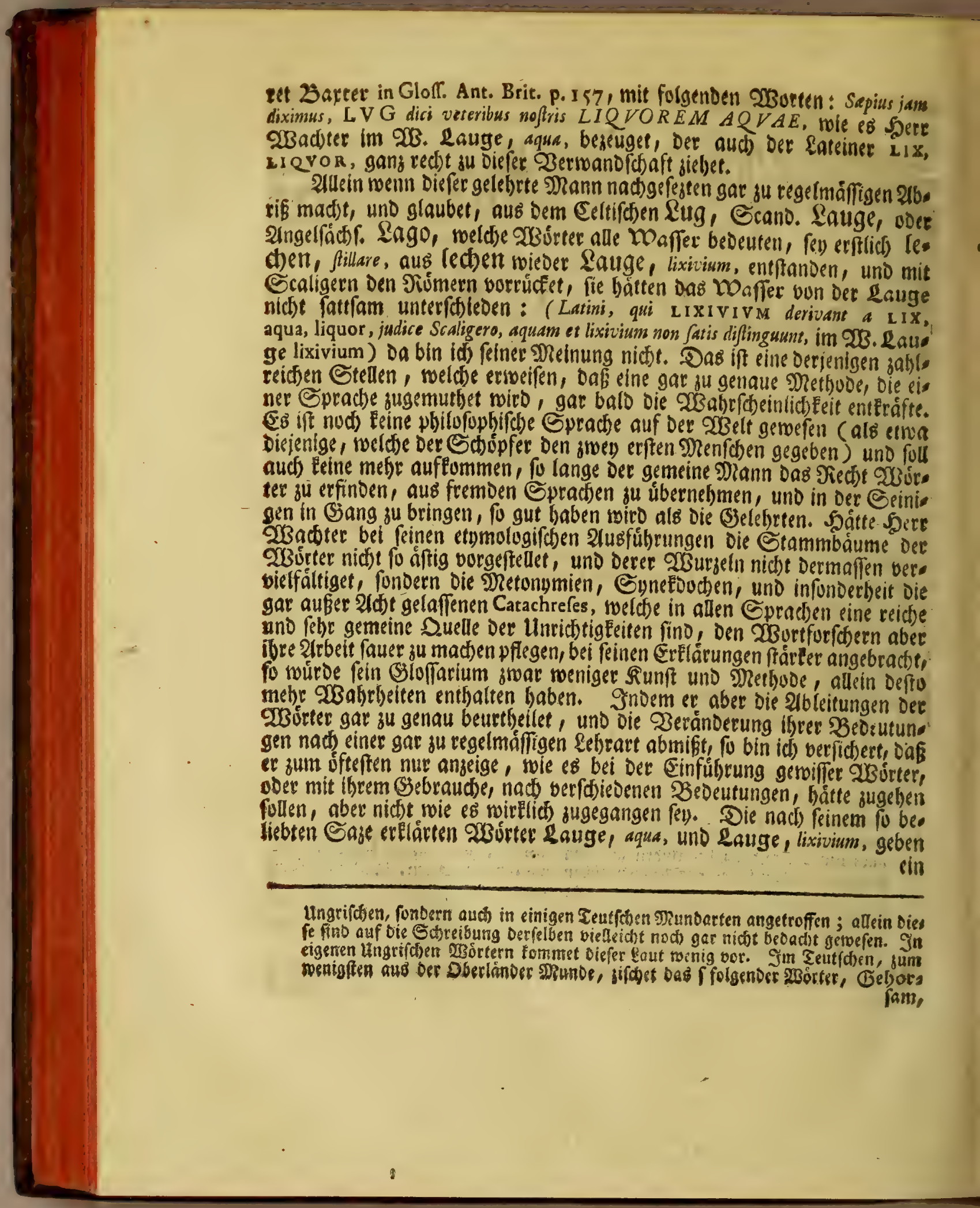




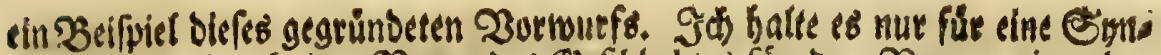

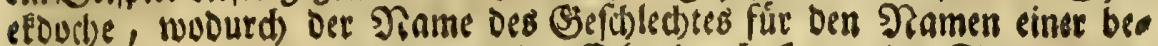
fundern 2att gefegt mird, menn Der Eelte Durd Lug, ber Scande voes Eviune Durd) Rauge, aquam; ein beutiger X్ (Jinde aber Durd) Rug, lixiviam,

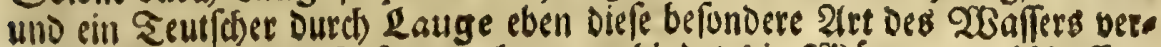

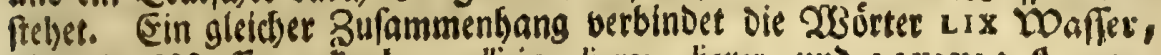

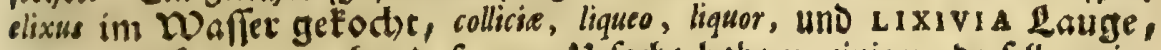

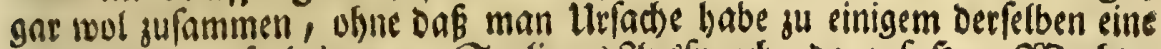
neue Duelle aufaubringen. Scaligers 2usfpruch, Darauf Serr 23 acteter

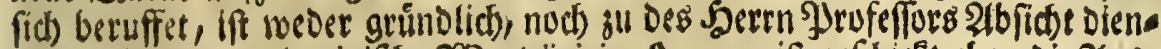

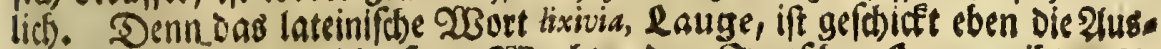

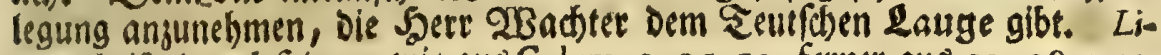
quare beist ourch feigen, wie aus Colum. 9, 15, I2, ferner aus 12, 38, $72 \mathrm{c}$.

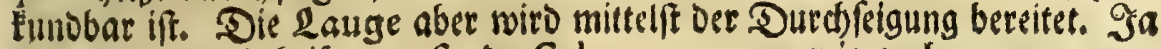
lixivus (lixirius) beift treufeno, Colum, 12, 27, wie auch 12,50 , II.

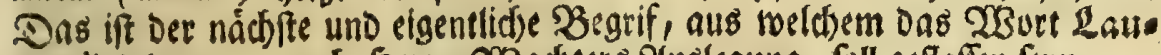
ge, lixivia aqua, nad Serrn 23 ad)eers 24ülegung, foll gefloffen feyn.

EFiv. Magnificenzien und Sodedelgebohtrnen exlennen bieraus, Das aud) fo gar úbel befd)affene Leberrefte Der 2 Bendifoten

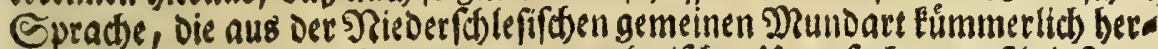

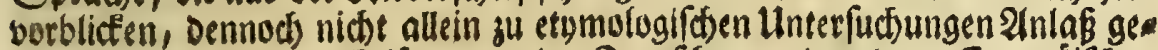

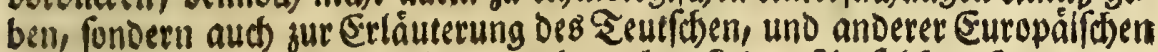
Speadsen nitht whine $30 r t b e i l$ u gebraudsen fins. 2(n foldsen Drten, wo bor vielen Jabrhunderten, zur Beit Der weit ausgebreiteten 23ayerifden

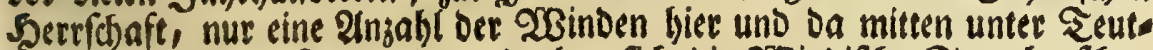

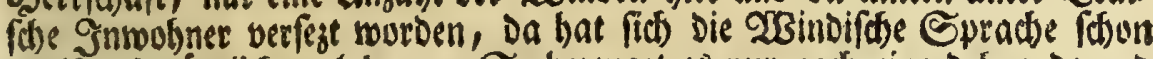
vorlángft gánilid berlobren. So bezeuget es nut nod eine Defnende und fingende 2(usfpradje Der heutigen Stoderer (nodurd) aud) Die beutigen

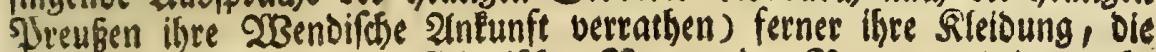

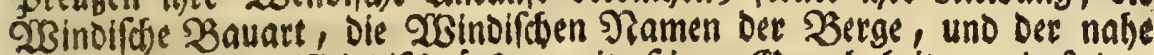
gelegene Flecten 23 Bindifó)gárfen mit feinen Serwobnbeiten, Das Das Fusine Shat Etoder im Eande ob der Ens, Darinnen Das Stiriate bergeblid. gefudt wiro, von Den 23 inden Wurseiten ift bewolgnt gemefen. Das nud b 3 úbrige

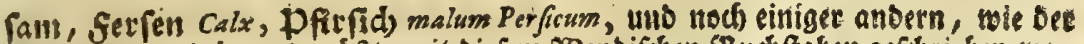

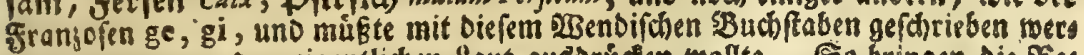
ben, wenn man ben eigentlichen Eaut auboriden toolte. Eo bringen Die פies

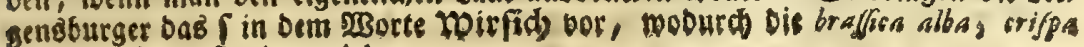
cafp. Bauh. berfanben wirb. 


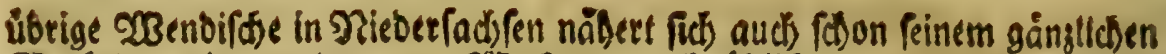
Berfalle, sole auß Dem um 23 frtau nod) úbliden, und von Jennigen vorgefelltem 23 endiften Dacecunfer (EccaRD. hift, ftud. Etymol, p. 269) erbellet, in Derm otele Eeurfate 230 irter nur mit 233 endifchen Endungen vermummt bortummen, mandtes aber gans ₹eutfd) lautel, mie es biefe SBitte, tia vif tomma, D. i. Dein Reich Eomme, Deutlich ausmeifes.

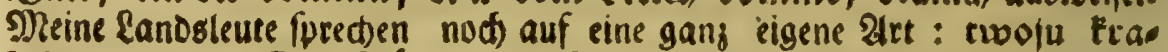
leftwu pridi. Die 230 steter Des 23 ufrenuiften 2 aterunfer woarda, willya, bring, warfitenge, lofoag, find die ₹eutfidon Das ter, werde, Dolle, bring, Derfuntung, lófe, D. i. erlófe, weldes ale les die mittágigen 23 enden nuch mit unerburgten 233 úrtern ausorúten lúnnen.

Das Sorabifthe, fo in Der Nieberlaufis, mie aud um Bauzen uno Eơbau in Der Oberiaufiz, nod beftehet, enthált biele gute Etammmórter Der

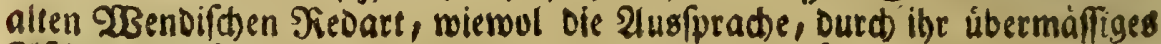

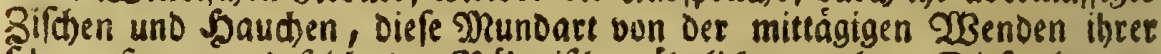

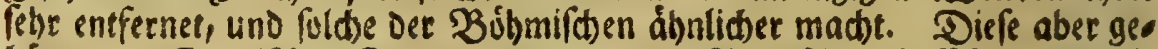

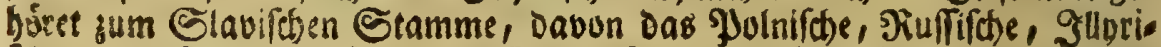

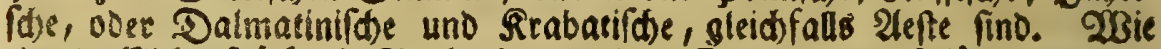

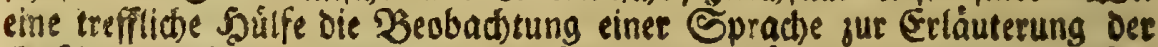

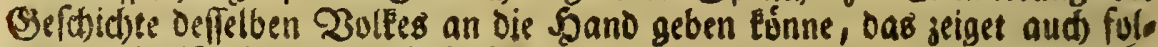

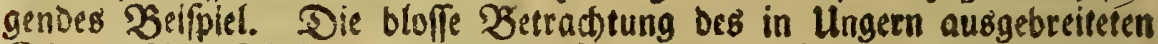

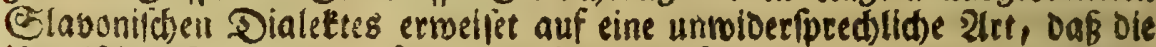

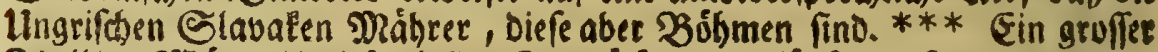

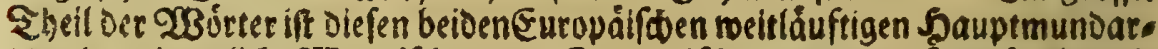

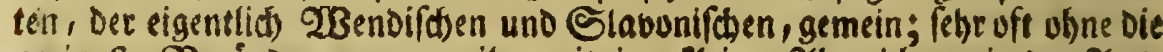

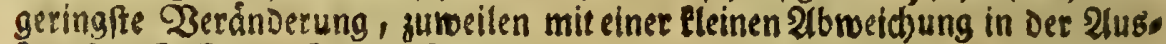
fpradje. 3. E. Der 233ende fpridt Smeict, rijus; Der Slave vereebret Den Duppellout, und bringet Smied) beraus.

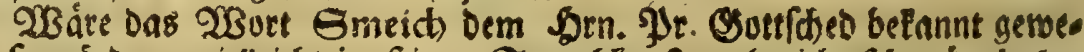
fen, fo wúrbe er vielleidst in peiner Spreade blandiri, fondern, nach Der bisiber gebrauchliden 23 eife, fammeicheln, ges

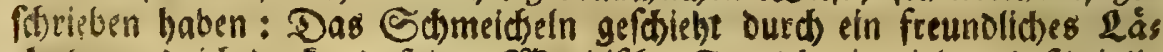

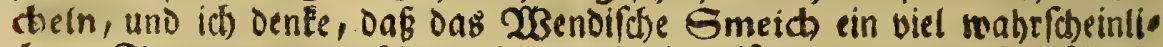

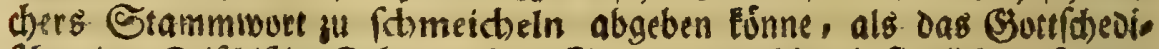

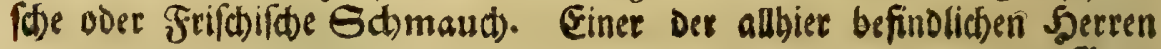

Sotts

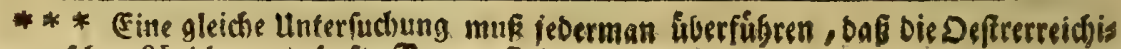

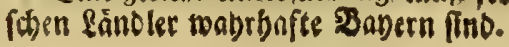




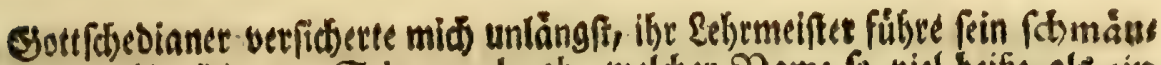

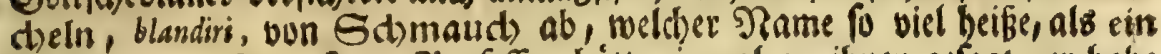
Bertieger. Der Serr Syrofeffur bátte einmal zu ibnen gelagt, er babe

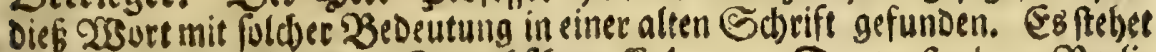
Daffelbe auch in Syateng Sprachiftaje Col. 1253 . Der verfturbene $\mathfrak{B}$ erti-

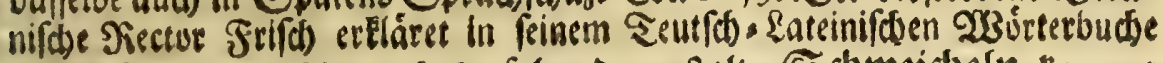
Den llefiprung von fameict)ein folgender geftalt: Schmeid)eln tomme von (Shmaud), einem einen woblriectenden Raud) zuveben, eí nem tảud)ern, verebren init Raud)werk, wie die franzofen fagen fluser, gleidffam zublafen oder zubaudben, wovon man beucteln fage, als f(t)meidteln von S(t)maudt). Allein vb dab S(t)maud)en,

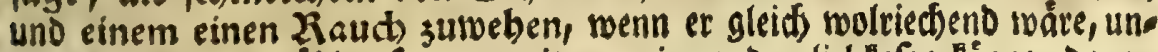
ter bie Dinge zu záblen fey, numit man jemanden liebfuen lónne, Daran

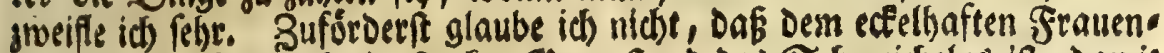

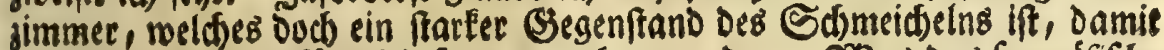

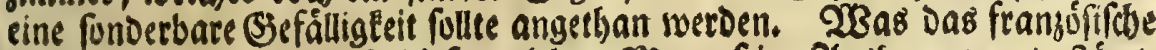
fater anlanget, woouré) Diefer gelebete Mann feine 2lublegung unterftüget, und weldses er mit Dem Nicod sum lateiniften flatare, (blafen, frequ. bun fare) berleiret, oa geftebe id, Daf in Erroágung bee ftarken Ueberein-

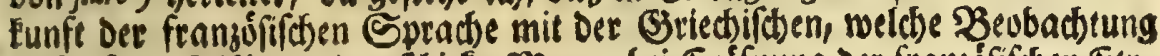
Diefer fonft feikige und gefdictete SMann, bei Erófnung Der franzơfifden Etye mologien, in feinen Diat, des Pafagers, Dod) gẳnglids auf Die Seite gefett bat,

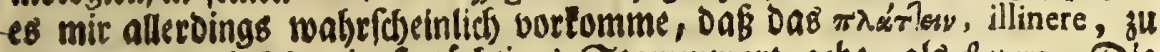
flater um wenigften ein fo túditiges Stammwort gebe, als flatare Die

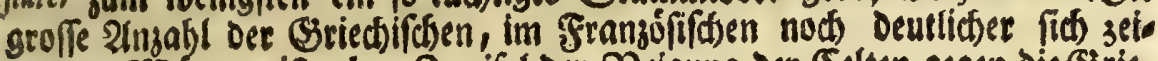
genden 230 orter, ift obne Zweifel Der YReigung Der Eelten gegen bie Sries

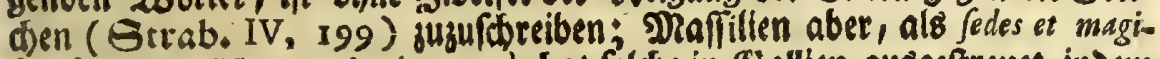
fer fudiorum (TACIT. Agric, 4, 4) bat foldoe in (Sallien qusgeftreuef, indem

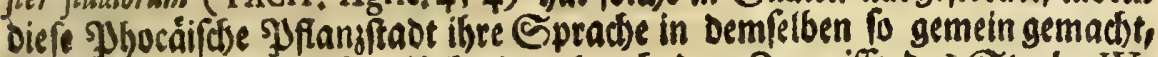
Daß́ aud) Dle geridstlidsen Urênden (nac) Dem Beugniffe Des Strabo IV, 181) in Derfelben abgefaffet murden. Der Siaum geftattet mir nidjt ein

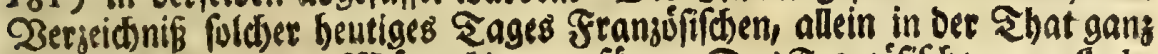

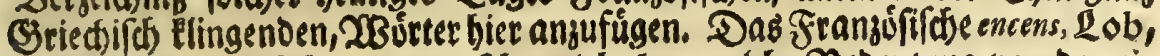

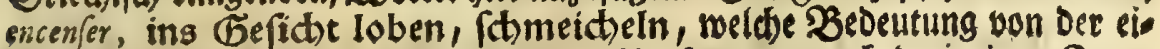
gentlicken Des 2 senbraudfis entftanden ift, Pommet aud) Derienigen Seuto

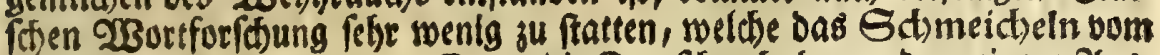
2iàchern herbulen will. Denn bie Seutfoben haben andere cigene 2lus. orúdungen, welibe mit Dem encenfer úbereinEommen. Man lagt, einen auf 


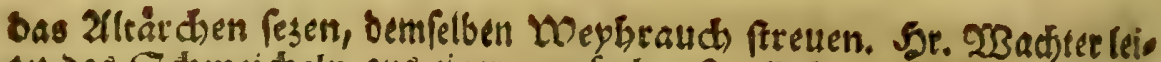
tet Das Sa)meidseln aus einer zroeyfad)en Duelle ber. In Feiner Stelle

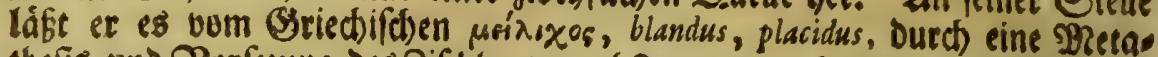
thefis und $20 r f e j u n g$ Des Zifdlautes, abftammen. 2/n einem andetn Drte ertennet ex Dab IDIJE:S, lenis, mitis, weldfer die Englánder meet, die Scandi in Den jufammengefegten 2 Burtern miute vorbráchten, uno reldjes mit Dem lateinifthen mitis einerley toáre, (Daber die Schweden fmetia, mulcere, bátten ) fúc Das mabre (Srundwort bon f(t)meid)ein.

23 enn jemano mein SHutbủnen Darúber abfurderte, Dem múrde id fagen, mir gefalle Stielers uno Steinbactbs Sedanten am beften, weldse oas fameict)eln als cine 2lblunft von famiegen balten. Schmiegelt beist kiect)en, fith winden, fidt Elein mactien. So thun es die Saun De, wenn fie fobmeicbein; uno die Denfd)en machen es meiftentheilse auds nidst anders. Die Metathefis Des Doppellauts fatmie in fthmei, if

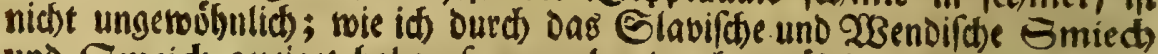
und Smeich gejeiget habe, ferner aber Durch unzáblige andere $\mathfrak{B}$ eifpiele

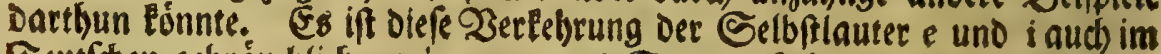
seutfhen gebrauchlid), wie man aus Eriege, fcala, uno fteigen, afcendere, fiefte. Sa an einigen Drten in Niederfadfen fpridst man Steige fúr Stiege, wie oas ẩort Gtriemen (vibices) von einigen Streimen vurgebract miro, welches der Spate im Eprachft). Eol. 22 I2. bejeuget. $21 u s$ fatmeigen nun (Steinbad fúbret bon fthmiegen, id fdimeige an) bat fomeigeln, und nach einer baudsenden 2 (usforache f(t)meidieln, als ein útronogssısò, leich)t entfteben Eónnen. Saanze Dialette betráftigen Die Qerwandelung des $g$ in Den Saud). Die Bófmen baben gar lein g. Sie verlebren fpriche aud ein Sheil ber $\mathscr{W}$ Binden, fo in शiedertárnten und in Oberkrain

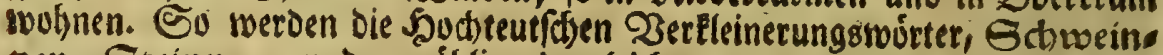
gen, Eteingen, und unjählige Dergleiden, von andern Schweind)en, Steind)en, auegefproctien. Das fdbmiegen lautet nad) Der eigenthumlichen altteutfoben 2tustede der Stevermárker famuden. Sie fagen \%. E. vee bei ber zeit fortfommen will, ber mus fid) f(t)muden uno ouclen, D. i. Der mus fíd) ftumiegen uno biegen.

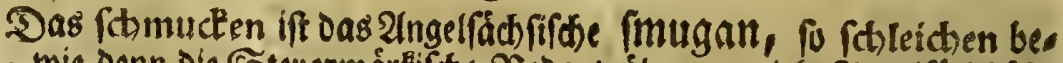

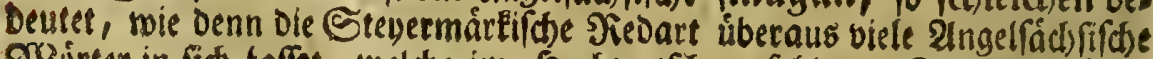

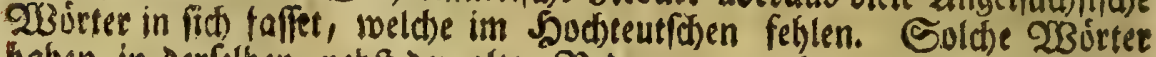
haben in Derfelben, nebfe Der alten Bedeutung, nod Den alten \&aut, ausee

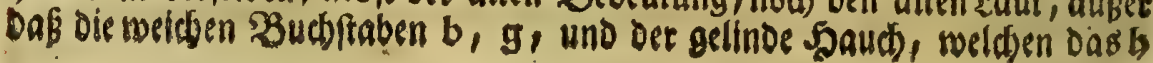




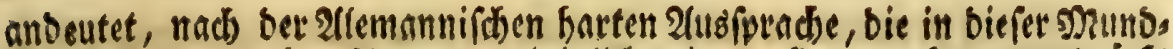

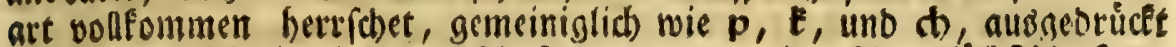

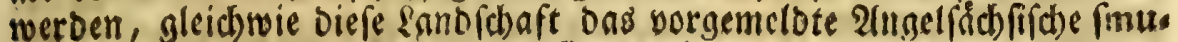
gan, naeb ifrer Sprechart fatmucten vorbringet. Das E biefes 230 ts

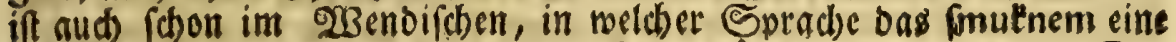
mit (mugan verwanote Bebeutung bat, nơmlich) furtim infinuo. Dee

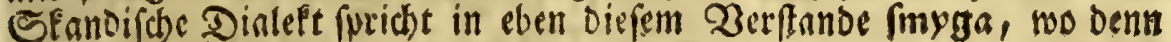

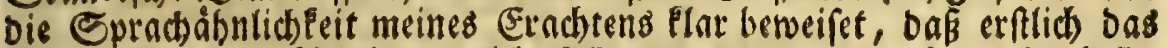
(d) meidseln bon fit)miegen nid)t foll gettennet werben; betradb erbellet

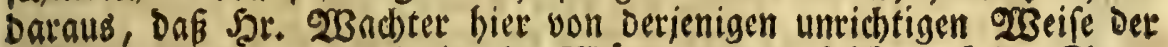
EBortforfatung, baourd) cimerley 230 orter (wenn foldbe nad) ber Spras den unbeftanoigfeit ibre 3 edeufung in etwa verándern) gar oft als

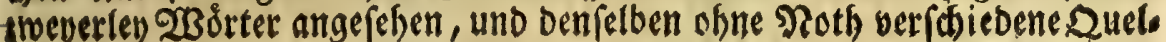
len angewiefen werden, abermal ein 2 eifpiel barleget, inbem er bas fđ̈miegen mit bem Dorifdent pssròs, Elein, bas mieg, fómeidoln,

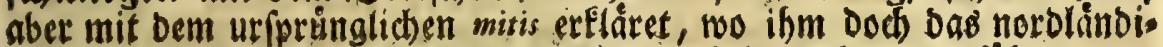
(d)e alte miut, Defien Einftimmung er an beiben Drten anfúbret, Den

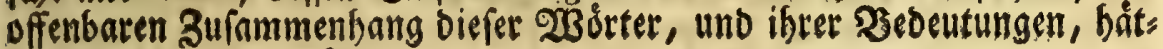
te follen vor Augen ftellen.

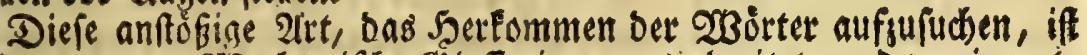
Durch Das ganje 23 ad)terifose Giloffarium aubgebreitet, und vertingert, nad) meiner wenigen Einficht, Den Yrsertb biefeg tibrigens vortreffliden

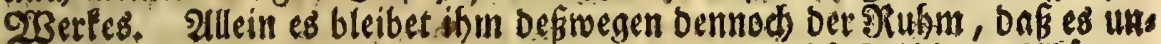
ter allen 2tusfertigungen von biefer (s)attung, nebft Frifochens 23orters buche, bisher bas befte, uno für einen ₹eutichen Betefrten, weldser bie

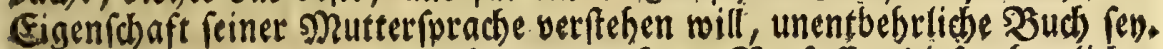

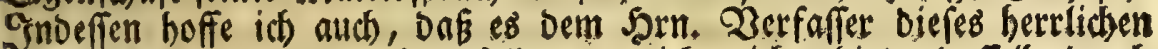
23ertes nid)t entgegen feyn foll, wenn id mid) erbiete, oaffelbe burds

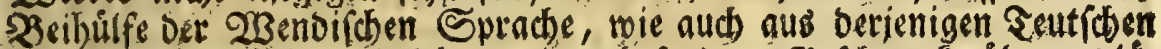

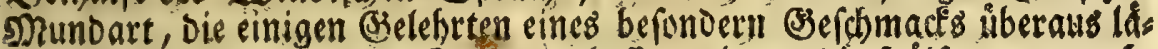

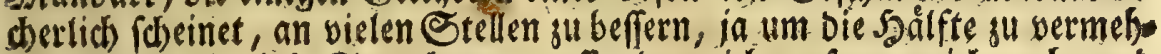
ren, bevor idh Diefe Spradben vergeffe, Denn idh entferme midh mehr uno mehr von ben \&ánbern, wo foldse ifreñ Sis baben. Diefe Erflärung,

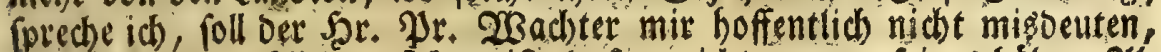

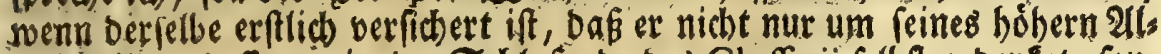
ters willell, Deffen er in ber Shlufrede bes Gloffarii felbft geocneet, fort. Dern aud wegen feiner (selefrfanileit, und zumal wegen ber fonberbaren

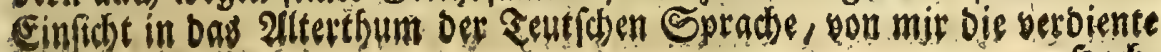


5odiactung gu geroarten babe. Gnoem berfelbe aber in ben lejten 230 ss

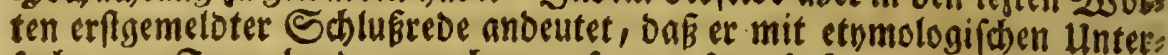
fudungen Fenerabend zu machen, gefonnen fen; fo fann es beinfelben auf teine 23 eife misfallen, menn andere fich bemúben es ifm nacbsutbun, uno Dieflaggen von bem Drte, wo er geantert hat, weiter binftreichen laffen.

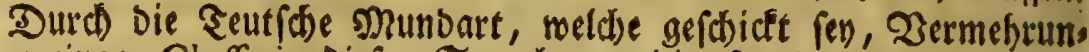
gen zu einem Gloffario Diefer Spradbe an bie Santo zu geben, bers

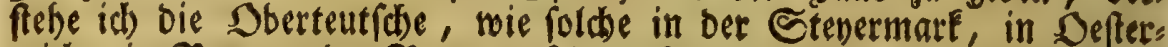
reid), in Baveen, Der Bauer auf bem Eande, uno bas gemeine Yolf in ben Etábten fpridht, wovon aud) in benjenigen Edbriften fattfame Epuren fich seigen, melthe bie Gelefrten erroefnter Eänoer ₹eutín berausgeben, weil Durch eine unverantwortliche Verfaffung Der Sdus len, bie Yerbefferung Der Mutterfirache nus Der Zahl Derienigen Hlebungen ausgefetlofien bleibet, relde oer Gugeno vorgeftrieben fino, unb auf ben Univerfitäten, Gymnafiis, श̂cabemien, geoacbter

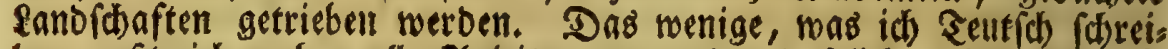
be, muste id), obne alle Anleitung, aus ben bafelbft verbotenen $\mathfrak{B}$ h́

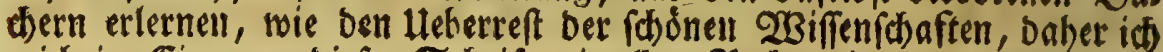

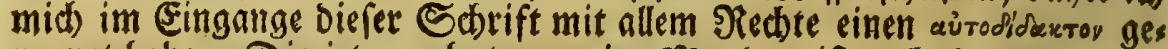
nennet habe. Die ift erwehnte gemeine Munoart ift aubs eben Diejenige,

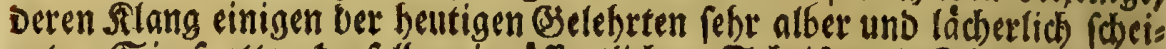
net. Eie fpotten Derfelben in offentlichen Schriften. Sie baben vor 5 Sabren eimen úbel gerathenen 2luşug oruten loffen, welder ein פous fter biefer Spradie vorftellen roll; wo id aber, Die 2 sabrbeit zu seftes ben, weber bie vernưnftige 2(bfid)t, ein fold)eg 20 erE zu verfertigen, ers rathen fann, nod einigen (3eift, ia aud) feinen gulltigen 20 rwano einer

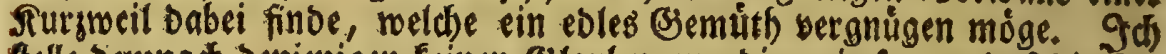

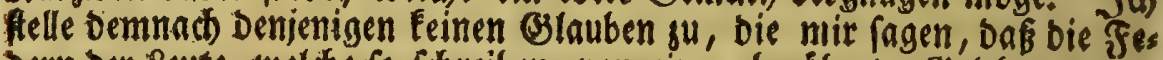

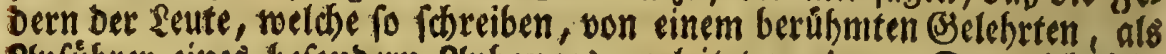

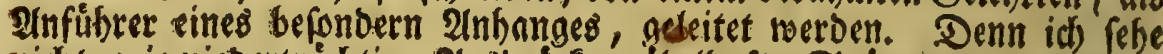
nicbt, mie niebertrádtige 2luzbrúcke, pöbelhafte Spdtterenen, uns ans Dere Dergleichen Эroben eines ungeitigen Derffanbeb, weldser bei jungen qeuten vielmehr zu beffern, zu reinigen, zu fabårfen, als in tabelfaften Hebungsn zu unterhalten ift, von tinem Ehbrenmanne nur fonnen gebillis get werden, zu geft)meigen, Dafe er feine subơrer ober 2anfanger zu ber gleidjen Huternehmungen vermogen vber serhesen foll. Job begreife

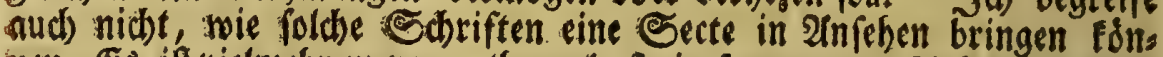
aten. Es aft vielmefr zu bermutben, bas cin fo gearteter 2lngang fo viele

Seinde 
Seinbe segen fich ertegen miffe, als es eble (Steifter in Teut(d)lano gibf,

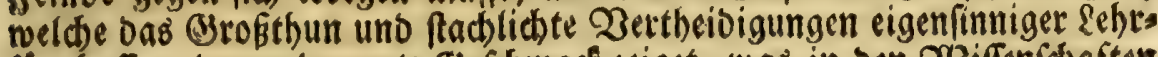

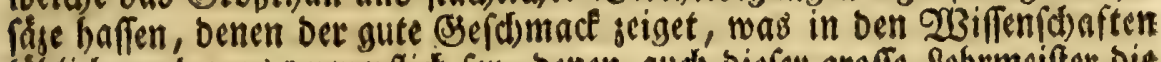

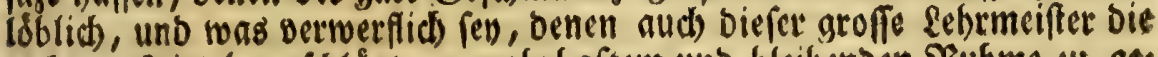
red)ten s) Rittel voridblăgt, su wabrbaftem uno bleibenoen Fubme zu ges langell.

\section{MAGNIFICI, hod)edelgebobrne,}

Die Siebe sur $23 a f r b e i t$, weldbe aus Dero Sctriften fo mertlid bervorleudtet, läßst midb hoffen, oaß̧ Diefelben weber meine freumuthis gen SSeDanfen übel Deuten, nod Das SBetragen Derienigen unterftügen

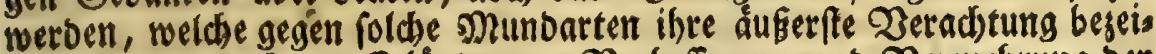
gen; Dacaus Dod sur Erlåuterung, Derbefferung uno Dermefrung Der

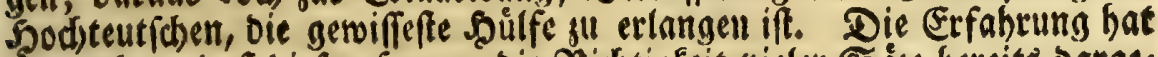

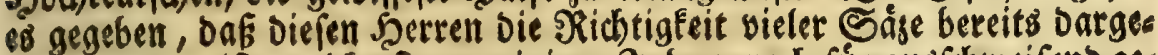
than worben ift, weld)e fie bor einigen Jahren nod fur ausfdweifeno ges halten hatten. Es Dorrfte innen Die Zeit audh Den Heberreft folcher vers borgener 23 aherheiten balb aufoecten. 23 enn diefe Serren von obbefags

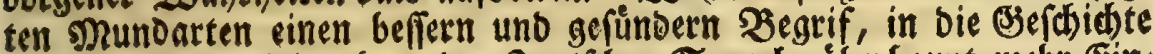
aber uno in Das 2ltterthum ber Seutfien Sprad)e tiberbaupt mebr Eint

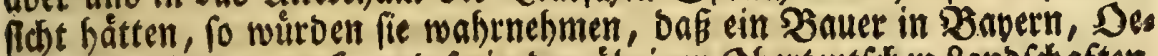

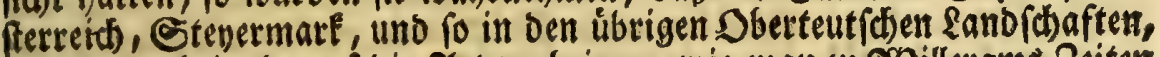
noch vieles beinabe auf bie shet vorbrings, wie man ju YSBillerams Zeiten in ₹eutfdhlano gefprodsen hat. Es fino alfo biefe Dialefte nod gleids.

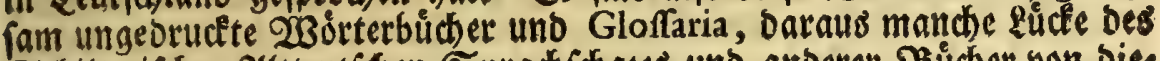

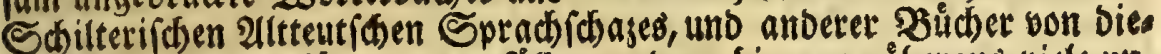

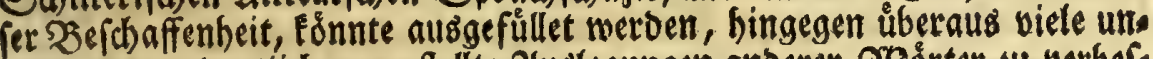

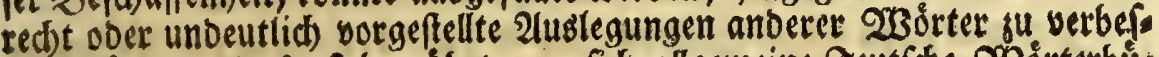

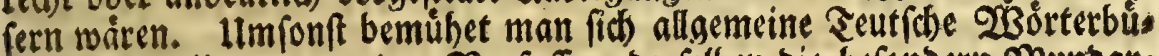
wer zu idhreiben, wenn ben Oerfaffern berfelben bie befondern Munbats

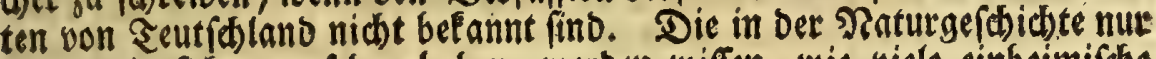
ein wenig fid umgefeben baben, werben reiffen, wie viele einheimifodse

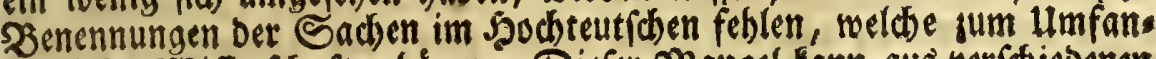
ge Diefer $23 i f f e n f(h)$ ft gehóren. Diefer Mangel fann aus verfobiebenen Sberteutfich Dialeften reidhlid) erfeft werben. \$ch will ein Beifpiel

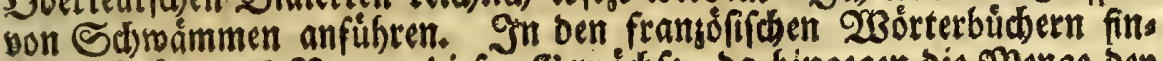
ben fich faum 6 Namen biefer Bencwable, ba hingegen bie Menge ber

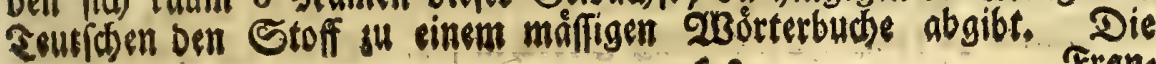
C 2

Sran 


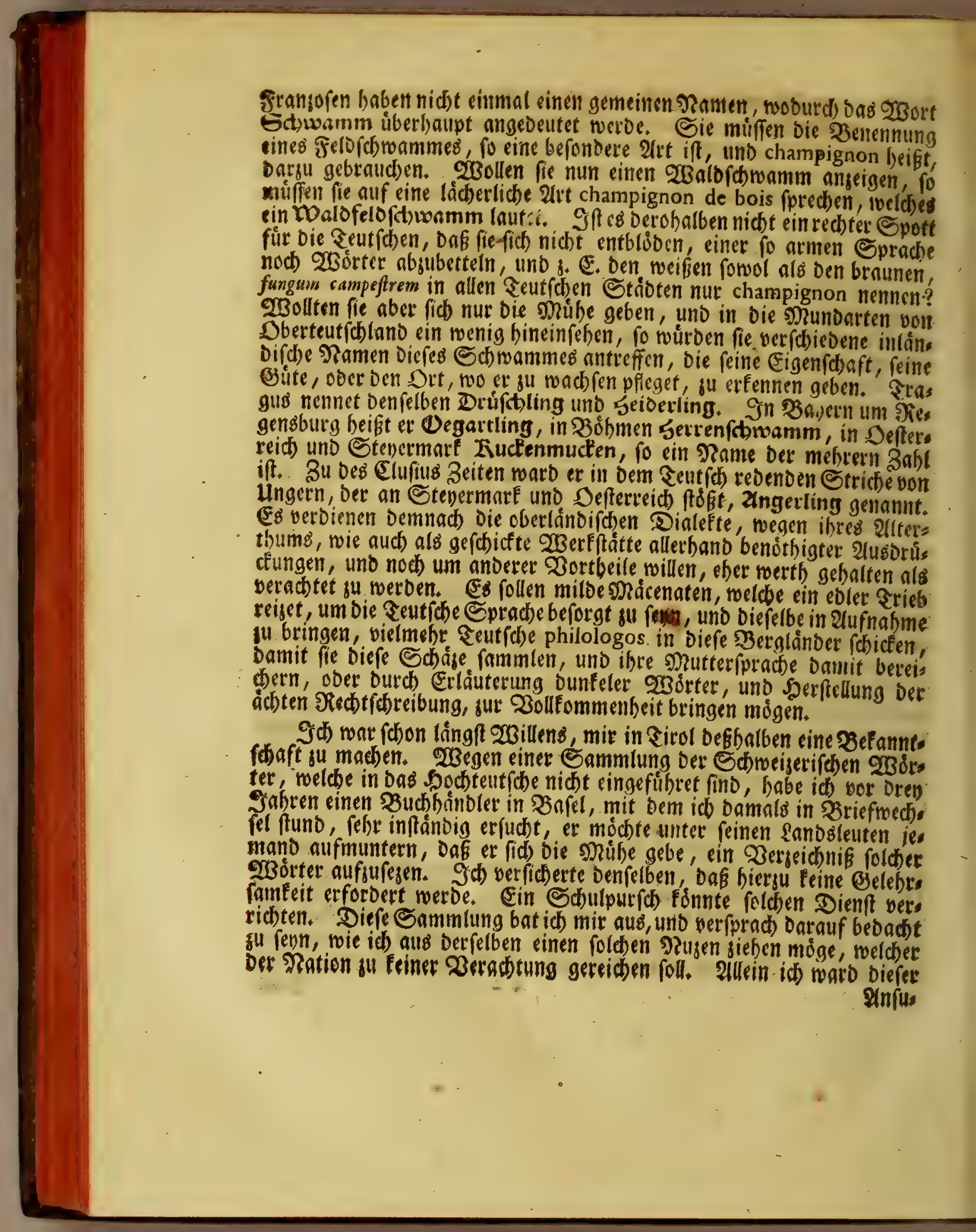




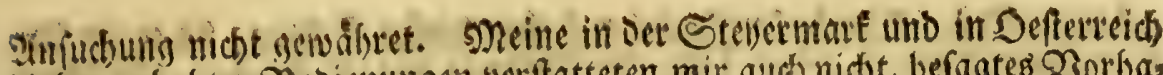
bisher gethabtell Bedienungen verftatteten mir auth nidbt, befagtes Dorha

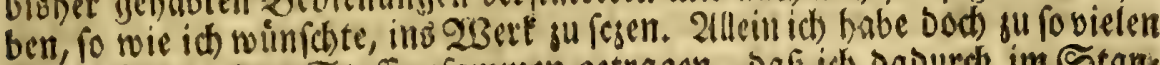
Anmerfungen oen Etoff zufammen getrngen, DnÉ i(d) Daburds im Stan De midh befinde, Denienigen Belebrten, welche mit erwehnten Borurtheis len cingenommen finto, hanogreiflich zu erweifen, das fie eine Eprache

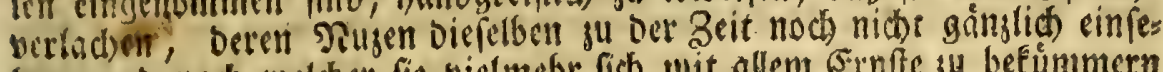

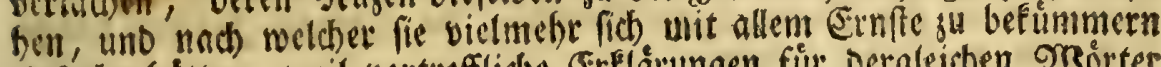

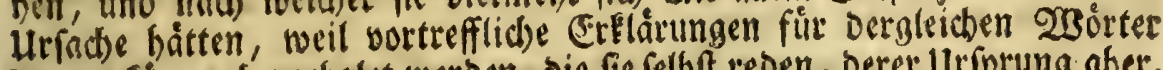
Daraus fónnen bergeholet werden, bie fie felbft reden, Deret uriprung aber, und bic erfte Bebeutung nid)t verftelsen.

Es ift wabt, baß bie heutigen oberlänbifhen Munbarten (Das ges

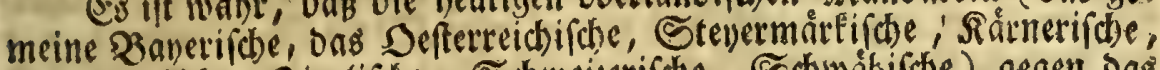

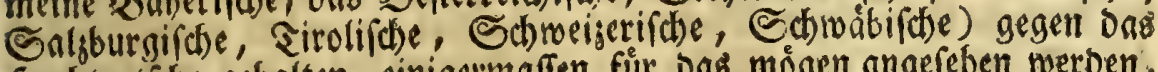
Şodjtentfide gehalten, einigetmaffen für bas moggen angefehen werben,

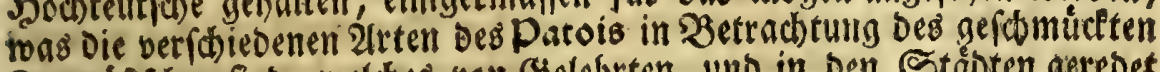

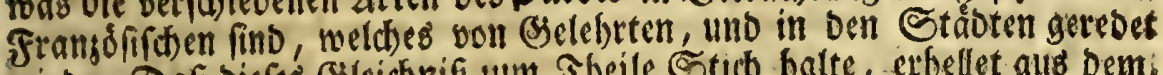

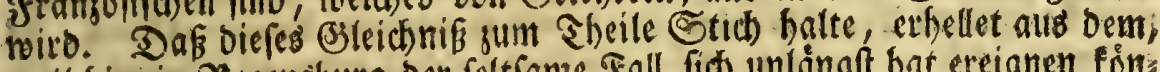
weil hier in Fegensburg Der fettfame Fall fid) unlängft hat ereignen fơn

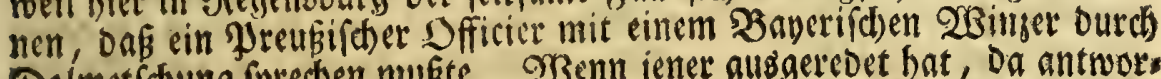
Dolmet(f)ung forectsen muste. MBenn jenter ausgercoet hat, Da antwors

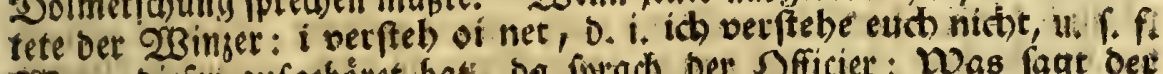
$23 e n n$ biefer nufgeboret hat, oa (prad) ber Officier: Was fagt det Zauer? Die umftehenden Siegensburger musten Des cinen SReben bem

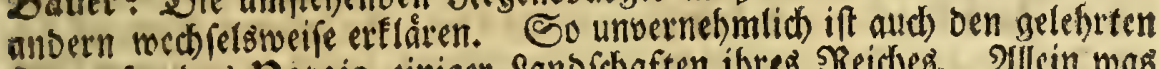

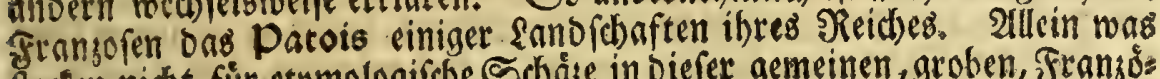
fecten niøt für etymologifabe Scháze in oiefer gemeinen, groben, Franzo: fríden Eprade? $2 B e n n$ mir ein Esafenter, ein Eangedofer, oder ein

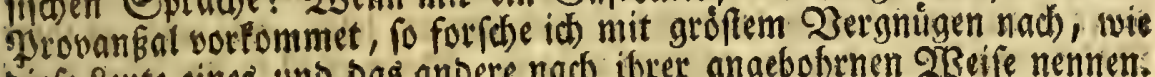
oiefe seute cines uno ons anoere nad) ihter angebohenen gBeife nenten. Es seiget fít bei bem allererfen fo angeftellten Werfucbe, oas aus Diefen verfd ievenen Sprectarten Des gemeinen Mannes in Franfreid, bie Spus ren ber wabren Eeltifonen Sprad)e biel beutlidber bervorfendten, als aus Der yertichen, erbabenen, unb mit gar ju vielem Satein vermengten fram

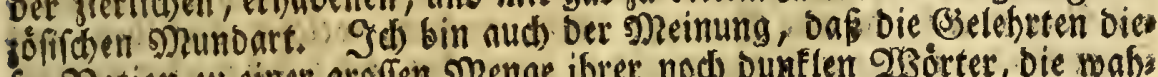

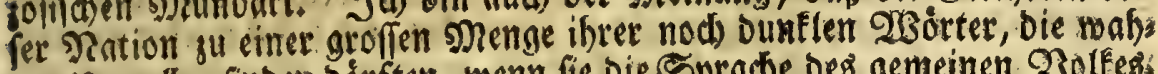
ren Lirquellen finden bórften, wenn fie bie Sprad)e bes gemeinen Dolfeg;

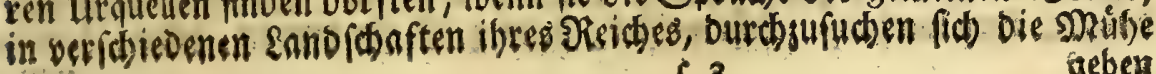
ilit:? 


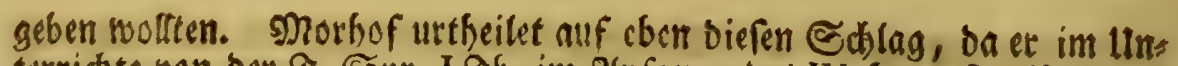

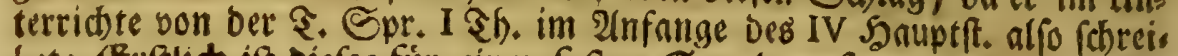

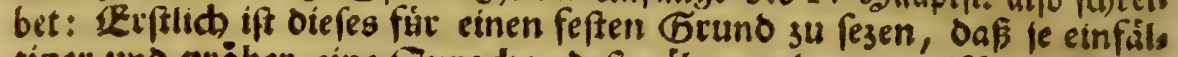
tiger uno gröber eine 3 pradue, oefto ślter uno ungemift)ret fie fey, uno den andern vorgebe. Dill man nun die Erammworter einer jezo ausgebreiteten Sprache fuct)en, fo mus man nid) 3 u einev ges ben, oie in gleidter Dollfommienbeit ift, fondern man mups auf oem lande unter den 2 auetn, an Dertern, oa niemals fiembe binges Eommen, oiefelben futhen.

Diefes fab Der weltberúbmte Reibnis auch gar wol eit. Denn als er an ben Damals lebenden Túrtifthen Dolmetfeten am Froferl. Saofe, Job. Bapt. Pooefta, einige Fragen, bie Epractent verfdsiedener Doóls ter betreffent, ergeben lies, uno an ber erften Stelle fich erfunbigte, wie

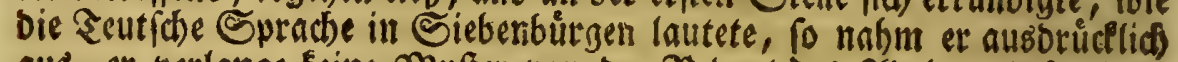
aus, er verlange feine mufter yon Der SReoart Des 2locls uno fubirter \{eute, fonoern ar begefre zu wiffen, wie Das $\mathfrak{B} a u e r b o f$ uno ber gemeine Mann fprecbe. Defideratur Specimen vocabulorum et modorum loquendi peculia. rium Saxonibus Tranfylvaniae, id eft, non ut loquuntur homines cultiores, fed ut loquitur plebs, ut comparari pofint cum lingua plebeja noftrorum Saxonum. Dicitur enim effe in plebe illa multas voces nec Hungaricas, nec Slavonicas, et tamen aliis Germanis commaniter non intellectas. Mifcellan. Leibnit. p. 50. Es wat nảmlich biefer fobarffichtige Mann gans anbers gefinnet, ats Diefe verbafs. ten Nunftrichter, oie aud einige, ibrer Neinung nad, unteut(t) Flingens ben 20 orter fammlen, allein aus einer verfehrten 26 ficht, Damit fie name lid in ibren fogennmuten fritifden Shriften, ifre alberes Fagtwerk bas mit treiben, unb ben Sjefdsmact ibrer \&anosteute, foviel es an ihnen liegt,

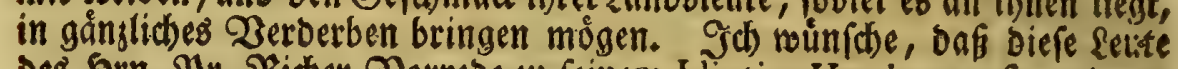

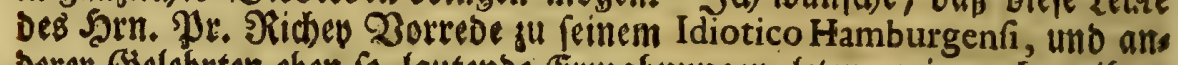
Derer Brelebrten eben fo lautende Ermahnungen, lefen, wie aud) fu ifjrer OSefefrung Pinlas Daraus nefmen mogen. Denn es ift in ber Shat nidit allein Dem guten Gefdimacte, fonbern uberhnupt ber Wernunft, fónurges

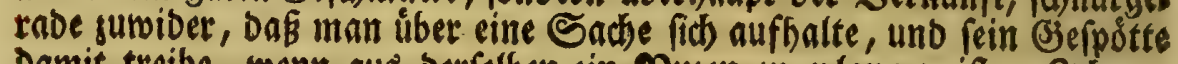
Damit treibe, wenn aus berfelben ein squsen gu erlangen ift. Th) ges

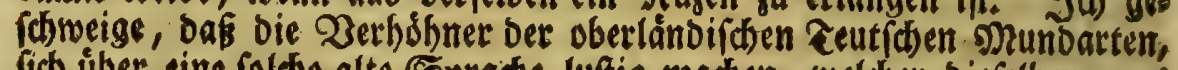
(ich) úber eine pold)e alte Epradbe luftig mad)en, welder biefelben, aus 2Begierbe bie ihrige zu reinigen unb gu fáminten, fich felbet wieber nábern, wis bie alten feute julest wieber finbish werben. Sie verlacben alfo Dabubd ibre wirflichen sefremeifter; benn of E. ift sween, 3woo; swees 
men, 3woen, uno mebr anoete 230 ster, baruber viele, bie fich bemuiben gut zu fprecten, nid)t unbillid die Stirne rumpfen, babenfie Den Sprad. senoffen Des Zlauroctels abgelernet.

Unter ben Fbfichten, um beren willen ith nath seipsing gehen wets longe, ift aud biefe nid)t bie geringfte mit, bas id Die Sadhfifden श्र?a:

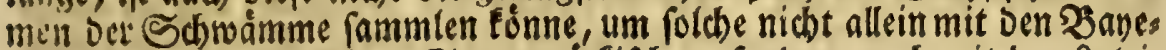

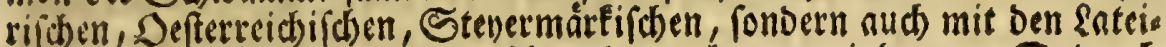
nifben, Jranjofifenen, Stalienifhen, barnach zu vereinbaren. Sabures boffe id einen $23 \mathrm{eg}$ ju babnen, wie nidt allein biefes nods fefre vernach: lâfigte Stuck ber Draturgefchichte leidter foll ausgearboitet roerben, fon.

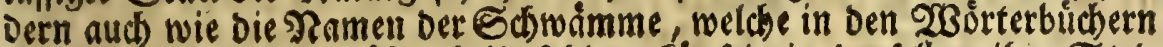
aller Spraden nodb gróftentbeils feflen, fünftig in oenjelben ibre Stel.

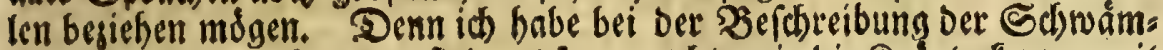
me, bie mir borgefommen fino, es fo gemacht, wie bie Sränterfenner mit

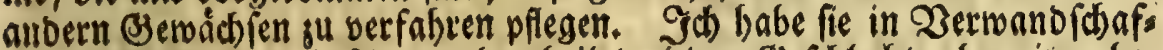
ten, in (Se)

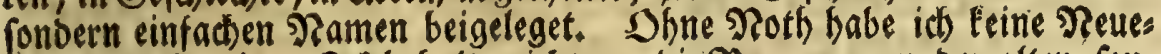
rung aufgebracbt. Sob bebalte nidt nur bie Denennungen ber alten, fons bern aud ber fpatern Sdriftfteller, wenn folche mit einer regelmáffigen

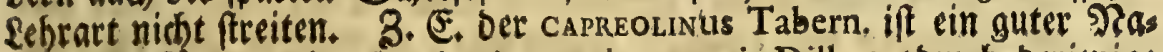
me, und furjer, als Amanita lutea oris contortis Dill. woourch berienige Sedwamm berftanben wirb, Der an vielen Drten von Dberteutfaland Rebling, in ber Stevermare mit geboppeltem Saudhe Rechling, fu Danjig aber Pfefferling beift, bermutblich un [eines beifenoent (Se: (d) mades millen, oen man auf ber Bunge fwuret, wenn biefer Sdwamm rof gefauet wirb, wie es Daillant gant redt angemerlet bat. In einis

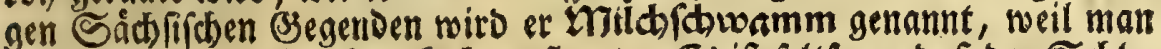
Denfelben in ber milds ju foden pileget. Es ift feltfam, oaf ber Sales fif bent शreapolitanifben gallucrio ubereinftimmet; ofne Bweifel wegen ber gelben Farbe; benn bie Allten fpradben gal, gál, geel, wie nod) Die ß3auern in Schlefien gallold, fur gelb. Shingegen weil bie Amanita lateritii coloris, croceo fucco turgens Dill. meines $\mathscr{2 B i f f e n s}$ nod feinen einfadjen lateinis

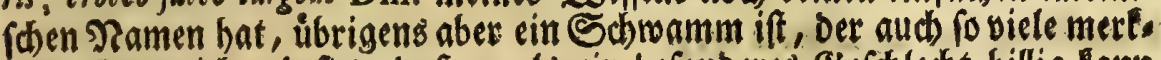
lido Sennzeithen befizt, Das ex als ein befonberes ssefhlecht billig Pann

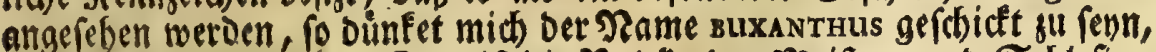
beniclben anjubeuten. Das ift Die Reizte Der sneifner uno Sd)lefier,

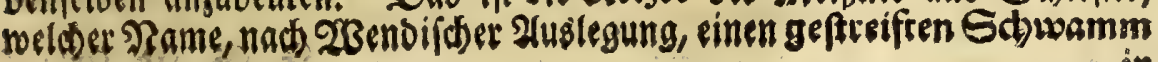




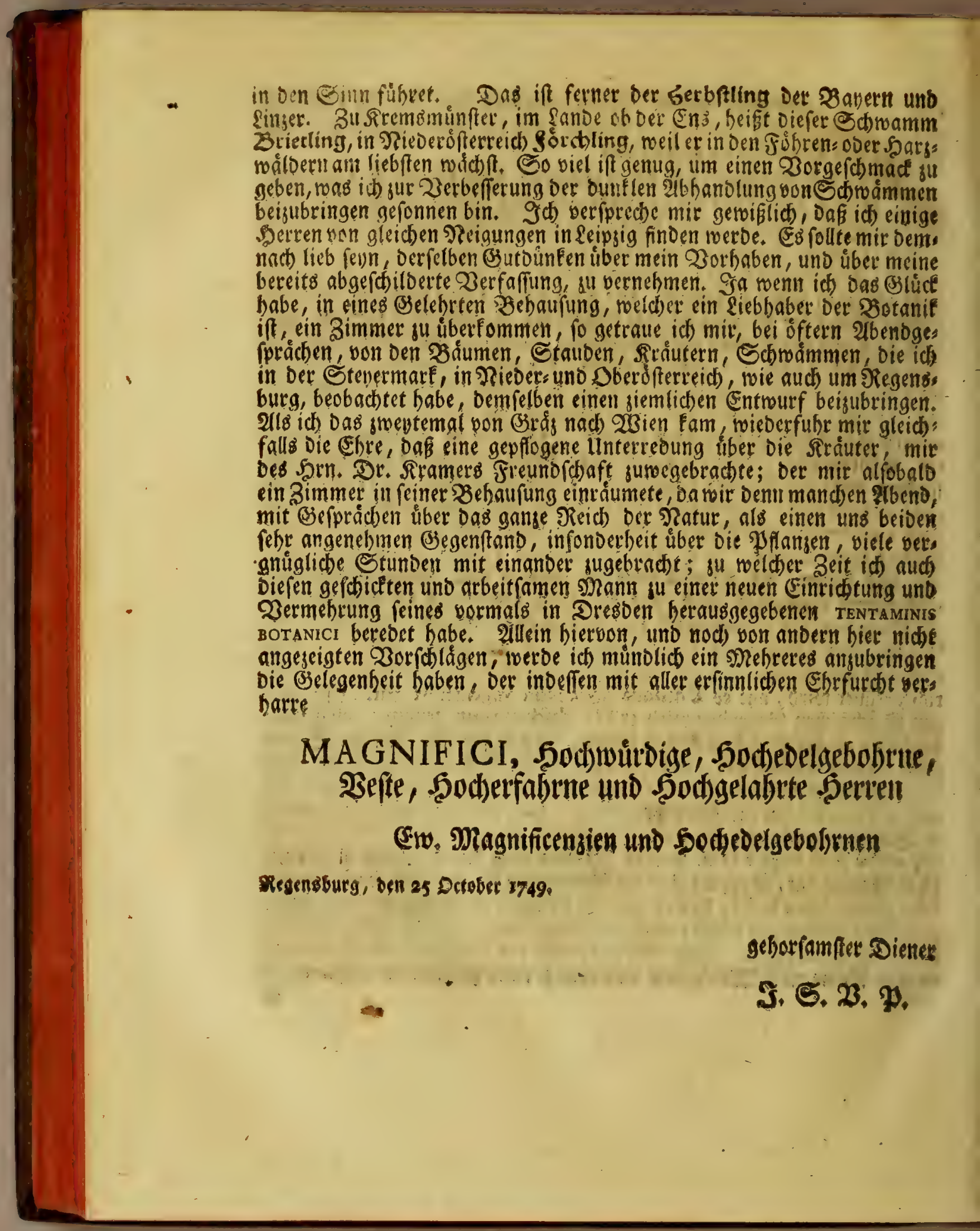




\section{2ergifter.}

Die Nomifenen Zahlen, wor benen fein n. fich befindet, fo numero ges

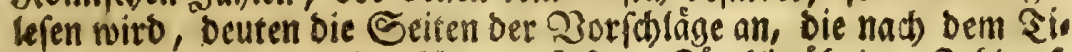

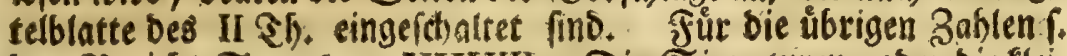
ben 2 eriđit) S.406, n. XXVIII. Die Signaturen, ober bie flei:

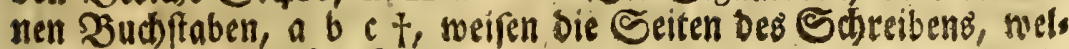
कes vor Dent Pegifter ftebet.

21.

2 amenexley in Oberteutifilano $892 \%$ ausfubrlichere 216 bandlung von biefen Selbftlauter 288 u. . .

2', baв Defterreidjifde ober Dberteus: tíche betle $a^{\prime}$ 295. 411 . 2 $d^{\prime}$ if aud ber Celtifa)e unbeftimmte Mrtifel 308 u. f. wirb vor einem Eelbftlauter a'n 308 u. f. wirb burch bie oreb Bjes (b)lechter nicht verdinbert, unb fann

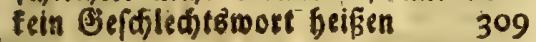

औ

, bas Edjorsifhe tief auछgefprodje! ne a

LIII. 292

Die niestenben $\boldsymbol{x}$

$292 \cdot 294$

2ujudt cloaca, guteg 530 rt 427 2. * Acipenfer Stór, ein fifich,

- acum ras biefe Eadung in ben Eel. tifajen Damen be beute

LXVI

₹ Gignatur if cui. Futchorudermort, Daburch Derienige Buchfabe verfanden wiro, oer inter bem Eerte anf allen Bogen, in ber Nitte ber columne ober Geite, allein ftes bet. Cin jeser Banen bat einen andern Bllwhabeu bCb alphabets fur Signatur, Damit ber Bubbirber solfe, wie fie nuf eiranber folgen. sadb Diefem Sorberidite sveroen oie \$stfúbrutgen mit Eignarmen leidit su verfieben fent. EB iff ismlich). E. bie erfte Seite beB Bogens b. DaE b. Die andere Seite bes erfiten Slattes von vies fem Sogent. Das 52 if vas givente 3 latt tiefes SBorents b 2 - Die anocre obet bis umgetwanote Seite diefes sweinter Blatte?. b 3 oas ovitte SBlatt', b3- Deffen ungdebr: te Seite. 24uf Das victe Blatt bes Sogents
Adjętiva nomina f. Beitoditer.

IDriatifdoes MReer f. IRice.

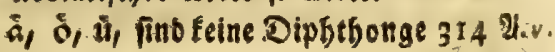

Zegypten if feine Babe (dwojor) obec Erjeugung Des Nulfirons, wie Seto! botus bafurgebalten bat 139 g.

Heltern, parentes, Edicfal biefts ISortes $318 \%$.

Zenol Defferteichifio 52 , avus ... 297 2lenglänoer Angli 3 T9 24, t 21epfelbäume lieben tältere Bjegenoen: felt jame Ramen oer Alepfel 359 \&.

Zerj (æs, eris) ift redt gef hriebet,

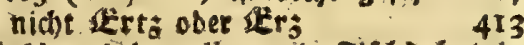

Zieidse (thymallus, ein sif(b) bat in

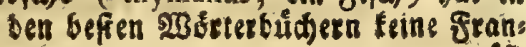
zoffis

resen bic Эucbsruder bei einem Duartfor mate, wie baß gegentwărtige ift, feine Gi: sttatur. Der Refer verfielset alfo burd b 4 bieicuige Seite, Die feine Signatt! bat; burd b4-Die antore Seite siejes vierter 3lattes, unb folute if von ben übriges Sogen fu verfebeir, berer Geiten mit Si: snaturen antaefeigt toerden. Soh muste die: fen Sortbeil ergteifen, weil Der 3 rief yot Den Interfudungen, uns titht in Der \$ab: fidht, biefen beigefüget zu werben, ohne ${ }^{2}$ : tummentiforn gescudt worden. 2hein es if foldiez weber ungereint, nod thges wobnlidf. Tin Leibnitil Script. Rer. Branjv.

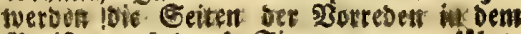
gregifer nuch burot Gignaturen angefulut. 
Piegifter.

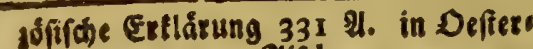
reid) (pric)t man $x^{\prime}$ (d)

Aetna, ber brennende Sicilifape berg, fiebt bon ferne mie ein Rauhfang

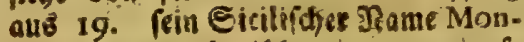
gibélo if tautologifar $\quad 2$ U.f.

Mlplyabet (Dablateinifo) Intúchtig jur Sdreibuay Der beutigen Epros कen XVIII $u_{0} f_{\text {. }}$ feine Berbefferung XXII u. f. beģ verbefferten Rujen jur Esegraphie

XXXIII

alt (bie) if fhiffear gemache worden 213

Anavites fino uníere Pilje $39 \mathrm{I}$ थ.

Ameritaner (ole mitternåd)tigen) mif: fen auB ber Sdjmeljung bez IReerei.

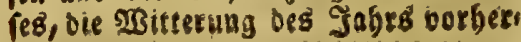
guraget

Amphitheatrum beg alten Capua, $\mathrm{OAB}^{\circ}$ pråchtigfze in gang Stalien $\quad 323$

X'no el Deft. $\mathfrak{H}_{\text {B }}$ avia

Zungerling, sin Edwamm,

Anlâิ, nid)t Znlas

Antacæus, Aprakaíos Herodoti, iff bex 5aufen

X'njen wirb exfláret

329. u. f.

Ireabifhes scunnen if eine fitfe Quel te am 5osen Des गeeres $\quad 176$ थ. 2realifwer Eee, Aralius lacus, 344 \%.

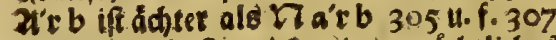

Arrt in Defterretion ein beráchtlides isort

Afperugo

Afphaltites lacus f. IIReê.

Athamanta Linn.

Ztlantio des plato

Zitter \&̊lter und åchter als hatter 305

u. f.

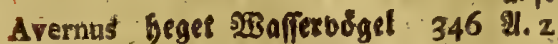
Def(breibung biefes See8: Urforung Des शamens

347 U. 2

*ugenbrám wirb exflåret $297 \mathscr{U}$.

$316 \%$

Plugbuinfungen find bie urquellen al Les rúfien 2 saffers 122 u. f. Hec Menge if fdomer bu beftimmen 342 *Hefprade ber Rieberfactien reiner und riकtiget, als bie Oberfáchfifche

91 श्य.

23.

3 lautet fu Iinfange bee 230 rtee, nad) Dex Nlemannifacen : Rupbart, wie D

25. fript freibelberen 364 \%. in in Büume ( menige) in ben aufierfen शRordiandern

Bammia Riv. 189

3orbarn 367 2. Thme, ift bas gelebrte Baffand Srobber. Torcanifater Reibries Dicus 394

Battpan (Baltbajar von) $\quad 395$

Bauart Der Rómer oon ber Geutigen uns terfánieden

Sedauern, nia)t betauern

VI

Befabren miro ertláret

413

422 u. F.

bebaim. (INantin) Erfinber ber neuen 201t $15-17 \cdot 31-35$

Beimortek, bie von ben eigenen פRamen betfonmen, foreibet bet Berfaffer bet Unterfuctungen mit cinem grofíen Infarigb buchftaben 412. Was et bei bet 3ufammenfejung bet Deimórter mit ben froupemoirtern beobachtet bas be

429

Betiî peregrinitas linguze Hung, mirs. bes ukibeilet 288 थ. 302 भ.

Fendel (von) ain stieneriftier Canoi ritcus $258.260 \%$ Sterge fino, unter andern gbfiditen, gue Sefundbeif bes Menfoben unb bet Sbiere erfalfen worben 187 थ. $t \mathrm{t}$. andere 23 ortbeile ber Derge 191- ets lidbe feben bon ferne nite Equien aน8 4.19 . metten niebriger $178-186$. ibre Erniebrigung miso Durch gemerfe 2usfinten (182), ferner burch die uns fágliche Mgenge Sanves bargetban 183-186. Det Edutt, fo bon ben Dets gen berabfommet, bermiftet gange Conberenen 179 21, an, Erniebrigung 


\section{Megifter.}

Der Serge auв ber Satrift betwicfen 187 2. ss s. J̧olggeburiner, STell, van Bergen berabjubringen 336 \% . - fetterpeyende: roie ifo geuer bes f doffen fer) 324 u. p. Waruma nut auf ben Esipfeln ber Berge bas fenter auğ breche 325 . einen ferserpenenten Bexg in fleinem borjuffeflet 139 . n n. einen in 3immer fich oosjubils ben 325. f. aud \$3runften, Enf gư bunger.

- allegebrannte: Pipare 139. 30l fatara bei Pojudolo (Puteoli) I4I. mebs Epuren von foldjen Bergen in ermelgnter Siegeno $346 \mathrm{Al}$ z

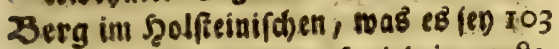

Bergftáutet wad)fen auf niebrigern $\mathfrak{E a}$

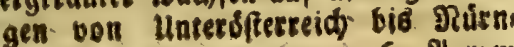
berg $3642 . \mathrm{mm}$

Beramerfe entwenten sirenfacen und

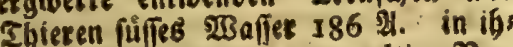
ren 3 ången trifft man gewoltige $\mathfrak{Z}_{\text {er }}$ enberungen ber 23 årme uno Rálte an

189 ․․

Betulius f. Dirten.

SBevieto di Eertanova

2382

Zemanbenif if redit gefofrieben 412

Bianchi (Giovanni) ift Fanus Planeus 56

Bieten, nidst bietben 428

Bimaftein an ben Stalabrifhen Rúften 347 2. c c

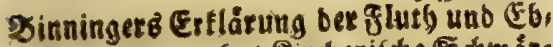
be 75-80. ex bat Sircherifohe Sdináes mereden nad)gefdrieben 197 2 . сcсc

Birten (von) itret in ber singeige ber Irajanifhen Brưçe 209 2.

Sixnen rerben bon ben elepfeln am ges nifferten burd ben BSefdrmad unters rifisten 360 11. f. 362 II.

Bifirifa mirb ertiăret LXIV Dladfifh fang wo er fiart getrirben net be

Dlaues IfReer f. IReer. 184 2. 999

Doethjoe unglưfith in Musforfdrung bet Elufifichen Edjoämine

394
Buletus ber Nodmer, if ber Raifeting 395

2. $\mathrm{h}$

Boloccialo ber Neapolitaner, ift Det Trasi ferling $396 \mathrm{U}$.

$300 t$ wirb etfläret $\quad 104$

Sorlens noirt erflătet $\quad 273$

zof bebeutet runs; baher bas frean. boffe, bas Jitalien boccia, ber Name

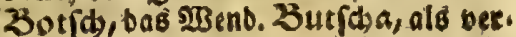

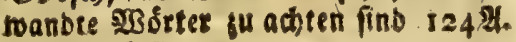

Sotanif f. Pflangen.

3otf(b) ein runber berg in siektel 3ils Ii $\quad$ 124. 2 . Bovifta Dillen. $\quad 3782392 \mathcal{A}$. 3 rómen linbum prætexere, iff redit gcíchieben, nicht bremen 297 थ

Brátling ein Echramm 373

Branounger IO $32 \mathrm{~s}$. XII

Breit, latus, wober es fomme - 29r

Brietling, ein Ed)wamm : $c_{4}$

Brigx was es in ben Ramen ber Celti. iden Deree bebeute LXVII

Brown bef(h)teibre bie Irajanifhe Btude 209 \%:

Srufte S. Trajans 207 2. 242.249 .

Brunftrugel Deft. $23 . \quad 392 \%$.

Drunfen aus bem \&egåifohen Dierte, uns an bemfelben 13I-133. in Dem Mits tellanbifaten IRecte I34. Die ganfe B̈es genben von eåndern anfecten 142. F. aud) Entgunoungen.

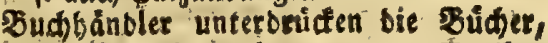
bie fie nidjt berlegen $37, n$.II. ibre

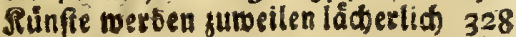

Ђtider; bie ein Gelebrter zu feinem Ges braudie mit fid fúbret, múffen gu $25 i e n$ ben 30 fl entridi ten, wie biejenigen, wos mit cer Bithbäbler fein Generbe treibet

274

Buffong Hiftoive Naturelle wiro ges rübmet 338. biefer grangofe fadreibet mit Beradtung von ben Seutidien. $G_{*}$ lebrten, und (a)abet fid baburd) 339. estläret auf eine unriditige Irt ben urfprung bes Meetfalzes 346 श. x. lábt in ben speetengen feine Strône

b 2
औ $)$ 
Regifter:

Iu, bie eine wibrige झichtung båtten 34I. rebet gat su beftimmeno über

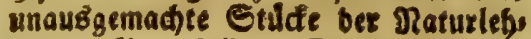
se 341 M. n. Foll den Etrabo fieifiger anfubten 342 थ. p. mas et nod in reine Hifoire Naturelle, gus Ebre fei. ner Eandesleute, unb ben gremoen, Die ibee Eprache lernen, sur Erleichs terung cinfualten tonne $33 \mathrm{I}$ थ.

פoifel liegen in 2ipulien, gut 3eit ber gro:

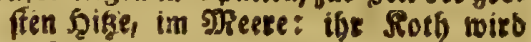
anftatt bes Torfs ober scolyes fum Fifichbraten gebtaud)e - 184 \%. 999 Bublel collis

Buxanthus, ein Edinamm,

3y in ben alten Norbipracten ein Sles cen, anfebulides Dorf

\section{c.}

Cæefius laçus

Campaniens fev

Campi Phlegrai

Capreolinus Tabern. 378. 396 U.f. bie Seutichen शamen Diefes Shroamms

c 4

Cataractr Danubii 204 u. f. in bex $2 n$ ners fung; fernes

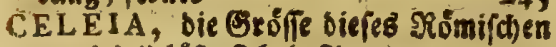
municipii lást fít beftimmen

Sellarius bieng fu fehr an bic olten Schriftitelles 208 2. 345. 2. $t$

Eeuta, nte diefe Etadt latkimift) bcifie 29

Champignon, Seurfकe Ramen biefes Edjwamms

$\mathrm{C} 2$ -

Sbarpboiz 143-147. 151-155. Ob bies fer Firbel orenmal bes इageb bas sisafier follucte uno fpene 152.153. bált fich manchmal gans friebram 54 . man fif́chet barinnnen 155. wie elu. berius die :Befchaffenbeit deffeloen ex: flåre 146 भ.s s. fireitige Prexict)te von bifem 23 irbel werben entfatided 165. 166. Borfoflag, eine grúnolichere Gejhidje bon bemielben ju enbalien
154 2. Der €dhlunb bei Taormina in Eicitien, if cine Ebarnbois 149. थ. yy Ebarybois if ferner ber Salunb eines fluter

Cilli obet šlli ift bie ređte Sdreibart, Cilley die bermorfene

254 X.

Ciuccia in Eicilien eine fleine Lucia, im গTeapolitanifonen eine Efelin 265

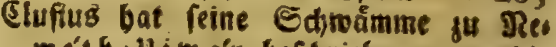
métb llima'r befatrieben 394. Die 2ueforfa)ung berfelben if móglid, allein unnufge 394-398 Die शinfuibs rung berfelben if zu ibet Ertenntnie

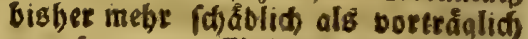
getoefen 395. Elufub bat geftummels te Schnămme abgeŕbildert 397 . etlis dise feizer Seutfdien Ramen bet Sdproamme find exbidhtet, bie ungrio (d)en nid)t rid)tig 397 u.f. feine gut aufgefdriebenen ungrifon Ramen Dee Edjrămme jeigen oiefe Gemåđfe befier an, alì feine figuren unb $\mathrm{B}_{\mathrm{e}}$ fatreibungen 398. Peine Befhretbuns gen ber Edhwarme fino unverftanto lid, weil et oie farben ber(elben nid)t muşte iu nennen 398 Cluverii Meinung von ber (Ebarnbois Cola Pefce 146 2. ss

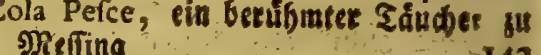

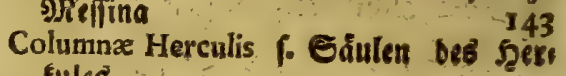
fuleg.

Corno (monte) Det 5ornberg, oter it gran Saffo d'Italia, ein Ttalienifoner Ed)neeberg i ein 'Etúd beg Epen: nins

Correatores fins mandimal noienmeif Cratzens ein Bergbarim 208.410

Crecerelle $365 \%$.

Crecerelle frtanf. $\mathfrak{N B}^{3}$, ift bet tinnunculus

305 2.

Crufis (egrift. Iutg.) MReinung, wie bad fúfie जुaffer entffebe

Cuttius irret in bet Bofforeibung bes Rafviffien IRecres Cyclamen 366 थ. Dै ámen 
ఇegiffer.

\section{D.}

Dámen exhalatione humere 297. 393 2. $\mathrm{g}$

Daucus Creticus måchit wilb in Defter reich

Dauern, nidfe tauern

370 थ.

D) $a^{\prime} ;$, llimgelb

Deids wirb ertláret

413

304

104

Delos, wie biefe Snfel entfanden fep 52 ม.

Demirfapi geföfrlidet Ort in ber Dor nau 204 I. 24 I, n. II. 244 U. f.

Der, Jie, Dag, ein bejiebenbes Seutihes frúrwort ; wie es ber 2 erfaffer ber LIn terfudungen gebogen babe 430

Dinieper und Dutiefter, redit gefdrier bert

413

Dórnling, ein Echmamm

397

Dominicane: fommlen Urfunden gu einet Befhidte ibres Drbeng 259. Die ju Eoriano tragen einen \$erg burch $\$$ eis búlfe Des $2 B a$ aferb $a b$

178

Donas, ibre Befos affenteit bei Drichome 242 u.f. unter Demirfapi 248. f. auds Cadotali.

Donaumaffer vermenget fich nict mit Dem 253 affer bes fatmarsen 2 Reeres 219

Dràmel Deft. গ⿰冫欠⿰亻⿱丶⿻工二

Drás cin Slup̃ 273

Dren

402

Drillo, ein Sicilifore gflü, Achates ber gilten 236

Drittel sin bequemeres 200 ort, als Drits thesl

Drvichling, ein Edmamm,

Dryas Linn, auf bet \$ejsen

Durn (bie) ein bुerg

418 u.f.

C 2 .

$365 \mathfrak{A}$.

370 श.

Dunum, durum, taas biefe 250 óster in ben lateinitकen शamen ber Eeltifchen Des! ter bebeuten

Duzen (baB) abgefommen $\quad 262 \mathrm{~g} . \xi$

\section{E.}

$\mathcal{E}$, wie es in Seutfकen loute 912. fernere abbanblung vor biffem Selofi. lauter $286, \mathrm{n}$. IX. Die franjofen baben

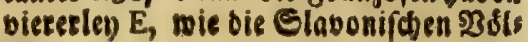
fer

287

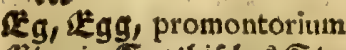

LX

2'g ein Ecutbifches Stammwort 287 H.

Cbrentifel (vielfáltige) find anftatt $\mathrm{DCB}^{3}$ aufrichtigen alten Du aufgebradt worben 262.21 ,

Cibe (taxus) wie ibre Tangeln ausfeben 3632.16

LEin (bet Seutfde Itrtifel) ift aus a in entftanden; ain aus a'n, a't1 aus $a^{\prime}$ 308. U. f. 3 II

Eis bes Sicilifanen Ealffuffes tann

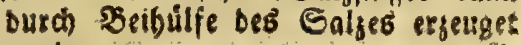
werben

Eiferne Thor (bas) f. Dentrapi.

Litenefifel, nidh Seiterneffe! 306

Elyfifone felder

Enten find von Linnzo in Gánfe ves manbelt morben $\quad 373$ M. $\mathrm{ga}$

Entben Defiert. WBort 417\%.

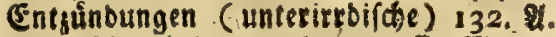
gg, hh. bringen eine groffe शRenge Bimsffeins bervor, uno fhieben ganse Sinjeln aus dem 21b grunde empor I 33 2. blajen bas Deer auf 30 (Ellen boch aufi, unt erfúllen Die fuft mit fintendem Rauche, ber ben Eugen fobsolich if 134 21. Fieb aud Zrunften, Seuer, uno Zerge (Seutripeyento).

croe, ein Thier 110-112, ibre mabet (d)einliche SEeidaffenbeit unter bem Rocopole $280, \mathrm{n} . V$. of fie von bet:

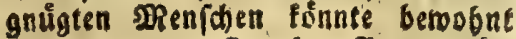
werben, renn fie obne Berge wåre 177-194; benn baßs fie bermaleinft flach, uno babei ein Parabies, foll roek: ben, träumet cinem Poeten. Unges reime folgen, wenn biefer Staum follte rabe merben: eine fo befochaffer ne Erofugel båtte meder flúffe noof Brunien; viele Thiere wutben bers geben 187 , befigleichen einige Pflans gen 188. bie gntwobner einer roldsen Erbfugel murben viele Ergezlionteiten

eats 
Fiegifier.

entbebren múfen r 90 u. f. lingemách. lid)leiten varfelben 192 u. f. unfere Eroe fơnate, nad) ben isigen (Bsefezen

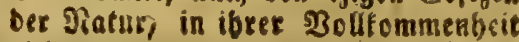
nid)t ewig beftegen 186. fie muskte endich miaber áberfanemmet werben 181. 194 3. EDDtt wirb bosber ber gegenwástigen $\mathfrak{B}_{\text {eltuer faffuag ein }}$ En. be madoen 193

Eroped farwimmet nuf bem Ilegaifden IReere 232. wie ex entfteben tôn ne $232 \mathcal{2}$.

Ernolatia, ein ?ómifcher Drt XXXII

Euripty in bem Archipelago 78 . Diefer शame wies in Dem Saubneriftsen Zeis tung8:Lexico irrig erfláret I68 $\mathcal{U}$. hhh. Der Daburch verfandene Drt von Varenio, f̧rn. Crufio, u. a m. un. ter einem irkigen 5 egrife vorgeftellt

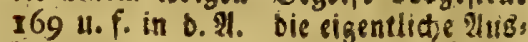
legung auछ bem Mela, Eutraह, Pli: ntag 169 U. Etrabo $17=2$. I in ben 20 Ẽterbúchern des Pafiag. unb Voyag. wirb Euripe red)t mit ineer. enge tiberfest $172 \%, \mathrm{hhh}$. oftmals abivechfelnbe fluth und Ebbe biefer EReerenge wirb extläret 170 2. n. toi berfprechende \$erid)te von Derpelben werben aubeinanber gefegt ' $167-17$ I eylano infula, ift redit gefdrieben 4I 4

\section{f.}

Sarben baben nod feine fulånglidsen tar teinifden Ramen. V Yoríchlag biefen Mangel zu exfegen $280 \mathcal{2}$. wie ber

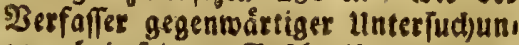
gen bei feinen bejhreibungen ber Echnámme die farben aufgefeidnet babe

Faro maz es fen 382 S. a Seiftrio in wet 200 ort 298 Der Elaboniex Biftrita LXIV feticilain 24I थ. fo auch bie Inmerf. ffff $\mathrm{S} .203$ u. f.

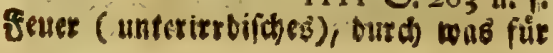

2luten ber verbrennliden Rorper $e^{6}$ unterhalsen, nerde, exfirnit man aus ber Sefdhoffenbeit bet auggeroorienen Edlacten, aug bem Beruche Des

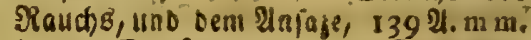
f. atch Entsuriburngen, Bbrunteti, unb feueripenende 5erge, im 23 . Zerge: Sidote, wie ibee Zangeln ausfeben 364

\section{ginfifa) f. Wrallfift)}

21. 11 . gifiche (Sibirifabe) verlieren fich aub ben Eeer, berer $233 a f f e r$ gejalyen wirb

$$
\text { 188. } 236 \text { भ. }
$$

Fifकtbran ift eine Epeife Der mitternåd. tigen $\mathfrak{B}$ slfer, verfdjaffet ibnen lidit unb feuct gum $2 B$ ărmen

Flater mirb exflåret,

189.

Fliegenfoc)wamm iff vor bem Raiferling leiäe zu unterfobeiben: wirb surds ein

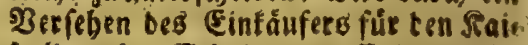
ferling obne Schaben genoffen 397 2. Etuffie, bie aus Jtalien in ben शoriati. (d)en 2l?erbufen fallen, etgieffen ibe sBaffer gegen ben Strom diefez Ineer - res. 82 ibe 5 bettungen werben bos bet 179. 181.4 .6 . glutb unb ebte : ungleide in einis gen sReeren, in andern feine 69. Det Mond und bie Eonne geforen zum Sriebwerte bexfelben 69.70. fie wirb von Herbinio burd bie Rircherifote Pericoclofis mit (a)ledtem Srunbe exfláret $71-75$. nidht beffer bon Şrk. Binninger Ju Eerlin $75-80$. Deß Italieners \$appini Meinung bon bet. felben ift feltfam unb irrig 80 . feel nere Erinnerung fu biefer Beurtbei lung 286 .n. VUI, wie BoffuB biefe

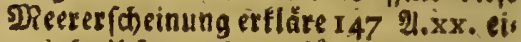
nes Jzalbfrangofen gufálige Gebanfen

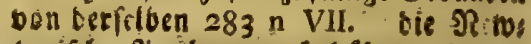
tonifhe Aluslegung bebåt nod ben

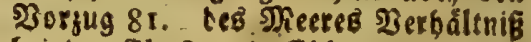
bei ber fluth uno cobe glesthet ber Bridhaffenbeit der Ruft beim şalle und 3 Breberballe, $70 \%$ \%. beronbere 
Regifter.

flutb und cbbe in einet sReerenge, bie swifhen ben weftlichen Edjotts foten Enlanden fid befinbet 84 . bos be in bem Perfifinen \$eerbufen unb in bem Rothen Meere $34 \%$ in Det Magellaniftien Deerenge unb. beim

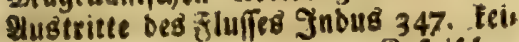
ne in bez Opfipe, in Dem Rafpifasen SReere 78. 340. nidst mextlidse in

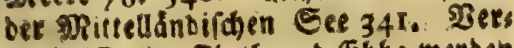
tetdiniffe ber fiuth uno cobe werben in sen norolidien Seeftáden in bie Ralenter arfegt 7 7 . . o. Flutben mas den gifela, uns gertbeilen fie fezner 49. 50 . firirgen Şăfor um, ferbechen fis, ober fubrestiefelben binweg, wenn Tie betfern fint 95 2. f. aud Ueber: dojemmungen.

Sordbling ein Edroamm,

4-

Sranj (P. Iof. ein WSienerifoser Jefuite) nimmt fich ber Naturgefóichte an. IRan ruinfohet viele Nach folget $258 \%$.

Era't fde In Deft. Wort

298

frólid ( $P$, Erafmus) ein Stenermåtfi: fhes in 2 Bien lebender Jefuite 255 शै. eine 3ierbe feinet Biefellichaft 257 20.

fruchrbarteit bet Ġegend um Reapel ei

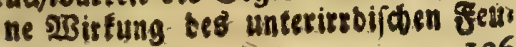
ers

136

fubtmanne (\$.) itrige spreinung bon bet SRichtung bet Europdif re

84 थ.

getivfenfelo XXXVI

Fyrth in Sdjottlanb, zeftuarium, LIX Fungus D, Georgii 397. umbilicum re. ferens 388 घ.

6.

Gaber wirb ettlátet

Gabromagus in Norico

$\mathrm{XXX}$, u. XXIX

Gadeg, Bebeutung Diefer Pamen 27 Sånge (unteritebifa)e) tónnen niche ges låugnet metben

149 भ.

Ball im Evionirden refonuit 299 . Ballurdacl, ein Schroamm, iff ber Reás politanes galluccio 14 .
Gars ein Bొepfåble, barinnen ber f̧aus fen in ber Donau gefangen miet 204 21. ๓aรี bebeute

Serten im Sande 185 9

Гasn'e nach ber Racebåmonifóen MRunbart eine Kube

Ga'cen leinene unterbofen 299

Gatrer und B a'ter 315 u. fo

Gobel Carif nirb erflairet 12 Jै:

Gebante (oer) fur Gebanten, uns rithtige Enoung . 4I4

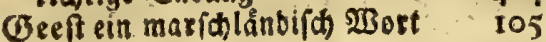

\& e iáb venatio $\quad 298$

Gersbart ein Ediwamm 392 थ.

Bela bebeutete Lis in $^{2}$ ber Epradeber Ópifer unb Cifuler $12 \mathrm{I} \mathscr{H}$. eine al! te Sicilifche Stabt biefes ఇameng̈, wo fie geftanben 238 \&. Setranoda

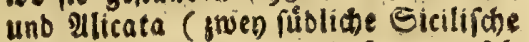
Stáote) fiteiten um die lage berfelo ben

I 2021.

Gelæ ftagnum $\quad 238$ \%.

Gellen culex 298

Gems follte Gäms gefdrieben wers ben 291

Genifta Riv. 367 थ. humilior Panno. nica $i b$.

B̈eograpbifthes Ramen: unb B̈efdreio bungsbuch : XXXIII

Germ fermentum 306

Gelabidate (bie) in bet mebrenz $3 a b l$, unridhtige Enoung 415

Befdhled)t genus, foll red)tömegen Ges idhlädrt gejdrieben merben $424 \%$. $^{* *}$

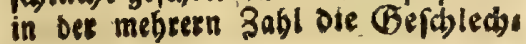
ter 415

Serner ( $\xi_{06}$ ) um bie Raturgefoichte moloerdient 410

Befiners ( J) Rattb.) THESAVRVS 38. mabres Urtbeil bato defen Werte XII u.f. 33I-334. Det 52r. Scerausgeber ent: fauloiget in Der Borrede fébe (c)liche

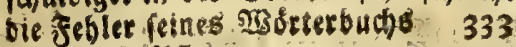
Gêtwåtie r. \$flanjen

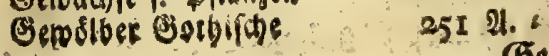

Get 


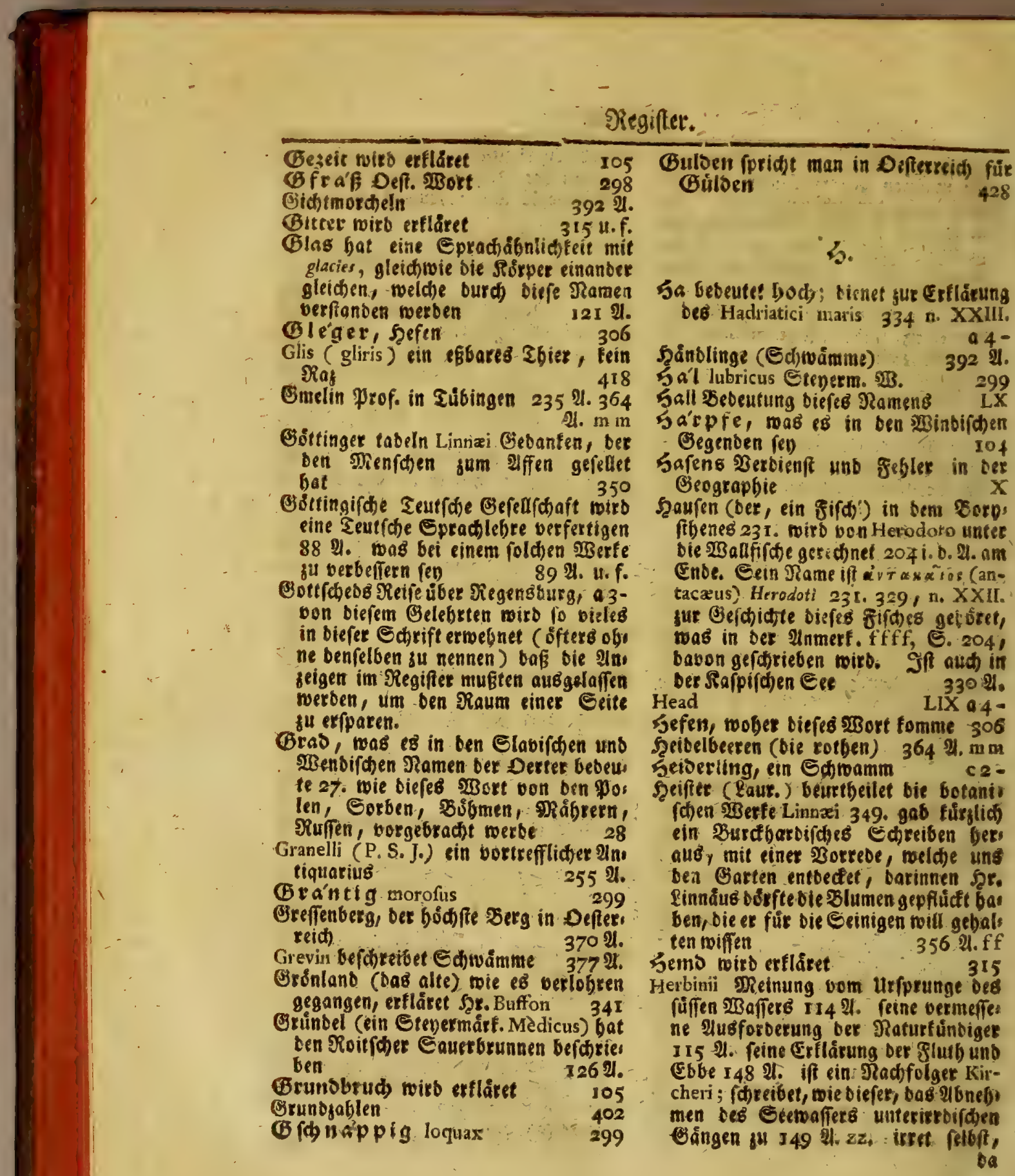


3irginter.

bo w ben Etrabs cineo Jarbuns bes fotuloigen mill

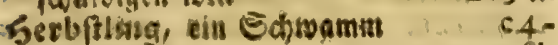
Sertentoróeln 39121. Herculis Thatin folfen eine Borffellung Der Eierchithle Des Jofus uno Eami fone reyn 319. bo: Varrone wetson XLIII jetoen siefę Ramens gesăfilit

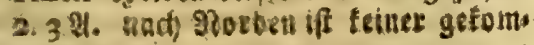
men

Sertuliphe Esuten f. Eåulen.

Herodati utrige Deinung, Daf ber æal neue Lånê anfege

Sersenfdosoamiti $138 \%$.

c 2 -

5rïgarig, ein 2trm ber Donat $210 \%$

Setmann (Job.) Gat 2Bienerifa)e 210 tet gefammlet

29.5 U. f.

Sodjuentoig, Unterfudyung oiefes (5) rentoortez 262 थ. $\xi$

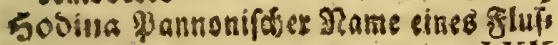
reg

LXX Golgat carnifex,

a 4 3obler Deft. fambucus

317

Jollónber ein ₹eutrobes $\mathfrak{B}$ olf $320 \mathrm{n}$ XI

5olm Satweb. cine Jiniel

LI

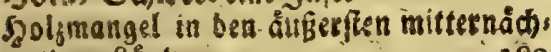
tigen Rånbern

189

5rav, toas. es in ben soffmiftaen unb S) dérifigen Ramen ter Derter bebeus ie

28

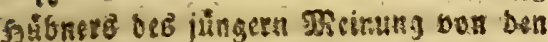

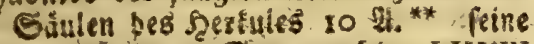
vollftânoige Geographie LXXIII berfelben, wis aud bes 3eitung ci, unriatig Befá) teibung bes Defter retaifichen Donaumirbels ISgu.

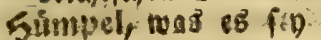

xO5

Sunbefifd catcharias, bat, nađ̆ einiger Daturfunbiger Mreinumg, ben Tonas verfor)lungen

277

Hydnum von Linnsec vetwedffelt 39.

$$
7 .
$$

Ta'gevberg in Dbereff. $370 \%$.

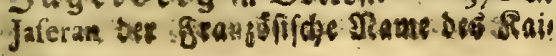

felings, ber um Rontpelier jaune d'iau beist du-396\%. Tzrescy 23 ind. Bartholonzeus 267 it. St. Jैiegenfónamm $\quad 397$ Jouvin be Riodosfort unterfu(bet tie Brfdoffenbeit Der (Śgernbeis $155 \%$ Staliener verftummeln auf eine abens sfeuterlid) Sirt bie Zeutfdien Pames 269 \%. f. O4 $2062 \%$.

Iuri $233 i n b$. Georgins $267 \%$ $i_{3}$ ition, was biefe croungen in ben Mamen ber Derter anjeigen LXIt

Z.

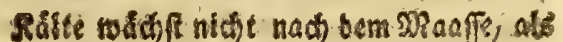
man ber Begent unter ben Rorenole

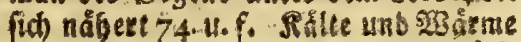

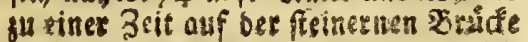
fu Regensourg $74.282 \mathrm{n}$. VI Saiferling, cin ebler Edswantm 395. feis ne gefábrlid)e glebnlid)eit mit bent fliegenfohwanme, verfarget nue thas me ober uner fabene seute $\quad 396$ u. f. Zi $a^{\prime} \mathrm{f}^{\prime} 3$ e

Kalína ift opulus Ruelii 304 U1.?

R. Serl ber VI in bet Sunfe bie Etraffen fu babnen, uno gléfe foiffoar gu mas

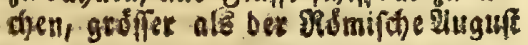
$2 I I=213$

f. Rarls beछ V. 2305 (pruto PLVS VI,TRA 14.15 - Kart Went. cin naulwurf XLIV Pafpifhe Meet (baB) T. Meet.

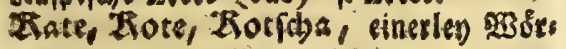
ter

K $8 \gamma \times$ is, ein $B \circ g e l$

107

T. 305 औ. Den Minoifchen Gegenben beseuten ro\% Sies unb 53 ofiter macten Enttúnbungen I39. I.42

Sixchers sgeinung on bet Sbarmbois r95 2.6 b bb, oon bat Solunbe bei

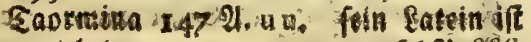
tuntiditig. r66.9. if te. Toudap da Tralia $-84$ Elat 
Pegiffer.

Tlaa in Deft, ungula, Rlaue XLIX Zlasomo 209 श्. Surfifid Setiflam Klat $28 \mathrm{enb}$. fpaltels $241, n$, II. f. aud 248

Xleit beurtbeilet Linnei Eintbetung bet Thiete

Klippa Sdbeb. foncisen, bavon fom: met oag Keutipe Zilippe XLIX Knautia Linn. 353 2.

Knawel (fi nach bez finnaii(h)en (Einlei tung übel iu etfennen 353. cocciferum

Poक (Jac.) vom Pulsfdiage ser 355 भ. fugel 284

Sober (ber) palear 300

Rofpte und 3ăbne von Eeefilonen, Heber: refte ber SLinbflutb, merden fu Rrems, mulnfer aub ben Eanblagen augges graben

119 \%.

Rọping was es im Eकhwediftien fen LV

Rola'tfo ein \$inbifh gebactertes

Ko tigen Erriedsen, cin Eteuermann 2062.

Kommen, venire, wie es in Deffets reid) ausgefproci)en werbe

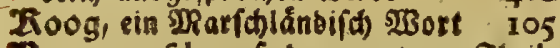

Ziormanofid auf bem untern Ibeile bet Donas ein Steusmann 206

Zoy mandibula

$\operatorname{Rr} \operatorname{cor}(50,000$

Sramer (J̦o. S. Seint.) 338 2. i. 261 2.

Reefmis befwreibet ridtig ben Etrubel

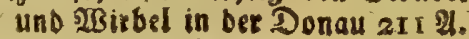

Siremsminfer, eine Mbten Der Sentebicti: net in lanbe 06 . Det (Engे II $\mathcal{U}$. ibse Bibliotbet ift ben Ëelebrten beríthiofs fen

393.

Stummidonabel, loxia Aldrov. 330 ओ.

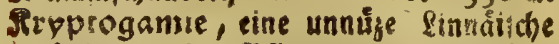
Drbnung der pifangen 353 erfláret foviel, als die qualitates occult $390 \%$.

Ritfenmuden, ein Stmamm, c2. Siufe, ein (B)efák

Rúbiung bes Tranţ mit cife ober
Sdonee, ift in ben beisen faindern bee Gejunbbeit jutedglid 192 u.

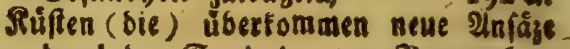
burd ben Sanb, ber von Bergen bers untergejohmemmet wirb $x 79$, biefe $21 m$ făfe finb grớfer, alB bet 叉erluf, ben bas fefte lano an anbern Drten letset

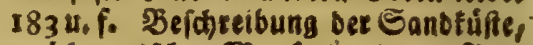

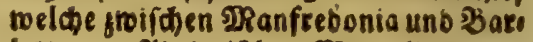
letta, am Oroviatifकen IReete liegt 184 ข. $\mathrm{q} 7 \mathrm{q}$

guno witb extlaret unb vertbeibiget 425 2.

Laborix, ein Plinifajer Name, bakaus vermutblid Terra di Lavoro gemact worben, feblet in Cellarii Geogr. ant.

Lacus Cocasicus Plin. 1362. 238 \%.

Lansfarten su verbeffern, werben in ber Bufhrift an Die Rofmoge. Bef. biet

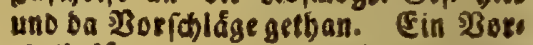
theil fur bicjenigen, weldhe ben airen Suftand ber Eanber angeigen, mirb $E$. XXVil oorgetzagen.

Eánol, Eánsler, eánslerifb, toos burch biefe 230 rtet verftanben reste

fauge, 416 u.f.

Lecce eine der pråchtigften Italieniŕnen Etăde XXV

Leèt, vacuus, fodte lär gefdoricben wet ven $\quad 29 I$

Rerbus ein Martifleden LXIV

Eetten mieb extlátet LXII

Lilybzum promontorium, beffen - Fe idalienbsit

Linnzeus ber If Diofcorides 377. Untbeil o Baffeferb Det-Unterfudbungen vom here, ưber einige Situde Deb

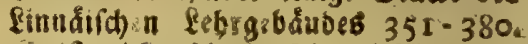

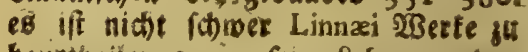
beurtbcilen 349. feine febre von Den. - Whangen it fibon wegen ber Rryptes gavie groflentbeilo unnuge 353 . fie if abes 
Siegifter.

aber aud fohsolid uns verfiberifich $354-36 r$. man Eann ourch Beiturlfe berfelben bie şirnea von den Ilepfein nicht untericheibes $356-360$. fie wh berleget fid feloft 360 u. f. Linnxi Grundfaje fint nad) feinem gaten (Bie! (d) macte abgefä́t 36I-368. er fáseis bet nut anbern vor, wag fie thun fol, len 368 u. f. es beobachert fene eiges nen Ëerege nid)t 36 I 2. 367 . 21: $\mathrm{nn}$. 373 2.00 , verwirfe die giguren ber Pflangen, und beaudhet fie feloft gus Erflárung ber Seinigen 387. er ficl. pert über bie gegein ber lateinifhen Spradiefre $369-372$. verfebret bie Sebeutungen bet lateinifóen Namen 372. freflet fich felbif faflen 357.373 11. fo bat fich in bie $23 i f$ enf(h) aft ber Sod)wámme nidbt alliufelge vertiefet 374-380. in Eile entworfene $\mathfrak{B}$ or.

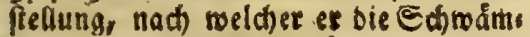
me bătte eintbeilen tơnnen $390 \%$.

Beffelfraut von gesinget Edårfe aur tem Epibbergifaten $5 a b e n$ 189

Roibel, wunberbare Etraffe úber bies ren Bers

2132 .

Loxja ber Rrummidinabel 330 श.

Rued ein 21:m bet Donau 209 N. gggg. Lug, Lugea palus, deluge

\section{m.}

Maella, ein Stalienifdet Sdneebetg is9

Maclftroom, ein Rormegif́cher Eeerwiks bel I50.151. bált fich mauchmal gang frietfan: eb wirb bariunen gefifichet

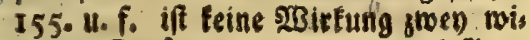
origer Stróme $146 \mathrm{Mt}$. $t$

SNagri (Dominicuš) ein Beftåtiger bes शrábrchens bom Eabbatfuffe $76 \%$.

Magus, was es in ben Ramen ber Eel. tifiten Derter bederte XXX Malta, biefer Infal Mbpand bon Sich lien

20 Mann, nober biefes sosort fomme XXX DRorilenbaum (malus :Armeniaca) if ton Linneo in ben 310etfdifenbaum vermanbelt worben $370 \%$ Darmelfteine, wie fle entfteben 323 Inarfds; bavon bie SRaríd lánber bell Ramell baben, wirb ertleret 106 Marfilii 刃reinung vom Salze bes mReer. maffere 177 Q.116 Marje Prab. ein Eeebafen LVII Mas wober biefes $\mathfrak{X}$ ort fomme XXX Mauradien $391 \%$

\$leer insgemein:

Die Befdid)te bes mecres ftedet nod in groffer Dunfelgeit 83-85. bie 216 ten baben won ben meeren, bie ibner befanni geroefen, gut gefdriteben 62 . bie Dberfléd)e Der Meere bebålt nicht

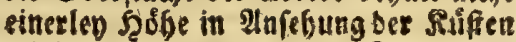

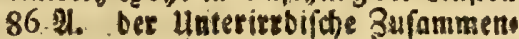
bang, ben bie eingeff,lofienen gisete

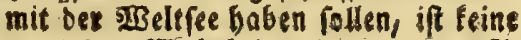
exmiefene $\mathfrak{W}_{\text {abtereit }}$

5921.

\section{Defonoere गeere:}

Das Zoriatifdse vieer bålt im Mins tex mebr 53 afferb, alB in Sommer 160. Die Fluth und Ebbe ift in Dems felben mertlicher als in bem Meittel, lănbifden 34I. von ben Seeftrómen biefes - Reetbufens f. untet bem 2ufo (d) lage theerftrone.

Das 3 laue Meer, mare Aral, $344 \%$.

$$
345 \text { 26t }
$$

Das Rafpifhe Meer überlåf nidyt 57 4. f. ob es unter bet Erbe mit ans Detn פeeten gufammentange i 48 . 149 220 \%. Fein 23 affer ift fúfer, als an Dere Meerwoffer 221 น. f. von fart. Buffon befarieben 343. bat gefábrlis die Strume 344. bie bie Rafvif́ch Ediffe gebaul werben 344 u. f. bie mabre Geftalt biefes aReeres 345 \%.t

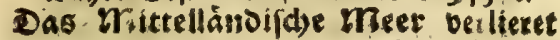
mege $23 a f f e r 6$ burch Die 2lubbirifuns gen, als es beffen bon ben gluffen empfôngt 129. 137. Be(d)affenbeit rei: 


\section{Fegifet:}

feiner 203 ellen 130, 13I. Fenes unter feinem lager 13 - 137. fein $\mathfrak{B}_{3}$ affer if

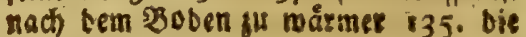
luft um baffelbe ift auch rårmer, alB auf bem feften fande 135 . wat borseis ten ein eingef(l) lofenes See, uno wei: ter ausigebreitet als ist $137 \%$. ob $\mathrm{eg}$ Surch unterirtbifose Defmungen mit an, bern giereen fid vereinige 137-139. 148. erbált bon einigen, infonbeebeit grofien, gotuffen in $2 B$ inter menige: Maffirs 157. ob eह von ben Eleinetn im Winter mehr Woffers empfange 159. ift su Diefer Zeit beficindigen গReers furmen unterworfen 158. bat einen

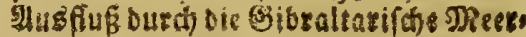
enge, bor plinius nut bon eincm cins tritte meloet 7. Ser. Buffon bertbaiois get bie Plinifche seinung 340. Das IRittellanoifose Meet úberfonmet bei

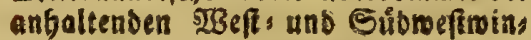
Den einen fatten Innache bom B̈e máffer aub ber Atlantifchen See 173 \%. mebs toiberiprediende Bertdite, ob eछ einen Eirfluf aus ber 5 Belffee babe, - Der feinen, ferner do ber Eintritt bes fremben, ober ber Itustritt bes eiges nen (B) ếf unter(ucht anb beigeleget $161-164$

Die Torofee ife an mandien Drten bo: ber als bas lant 102. Heberfchrema mungen berfelben 62 u.f. 90-103

Die Ofter bat feine Giluth und E6b

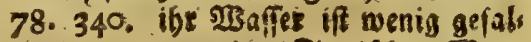

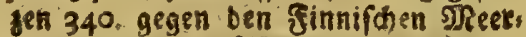
bujen bin noch fuffer 222. Vertoandt rhafe ber Diffee mit bem Schnaksen SReere

224

Das Zotbe Meer bat zut 3eit bes glutb reat bobes 280 fiet

Das Gdywarze meet hat nur einen

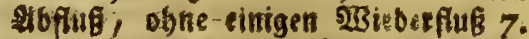
2r5. biefez to egen ber $22 R$ enge deg 23 af fere, nidt negen oer bobern Eage 326.

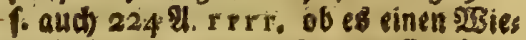
berfus unter bem Doerwaffer babe
226-230. ift fuffer, alb Das sRittel ISndifb) झूeet 220-222.237. aud truber 340. gefábrlid)en Seefturmen untertoorfen 340. frieret in 203 inter ginglich it 340. if sorzeiten ein $E_{e r}$ obne 216fur gemefen 341 . tonn wies ber einer merden 342.06 es unterire. bifast $\mathfrak{Y Z}_{3}$ d) babe 223-225. Foauch 329 ‥ XXI $216 g r u n d$ in bemfelben 223. norutn beffen s\$affer nidjt gang fü terte $218-237$

Das Coste Meer ober bas Ealimeer in Palåftina tritt niát a $011658.06 \mathrm{es}$ mit andern 59 Reren verborgene Bes meinianaft phege 148 u.f. 220 \#. bat firithe, Bogel tơnes obne Ges fahe batúber fliegen und leute baten Dazinnen

Das weifse breer menig 345 u. f.

\section{Meerengen,}

Die Compantinoplitaje oder ber 80 fphorus Clyracius, if erft mit ber Zeit entranben 51 u.f. leitet nur for biel 2 Baffers von bem Edjwazjen IRcere ab, als ein anfebolider Ereon Demfelben zufúben tơnnte 68.224 2.rrr. 237. bas Eurmifche 230 afo fer froomet in bieper sjeerenge oben beraus, ba inteffen das Bpropontiche burdh etren wrorigen fauf unten bins einflieffet 226 น. f. was Dabei zu bes obactiten

Diebubraltarifbe: ibre alfen u. neuern

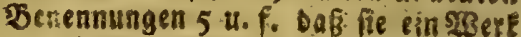
bes berfules-feD, eine fabel 5. UH, tetiuchung bufes Sorgrben8 49-59.

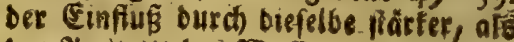
beः 2lusititt bes 253 fferb 7. 108. bies fé wito in 3petfal gezogen: Erflas rung, wie foldies gleid wol gerdergen fonnte 130. u. f. fernert linterfitchung unt Entfocioung bet freitigen $\sigma_{01}$ sid)te blexú6et 16r-164 172. bet

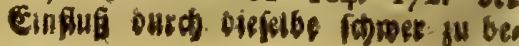


Piegifer.

fimmen 228 2\%. auferordentlich fiars fer 164 . diefe Niecreage ift exf mit Der 3eit entftanben 49 u. f. $54-56$. iff burd bie Pillantifche See gemadts norbell 57 21. Fe verbutee lleberid)rem

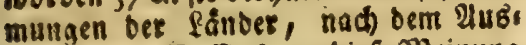

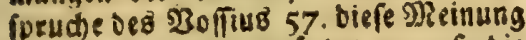
ift nicht beftens gegrừnbit 57 . U.f. bie

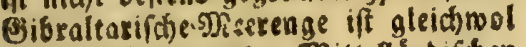
eine 23 afferwage ber Sittellandifden Ere $60 \%$. f. Die Eicilifare, bie Sicilien von Salas brien idteiber, nird befchrieben 216 u. f. ibre Eeftalt 153 M. b b b. roarum fieben Secleisten beatigeb Tages nicht fo gefäbrlid) fev 167 U..gg g. Sdiffs fe bletben in serfelten mit auzgerpann ten Esgeln fiethen $168 \%$. bie $2 B$ eite ibret mitternădigen Defnùng bon Plinio ikeig (ober vielmebe burd) eine verberbie Etelle) angebeutat 53 21. C

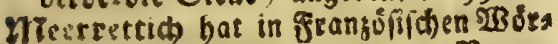
terbuichern feinen red)ten Ramen 3312.

Tsecefalb, wie es enftanben fen 175 u. f. Búffons Mrinung biertíber

SReerfa) Iuno bei Saormina 545 . (. aud Charybois.

IReerfirome 63-68. ifre Ramen in vev" fobiebenen Eprachen 63. Marfili $\mathfrak{B o r}$ (i) lag gut Beobahtuttg berpelben 85 ber Sauptiftam bes 53 iltmeers 63.64. 65. 67. Den Umlauf des 2 Selmeeres unter ber Rinic extlátet. Buffon 346. gegen Porden un Euben jietends Etróme 66. 4 . mo von mebr Etrơmen Deriat gu finden fen 280 n. IV wie Die mittedåndíć) See firo̊me 67.4. f. wie ber 21briatiphe DReerbufen fto ơme 68.81 a.f. Der Etrom biefes गReers wirs vin Voffio mi fólechtem Srun be bem 2lisffuffe ber 23 affers aur bem Ponto-Euxino jugefdrieben 68. to

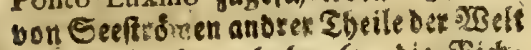

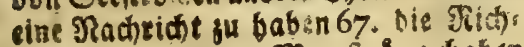
cungen ber unteen

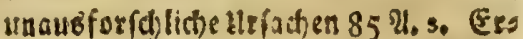
finbung, mittelf wathor man bie Ridhs tung unb (s)efchrembigleit berfelben ezs

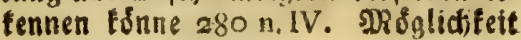
Der mibrigen Sirưme 348. f. auch 230 Deerfurm esteget ein Bisis fe, rocichesె Dem ssafferfalle cines groffon gluffes gleichet $132 \%$. f $f$

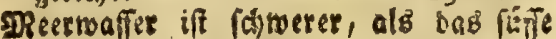
219. ob Das obere ober bas untere IDecrwafier mebre gé́lgen fen $172-174$. if ungleich am (Sefdimacte, nach vers fḥiebenen Umftånden, Drten, Gasgen Den, Zeiten 174 . 175. Eann osm Erein: falge feinen falficheen befhmate ba ben $232-237$

Mebr, ein beimort, bålte cine Inmers

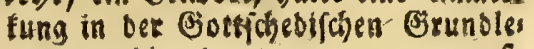
gung verbienet . 399 i.f.

Deforung cloaca 426

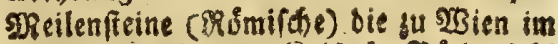
כorgematie DeB Saiferl. Bưcherfals fich befinden, (3is nueiner కrit fit) befandens) to fie aufgefractit wors ben 24. (. aud) $278 \mathrm{n}$. II Menandri Excerpta de Legat. 343 औ. 1 .

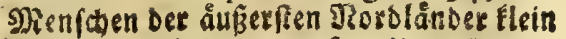
uno ungeftalt 188 \%. f. Jnroiffenbeitber Renchen in naturtichen Dinget,

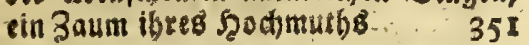

Metatbefis einiget Teuticher Senennuni gen 22 Meum, latetnifder Rame ber Boitnukg, wiró von $50 \mathrm{kn}$. Linnæo aus einer felt fä: men Urfacte abgef(h) offt $370 \%$.

Meners ( $\$$. San.) eines Nünbergifoten Miniaturmablets Erbeten, sie Bes. fabretbung Det Deftereechtiogen und

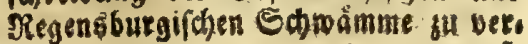
legen

381 u. f.

Milch fकwamm c4 MRittentundifches Mreet f. Meer.

Whia 25ino. Maria $267 \%$.

Mókiowna oet $\mathfrak{B} i n e^{2}$, crategus 365 ‥

notge in Befås 106

Mon- 
Regifter:

Monconnys befd)reibung eines SDicer, ftroms auf Der spittell. ERe 230\%. IRoråfte: ibre Austrodnung veturfas det einen sRangel beg fúfen 2 Paffers $186 \%$.

Morbeln ( 2urt bet Echtormme) 30121. munb, Minse, oftium fuvii LXI Nunbart : Nutrnbergifche XLIII. 422. Sofbmifhe bauchende, bat tein $B_{4}$ b 4 -

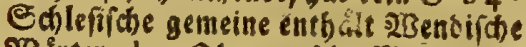
SOSorter, $b$ - Dberteutide Nunbarten rerben berfofbnt, $c$ - verth isiget, $c 2$ u. f. Tieb aud Sprade.

Muroëla ein Fióniifher Drt

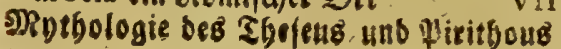
279, n. III

\section{2.}

Ha'binger terebra

ก⿵ंs mas eB bebcute

300

Ramen (bie Sebråifden) weld in ber 万ृ. Edrift vorfommen, werten von ben Ratbolifen anders gefoticben, als bon ben übrigen (E) riftlichen Ëes meinben 18. Duelle ber verberbten eis

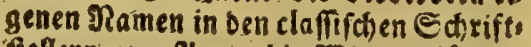
Pielleun $270 \%$. o. Die 25 inberi fơnnen in ifret SRutterfpradje gemiffe Namen bilben, weldhe bleB ourd eine befondere Eabung, eine $\mathfrak{B e r a c h t u n g ~ o d e r ~ e i n e n ~}$ Unwillen angeigen $268 \%$. Rebnliaffeit bet Ramen unfiderer Erunb bie alten Derter ju beftimmen

VII

Napftroom eine Rortwegifche feft ichmas le sReerenge, roie ber Euripus $170 \%$.

Ha'x b Deft. Wort 30r. wirb ertláret 305 U. f. $31 \mathrm{I}$

Tatter ferpens: bet urfprung biefes 30 tes wirb unterfucht 305 u. f. Fieb

aud ebret 384 2. the Nusen XI

Rafurlefire: ibre IReinungen find bem

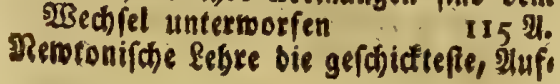

gaben ber notrirlichen Exfl)einungen aufjulofen; an was es berfelben feg. le $32 \mathrm{~T}$ n. XIII Dievere (bie) ein gutes şauptroet 423 Morblee i. \$gieer.

Noricifni Gelfen gut 2นชิ|purung bee anonynorum

Fiuta ein Deft. 4092. 306

(1).

Obfervatorium Eann mit Warte exflaret roercer

Doft, wober vetfdiebene irten feffelben ibre গamen úbertommen $358 \%$.

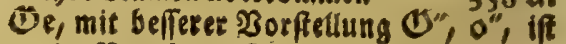

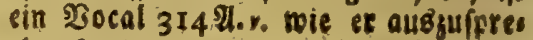
(b) en fer $90 \%$. Oc (im Edroebifhen) eine Infel LII U ega'r tiitg, cin Ed;ramm, c2Derter (alie jerftorte) Gincerlaffen tenns. bart Eruren

Dlferreich bat ben fruchtbarfen Boten zur Jृerborbringung feltener Pflarien 274. biefer ift von Dem Etenermárfis fohen febr unterfaieden 366 2. Dbers

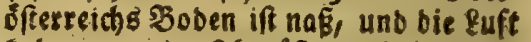
falt 393: in Dberofferreich pflanget man eine geoffe sienge bon Doftbau. men, injondergeit bon $2 l e p f e l$, uns. SBirnbiumen $358 \%$. Defterteid if vor einigen Jabrbunberten ein Eij bet Seutfden Gelebrfamfeit getwefen. Die Einfubrung anbete Schulen bat bob Slatt verfehrt 3 I0. c - Defterreichis

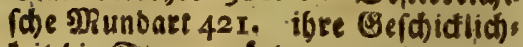
feit bie Etammmoirter anjufeigen 3I4 u. f. Die Defterteidifdien Zeitmórter geben in $a^{\prime}$ aus

Oronge ber Beatner if bet Kaifers ling

Q1 fromi, IMenbicher Mame $396 \%$.

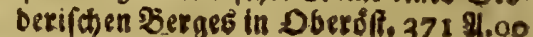
Dltife Po Meet.

Ovolo bet Reapolitanet if bex Ratfer ling 396 \&. Dutr 
Piegifet.

Outman \$lbrambs fommet nabe unter Den Roropol

p.

Padee cin פiettelsidetifaer \$erg 364 ‥ $\mathrm{m}$ m

Palus Mreotis wirb bon Gabren iu Gab: ren mebe betfálåmmet

Parft $2 \mathrm{~B}$ ind. ein Jinger

182

XLIV

partey, parteyifd, unparteyifd, nid) mit th

428

parvio (Dos) entbalt gute Stammiode: tet

c 3

Spertn (i. 5t. v. Kupt.) Betid)t vom Stafpifden Sieere 219 U.

Betalf eine ङtadt XXXVII

Petauerfelo trägt feltene Pflanjen 273

Petovium Dacic $\quad$ XXXVIII

Peucedanum

Pezizz Dillen.

Dfásletin Deft. Bort

Ş fofenbute (Shtoămme)

$366 \%$.

3912. 301

Dfefferling, ein Sobromm, $c_{4} ;$ bom pfifferling bet Stenermásfer unter: fdieben

380

oferfichbatm ift von Linnzeo in Bea IRanbelbaum verwandelt mosben $370 \%$.

spfferling ber Stensemåter (piperitis) ein Sornamm

380

yplangen (tonige) in ben axufierften Norblandern 188 . ibre Seaft ift alloa fchmåd)er 189 . S'Dtt entosdet bon Gabren su Jabren ben Menichen, aud Seiben, neue 2Birfungen bet Dflanjen 352, biefe bereiten fi fie in set natuzlichen $\mathfrak{B}$ oufommenbeit gelafien werben, aus bem gefalgenen

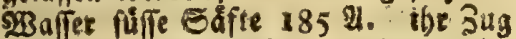
burch bie fanber ift anmatbig fu bes tracten $366 \%$. Jenforn follen nid

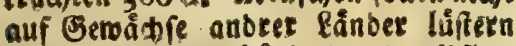
fent 352. Rebrgebaube bon ben Pfians ien, weld)es ber शatur burdsgebenos gemás fev, unmóglich 351.355 .386
Pfügen madjen nicbt allemal ungefunbe Ruft

Phalli Gidemorcheln

Pharus ein leuchteburm 240 H.f.

Phlegrai campi 142

Phyficus, in Deftereich ein Medicus 426

Piperitis ein Soroamm 380

Plancus (Biancbi) bat im Sanbe bes IDriatifon J) Reeres Eleine Cornua Ammonis entbedt 56. Gat bei Rimini eine Meerwarte gebauet 68 . irre: in Rafebung ber Roubfurber, wie Stra: 60

Platteutidie 20 oirter

$100 \div 102$

$32 t$

Olintiche Sablen Dar Meilen find uns richtig. Fine Stelle wirb verbeffert 53. श. c, eine anber? I $40 \%$. 00

Po (ber ffluß̂) lâuft gegen Morgen, toie Die Donau 84 U

Pontus Euxinus f.JReex. (Sas Sd)warje)

Porcini der Gtaliener fint unfere Bilje 391 थ.

Poretch, Inf. i. b. Donau 205 2. 245 थ. porfturfer 358 . wo et 5 afenapfel beiहีe, in bet Anmertung Dafelbf.

poftowka, tinnunculius, 305 \%. Woti330 WBenbifa gebacfenes 304 M.? Pott ( Job. Seint.) beurtbeilet Linnai 23orftelung bes Steinreich $8 \quad 350$ Mowviat, toas in ber Ranbbefdreis bung bon Polen bebeute LXX

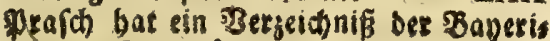
Then Qanowitter Geraubigegeben 295 9riel, ein Stoderiforer Berg; feine $\mathcal{B}^{2}$. toedfelung mit Dem Greffenberge

Priorin (ber gnádigen 5 rau) oon Stuber nis Tite!

272

Promontorium wirs im Seutfinen unrecht mit Dargebirge liberfest; wober es muffe abgeleiter werben 50 u.f. Puich (P.Sigism, S.J.) 256 मे. Por (Purn), Sebeutung biefre ßa: mene

aI. VIIL

X๋ล์เตี 
Sectitut.

2i.

Räthjel æenigma, if redjt gifditicten IRagondo Art. (Ragando Tab.) XXVIII. Xatfdien oefi. .

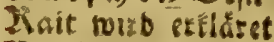
26121. 302

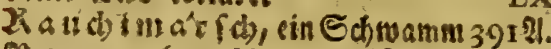

SRavenna efemale ein pfúgictet unb gleidfuol gefunder Dort: ift if bas Segeniptel wagk 18121000

Reaunur wunfdiet bie Teut(a)e Spradie gu verfeben

Siebenfetcle gang niebrige, bide, mattio fen im Sante 185.21.

Sircenfionen werben von einem Buds Gånbler beurtbeilet $37 \mathrm{n}, 11$

Regeneburgifote Edjiffeute fenmon tie

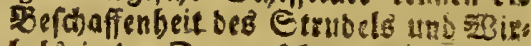
bele in ber Donau frbe webl $201 \%$ Reblinge $378.396 . c_{4}$

Reifen verbeffern die Beograpbie . IX Reiferegifter ber $\Re$ Rơmer

Reijere, ein Edhantm,

Zieut witb ertlátet

c4

Rhinefrimus ein $\Re a f e n b a u$ o $292-294$

Xidj3a, Eophien (ber Etiftetin von (Erubenis) Sdjwefere 356 . Unter (us d) rosiederie (265 2.) nerberbite $(269 \mathfrak{2}$.) E(j) reibarten Diefes गRameng. Hus

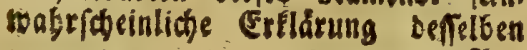
2cop.) ein Eteners nRiet, SRiet,

2irfen Deff. SBsort 313. 2.

LX

Riffole tin baumfónamm $37 \%$ eigents lid) eine woilsprärpaftete, in bers 24 merefung bafelbft

Zoljars (Albertus von) 255. Inlei

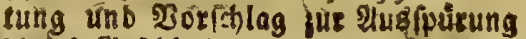

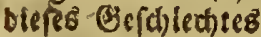

Rotbe DReer (OAB) F. NReet.
Kotonda; begrátríg bed DRgerh. Theodurici fu शavema 18224.000 Rugi babrn audy in ocrn Eeridte bes

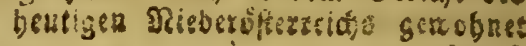
Xutchen toof ed abfamm 336 u.f.

\section{8.}

ভ unb $\Re$ merden vertsectifelt

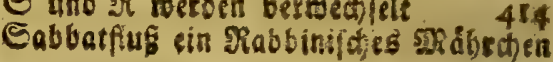

Eanlen, worju fie getient 4 u. f. Eât: Ien bes fretturs, mereen oon ben Brziechifchen Echriffellern folidsts weg sñas (Góulen) genarint I. fino bie Berge gibpla uno galpe 3. Dis fer Berge natese Ramen II. L. folg. Des Eiciliforen Dioborg nioerfures dences 3cugnifi 8. Dercinigung beis Det 5jeinunger 9; $10 \%$ \% * Columne Herculis fino nidft bie metallenen Eăr Ten bez Sertfulifáen Sempels-9: 10 2. ** eine betiobrne Esule mit 20 mifaten शuffdrifen 25. F. aud) DP( Ienpeine.

Cold bermefret bie Rălte 405 2. Dagి Eicilifabe von Plinio bejonrieben 238 2. vom Salge be8 TRerwaftre 172 -

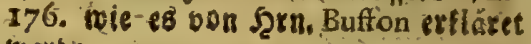

Salfbeunn in Dberdferesch beilet Sifo pfe 322

Ealsfiug bei Allicata in Eicilien -119 2. Salimeer f. in Iuffolage Meer, tas Toste vrieer.

Ealyteid) ( ein Eicilifter ) bei oet IRazja 234. ein anbret bei Ietranou va 235. 236. Diefer if úbernus fichs reich 236. if auf ben Lambtorten ausi geleffer

Gán sin glug 2235

Sond verfhuttet Pirctien 5273 185. betódet ganje Bebiete i 85.186. Drfien unbefaterblide srenge ift ein 
Regiftet.

Eeneis des : Mntebuten Det \$etge 183-186. mie es entrietge

Saned ift nidis Santicum.

Santonicurn Linn.

Sarmaten tegen fio beutigea 319 2. s bie Eelefriamfeit

Gauer (Grafoon) ein gelebrter Eten! - exmártifócer Cevalier

Sđ̛́r talpa

272 u. f.

Sdara ein Sicilifd Mort L
Edbentil Mind. S. Aegidius 267 .

XLIV Shiferftein, \$erg in Dber\&f. $370 . \mathfrak{X}$.

Shiffe tommen mit gleid) frartem 2 th be aber aus Pboenicien nad Epanten, als wan bost beriber 7 . Lnterfudqung

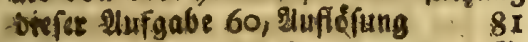

Schlagen brouttet audh generare 425 H.

Edjlenorian (oer alte) foul nod ferner in berr Ip potbeten betrfichen

313

Bdblenge, was es bei Deiden fev 106

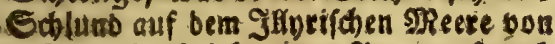
Sucan befdrieben $x_{49}$ 9. y y. (⿳aud clyavy boris

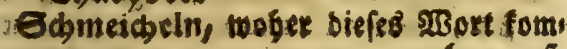
mie

Sthmuten Stenerm. 23.

$b_{3}-H_{0} f_{0}$

S.4.

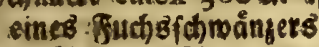

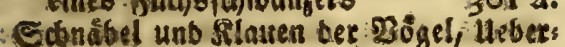
refte ber Sunofluth, werben in Dbes. fiteurtio, luber ber Trasn, mit ben 2extirget ausigegraben

I19थ.

Sdynebberg, ein S6rtg in Niebersifer, teid): (eine Bef(d)reibung toiro hinter, trieben

XXIV

Edineegurben bet Sicilianer 405 2. mas man bei ben natirltiben Sdneegrtu ben auf : Den Mlpen erfabren fốnne I89: 21.

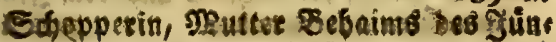
getn, bat Agnes gebeifen 16.32.35 Sdreibart, welchs bas boppelte ff auछs, mâtset, miro getabett 407.21 . wie aud

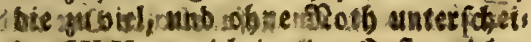
shet XLV. unaiding - ve Deftureicher

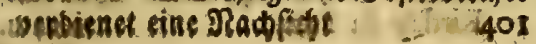

Edarofidst wirs enfláret

Gdist eine filusinfel

425

Sdjwämme wiffen bie aelehrten freantor fet nidhe uiber 6 in ibrer Sprade fut nenien $330 \%$. in SBepern unb Defters reid) Gălt man nur ungefábr 30 Eats tungen berfelben fute eßBbar 383. Das ben die fob̆nften uno bisd)ften farben 380. Untericheib ber soumid toanme bon Den Eebfónámmen $376-380$. Borfeblag Die Edjobămme einex Eses gens $\mathrm{ju}$ beforreifen

386 u. f.

6d)toars nennen mebt nich)t gut, inglíclich $x 6$. if $25 \mathrm{I} 24.9$

Edowarge Meer (bas') f. Meer.

Sd)wex, gravis, difficilis, folte fdwą: gefojrieben merten 29

Ecribent, beffer $\Theta d r i f t$ teller 421

Eçulla, gefábetidie slippen uno Etcins mainbe in Ralabrien. . 216

Selinis, ein alter Sicilifdoer Drt, unt beffen lage gtwev Stábte firziten $239 \%$.

Selbftauter (Folgenbe Teutf(c)en) $a^{\prime \prime}, 0^{\prime \prime}$ in, werben gefthiceter fo gebiloet, als $\bar{a}_{1} \delta, \hat{H}, 3$ 工 3. ungereimtes $\mathfrak{X}$ orurtheil, fo ben Europåifhen Spraden, burd Эerfübrung ber Rateinifchen, nur fúnf Selbftlauter furignet $\quad 314 \mathrm{M}$. Sepia ein fifth, (. Blacffith.

Septa, grammatifalifotse Unterfuchung biefes Mamens 29-3I

Seffel if trin Stub ... 303

Severin, ein Drt an bet Donat 2422 .

Sherardia Dillen. 251 M.

Shire Engl. Erafichaft ober Ianofichaft

LXVIII

Cibirifoe Coenen exfeugen Bergtxatu: ter 1902. bie Luft befielben Ranbes if falt $190 \%$.

Sicilien ift oon Jtalien abgeriffen wors ben, wise es Pdon ber शame begeuget 52 Siegesbed beurtbeilet bie botanifaen wevere- Linnes:

Gil doitb extlánt

349 106

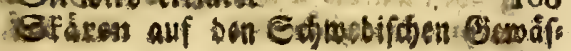

fert 
Fiegiffer. fern LXH. Erlduterung biefer Plas
XLIII u.f.

Skarje 20 ent forfox

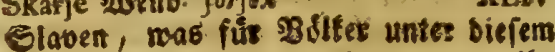
Namen begrifen metben 337. ibt Yob

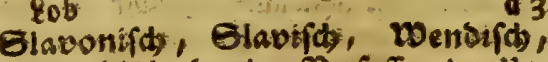
winswidy bat bex 23 erfaffer ber uns

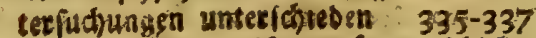

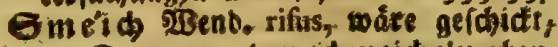
ein Stammort zu id meidgein abjus geben

Bofu Edrwer ein Rirdofpiet

by-

Eonnentwendtåfert cicindela

Sophia Etifteztin bes Elofters nis.

Eprabliche Eptadie

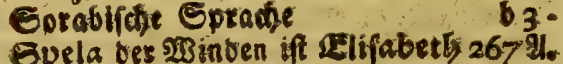

Spracter (Die beutigen fino ein Imittel gelebet fur merben 398 थ. bie Eateini

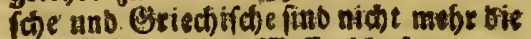

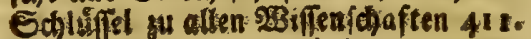
bie solmílie bie fotionfte unter ben Slabonifonen XVHI. bie Herainifote ungefälf che uno rein 303 2. ?. Fauch Die Intueigen bon Epradien untet ben Nornamen ber $2 B$ diter, ald Ceatider Eptache, Oefterceichifdge Epsadjer Densifolse Sprache. it. munoart.

Epringfutls miro extlátet 70.107 srovenka bex $25 i n b e n$ if bo Brât. ling

Gtáote befinoen fich if metr bon mieere, bie ebernals von Demiflben angefpútit murben

Gracoftey mirs attaret

Statice ein Mlpenftaut

179 uf

LXX 365 3.

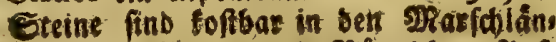

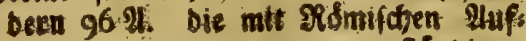
fariften werben oon unoerftånoigen Seuter verwaftet

Gteinlainen verfoutten solufer un Dofret

Steinfaly in geoffar SDenge in ber Se senbet um vie Sdyange Eet $23 x$. in able andern Bondern

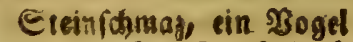

Stelechides Etodfidmón

Stiriate Tabule

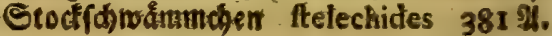

Stoser ( Oer) eir Dberdfferteidiface Thal Vill if ejemals wan den sisins

Den beroobnt gervefen

Etít acipenfer

Stoiber f. Etreber.

Strabonis geograpbifde Unribtigleiten 9T. feine irrige IDR einung bon ben flu then bet Rorofee 64 11.91 .95 .97 . et mieb hingeger, wegen bes redsten itho - geige Des 23 afferfalle bet Donay, ges gen ben Serbinine vertbeibiget 203 M.

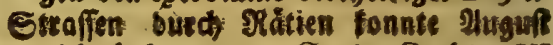
nidb: babnen 2t I. Sapies Saet det VI befás biefe Stunft 23r. H. f. Estrubel in bes Donan 200 24. 207 Hof.

\section{Gtrứzet toirb extåtet} 209.251

Eruser witb midur 303 ruoeniz, eis frauenfift in sitestel 3illi, wirt 0.0.250 Seife an betannt gentacht. Ift ein abetiches Stift 259 Studnif (ein (sefthlectotiant) 270 Suide Stelle de cataractis nito exlaus tert 306. 2. बbet 247 थ. ?

SVHLL Plinil, Martialis \&ce. fino unfere

Guno (bev) Sdfort fretum LVL bat einen untetn, bem Dbetwaffer entges gen laufenben, Strora - 227 u.f.

Gumegt (Rieherus bont)

Guppan im siertel 3tti

iXXIt

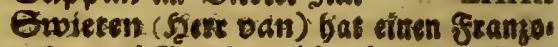
fen aus \$aris berfóstiefien, bamit et bie Sotanif jut $985 i e n$ legre $37 \mathrm{I}$ \%० 00

Szamár baben bie tingetn aus bem İtas Iheniloten af fernommen

$30 x \%$

\section{हैं}

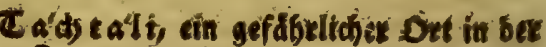

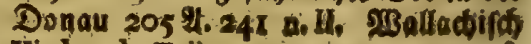
Kirdap da Iatio 
Siegifter:

C a dit w(Die) ftorea

Caublinge (Edwåmme) 388. 304

$$
\text { bet Rånoer bebeute }
$$

LXVII

Tanne, wie ibre Tangeln ausfeben $3^{63}$

Cafig tin Deft. 2 Bout

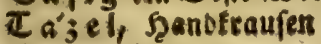

Cazen (MPoten)

2.11

297

304

Seutide Epradie bebarf einex $\mathfrak{B}$ erbeffer

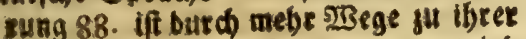
Do Ute onmenteit ju bringen 405. roirb burd) vetmeinteb̂ $\mathfrak{B}$ erbef Tern ciniger Setren nefer verberbet 315 \%. Mor

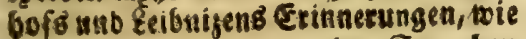
man bie Unterfudungell ber Spradien anfellen foll $\mathrm{C} 3$ - bie D berteutiche bat Hebertefie ber alten (eltifit)en, wie bie Englifthe 309. Die Seutfichen IRunds arten geben idjon fo febr von einanber

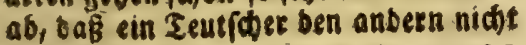
berftebet

C 3

Ibefeus uno piritfous: ibee 9Rotbolo: gie miro oom Etrabo fかón exfláret

Tinnunculus थict eines $\mathfrak{3}$ ogels $279 \mathrm{n}$. IIL - tius (mie in Horatius) baben bie SR๊。 mete nicht jius gelefen 409

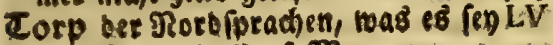
Sobte sReet (DAB) f. Reer.

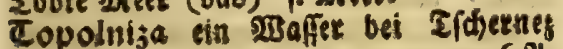
246 शi:

Tetw (Setr Şoftat\$) Бeuktbeilet Linnzi Eebre von ben Pflanjen 349 . if eis Bater bet Stubirenden $343 . \mathscr{2}$. $\mathrm{r}$. dies rea bochgelebrten unb toeltberubmten Artes grofimútbigce Inbieten feinet

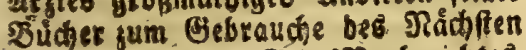

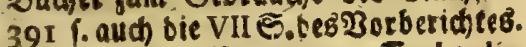

Topress if bet Rame von Eadotali; Den bie beutigen Eriedsen biefem Drte beilegen

206 U.

Cron, Shottl. nafus

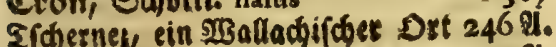
Tidernigeab $249 \cdot 2$.

Tubera Sartufeln 392 2.
Suf bon manderleg Irt im lambe of ber Ens . $118 \%$. Tutatio ein Rómifder Drt XXXII Cuy 2 sendifige Rame ber Erabt Pes tar XXXIX

11.

Vár, eit Angrij̄ 2030 ot, wirb exfla: ret

LXV

Hos mas es im Sdjwebif $u^{\prime \prime}$ if ein Bocal - 314 M. Leberfditwemmungen ber Rorbfee 62. Zeugniffe bon benfelben 9o-103. In reige bet mextmúrbigern, bie fid feit einem Jabxbunberte exeignet bas ben

Beiftis f. Fifeiftis.

VELDIDENA vermeinte 5auptftast bon Ristien: Entfouloigung wegen ber bisber ausgebliebenen In gen, weldie ju biefer edrift berforon den worben 36 . Fouch 336 \%. Benetianer bejorgen, ibre Stabe modhte auf feftes Bano gefegt werben 180

Derba'nit wiro erfläret $\quad 304$

Derbunsen $\ldots$ 4I8

Dernachláfigen Oeft. Bort 4 I8

Berfeinerungen, ob neus nach bes Cunbe futh entftesen

323

Dertvandíd aft if redt sefhriebea

4I3

Via mala, sine bofre und gefäbrliche Straffe in B̈raubintertanbe $212 \%$.

VICTORINVS ein Bifdof bon \$etau, nidje von Poitiers XL

Diel, ein Beiwort, baitte in Injegung reiner gub andolung, einen seridht in bet Botefoctifhen Orundegung vet: Dienet 399. u. f. F. aud 402 \%.

Biertel Billi 254

Diertel, Drittel zc. Bequemere 20 Dre tet, als Diertbeil, Drittheil $3 e^{2}$

Viminacium 208 श.

Din, eine storle $276 \%$

Docalen 


\section{Figifter.}

Bocaler f. Selbftlauter.

Dorgebirge ift fein eigentlidex, aftereit wabrer, 2hiboruct

Dorle SBort.

415

Dorvorlezter (ber) antepenultimus, ein notbwentiges 30 ort 415 \%.

Vofii Erf́ląung ber fflutb uno Ebbe

Ura' ift ádhto alB NItura 147 A. $\mathrm{xx}$

Trva urifi auf ber Pessen

365 ग.

\section{wo.}

Das w foll aus beit Fudboructerenen nidi) ganglid) abgefichafit, fondern in Diefer lăngft angenommenen, uno outch suebt Jabrbunberte beftätigten Bil. sung, fut Sctreibung oet Teutfolo uno Slavonifăen Ramen, beibebal teri netsen

$302 \pi$.

SEad)ters Gloffarium wirs betrtheilet 315 H. f. fief aud b2.c

$203 a^{\prime}$ o ext flabelluin

Wólben, nicht wetgen, flare, fpirare

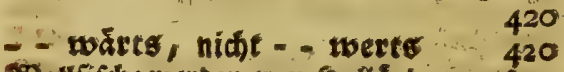

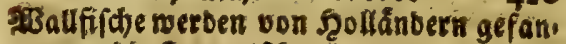
get, bie Japanifa) scarpunen im \&et: be fiecten baben 281. laffen fich auds.

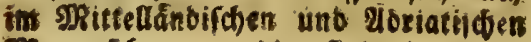
greere feben 275 . biefe fint bie eigents lid to genaniten Jinfifore 276 . ein foldjet grifh iffeinet bie numberbate Serberge bes Propbeten Jonas geme. fen zu fenn

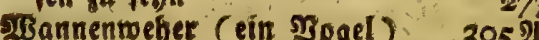

Warfoneg, sosenbiforer Name 305 2. Stoberifonen Derges in Dberffferzeich

Wavte wirb extláret 371 भ. .0

Essafier (fúfted) wober es tomme 100 (SI ) - 129. bie Refre bes Eartefius úber biefes michtige Stúcf bet शatur. miffenforaft II2, ift irrig II3. Meis nung Des Durdfeige II3-115, if aud falfa) $116-122$, grtinbliober Un, terricht toie bas fúfe 283 affer exiffebe 122-125. Fisterleoung ber Einmuxfe wiber biefe febre 125-128, 156-160. Derieltien miso in ₹kutictien 2 erfen ges bache 177. Dueflen füfles 53 afier im

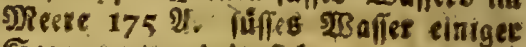
Eeen verwandelt fid in gefalgener 235 21. Dusd) wie vielerley şsege bes

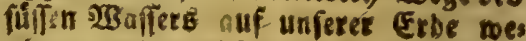
niger merbe 1862 . \$Waffer ber filúfe nimint in allen fănbern ab 186. úbers ffeinernoeE, bon Zrcueil ober Rone gis gugenannt, $x$ I 7 थ. Dergleiden vies Ie um Tremsmúnfee in Dberofferreid 118 \%. merben of rie Edaben getruns fen 322. fónmen mit ber Zeit anfebnliv che Erbebungen bes Eibreidis exfeus get 119 थ. bas 20 affet fälit im 253 in. tex bei groffer Rálte gemaltig $\quad 158$ 3 Bufferfalt in oex Donau: rine Stunbe unter Drfohotwa 2032. bit redie 6 Ef. IJseges úber Orfisoma $205 \%$

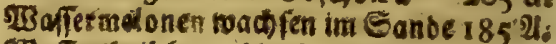
Waffertbeildyen (oie), melche gur Zeit ber Eecfúrme um Epizbergen in bie

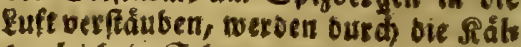
te gleid) in Sơnee verwanbelt I3I थ. bebrmut wirt ertlaicet $317 \mathrm{kf}$. Weil, Weiles 317 LXi 203ein, wo ex falficht wachfe 1852 . ISeingăten im Cande 185 थ. sBielfenwerfen (On\&) fichuatio 61 Welt fańn auch fúr unfere Exbfugel ges nommen merben 327. f. Crobtugel. 5jenden virfellen in ibres Epradse bie eigenen গamen 2672 . ibre frauen fino gefoldifte 5 robbäderinnen 303

wendifd unb Winsifd ift niche einer (et), b 2. wie man viefe $2 B 8$ stee, wem orfi, Winorfa, Slavonifd, Slat vifh, unterfcheiben tónne, wirb beut: licher angejeiget $335-337$. \% aud Winden. Das senbiphe fann, nad bemeigentlidgen faute ber SBBfrter, mit ben 
Pegiffer.

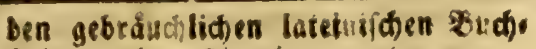
fiaben nidt gefdereben wet ben, a 4 . nuget mebr ju seutichet Interius hungen, alo as Slaviche a 4- bie

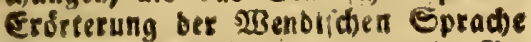
bienet sur wiftlurung bet buntien E)es

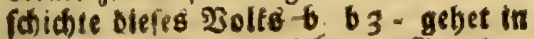
Doer und Ri i exfachfen ju Grunbe,

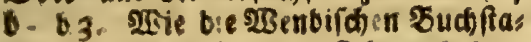
ben w unb is lauten, fieg nack bem Tigifier.

Denig, mos in Infebung ber Moreatt

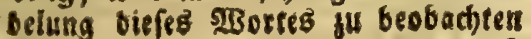
(ev) 399 u.f.

Wets, eine Sinfel ober Szalbinfel LXil

Werli, bie werlent, ein $23 e n d i f($ ) 2016 336, of fie bie Heruli fino $337 \%$. $h$ swiegmebe, Int cines 20gel8, 3052.

WDif, edfoes. finas maris vel fuvii: mas co auf bem feften lonbe beterute LIL.

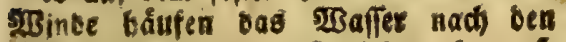
Eegentert, babit fie jiegen $6 \mathrm{r}$ u.f. die beftia furmenden fonner felfen - von ben Bergen beruntertwerfen $178 \%$

amben (bie, rin 20 olf) mo fie izt ibi. ren St babza 335. ibre \$oráltern baben an ber Difiee gemohuet, $b$. fieb aud LVI. ibre Epradie entbălt viele Hebereinftimmungen mit ben \$?oro. (prachert

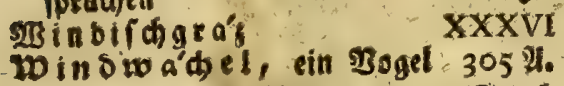

Birbel unter ben ?ozbpole, bet Styif: fe, unb alled auf bem greere fajwes benoe, won bet ferne an fid jiege, und v:eidlinge, if ein (rebid)te 67. 74.u.f. wie bas Soluden eines Edjottifoin ineermirbels gebimmet werb 199. wi: es yagbe, wonn eill Sohif bon enem Miebil oerfolungen mizb 144 ม. ๆๆ. bic Jienung, baf̈ Die Misermintel ficter fino, ourd weld) bis Woffer unter bie Erbe gebe,

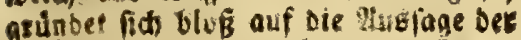
Sóud) 155 \%. am EnDe H. I. S.
Woitbel (Defterreidifder) in ber Dos nal 195-214. ungegrưndete Jieis nung von bemielben 195-198. ift feis ne Egarpbois 197 2.bbbb. wirb richtig befarieten 200. unsichtig 199 24. Herbinii - Jrthum bon temielben 201 U. f. Wibetlegung biefez 2 abng 203-207. 210. worinnen bie Befabe biefes 28 irbels und Des naben Stras bele beftebe 207-209. Sittel biefer Gefabr fu fieuren $210-214$. an S. ift regirente Rom. Sayf. IRaj. bes

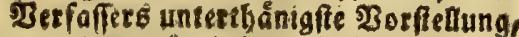
oon ber gếnglictien glufbebung Des Wrirbels und Serbefferung Des Etru Dele in bet Donas

SBirbel in bem unfern Sbetle ber Do: nau, f. I a'd t at is

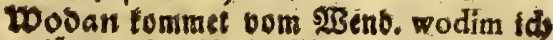
fitbre

LXIX

\$Boltetsborf beurtbeilet Linnzi febre bon Steinen

worm: 1000s Engl. abfinthinm 318

Woytwoojhaft wirb extlåtet LXVIII

Wutめ, Wint. Vdahicus $\quad 267 \%$.

ISurnitraut, Murmiamen $\quad 318$

$\mathfrak{X}$

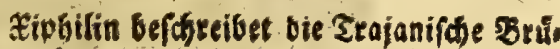
cie 207 u. f.in Der 3 .

ว.

Fell, was es in ben פamen Dex Detter bebeute LXII

Jerntgtad 28. Die 3efdreibung Diefeß alten Sdjlofies 248 म1.

Jerren, folte 3ăxen geforieben wez, ben

Jiegenbart ein Sotramin 291

zilli ober Cilli if redit gefátieben, uns sect) Cilley 254 U. ift bet $\Re$ simer Celeia VI. 6. aนd 24 . biefe Stabt bat 


\section{Sircifien:}

in ben tunftigen Zeiten greffere Hebeg f(d)remmingen gu befabren. 18a-9. Zorgbeagers überfęte eirơnlånbifche f̧u fiderev, ift regen ber eigenfinnigen

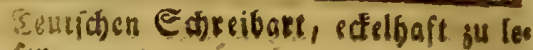 pen Zupani oex Slavonien 3 meg}

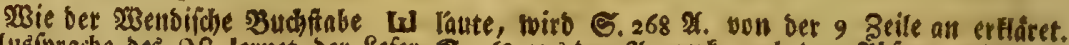

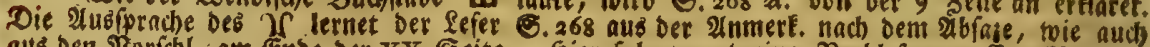

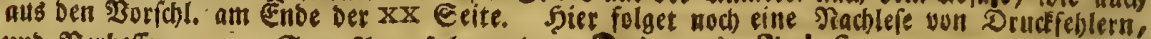

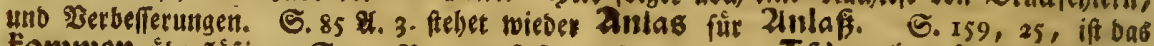

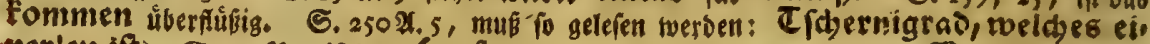

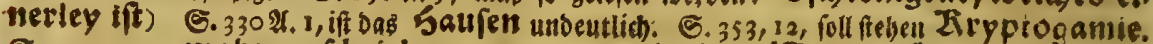
S. $387,2 x$ wabe geforieben. $5.407,31$, in sen hotencuftos s:o il (uno

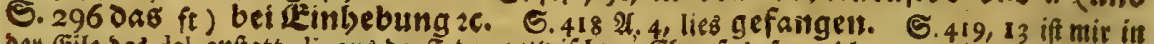

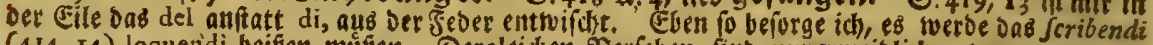
(414, I4) loquendi beifien múpen. Dergleiden Serfeben fins unvermeislich, wenn man ges

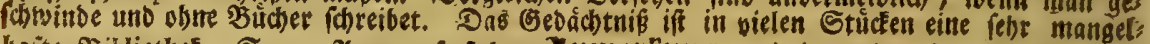

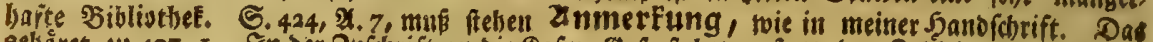

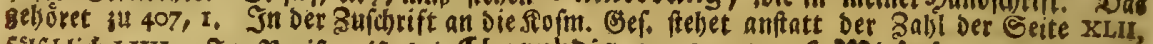
fâlf(blich LX1I. Im Regifter ift bei Charybois Die Anzeige, $f$. Wirbel, beifufezen ver:

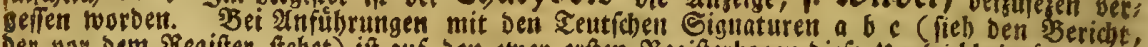

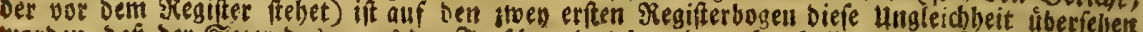

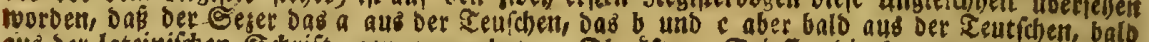

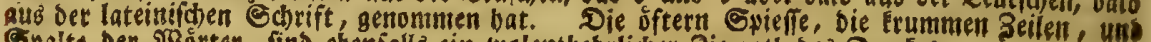

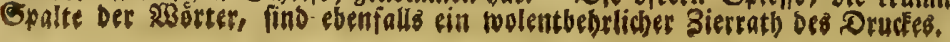

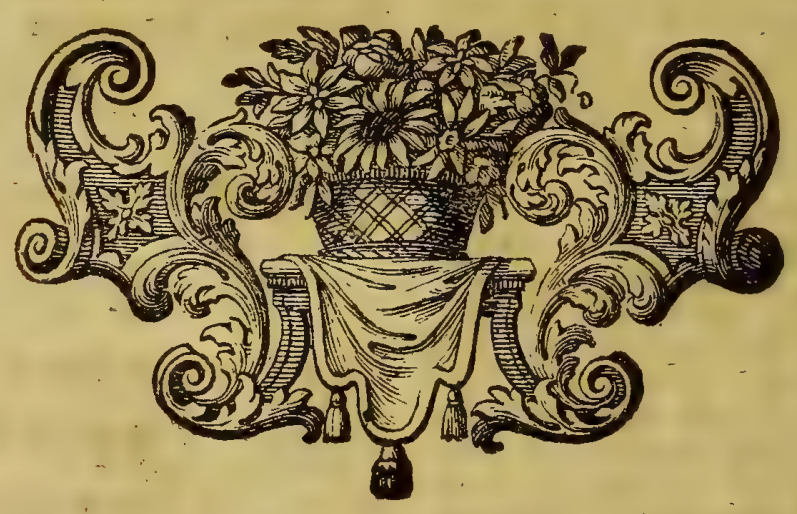





\section{Betidht an bett $\mathfrak{s u d f b i n d e r . ~}$}

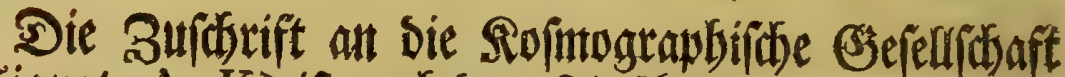
(Signat. $A-K$ ) if nach) Dent Sitelblatte bez zweyten Theils cinzuladalten. Diefe Signaturen $A-K$ vertres tent bie Stelle bes bafưr ausgebliefenen 20 gens $\delta$. WHo Das Gareiben an einige vornebme Gelebr: ten in Leipzig anzutringen fen, weifet ber borber

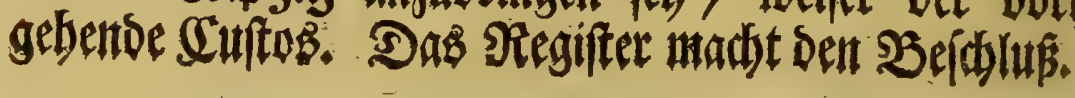






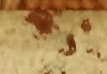

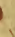

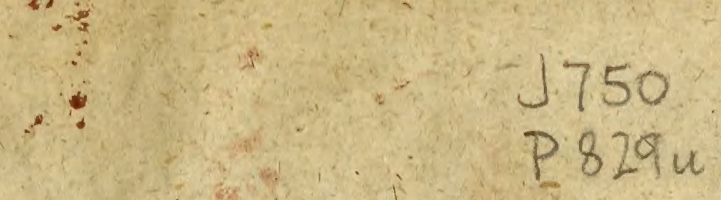

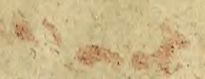

- i +2

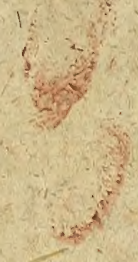

...n then 


$$
\text { 2. }
$$

a.c-

(20) (1)

6.

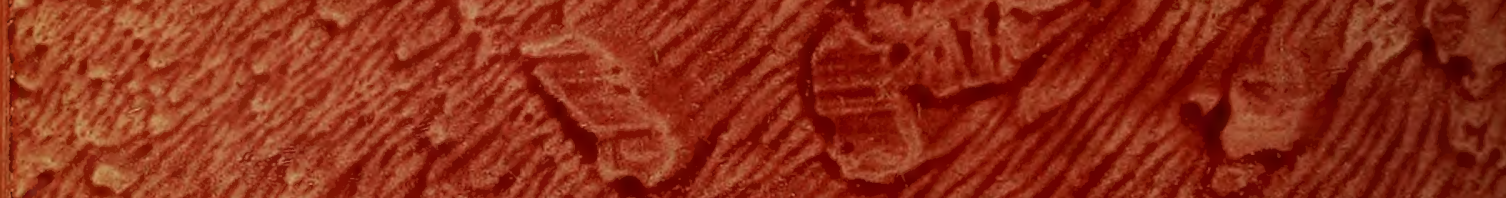
- 2)

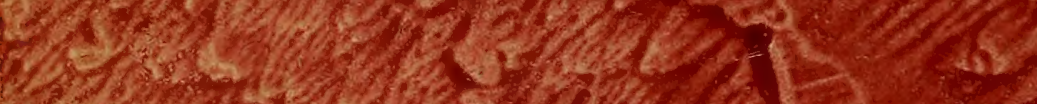
- 2.1.

$x=2.20$ x.2.

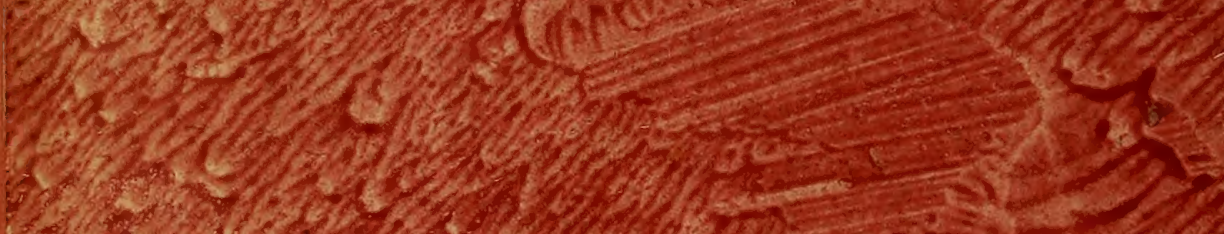
- 4 - 125. me- 28 (2) 2 -

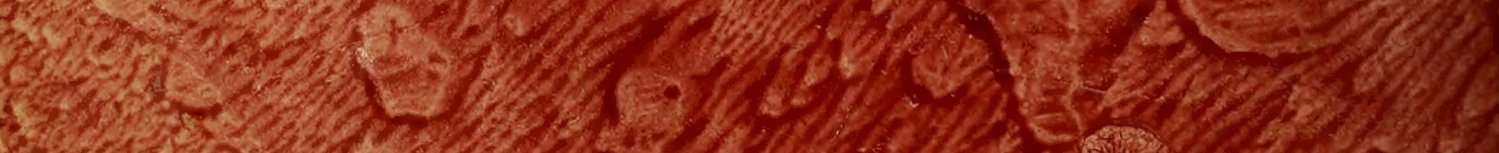
3.

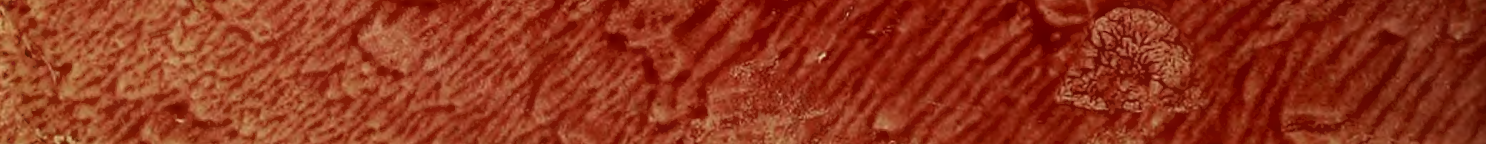


Q6)

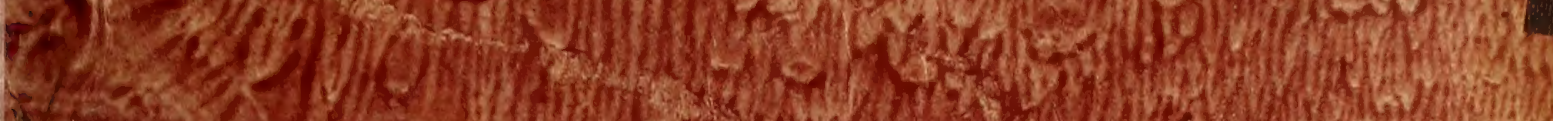

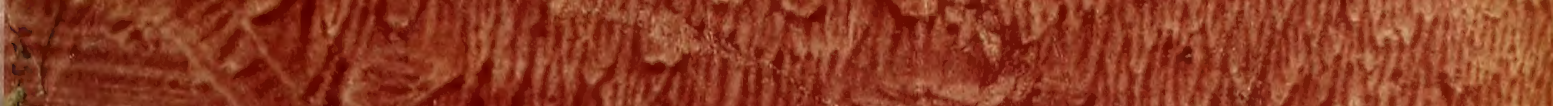
30.

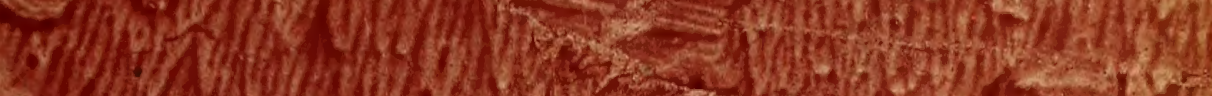

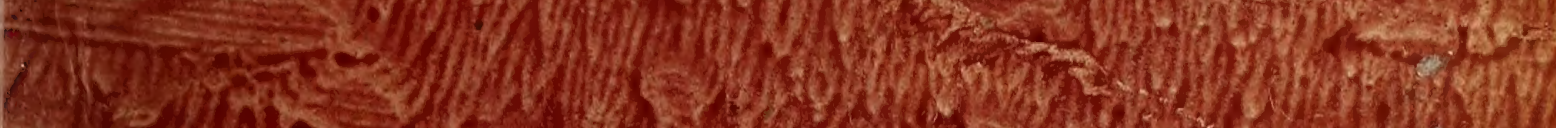

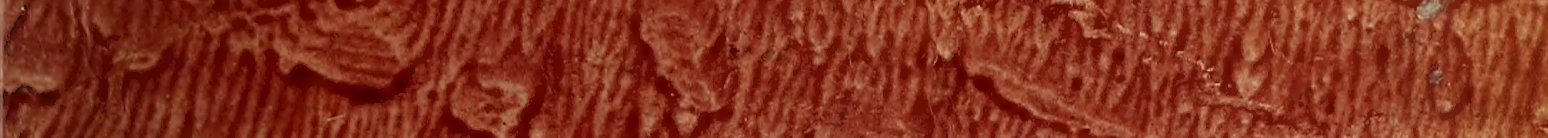

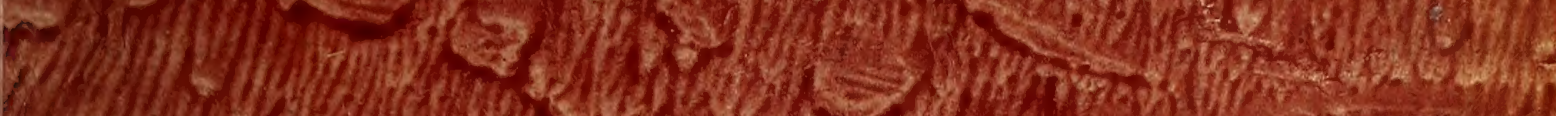
(1) 13. 4) (19 (2) I 10.10) (1) (1) (1)

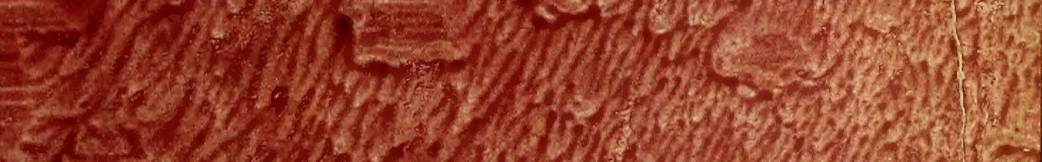
zos

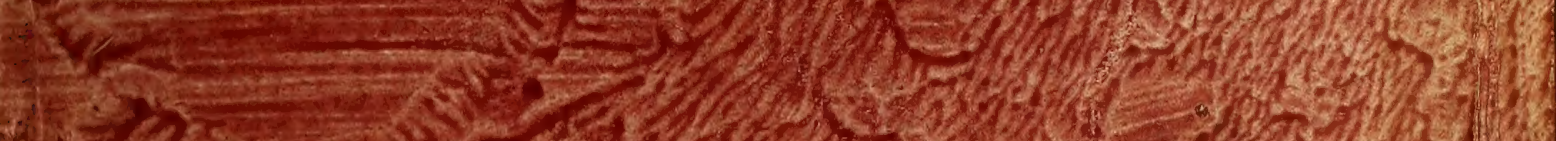

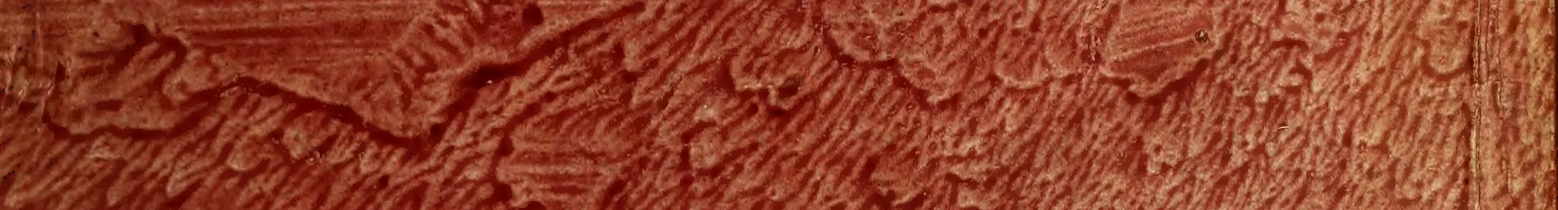
(1)

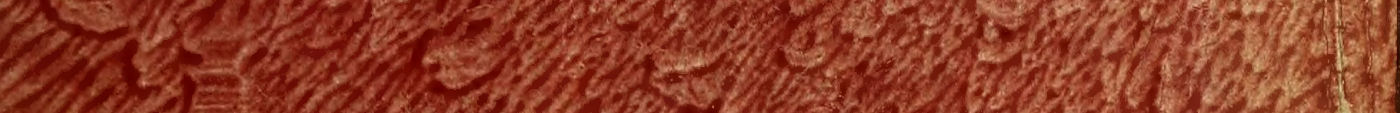

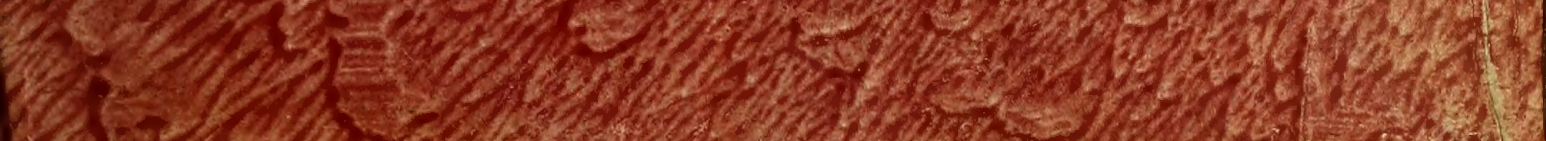

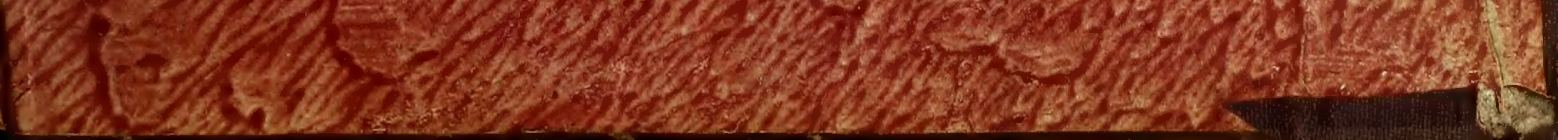




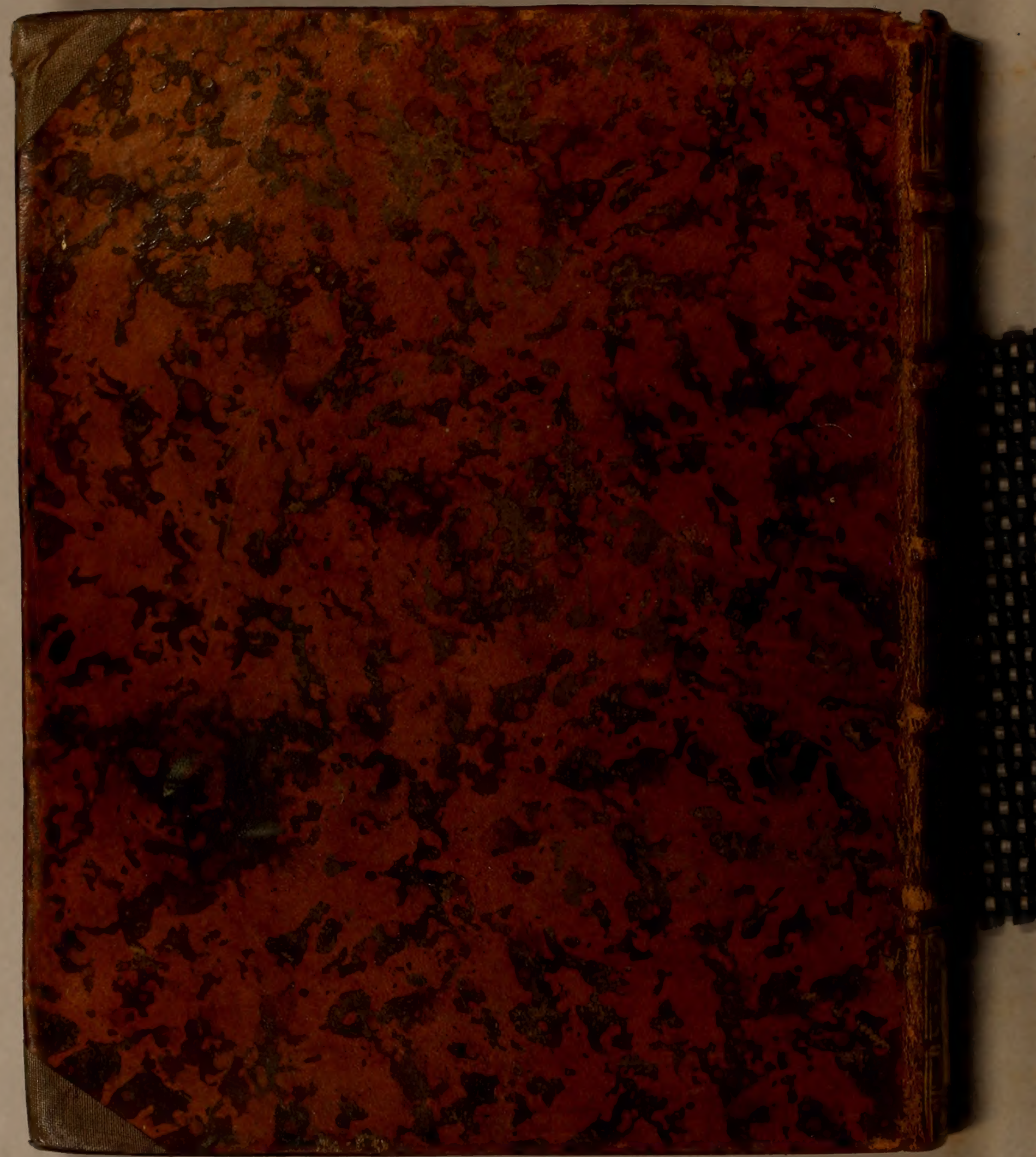

